terira australis 47 
Terra Australis reports the results of archaeological and related research within the south and east of Asia, though mainly Australia, New Guinea and Island Melanesia — lands that remained terra australis incognita to generations of prehistorians. Its subject is the settlement of the diverse environments in this isolated quarter of the globe by peoples who have maintained their discrete and traditional ways of life into the recent recorded or remembered past and at times into the observable present.

\section{List of volumes in Terra Australis}

Volume 1: Burrill Lake and Currarong: Coastal Sites in Southern New South Wales. R.J. Lampert (1971)

Volume 2: Ol Tumbuna: Archaeological Excavations in the Eastern Central Highlands, Papua New Guinea. J.P. White (1972)

Volume 3: New Guinea Stone Age Trade: The Geography and Ecology of Traffic in the Interior. I. Hughes (1977)

Volume 4: Recent Prehistory in Southeast Papua. B. Egloff (1979)

Volume 5: The Great Kartan Mystery. R. Lampert (1981)

Volume 6: Early Man in North Queensland: Art and Archaeology in the Laura Area. A. Rosenfeld, D. Horton and J. Winter (1981)

Volume 7: The Alligator Rivers: Prehistory and Ecology in Western Arnhem Land. C. Schrire (1982)

Volume 8: Hunter Hill, Hunter Island: Archaeological Investigations of a Prehistoric Tasmanian Site. S. Bowdler (1984)

Volume 9: Coastal South-West Tasmania: The Prehistory of Louisa Bay and Maatsuyker Island. R. Vanderwal and D. Horton (1984)

Volume 10: The Emergence of Mailu. G. Irwin (1985)

Volume 11: Archaeology in Eastern Timor, 1966-67. I. Glover (1986)

Volume 12: Early Tongan Prehistory: The Lapita Period on Tongatapu and its Relationships. J. Poulsen (1987)

Volume 13: Coobool Creek. P. Brown (1989)

Volume 14: 30,000 Years of Aboriginal Occupation: Kimberley, North-West Australia. S. O’Connor (1999)

Volume 15: Lapita Interaction. G. Summerhayes (2000)

Volume 16: The Prehistory of Buka: A Stepping Stone Island in the Northern Solomons. S. Wickler (2001)

Volume 17: The Archaeology of Lapita Dispersal in Oceania. G.R. Clark, A.J. Anderson and T. Vunidilo (2001)

Volume 18: An Archaeology of West Polynesian Prehistory. A. Smith (2002)

Volume 19: Phytolith and Starch Research in the AustralianPacific-Asian Regions: The State of the Art. D. Hart and L. Wallis (2003)

Volume 20: The Sea People: Late-Holocene Maritime Specialisation in the Whitsunday Islands, Central Queensland. B. Barker (2004)

Volume 21: What's Changing: Population Size or Land-Use Patterns? The Archaeology of Upper Mangrove Creek, Sydney Basin. V. Attenbrow (2004)

Volume 22: The Archaeology of the Aru Islands, Eastern Indonesia. S. O'Connor, M. Spriggs and P. Veth (2005)

Volume 23: Pieces of the Vanuatu Puzzle: Archaeology of the North, South and Centre. S. Bedford (2006)

Volume 24: Coastal Themes: An Archaeology of the Southern Curtis Coast, Queensland. S. Ulm (2006)

Volume 25: Lithics in the Land of the Lightning Brothers: The Archaeology of Wardaman Country, Northern Territory. C. Clarkson (2007)

Volume 26: Oceanic Explorations: Lapita and Western Pacific Settlement. S. Bedford, C. Sand and S. P. Connaughton (2007)

Volume 27: Dreamtime Superhighway: Sydney Basin Rock Art and Prehistoric Information Exchange. J. McDonald (2008)

Volume 28: New Directions in Archaeological Science. A. Fairbairn, S. O'Connor and B. Marwick (2008)

Volume 29: Islands of Inquiry: Colonisation, Seafaring and the Archaeology of Maritime Landscapes. G. Clark, F. Leach and S. O'Connor (2008)

Volume 30: Archaeological Science Under a Microscope: Studies in Residue and Ancient DNA Analysis in Honour of Thomas $H$. Loy. M. Haslam, G. Robertson, A. Crowther, S. Nugent and L. Kirkwood (2009)

Volume 31: The Early Prehistory of Fiji. G. Clark and A. Anderson (2009)

Volume 32: Altered Ecologies: Fire, Climate and Human Influence on Terrestrial Landscapes. S. Haberle, J. Stevenson and M. Prebble (2010)

Volume 33: Man Bac: The Excavation of a Neolithic Site in Northern Vietnam: The Biology. M. Oxenham, H. Matsumura and N. Kim Dung (2011)

Volume 34: Peopled Landscapes: Archaeological and Biogeographic Approaches to Landscapes. S. Haberle and B. David (2012)

Volume 35: Pacific Island Heritage: Archaeology, Identity \& Community. Jolie Liston, Geoffrey Clark and Dwight Alexander (2011)

Volume 36: Transcending the Culture-Nature Divide in Cultural Heritage: Views from the Asia-Pacific region. Sally Brockwell, Sue O'Connor and Denis Byrne (2013)

Volume 37: Taking the High Ground: The archaeology of Rapa, a fortified island in remote East Polynesia. Atholl Anderson and Douglas J. Kennett (2012)

Volume 38: Life on the Margins: An Archaeological Investigation of Late Holocene Economic Variability, Blue Mud Bay, Northern Australia. Patrick Faulkner (2013)

Volume 39: Prehistoric Marine Resource Use in the Indo-Pacific Regions. Rintaro Ono, Alex Morrison and David Addison (eds) (2013)

Volume 40: 4000 Years of Migration and Cultural Exchange: The Archaeology of the Batanes Islands, Northern Philippines. Peter Bellwood and Eusebio Dizon (eds) (2013)

Volume 41: Degei's Descendants: Spirits, Place and People in Pre-Cession Fiji. Aubrey Parke. Matthew Spriggs and Deryck Scarr (eds) (2014)

Volume 42: Contextualising the Neolithic Occupation of Southern Vietnam: The Role of Ceramics and Potters at An Son. Carmen Sarjeant (2014)

Volume 43: Journeys into the Rainforest: Archaeology of Culture Change and Continuity on the Evelyn Tableland, North Queensland. Åsa Ferrier (2015)

Volume 44: An Archaeology of Early Christianity in Vanuatu: Kastom and Religious Change on Tanna and Erromango, 1839-1920. James L. Flexner (2016)

Volume 45: New Perspectives in Southeast Asian and Pacific Prehistory. Philip J. Piper, Hirofumi Matsumura and David Bulbeck (eds) (2017)

Volume 46: Ten Thousand Years of Cultivation at Kuk Swamp in the Highlands of Papua New Guinea. Jack Golson, Tim Denham, Philip Hughes, Pamela Swadling and John Muke (eds) (2017) 


\section{terra australlis 47}

\section{The Archaeology of Rock Art in Western Arnhem Land, Australia}

Edited by Bruno David, Paul S.C. Taçon, Jean-Jacques

Delannoy and Jean-Michel Geneste 


\section{ANU \\ PRESS}

Published by ANU Press

The Australian National University

Acton ACT 2601 Australia

Email: anupress@anu.edu.au

This title is also available online at press.anu.edu.au

National Library of Australia Cataloguing-in-Publication entry

Title:

The archaeology of rock art in western Arnhem Land, Australia / editors : Bruno David, Paul

S.C. Taçon, Jean-Jacques Delannoy, Jean-Michel Geneste.

ISBN

9781760461614 (paperback) 9781760461621 (ebook)

Series:

Terra Australis ; no.47.

Subjects:

Archaeology--Northern Territory--Arnhem Land.

Rock paintings--Northern Territory--Arnhem Land.

Art, Aboriginal Australian--Northern Territory--Arnhem

Land.

Painting, Aboriginal Australian--Northern Territory--Arnhem

Land.

Historic sites--Northern Territory.

Arnhem Land (N.T.)

Other Creators/Contributors:

David, Bruno, editor

Taçon, Paul S. C. (Paul Stephen Charles), 1958- editor.

Delannoy, Jean-Jacques, editor.

Geneste, Jean-Michel, editor.

Copyright of the text remains with the authors, 2017. This book is copyright in all countries subscribing to the Berne convention. Apart from any fair dealing for the purpose of private study, research, criticism or review, as permitted under the Copyright Act, no part may be reproduced by any process without written permission. Inquiries should be made to the publisher.

Terra Australis Editorial Board: Sue O’Connor, Jack Golson, Simon Haberle, Sally Brockwell, Geoffrey Clark.

Cover design and layout by ANU Press. Cover photograph by Robert Gunn.

This edition @ 2017 ANU Press 


\section{Contents}

List of figures vii

List of tables xxiii

1. The archaeology of western Arnhem Land's rock art 1

Bruno David, Paul S.C. Taçon, Robert Gunn, Jean-Jacques Delannoy

and Jean-Michel Geneste

\section{Part A: Archaeology of rock art in northwestern Arnhem Land}

2. People and fish: Late Holocene rock art at Wulk Lagoon, Arnhem Land

Daryl Wesley, Tristen Jones and Rose Whitau

3. The rock art of Ingaanjalwurr, western Arnhem Land, Australia

Sally K. May, Denis Shine, Duncan Wright, Tim Denham, Paul S.C. Taçon,

Melissa Marshall, Inés Domingo Sanz, Faye Prideaux and Sean Paul Stephens

4. The agency of artefacts: Socio-ideological functionality and the long-necked spearthrowers of Mirarr Country, northern Australia

John A. Hayward

5. The rock art of Madjedbebe (Malakunanja II)

Sally K. May, Paul S.C. Taçon, Duncan Wright, Melissa Marshall, Joakim Goldhahn and Inés Domingo Sanz

6. Dynamic Figures of Mirarr Country: Chaloupka's four-phase theory and the question of variability within a rock art style

Iain G. Johnston, Joakim Goldhahn and Sally K. May

7. How old is X-ray art? Minimum age determinations for early X-ray rock art from the 'Red Lily' (Wulk) Lagoon rock art precinct, western Arnhem Land

Tristen Jones, Vladimir Levchenko and Daryl Wesley

8. Art and megafauna in the Top End of the Northern Territory, Australia:

Illusion or reality?

Paul S.C. Taçon and Steve Webb

\section{Part B: Archaeology of rock art on the central-western Arnhem Land plateau}

9. Postcards from the outside: European-contact rock art imagery and occupation on the southern Arnhem Land plateau, Jawoyn lands

Robert Gunn, Bruno David, Ray Whear, Daniel James, Fiona Petchey, Emilie Chalmin, Géraldine Castets, Bryce Barker, Jean-Michel Geneste and Jean-Jacques Delannoy

10. Engineers of the Arnhem Land plateau: Evidence for the origins and transformation of sheltered spaces at Nawarla Gabarnmang Jean-Jacques Delannoy, Bruno David, Jean-Michel Geneste, Margaret Katherine, Benjamin Sadier and Robert Gunn 
11. Dating painted Panel E1 at Nawarla Gabarnmang, central-western Arnhem Land plateau

Bruno David, Jean-Jacques Delannoy, Robert Gunn, Emilie Chalmin, Géraldine Castets, Fiona Petchey, Ken Aplin, Magen O'Farrell, Ian Moffat, Jerome Mialanes, Jean-Michel Geneste, Bryce Barker, Benjamin Sadier, Margaret Katherine, Meropi Manataki and Ursula Pietrzak

12. The past 500 years of rock art at Nawarla Gabarnmang, central-western Arnhem Land

Robert Gunn, Bruno David, Jean-Jacques Delannoy and Margaret Katherine

13. Archaeology of rock art at Dalakngalarr 1, central-western Arnhem Land

Daniel James, Bruno David, Jean-Jacques Delannoy, Robert Gunn, Alexandria Hunt, Ian Moffat, Nadia Iacono, Sean Paul Stephens and Margaret Katherine

14. Determining the age of paintings at JSARN-113/23, Jawoyn Country, central-western Arnhem Land plateau

Bruno David, Jean-Jacques Delannoy, Robert Gunn, Liam M. Brady, Fiona Petchey, Jerome Mialanes, Emilie Chalmin, Jean-Michel Geneste, Ian Moffat, Ken Aplin and Margaret Katherine

15. Archaeology of JSARN-124 site 3, central-western Arnhem Land: Determining the age of the so-called 'Genyornis' painting

Bryce Barker, Lara Lamb, Jean-Jacques Delannoy, Bruno David, Robert Gunn, Emilie Chalmin, Géraldine Castets, Ken Aplin, Benjamin Sadier, Ian Moffat, Jerome Mialanes, Margaret Katherine, Jean-Michel Geneste and Stéphane Hoerlé

Contributors 


\section{List of figures}

Figure 1.1 Location of excavated sites in western Arnhem Land, relative to land greater than $200 \mathrm{~m}$ above sea level (ASL). 2

Figure 2.1 Location of Wulk Lagoon study area, western Arnhem Land, Northern Territory. 22

Figure 2.2 Composite rock art phases. 28

Figure 2.3 Survey area showing location of rock art sites. 31

Figure 2.4 Types of archaeological materials present at rock art sites $(\mathrm{n}=77$ sites $) . \quad 31$

Figure 2.5 Distribution of rock art sites, showing number of artworks in each site. 32

Figure 2.6 Proportion of sites with each rock art style ( $\mathrm{n}=77$ sites). 32

Figure 2.7 Proportion of sites with each type of zoomorph ( $\mathrm{n}=77$ sites). 33

Figure 2.8 Number of paintings by fish taxa. 33

Figure 2.9 Painting manner for fish, by topographic zone. 34

Figure 2.10 Proportion of sites with paintings of anthropomorphs and items of material culture ( $\mathrm{n}=77$ sites). $\quad 34$

Figure 2.11 Number of paintings by colour, sites MN01, MN05 and MN12. 35

Figure 2.12 Number of artworks by motif type, sites MN01, MN05 and MN12. 35

Figure 2.13 Distribution of panel sizes, sites MN01, MN05 and MN12 ( $=65$ panels). 35

Figure 2.14 Frequency of impacts on rock art across 65 rock art panels, sites MN01, MN05 and MN12. 35

Figure 2.15 Site MN05. 36

Figure 2.16 Relative frequency of rock art sites and motifs by temporal phase (number of sites $=77$; estimated number of motifs $=13,000)$.

Figure 2.17 Proportion of motifs, panels and sites by topographic zone (number of motifs = 13,000; number of panels = 459; number of sites $=77) . \quad 38$

Figure 2.18 Number of rock art sites by phase and topographic zone. 38

Figure 2.19 Sum of the number of different art styles represented per site, by phase and topographic zone. 39

Figure 2.20 Example of complex late Holocene art scene, Wulk Lagoon site RLL004. $\quad 40$

Figure 3.1 Location of Ingaanjalwurr and other key sites mentioned in this chapter, in relation to topography.

Figure 3.2 View towards Red Lily Lagoon from the escarpment at the rear of Ingaanjalwurr. $\quad 53$

Figure 3.3 Ingaanjalwurr rockshelter from the north. 53

Figure 3.4 An example of the red painted anthropomorphs of Ingaanjalwurr. 55

Figure 3.5 A white-infilled red-outlined painting (sorcery figure) from Ingaanjalwurr. $\quad 55$ 
Figure 3.6 Digital tracings of photographed beeswax images from Ingaanjalwurr (images are at different scales to each other).

Figure 3.7 Beeswax image of a fish, with arrow indicating location from which Sample 1 was taken.

Figure 3.8 Unidentified beeswax quadruped from Ingaanjalwurr. 58

Figure 3.9 Painting of a fish with head broken to assist with carrying, Injalak Hill.

Figure 3.10 Single row of beeswax pellets, with arrow indicating location from which Sample 2 was taken.

Figure 4.1 Location of the Djawumbu Madjawarnja massif in relation to the township of Jabiru and the Jabiluka mineral lease.

Figure 4.2 Four typical spearthrower types recorded during the Mirarr Gunwarddebim project (not to scale).

Figure 4.3 Type A (rectilinear) long-necked spearthrowers from Mirarr Country.

Figure 4.4 Type B (curvilinear) long-necked spearthrowers from Mirarr Country.

Figure 4.5 Type C (concave-sided) and Type D (multi-sided) long-necked spearthrowers from Mirarr Country.

Figure 4.6 Long-necked spearthrowers from other locations as recorded by Brandl (1973), Lewis (1998), Chaloupka (1993) and Welch (1997).

Figure 4.7 Three male figures with morphologically singular long-necked spearthrowers, from Site 20029.

Figure 4.8 Individual human figure with a long-necked spearthrower and goose-wing fan, from site 10041.

Figure 4.9 Group of three male figures, from site 10039.

Figure 4.10 Human-like figure with near-horizontal legs launching a spear with a rectilinear long-necked spearthrower, from site 30116.

Figure 4.11 Group of eight stick-figures holding two types of spearthrowers, engaged in choreographed movement, from site 10040.

Figure 4.12 Human-like figures with a dog-like animal and items of material culture, from site 10041.

Figure 4.13 Two broad spearthrowers.

Figure 4.14 Painting of a concave-sided long-necked spearthrower, from site R10018.

Figure 5.1 Madjedbebe, aerial view, 2012. The rock art can be found at the very base of the rock face.

Figure 5.2 View of Madjedbebe showing the height of the rock face and some key painted panels at its lower levels, 2012.

Figure 5.3 Distribution of key rock art and other archaeological sites mentioned in this chapter.

Figure 5.4 Toby Gangali in 1985.

Figure 5.5 View of some of the painted panels at Madjedbebe, 2012. 
Figure 5.6 View of some of the painted panels at Madjedbebe, 2012.

Figure 5.7 Depiction of bundled human bones at Madjedbebe, 2013.

Figure 5.8 Painted hand and forearm stencil from Madjedbebe. The hand was first stencilled, then outlined and infilled.

Figure 5.9 Painting of a firearm from Madjedbebe, one of 16 depicted at the site. This example is shown hanging upside down as though on the side of a horse or across the shoulder of the carrier.

Figure 5.10 European-contact painting featuring a person wearing European-style clothing, smoking a pipe and with oversized gun depicted above head.

Figure 5.11 Example of an X-ray fish painting from Madjedbebe.

Figure 6.1 Dynamic Figures scene from Mirarr Country.

Figure 6.2 Examples of Chaloupka’s four phases of Dynamic Figures from Jabiluka, from left to right representing the oldest to youngest phases.

Figure 6.3 Dynamic Figure from Chaloupka's Site 124, described as a later Dynamic Figure but not showing any evidence of dotting and with characteristics more consistent with his earlier phases.

Figure 6.4 Map of the Djawumbu-Madjawarna Massif.

Figure 6.5 The second-largest scene of the Jabiluka Dynamic Figures, depicting what appears to be a similar cultural activity as evident in the largest scene.

Figure 6.6 The large central Dynamic Figure is depicted in the Phase 1 style running with spears across its body; other Dynamic Figures are below and above it running yet depicted in Phase 3 style, while the Dynamic Figure to the right has Phase 2 muscular arms.

Figure 6.7 Two scenes of Dynamic Figures.

Figure 6.8 Two examples of Dynamic Figures with material culture objects constructed of dots.

Figure 6.9 A long-arm Dynamic Figure from Mirarr Country.

Figure 7.1 Plan of Red Lily Lagoon Site 3, Area D.

Figure 7.2 Red Lily Lagoon Site 3, Area D Panel 2, highlighting the sequence of rock paintings.

Figure 7.3 Early X-ray attributes, some of which are depicted in Motif 3.

Figure 7.4 Panel 2 showing sample locations for radiocarbon age determinations.

Figure 7.5 Location of samples collected for radiocarbon dating.

Figure 8.1 The painting of the megafauna species Palorchestes that displays two prominent tufts of chest hair and is accompanied by a smaller (younger?) version of the same animal.

Figure 8.2 This painting depicts a predatory quadruped with a distinctively developed head and muzzle region unlike a thylacine. It is suggested that the robust proportions of the head represent a morphology similar to that of the marsupial lion Thylacoleo carnifex. 
Figure 8.3 Top: An image of the large, short-faced kangaroo painted in life-like proportions in Kakadu National Park. Bottom: Enhanced image using DStretch. Note the large claw, thick tail and short face of the animal. The large flightless bird mentioned in the text is also plainly visible.

Figure 8.4 The thick tail structure of the kangaroo painted in Figure 8.3, which is unlike the tail of any modern animal and suggests the proportions required to balance the body of a large megafauna macropod.

Figure 8.5 A close-up of the prominent single claw that is a distinct feature of the largest of short-faced kangaroo Procoptodon goliah.

Figure 8.6 The distinct head region of the kangaroo in Figure 8.3 showing the rounded, shortened face structure and long hair on the ears.

Figure 8.7 A large kangaroo that is a possible representation of Protemnodon(?), painted in the Wellington Range northeast of the Kakadu painting.

Figure 8.8 This animal has a longer face than the Kakadu kangaroo, and other features that might represent one of the long-faced extinct varieties, such as Protemnodon of which there were three species, all believed to exist until after humans arrived (Table 8.1; see also Figure 8.3). Scale $10 \mathrm{~cm}$.

Figure 8.9 The tail is very broad, up to $20 \mathrm{~cm}$ wide, and much broader than any extant kangaroo. Scale $10 \mathrm{~cm}$.

Figure 8.10 A close up of the feet of the large kangaroo (Protemnodon?). These feet are quite different from those of the image depicted in Figure 8.5. They are much broader, shorter and show a distinct paw-like morphology absent from the animal in Figure 8.5. Scale $10 \mathrm{~cm}$.

Figure 8.11 The front feet are shown with huge pointed claws. Scale $10 \mathrm{~cm}$.

Figure 8.12 The unidentified 'flightless' bird that underlies the large short-faced kangaroo.

Figure 9.1 Location of Jawoyn lands.

Figure 9.2 Distribution of rock art sites with European-contact motifs.

Figure 9.3 Boat A, site ARN-088/6. Scale $10 \mathrm{~cm}$.

Figure 9.4 Boats B-D, site ARN-088/6.

Figure 9.5 Boat E, site ARN-088/6. Scale $10 \mathrm{~cm}$.

Figure 9.6 Overlapping boat motifs, site ARN-088/6. Scale $10 \mathrm{~cm}$.

Figure 9.7 Art panel with European figure, site ARN-107/3. Insert is a photo-tracing of the central figure. Scale $10 \mathrm{~cm}$.

Figure 9.8 European figure with floppy hat and carrying a long object (rifle?), site ARN-019/M.

Figure 9.9 Horse painting, site ARN-074/A.

Figure 9.10 Panel with horse painting showing complex of superimpositions, site ARN-074/A. Head (at far right) and tail (at far left) of horse motif indicated. Scale $10 \mathrm{~cm}$.

Figure 9.11 Site ARN-087/1 showing location of the horse-and-rider painting marked with yellow arrow. 
Figure 9.12 Horse-and-rider painting at site ARN-087/1.

Figure 9.13 X-ray fish (barramundi and saratoga) painted with colours similar to those used on the axe painting, site ARN-082/1 (Dalakngalarr 1). Scale $10 \mathrm{~cm}$.

Figure 9.14 Bullock with bell panel, site ARN-031/1.

Figure 9.15 Panel of Bullock with bell, site ARN-031/1. Scale $10 \mathrm{~cm}$.

Figure 9.16 A: SEM-EDX (in secondary electron mode, $15 \mathrm{kV}$ ) micrograph of pigment sample from the 'Jawoyn Lady'. B: SEM-EDX (in secondary electron mode, $15 \mathrm{kV}$ ) micrograph of pigment sample from the spotted fish. C: FTIR spectra focused on the $3300-3900 \mathrm{~cm}^{-1}$ region. D: X-ray fluorescence spectrum from the spotted fish sample.

Figure 9.17 Early European travels on and around the Arnhem Land plateau. Leichhardt, Stuart, McKinlay and Lindsay's routes are plotted from maps and textual details in the explorers' published journals.

Figure 9.18 Suitcase frame elements from the European-contact period found as surface artefacts at site ARN-129/3.

Figure 9.19 Cat's-eye marble from the European-contact period found as a surface artefact at site ARN-091/20a.

Figure 9.20 Small metal billy-can from the European-contact period found as a surface artefact at site ARN-116/1.

Figure 9.21 Non-European wooden artefact cut with a metal blade, site ARN-107/12. Scale $10 \mathrm{~cm}$.

Figure 9.22 Non-European wooden spear point cut with metal blade, site ARN-133/29.

Figure 9.23 Non-European bag made from plant fibre, site ARN-110/1. Identified by Margaret Katherine (pers. comm. to Ray Whear 2009) as a bag for washing yams. AMS radiocarbon date Wk-31833 was obtained from a fragment of fibre from this bag.

Figure 9.24 Non-European cache of cord and wooden artefacts, site EVA-12/4. Scale $10 \mathrm{~cm}$.

Figure 9.25 Non-European artefacts made of wood. A: Barbed spear point with radiocarbon date Wk-28114, site ARN-074/A. B: Spearthrower with radiocarbon date Wk-28113, site ARN-074/A. C: Point with adhering resin with radiocarbon date Wk-31834, site ARN-087/1. D: Barbed spear point with radiocarbon dates Wk-28115 and Wk-31835, site ARN-074/A.

Figure 9.26 Distribution of European-contact period and organic artefacts in Jawoyn lands.

Figure 9.27 Proposed chronological sequence of introduced fauna (horse, cattle) motifs in Jawoyn lands. A: Early. B: Intermediate. C: Late.

Figure 10.1 Location of Nawarla Gabarnmang on the Arnhem Land plateau.

Figure 10.2 Aerial photograph of Nawarla Gabarnmang and surrounding features, looking south.

Figure 10.3 Location of rock art panels, with all features mapped on the ceiling.

Figure 10.4 South wall of Squares $\mathrm{F}+\mathrm{I}+\mathrm{L}+\mathrm{M}$, showing sharp and thin interfaces between stratigraphic units in the excavations in progress. 
Figure 10.5 Flat rock slab originating from the ceiling, lying horizontally in Square E.

Figure 10.6 The sheltered pillarscape, with senior Jawoyn Elder and Traditional Owner Margaret Katherine.

Figure 10.7 Location of Nawarla Gabarnmang, showing expanses of outcropping rock (orange) and the headwaters of river systems amidst the high basins of the central Arnhem Land plateau.

Figure 10.8 Rockshelter landscape of the western Arnhem Land plateau, Jawoyn Country.

Figure 10.9 Environmental context.

Figure 10.10 The low-lying 'courtyard' between Nawarla Gabarnmang and the edge of the rock outcrop to the south.

Figure 10.11 Views of Nawarla Gabarnmang from southern (top) and northern (bottom) entrances, as generated from the laser 3-D model.

Figure 10.12 South-north transect across the open, central-eastern sector of the site, showing Squares $\mathrm{C}+\mathrm{G}+\mathrm{K}+\mathrm{N}, \mathrm{E}+\mathrm{J}$, and $\mathrm{F}+\mathrm{I}+\mathrm{L}+\mathrm{M}$ to their base.

Figure 10.13 Geomorphological map of the ceiling. The zone between the dashed lines delimits the archaeological site studied in this chapter.

Figure 10.14 Rock strata making up the bedrock on the ground, pillar and ceiling levels.

Figure 10.15 Results of XRF core scanner analysis of individual rock strata.

Figure 10.16 Transect across Nawarla Gabarnmang, relative to the basin to the north and the courtyard to the south.

Figure 10.17 Northern edge of the rock outcrop that delimits the southern side of the courtyard, to the south of the site.

Figure 10.18 Different stages in the natural, geological evolution of the pillarscape along the edge of the rock outcrop that delimits the southern side of the courtyard.

Figure 10.19 Different stages in the natural, geological evolution of the pillarscape along the edge of the rock outcrop that delimits the southern side of the courtyard, from thin fissure lines (1), to the weathering of the matrix surrounding the fissures (phantomisation), to the erosion of weathered products leading to the formation of remnant rock (pillars) separated by voids $(2-5)$.

Figure 10.20 Stages in the process of phantomisation and creation of pillarscapes on the Arnhem Land plateau.

Figure 10.21 Nawarla Gabarnmang.

Figure 10.22 Plan of site floor, based on details recorded during on-site archaeomorphological mapping and the 3-D laser model.

Figure 10.23 Nawarla Gabarnmang present ceiling, showing also remnant traces of missing pillars.

Figure 10.24 Southwestern sector, showing two remnant traces of missing pillars on the ceiling.

Figure 10.25 Archaeomorphologial mapping of southwestern sector of Nawarla Gabarnmang. 
Figure 10.26 Alcove A of the southwestern sector, showing the horizontal and vertical relationships of features discussed in text.

Figure 10.27 North-south transect across Alcove A in the southwestern sector.

Figure 10.28 North-south transect across Alcove B, southwestern sector, as based on the laser 3-D model. This alcove retains elements of a partially dismantled pillar (including the 'pillar base').

Figure 10.29 Photograph and reconstruction of sequence of events in Alcove B, southwestern sector.

Figure 10.30 Strewn rocks on and near a remnant pillar base in Alcove B.

Figure 10.31 Transition zone between Alcoves A and B, and the darker, more close-knit pillar space immediately to the north, showing a toppled pillar on the floor in the mid-ground.

Figure 10.32 Partially removed pillar, with upper parts missing, southwestern sector.

Figure 10.33 Two ways of removing the upper level of pillars prior to toppling, southwest sector of site.

Figure 10.34 Alcove B in southwest sector, showing standing lower sections of pillars with upper sections missing (from laser 3-D model).

Figure 10.35 Area of contiguous Squares $\mathrm{F}+\mathrm{I}+\mathrm{L}+\mathrm{M}$, northwest sector, showing the stratigraphy along the south wall of the excavation against Pillar 20.

Figure 10.36 Area of contiguous Squares $\mathrm{F}+\mathrm{I}+\mathrm{L}+\mathrm{M}$ in the 3-D model, northwest sector, showing the natural accumulation of fallen rocks on the ground prior to human arrival (B, C) followed by a more elevated floor caused by the accumulation of aeolian sands and removal of pillar during the period following the first arrival of people (D).

Figure 10.37 Heavily weathered cupules on the western side of Pillar 28.

Figure 10.38 Dynamic Figure carrying boomerangs, Nawarla Gabarnmang.

Figure 10.39 The collapsed rockshelter that once formed the entry way into the courtyard from the southwest of the extant Nawarla Gabarnmang.

Figure 11.1 Detail of the vast rockshelter landscape of the central-western Arnhem Land plateau.

Figure 11.2 Nawarla Gabarnmang, northern entrance.

Figure 11.3 Inside Nawarla Gabarnmang, showing pillared site structure.

Figure 11.4 Map of ceiling of Nawarla Gabarnmang, showing location of Panel E1 relative to other ceiling art panels and excavation squares.

Figure 11.5 Location of Panel E1 within the centre-eastern ceiling.

Figure 11.6 Panel E1.

Figure 11.7 Photo-tracing of Panel E1.

Figure 11.8 Harris Matrix showing pattern of superimpositions for all 82 images of Panel E1.

Figure 11.9 Interpretation of the Panel E1 Harris Matrix, with phases indicated. 
Figure 11.11 Phase II images (yellow = Layer 13) and Phase III images $($ red = Layer 12), Panel E1.

Figure 11.12 Phase IV images (Layers 9-11), Panel E1.

Figure 11.13 Phase IV images (Layers 7 and 8), Panel E1.

Figure 11.14 Phase IV images \#59-\#74 (Layers 5-6) and Phase V image \#75 (Layer 4), Panel E1.

Figure 11.15 Phase VI images (Layers 1-3), Panel E1.

Figure 11.16 Details of monochrome X-ray fish Image \#15.

Figure 11.17 Details of body decoration on 'Jawoyn Lady' Image \#57.

Figure 11.18 Bula-style turtle, Image \#75.

Figure 11.19 Macropod Image \#76 in a unique X-ray style variation. 256

Figure 11.20 Large X-ray barramundi Image \#77. 257

Figure 11.21 X-ray barramundi Image \#78.

Figure 11.22 Image \#79 painted on a smeared background (B) and subsequently partially over-painted by a second smear (A).

Figure 11.23 Contrasting the differences in brushwork between the underlying (older) fine and overlying (more recent) broad lines of Images \#56, \#75 and \#76.

Figure 11.24 Detail of painting quality of Image \#78.

Figure 11.25 Detail of retouching over the stomach pattern of Image \#77. A = purple over-paint; arrows highlight underlying orange mesh pattern.

Figure 11.26 Square P before excavation, below painted Panel E1.

Figure 11.27 Square P after completion of excavation showing south and west walls (the green string is the south side of the square). Note the flat rock surface at base.

Figure 11.28 Square P east and south sections, with XUs and radiocarbon dates back-plotted.

Figure 11.29 Square P showing sediments at the base of A: XU16 (average basal depth $=22 \mathrm{~cm}$ below ground), a stratigraphic level above that of the dried paint drops; B: XU21 (average basal depth $=28 \mathrm{~cm}$ below ground), a stratigraphic level below that of the dried paint drops; C: XU18 (average basal depth $=24 \mathrm{~cm}$ below ground), at the stratigraphic level containing the dried paint drops, here visible as lighter-coloured patches.

Figure 11.30 Profile view (top) and interpretation (bottom) of GPR data from the southeast to northwest ends of the rockshelter passing through Square P.

Figure 11.31 Bayesian age model for Square P produced with OxCal v4.2 (see text for discussion).

Figure 11.32 Section drawings of excavation squares, showing the relative depth of pits. 276

Figure 11.33 3-D projections of excavation squares, from the laser mapping of the site. 276

Figure 11.34 View of the ceiling (A) and ground (B) levels around Square P, as evident from the 3-D model. 
Figure 11.35 Ceiling view of the central-eastern and western parts of Nawarla Gabarnmang, showing the location of Square P.

Figure 11.36 Southwest section of rockshelter, showing remnants of a missing pillar.

Figure 11.37 Edge of the densely pillared, slightly elevated area to the south of the shelter.

Figure 11.38 Projected view of the Nawarla Gabarnmang shelter and the densely pillared edge of the slightly elevated area to the south.

Figure 11.39 Geomorphological reconstitution of the area around Square P.

Figure 11.40 Square P: Distribution of stone artefacts and bone + teeth (excluding a particularly large stone artefact weighing $164.0 \mathrm{~g}$ from XU3, to enable better visualisation of the overall distribution down the $\mathrm{XU}$ profile).

Figure 11.41 Square P: Raw material distribution by number and by weight.

Figure 11.42 Square P: Distribution of stone artefact types by number.

Figure 11.43 Square P: Formal stone tool types.

Figure 11.44 Square P: Burning composition (by weight) of recovered bones and teeth through the stratigraphic profile.

Figure 11.45 EDX spectrum of light-coloured pigment powder from XU18 in situ sample \#4.

Figure 11.46 Square P: Examples of excavated solid coloured pieces showing the range of morphological characteristics, Nawarla Gabarnmang.

Figure 11.47 2-plot diagram representing the major element contents of solid pieces (in \% of oxide mass).

Figure 11.48 XRD pattern of a sample of red pigment from XU14 (laboratory sample code: A74PXU14_powder).

Figure 11.49 Raman spectra of a red piece with tiny white specks from XU14 (laboratory code: A74PXU14R).

Figure 11.50 Square P: Number of solid pieces of pigment by colour, by XU.

Figure 12.1 Nawarla Gabarnmang shelter from the northwest.

Figure 12.2 Interior of shelter showing the highly decorated ceiling.

Figure 12.3 Plan showing location of the ceiling art panels. Panels D, F1 and $\mathrm{H}$ are highlighted.

Figure 12.4 Photomosaic of Panel F1.

Figure 12.5 Tracing from the photomosaic of the Panel F1 art (colours approximate).

Figure 12.6 Harris Matrix of the Panel F1 superimpositions.

Figure 12.7 Interpretation of the Panel F1 Harris Matrix, grouping the motifs into contemporaneous layers on the basis of stylistic attributes and preservation.

Figure 12.8 Beeswax pellets F-27 to F-30 showing overlying radial designs.

Figure 12.9 Beeswax Pellets F-105 to F-108 overlying painting F-104.

Figure 12.10 Beeswax figure dated to 1660->1900 cal AD on Panel K4. 
Figure 12.12 Harris Matrix of the Panel H superimpositions.

Figure 12.13 Interpretation and phasing of the Panel H Harris Matrix.

Figure 12.14 Beeswax Image H-122 (arrowed) dated to 1650->1910 cal AD.

Figure 12.15 Photo-tracing of Panel D.

Figure 12.16 Horse image D-48, likely to represent a horse of the Leichhardt expedition in 1845 (see Chapter 9).

Figure 12.17 Harris Matrix of the Panel D superimpositions.

Figure 12.18 Interpretation and phasing of the Panel D Harris Matrix.

Figure 12.19 Anthropomorphs produced after $1430 \mathrm{cal}$ AD. Beeswax pellets and beeswax figures shown in black.

Figure 12.20 Fish images depicted after $1430 \mathrm{cal}$ AD.

Figure 12.21 Other faunal images depicted after $1430 \mathrm{cal}$ AD.

Figure 12.22 Implements depicted after $1430 \mathrm{cal}$ AD.

Figure 12.23 Non-figurative designs depicted after $1430 \mathrm{cal}$ AD.

Figure 12.24 Polychrome X-ray fish (barramundi) from Panel E1. Scale $10 \mathrm{~cm}$.

Figure 12.25 Bichrome 'Jawoyn Lady' from the nearby site A081-11. Scale $10 \mathrm{~cm}$.

Figure 13.1 Dalakngalarr site complex, looking southeast. Yellow rectangle locates Dalakngalarr 1.

Figure 13.2 Plan and cross-sections of Dalakngalarr 1 showing location of rock art panels.

Figure 13.3 Faded, ancient rock art of Panel A5 on eastern wall of Dalakngalarr 1.

Figure 13.4 Evidence of water flow at ground level and along the eastern wall adjacent to Panel A5.

Figure 13.5 Dalakngalarr 1, looking south.

Figure 13.6 Eastern wall showing evidence of ceiling collapse at ground level, looking northwest.

Figure 13.7 Stitched panorama of the western outer wall, looking east-southeast.

Figure 13.8 Western wall in a part of the site well protected from the elements and cool in the afternoon.

Figure 13.9 Shelter interior, looking south.

Figure 13.10 The X-ray paintings that dominate the back wall.

Figure 13.11 Plan of Dalakngalarr 1 showing magnetic intensity, with relative magnetic highs in black and relative magnetic lows in white.

Figure 13.12 View from western side inside the shelter, looking eastward across Square A.

Figure 13.13 Square A (front) and Square B (rear) inside the shelter, prior to excavation.

Figure 13.14 Square A prior to excavation, positioned against the boulder with painted macropod. 
Figure 13.16 Staggered ceiling surface, indicating a history of collapse.

Figure 13.17 Square B prior to excavation.

Figure 13.18 Details of metal blade cut marks on hardwood log near Square B.

Figure 13.19 Chris Urwin stringing up Square B prior to excavation.

Figure 13.20 Sorting in progress, excavated materials from Square B XU1.

Figure 13.21 West and north sections of Square A, showing back-plotted XUs.

Figure 13.22 Rocks at base of Square A excavation.

Figure 13.23 East and south sections of Square B, showing back-plotted XUs.

Figure 13.24 Collapsed rock over bedrock at base of Square B.

Figure 13.25 Top: Broken piece of red ochre from Square A XU5. Bottom: Piece of yellow 'ochre' from Square A XU6.

Figure 13.26 Digitally enhanced red-painted macropod on boulder at edge of Square A.

Figure 13.27 Evidence of quarrying at Dalakngalarr 1 . Scale $10 \mathrm{~cm}$.

Figure 13.28 Faunal scat (likely echidna) attached to paperbark in the southwestern corner of Dalakngalarr 1.

Figure 13.29 Southwestern corner of shelter interior, with cleft indicated by red box, standing stone by yellow box, and location of paperbark by blue box.

Figure 13.30 Standing stones in southwestern corner of shelter interior, photograph taken from above. Scale $10 \mathrm{~cm}$.

Figure 13.31 Excavated metal objects and glass bead.

Figure 13.32 Radiograph image of metal objects recovered from Square A XU2 (left, centre) and XU3 (right).

Figure 13.33 Paintings of two axe/hoes with metal heads, Dalakngalarr 1, Panel C1.

Figure 13.34 Evolution of rock stacks on the Arnhem Land plateau.

Figure 13.35 Northwestern section of Dalakngalarr 1, showing the different rock strata referred to in the geomorphological discussion.

Figure 13.36 Geomorphological evolution of Dalakngalarr 1.

Figure 13.37 Beeswax Figure 1. Scale $10 \mathrm{~cm}$.

Figure 13.38 Ceiling panel showing location of Beeswax Figure 1 (in box) and picture numbers from Harris Matrix.

Figure 13.39 Harris Matrix showing chrono-stratigraphic relationship of images for painted ceiling at Dalakngalarr 1.

Figure 13.40 Location of Beeswax Figure 2 (yellow box). Visible portion of scale, $1 \mathrm{~cm}$ per black or white square.

Figure 13.41 Red macropod/bird-footed anthropomorph superimposing Beeswax Figure 2, Panel C18.

Figure 13.42 Red macropod/bird-footed anthropomorph beneath Beeswax Figure 2, Panel C18, after DStretch_yrd10 enhancement. Scale $10 \mathrm{~cm}$. 
Figure 13.43 Macropod-footed female anthropomorph on ceiling panel that contains Beeswax Figure 1.

Figure 13.44 Close-up of Beeswax Figure 3. Scale units in $1 \mathrm{~cm}$ white or black squares. 365

Figure 13.45 Location of Beeswax Figure 3, in small yellow square near bottom right. 365

Figure 13.46 Close-up photograph of Beeswax Figure 4. Scale units in $1 \mathrm{~cm}$ squares. 366

Figure 13.47 Panel C4 panorama showing location of Beeswax Figure 4, yellow rectangle. 366

Figure 13.48 Panel C4 panorama of art panel with Beeswax Figure 4, after DStretch_yre10 enhancement.

Figure 14.1 Massive quartzite boulder stack containing JSARN-113/23 (on left-hand side of boulder) and JSARN-113/19 (overhang, right-hand side of boulder) on opposite sides. Excavations in progress, 2012.

Figure 14.2 Site JSARN-113/23, excavation in progress.

Figure 14.3 Plan of JSARN-113/23.

Figure 14.4 Squares A and B after excavation in 2012.

Figure 14.5 South section with XUs and radiocarbon samples back-plotted.

Figure 14.6 West and north sections of Square A with XUs and radiocarbon samples back-plotted.

Figure 14.7 South wall of Squares A and B after completion of 2011 and 2012 excavations.

Figure 14.8 GPR data and GPR interpretation prior to excavation of Square B.

Figure 14.9 North section of Square B with XUs and radiocarbon samples back-plotted.

Figure 14.10 Location of the GPR transect line superimposed on a photograph of the Squares A and B excavation at a mean Square B excavation depth of $40.9 \mathrm{~cm}$.

Figure 14.11 Squares A and B: Raw weight of charcoal by XU (right-hand graphs, converted to depths).

Figure 14.12 Squares A and B. Standardised weight of charcoal per $\mathrm{m}^{2}$ per 100 years by Burning Phase.

Figure 14.13 Square B: Excavated grindstones.

Figure 14.14 Squares A and B: Distribution of flaked stone artefacts by XU.

Figure 14.15 Squares A and B: Distribution of flaked stone artefacts by depth.

Figure 14.16 Squares A and B. Distribution of flaked stone artefact weight $(\mathrm{g}) / \mathrm{m}^{2} / 100$ years, by Burning Phase.

Figure 14.17 Squares A and B: Distribution of flaked stone artefacts by raw material, by XU.

Figure 14.18 Squares A and B: Distribution of flaked stone artefacts by raw material weight $(\mathrm{g}) / \mathrm{m}^{2} / 100$ years by Burning Phase.

Figure 14.19 Squares A and B: Volume of coarse-grained quartzite artefacts by depth.

Figure 14.20 The quartzite flaked piece excavated from Square A XU29 that fits onto the painted rock wall. 
Figure 14.21 Digitally enhanced and traced frieze near base of Wall 2.

Figure 14.22 Red ochre crayon from Square A XU26.

Figure 14.23 A: Macro-observation of the red ochre crayon ground surface

(Square A XU26). B: Raman spectra obtained on several points on and near the released red particles adhered to the ground surface, confirming the presence of well-crystallised haematite.

Figure 14.24 Location of the three wall sections.

Figure 14.25 Four-level hierarchical classification scheme applied to the rock paintings, showing number of images in each category.

Figure 14.26 Number of determinate paintings by General Motif Form.

Figure 14.27 Echidna (\#47) on Wall 1.

Figure 14.28 Two red-outlined and white-infilled flying-foxes (\#90, \#91), a macropod (\#113), a red stick-figure (\#92), and seven indeterminate images (\#93-\#99) on Wall 1.

Figure 14.29 Probable macropod/bandicoot/possum (\#76) on Wall 3.

Figure 14.30 White anthropomorphs (\#78, \#81) and yellow anthropomorph (\#89) on Wall 1.

Figure 14.31 Red anthropomorph (\#52) on Wall 1.

Figure 14.32 Yellow stick-figure (\#61) on Wall 2.

Figure 14.33 Red Ngar-mimi figure (\#55) on Wall 2.

Figure 14.34 Red Ngar-mimi figure (\#62) on Wall 2. Scale $10 \mathrm{~cm}$.

Figure 14.35 Anthropomorphs with 'beehive' headdresses (\#66, \#71, possibly \#70), a hooked stick (\#69) and a beeswax figure (\#64) on Wall 2.

Figure 14.36 Wall 2: Left: Full hooked stick (\#69). Right: Adjacent vertical line that is either a spear - with spearhead above the haft thickening weathered away, probably because it was painted with a more fragile pigment - or a club (\#68).

Figure 14.37 Two bichrome anthropomorphs (\#40, \#41) on Wall 2.

Figure 14.38 Anthropomorphs, spears and non-figurative figures near base of Wall 2.

Figure 14.39 Red anthropomorph (\#72) on Wall 3.

Figure 14.40 Non-figurative images (\#83, \#84) on Wall 1.

Figure 14.41 Non-figurative image (\#49) on Wall 1.

Figure 14.42 Beeswax figure (\#58) on Wall 2. Scale $10 \mathrm{~cm}$.

Figure 14.43 Beeswax figure (\#56) on Wall 2. Scale $10 \mathrm{~cm}$.

Figure 14.44 Hand stencil (\#88) on Wall 1.

Figure 14.45 Interpretation of the Harris Matrix for the frieze at the base of Wall 2 immediately above Square A, showing the pattern of superimposed paintings.

Figure 14.46 Digital tracings of the enhancement photograph of the D3/D2 frieze, showing separation of layers of superimposition as determined by the Harris Matrix (Figure 14.45). 
Figure 14.47 Bedrock strata, with interpretative cross-section showing the location of where the Square A XU29 flaked piece that fitted the rock surface above was found.

Figure 14.48 Summary interpretation of the development of the site.

Figure 14.49 Graphic summary of the site's development.

Figure 15.1 JSARN-124 site 3 (bottom right-hand rock stack), excavation of Squares B and D in progress.

Figure 15.2 Northern side of JSARN-124 site 3, showing collapsed overhang at ground level.

Figure 15.3 Profile view and map of JSARN-124 site 3, showing the collapsed overhang and location of excavation squares.

Figure 15.4 Location of art Panel A.

Figure 15.5 Panel A.

Figure 15.6 Photo-tracing of the Panel A images.

Figure 15.7 Detail of the placement of the spear (Image \#9), the large bird motif (Image \#5) and the large anthropomorph (Image \#6) paintings.

Figure 15.8 Location of Panel B.

Figure 15.9 Panel B.

Figure 15.10 Photo-tracing of the Panel B images.

Figure 15.11 Location of Panel C.

Figure 15.12 Panel C.

Figure 15.13 Photo-tracing of the Panel C images.

Figure 15.14 Location of Panel D.

Figure 15.15 Panel D.

Figure 15.16 Photo-tracing of the Panel D images.

Figure 15.17 Location of Panel E.

Figure 15.18 Stitched photograph of Panel E.

Figure 15.19 Photo-tracing of the Panel E images.

Figure 15.20 Panel D, Image \#51: The position of sample GN1-9 is marked by the tip of the scalpel blade.

Figure 15.21 Four samples (together comprising GN1-11) from the intersection of the spear painting (Image \#9) and large bird motif (Image \#5).

Figure 15.22 Cross-sections from Panel A.

Figure 15.23 SEM-EDX (ZEISS-Ultra+, $30 \mathrm{kV}$ ) chemical mapping across the cross-section of sample GN1-11.

Figure 15.24 Raman spectra obtained on samples GN1-2, GN1-3, GN1-6 and GN1-8, revealing the presence of haematite $(\mathrm{H})$, goethite $(\mathrm{G})$, quartz $(\mathrm{Q})$ and gypsum $(\mathrm{Gy})$.

Figure 15.25 Main art panel (Panel A), showing collapsed overhang fronting the artworks. 
Figure 15.27 Square A west and north section drawings, with back-plotted XUs and radiocarbon dates.

Figure 15.28 Distribution of charcoal and stone artefacts by XU, Square A.

Figure 15.29 Mean maximum length and weight distribution of stone artefacts from Square A, by XU.

Figure 15.30 Distribution of stone artefacts by raw material type for Square A, by XU.

Figure 15.31 Square B after completion of excavation.

Figure 15.32 Squares B+E north section drawing, with back-plotted XUs and radiocarbon dates.

Figure 15.33 Distribution of charcoal and stone artefacts by XU, Square B.

Figure 15.34 Mean weight and maximum length of stone artefacts from Square B, by XU.

Figure 15.35 Number (A) and weight (B) of stone artefacts by raw material type for Square B, by XU.

Figure 15.36 Square $\mathrm{C}$ after completion of excavation.

Figure 15.37 Square C west and north section drawings, with back-plotted XUs and radiocarbon dates.

Figure 15.38 Distribution of charcoal and stone artefacts by XU, Square C.

Figure 15.39 Number (A) and weight (B) of stone artefacts by raw material type for Square C, by XU.

Figure 15.40 Mean weight of stone artefacts from Square C, by XU.

Figure 15.41 Square D, showing in situ termite nest at base of excavation.

Figure 15.42 Square D north section with back-plotted XUs and radiocarbon dates.

Figure 15.43 Distribution of charcoal and stone artefacts by XU, Square D.

Figure 15.44 Number (A) and weight (B) of stone artefacts by raw material type for Square D, by XU.

Figure 15.45 Mean weight and maximum length of stone artefacts from Square D, by XU.

Figure 15.46 Square E after completion of excavation.

Figure 15.47 Ground penetrating radar work in progress in the area within and surrounding Square E, prior to excavation.

Figure 15.48 Distribution of charcoal and stone artefacts by XU, Square E.

Figure 15.49 Distribution of stone artefacts by raw material type for Square E, by XU. 477

Figure 15.50 Mean weight and maximum length of stone artefacts from Square E, by XU.

Figure 15.51 South and north-northwest faces of the rock stack at JSARN-124 site 3, showing the contrasting textures of the rock surfaces. Rock art Panels A-D are shown on those surfaces.

Figure 15.52 Excavation Squares B+E (western side) and Square C (eastern side), viewed from south side of the rock stack. 
Figure 15.53 Location of Square A in relation to Panel B and the detached stratum D8 slab (outlined in white-dashed line) that was moved by people to its present position immediately to the north of Square A.

Figure 15.54 The dotted horizontal white lines represent the level of the flat rock surfaces at the base of Squares $\mathrm{C}$ and $\mathrm{E}$.

Figure 15.55 Evolution of the overhang above Squares B+E, showing the build up of sediments as evidenced from the north section of those two excavation squares.

Figure 15.56 Northwestern corner of the rock stack showing location of Square D relative to nearby collapsed blocks and ceiling of present overhang immediately overhead.

Figure 15.57 Western side of JSARN-124 site 3, in the vicinity of Squares B+E and Square D (laser mapping undertaken when Squares B+E pits were open).

Figure 15.58 The JSARN-124 site 3 rock stack before and after the overhang collapses that resulted in the creation of the flat, vertical rock surfaces of Panels A-E.

Figure 15.59 Summary chronological schema for JSARN-124 site 3.

Figure 15.60 Collapse of northwestern overhang, resulting in the shown extant smooth vertical rock faces of Panels A, D and E.

Figure 15.61 Zoomorphs painted with shared artistic conventions, or similar and apparently shared conventions, at JSARN-124 site 3. 


\section{List of tables}

Table 2.1 Geomorphological context of rock art sites.

Table 2.2 Descriptive statistics for the 77 surveyed rock art sites at Wulk Lagoon.

Table 2.3 Radiocarbon dates on charcoal from Test Pits B and C, MN05.

Table 3.1 General interpretation of the painted art at Ingaanjalwurr rockshelter.

Table 3.2 General classification and description of beeswax images from Ingaanjalwurr rockshelter.

Table 3.3 Radiocarbon dates from Ingaanjalwurr beeswax figures.

Table 3.4 Radiocarbon dates on charcoal from Ingaanjalwurr (Squares 1 and 2).

Table 4.1 Numbers of long-necked spearthrower paintings, by sub-type.

Table 5.1 Colours and colour combinations used to produce rock paintings at Madjedbebe.

Table 5.2 General interpretation of the painting forms at Madjedbebe.

Table 5.3 General interpretation of the stencils at Madjedbebe, with colours shown for the first three categories.

Table 5.4 Types of fish depicted at Madjedbebe.

Table 5.5 Proposed stylistic chronology for western Arnhem Land rock art.

Table 6.1 Number of individual Dynamic Figures recorded from Mirarr Country by each of Chaloupka’s Dynamic Figures phase.

Table 6.2 Average size of Dynamic Figures within a scene that includes both Phase 1 and Phase 2 anthropomorphs.

Table 7.1 Radiocarbon determinations.

Table 8.1 Listing of short-faced and long-faced kangaroos in the extinct megafauna cohort.

Table 9.1 European contact-period rock paintings in Jawoyn lands, southwestern Arnhem Land plateau.

Table 9.2 List of paintings overlying European contact motifs in Jawoyn lands, southwestern Arnhem Land plateau.

Table 9.3 Description of the pigment samples from Djurray site ARN-088/6.

Table 9.4 European contact-period artefacts found within rockshelters on the plateau (some sites contain more than one artefact type).

Table 9.5 Non-European artefacts made of organic materials found within rockshelters on the plateau (some sites contain more than one artefact type).

Table 9.6 Radiocarbon determinations on surface cultural features on the plateau, Jawoyn lands.

Table 9.7 Sites with European-contact imagery on the plateau in Jawoyn lands. 
Table 10.1 Details of the excavated squares, Nawarla Gabarnmang. 217

Table 11.1 Panel E1: List of paintings and stencils. 260

Table 11.2 Panel E1: Superimpositions. 264

Table 11.3 Panel E1: Summary of the art phases. 264

Table 11.4 Square P: Details of Excavation Units. 265

Table 11.5 Square P: Sediment $\mathrm{pH}$, percentage of organic matter and particle size analysis by XU. 269

$\begin{array}{ll}\text { Table 11.6 Square P: Radiocarbon determinations. } & 273\end{array}$

Table 11.7 Square P: Distribution of excavated cultural materials. 285

Table 11.8 Square P: Incidence of stone artefacts by raw material. 286

Table 11.9 Square P: Taxonomic determinations from bones and teeth in each XU. 291

Table 12.1 Radiocarbon dates on beeswax rock art. 306

Table 12.2 Summary of the Panel F1 art phases. 311

Table 12.3 Panel F1 motifs by art phase. $\quad 312$

$\begin{array}{ll}\text { Table 12.4 Panel F1 colours by art phase. } & 313\end{array}$

Table 12.5 Summary of the Panel H art phases. 313

Table 12.6 Panel $\mathrm{H}$ motifs by art phase (excluding fragments). 317

$\begin{array}{ll}\text { Table } 12.7 \text { Panel } \mathrm{H} \text { colours by art phase. } & 317\end{array}$

Table 12.8 Summary of the Panel D art phases. 318

Table 12.9 Panel D motifs by art phase. $\quad 320$

Table 12.10 Panel D colours by art phase. 321

Table 12.11 Cross-correlation of panel phases and time periods. 321

Table 12.12 Motifs by cross-correlated time periods (total \# of images = 324). 322

Table 12.13 Colours of images by cross-correlated time periods (total \# of images = 324). 322

Table 13.1 Contents of site complexes. 332

Table 13.2 Number of rock art images at the major site of each site complex. 332

Table 13.3 Details of Excavation Units, Dalakngalarr 1, Square A. 344

Table 13.4 Stratigraphic Units, Dalakngalarr 1, Square A. 344

Table 13.5 List of excavated materials by XU, highlighted by SU, Dalakngalarr 1,

Square A.

Table 13.6 Details of Excavation Units, Dalakngalarr 1, Square B. 346

Table 13.7 Stratigraphic Units, Dalakngalarr 1, Square B. 346

Table 13.8 General list of excavated materials by XU, Dalakngalarr 1, Square B. 347

Table 13.9 Radiocarbon dates from Dalakngalarr 1. 349

Table 13.10 Ochre pieces excavated from Dalakngalarr 1, Square A. 351

Table 13.11 Radiocarbon dates on the beeswax art of Dalakngalarr 1. 362 
Table 14.1 Square A: Details of XUs.

Table 14.2 Square B: Details of XUs.

Table 14.3 Radiocarbon determinations.

Table 14.4 Square A: Distribution of excavated cultural materials.

Table 14.5 Square B: Distribution of excavated cultural materials.

Table 14.6 Squares A and B: Flaked stone artefacts by raw material.

Table 14.7 Square A: Flaked stone artefacts by fracture type.

Table 14.8 Square B: Flaked stone artefacts by fracture type.

Table 14.9 Square A: Complete quartzite flakes: Weights and dimensions.

Table 14.10 Square B: Complete quartzite flakes: Weights and dimensions.

Table 14.11 Square A XU26 red ochre crayon: Semi-quantitative chemical fingerprint of major (\%), minor (\%) and trace (ppm) elements on the ground surface of the crayon $(<\mathrm{LOD}=$ below limit of detection).

Table 14.12 Four-level hierarchical classification scheme applied to rock paintings and beeswax images.

Table 14.13 List of Level 4 (Specific Motif Form) paintings and beeswax images, plus the hand stencil, on the bedrock wall strata.

Table 14.14 Colour frequencies of all paintings, excluding the beeswax figures and stencil.

Table 15.1 Panel A: Simplified superimposition sequence involving the earliest and latest images (most recent image at top of table; earliest at bottom).

Table 15.2 Description of samples from JSARN-124 site 3.

Table 15.3 Details of Square A excavation, by XU.

Table 15.4 Radiocarbon determinations from Squares A-E.

Table 15.5 Excavated materials retained in $2 \mathrm{~mm}$ mesh sieves from Square A, by XU.

Table 15.6 Distribution of fracture types among the stone artefacts, Square A, by XU.

Table 15.7 Details of Square B excavation, by XU.

Table 15.8 Excavated materials retained in $2 \mathrm{~mm}$ mesh sieves from Square B, by XU.

Table 15.9 Quantitative composition of the two analysed pisoliths from XU21 and XU26 in Square B, as determined by PIXE analyses (in oxide weights).

Table 15.10 Distribution of fracture types among the stone artefacts, Square B, by XU.

Table 15.11 Details of Square C excavation, by XU.

Table 15.12 Excavated materials retained in $2 \mathrm{~mm}$ mesh sieves from Square C, by XU.

Table 15.13 Distribution of fracture types among the stone artefacts, Square C, by XU.

Table 15.14 Details of Square D excavation, by XU.

Table 15.15 Excavated materials retained in $2 \mathrm{~mm}$ mesh sieves from Square D, by XU. 
$x x v i$

The Archaeology of Rock Art in Western Arnhem Land, Australia

Table 15.16 Distribution of fracture types among the stone artefacts from Square D, by XU.

Table 15.17 Details of Square E excavation, by XU.

Table 15.18 Excavated materials retained in $2 \mathrm{~mm}$ mesh sieves from Square E, by XU. 474

Table 15.19 Distribution of fracture types among the stone artefacts, Square E, by XU. 476 


\title{
The archaeology of western Arnhem Land's rock art
}

\author{
Bruno David, Paul S.C. Taçon, Robert Gunn, Jean-Jacques Delannoy \\ and Jean-Michel Geneste
}

\section{Introduction}

Western Arnhem Land, in the Top End of Australia's Northern Territory, holds a special place in the history of Australian archaeology. Over 65 years of research since the late 1940s has led to numerous rockshelters being excavated and the documentation of an astonishing array of imagery on shelter walls and ceilings (Figure 1.1). Arnhem Land's spectacular rocky landscapes, home to rare flora and fauna, hold one of the richest and longest archaeological records in Australia. To the broader world remote and rugged in its physical state, Arnhem Land was transformed over tens of thousands of years of Aboriginal settlement into sequential networks of cultural landscapes, clan estates, sacred sites and places imbued with complex history. Its rock art is amongst the richest, most diverse and visually most impressive regional assemblage anywhere in the world. Themes in recent rock art research include detailed analysis of changing subject matter, radiocarbon dating of beeswax figures, Harris Matrix sequences and excavating in deposits under painted surfaces all further developed in this monograph.

Interest in the rock art of western Arnhem Land began with overland explorer Ludwig Leichhardt, the first person of European descent to observe and comment on some of the paintings he saw while travelling over and around the massive Arnhem Land plateau in 1845: 'A turtle was depicted very accurately on a rock with red ochre, and a fish in caves, in which the natives were accustomed to paint themselves for corrobories' (Leichhardt 1846:6).

The first scientist formally to study the Aboriginal people of western Arnhem Land was W. Baldwin Spencer. In 1912, he spent over two months at Oenpelli (now called Gunbalanya), near the East Alligator River, as a guest of buffalo shooter Paddy Cahill. Spencer was particularly interested in the art and material culture of the region, collecting and photographing many objects, including paintings on sheets of bark. Remarking on the art he viewed, Spencer commented: 'the bark and rock drawings of Kakadu, Geimbio, and Umoriu tribes represent, I think, the highest artistic level amongst Australian aboriginals with the possible exception of the Melville and Bathurst Islanders' (1914:439). He was particularly struck by the widespread distribution of rock art across the greater Oenpelli landscape:

Up on the hill sides, among the rocks, wherever there is an overhanging shelter where the native can screen himself from the sun and rain, these drawings are certain to be found in the country of the Kakadu. 
The colours used are red, white, black and yellow. They represent the animals with which the natives come in contact, and also their ideas in regard to the nature of certain mythical and mischievous spirits. So far as the animals are concerned, it is interesting to notice that the drawings are always more or less anatomical, that is they represent not only the external form, but, to a certain extent, the internal structure. The backbone is almost always represented, as are the heart and main features of the alimentary canal (Spencer 1914:432-433).

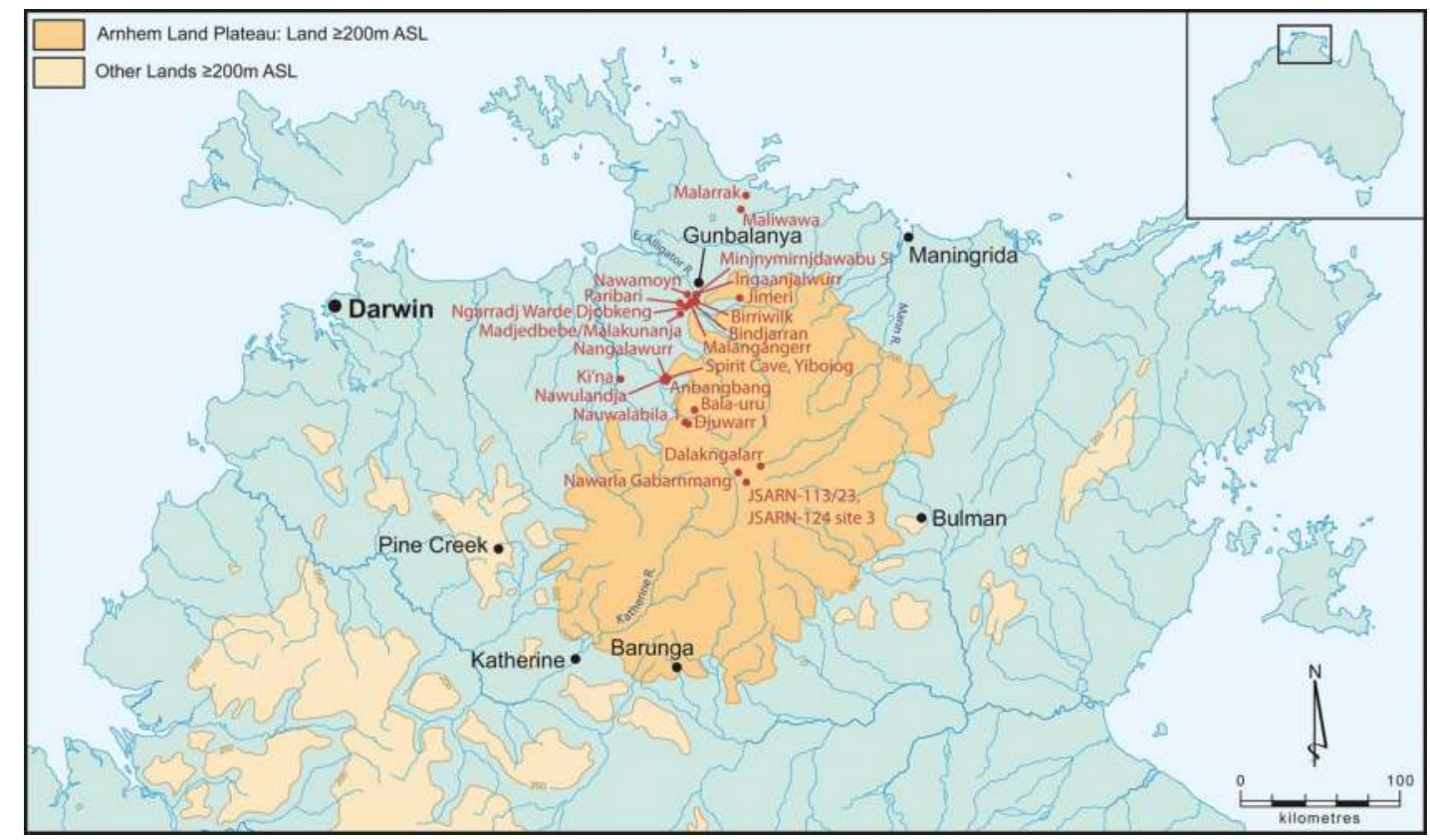

Figure 1.1 Location of excavated sites in western Arnhem Land, relative to land greater than $200 \mathrm{~m}$ above sea level (ASL).

Source: Map by Kara Rasmanis and Bruno David.

The 1948 National Geographic Society expedition to Arnhem Land put the art and archaeology of the region on the world map, particularly as a result of detailed rock art recording by Charles Mountford and numerous excavations by Frederick McCarthy (see May 2009). This was the first major scientific expedition with a strong archaeological focus by Australian and American scientists in Australia. Results not only led to decades of further archaeological research by others but also highlighted the potential of Arnhem Land to address major archaeological and art history questions of global concern.

Western Arnhem Land was the subject area of Carmel White's (now Schrire) doctoral research, resulting in the second $\mathrm{PhD}$ thesis ever produced on Australian Indigenous archaeology within Australia (White 1967), and preceded only by Isabel McBryde's 1966 study of the archaeology of the New England region of New South Wales. It was in western Arnhem Land that, dating to sometime between 18,000 $\pm 400 \mathrm{BP}$ and 22,900 $\pm 1000 \mathrm{BP}$ at Malangangerr, and to c. 21,450 $\pm 380 \mathrm{BP}$ at Nawamoyn (Schrire [White] 1982:118, 143), White $(1967,1971)$ excavated what were then the earliest known ground-edge stone axes in the world; indeed, these artefacts represented the oldest evidence of stone grinding technology of any kind.

At the same time, Arnhem Land rock art began increasingly to capture the imagination of archaeologists both in Australia and abroad, as material evidence of intangible creativities in the Aboriginal past, eventually leading to the first $\mathrm{PhD}$ in Australia that focused exclusively on rock art and combined both archaeological and ethnographic investigations (see Taçon 1989). But this same body of rock art was not initially embraced as a field of study by most Australian 
archaeologists, in large part because at first it could not be dated, and therefore it could not be located within chronological models of the past. Eventually, tentative chronologies were developed through the presence of paintings of extinct fauna (Brandl 1972) and the attributions of faunal types in the art to particular environmental conditions of independently known, measured ages (Chaloupka 1984). These attempts achieved limited success, however, mainly because it still simply was not known how old the art was, nor quite how this could be determined.

The late 1980s saw major changes to this problem of age with the development of accelerator mass spectrometry (AMS) radiocarbon dating, which for the first time, gave archaeologists real hope of situating rock art into chronological frameworks and regional cultural histories. While these potentials were not fully carried through in western Arnhem Land - the one exception being the dating of beeswax art (e.g. see Nelson 2000) - the method gave hope, with Alan Watchman's (1987) experimental work extracting carbon trapped in micro-strata near rock surfaces showing one way by which maximum and/or minimum ages could be obtained for inorganic art. But, again, these methods have largely remained an untapped potential.

In this volume, we present the results of the most recent investigations into the archaeology of western Arnhem Land's rock art. While the recording and analysis of rock art flourished through the 1980s to the present (e.g. Chaloupka 1993; Chippindale and Taçon 1993, 1998; Lewis 1988; Taçon 1987, 1988, 1989), excavation slowed after Rhys Jones's (1985) research project in Kakadu National Park in the early 1980s (see below). After some 30 years of inactivity, a renewed phase of archaeological fieldwork involving co-ordinated survey, rock art recording and excavation programs began to flourish in different parts of Arnhem Land. As many as six independent or semi-independent projects suddenly dotted western Arnhem Land, projects that were co-ordinated from three different Australian universities and partner organisations. From 2008 onwards, projects were run by The Australian National University and Griffith University in the Wellington Range of northwest Arnhem Land, the Red Lily area near the East Alligator River and the Jabiluka Leasehold area surrounded by Kakadu National Park (see Chapters 2-8); and from 2009 onwards, by Monash University in Jawoyn Country in the southern half of the western Arnhem Land plateau (see Chapters 9-15), as well as another part of the Red Lily area (see Chapter 3).

By 2012, the multiplicity of research investigations had become more or less obvious to all of us working in the region, so we soon embarked on various attempts to collaborate, at first by making contact in the field or in the laboratory. In early 2014, these initially fruitful but limited attempts further ripened when we all decided to assemble a series of research papers into a joint publication that would showcase both Arnhem Land rock art and how we were investigating it. This was done in a spirit of enhanced collegiality, and because we realised that the research results were not only fascinating but of intellectual benefit to the Australian archaeological research community as a whole. Some of the research also has global implications.

This monograph is the outcome of this collaboration. It presents a series of results available at the time of publication by each of the research teams investigating the archaeology of rock art in various parts of western Arnhem Land.

\section{Overdue collaborations}

While these new academic collaborations may be both welcome and exciting, there lies at the heart of all these investigations an even more crucial conception of research. This is a recognition that all the places we are working in are Indigenous homelands and that for Aboriginal Traditional Owners and Custodians they are each 'Country', places of the ancestors and Spirit-Beings who imbue 
the art and the sites themselves with life, and areas where living Aboriginal descendants continue to care for rock art sites as at once material and numinous emplacements. All the research projects worked on here, and the results presented, were either requested by local Indigenous communities or clan members in the first place, or discussed and negotiated with the blessing and close involvement of local Aboriginal families or family members. All of us are grateful, and recognise the privilege, of having been entrusted to undertake what is in each case local family historical research into ancestral clan estates, where local Indigenous communities are the hosts and the university researchers are the guests (see McNiven and Russell 2005).

\section{Environmental context}

It has become normal, and even somewhat expected, to report on local climates, topography, geology, geomorphology and biogeography when writing about rock art sites. This is usually done to situate a site in its environmental context. Other than giving a context to the site, however, such environmental considerations are really of interest only if they enable us to better understand the art, the site or their surroundings. Examples include identifying the position and configuration of extant rock surfaces at the time the art was done; determining the antiquity of human presence; working out how regional landscapes changed with the arrival of people; exploring relationships between living fauna and faunal representations in the art, thereby allowing explorations of past symbolism; or understanding why rock paintings survived in some parts of a site but not in others. Such contextualisations of rock art, that variably take into account local Indigenous knowledge, results of archaeological excavations and geomorphological and other environmental contexts, are at the heart of this volume. Each studied site is positioned in its extant environment, and wherever possible in its past landscape setting relating to times of use and rock art creation.

The sites reported here are located in two very different environmental settings. The first corresponds with a part of Arnhem Land where the plateau meets the alluvial plains of the East Alligator River (Chapters 2-7). This plain has long acted as a sedimentary trap for floodborne sediments, and in this it constitutes an excellent record of regional palaeoenvironments. Taking into account that the bedrock associated with local watersheds consists of very hard rocks (quartzites, hard sandstones, conglomerates rich in quartz) highly resistant to erosion, the plain's fluvial sediments tend to be more sensitive to eustatic, climatic and ecological influences than to the erosion of the rock. The floodplain's sediments are thus useful indicators of Holocene environmental dynamics associated with oscillations in climate and human land use. This has allowed researchers to determine in considerable detail what local environments were like when people occupied archaeological sites or made the art. On the other hand, here the shape of past landscapes is more difficult to determine, as landscape formations are highly variable. The contact zone between the plateau's lower slopes and the alluvial plain (see Chapters 2-5) could have had features unlike those visible today.

Against this variable and dynamic landscape in which are situated the sites discussed in the first part of this volume, are those of the second part where the morphology of the landscape has changed little over long geological time scales (Chapters 10-15). These sites are found in a very particular region at the height of the Arnhem Land plateau. This is an elevated watershed boundary zone where waters drain across all parts of the compass into a number of major hydrological basins (East Alligator River, Mann River, Katherine River). Here soft sediments are either absent or extremely shallow and initial erosional-depositional processes are very weak because there is a commensurately poor capacity to erode the headwaters' low gradient, highly resistant bedrock (quartzites, hard sandstones rich in quartz). The extreme shallowness of surface sediments and 
poor sediment load of waterways on the plateau has resulted in generally poor sediment build-up within waterholes, again signalling weak morphological dynamics in this particularly elevated region of the Arnhem Land plateau. Unlike the situation on the floodplains where landscape dynamics have had major impacts over much shorter time spans, here the exposed rock surfaces enable us to see how the landscape's relief has evolved over millions of years. On the one hand, this slow landscape evolution is a handicap for the study of rock art sites, as it does not allow us to say much about how the landscape has evolved, nor about details of the environment through the course of human presence. On the other hand, those limitations can be turned into an asset when looked at through a different geomorphological lens, as detailed here in the study of a number of sites from this part of the Arnhem Land plateau (Chapters 10, 11, 14 and 15). Slow natural morphogenic processes have allowed for a more detailed reading of how human engagements have impacted sites and their environments, such as the anthropic modification of rock surfaces over tens of thousands of years (Chapter 10) and the contemporaneity of earliest human occupation and commencement of aeolian mobilisation and redeposition of sands across the landscape shortly before 50,000 years ago (e.g. Jones 1985). Similarly, slow erosional and weathering processes enable researchers to distinguish relatively easily between natural and anthropic impacts on rockshelters, such as how different parts of a site have fragmented through gravitational overhang collapse, thermoclastic exfoliation, anthropic flaking and so forth. This preserved and analysable evidence enables researchers to study how the morphology of individual rockshelters has changed before, during and after human presence. It is from this potential that a chronology of geomorphological events was able to be determined for the so-called 'Genyornis' site and its art (Chapter 15).

The diverse range of environments that sets the scene for the rock art sites discussed in this volume highlights the fact that each geomorphological context brings with it a particular set of opportunities and limitations for researching both site-specific and landscape histories. Consideration of such opportunities and limitations is a fundamental starting point for any research program relating to the long-term history of rock art sites, anywhere in the world; research undertaken needs to be commensurate with questions asked.

\section{Western Arnhem Land's rock art: The dating dilemma}

We are now well aware that Arnhem Land contains one of the world's richest and most diverse bodies of rock art, and is widely thought to span tens of thousands of years, with rock art produced since at the very least 27,000 years ago (David et al. 2013a) up until the late 20th century (e.g. May et al. 2010; Taçon 1992a). Despite decades of archaeological research within this region, the only rock art images to have been dated directly prior to this monograph are $151 \mathrm{mid}$ to late Holocene beeswax images mainly dating to the past 600 years (Gunn and Whear 2008; Gunn et al. 2012; Nelson 2000; Nelson et al. 1995; Taçon et al. 2004, 2010) - with a total of 111 other pictograms superimposed over or subimposed under these (Gunn 2016: Chapter 4; Gunn et al. 2012:59-60; Taçon et al. 2010:2-4) - and a small excavated broken rock with part of a black linear painting or drawing from an original image of indeterminate form dated to c. 27,000 years ago from Nawarla Gabarnmang Square E (David et al. 2013a; see David et al. 2014 for the latest calibrations of the originally reported radiocarbon dates).

Watchman (1987) also obtained AMS radiocarbon dates on mineral salts in rock crusts to elucidate the ages of associated paintings from four sites in western Arnhem Land. During this early, experimental work, the micro-layers of carbon-bearing whewellite were not individually isolated from the multi-layered crusts, the radiocarbon determinations coming from the carbon trapped in the sum of micro-layers (see e.g. Watchman 1993, 2000 for subsequent studies from other 
parts of Australia where individual layers of cortex were scraped or laser-ablated and separately radiocarbon dated). In that work, Watchman obtained radiocarbon determinations of 12,250 \pm 105 BP from Spirit Cave at Angbangbang, $8880 \pm 590$ BP and $8200 \pm 460$ BP from Ngarradj Warde Djobkeng, $7040 \pm 200$ BP from Baroalba Springs, and $4850 \pm 300$ BP from Nangalor, as well as younger, late Holocene ages, but it is not clear whether these radiocarbon dates relate to the age of rock crusts underlying (Watchman 1987:38), overlying (Watchman 1987:40), overlying and underlying (Watchman 1987:39) or near but away from the art (Watchman 1987:39). It is thus uncertain whether these results should be taken as maximum or minimum ages for the art, although Watchman (1987:40) concludes that 'this study has established a minimum age of $8880 \pm 590$ years BP for some rock art paintings' (see also David et al. 2013b:3).

To this day, the oldest stylistically visible image whose age has been confirmed from Arnhem Land is a naturalistic beeswax turtle figure (BW-4) from Gunbilngmurrung, from which radiocarbon determinations of $4040 \pm 80 \mathrm{BP}$ (Nelson et al. 1995) and $4460 \pm 80 \mathrm{BP}$ (Watchman and Jones 2002) have been obtained (calibrating within 4410-4800 cal BP and 4970-5290 cal BP respectively; we cite calibrated ages at 68.3 per cent probability using OxCal 4.2 with IntCal13 curve selection throughout this chapter), with older paintings lying underneath (see David et al. $2013 \mathrm{~b}$ for a review). Yet this has not stopped a multitude of chronological models going back 40,000 years or more for rock art styles from being influentially posited for the region as a whole.

\section{Modelling the chronology of western Arnhem Land's rock art}

The vast quantity of rock art in Arnhem Land and the complexity of many of its heavily superimposed panels were apparent from W. Baldwin Spencer's photographs of the panels around Oenpelli taken over a century ago (Spencer 1914). Charles Mountford (1956) later subdivided the region's rock art into 'polychrome X-ray', 'monochrome Mimi' and 'hand stencils and prints'. He noted that X-ray paintings invariably overlie Mimi figures, indicating that the X-ray form was the more recent (Mountford 1956:262). The so-called Mimi class was expanded by Eric Brandl (1973) into 'Early Mimi' and 'Late Mimi (including types LM I and LM II)' on the basis of differences in composition and associated weaponry. Brandl divided the later X-ray art into four classes (Types $0-\mathrm{III}$ ) according to the degree of internal detail depicted. A similar subdivision was utilised by Jan Jelinek $(1978,1989)$, although he considered hand stencils as the earliest group (preceding the Mimi) and included a class of white dynamic paintings into the more recent group on the basis that they appeared to be contemporaneous with Type III X-ray paintings.

Perhaps the most influential chronological model for western Arnhem Land's rock art has been that of George Chaloupka. He $(1984,1993)$ proposed a far more exclusive classification than his predecessors, dividing the Mimi art into seven 'styles/techniques' (although these were not adequately defined) and the more recent art into four stylistic groups. The earliest style/technique included hand stencils and hand prints, while he subdivided the most conspicuous of the recent styles - X-ray art - into 'descriptive' and 'decorative' phases (Chaloupka 1993:162-165). He ordered his seven styles/techniques into a chronological sequence through perceived patterns of superimposition and then allocated each to a distinct chronological period on the basis of select faunal representations that he equated with particular environmental conditions. These broad periods were: Pre-Estuarine (from initial Aboriginal occupation some 50,000 years ago to 8000 years ago); Estuarine ( 8000 to 1500 years ago); Freshwater (1500 to 300 years ago); and Contact (300 years ago to the 'ethnographic present'). Chaloupka equated Brandl's Mimi period with the environmental Pre-Estuarine period (prior to 8000 years ago) identified by Quaternary researchers (e.g. Woodroffe et al. 1986), and the more recent art with the Estuarine period of the 
past 8000 years. While Chaloupka’s stylistic groupings have to some degree (but not entirely) been accepted by his peers researching in western Arnhem Land, they remain largely subjective and dissenting views have also emerged (e.g. Chippindale and Taçon 1993, 1998; Haskovec 1992).

Identifying some of the shortcomings of Chaloupka's formal classification and chronology, Darrell Lewis $(1983,1988)$ divided the art of western Arnhem Land into four periods: Boomerang, Hooked Stick, Broad Spearthrower and Long Spearthrower. On the basis of changes in depicted items of material culture in the rock art, and linking these changes more systematically to the archaeological and environmental evidence, Lewis (1988:ix) proposed a somewhat different chronology to that of Chaloupka. Lewis also suggested that there were regional variations within the Hooked Stick period (pre-6000 BP).

Paul Taçon (1993) also identified regional variations in the most recent art (post-5000 BP), particularly manifest in a higher proportion of fish motifs (including those in the X-ray form) in the northern areas of the Arnhem Land plateau (see also Taçon 1988). Taçon undertook a re-classification of X-ray art (Taçon 1987, 1989, 1992b), subdividing it into Early and Recent. Taçon's Early versus Recent types of X-ray art are not simply a reiteration of Chaloupka’s 'descriptive' versus 'decorative' types (Chaloupka 1984, 1993), which Taçon sees more as variations of types of X-ray infill often made at the same time and sometimes even by the same artists rather than as chronological phases (although Taçon also notes that there is more so-called 'decorative' $\mathrm{X}$-ray art in the past 1000 years than previously). For instance, Early X-ray rock art is much less detailed than Recent X-ray art (Chaloupka's decorative and descriptive X-ray paintings), and was used primarily for faunal depictions (i.e. Early X-ray human-like figures are rare unlike Recent $\mathrm{X}$-ray rock art). Early X-ray paintings usually just show a rectangular or circular body cavity but sometimes also have a thin line backbone, as in the beeswax turtle dated to more than 4000 years ago (see above). More recently, and with particular reference to western Arnhem Land, Taçon and others have highlighted the incorporation of outside influences (Contact art) - European but also including Macassan from Island Southeast Asia - into much recent Aboriginal rock art (e.g. May et al. 2010; Taçon et al. 2010).

In the most recent revision of the sequence and chronology of western Arnhem Land rock art, Christopher Chippindale and Taçon reduced the range of categories to three: New, Intermediate and Old (Chippindale and Taçon 1998; Taçon and Chippindale 1994). Each period had a number of particular styles or used particular techniques, although within each period different styles could coexist and overlap (Chippindale and Taçon 1998:105). The New period, including $\mathrm{X}$-ray art and beeswax figures, is suggested to be the period from the present day to c. $6000 \mathrm{BP}$; the age of the Intermediary period remains unknown, but one of its stylistic groups (Dynamic figures) is proposed to have occurred around 10,000 BP; and the age of the Old period, with 'Panaramitee-like rock-engravings' and 'pigment in shelter deposits' (Chippindale and Taçon 1998:107), is also unknown although they suggest an age of $\geq 30,000-50,000 \mathrm{BP}$. The latter is based on the period of presumed earliest occupation of the region, as dated by Roberts et al. (e.g. 1994) to shortly before 50,000 years ago. Unlike Chaloupka (1993), who proposed that hand stencils occurred within his earliest styles/techniques, Chippindale and Taçon (1998) proposed that hand stencils (excluding the 3MF type, which has the three middle fingers pressed together and thumb and little finger splayed) and prints are not diagnostic and do not belong to a single style or period, as they are represented in both the Old and Recent categories. They also provide a cautionary note regarding the ages of extinction of some of the key animal species such as had been used by Chaloupka in developing his chronology (Chippindale and Taçon 1998:98-99). 


\section{Dating rock art}

In such a context of variable modelling and uncertain antiquity for all of Arnhem Land's rock art styles (for a discussion on the use of the term 'style', see Chapter 6), and a total absence of dates on all forms of art except for a few dating to the mid-Holocene and more dating to the late Holocene, a major challenge for archaeologists in Arnhem Land - as elsewhere in the world of rock art - is to determine accurately the age of the art. Any evidence helping to elucidate the age of rock art styles, motifs or individual artistic traits, or even the antiquity of particular rock surfaces with implications for the maximum possible age of art on those surfaces, is of considerable service to both rock art research in Australia and archaeological modelling of symbolic behaviour, social practice as indicated by painted scenes and territoriality for the region.

The challenge is thus 'how do we date the art?'. Chippindale and Taçon (1998) outline 'many ways' by which Arnhem Land's rock art can be, and in some cases has been, dated. In exploring how we can refine our understanding of the antiquity of the region's rock art, here we restrict ourselves to some general principles along with the major absolute methods that can readily be applied - that is, those major methods that can accurately reveal actual or approximate ages.

\section{'Direct' and indirect methods: Constructing scientifically rigorous and archaeologically meaningful chronological frameworks}

Numerous methods are used to obtain absolute dates on materials directly implicated in the creation of rock art. Predominant among these is radiocarbon dating, where organic materials most commonly form part of the art's pigment.

Other dating methods can also reveal the age of events that through time have been associated with art on rock faces. One of these involves the dating of calcite accretions over or under rock art through Uranium-series dating $\left(\mathrm{U} /{ }^{230} \mathrm{Th}\right.$ series), enabling minimum or maximum ages to be determined for the creation of the art (see Chapter 7 for a comparable application of radiocarbon dating).

Thus, today most rock art dating projects in Australia and internationally try to employ as many 'direct' and indirect dating methods as possible, and on a range of materials. Following Wylie (1989), Chippindale and Taçon (1998:93) have termed such applications and cross-examinations of multifarious approaches towards the formulation of stronger and more reliable chronologies, 'cabling' (see David et al. 2013b for an example).

\section{Notes on the construction of rock art chronologies}

Numerous scientifically reliable methods enable the systematic construction of independently reproducible relative rock art chronologies. Essentially, all methods that reliably allow us to distinguish and sequence events or phases of activity over time frames of interest to archaeologists are usable in the construction of rock art chronologies. In this sense, those dating methods are not restricted to rock art dating.

It is necessary also to emphasise the importance of contextual evidence when interpreting relative or absolute age determinations. In the first instance, the relative chronological position of analysed samples should be worked out, and the relative position of a sample in a sequence should always be taken into account when interpreting the meaningfulness of absolute age determinations. Furthermore, it is imperative to 1 ) determine from the onset how the dated material(s) relate to the anthropic event(s) in question; and 2) take a diachronic approach so that various contextual events or phases can be sequenced relative to each other (e.g. a roof-fall event causing a new ceiling surface to be created, the first creation of a painting, the deposition of a rock surface crust, 
the partial flaking of the rock wall, a repainting event). It will often be necessary to date one or more of the archaeological phases at a site to better understand the age of artistic events, rather than to base one's conclusions solely on one isolated 'direct' date that somehow relates to an item of rock art. For example, we can try to understand the age of art by analysing the stratigraphic context of fallen and now buried painted rocks (e.g. David et al. 2013a); or of the sequence of unpainted to painted exfoliated cortex that now lies buried underground below painted walls (see David et al. 1990 for such an approach applied to Yiwarlarlay 1, the 'Lightning Brothers' site on Delamere Station in Wardaman Country, between Arnhem Land and the Kimberley). Or we can apply geomorphological arguments for the evolution of rock surfaces that today exhibit art (see Delannoy et al. 2013), as has been done to resolve definitively the broad time frame when the large bird painting suspected to be of a Genyornis was made at JSARN-124 site 3 in Jawoyn Country (see Chapter 15). Another example of the use of stratigraphic context to understand the age of rock art is the radiocarbon dating of small charcoal fragments found adjacent to dried paint drops now buried amidst the sands of ancient ground surfaces (see Chapter 11). Another example again is the revelation of the antiquity of art relative to the heating of rock wall surfaces at Chauvet Cave - that is, drawings were made on top of a rock surface that had been heated by nearby fires (Brodard et al. 2014; Ferrier et al. 2014).

\section{Methodological considerations}

Robust chronologies require reliable and multiple results, and absolute chronologies require large numbers of age determinations that cover the full diversity of targeted art and art types. It is always a good thing to seek to employ as many reliable analytical methods as possible, so that independent results can be cross-examined towards a stronger conclusion capable of withstanding critical examination. Let us not forget that each analytical technique brings with it its own particular strengths and limitations; the use of multiple techniques potentially enables cross-examination of results that do not share the same kinds of embedded technical limitations. Obtaining multiple dates through a range of dating techniques also allows for increasingly robust statistical results, including the application of Bayesian methods and the construction of chronological models that enable the researcher to better constrain archaeological interpretations (e.g. Quilès et al. 2014a, 2014b).

\section{Major dating methods in rock art research}

\section{Indirect dating methods}

Before absolute methods of dating rock art (outlined below) were invented, indirect dating was used to establish rock art chronologies. This approach is still useful today, especially in combination with absolute methods (Chippindale and Taçon 1998). Essentially, indirect dating involves examining the sequence of superimposed styles at rock art sites, determining subject matter as best as possible within styles, correlating subject matter with changing environmental records, bridging to the excavated archaeological record and its dates wherever possible and looking for indicative subject matter within styles to help better place them in sequences, such as depictions of extinct taxa (e.g. thylacines, Tasmanian devils), animals introduced thousands of years ago (e.g. the dingo) and contact period subject matter such as ships, horses and firearms. For instance, a painting of a kangaroo in a particular style under a painting of a thylacine would be at least c. 3500 years of age, and possibly much older, while a painting of a kangaroo in a different style on top of a European-introduced horse is necessarily less than about 200 years of age. Exciting results from indirect dating can be found in many of the chapters, along with results from more direct methods. 


\section{Accelerator mass spectrometry radiocarbon dating}

Radiocarbon dating of rock art made of wood charcoal remains the most common 'direct' dating method in rock art research (e.g. Valladas et al. 2005), although it is critical never to lose track of the fact that such radiocarbon dates are proxies for when the wood died, rather than dating its burning to charcoal or the artistic events themselves. We must also remember that 'charcoal' can also be made of other materials, such as burnt bone. It is also possible to date meaningfully calcite layers that may have accumulated below or above art, thereby potentially revealing maximum or minimum ages for the associated art (e.g. Beck et al. 2001; Genty et al. 1999, 2001, 2004; Plagnes et al. 2003; see also Chapter 7). Those same calcite deposits can be dated by U/Th, allowing for the useful cross-examination of results. Major, regular inter-comparison programs that enabled the cross-interrogation of results are warranted (Cuzange et al. 2007; Quilès et al. 2014b).

\section{Uranium-Thorium series dating}

In rock art research, Uranium-Thorium $(\mathrm{U} / \mathrm{Th})$ dating is most rewarding when dating calcite that is directly associated with art, be they stencils, paintings or engravings. The dated calcite can lie underneath an artwork and thus predate it, or it can have accreted over it and thus post-date the art. It is most common to apply U/Th dating to layers of calcite that overlie items of rock art; its aim is thus to give a minimum age for that art.

Uranium-Thorium dating, long used for dating corals and speleothems (stalagmites, stalactites), is more difficult to apply to very thin and irregular layers of calcite that lie on rockshelter and cave wall surfaces. In effect, water runoff on rock walls could lead to the dissolution of Uranium and the distortion of age determinations, by making them older than would otherwise be the case (for a recent critical review, see Sauvet et al. 2015). One way to verify the validity of U/Th ages is to couple them with other methods such as radiocarbon dating that also allows the dating of calcite subject to minor corrections for 'dead' carbon (Beck et al. 2001; Fontugne et al. 2013; Genty et al. 1999, 2001; Plagnes et al. 2003; see also Chapter 7). At the limestone site of Chauvet Cave in France, speleothems 'growing' at ground level were covered with wood charcoal stains. The independent U/Th dating of the speleothems and radiocarbon dating of the charcoal revealed slightly older ages for the charcoal. This is consistent with their expected relative chronologies, as the speleothems could only have incorporated the charcoal in their growth if the charcoal already occurred on the ground prior to their development (taking into account that no new charcoal could enter the cave after the roof collapse that sealed off its entrance by 21,000 years ago). This cross-examination of two independent dating methods gave further confidence to the reliability of the results (Genty et al. 2004). Refinements in U/Th methods have taken place in recent years (e.g. TIMS U/230 Th), giving rise to MC-ICPMS (multicollector-inductively coupled plasma mass spectrometry) U/230 Th dating (Aubert et al. 2014; Fontugne et al. 2013; Pike et al. 2012).

\section{Thermoluminescence}

Thermoluninescence (TL) can be used to date rock surfaces that have been heated, including limestone surfaces (Guibert et al. 2015; Roque et al. 2001). The dating of extant surfaces through TL is useful to rock art research in cases where decorated surfaces were created as a result of rock collapse or exfoliation caused by heating (i.e. giving maximum ages for the art), or where the pigments of the art contain minerals that were affected by the heating events, and where the heating events can be TL-dated through those mineral inclusions (giving minimum ages for the art) (Brodard et al. 2014; Ferrier et al. 2014; Watanabe et al. 2003). 


\section{Single grain optically stimulated luminescence}

Single grain optically stimulated luminescence (OSL) dating of sand grains incorporated in pigments, or of mineral grains in biological structures such as wasp nests or bird nests found below or above layers of pigment, offer promising potential for better understanding the age of rock art (e.g. Roberts et al. 1997; Wallis 2002). Again, such investigations are best done by applying multiple dating techniques, such as OSL and radiocarbon dating of individual wasp nests overlying or underlying the art.

\section{Cosmogenic dating of the rock support}

The timing of changes in the configuration of rock walls as a result of rock collapse can in some cases be determined by cosmogenic dating. That is, it is possible in some situations to determine when a rock surface was created by dating when it became exposed to cosmogenic radiation, thereby offering maximum ages for art on those rock surfaces. Cosmogenic dating can be undertaken on a number of different isotopes, depending on the mineralogy of the rock in question. The dating of the closure of the entrance of Chauvet Cave is an example of how cosmogenic dating can help better understand the age and context of rock art. Cosmogenic dating $\left({ }^{36} \mathrm{Cl}\right)$ showed that the cliff above the entrance of Chauvet Cave collapsed a number of times between 29,000 and 21,000 years ago, sealing the cave during its later stages of collapse. Determining the age of the cave's closure enabled the Chauvet Cave researchers to narrow the timing of when people could have entered the cave to make the art within the site (Sadier et al. 2012). By comparing when the cave was open (as determined by ${ }^{36} \mathrm{Cl}$ dating of the entrance collapse) with radiocarbon and U/Th dates for periods of human activity including rock art inside the cave, a coherent and more robust chronological model could be constructed for human activity within the site (see Quilès et al. 2014a, 2014b; Sadier et al. 2012).

\section{Conclusion}

The case studies presented in this monograph are in many ways a work in progress, in the sense that none of these projects have yet finished. Thus, this monograph is not a single story with a beginning and an end, but rather something that brings together the results of many recent research projects on the archaeology of western Arnhem Land rock art. Clearly, significant results have already been achieved, both in terms of particular findings (e.g. Chapters 3, 4, 7, 11, 12, 14, 15) and in terms of the development of novel investigative methods (e.g. Chapters 10, 15). These results have allowed innovative chronological models to be developed for the art (e.g. Chapters 4, $6,11,12)$, setting the scene for further challenges as well as reflections and reassessments. We see this volume as the start of something new, not as the presentation of the results of past projects from which we can comfortably brush aside the cobwebs and exit the scene.

In presenting this volume, there has been little need to standardise terms across chapters, as the language used by each author has generally been comparable from the onset. The one exception is in the use of the term 'motif', which different authors initially used in very different ways. Throughout this volume, 'motif' is used to refer to an image type, while individual paintings and other art are referred to as 'images'. For example, three paintings of circles and one painting of a square would equate to two motifs (circles and squares) but four images.

Finally, as local families have told us, we hope that the research presented in this volume will both instil new pride about heritage and culture in Arnhem Land Aboriginal communities, and inspire a new generation of rock art researchers so that collaborative research on Arnhem Land rock art will continue to grow. We also would like this volume to influence federal, territory and local governments to initiate new programs that will assist with the conservation and management of Arnhem Land rock art so that it may continue to inform and inspire the world long into the future. 


\section{Acknowledgements}

BD, RG, JJD and JMG extend our deepest thanks to Margaret Katherine and family, Wes Miller, Ray Whear and the Jawoyn Association Aboriginal Corporation for inviting us to research and making us feel at home in Jawoyn (Buyhmi clan) Country. Thanks to Elisa Boche, Magen O'Farrell, Daniel James, Jacqueline Matthews and Chris Urwin for helping with the excavations, and Daniel James for systematically photographing the rock art. BD thanks the Australian Research Council for ARC Linkage grant LP110200927, ARC Discovery grants, QEII and Discovery Outstanding Research Award (DORA) Fellowships DP0877782 and DP130102514, and the ARC Centre of Excellence for Australian Biodiversity and Heritage grant CE170100015. RG thanks the many senior Jawoyn Elders he has worked with over the past 30 years who have provided a social and cultural background to the current research, and the George Chaloupka Fellowship 2009 (MAGNT Foundation and ERA Pty Ltd) and grants from the Department of Sustainability, Environment, Water, Population and Communities, Canberra.

PT, in particular, thanks Ronald Lamlami and Cecil Namindjbuk (also known as Patrick Lamilami) not only for permission and encouragement to conduct field research within the Naminidjbuk clan estate of Arnhem Land's Wellington Range but also for their warm friendship and generous hospitality. PT also thanks the many dozen Traditional Owners he has worked closely with across Arnhem Land since 1981. The Australian Research Council is thanked for ARC Discovery grant DP0877463 and ARC Laureate Fellowship FL160100123. Kakadu National Park, the Northern Land Council, the Australian Museum and Griffith University have generously supported PT's Arnhem Land Research since the early 1990s. Thanks also to Sally K. May, Christopher Chippindale and many other close friends and collaborators who participated on numerous adventures of discovery, Kara Rasmanis for drafting Figure 1.1, and two anonymous referees who helped improve this monograph.

Last but not least, we would like to thank the many, many past generations of Arnhem Land artists. You have left a legacy that is an inspiration to us all.

\section{References}

Aubert, M., A. Brumm, M. Ramli, T. Sutikna, E.W. Saptomo, B. Hakim, M.J. Morwood, G.D. van den Bergh, L. Kinsley and A. Dosseto 2014. Pleistocene cave art from Sulawesi, Indonesia. Nature 514:223-227. doi.org/10.1038/nature13422

Beck J.W., D.A. Richards, R.L. Edwards, B.W. Silverman, P.L. Smart, D.J. Donahue, S. HererraOsterheld, G.S. Burr, L. Calsoyas, A.J.T. Jull and D. Biddulph 2001. Extremely large variations of atmospheric ${ }^{14} \mathrm{C}$ concentration during the last glacial period. Science 292(5526):2453-2458. doi. org/10.1126/science.1056649

Brandl, E.J. 1972. Thylacine designs in Arnhem Land rock paintings. Archaeology and Physical Anthropology in Oceania 7(1):24-30.

Brandl, E.J. 1973. Australian Aboriginal Paintings in Western and Central Arnhem Land. Australian Institute of Aboriginal Studies, Canberra.

Brodard, A., P. Guibert, C. Ferrier, E. Debard, B. Kervazo and J.-M. Geneste 2014. Les rubéfactions des parois de la grotte Chauvet: Une histoire de chauffe? In P. Paillet (ed.), Les Arts de la Préhistoire: Micro-analyses, Mises en Contextes et Conservation. Paleo (special issue) 2014:233-235.

Chaloupka, G. 1984. From Palaeoart to Casual Paintings. Monograph Series 1. Northern Territory Museum of Arts and Sciences, Darwin. 
Chaloupka, G. 1993. Journey in Time: The World's Longest Continuing Art Tradition. Reed, Chatswood.

Chippindale, C. and P.S.C. Taçon 1993. Two old painted panels from Kakadu: Variation and sequence in Arnhem Land rock art. In J. Steinbring, A. Watchman, P. Faulstich and P.S.C. Taçon (eds), Time and Space: Dating and Spatial Considerations in Rock Art Research, pp. 32-56. Occasional AURA Publication 8. Australian Rock Art Research Association, Melbourne.

Chippindale, C. and P.S.C. Taçon 1998. The many ways of dating Arnhem Land rock-art, north Australia. In C. Chippindale and P.S.C. Taçon (eds), The Archaeology of Rock-Art, pp. 90-111. Cambridge University Press, Cambridge.

Cuzange, M.-T., E. Delqué-Kolic, T. Goslar, P.M. Grootes, T. Higham, E. Kaltnecker, M.-J. Nadeau, C. Oberlin, M. Paterne, J. Van der Plicht, C. Bronk Ramsey, H. Valladas, J. Clottes and J.-M. Geneste 2007. Radiocarbon intercomparison program for Chauvet Cave. Radiocarbon 49(2):339-347. doi. org/10.1017/S0033822200042272

David, B., I. McNiven, J. Flood and R. Frost 1990. Yiwarlarlay 1: Archaeological excavations at the Lightning Brothers site, Delamere station, Northern Territory. Archaeology in Oceania 25:79-84. doi. org/10.1002/j.1834-4453.1990.tb00237.x

David, B., B. Barker, F. Petchey, J.-J. Delannoy, J-M. Geneste, C. Rowe, M. Eccleston, L. Lamb and R. Whear 2013a. A 28,000 year old excavated painted rock from Nawarla Gabarnmang, northern Australia. Journal of Archaeological Science 40:2493-2501. doi.org/10.1016/j.jas.2012.08.015

David, B., J.-M. Geneste, F. Petchey, J.-J. Delannoy, B. Barker, M. Eccleston 2013b. How old are Australia's pictographs: A review of rock art dating. Journal of Archaeological Science 40:3-10. doi. org/10.1016/j.jas.2012.08.019

David, B., B. Barker, J.-J. Delannoy, J.-M. Geneste, F. Petchey and L. Lamb 2014. A Pleistocene charcoal drawing or painting from northern Australia. International Newsletter on Rock Art 69:18-22.

Delannoy, J.-J., B. David, J.-M. Geneste, M. Katherine, B. Barker, R.L. Whear and R.G. Gunn 2013. The social construction of caves and rockshelters: Chauvet Cave (France) and Nawarla Gabarnmang (Australia). Antiquity 87:12-29. doi.org/10.1017/S0003598X00048596

Ferrier, C., É. Debard, B. Kervazo, A. Brodard, P. Guibert, D. Baffier, V. Feruglio, B. Gély, J.-M. Geneste and F. Maksud 2014. Les parois chauffées de la grotte Chauvet-Pont d'Arc (Ardèche, France): Characterisation et chronologie. Paleo 25:59-78.

Fontugne, M., Q. Shao, N. Frank, F. Thil, N. Guidon and E. Boeda 2013. Cross-dating (Th/U_- $\left.{ }^{14} \mathrm{C}\right)$ of calcite covering prehistoric paintings at Serra da Capivara National Park, Piaui, Brazil. In A.J.T. Jull and C. Hatté (eds), Proceedings of the 21st International Radiocarbon Conference. Radiocarbon 55(2-3):1191-1198.

Genty, D., M. Massault, M. Gilmour, A. Baker, S. Verheyden and E. Kepens 1999. Calculation of the past dead carbon proportion and variability by the comparison of AMS ${ }^{14} \mathrm{C}$ and TIMS U/Th ages on two Holocene stalagmites. Radiocarbon 41(3):251-270. doi.org/10.1017/S003382220005712X

Genty, D., A. Baker, M. Massault, C. Proctor, M. Gilmour, E. Pons-Branchu and B. Hamelin 2001. Dead carbon in stalagmites: Carbonate bedrock paleodissolution vs. ageing of soil organic matter. Implications for ${ }^{13} \mathrm{C}$ variations in speleothems. Geochimica Cosmochimica Acta 65(20):3443-3457. doi.org/10.1016/S0016-7037(01)00697-4

Genty, D., B. Ghaleb, V. Plagnes, C. Causse, H. Valladas, D. Blamart, M. Massault, J.-M. Geneste and J. Clottes 2004. Datations U/Th (TIMS) et ${ }^{14} \mathrm{C}$ (AMS) des stalagmites de la grotte Chauvet (Ardèche, France): Intérêt pour la chronologie des évènements naturels et anthropiques de la grotte. Comptes Rendus Palevol 3:629-642. doi.org/10.1016/j.crpv.2004.06.005 
Guibert P., A. Brodard, A. Quiles, J.-M. Geneste, D. Baffier, É. Debard, C. Ferrier 2015. When were the walls of the Chauvet-Pont d'Arc cave heated? A chronological approach by thermoluminescence, Quaternary Geochronology 29:36-47.

Gunn, R.G. 2016. Art of the Ancestors: Spatial and Temporal Patterning in the Rock Art of Nawarla Gabarnmang, a Major Jawoyn Cultural Site on the Arnhem Land Plateau. Unpublished PhD thesis, Monash University, Clayton.

Gunn, R.G. and R.L. Whear 2008. A singular beeswax representation of Namarrkon, the Lightning Man, from western Arnhem Land. Australian Aboriginal Studies 2008(2):54-69.

Gunn, R.G., R.L. Whear and L.C. Douglas 2012. Dating the present at Nawarla Gabarnmang: Time and function in the art of a major Jawoyn rock art and occupation site in western Arnhem Land. Australian Archaeology 75:55-65. doi.org/10.1080/03122417.2012.11681950

Haskovec, I.P. 1992. Mt Gilruth revisited. Oceania 27:61-74. doi.org/10.1002/j.1834-4453.1992. tb00285.x

Jelinek, J. 1978. Mimi or the archaic art of Arnhem Land. Archaeology and Physical Anthropology in Oceania 13:229-233.

Jelinek, J. 1989. The Great Art of the Early Australians: The Study of the Evolution and Role of Rock Art in the Society of Australian Hunters and Gatherers. Moravian Museum, Anthropos Institute, Brno.

Jones, R. (ed.) 1985. Archaeological Research in Kakadu National Park. Special Publication 13. Australian National Parks and Wildlife, Canberra.

Leichhardt, L. 1846. Dr Leichhardt's lectures - lecture II. Sydney Morning Herald, 27 August 1846 (lecture delivered at School of Arts, Sydney University on 25 August 1846).

Lewis, D. 1983. Art, archaeology and material in Arnhem Land. Unpublished B.A. (Honours) thesis, Department of Prehistory and Anthropology, The Australian National University, Canberra.

Lewis, D. 1988. The Rock Paintings of Arnhem Land, Australia. BAR International Series 415. British Archaeological Reports, Oxford.

May, S.K. 2009. Collecting Cultures: Myth, Politics, and Collaboration in the 1948 Arnhem Land Expedition. AltaMira Press, Lanham.

May, S.K., Taçon, P.S.C., Wesley, D. and M. Travers 2010. Painting history: Indigenous observations and depictions of the 'other' in northwestern Arnhem Land, Australia. Australian Archaeology 71:57-65. doi.org/10.1080/03122417.2010.11689384

McBryde, I. 1966. An Archaeological Survey of the New England Region, New South Wales. Unpublished PhD thesis, University of New England, Armidale.

McNiven, I.J. and L. Russell 2005. Appropriated Pasts: Indigenous Peoples and the Colonial Culture of Archaeology. AltaMira Press, Lanham.

Mountford, C.P. 1956. Records of the American-Australian Scientific Expedition to Arnhem Land, Vol. 1: Art, Myth and Symbolism. Melbourne University Press, Melbourne.

Nelson, D.E. (ed.) 2000. The Beeswax Art of Northern Australia. Simon Fraser University, Burnaby.

Nelson, D.E., G. Chaloupka, C. Chippindale, M.S. Alderson and J.R. Southon 1995. Radiocarbon dates for beeswax figures in the prehistoric rock art of northern Australia. Archaeometry 37:151-156. doi.org/10.1111/j.1475-4754.1995.tb00733.x 
Pike, A.W.G., D.L. Hoffman, M. Garcia-Diez, P.B. Pettitt, J. Alcolea, R. De Balbin, C. González-Sainz, C. de las Heras, J.A. Lasheras, R. Montes and J. Zilhão 2012. U-series dating of Paleolithic art in 11 caves in Spain. Science 336(6087):1409-1413. doi.org/10.1126/science.1219957

Plagnes, V., C. Causse, M. Fontugne, H. Valladas, J.-M. Chazine and L.-H. Fage 2003. Cross dating $\left(\mathrm{Th} / \mathrm{U}-{ }^{14} \mathrm{C}\right)$ of calcite covering prehistoric paintings in Borneo. Quaternary Research 60(2):172-179. doi.org/10.1016/S0033-5894(03)00064-4

Quiles, A., H. Valladas and J.-M. Geneste 2014a. Datation ${ }^{14} \mathrm{C}$ : Méthode, calibration et modélisation, de nouvelles perspectives? Contribution à la chronologie de l'art pariétal au Paléolithique supérieur. In P. Paillet (ed.), Les Arts de la Préhistoire: Micro-analyses, Mises en Contextes et Conservation. Paleo (special issue) 2014:27-40.

Quiles, A., H. Valladas, J.-M. Geneste, J. Clottes, D. Baffier, B. Berthier, F. Brock, C. Bronk Ramsey, E. Delque-Količ, J.-P. Dumoulin, I. Hajdas, K. Hippe, G.W.L. Hodgins, A. Hogg, A.J.T. Jull, E. Kaltnecker, M. de Martino, C. Oberlin, F. Petchey, P. Steier, H.-A. Synal, J. Van der Plicht, E.M. Wild and A. Zazzo 2014b. Second radiocarbon intercomparison program for the Chauvet-Pont d'Arc Cave, Ardèche, France. Radiocarbon 56(2):833-850. doi.org/10.2458/56.16940

Roberts, R.G., R. Jones, N.A. Spooner, M.J. Head, A.S. Murray and M.A. Smith 1994. The human colonisation of Australia: Optical dates of 53,000 and 60,000 years bracket human arrival at Deaf Adder Gorge, Northern Territory. Quaternary Science Reviews 13:575-583. doi.org/10.1016/02773791(94)90080-9

Roberts, R.G., G. Walsh, A. Murray, J. Olley, R. Jones, M. Morwood, C. Tuniz, E. Lawson, M. Macphail, D. Bowdery and I. Naumann 1997. Luminescence dating of rock art and past environments using mud-wasp nests in northern Australia. Nature 387:606-699. doi. org/10.1038/42690

Roque, C., P. Guibert, E. Vartanian, F. Bechtel and M. Schvoerer 2001. Thermoluminescencedating of calcite: Study of heated limestone fragments from Upper Paleolithic layers at Combe Saunière, Dordogne, France. Quaternary Science Reviews 20:935-938. doi.org/10.1016/S02773791(00)00049-4

Sadier, B., J.-J. Delannoy, L. Benedetti, D. Bourlès, S. Jaillet, J.-M. Geneste, A.E. Lebatard and M. Arnold 2012. Further constraints on the Chauvet cave artwork elaboration. Proceedings of the National Science Academy (PNAS) 109(21):8002-8006. doi.org/10.1073/pnas.1118593109

Sauvet, G., R. Bourillon, M. Conkey, C. Fritz, D. Gárate-Maidagan, O.R. Vilá, G. Tosello and R. White 2015. Uranium-thorium dating method and Palaeolithic rock art. Quaternary International. doi.org/ 10.1016/j.quaint.2015.03.053

Schrire, C. 1982. The Alligator Rivers: Prehistory and Ecology in Western Arnhem Land. Terra Australis 7. Department of Prehistory, Research School of Pacific Studies, The Australian National University, Canberra.

Spencer, B. 1914. Native Tribes of the Northern Territory of Australia. MacMillan, London.

Taçon, P.S.C. 1987. Internal-external: a re-evaluation of the 'x-ray' concept in western Arnhem Land rock art. Rock Art Research 4(1):36-50.

Taçon, P.S.C. 1988. Identifying fish species in the recent rock paintings of western Arnhem Land. Rock Art Research 5(1):3-15.

Taçon, P.S.C. 1989. From Rainbow Snakes to X-Ray Fish: The Nature of the Recent Rock Painting Tradition of Western Arnhem Land, Australia. Unpublished PhD thesis, The Australian National University, Canberra. 
Taçon, P.S.C. 1992a. The last rock painters of Kakadu. Australian Natural History 23(11):866-873.

Taçon, P.S.C. 1992b. Somewhere over the rainbow: An ethnographic and archaeological analysis of recent rock paintings of western Arnhem Land, Australia. In J. McDonald and I.P. Haskovec (eds), State of the Art: Regional Rock Art Studies in Australia and Melanesia, pp. 202-215. Occasional AURA Publication 6. Australian Rock Art Research Association, Melbourne.

Taçon, P.S.C. 1993. Regionalism in the recent rock art of western Arnhem Land, Northern Territory. Archaeology in Oceania 28(3):112-120. doi.org/10.1002/j.1834-4453.1993.tb00302.x

Taçon, P.S.C. and C. Chippindale 1994. Australia’s ancient warriors: Changing depictions of fighting in the rock art of Arnhem Land, (N.T.). Cambridge Archaeological Journal 4:211-248. doi. org/10.1017/S0959774300001086

Taçon, P.S.C., E. Nelson, C. Chippindale and G. Chaloupka 2004. The beeswax rock art of the Northern Territory: Direct dating results and a 'book of record'. Rock Art Research 21(2):155-160.

Taçon, P.S.C., S.K. May, S.J. Fallon, M. Travers, D. Wesley and R. Lamilami 2010. A minimum age for early depictions of Southeast Asian praus in the rock art of Arnhem Land, Northern Territory. Australian Archaeology 71:1-10. doi.org/10.1080/03122417.2010.11689379

Valladas, H., N. Tinsnerat-Laborde, H. Cacher, É. Kaltlecker, M. Arnold, C. Oberlin and J. Évin 2005. Bilan des datations carbone 14 effectuées sur des charbons de bois de la grotte Chauvet. Bulletin de la Société Préhistorique Française 102(1):109-113. doi.org/10.3406/bspf.2005.13342

Wallis, L.A. 2002. AMS dates and phytolith data from mud wasp and bird nests at Carpenter's Gap 1, Northern Australia. Australian Archaeology 55:35-39.

Watanabe, S., W.E.F. Ayta, H. Hamaguchi, N. Guidon, E.S. La Salvia, S. Maranca and O. Baffa 2003. Some evidence of a date of first humans to arrive in Brazil. Journal of Archaeological Science 30(3):351-354. doi.org/10.1006/jasc.2002.0846

Watchman, A.L. 1987. Preliminary determinations of the age and composition on mineral salts on rock art surfaces in the Kakadu National Park. In W.R. Ambrose and J.M.J. Mummery (eds), Archaeometry: Further Australasian Studies, pp. 36-42. Department of Prehistory, Research School of Pacific Studies, The Australian National University, Canberra.

Watchman, A.L. 1993. Evidence of a 25,000-year-old pictograph in northern Australia. Geoarchaeology 8:465-473. doi.org/10.1002/gea.3340080603

Watchman, A.L. 2000. Micro-excavation and laser extraction methods for dating carbon in silica skins and oxalate crusts. In G. Ward and C. Tuniz (eds), Advances in Dating Australian Rock Markings: Papers from the First Australian Rock Picture Dating Workshop, pp. 35-39. Occasional Aura Publication 10. Australian Rock Art Research Association, Melbourne.

Watchman, A.L. and R. Jones 2002. An independent confirmation of the 4 ka antiquity of a beeswax figure in western Arnhem Land, northern Australia. Archaeometry 44:145-153. doi.org/10.1111/ $1475-4754.00049$

White, C. 1967. Plateau and Plain: Prehistoric Investigations in Arnhem Land, Northern Territory. Unpublished $\mathrm{PhD}$ thesis, The Australian National University, Canberra.

White, C. 1971. Man and environment in northwest Arnhem Land. In D.J. Mulvaney and J. Golson (eds), Aboriginal Man and Environment in Australia, pp. 141-157. Australian National University Press, Canberra. 
Woodroffe, C.D., J. Chappell, B.G. Thom and E. Wallensky 1986. Geomorphological Dynamics and Evolution of the South Alligator Tidal River and Plains, Northern Territory. North Australia Research Unit, The Australian National University, Darwin.

Wylie, A. 1989. Archaeological cables and tacking: The implications of practice for Bernstein's 'Options beyond objectivism and relativism'. Philosophy of the Social Sciences 19:1-18. doi.org/ $10.1177 / 004839318901900101$ 



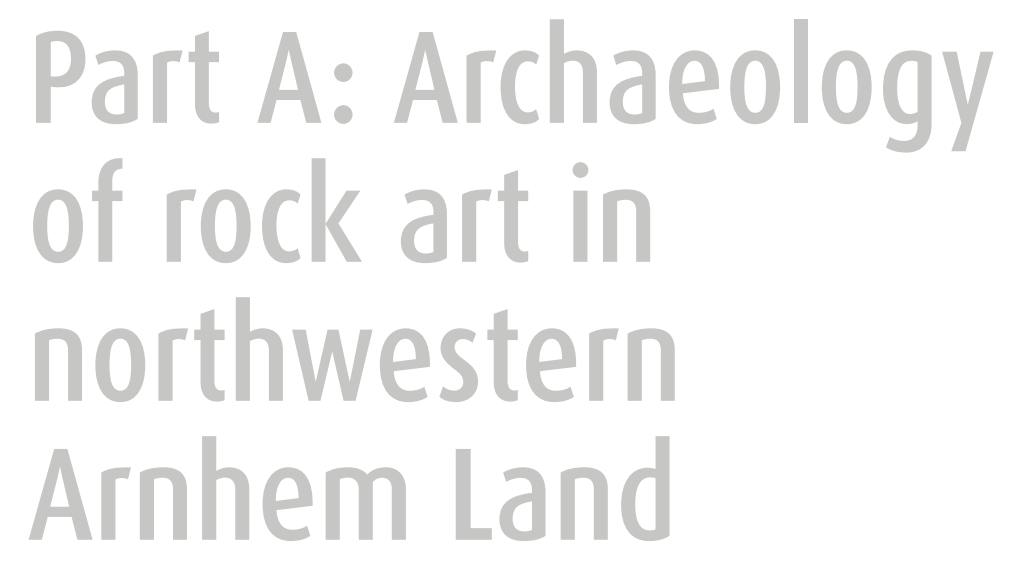





\title{
People and fish: Late Holocene rock art at Wulk Lagoon, Arnhem Land
}

\author{
Daryl Wesley, Tristen Jones and Rose Whitau
}

\section{Introduction}

Taçon and Brockwell (1995) made an important contribution to the study of Arnhem Land archaeology by showing that, in combining rock art with environmental change, archaeological sequences and artefact assemblages, a multi-disciplinary synthesis for a regional archaeological narrative could be achieved. A similar approach was taken by David and Lourandos (1998) in an overview of rock art and archaeology in Cape York Peninsula, northern Queensland. This chapter proposes to examine the rock art of the Wulk Lagoon area, northwestern Arnhem Land, by using approaches discussed by Taçon and Brockwell (1995) and David and Lourandos (1998) to analyse rock art, with a methodology that includes reference to environment, ecology and climate change along with local archaeological sequences from excavated rockshelters.

The late Holocene archaeological record of Arnhem Land is abundant, owing to high levels of Aboriginal occupation around the extensive wetlands and on the Arnhem Land plateau. Investigations of stone artefact assemblages in Australia have utilised approaches such as manufacturing technologies and proliferation events apparently linked to El Niño/Southern Oscillation (ENSO) and subsequent responses to risk in a context of environmental change (see Attenbrow et al. 2009; Clarkson 2002, 2007; Hiscock 2002, 2008, 2011; Hiscock and Attenbrow 1998, 2005; Lamb and Clarkson 2005; Veth et al. 2011). Residential mobility has also been assessed through characteristics such as the diversity and abundance of cultural materials in archaeological assemblages (see Andrefsky 2005, 2009; Kintigh 1984, 1989; Thomas 1973, 1989). In our case, here we try to understand Aboriginal occupation and behaviour in the Wulk Lagoon area, on the East Alligator River, over the past 1500 years via the distribution of its rock art (Figure 2.1).

Previous archaeological investigations in the region have usually paid minor attention to the rock art (see Allen and Barton 1989; Hiscock 1999, 2008, 2011; Schrire 1982). Hiscock (2008) has repeatedly pointed out that the art encodes valuable information, but identifies current shortcomings for true archaeological interpretation. Nevertheless, valuable advances in rock art research elsewhere have drawn on climate and environmental change (see McDonald 2015; McDonald and Veth 2013), pigment studies (see Huntley 2012; Huntley et al. 2014; Wesley et al. 2014) and 'direct' dating (see McDonald et al. 2014; Smith et al. 2009; Watchman 2000; Watchman and Jones 2002; Watchman et al. 1997, 2010). Each provides valuable information, allowing rock art to be better integrated into discussions of Aboriginal pasts. 


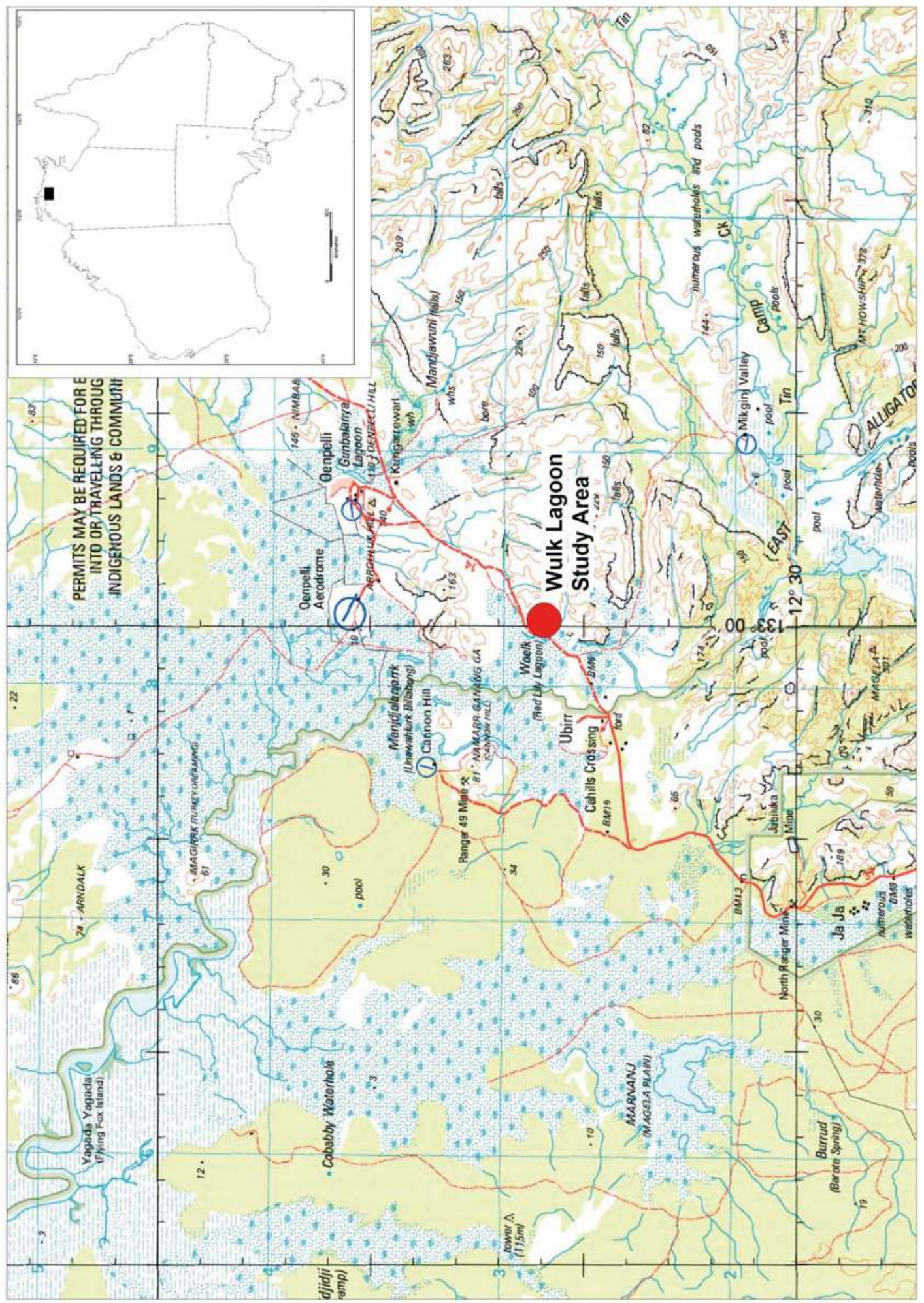

Figure 2.1 Location of Wulk Lagoon study area, western Arnhem Land, Northern Territory.

Source: Base map after SD-5301 Geoscience Australia. @ Commonwealth of Australia (Geoscience Australia) 2015. This material is released under the Creative Commons Attribution 4.0 International Licence. 
At Wulk Lagoon, faunal themes are well evident, especially fish. Fish and other animals not only represent food resources, but also reference points for more esoteric aspects of life, as we know from ethnography both here and elsewhere. In the East Alligator River region, fish signal estuarine and freshwater ecologies and the widespread geomorphological changes that took place during the mid to late Holocene. Wulk Lagoon's rock art also contains many examples of the anthropomorphic 'Energetic Figure' (Taçon 1989a, 1989b), 'Complete Figure', and 'X-ray' styles (see Chippindale and Taçon 1993, 1998) (for descriptions of the various art styles mentioned in this chapter, see Wesley 2015). The emergence of these rock art styles, or manners of depiction, their variation and their distributions across the landscape are important for understanding late Holocene occupation of the region. We thus ask of Wulk Lagoon's rock art:

- Was it evenly produced across the landscape during the late Holocene?

- To what degree have climate and environment influenced human occupation and mobility, and how can the art aid us in this quest?

- Through time, did the positioning of rock art change across the landscape?

- What were the major subjects expressed in the art, and did these vary across space or change through time?

- Within rockshelters, was the rock art produced during occupation, or were the two largely mutually exclusive?

Significant changes in the environment and ecology of the East Alligator River have previously been noted for the period following sea level stabilisation c. 6000 years ago (e.g. Chappell 1988; Chappell and Grindrod 1985; Clark and Guppy 1988; Grindrod 1988; Hope et al. 1985; Russell-Smith 1985a, 1985b; Wasson 1992; Woodroffe 1988; Woodroffe et al. 1985a, 1985b, $1986,1987,1988)$. Archaeological research nearby has shown the subsequent dramatic impacts of marine and estuarine change on human occupation and mobility, on the plains and on the plateau generally (Allen and Barton 1989; Bourke et al. 2007; Brockwell 1989, 1996; Hiscock 1999; Hiscock et al. 1992; Jones 1985; Kamminga and Allen 1973; Meehan et al. 1985; Schrire 1982). The last 6000 years saw new economic strategies develop, presumably to deal with these environmental changes, but also in response to social conditions. Excavations at rockshelter sites such as Birriwilk, Ngarradj Warde Djobkeng, Malakunanja II (Madjedbebe), Nawamoyn, PariPari and Jimeri (Jimede) clearly show the changes that occurred in diet, occupation and stone tool technologies (see Figure 1.1 for site locations) (Allen and Barton 1989; Hiscock 1999, 2011 ; Kamminga and Allen 1973; Schrire 1982; Shine et al. 2013). However, these excavations tell us much less about changes in rock art for that same period of time.

Wulk Lagoon's rock art appears to be consistent with Chaloupka's (1977, 1984, 1985, 1993) sequence of major rock art styles that followed post-glacial sea-level rise. But there are also limitations to attributing, reducing even, stylistic change to environmental change (see Chippindale and Taçon 1998; Lewis 1988). The late Holocene rock art is diverse and abundant, even within broad stylistic phases (Chaloupka 1977, 1984, 1985, 1993; Chippindale and Taçon 1998; Lewis 1988; Taçon 1989a, 1989b), and preservation has played its part. Nevertheless, it presents a rich opportunity to examine depictive or symbolic aspects of culture and cultural diversity, and in relation to occupation.

\section{The study area: Wulk Lagoon}

To investigate degrees of abundance and diversity in depictive behaviour - how people marked the land - a $3.5 \mathrm{~km}^{2}$ sandstone outcrop next to Wulk Lagoon was surveyed on the western side of the East Alligator River's coastal plain (Figure 2.1). Wulk Lagoon is in the traditional estate of the Manilakarr clan of the Erre language group. It and nearby palaeo-channels form important 
water features parallel to the northwestern edge of the sandstone plateau. It is in Mamadewerre Sandstone (part of the Kombolgie Sub-Group), a cross-bedded quartzose sandstone with medium to very coarse grain, and siliceous sandstone. Outcropping rock is generally found as sandstone tors, platforms and escarpment features (Duggan 1994; Needham 1984; Senior and Smart 1976; Sweet et al. 1999). The sandstone outcrop at Wulk Lagoon is bounded by extensive coastal plains of the East Alligator River, rich in alluvial sediments with large lagoons, palaeo-channels and Melaleuca sp., Eleocharis dulcis and Oryza rufipogon-dominated swamps and sedge-lands.

The Wulk Lagoon area first came to prominence for its rock art during the 1948 AmericanAustralian Scientific Expedition to Arnhem Land through a number of publications by Charles Mountford (1956, 1964, 1965, 1975). The outlying sandstone hills next to Wulk Lagoon were called 'Inagurdurwil' by Mountford (1956). This is a name that is not recognised by Manilakarr Traditional Owners today; Gunn (1992) suggested that it may have been provided by an Aboriginal informant from Gunbalanya rather than by an Erre speaker. Mountford was particularly attracted to the detailed hunting scenes in the art, discussing them in detail along with the greater significance of the rock art seen during the expedition. These scenes and motifs at the Inagurdurwil galleries include images of running figures and men hunting (see Bühler et al. 1965:209). Mountford $(1964,1965,1975)$ discussed techniques, materials and pigments used to make rock art in the region, using Inagurdurwil as a primary example. He refers to the rock art of western Arnhem Land as by far the most colourful he had encountered in Australia, again with specific reference Inagurdurwil (Mountford 1964:12).

Fred McCarthy (1965) was also part of that same 1948 expedition; he provided an overview of the archaeology. Some of the material he wrote about includes rock paintings from western Arnhem Land, X-ray and 'spirit' paintings, and painted caves at Red Lily (Wulk) Lagoon and elsewhere on the Manilakarr estate. McCarthy (1965) discusses 'Mormo' and 'Mimi' spirits, and reports X-ray paintings from Inagurdurwil, along with descriptions of the purposes of magic, increase rites and the education of boys, each a significant feature of cultural knowledge for Manilakarr Traditional Owners. Further research at Wulk Lagoon was later undertaken by Jan Jelinek. Jelinek (1986) incorporated Inagadurwil in his general schema of western Arnhem Land rock art, studying rock art sites Inagurdurwil I to VI in particular. His stylistic identifications, chronological assessments and interpretations of the archaeological significance of these sites are highly problematic, as they were made without reference to previous research while making highly improbable stylistic chronologies. Later, in 1990, Gunn (1992) undertook a detailed survey of surrounding parts of the Manilakarr estate, recording rock art imagery from numerous sites, including several at Wulk Lagoon. He documented sacred and cultural knowledge relating to Dreaming images and Spirit-Beings, such as Birriwilk ('old lady'), Rainbow Serpent (Ngalyod), barramundi, malevolent spirits (Namarodo and Marlwah), 'old hairy spirit' (Djidjnguk) and 'scarecrow figure' (Djiworrn Djiworrn).

\section{Western Arnhem Land during the late Holocene}

Previous archaeological discussions by Allen and Barton (1989), Brockwell (1989, 1996), Hiscock (1999), Hiscock et al. (1992), Jones (1985), Meehan et al. (1985), Schrire (1982) and others all refer to important Holocene environmental transformations for the region. Initial postglacial sea-level rise would have affected Aboriginal economic and, probably, social order, given the vast exposed landscapes that came to be inundated by rising seas. Since then, the past c. 6000 years saw two major environmental phases along the Alligator Rivers: a major 'Big Swamp' phase (c. 6000 to $4000 \mathrm{BP}$ ) followed by 'Sinuous' and 'Cuspate' phases (4000 BP to present), which, in due course, came to see a 'Freshwater' period of wetland development (1500 BP to present) (Allen and Barton 1989; Jones 1985; Kamminga and Allen 1973; Schrire 1982). Throughout

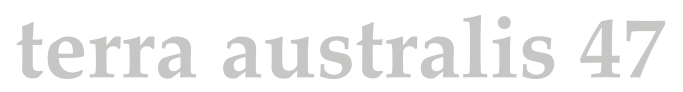


this time, Aboriginal people continued to occupy the region, as indicated by archaeological deposits in rockshelter sites at and near Wulk Lagoon, including the Birriwilk site a short distance south (Shine et al. 2013). Shine et al. (2013:72) dated the initial use of the Birriwilk shelter c. 4865-5065 cal BP, with occupation continuing into the European-contact period.

Archaeological research in late Holocene wetlands of the nearby plains found ecological diversity to be as important as biomass for Aboriginal settlement (Brockwell 1989; Brockwell et al. 2001; Guse 1992; Hiscock et al. 1992; Meehan et al. 1985). Resource biodiversity is usually highest along ecotonal margins between environmental zones. Archaeological studies have demonstrated that ecotones between coastal plains and sandstone plateaux, such as at Wulk Lagoon, provided attractive environments for occupation (Allen and Barton 1989; Hiscock 1999; Jones 1985; Schrire 1982). Such ecotones helped structure resource distributions, and therefore affected the mobility of resident and visiting groups. Areas of higher ecological diversity and resource abundance were targeted, forming sustained subsistence-settlement strategies that made their mark on the archaeological record (Allen and Barton 1989; Brockwell 1989, 1996; Hiscock 1999; Hiscock et al. 1992; Jones 1985; Meehan et al. 1985; Schrire 1982). Archaeological sites located at such ecotones, and in areas of high biodiversity and resource abundance, have thus been found to have substantial archaeological records, including rock art. But whereas these past studies have focused on faunal remains and stone artefacts, here we examine the art on the rocks.

\section{Environmental change during the late Holocene}

A number of geomorphological studies have investigated landscape history in the greater Alligator Rivers region (see above), but there are currently no palaeo-environmental reconstructions specific to the East Alligator River at Wulk Lagoon. The closest research occurred c. $13 \mathrm{~km}$ west, at Magela Creek, which focused on the ecological history of this backwater swamp and palaeotributary of the East Alligator River (East et al. 1987a, 1987b). Pollen evidence and radiocarbon dates from mangrove muds and shell middens in the Magela floodplain suggest a longer Big Swamp phase for the western East Alligator River region than for the South Alligator River, with Rhizophora forest dominating the pollen record from c. 8000 to 3000 BP (Clark and Guppy 1988:680-681). The Sinuous phase, which Clark and Guppy (1988:680-681) define as a transitional period from mangrove forest to freshwater wetland, has a later and slightly shorter record in the Magela floodplain than in the main South Alligator River region, lasting c. 1700 years from 3000 to $1300 \mathrm{BP}$. The increase in sedimentation rates during this period, together with a subsequent phase of levee formation, may also be related to an increase in precipitation and seasonality (Denniston et al. 2013; Lees and Clements 1987). This transitional period, which experienced maximum environmental instability, produced the greatest vegetation diversity and variability of the Holocene (Clark and Guppy 1988:680-681). This has major implications for understanding changing patterns of Aboriginal occupation.

\section{Climate change during the late Holocene}

Faulkner $(2009,2011)$ notes that across northern Australia, Holocene climate change occurred in tandem with sea-level rise, and stabilisation strongly influenced coastal ecology. Denniston et al. (2013) show that past activity of the Indonesian-Australian Summer Monsoon (IASM), InterTropical Convergence Zone (ITCZ) and El Niño/Southern Oscillation (ENSO) may have driven precipitation variability since at least the mid-Holocene. In particular, the IASM strengthened during the early Holocene, with enhanced peak rainfall between 8000 and 4000 years ago, with a possible phase of increasing aridity from 6300 to 4500 years ago. This was followed by a decrease in IASM strength around 4000 years ago, leading to lower rainfall. Denniston et al. (2013) found peak aridity between 2000 and 1000 years ago, followed by a strengthening IASM developing 
into the pattern we experience today. There is also evidence from Magela Creek and the Daly River indicating a significant dry phase lasting c. 160 years from 690 to 530 BP (Wasson et al. 2010:172).

Increasing and decreasing precipitation have major impacts not only on vegetation and faunal communities, but also on rates of sediment accumulation across the landscape, and on the evolution of rivers and coastal systems. In contrast to fluctuating climates, studies of plant species in plateau ravines have revealed that long-lived floristic communities survived all the major climate changes since the Last Glacial Maximum (LGM), a result of the presence of permanent water sources and other factors (Russell-Smith et al. 1997). On this basis, it is likely that fluctuating precipitation driven by ENSO-IASM interactions saw continuity in floristic and faunal communities in dissected sandstone environments, despite a higher overall aridity. Lower precipitation rates can have significant impacts on riverine evolution, with reduced water flows unable to flush out sediments from the sandstone plateau, leading to the siltation of major river systems, thereby choking mangrove communities and establishing massive floodplains, such as at Wulk Lagoon (Chappell 1993, 1988; Woodroffe et al. 1993). These late Holocene fluctuations in IASM precipitation would have aided the proliferation of freshwater swamps and wetlands, significantly influencing shifts in woodland communities.

\section{Recent rock art research in Arnhem Land}

Archaeological research has shown the great length of Aboriginal occupation across the 'Top End' of the Northern Territory (e.g. Allen and Barton 1989; Bird et al. 2002; Brockwell et al. 2009, 2011; Clarkson et al. 2017; David et al. 2012; Delannoy et al. 2013; Geneste et al. 2010, 2012; Gunn and Whear 2007a, 2007b; Gunn et al. 2010a, 2010b, 2011; Hiscock 1999; Hiscock et al. 1992; Jones 1985; Meehan et al. 1985; Roberts et al. 1990; Schrire 1982; Shine et al. 2013). At Nawarla Gabarnmang, a small piece of quartzite with charcoal lines was retrieved from buried sediments dated to 27,000-28,000 cal BP, one of the oldest dated painted images in Australia (David et al. 2012). Around that time, Aboriginal people were actively modifying the shape of the shelter by knocking down rock pillars to expand the space within (see Chapter 10). Gunn et al. (2012) further document that, during the late Holocene, rock art at this site included a range of conventions, including what they termed 'Northern', 'Bula' and 'Jawoyn' styles, indicating multiple signalling behaviour at a single site. The Nawarla Gabarnmang research demonstrates how one site or site complex can reshape our understanding of rock art and Aboriginal occupation of the Arnhem Land region.

At the other end of the time scale, to the north of both Nawarla Gabarnmang and Wulk Lagoon, in the coastal sandstone of the Wellington Range, major archaeological and rock art results have also changed our way of thinking: in this case, as it relates to the period of culture contact between Macassans, Europeans and Aboriginal peoples (Clark and May 2013; May et al. 2010, 2011; Taçon et al. 2010; Theden-Ringl et al. 2011; Wesley 2013; Wesley et al. 2012). Analysis of painted ships and firearms caused us to rethink the involvement of Aboriginal people in maritime and terrestrial industries in northern Australia (Wesley 2013; Wesley et al. 2012). 


\section{Methods}

\section{Rock art styles as chronologies}

As noted above, there has been a significant amount of research on Arnhem Land's rock art since the 1960s, leading to the identification of a number of major styles and chronologies (e.g. Brandl 1970, 1980; Chaloupka 1984, 1985, 1993; Chippindale and Taçon 1998; Edwards 1979; Jelinek 1986; Lewis 1988; Taçon 1989a, 1989b). These regional style chronologies have not made much use of absolute chronometric dates, except in the case of beeswax figures (e.g. Taçon et al. 2004). Although Rosenfeld and Smith (1997:407) note that using 'style' can be problematic for the definition of chronologies, they also emphasise its value when rigorously applied.

Here we rely largely on Chippindale and Taçon's $(1993$, 1998) revised style chronology for western Arnhem Land. In a study such as ours at Wulk Lagoon, we need to be clear as to how style, and age, are given to the art, for we are working without absolute dates. Chaloupka (1993), Chippindale and Taçon (1998), Lewis (1988) and Taçon's (1988) identifications of late Holocene art styles, for example, have significantly affected how most, and perhaps all, researchers think of the sequence of stylistic conventions for this broad period of time (see the chronological table in Chippindale and Taçon 1998:107). As Chippindale and Taçon (1998) note, the Arnhem Land sequence has been developed mostly by seriating superimposed classes of painted motifs (cf. Lyman and O'Brien 2006). This includes both the presence and absence of fauna known, or thought, to have been associated with particular environmental conditions (Chaloupka 1993) and weaponry (Lewis 1988). These were perhaps the most viable approaches available to researchers since critical analysis of Arnhem Land rock art began in the early 1970s. Formal analyses of Rainbow Serpents, 'Yam' figures, and X-ray motifs have added to this schema, with links to climate and environmental change (Chaloupka 1993; Chippindale and Taçon 1998; Taçon 1994; Taçon and Brockwell 1995; Taçon et al. 1996).

Although each chronological model has its problems and limitations (see Bednarik 2012, 2014a, 2014b), the Arnhem Land style chronologies proposed by the above authors largely converge towards a broadly acceptable temporal schema (Figure 2.2), with all researchers also recognising that absolute dates are required to better understand the 'real' age of each style.

\section{Survey strategy}

Wulk Lagoon provides an important lens for the archaeology of art at the interface of the Stone Country and the extensive coastal plains. This is a varied landscape, where questions of taphonomy are important for understanding the frequency of art and of art styles and conventions. To deal with such questions, a small sample area was intensively surveyed at Wulk Lagoon as a way of assessing how the larger rock art galleries that preferentially feature in the archaeology, and focal research areas in the escarpment base, compare to the whole. Also to be considered is the three-dimensional nature of the rock escarpment. Rock art occupies a complex space in this landscape, where elevated areas erode and valleys tend to accumulate rocks and finer sediments (see Chapter 1), so we divide the study area into three major zones: the escarpment base, the steeply eroded sides and the rocky hilltops. This enables us to provide samples from different geomorphological, and erosional/depositional, zones. Of particular interest is whether the late Holocene saw all these zones used for rock art production and occupation. By stratifying the survey area in this way, we could also test for preservation and occupation bias in the resulting patterns. 


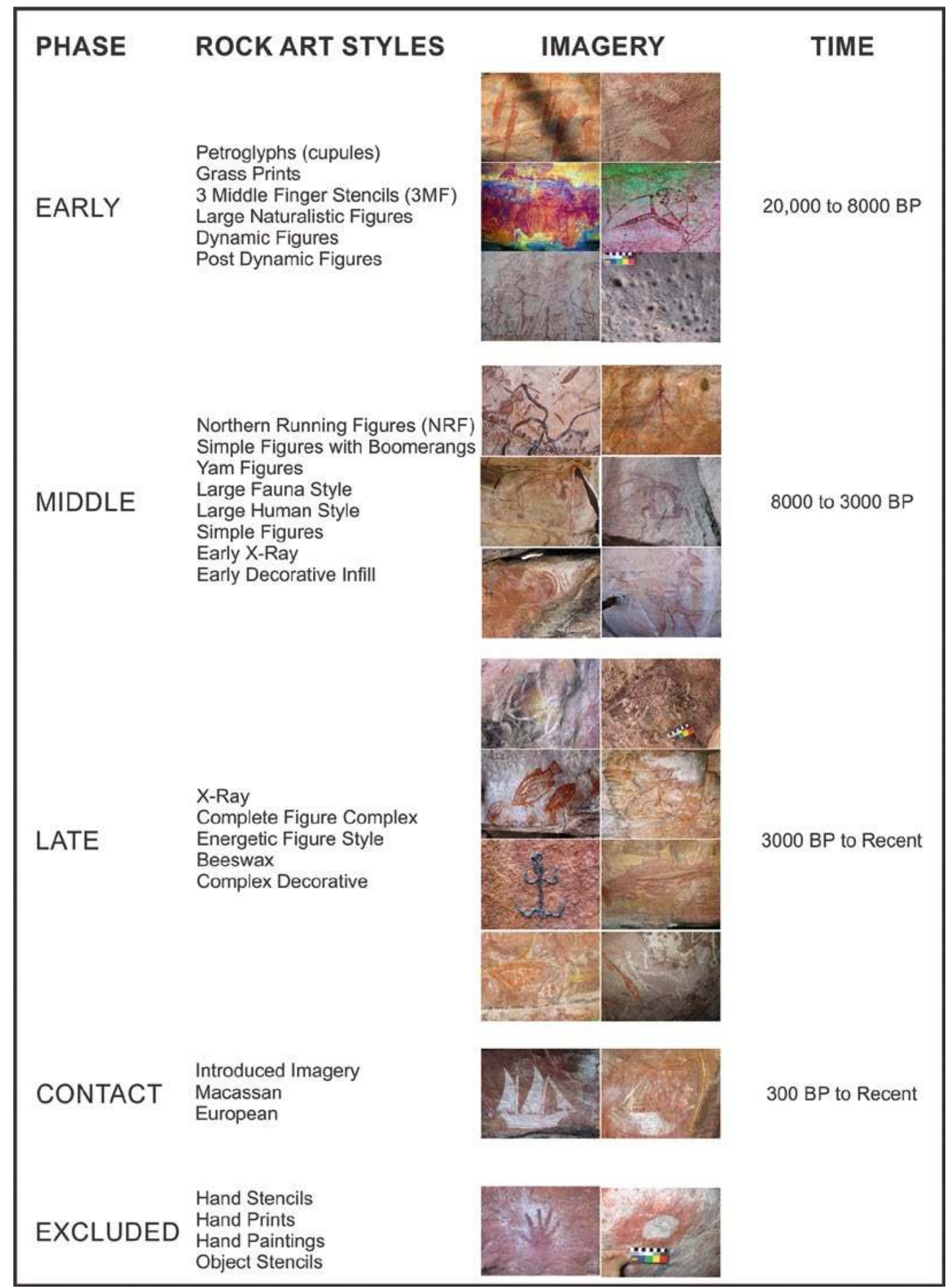

Figure 2.2 Composite rock art phases.

Source: After Chippindale and Taçon (1998:107), with amendments after David et al. (2012) and Gunn et al. (2012). 


\section{Assessing mobility}

A number of analytical techniques have been developed to model mobility and intensities of site use (e.g. Andrefsky 2005; Baxter 2001; Kaufmann 1998; Kintigh 1984, 1989; Thomas 1973, 1989). Many make use of measures of resource diversity and/or richness in the environment, or as evident in the archaeological record. Two properties are usually considered: the number of distinct classes present; and their degree of evenness or uniformity (Kintigh 1989:26). Thomas (1989:86) proposes that the overall relationship between the number of archaeological classes and the number of individual items is influenced by ecological, technological, informational (i.e. 'traditional ecological knowledge') and scheduling factors. He describes three types of sites, distinguished (and measurable) by their archaeological richness: single-use/activity-specific sites, short-term occupation sites and long-term occupation sites. Frequently occupied sites are identified by technologically and typologically diverse stone tool assemblages that might have been used for many purposes, and over long periods of time. Less frequently occupied sites were usually used for more ephemeral, more specific, even single tasks; they have less diverse stone tool assemblages than the more frequently occupied sites. Infrequently occupied sites were even more task-specific, and here stone tool assemblages are the least diverse and least abundant (Thomas 1989:86).

Does this kind of diversity and richness modelling also apply to rock art, and to the rock art sites of Wulk Lagoon? To explore this, we apply Thomas's (1989) principles of frequency and abundance of stone artefacts to the art. The production of rock art involves the use of materials, and it takes time and energy, much like the production and use of stone tools does. We would thus expect the greatest diversity and frequency of rock art styles, motifs and elements to occur also at the most frequented places (Thomas 1989:86). The archaeological classes we use are the rock art styles, anthropomorphic motif types and elements and zoomorphic motif types. Places where rock art was frequently produced are predicted to be rich and diverse in their art styles, motifs and elements; less frequented sites to have intermediate levels of diversity and abundance; and rarely visited places, low diversity and low abundance. Applying these principles of diversity and abundance to rock art may provide a new way of investigating patterns of visitation and engagement, including aspects of occupational intensity not previously considered in Australian rock art research.

\section{Taphonomy}

All archaeological assemblages in Arnhem Land possess taphonomic limitations. Owing to high rainfall levels associated with the IASM, and the predominantly sandy soils, faunal remains and other organic materials are usually poorly preserved (see Jones 1985; Schrire 1982). Highly seasonal climates see annual cycles of drying and wetting, burrowing animals and high levels of soil mobility and/or soil acidity - all poor conditions for the preservation of organics (see Bourke 2000; Brockwell 2009; Gregory 1998; Guse 2006; Mowat 1994, 1995). Therefore, the potential for long-term preservation of both on-wall art and buried pigments requires systematic assessment.

At Wulk Lagoon, a number of pigment types have been found, some in reasonable quantities, during excavations: ferrous oxides and haematite (reds, orange), kaolinite (white), whelwellite (white), kaolinitic claystone (white, red, yellow, orange) (Chaloupka 1993; Taçon 1989a, 1989b; Wesley et al. 2014). Claystone, whelwellite and kaolinite pigments are thought not to preserve well, in part because they are soluble in water. This has often led researchers to assume that paintings (and motif types) made with such pigments date to the mid to late Holocene, but not earlier, for surely they would have disintegrated since then. Climatic regimes with annual wet tropical monsoons will have quickened the dissolution of these soluble pigments, and the strengthening of the IASM through the mid to late Holocene with increased seasonal rainfall 
would have impacted on the art. The presence of white pigment in Arnhem Land rock art may not mean a late antiquity, but in more exposed conditions it more likely does, and thus helps in assigning a time frame.

\section{Results}

In 2011, a total of 77 rock art sites were recorded within the $3.5 \mathrm{~km}^{2}$ Wulk Lagoon study area, providing a mean density of 33.4 sites per $\mathrm{km}^{2}$ (Figure 2.3). In this region, we estimate there are 13,000 rock art motifs painted on approximately 460 sandstone panels. Eight rock art sites face the coastal plain, with the remainder 70 sites on the sandstone outlier itself. The majority of sites were found on the escarpment base, hillside, hilltop or on independent tor outcrops (Table 2.1). Of the 77 rock art sites, 44 are 'rock art panels' (rock art on one to three panels with no other archaeological features) and 33 are 'rockshelters'; this differentiation was made to assess the location of the art relative to the size and nature of its site context. Documented archaeological features include grinding hollows and surfaces, buried cultural deposits, stone arrangements, hearths, stone artefacts, stone quarries, faunal remains, human burials, 'contact' materials and wooden artefacts. Figure 2.4 shows their distribution at Wulk Lagoon. Table 2.2 indicates that, on average, only two archaeological features are present per site. An archaeological excavation was undertaken at Minjnymirnjdawabu 5 (MN05); in conjunction with the survey, it added valuable information regarding the timing of occupation and geomorphological processes at Wulk Lagoon.

Table 2.1 Geomorphological context of rock art sites.

\begin{tabular}{|l|r|}
\hline Context & \# of sites \\
\hline Bluff face & 2 \\
\hline Boulder & 3 \\
\hline Escarpment base & 18 \\
\hline Hillside & 24 \\
\hline Hilltop & 16 \\
\hline Tor & 14 \\
\hline
\end{tabular}

Source: Authors' data.

Table 2.2 Descriptive statistics for the 77 surveyed rock art sites at Wulk Lagoon.

\begin{tabular}{|c|c|c|c|c|c|c|}
\hline & $\begin{array}{c}\text { \# of } \\
\text { archaeological } \\
\text { features/site }\end{array}$ & $\begin{array}{l}\text { \# of styles/ } \\
\text { site }\end{array}$ & $\begin{array}{l}\text { \# of zoomorphic } \\
\text { classes/site }\end{array}$ & $\begin{array}{c}\text { \# of anthropomorphic } \\
\text { classes and } \\
\text { elements/site }\end{array}$ & $\begin{array}{c}\text { \# of } \\
\text { motifs/ } \\
\text { site }\end{array}$ & $\begin{array}{l}\text { \# of rock art } \\
\text { panels/site }\end{array}$ \\
\hline Mean & 2.4 & 4.5 & 4.5 & 5.1 & 167.7 & 6.0 \\
\hline $\begin{array}{l}\text { Standard } \\
\text { deviation (SD) }\end{array}$ & 2.3 & 3.9 & 4.4 & 5.8 & 485.3 & 13.2 \\
\hline $\begin{array}{l}\text { Standard error } \\
\text { of mean (SEM) }\end{array}$ & 0.264 & 0.449 & 0.503 & 0.665 & 55.308 & 1.502 \\
\hline $\begin{array}{l}\text { Lower } 95 \% \\
\text { confidence limit }\end{array}$ & 1.85 & 3.58 & 3.46 & 3.75 & 57.38 & 2.96 \\
\hline $\begin{array}{l}\text { Upper 95\% } \\
\text { confidence limit }\end{array}$ & 2.90 & 5.37 & 5.47 & 6.40 & 278.02 & 8.95 \\
\hline Minimum & 1 & 1 & 0 & 0 & 1 & 1 \\
\hline Median & 2 & 3 & 3 & 3 & 15 & 2 \\
\hline Maximum & 12 & 19 & 19 & 24 & 3000 & 100 \\
\hline
\end{tabular}

Source: Authors' data. 


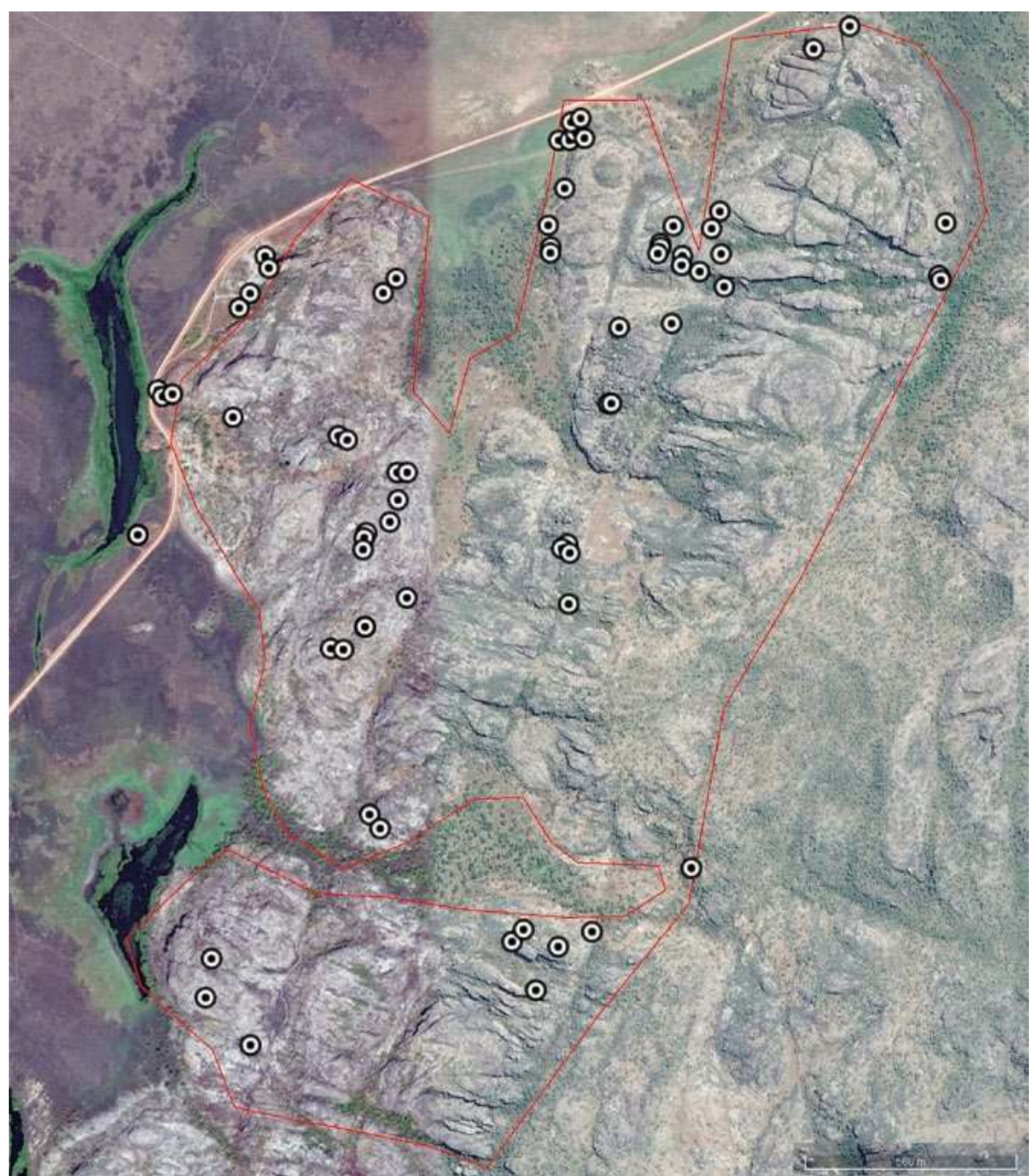

Figure 2.3 Survey area showing location of rock art sites.

Source: @ Google Earth 2014.

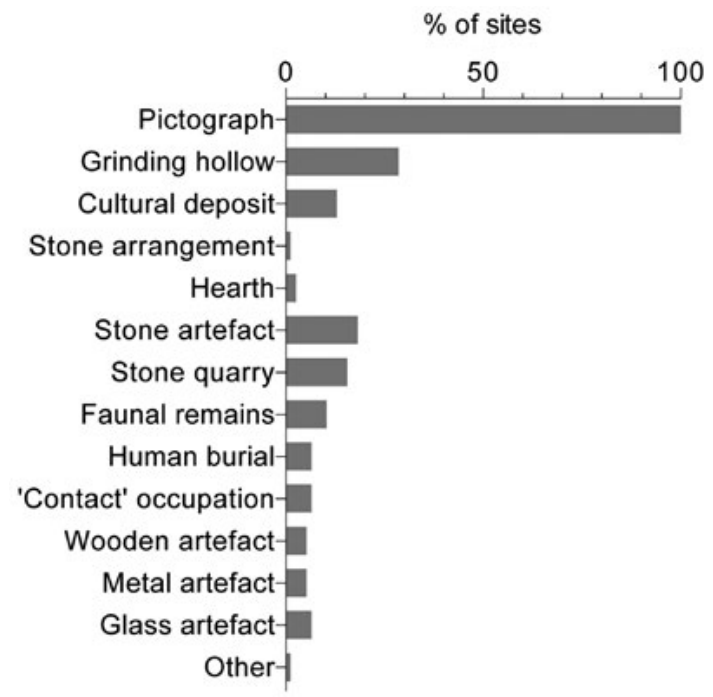

Figure 2.4 Types of archaeological materials present at rock art sites ( $n=77$ sites). Source: Jerome Mialanes. 
Table 2.2 provides descriptive statistics for the art. There are, on average, 4.5 rock art styles per site (median $=3$; maximum $=19$ ). Zoomorphs and anthropomorphs are evenly represented (in 84.4 per cent vs 83.1 per cent of sites, respectively, averaging 4.5 vs 5.1 per site). Eighteen sites have 100 or more images, the largest being RLB032 with c. 3000 (Figure 2.5). The median of 15 motifs per site is more indicative of the trend, as a high standard deviation of 485.3 shows considerable variation in numbers, which range from one to c. 3000 . The average number of panels per site is skewed by a few sites with high numbers.

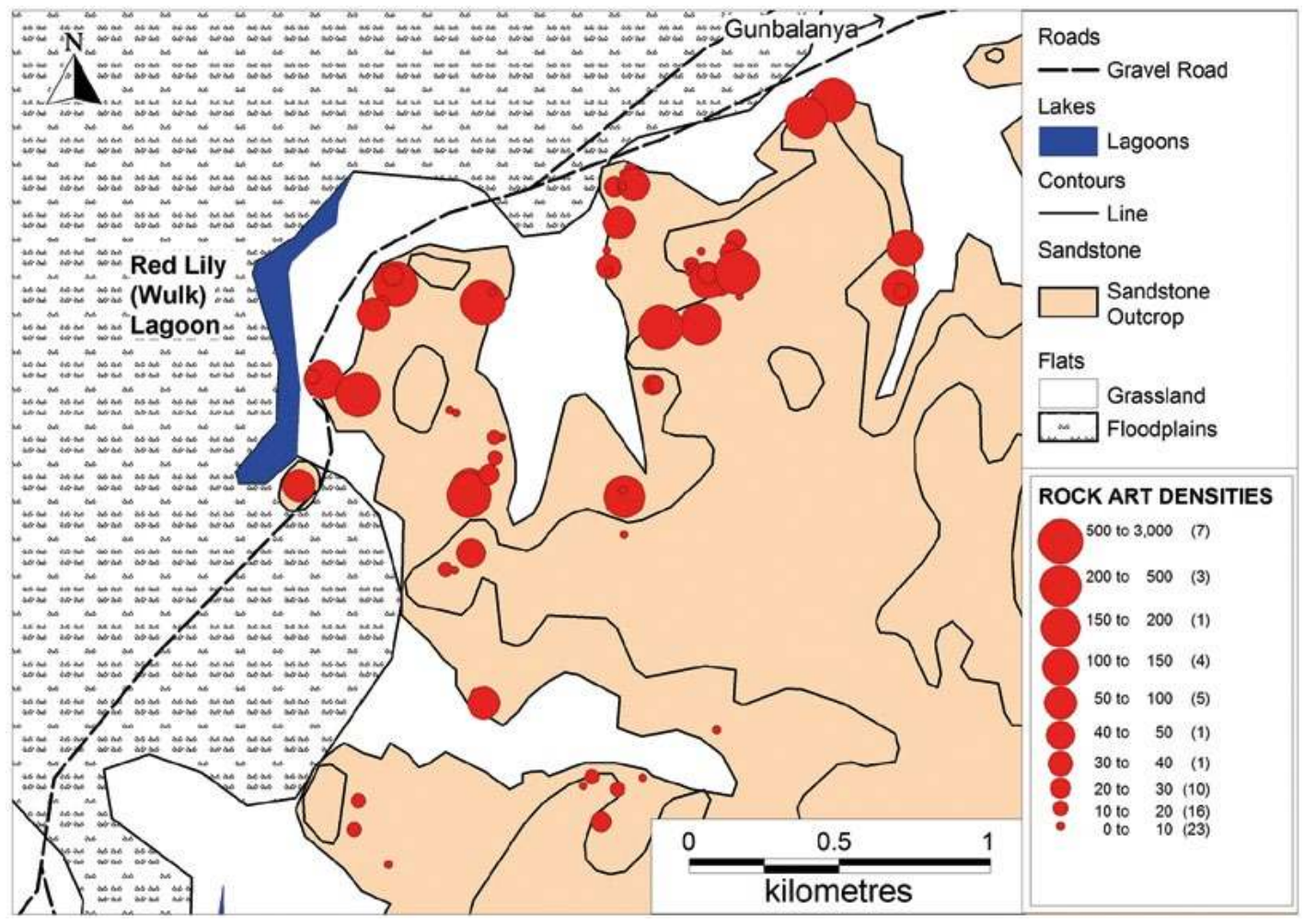

Figure 2.5 Distribution of rock art sites, showing number of artworks in each site.

Source: Daryl Wesley.

A broad range of rock art styles is found at Wulk Lagoon (Figure 2.6). Large Fauna, Large Human, Simple Figures and Complete Figure Complex paintings predominate, followed by X-ray, Early X-ray and Early Decorative Infill. Energetic Figure and X-ray motifs are most common in the major site complexes. Energetic Figures are especially common at the base of the rock outcrops, whereas X-ray and Complex Decorative figures are most common at the two major art complexes on top of the plateau. These three rock art styles clearly superimpose most others, indicating that they are amongst the most recent. Many rock art panels have multiple layers of superimposition.

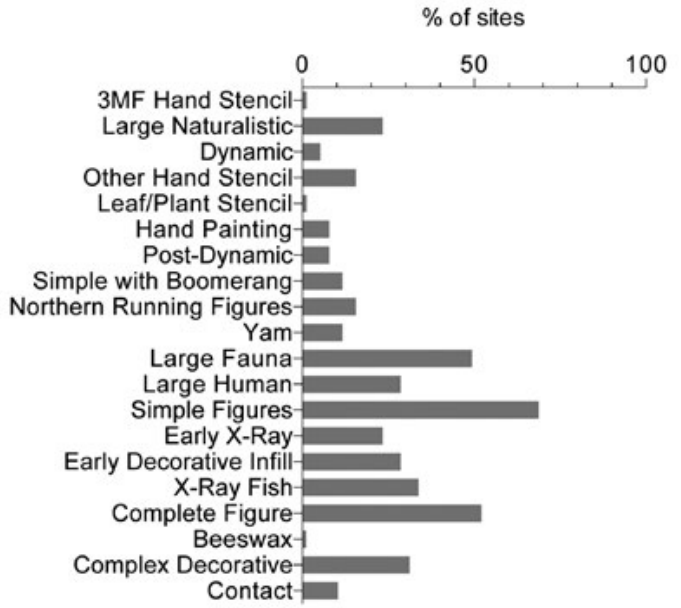

Figure 2.6 Proportion of sites with each rock art style ( $\mathrm{n}=77$ sites).

Source: Jerome Mialanes. 


\section{Zoomorphs}

Zoomorphs include dingo, marsupial, echidna, flying fox, macropod, reptile, goanna, frill-neck lizard, crocodile (freshwater and saltwater), snake, python, long-necked turtle, short-necked turtle, fish, thylacine and bird. Fish motifs are the most abundant; they are discussed at greater length below. Macropods, reptiles, birds, goannas and snakes are each present in more than 20 per cent of sites (Figure 2.7).

Paintings of fish occur in 55 sites. Taçon (1988:5) noted that 43 different native fish species are known from the Alligator Rivers region, with a dozen being consistently depicted in the rock art. He further found that most X-ray depictions are of barramundi, saratoga, fork-tail catfish, eeltail catfish and mullet. Other depicted species include the freshwater longtom, archer fish, black bream, boney bream and terapon perches or grunters (Tacon 1988:5).

Here we analyse 385 fish motifs from the art at Wulk Lagoon. Species include barramundi (Lates calcarifer), saratoga (Scleropages jardini), fork-tailed catfish (a.k.a. 'boofhead' catfish) (Hexanematichthys leptaspis), eel-tailed catfish (Neosilurus hyrtlii), mullet (Liza alata), freshwater longtom (Strongylura kreffti), archer fish (Toxotes chatareus), toothless catfish (Anodontiglanis dahli) and black catfish (a.k.a. narrow-fronted tandan) (Neosilurus ater) (Figure 2.8). Additional to these, many fish depictions could not be identified to species.

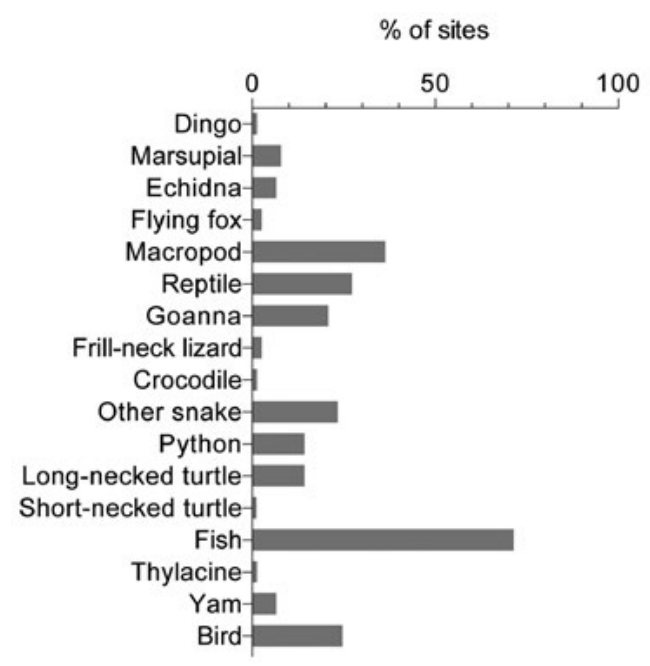

Figure 2.7 Proportion of sites with each type of zoomorph ( $\mathrm{n}=77$ sites).

Source: Jerome Mialanes.

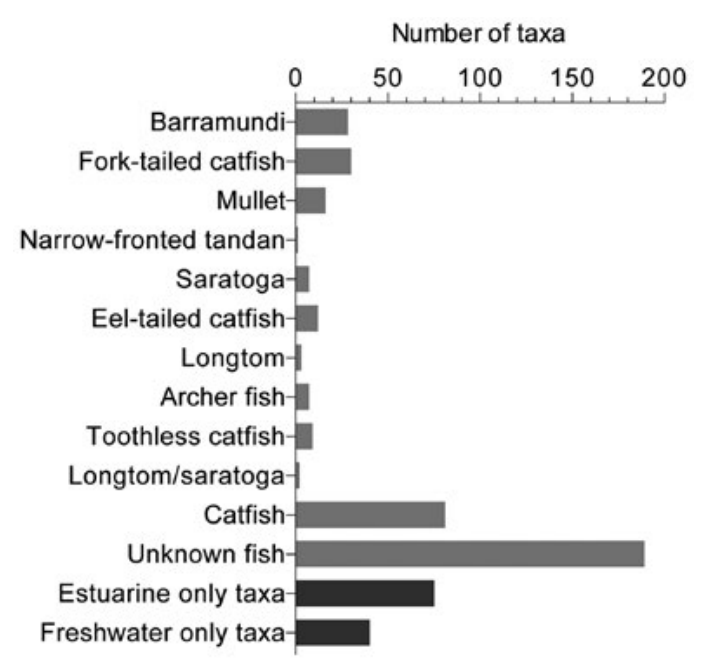

Figure 2.8 Number of paintings by fish taxa.

Source: Jerome Mialanes.

Figure 2.9 indicates the manner in which the fish were painted. The study found 54.5 per cent of the fish paintings were in a Late Phase-style. Estuarine species are more frequent than freshwateronly species. Fork-tail catfish, and catfish in general, are the most common. Their habitats can vary from brackish estuaries to only freshwater: for example, Hexanematichthys leptaspis inhabits both estuarine and freshwater habitats, whereas Neosilurus hyrtlii and Neosilurus ater only live in freshwater, be it still or flowing in streams, billabongs or pools.

The painted fish at Wulk Lagoon are associated with types of waterways that evolved locally only after post-glacial sea-level rise c. 8500-8000 BP (Woodroffe et al. 1985a, 1985b, 1986, 1988). Between 8000 and 3000 BP, the Wulk Lagoon sandstone headland became surrounded by wetlands, swamps and paleo-channels of the former East Alligator River (Hope et al. 1985:239). Large backwater swamps and billabongs are thought to have increased in number in the Alligator 
Rivers region after 3000 BP (Clark and Guppy 1988:680-681; Hope et al. 1985:240). Figure 2.9 also shows the distribution of fish paintings by geographic zone at Wulk Lagoon. There is a preference for sandstone hillsides and hilltops.

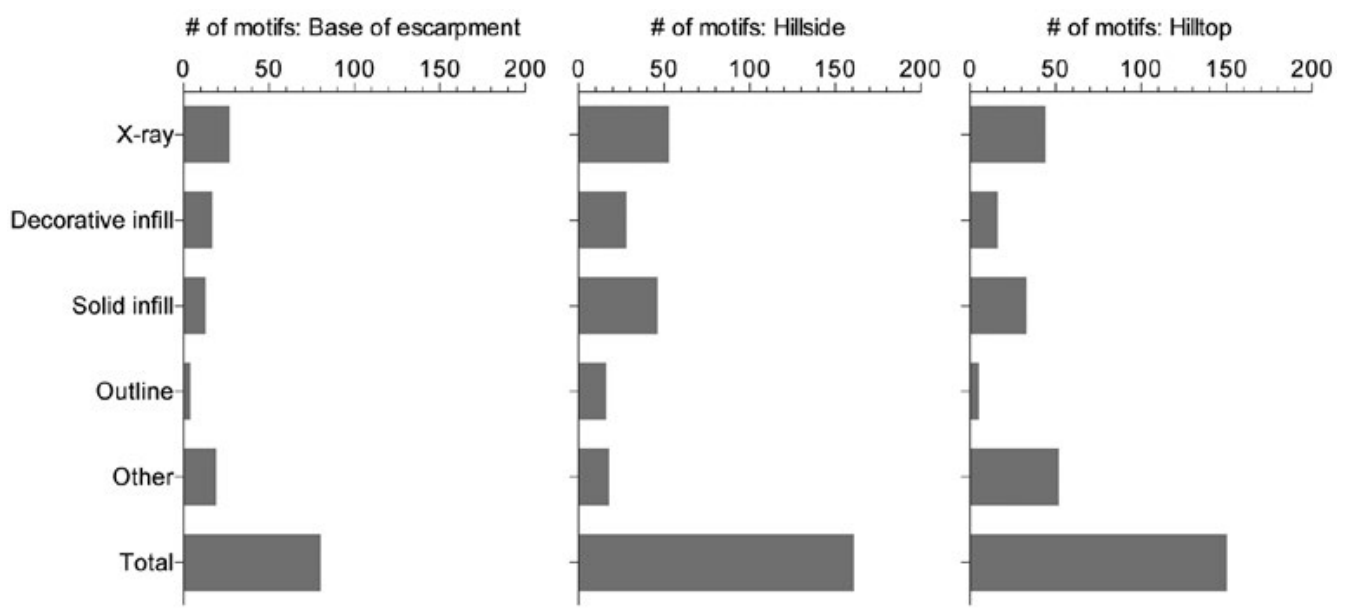

Figure 2.9 Painting manner for fish, by topographic zone.

Source: Jerome Mialanes.

\section{Anthropomorphs}

At Wulk Lagoon, anthropomorphs include a range of shapes and associated items of material culture (see Figure 2.10). Human or human-like figures occur in over 80 per cent of art sites. The majority are males with spears. Many have headdresses and spearthrowers, and a range of spear types is depicted. There is greater diversity in types of weapons than there is in armlets, neckbands, aprons, fans and bags. There are also high numbers of scenes where human figures are engaged in what appear to be ceremony (10.3 per cent), fighting (11.6 per cent) and hunting (23.3 per cent); most of these are in what are thought to be late Holocene styles. Some scenes are in the Northern Running Figure style.

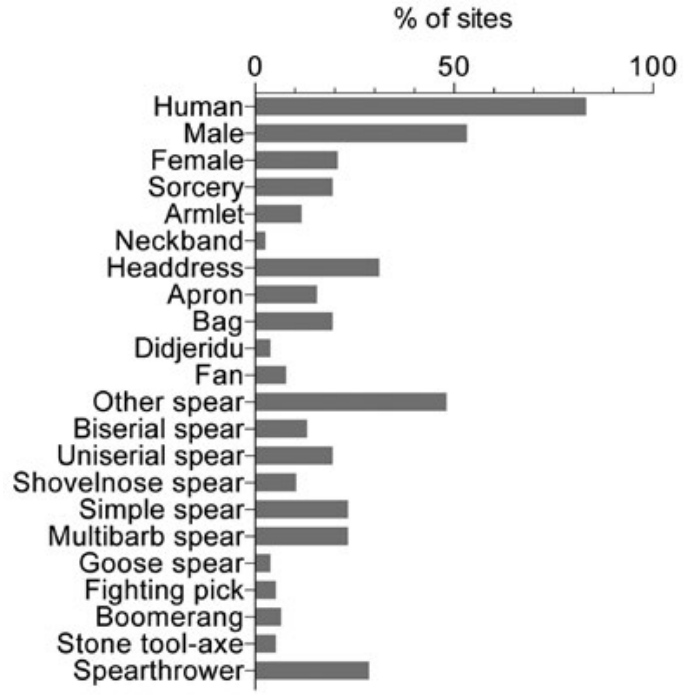

Figure 2.10 Proportion of sites with paintings of anthropomorphs and items of material culture ( $\mathrm{n}=77$ sites).

Source: Jerome Mialanes.

\section{The Minjnymirnjdawabu sites: MN01, MN05 and MN12}

A detailed study was undertaken of 65 rock art panels at three of the Minjnymirnjdawabu sites (MN01, MN05 and MN12). Here the art is again mainly in late Holocene styles. Pigment colours are diverse, many consisting of hues of red, white, orange or yellow (Figure 2.11). Many paintings are in two or more colours, and much pigment was used. Anthropomorphs and fish motifs are again common. Fish were painted in three distinctive patterns: solid infill, outline and X-ray (Figure 2.12). 
The size of art panels appears to have largely been affected by local geology, although there is a continuum in the area of the wall surface selected for painting (Figure 2.13). Figure 2.14 indicates moderate levels of damage on the 65 art panels.

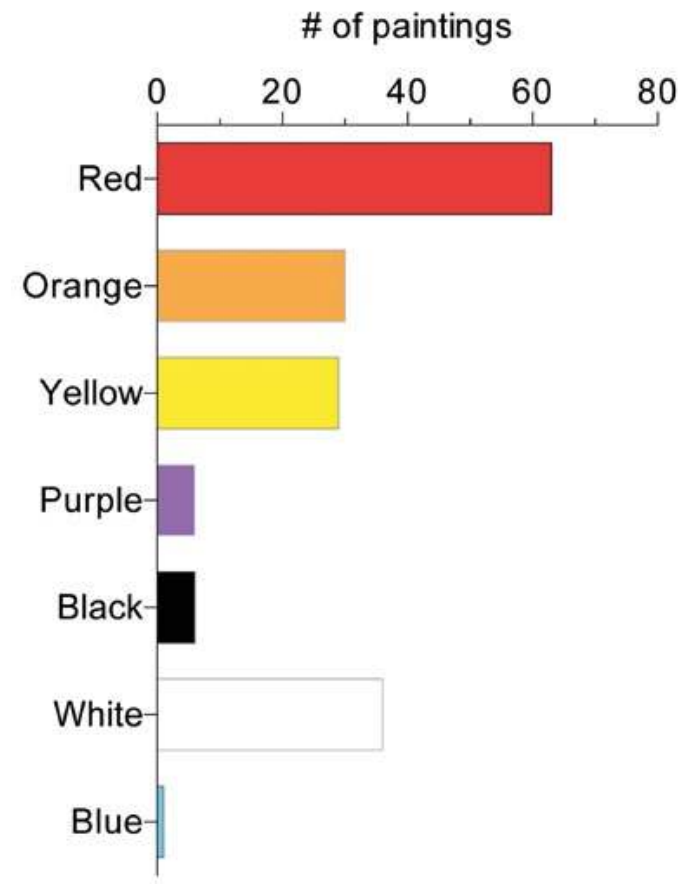

Figure 2.11 Number of paintings by colour, sites MN01, MN05 and MN12.

Source: Jerome Mialanes.

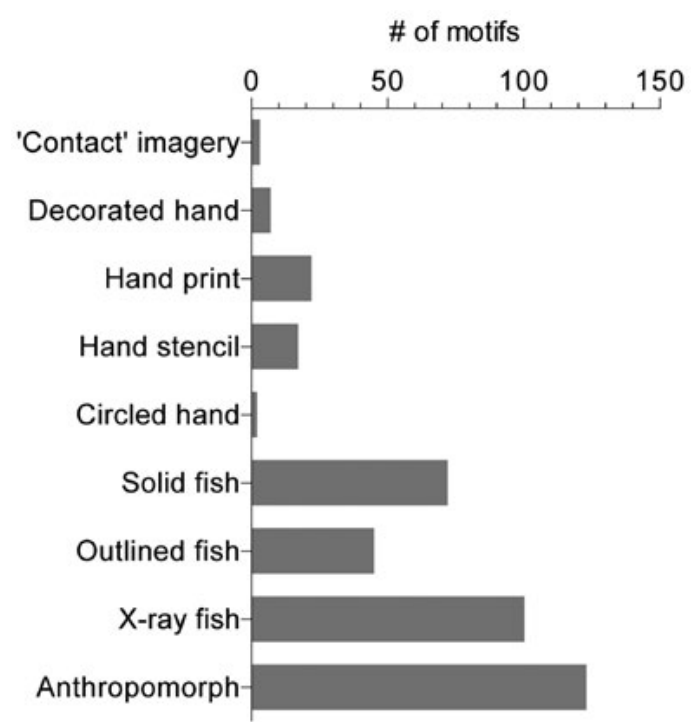

Figure 2.12 Number of artworks by motif type, sites MN01, MN05 and MN12.

Source: Jerome Mialanes.

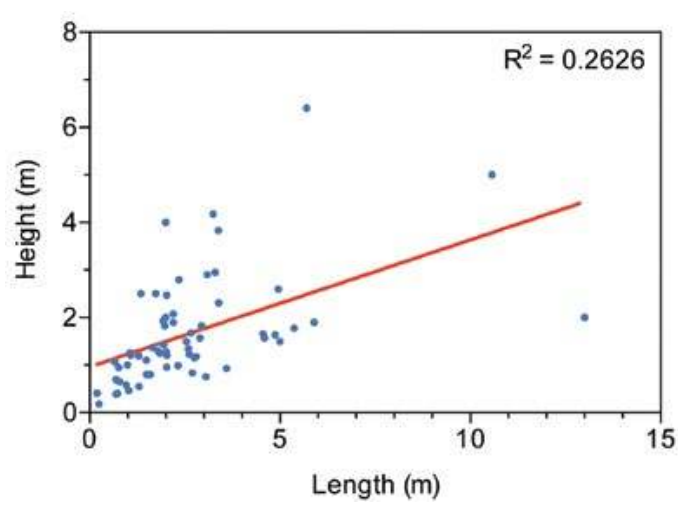

Figure 2.13 Distribution of panel sizes, sites MN01, MN05 and MN12 ( $n=65$ panels). Source: Jerome Mialanes.

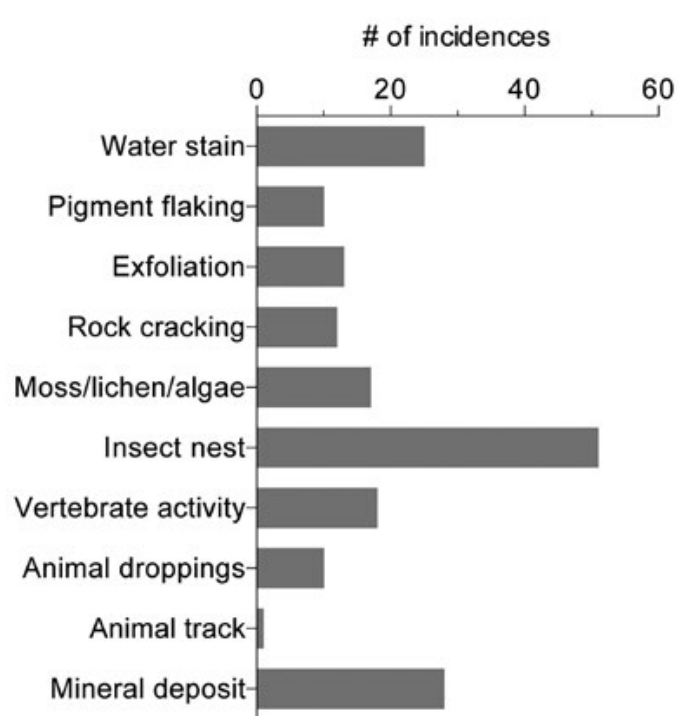

Figure 2.14 Frequency of impacts on rock art across 65 rock art panels, sites MN01, MN05 and MN12.

Source: Jerome Mialanes. 


\section{Archaeological excavation: MN05}

MN05 was selected for excavation because it appeared to have the best potential for datable occupational deposits (Figure 2.15). This is a rockshelter with a large overhang, $8 \mathrm{~m}$ long, $5 \mathrm{~m}$ wide, with an average height of $2.75 \mathrm{~m}$ from floor to ceiling. The ceiling and walls have a number of panels with multiple layers of art, including an impressive array of $\mathrm{X}$-ray paintings of local freshwater fish. The site also contains the famous 'blue' contact painting of a sailing ship. Grinding hollows and surfaces are abundant, attesting to much occupation.

Three $1 \times 1 \mathrm{~m}$ test pits were excavated: one against the wall (Test Pit B), one just outside the dripline (Test Pit A) and one outside the overhang to test the depth of sediment drop-off (Test Pit C). Test Pit A quickly bottomed out on a slab of sandstone. Test Pits B and C were deeper, providing information on occupation beginning shortly after 1000 cal BP (Table 2.3).

Table 2.3 Radiocarbon dates on charcoal from Test Pits B and C, MN05.

\begin{tabular}{|l|c|c|c|c|c|c|c|}
\hline Laboratory code & $\begin{array}{c}\text { Test } \\
\text { Pit }\end{array}$ & Excavation unit & $\begin{array}{c}\text { Depth } \\
\text { (cm) }\end{array}$ & $\begin{array}{c}{ }^{13} \text { ( per } \\
\text { mil }\end{array}$ & $\begin{array}{c}\text { \% modern } \\
\text { carbon }\end{array}$ & $\begin{array}{c}\text { Radiocarbon } \\
\text { date (BP) }\end{array}$ & $\begin{array}{c}\text { Calibrated age } \\
\text { (95.4\% probability) } \\
\text { (cal BP) }\end{array}$ \\
\hline D-AMS 007849 & B & 21 & 47 & -24.2 & $97.95 \pm 0.25$ & $166 \pm 21$ & $165-225$ \\
\hline D-AMS 007850 & C & 23 & 95 & -24.5 & $88.97 \pm 0.24$ & $939 \pm 22$ & $795-950$ \\
\hline
\end{tabular}

Source: OxCal v4.2.3 Bronk Ramsey (2009); IntCal13 atmospheric curve (Reimer et al. 2013).

The deposits contain post-contact objects such as glass flakes and fragments, ceramic sherds, buttons, bullets, metal fragments and glass beads. Stone artefacts are mostly quartz flakes and quartzite. There are many red, yellow, orange and white 'ochre' fragments. A number of these are haematite crayons with striations clearly evident. Five beeswax fragments and a nodule of Reckitt's Blue were recovered from Test Pit B. Faunal remains include barramundi (Lates calcarifer) and catfish (Arius leptaspis) otoliths, freshwater turtle bone fragments, varanid (monitor lizard) teeth and freshwater bivalve shells (Mytilus sp.); highly fragmented, non-diagnostic burnt bone is abundant. There is evidence of bioturbation of sediments by macropods, introduced feral animals and human hearth-building.

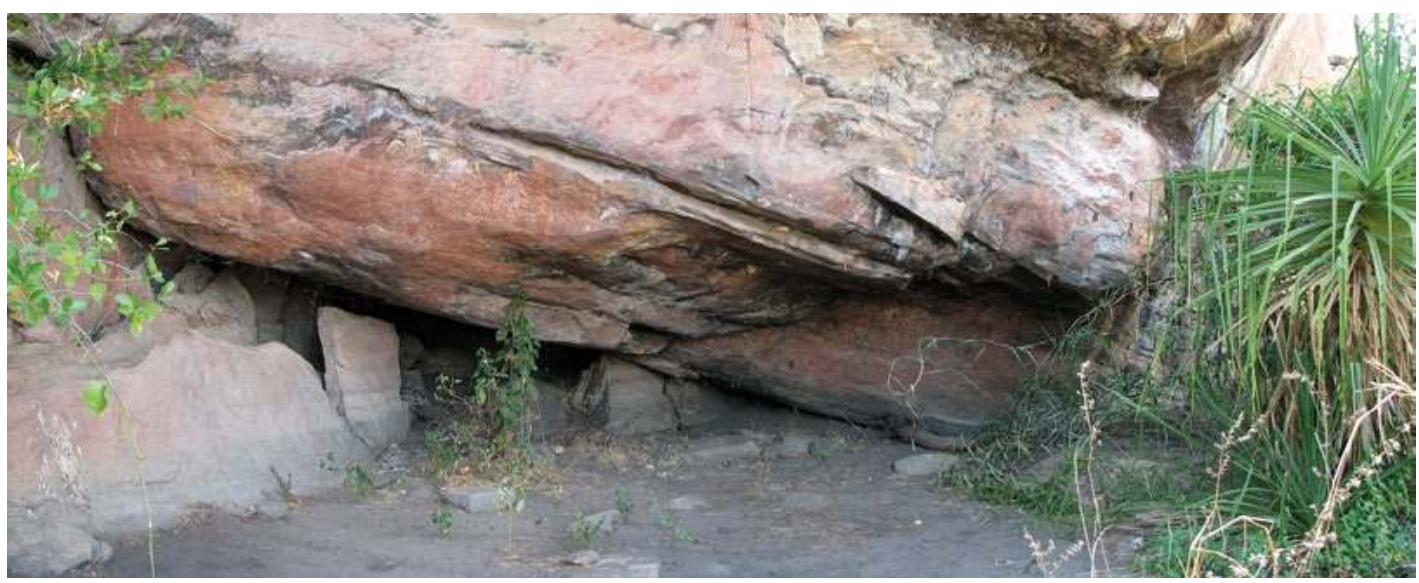

Figure 2.15 Site MN05.

Source: Photograph by Daryl Wesley.

Excavation and ground penetrating radar (GPR) surveys indicate significant build-up of sands at the base of the Wulk Lagoon sandstone escarpment. Nott (2003) provides estimates of up to $6 \mathrm{~m}$ of accumulated sands from the plateau onto the coastal plains, dating back from Pleistocene times. In Test Pit C outside the MN05 shelter, $1 \mathrm{~m}$ of sand has accumulated in 1000 years. 
Excavations at MN05 and nearby Birriwilk (Shine et al. 2013; see Figure 1.1) show that cultural deposits have limited depth confined to the last 5000 years at the edge of the Wulk Lagoon sandstone outlier. Here any evidence of early Holocene or Pleistocene occupation would be buried under several metres of aggraded sand and flood deposits.

\section{Discussion}

Figure 2.16 shows two things for Wulk Lagoon's rock art by temporal phase: 1 ) the proportion of total number of rock art styles; and 2) the proportion of total number of motifs (of any style) (see Figure 2.2 for details of each phase). There are few sites with Early Phase styles (those that are thought to be older than c. $8000 \mathrm{BP}$ ), and few motifs within those sites that do have them. Many (58 per cent) of the sites have Middle Phase styles (c. 8000 to 3000 BP), but these contain a moderate proportion of motifs (only 25 per cent of the overall rock art assemblage). There are a moderate number (33 per cent) of sites with Late Phase (c. 3000 BP to present) styles, but these contain the majority of motifs (accounting for 70 per cent of the total assemblage). Most of the art in the 18 sites with more than 100 images (which together account for 90 per cent of Wulk Lagoon's rock art) are in late Holocene styles. At Wulk Lagoon, therefore, during the late Holocene, rock art becomes very abundant in a moderate number of focal sites; it is less evenly distributed across the landscape than previously.

Paintings of fish are fairly evenly distributed between the Middle and Late Phases: 45.5 per cent are in styles of the Middle Phase, 54.5 per cent in those of the Late Phase. This is consistent with a heightened importance of fish following risen sea levels, coastal infill and the development of swamps and waterways on the floodplains after c. 6000 BP. At sites MN01, MN05 and MN12, most paintings are of fish (55.5 per cent) and anthropomorphs (31.5 per cent), and of these most are in Late Phase (i.e. late Holocene) styles; 71 per cent of rock art scenes at Wulk Lagoon (i.e. ceremony, fighting and hunting) are also in Late Phase styles (all others are of the Middle Phase). Here, there is clearly a proliferation of rock art in the Middle and Late Phases when fish, anthropomorphs and scene depictions predominate.

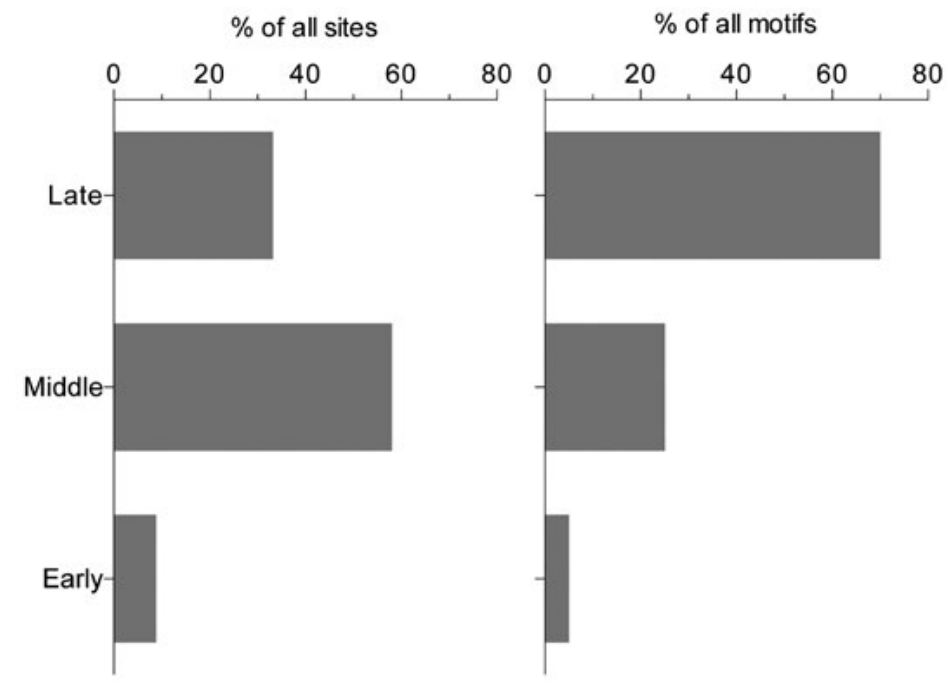

Figure 2.16 Relative frequency of rock art sites and motifs by temporal phase (number of sites $=77$; estimated number of motifs $=13,000$ ).

Source: Jerome Mialanes. 
Macropods occur in 36.3 per cent of Wulk Lagoon sites, often in Large Naturalistic or Large Fauna styles. An $\mathrm{R}^{2}$ value of 0.4846 indicates no preferential co-occurrence of zoomorphs with anthropomorphs. This suggests that in many cases sites were selected to paint zoomorphs or anthropomorphs, but not both.

Much of Wulk Lagoon's rock art is found at the top of the sandstone outlier, with fewer sites along the base of the escarpment (Figure 2.17). Figures 2.18 and 2.19 show the number of rock art sites and art styles that occur, by geographic zone for each phase (see caption to Figure 2.19 for further description on calculation of number of art styles represented). During the Early and Middle Phases, the art is most abundant on the hillsides; however, during the Late Phase, it is fairly evenly distributed across all three zones.

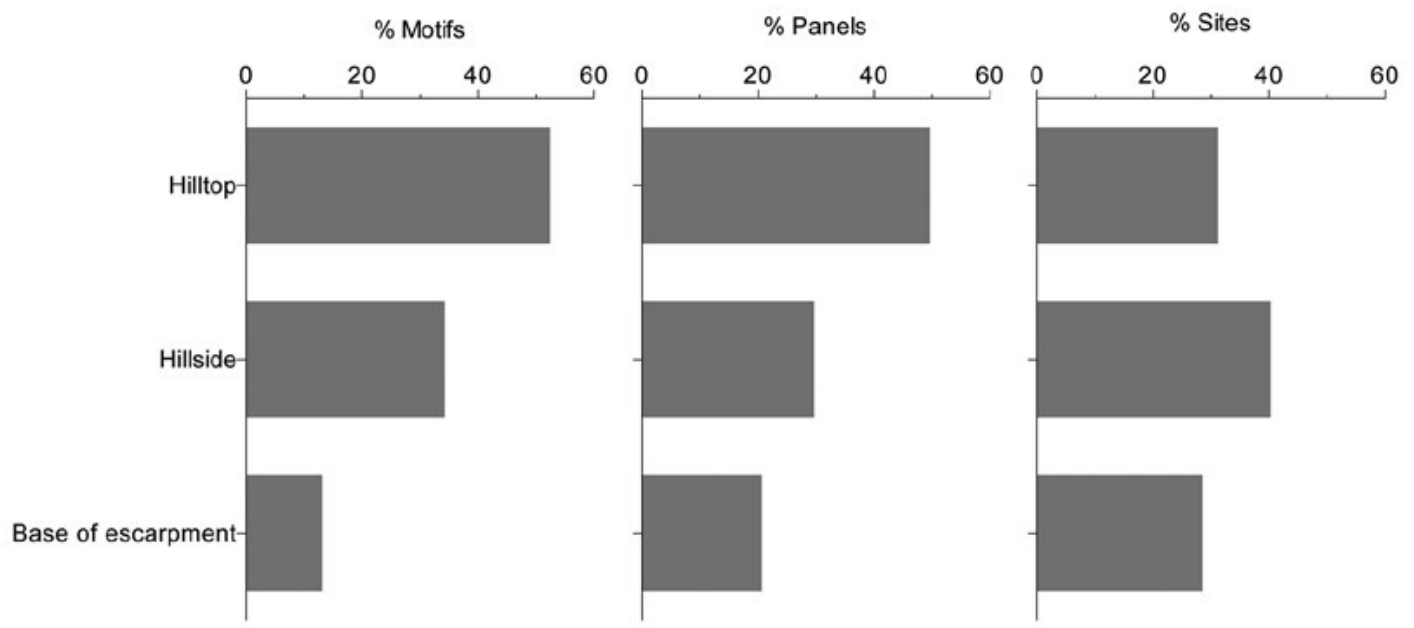

Figure 2.17 Proportion of motifs, panels and sites by topographic zone (number of motifs $=13,000$; number of panels $=459$; number of sites $=77$ ).

Source: Jerome Mialanes.

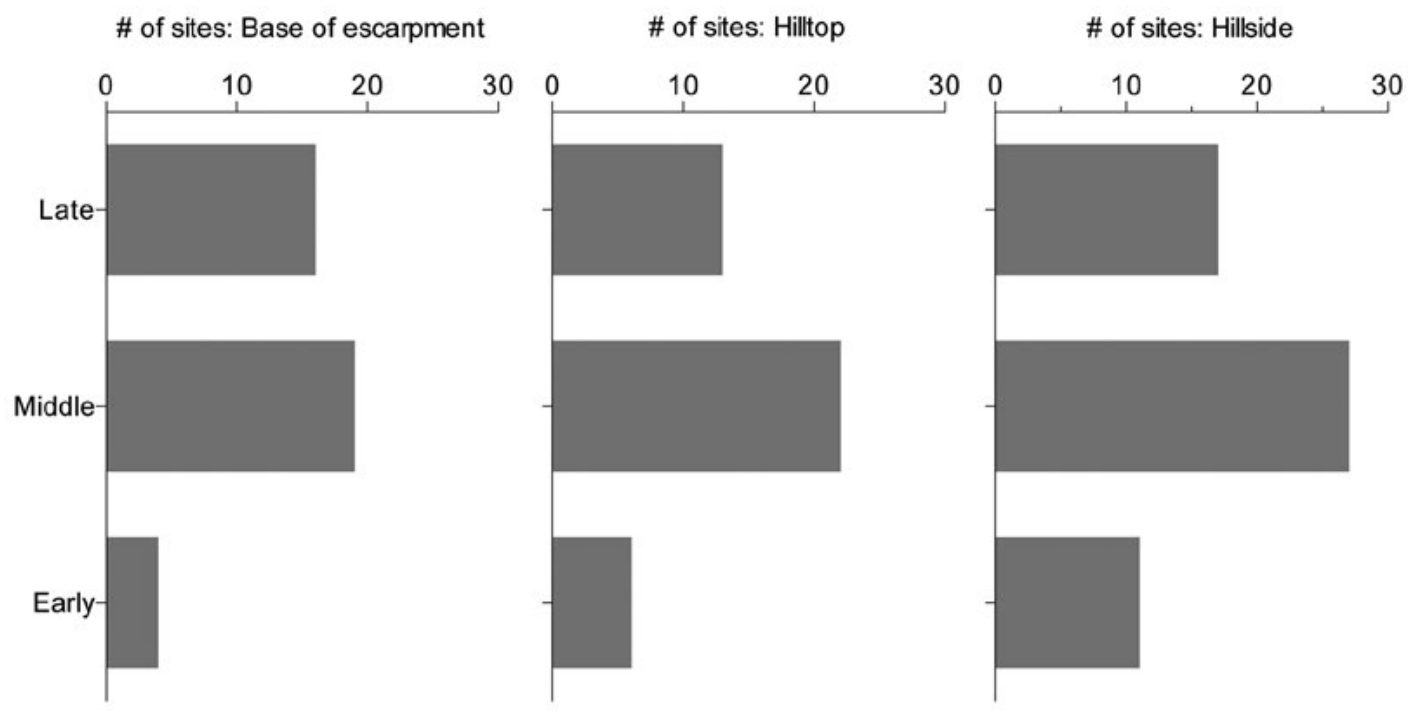

Figure 2.18 Number of rock art sites by phase and topographic zone.

Source: Jerome Mialanes. 

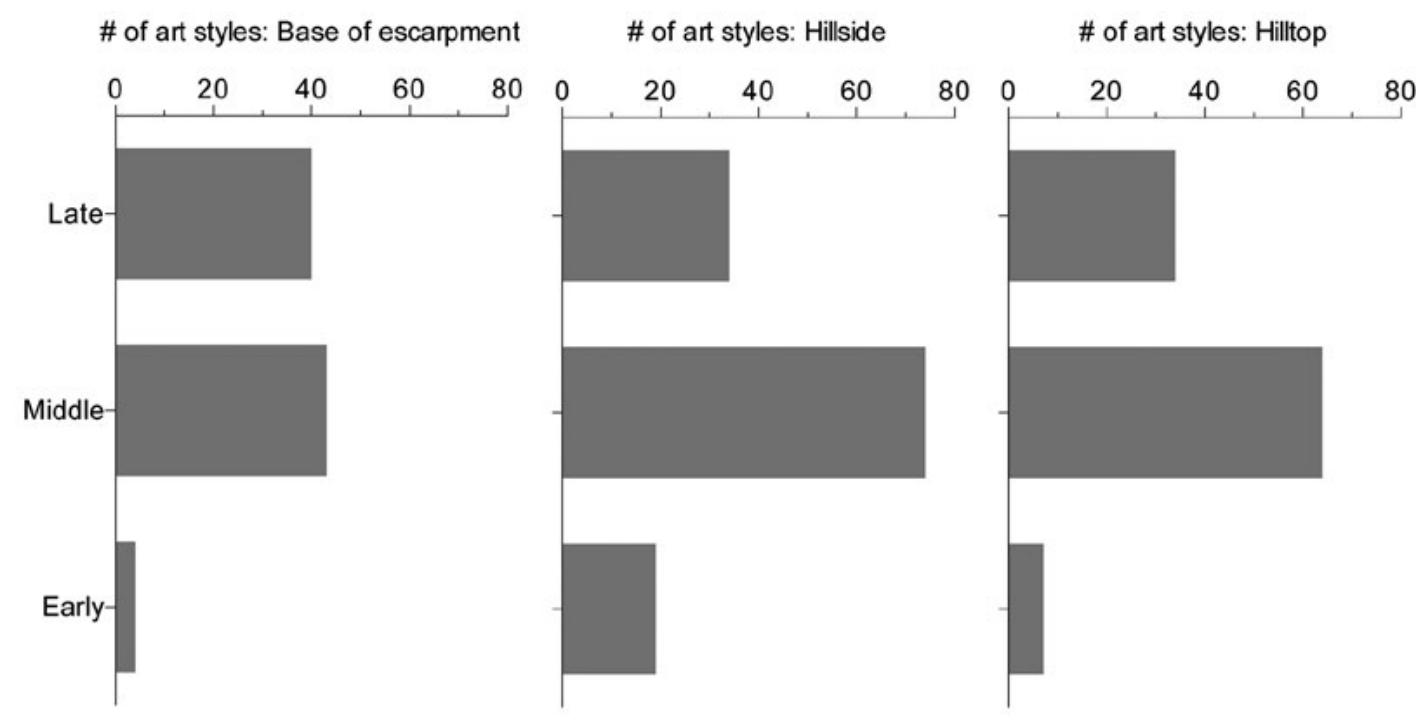

Figure 2.19 Sum of the number of different art styles represented per site, by phase and topographic zone.

(e.g. if there are two Late Phase sites on a hillside, one site with five paintings of one style and the other with three paintings of another style, then that site will have two different art styles represented for that phase; to work out how many art styles are represented in the hillside environment, all such Late Phase site values are summed).

Source: Jerome Mialanes.

These results suggest that during the late Holocene, pretty much all topographic zones of the Wulk Lagoon sandstone outlier were inscribed with rock art. Taçon and Chippindale (1994), Taçon and Brockwell (1995) and Hiscock (1999) have argued that the late Holocene saw rich resource supplies on the floodplains, resulting in population growth and increasing regionalism of clan estates: social organisation and land tenure systems shifted as clan estates with geographically based totemic associations changed. This is consistent with the shifting distributions and peak densities of rock art seen during the late Holocene at Wulk Lagoon. Here small clan estates with focalised occupation used sites intensively into the ethnographic period, as evident by the diverse and abundant rock art of the late Holocene. We suggest that this is evidence for lower levels of residential mobility and greater rock art production than previously. This happened at a time of increasing precipitation and strengthening of the IASM c. 1000 years ago, when the East Alligator floodplain developed deep lagoons, shallow lakes and productive Eleocharis and Melaleuca swamps. Across much of Arnhem Land, X-ray art and the Complete Figure Complex flourished at this time, and there was a notable increase in the movement of exotic raw materials for the production of stone artefacts (e.g. Shine et al. 2013). The rock art and buried archaeological deposits of that time both seem to signal the onset of the kinds of cultural practices encountered at the time of European contact.

In support of this interpretation, Wulk Lagoon boasts a wide variety of rock paintings we might consider as scenes $(n=35)$ (Taçon 1994). May and Domingo Sanz (2010:41) discuss the significance of rock art scenes as modes of encoding socio-cultural practices. At Wulk Lagoon, late Holocene scenes have long been a focus of research (e.g. Chaloupka 1993; Jelinek 1986; Mountford 1956; Moyle 1981), especially those depicting the playing of didjeridus, prominent in at least eight scenes. The didjeridu is considered by Moyle (1981) to be a late Holocene musical development in Arnhem Land, because of the rock art styles it is associated with.

Although scenes are also found during earlier phases, their proliferation and increased variability during the late Holocene may be a reflection of the increasing density of local populations in the Alligator Rivers region (May and Domingo Sanz 2010). In contrast to the early battle scenes 
reported by Taçon and Chippindale (1994), at Wulk Lagoon those of the late Holocene generally involve fewer personages. Scenes depicting groups of $>10$ males engaged in either actual or ritual combat, or hunting, express individual engagements in social events (see Figure 2.20).

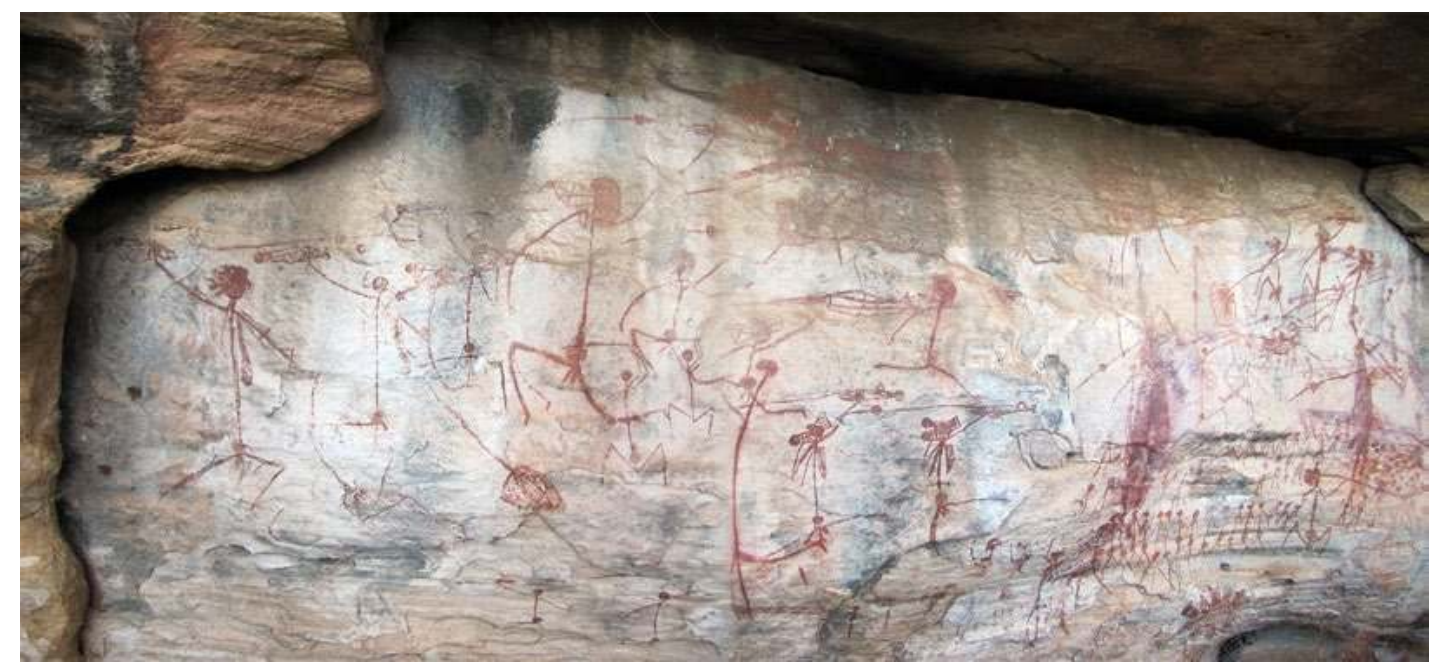

Figure 2.20 Example of complex late Holocene art scene, Wulk Lagoon site RLL004.

Source: Photograph by Paul Brugman.

That people and fish predominate in the rock art of the late Holocene might be linked to a number of factors. The emergence of freshwater wetlands c. 1500 years ago provisioned people with an enormous diversity and abundance of resources, driving population numbers and densities (see Hiscock 1999; Jones 1985). An intensifying IASM after c. 1000 years ago saw greater precipitation and major flooding events that would have significantly impacted on the development of freshwater systems in the Wulk Lagoon area (Denniston et al. 2013; Sandercock and Wywroll 2005; Wasson et al. 2010). Whether regional population densities were a result of actual population growth or a reorganisation of existing groups from the broader region, mid to late Holocene rock art production signal increasing occupation intensities in the vicinity of Wulk Lagoon. With a greater population exploiting newly developed wetland resources came greater levels of rock art production, increased rates of deposition of food refuse within sites and increased stone artefact production (see also Allen and Barton 1989; Jones 1985; Schrire 1982; Shine et al. 2013).

In Arnhem Land, the proliferation of rock art during the late Holocene has been noted in a number of previous studies (e.g. Chaloupka 1993; Taçon 1989a, 1989b). However, its significance is often ignored or sidelined in narratives of the past (Hiscock 1999). Alongside the development of new stone tool technologies, perhaps to manage risks or exploit emerging environments, the proliferation of late Holocene rock art at Wulk Lagoon is an integral expression of the reorganisation of human populations in the Alligator Rivers region.

\section{Acknowledgements}

We thank Nagajok Nayingull, the Nayingull family and Manilakarr Traditional Owners for their support, guidance and enthusiasm in the field. Fieldwork by Daryl Wesley (DE170101447) was undertaken with the assistance of a George Chaloupka Fellowship from the Museum and Art Gallery of the Northern Territory, kindly funded by ERA Rio Tinto. We also thank Sue O'Connor for assisting in the field via ARC Linkage project LP0882985, Tony Barham (The Australian National University, ANU) for helping organise the ARCH8002 field class, the

\section{terra australis 47}


Masters of Archaeological Science (ARCH8002) participants for field assistance, Jack Fenner and Bruce Brown for GPR surveys, Christian Reepmeyer, Paul Brugman, Noel Hildago-Tan, the Bushfires Council Northern Territory, the Commonwealth Department of Sustainability, Environment Heritage and Water, the Office of the Supervising Scientist, the Northern Land Council for research approvals, the North Australia Research Unit (ANU) for providing a base of operations for the fieldwork, Eva Purvis and Anna Yeo for assisting with anthropological matters and Jerome Mialanes (Monash University) for drafting most of the figures.

\section{References}

Allen, H. and G. Barton 1989. Ngarradj Warde Djobkeng: White Cockatoo Dreaming and the Prehistory of Kakadu, Northern Territory, Australia. Oceania Monograph 37. Oceania Publications, Sydney.

Andrefsky, W. 2005. Lithics: Macroscopic Approaches to Analysis. Cambridge University Press, Cambridge. doi.org/10.1017/CBO9780511810244

Andrefsky, W. 2009. The analysis of stone tool procurement, production, and maintenance. Journal of Archaeological Research 17(1):65-103. doi.org/10.1007/s10814-008-9026-2

Attenbrow, V., G. Robertson and P. Hiscock 2009. The changing abundance of backed artefacts in southeastern Australia: A response to Holocene climate change? Journal of Archaeological Science 36:27652770. doi.org/10.1016/j.jas.2009.08.018

Baxter, M.J. 2001. Methodological issues in the study of assemblage diversity. American Antiquity 66(4):715-725. doi.org/10.2307/2694184

Bednarik, R.G. 2012. The use of weathering indices in rock art science and archaeology. Rock Art Research 29(1):59-84.

Bednarik, R.G. 2014a. Mud-wasp nests and rock art. Rock Art Research 31(2):225-231.

Bednarik, R.G. 2014b. Pleistocene paleoart of Australia. Arts 3(1):156-174. doi.org/10.3390/ arts3010156

Bird, M.I., C.S.M. Turney, L.K. Fifield, R. Jones, L.K. Ayliffe, A. Palmer, R. Cresswell and S. Robertson 2002. Radiocarbon analysis of the early archaeological site of Nauwalabila I, Arnhem Land, Australia: Implications for sample suitability and stratigraphic integrity. Quaternary Science Reviews 21:1061-1075. doi.org/10.1016/S0277-3791(01)00058-0

Bourke, P. 2000. Late Holocene Indigenous Economies of the Tropical Australian Coast: An Archaeological Study of the Darwin Region. Unpublished PhD thesis, Northern Territory University, Darwin.

Bourke, P., S. Brockwell, P. Faulkner and B. Meehan 2007. Climate variability in the mid to late Holocene Arnhem Land region, north Australia: Archaeological archives of environmental and cultural change. Archaeology in Oceania 42:91-101. doi.org/10.1002/j.1834-4453.2007.tb00022.x

Brandl, E.J. 1970. Arnhem Land X-ray: Part One. Unpublished report. Australian Institute of Aboriginal Studies, Canberra.

Brandl, E.J. 1980. Some notes on faunal identification and Arnhem Land rock paintings. Australian Institute of Aboriginal Studies (AIAS) Newsletter 14:6-13.

Brockwell, C.J. 1989. Archaeological Investigations of the Kakadu Wetlands, Northern Australia. Unpublished MA thesis. The Australian National University, Canberra. 
Brockwell, S. 1996. Open sites of the South Alligator River wetland, Kakadu. In P. Veth and P. Hiscock (eds), Archaeology of Northern Australia, pp. 90-105. Tempus No. 4. Anthropology Museum, University of Queensland, St Lucia.

Brockwell, S., P. Bourke, A. Clarke, C. Crassweller, P. Faulkner, B. Meehan, S. O'Connor, R. Sim and D. Wesley 2011. Holocene settlement of the northern coastal plains, Northern Territory, Australia. The Beagle: Records of the Museums and Art Galleries of the Northern Territory 27:1-22.

Brockwell, S., A. Clarke and R. Levitus 2001. Seasonal movement in the prehistoric human ecology of the Alligator Rivers region, north Australia. In A. Anderson, I. Lilley and S. O'Connor (eds), Histories of Old Ages: Essays in honour of Rhys Jones, pp. 361-380. Pandanus Books, Canberra.

Brockwell, S., P. Faulkner, P. Bourke, A. Clarke, C. Crassweller, D. Guse, B. Meehan and R. Sim 2009. Radiocarbon dates from the Top End: A cultural chronology for the Northern Territory coastal plains. Australian Aboriginal Studies (1):54-76.

Bronk Ramsey, C. 2009. Bayesian analysis of radiocarbon dates. Radiocarbon 51(1):337-360. doi.org/10.1017/S0033822200033865

Bühler, A., T. Barrow and C.P. Mountford 1965. Oceania and Australia: The Art of the South Seas. Holle and Co., Germany.

Chaloupka, G. 1977. Aspects of the chronology and schematisation of two prehistoric sites on the Arnhem Land plateau. In P.J. Ucko (ed.), Form in Indigenous Art: Schematisation in the Art of Aboriginal Australia and Prehistoric Europe, pp. 243-259. Australian Institute of Aboriginal Studies, Canberra.

Chaloupka G. 1984. From Palaeoart to Casual Paintings: The Chronological Sequence of Arnhem Land Plateau Rock Art. Monograph Series 1. Northern Territory Museum of Arts and Sciences, Darwin.

Chaloupka, G. 1985. Chronological sequence of Arnhem Land plateau rock art. In R. Jones (ed.), Archaeological Research in Kakadu National Park, pp. 2692-80. Special Publication 13. Australian National Parks and Wildlife Service, Canberra.

Chaloupka, G. 1993. Journey in Time: The World's Longest Continuing Art Tradition. Reed, Chatswood.

Chappell, J. 1988. Geomorphologic dynamics and evolution of tidal river and floodplain systems in northern Australia. In D. Wade-Marshall and P. Loveday (eds), Floodplains Research, Northern Australia: Progress and Prospects Volume 2, pp. 34-57. North Australia Research Unit, The Australian National University, Darwin.

Chappell, J. 1993. Contrasting Holocene sedimentary geologies of lower Daly River, northern Australia, and lower Sepik-Ramu, Papua New Guinea. Sedimentary Geology 83:339-358. doi.org/10.1016/ 0037-0738(93)90020-6

Chappell, J. and J. Grindrod 1985. Pollen analysis: Key to past mangrove communities and successional changes in north Australian coastal environments. In K.N. Bardsley, J.D.S. Davie and C.D. Woodroffe (eds), Coasts and Tidal Wetlands of the Australian Monsoon Region, pp. 225-238. Mangrove Monograph No. 1. North Australia Research Unit, The Australian National University, Darwin.

Chippindale, C. and P.S.C. Taçon 1993. Two old painted panels from Kakadu: Variation and sequence in Arnhem Land rock art. Time and Space: Dating and Spatial Considerations in Rock Art Research, pp. 32-56. Australian Rock Art Research Association, Melbourne.

Chippindale, C. and P.S.C. Taçon 1998. The many ways of dating Arnhem Land rock art, north Australia. In C. Chippindale and P.S.C. Taçon (eds), The Archaeology of Rock Art, pp. 91-111. Cambridge University Press, Cambridge. 
Clark, M. and S.K. May (eds), 2013. Macassan History and Heritage: Journeys, Encounters and Influences. ANU E Press, Canberra.

Clark, R.L. and J.C. Guppy 1988. A transition from mangrove forest to freshwater wetland in the monsoon tropics of Australia. Journal of Biogeography 15(4):665-684. doi.org/10.2307/2845444

Clarkson, C. 2002. An index of invasiveness for the measurement of unifacial and bifacial retouch: A theoretical, experimental and archaeological verification. Journal of Archaeological Science 1:65-75. doi.org/10.1006/jasc.2001.0702

Clarkson, C. 2007. Lithics in the Land of the Lightning Brothers: The Archaeology of Wardaman Country, Northern Territory. Terra Australis 25. ANU E Press, Canberra.

Clarkson, C., Z. Jacobs, B. Marwick, R. Fullagar, L. Wallis, M. Smith, R.G. Roberts, E. Hayes, K. Lowe, X. Carah, S.A. Florin, J. McNeil, D. Cox, L. J. Arnold, Q. Hua, J. Huntley, H.E.A. Brand, T. Manne, A. Fairbairn, J. Shulmeister, L. Lyle, M. Salinas, M. Page, K. Connell, G. Park, K. Norman, T. Murphy and C. Pardoe 2017. Human occupation of Australia by 65,000 years. Nature 547(7663): 306-310 doi.org/10.1038/nature22968

David, B. and H. Lourandos 1998. Rock art and socio-demography in northeastern Australian prehistory. World Archaeology 30(2):193-219. doi.org/10.1080/00438243.1998.9980407

David, B., B. Barker, F. Petchey, J.-J. Delannoy, J.-M. Geneste, C. Rowe and R. Whear 2012. A 28,000 year old excavated painted rock from Nawarla Gabarnmang, northern Australia. Journal of Archaeological Science 40(5):2493-2501. doi.org/10.1016/j.jas.2012.08.015

Delannoy, J.-J., B. David, J.-M. Geneste, M. Katherine, B. Barker, R.L. Whear and R.G. Gunn 2013. The social construction of caves and rockshelters: Chauvet Cave (France) and Nawarla Gabarnmang (Australia). Antiquity 87(335):12-29. doi.org/10.1017/S0003598X00048596

Denniston, R.F., K. Wyrwoll, V.J. Polyak, J.R. Brown, Y. Asmerom, A.D. Wanamaker, Z. La Pointe, R. Ellerbroek, M. Barthelmes, D. Cleary, J. Cugley, D. Woods and W.F. Humphreys 2013. A stalagmite record of Holocene Indonesian-Australian summer monsoon variability from the Australian tropics. Quaternary Science Reviews 78:155-168. doi.org/10.1016/j.quascirev.2013.08.004

Duggan, K. 1994. Erosion and sediment yields in the Kakadu region of northern Australia. In L.J. Olive, R.J. Loughran and J.A. Kesby (eds), Variability in Stream Erosion and Sediment Transport (Proceedings of the Canberra Symposium, December 1994), pp. 373-383. International Association of Hydrological Sciences Publication 224, Oxfordshire.

East, T.J., R.F. Cull, A.S. Murray, A. Johnston, B. Noller, R.J. Wasson, I.R. Willett, G. Pickup and R.F. Warner 1987a. Late Quaternary evolution of the Magela Creek backwater plain. In Alligator Rivers Research Institute Annual Research Summary 1986-7, pp. 29-36. Australian Government Publishing Service, Canberra.

East, T.J., A.S. Murray, G.C. Nanson and R.L. Clark 1987b. Late Quaternary evolution of the Magela Creek sandbed channels and floodplain. In Alligator Rivers Research Institute Annual Research Summary 1986-7, pp. 22-29. Australian Government Publishing Service, Canberra.

Edwards, R. 1979. Australian Aboriginal Art: The Art of the Alligator Rivers Region, Northern Territory. Australian Institute of Aboriginal Studies, Canberra.

Faulkner, P. 2009. Focused, intense and long-term: Evidence for granular ark (Anadara granosa) exploitation from late Holocene shell mounds of Blue Mud Bay, northern Australia. Journal of Archaeological Science 36(3):821-834. doi.org/10.1016/j.jas.2008.11.005 
Faulkner, P. 2011. Late Holocene mollusc exploitation and changing near-shore environments: A case study from the coastal margin of Blue Mud Bay, northern Australia. Environmental Archaeology 16(2):137-150. doi.org/10.1179/174963111X13110803260976

Geneste, J.-M., B. David, H. Plisson, C. Clarkson, J.-J. Delannoy, F. Petchey and R. Whear 2010. Earliest evidence for ground-edge axes: 35,400 4410 cal BP from Jawoyn country, Arnhem Land. Australian Archaeology 71:66-69. doi.org/10.1080/03122417.2010.11689385

Geneste, J.-M., B. David, H. Plisson, J.-J. Delannoy and F. Petchey 2012. The origins of ground-edge axes: New findings from Nawarla Gabarnmang, Arnhem Land (Australia) and global implications for the evolution of fully modern humans. Cambridge Archaeological Journal 22(1):1-17. doi.org/ $10.1017 /$ S0959774312000017

Gregory, R.L. 1998. Aboriginal settlement patterns in the Ord-Victoria River region. Unpublished PhD thesis. Northern Territory University, Darwin.

Grindrod, J. 1988. Holocene Mangrove History of the South Alligator River Estuary, Northern Territory, Australia. Unpublished PhD thesis. The Australian National University, Canberra.

Gunn, R.G. 1992. Mikinj: Rock art, myth and place - sites of significance to Jacob Nayinggul. Unpublished report to the Australian Institute of Aboriginal and Torres Strait Islander Studies. AIATSIS, Canberra.

Gunn, R.G. and R.L. Whear 2007a. Dynamic sketches: 6000+ year old dry-pigment drawings from Arnhem Land. Archaeology in Oceania 42(1):22-28. doi.org/10.1002/j.1834-4453.2007.tb00011.x

Gunn, R.G. and R.L. Whear 2007b. The Jawoyn rock art and heritage project. Rock Art Research 24(1):5-20.

Gunn, R.G., C. Ogleby, D. Lee and R. Whear 2010a. A method to visually rationalise superimposed pigment motifs. Rock Art Research 27(2):131-136.

Gunn, R.G., R.L. Whear and L.C. Douglas 2010b. A dingo burial from the Arnhem Land plateau. Australian Archaeology 71:11-16. doi.org/10.1080/03122417.2010.11689380

Gunn, R.G., L.C. Douglas and R.L. Whear 2011. What bird is that? Identifying a probable painting of Genyornis newtoni in western Arnhem Land. Australian Archaeology 73:1-12.

Gunn, R.G., R.L. Whear and L.C. Douglas 2012. Dating the present at Nawarla Gabarnmang: Time and function in the art of a major Jawoyn rock art and occupation site in western Arnhem Land. Australian Archaeology 75:55-65. doi.org/10.1080/03122417.2012.11681950

Guse, D.L 1992. Predictive models of prehistoric settlement and subsistence patterns for the South Alligator and Mary River wetlands, Northern Territory. Unpublished BA (Honours) thesis. Department of Anthropology, Northern Territory University, Darwin.

Guse, D.L. 2006. Our home our country: A case study of law, land, and Indigenous cultural heritage in the Northern Territory, Australia. Unpublished Masters of Aboriginal and Torres Strait Islander Studies, Faculty for Aboriginal and Torres Strait Islander Studies, Charles Darwin University, Darwin.

Hiscock, P. 1999. Holocene coastal occupation of western Arnhem Land. In J. Hall and I.J. McNiven (eds), Australian Coastal Archaeology, pp. 91-103. Department of Archaeology and Natural History, The Australian National University, Canberra. 
Hiscock, P. 2002. Pattern and context in the Holocene proliferation of backed artefacts in Australia. In R.G. Elston and S.L. Kuhn (eds), Thinking Small: Global Perspectives on Microlithization, pp. 163-177. Archaeological Papers of the American Anthropological Association 12(1):163-177.

Hiscock, P. 2008. Archaeology of Ancient Australia. Routledge, London. doi.org/10.4324/9780203448359

Hiscock, P. 2011. Changing perspectives in Australian archaeology, Part VI: Point production at Jimede 2, western Arnhem Land. Technical Reports of the Australian Museum 23(6):73-82. doi.org/10.3853/j.1835-4211.23.2011.1571

Hiscock, P. and V. Attenbrow 1998. Early Holocene backed artefacts from Australia. Archaeology in Oceania 33(2):49-62. doi.org/10.1002/j.1834-4453.1998.tb00404.x

Hiscock, P. and V. Attenbrow 2005. Reduction continuums and tool use. In C. Clarkson and L. Lamb (eds), Lithics 'Down Under': Australian Perspectives on Lithic Reduction, Use and Classification, pp. 43-55. Archaeopress, Oxford.

Hiscock, P., F. Mowat and D. Guse 1992. Settlement patterns in the Kakadu wetlands: Initial data on site size and shape. Australian Aboriginal Studies 2:84-89.

Hope, G., P.J. Hughes and J. Russell-Smith 1985. Geomorphological fieldwork and the evolution of the landscape of Kakadu National Park. In R. Jones (ed.), Archaeological Research in Kakadu National Park, pp. 229-240. Special Publication 13. Australian National Parks and Wildlife Service, Canberra.

Huntley, J. 2012. Taphonomy or paint recipe: In situ portable x-ray fluorescence analysis of two anthropomorphic motifs from the Woronora Plateau, New South Wales. Australian Archaeology 75:78-94. doi.org/10.1080/03122417.2012.11681952

Huntley, J., H. Brand, M. Aubert and M.J. Morwood 2014. The first Australian synchrotron powder diffraction analysis of pigment from a Wandjina motif in the Kimberley, Western Australia. Australian Archaeology 78:33-38. doi.org/10.1080/03122417.2014.11681996

Jelinek, J.J. 1986. The Great Art of the Early Australians: The Study of the Evolution and Role of Rock Art in the Society of Australian Hunters and Gatherers. Moravian Museum Anthropos Institute, Brno.

Jones, R. (ed.) 1985. Archaeological Research in Kakadu National Park. Special Publication 13. Australian National Parks and Wildlife, Canberra.

Kamminga, J. and H. Allen. 1973. Report of the Archaeological Survey: Alligator Rivers Environmental Fact-Finding Study. Government Printer, Darwin.

Kaufmann, D. 1998. Measuring archaeological diversity: An application of the Jackknife Technique. American Antiquity 63(1):73-85. doi.org/10.2307/2694777

Kintigh, K.W. 1984. Measuring archaeological diversity by comparison with simulated assemblages. American Antiquity 49(1):44-54. doi.org/10.2307/280511

Kintigh, K.W. 1989. Sample size, significance and measures of diversity. In R.D. Leonard and G.T. Brown (eds), Quantifying Diversity in Archaeology, pp. 25-84. Cambridge University Press, Cambridge.

Lamb, L. and C. Clarkson 2005. Lithics 'Down Under': Australian Perspectives on Lithic Reduction, Use and Classification. Archaeopress, Oxford.

Lees, B.G. and A. Clements 1987. Climatic implications of chenier dates in northern Australia. Radiocarbon 29(3):311-317. doi.org/10.1017/S003382220004371X 
Lewis, D.J. 1988. The Rock Paintings of Arnhem Land, Australia: Social, Ecological and Material Culture Change in the Post-Glacial Period. International Series S415. British Archaeological Reports, Oxford.

Lyman, R.L. and M.J. O’Brien 2006. Measuring Time with Artifacts: A History of Methods in American Archaeology. University of Nebraska Press, Lincoln.

May, S.K. and I. Domingo Sanz 2010. Making sense of scenes. Rock Art Research 27(1):35-42.

May, S., P.S.C. Taçon, D. Wesley and M. Travers 2010. Painting history: Indigenous observations and depictions of the other in Northwestern Arnhem Land. Australian Archaeology 71:57-65. doi.org/10.1080/03122417.2010.11689384

May, S.K., P.S.C. Taçon and M. Pearson 2011. Painted ships on a painted landscape. In M. Thomas and M. Neale (eds), Exploring the Legacy of the 1948 American-Australian Scientific Expedition to Arnhem Land, pp. 1-23. ANU E Press, Canberra.

McCarthy, F.D. 1965. The Northern Territory and central Australia: Report from the Select Committee on the Native and Historical Objects and Areas Preservation Ordinance 1955-1960, together with minutes of proceedings of the committee. Unpublished manuscript, AIATSIS, Canberra.

McDonald, J. 2015. I must go down to the sea again: Or, what happens when the sea comes to you? Murujuga rock art as an environmental indicator for Australia's north-west. Quaternary International 385:124-135. doi.org/10.1016/j.quaint.2014.10.056

McDonald, J. and P. Veth 2013. Rock art in arid landscapes: Pilbara and Western Desert petroglyphs. Australian Archaeology 77:66-81.

McDonald, J., K.L. Steelman, P. Veth, J. Mackey, J. Loewen, C.R. Thurber and T.P. Guilderson 2014. Results from the first intensive dating program for pigment art in the Australian arid zone: Insights into recent social complexity. Journal of Archaeological Science 46:195-204. doi.org/10.1016/j. jas.2014.03.012

Meehan, B., S. Brockwell, J. Allen and R. Jones 1985. The wetland sites. In R. Jones (ed.), Archaeological Research in Kakadu National Park, pp. 103-153. Special Publication 13. Australian National Parks and Wildlife, Canberra.

Mountford, C.P. 1956. Records of the American-Australian Scientific Expedition to Arnhem Land: Volume 1 - Art, Myth and Symbolism. Melbourne University Press, Melbourne.

Mountford, C.P. 1964. Aboriginal Paintings from Australia. Collins, London.

Mountford, C.P. 1965. Aboriginal Art. Longmans, Green and Company, Croydon.

Mountford, C.P. 1975. The Aborigines and their Country. Rigby, Adelaide.

Mowat, F. 1994. Size really does matter: Factors affecting shell size fragmentation. In M. Sullivan, S. Brockwell and A. Webb (eds), Archaeology in the North: Proceedings of the 1993 Australian Archaeological Association Conference, pp. 201-212. North Australia Research Unit, The Australian National University, Darwin.

Mowat, F. 1995. Variability in western Arnhem Land shell midden deposits. Unpublished Masters thesis, Northern Territory University, Darwin.

Moyle, A.M. 1981. The Australian didjeridu: A late musical intrusion. World Archaeology 12(3):321-331. doi.org/10.1080/00438243.1981.9979807 
Needham, R.S. 1984. Alligator Rivers, Northern Territory. 1:250,000 Geological Series Explanatory Notes. Bureau of Mineral Resources, Geology and Geophysics. Australian Government Publishing Service, Canberra.

Nott, J. 2003. Kakadu-Arnhem Land Region, Northern Territory. Cooperative Research Centre for Landscape Environments and Mineral Exploration, Kensington. crcleme.org.au/RegLandEvol/ KakaduArnhem.pdf

Reimer, P., E. Bard, A. Bayliss, J. Beck, P. Blackwell, C. Ramsey, C. Buck, H. Cheng, R. Edwards, M. Friedrich, P. Grootes, T. Guilderson, H. Haflidason, I. Hajdas, C. Hatte, T. Heaton, D. Hoffmann, A. Hogg, K. Hughen, K. Kaiser, B. Kromer, S. Manning, M. Niu, R. Reimer, D. Richards, E. Scott, J. Southon, R. Staff, C. Turney and J. van der Plicht 2013. IntCal13 and Marine13 radiocarbon age calibration curves 0-50,000 years cal BP. Radiocarbon 55(4):1869-1887. doi.org/10.2458/azu_js_rc.55.16947

Roberts, R.G., R. Jones and M.A. Smith. 1990. Thermoluminescence dating of a 50,000-year-old human occupation site in northern Australia. Nature 345:153-156. doi.org/10.1038/345153a0

Rosenfeld, A. and C. Smith 1997. Recent developments in radiocarbon and stylistic methods of dating rock art. Antiquity 72(272):405-411. doi.org/10.1017/S0003598X00085008

Russell-Smith, J. 1985a. A record of change: Studies of Holocene vegetation history in the South Alligator River region. Proceedings of the Ecological Society of Australia 13:191-202.

Russell-Smith, J. 1985b. Studies in the jungle: People, fire and monsoon forest. In R. Jones (ed.), Archaeological Research in Kakadu National Park, pp. 241-267. Special Publication 13. Australian National Parks and Wildlife Service, Canberra.

Russell-Smith, J., D. Lucas, M. Gapindi, B. Gunbunuka, N. Kapirigi, G. Namingum, K. Lucas, P. Giuliani and G. Chaloupka 1997. Aboriginal resource utilization and fire management practice in western Arnhem Land, monsoonal northern Australia: Notes for prehistory, lessons for the future. Human Ecology 25(2):159-195. doi.org/10.1023/A:1021970021670

Sandercock, P. and K. Wyrwoll 2005. The historical and palaeoflood record of Katherine River, northern Australia: Evaluating the likelihood of extreme discharge events in the context of the 1998 flood. Hydrological Processes 1(20):4107-4120. doi.org/10.1002/hyp.5875

Schrire, C. 1982. The Alligator Rivers: Prehistory and Ecology in Western Arnhem Land. Terra Australis 7. Department of Prehistory, Research School of Pacific Studies, The Australian National University, Canberra.

Senior, B.R. and P.G. Smart 1976. Coburg Peninsula - Melville Island, Northern Territory. 1:250,000 Geological Series Explanatory Notes. Bureau of Mineral Resources, Geology and Geophysics. Australian Government Publishing Service, Canberra.

Shine, D., D. Wright, T. Denham, K. Aplin, P. Hiscock, K. Parker and R. Walton 2013. Birriwilk Rockshelter: A mid- to late Holocene site in Manilikarr country, southwest Arnhem Land, Northern Territory. Australian Archaeology 76:69-78. doi.org/10.1080/03122417.2013.11681967

Smith, M.A., A. Watchman and J. Ross 2009. Direct dating indicates a mid-Holocene age for archaic rock engravings in arid central Australia. Geoarchaeology 24(2):191-203. doi.org/10.1002/gea.20262

Sweet, I.P., A.T. Brakel and L. Carson 1999. The Kombolgie Subgroup - a new look at an old 'formation'. AGSO Research Newsletter 30:26-28.

Taçon, P.S.C. 1988. Identifying fish species in the recent rock paintings of western Arnhem Land. Rock Art Research 5(1):3-15. 
Taçon, P.S.C. 1989a. From Rainbow Snakes to 'X-Ray' Fish: The Nature of the Recent Rock Painting Tradition of Western Arnhem Land, Australia. Unpublished PhD thesis. The Australian National University, Canberra.

Taçon, P.S.C. 1989b. From the 'Dreamtime' to the present: The changing role of Aboriginal rock paintings in western Arnhem Land, Australia. The Canadian Journal of Native Studies IX(2):317-339.

Taçon, P.S.C. 1994. Socialising landscapes: the long-term implications of signs, symbols and marks on the land. Archaeology in Oceania 29:117-129.

Taçon, P.S.C. and S. Brockwell 1995. Arnhem Land prehistory in landscape, stone and paint. In J. Allen and J.F. O'Connell (eds), Transitions: Pleistocene to Holocene in Australia and New Guinea. Antiquity 69 Special Number 265:676-695. doi.org/10.1017/s0003598x00082272

Taçon, P.S.C. and C. Chippindale 1994. Australia’s ancient warriors: Changing depictions of fighting in the rock art of Arnhem Land, NT. Cambridge Archaeological Journal 4:211-248. doi.org/10.1017/ S0959774300001086

Taçon, P.S.C., S.K. May, S.J. Fallon, M. Travers, D. Wesley and R. Lamilami 2010. A minimum age for early depictions of Southeast Asian praus in the rock art of Arnhem Land, Northern Territory. Australian Archaeology 71:1-10. doi.org/10.1080/03122417.2010.11689379

Taçon, P.S.C., E. Nelson, C. Chippindale and G. Chaloupka 2004. The beeswax rock art of the Northern Territory: direct dating results and a 'book of record'. Rock Art Research 21(2):155-160.

Taçon, P.S.C., M. Wilson and C. Chippindale 1996. Birth of the Rainbow Serpent in Arnhem Land rock art and oral history. Archaeology in Oceania 31(3):103-124. doi.org/10.1002/j.1834-4453.1996. tb00355.x

Theden-Ringl, F., J.N. Fenner, D. Wesley and R. Lamilami 2011. Buried on foreign shores: Isotope analysis of the origin of human remains recovered from a Macassan site in Arnhem Land. Australian Archaeology 73:41-48.

Thomas, D.H. 1973. An empirical test for Steward's model of Great Basin settlement patterns. American Antiquity 38:155-176. doi.org/10.2307/279362

Thomas, D.H. 1989. Diversity in hunter-gatherer cultural geography. In R.D. Leonard and G.T. Jones (eds), Quantifying Diversity In Archaeology, pp. 85-91. Cambridge University Press, Cambridge.

Veth. P, P. Hiscock and A. Williams 2011. Are Tulas and ENSO linked in Australia? Australian Archaeology 72:7-14. doi.org/10.1080/03122417.2011.11690526

Wasson, R. (ed.) 1992. Modern Sedimentation and Late Quaternary Evolution of the Magela Creek Plain. Research Report 6, Supervising Scientist for the Alligator Rivers Region. Australian Government Publishing Service, Canberra.

Wasson, R.J., L. Furlonger, D. Parry, T. Pietsch, E. Valentine and D. Williams 2010. Sediment sources and channel dynamics, Daly River, northern Australia. Geomorphology 114(3):161-174. doi.org/ 10.1016/j.geomorph.2009.06.022

Watchman, A. 2000. Micro-excavation and laser extraction methods for dating carbon in silica skins and oxalate crusts. In G.K. Ward and C. Tuniz (eds), Advances in Dating Australian Rock-Markings, pp. 35-39. Occasional AURA Publication 10. Australian Rock Art Research Association, Melbourne.

Watchman, A. and R. Jones 2002. An independent confirmation of the 4 ka antiquity of a beeswax figure in western Arnhem Land, northern Australia. Archaeometry 44(1):145-153. doi.org/ 10.1111/1475-4754.00049 
Watchman, A.L., G.L. Walsh, M.J. Morwood and C. Tuniz 1997. AMS radiocarbon age estimates for early rock paintings in the Kimberley, N.W. Australia: Preliminary results. Rock Art Research 14:18-26.

Watchman, A., G.K. Ward, M. Crocombe and K. Mulvaney 2010. Dating of rock paintings in the Wadeye-Fitzmaurice region, Northern Territory. Rock Art Research 27(2):223-228.

Wesley, D. 2013. Firearms in rock art of Arnhem Land, Northern Territory. Rock Art Research 30(2):235-247.

Wesley, D. 2015. Bayini, Macassans, Balanda and Bininj: Defining the Indigenous Past of Arnhem Land through Culture Contact. Unpublished PhD thesis. The Australian National University, Canberra.

Wesley, D., J. McKinnon and J. Raupp 2012. Sails set in stone: A technological analysis of nonIndigenous watercraft rock art paintings in north western Arnhem Land. Journal of Maritime Archaeology 7(2):245-269. doi.org/10.1007/s11457-012-9103-z

Wesley, D., T. Jones and C. Reepmeyer 2014. Pigment geochemistry as chronological marker: The case of lead pigment in rock art in the Urrmarning 'Red Lily Lagoon' rock art precinct, western Arnhem Land. Australian Archaeology 78:1-9. doi.org/10.1080/03122417.2014.11681993

Woodroffe, C. 1988. Changing mangrove and wetland habitats over the last 8000 years, northern Australia and Southeast Asia. In D. Wade-Marshall and P. Loveday (eds), Floodplains Research, Northern Australia: Progress and prospects Volume 2, pp. 1-33. North Australia Research Unit, The Australian National University, Darwin.

Woodroffe, C., J.M.A. Chappell, B.G. Thom and E. Wallensky 1985a. Geomorphology of the South Alligator tidal river and plains, Northern Territory. In K.N. Bardsley, J.D.S. Davie and C.D. Woodroffe (eds), Coasts and Tidal Wetlands of the Australian Monsoon Region, pp. 3-16. Mangrove Monograph 1. North Australia Research Unit, The Australian National University, Darwin.

Woodroffe, C., J.M.A. Chappell, B.G. Thom and E. Wallensky 1985b. Stratigraphy of the South Alligator tidal river and plains, Northern Territory. In K.N. Bardsley, J.D.S. Davie and C.D. Woodroffe (eds), Coasts and Tidal Wetlands of the Australian Monsoon Region, pp. 17-30. Mangrove Monograph 1. North Australia Research Unit, The Australian National University, Darwin.

Woodroffe, C., J.M.A. Chappell, B.G. Thom and E. Wallensky 1986. Geomorphological Dynamics and Evolution of the South Alligator Tidal River and Plains, Northern Territory. Mangrove Monograph 3. North Australia Research Unit, The Australian National University, Darwin.

Woodroffe, C., B.G. Thom, J.M.A. Chappell, E. Wallensky, J. Grindrod and J. Head 1987. Relative sea level in the South Alligator River region, north Australia, during the Holocene. Search 18:198-200.

Woodroffe, C., J.M.A. Chappell and B.G. Thom, 1988. Shell middens in the context of estuarine development, South Alligator River, Northern Territory. Archaeology in Oceania 23:95-103. doi.org/ 10.1002/j.1834-4453.1988.tb00196.x

Woodroffe C.D., M.E. Mulrennan and J.M.A. Chappell 1993. Estuarine infill and coastal progradation, southern van Dieman Gulf, Northern Australia. Sedimentary Geology 83:257-275. doi.org/10.1016/ 0037-0738(93)90016-X 



\title{
The rock art of Ingaanjalwurr, western Arnhem Land, Australia
}

\author{
Sally K. May, Denis Shine, Duncan Wright, Tim Denham, \\ Paul S.C. Taçon, Melissa Marshall, Inés Domingo Sanz, \\ Faye Prideaux and Sean Paul Stephens
}

\section{Introduction}

The painted and beeswax rock art of Ingaanjalwurr rockshelter in western Arnhem Land is a unique assemblage of art within an unassuming rockshelter. By combining a variety of approaches and methods to the study of Ingaanjalwurr, we were able to draw together an important archaeological context for inferring the antiquity of the painted rock art, as well as direct dates for the age of beeswax art. This chapter provides an overview of the rock art at Ingaanjalwurr, ethnographic information regarding the use and production of art at the site, archaeological information relevant to understanding the antiquity and context of painted rock art, and the results of direct dating of beeswax art.

It has been argued that rock art on the northwestern Arnhem Land plateau provides evidence for 'outbursts of art production' as opposed to 'a steady, constant rate over time' (Taçon 1993:113). Taçon (1993) reached this conclusion by examining the chronology of different styles within his study areas, and counting the number of images representing each style. He suggests that two of the most significant such outbursts are represented by Dynamic Figure art and the later Freshwater, Recent X-ray art (Taçon 1989, 1993), with relatively little rock art production between these two periods (Taçon 1993:113). A similar conclusion is reached by Gunn et al. (2012:61) for Nawarla Gabarnmang in Jawoyn Country, western Arnhem Land, arguing that a large quantity of rock art was produced in that site within the past c. 350 years (see also Chapters 11 and 12; David et al. 2011:76; Gunn et al. 2012:61). The Ingaanjalwurr site provided an opportunity to further explore such 'outbursts of art production' for western Arnhem Land.

\section{Ingaanjalwurr rockshelter}

Ingaanjalwurr is a rockshelter located in Manilikarr Country, western Arnhem Land. It is situated at the base of an escarpment that overlooks Red Lily Lagoon (Urrmarning) (Figure 3.1). The escarpment runs broadly east-west, parallel to the main Jabiru-Gunbalanya (Oenpelli) road, and reaches a maximum elevation of $75 \mathrm{~m}$ above sea level directly behind Ingaanjalwurr. The rockshelter is c. $9 \mathrm{~km}$ southwest of Gunbalanya, with Ingaanjalwurr being the Urningangk 
name (original language of the Nayinggul family and Manilakarr clan) for the site provided by senior Traditional Owner Nakodjok (who passed away in 2012; in respect of his family's wishes, we refer to him only by his skin name).

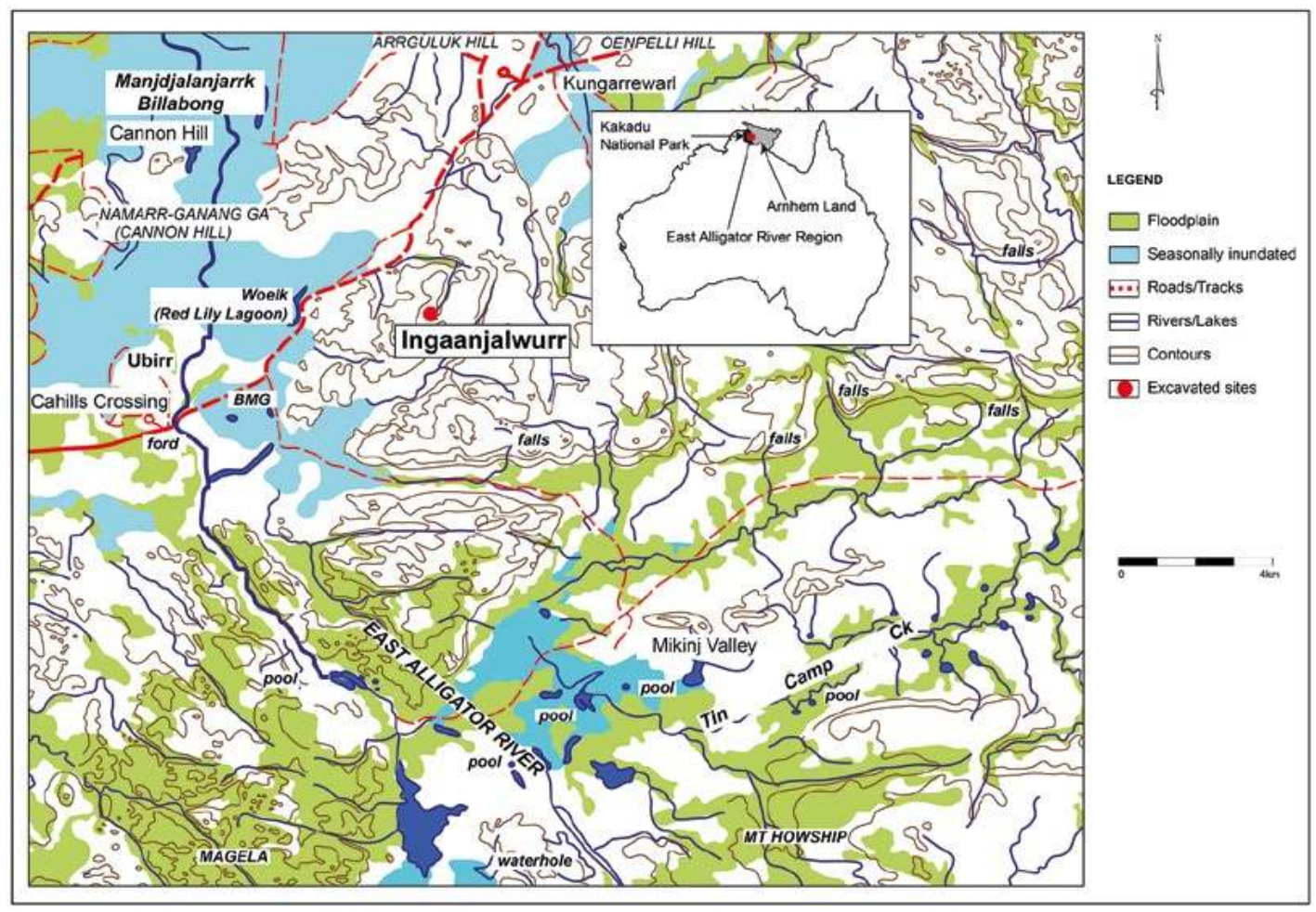

Figure 3.1 Location of Ingaanjalwurr and other key sites mentioned in this chapter, in relation to topography.

Source: Map by Duncan Wright.

The name Urrmarning derives from a purple lily (Nymphaeaceae spp.) that is common within Red Lily Lagoon. It applies to a rockshelter (Urrmarning rockshelter), the lagoon and much of the surrounding landscape (Figure 3.2). The English name Red Lily Lagoon is commonly used today, and has been in use since c. 1900 when the buffalo hunter Paddy Cahill was working in the area (Mulvaney 2004). The Red Lily vicinity also contains a rockshelter complex named Minjnyimirnjdawabu, which was partially recorded as Inagurdurwil during the AmericanAustralian Scientific Expedition to Arnhem Land (the 'Mountford Expedition') in 1948 (Mountford 1956). The rock art of both Minjnyimirnjdawabu and Urrmarning have been partially recorded in more recent times by Robert Gunn (1992).

The Ingaanjalwurr site itself is $10.5 \mathrm{~m}$ wide, $3.5 \mathrm{~m}$ deep and has a maximum height of $1.6 \mathrm{~m}$. It is located under a c. $15 \mathrm{~m}$ wide sandstone boulder that possesses a wall inclined at an angle of c. $45^{\circ}$ on its northern side (Figure 3.3). A semi-circular ring of roof-fall surrounds the shelter floor, providing some protection to the accumulated deposits and rock art. While no disturbance of the floor deposits from feral animals or macropods is apparent, two dormant termite mounds were observed at the dripline. A number of small trees are positioned at the northern limit of the overhang. Surface deposits of charcoal, as well as the painted and beeswax art, indicated prior human use of the rockshelter. The rock art and surface charcoal are concentrated in two locations where rockfall seemed to have provided greatest head room. 


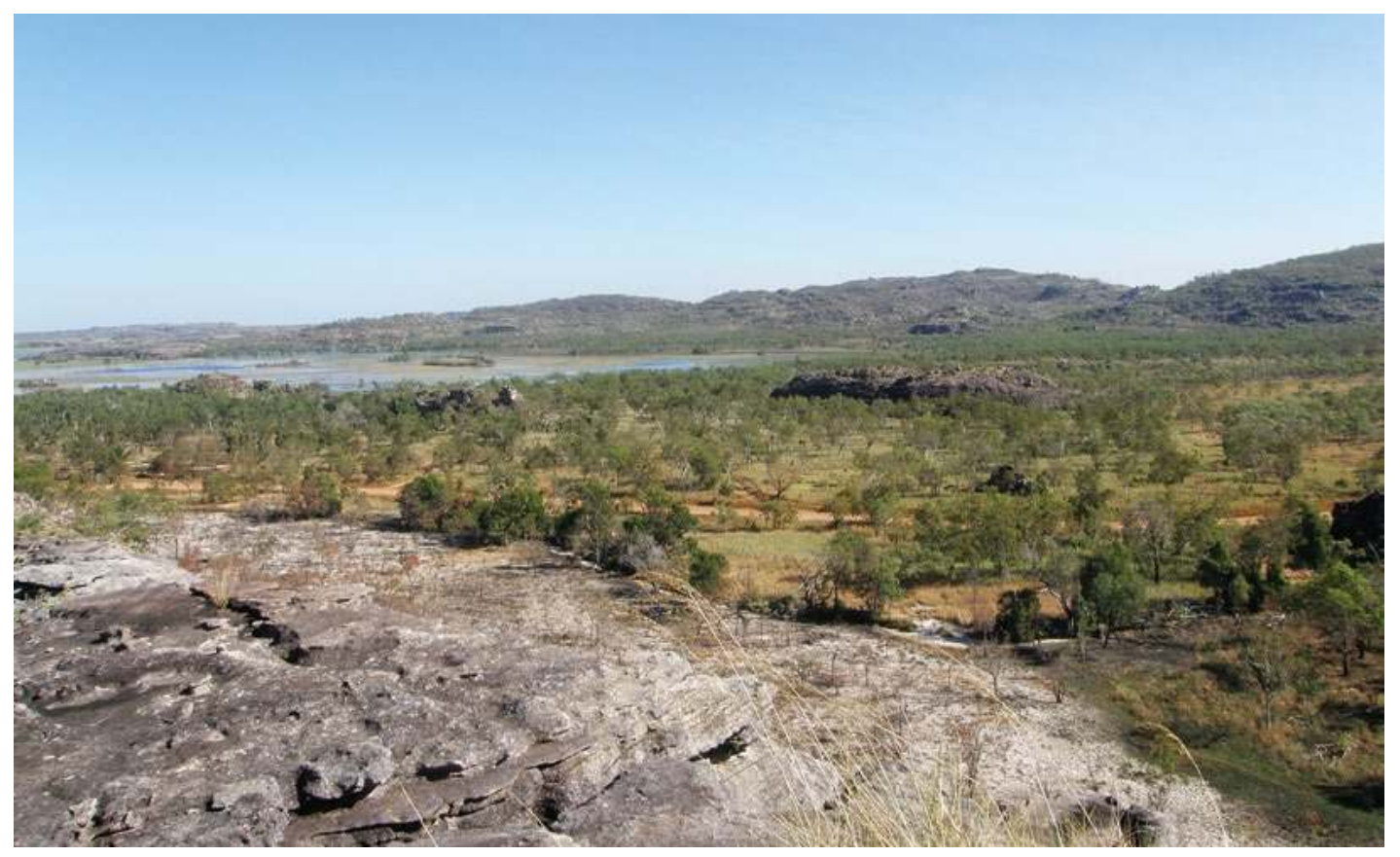

Figure 3.2 View towards Red Lily Lagoon from the escarpment at the rear of Ingaanjalwurr. Source: Photograph by Duncan Wright.

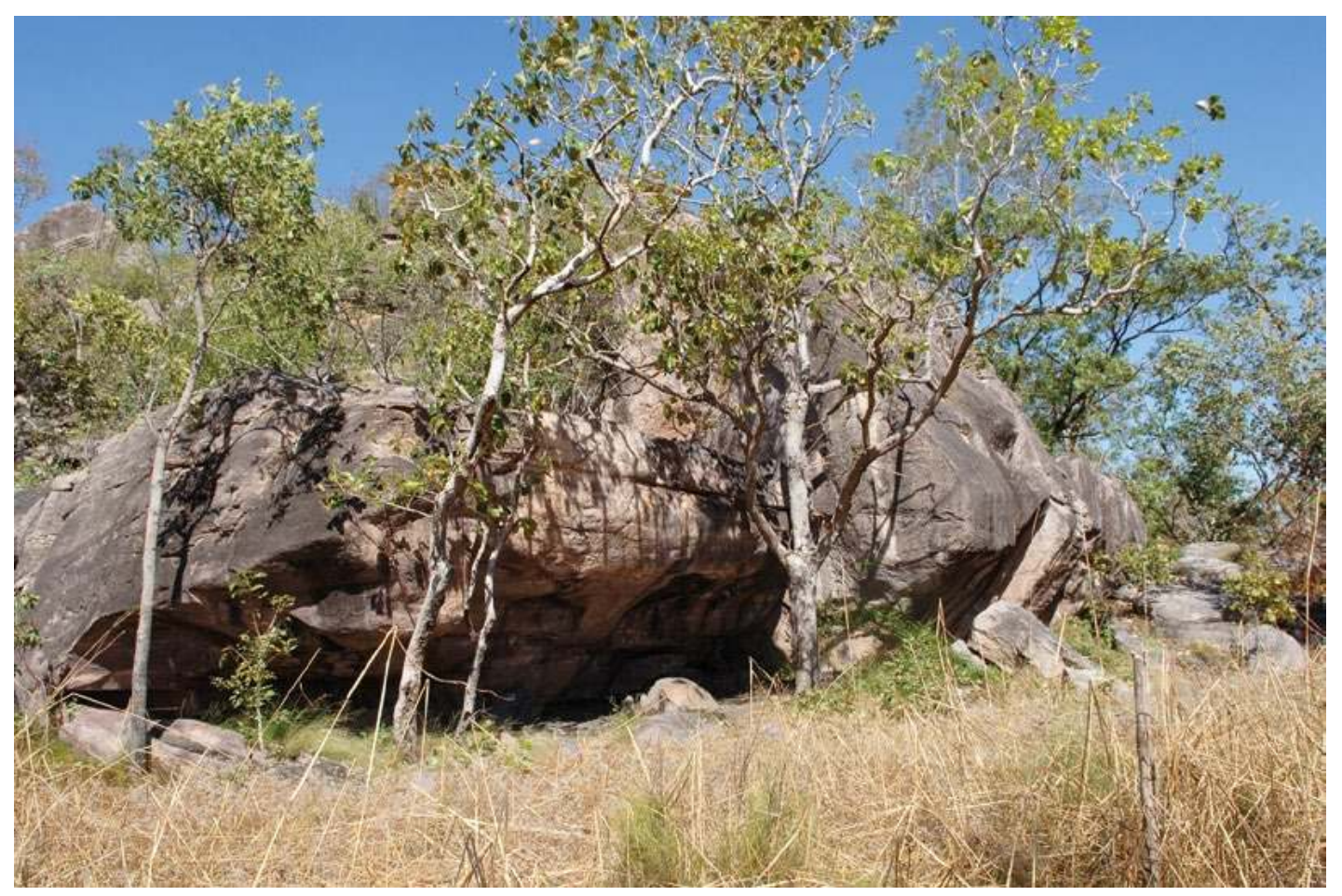

Figure 3.3 Ingaanjalwurr rockshelter from the north.

Source: Photograph by Sally K. May. 


\section{Rock art of Ingaanjalwurr}

Western Arnhem Land, and in particular Kakadu National Park within it, are widely acknowledged as one of the world's great rock art provinces. Internationally recognised through UNESCO World Heritage Listing for its rock art heritage, this region has one of Australia's largest concentrations of rock art sites (Chaloupka 1993; May and Taçon 2014:4235). The vast majority of rock art in this region is painted or stencilled, with fewer engravings, prints and beeswax figures. Ingaanjalwurr has a high density of beeswax art ( 45 examples) compared to the more typical painted art (76 examples).

Beeswax rock art concerns the application of native Australian beeswax onto rock surfaces in what Brandl (1968:19) describes as an 'assumed deliberate design'. Such designs can be made by forming pellets, strips and sheets from the prepared wax. The use of the word 'beeswax' for this type of rock art is not as straightforward as it first appears. The 'beeswax' used for rock art is a resinous compound. There are rare examples of rock art made from other resinous substances including gabbai, made from the roots of the ironwood tree (Erythrophleum chlorostachys), and another resin called kalapartaman found in central Arnhem Land (Chaloupka 1993:161; Taçon and Garde 2000:71). Throughout this chapter, the term 'beeswax' (sugarbag wax such as that found at Ingaanjalwurr) is used as a common name for the substance left when the honey has been extracted from a clump of sugarbag (the nest-building material of the Australian native stingless bee). The majority of beeswax art is found in northern Australia, specifically western Arnhem Land and the Kimberley, with a few scattered examples in northern Queensland.

The first researcher to publish specifically on beeswax art was Brandl (1968). Brandl (1968:1929; 1973:177) recorded nearly 30 images from eight rock art sites in western Arnhem Land and recognised the potential for directly radiocarbon dating beeswax art. Following Brandl's work, there was a break in detailed published research that lasted nearly 20 years and ended with the commencement of the 'Beeswax Art Project' in the 1990s (Nelson 2000; Nelson et al. 2000; Taçon and Garde 2000). Other researchers (e.g. Bednarik 2001; Chaloupka 1993:158-161; Gunn and Whear 2008; Gunn et al. 2012; Morwood et al. 2010; Taçon et al. 2003, 2004, 2010; Walsh 1988; Welch 1995) have used beeswax art to develop site chronologies and as part of general rock art studies. Most beeswax art dates to within the past 1500 years (e.g. see Gunn and Whear 2008; Morwood et al. 2010; Taçon and Garde 2000:74), although one example has been dated to c. 4000 years ago (Nelson et al. 1995:152; Watchman and Jones 2002).

Previous ethnographic research offers interpretations into the social role of beeswax art in Arnhem Land. Brandl (1968:28) suggested that retouched beeswax art may have been indicative of increased ritual use of a site. Other researchers have noted that single pellets or irregular lumps of beeswax were stuck to rock for good luck when playing cards in central Arnhem Land and as a tick removal procedure in western Arnhem Land (Chaloupka 1993:158; Taçon and Garde 2000:74). It has also been argued that by forming double rows of dots or depicting the SpiritBeing Narmarnde, it was possible to make a rockshelter habitable for the next season (Chaloupka 1993:158; Taçon and Garde 2000:74).

Rock art recording took place at Ingaanjalwurr in 2006 (beeswax art) and again in 2011 (paintings), with the latter occurring at the same time as the archaeological excavations.

\section{Rock paintings}

A total of 76 painted images were identified at Ingaanjalwurr, a considerable number given the small size of the rockshelter and relative exposure of the panels to direct sunlight and rain in the wet season. Two clearly distinct groups of paintings were recorded - red images (including all anthropomorphic figures, e.g. Figure 3.4) and white-infilled images usually with red outlining (Figure 3.5). While often in poor states of conservation, and superimpositions at times partly obscure underlying images, Table 3.1 presents a general list of motif shapes. 
Table 3.1 General interpretation of the painted art at Ingaanjalwurr rockshelter.

\begin{tabular}{|l|r|}
\hline Interpretation & Number \\
\hline Human-like figure & 33 \\
\hline Unidentified & 15 \\
\hline Line/s & 11 \\
\hline Geometric & 9 \\
\hline Fish & 4 \\
\hline Material culture (spear) & 2 \\
\hline Snake & 2 \\
\hline Total & 76 \\
\hline
\end{tabular}

Source: Authors' data.

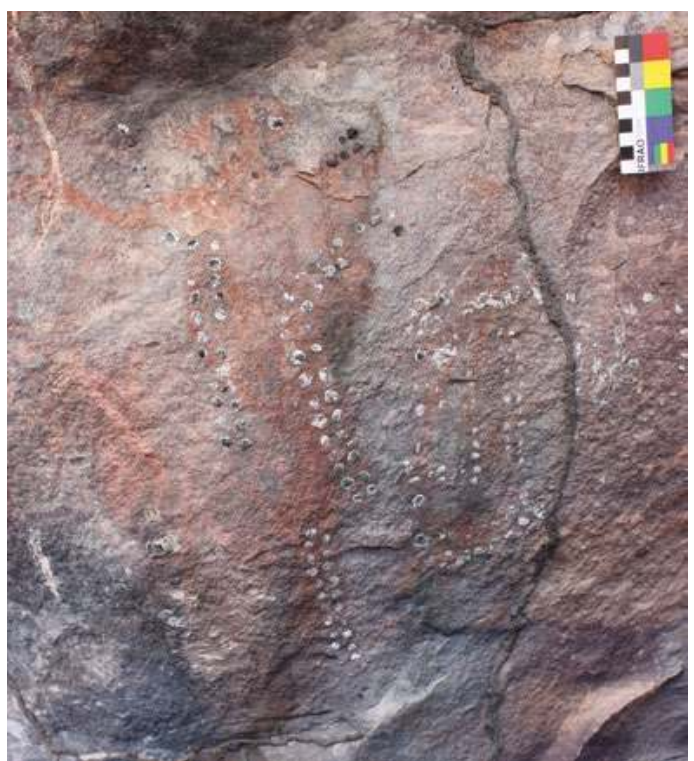

Figure 3.4 An example of the red painted anthropomorphs of Ingaanjalwurr.

Source: Photograph by Melissa Marshall.

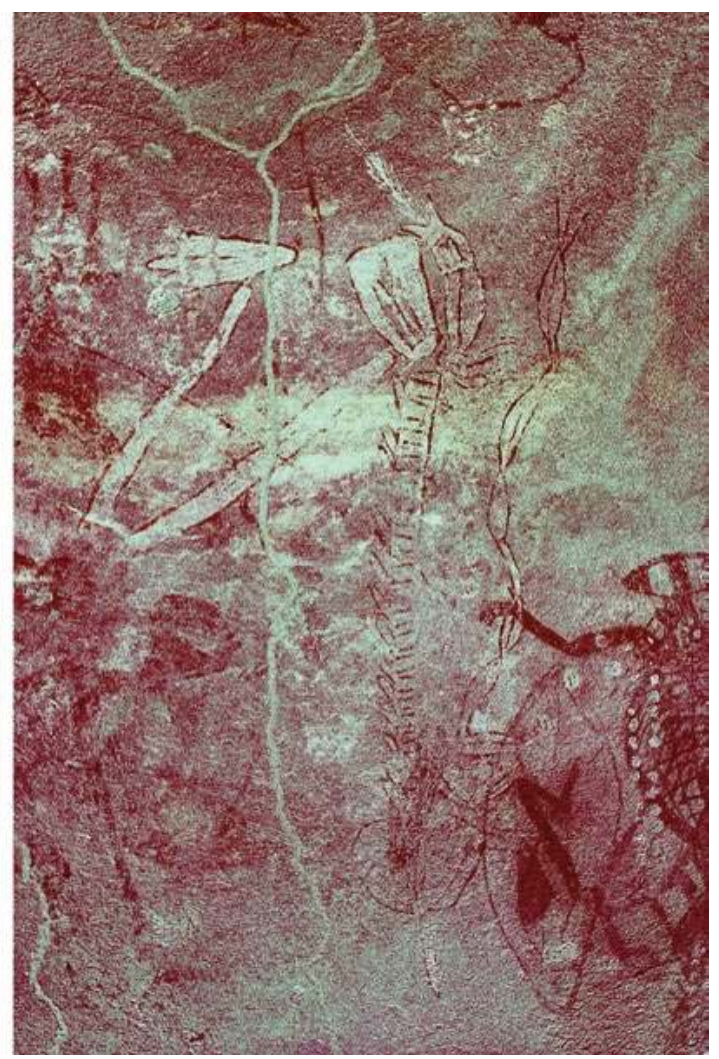

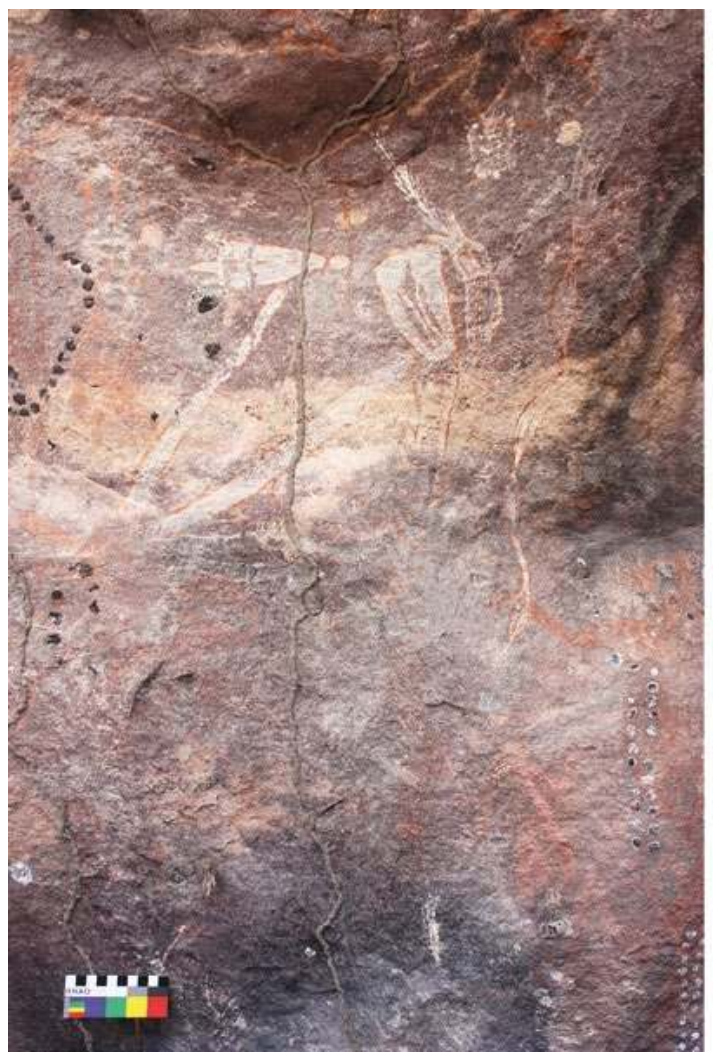

Figure 3.5 A white-infilled red-outlined painting (sorcery figure) from Ingaanjalwurr.

The image on the right was digitally enhanced using Dstretch YRD colourspace.

Source: Photograph by Melissa Marshall. 
Anthropomorphs dominate the painted art, followed by unidentified forms, simple single or double line paintings and geometric figures. While fish and snakes (including one doubleheaded snake) occur, they do so in small numbers (Table 3.1). Fourteen of the anthropomorphs display aspects of so-called 'sorcery' art previously documented from across much of western Arnhem Land, such as distorted limbs and/or spears in their joints and appendages (see Figure 3.5). Sorcery images are common throughout the East Alligator River region and elsewhere in Arnhem Land (Chaloupka 1993:207-211). On nearby Injalak Hill, one sorcery painting was ethnographically documented to have been produced to bring pain to the depicted individual, and other sorcery figures were painted to represent evil spirits such as Namorrodoh (May 2006; Taylor 1996; W. Nawirridj, pers. comm. to Sally K. May 2010).

Another four of the human-like rock art figures appear to have Yawk Yawk (female water spirit/ mermaid) tails instead of legs. Yawk Yawk is the Kunwinjku language term used for young women, but it is also used for special female water spirits that have fish tails. Sometimes they are described as mermaids that are said to live in water in special places in western Arnhem Land. They are considered minor regional spirits (alongside Mimi, Namorrodoh and other types of Spirit-Beings) that are still painted today by artists in western Arnhem Land (May 2006; Taylor 1996:88).

The painted art at Ingaanjalwurr is dominated by depictions of human figures and minor Spirit-Beings that are still widely known today in western Arnhem Land. This is unusual for painted shelters of this region, where the recent rock art is more often dominated by depictions of local food sources such as fish (Taçon 1988, 1989). On stylistic grounds, painted images at Ingaanjalwurr correspond to the later Estuarine Period and early Freshwater Period, which are thought to date to the past 3000 years or so (Chaloupka 1993:153-189).

\section{Beeswax rock art}

Forty-five beeswax images have been recorded at Ingaanjalwurr rockshelter. These are in varying states of preservation. The beeswax images appear to follow contours of the rock surface, and cluster in small groups of stylistically similar images. Figure 3.6 and Table 3.2 illustrate and describe each of the recorded beeswax images.

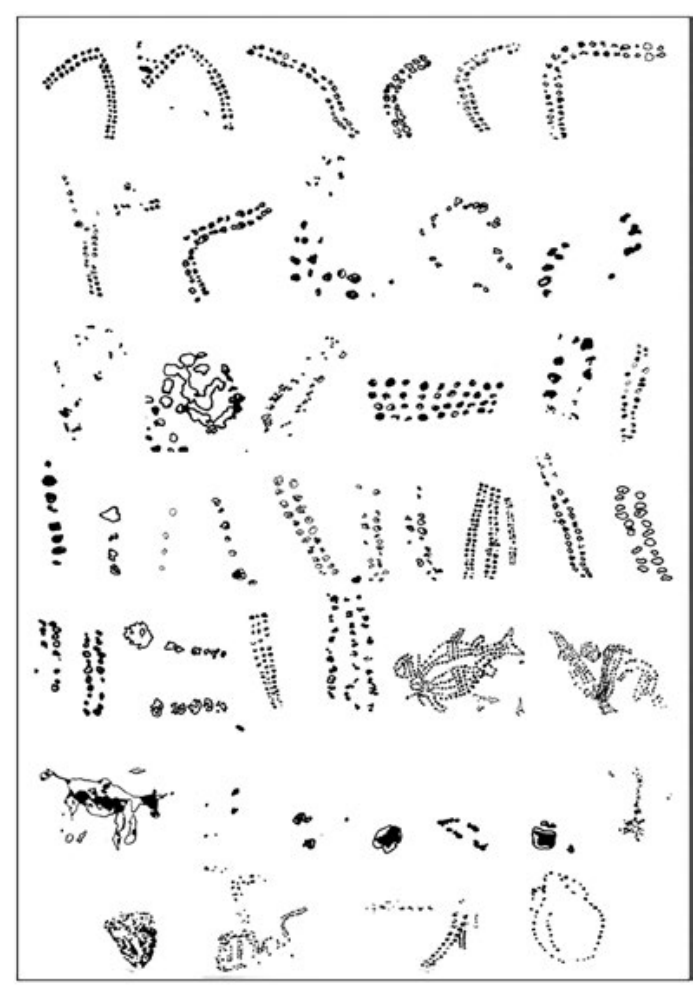

Figure 3.6 Digital tracings of photographed beeswax images from Ingaanjalwurr (images are at different scales to each other). Darker colouring indicates greater thickness of surviving beeswax, with lighter areas signalling only staining remaining on the rock surface.

Source: Digital tracings by Faye Prideaux. 
Table 3.2 General classification and description of beeswax images from Ingaanjalwurr rockshelter.

\begin{tabular}{|c|c|c|}
\hline Classification & Description & Number \\
\hline \multicolumn{3}{|l|}{ Geometric } \\
\hline & Circular, outlined & 5 \\
\hline & Double rows, vertical & 4 \\
\hline & Double rows, horizontal & 4 \\
\hline & Arched double row, facing left & 3 \\
\hline & Arched double row, facing right & 3 \\
\hline & Single rows, vertical & 2 \\
\hline & Triple rows, vertical & 2 \\
\hline & Rectangles, in-filled & 2 \\
\hline & Rectangles, outlined & 1 \\
\hline & S-shape & 1 \\
\hline \multicolumn{3}{|l|}{ Figurative } \\
\hline & Barramundi & 1 \\
\hline & Unidentified fish & 1 \\
\hline & Unidentified fish or turtle & 1 \\
\hline & Horse or cow & 1 \\
\hline \multicolumn{3}{|l|}{ Abstract } \\
\hline & Unknown & 4 \\
\hline & Combination geometric shapes & 3 \\
\hline \multicolumn{3}{|l|}{ Pellets } \\
\hline & Single pellets & 4 \\
\hline & More than one pellet & 3 \\
\hline Total & & 45 \\
\hline
\end{tabular}

Source: Authors' data.

As can be seen in Figure 3.6, most (93 per cent) of the beeswax images at Ingaanjalwurr consist of applied dots. Only one image was created using the strips of beeswax, and two images (including a quadruped) were constructed by applying sheets of beeswax.

The beeswax images are mainly geometric in design, with circular and row designs being most common (Table 3.2). Of the row designs, double rows and arched double rows predominate (see Figure 3.6). Only four figurative images were clearly identified: a barramundi (Figure 3.7), an unidentified fish, an unidentified fish or turtle and a horse or cow (Figure 3.8). The barramundi is depicted with its head broken, said to assist with carrying the fish back to camp (Thompson Yulidjirri, pers. comm. to Sally K. May 2005). This manner of depiction is common in painted art of this region (Taçon 1989) (Figure 3.9). The beeswax fish are the only examples yet published of such imagery from western Arnhem Land.

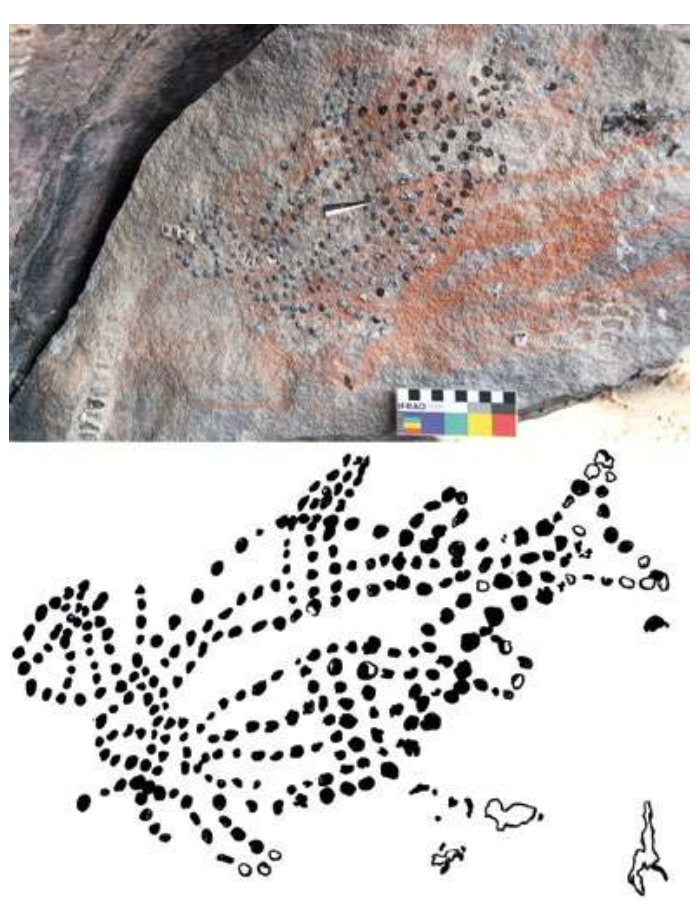

Figure 3.7 Beeswax image of a fish, with arrow indicating location from which Sample 1 was taken.

Source: Photograph by Paul S.C. Taçon. 

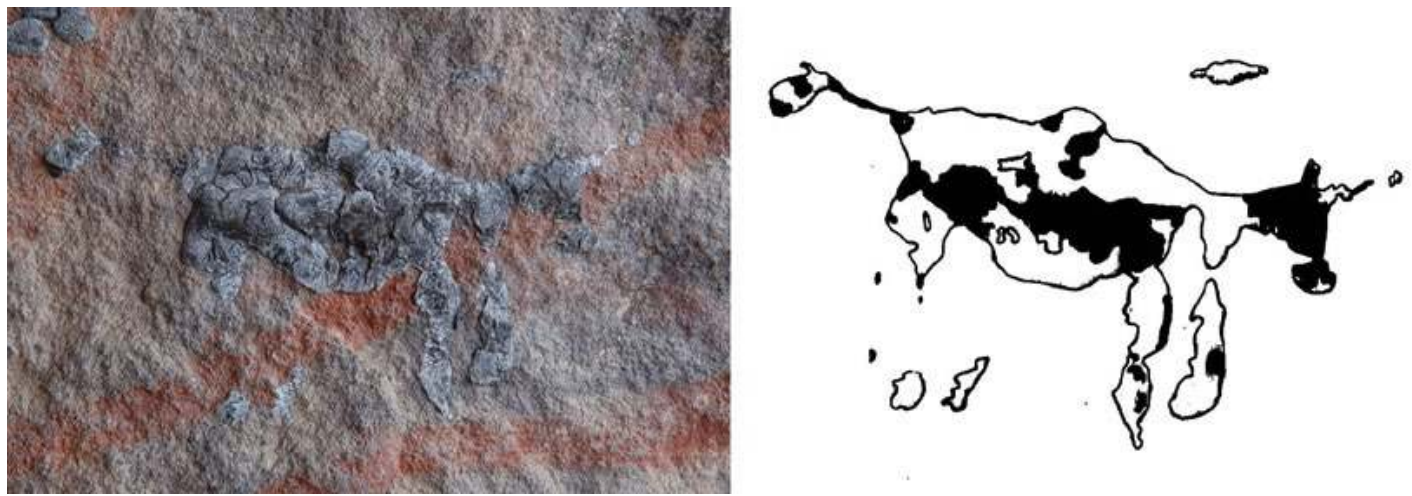

Figure 3.8 Unidentified beeswax quadruped from Ingaanjalwurr.

Source: Photograph by Sally K. May.

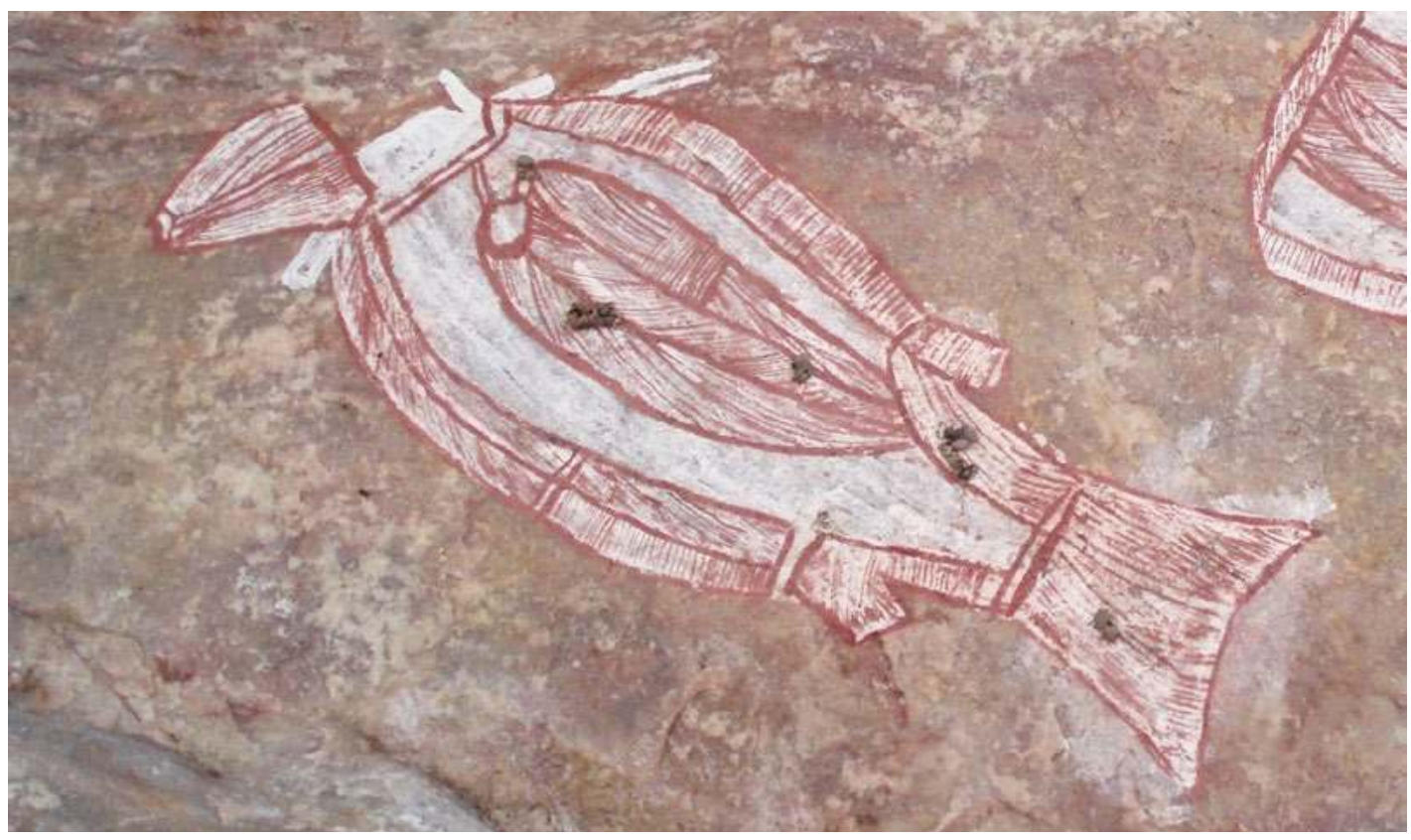

Figure 3.9 Painting of a fish with head broken to assist with carrying, Injalak Hill.

Source: Photograph by Sally K. May.

The quadruped is clearly a European-contact period figure, most likely depicting a horse. Rock art produced during the contact period is widely documented for western Arnhem Land (e.g. see Chaloupka 1979, 1993; Gunn et al. 2012; May et al. 2010; Taçon et al. 2010). The depiction of horses is rare but not unique in this region. A remarkable example of a painted image of a horse was recently documented at Nawarla Gabarnmang in Jawoyn Country (Gunn et al. 2012:60; Chapter 12), and may date from Leichhardt's 1845 expedition across the region. The Ingaanjalwurr depiction of a horse or cow in beeswax is unique, however, as no other such depictions are known.

Most of the beeswax art at Ingaanjalwurr is in a poor state of preservation, with pellets exfoliating from the rockshelter walls. Despite the detachment of pellets from the wall, none were recovered in the excavations. Many of the geometric images are badly deteriorated, with termite tracks observed over several of the beeswax designs. Numerous images using dots have almost no beeswax remaining and remain identifiable only as stains or 'shadows' on the rock surface. This degradation made identification of several of the images difficult. 


\section{Direct radiocarbon dating of beeswax art}

To ascertain the antiquity of beeswax art, pellets from two images were collected for accelerator mass spectrometry (AMS) radiocarbon dating:

- Sample 1: A beeswax figure of a fish (Figures 3.7). This fish image is superimposed over a red painting of a human-like figure and, as such, provides a minimum age for that painting.

- Sample 2: A single line of beeswax pellets (Figure 3.10). This beeswax linework is superimposed over a red painted sorcery figure.

The resultant AMS dates on these beeswax pellets are both in good chronological agreement, suggesting they were both made sometime within the period 8-275 cal BP, and most likely sometime after 150 cal BP (Table 3.3). The similarity of the two radiocarbon dates for the two beeswax images suggests that these two types of figurative and geometric forms are broadly contemporaneous. The dating of the beeswax art also provides minimum ages for the paintings that underlie them. At Ingaanjalwurr, beeswax images frequently overlie the painted art in patterns of superimposition, but never the reverse.

Table 3.3 Radiocarbon dates from Ingaanjalwurr beeswax figures.

\begin{tabular}{|l|c|c|c|c|}
\hline Sample & Laboratory code & $\delta C 13$ & Radiocarbon age (BP) & Calibrated age (95.4\% Probability) (cal BP) \\
\hline 1 & ANU-31021 & $-22.9 \pm 0.7$ & $130 \pm 30$ & $275-172(37.9 \%)$ \\
& & & & $152-56(42.5 \%)$ \\
& & & & $45-8(15.0 \%)$ \\
\hline 1 (duplicate) & ANU-31023 & $-22.6 \pm 0.9$ & $120 \pm 30$ & $271-186(32.4 \%)$ \\
& & & & $176-174(0.4 \%)$ \\
& & & & $150-10(62.6 \%)$ \\
\hline 2 & ANU-31024 & $-24.9 \pm 0.2$ & $120 \pm 25$ & $270-186(31.3 \%)$ \\
& & & & $150-11(64.1 \%)$ \\
\hline
\end{tabular}

Calibration after 0xCal 4.1 (Bronk Ramsay 2009). Ingaanjalwurr lies at the southern boundary of the Inter-tropical Convergence Zone (ITCZ), an area that may be influenced by Northern Hemisphere air masses (Hogg et al. 2013; Hua et al. 2012). For this reason the calibrations were performed with the IntCal 09 dataset of Reimer et al. (2009).

Source: Authors' data.

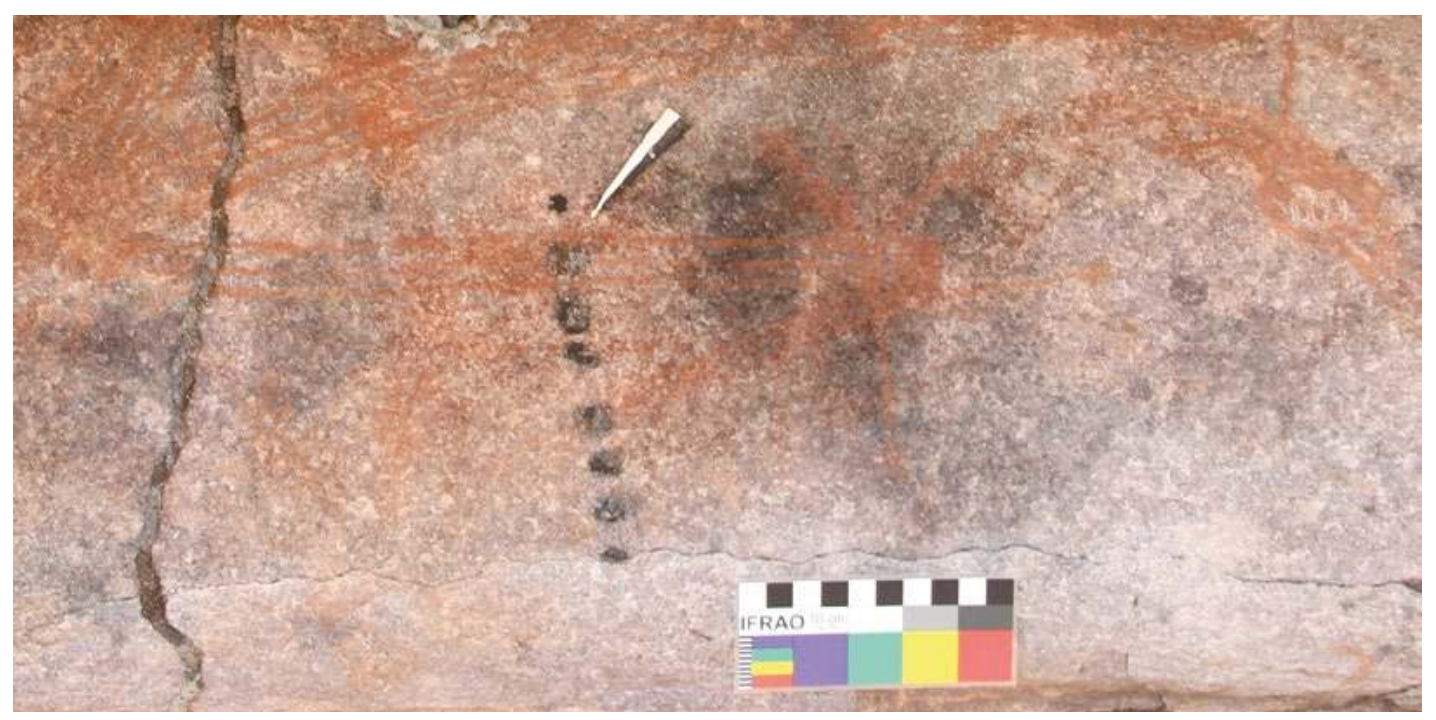

Figure 3.10 Single row of beeswax pellets, with arrow indicating location from which Sample 2 was taken.

Source: Photograph by Paul S.C. Taçon. 


\section{Archaeological excavations}

During June and July 2011, two $1 \times 1 \mathrm{~m}$ squares were excavated at Ingaanjalwurr (Squares 1 and 2). These were designed to provide information regarding the settlement history of the site and to explore relationships between sub-surface archaeology and the various rock art traditions evident on the rock walls (see Shine 2014 for detailed information on the excavation methods and results). Square 1 was positioned within the rockshelter's dripline in proximity to surface charcoal, the main concentration of rock art and smoke staining on the ceiling. The square was excavated in 34 excavation units (XUs) to a maximum depth of $68 \mathrm{~cm}$ below ground, although rockfall significantly reduced the excavation area below XU2. Square 2 was excavated just outside the dripline, c. $4.1 \mathrm{~m}$ northwest of Square 1 and beyond apparent surface rockfall. Square 2 was excavated in $40 \mathrm{XUs}$ and reached a maximum depth of $88 \mathrm{~cm}$, although here from XU6 down rockfall reduced the excavation area. Confined space forced the discontinuation of both excavations without reaching culturally sterile deposits.

The arbitrary XUs followed the observed strata during excavation. XUs averaged $2.0 \mathrm{~cm}$ in thickness in Square 1 and $2.2 \mathrm{~cm}$ in Square 2. All excavated sediments were dry-sieved through $2.1 \mathrm{~mm}$ mesh on-site, and then archaeologically floated through $250 \mu \mathrm{m}$ mesh at a dedicated field facility at Gunbalanya. The resultant floated and sieved materials were air-dried before being transported to Monash University (Clayton) for sorting and analysis. The provenance of artefacts observed in situ and large fragments of charcoal were plotted in three dimensions and individually bagged.

Both squares contained relatively homogenous brown sands, differentiated into three stratigraphic units based on variations in compaction and inclusions (primarily charcoal). Sediments were acidic, varying in $\mathrm{pH}$ from 3.0 to 3.4 in Square 1 and from 2.7 to 3.0 in Square 2. Minor biogenic disturbance from insects and roots was recorded in both squares.

Both squares exhibit good chronostratigraphic integrity (Table 3.4). In Square 1, the upper four dates span the period c. $500 \mathrm{cal}$ BP onwards; minor chronostratigraphic reversals are consistent with the 'old wood effect'. In general, in Square 1 the radiocarbon dates suggest relatively rapid sediment accumulation from XU26 onwards, from c. $500 \mathrm{cal}$ BP to very recent times. A basal date from XU34 (Wk-33539) looks anomalously old (given the date from XU31) and potentially represents older, residual charcoal within mixed ancient and more recent sediments associated with the roof fall event. A broadly similar chronostratigraphic sequence occurs in Square 2, except for a younger-than-anticipated date from XU33 (Wk-33534) that is interpreted as intrusive, younger charcoal.

Archaeological excavations recovered a total of 617 stone artefacts; worked $(27.6 \mathrm{~g})$ and unworked (44.8 g) ochre, neither of which is natural to the site; three metal artefacts and one glass artefact from Square 2. Large quantities of charcoal were collected as sieved macrocharcoal pieces $(>2.1 \mathrm{~mm}$ : Square $1=1979 \mathrm{~g}$; Square $2=1607 \mathrm{~g}$ ), and also comprised the majority of retrieved flotation organics $(>250 \mu \mathrm{m}$ and $<2.1 \mathrm{~mm}$ : Square $1=2353 \mathrm{~g}$; Square $2=5231 \mathrm{~g}$ ). The vast majority of both the macro and floated charcoal from Ingaanjalwurr is considered to be associated with human occupation at the site, because peaks in macrocharcoal and flotation correspond to peaks in stone artefacts.

Ochre was recovered in both excavation squares: six pieces of unworked ochre $(1.0 \mathrm{~g})$ and two pieces of worked ochre $(8.3 \mathrm{~g})$ in Square 1, and 25 pieces of unworked ochre $(43.8 \mathrm{~g})$ and 11 pieces of worked ochre $(19.3 \mathrm{~g})$ in Square 2. Even allowing for its greater depth and greater amount of excavated sediment, Square 2 still contained significantly greater amounts of worked 
ochre than Square 1, with 85 per cent of the total number of worked ochre pieces coming from Square 2. This pattern of peak ochre deposition occurring outside the dripline may suggest spatial patterning of site use at Ingaanjalwurr.

Table 3.4 Radiocarbon dates on charcoal from Ingaanjalwurr (Squares 1 and 2).

\begin{tabular}{|c|c|c|c|c|c|c|}
\hline Laboratory code & $\mathrm{XU}$ & Square & $\begin{array}{l}\text { Depth below } \\
\text { ground }(\mathrm{cm})\end{array}$ & $\delta C 13$ & Radiocarbon age (BP) & $\begin{array}{c}\text { Calibrated age ( } 95.4 \% \\
\text { probability) (cal BP) }\end{array}$ \\
\hline Wk-33537 & 6 & 1 & 13 & $-27.4 \pm 0.2$ & $411 \pm 26$ & $\begin{array}{c}516-436(87.5 \%) \\
350-332(7.9 \%)\end{array}$ \\
\hline Wk-31823 & 11 & 1 & 23 & $-25.02 \pm 0.2$ & $233 \pm 25$ & $\begin{array}{c}310-270(51.4 \%) \\
187-149(35.1 \%) \\
127-(-) 4(8.9 \%) \\
\end{array}$ \\
\hline Wk-31822 & 14 & 1 & 28 & $-25.7 \pm 0.2$ & $296 \pm 25$ & $\begin{array}{c}455-444(1.9 \%) \\
439-348(65.8 \%) \\
334-296(27.7 \%) \\
\end{array}$ \\
\hline Wk-33538 & 26 & 1 & 53 & $-24.9 \pm 0.2$ & $301 \pm 25$ & $\begin{array}{l}456-348(70.5 \%) \\
334-300(24.9 \%) \\
\end{array}$ \\
\hline Wk-33589 & 31 & 1 & 62 & $-26.2 \pm 0.2$ & $1635 \pm 25$ & $\begin{array}{l}1606-1485(76.9 \%) \\
1469-1417(18.5 \%)\end{array}$ \\
\hline Wk-33539 & 34 & 1 & 68 & $-25.5 \pm 0.2$ & $8690 \pm 39$ & $\begin{array}{c}9762-9753(0.6 \%) \\
9744-9543(94.8 \%)\end{array}$ \\
\hline Wk-33535 & 5 & 2 & 6 & $-24.8 \pm 0.2$ & $157 \pm 25$ & $\begin{array}{c}284-244(16.6 \%) \\
230-166(38 \%) \\
155-131(10.6 \%) \\
118-68(11.7 \%) \\
36-(-) 3(18.5 \%) \\
\end{array}$ \\
\hline Wk-33533 & 13 & 2 & 26 & $-25.6 \pm 0.2$ & $241 \pm 25$ & $\begin{array}{c}422-407(1.9 \%) \\
317-272(58.8 \%) \\
184-150(28.9 \%) \\
10-(-) 4(5.9 \%) \\
\end{array}$ \\
\hline Wk-31821 & 21 & 2 & 43 & $-26.02 \pm 0.2$ & $1431 \pm 25$ & 1370-1295 (95.4\%) \\
\hline Wk-35590 & 28 & 2 & 56 & $-25.5 \pm 0.2$ & $1883 \pm 25$ & $\begin{array}{c}1860-1850(1.5 \%) \\
1826-1706(93.9 \%)\end{array}$ \\
\hline Wk-33534 & 33 & 2 & 68 & $-25.9 \pm 0.2$ & $237 \pm 25$ & $\begin{array}{c}418-414(0.5 \%) \\
315-270(55.4 \%) \\
186-150(32.2 \%) \\
12-(-) 4(7.4 \%) \\
\end{array}$ \\
\hline Wk-33536 & 39 & 2 & 85 & $-26.1 \pm 0.2$ & $1867 \pm 26$ & 1873-1726 (95.4\%) \\
\hline
\end{tabular}

Calibrations after OxCal 4.1 (Bronk Ramsay 2009). Ingaanjalwurr lies at the southern boundary of the Inter-tropical Convergence Zone (ITCZ), an area that may be influenced by northern hemisphere air masses (Hogg et al. 2013; Hua et al. 2012). For this reason the calibrations were performed with the IntCal 09 dataset of Reimer et al. (2009).

Source: Authors' data.

The colour of ochre pieces recovered from the excavations is consistent with the rock paintings at the site, consisting primarily of red, red-purple and red-yellow, with one unworked yellow piece recovered from XU19 in Square 2. Although white pigment is absent from the excavated assemblage, 18 per cent of paintings recorded at the site $(\mathrm{N}=14$ of 76 paintings) were either white $(\mathrm{N}=6)$ or contained white $(\mathrm{N}=8)$. Colour differentiation in the excavated red ochres, both worked and unworked, was in a comparable range as evident in the rock art, with 15 red, 15 red-purple and 13 red-yellow excavated pieces. 
There is a clear concentration of ochre, especially worked ochre, in the upper levels of both excavation squares. The uppermost 11 XUs of both squares contained all but two ( 85 per cent) of the worked ochre pieces. Taken at face value, this distribution indicates a concentration of ochre grinding after c. 300-460 cal BP, namely upward from XU11 in Square 1 and XU13 in Square 2. However, such an interpretation does not take into account preservation biases, such as increased rates of ochre disintegration with depth and through time.

Archaeological evidence for an earlier phase of ochre use is limited to one stone covered with red ochre, and a single piece of worked ochre, both from XU24 in Square 2. A radiocarbon date from XU21 indicates that XU24 is older than $1295-1370$ cal BP (Wk-31821). The decorated stone (size: $32.9 \times 21.8 \times 7.4 \mathrm{~mm}$; weight: $4.8 \mathrm{~g}$ ) is a fragment of an originally larger piece, possibly originating from the ceiling of the rockshelter. A major period of site use at this time is suggested by elevated rates of stone artefact discard and charcoal deposition.

In short, archaeological excavations at Ingaanjalwurr point to two primary periods of human activity: (a) an earlier phase from c. 1900 to c. 1300 cal BP; and (b) a later phase commencing c. 300-460 cal BP, which seemingly increases in intensity towards European contact. These two key periods of occupation at Ingaanjalwurr are separated by low-intensity site use. Although there is no guarantee that the excavated pieces of ochre relate to nearby on-wall paintings (see also McNiven et al. 2009), the chronostratigraphic integrity of excavated deposits and the congruence of peaks of worked ochre with those of stone artefacts suggest that the worked ochre is associated with pulses of occupation.

\section{Ethnographic evidence for activities at Ingaanjalwurr}

Discussions with Nakodjok and other Traditional Owners took place during June 2011 concerning past activities at Ingaanjalwurr. Over the past 100 years, the rockshelter has been used as a shortterm camp by people walking between Gunbalanya, Mudginberri, Pine Creek and other smaller settlements. Nakodjok was born in 1943 and recalled camping at the shelter in his youth 'for a day or two or maybe a week ... it was a good feeding ground for people those days ... looking for small breams and mussels' (Nakodjok, pers. comm. to Denis Shine 2011). Nakodjok stated that the camp was used during the dry season when the floodplains were drying out and bream could be easily caught with nets in retreating water pools around Ingaanjalwurr Creek.

None of Nakodjok's children remember camping at the site, suggesting that it had ceased to be used as a camping place by the 1960s, but they had occasionally visited the area to hunt rock wallaby (Petrogale spp.) since that time. Other Aboriginal Elders from Gunbalanya, including J. G. Namarnyilk (this senior Traditional Owner passed away in 2012; we refer to him by a shortened version of his name out of respect for his family's wishes) and Don Namundja, agreed that hunting was particularly rich around Ingaanjalwurr Creek. While not having specific knowledge of the site, they referred to the broader Ingaanjalwurr vicinity as an area that was regularly visited to hunt.

Nakodjok was interested in the high density of beeswax art present at Ingaanjalwurr. He understood that previous Traditional Owners of the area 'would invite other people to come and stay and that is why they did all those paintings'. He believed the density of beeswax art at the site resulted from 'somebody ... learning how to use the beeswax and paint'; 'when he learnt he'd do more better one ... somewhere else' (Nakodjok, pers. comm. 2011). Nakodjok also suggested that the concentration of beeswax art may simply reflect an availability of materials, as ochre is not easily available on the adjacent floodplains: 'because they had no colours you see a lot of wax painting there is no black or white, red, yellow ochre, all just wax, well you know they had plenty of wax to do the job'. 
Nakodjok believed the beeswax quadruped at Ingaanjalwurr depicts a horse. Horses were first introduced at early British fortified settlements such as Port Essington (AD 1838-1849) (Powell 1996). The image could also post-date AD 1845, when Leichhardt visited the region on horseback; or possibly dates to the early 1900s when these animals were first introduced in large numbers by buffalo hunter Paddy Cahill (May 2006; May et al. 2010; Mulvaney 2004). Nakodjok had no recollection of people making beeswax art when he camped at the site, indicating that beeswax art was probably no longer being practised at Ingaanjalwurr in the mid-20th century.

\section{Discussion and conclusion}

We began this chapter by exploring the idea that in many rockshelters across western Arnhem Land, rock art was produced during bursts of activity (Taçon 1993:113) rather than gradually accumulating over prolonged periods of time as implied by Chaloupka's (1993) notion of 'longest continuing art tradition'. Accordingly, rock art at Ingaanjalwurr and elsewhere, as reported by Tacon (1993) and Gunn et al. (2012), was produced during relatively short periods of time associated with intense periods of occupation. Comparisons with the published data from Nawarla Gabarnmang to the south are of particular interest. Here Gunn et al. (2012:61) argued that a large quantity of art was produced within the past c. 350 years, while associated archaeological evidence suggests low-density occupation during the preceding 1000 years or so (David et al. 2011:76; Gunn et al. 2012:61; see Chapters 11 and 12). At Ingaanjalwurr, we found a period of beeswax art production dating to sometime after c. $275 \mathrm{cal} \mathrm{BP}$, either commencing in, or continuing into, the European-contact period (as indicated by the likely depiction of a horse). This period of heightened artistic activity coincides with a peak period of occupation commencing around c. 300-460 cal BP, as evidenced in the results of the archaeological excavations. There is also evidence for an earlier phase of activity at the site (including the use of red ochre) commencing within the calibration range 1726-1873 cal BP and continuing until c. 1295-1370 cal BP. However, the vast majority of the excavated red ochre fragments date to the later period of occupation, c. 300-460 cal BP. In short, the majority of surviving art at Ingaanjalwurr appears to have been produced during a short burst of activity incorporating the European-contact period.

If we accept that the past few hundred years witnessed increased human activity at the site, along with the appearance of beeswax and painted sorcery figures, then we must also question what cultural conventions inspired the making of such assemblages of art. Any such assessment requires consideration of the site within the transformational social contexts of the past 500 years, i.e. the period preceding and including European contact.

For at least the past 350 years, Aboriginal people in the East Alligator River region were in regular contact with Macassans (e.g. Macknight 1969, 1976, 1986; Taçon et al. 2010; Theden-Ringl et al. 2011) and, later, European explorers, hunters, settlers, police, World War II personnel and missionaries (i.e. Forrest 1985; Levitus 1995; Mulvaney 2004; Robinson 2005). Connections with more recent European settlement are suggested by the geographic positioning of Ingaanjalwurr rockshelter on an Aboriginal walking route linking Oenpelli with other settlements, such as the cattle station and Aboriginal encampment at Mudginberri (Levitus 1982; Esther Manakgu, pers. comm. to Sally K. May 2011). During the European-contact period, Aboriginal migration to, and between, European settlements was known to have been extensive in the East Alligator River region (Levitus 1995). Here, European contact resulted in a retraction of Aboriginal movements across the landscape, to direct routes between historic settlements such as the Oenpelli Mission (May et al. 2010). We suggest that Ingaanjalwurr was used intermittently, perhaps opportunistically, as Aboriginal people journeyed between these emerging settlements. 
The use of Ingaanjalwurr as a temporary camp on such journeys (as opposed to sustained occupation) is also reflected in the archaeological record for the site, with its relatively small number of artefacts but large volumes of charcoal and considerable number of rock art images, including contact period rock art. Likewise, the ethnographic information provided by Nakodjok specifically suggests that Ingaanjalwurr was a short-term camp for people moving along walking routes between settlements and utilising areas known for particular food resources.

There is also an interesting link between the earlier painted art of Ingaanjalwurr and the Europeancontact period. An important feature of this painted rock art is the presence of sorcery figures. Associations between rock art, sorcery and European illnesses across the region are well established (e.g. Chaloupka 1993; Taçon 1993). For the East Alligator River region, Chaloupka suggests that the majority of sorcery paintings date to the contact period and that they were probably a 'direct product of the stresses and sicknesses introduced by contact, such as the documented epidemics of influenza, measles, and leprosy which affected perhaps the majority of the population in the vicinity of Oenpelli' (Chaloupka 1983:15).

European diseases in the East Alligator River region, possibly deriving from contact with residents of or visitors to early British fortified settlements (Allen 2008), were recorded as early as the mid19th century (McKinlay 1866). However, both the incidence and array of European diseases increased massively following the foundation of Oenpelli and its development as an Anglican Mission Station after 1925 (e.g. see Barker 1978:12; Mulvaney 2004:53-55).

As Oenpelli grew, it became the primary source of European disease in the East Alligator River region (Taçon 1989:161-162) as well as, ironically, a place of pilgrimage and refuge for those seeking treatment. Sorcery figures are common in this area and are generally considered to be 'recent' in age, with none thought to be associated with art forms more than a few hundred years old (Chaloupka 1983:15; Taçon 1989:161).

The sorcery figures at Ingaanjalwurr are depicted with swollen/malformed joints. Taçon (1989:161) has previously contended that swollen joints were painted by Aboriginal people to document a symptom of Ross River fever, a type of mosquito-borne virus, which causes an influenza-like illness and polyarthritis (causing swelling and stiffness of joints). While Ross River fever was not officially named until the mid-20th century, Paddy Cahill documented serious outbreaks of a similar illness, which he classified as influenza, in 1917 and the early 1920s. The depiction of swollen joints on sorcery figures at Ingaanjalwurr, as at several other sites, could record Aboriginal perceptions of the disease that was at that time understood to be influenza. Alternatively, the disfigurement on these figures could relate to physical deformities caused by other diseases, such as leprosy and smallpox, which were also common in the East Alligator River region.

As noted above, some painted sorcery figures have been connected ethnographically to Namorrodoh, a malevolent magic man who Aboriginal people in the East Alligator River region associate with death and illness (e.g. Taçon 1989). Namorrodoh features heavily in Aboriginal narratives of the East Alligator River region, and have been documented from the Manilikarr and neighbouring Bunidj clans (see Shine et al. 2014). Among these clans, oral traditions pertaining to Namorrodoh have been recorded for Canon Hill, as well as for Owurrngarndt and Ubirr (e.g. Gunn 1992; Taçon 1989). Within the Manilikarr estate, Namorrodoh's image is depicted at Ubirr and Minjnyimirnjdawabu. Also located close to Minjnyimirnjdawabu, and contained within Red Lily Lagoon (Urrmarning) is Kungk, an Aboriginal sickness site, which was previously documented by Gunn (1992). Kungk, the Kunwinjku word for 'gut' or 'waist', is the only recorded sickness site within the Manilikarr estate and is associated with severe diarrhoea in local Aboriginal narratives (Gunn 1992:93). 
Ethnographic associations between beeswax art and sorcery, evil spirits and ritual activity have also been documented (Taçon et al. 1997, 2003:8). As mentioned above, Brandl (1968:28) suggested that some beeswax art could indicate increased ritual activity at a site. It has also been argued that by forming double rows of beeswax dots, or depicting the evil and dangerous spirit Narmarnde, it was possible to make a rockshelter habitable for the next season, presumably by ridding the shelter of these spirits (Chaloupka 1993:158; Taçon and Garde 2000:74). While this is, of course, just one level of interpretation, it does provide an interesting insight into the cultural complexity of this art form. Beeswax art has also been associated with the containment of deceased Ancestral spirits, the empowerment of body parts, and beliefs relating to the Rainbow Serpent (Chaloupka 1993:158; Chaloupka and Alderson 2000:24; Taçon et al. 2000). Each of these studies indicates that beeswax art can be imbued with a vital spiritual element, and that beeswax art is recalled ethnographically as being related to death, sickness and/or sorcery.

The concentration of sorcery figures at Ingaanjalwurr may be deliberate and part of a trend in the East Alligator River region, whereby Aboriginal people recorded the impact of European illnesses in both oral and visual (i.e. rock art) means. Thus we propose that much of the beeswax art and the painted sorcery figures may detail Aboriginal perceptions of a traumatic period in western Arnhem Land's history, a time that saw new introduced illnesses spreading quickly. The art thus arguably represents a form of social response to, and/or documentation of, a time of radical societal change.

\section{Acknowledgements}

We thank Nakodjok Nayinggul and his family for permission to undertake this research. We thank Stewart Fallon (The Australian National University) for radiocarbon dating, Injalak Arts (Gunbalanya) and the Northern Land Council for their ongoing support. Thanks to W. Nawirridj, Alfred Nayinggul, Gabriel Maralngurra, B. Nabegeyo, J.G. Namarnyilk, Don Namundja, Lionel Nayinggul, E. Manakgu, T. Yulidjirri, Lawrence Nayinggul and Garry Djorlom who have engaged with the project in many ways over the years. Special thanks to Andronicus Nayinggul for assisting in the excavation.

The excavations were funded by a Monash Research Accelerator grant awarded to Tim Denham, and ongoing analyses are partially funded by an Australian and Pacific Science Foundation grant awarded to Tim Denham and Denis Shine. Radiometric dating was provided by TD and Bruno David. Archaeological sorting was funded by the Student Summer Scholarship Scheme at Monash University. The PhD research of Denis Shine, including the excavations at Ingaanjalwurr, was supported by a Monash International Postgraduate Research Award Scholarship, Monash University Faculty of Arts Scholarship and internal support from the School of Geography and Environmental Science at Monash University. Finally, we thank the Place, Evolution and Rock Art Heritage Unit at Griffith University and the School of Archaeology and Anthropology at The Australian National University for supporting this research.

\section{References}

Allen, J. 2008. Port Essington: The Historical Archaeology of a North Australian Nineteenth-Century Military Outpost. University of Sydney Press, Sydney.

Barker, G.H. 1978. Alligator Rivers region - Historical Sketch to World War II. Australian Institute of Aboriginal Studies, Canberra.

Bednarik, R.G. 2001. The taphonomy of beeswax figures. Rock Art Research 18(2):91-95. 
Brandl, E.J. 1968. Aboriginal rock designs in beeswax and description of cave painting sites in Western Australia. Archaeology and Physical Anthropology in Oceania 3(1):19-29.

Brandl, E.J. 1973. Australian Aboriginal paintings in Western and Central Arnhem Land: Temporal Sequences and Elements of Style in Cadell River and Deaf Adder Creek Art. Australian Institute of Aboriginal Studies, Canberra.

Bronk Ramsey, C. 2009. Bayesian analysis of radiocarbon dates. Radiocarbon, 51(1):337-360. doi.org/ $10.1017 /$ S0033822200033865

Chaloupka, G. 1979. Pack-bells on the rock face: Aboriginal paintings of European contact in northwestern Arnhem Land. Aboriginal History 3(1):92-95.

Chaloupka, G. 1983. Kakadu rock art: Its cultural, historic and prehistoric significance. In D. Gillespie (ed), The Rock Art Sites of Kakadu National Park: Some Preliminary Research Findings for their Conservation and Management, pp. 3-33. Australian National Parks and Wildlife Service, Canberra.

Chaloupka, G. 1993. Journey in Time: The World's Longest Continuing Art Tradition. Reed, Chatswood.

Chaloupka, G. and M.C. Alderson 2000. Gunbirdi Bim: Beeswax art. In D.E. Nelson (ed.), The Beeswax Art of Northern Australia, pp. 17-28. Simon Fraser University, Burnaby.

David, B., J.-M. Geneste, R.L. Whear, J.-J. Delannoy, M. Katherine, R.G. Gunn, C. Clarkson, H. Plisson, P. Lee, F. Petchey, C. Rowe, B. Barker, L. Lamb, W. Miller, S. Hoerle', D. James, E. Boche, K. Aplin, I.J. McNiven, T. Richards, A. Fairbairn and J. Matthews 2011. Nawarla

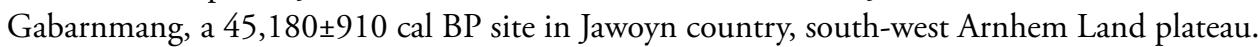
Australian Archaeology 73:73-77.

Forrest, P. 1985. An outline of the history of the Gunbalanya locality. Unpublished report for FACTS Pty Ltd, Darwin.

Gunn, R.G. 1992. Mikinj: Rock Art, Myth and Place. Unpublished report to Australian Institute of Aboriginal and Torres Strait Islander Studies, Canberra.

Gunn, R.G. and R.L. Whear 2008. A singular beeswax representation of Namarrkon, the Lightning Man, from western Arnhem Land. Australian Aboriginal Studies 2:54-69.

Gunn, R.G., R.L. Whear and L.C. Douglas 2012. Dating the present at Nawarla Gabarnmang: Time and function in the art of a major Jawoyn rock art and occupation site in western Arnhem Land. Australian Archaeology 75:55-65. doi.org/10.1080/03122417.2012.11681950

Hogg, A., Q. Hua, P. Blackwell, M. Niu, C. Buck, T. Guilderson, T.J. Heaton, J.G. Palmer, P.J. Reimer, R.W. Reimer, C.S.M. Turney and S. Zimmerman 2013. SHCAL13 Southern Hemisphere calibration, 0-50,000 years cal BP. Radiocarbon, 54(4):1889-1903. doi.org/10.2458/azu_js_ rc. 55.16783

Hua, Q., M. Barbetti, V. Levchenko, R. D’Arrigo, B. Buckley and A. Smith 2012. Monsoonal influence on Southern Hemisphere 14CO2. Geophysical Research Letters 39(19). doi.org/ 10.1029/2012GL052971

Levitus, R. 1982. 'Everybody bin all day work': A Report on the Social History of the Alligator Rivers Region of the Northern Territory 1869-1973. Unpublished report, Australian National Parks and Wildlife Service, Canberra.

Levitus, R. 1995. Social history since colonisation. In T. Press, D. Lea, A. Webb and A. Graham (eds), Kakadu Natural and Cultural Heritage and Management, pp. 64-93. Australian Nature Conservation Agency and the North Australian Research Unit, The Australian National University, Darwin. 
Macknight, C.C. 1969. The Macassans: A Study of the Early Trepang Industry along the Northern Territory Coast. Unpublished PhD thesis. The Australian National University, Canberra.

Macknight, C.C. 1976. The Voyage to Marege: Macassan Trepangers in Northern Australia. Melbourne University Press, Melbourne.

Macknight, C.C. 1986. Macassans and the Aboriginal past. Archaeology in Oceania 21(1):69-75. doi.org/10.1002/j.1834-4453.1986.tb00126.x

May, S.K. 2006. Karrikadjurren: Creating Community with an Art Centre in Indigenous Australia. Unpublished PhD thesis. The Australian National University, Canberra.

May, S.K. and P.S.C. Taçon. 2014. Kakadu National Park: Rock art. In C. Smith (ed.), Encyclopedia of Global Archaeology, pp. 4235-4240. Springer, New York. doi.org/10.1007/978-1-4419-0465-2_2241

May S.K, P.S.C. Taçon, D. Wesley and M. Travers 2010. Painting history: Indigenous observations and depictions of the 'Other' in north-western Arnhem Land, Australia. Australian Archaeology 71:57-65. doi.org/10.1080/03122417.2010.11689384

McKinlay, J. 1866. J. McKinlay's Northern Territory Explorations, 1866: Journal of Exploring Expedition. Ordered by the House of Assembly to be Printed, 2nd October, 1866. Government Printer, Adelaide.

McNiven, I.J., L.M. Brady and A.J. Barham 2009. Kabadul Kula and the antiquity of the Torres Strait rock art. Australian Archaeology 69:29-40. doi.org/10.1080/03122417.2009.11681899

Morwood, M.J., G.L. Walsh and A. Watchman 2010. AMS radiocarbon ages for beeswax and charcoal pigments in north Kimberley rock art. Rock Art Research 27:3-8.

Mountford, C.P. 1956. Records of the American-Australian Expedition to Arnhem Land 1948: Art, Myth and Symbolism. Melbourne University Press, Melbourne.

Mulvaney, D.J. 2004. Paddy Cahill of Oenpelli. Aboriginal Studies Press, Canberra.

Nelson, D.E. 2000. The Beeswax Art of Northern Australia. Simon Fraser University, Burnaby.

Nelson, D.E., G. Chaloupka, C. Chippindale, M.S. Alderson and J.R. Southon 1995. Radiocarbon dates for beeswax figures in the prehistoric rock art of northern Australia. Archaeometry 37(1):151-156. doi.org/10.1111/j.1475-4754.1995.tb00733.x

Nelson, D.E., C. Chippindale, G. Chaloupka and P.S.C. Taçon 2000. The plateau sites. In D.E. Nelson (ed.), The Beeswax Art of Northern Australia, pp. 67-82. Simon Fraser University, Burnaby.

Powell, A. 1996. Far Country: A Short History of the Northern Territory. Melbourne University Press, Melbourne.

Reimer, P.J., M.G. Baillie, E. Bard, A. Bayliss, J.W. Beck, P.G. Blackwell, C.B. Ramsey, C.E. Buck, G.S. Burr, R.L. Edwards and M. Friedrich 2009. IntCal09 and Marine09 radiocarbon age calibration curves, 0-50,000 years cal BP. Radiocarbon 51(04):1111-1150. doi.org/10.1017/ S0033822200034202

Robinson, C.J. 2005. Buffalo hunting and the feral frontier of Australia's Northern Territory. Social and Cultural Geography 6(6):885-901. doi.org/10.1080/14649360500353285

Shine, D. 2014. Changing Places: An Archaeological Study of Manilikarr Country in Western Arnhem Land. Unpublished PhD thesis, Monash University, Clayton. 
Shine, D., D. Wright, T. Denham, K. Aplin, P. Hiscock, K. Parker and R. Walton 2014. Birriwilk rockshelter: A mid- to late Holocene site in Manilikarr Country, southwest Arnhem Land, Northern Territory. Australian Archaeology 76:69-78. doi.org/10.1080/03122417.2013.11681967

Taçon, P.S.C. 1988. Identifying fish species in the recent rock paintings of western Arnhem Land. Rock Art Research 5(1):3-15.

Taçon, P.S.C. 1989. From Rainbow Snakes to 'X-Ray' Fish: The Nature of the Recent Painting Tradition in Western Arnhem Land. Unpublished PhD thesis. The Australia National University, Canberra.

Taçon, P.S.C. 1993. Regionalism in the recent rock art of western Arnhem Land, Northern Territory. Archaeology in Oceania 28(3):113-120. doi.org/10.1002/j.1834-4453.1993.tb00302.x

Taçon, P.S.C. and M. Garde 2000. Dating beeswax figures on rock: The view from central Arnhem Land. In G. Ward and C. Tuniz (eds), Advances in Dating Australian Rock-Markings: Papers from the First Australian Rock-picture Dating Workshop, pp. 71-75. Occasional AURA Publication 10. Australian Rock Art Research Association, Melbourne.

Taçon P.S.C., R. Fullagar, S. Ouzman and K. Mulvaney 1997. Cupule engravings from JinmiumGranilpi (northern Australia) and beyond: Exploration of a widespread and enigmatic class of rock markings. Antiquity 71(274):942-965. doi.org/10.1017/S0003598X00085847

Taçon, P.S.C., M. Garde, M. Kubarkku and B. Birriyabirriya 2000. Notes from central Arnhem Land. In D.E. Nelson (ed.), The Beeswax Art of Northern Australia, pp. 29-30. CD-ROM. Simon Fraser University, Burnaby.

Taçon, P.S.C., K. Mulvaney, S. Ouzman, R. Fullagar, P. Carlton and L. Head. 2003. Changing ecological concerns in the rock-art subject matter of north Australia's Keep River Region. Before Farming 2003/3(4):1-14. doi.org/10.3828/bfarm.2003.3.4

Taçon P.S.C., E.D. Nelson, C. Chippindale and G. Chaloupka 2004. The beeswax art of the Northern Territory: Direct dating results and a book of records. Rock Art Research 21(2):155-160.

Taçon, P.S.C., S.K. May, S. Fallon, M. Travers, D. Guse and R. Lamilami 2010. A minimum age for early depictions of Macassan praus in the rock art of Arnhem Land, Northern Territory. Australian Archaeology 71:1-10. doi.org/10.1080/03122417.2010.11689379

Taylor, L. 1996. Seeing the Inside: Bark Painting in Western Arnhem Land. Clarendon Press, Oxford.

Theden-Ringl, F., J.N. Fenner, D. Wesley and R. Lamilami. 2011. Buried on foreign shores: Isotope analysis of the origin of human remains recovered from a Macassan site in Arnhem Land. Australian Archaeology 73:41-48.

Walsh, G. 1988. Australia's Greatest Rock Art. E. J. Brill-Robert Brown and Associates, Sydney.

Watchman, A.L. and R. Jones 2002. An independent confirmation of the 4 ka antiquity of a beeswax figure in western Arnhem Land. Archaeometry 44(1):145-153. doi.org/10.1111/1475-4754.00049

Welch, D. 1995. Beeswax art in the Kimberley, Western Australia. Rock Art Research 12(1):23-28. 


\title{
The agency of artefacts: Socio- ideological functionality and the long-necked spearthrowers of Mirarr Country, northern Australia
}

\author{
John A. Hayward
}

\section{Introduction}

The seemingly symbiotic relationship between spears and spearthrowers in the history of Australian Aboriginal technologies is not as equal as it may appear. Spears can, and have, happily survived without spearthrowers, whereas, as instruments of propulsion, spearthrowers appear to be solely dependent upon spears for their raison d'être. The first people to arrive in Australia probably came with spears (see also Davidson 1934:42), but it was not until many thousands of years later that spearthrower technology was introduced into the region (see also Davidson 1936). Some parts of Australia such as Tasmania, Melville Island, parts of the Queensland coast and possibly southern Queensland, northern New South Wales and eastern South Australia never adopted the technology (Cundy 1989:1; Davidson 1936:453). In the rock art of Arnhem Land, some of the earliest depictions of human figures with material culture, known as 'Dynamic Figures', only launched their spears by hand, with the first images of spearthrower-like implements appearing towards the end of the Dynamic Figure phase as a hooked stick that could have functioned as either a fighting pick or a prototype spearthrower (Lewis 1996:17), and may have functioned as both in those transitional times. Rock art images suggest that these implements were first used sometime after the Pleistocene/Holocene transition, more than 40,000 years after colonisation of the continent, but the images do not tell us if the new technology was a local invention, or introduced from elsewhere through diffusion as proposed by Davidson (1936:446).

It is generally considered or assumed that since its adoption at the end of the period of Dynamic Figures art or slightly later in Arnhem Land, the spearthrower was instrumental in increasing the power and efficiency of spear throwing (see Allen and Akerman 2015:82-83; Cundy 1989:16). However, some rock art images from the northeast Kakadu region testify to another, independent role for the implement. 

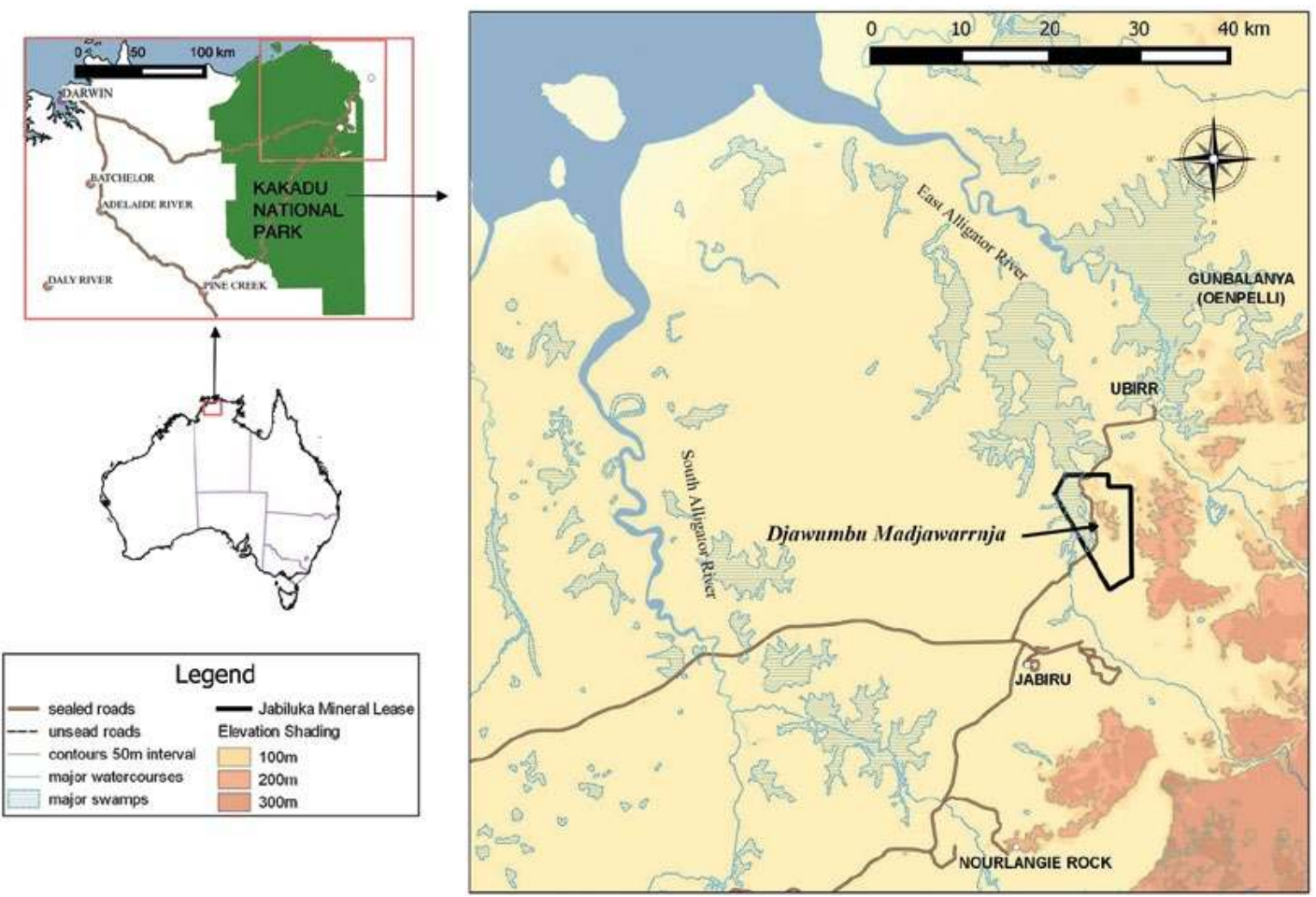

Figure 4.1 Location of the Djawumbu Madjawarrnja massif in relation to the township of Jabiru and the Jabiluka mineral lease.

Source: Phil Davill.

\section{Long-necked spearthrowers in the rock art of Arnhem Land}

This chapter focuses on images of long-necked spearthrowers, a particular type of spearthrower depicted in the rock art of a discrete region of western Arnhem Land. These images were documented during the 2012-2014 field seasons of the Mirarr Gunwarddebim (rock art) project in the traditional Country of the Mirarr people in northeastern Kakadu National Park. The study focused on the Djawumbu Madjawarnja massif located within the Jabiluka mineral lease a few kilometres north of the Jabiru township (Figure 4.1). The massif has a high concentration of rock art; during the first three years of the Mirarr Gunwarddebim project, 528 cultural sites were documented within an area approximately $5 \times 2.7 \mathrm{~km}$ in size.

One of the prevailing views relating to Aboriginal artefacts includes the idea that the design variation of implements be analysed through their function in the technological sub-system, where form follows function (Cundy 1989:3). Long-necked spearthrowers, however, represent an unusual and distinctive graphic within the rock art landscape of this region, because they appear as functional spearthrowers used to launch a range of spear types, but the elaboration, form and variation of their design elements give the impression of being functionally impractical. It is due to this apparent impracticality that these implements have been analysed within the social, ideological and symbolic framework of rock art, rather than as technological items.

It is the extended central shaft of the implement protruding like a long neck from its body that unites this spearthrower type under the common banner of 'long-necked spearthrowers' (Figure 4.2). This implement type has also been described by Lewis (1988) and mentioned by Chaloupka (1993:150) as 'long-necked spearthrowers', and Chaloupka (1993:217) as 'complex spearthrowers'. In all cases, the central shaft of the spearthrower appears to be a stout stick with 
a hooked end for articulation with a spear. There is generally a handle, or enlarged form at the proximal end, which can take on a number of different shapes; some appear to have tassels on either or both the proximal and terminal ends. The central body of the implement takes on a variety of shapes that are often depicted as disproportionally large forms, sometimes with distinctive patterning inside them.

In his 1988 monograph, Darrell Lewis proposed a chronology for Arnhem Land rock art based principally on his observations of technological change of implements such as boomerangs, spears and spearthrowers in paintings, but also backed up by other chronological markers, such as cultural and stylistic conventions, broad environmental changes and faunal extinctions. Lewis's methodologies were very much influenced by Eric Brandl, an earlier researcher who is credited not only with recognising Mimi art as having early and late periods (Brandl 1973), but also as observing the technological transition within those periods from hand-thrown spears to spearthrower-launched spears (Lewis 1988:16). Some of the earliest human forms depicted in the art (Dynamic Figures) are devoid of spearthrowers but are commonly associated with boomerangs, a type of implement that subsequently became quite scarce in that same region's rock art. Lewis's first chronological period, the boomerang period, was thought to have lasted until at least 9000 years ago, at which point it morphed into the hooked stick period when both boomerangs and hooked fighting sticks were concurrently depicted. By Lewis's estimate, approximately 6000 years ago the first unambiguous spearthrower types are seen. These 'broad spearthrowers', which along with basic 'cylindrical spearthrowers' and a wide variety of new spear types begin to appear in the rock art that defines the broad spearthrower period, are thought to have begun no more than 6000 years ago, lasting to at least 1000-2000 years ago. The subsequent long spearthrower period, which Lewis estimates to have spanned from a maximum of 2000 years ago to ethnographic times, was named after the introduction of a type of spearthrower that is longer and thinner than broad spearthrowers and that is defined by a notch functioning as a handle at its proximal end (see Figure 4.2).

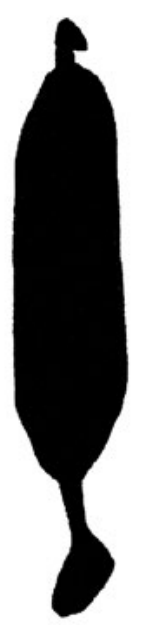

Broad
spearthrower

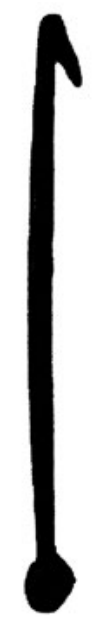

Cylindrical spearthrower

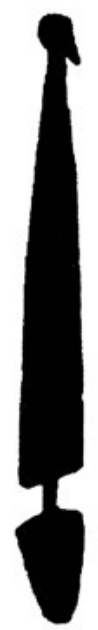

Long-notched lath spearthrower

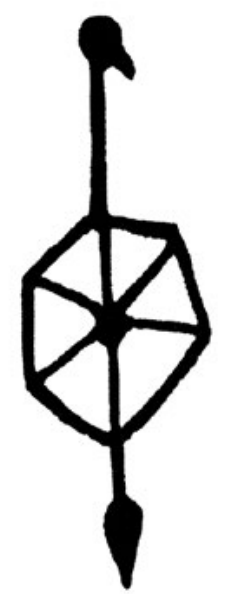

Long-necked spearthrower

Figure 4.2 Four typical spearthrower types recorded during the Mirarr Gunwarddebim project (not to scale).

Source: John Hayward. 
According to Lewis (1988:111), long-necked spearthrowers appear in rock paintings of western Arnhem Land during the transition between broad to long spearthrowers. Lewis's (1988:62) assessment is as follows:

The long-necked spearthrower does not appear to have an ethnographic parallel anywhere in Australia. The possibility of artistic license must always be considered, but in this instance the very fine line-control and carefully executed patterns inside the round or squared section of some examples suggest that its shape is being accurately rendered and that these are depictions of an archaic spearthrower type. Several examples bear very similar designs inside their borders which suggests that they are not mere infill patterns. Whether these patterns represent part of the construction of the spearthrower or a painted or incised design is a problem for future research.

The variety of shapes apparent among long-necked spearthrowers suggests that they were produced during a period of experimentation with spearthrower/spear technology. If this is so it is possible that long-necked spearthrowers were only produced for a short period and were not adopted throughout the Arnhem Land region.

Here, I reassess the chronology of Lewis's broad and long spearthrower periods in relation to the abundance of long-necked spearthowers observed in motifs recorded during the Mirarr Gunwarddebim project. Along with these new field observations, two artefacts recently recorded from an ethnographic collection (see below) have possible implications for the age of this type of spearthrower, and therefore for the age of artworks that contain such artefacts.

A total of 107 individual paintings of, and scenes with, long-necked spearthrowers were recorded during the first three field survey seasons of the Mirarr Gunwarddebim project. Some scenes depict multiple spearthrowers, giving a total of 138 long-necked spearthrowers counted from photographs taken at 67 rock art sites. Of the 667 paintings of spearthrowers of various types recorded from all sites in the Djawumbu region, long-necked spearthrowers represent 20.7 per cent, or over one-fifth of the total (long-notched lath spearthrowers $=38.2$ per cent; cylindrical spearthrowers $=22.6$ per cent; broad spearthrowers $=7.5$ per cent) (Figure 4.2). My use of the term 'long-notched lath spearthrower' throughout this chapter is equivalent to Davidson's (1936) 'North Australian type', Cundy's (1989) notched 'lath spearthrower' and Lewis's (1988) 'long (notched lath) spearthrower', although Lewis oscillates between 'long notched' and 'long (notched lath)' spearthrower.

The main attribute of long-necked spearthrowers is that, unlike the broad, cylindrical and longnotched lath spearthrowers, each of which displays considerable graphic conformity, individual representations of long-necked spearthrowers are generally quite different from each other. Of the 138 recorded cases, 78 representations ( 57 per cent) have unique characteristics, with the remaining exhibiting varying degrees of difference to each other (Table 4.1). This uniqueness or individuality of each long-necked spearthrower in the rock art can be expressed in a number of ways, including the shape of the body, the infill pattern of the body, the shape of the handle, the shape of the hook and/or the addition of tassels. The 78 renditions of long-necked spearthrowers recorded during this survey are shown in Figures 4.3-4.5. Another 22 examples recorded by previous researchers from parts of western Arnhem Land outside the Jabiluka area (Figure 4.6) suggest that the general distribution of this spearthrower type is restricted to the northwest section of what is today Kakadu National Park, and seems to follow similar distribution patterns to other motifs such as Mountford Figures and Energetic Figures (see Haskovec 1992; Lewis 1996:13; Taçon 1989:136). Chaloupka (1993) recorded a number of sites with long-necked spearthrowers at Injalak near Oenpelli, as has Lewis (1988) at Cannon Hill that appears to represent the northernmost reach of this motif. Both Welch (1997) and Lewis (1988) have recorded long-necked spearthrower motifs at Nourlangie, as has Brandl (1973:48) at Mt Gilruth, the latter being the southernmost mention of this type of spearthrower. 


\section{Sub-types of long-necked spearthrowers}

For purposes of classification and discussion, the diversity of shapes among long-necked spearthrowers can be divided into four main sub-types: Type A: rectilinear; Type B: curvilinear; Type C: concave-sided; Type D: multi-sided (Table 4.1). These four sub-types represent morphological variations on the common theme of spearthrowers with long necks, although whether or not this four-part division was recognised by the artists is unknown. As with many classification systems, some paintings are borderline cases that could have fitted into more than one category but have been allocated the sub-type considered 'best fit'.

Table 4.1 Numbers of long-necked spearthrower paintings, by sub-type.

\begin{tabular}{|l|c|c|c|}
\hline Long-necked spearthrower types & Number of paintings & \multicolumn{2}{|c|}{ Unique examples } \\
\hline A: Rectilinear & 24 & 20 & $83 \%$ \\
\hline B: Curvilinear & 86 & 39 & $45 \%$ \\
\hline C: Concave-sided & 16 & 12 & $75 \%$ \\
\hline D: Multi-sided & 12 & 12 & $100 \%$ \\
\hline Total & 138 & $\mathbf{7 8}$ & $\mathbf{5 7} \%$ \\
\hline
\end{tabular}

Source: Author's data.

There are more paintings of curvilinear long-necked spearthrowers than of all other sub-types put together, and the curvilinear sub-type is more standardised than any other (Table 4.1). Some spearthrowers from a given sub-type appear in scenes where large groups of human figures are engaged in possible ceremonial, conflict or other activities. No two spearthrower depictions are exactly the same within any sub-type; by definition, those that are considered 'similar' to each other have fewer degrees of difference than those classed as 'unique'. The examples depicted in Figures 4.34.5 show clear morphological differences from each other and are those classed as 'unique'. Of these 78 unique designs, 18 are identified as the models for other 'similar' cases found in either the same, or in different, paintings.

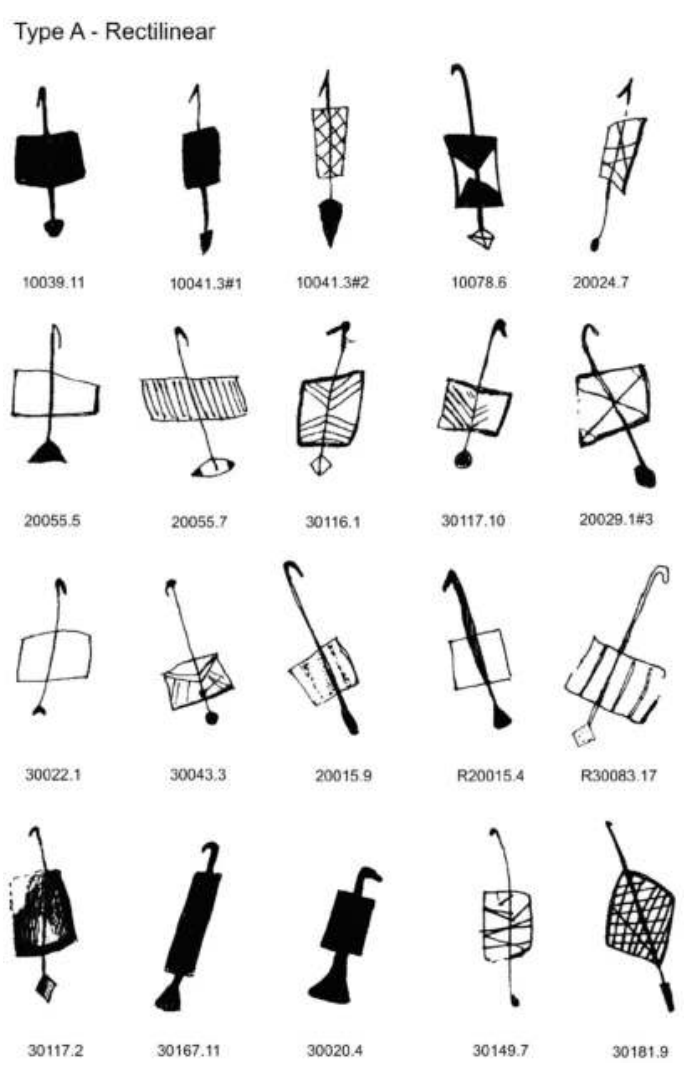

Figure 4.3 Type A (rectilinear) long-necked spearthrowers from Mirarr Country. Individual codes refer to site and image numbers. Source: John Hayward. 


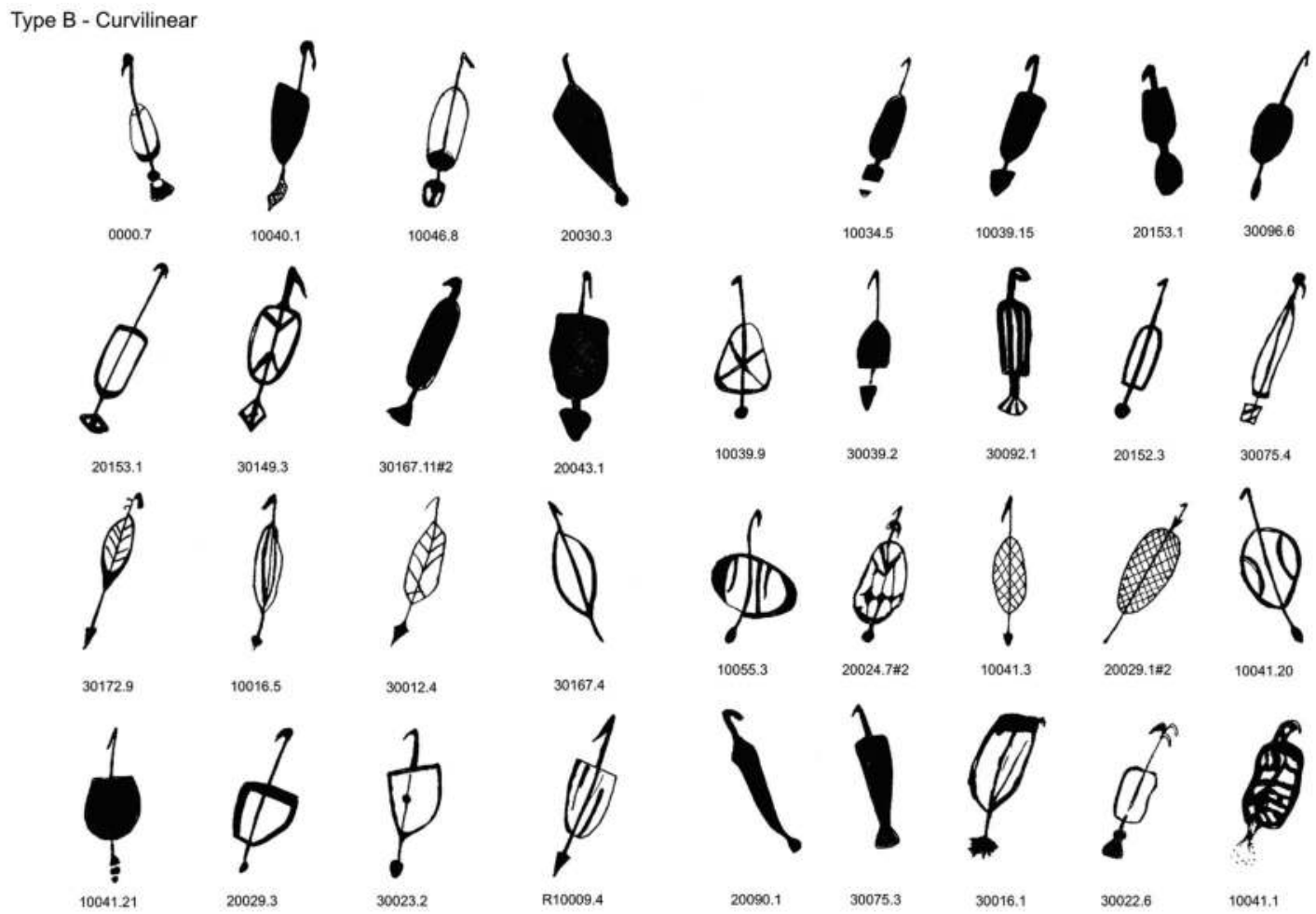

Figure 4.4 Type B (curvilinear) long-necked spearthrowers from Mirarr Country.

Individual codes refer to site and image numbers.

Source: John Hayward.

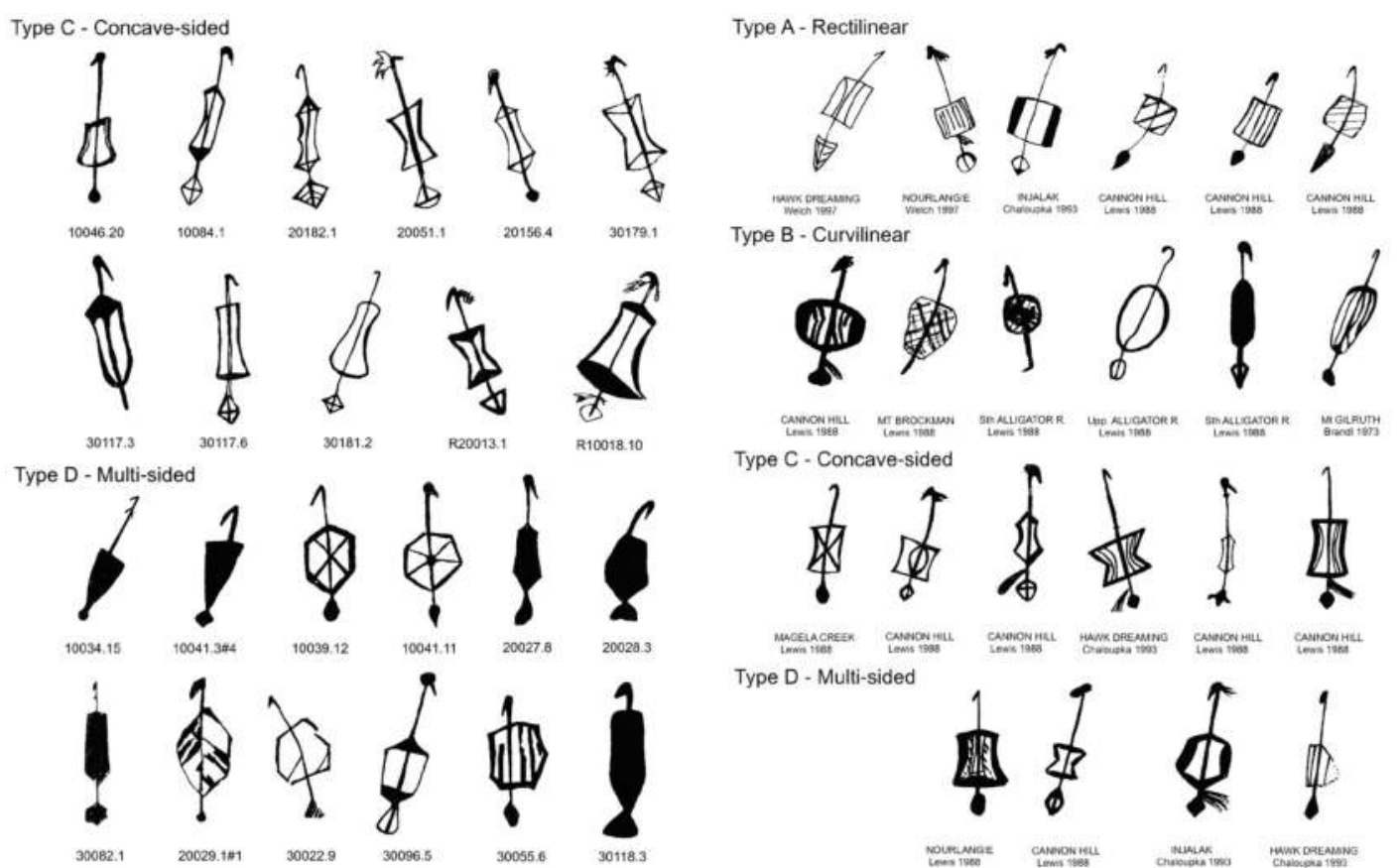

Figure 4.5 Type C (concave-sided) and Type D (multi-sided) long-necked spearthrowers from

Figure 4.6 Long-necked spearthrowers from other locations as recorded by Brandl (1973), Lewis (1998), Chaloupka (1993) and Welch (1997). Source: Drawing by John Hayward after Brandl (1973), Lewis (1998), Chaloupka (1993) and Welch (1997). Individual codes refer to site and image numbers. Source: John Hayward. 


\section{Case studies}

The following examples illustrate different aspects of long-necked spearthrower depictions in western Arnhem Land rock art. Some of the images have been digitally enhanced using the DStretch program and inked-in to highlight the artworks.

\section{Site 20029}

The three male human-like figures in Figure 4.7 have been superimposed by some yellow elongated human-like figures that have since faded. Two of the male figures have straight, widely spread legs and are superimposed over a third male figure with slightly curved near-horizontal legs. All three are superimposed over a number of other weathered black human-like figures. The leading male figure uses a multi-sided spearthrower with an internal design to launch a uni-serial square-barbed spear. This figure also carries a second, different type of uni-serial spear, traditionally called bokko (Chaloupka 1993:146), in the other hand along with a small goose-wing fan and wears a small tasselled headdress. Goose-wing fans were made from the wings of the magpie goose and are typical of Chaloupka's (1984, 1993:185) recent 'Freshwater Period' of the past 1500 years, when large wetland areas developed along the floodplains near the base of the Arnhem Land escarpment, attracting higher numbers of fish species and water-birds than previously.

One of the leading male figure's two companions has a three-pronged barbed spear being launched by a curvilinear long-necked spearthrower with a distinctive cross-hatched internal pattern. The more weathered curved-leg male figure is launching a bokko with a rectilinear spearthrower that has an indistinct internal design. This latter male figure has a pronounced headdress and wears a small bag around his neck, perhaps a 'biting bag' (for an ethnographic example, see Hamby 2010:261-264).

The two male figures with widely spread angular legs have 'hairy' upper arms. Chaloupka (1993:217) notes of such figures: 'Nalbidji figures, the "hairy armed" people, are clearly human beings and are depicted performing traditional activities. They occur in individual representations and in compositions, and seem to represent a local group of people'. Such figures conform to a number of other humanlike painting types such as Mountford Figures (Haskovec 1992; Lewis 1996:13) and Energetic Stick-Figures (Taçon 1989:136), each of which has a limited spatial distribution in much the same area along the northwestern margin of the Arnhem Land plateau. Chaloupka thought that the hairy arms on such figures represent feathers or pelts tied to the arms as a form of decoration. Images of Nalbidji often depict long-necked spearthrowers along with capelike adornments and tasselled spears as part of their repertoire of material culture items (Chaloupka 1993:217).

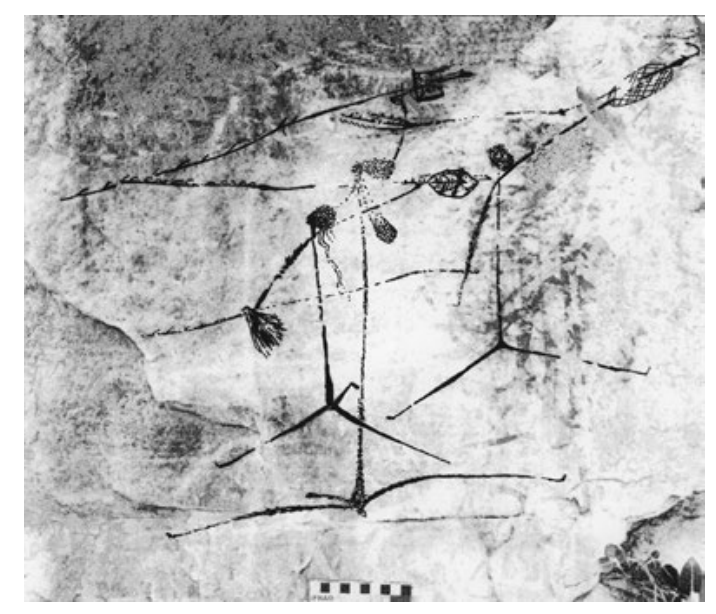

Figure 4.7 Three male figures with morphologically singular long-necked spearthrowers, from site 20029.

Source: Photograph by John Hayward. 
The male figures in the painting scene discussed above appear to represent a seemingly active and unified force, all moving in one direction with spears ready, albeit each carrying a different kind, or set, of spears and spearthrower. In this sense, each male figure identifies as an individual personality through his associated items of material culture, rather than being reduced to an undifferentiated member of a group.

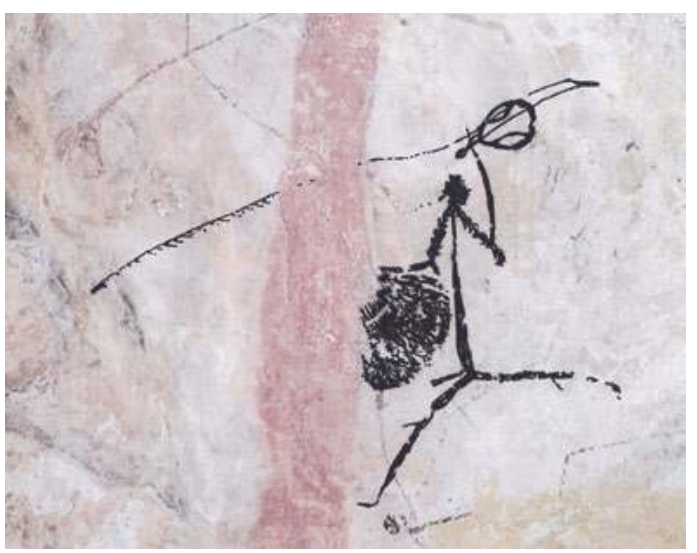

Figure 4.8 Individual human figure with a longnecked spearthrower and goose-wing fan, from site 10041.

Source: Photograph by Inés Domingo Sanz, enhancement by John Hayward.

\section{Site 10041}

The human-like figure depicted in Figure 4.8 is holding a curvilinear long-necked spearthrower with a very distinctive internal design. The depiction of the central section of this spearthrower allows the shaft of the spear to be seen through the body of the spearthrower. This Nalbidji hairy-armed figure has a more solid body and limbs than the stick-figures of Figure 4.7 and carries a large goose-wing fan.

\section{Site 10039}

All three figures in Figure 4.9 are males with accentuated penises, and have widely spaced but not horizontal legs that suggest a walking action. Two hold rectilinear long-necked spearthrowers and are superimposed over a number of weathered black stick-figures, one of which also holds a long-necked spearthrower. The largest and most dominant human-like male figure is heavily adorned with arm pelts, tassels and a body covering that simultaneously resembles a long cape, a goose-wing fan and a basket.

The largest male figure in Figure 4.9 wields a large, square-shaped rectilinear long-necked spearthrower that either has a pronounced hafting or a short tassel and is used to launch a bokko spear. It is unclear if the square-shaped bodies of the two rectilinear long-necked spearthrowers on this panel are internally decorated. What is clear, however, is the stark contrast between the elaborate adornment of the largest, dominant male figure and that of the other male figure with a squareshaped rectilinear long-necked spearthrower, which has none. Below these two figures is the third male figure who carries a hooked stick-shaped cylindrical spearthrower, a long string bag around his neck and an unusual, pronounced headdress or tasselled hair. As with many other paintings containing long-necked spearthrowers, the emphasis is on the depiction of individual differences rather than on undifferentiated conformity.

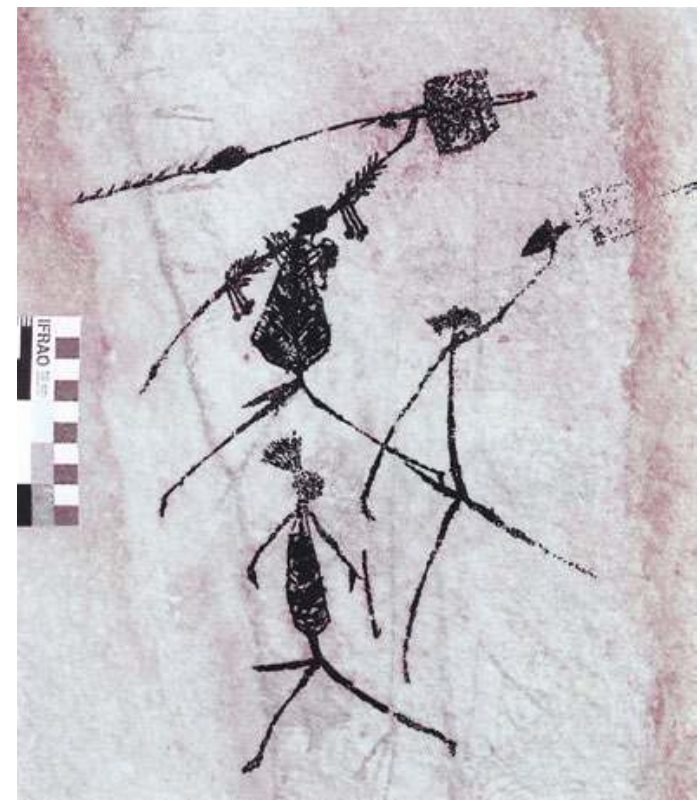

Figure 4.9 Group of three male figures, from site 10039 .

Source: Photograph by Inés Domingo Sanz, enhancement by John Hayward. 


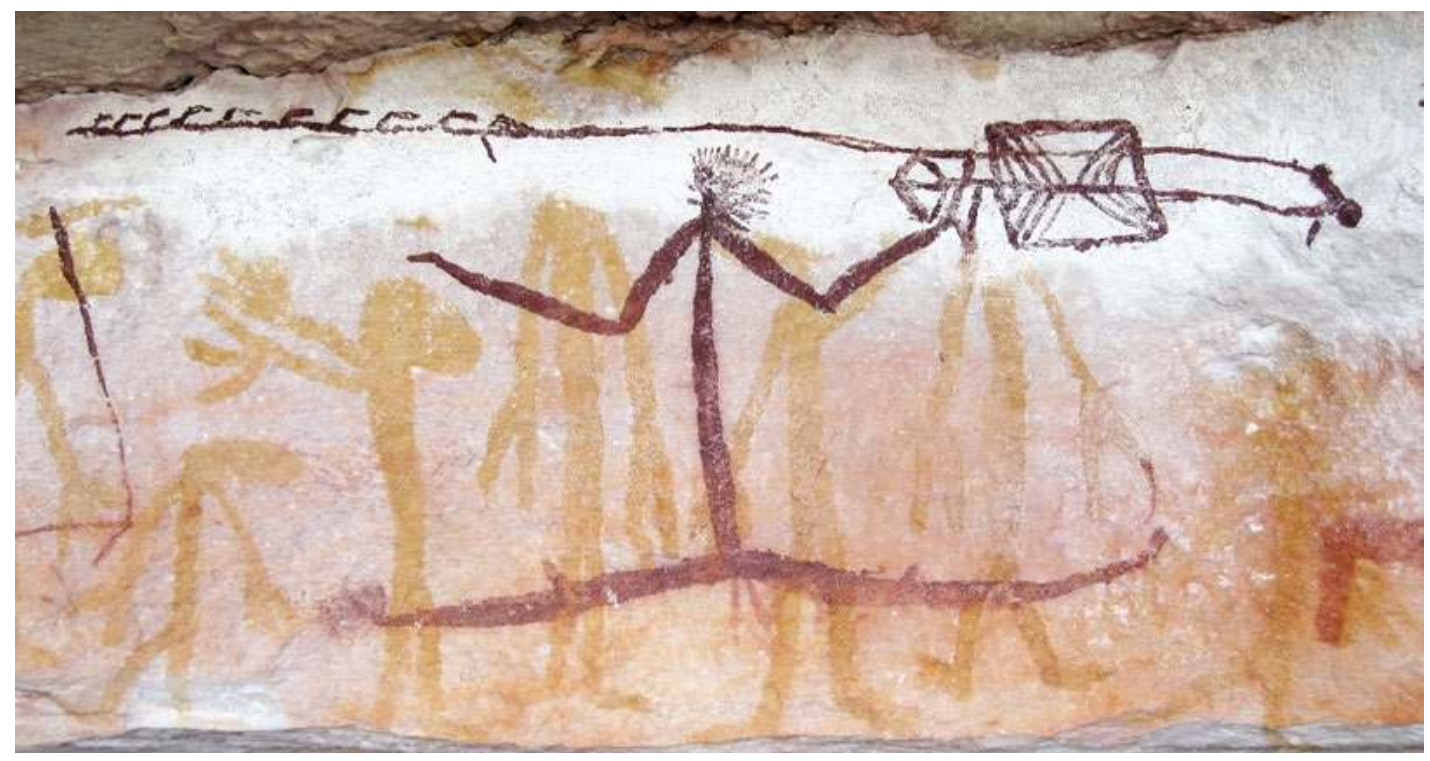

Figure 4.10 Human-like figure with near-horizontal legs launching a spear with a rectilinear longnecked spearthrower, from site 30116.

Source: Photograph by John Hayward.

\section{Site 30116}

The human-like figure in Figure 4.10 is distinctive for its spiky hair and energetic stance. The image is painted in a deep red pigment over yellow pigment human figures at a site with commanding views over Magela Creek to the southwest of the Madjawarrnja massif. This human-like figure is launching a square-barbed spear with a rectilinear long-necked spearthrower that has a unique internal design and a diamond-shaped handle. The square body of the implement sits closer to the handle than the exaggerated large 'hook', and its depiction appears as an open construction or see-through representation that allows us to see the spear shaft behind it, although alternatively the spear could be held in front of it. The human-like figure in this painting exudes an air of confidence and command over 'his' body and implements; one finger controls the balance of the spear while the other handles the spearthrower with a sense of deftness and assurance. The contrast between this finely painted image and the somewhat less-refined yellow human-like paintings that underlie it is quite dramatic, almost as if the artist chose this position to highlight the differences. The fresh appearance of the red pigment used in this painting over a salt crust on the rock suggests is a very recent painting, further adding to the mystery of what happened to the long-necked spearthrower in the 'recent' history of this region.

\section{Site 10040}

The group of eight stick-figures in Figure 4.11 is, in my opinion, one of the highlights of rockpainting visual composition in the Jabiluka region. Eight male figures, painted in light red, move as one in a choreographed performance of unity, individuality and ambiguity. The figures and the implements have equal importance in the composition, emphasising the relationship between them and the role of each. Four of the figures carry curvilinear long-necked spearthrowers and four others carry another kind of spearthrower previously unrecorded in this region. These latter spearthrowers appear to be very long implements with the characteristic hook at the distal end and an enlarged proximal end that could act as a counterweight balance to the length. These implements are held by their carriers at the intersection of the weighted end and the shaft. No spears are depicted in this image, allowing the spearthrowers an autonomous significance. 
The leading and trailing figures are differently adorned to all six central figures. The leading figure wears arm pelts while the trailing figure wears a cape of sorts. The leading figure also carries three extra stick implements that could be fighting sticks with enlarged ends. Three of the trailing figures raise their long-necked spearthrowers in the air; the front three raise their spearthrowers higher still. The middle couple, in defiance of the group, behave a little differently, the front of the two holding both arms down with a curvilinear spearthrower in one hand and another stick implement in the other, and the second of the two raising a long spearthrower, but lower than the rest.

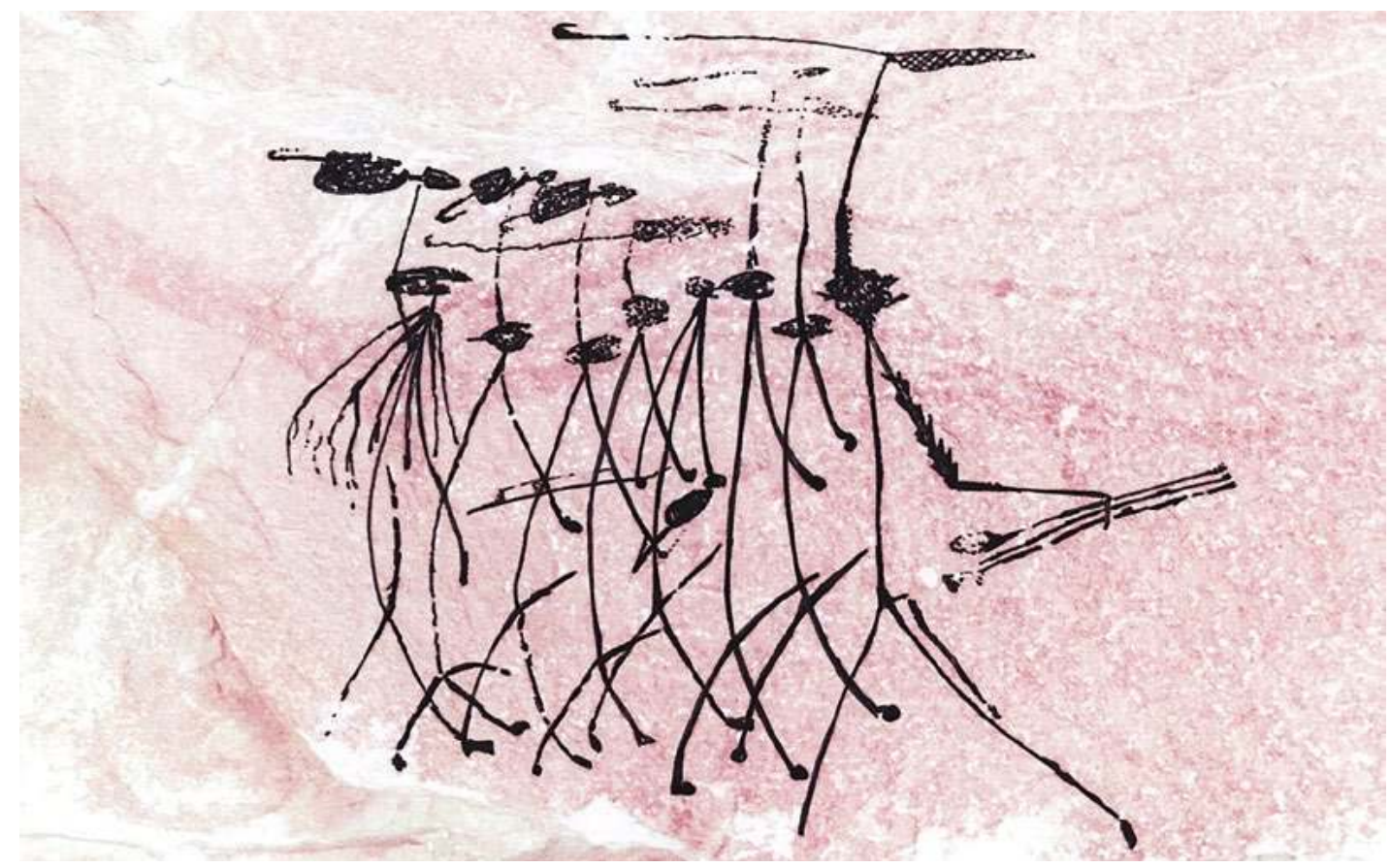

Figure 4.11 Group of eight stick-figures holding two types of spearthrowers, engaged in choreographed movement, from site 10040.

Source: Photograph by Inés Domingo Sanz, enhancement by John Hayward.

Despite these anomalies to conformity, there is a rhythm to the composition that is pronounced by the bend of the torsos, the alignment of the heads and the angles of the penises which follow through on the line of the legs, except for the front figure whose alignment of the 'broken' penis is replaced by the alignment of the fighting sticks. The counterpoints to this unified rhythm are the three levels of raised and lowered spearthrowers above the heads and among the bodies. Overall, the whole image expresses a complex unity composed of differentiated individuals and artefacts, with an added masterly touch of ambiguity, the essence of all good art making, according to Zeki (2006:243). This scene also embodies the concept of 'methexis' where, through performance and participation, the 'one' is the unified one and the 'many' are the individuals, as opposed to the contemporary Western notion of the 'one' being the individual and the 'many' being the group (Bolt 2004:139). In methexis, the 'one' symbolises a cosmic entity that can only be experienced through the many and, according to Carter (1996:71), is at the heart of all ritual and ceremony in Aboriginal culture (Bolt 2004:139; see also Durkheim 1915; Morphy 1991:116; Taylor 1996:103).

\section{Site 10041}

In Figure 4.12, three different types of long-necked spearthrowers are depicted. The two main human-like figures hold rectilinear sub-types. The body of each spearthrower has a cross-hatched design that matches the body covering of the male figures. In the horizontal plane, a curvilinear

\section{terra australis 47}


long-necked spearthrower lies next to a barbed spear; to the left of the panel, a triangular-shaped long-necked spearthrower stands vertically next to a very short three-pronged spear. This last spearthrower defies the existing taxonomy but was included in the multi-sided sub-category for want of a better place. Here there are three identifiable layers of painting:

- The lowest layer with a faded double-line human-like figure being superimposed by the figures enhanced in blue.

- An intermediate layer with two other figures (one partially painted) and an oval-shaped crosshatched curvilinear spearthrower and bokko spear, indicated in blue and superimposed over the faded figures but under the black layer.

- The top layer consisting of the human-like figures and artefacts enhanced in black.

All these images are painted in shades of red pigment. The image includes a rare depiction of a dog-like animal (dingo?) and a smaller figure, which I read as a probable child who appears to carry an unidentified bundle on its head. The large male figure just in front of the 'child' holds two short square-barbed spears in one hand and has a tassel or small bag hanging from his neck. The other large male figure near the front has two baubled tassels hanging from his neck. It is unclear if the cross-hatched shapes over the bodies of the two large male figures are capes, long bags, some other covering or simply a decorative convention for the torso.

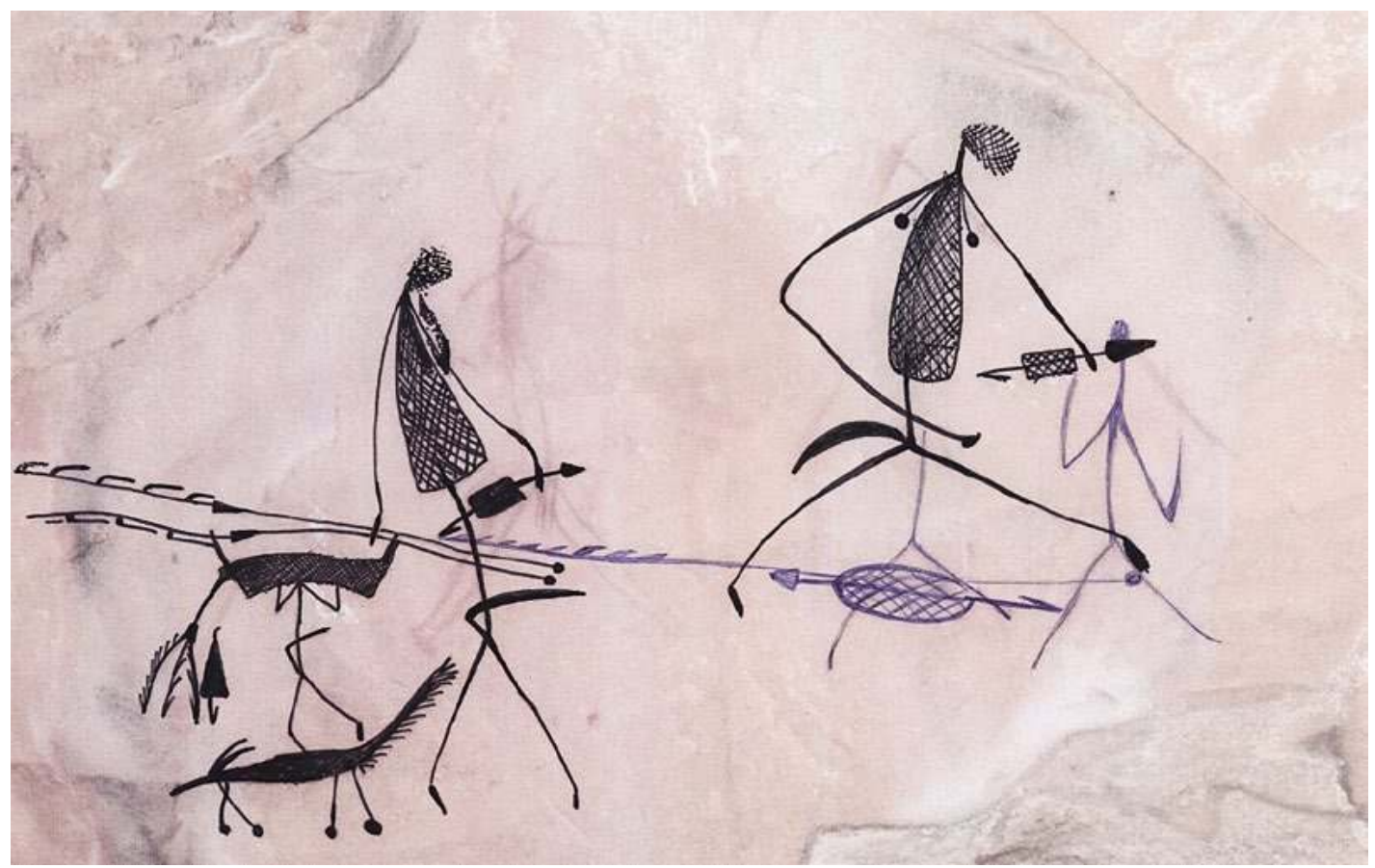

Figure 4.12 Human-like figures with a dog-like animal and items of material culture, from site 10041.

Source: Photograph by Duncan Wright, enhancement by John Hayward.

The manner in which these human-like figures are painted does not conform to any particular common or recognised style for the region, but has highly stylised features such as curved torsos, thin, tapering limbs that are thickest at the top, delicate hands and feet, fine-hatched infill and attention to the details of material culture items. The individuality expressed in this image conforms on a number of levels to previous images, but exudes a uniqueness of manner and deftness with the brush and pigments. This singularity and deftness appears to signal the personal style of the artist and one that is identifiable by the subtleness of the lines, the repetition of texture and the inventiveness of spearthrower diversity. 


\section{Spearthrower construction}

One major variation in the painting of spearthrowers in the rock art is that some are depicted with solid infill and others are depicted with distinctive patterns and outlines. Such differentiation could indicate structural variations in the construction of actual 'real world' artefacts, with some being made from solid materials and others from linear or 'open' materials. The other possibility is that the linear patterns suggest incised or painted decorations on a solid surface. Lewis (1988:62) speculated that the 'fine line-control and carefully executed patterns inside the round or squared sections of some examples suggest that its shape was accurately rendered', although he also recognised that some artistic licence may have influenced the depictions. The construction methods of such items are worth considering, especially if depictions of longnecked spearthrowers represent a transition from broad to long spearthrower types.

The possible solid construction method of some long-necked spearthrowers could have been similar to broad spearthrower types that were presumably shaped from single pieces of timber, in much the same way as ethnographic spearthrower examples from central Australia, which also have wide bodies, and long-notched lath spearthrowers from Arnhem Land and are commonly seen in museum collections. Previously, there was little conclusive ethnographic evidence of any broad spearthrower types from Arnhem Land, but during the June 2013 survey of the southern section of Djawumbu Madjawarrnja massif a stencil of a spearthrower that fits more comfortably into the category of a solidbodied broad type rather than a long type spearthrower was discovered (Figure 4.13). Adding to the evidence, I recently came across two broad spearthrowers at Museum Victoria, collected by Baldwin Spencer from the Roper River region of eastern Arnhem Land, which is approximately $300 \mathrm{~km}$ from the painting sites. These artefacts are morphologically similar to the aforementioned stencilled broad spearthrower from the Djawumbu Madjawarrnja massif, and were described in Spencer's notes as 'short, broad and spatulate' (Figure 4.13). The handle, body and hook extensions have each been shaped from a single piece of softwood; the hook itself is a harder timber piece that had been attached to the neck with resin. It is possible that the solid-infilled long-necked spearthrower types evident in the rock art were also made in a similar fashion to the broad spearthrowers from the Roper River collected by Spencer, but alternatively it is possible that they were made as two-piece constructions, with the basic central shaft used to attach a solid body made from a separate, shaped piece of timber or bark.
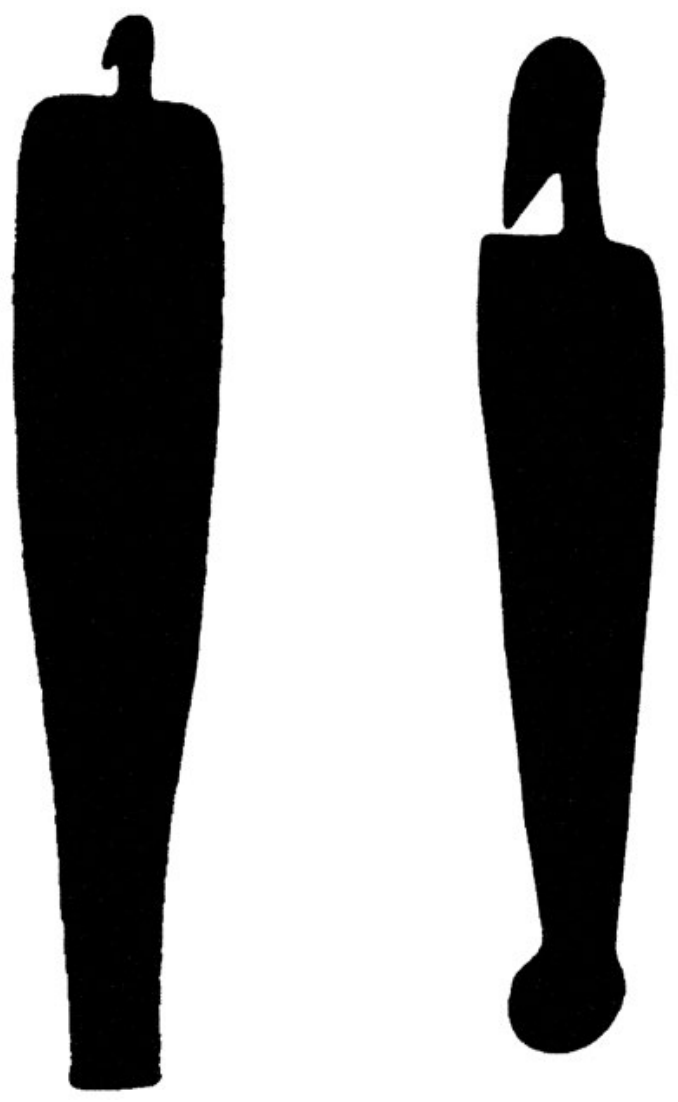

Figure 4.13 Two broad spearthrowers.

Left: drawing of a broad spearthrower collected by Baldwin Spencer from the Roper River region. Right: solid infill interpretation of a stencil from the Djawumbu Madjawarrnja massif. Not to scale.

Source: John Hayward. 
The construction methods of the more common 'open' construction long-necked spearthrower type is speculative, as there are no stencilled or ethnographic examples for comparison. There appears to be a basic hooked stick central shaft, which resembles a cylindrical spearthrower, onto which was added an elaborate body form that could have been made from shaped or natural timber, bamboo or reed and infilled with similar materials or other fibres held together with twine and resin. The construction could have been quite light but also quite fragile, and probably would have had a very short life span unless it was purely for display.

One painted example of a possibly 'open' construction long-necked spearthrower (Figure 4.14) depicts a single concave-sided spearthrower by itself. The handle of the artefact is a diamond shape and displays the central shaft of the spearthrower. The same shaft extends through the centre of the body and protrudes beyond the top end for a short distance before the hook is formed at the distal end. Tassels of some sort have been added to the hook and handle. The body appears to have been constructed from four pieces of shaped material joined at the corners in an unspecified way. The sides are made of curved forms, not dissimilar to boomerangs, the right-hand side having a more pronounced curve than the left. The shape of this example is not dissimilar to others in the Type $\mathrm{C}$ classification of longnecked spearthrowers, but is proportionally wider and the curves are more exaggerated. Whether this painting truly depicts an open structure, or a solid form with a defined pattern applied to the surface, is unclear, although the continuation of the central shaft through the body suggests the former.

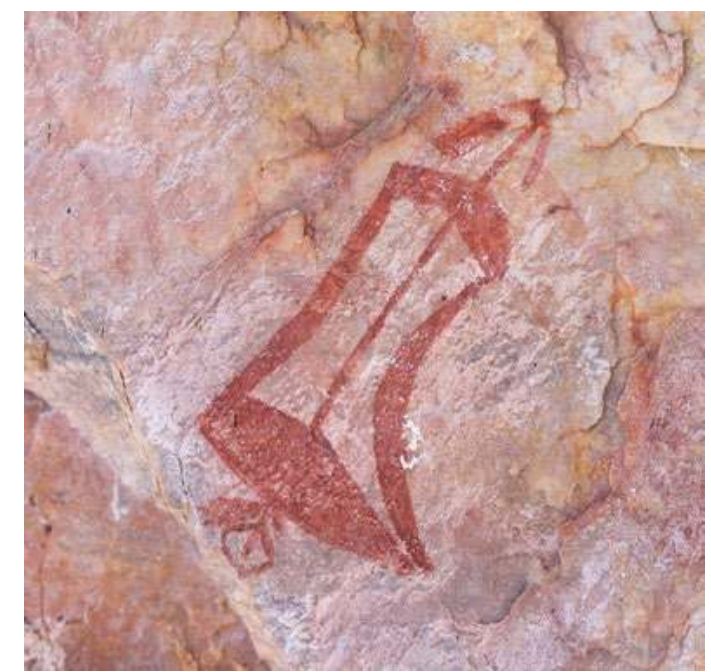

Figure 4.14 Painting of a concave-sided longnecked spearthrower, from site R10018.

Source: Photograph by lain Johnston.

It is not difficult to speculate on how a broad, solid spearthrower form could have evolved into a narrower, long shape. This transformation might have followed, or driven, the transition from heavier and slower single-piece hardwood spears to the lighter and faster bamboo and reed-shafted spears. These spears were made from the Bambusa arnhemica and Phragmites karka, species that proliferated during the influx of freshwater wetlands in the last 1500 years, and required a lighter but longer spearthrower technology for propulsion (Cundy 1989). This apparent change in the spear/spearthrower technology, from high-energy and low-velocity to lowenergy and high-velocity technology systems highlights the anomaly of the long-necked spearthrower, which plays no obvious part in that transition. The introduction of a large and complex-shaped central body, whether of solid or 'open' construction, was clearly not an essential, or perhaps even desirable, addition to basic spearthrower design or function. Rather, other reasons for the existence of longnecked spearthrowers in rock art are worthy of discussion. 


\section{Symbology of the long-necked spearthrower}

Long-necked spearthrowers in rock art are associated with a range of material culture items, all of which can be recognised from ethnographic collections and are, therefore, considered as artefacts that belong to one of the more recent rock art traditions. Long-necked spearthrowers, however, have no known ethnographic equivalents, and so the only 'proof' of their existence is as rock art depictions.

Besides a lack of ethnographic evidence, there are other strong arguments against the existence of these cultural items in the material world that are based on the technological question of their functional benefit for spear-throwing. There is seemingly nothing about the size, shape and form of the spearthrower design that would improve the efficiency of the technology and, conversely, the large body of the implement would actually hinder practical spear-launching. Carrying such a large item would be difficult and impractical, plus there would need to have been a substantial investment of time and energy to make each item, which, because of its fragility, may have had a very short lifespan. A conclusion of such logic is that these items have little or no sociotechnical function and, therefore, did not exist as everyday artefacts.

It can be argued, however, that such artefacts had some symbolic (e.g. totemic) reference or other such cultural significance, and that the uniqueness of each spearthrower emblem was an expression of personal or group identity emanating from its display at public events such as ceremonies, as well as during personal use (Taylor 1996:104). The elaboration of the spearthrower form would also have had a socio-ideological function that allowed for a demonstration of construction and carving skill by an individual maker (Dobres 1995:41). Such items may also have had unique values that prevented them being traded or exchanged to anthropologists and collectors during early encounters, thus ensuring their non-appearance in ethnographic collections.

Any of the above reasons could explain the existence of long-necked spearthrowers as items with ideological functionality that came into fashion or customary use at a particular time in 'recent' history, but they do not adequately explain why long-necked spearthrowers fell out of fashion and did not survive through to ethnographic times along with the large number of other items such as certain barbed spears, goose-wing fans and other spearthrower types with which they were concurrently depicted. One explanation for this is that they only existed as graphic signatures in rock art and were still used as such until colonial times at which time other concerns and influences prevailed. If this is the case, then long-necked spearthrowers as items of material culture are a depicted fiction, or at least characters in a fiction who act in a number of roles to help render a story. Their agency as fictional characters is not unreasonable as long-necked spearthrowers project a uniqueness and individualism at least equal to the human-like depictions they associate with. Long-necked spearthrower agency, as I argue here, is not so much sociotechnical as socio-ideological and, as such, has no reducible bearing upon the technical world. The performative actions of long-necked spearthrowers, then, are largely limited to the socioideological and, as far as we know, to the symbolic realm of rock art where they were created and where they share their individuality with the human-like figures they associate with, creating the illusion that it is the human-like being who has the individuality.

This relationship between human beings and artefacts is already complex in the real material world as people and material culture share linked histories, shared intentions, distributed agency and connected subliminal influences (David 2002:211-213; Dobres 2000; Gosden 1999:120; Introna 2012:35; Latour 2003:39). In the realm of rock art, relationships between human actors and material culture become even more complex, as the rock art motif is also an artefact and in this sense a depiction of a long-necked spearthrower is an artefact within an artefact. While it may be apparent that the image of a long-necked spearthrower has agency as painting - i.e. as a 
representation of individuality - it seems that its agency is not confined to the painted realm, for we, the viewers, are also drawn into its influence. In the real world an artefact, as technology, behaves as 'a way of revealing' (Heidegger 1977:12). In this hypothesis, the artefact comes into being not because the artisan manufactured it but because the concept of the artefact reveals itself to the artisan through the realm of revealing and unconcealment (Heidegger 1977:13; see also David 2002:211-212). It is this shared responsibility, or what Barad (2003:814) calls 'intra-action' and Introna (2012:39) calls 'co-constitutive agency', which infuses the social with the technical, and the maker with the artefact, and which brings the artefact into being. If the artefact exists only in the realm of rock art, the same applies, except that here the revealing of the artefact (the rock art motif) comes about through the social and the ideological.

Consequently, it appears that in western Arnhem Land the long-necked spearthrower is an artistic invention whose function is that of a signifier of both individual and group identity in and via rock art motifs. In many cases, the morphology of long-necked spearthrowers in rock art reference all other main spearthrower types found in both rock art and ethnographic collections, but this is not evidence that they existed in both worlds. The assumption that because an image appears in rock art means it must have also existed in reality results from the inter-tangled realm of rock art with the so-called real material world, and is no more true than the idea that every item that existed in the real material world was painted in rock art. These artefacts were probably painted during the recent chronological rock art period of the region at a time when cylindrical, broad and long-notched lath spearthrowers all existed together as functioning spearthrower technologies. The artists that painted these images during that period appear to have used the long-necked spearthrower as a device to convey both the individuality of their paintings and of themselves.

\section{Conclusion}

The diversity, creative inventiveness and ideological scope of the long-necked spearthrower seems unmatched by other depictions of material culture items in western Arnhem Land rock art, and appears to have no equivalent in ethnographic material culture collections from the wider region. More than half the long-necked spearthrowers recorded for this study are unique representations of the spearthrower type; the rest exhibiting variations on the original themes. Paintings with multiple long-necked spearthrowers, each with individual designs, appear to reinforce the individuality of each human-like figure they are associated with. Those images, on the other hand, that have many, choreographed human figures all holding similarly shaped long-necked spearthrowers, suggest group solidarity. I argue, therefore, that a principal function of long-necked spearthrowers is that of an agent within the graphic symbology of the rock art of a discrete region of western Arnhem Land.

Those long-necked spearthrower depictions, which appear as solid forms, appear to reference the morphology of broad spearthrowers; others have similarities to cylindrical and long-notched lath spearthrowers. In such cases, rock art depictions of long-necked spearthrowers could be considered as having material connections with documented ethnographic artefact types, and in this sense have one foot in the material world and one in the symbolic. The existence of broad, cylindrical and long-notched lath spearthrower types in ethnographic collections, and the morphological connection of long-necked spearthrowers with all types through rock art alone, complicates Lewis's chronology that suggested a material world transition from broad to long types some 1000-2000 years ago, with the long-necked spearthrower as an intermediary experimental form or aberration. I suggest that all these spearthrower types existed side-by-side, for a period before European contact, as items with separate functions in the material world: 
the broad and cylindrical spearthrowers, associated with heavier composite and one-piece spears; the long-notched lath spearthrower, used exclusively for a range of lighter hafted spears; and long-necked spearthrowers, as mediating agents between the material and graphic worlds, not reducible to technological functions but rather having a wide-ranging ideological function.

\section{Acknowledgements}

The data for this chapter were collected during the 2012-2014 fieldwork surveys conducted for the Mirarr Gunwarddebim (rock art) project. The project was initiated and is supported by the Mirarr community and the Gundjeihmi Aboriginal Corporation (GAC). I would like to thank all GAC board members, in particular Yvonne Margarula and GAC Chief Executive Officer Justin O'Brien for their ongoing support. Thanks also to Kakadu National Park, Natural Cultural Programs Unit and Energy Resources of Australia mining for access to survey areas including Jabiluka mineral lease. Special thanks are also extended to all members of the Mirarr Gunwarddebim survey teams (too many to mention), but in particular Sally May as co-ordinator, Paul Taçon as mentor, Phil Davill (Mirarr Gunwarddebim team member) for maps and technical support and Iain Johnston (The Australian National University) for companionship. I am grateful to Darrell Lewis (University of New England) for giving me an electronic copy of his 1988 monograph that has been used extensively for this chapter. This chapter benefited from input and comments from my friend Ian Hamilton, Sally May (Griffith University), Susanne Schech (Flinders University), the editors of this publication Paul Taçon and Bruno David and independent reviewers.

\section{References}

Allen, H. and K. Akerman 2015. Innovation and change in northern Australian Aboriginal spear technologies: The case for reed spears. Archaeology in Oceania. 50:82-92. doi.org/10.1002/arco.5051

Barad, K. 2003. Posthuman performativity: Towards an understanding of how matter comes to matter. Signs 28(3):801-831. doi.org/10.1086/345321

Bolt, B. 2004. Art beyond Representation: The Performative Power of the Image. I.B. Tauris, London.

Brandl, E.J. 1973. Australian Aboriginal Paintings in Western and Central Arnhem Land: Temporal Sequences and Elements of Style in Cadell River and Deaf Adder Creek Art. Australian Institute of Aboriginal Studies, Canberra. (2nd edition 1988.)

Carter, P. 1996. The Lie of the Land. Faber and Faber, London.

Chaloupka, G. 1984. From Palaeoart to Casual Paintings: The Chronological Sequence of Arnhem Land Platean Rock Art. Monograph Series 1. Northern Territory Museum of Arts and Sciences, Darwin.

Chaloupka, G. 1993. Journey in Time: The World's Longest Continuing Art Tradition. Reed, Chatswood.

Cundy, B.J. 1989. Formal Variation in Australian Spear and Spearthrower Technology. British Archaeological Reports International Series 546, Oxford.

David, B. 2002. Landscapes, Rock Art and the Dreaming: An Archaeology of Preunderstanding. Leicester University Press, Leicester.

Davidson, D.S. 1934. Australian spear-traits and their derivations. Journal of the Polynesian Society 43:41-72. 
Davidson D.S. 1936. The spearthrower in Australia. Proceedings of the American Philosophical Society LXXVI:445-483.

Dobres, M. 1995. Gender and prehistoric technology: On the social agency of technical strategies. World Archaeology 27(1):25-49. doi.org/10.1080/00438243.1995.9980291

Dobres, M. 2000. Technology and Social Agency. Blackwell, Oxford.

Durkheim, E. 1915. The Elementary Forms of the Religious Life. Allen and Unwin, London.

Gosden, C. 1999. Anthropology and Archaeology: A Changing Relationship. Routledge, Florence.

Hamby, L. 2010. Containers of Power. Utber and Patulio, Richmond.

Haskovec, I.P. 1992. Northern Running Figures of Kakadu National Park: A study of regional style. In J. McDonald and I.P. Haskovec (eds), State of the Art: Regional Rock Art Studies in Australia and Melanesia, pp. 140-158. Occasional AURA Publication 6. Australian Rock Art Research Association, Melbourne.

Heidegger, M. 1977. The Question Concerning Technology and Other Essays. Garland, New York.

Introna, L.D. 2012. Towards a post-human intra-actional account of socio-technical agency (and morality). In P. Kroes and P. Verbeek (eds), The Moral Status of Technical Artefacts, pp. 31-53. Springer Netherlands, Dordrecht.

Latour, B. 2003. The promise of constructivism. In D. Ihde and E. Selinger (eds), Chasing Technoscience: Matrix for Materiality, pp. 27-46. Indiana University Press, Bloomington.

Lewis, D. 1988. The Rock Paintings of Arnhem Land, Australia: Social, Ecological and Material Culture Change in the Post-Glacial Period. British Archaeological Reports International Series 415, Oxford.

Lewis, D. 1996. In defence of Arnhem Land rock art research. Australian Archaeology 43:12-20. doi.org/10.1080/03122417.1996.11681578

Morphy, H. 1991. Ancestral Connections: Art and an Aboriginal System of Knowledge. University of Chicago Press, Chicago.

Taçon, P.S.C. 1989. From Rainbow Snakes to 'X-Ray' Fish: The Nature of the Recent Rock Painting Tradition of Western Arnhem Land, Australia. Unpublished PhD thesis. The Australian National University, Canberra.

Taylor, L. 1996. Seeing the Inside: Bark Painting in Western Arnhem Land. Clarendon Press, Oxford.

Welch, D.M. 1997. Fight or dance? Ceremony and the spearthrower in northern Australian rock art. Rock Art Research 14(2):88-112.

Zeki, S. 2006. The neurology of ambiguity. In M. Turner (ed.), The Artful Mind: Cognitive Science and the Riddle of Human Creativity, pp. 243-270. Oxford University Press, Oxford. doi.org/10.1093/acpr of:oso/9780195306361.003.0013 



\title{
The rock art of Madjedbebe (Malakunanja II)
}

\author{
Sally K. May, Paul S.C. Taçon, Duncan Wright, Melissa Marshall, \\ Joakim Goldhahn and Inés Domingo Sanz
}

\section{Introduction}

The western Arnhem Land site of Madjedbebe - a site hitherto erroneously named Malakunanja II in scientific and popular literature but identified as Madjedbebe by senior Mirarr Traditional Owners - is widely recognised as one of Australia's oldest dated human occupation sites (Roberts et al. 1990a:153, 1998; Allen and O'Connell 2014; Clarkson et al. 2017). Yet little is known of its extensive body of rock art. The comparative lack of interest in rock art by many archaeologists in Australia during the 1960s into the early 1990s meant that rock art was often overlooked or used simply to illustrate the 'real' archaeology of, for example, stone artefact studies. As Hays-Gilpen (2004:1) suggests, rock art was viewed as "intractable to scientific research, especially under the science-focused "new archaeology" and "processual archaeology" paradigms of the 1960s through the early 1980s'. Today, things have changed somewhat, and it is no longer essential to justify why rock art has relevance to wider archaeological studies.

That said, archaeologists continued to struggle to connect the archaeological record above and below ground at sites such as Madjedbebe. For instance, at this site, Roberts et al. (1990a:153) recovered more than 1500 artefacts from the lowest occupation levels, including 'silcrete flakes, pieces of dolerite and ground haematite, red and yellow ochres, a grindstone and a large number of amorphous artefacts made of quartzite and white quartz'. The presence of ground haematite and ochres in the lowest deposits certainly confirms the use of pigment by the early, Pleistocene inhabitants of this site. However, we know very little about what the materials were used for. Many of the earliest occupation sites in Australia, including Madjedbebe, have revealed finds of ochre with ground facets, sometimes in considerable quantities (Clarkson et al. 2017; Davidson and Noble 1992:139), and it would not be too far-fetched to suggest that the haematite and other ochres were used for cultural 'business', such as body art, decoration of objects (spears, dilly bags, etc.), the production of rock art or other such activities. Whatever the case, here we argue that the rock art is an important part of the archaeological story of Madjedbebe, and it deserves particular attention.

In this chapter, we focus on the 1068 paintings, stencils and beeswax figures that exist above current ground level at Madjedbebe. Our work draws on environmental, archaeological and ethnographic evidence to place the art and the site in their wider regional contexts. 


\section{The study area}

Madjedbebe is in Mirarr Country and currently sits within the Jabiluka Leasehold (Figures 5.1-5.3). It is bordered on all sides by the World Heritage-listed Kakadu National Park. The recording of the site took place as part of the Mirarr Gunwarddebim (Mirarr Rock Art) project, which aims to document, study and promote rock art sites in Mirarr Country.

Keen (1980:147) broadly defines the area of Mirarr Country as covering 'the upper reaches of the Magela Creek, between Leichhardt billabong in the north and Mount Brockman and Whistleduck dreaming in the south, "Urralugoorwa" waterhole in the west and the escarpment in the east'. When we refer to 'Mirarr Country' in this chapter, we are referring both to Country (as Aboriginal concept of ancestrally connected and territorial place) owned by Mirarr directly and the Country they are currently responsible for looking after as part of customary law.

Madjedbebe is a northwest-oriented bluff face that is part of the Djawumbu massif, often referred to as the Djawumbu-Madjawarrnja Complex. The majority of art stretches along a $48.5 \mathrm{~m}$ long panel (Figures 5.1 and 5.2). There is little shelter from the elements at the site. Importantly, earlier living ground surfaces and, most likely, early painted or engraved rock surfaces additional to those that are presently visible, were at considerably lower levels than today. The rock art produced during the earliest occupation of this shelter is likely buried beneath many metres of accumulated sediment.

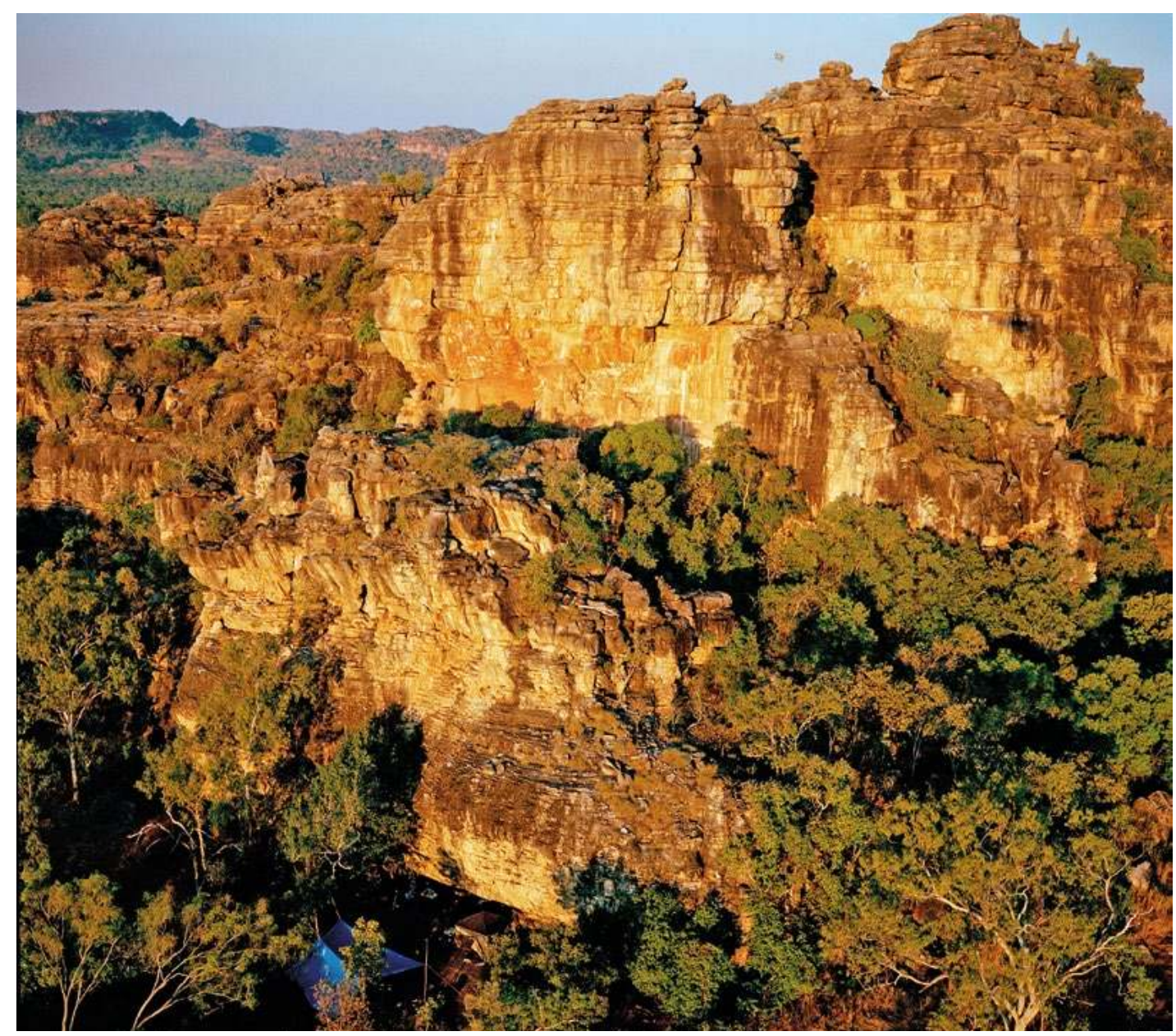

Figure 5.1 Madjedbebe, aerial view, 2012. The rock art can be found at the very base of the rock face. Source: Photograph by Matthew Abbott. 


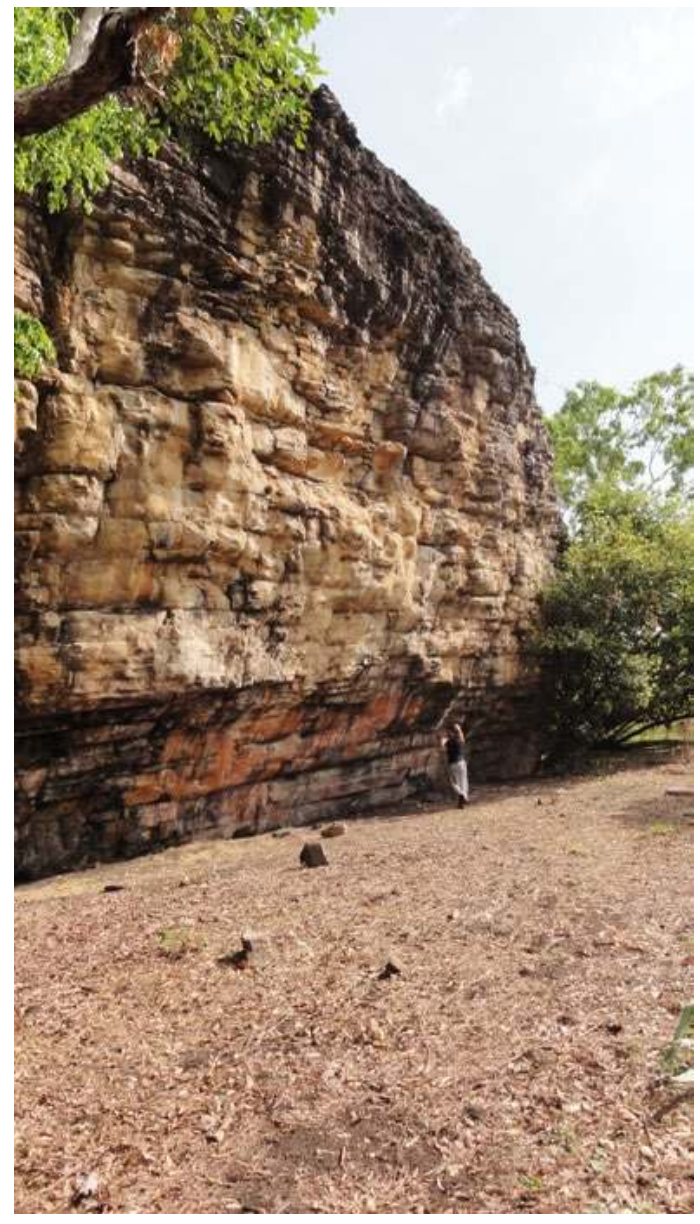

Figure 5.2 View of Madjedbebe showing the height of the rock face and some key painted panels at its lower levels, 2012.

Source: Photograph by Justin $0^{\prime} B$ Brien.

\section{Environmental setting}

At the time that Aboriginal people first moved into the area the sea was some 100 metres below its present level. Jabiluka instead of being 20 metres above sea level and $50 \mathrm{~km}$ inland had an altitude of 120 metres and was over $200 \mathrm{~km}$ inland. Instead of the broad flat Magela floodplain there was a deeply eroded trench sloping up towards the escarpment (Allen 1978:6).

Human-environment relations have long been a subject of interest for researchers working in Arnhem Land (e.g. Allen 1978, 1996; Allen and Barton 1989; Bourke et al. 2007; Brockwell et al. 2009; Faulkner 2009; Jones 1969; Taçon and Brockwell 1995).
Chappell and Shackleton (1986:137; see also Woodroffe et al. 1989) suggest that seas rose from $-130 \mathrm{~m}$ to $-12 \mathrm{~m}$ between 19,000 and 8000 BP, flooding the Sahul land bridge and encroaching on present-day Arnhem Land. During this period, the area was drier than at present, with vegetation and faunal taxa being similar to those of the present-day drier areas south of Kakadu (Brockwell et al. 1995:17). Between 8000 and 6000 BP, seas are thought to have reached $0-3 \mathrm{~m}$ above current levels in northern Australia, a result of glacio-hydroisostaticity (Chappell and Grindrod 1983:67; Lambeck and Chappell 2001). Low-lying areas such as the Magela system and South and East Alligator Rivers plains flooded, and Rhizophora mangroves colonised newly formed estuaries and saline swamps (Woodroffe et al. 1989:749-53). As sea levels dropped and stabilised in the subsequent 'transitional period' (between 5000 and 2500 BP), coastal plains prograded seaward and mangroves retreated. Major climatic uncertainty, associated with late Holocene ENSO events, occurred and a mosaic landscape of tidal channels, saline swamps and freshwater streams developed (Clark et al. 1992:89; Woodroffe et al. 1989:753). Sediment archives and pollen cores suggest that increased climatic variability, associated with the Little Climatic Optimum (1200$700 \mathrm{BP})$ and Little Ice Age (600-100 BP), occurred during the past 2000 years (Clark and Guppy 1988; Clark et al. 1992; Hope et al. 1985; Jones et al. 2001). A general trend towards increased precipitation and seasonality in the late Holocene enabled stabilisation of the current wetland environment, with seasonally inundated grasslands replacing mangrove swamps (Allen 1996; Bourke et al. 2007; Brockwell et al. 2009:61; Lees 1992:8).

A link may exist between changes in human settlement and the development of estuarine and then freshwater floodplain environments. Between 7000 and 5000 BP new sites appear, including shell middens (Ngarradj Warde Djobkeng, Madjedbebe, Nawamoyn and Malangangerr) containing species of shellfish, fish and crab associated with mangroves and mudflats (Allen 1996:198; Schrire 1982:233). 
Brockwell et al. (2009:61) suggested, 'Increased climatic variation after 4000 BP coincided with increasing numbers of shell mounds, earth mounds and shell middens recorded for this time period, along with continued occupation of rock-shelters'. After $2500 \mathrm{BP}$, during a period of intensive burning on freshwater floodplains including the Magela system (Clark et al. 1992), an occupation shift occurred away from some rockshelters (e.g. Nawamoyn, Madjedbebe and Ngarradj Warde Djobkeng). During this period, there was extinction of at least one marsupial, Sarcophilus harrisii (Tasmanian devil) (Russell-Smith et al. 1997:178; Schrire 1982) and an increase in the formation and presumably use of open sites (predominately shell middens and earth mounds) and small rockshelters located close to permanent freshwater systems (e.g. Nauwalabila I, Jimeri I and Nawulandja) and tidal rivers (Malangangerr and Paribari) (Allen 1996:199; Brockwell 2006; Brockwell et al. 2009:61; Meehan et al. 1985:152).

\section{Archaeological research}

The area now known as Kakadu National Park has been of interest to archaeologists since the 1960s especially (Figure 5.3). Research has focused on the escarpment (e.g. Allen and Barton 1989; Jones and Negerivich 1985; Schrire 1982) as well as the floodplains (e.g. Brockwell 1996; Hiscock et al. 1992; Meehan et al. 1985; Woodroffe et al. 1988). Detailed overviews of archaeological research in Kakadu are provided elsewhere (Hiscock 1999; Jones 1985). We focus here on previous archaeological, rock art and ethnographic work relating to Mirarr Country and, where possible, specifically to Madjedbebe.

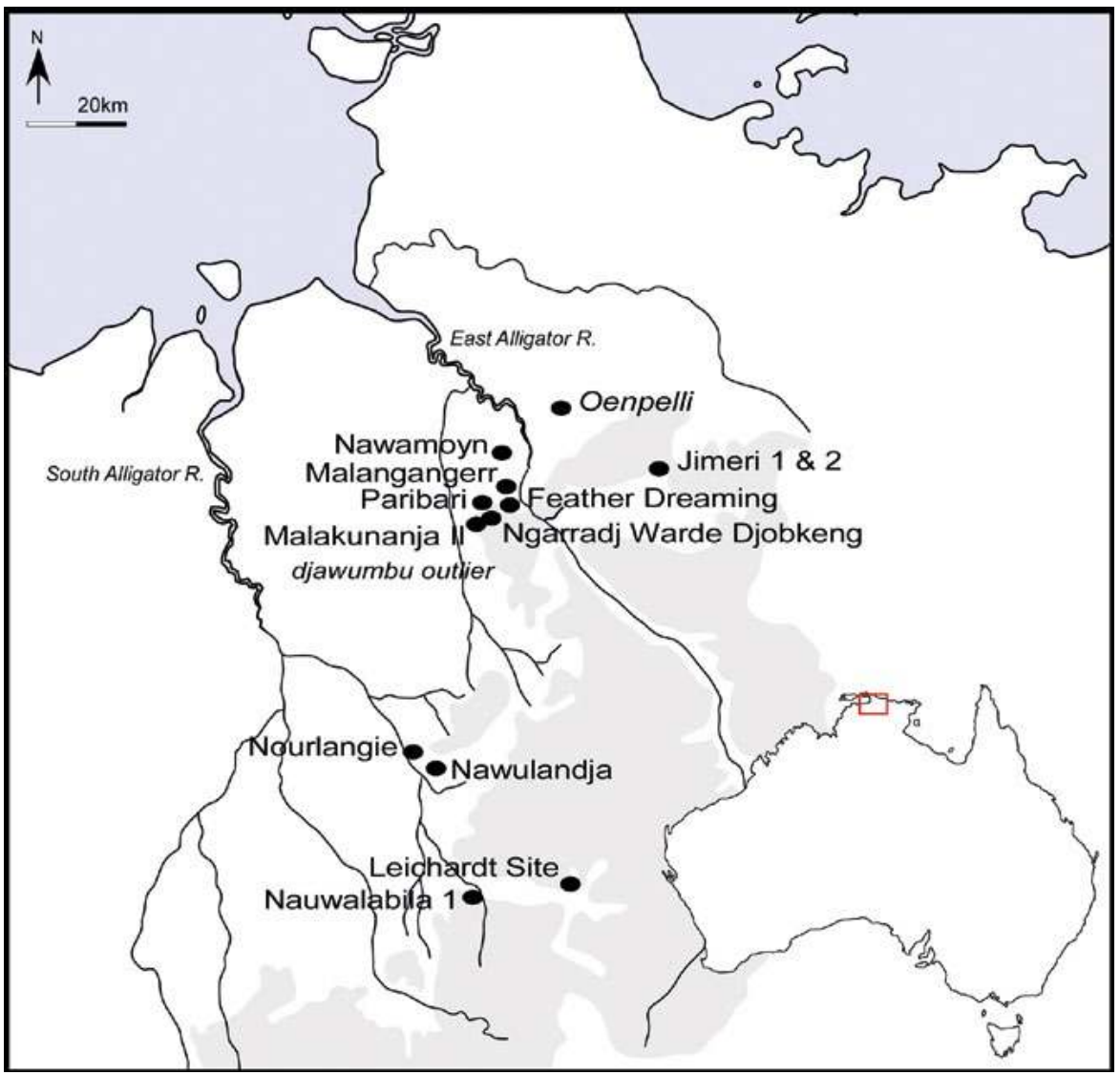

Figure 5.3 Distribution of key rock art and other archaeological sites mentioned in this chapter. The grey area marks the escarpment, also known by local Aboriginal people as 'Stone Country'. Source: Duncan Wright. 
White (now Schrire) conducted the first major scientific archaeological study in Mirarr Country and surrounds during the 1960s (Schrire 1982; White 1967a, 1967b, 1967c, 1971). Her rockshelter excavations targeted the lower slopes of small plateau outliers (Nawamoyn, Paribari and Malangangerr) and the plateau valleys (Tyimede or Jimerri I and II) (Figure 5.3). At Malangangerr and Nawamoyn, a (primarily estuarine) shell midden was dated to 7000-6000 BP and capped sandy layers dated to 23,000-18,000 BP (Schrire 1982:230; White 1967a:191253). Pieces of ochre, many with striations suggesting use-wear, were recorded in the Pleistocene deposits (Schrire 1982:103). A chronostratigraphic transition or interface was observed after 6000-4000 BP, from flaked core tools, steep-edged scrapers, utilised flakes, small edge-ground axes to unifacially and bifacially flaked stone points, small rectangular scrapers/adzes, bone points and shell scrapers (Schrire 1982:239; White 1971:145-67). Excavations at Paribari revealed estuarine shell midden, wooden tools and ethnobotanical materials (i.e. fragments of basket, string, bone, shell, resin and plant remains) dating within the past 3000 years. At plateau valley sites Jimeri I and II, radiocarbon dates cluster within the past 7000 years, with a single, earlier date of 10,790 \pm 200 BP from the base of Jimeri I (Schrire 1982:229).

Schrire (1982:231-234) suggests that the Arnhem Land cultural assemblages she studied were intimately linked with environmental change, particularly relating to formation of estuarine and freshwater landscapes within the past 7000 years. There was also archaeological evidence for seasonality of site use, which she interpreted as suggesting that floodplain sites were mainly visited during dry (and end of wet) seasons while plateau sites were occupied year-round (Schrire 1982:251-252).

Later, large-scale archaeological surveys of Mirarr Country were undertaken as part of the Alligator Rivers Environmental Fact-Finding Study (Christian and Aldrick 1977:1). Kamminga and Allen (1973) were commissioned to undertake the archaeological surveys, while Edwards $(1978,1979)$ focused on Aboriginal art.

Kamminga and Allen (1973) conducted their extensive survey on outliers, valleys and escarpment margins between the South Alligator and East Alligator Rivers. More than 120 sites were recorded, mostly rockshelters situated along the edges of the plateau outliers between Cannon Hill and the Djawumbu (Djawumba) massif (Kamminga and Allen 1973:iv). Six rockshelters (DJAW 1-6) were directly associated with the base or lower slopes of the Djawumbu massif.

Kamminga and Allen (1973) undertook eight test excavations on plateau outliers (Nawamoyn, Malangangerr, Ngarradj Warde Djobkeng, Feather Dreaming, Madjedbebe and Nourlangie) and in plateau valleys (Leichhardt, Nauwalabila I and Disturbed Site) (Figure 5.3). They suggested settlement at Malanganger, Madjedbebe and Nauwalabila I from 24,000-20,000 BP (Kamminga and Allen 1973:27, 48, 95). Pieces of red and yellow ochre were associated with Pleistocene deposits at Nauwalabila I, Nourlangie and Madjedbebe. Grinding stones were also found in Pleistocene deposits at Malangangerr and Nawamoyn rockshelters, with one stone from Madjedbebe impregnated with red and white ochre (Kamminga and Allen 1973:48-49). Midden deposits at Malangangerr, Madjedbebe, Ngarradj Warde Djobkeng and Nawulandja all dated after 7000 years ago, interspersed at Ngarradj Warde Djobkeng and Madjedbebe with human remains (Gillespie and Temple 1976:100; Kamminga and Allen 1973:31). Allen (1987:7) argued that Ngarradj Warde Djobkeng and Madjedbebe were valuable rock shelters close to the tidal flats' during the estuarine phase. However, the change from estuarine to freshwater conditions affected their usefulness and both sites appear to have been rarely used during the past few hundred years. A burial pit cut into midden shell at Madjedbebe was dated to $450 \pm 80$ BP, suggesting late Holocene funerary activity in the upper deposits of the Djawumbu outlier (Kamminga and Allen 1973:31; see also Gillespie and Temple 1976:100). 
Subsequent excavation and sand auguring allowed Rhys Jones and colleagues to re-date Madjedbebe and Nauwalabila I (Roberts et al. 1990a, 1998). The earliest occupation layer at Nauwalabila I was dated with Optically Stimulated Luminescence (OSL) to between 53,400 \pm 5400 and $60,300 \pm 6700$ years ago, while thermoluminescence (TL) determinations from Madjedbebe suggested an antiquity of between 45,000 \pm 9000 and 61,000 $\pm 13,000$ years ago (Roberts and Jones 1994; Roberts et al. 1990a:154, 1998:20). Hiscock (1990) and Bowdler (1990) questioned these long chronologies, citing large standard errors for the TL dates and the possibility that cultural materials had moved through the loose, sandy sediment into older deposits. Roberts et al. (1990b, 1990c) defended their original dates, citing the good chronostratigraphic integrity of the dates, consistency between upper radiocarbon and TL determinations, and the flat (rather than angled or vertical) positions of lithics. Recently reported excavations at the site returned dates for cultural levels going back to c. 65,000 years ago, and a larger and more diverse artefact assemblage than reported from previous excavations; analysis is ongoing (Clarkson et al. 2017).

\section{Rock art surveys}

In contrast to the excavation and lithic-based archaeology, early rock art surveys of Mirarr Country did not adequately document the extent or significance of the art. For instance, given the high level of detail provided in the archaeological report for the 1973 Alligator Rivers study, the rock art results are largely understated and not based on any systematic survey methods or analytical processes. It appears as though Edwards' $(1978,1979)$ assessments of significance were based largely on the number of sites at each location, rather than on the importance of the imagery at each site, such as rare depictions or diversity of styles.

Pancontinental Mining Ltd soon afterwards commissioned its own study of the rock art of the Jabiluka Leasehold area with work undertaken by company employee A.W. Morley (1979; Morley and Lovett 1980). The reports identified numerous sites, but interpretations were limited and sometimes problematic. Many site locations were provided to Morley by the Museum and Art Gallery of the Northern Territory, based on earlier work by Chaloupka. Chaloupka had been walking Country and recording rock art sites in this region since the early 1970s as part of his wider regional surveys that were to expand in the following decades (see, for example, Chaloupka 1993, 1984a, 1984b; Chaloupka et al. 1985).

In more recent years, little systematic rock art survey and recording work has taken place in Mirarr Country, although photographs of Mirarr rock art have been published in general rock art books relating to Kakadu, and there are certainly unpublished records of Mirarr sites in private collections and individual researchers' archives.

\section{Ethnographic evidence of site use}

Only fragmentary ethnographic information has been recorded for sites in Mirarr Country, but the records do reveal some interesting insights into site use and seasonality. For instance, Layton (1981) undertook research into traditional foraging and camping patterns, as well as aspects of rock art as part of the Alligator Rivers Stage 2 Land Claim. His report summarises earlier ethnographic and anthropological findings for the area and incorporates new discussions with Elders. In his report, he relies heavily on Nakodjok (recently deceased, so his skin name is used here out of respect and cultural convention), Toby Kangele (Gangali) and Bill Nayidji (Neidji) three now-deceased senior Traditional Owners who were widely recognised as knowledgeable men of the region. Of particular interest is Layton's assertion that, 'The seasons have a major influence 
on camping patterns'. For example, 'at Narradj Warde Djobkeng shelter ... [Nayinggul] told me that people went there to camp at the beginning of the Wet and stayed there as long as there was water to drink' (1981:9). Likewise, Nayinggul suggested that 'when it started to get dry people left the rock shelters and went to a sand ridge or, for example, Djabiluku billabong' (Layton 1981:9). Overall, Layton surmises that people generally moved towards the escarpment with the coming of the wet and then retreated as water resources dried up. While he does not individually name the site of Madjedbebe, several nearby large areas are specifically referred to as either wet season or dry season camps by the Elders. These sites include Narradj Warde Djobkeng, Djawumbu and Madjawarrnja as wet season camps (Layton 1981:10). Importantly, he further questioned the Elders about their movements away from these camps at different times of the year:

On the 16th of December at Mawundaddjawu, a wet season camp ... I asked [Nakodjok] whether people stayed in one camp for the duration of the Wet Season. He replied that people would get bored sitting in one place: People moved along the foot of the escarpment, or to Oenpelli, or up onto the top of the escarpment hunting for wallaby, or out onto the flooded plain. (Layton 1981:11).

Senior Mirarr Elder Toby Gangali (Figure 5.4) provided further insights into camp life:

Toby says of Barribarri, 'it was just a different camp - we never used to sit; if there was no game, no goanna or anything, we used to shift to other place. All the time we kept moving around'. In conversation, Toby told me that people could stay about one week at a particular camp. When the game had been frightened away, it was time to move to the next one. (Layton 1981:13).

Gangali also suggested that 'a man walking alone could cover ten to twenty miles in a day, but a family travelling with children would only travel five to six miles between camps' (Layton 1981:14). For Djawumbu, Gangali suggested it was a camping place mainly for Mirarr, Dadjbaku and Bunidj, and that 'they went there to get away from mosquitoes and for ceremonies' (Layton 1981:17).

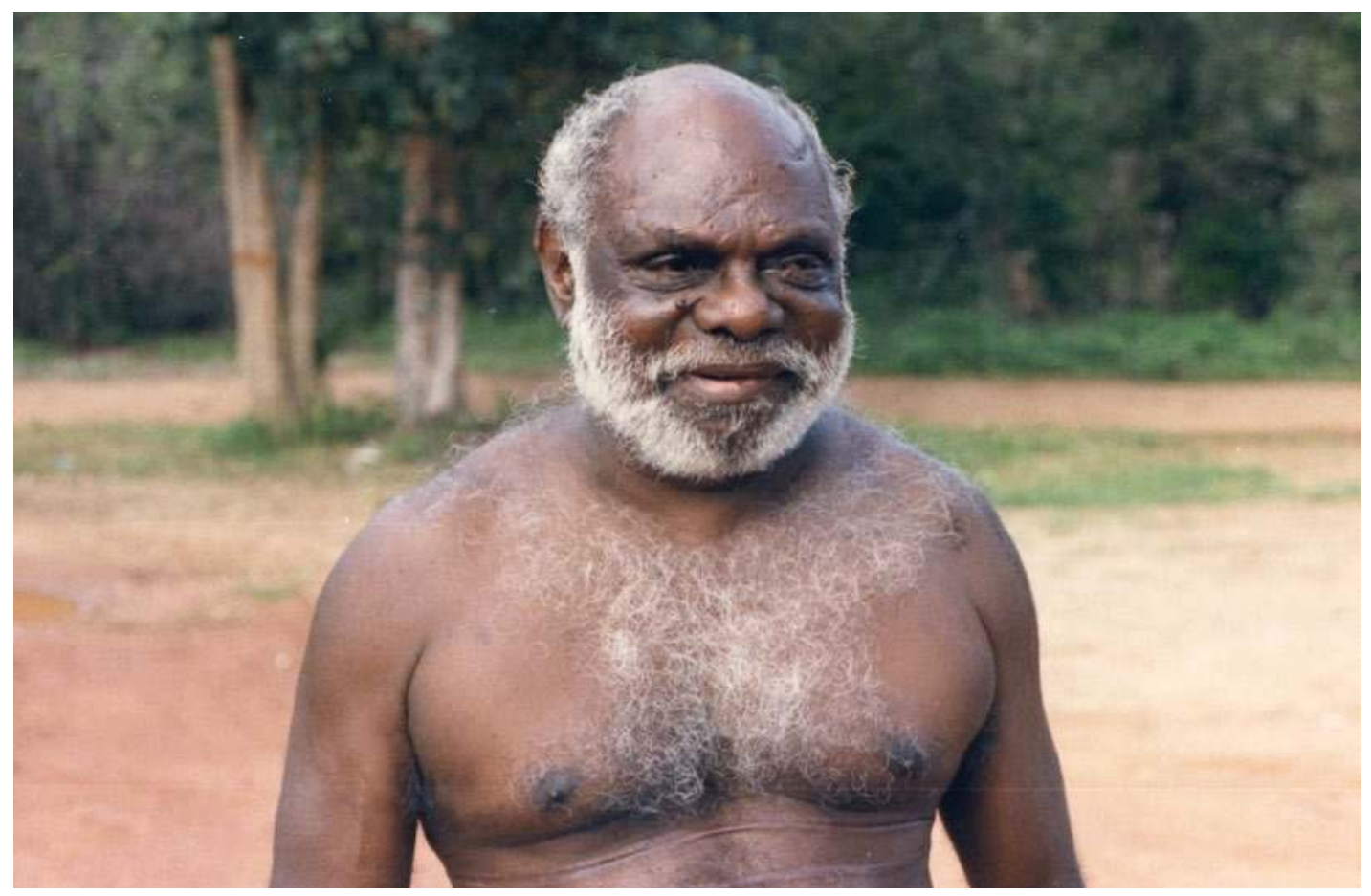

Figure 5.4 Toby Gangali in 1985.

Source: Photograph by Paul Taçon. 
Gangali also includes Djawumbu in his description of walking routes, in particular a route between the European contact-period sites of Oenpelli and Baroalba Timber Camp (Layton 1981:19; see also Kamminga and Allen 1973:44, 53). While he is clearly describing walking routes used in the European-contact period, many such routes would have followed earlier, pre-contact seasonal movements, making use of known rockshelters and water sources along the way.

In the same year as Layton (1981) produced his report, Chaloupka (1981) published a brief article titled 'The traditional movement of a band of Aboriginals in Kakadu'. In this work, he documented the movements of members of the Badmardi clan across many different territories including Mirarr Country. He states that after leaving the Djabiluku waterhole, the group 'followed the Djawumbu-Madjawarnja outlier past the knob-tailed gecko, the mosquito egg, paperbark raft, and dog Dreaming sites on to the plains of the many-braided Magela Creek' (Chaloupka 1981:169). This clearly places the Madjedbebe site along the walking route of this other clan group and suggests that the Mirarr regularly hosted other clan groups in their Country. Chaloupka (1981:162) explains why the Badmardi regularly made these trips:

Although the food resources of their valley were quite plentiful, the members of this clan visited the territories of nearby groups to share in the seasonal bounty of certain animal species such as the magpie geese and file snakes, and to collect materials not available in their own land.

The collecting of materials for tools, fabric and weapons outside the clan group are also mentioned in other ethnographic sources (Berndt and Berndt 1970). Importantly, such journeys were not just about acquiring resources, but were linked to marriage, trade, ceremony and the instruction of youths in traditional law and cultural stories.

With this background and context in mind, we now turn to the rock art of Madjedbebe.

\section{The rock art at Madjedbebe}

Fieldwork for the Mirarr Gunwarddebim project began in 2012 as part of a five-year project. Armed with general information on previous site surveys, an intensive field survey methodology was adopted and, with the assistance of a $500 \mathrm{~m} \times 500 \mathrm{~m}$ grid system, teams walked the entire study area, which is the Jabiluka Leasehold.

To document the sites, a three-stage process was adopted. Basic information was recorded for every site, including location, the presence of rare or unusual rock art and management/ conservation recommendations. This was followed by the collection of more specialised data relating to the site, the rock art and conservation issues. Some sites were chosen for full detailed site recording based on the number of images located within a site, and elements contained within individual paintings.

Of the 528 sites recorded from 2012 to 2014, two were selected for detailed recording, including Madjedbebe. At each of these rockshelters, a full detailed inventory was made of the art including description, colour, style, condition, scaled and unscaled photographs and measurements for each figure. Scenes were recorded as single images.

\section{The rock art assemblage}

A total of 1068 individual images were recorded at Madjedbebe over a three-week period. Given that many other images probably once existed but have either been buried by sediments, deteriorated and disappeared over time, or been painted over and totally obscured by newer artworks, this number of recorded images should be seen as a minimum number of the original corpus of artworks. Today, the art stretches from one end of the shelter to the other, a distance of nearly $50 \mathrm{~m}$ (Figures 5.5 and 5.6). Artworks are often superimposed over each other, with many layers of art being evident. The following is a general description of the Madjedbebe rock art. 


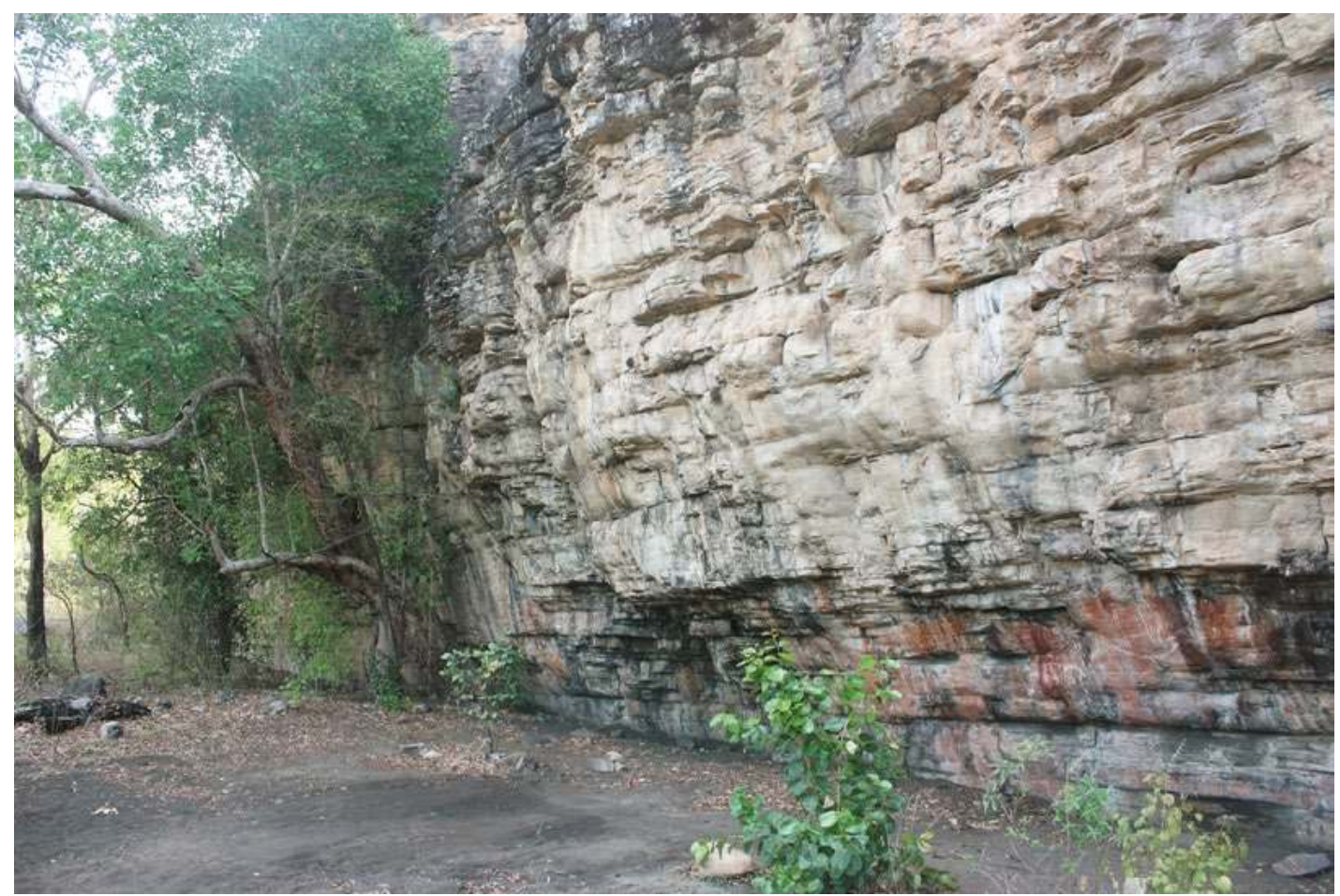

Figure 5.5 View of some of the painted panels at Madjedbebe, 2012.

Source: Photograph by Sally K. May.

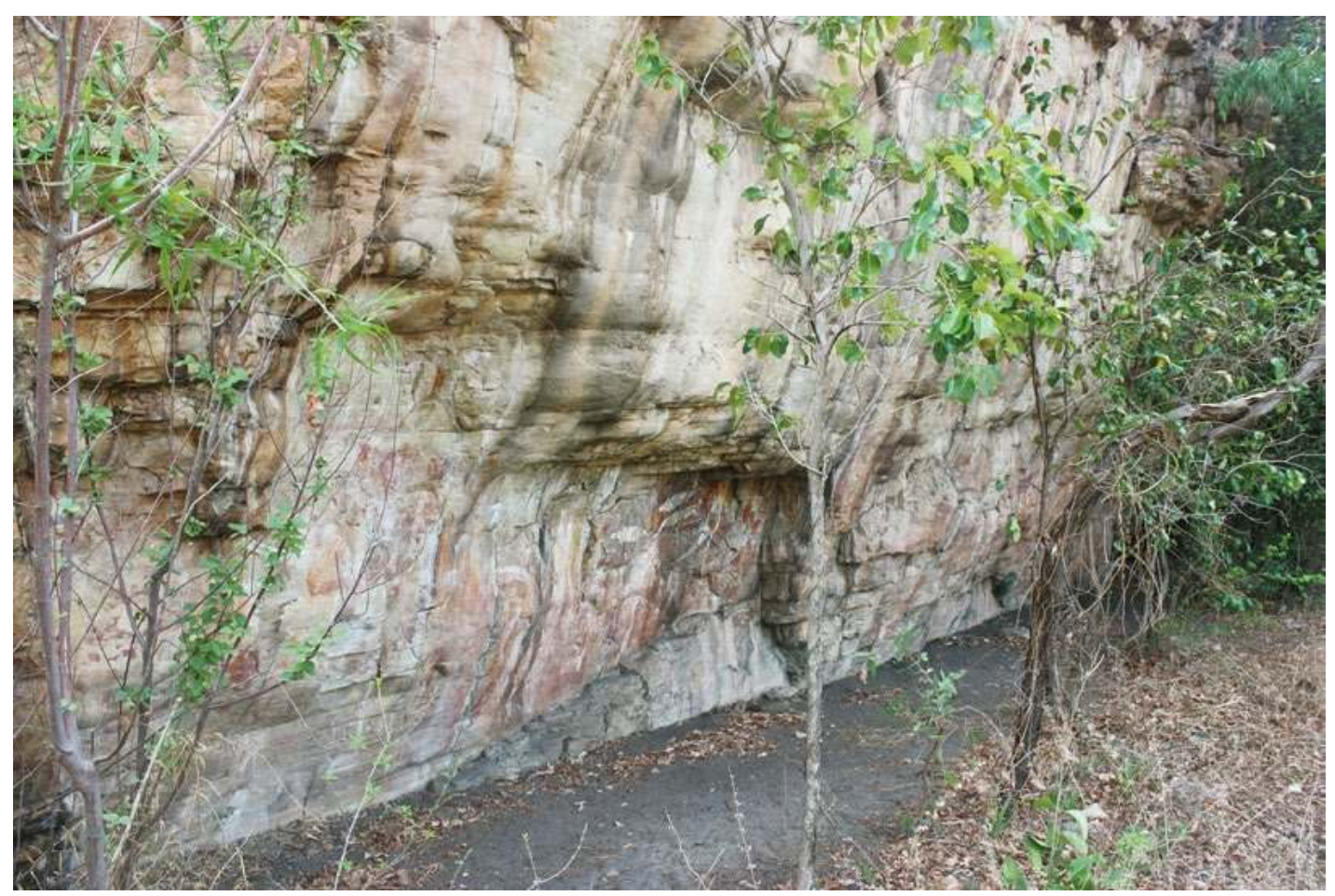

Figure 5.6 View of some of the painted panels at Madjedbebe, 2012.

Source: Photograph by Sally K. May. 


\section{Technique and colour}

Of the 1068 surviving images at this site, 894 ( 83.7 per cent) are paintings, 128 (12 per cent) are stencils, 28 (2.6 per cent) are beeswax figures and 18 (1.7 per cent) are charcoal drawings. While the proportional representation of each technique is relatively standard for the Arnhem Land region, the overall number of individual images makes this one of the most prolifically painted sites in the area. Given the shallow overhang and therefore partial exposure of the rock surface, it is surprising to find so many images, possibly suggesting that the site was once home to a much larger rock art corpus. Furthermore, feral animals have severely damaged or destroyed the lower rock art by rubbing against the surface of the shelter. For this latter reason, little art survives less than $1 \mathrm{~m}$ above ground level.

A broad range of ochre colours and mineralogies are represented within the painting assemblage, with a predominance of red haematite ( $\mathrm{n}=256$ images), white kaolin clay $(\mathrm{n}=144)$ and yellow ochre $(n=138)$ (Table 5.1). The overall broad range of colours is not unusual for this region and may be partly due to the nature of the composition of the pigments and the binding agents used in their preparation. The high number of images using white may also be attributed to the interpreted age of the paintings that, based on stylistic analysis, fall within the most recent phases of the rock art chronology of Arnhem Land. While preferential preservation may be a key factor in the predominance of red images (red ochre is known to sometimes form a strong bond with the rock surface), ethnographic and archaeological research in this region also suggests a high level of cultural significance for the colour red (Taylor 1996).

Table 5.1 Colours and colour combinations used to produce rock paintings at Madjedbebe.

\begin{tabular}{|l|r|}
\hline Colour & Number of images \\
\hline Red & 256 \\
\hline White & 144 \\
\hline Yellow & 138 \\
\hline Red and white & 121 \\
\hline Purple & 73 \\
\hline Red and yellow & 64 \\
\hline Black & 34 \\
\hline Purple and yellow & 20 \\
\hline Purple and white & 19 \\
\hline Red, white and yellow & 7 \\
\hline Black and red & 3 \\
\hline Purple and red & 3 \\
\hline Purple, red and white & 3 \\
\hline White and yellow & 3 \\
\hline Purple, red and yellow & 2 \\
\hline Black and white & 1 \\
\hline Brown & 1 \\
\hline Gray & 1 \\
\hline Purple, white and yellow & 1 \\
\hline Black and yellow & 1 \\
\hline
\end{tabular}

Source: Authors' data.

\section{Subject matter}

Interpreting rock art subject matter is often speculative, not least in an early stage of any project, so here we take a conservative approach to the interpretation of the many images at Madjedbebe. In short, we take a descriptive approach and do not speculate on deeper meanings. One important reason for this approach is that there is ample ethnographic evidence to suggest Aboriginal artists working on both bark and rock in western Arnhem Land concealed multi-layered meanings in their works. Luke Taylor's (1996) work with artists in the 1980s highlighted that apparently 'simple' paintings (such as fish) were more often than not imbued with 'inside' knowledge that artists were communicating to initiated individuals. Taçon (1989) found this was also true of recent rock art. In other words, depending on your cultural standing, paintings hold different meanings to different people (May 2008:171-194). Our overview for this chapter, therefore, presents only the 'outside' or public stories behind the rock art.

In common with many rock art sites across the region (e.g. Chaloupka 1993), there is a predominance of human-like figures (22 per cent) and geometric designs (16 per cent) at this site (Table 5.2). Many of 
the paintings could not be allocated an image form because of their poor condition or superimposition by subsequent art.

Of interest is the high proportion of disarticulated human-like figures and paintings of bundled bones $(\mathrm{n}=26)$ at the site (Figure 5.7). In addition to the paintings, 128 stencils were also recorded (Table 5.3). There is a high incidence of hand stencils, evenly spread between left $(n=38)$ and right hands $(n=35)$. There is also an unusually large number of painted hand or painted hand and forearm stencils ( $\mathrm{n}=12$; Figure 5.8).
Table 5.2 General interpretation of the painting forms at Madjedbebe.

\begin{tabular}{|l|r|}
\hline Image form & Number of images \\
\hline Unknown & 310 \\
\hline Human-like figure & 232 \\
\hline Geometric design & 177 \\
\hline Fish & 86 \\
\hline Contact & 36 \\
\hline Reptile & 28 \\
\hline Material culture & 15 \\
\hline Mammal & 4 \\
\hline Flora & 6 \\
\hline
\end{tabular}

Source: Authors' data.

Table 5.3 General interpretation of the stencils at Madjedbebe, with colours shown for the first three categories.

\begin{tabular}{|c|c|c|}
\hline Stencil type & Number of images & Colour \\
\hline Left hand & 38 & Yellow $=19$, white $=18$, Red $=1$ \\
\hline Right hand & 35 & Yellow $=17$, white $=15$, Red $=3$ \\
\hline Hand (unknown) & 9 & White $=4$, Yellow $=5$ \\
\hline Unidentified & 8 & \\
\hline Right hand and forearm & 7 & \\
\hline Left hand and forearm & 6 & \\
\hline Painted left hand and forearm & 6 & \\
\hline Finger & 5 & \\
\hline Left foot & 3 & \\
\hline Painted right hand and forearm & 3 & \\
\hline Right foot & 1 & \\
\hline Painted left hand & 1 & \\
\hline Painted right hand & 1 & \\
\hline Painted hand and forearm & 1 & \\
\hline
\end{tabular}

Source: Authors' data.

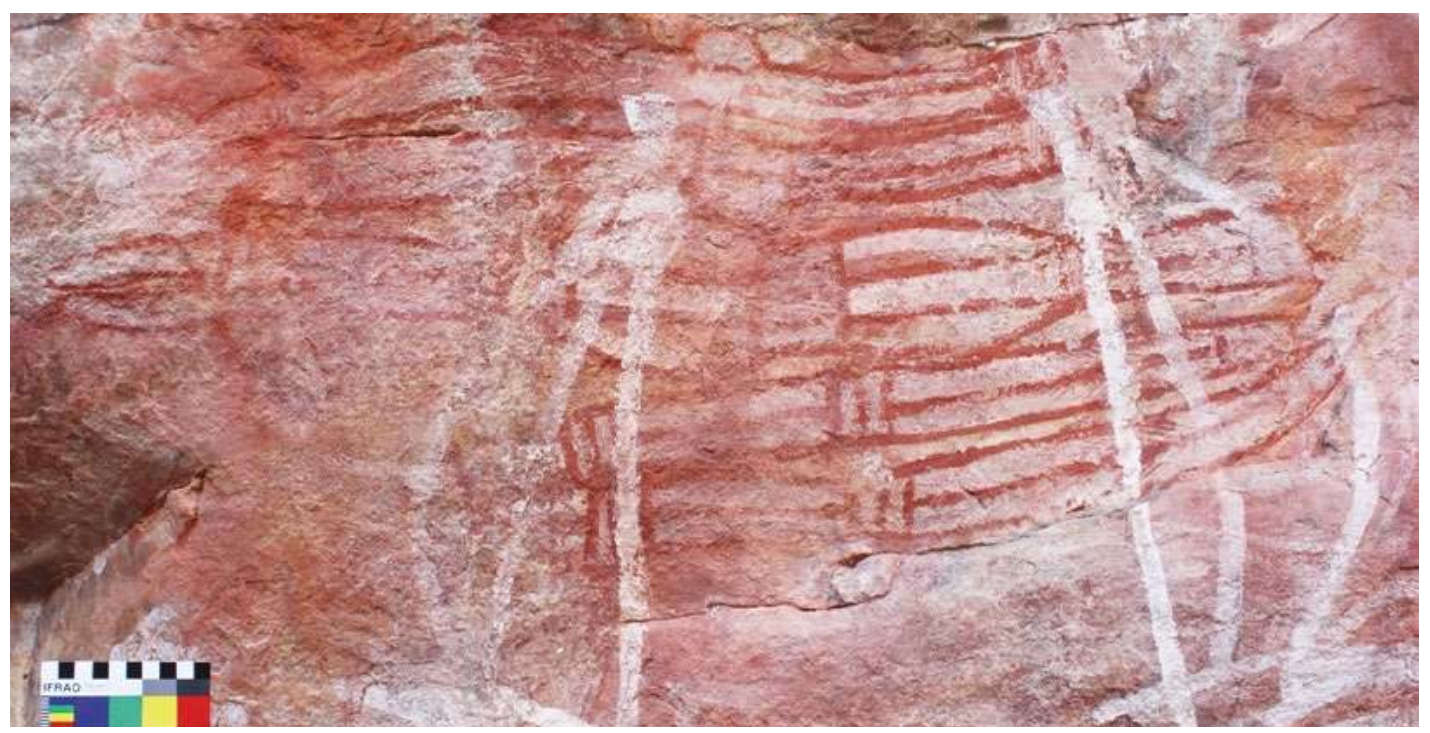

Figure 5.7 Depiction of bundled human bones at Madjedbebe, 2013.

Source: Photograph by Melissa Marshall. 


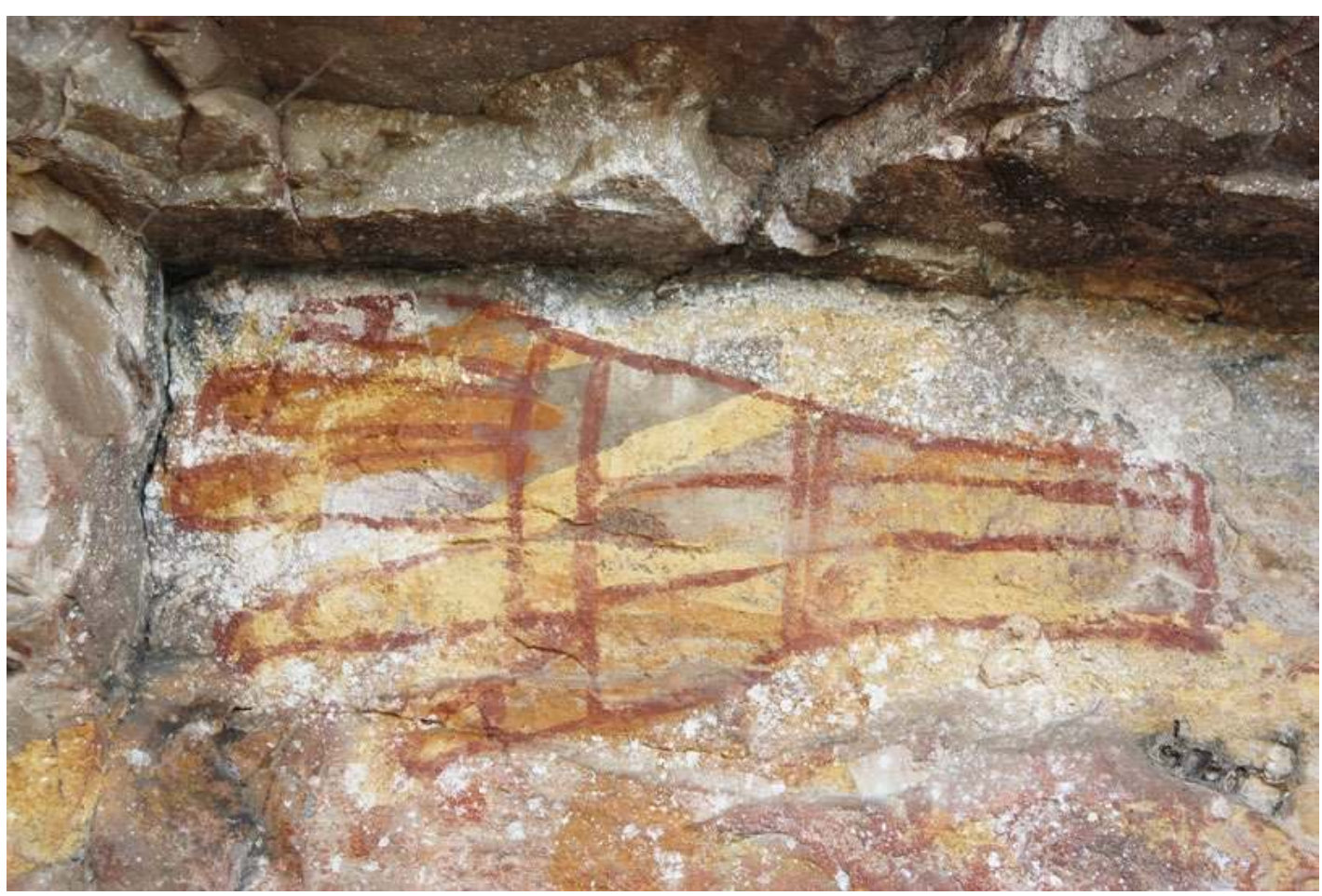

Figure 5.8 Painted hand and forearm stencil from Madjedbebe. The hand was first stencilled, then outlined and infilled.

Source: Photograph by Melissa Marshall.

Of the fish species that could be identified, catfish predominate, with 13 examples each of eeltailed and lesser salmon catfish, and two that could not be attributed to a particular taxon (Table 5.4). Also occurring in significant numbers are barramundi, freshwater long-tom, mullet and saratoga.

Table 5.4 Types of fish depicted at Madjedbebe.

\begin{tabular}{|l|l|l|r|}
\hline Fish & Gundjeihmi name & Scientific name & Number of images \\
\hline Unidentified & - & - & 23 \\
\hline Eel-tailed catfish & Binjdjarrang & $\begin{array}{l}\text { Tandanus tandanus, } \\
\text { Neosilurus ater, Neosilurus hyrtlii }\end{array}$ & 13 \\
\hline Lesser salmon catfish & Almakkawarri & Arius leptaspis & 13 \\
\hline Barramundi & Namarn.gol & Lates calcarifer & 10 \\
\hline Freshwater long-tom & Burrugulung & Stongylura kreffti & 7 \\
\hline Mullet & Madjabarr & Liza diadema and Liza dusumieri & 7 \\
\hline Saratoga & $\begin{array}{l}\text { 1. Ngaldadmo } \\
\text { 2. Guluibirr }\end{array}$ & Scleropages jardini & 6 \\
\hline $\begin{array}{l}\text { 1. Archer fish } \\
\text { 2. Primitive archer fish }\end{array}$ & $\begin{array}{l}\text { 1. Njarlgan } \\
\text { 2. Bodjdjalk }\end{array}$ & $\begin{array}{l}\text { 1. Toxotes chatareus } \\
\text { 2. Toxotes lorentzi }\end{array}$ & 2 \\
\hline Boney bream & $\begin{array}{l}\text { Nabardebarde } \\
\text { (variant: bardebarde) }\end{array}$ & Nematolosa erebi & 2 \\
\hline Catfish (type unidentified) & - & -- & 85 \\
\hline Total & & & \\
\hline
\end{tabular}

Note the unidentified fish were too poorly preserved to ascertain species.

Source: Authors' data. Gundjeihmi names provided by Murray Garde. 
Of the 894 paintings, 36 are images of subject matter from the European-contact period. This includes an unusually large number of firearms ( $n=16$; Figures 5.9 and 5.10) (May et al. 2017), as well as knives, people with hands on hips, watercraft (two ships and a row boat) and a series of smoking pipes. Other paintings featuring more traditional subject matters were identified as having been painted during the European-contact period as they are superimposed over paintings of European subject matters.

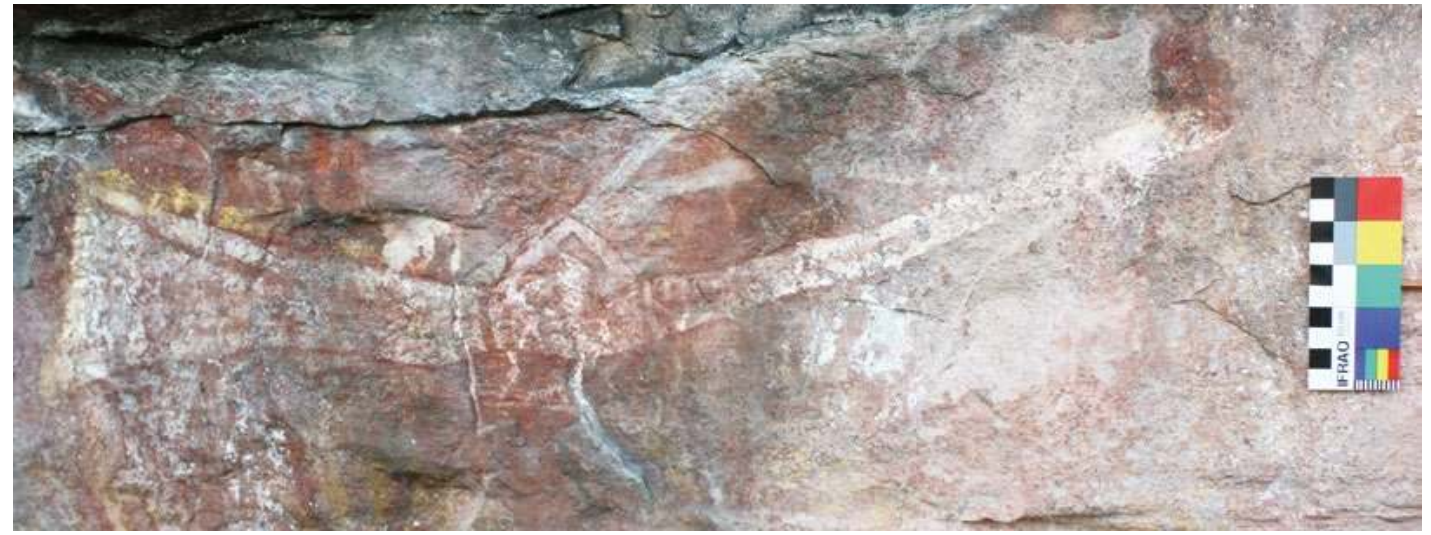

Figure 5.9 Painting of a firearm from Madjedbebe, one of 16 depicted at the site. This example is shown hanging upside down as though on the side of a horse or across the shoulder of the carrier. Source: Photograph by Melissa Marshall.

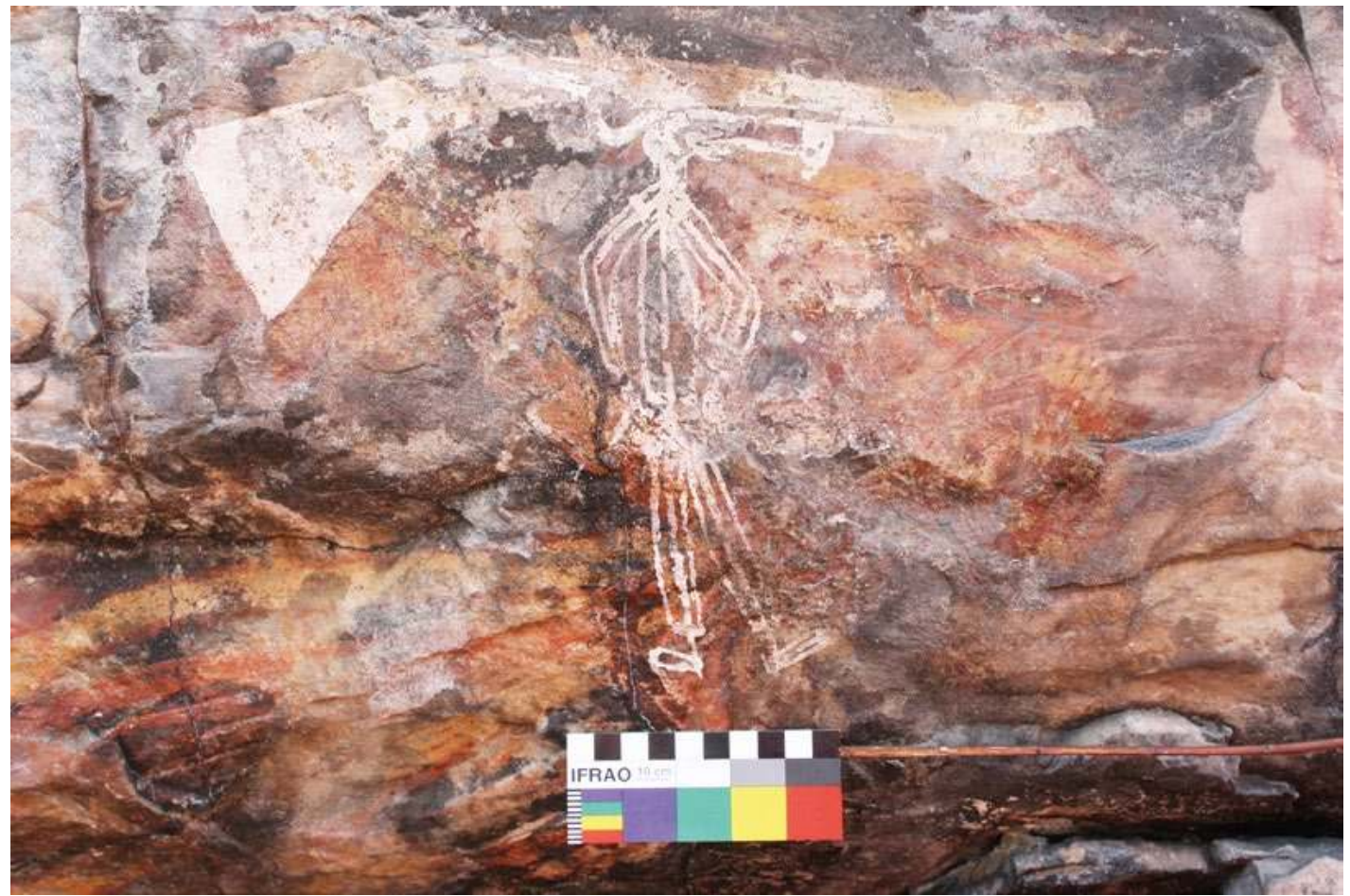

Figure 5.10 European-contact painting featuring a person wearing European-style clothing, smoking a pipe and with oversized gun depicted above head.

Source: Photograph by Sally K. May. 


\section{Style and chronology}

While a number of stylistic chronologies have been proposed for western Arnhem Land rock art (e.g. Chaloupka 1993; Chippindale and Taçon 1998; Lewis 1988), little 'direct' dating of the art has taken place (beeswax art being an exception, e.g. see Nelson 2000; Taçon et al. 2004). However, there is a range of evidence to suggest that the oldest surviving rock art of this region, including paintings of large naturalistic animals, is over 15,000 years of age and possibly as much as 30,000 years (for an example of early art, see David et al. 2013). Chaloupka (1984a, 1984b, 1993) has argued that, taken as a corpus, the rock art of western Arnhem Land illustrates significant environmental, technological and stylistic change over time. A number of sequential art styles have thus been identified by studying the superimposition of individual paintings and comparing these across many hundreds of sites (e.g. Chippindale and Taçon 1993, 1998; Lewis 1988). These studies have used depictions of extinct animals, a variety of artefact types, clothing and other types of worn paraphernalia and/or recent subject matters to mark changes in style from the pre-estuarine to estuarine, freshwater and historic periods (see Table 5.5).

Table 5.5 Proposed stylistic chronology for western Arnhem Land rock art.

\begin{tabular}{|c|c|c|c|}
\hline \multicolumn{4}{|l|}{ Pre-estuarine } \\
\hline \multicolumn{2}{|c|}{$\begin{array}{l}50,000 \text { years ago } \\
\text { From this date, haematite and red and yellow ochres } \\
\text { were used to prepare pigment }\end{array}$} & object imprints & $\begin{array}{l}\text { Hand prints; imprints of grass and other } \\
\text { thrown objects }\end{array}$ \\
\hline \multirow[t]{6}{*}{20,000 years ago } & Naturalistic & $\begin{array}{l}\text { Large naturalistic } \\
\text { figures complex }\end{array}$ & $\begin{array}{l}\text { Possible extinct megafauna; thylacine; } \\
\text { Tasmanian devil; terrestrial animals, rock } \\
\text { python; freshwater crocodile; human beings; } \\
\text { earliest x-ray paintings }\end{array}$ \\
\hline & & Dynamic figures & $\begin{array}{l}\text { Human beings in complex apparel; } \\
\text { anthropomorphs; zoomorphs; terrestrial } \\
\text { animals; freshwater fish; stencils; hand of } \\
\text { 3MF convention, boomerangs; one-piece } \\
\text { multi-barbed spears; detailed compositions }\end{array}$ \\
\hline & Stylisation & Post-dynamic figures & $\begin{array}{l}\text { Human beings in headdresses, pubic aprons } \\
\text { and bustles; macropods; lizards; fighting pick/ } \\
\text { hooked stick introduced }\end{array}$ \\
\hline & Schematisation & $\begin{array}{l}\text { Simple figures with } \\
\text { boomerangs }\end{array}$ & $\begin{array}{l}\text { Human beings in headdresses, pubic aprons } \\
\text { and bustles; conflict; fighting pick; single- and } \\
\text { multi-pronged barbed composite spears; } \\
\text { possible spearthrower }\end{array}$ \\
\hline & Stylisation & Mountford figures & $\begin{array}{l}\text { Human beings (many elongated); } \\
\text { spearthrower }\end{array}$ \\
\hline & Naturalistic symbolism & Yam figures & $\begin{array}{l}\text { Anthropomorphised yams; phytomorphised } \\
\text { animals; Rainbow Serpent; ibis; egret; short- } \\
\text { necked turtle; flying fox; long-arm prawn; } \\
\text { segmented circle symbol }\end{array}$ \\
\hline \multicolumn{4}{|l|}{ Estuarine } \\
\hline 8000 years ago & Naturalistic & $\begin{array}{l}\text { Early estuarine } \\
\text { complex }\end{array}$ & $\begin{array}{l}\text { Estuarine fish: barramundi, mullet, catfish; } \\
\text { saltwater crocodile; variety of spearthrowers }\end{array}$ \\
\hline \multirow[t]{2}{*}{4000 years ago } & & Beeswax designs & $\begin{array}{l}\text { Human beings; anthropomorphs; non- } \\
\text { figurative designs }\end{array}$ \\
\hline & $\begin{array}{l}\text { Intellectual realism and } \\
\text { contemporaneous naturalism }\end{array}$ & X-ray complex & $\begin{array}{l}\text { Lightning Man; stone-tipped spear; x-ray } \\
\text { paintings of animals and humans with } \\
\text { detailed and decorative features }\end{array}$ \\
\hline
\end{tabular}




\begin{tabular}{|l|l|l|l|}
\hline \multicolumn{2}{|l|}{ Freshwater } & & $\begin{array}{l}\text { Hook-headed human beings; magpie geese; } \\
\text { water lilies; 'goose' spears; goose-wing 'fan'; } \\
\text { didjeridu; complex spearthrower }\end{array}$ \\
\hline 1500 years ago & \multicolumn{2}{|l|}{} \\
\hline 300 years ago & & & $\begin{array}{l}\text { Macassan and European subjects; introduced } \\
\text { animals; sorcery paintings; decorated hands }\end{array}$ \\
\hline Ethnographic present & & Casual paintings & \\
\hline
\end{tabular}

'3MF' stands for three middle fingers together, with the thumb and small finger to one side. Source: After Chaloupka (1993).

The paintings recorded at Madjedbebe mostly stem from Chaloupka's (1984b, 1993) 'Freshwater' and 'Contact' periods, with some X-ray images also present (Figure 5.11). This range of paintings signals the presence of artworks over a variety of climatic and social conditions. The incidence of human-like figures is relatively high, and that of fish, reptiles and mammals notably small. With the proximity of the site to the nearby floodplain resources, a higher proportion of these latter images could arguably have been expected, if the images related mainly to food resources and/or to animals from nearby settings.

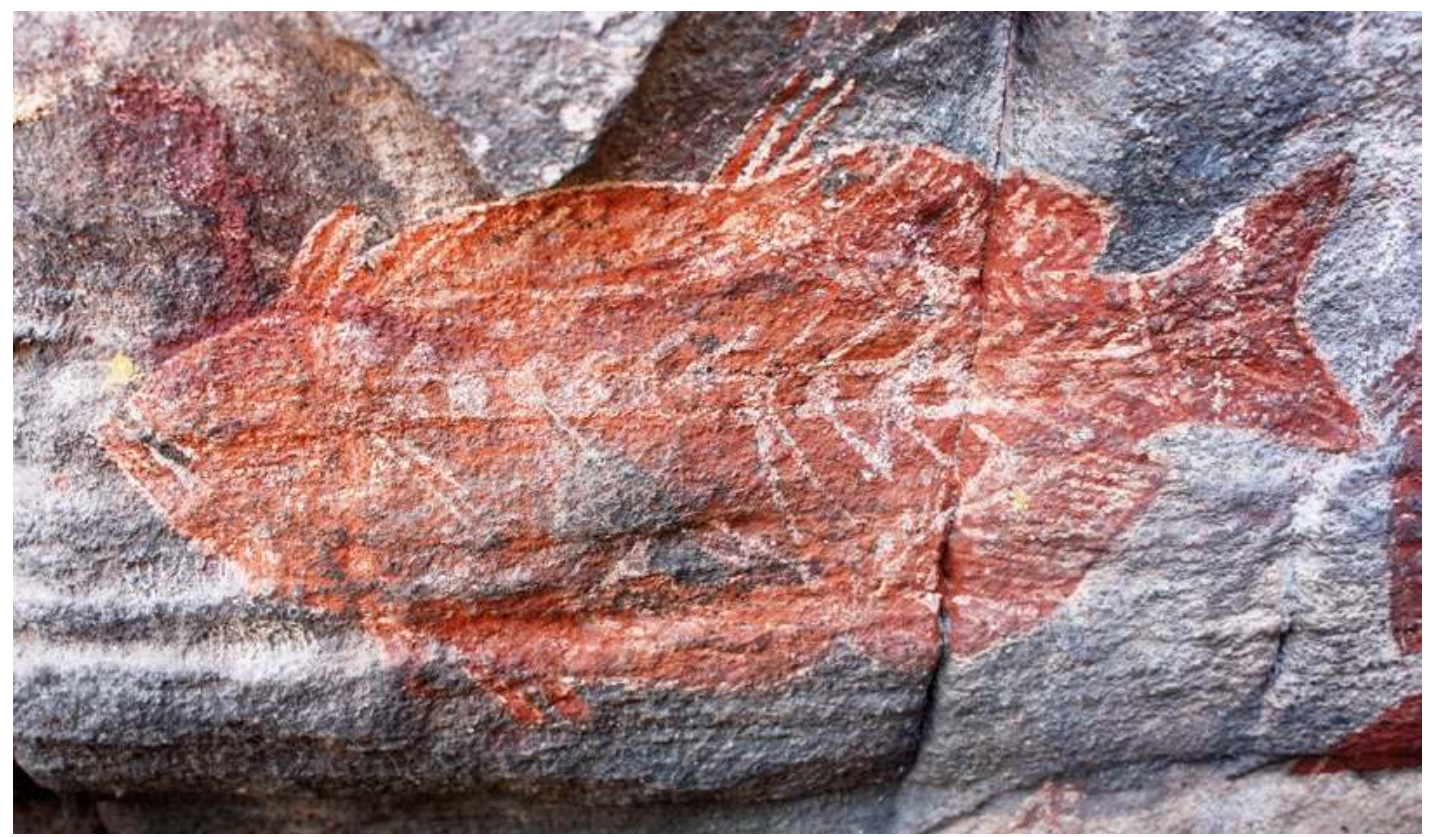

Figure 5.11 Example of an X-ray fish painting from Madjedbebe.

Source: Photograph by Joakim Goldhahn.

\section{Discussion and conclusion}

Madjedbebe may be one of the oldest dated human occupation sites in Australia, but it is also a site that remained significant to local Aboriginal people long after European incursions into the area began to disrupt and/or transform other traditional land-use patterns. It is clear from local ethnography and rock art that, at least in the recent past, this site was used as a stopping point along a dry season walking route between a number of settlements, including the Oenpelli 
Mission and buffalo shooters' camps. Artists have clearly documented some of their experiences on the walls of this bluff face, and depictions of items of high value - or, perhaps, high curiosity - such as firearms, illustrate the artists' changing lives (Figures 5.9 and 5.10) (May et al. 2017).

Evidence from other studies (e.g. May et al. 2010; Taçon et al. 2010) suggests that this walking route may have extended beyond Oenpelli to as far as the Coburg Peninsula, and that it may well have been associated with Macassan-Aboriginal, and later missionary, trade systems along the northern coastline at sites such as Anuru Bay (see, for example, Wesley et al. 2014). At the same time, European contact-period walking routes must have relied on traditional knowledge of shelter, water and food supplies, as well as alliances with neighbouring groups and movements across Country for ceremonies.

It is particularly interesting that the Madjedbebe site continued to be used into the Europeancontact period: of the 528 sites documented within the Jabiluka Leasehold, very few show clear evidence of contact rock art in the form of identifiable European-based images (e.g. Western items of material culture). Does this indicate a site of differing cultural value than others, or simply a site well positioned as a stopping point in the landscape before and after the contact period? Rockshelters offering better protection from the weather and better visibility across the landscape are available in very close proximity to Madjedbebe. As such, there must have been a cultural aspect to the preference for Madjedbebe during the European-contact period. All of these issues point to the Djawumbu massif as an important location in the landscape, both before and during contact and a site only to be adequately understood in its wider geographical and inter-cultural contexts. Most importantly, Mirarr individuals and families continue to visit Country, retaining close cultural associations with sites such as Madjedbebe.

Archaeological results demonstrate that Madjedbebe was visited during late Pleistocene and early to mid-Holocene times. The presence of haematite and other pigments, and grinding stones stained with pigment within dated archaeological deposits, support an early period of art (Clarkson et al. 2017; Kamminga and Allen 1973:48-49). However, paintings of the region's earliest identified styles, such as Dynamic and Yam Figures, have either not survived at the site, or are buried below deep deposits. At Madjedbebe and the adjacent site of Ngarradj Warde Djobkeng, shellfish middens (incorporating remains of marsupials, reptiles, birds and fish) date back to 7000 years ago, suggesting extensive site use during the estuarine phase. Allen (1987) and others (e.g. Jones 1985) argue that reduced settlement activity after 2500 years ago was due to major environmental changes and associated movements of people towards new freshwater systems. While no direct dates have been obtained for the on-wall rock art at Madjedbebe, the principal period of rock art is arguably contemporaneous with a period of reduced occupational activity at the site dating from c. 2500 years ago to present (Allen 1987). This relatively recent time period is evident through the dominance of more recent rock art styles, and the prominence of freshwater (mixed freshwater/saltwater) fish depicted in the rock art. The unusual prominence of human-like figures, disarticulated bones and deformed human figures in the art corresponds with ethnographic records for Djawumbu, suggesting that Madjedbebe may have been an important site for cultural activity during this late Holocene period. Importantly, the re-excavation of Madjebebe in 2012 revealed 17 individuals buried at this site (Lowe et al. 2014:157). Could the unusually high number of paintings of disarticulated human remains be somehow linked to the high number of actual burials at this site, or in other ways to the death of these individuals (e.g. sorcery art causing or responding to their deaths)? There is a significant relationship existing between the placement of rock art and the human remains at this site. The artists are perhaps marking this place with visual signs of cultural activities and beliefs relating to death. Further research relating to the age of the burials and the art may provide greater evidence for such relationships. 
Madjedbebe is well known for being an important site in terms of early evidence for the human settlement of Australia. Less well known, but arguably no less important, is the emerging late Holocene record of complex human activities, as demonstrated in the rock art assemblage. Work to date, including the analysis of Madjedbebe's rock art, has produced some important findings and directed us towards new research angles and lines of enquiry for the coming years.

\section{Acknowledgements}

We would like to thank the Mirarr people and the Gundjeihmi Aboriginal Corporation for working with us on the Mirarr Gunwarddebim project and, in particular, Yvonne Margarula and Justin O'Brien. Thanks are due to Energy Resources of Australia for allowing us access to the Jabiluka Leasehold area to undertake these surveys, the Kakadu National Park Natural Cultural Programs Unit for their time, assistance and ongoing support and to the Northern Land Council and Aboriginal Areas Protection Authority for permits, maps and more. Many people have contributed to the Mirarr Gunwarddebim project in various ways and we thank you for your support. We would especially like to thank volunteers Janet Davill and Jessica Blackman, who spent weeks at the sites helping to document individual images. Murray Garde (The Australian National University) kindly provided the Gundjeihmi spellings for different fish species. Finally, we thank our archaeological colleagues who, while excavating, shared the Madjedbebe space with us during much of the 2012 field season.

\section{References}

Allen, H. 1978. The Jabiluka Project: Draft Environmental Impact Statement. In G. Chaloupka (ed.), Djawumbu-Madjawarnja Site Complex: Nomination for Inclusion on the Register of the National Estate, Canberra. Unpublished report, Australian Institute of Aboriginal Studies, Canberra.

Allen, H. 1987. Holocene mangroves and middens in northern Australia and Southeast Asia. Indo Pacific Prehistory Association 7:1-16. doi.org/10.7152/bippa.v7i0.11248

Allen, H. 1996. The time of the mangroves: Changes in mid-Holocene estuarine environments and subsistence in Australia and Southeast Asia. Bulletin of the Indo-Pacific Prehistory Association 15:193-205. doi.org/10.7152/bippa.v15i0.11548

Allen, H. and G. Barton 1989. Ngarradj Warde Djobkeng: White Cockatoo Dreaming and the Prehistory of Kakadu. Oceania Monograph 37, Oceania Publications, Sydney.

Allen, J. and J.F. O'Connell 2014. Both half right: Updating the evidence for dating first human arrivals in Sahul. Australian Archaeology 79: 86-108. doi.org/10.1080/03122417.2014.11682025

Berndt, R.M. and C.H. Berndt 1970. Man, Land and Myth in North Australia. Ure Smith, Sydney.

Bourke, P., S. Brockwell, P. Faulkner and B. Meehan. 2007. Climate variability in the mid-late Holocene Arnhem Land region, north Australia: Archaeological archives of environmental and cultural change. Archaeology in Oceania 42:91-101. doi.org/10.1002/j.1834-4453.2007.tb00022.x

Bowdler, S. 1990. 50,000 year-old site in Australia - Is it really that old? Australian Archaeology 31:93. doi.org/10.1080/03122417.1990.11681394

Brockwell, S. 1996. Open sites of the South Alligator River wetland, Kakadu. In P. Veth and P. Hiscock (eds), Archaeology of Northern Australia, pp. 90-105. Tempus 4. Anthropology Museum, University of Queensland, St Lucia. 
Brockwell, S. 2006. Earth mounds in northern Australia: A review. Australian Archaeology 63:47-56. doi.org/10.1080/03122417.2006.11681837

Brockwell, S., R. Levitus, J. Russell-Smith and P. Forrest 1995. Aboriginal Heritage. In A.J. Press, D. Lea, A. Webb and A. Graham (eds), Kakadu Natural and Cultural Heritage and Management, pp. 15-63. Australian Nature Conservation Agency, North Australia Research Unit, The Australian National University, Canberra.

Brockwell, S., P. Faulkner, P. Bourke, A. Clarke, C. Crassweller, D. Guse, B. Meehan and R. Sim. 2009. Radiocarbon dates from the Top End: A cultural chronology for the Northern Territory coastal plains. Australian Aboriginal Studies 1:54-76.

Chaloupka G. 1981. The traditional movement of a band of Aboriginals in Kakadu. In T. Stokes (ed.), Kakadu National Park Education Resources, pp. 162-171. Australian National Parks and Wildlife Service, Canberra.

Chaloupka, G. 1984a. Rock Art of the Arnhem Land Plateau: Paintings of the Dynamic Figures Style. Unpublished report for the Northern Territory Museum of Arts and Sciences, Darwin.

Chaloupka, G. 1984b. From Palaeoart to Casual Paintings: The Chronological Sequence of Arnhem Land Plateau Rock Art. Northern Territory Museum of Arts and Sciences Monograph Series, Darwin.

Chaloupka, G. 1993. Journey in Time: The World's Longest Continuing Art Tradition. Reed, Chatswood.

Chaloupka, G., N. Kapirigi, B. Nayidji and G. Namingum 1985. A Cultural survey of Balawurru, Deaf Adder Creek, Amarrkananga, Cannon Hill and the Northern Corridor. Unpublished report for Museum and Art Galleries Board of the Northern Territory, Darwin.

Chappell, J. and J. Grindrod 1983. Chenier plain formation in northern Australia. In B.G. Thom (ed.), Recent Advances in Australian Coastal Studies, pp. 197-231. Academic Press, New York.

Chappell, J. and N.J. Shackleton 1986. Oxygen isotopes and sea level. Nature 324:137-140. doi. org/10.1038/324137a 0

Chippindale, C. and P.S.C. Taçon 1993. Two old painted panels from Kakadu: Variation and sequence in Arnhem Land rock art. In J. Steinbring, A. Watchman, P. Faulstich and P.S.C. Taçon (eds), Time and Space: Dating and Spatial Considerations in Rock Art Research, pp. 32-56. Australian Rock Art Research Association, Melbourne.

Chippindale, C. and P.S.C. Taçon 1998. The many ways of dating Arnhem Land rock-art, north Australia. In C. Chippindale and P.S.C. Taçon (eds), The Archaeology of Rock-Art, pp. 90-111. Cambridge University Press, Cambridge.

Christian, C.S. and J.M. Aldrick 1977. Alligator Rivers Study: A Review Report of the Alligator Rivers Region Environmental Fact-Finding Study. Australian Government Publishing Service, for the Department of Northern Territory and the Australian Mining Industry Council, Canberra.

Clark, R.L. and J.C. Guppy 1988. A transition from mangrove forest to freshwater wetland in the monsoon tropics of Australia. Journal of Biogeography 15:665-84. doi.org/10.2307/2845444

Clark. R.L., J. Guppy, D. Mahon, P. McBride and R.J. Wasson 1992. Late Quaternary evolution of the Magela Plain. In R.J. Wasson (ed.), Modern Sedimentation and Late Quaternary Evolution of the Magela Creek Plain, pp. 28-80. Research Report 6. Supervising Scientist of the Alligator Rivers Region, Australian Government Printer, Canberra. 
Clarkson, C., Z. Jacobs, B. Marwick, R. Fullagar, L. Wallis, M. Smith, R.G. Roberts, E. Hayes, K. Lowe, X. Carah, S.A. Florin, J. McNeil, D. Cox, L. J. Arnold, Q. Hua, J. Huntley, H.E.A. Brand, T. Manne, A. Fairbairn, J. Shulmeister, L. Lyle, M. Salinas, M. Page, K. Connell, G. Park, K. Norman, T. Murphy and C. Pardoe 2017. Human occupation of Australia by 65,000 years. Nature 547(7663): 306-310 doi.org/10.1038/nature22968

David, B., B. Barker, F. Petchey, J.-J. Delannoy, J.-M. Geneste, C. Rowe, M. Eccleston, L. Lamb and R. Whear 2013. A 28,000 year old excavated painted rock from Nawarla Gabarnmang, northern Australia. Journal of Archaeological Science 40(5):2493-2501. doi.org/10.1016/j.jas.2012.08.015

Davidson, I. and W. Noble 1992. Why the first colonisation of the Australian region is the earliest evidence of modern human behaviour. Archaeology in Oceania 27(3):135-142. doi.org/10.1002/ j.1834-4453.1992.tb00297.x

Edwards, R. 1978. Rock art in the Alligator Rivers Region. Aboriginal News 3(3):9-12.

Edwards, R. 1979. Australian Aboriginal Art: The Art of the Alligator Rivers Region, Northern Territory. Australian Institute of Aboriginal Studies 15 (new series). Australian Institute of Aboriginal Studies, Canberra.

Faulkner, P. 2009. Focused, intense and long-term: Evidence for Granular Ark (Anadara granosa) exploitation from late Holocene shell mounds of Blue Mud Bay, northern Australia. Journal of Archaeological Science 36:821-834. doi.org/10.1016/j.jas.2008.11.005

Gillespie, R. and R.B. Temple 1976. Sydney University natural radiocarbon measurements III. Radiocarbon 18:96-109. doi.org/10.1017/S0033822200002393

Hays-Gilpin, K. 2004. Ambiguous Images: Gender and Rock Art. Rowman Altamira, Lanham.

Hiscock, P. 1990. How old are the artefacts in Malakunanja II? Archaeology in Oceania 25(3):122-124. doi.org/10.1002/j.1834-4453.1990.tb00242.x

Hiscock, P. 1999. Holocene coastal occupation of western Arnhem Land. In J. Hall and I. McNiven (eds), Australian Coastal Archaeology, pp. 91-103. Research Papers in Archaeology and Natural History 31. ANH Publications, The Australian National University, Canberra.

Hiscock, P., F. Mowat and D. Guse 1992. Settlement patterns in the Kakadu wetlands: Initial data on site size and shape. Australian Aboriginal Studies 2:84-89.

Hope, G.S., P.J. Hughes and J. Russell-Smith 1985. Geomorphological fieldwork and the evolution of the landscape of Kakadu National Park. In R. Jones (ed.), Archaeological Research in Kakadu National Park, pp. 229-240. Special Publication 13. Australian National Parks and Wildlife Service, Canberra.

Johnson, I. and R. Jones 1985. Fieldwork methods. In R. Jones (ed.) Archaeological Research in Kakadu National Park, pp. 31-37. Special Publication 13. Australian National Parks and Wildlife Service, Canberra.

Jones, R. 1969. Fire-stick farming. Australian Natural History 16:224-228.

Jones, R. (ed.) 1985. Archaeological Research in Kakadu National Park, Special Publication 13. Australian National Parks and Wildlife Service, Canberra.

Jones, R. and T. Negerivich 1985. A review of previous archaeological work. In R. Jones (ed.), Archaeological Research in Kakadu National Park, Special Publication 13, pp. 1-16. Australian National Parks and Wildlife Service, Canberra.

Jones, R., T. Osborn and K. Briffa 2001. The evolution of climate over the last millennium. Science 292:662-667. doi.org/10.1126/science.1059126 
Kamminga, J. and H. Allen 1973. Alligator Rivers Environmental Fact-Finding Study: Report of the Archaeological Survey. Government Printer, Darwin.

Keen, I. 1980. The Alligator Rivers Stage II Land Claim. Unpublished report for the Northern Land Council, Darwin.

Lambeck, K. and J. Chappell 2001. Sea level change through the last glacial cycle. Science 292:679-686. doi.org/10.1126/science.1059549

Layton, R. 1981. Statement on the Alligator Rivers Stage Two land Claim: (1) Traditional Foraging and Camping Patterns; (2) Rock Paintings. Unpublished report for the Northern Land Council, Darwin.

Lees, B.G. 1992. Geomorphological evidence for late Holocene climatic change in northern Australia. Australian Geographer 23(1):1-10. doi.org/10.1080/00049189208703048

Lewis, D. 1988. The Rock Paintings of Arnhem Land, Australia: Social, Ecological and Material Culture Change in the Post-Glacial Period. British Archaeological Reports International Series 415, Oxford.

Lowe, K.M., L. Wallis, C. Pardoe, B. Marwick, C. Clarkson, T. Manne, M. Smith and R. Fullagar 2014. Ground-penetrating radar and burial practices in western Arnhem Land, Australia. Archaeology in Oceania 49:148-157. doi.org/10.1002/arco.5039

May, S. 2008. Learning art, learning culture: Art, education, and the formation of new artistic identities in Arnhem Land, Australia. In I. Domingo Sanz, S. May and D. Fiore (eds), Archaeologies of Art: Time, Place and Identity, pp. 171-194. Left Coast Press, Walnut Creek.

May, S., P.S.C. Taçon, M. Travers and D. Guse 2010. Painting history: Indigenous observations and depictions of the 'other' in far north Australia. Australian Archaeology 71:57-65. doi.org/10.1080/03 122417.2010.11689384

May, S.K., D. Wesley, J. Goldhahn, M. Litster and B. Manera 2017. Symbols of power: The firearm paintings of Madjedbebe (Malakunanja II). International Journal of Historical Archaeology 21:690-707. doi.org/10.1007/s10761-017-0393-6

Meehan, B., S. Brockwell, J. Allen and R. Jones 1985. The wetland sites. In R. Jones (ed.), Archaeological Research in Kakadu National Park, pp. 103-153. Special Publication 13. Australia National Parks and Wildlife Service, Canberra.

Morley, A.W. 1979. Aboriginal Site Survey of the Jabiluka Project Area. Unpublished Report for Pancontinental Mining Limited, Darwin.

Morley, A.W. and D.W. Lovett 1980. Aboriginal Site Survey of the Jabiluka Project Area. Unpublished report for Pancontinental Mining Limited, Environment Division, Jabiluka Division, Darwin.

Nelson, E. (ed.) 2000. The Beeswax Art of Northern Australia. Simon Fraser University, Burnaby.

Roberts, R.G and R. Jones 1994. Luminescence dating of sediments: New light on human colonization of Australia. Australian Aboriginal Studies 2:2-17.

Roberts, R.G., R. Jones and M.A. Smith 1990a. Thermoluminescence dating of a 50,000-year-old human occupation site in northern Australia. Nature 345:153-156. doi.org/10.1038/345153a0

Roberts, R.G., R. Jones and M.A. Smith 1990b. Early dates at Malakunanja II, a reply to Bowdler. Australian Archaeology 31:94-97.

Roberts, R.G., R. Jones and M.A. Smith 1990c. Stratigraphy and statistics at Malakunanja II: reply to Hiscock. Archaeology in Oceania 25:125-129. doi.org/10.1002/j.1834-4453.1990.tb00243.x 
Roberts, R., H. Yoshida, R. Galbraith, G. Laslett, R. Jones and M. Smith 1998. Single-aliquot and single-grain optical dating confirm thermoluminescence age estimates at Malakunanja II rock shelter in northern Australia. Ancient TL 16:19-24.

Russell-Smith, J., D. Lucas, M. Gapindi, B. Gunbunuka, N. Kapirigi, G. Namingum, K. Lucas, P. Giuliani and G. Chaloupka 1997. Aboriginal resource utilization and fire management practice in western Arnhem Land, monsoonal northern Australia: Notes for prehistory, lessons for the future. Human Ecology 25(2):159-195. doi.org/10.1023/A:1021970021670

Schrire, C. 1982. The Alligator Rivers: Prehistory and Ecology in Western Arnhem Land. Terra Australis 7. The Australian National University, Canberra.

Taçon, P.S.C. 1989. From Rainbow Snakes to 'X-Ray’ Fish: The Nature of the Recent Rock Painting Tradition of Western Arnhem Land, Australia. Unpublished PhD thesis. The Australian National University, Canberra.

Taçon, P.S.C. and S. Brockwell 1995. Arnhem Land prehistory in landscape, stone and paint. Antiquity 69:676-695. doi.org/10.1017/S0003598X00082272

Taçon, P.S.C., E. Nelson, C. Chippindale and G. Chaloupka 2004. The beeswax rock art of the Northern Territory: Direct dating results and a 'book of record'. Rock Art Research 21(2):155-160.

Taçon, P.S.C., S.K. May, S. Fallon, M. Travers, D. Guse and R. Lamilami 2010. A minimum age for early depictions of Macassan praus in the rock art of Arnhem Land, Northern Territory. Australian Archaeology 71:1-10. doi.org/10.1080/03122417.2010.11689379

Taylor, L. 1996. Seeing the Inside: Bark Painting in Western Arnhem Land. Clarendon Press, Oxford.

Wesley, D., T. Jones, S. O'Connor, J. Fenner and W. Dickinson 2014. Earthenware of Malarak, Anuru Bay: A reassessment of potsherds from a Macassan trepang processing site, Arnhem Land, Australia, and implications for Macassan trade and the trepang industry. Australian Archaeology 79:14-25. doi.org/10.1080/03122417.2014.11682015

White, C. 1967a. Plateau and Plain. Prehistoric Investigations in Arnhem Land, Northern Territory. Unpublished PhD thesis, The Australian National University, Canberra.

White, C. 1967b. The prehistory of the Kakadu People. Mankind 6:426-431.

White, C. 1967c. Early stone axes in Arnhem Land. Antiquity 41:149-152. doi.org/10.1017/ S0003598X00112839

White, C. 1971. Man and environment in northwest Arnhem Land. In D.J. Mulvaney and J. Golson (eds), Aboriginal Man and Environment in Australia, pp. 141-57. Australian National University Press, Canberra.

Woodroffe, C.D., J. Chappell and B. Thom 1988. Shell middens in the context of estuarine development, South Alligator River, Northern Territory. Archaeology in Oceania 23:95-103. doi.org/10.1002/j.1834-4453.1988.tb00196.x

Woodroffe, C.D., J. Chappell, B. Thom and E. Wallensky 1989. Depositional model of a macrotidal estuary and floodplain, South Alligator River, northern Australia. Sedimentology 36:737-756. doi.org/10.1111/j.1365-3091.1989.tb01743.x 



\section{Dynamic Figures of Mirarr Country: Chaloupka's four-phase theory and the question of variability within a rock art style}

Iain G. Johnston, Joakim Goldhahn and Sally K. May

\section{Introduction}

This chapter highlights the concept of 'style' within rock art research in relation to Dynamic Figure rock art found in western Arnhem Land, Australia (Figure 6.1). Our aim is to reassess George Chaloupka's four-phase chronology for this art style. The data for this revision are 155 Dynamic Figure paintings, documented through our ongoing fieldwork in Mirarr Country as part of the Mirarr Gunwarddebim (Rock Art) Project.

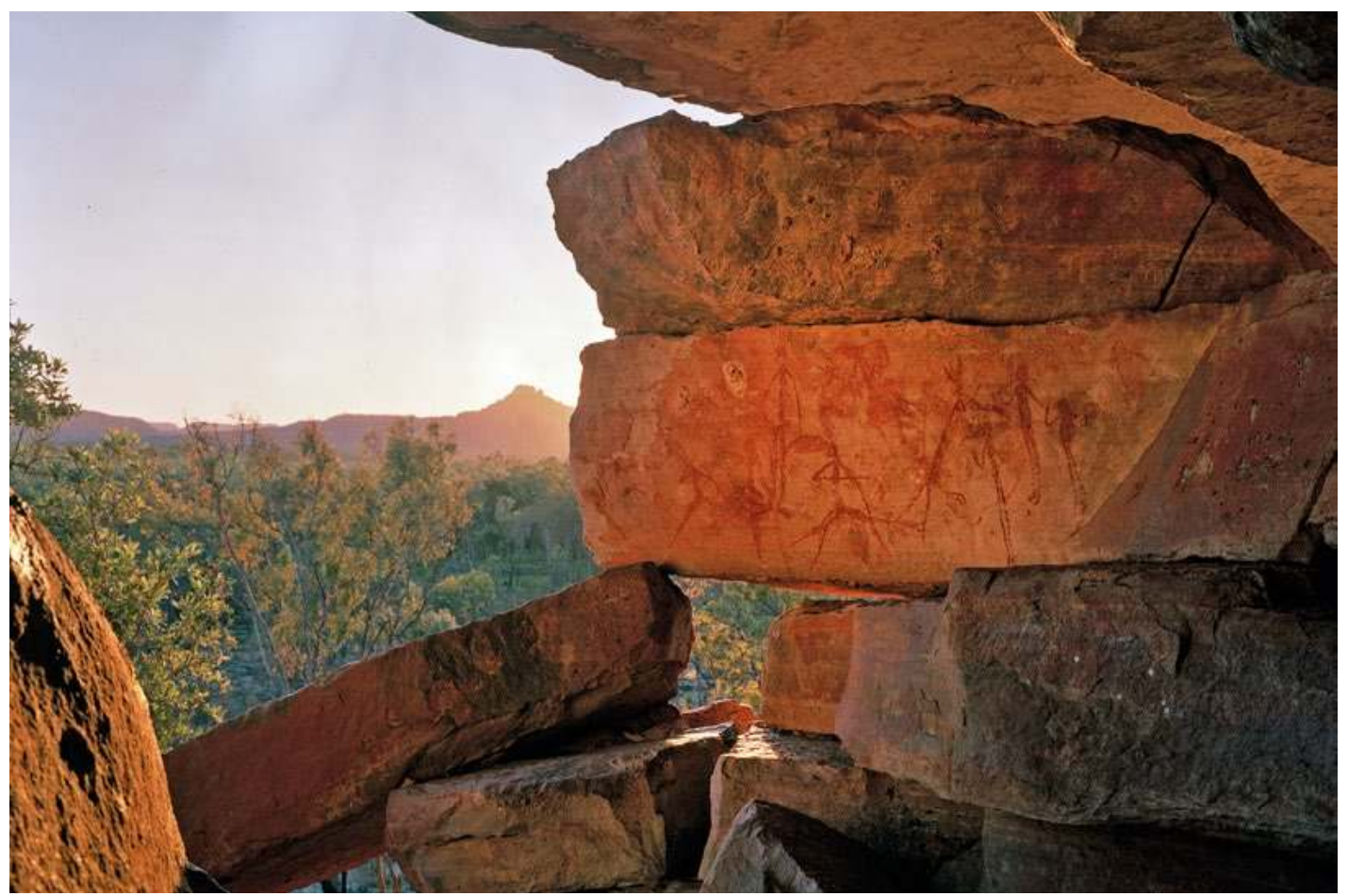

Figure 6.1 Dynamic Figures scene from Mirarr Country. Source: Photograph by Matthew Abbott. 
Throughout his life, Chaloupka sought to document rock art across western Arnhem Land, amassing a remarkable collection of site recordings, ethnographic records and vast general knowledge relating to this region's rock art. His work spanned decades, and his publications, particularly Journey in Time (Chaloupka 1993a), helped to promote the importance of this body of art, both within Australia and internationally, arguing that it is the world's longest continuing art tradition. Chaloupka considered Dynamic Figures to be 'the most vital and exciting paintings of the region's long art sequence' (Chaloupka 1993a:106). While in this chapter we critique his work, we do so with the utmost respect for his pioneering achievements.

Chaloupka took his investigations of Dynamic Figures one step further than any other rock art style he wrote about. He attempted to develop an internal chronology within the Dynamic Figure style, following his observation that 'at first [Dynamic Figures] seem to be a homogenous body of art, but several well defined subgroups can be identified' (Chaloupka 1993a:106). In this chapter, we focus on Chaloupka's attempt to define chronological subgroups among Dynamic Figures, a difficult but crucial undertaking that identified significant attributes of the style and facilitated similar future studies. We explore the theories motivating such a process and, based on our analysis of Mirarr rock art, we discuss newly identified problems with Chaloupka's proposal.

The results of our analysis show few correlations between Mirarr Country Dynamic Figures and Chaloupka's four-phase chronology. We present evidence for a lack of distinct differences between his phases, for example by showing that a large percentage of images and scenes within the overall assemblage bear traits that belong to more than one phase. Our work suggests that variability within Dynamic Figure art is more representative of motivations unrelated to chronology, and we argue that such variability should thus be interpreted in other ways.

\section{Style and chronology in Arnhem Land rock art research}

The concept of 'style' was introduced to rock art research as a typological tool during the early 20th century (Francis 2001). In many ways, this was a result of increased and more systematic fieldwork that demonstrated the immense variation of rock art traditions in different parts of the world. At first, the concept of 'style' was used to distinguish particular rock art traditions from each other, such as Palaeolithic versus post-Palaeolithic rock art in southern Europe (e.g. Breuil 1920), or differences between 'hunter-gatherer' and 'farmer' rock art in northern Europe (e.g. Almgren 1927, 1934; Gjessing 1936, 1939). Soon after, the notion of style came to be used to construct chronological phases within specific rock art traditions (e.g. Althin 1945; Anati 1976; Breuil 1952, 1955-1975; Gjessing 1936; Glob 1969; Hallström 1938; Leroi-Gourhan 1967; Marstrander 1963). In this context, 'style' came to be used as the kind of analytical tool that is still prominent today (Francis 2001; Sanz and Fiore 2014).

Even though the concept of 'style' has been widely debated within archaeology, material culture studies and social anthropology (e.g. Carr and Neitzel 1995; Conkey and Hastorf 1990; Hodder 1982; Layton 1991), most rock art researchers have been reasonably conservative in their efforts to challenge the concept (Francis 2001). We also find some general differences in how the notion of 'style' has been formulated by rock art researchers belonging to different schools of thought. In traditional culture-historical approaches to archaeology (Trigger 1989), stylistic change within a corpus of rock art was generally treated as indicative of chronological change (e.g. Breuil 1952; Hallström 1938), an approach that continues to linger in some rock art research. Changes in thinking since the 1960s in particular have led to a number of new approaches. For example, Conkey (e.g. Conkey and Hastorf 1990) argued that 'style' should not be seen as indicating peoples, chronological phases or the like, but rather as a context of doing things. In the late 1970s and early 1980s, a strong intellectual movement away from treating style from an etic perspective 
as passive adaption to environmental conditions (e.g. Binford 1972) saw the emergence of style as active, emic social engagements. In these latter formulations, the notion of style came to feature in more conscious social and ideological uses of material culture through the notion of 'symbols in action' (e.g. Hodder 1982). The latter has often been discussed in relation to theories of information exchange, with deep roots in various forms of structuralism (e.g. Wobst 1977; see also Clegg 1977; Conkey 2001; Leroi-Gourhan 1967; Lewis-Williams 2002; McDonald 2008; Nordbladh 1978; Smith 1989; Taylor 1996; Tilley 1991).

From an etic, formalistic perspective, there are several reasons to rethink the 'style' concept in rock art research. When direct accelerator mass spectrometry (AMS) radiocarbon dating of rock art was introduced in the 1980s, researchers rapidly showed that what had been thought of as established rock art chronologies born of stylistic criteria now had to be reconsidered (e.g. Lorblanchet and Bahn 1993). While there were some agreements between the established chronologies and the new absolute dates, there were also numerous differences. One possible reason for such inaccuracies is that already-present images influence the creation of new art, a phenomenon that is evident in both past and contemporary artworks in western Arnhem Land (see May 2008; Taylor 1996).

Moreover, Chippindale and Taçon (1993) have shown that sometimes it is only a fraction of the rock art images of a given region that fall within proposed stylistic criteria. In their work at Mt Brockman and Twin Falls in western Arnhem Land, only 35 per cent and 18 per cent, respectively, of the rock art figures could be placed within existing chronological frameworks, leaving the majority of the art undefined and unaccounted for (Chippindale and Taçon 1993:38, 48-56, Tables 1 and 2). This led them to abandon the use of the term 'style' when describing rock art, using the expression 'manner of depiction' instead (Chippindale and Taçon 1993:36).

There are also reasons to challenge the 'style' concept from an exclusively emic perspective. Studies of material culture within anthropology have listed more than 150 reasons why stylistic differentiation will appear (Roe 1995; see also Layton 1991); chronology is only one of these reasons. In this context, the recent history of making rock art in western Arnhem Land is instructive. Here, particular stylistic traits are shown to be the result of specific individuals or artistic groups working closely together (e.g. Taylor 1996). A telling example is the life, work and legacy of Najombolmi, a Narwagite man born around 1895 within what is today Kakadu National Park. Najombolmi is often recognised as one of the last great rock artists of western Arnhem Land (Chaloupka 1993a; Haskovec and Sullivan 1989; Taçon and Chippindale 2001b). There are more than 600 rock paintings attributed to him. These paintings are found over an area of $1800 \mathrm{~km}^{2}$, stretching over the territories of several languages groups, including at least six recognised clans (Haskovec and Sullivan 1989:62). Seen from an etic, Eurocentric perspective, the distinctive individual style of Najombomi's artworks, characterised as 'decorative X-ray' by Chaloupka (1993a), could easily have been classified as its own art style or sub-style within a larger corpus of rock art (cf. Taçon 1987, 1989). This raises questions not only about what the notion of 'style' represents per se, but also how it is defined and used in rock art research more generally.

Despite these concerns, 'style' is still used as a basic concept when creating rock art chronologies. One reason for this can be found in the widely recognised problem of dating rock art. Notwithstanding advances in dating techniques, many, if not most, rock art chronologies still continue to be built following a stylistic logic first formulated and introduced in rock art research in the early 20th century (Francis 2001), albeit with new theoretical perspectives (e.g. Sanz 2012; Sanz and Fiore 2014; Smith 2008). Rock art chronologies of western Arnhem Land are no exception to this trend. 
The manifold artistic assemblage of western Arnhem Land rock art is indeed overwhelming. Based on its diversity and density, researchers have been able to distinguish at least 11 overarching rock art styles by which to create rock art sequences and chronologies (e.g. Brandl 1982; Chaloupka 1984b, 1993a, 1993b; Chippindale and Taçon 1998; Lewis 1988; Taçon and Chippindale 1994).

Many of these chronologies have been developed from sequences created at key sites and then tested, to various degrees, more widely across the region (e.g. Chaloupka 1977; Chippindale and Taçon 1993; Haskovec 1992). Chaloupka's chronological model was mainly based on superimpositions observed in the rock art of Mt Gilruth and extended via data obtained from his more widespread surveys, the most detailed of which came from Deaf Adder Gorge and Mt Brockman (Chaloupka 1977, 1984a, 1984b). His observed patterns of superimposition among specific rock art faunal motifs were later related to what environmental researchers had identified as regional environmental changes (Chaloupka 1984a, 1993a, 1993b). His resulting chronology consists of three environmental periods, Pre-Estuarine, Estuarine and Freshwater, followed by so-called Contact rock art. The PreEstuarine period, which is the main focus of this article, consists of seven styles, which from oldest to most recent read in the following chronological order: Object Prints, Large Naturalistic Figures Complex, Dynamic Figures, Post-Dynamic Figures, Simple Figures with Boomerangs, Mountford Figures and Yam Figures (Chaloupka 1993a:89).

In contrast, Lewis's (1988) chronology is largely constructed from observations of technological changes in depicted material culture, principally spearthrowers, but other material culture associated with different styles and regions were considered as well. Even though some differences are noticeable between Chaloupka's and Lewis's chronological models, their main sequences both hold Dynamic Figures in a similar position as the first substantial group of depicted human figures with distinct items of material culture (May et al. 2017).

\section{Definition, distribution and chronology}

Brandl (1982:169, 172-173) was the first researcher to identify Dynamic Figures, which he described as 'early' Mimi art, as a specific, chronologically meaningful rock art style for western Arnhem Land. Various, more detailed definitions of the style now exist, including Chaloupka's (1984b:8) detailed report on Dynamic Figures:

This style consists of small drawings of human figures, anthropomorphs, animals and composite beings, predominately portrayed in animated action. In the depictions of running figures with their wide spread legs, the artist of this style translated the intensity of physical motion into pictorial dynamics.

Chaloupka (1984b:4) understood the notion of 'style' to be both an objective and subjective tool in rock art research:

In my study of the Arnhem Land Plateau rock art I have considered the paintings in a broader perspective, and used style - art's objective, descriptive aspects of constant form and elements, and the subjective, evaluative aspects of qualities and expressions, as the most important factors in its analysis. It is by identifying individual styles and by arranging them in chronological sequence that a meaningful division in a body of art can be achieved, and it is only then that other forms of analysis can be used.

It follows that Chaloupka viewed the concept of style from an etic perspective, and first and foremost as a chronological tool within rock art research, something that we will try to reconsider through our case study from Mirarr Country. 
The current known distribution of Dynamic Figure art falls within an area that measures northsouth about $180 \mathrm{~km}$ in length and east-west $200 \mathrm{~km}$ in width, stretching from the Cadell and Mann rivers in the east to the outliers of the Arnhem Land escarpment to the west, and from the Wellington Ranges in the north to Birdie Creek in the south (Chaloupka 1984b, 1993; Chippindale et al. 2000:66, Figure 1; cf. Gunn and Whear 2007; May et al. 2017).

Dynamic Figures have received more attention than any other style, arguably because of their regional distribution, complexity and quality of depiction and their apparently key role for understanding how the rock art of western Arnhem Land has changed over time (Chaloupka 1984b, 1988, 1993a, 1993b; Chippindale et al. 2000; Gunn and Whear 2007; Haskovec 1992; Lewis 1997; Taçon and Chippindale 2001a). At the moment, no direct dating exists for the earliest styles of rock art in western Arnhem Land. That said, researchers broadly agree on the relatively early position of Dynamic Figures in western Arnhem Land rock art sequences (Brandl 1982; Chaloupka 1977, 1984b, 1993a; Chippindale and Taçon 1993, 1998; Haskovec 1992; Lewis 1988; Taçon and Chippindale 1994). These chronologies propose that Dynamic Figures form the first substantial collection of depicted humanoid figures to feature in recognised rock art styles, and contain the first explicit scenes, providing unparalleled opportunities to understand aspects of the cultures that produced them.

Chaloupka is the only researcher who has established an internal sequence for Dynamic Figures, a chronology based on variations in the ways anthropomorphs were depicted and for which he proposed four distinct temporal phases (Chaloupka 1993a:106). These phases are defined in relation to how they vary from the second phase, which he named Classical Dynamic Figures (Figure 6.2):

The first representations of this style are considered larger than the following, classical dynamics when the figures attained the maximum of visual movement. In a third phase the bodies of the male figures became stockier, their arms lost their musculature and became one-line thick as did the associated boomerangs. That the stylistic variation was also expressed for some time is suggested by differentially weathered superimpositions. The final figures in this phase are fully composed of dots (Chaloupka 1993b:93).

Chaloupka's suggested chronology was built on stylistic differences within the corpus of Dynamic Figures. His analysis takes in evidence from at least 250 sites (Chaloupka 1984b:8), although he notes knowing of 350 sites (Chaloupka 1993a:106, 1993b:92-95). Even though his general rock art chronology from western Arnhem Land has been, to some extent, reviewed and revised by subsequent researchers (e.g. Chippindale and Taçon 1993, 1998; Haskovec 1992; Lewis 1988; Taçon and Chippindale 1994), so far Chaloupka’s four-phase chronology for Dynamic Figures has not been subject to any critical assessment.

Chaloupka did not provide specific examples and descriptions of each of his four phases. As a result, his classification and identification is to some degree problematic. However, based on his published and unpublished reports, we have ascertained the key aspects of classification for Chaloupka's Dynamic Figure phases (Figure 6.2).

In summary, Phase 1 images are described as the largest Dynamic Figures, with similarities to the Phase 2 'Classical Dynamic Figures'. Classical Dynamic Figures are described as expressing the most exaggerated 'movement' among all Dynamic Figures; these figures are smaller than those of Phase 1. In Phase 3, the depiction of male bodies becomes 'stockier', with arms and legs now expressed as single lines and losing musculature and definition in the process. Finally, Phase 4 are 'pointillistic' figures, with small dots being applied to form an image. This includes dots around the body, and in some cases dots replace solid brush strokes (Chaloupka 1993a:106, 1993b:93; see Figure 6.2). 'Pointillistic' Dynamic Figures are distinctly different from some Dynamic Figures that are depicted with dots around them or emanating from their mouths to indicate intangible aspects of a scene (see Chippindale et al. 2000). 
PHASE 1

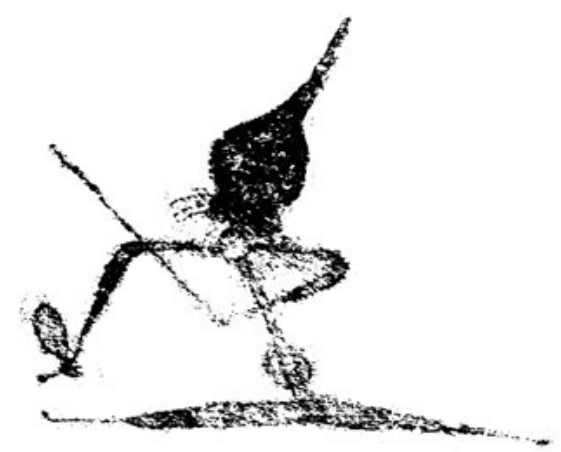

PHASE 3

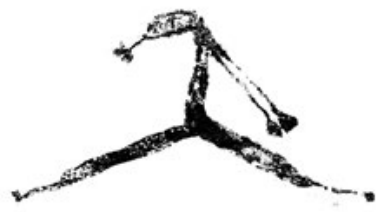

PHASE 2

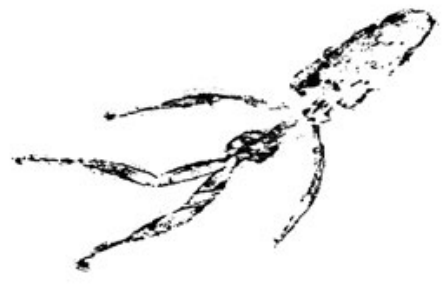

PHASE 4

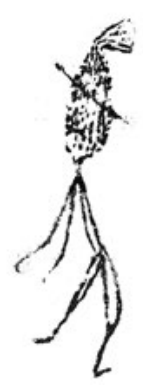

Figure 6.2 Examples of Chaloupka's four phases of Dynamic Figures from Jabiluka, from left to right representing the oldest to youngest phases.

The Phase 4 image does not strictly conform to a 'pointillistic' form but demonstrates the dot-technique; no Dynamic Figure in the Jabiluka study area is formed of dots alone. Not to scale.

Source: Iain Johnston.

The distinction between Phases 1 and 2 is the most problematic, as Chaloupka does not give actual measurements or size parameters for Dynamic Figures associated with each phase. However, as he recorded some sites from the same region as our study area, we were able to re-record these same figures and determine his method of measuring Dynamic Figures. The criteria for determining whether a Dynamic Figure belongs to Phase 3 or Phase 4 are easier to follow, as the determining single-line arm depiction versus dot construction are simple presence/ absence criteria (Figure 6.2).

Another problem with Chaloupka's four-phase chronology is that he does not provide a great deal of evidence for the suggested temporality of Dynamic Figures. In his 1984b report, the most detailed analysis of western Arnhem Land's Dynamic Figures that Chaloupka completed, he mentions 28 sites that show temporal evidence. For example, he notes nine examples of superimposition among Dynamic Figures. Four of these sites (Sites 83, 144, 179, 188) each have larger figures over smaller figures; a further four sites (Sites 13, 192, 233, 234) are simply discussed as having unspecified superimpositions. It is hardly convincing as evidence for a reliable fourphase chronological sequence if many examples exist that contradict the claimed or hypothesised chronology. That said, Site 113 has superimpositions consistent with Phase 2 following Phase 3 , although Chaloupka (1984b) does not describe the superimposition in as much detail as he does with other Dynamic Figure sites. 


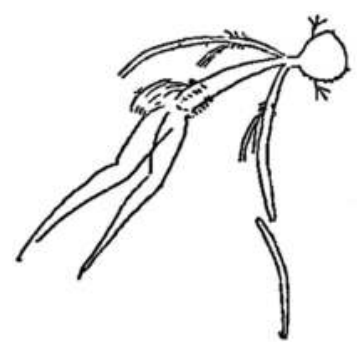

Figure 6.3 Dynamic Figure from Chaloupka's Site 124, described as a later Dynamic Figure but not showing any evidence of dotting and with characteristics more consistent with his earlier phases.

Source: After Chaloupka 1984b:192, courtesy of the Museum and Art Gallery of the Northern Territory.
There are other examples of inconsistencies in his chronological framework - a painting at Site 124 (Figure 6.3) is described as a later Dynamic Figure but it has no example of dotting; according to our understanding, these particular Dynamic Figures are more consistent with his Phase 1 or Phase 2.

Our overall impression of Chaloupka's presented evidence is that there are some contradictions in his suggested Dynamic Figure chronology, which means that the chronology is itself problematic. These problems are further explored below by reference to Dynamic Figures of Mirarr Country.

\section{Research area}

Our team conducted a systematic survey of the Jabiluka Leasehold area (henceforth, Jabiluka) within Mirarr Country between 2012 and 2014. The area is bordered on all sides by the World Heritage-listed Kakadu National Park. Within Jabiluka, the Dynamic Figures recorded for this research come from the Djawumbu-Madjawarrnja complex, which is the largest rock formation within Jabiluka, at approximately $5 \times 2.7 \mathrm{~km}$ in area (including outlying rock formations) (Figure 6.4). As of 2014, we recorded a total of 528 rock art sites within Jabiluka. Ethnographic sources suggest that the Djawumbu-Madjawarna complex was a significant area for cultural activities for several clan/language groups during ethnographic times, including Mirarr, Dadjbaku and Bunidj (Chaloupka 1978; Kamminga and Allen 1973; Layton 1981, cited in Wright et al. 2014). This and further information on the ethnographic evidence for occupation of the Jabiluka area are discussed elsewhere (see Chapters 3 and 5).

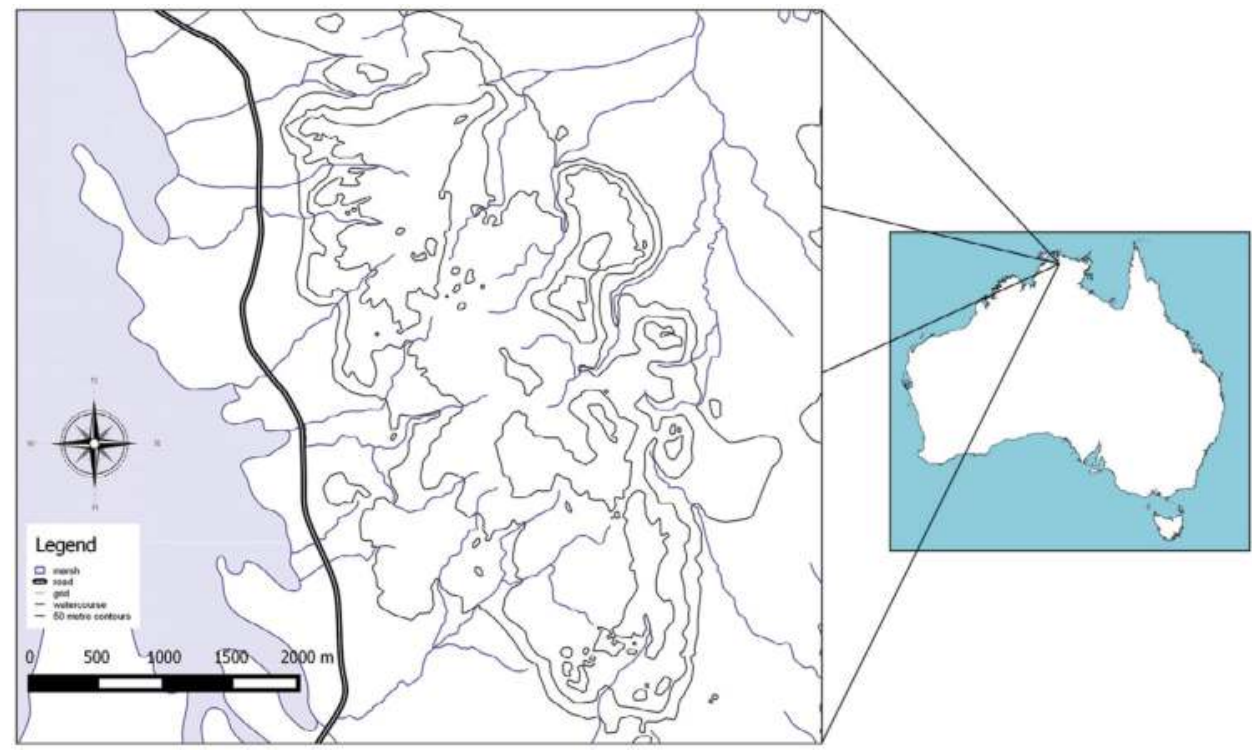

Figure 6.4 Map of the Djawumbu-Madjawarna Massif.

The vast majority of Dynamic Figures analysed were recorded on the eastern and southern rock formations. The Mirarr people have requested that the exact location of sites are not shown.

Source: Map by Phil Davill. 


\section{Survey areas compared}

As already stated above, Chaloupka explains that Dynamic Figures are present at 350 sites recorded in an area $180 \mathrm{~km}$ in length by $200 \mathrm{~km}$ in width, representing much of the western Arnhem Land plateau and surrounds. This area includes unknown numbers of sites with Dynamic Figure animal images, hand stencils of the three middle finger type (3MF) and object stencil sites, which Chaloupka (1993a:106, 1993b) argues were largely contemporaneous with Dynamic Figures (see also Lewis 1988:56-57). Our own survey area consists of a significantly smaller area measuring approximately $5 \times 2.7 \mathrm{~km}$, within which 117 sites with Dynamic Figures, boomerang stencils or $3 \mathrm{MF}$ stencils have been recorded. Leaving aside other, possibly contemporaneous art such as boomerang stencils, our team recorded 33 sites with 155 Dynamic Figure anthropomorphs, some with eight to 10 figures making up single scenes. Whether the high proportion of sites with Dynamic Figures in our study area is due to more thorough and detailed surveying and recording methods used in the Mirarr Gunwarddebim Project, an unusually high density of Dynamic Figures within Jabiluka or for other reasons can only be determined by comparative studies of similarly systematically surveyed areas.

\section{Recording method}

To ensure comprehensive survey coverage, the Jabiluka study area was divided into $500 \times 500 \mathrm{~m}$ survey units. This quadrat grid system was then used to guide the survey work. The survey teams worked systematically through the quadrats, relocating sites that had been previously recorded and documenting previously unrecorded ones. This is a time-consuming process that ensures a certain level of confidence that the majority of sites have been recorded (or re-recorded) and are appropriately documented within each survey quadrat. Once Dynamic Figures were identified at a site, site recording forms were completed and information entered into both the Mirarr data management system and the Dynamic Figure database. The recording and subsequent analysis included attempts to allocate individual Dynamic Figures to Chaloupka's phases.

\section{Analysis}

We now provide an analysis of the Dynamic Figures recorded within Jabiluka in line with the methodology used by Chaloupka to construct his four-phase chronology.

In Table 6.1 we have attempted to categorise the Jabiluka Dynamic Figures into Chaloupka's four phases. This was done to determine the number of Dynamic Figures that actually conformed to the parameters of his phases. Alongside of this, testing Chaloupka's argument that the size of Dynamic Figures relates to their place within the chronology is difficult, as he did not provide exact parameters for size differences between phases. As such, Table 6.2 simply illustrates the average size of anthropomorphs within a scene for both Phases 1 and Phase 2. Phase 2 anthropomorphs were classified as such based on their size similarities to Phases 3 and 4 and their exclusion from Phase 3 and 4 based on other criteria such as single-line arms and 'pointellistic' characteristics. Phase 1 anthropomorphs are the largest remaining examples of Dynamic Figures of the four phases. This is as close as we could come to replicating Chaloupka's impressionistic method of categorisation. 
Table 6.1 Number of individual Dynamic Figures recorded from Mirarr Country by each of Chaloupka's Dynamic Figures phase.

\begin{tabular}{|l|r|}
\hline Chaloupka's Dynamic Figures phases and combined phases & Total \\
\hline Phase 1 & 45 \\
\hline Phase $1 / 2$ & 8 \\
\hline Phase $1 / 3$ & 4 \\
\hline Phase $1 / 3 / 4$ & 13 \\
\hline Phase $1 / 4$ & 7 \\
\hline Phase 2 & 15 \\
\hline Phase 2/3 & 20 \\
\hline Phase 2/3/4 & 4 \\
\hline Phase 2/4 & 7 \\
\hline Phase 3 & 20 \\
\hline Phase 3/4 & 1 \\
\hline Phase 4 & 0 \\
\hline No phase & 11 \\
\hline Total & 155 \\
\hline
\end{tabular}

Source: lain Johnston.

Table 6.2 Average size of Dynamic Figures within a scene that includes both Phase 1 and Phase 2 anthropomorphs.

\begin{tabular}{|c|c|c|c|c|c|c|c|}
\hline $\begin{array}{l}\text { Average size of Dynamic Figures } \\
\text { in scenes (cms) }\end{array}$ & $10-25$ & $25-40$ & $40-55$ & $55-70$ & $70-85$ & $\begin{array}{c}\text { No measurements } \\
\text { recorded }\end{array}$ & Total \\
\hline Phase 1 & & 7 & 5 & 4 & 3 & 3 & 22 \\
\hline Phase 2 & 5 & 7 & & & & & 12 \\
\hline Grand Total & 5 & 14 & 5 & 4 & 3 & 3 & 34 \\
\hline
\end{tabular}

Source: lain Johnston.

Overall, only 52 per cent (80 of the 155 examples) of Dynamic Figures we recorded conform to one or other of Chaloupka's four phases. No Jabiluka Dynamic Figure could be allocated to Phase 4 alone.

In order to explore Chaloupka's idea that the size of Dynamic Figures changed over time, we have analysed the average size of each Dynamic Figure within given scenes. The results presented do not show clear size differentiation between all of Chaloupka’s phases (Table 6.2). Rather, Phase 1 Dynamic Figures are generally of a range of sizes larger than those of the other phases, but other factors may be influencing these findings.

\section{Phases within Mirarr Country}

Only slightly more than half of the Jabiluka Dynamic Figures conform to a single Chaloupka phase (Table 6.1). Moreover, in many instances adjacent anthropomorphs composing individual scenes belong to several of Chaloupka's phases. A large proportion of the Dynamic Figures in our analysis possess distinctive traits belonging to two or more of Chaloupka's phases (Table 6.1). A similar situation of anthropomorphs not conforming to any one style has been noted for western Arnhem Land rock art chronologies in the past (Brandl 1982; Chippindale and Taçon 1993; Lewis 1988). 
Other problems are also evident in each of Chaloupka's four-phase division. The Jabiluka Dynamic Figures show little distinction between Phase 1 and Phase 2 imagery. Chaloupka (1993a:106) explains that Phase 1 consists of large, very finely executed examples of Dynamic Figures compared to Phase 2 images, which are smaller yet equally as detailed and skilfully depicted. If these phases are meaningful as chronological markers, Table 6.2 would need to show a separate clustering of larger figures in Phase 1, with a clear decrease in size into Phase 2 and possibly Phases 3 and 4. It should be noted, however, that Chaloupka never clearly stated whether the decrease in size continued past Phase 2 and on to Phases 3 and 4.

There are other concerns with the Phase 1/Phase 2 division. The three largest scenes of Dynamic Figures from our study area (e.g. Figure 6.5) suggest that the activities depicted in a scene may influence how Dynamic Figures are depicted, indicating that size is a problematic temporal indicator. These three scenes that have the Dynamic Figures in similar positions, with straight legs and stretched out arms, are stylistically very different to each other; the thickness of lines, internal patterns, form of limbs, etc. are dissimilar in each case (see Figure 6.5; Chaloupka 1993a:230, Figure 263). The largest two scenes (Figure 6.5 and Chaloupka 1993a:230, Figure 263) appear to depict cultural activities similar to each other in each scene, further signalling how the activity may influence the size of the images. In each of these two latter scenes, a Dynamic Figure is shown lying down with arms outstretched above its head, while another is crouching over it as it performs some cultural activity over the lying figure.
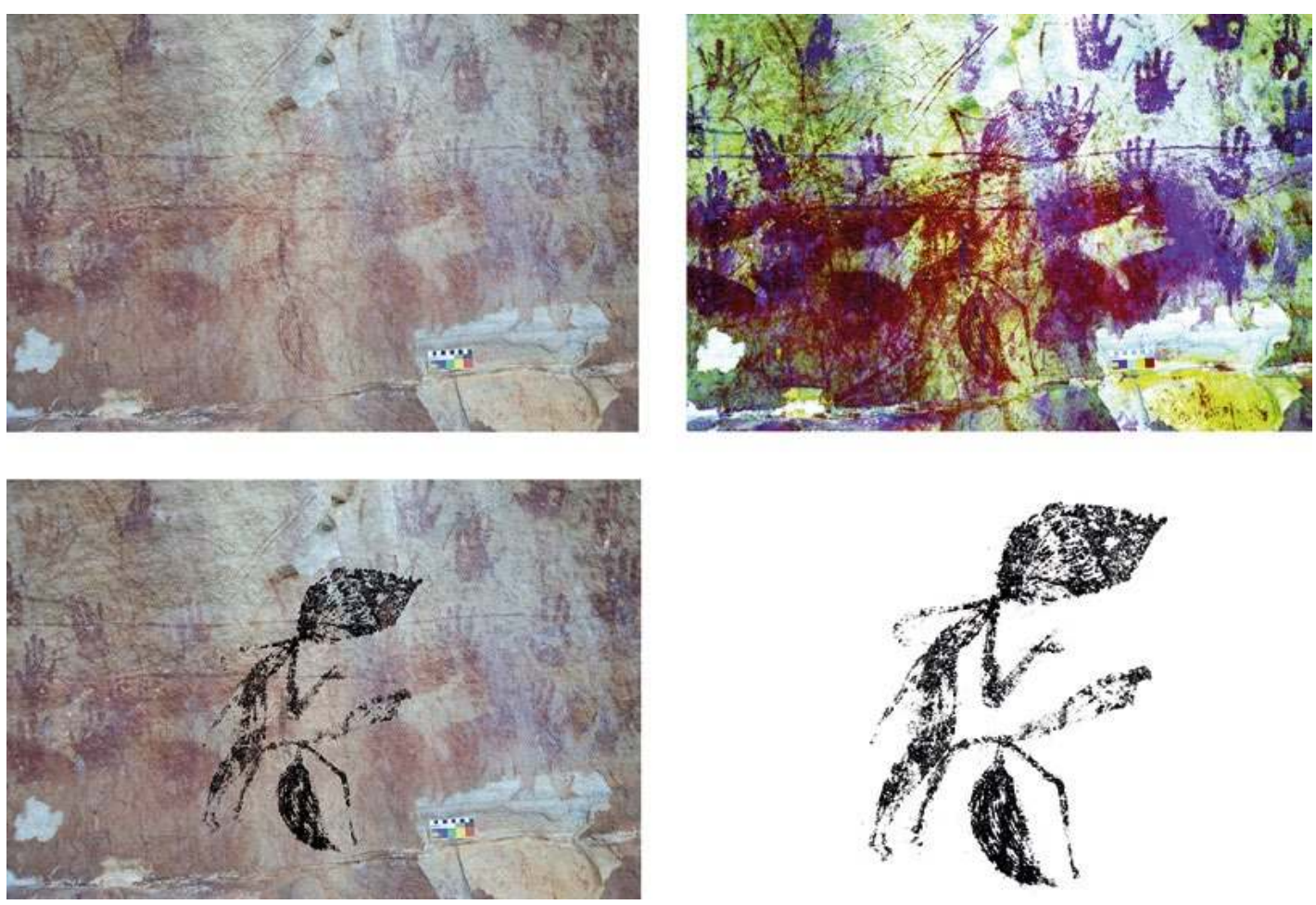

Figure 6.5 The second-largest scene of the Jabiluka Dynamic Figures, depicting what appears to be a similar cultural activity as evident in the largest scene.

Two anthropomorphs are depicted with large headdresses; one Dynamic Figure leans over another, lying figure. Top left: Original photo of panel. Top right: Panel enhanced with D-stretch. Bottom left: Panel with Dynamic Figures traced in black using Photoshop CS6. Bottom right: Traced Dynamic Figures.

Source: Photograph and enhancement by lain Johnston. 
A further issue with using size as a temporal indicator is that, in some scenes, one Dynamic Figure is depicted considerably larger than the others (Figure 6.6). Ultimately, the size of Dynamic Figures more likely relates to preferences of individual artists and artistic groups, or the purpose of the scene and the desire by the artist to emphasise some particular individuals within a scene, rather than to a chronological phase.

The identification of Phase 3 is also problematic. In nine scenes from our research area, each Dynamic Figure has its arms depicted as single-line strokes. It is this single-line convention that characterises the Phase 3 Dynamic Figures (Figure 6.7). However, in six scenes one figure has single-line arms, while other Dynamic Figures in those same scenes have muscular definition in their arms (see Figure 6.6). These are examples of multiphase scenes, a phenomenon that Chaloupka suggests does not exist. Each of these same scenes is stylistically diverse and covers a range of image sizes.

Chaloupka (1993a:106, 1993b:93) specifies that Phase 3 single-line arms are specific to male figures (he does not include indicators for female figures at all in his phases). However, in our study, three of the scenes consist of female figures depicted with single-line arms together with male or non-sexed Dynamic Figures with muscular arms. Furthermore, three scenes depict male and female Dynamic Figures, each with muscular arms. Consequently, the stylistic criteria of the single-line arm is better interpreted as a convention used by specific artists in certain paintings, principally as its infrequency and presence in scenes with muscular arms do not suggest that this convention can be used as a chronological indicator among Dynamic Figures.
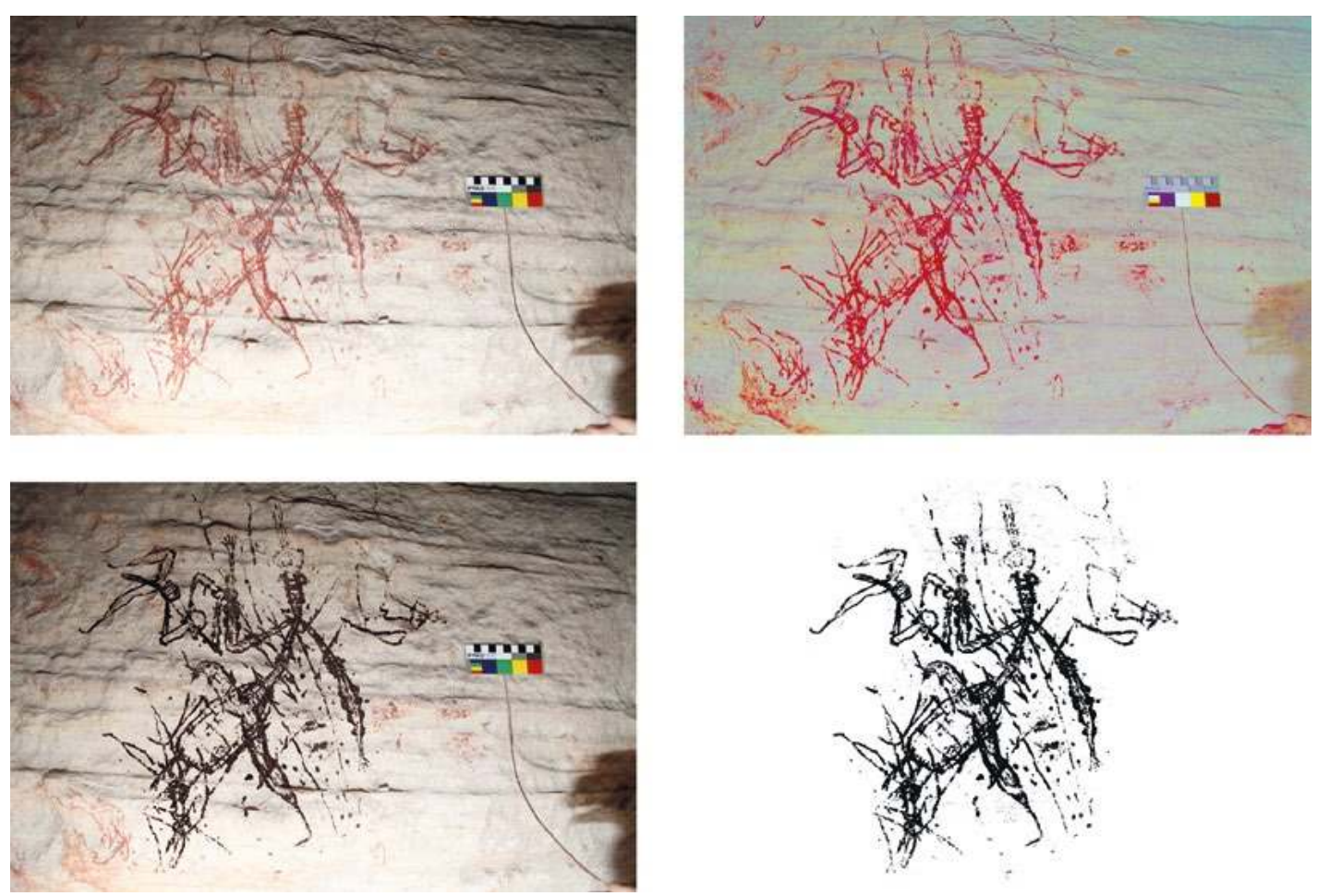

Figure 6.6 The large central Dynamic Figure is depicted in the Phase 1 style running with spears across its body; other Dynamic Figures are below and above it running yet depicted in Phase 3 style, while the Dynamic Figure to the right has Phase 2 muscular arms.

The ensemble of images demonstrates that these image attributes do not signify temporal phases. Top left: Panel. Top right: Panel with colours enhanced with D-stretch. Bottom left: Panel with Dynamic Figures traced in black using Photoshop CS6. Bottom right: Traced Dynamic Figures.

Source: Photographs and tracing by lain Johnston. 
Figure 6.6 demonstrates most clearly the problems associated with Chaloupka's Dynamic Figure phases, as it encompasses attributes of each phase. It consists of one large Dynamic Figure being speared, depicted in great detail, suggesting Phase 1. Around this large figure are three smaller Dynamic Figures, one with muscular definition to its arms and the other two without, suggesting both Phases 2 and 3. Finally, dots are used to provide animation to the scene, an aspect used in all phases, as Chaloupka notes, but particularly in Phase 4 (Chaloupka 1993a:106, 1993b). This scene alone provides enough evidence to debunk the four-phase chronology.
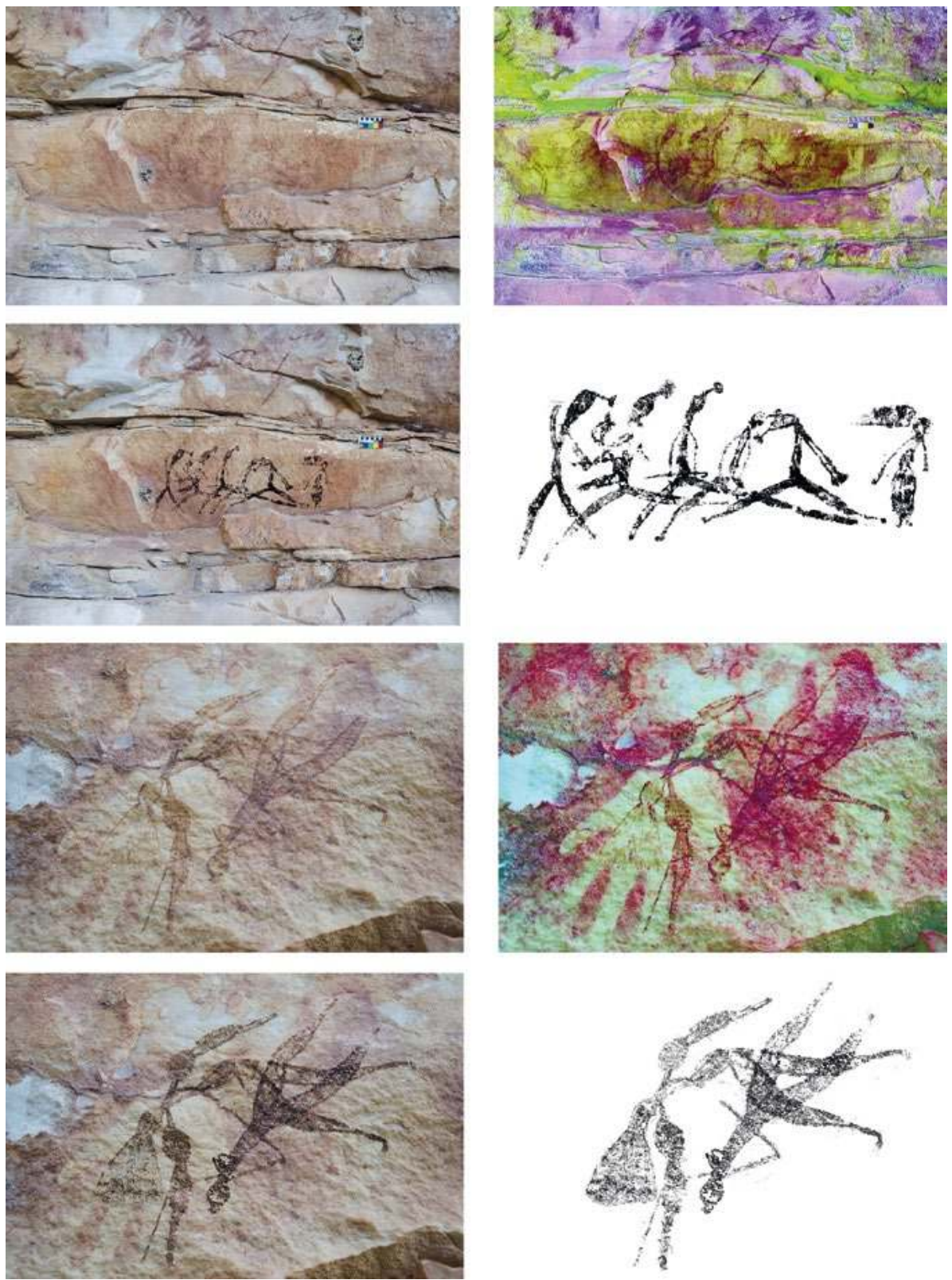

Figure 6.7 Two scenes of Dynamic Figures.

The top set of four images are of a row of six Dynamic Figures all conforming to the Phase 3 convention of single-line arms. Four anthropomorphs are running to the left while the last two are running to the right and standing, respectively. Each Dynamic Figure wears a headdress. The bottom set of four images is of a scene of two Dynamic Figures intertwined with each other, one with muscular arms and a female with single-line arms. For each set of four images: Top left: Panel. Top right: Panel with colours enhanced with D-stretch. Bottom left: Panel with Dynamic Figures traced in black using Photoshop CS6. Bottom right: Traced Dynamic Figures.

Source: Photographs and tracing by lain Johnston. 
No Dynamic Figures from our study area completely conform to Chaloupka's 'pointillistic' fourth phase; that is, no Dynamic Figure has a body constructed of dots. Twenty scenes each have at least one figure with a material culture object constructed of dots, often a headdress or pubic skirt (Figure 6.8). However, these Dynamic Figures are stylistically diverse. Here each Dynamic Figure also exhibits conventions present in the other three phases, such as single-line arms, large sizes and so forth. As Phase 4 proper appears to be absent from the Jabiluka Dynamic Figures, this phase could be restricted to areas away from where we undertook our study, or as we prefer to see it, it is probably a regionally specific artistic convention limited to the Mt Brockman and Deaf Adder Gorge areas rather than a temporal phase.
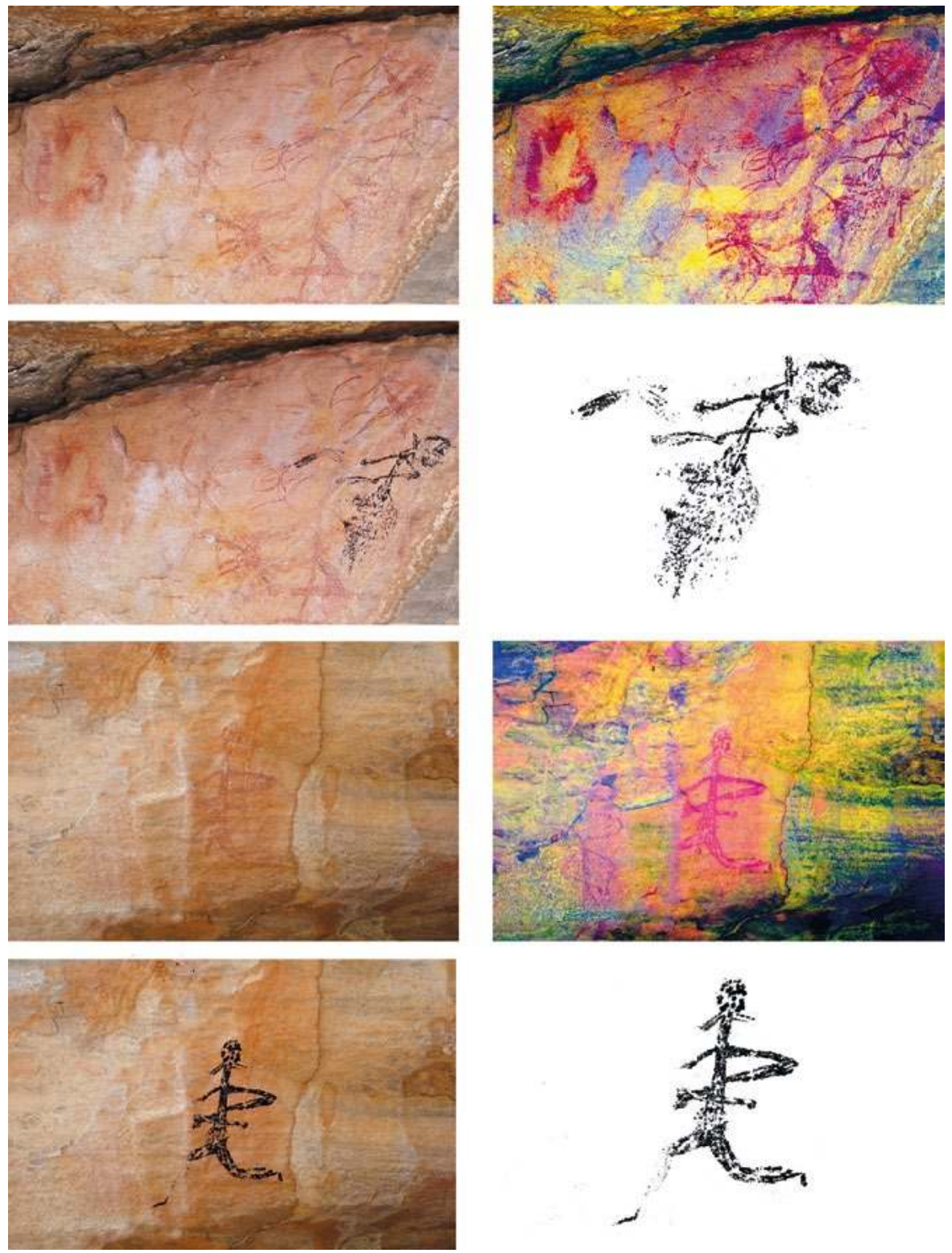

Figure 6.8 Two examples of Dynamic Figures with material culture objects constructed of dots.

The top set of four images of a Dynamic Figure wearing a skirt, holding boomerangs and engaged in a complex activity with other figures and a therianthrope. The bottom set of four images is a running Dynamic Figure with a dot headdress. Such depictions do not match precisely the Phase 4 Dynamic Figures that Chaloupka described, but nonetheless possess the dotting attribute of Phase 4. For each set of four images: Top left: Panel. Top right: Panel with colours enhanced with D-stretch. Bottom left: Panel with Dynamic Figure traced in black using Photoshop CS6. Bottom right: Traced Dynamic Figure.

Source: Photographs and tracings by lain Johnston. 


\section{Discussion and conclusions}

Examination of Jabiluka Dynamic Figures does not support Chaloupka’s four-phase sequence. Our rejection of this sequence implies that his conclusions about changing Aboriginal lifeways for the broader period must also be reconsidered. For example, Chaloupka (1993a:106) suggested that the presence of his four phases within a Dynamic Figures style indicates the long duration of the overall style. While it still may be the case that Dynamic Figures were painted over a long time, the phase evidence cannot be used to support this possibility.

We further suggest that the absence of distinct chronological style phases among Dynamic Figures from our study area in Mirarr Country signals the importance of variability in ways of depicting among individual artists or artistic groups. The size differences between Dynamic Figures within a scene are not directly related to the relative antiquity of those figures, but more likely signal their narrative role (cf. May and Sanz 2010). In short, instead of viewing these stylistic traits from an etic normative perspective, the stylistic pattern that Dynamic Figures do demonstrate could be interpreted as a social and cultural positioning within and between those groups that created the paintings. This situation may not be unique to Dynamic Figure art but is clearly observed because of the quality of painting and skill of the artist(s). Furthermore, the sporadic use of single-line arms may also represent a component of narrative purpose in Dynamic Figure scenes. The ubiquity and uniformity of the convention in certain scenes, and select use in others, visually articulate to viewers messages of formal differentiation within particular social scenarios.

The absence of distinct phases in our study area also requires a reconsideration of Chaloupka's (1993a:106) arguments about the spatial distribution of Dynamic Figures across the western Arnhem Land plateau. The geographical distribution of Dynamic Figures has been used to model past socio-cultural boundaries across Arnhem Land. The contrasting spatial extent of Dynamic Figures relative to later rock art styles has provided a point of departure for theoretical discussions about Aboriginal lifeways through time. Such discussions have often included debate about how changes in the art reflect changing environmental conditions (Chaloupka 1984a, 1988, 1993a, 1993b; Chippindale and Taçon 1998; Lewis 1988; Taçon and Brockwell 1995). Taçon and Chippindale (1994) further discuss changes in artistic scenes where conflict is depicted. They argue that, through time, smaller conflicts make way for large battles, which they see as evidence of changing cultural organisation as the result of changing environmental conditions. Lewis (1988) developed another hypothesis of how the size of cultural boundaries changed over time, based upon the homogeneity of Dynamic Figures, his estimation of their age and the environmental conditions of the period. Our results do not reject any of these conclusions per se, as they are based on different methodologies, but the results of our analysis of Dynamic Figures from the Jabiluka area demonstrate that variation between regions within western Arnhem Land may well exist, something that needs further investigation.

Other results from our analysis suggest that variable conventions practised by individual artists or regional artistic groups may be responsible for spatial and stylistic variations among Dynamic Figures. For example, Chaloupka's Phase 4 appears to be restricted to or concentrated within a specific region. Similarly, individual Dynamic Figure styles also appear to be present within our own study area. For example, the Jabiluka Dynamic Figures have four scenes in which the anthropomorphs have unusually long arms, a trait that, to our knowledge, is not often found elsewhere. Here the arms are often bent and are as long as or longer than the length of the torso and legs combined (Figure 6.9). The Dynamic Figures in these scenes are stylistically similar to each other, although they are differentially weathered. In other words, we have detected some regional variability that may reflect the work of a particular artist or 'school'. Such stylistic variability across space is in line with Haskovec and Sullivan's (1989:73) conclusion in relation to Najombolmi's art: 'a small number of individuals may be responsible for a large proportion of a particular body of art'. 

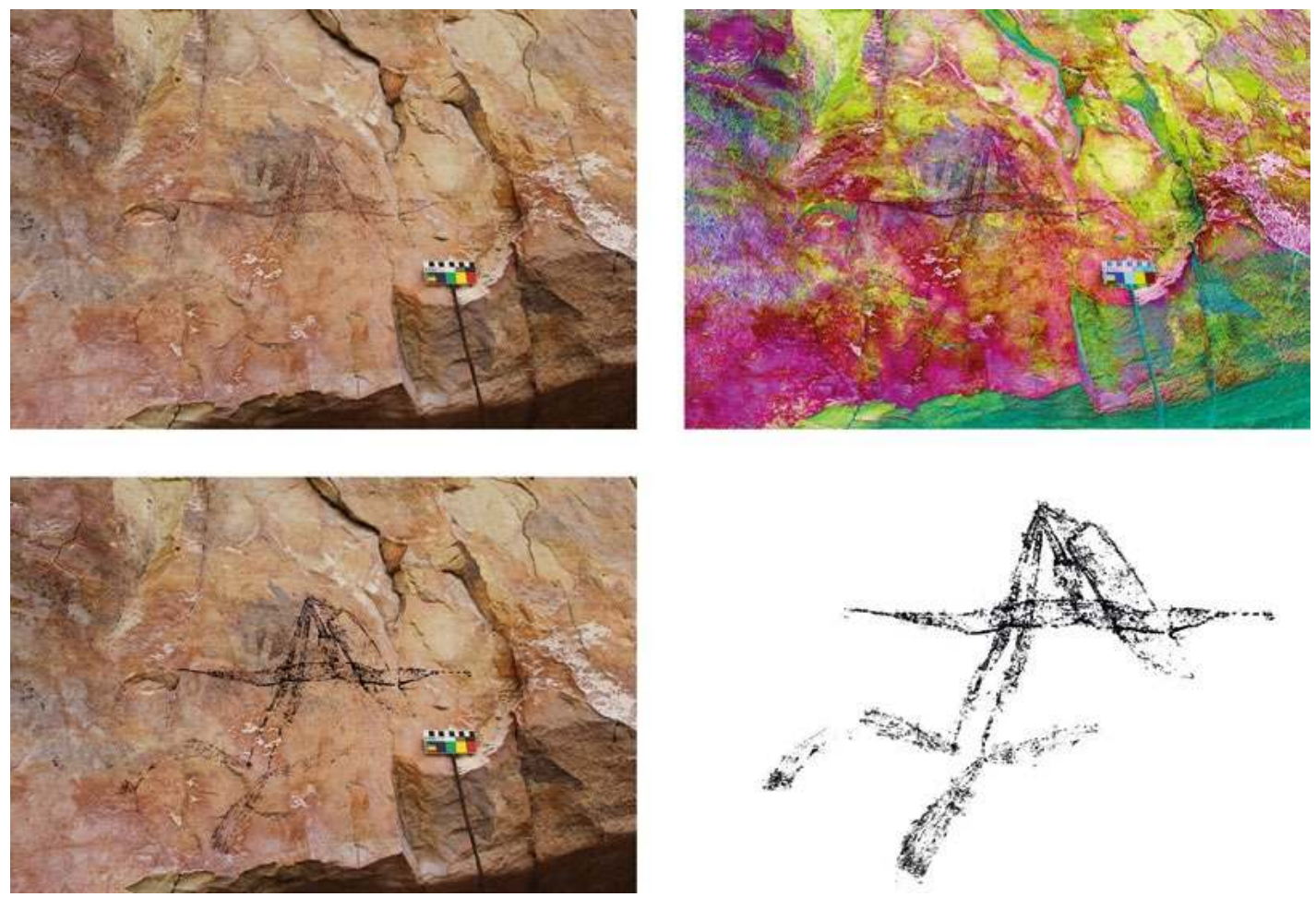

Figure 6.9 A long-arm Dynamic Figure from Mirarr Country.

The anthropomorph is running in a 'splits' pose holding a bunch of boomerangs in both arms bellow its legs. The exceptionally long-arm may be an example of an attribute used by a particular artist or artistic group. Top left: Panel. Top right: Panel with colours enhanced with D-stretch. Bottom left: Panel with Dynamic Figures traced in black using Photoshop CS6. Bottom right: Traced Dynamic Figures.

Source: Photographs and tracing by lain Johnston.

Finally, as Chaloupka notes, Dynamic Figures represent one of the most visually exciting art periods in the Arnhem Land sequence, a body of art crucial for understanding past Aboriginal lifeways. Chaloupka argues that the depiction of Dynamic Figures (and the existence of a fourphase chronology) is uniform across Arnhem Land. Our research has concluded that Chaloupka's four phases are not accurate for the Jabiluka Dynamic Figure assemblage. Therefore, his proposed temporal explanation for stylistic variation must also be rejected. We suggest that Chaloupka's conclusions about relationships between the Dynamic Figure rock art style, temporality and artistic expressions need to be reconsidered.

\section{Acknowledgements}

We thank the Mirarr people and the Gundjeihmi Aboriginal Corporation for working with us on the Mirarr Gunwarddebim Project and, in particular, Yvonne Margarula and Justin O’Brien. We would especially like to thank Paul Taçon, John Hayward and Inés Domingo Sanz who helped to document individual Dynamic Figures. We also thank Darrell Lewis (University of New England) for his review of an earlier version of this paper and Phil Davill for his help with creating maps. Finally, thanks to Bruno David, Paul Taçon and two anonymous reviewers for their detailed feedback on drafts of this chapter. 


\section{References}

Almgren, O. 1927. Hällristningar och Kultbruk. Bidrag till Belysning av de Nordiska Bronsåldersristningarnas Innebörd. KVHAA Handlingar 35, Stockholm.

Almgren, O. 1934. Nordische Felszeichnungen als Religiöse Urkunden. Verlag Moritz Diesterweg, Frankfurt AM.

Althin, C.-A. 1945. Studien zu den Felszichnungen von Skàne I-II. C.W.K. Gleerup, Lund.

Anati, E. 1976. Evolution and Style in Camunian Rock Art. Edizioni del Centro, Capo di Ponte.

Binford, L.R. 1972. An Archaeological Perspective. Seminar Press, New York.

Brandl, E.J. 1982. Australian Aboriginal Paintings in Western and Central Arnhem Land, Temporal Sequences and Elements of Style in Cadell River and Deaf Adder Creek Art. Australian Institute of Aboriginal Studies, Canberra.

Breuil, H. 1920. Les peintures rupestres de la Peninsula Ibérique: Les roches peintes de Minateda (Albacete). L'Anthropologie XXX:1-50.

Breuil, H. 1952. Four Hundred Centuries of Cave Art. Fernand Windels, Montignac.

Breuil, H. 1955-1975. The Rock Paintings of Southern Africa. Trianon Press, Paris.

Carr, C. and J.E. Neitzel (eds) 1995. Style, Society and Person: Archaeological and Ethnological Perspectives. Plenum Press, New York.

Chaloupka, G. 1975. Report on Aboriginal traditional land ownership of the Alligator Rivers Region, Part II. The land-owning groups (clans) and their traditional territories, Unpublished report, Northern Land Council, Darwin.

Chaloupka, G. 1977. Aspects of the chronology and schematisation of two prehistoric sites on the Arnhem Land Plateau. In P.J. Ucko (ed), Form in Indigenous Art: Schematisation in the Art of Aboriginal Australia and Prehistoric Europe, pp. 243-259. Australian Institute of Aboriginal Studies, Canberra.

Chaloupka, G. 1978. Djawumbu-Madjawarnja Site Complex. Unpublished report to the Australian Heritage Commission, Canberra.

Chaloupka, G. 1984a. From Palaeoart to Casual Paintings. The Chronological Sequence of Arnhem Land Plateau. Northern Territory Museum of Arts and Sciences, Darwin.

Chaloupka, G. 1984b. Rock Art of the Arnhem Land Plateau: Paintings of the Dynamic Figures Style. Northern Territory Museum of Arts and Sciences, Darwin.

Chaloupka, G. 1988. Rock Paintings of the Dynamic Figures style, Arnhem Land plateau region, Northern Territory, Australia. Ars Praehistorica VII/VIII:329-339.

Chaloupka, G. 1993a. Journey in Time: The World's Longest Continuing Art Tradition. Reed, Chatswood.

Chaloupka, G. 1993b. You gotta have style. In M. Lorblanchet and P.G. Bahn (eds), Rock Art Studies: The Post-stylistic Era or Where Do We Go from Here? Papers Presented in Symposium A of the 2nd AURA Congress, Cairns 1992, pp. 77-98. Oxbow Monograph 35. Oxbow, Oxford.

Chippindale, C., B. Smith and P.S.C Taçon 2000. Visions of dynamic power: Archaic rock-paintings, altered states of consciousness and 'Clever Men' in western Arnhem Land (NT), Australia. Cambridge Archaeological Journal 10:63-101. doi.org/10.1017/S0959774300000032 
Chippindale, C. and P.S.C. Taçon 1993. Two old painted panels from Kakadu: Variations and sequence in Arnhem Land rock art. In J.A. Steinbring, A. Watchman, P. Faulstich and P.S.C. Taçon (eds), Time and Space: Dating and Spatial Considerations in Rock Art Research, pp. 32-56. Occasional AURA Publication 8, Australian Rock Art Research Association, Melbourne.

Chippindale, C. and P.S.C. Taçon 1998. The many ways of dating Arnhem Land rock-art. In C. Chippindale and P.S.C. Taçon (eds), The Archaeology of Rock-Art, pp. 90-111. Cambridge University Press, Cambridge.

Clegg, J.K. 1977. A method of resolving problems which arise from style in art. In P. Ucko (ed), Form in Indigenous Art: Schematisation in the Art of Aboriginal Australia and Prehistoric Europe, pp. 260-276. Australian Institute of Aboriginal Studies, Canberra.

Conkey, M.W. 2001. Structural and semiotic approaches. In D.S. Whitley (ed.), Handbook of Rock Art Research, pp. 273-310. AltaMira Press, Walnut Creek.

Conkey, M.W. and C.A. Hastorf (eds) 1990. The Uses of Style in Archaeology. Cambridge University Press, Cambridge.

Francis, J.E. 2001. Style and classification. In D.S. Whitley (ed), Handbook of Rock Art Research, pp. 221-244. AltaMira Press, Walnut Creek.

Gjessing, G. 1936. Nordenfjelske Ristninger og Malninger av den Arktiske Gruppe. Instituttet for Sammenlignende Kulturforskning Serie B. XXX, Oslo.

Gjessing, G. 1939. Østfolds Jordbruksristninger. Idd, Berg og delvis Skjeberg. Instituttet for Sammenlignende Kulturforskning Serie B LIII, Oslo.

Glob, P.V. 1969. Helleristninger i Danmark. Jysk Arkæologisk Selskabs Skrifter Bd VII, Odense.

Gunn, R.G. and R.L. Whear 2007. Dynamic sketches: 6000+ year old dry-pigment drawings from Arnhem Land. Archaeology in Oceania 42(1):22-28. doi.org/10.1002/j.1834-4453.2007.tb00011.x

Hallström, G. 1938. Monumental Art of Northern Europe 1: The Norwegian Localities. Thule, Stockholm.

Haskovec, I.P. 1992. Mt. Gilruth revisited. Archaeology in Oceania 27:61-74. doi.org/10.1002/j.18344453.1992.tb00285.x

Haskovec, I.P. and H. Sullivan 1989. Reflections and rejections of an Aboriginal artist. In H. Morphy (ed.), Animals into Art, pp. 57-74. One World Archaeology 7. Unwin Hyman, London.

Hodder, I. 1982. Symbols in Action. Cambridge University Press, Cambridge.

Kamminga, J. and H. Allen 1973. Alligator Rivers Environmental Fact-finding Study: Report of the Archaeological Survey. Government Printer, Darwin.

Layton, R. 1991. The Anthropology of Art. Cambridge University Press, Cambridge.

Leroi-Gourhan, A. 1967. Treasures of Prehistoric Art. H.N. Abrams, New York.

Lewis, D. 1988. The Rock Paintings of Arnhem Land, Australia - Social, Ecological and Material Culture Change in the Post Glacial Period. BAR International Series 415. British Archaeological Reports, Oxford.

Lewis, D. 1997. Bradshaws: The view from Arnhem Land. Australian Archaeology 44:1-16. doi.org/10.1 080/03122417.1997.11681585

Lewis-Williams, D.J. 2002. A Cosmos in Stone: Interpreting Religion and Society through Rock Art. AltaMira Press, Walnut Creek. 
Lorblanchet, M. and P.G. Bahn (eds) 1993. Rock Art Studies: The Post-stylistic Era or Where Do We Go from Here? Papers Presented in Symposium A of the 2nd AURA Congress, Cairns 1992. Oxbow Monograph 35. Oxbow, Oxford.

Marstrander, S. 1963. Østfolds Jordbruksristninger. Skjeberg. Instituttet for Sammenlignende Kulturforskning Serie B LIII, Oslo.

May, S.K. 2008. Learning art, learning culture: Art, education, and the formation of new artistic identities in Arnhem Land, Australia. In I.D. Sanz, D. Fiore and S.K. May (eds), Archaeologies of Art: Time, Place and Identity, pp. 171-194. Left Coast Press, Walnut Creek.

May, S.K. and I.D. Sanz 2010. Making sense of scenes. Rock Art Research 27:35-42.

May, S.K, I. Johnston, P. Taçon, I. Domingo Sanz and J. Goldhahn 2017. Early Australian anthropomorphs: Jabiluka's Dynamic Figure rock paintings. Cambridge Archaeological Journal. doi.org/10.1017/S095977431700052X

McDonald, J. 2008. Dreamtime Superhighway: An Analysis of Sydney Basin and Prehistoric Information Exchange. Terra Australis 27. ANU E Press, Canberra.

Nordbladh, J. 1978. Images as messages in society: Prolegomena to the study of Scandinavian petroglyphs and semiotics. In K. Kristiansen and C. Paludan-Muller (eds), New Directions in Scandinavian Archaeology, pp. 63-78. Denmark National Museum, Copenhagen.

Roe, P.G. 1995. Style, society, myth, and structure. In C. Carr and J.E. Neitzel (eds), Style, Society and Person. Archaeological and Ethnological Perspectives, pp. 27-76. Plenum Press, New York. doi.org/ 10.1007/978-1-4899-1097-4_2

Sanz, I. D. 2012. A theoretical approach to style in Levantine rock art. In J. McDonald and P. Veth (eds), A Companion to Rock Art, pp. 306-322. Blackwell, Oxford. doi.org/10.1002/9781118253892.ch18

Sanz, I.D. and D. Fiore 2014. Style: Its role in the archaeology of art. In C. Smith (ed), Encyclopedia of Global Archaeology, pp. 7104-7111. Springer, New York. doi.org/10.1007/978-1-4419-0465-2_1276

Smith, C. 1989. Designed Dreaming: Assessing the Relationship between Style, Social Structure and Environment in Aboriginal Australia. Unpublished BA (Hons) thesis, University of New England, Armidale.

Smith, C. 2008. Panache and protocol in Australian Aboriginal art. In I.D. Sanz, D. Fiore and S.K. May (eds), Archaeologies of Art: Time, Place and Identity, pp. 215-242. Left Coast Press, Walnut Creek.

Taçon, P.S.C. 1987. Internal-external: A re-evaluation of the 'X-ray' concept in western Arnhem Land rock art. Rock Art Research 4(1):36-50.

Taçon, P.S.C. 1989. From Rainbow Snakes to 'X-Ray' Fish: The Nature of the Recent Rock Painting Tradition of Western Arnhem Land, Australia. Unpublished PhD thesis. The Australian National University, Canberra.

Taçon, P.S.C. and S. Brockwell 1995. Arnhem Land prehistory in landscape, stone and paint. Antiquity 69:676-695. doi.org/10.1017/S0003598X00082272

Taçon, P.S.C. and C. Chippindale 1994. Australiass ancient warriors: Changing depictions of fighting in the rock art of Arnhem Land, N.T. Cambridge Archaeological Journal 4(2):211-248. doi.org/10.1017/ S0959774300001086

Taçon, P.S.C. and C. Chippindale 2001a. Transformation and depictions of the First People: Animalheaded beings of Arnhem Land, N.T., Australia. In K. Helskog (ed), Theoretical Perspectives in Rock Art Research ACRA: The Alta Conference on Rock Art, pp. 175-210. Novus Forlag, Oslo. 
Taçon, P.S.C. and C. Chippindale 2001b. Najombolmi’s people: From rock painting to national icon. In A. Anderson, I. Lilley and S. O'Connor (eds), Histories of Old Ages: Essays in Honour of Rhys Jones, pp. 301-310. Pandanus Books, The Australian National University, Canberra.

Taylor, L. 1996. Seeing the Inside: Bark Painting in Western Arnhem Land. Clarendon Press, Oxford.

Tilley, C. 1991. Material Culture and Text: The Art of Ambiguity. Routledge, London.

Trigger, B.G. 1989. A History of Archaeological Thought. Cambridge University Press, Cambridge.

Wobst, H.M. 1977. Stylistic behavior and information exchange. In E.H. Cleland (ed), For the Director: Research Essays in Honor of James B. Griffen, pp. 317-342. Anthropological Papers 61. University of Michigan Museum of Anthropology, Michigan.

Wright, D., S.K. May, P.S.C. Taçon and B. Stephenson 2014. A scientific study of a new cupule site in Jabiluka, western Arnhem Land. Rock Art Research 31:92-100. 



\title{
How old is X-ray art? Minimum age determinations for early X-ray rock art from the 'Red Lily' (Wulk) Lagoon rock art precinct, western Arnhem Land
}

\author{
Tristen Jones, Vladimir Levchenko and Daryl Wesley
}

\section{Introduction}

A central and fundamental issue in rock art research is where the art is placed in space and time (David et al. 2013). Discovering and applying new techniques to understand motif styles and their chronology will provide us with this information. Here we use a 'cabled' methodology (see Chippindale and Taçon 1998:93), where multiple lines of evidence are developed together, by combining absolute and relative dating techniques. Absolute radiocarbon dates are made on two different substances that have been related with relative dates derived by assessing motif superimpositions, the stylistic analysis of motifs and degrees of preservation. Combined, the absolute and relative methods provide reliable dates for the painted motifs on a rock art panel at Red Lily Lagoon Site 3 (see Figure 2.1). Radiocarbon dates were obtained for mineral accretions suspected to contain the minerals whewellite and whedellite (both are hydrated forms of calcium oxalate $\mathrm{CaC}_{2} \mathrm{O}_{4}$, and called hereafter 'calcium oxalate'), and from preserved non-reactive organics contained within ancient mud wasp nest stumps. This is the first attempt to apply radiocarbon dating to these two different materials, calcium oxalate and mud wasp nests, directly associated with the same rock art.

A combination of radiocarbon dating and optically stimulated luminescence (OSL) dating on mud wasp nests has proved fruitful in dating rock art in the Kimberley (see Roberts et al. 1997). A previous Australian study used radiocarbon determinations for a calcium oxalate crust encasing rockfall within excavated deposits. Those results were compared with radiocarbon ages for charcoal samples in the same stratigraphic units (Watchman et al. 2005). These studies show the potential of both calcium oxalate and mud wasp nests for radiocarbon dating of rock art. While both calcium oxalate and mud wasp nest samples each have limitations for radiocarbon dating (cf. Aubert 2012; Bednarik 1996, 2000, 2002, 2007; David et al. 2013; Gillespie 1997; Rosenfeld and Smith 1997), our study has found that multiple radiocarbon age determinations from these two different substances can together generate robust dates for rock art. 


\section{Red Lily Lagoon Site 3}

Red Lily (Wulk) is a coastal freshwater lagoon within the vast floodplains of the East Alligator River catchment area. The lagoon is found c. $5 \mathrm{~km}$ northeast of Cahill's Crossing on the main Oenpelli Road (Figure 2.1). The region falls within the territory of the Gagudju/Erre/ Mangereridju language group, and forms part of the Manilakarr clan estate. Red Lily Lagoon is bordered on its eastern side by the western Arnhem Land Proterozoic Kombolgie Sandstone massif. This most western section of the plateau converges with Red Lily Lagoon, and the adjacent Kakadu wetlands, as a steep escarpment, varying in elevation from $50 \mathrm{~m}$ to $400 \mathrm{~m}$ above sea level (ASL).

The floodplains that surround the escarpment are annually inundated, re-filling permanent lagoons and billabongs, and at times submersing the majority of the land surface. It is within this landscape that the major archaeological site complex of Red Lily is situated (for a more comprehensive environmental and historical background for Red Lily Lagoon, see Chapter 2).

Red Lily Lagoon Site 3 is situated on top of the plateau at an approximate elevation of $70 \mathrm{~m}$ ASL, $700 \mathrm{~m}$ west of Red Lily Lagoon. The site is a major sandstone rock stack. On all sides of the rock stack, intensive weathering has generated deep overhanging shelters with rock floors, some with shallow sandy deposits, and isolated sandstone boulders. (For a description of the formation of rockshelters in Arnhem Land's quartzitic sandstone stacks, see Chapter 13.)

Each side of the rock stack is reported as a separate section, termed Areas A-D; each is a distinct and major rock art shelter in its own right. As field time was limited, all art panels were mapped, but not all individual motifs recorded. Overall, the Red Lily Site 3 rockshelters contain over 700 rock art images in a range of different art styles. These span the Early, Middle and Late periods outlined in Chippindale and Taçon's regional stylistic chronology (Chippindale and Taçon 1998:107). For example, rock art includes hand and foot stencils, 'Large Naturalistic' figures, Northern Running/Mountford figures, early X-ray and representations of the Complete Figure Style, including stick-figures, simple energetic figures, full figures and recent X-ray figures. There is also European contact-period imagery. Painting methods, forms and pigment types are variable. Motifs range from full-bodied, intricately detailed figurative representations of animals, applied with fine brushwork, to rudimentary-lined human figures. Pigment colours include red, orange, black, white and yellow, with many complex images bichromatic or polychromatic. Notable motifs include four painted in Reckitt's Blue pigment in Area B, and a high number of hand, forearm and foot stencils in Area C. Reckitt's Blue is the commercial name given to a laundry product used to whiten clothing (Chaloupka 1993:84). The use of Reckitt's Blue as a paint was first reported in the Alligator Rivers region in 1912 by Baldwin Spencer (1928:831). Chaloupka (1993:84) suggests that the blue pigment found widespread use after the introduction of Reckitt's Blue by Oenpelli missionaries in 1925.

The panel here studied is in Area D (Figure 7.1). Area D consists of three panels, with Panel 2 containing the majority of rock art images. The rock wall surface, facing northwest, measures $6 \mathrm{~m}$ in width by $1.2 \mathrm{~m}$ in height. The rock surface is well sheltered from the elements, with the dripline more than $1 \mathrm{~m}$ from the panel surface. However, the condition of the panel is quite poor: it is affected by both mud wasp nests and termites; mineral crusts and some parts of the rock face are spalling. The recording team perceive about 40 highly weathered rock paintings, some superimposed on the rock wall. Nonetheless, some images, and a basic sequence of superimposition of the clearest motifs on the rock wall, can be deciphered (Figure 7.2). 


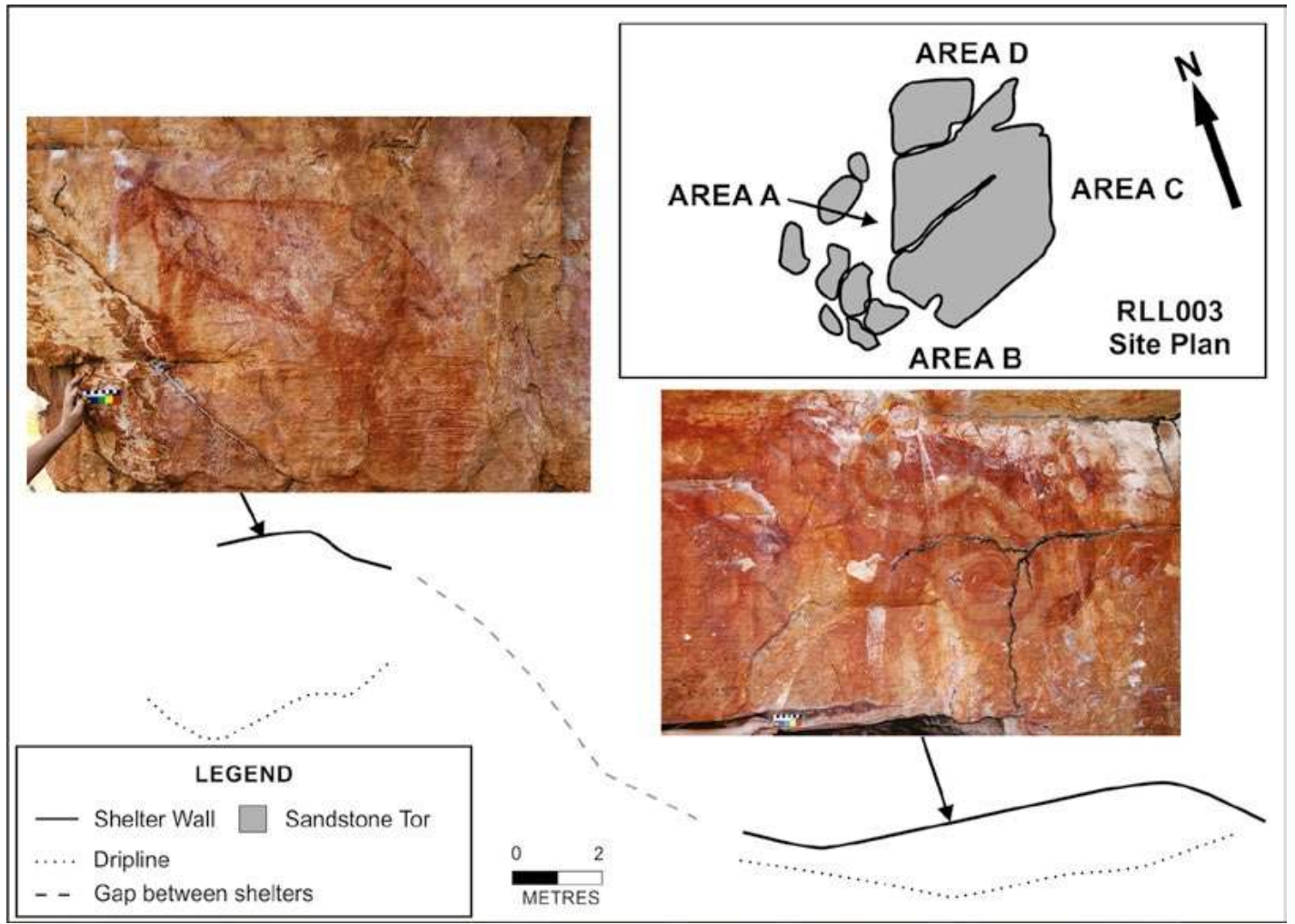

Figure 7.1 Plan of Red Lily Lagoon Site 3, Area D.

Source: Rose Whitau and Daryl Wesley.

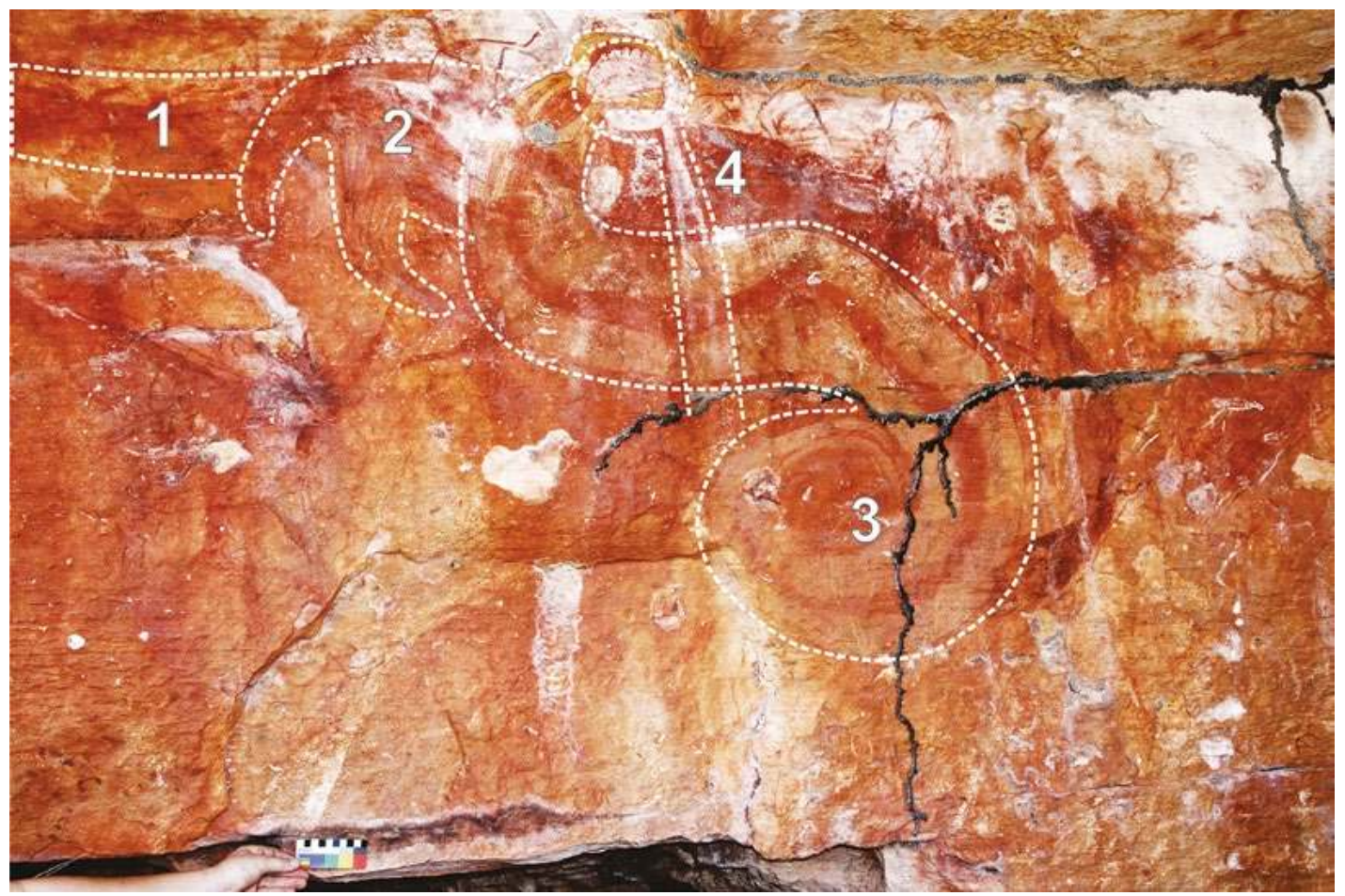

Figure 7.2 Red Lily Lagoon Site 3, Area D Panel 2, highlighting the sequence of rock paintings. The numbers of the highlighted sections 1-4 refer to the motifs 1-4 contained within them. Source: Photograph by Damien Finch with line drawing by Daryl Wesley. 


\section{Motif 1}

Motif 1 is a very large red motif, composed of distinct curved lines. It spans much of the rock wall. Parts of the motif are solid infilled with protruding lines that are suggestive of spines. The motif spans left to right, across and down the rock surface. It is unknown where this motif lies in the relative sequence of artworks on this panel. The image is not clear enough to determine its exact shape, or indeed its corresponding style. The 'spines' are reminiscent of those common in 'Yam'-style Rainbow Serpents (Taçon et al. 1996). The image is superimposed by others, as outlined below.

\section{Motif 2}

Motif 2, in the upper left-hand section of the panel, is a red unidentifiable animal with hind limbs and the remnants of a tail. It is delineated by a solid line and decorated with the linear infill characteristic of 'Large Naturalistic' figures (Chaloupka 1993:94). Motif 2 overlies Motif 1.

Motif 3

Motif 3, the predominant image on the panel, is the best preserved. It is a red-outlined bichrome S-shaped motif, clearly depicting a snake. The motif is large, measuring $110 \mathrm{~cm}$ in length and $90 \mathrm{~cm}$ in width. The red pigment is better preserved than the yellow. The head of the snake is segmented, and is red and solid. Throughout the length of the body, a solid red segment also features, outlined by yellow pigment on either side. Starting from the head of the snake, two parallel red-lined segments following the curved S-shape of the snake border the main solid infill. The decoration features areas of solid infill, creating a block yellow to red patterning. This feature is lost throughout most of the snake's body due to weathering. There are also early $\mathrm{X}$-ray features, such as a characteristic main body cavity with a thick line running through it representing a backbone (e.g. Taçon 1989: Figure 18; see Figure 7.3). Motif 3 overlies Motif 2.

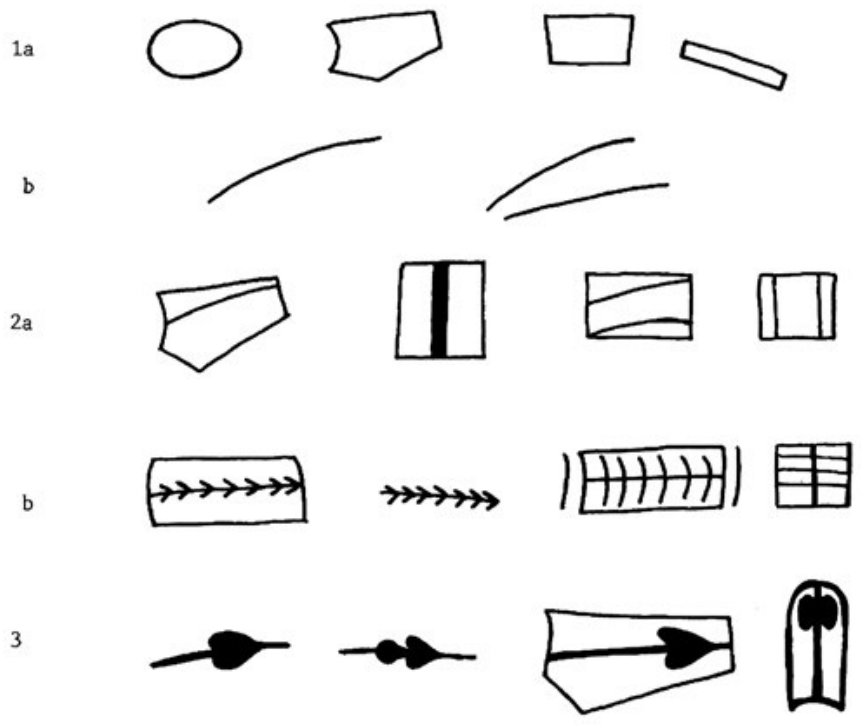

KEY: 1a --- body cavities.

b --- thin line backbone and/or digestive tract.

2a --- combination of cavity and thin line backbone and/or digestive tract.

b --- combination of backbone and ribs; backbone ribs and cavity.

3 --- combination of backbone and lungs and/or heart; backbone, cavity

Figure 7.3 Early X-ray attributes, some of which are depicted in Motif 3.

Source: Taçon 1989: Figure 18, reproduced with permission. 


\section{Motif 4}

The topmost layer in the painting sequence is comprised of a white anthropomorphic figure. Extensive weathering has resulted in only part of the motif remaining on the rock wall, that of the head and upper body. The bichrome figure consists of a red outline, infilled with white pigment. The figure is depicted in profile, as is common in human-like representations, with the head a hollowed C-shape. Chaloupka (1993:148-149) refers to such depictions as 'hooked face' figures. These types of human figures have been categorised as part of the 'Complete Figure Style' (Taçon 1992:204-205). Motif 4 overlies Motif 3.

\section{Style and preservation as indicators of antiquity}

For many decades, rock art researchers have utilised the method of grouping rock art motifs into 'styles' or manners of depiction, creating a relative sequence of change in artistic depiction over time. For western Arnhem Land, the original stylistic sequence proposed by George Chaloupka in various publications, including his hallmark Journey in Time (Chaloupka 1993:89), was modified and further developed by Chippindale and Taçon (1998:107), which is referenced in this study.

The classification of motifs according to style at Red Lily Lagoon Site 3 Area D Panel 2 is problematic. While the shape of Motif 1 is uncertain, the presence of spines suggesting a backbone signals some kind of zoomorph. While the decorative attribute of spines has previously been categorised as typifying 'early X-ray' art (Figure 7.3), the spines feature on the outside of the painting. Therefore the spines are more likely to indicate decorative features seen in 'Yam'-style Rainbow Serpents (Taçon et al. 1996). Taçon (1989) defines the internal attributes that constitute the 'early X-ray' style (see Figure 7.3), some of which are present in Motif 1, but also occur in Motif 3 of Panel 2.

Motif 2 is a depiction of a naturalistic macropod, as the motif is drawn with a free-flowing outline and is textured with linear infill (Chaloupka 1993:94). Chaloupka's categorisation of 'Large Naturalistic' animals as one discrete category of painting type that only appears at the beginning of the Arnhem Land sequence is inaccurate. Lewis succinctly summarises the issue as follows: 'The style of large naturalistic animals and humans is ill-defined and it may actually consist of a number of similar styles present throughout the entire sequence of Arnhem Land art' (1988:72). Indeed, the depictions of large animals are very common, many researchers having identified paintings in a 'Large Naturalistic' manner throughout the entire sequence, particularly throughout the Early and Intermediate period (cf. the Large Fauna Style of Chippindale and Taçon 1998).

The predominant motif in Panel 2 - Motif 3 - is a large snake. This motif is better preserved than any other rock painting on the panel. The segmentation of the head and the inclusion of both solid and patterned infilled segments clearly denote this image as an X-ray painting. The X-ray painting tradition has been argued to span some 8000 years (Taçon 1989, 1992), and therefore the categorisation of the motif according to 'style' does not provide a high resolution age estimation for the motif. The use of two colours, red and yellow in combination, suggests that the motif may have been painted in the late Holocene. Instances of bichromatic early X-ray are uncommon, accounting for only 5.7 per cent of the total number of paintings recorded by Taçon (1989:121-122). On the other hand, in recent X-ray art, which Taçon (1989:124) defines as occurring from $3000 \mathrm{BP}$ to present, bichromatic representations are the most common, making up 60.2 per cent of the samples. Additionally, the combination of red and yellow pigment is the second-most popular extant pigment combination after red and white in recent X-ray rock art (Taçon 1989:126). Differentiation of motifs as either early or recent X-ray in style may also 
rely on the subject matter of the motif. Many researchers have argued that changes in faunal depictions through time signal changing environmental conditions (Chaloupka 1993:88). Taçon rightly notes that freshwater animal species begin to predominate in early X-ray paintings. As such, the commencement of early X-ray art is thought by many researchers to correspond with mid to late Holocene environmental conditions, such as are evident in the Kakadu wetlands of today (Brockwell 1996; Taçon and Brockwell 1995). As the subject matter of Motif 3 is formally a generic depiction of a snake, and as snakes are known to exist in both wet and dry environments, the faunal taxon cannot itself be used as an indicator of the painting's age. The snake's depiction in this instance does not have any characteristic features of a 'Rainbow Serpent'. Rainbow Serpents are commonly depicted with elaborately detailed tails, and plant and animal appendages, macropod-like heads and cross-hatching decorative features (Taçon et al. 1996). Motif 3 does not feature any of these attributes.

'Indirect' dating methods place Motif 4 in the late Holocene. While the full diversity of humanlike representations in western Arnhem Land art remains a topic of ongoing research (Chippindale and Taçon 1993), the attribute of a hooked face, or C-shaped head, is akin to the facial features of 'Energetic' stick-figures. 'Energetic' stick-figures are commonly depicted in the rock art record of the wider Red Lily Lagoon area. Typically, these figures are frequently painted with material culture, particularly weaponry (Chaloupka 1993:148-149). The presence of weaponry in rock art paintings has previously been used as an indicator of the relative age of depictions (Lewis 1988). However, poor preservation of the painting has eliminated any potential evidence of material culture, and as such cannot be used to assist in estimating the age of Motif 4. It is assumed that the condition is due to the fact that the motif is painted in white pigment, which is acknowledged to have the least permanency of all pigment types perhaps apart from charcoal (Chippindale and Taçon 1998:103-104). According to Taçon, 'Energetic' stick-figures are a subcategory of the 'Complete Figure Style'. This style incorporates many different forms of art, including 'full figures', 'stick-figures', stencils, beeswax images and prints. Taçon (1992:204-206) argues that the 'Complete Figure Style' co-existed with 'Recent X-Ray' and is assigned an age range from 3000-2000 BP to present. On this basis, we assume that Motif 4 was painted during this period and has a maximum age of $3000 \mathrm{BP}$.

\section{Sample selection and methodology}

The rock surfaces and panels of Area D were surveyed for radiocarbon sampling, with particular attention concentrated on the white accretions and mud wasp nests present along sections of the rock wall. The presence of a mineral coating possibly containing calcium oxalate (whewellite $\mathrm{CaC}_{2} \mathrm{O}_{4} \cdot \mathrm{H}_{2} \mathrm{O}$ and weddellite $\mathrm{CaC}_{2} \mathrm{O}_{4} \cdot 2 \mathrm{H}_{2} \mathrm{O}$ ) was identified and in areas the whitish growth was covering part of Motif 3. Additionally, remnants of an ancient mud wasp nest were also present in close proximity to the mineral crust and located adjacent to Motif 3 (Figures 7.4 and 7.5). Three samples of coating material were collected from the rock surface (Sample 3-4-1, Sample 3-4-2 and Sample 3-4-3) (Figures 7.4 and 7.5). Sample 3-4-1 is of the mineral accretion that overlies part of Motif 3 . The accretion covers the red and yellow segment patterning depicted in the upper neck of the snake (Figure 7.5). Sample 3-4-2 is from the remnant mud wasp nest. The mud wasp nest is situated adjacent to the right of the main body of the snake painting (Figure 7.5). Sample 3-4-3 is a mineral accretion that overlies the red outline of the mid-body of the snake painting (Figure 7.4). All samples were removed using a diamond disk Dremel ${ }^{\bullet}$ drill, producing bulk crust removal in powdered form. Powder was captured in clean individual sheets of aluminium foil, and emptied into clean centrifuge tubes. 


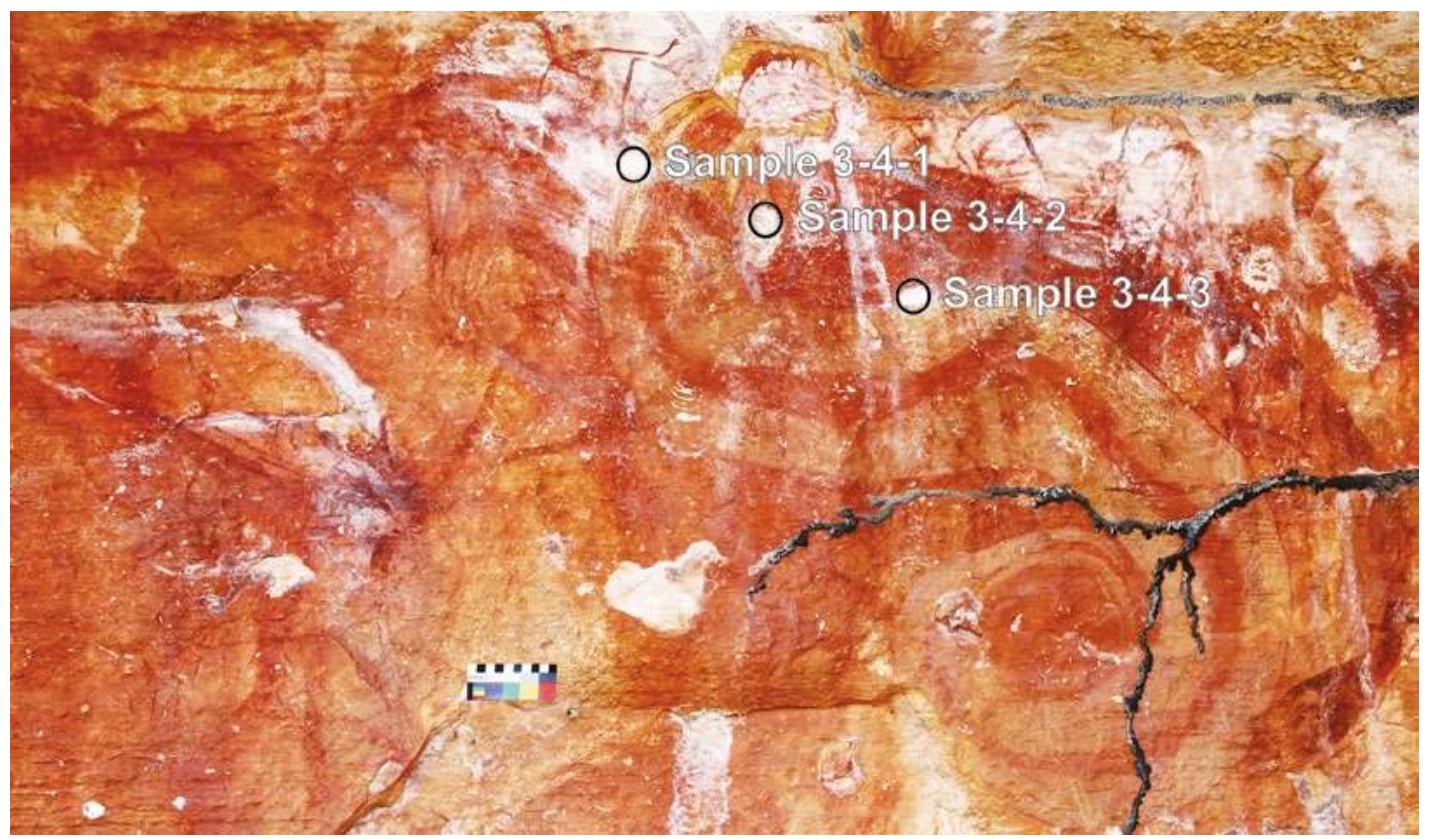

Figure 7.4 Panel 2 showing sample locations for radiocarbon age determinations.

Source: Photograph by Damien Finch.

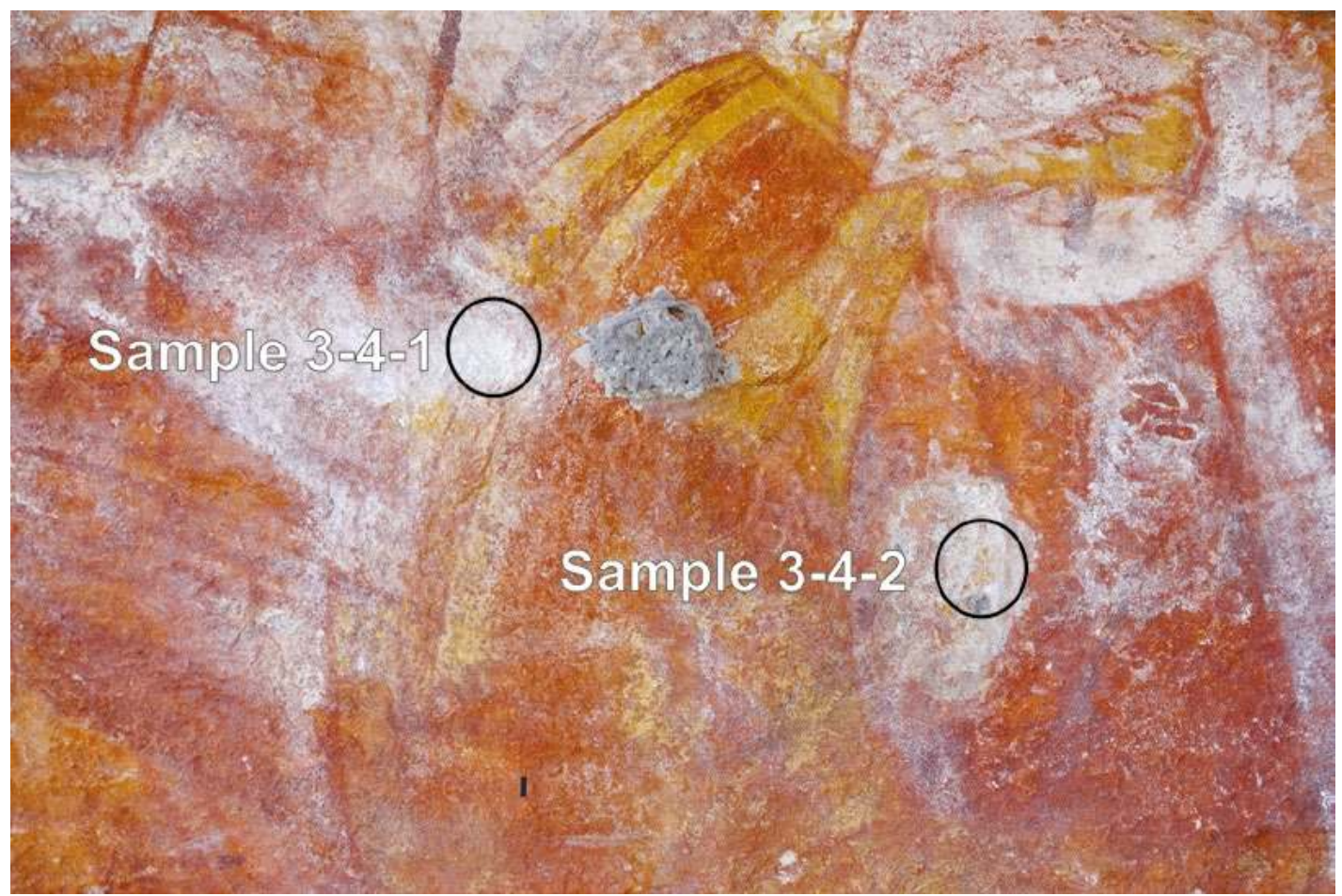

Figure 7.5 Location of samples collected for radiocarbon dating.

Source: Photograph by Vladimir Levchenko. 
Once removed from the field, all samples were taken to the Australian Nuclear Science and Technology Organisation (ANSTO) research laboratories. Samples were registered and weighed, and aliquots taken from those expected to be of oxalate origin (RLL3-4-1 and RLL3-4-3). Aliquots were sent to The Australian National University's (ANU) Research School of Earth Sciences laboratories to test for the presence of calcium oxalate using Fourier Transform Infrared Spectroscopy (FTIR) and X-Ray Diffraction (XRD). The latter two mineralogical methods did not detect calcium oxalate suggesting that any oxalate that might be present was below the level of a few per cent. Additionally, the FTIR and XRD results confirmed the presence of minor phosphates (tinsleyite, taranakite), sulfate (gypsum) and natural weathering products such as amorphous materials, quartz and mica/kaolinite. The samples from Red Lily 3 have comparable mineral compositions to other rock art dating samples analysed from the study area (King et al. 2017)

Sample RLL3-4-1 was processed at ANSTO. The sample was pre-treated to remove potential carbon-bearing contaminants according to the following procedure. The powdered material was placed in a centrifuge tube with excess of 5 per cent $\mathrm{NaOH}$ solution at $60^{\circ} \mathrm{C}$ for one hour. At this step, various organic acids and non-acid soluble paint solids were transferred into the solution. Solution was centrifuged and the supernates decanted and retained in case of further analysis. After rinsing with Milli- $\mathrm{Q}^{\circ}$ water, the samples were treated with $6 \mathrm{M} \mathrm{HCl}$ at $60^{\circ} \mathrm{C}$, to remove possible carbonates and to dissolve whewellite and whedellite minerals. After one hour, the solution was centrifuged and supernates decanted and saved. This time the precipitates, possibly containing various more or less inert solids (silica, pollen, charcoal, some non-reactive organic matter) were retained for separate analyses; these are referred to as the 'residue' in this chapter. The decanted solutions containing oxalic and $\mathrm{HCl}$ acids and their salts were dried down $\left(\mathrm{HCl}\right.$ volatilises), sealed in quartz combustion tubes and combusted at $900^{\circ} \mathrm{C}$, as described elsewhere (Hua et al. 2001). Separate residue fractions were rinsed in Milli- ${ }^{\bullet}$ water multiple times, dried and also sealed in combustion tubes and correspondingly combusted in the same conditions. Evolved $\mathrm{CO}_{2}$ was cryogenically purified and collected and its yield determined. Then it was converted to graphite following standard graphitisation procedures (Hua et al. 2004).

Sample RLL3-4-2, the remnants of the mud wasp nest, was pre-treated at ANSTO following standard ABA procedures (Hatté et al. 2001). As per the following, the weighed powder was placed in a centrifuge tube and treated with $2 \mathrm{M} \mathrm{HCl}$ for two hours at $60^{\circ} \mathrm{C}$, followed after centrifuging by multiple Milli- $\mathrm{Q}^{\bullet}$ rinses. The next step included multiple treatments of 0.5 per cent up to 10 per cent $\mathrm{NaOH}$ for 2 hours each at $60^{\circ} \mathrm{C}$ (until two consecutive treatment solutions remained clear). After another Milli- $\mathrm{Q}^{\circ}$ rinse, the third step consisted of $2 \mathrm{M} \mathrm{HCl}$ at room temperature overnight and multiple Milli- $\mathrm{Q}^{\circ}$ rinses until a near-neutral $\mathrm{pH}$ of the solution was achieved. The sample was oven-dried at $60^{\circ} \mathrm{C}$. This treatment effectively removes all carbonates, humic and fulvic acids, fats and lipids, leaving behind pollen, charcoal dust (soot) and possible powdered macrofossils material. The dried sample was placed in a sealed quartz combustion tube similar to the oxalate sample, combusted to $\mathrm{CO}_{2}$, which was again cryogenically purified and collected and converted to graphite.

Graphite targets were pressed into aluminium cathodes, and the ${ }^{12} \mathrm{C} /{ }^{14} \mathrm{C}$ ratio determined on ANSTO's STAR and ANTARES accelerator mass spectrometry (AMS) installations (Fink et al. 2004). In parallel with real samples, a set of chemistry procedural blanks was prepared to determine the level of possible contamination through the preparation process and corrected for this in data evaluations. Smaller samples are more likely to be contaminated, resulting in relatively large error bars of radiocarbon determinations for the smallest sample sizes. 
Determinations of $\delta^{13} \mathrm{C}$ were done on the residue of graphite targets derived from the studied fractions after the radiocarbon measurements were completed. Measurements were performed on a separate elemental analyser Elementar varioMICRO CUBE coupled to a Micromass Isoprime IRMS machine. If graphite residues were too small for a measurement, the average value for the same type of samples from the area was used for isotope fractionation correction.

\section{Radiocarbon age determinations}

The radiocarbon calibrated age determinations of the calcium oxalate and mud wasp nest samples fall within c. 210 years between their median values. They both indicate an early to mid-Holocene age of somewhere between $5068 \mathrm{cal} \mathrm{BP}$ and $6636 \mathrm{cal} \mathrm{BP}$, taking the 95.5 per cent probability calibrated age ranges into account (Table 7.1). That the ages of two different dated material types converge - calcium oxalate and the mud wasp nest - is very encouraging. Each of these sample types has a different kind of formation history, has been subject to different pre-treatments and has a different dated fraction. This suggests the robustness of radiocarbon method for both of the dated materials, particularly in the utilisation of calcium oxalate minerals for radiocarbon dating.

Table 7.1 Radiocarbon determinations.

\begin{tabular}{|c|c|c|c|c|c|c|c|c|}
\hline ANSTO code & Sample type & $\begin{array}{c}\text { Submitter } \\
\text { ID }\end{array}$ & $\begin{array}{l}\text { Extracted } \\
\text { carbon } \mu g\end{array}$ & $\delta^{13} \mathrm{C} \%$ & $\begin{array}{c}\text { Radiocarbon } \\
\text { pMC }( \pm 1 \sigma)\end{array}$ & $\begin{array}{c}\text { Radiocarbon } \\
\text { age BP }\end{array}$ & $\begin{array}{l}\text { Cal BP age } \\
\text { (2o range) }\end{array}$ & $\begin{array}{c}\text { Median } \\
\text { probability }\end{array}$ \\
\hline OZR994U1 & $\begin{array}{l}\text { Mineral crust: } \\
\text { oxalate }\end{array}$ & RLL3-4-1 & 9 & -10.0 & $52.40 \pm 2.02$ & $5190 \pm 310$ & $5068-6636$ & 5906 \\
\hline OZR994U2 & $\begin{array}{l}\text { Mineral crust: } \\
\text { residue }\end{array}$ & RLL3-4-1 & 23 & $-11.3^{*}$ & $57.94 \pm 1.15$ & $4380 \pm 160$ & $4445-5446$ & 4953 \\
\hline OZR995 & $\begin{array}{l}\text { Mud wasp } \\
\text { nest }\end{array}$ & RLL3-4-2 & 520 & $-6.7 \pm 0.1$ & $53.56 \pm 0.21$ & $5015 \pm 35$ & $5605-5875$ & 5697 \\
\hline
\end{tabular}

"Results have been calibrated using CALIB 7.1 (Stuiver and Reimer 1993) using Sothern Hemisphere 2013 calibration curve (ShCal13) (Hogg et al. 2013). The value of $\delta^{13} \mathrm{C}$ is assumed from determinations of similar type samples. A measured value is not available due to the small size of samples. For explanations of two dated fractions for mineral crust sample, see text.

Source: Authors' data.

In this study, we have reported two radiocarbon age determinations for sample RLL3-4-1. The first date is produced from the carbon contained within the calcium oxalate mineral only, isolated in sample pre-treatment. The second radiocarbon age determination is produced from the mineral crust residues (inert solids such as silica, pollen, charcoal, some non-reactive organic matter) contained within the sample. The calcium oxalate mineral crust returned an age of 5068-6636 cal BP, which, judging by the median age probability, precedes the mud wasp nest formation on the rock wall by a few centuries (Table 7.1). The calcium oxalate mineral crust has produced the oldest age, and as such it can be considered the terminus ante quem for the underlying snake image (Motif 3). The radiocarbon determination for the calcium oxalate sample was produced as a bulk measurement. Therefore all calcium oxalate mineral deposits that relate to mineral formation events and are stratified temporally in the crust have been combined into one sample. Hence, the produced age of the calcium oxalate represents an averaged result.

The mineral crust residue radiocarbon age $-4445-5446 \mathrm{cal} \mathrm{BP}-$ is determined from the carbon contaminates contained within and on the mineral crust (Table 7.1). The younger age of the residue may be due to the continual integration of carbon contaminants throughout the growth history of the crust, in conjunction with a build-up of carbon pollutants on the rock surface. Mineral crusts are known to grow sporadically over a period of time dependent on micro- 
environmental conditions. Considering the age spread between the coating minerals and the mineral crust residue, we can assume that the calcium oxalate mineral has been growing over a considerable length of time (Hassiba et al. 2012).

The radiocarbon age determination for the mud wasp nest is $5605-5875 \mathrm{cal} \mathrm{BP}$ (Table 7.1). This date is interpreted as representing the moment of mud wasp nest construction, as the organic components, such as pollen, spores, phytoliths and charcoal dust, are gathered and integrated into the structure of the nest by mud dauber wasps during the construction process (Bednarik 2014; Roberts et al. 1997). While some mud dauber wasps prefer to construct nests on the remnants of pre-existing nests, visual inspection upon sampling the mud wasp nest residue in the field indicated that in this instance there was only a single nest-building event. Therefore, carbon age averaging from multiple nest-building events is unlikely. Contrary to the calcium oxalate sample, the mud-wasp nest does not overlie Motif 3 or Motif 4 . The mud wasp nest is located adjacent to the snake motif. As the mud wasp nest is younger than the calcium oxalate crust, it must have developed on the rock surface after the painting of Motif 3.

\section{Discussion}

A paucity of chronometric ages directly dating rock art remains an ongoing issue in rock art research worldwide (Aubert 2012; David et al. 2013). In Australia, a recent review of direct dates revealed that while there is a substantial number of age determinations for rock art, particularly in the Northern Territory (244 age determinations accounting for 56.4 per cent of the national data-set), the majority ( 74 per cent) of the age determinations are from beeswax rock art designs (Langley and Taçon 2010). The ages produced from beeswax figures are predominately of late Holocene antiquity; indeed, 81 per cent of the age determinations generated from beeswax samples in the Northern Territory are less than 500 years old (Langley and Taçon 2010). The predominance of chronometric age determinations from beeswax motifs is largely due to the fact that the material generally contains the most ${ }^{14} \mathrm{C}$ for radiocarbon dating. Additionally, dating beeswax motifs produces age determinations for the actual art object and the material is far less likely to be affected by carbon contamination, carbon recycling and sampling issues that plague the use of calcium oxalate and mud wasp nest substances for radiocarbon dating (Bednarik 2012). Langley and Taçon (2010:71) conclude of western Arnhem Land: 'The dominance of dated beeswax figures in this region means that while the chronology of this medium is now quite well understood, three remaining media (paintings, engravings and cupules) remain largely disarticulated from a regional chronology'.

Concerns in the literature regarding the use of calcium oxalate minerals for radiocarbon dating rock art have focused on the unclear nature of the mineral's developmental pathway, the unknown rate of mineral formation and the technical sample processing limitations in the separation of carbon-bearing components. These issues have previously stalled the widespread use of calcium oxalate as a substance for radiocarbon dating and acceptance of published radiocarbon age determinations generated from calcium oxalate minerals. The sample preparation methodology utilised in this study is a novel carbon compound-specific separation technique, which effectively isolates the carbon compound in the calcium oxalate minerals in sample pre-treatment (refer to methodology above). The result is two separate age determinations produced from the calcium oxalate mineral and the carbon 'residues' contained within the mineral crust. The residue carbon is assumed to be integrated into the formation of the mineral growth throughout the mineral crust's life span, and may also incorporate carbon pollutants residing on the mineral crust's surface. The refinement of this sampling procedure and the ramifications for the interpretation of radiocarbon age determinations is the subject of ongoing research and will be discussed in future 
publications (Jones et al. 2017). For this study, however, the considerably younger age of the mineral crust residue is proposed to be a result of the continuing build-up of carbon pollutants on the crust's surface. While the calcium oxalate mineral crust at some unknown point in time ceased growing, accumulation of carbon pollutants has remained ongoing to the present day.

The younger age of the mineral crust residue demonstrates the efficiency of the sampling pretreatment cleaning procedures and compound-specific isolation method employed in this study. Previous radiocarbon age determinations using traditional acid-base-acid (ABA) sampling pre-treatment techniques may have failed to remove some carbon contaminants present in calcium oxalate mineral crust samples, such as charcoal dust, pollen, etc. This previously unresolved reliable pre-treatment issue has been the cause of much of the critique of the calcium oxalate radiocarbon dating results. The radiocarbon age determinations produced in this study highlight the potentially significant impact that carbon pollutants can have on radiocarbon age determinations. In this example, it can be assumed that without the separation of the mineral crust residues from the calcium oxalate, the mineral crust radiocarbon age determination would have been significantly younger.

Recent discussions in rock art dating have noted the rich organics contained within mud wasp nests, and their suitability for radiocarbon dating has remained an under-exploited resource in rock art dating (Bednarik 2014). While previous studies have assessed radiocarbon ages from organics within mud wasp nests in comparison to OSL ages (Roberts et al. 1997, 2000), the potential to exploit other methods, such as calcium oxalate radiocarbon dating, for comparative analysis in determining age estimations for rock art has been identified as a growing area of research (Bednarik 2014). The fact remains that problems persist for all 'direct' dating methods in rock art research, placing significant constraints on our ability to generate chronometric age estimates for rock art. However, while we have only presented three age determinations in this study, the results demonstrate that robust age determinations using both radiocarbon dating approaches can be produced. The resolution of questions surrounding the validity of methods in this case is in the combination of multiple radiocarbon age determinations generated from different substances. This methodology has been suggested previously on many occasions by rock art researchers (e.g. Bednarik 2012). In this instance, generating age determinations from multiple sources also lends weight to the potential of dating both calcium oxalate and mud wasp nests, and advocates for the ongoing adoption of both approaches. It also highlights the substantial opportunity for rock art researchers to date both materials more frequently, due to the common occurrence of both calcium oxalate mineral accretions and mud wasp nests overlying rock art in northern Australia.

The radiocarbon ages indicate that the minimum age (median probability) for the snake painting (Motif 3) is 5906 cal BP (Table 7.1). The painting has been interpreted as being of the early X-ray style, due to the presence of linear and segmented infill features. These decorative features are highlighted by the use of yellow and red pigments. While the poor preservation of both Motif 1 and Motif 2 render it difficult for a complete description to be established for either motif, they must be older than Motif 3 as they occur beneath it.

According to Chippindale and Taçon's stylistic regional chronology, early X-ray style is positioned between the Intermediate and Late period, and is assumed to appear c. 6000 years ago, co-existing with 'Simple Figures', 'Yam Figures', 'Large Human' and 'Large Fauna' styles. The radiocarbon age determinations produced in this study supports the assumed ages for this art style in the relative regional chronology. Furthermore, our new age determinations complement the previous proposition by Taçon (1989:119, 1992:203), who, by utilising motif superimpositions and stylistic analysis, estimated an upper age limit for the introduction of the early X-ray technique to between 8000-6000 BP. His reasoning for this time frame was the existence of early X-ray 
attributes appearing underneath the 'Yam' and 'Simple Figures with Boomerang' styles, while acknowledging that the upper age limit may be open to further investigation. It is important to note that the radiocarbon age of Sample 3-4-1 is a minimum age for the underlying painting, as the calcium oxalate mineral crust overlies the snake painting (Motif 3 ). The age gap between the Motifs 1-3 painting events, and both the growth of the calcium oxalate mineral crust and mud wasp nest, are not known and the actual painting event may have taken place many years before.

Most rock art researchers have discussed the problems associated with generating age estimates for rock art by employing indirect dating methods. Yet in-depth discussions addressing the implications of underestimating style age ranges has been missing in the literature to date. The radiocarbon age determinations produced in this study demonstrate that X-ray attributes occur in rock art motifs from the mid-Holocene. In fact, they may potentially occur much earlier. In this instance, the painted rock art surface (Panel 2) occurring at Red Lily Lagoon Site 3 is well protected from environmental decay, particularly water erosion. The dripline above Panel 2 is at some points nearly $2 \mathrm{~m}$ from the painted rock wall, providing a micro-environment that has produced greater conservation outcomes than normally would occur at other rock art sites.

It must be noted that the appearance of early X-ray rock art during the early to mid-Holocene corresponds with major environmental and climatic changes that occur in the East Alligator River region after sea-level stabilisation c. 8000 to 6000 BP (for further discussion, see Chapter 2, this volume). Significant changes occur in archaeological assemblages during this period, such as the appearance of shell middens at Ngarradj Warde Djobkeng (Allen and Barton 1989; Kamminga and Allen 1973), major changes in stone artefact technologies (Hiscock 1999, 2011) and the occupation of Birriwilk to the south of Red Lily Lagoon Site 3 (Shine et al. 2013). Taçon and Brockwell (1995) and Taçon et al. (1996) suggest that these archaeological changes in the early to mid-Holocene parallel the development of new rock art traditions. The radiocarbon age determinations produced in this study support that proposition.

\section{Conclusion}

This study has undertaken radiocarbon dating on different types of materials in order to complement and test relative methods of assessing motif antiquity. First, the relative methods of motif superimposition, stylistic analysis of motifs and motif preservation were employed. Then radiocarbon dating was utilised on mineral accretions containing calcium oxalate and carbonbearing material contained within ancient mud wasp nests. This is the first attempt in rock art research to apply radiocarbon dating utilising these two different types of datable materials, calcium oxalate and mud wasp nests, directly associated with a single item of rock art. Novel developments in sampling pre-treatment for calcium oxalate mineral crusts have resolved some of the previous criticisms of this method of radiocarbon dating, increasing the confidence of age determinations. Combined with supplementary radiocarbon ages produced from mud wasp nests, the results of this study have demonstrated that the adoption of multiple radiocarbon age determinations generated from different substances can greatly assist rock art researchers to generate robust radiometric data regarding the antiquity of rock art. Coupled with an 'indirect' dating analysis, evaluating the painting sequence, stylistic and preservation attributes of the rock art, this study reliably proposes a minimum age of 5068-6636 cal BP for the introduction of early $\mathrm{X}$-ray art in western Arnhem Land rock art. This mid-Holocene age determination is supported by previous chronological schemas, and parallels the changes evident in other archaeological assemblages occurring during this period in the region. 


\section{Acknowledgements}

Many thanks to the Djabulukgu Association Incorporated, the Njanjma Rangers and the Manilakarr Traditional Owners, particularly Alfred and Leah Nayinggul, for their ongoing support and involvement. Many thanks also the field crew who assisted in the recording of Red Lily Lagoon Site 3, Rose Whitau and Damien Finch (both ANU). Research was funded by the George Chaloupka Fellowship 2014 and AINSE Grant ALNGRA12047P.

\section{References}

Allen, H. and G. Barton 1989. Ngarradj Warde Djobkeng: White Cockatoo Dreaming and the Prehistory of Kakadu, Northern Territory, Australia. Oceania Monograph 37. Oceania Publications, Sydney.

Aubert, M. 2012. A review of rock art dating in the Kimberley, Western Australia. Journal of Archaeological Science 39:573-577. doi.org/10.1016/j.jas.2011.11.009

Bednarik, R.G. 1996. Only time will tell: A review of the methodology of direct rock art dating. Archaeometry 38(1):1-13. doi.org/10.1111/j.1475-4754.1996.tb00757.x

Bednarik, R.G. 2000. Some problems with 'direct dating' of rock-pictures. In G.K. Ward and C. Tuniz (eds), Advances in Dating Australian Rock-Markings, pp. 104-109. Occasional AURA Publication 10, Australian Rock Art Research Association, Melbourne.

Bednarik, R.G. 2002. The dating of rock art: A critique. Journal of Archaeological Science 29 (11):1213-1233. doi.org/10.1006/jasc.2001.0711

Bednarik, R.G. 2007. Rock Art Science: The Scientific Study of Palaeoart (Second Edition). Aryan Books International, New Delhi.

Bednarik, R.G. 2012. The use of weathering indices in rock art science and archaeology. Rock Art Research 29(1):59-84.

Bednarik, R.G. 2014. Mud-wasp nests and rock art. Rock Art Research 31(2):225-231.

Brockwell, S. 1996. Open sites of the South Alligator River wetland, Kakadu. In P. Veth and P. Hiscock (eds), Archaeology of Northern Australia, pp. 90-105. Tempus 4. Anthropology Museum, University of Queensland, St Lucia.

Chaloupka, G. 1993. Journey in Time: The World's Longest Continuing Art Tradition. Reed, Chatswood.

Chippindale, C. and P.S.C. Taçon 1993. Two old painted panels from Kakadu: Variation and sequence in Arnhem Land rock art. In D. Steinbring, A. Watchman, P. Faulstich and P.S.C. Taçon (eds), Time and Space: Dating and Spatial Considerations in Rock Art Research, pp. 32-56. Occasional AURA Publication 8. Australian Rock Art Research Association, Melbourne.

Chippindale, C. and P.S.C. Taçon 1998. The many ways of dating Arnhem Land rock-art, north Australia. In C. Chippindale and P.S.C. Taçon (eds), The Archaeology of Rock-Art, pp. 90-111. Cambridge University Press, Cambridge.

David, B., J.-M. Geneste, F. Petchey, J.-J. Delannoy, B. Barker and M. Eccleston 2013. How old are Australia’s pictographs? A review of rock art dating. Journal of Archaeological Science 40(1):3-10. doi.org/10.1016/j.jas.2012.08.019 
Fink, D., M. Hotchkis, Q. Hua, G. Jacobsen, A.M. Smith, U. Zoppi, D. Child, C. Mifsud, H. van der Gaast, A. Williams and M. Williams 2004. The ANTARES AMS facility at ANSTO. Nuclear Instruments and Methods in Physics Research B 223-224:109-115. doi.org/10.1016/j. nimb.2004.04.025

Gillespie, R. 1997. On human blood, rock art and calcium oxalate: Further studies on organic carbon content and radiocarbon age of materials relating to Australian rock art. Antiquity 71(272):430-437. doi.org/10.1017/S0003598X00085033

Hassiba, R., G.B. Cieslinski, B. Chance, F.A. Al-Naimi, M. Pilant and M.W. Rowe 2012. Determining the age of Qatari Jabal Jassasiyah petroglyphs, Q Science Connect 4:1-16. doi.org/10.5339/ connect.2012.4

Haskovec, I.P. 1992. Northern Running Figures of Kakadu National Park: A Study of Regional Style. In J. McDonald and I. P. Haskovec (eds), State of the Art: Regional Rock Art Studies in Australia and Melanesia, pp. 148-158. Occasioinal AURA Publication 6. Australian Rock Art Research Association, Melbourne.

Hatté, C., J. Morvan, C. Noury and M. Paterne 2001. Is classical acid-alkali-acid treatment responsible for contamination? An alternative proposition. Radiocarbon 43:177-182. doi.org/10.1017/ S003382220003798X

Hiscock, P. 1999. Holocene coastal occupation of Western Arnhem Land. In J. Hall and I.J. McNiven (eds), Australian Coastal Archaeology, pp. 91-103. Department of Archaeology and Natural History, The Australian National University, Canberra.

Hiscock, P. 2011. Point production at Jimede 2, western Arnhem Land. Changing perspectives in Australian archaeology, part VI. Technical Reports of the Australian Museum 23(6):73-82. doi.org/10.3853/j.1835-4211.23.2011.1571

Hogg, A., Q. Hua, P.G. Blackwell, C.E. Buck, T.P. Guilderson, T.J. Heaton, M. Niu, J.G. Palmer, P.J. Reimer, R.W. Reimer, C.S.M. Turney and S.R.H. Zimmerman 2013. SHCal13 Southern Hemisphere Calibration, 0-50,000 Years cal BP. Radiocarbon 55(4):1889-1903. doi.org/10.2458/ azu_js_rc. 55.16783

Hua, Q., G.E. Jacobsen, U. Zoppi, E.M. Lawson, A.A. Williams, A.M. Smith and M.J. McGann 2001. Progress in radiocarbon target preparation at the ANTARES AMS centre. Radiocarbon 43(2A):275-282. doi.org/10.1017/S003382220003811X

Hua, Q., U. Zoppi, A.A. Williams and A.M. Smith 2004. Small-mass AMS radiocarbon analysis at ANTARES. Nuclear Instruments and Methods in Physics Research B 223-224:284-292. doi.org/ 10.1016/j.nimb.2004.04.057

Jones, T., V.A. Levchenko, P.L. King, U. Troitzsch, D. Wesley, A.A. Williams and A. Nayinggul 2017. Radiocarbon age constraints for a Pleistocene-Holocene transition rock art style: The Northern Running Figures of the East Alligator River region, western Arnhem Land, Australia. Journal of Archaeological Science: Reports 11:80-89. doi.org/10.1016/j.jasrep.2016.11.016

Kamminga, J. and H. Allen 1973. Report of the Archaeological Survey: Alligator Rivers Environmental FactFinding Study. Government Printer, Darwin.

King, P. L., U. Troitzsch and T. Jones 2017. Characterization of mineral coatings associated with a Pleistocene - Holocene rock art style: The Northern Running Figures of the East Alligator River region, western Arnhem Land, Australia. Data in Brief 10:537-543.

Langley, M. and P.S.C. Taçon 2010. The age of Australian rock art: A review. Australian Archaeology 71:70-73. doi.org/10.1080/03122417.2010.11689386

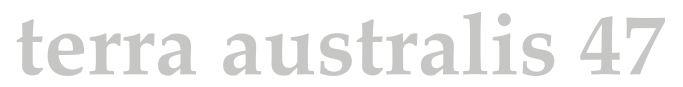


Lewis, D. 1988. The Rock Paintings of Arnhem Land, Australia. British Archaeological Reports, Oxford.

Roberts, R., G. Walsh, A. Murray, J. Olley, R. Jones, M. Morwood, C. Tuniz, E. Lawson, M. Macphail, D. Bowdery and I. Nauman 1997. Luminescence dating of rock art and past environments using mud-wasp nests in northern Australia. Nature 387:696-699. doi.org/10.1038/42690

Roberts, R.G., G.L. Walsh, J.M. Olley, A.S. Murray, M.K. Macphail, I.D. Naumann, R. Jones and M.J. Morwood 2000. Rock-picture chronologies and palaeoenvironmental records from fossil mud-wasp nests: Preliminary investigations using optical dating. In G.K. Ward and C. Tuniz (eds), Advances in Dating Australian Rock-Markings, pp. 40-44. Occasional AURA Publication 10, Australian Rock Art Research Association, Melbourne.

Rosenfeld, A. and C. Smith 1997. Recent developments in radiocarbon and stylistic methods or dating rock art. Antiquity 71(272):405-411. doi.org/10.1017/S0003598X00085008

Shine, D., D. Wright, T. Denham, K. Aplin, P. Hiscock, K. Parker and R. Walton 2013. Birriwilk Rockshelter: A mid- to late Holocene site in Manilikarr country, southwest Arnhem Land, Northern Territory. Australian Archaeology 76:69-78. doi.org/10.1080/03122417.2013.11681967

Spencer, B. 1928. Wanderings in Wild Australia. Macmillan and Company Ltd, London.

Stuiver, M. and P.J. Reimer 1993. Extended 14C data base and revised CALIB 3.0 14C Age calibration program. Radiocarbon 35(1):215-230. doi.org/10.1017/S0033822200013904

Taçon, P.S.C. 1989. From Rainbow Snakes to 'X-Ray' Fish: The Nature of the Recent Rock Painting Tradition of Western Arnhem Land, Australia. Unpublished PhD thesis. The Australian National University, Canberra.

Taçon, P.S.C. 1992. Somewhere over the rainbow: An ethnographic and archaeological analysis of recent rock art paintings of western Arnhem Land. In J. McDonald and I. P. Haskovec. (eds), State of the Art: Regional Rock Art Studies in Australia and Melanesia, pp. 202-215. Occasional AURA Publication 6. Australian Rock Art Research Association, Melbourne.

Taçon, P.S.C. and S. Brockwell 1995. Arnhem Land prehistory in landscape, stone and paint. Antiquity 69:676-695. doi.org/10.1017/S0003598X00082272

Taçon, P.S.C., M. Wilson and C. Chippindale 1996. Birth of the Rainbow Serpent in Arnhem Land rock art and oral history. Archaeology in Oceania 31:103-124. doi.org/10.1002/j.1834-4453.1996. tb00355.x

Watchman, A., S. O'Connor and R. Jones 2005. Dating oxalate minerals 20-45 ka. Journal of Archaeological Science 32:369-374. doi.org/10.1016/j.jas.2004.10.007 



\title{
Art and megafauna in the Top End of the Northern Territory, Australia: Illusion or reality?
}

\author{
Paul S.C. Taçon and Steve Webb
}

\section{Introduction}

The term 'megafauna' is used to describe 'an arbitrary compilation of relatively large mammalian, reptilian, and avian taxa, ranging in size from $-10 \mathrm{~kg}$ or less up to $>2,000 \mathrm{~kg}$ ' (Wroe et al. 2013a:8777). In Australia, there were over 50 species in at least six genera commonly discussed as becoming extinct since the arrival of modern humans about 50,000 years ago (for a detailed summary see Cane 2013:41-47); however, within a broader time frame, 88 taxa disappeared over the past 450,000 years (Webb 2013; Wroe et al. 2013a, 2013b).

Across the world, megafauna have long fascinated artists and scientists alike, as evidenced by European Upper Palaeolithic rock art and over 100 years of global palaeontological research, as well as fierce debates between scientists about regional- to continental-scale causes of megafaunal extinctions. The role of humans in Pleistocene megafaunal extinctions is a key question long debated in Europe, North America and Australia. Human predation in blitzkrieg fashion versus slower human-induced versus climate change-induced causes are the polemics, with contemporary debate being particularly fierce in Australia (e.g. Brook et al. 2013; Johnson 2006; Miller et al. 1999; Roberts et al. 2001; Webb 2013; Wroe and Field 2006; Wroe et al. 2004, 2006, 2013a, 2013b). However, 'a paucity of empirical data; shortfalls in radiometric dating; and, until recently, a limited appreciation of the paleoenvironmental record have placed considerable constraints on the ability to resolve "who" or "what" was responsible for these extinctions' (Wroe et al. 2013a:8777). A related debate in Australia focuses on whether Aboriginal people made depictions of Pleistocene megafauna at rock art sites and, if they did, whether such art survives. As with causes of extinction, there are extreme views varying from full acceptance that there are surviving rock art depictions of megafauna (e.g. Cane 2013) to full rejection (e.g. Bednarik 2013a; Lewis 2017).

\section{Megafauna in the Australian landscape}

The patchy fossil record in Australia is one of the main problems that limits resolution of the extinction debate (Wroe et al. 2013b), but also coarse-grained excavation techniques and problems of mixing of sediments at some sites. For instance, a recent continental survey of late Quaternary fossil megafauna in Greater Australia suggests most species lived in south-central, 
southeastern and eastern coastal areas (Webb 2008, 2013). Few species have been recovered from Australia's arid regions where only one or two individual bones have been found and large areas of desert have no evidence for them. Another region that has lacked remains is the Top End of the Northern Territory. The discovery of remains of a single Diprotodon sp. in 2012 on Auvergne Station in the Northern Territory is the one exception, although it remains undated. Nevertheless, one conclusion is that megafauna did not live in deserts, other than perhaps Genyornis. But their rarity in the Top End is puzzling because varied species occupied diverse environments elsewhere across the southern part of the continent. Australia's north probably offered a good occupational environment for megafauna even during glacial maxima, given their distribution elsewhere. Consequently, poor adaptation to a tropical environment among the full range of megafaunal species does not seem likely. Furthermore, it is probable that bone preservation in the north has not been as good as in other parts of the continent, partly due to the acidic nature of the soils. Also, much of the north has unsuitable sediments for bone preservation, and wet tropical, closed forest conditions over the past 15,000 years or so have promoted destruction and poor preservation as well as making the finding of fossil bone today difficult. Limited exposure of suitably aged sediments is likely to be another reason for the absence of fossil evidence. But the problem of missing megafauna and its survival into more recent times than previously argued may be more apparent than real, as suggested by rock paintings from the north of Australia.

\section{Rock art depictions and problems of interpretation}

Research over the past 30 years has shown that evidence for megafauna in northern Australia may come from rock art. Australia has more rock art sites than any other country, and most of these sites are scattered across the north (Taçon 2011). A growing archive of curious images in rock art galleries located in the Pilbara, Kimberley, Kakadu and broader Arnhem Land regions have long caught the attention of rock art specialists, archaeologists and palaeontologists (Akerman 1998, 2009; Akerman and Willing 2009; Brandl 1972; Chaloupka, 1993; Clegg 1978; Gunn et al. 2011; Mulvaney 2009, 2013; Murray and Chaloupka 1984; Ouzman et al. 2002; Walsh 2000). Some images have prompted their consideration as depictions of extinct animals and initiated serious analysis of their form, size and representation. Initially, one or two images were tentatively identified as unusual animals and then as possibly extinct megafauna (see Murray and Chaloupka 1984). The thylacine or Tasmanian tiger (Thylacinus cynocephalus) and Tasmanian devil (Sarcophilus harrisii) are two extinct animals so identified (Lewis 1977, 1988; Taçon et al. 2011). These latter two species became extinct on the Australian mainland c. 4000 years ago and c. 3000 years ago, respectively (Archer 1974; Brown 2006; Gollan 1984; note that Brown 2006 rejects a suggested age of c. 430 years ago for the extinction of the Tasmanian devil). While such images are interesting, neither species can be regarded as megafauna because of their small size and, although they may be very old, they survived well into the mid to late Holocene. Other depictions arguably include the long-nosed echidna (Zaglossus bruijnii), now only resident in New Guinea (Chaloupka 1993). Paintings of Zaglossus are - like the thylacine with its dog-like body and stripes and the Tasmanian devil - distinct and unmistakable, because of the long, slim nose and distinctive echidna body shape. But in the rock art there are other images of much larger and unknown animals painted in a realistic manner, prompting their identification as megafauna. These images of large fauna are single examples, stirring not only a reassessment of the geographical distribution of megafauna, but also the timing of their extinction and/or the age of the art itself.

Reports of megafauna in Australian Aboriginal rock art go back to the early 20th century (Basedow 1925). Recent examples include one of two species of large herbivores, Palorchestes parvus or P. azeal (Chaloupka 1993; Murray and Chaloupka 1984), the giant flightless bird 
Genyornis newtoni (Gunn et al. 2011; Ouzman et al. 2002; Trezise 1971) and the marsupial lion Thylacoleo carnifex (Akerman 1988, 2009; Akerman and Willing 2009; Wright 1972). All identifications are made with a great deal of caution, particularly because none have been dated and variable image preservation caused by weathering, water action, discolouration, mineral staining, over-painting, erosion or exfoliation of the rock surface.

Nevertheless, likely megafauna images depict an enigmatic creature whose morphology contrasts with known taxa in the region or anywhere on the continent; these are readily identified as something 'odd'. Informed Aboriginal Elders agree with this (e.g. see Chaloupka 1993:100). However, a problem is that we lack many details of exactly what megafauna species looked like, and usually depend on informed reconstructions based on fossil skeletal remains. Reconstructions are never precise in terms of the exact shape of the body. Furthermore, reconstructions do not account for natural body form variation, sexual dimorphism and other forms of minor or even major morphological variation, such as soft tissue details. On the other hand, rock art images can include hair type, coat colour, fur thickness and length as well as details such as spots, stripes, ear and rhinarium shape, tail shape, thickness and length, and other body details. Because of this, rock art images may contain unusual or equivocal features that are hard to identify or attribute from fossil reconstructions, even though in the art they may be naturalistic depictions of a living animal. Consequently, an animal depiction may not be securely identified, and Bednarik (2013a) takes the view that there are no strong identifications at all.

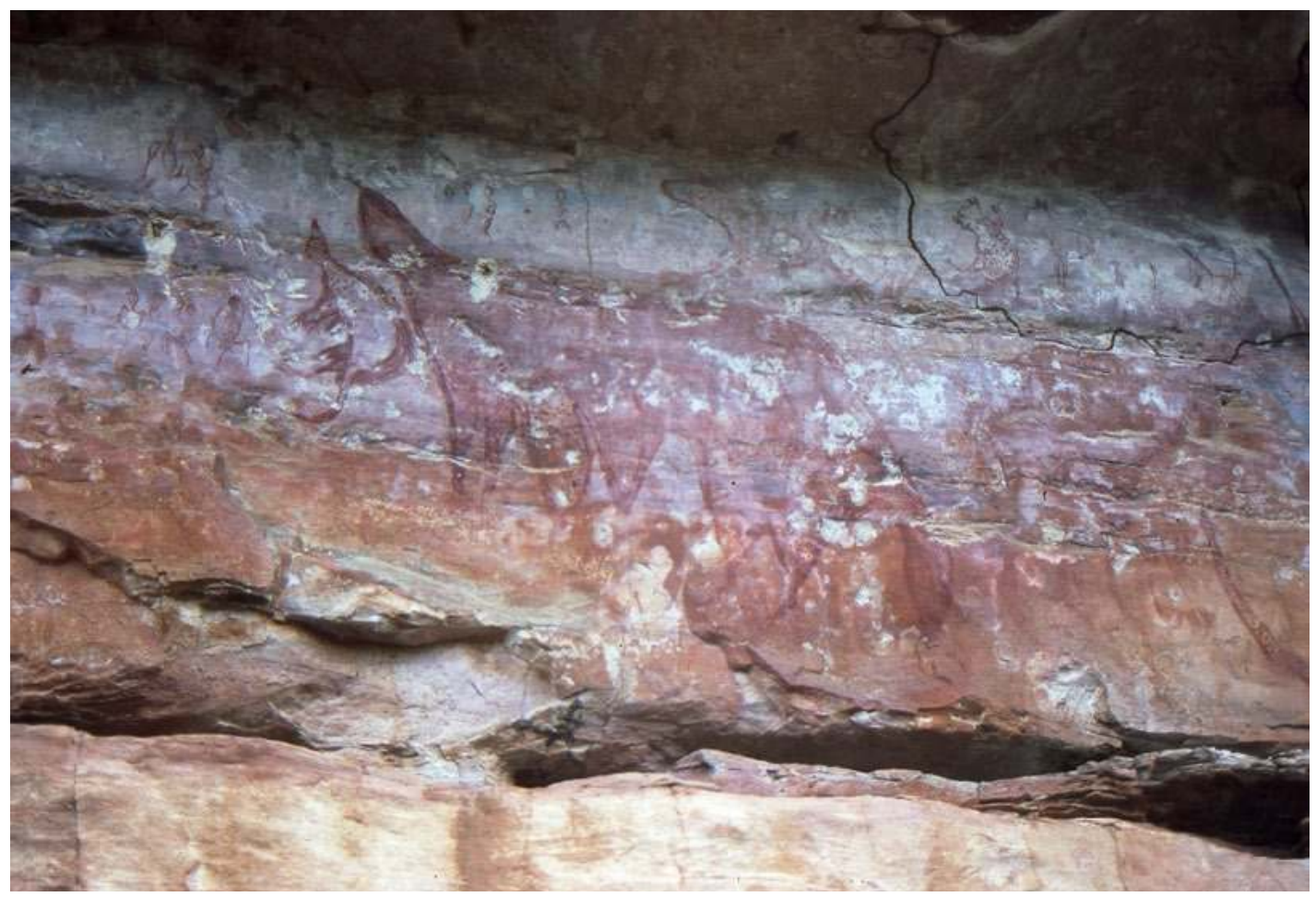

Figure 8.1 The painting of the megafauna species Palorchestes that displays two prominent tufts of chest hair and is accompanied by a smaller (younger?) version of the same animal.

Source: Photograph by Paul S.C. Taçon.

To illustrate this problem of uncertainty in interpretation, an image of a large animal at a site east of Nauwalabila in Deaf Adder Gorge, western Arnhem Land (Figure 1.1), shows a quadruped with muscular limbs, a long tongue, prominent claws, a long narrowing face, a coarse coat, robust legs and thick hair covering a thick tail. This image also has two bulky 'tufts' of chest hair or something similar (Figure 8.1). At its anterior end, there is a smaller version of the same 
creature that may or may not be a young animal. This smaller animal also has very prominent claws on its front feet. Both creatures have spotted coats and a mane extending from the head to the base of the tail. The appearance of the animals is consistent with expectations of a $350 \mathrm{~kg}$ Palorchestes, a genus of megafauna thought to have a short, trunk-like rhinarium and strong arms with large claws for ripping bark from trees and dead wood while searching for termites. This particular rock painting scene has indeed been identified as Palorchestes by some researchers, although the two images have not been allocated a species name (P. parvus or $P$. azeal) (Murray and Chaloupka 1984). It is difficult to explain the two tufts hanging from the larger creature's chest but, whatever they are, the smaller animal also has them. The larger of the two paintings is several metres long, suggesting that the large size is itself a naturalistic representation of a very large animal.

There were only three genera of large quadrupeds - all diprotodontids - that were possibly living at the time of early human occupation in Australia. They consist of Diprotodon optatum, Zygomaturus trilobus and the two species of Palorchestes. The distinctive form of Diprotodon does not fit the image of the two Palorchestes-like creatures discussed above, and Zygomaturus had prominent, laterally flared cheek bones, surely something an artist would depict and these are not shown on the rock paintings. Thus, the only animal whose gross morphology fits the image is Palorchestes, and that has also been the conclusion of others (Chaloupka 1993; Murray and Chaloupka 1994). There is another possibility, of course: the image is not one of a living fleshand-blood taxon but a spiritual creature or Ancestral Being (Ouzman et al. 2002). For instance, Bednarik (2013a:204) argues it is not naturalistic, while others such as Welch and Welch (2015) and Lewis (2017:95) contend it is likely a depiction of a mythical creature. However, the painting's close resemblance to present fossil reconstructions of Palorchestes lends support to that interpretation.

Below we present new evidence of four large depictions of strange animals unlike any extant in recent times, in order to elucidate debates about 1) whether Aboriginal people made pictures of megafauna; 2) the durability of rock art; 3) megafauna distribution; and 4) the nature of extinctions.

\section{New discoveries}

\section{Thylacoleo in the Kimberley and Arnhem Land?}

As already noted above, it has been suggested that some rock art images represent Thylacoleo in Arnhem Land (Murray and Chaloupka 1984) and the Kimberley (Akerman 1988, 2009; Akerman and Willing 2009; Wright 1992; although paintings reported by Akerman are more thylacine-like than Thylacoleo - see Lewis 2017; Taçon et al. 2011; Welch 2015). Another image is reported here, located during survey and recorded by one of us (PT) at the Djulirri rock art complex in the Wellington Range, northwest Arnhem Land (Figure 8.2). There were only two now-extinct dog-shaped quadrupeds that lived in Greater Australia during the past 60,000 years: thylacine and Thylacoleo. The difference between the two is obvious from their respective skeletons, particularly their individual head shapes. Thylacoleo had a large, robust jaw structure totally unlike that of the thylacine, which was much smaller. Also unlike the thylacine, Thylacoleo had prominent paws and claws, as well as strong front limbs. In the Kimberley painting reported by Akerman (1988, 2009; Akerman and Willing 2009), the front paws and claws are emphasised, unlike depictions of thylacines that have comparatively delicate dog-like front paws. 


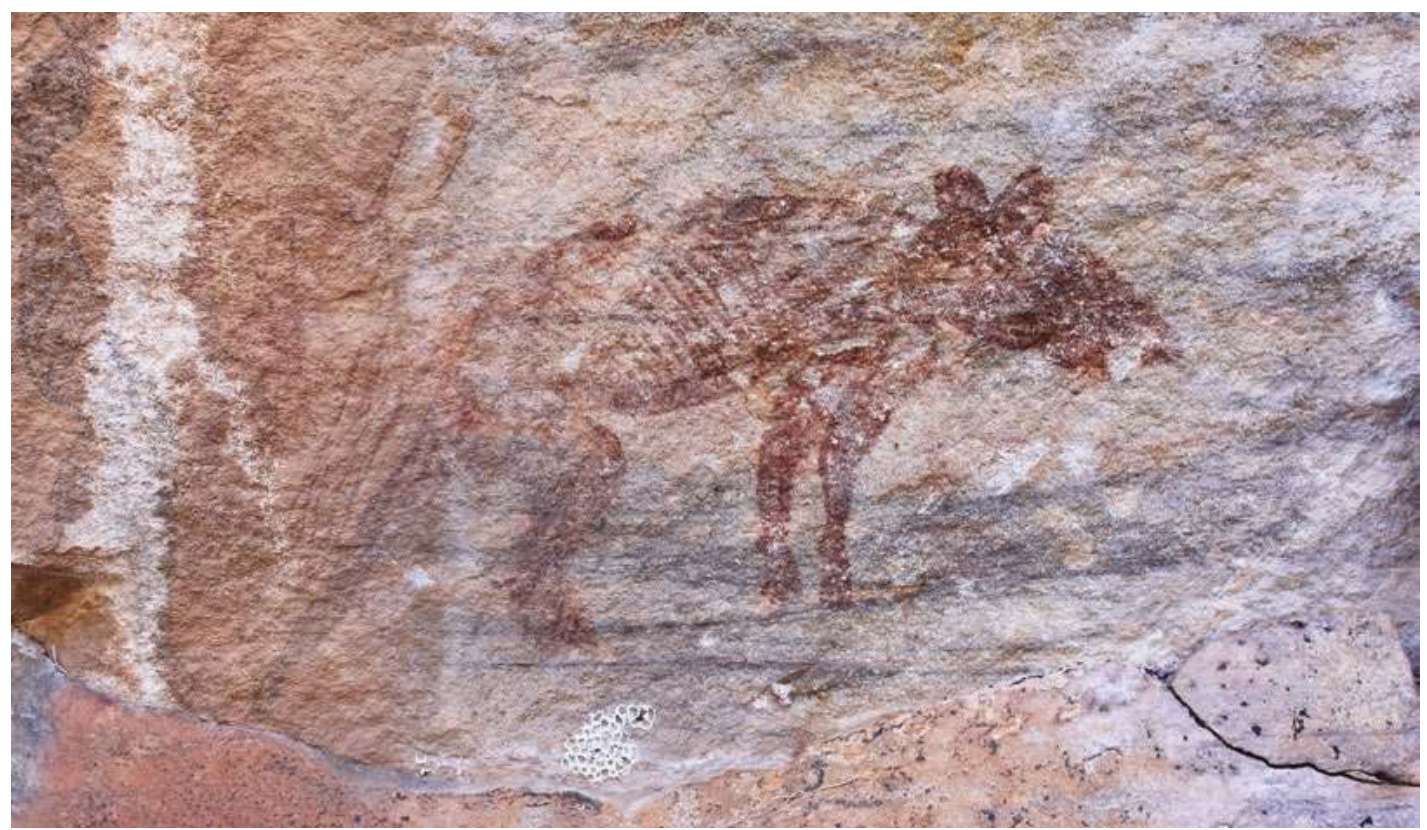

Figure 8.2 This painting depicts a predatory quadruped with a distinctively developed head and muzzle region unlike a thylacine. It is suggested that the robust proportions of the head represent a morphology similar to that of the marsupial lion Thylacoleo carnifex.

Source: Photograph by Paul S.C. Taçon.

The recently discovered northwest Arnhem Land painting measures $91 \mathrm{~cm}$ long by $46 \mathrm{~cm}$ high, smaller than an actual life-size Thylacoleo, but with a proportionally large head $28 \mathrm{~cm}$ long by $11 \mathrm{~cm}$ high, again quite unlike that of an actual thylacine and numerous Arnhem Land rock paintings of thylacines (e.g. see Taçon et al. 2011). The new painting is larger than that of most thylacine paintings, with a deeper, thicker muzzle and robust jaw; cranial features Thylacoleo-like but unlike those of the thylacine. However, the front legs and paws are smaller than those of the Kimberley paintings suggested to be of Kimberley Thylacoleo and the build of the legs is somewhat gracile - unlike that expected of a $150 \mathrm{~kg}$ Thylacoleo - although the back legs are robustly constructed. The Arnhem Land painting also lacks the distinctive stripes on the rear half of the body almost always painted in thylacine depictions, having instead a mix of diagonal and horizontal infill along with patches of solid or no infill as is typical of the oldest animal paintings. Lewis (2017) has not been to the site but made a drawing from a supplied photograph. His suggestion of stripes (2017:94) is not consistent with the clearly striped thylacine-like paintings documented elsewhere. Furthermore, his drawing (2017:93) has a longer overall head than the actual painted animal.

How do we explain the unusual mix of features in this painting? It appears that the animal image was repainted at least once, with a smaller more thylacine-like animal (with the diagonal lines and larger head) painted over the original more Thylacoleo-like animal. Rock paintings were often painted over in Arnhem Land (e.g. see example of overlapping thylacine images in different styles in Taçon et al. 2011) and many layers of painting are found at numerous sites. Perhaps the more recent image of a thylacine-like depiction was added after Thylacoleo became extinct and the painting was 'updated' to suit the environment of the second artist. For instance, there is a very recent example of this phenomenon with a painting of a European tall ship later repainted with a smoke stack to turn it into a steamer (May et al. 2013:91-94). The original possible Thylacoleo-to-thylacine image is more of a dark-red stain in the rock, while the second and more recent animal is slightly lighter in colour and has a longer snout. At the very least, the Arnhem Land animal depiction is not of an extant species, nor is it a representation of the more gracile thylacine. Exactly what was originally depicted remains to be resolved. 


\section{Procoptodon in Arnhem Land?}

Animal images made by ancient artists at other sites also provide probable identification as depictions of megafauna. One of these is in the Ubirr rock art complex in the north of Kakadu National Park. It is the largest image in a multi-layered complex of paintings spanning the width of a gallery that fills a small rockshelter. Although known for decades, this panel was not comprehensively studied until the site was visited in 2012 (by SW). While partially masked by more recent art, the image of interest here shows an outline of an extremely large and wellmuscled macropod measuring $235 \mathrm{~cm}$ long by $185 \mathrm{~cm}$ high (Figure 8.3). The artist has used short paint strokes in the outline, perhaps to depict coarse fur while also showing hairy ears. The tail has a thick base and remains stout along its entire length, unlike modern kangaroo tails and indicative of an appendage required to support a large, heavy body when sitting upright (Figure 8.4). The testes placed just below the base of the tail indicate a male animal, a detail the artist must have felt necessary to include. The legs are well-muscled, strong and end at a partially lifted foot with circular designs emphasising the ankle at the tarsometatarsal joint. The foot terminates in a single, large claw (Figure 8.5). The distinctive feature of this kangaroo painting, however, is its short face with rounded muzzle. Although the face is somewhat faded distally, close inspection and the tracing of lines from the brow shows the rounded form and shortened facial morphology (Figure 8.6).
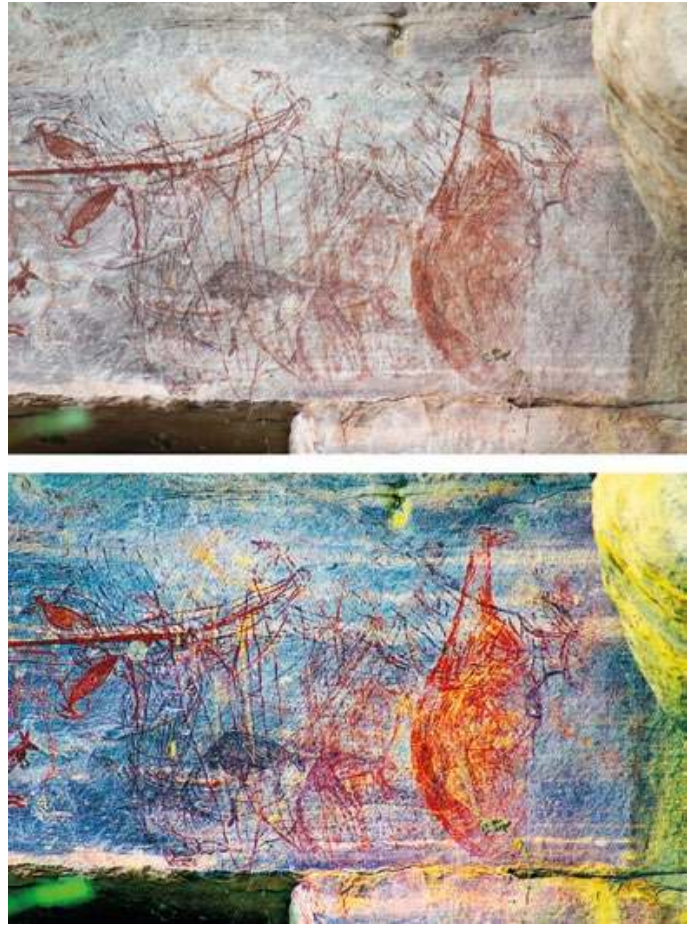

Figure 8.3 Top: An image of the large, shortfaced kangaroo painted in life-like proportions in Kakadu National Park. Bottom: Enhanced image using DStretch. Note the large claw, thick tail and short face of the animal. The large flightless bird mentioned in the text is also plainly visible.

Source: Photograph and enhancement by Steve Webb.
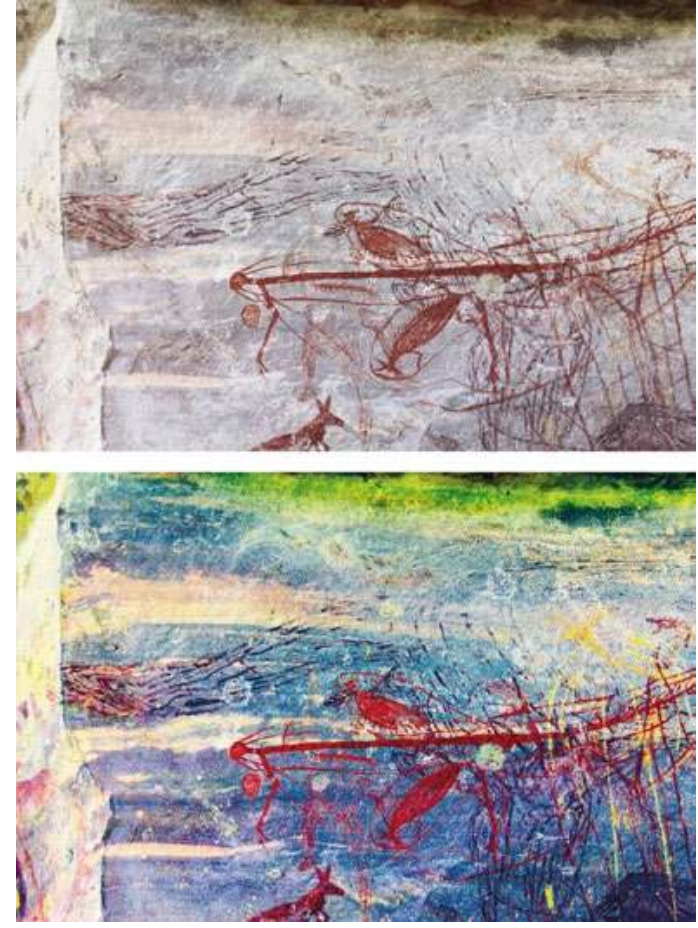

Figure 8.4 The thick tail structure of the kangaroo painted in Figure 8.3, which is unlike the tail of any modern animal and suggests the proportions required to balance the body of a large megafauna macropod. Top: Original image. Bottom: Enhanced image using DStretch.

Source: Photograph and enhancement by Steve Webb. 


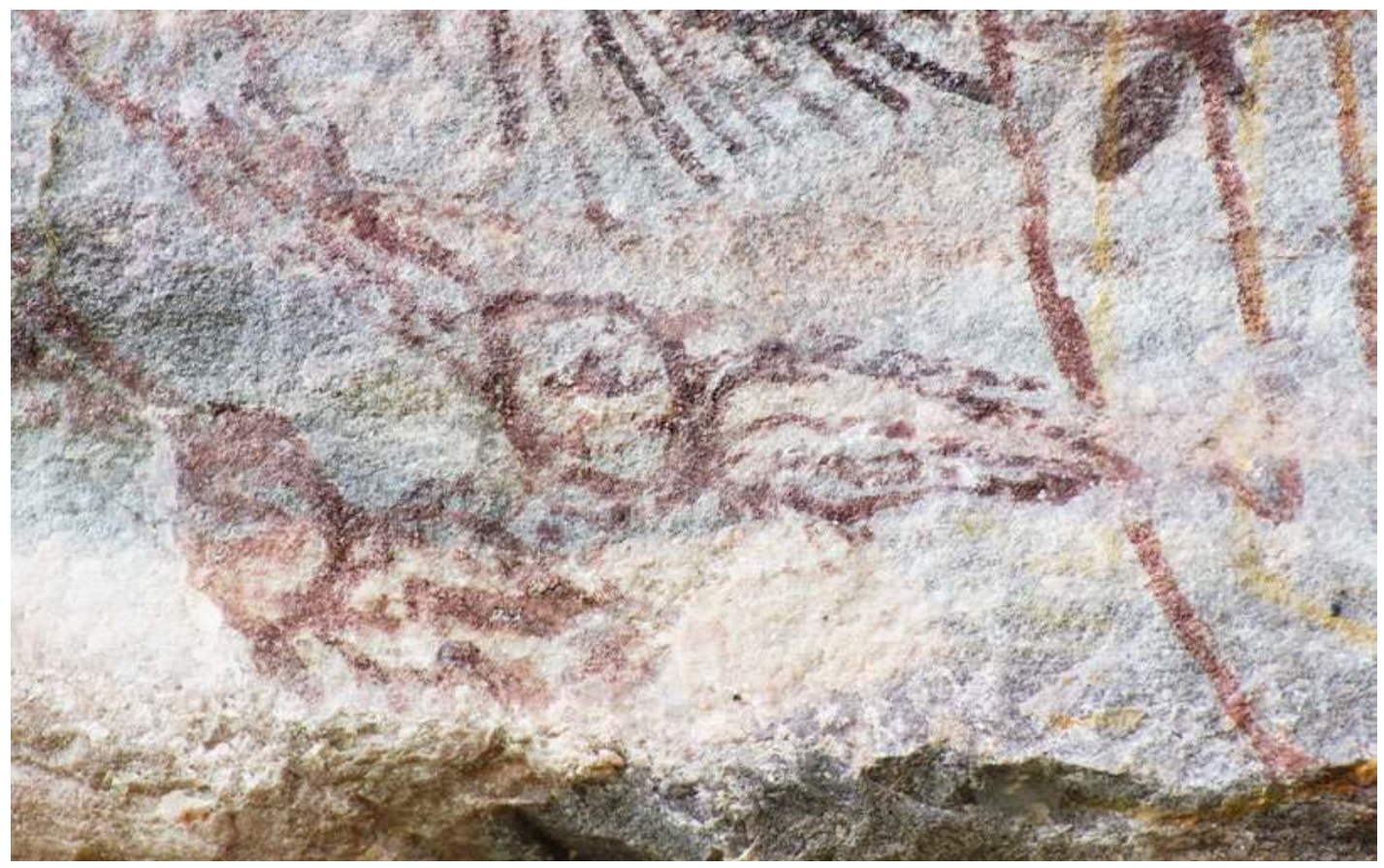

Figure $8.5 \mathrm{~A}$ close-up of the prominent single claw that is a distinct feature of the largest of shortfaced kangaroo Procoptodon goliah.

Source: Photograph by Steve Webb.
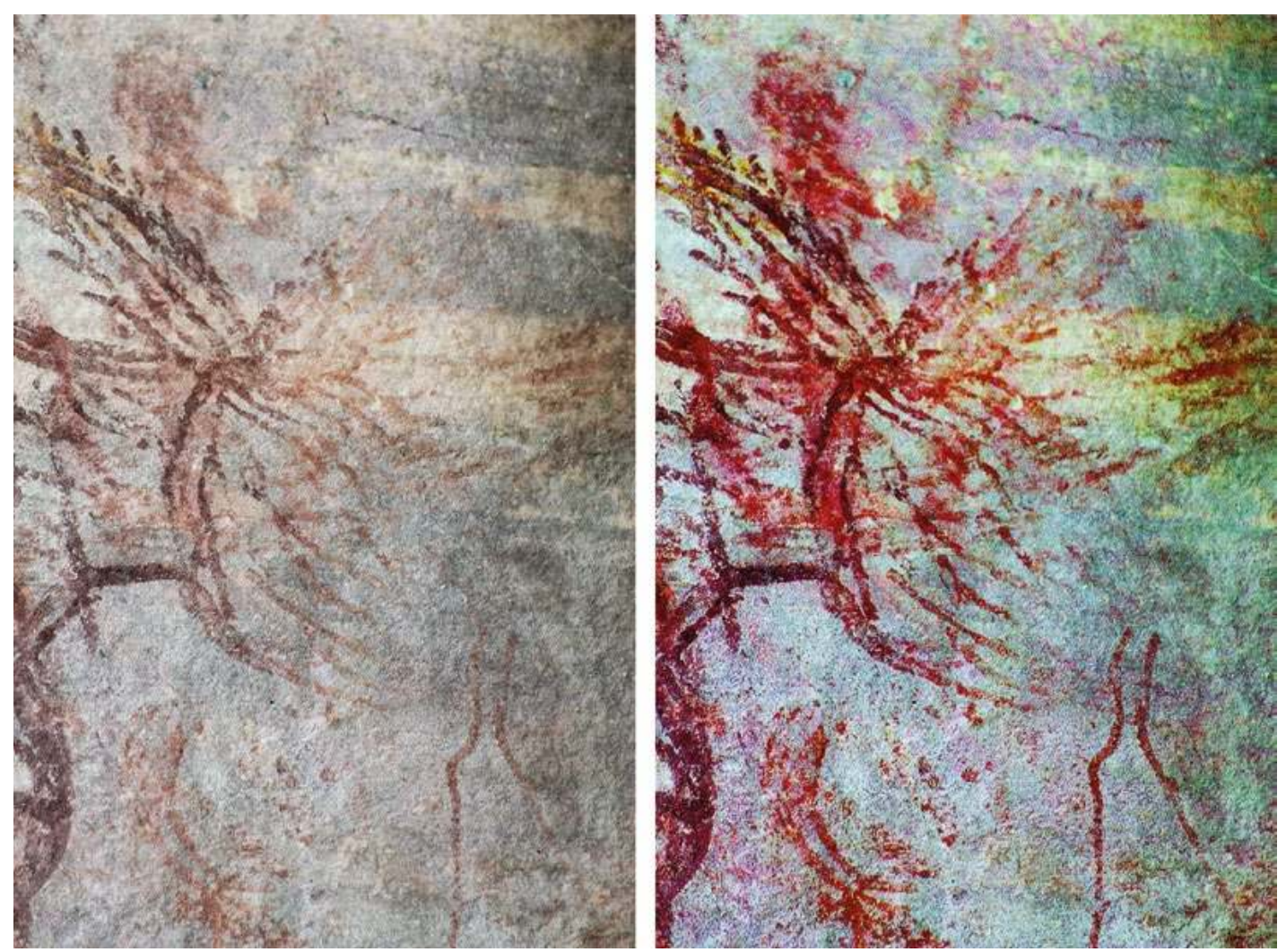

Figure 8.6 The distinct head region of the kangaroo in Figure 8.3 showing the rounded, shortened face structure and long hair on the ears. Left: Original image. Right: Enhanced image using DStretch. Source: Photograph and enhancement by Steve Webb. 
Features depicted in the above painting suggest a short-faced species of kangaroo. There were 23 short-faced kangaroo species, grouped in six genera, living in the mid to late Pleistocene in Greater Australia (Webb 2013) (Table 8.1). They include three species of Procoptodon, five (probable) 'Procoptodon', four Simosthenurus, four (probable) 'Simosthenurus', six Sthenurus and one Metasthenurus (Prideaux 2004). All were presumed extinct by the late Pleistocene, but a recent reassessment of the chronology of extinctions proposes that this timing was staggered, with seven short-faced species still around after humans arrived on the continent (Webb 2013; Wroe et al. 2013a). These surviving species include the largest short-faced species Procoptodon goliah (c. $250 \mathrm{~kg}$ ), the $150 \mathrm{~kg}$ 'Simosthenurus' pales, the $120 \mathrm{~kg}$ Simosthenurus occidentalis, 'Procoptodon' oreas (100 kg), Sthenurus andersoni $(75 \mathrm{~kg})$, 'Procoptodon' gilli and 'Procoptodon' browneorum (50-55 kg). Short-faced kangaroos lived widely across the south of the continent and in southeast Queensland, a distribution that does not preclude them from the Top End of the Northern Territory, particularly during glacial periods because at those times, environmental conditions were savannah-like in western Arnhem Land (Reeves et al. 2013). The short faces of these kangaroo species contrast with the long, slender, deer-like muzzles of modern and some extinct kangaroos. We propose that the painting in question is a short-faced species and a large animal given its bulky morphology and size. Any of the three largest extinct species listed above could be candidates for this image, although the presence of a prominent large claw suggests it might be Procoptodon goliah, as a large claw is a feature of this species.

Table 8.1 Listing of short-faced and long-faced kangaroos in the extinct megafauna cohort.

\begin{tabular}{|c|c|c|c|c|c|c|c|c|}
\hline Taxon & $\begin{array}{c}\text { Average } \\
\text { weight }(\mathrm{kg})\end{array}$ & QLD & NSW & VIC & LEB & SA & WA & TAS \\
\hline \multicolumn{9}{|l|}{ Short-faced kangaroos } \\
\hline 'Procoptodon' browneorum & 50 & $\checkmark$ & & $\checkmark$ & $\checkmark$ & $\checkmark$ & $\checkmark$ & \\
\hline 'Procoptodon' gilli & 54 & & $\checkmark$ & $\checkmark$ & $\checkmark$ & $\checkmark$ & $\sqrt{n}$ & \\
\hline 'Procoptodon' mccoyi & 50 & & & $S$ & & & & \\
\hline 'Procoptodon' oreas & 100 & $\checkmark$ & $\checkmark$ & & & $\checkmark$ & & \\
\hline 'Procoptodon' williamsi & 150 & & $\checkmark$ & & & $\checkmark$ & $\checkmark n$ & \\
\hline 'Simosthenurus' baileyi & 55 & & & & & $\checkmark$ & $\checkmark$ & \\
\hline 'Simosthenurus' brachyselenis & $>50$ & & $S$ & & & & & \\
\hline 'Simosthenurus' cf. antiquus & $>50$ & & & & & $S$ & & \\
\hline 'Simosthenurus' pales & 150 & $\checkmark$ & $\checkmark$ & & $\checkmark$ & $\checkmark$ & $\checkmark$ & \\
\hline Simosthenurus maddocki & 80 & $\checkmark$ & $\checkmark$ & $\checkmark$ & & $\checkmark$ & $\sqrt{n}$ & \\
\hline Simosthenurus occidentalis & 120 & & $\checkmark$ & $\checkmark$ & $\checkmark$ & $\checkmark$ & $\checkmark$ & $\checkmark$ \\
\hline Simosthenurus orientalis & $>50$ & $\checkmark$ & $\checkmark$ & & $\checkmark$ & $\checkmark$ & & $\checkmark$ \\
\hline Simosthenurus euryskaphus & $>50$ & & $S$ & & & & & \\
\hline Sthenurus agilis siva & $>50$ & $\checkmark$ & $\checkmark$ & & & $\checkmark$ & & \\
\hline Sthenurus andersoni & 72 & $\checkmark$ & $\checkmark$ & & $\checkmark$ & $\checkmark$ & $\checkmark n$ & $\checkmark$ \\
\hline Sthenurus atlas & 150 & $\checkmark$ & $\checkmark$ & $\checkmark$ & $\checkmark$ & $\checkmark$ & $\checkmark$ & \\
\hline Sthenurus murrayi & $>50$ & & $S$ & & & & & \\
\hline Sthenurus stirlingi & $>50$ & $\checkmark$ & & & $\checkmark$ & $\checkmark$ & & \\
\hline Sthenurus tindalei & 130 & $\checkmark$ & $\checkmark$ & $\checkmark$ & $\checkmark$ & $\checkmark$ & $\checkmark n$ & \\
\hline Metasthenurus newtonae & 55 & $\checkmark$ & $\checkmark$ & $\checkmark$ & & $\checkmark$ & $\checkmark$ & $\checkmark$ \\
\hline Procoptodon goliah & 230 & $\checkmark$ & $\checkmark$ & $\checkmark$ & $\checkmark$ & $\checkmark$ & $\checkmark n$ & \\
\hline Procoptodon pusio & 75 & $\checkmark$ & $\checkmark$ & & $\checkmark$ & & & \\
\hline Procoptodon rapha & 150 & $\checkmark$ & $\checkmark$ & $\checkmark$ & $\checkmark$ & $\checkmark$ & & \\
\hline Propleopus ocillans & 50 & $\checkmark$ & $\checkmark$ & $\checkmark$ & & $\checkmark$ & & \\
\hline
\end{tabular}




\begin{tabular}{|l|r|c|c|c|c|c|c|c|}
\hline Taxon & $\begin{array}{c}\text { Average } \\
\text { weight (kg) }\end{array}$ & QLD & NSW & VIC & LEB & SA & WA & TAS \\
\hline Long-faced kangaroos & 150 & & $\checkmark$ & & & $\checkmark$ & $\checkmark n$ & \\
\hline Macropus ferragus & 150 & $\checkmark$ & & & & & & \\
\hline Macropus pearsoni & 130 & $\checkmark$ & $\checkmark$ & $\checkmark$ & $\checkmark$ & $\checkmark$ & & $\checkmark$ \\
\hline Protemnodon anak & 110 & $\checkmark$ & $\checkmark$ & $\checkmark$ & $\checkmark$ & $\checkmark$ & $\checkmark$ & \\
\hline Protemnodon brehus & 170 & $\checkmark$ & & & & $\checkmark$ & $\checkmark n$ & \\
\hline Protemnodon roechus & $>50$ & $\checkmark$ & $\checkmark$ & $\checkmark$ & & & & \\
\hline Troposodon minor & $>50$ & & & $\checkmark$ & & & $\checkmark n$ & \\
\hline Baringa nelsonensis &
\end{tabular}

Black: Extant when humans lived in Australia. Underline: Extant until 51,000 years ago. Grey: Extant until the last interglacial (126,000 years ago). LEB stands for Lake Eyre Basin. ' $S$ ' means only a single species has ever been found. The ' $n$ ' means the species was found on the Nullarbor Plain or to the east, but not in the southwest of Western Australia. Note that no remains have been found in the Northern Territory.

Source: Steve Webb.

\section{Protemnodon in Arnhem Land?}

Another large macropod painting occurs in the Wellington Range, less than a kilometre from the Djulirri Thylacoleo-like painting discussed above. The painting shows a kangaroo bending over and measuring $251 \mathrm{~cm}$ wide and $146 \mathrm{~cm}$ high from the bottom of its left foot to the top of its bent back (Figures 8.7). The head is in profile with ears extending onto the shelter's ceiling (Figure 8.8). The side of the head is $40 \mathrm{~cm}$ in length and $10 \mathrm{~cm}$ wide at the muzzle, and there are huge ears spread over $38 \mathrm{~cm}$ (the left ear is $22 \mathrm{~cm}$ long). This is one of the largest macropod heads recorded in Arnhem Land. The tail is $75 \mathrm{~cm}$ long and $20 \mathrm{~cm}$ wide, much broader than for any extant species (Figure 8.9). The hind feet are very large, with the right foot measuring $40 \mathrm{~cm}$ long and a maximum width of $14 \mathrm{~cm}$ (Figure 8.10). The front feet are depicted with huge pointed claws (Figure 8.11). Other nearby paintings of extant species in the same style have essentially correct body proportions, so we assume that this is also true of this macropod painting. Exactly which species it represents is uncertain, but a very large animal with a longer face may be one of three Protemnodon species that weighed between 110-170 kg, all believed to be extant when humans arrived.

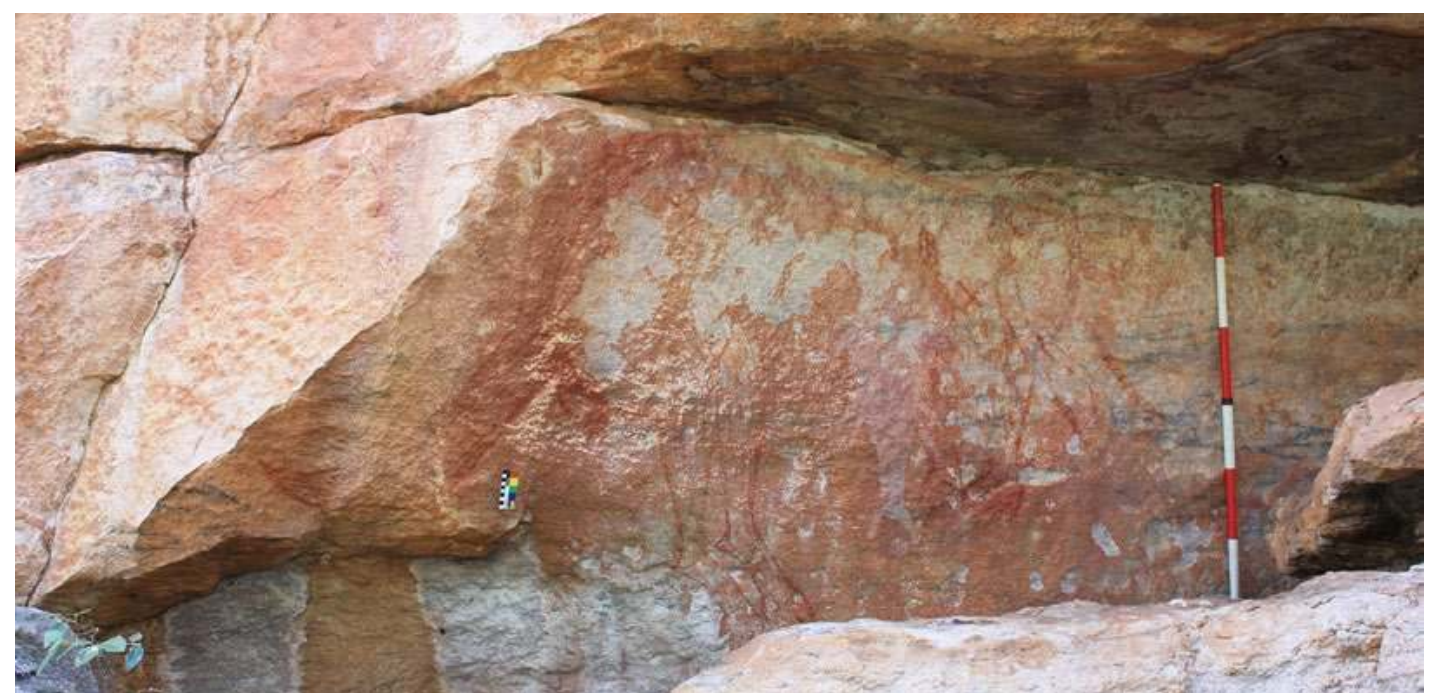

Figure 8.7 A large kangaroo that is a possible representation of Protemnodon(?), painted in the Wellington Range northeast of the Kakadu painting.

Source: Photograph by Paul S.C. Taçon. 

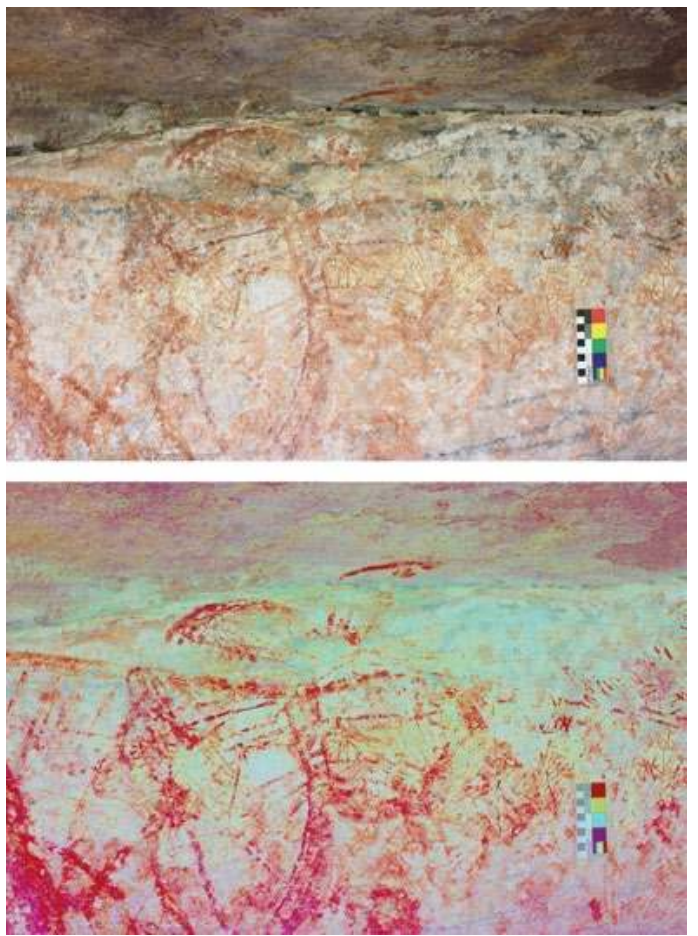

Figure 8.8 This animal has a longer face than the Kakadu kangaroo, and other features that might represent one of the long-faced extinct varieties, such as Protemnodon of which there were three species, all believed to exist until after humans arrived (Table 8.1; see also Figure 8.3). Top: Original image. Bottom: Enhanced image using DStretch. Scale $10 \mathrm{~cm}$.

Source: Photograph and enhancement by Paul S.C. Taçon.

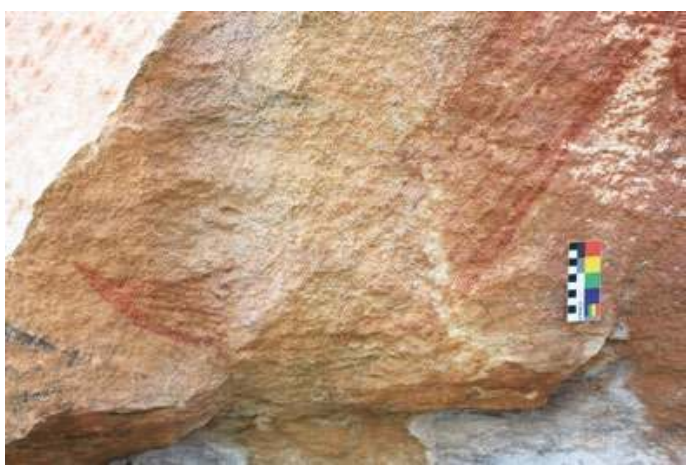

Figure 8.9 The tail is very broad, up to $20 \mathrm{~cm}$ wide, and much broader than any extant kangaroo. Scale $10 \mathrm{~cm}$.

Source: Photograph by Paul S.C. Taçon.

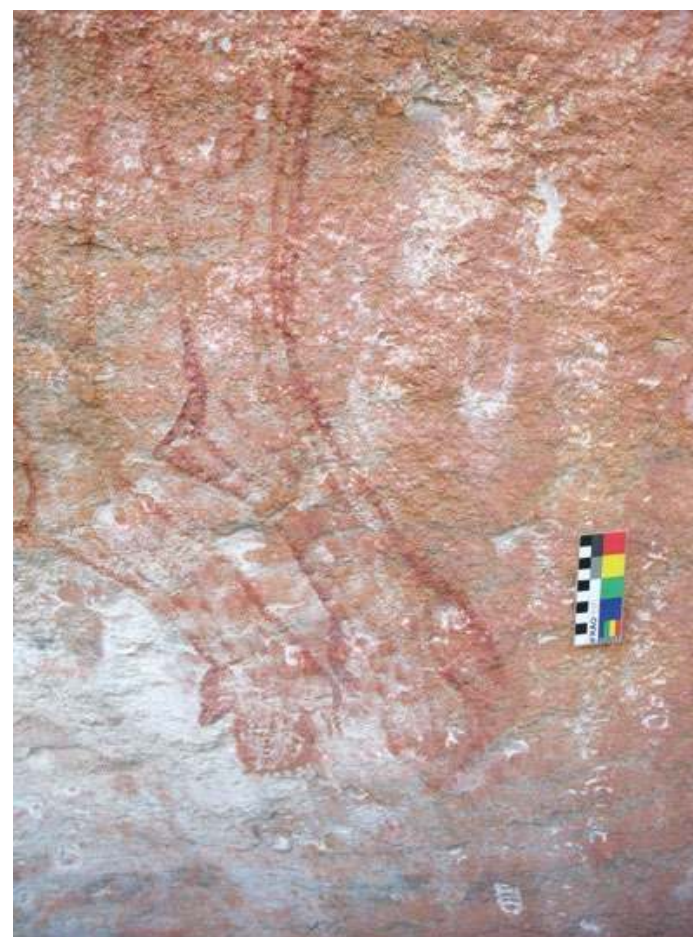

Figure $8.10 \mathrm{~A}$ close up of the feet of the large kangaroo (Protemnodon?). These feet are quite different from those of the image depicted in Figure 8.5. They are much broader, shorter and show a distinct paw-like morphology absent from the animal in Figure 8.5 . Scale $10 \mathrm{~cm}$.

Source: Photograph by Paul S.C. Taçon.

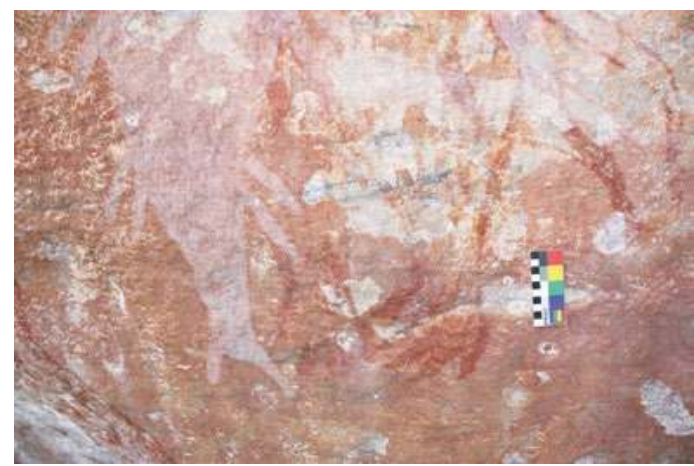

Figure 8.11 The front feet are shown with huge pointed claws. Scale $10 \mathrm{~cm}$.

Source: Photograph by Paul S.C. Taçon. 


\section{Genyornis in Arnhem Land?}

The image of a large bird underlying the shortfaced kangaroo on the Ubirr panel shows a bulky body covered with coarse feathers painted redbrown but lacking wings and legs. The short neck is painted in a much lighter colour, possibly indicating different plumage types and/or colour from the rest of the body (Figure 8.12). At a glance, this painting could be taken for an emu (Dromaius novaehollandiae), a species currently extant in the region. But the neck in the painting is shorter and the head is smaller and differently shaped to those of an emu. Moreover, in the painting, the prominent beak is broad, flat and long like a goose rather than the short, narrow design of an emu. Overall, the appearance is identified as an unknown type of flightless bird that is strongly underpinned by the bulky body shape. Is it a Genyornis, which also had a goose-like beak and solid body? The painting's appearance is unlike another image reported from southern Arnhem Land and believed by some researchers to be Genyornis (Gunn et al. 2011; but see Bednarik 2013a; see also Chapter 15, this volume), or of another from far north Queensland also thought by some to be of that genus (Trezise 1971). It is possible that sexual dimorphism or stage of maturity in Genyornis may account for the somewhat different appearances of apparent Genyornis paintings, but this is speculation. There could also be one more possibility: that there were several species of Genyornis, similar to the situation in New Zealand Moas of which there were nine species in six genera. What we can say is that the new image we report here is of a large, unknown, probably flightless bird of a ratite or dromornithid origin.

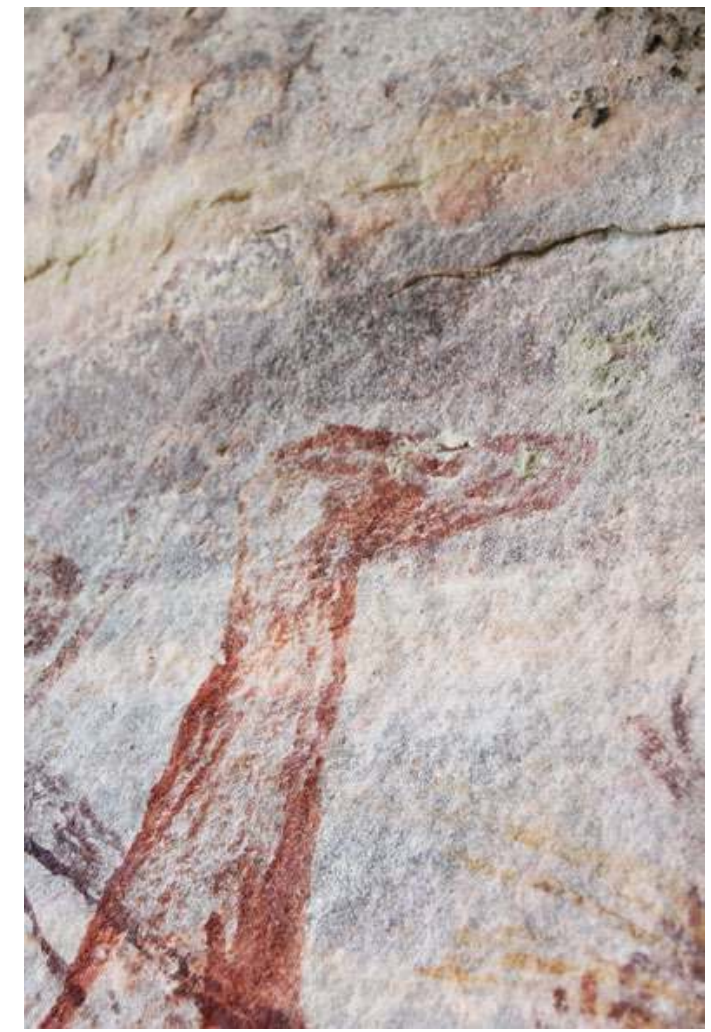

Figure 8.12 The unidentified 'flightless' bird that underlies the large short-faced kangaroo.

Source: Photograph by Steve Webb.

\section{How should we interpret these enigmatic images?}

Unknown animals in rock art could be dismissed as depictions of Ancestral Beings or spirit animals that are the products of cultural belief, imagination and creativity. The naturalistic images discussed here, however, are difficult to explain in that way. In some respects, these images parallel extinct fauna represented in Europe's Upper Palaeolithic cave art (e.g. woolly mammoths and rhinoceroses at Rouffignac, Chauvet Cave and elsewhere) and recently discovered engravings of 'mammoths' in North America (Clottes 2013; Molatki and Wallace 2011; but see Bednarik 2013b). In such a reading, the paintings discussed above are depictions of animals familiar to the artist, whatever the exact reason for their placement on the rock surface. As in the European and 
North American depictions, the Arnhem Land artists have painted readily identified animal forms that seemingly indicate known species of megafauna. Furthermore, spiritual or mythical beings and creatures in Aboriginal art are normally identified by their exaggerated or abstract forms and associated features that little resemble everyday creatures, with the most powerful often having a composite form made up of body parts of various animals (Taçon and Chippindale 2000; Taçon et al. 1996). In some of the relatively recent art of western Arnhem Land, and to a lesser extent the Kimberley and Pilbara regions, naturalism is evident not only in paintings of terrestrial and aquatic wildlife of the everyday world, but also in recent times of non-Aboriginal objects such as European ships, Macassan prau, aircraft, firearms and other objects (e.g. Chaloupka 1993; May et al. 2010; Wesley 2013). Such naturalistic imagery is easily recognisable and can often be identified to particular animal taxa or object types and makes.

Western Arnhem Land Aboriginal artists of the recent past as well as of more ancient times paint excellent and detailed likenesses of extant animals they live with, which can often be identified to species level by Western researchers and local Aboriginal people alike (Chaloupka 1993; Taçon 1988), just as has been done for European Upper Palaeolithic paintings of animals. If the images described above do show long-extinct species of megafauna, the question that then arises is when were they painted? If final extinction of the last megafauna took place c. 40,000-50,000 years ago (e.g. Miller et al. 1999), these paintings would pre-date the known age of naturalistic art of any fauna, extinct or not, anywhere in the world. On the other hand, if the Arnhem Land images are those of extinct megafauna - as they may well be - then it is also possible that these animals survived in Arnhem Land longer (see also Webb 2013; Wroe et al. 2013). Consistent with this latter interpretation, new rock art dating results are showing that rock paintings can survive at least 40,000 years (Aubert et al. 2014; Pike et al. 2012; Sadier et al. 2012), and there is probably much older rock art that has not yet been reliably dated.

All of the new discoveries reported here follow the earliest 'Large Naturalistic Animal' painting practice that underlies all other figurative styles in Arnhem Land and is argued to be Pleistocene in age (e.g. see Chaloupka 1993; Chippindale and Taçon 1993, 1998; Lewis 1988; Taçon and Brockwell 1995; a good example is in Taçon et al. 2011, but see Taçon and Chippindale 2008 for discussion of more recent [mid-Holocene] naturalistic animal paintings). In this regard, new dating results from rock art sites in Sulawesi to Australia's immediate north support the idea that extremely old rock art likely survives in the Greater Australian region. Uranium-series dating of speleothems over and under 12 hand stencils and two naturalistic animal depictions from seven sites in the Maros area of Sulawesi, on Greater Australia's northern doorstep, has revealed the oldest ages for these forms of rock art in the world. The earliest minimum age for a hand stencil is 39,900 years at Leang Timpuseng and the oldest animal painting, of a babirusa 'pigdeer' at the same site, is 35,400 years. A second animal painting (probably a pig) at another site has a minimum age of 35,700 years (Aubert et al. 2014). There are many other naturalistic animal paintings not yet dated, painted in ways reminiscent of some of the earliest rock art of the Kimberley and Kakadu/Arnhem Land region where hand stencils also appear early in local chronologies based on superimpositions. The Sulawesi paintings mostly survive in rockshelters, rather than in deep caves as in Europe. Aubert et al.'s (2014) research thus signals that it is conceivable that similarly old art survives in northern Australia and that the early art of both Sulawesi and northern Australia may have resulted from a shared practice undertaken by modern humans as they spread across the region (Aubert et al. 2014; Taçon et al. 2014). 


\section{Conclusion}

Unfortunately, little rock art in Arnhem Land has been scientifically dated, especially images argued to be the oldest, and we do not have minimum or maximum ages for large naturalistic paintings near the beginning of the Arnhem Land sequence, including what may be depictions of megafauna. Consequently, we can only rely on morphology as conveyed by artists in their paintings for identifying possible depictions of megafauna. Size is also important in that early depictions of extant and more easily identifiable fauna are usually at or near life-size, but size alone cannot be used as a criteria for identifying megafauna (Bednarik 2013a). And an important difference between Australia and Europe in terms of depictions of extinct megafauna is that in Europe there are multiple repetitions, while in Australia there are isolated finds or small numbers at sites. This may partly be a preservation and/or survey issue, and there may be other factors that influenced the frequency of megafauna depictions.

However, we have shown that there are sound grounds to support the argument that there are surviving Pleistocene depictions of megafauna at rock art sites in northern Australia (in particular, the two giant kangaroo paintings discussed above), based on 1) the naturalistic appearance of the animal images, 2) comparability with what is known from the fossil record to the south, and 3) new knowledge about the long-term survivability of rock paintings in the Greater Australian island Southeast Asian region (cf. Aubert et al. 2014). The new Arnhem Land rock art depictions interpreted as megafauna are important in that the paintings show the existence of probable megafauna species in the far north of the continent, a place at the forefront of human arrivals into Greater Australia. If they are indeed depictions of extinct megafauna, these paintings also show overlap with humans: humans encountered these creatures and made images of them. In an area where fossil bone preservation and/or visibility seem to be absent, we may now have the beginning of a record, albeit tentative, limited in terms of species and open to debate.

New and innovative dating programs are needed to ascertain the age of the paintings described here, because the dating of paintings in sandstone shelters is far less advanced than it is for limestone shelters where the oldest rock art of Indonesia and Europe are found. The oldest ages for the presence of humans in Australia, at least 65,000 years ago by optically stimulated luminescence dating, are derived from the Madjedbebe (Malakunanja II) rockshelter, located within the area where the apparent Arnhem Land megafauna paintings are found (Clarkson et al. 2017; Roberts et al. 1998). Even if some researchers are correct that most species of megafauna became extinct about 40,000-50,000 years ago, the Madjedbebe dates show that humans and megafauna probably co-existed for thousands of years in the Kakadu/Arnhem Land region. There may also have been a slow, climatically driven process of megafaunal attrition throughout the mid to late Pleistocene, as Wroe et al. (2013a, 2013b) and Webb (2013) have argued. Whatever the case, there was time for Australia's early inhabitants to record megafauna in north Australian rockshelters before they disappeared forever. The images described here appear to give us a unique window into aspects of what Australia looked like when humans first arrived. Advances in dating both megafaunal remains and rock art, as well as new discoveries, will allow us to better support or refute arguments about some of the unusual, seemingly ancient imagery described here.

\section{Acknowledgements}

Griffith University and Bond University supported this research. We thank Gabrielle O'Loughlin and other Kakadu National Parks staff as well as members of the Gunbalanya Community and Traditional Owners for facilitating access to the Kakadu site. The Northern Land Council, 
Ronald Lamilami and other Namunidjbuk Estate Traditional Owners are thanked for access and permission to record the Wellington Range sites. Wellington Range research was the result of Australian Research Council Discovery grant DP080877463.

\section{References}

Akerman, K. 1998. A rock painting, possibly of the now extinct marsupial Thylacoleo (marsupial lion), from the north Kimberley, Western Australia. The Beagle, Records of the Museum and Art Gallery of the Northern Territory 14:117-121.

Akerman, K. 2009. Interaction between humans and megafauna depicted in Australian rock art? Antiquity 83(322). www.antiquity.ac.uk/projgall/akerman322/

Akerman, K. and T. Willing 2009. An ancient rock painting of a marsupial lion, Thylacoleo carnifex, from the Kimberley, Western Australia. Antiquity 83(319). antiquity.ac.uk/projgall/akerman319/

Archer, M. 1974. New information about the Quaternary distribution of the thylacine (Marsupialia, Thylacinidae) in Australia. Journal of the Royal Society of Western Australia 57:43-49.

Aubert, M., A. Brumm, R. Ramli, T. Sutikna, E.W. Saptomo, B. Hakim, M.J. Morwood, G.D. van den Berg, L. Kinsley and A. Dosseto 2014. Pleistocene cave art from Sulawesi, Indonesia. Nature 524:223-227. doi.org/10.1038/nature13422

Basedow, H. 1925. The Australian Aboriginal. F.W. Preece and Sons, Adelaide.

Bednarik, R.G. 2013a. Megafauna depictions in Australian rock art. Rock Art Research 30(2):197-215.

Bednarik, R.G. 2013b. Proboscidean petroglyphs in the USA. INORA 67:1-7.

Brandl, E. 1972. Thylacine designs in Arnhem Land rock paintings. Archaeology and Physical Anthropology in Oceania 7(1):24-30.

Brook, B.W., C.J.A. Bradshaw, A. Cooper, C.N. Johnson, T.H. Worthy, M. Bird, R. Gillespie and R.G. Roberts 2013. Lack of chronological support for stepwise prehuman extinctions of Australian megafauna. Proceedings of the National Academy of Sciences (PNAS) 110(36):E3368. doi.org/10.1073/ pnas. 1309226110

Brown, O. 2006. Tasmanian devil (Sarcophilus harrisii) extinction on the Australian mainland in the mid-Holocene: Multicausality and ENSO intensification. Alcheringa: An Australasian Journal of Paleontology 30(1): 49-57. doi.org/10.1080/03115510609506855

Cane, S. 2013. First footprints: The epic story of the First Australians. Allen and Unwin, Crows Nest.

Chaloupka, G. 1993. Journey in Time: The World's Longest Continuing Art Tradition. Reed, Chatswood.

Chippindale, C. and P.S.C. Taçon 1993. Two old painted panels from Kakadu: Variation and sequence in Arnhem Land rock art. In J. Steinbring, A. Watchman, P. Faulstich and P.S.C. Taçon (eds), Time and Space: Dating and Spatial Considerations in Rock Art Research, pp. 32-56. Occasional AURA Publication 8. Australian Rock Art Research Association, Melbourne.

Chippindale, C. and P.S.C. Taçon 1998. The many ways of dating Arnhem Land rock-art, north Australia. In C. Chippindale and P.S.C. Taçon (eds), The Archaeology of Rock-Art, pp. 90-111. Cambridge University Press, Cambridge. 
Clarkson, C., Z. Jacobs, B. Marwick, R. Fullagar, L. Wallis, M. Smith, R.G. Roberts, E. Hayes, K. Lowe, X. Carah, S.A. Florin, J. McNeil, D. Cox, L. J. Arnold, Q. Hua, J. Huntley, H.E.A. Brand, T. Manne, A. Fairbairn, J. Shulmeister, L. Lyle, M. Salinas, M. Page, K. Connell, G. Park, K. Norman, T. Murphy and C. Pardoe 2017. Human occupation of Australia by 65,000 years. Nature 547(7663): 306-310. doi.org/10.1038/nature22968

Clegg, J. 1978. Pictures of striped animals: Which ones are thylacines? Archaeology and Physical Anthropology in Oceania 13(1)19-29.

Clottes, J. 2013. Two petroglyphs of Proboscideans at Upper Sand Island, Bluff, Utah (USA). INORA 67:7-10.

Gollan, K. 1984. The Australian dingo: In the shadow of man. In M. Archer, M. and G. Clayton (eds), Vertebrate Zoogeography and Evolution in Australia, pp. 921-927. Hesperian Press, Perth.

Gunn, R.G., Douglas, L.C. and R.L. Wear 2011. What bird is that? Identifying a probable painting of Genyornis newtoni in Western Arnhem Land. Australian Archaeology 73:1-12.

Johnson, C.N. 2006. Australia's Mammal Extinctions: A 50,000 Year History. Cambridge University Press, Melbourne.

Lewis, D.J. 1977. More striped designs in Arnhem Land rock paintings. Archaeology and Physical Anthropology in Oceania 12(2):98-111.

Lewis, D.J. 1988. The Rock Paintings of Arnhem Land, Australia: Social, Ecological and Material Culture Change in the Post-Glacial Period. BAR International Series 415. British Archaeological Reports, Oxford.

Lewis, D.J. 2017. Megafauna identification for dummies: Arnhem Land and Kimberley 'Megafauna' paintings. Rock Art Research 34(1): 82-99.

May, S.K., P.S.C. Taçon, D. Wesley and M. Pearson 2013. Painted ships on a painted Arnhem Land landscape. The Great Circle 35(2):83-102.

May, S.K., P.S.C. Taçon, D. Wesley and M. Travers 2010. Painting history: Indigenous observations and depictions of the 'other' in northwestern Arnhem Land, Australia. Australian Archaeology 71:57-65. doi.org/10.1080/03122417.2010.11689384

Miller, G.H., J. Magee, B.J. Johnson, M.L. Fogel, N.A. Spooner, M.T. McCulloch and L. Ayliffe 1999. Pleistocene extinction of Genyornis newtoni: Human impact on Australian megafauna. Science 283:205-208. doi.org/10.1126/science.283.5399.205

Molatki, E. and H.D. Wallace 2011. Columbian mammoth petroglyphs from the San Juan River near Bluff, Utah, United States. Rock Art Research 28(2):143-152.

Mulvaney, K. 2009. Dating the Dreaming: Extinct fauna in the petroglyphs of the Pilbara region, Western Australia. Archaeology in Oceania 44 Supplement: 40-48. doi.org/10.1002/j.18344453.2009.tb00067.x

Mulvaney, K. 2013. Iconic imagery: Pleistocene rock art development across northern Australia. Quaternary International 285:99-110. doi.org/10.1016/j.quaint.2011.07.020

Murray, P. and G. Chaloupka 1984. The Dreamtime animals: Extinct megafauna in Arnhem Land rock art. Archaeology in Oceania 19:106-116. doi.org/10.1002/j.1834-4453.1984.tb00089.x

Ouzman, S., P.S.C. Taçon, K. Mulvaney and R. Fullagar 2002. Extraordinary engraved bird track from North Australia: Extinct fauna, Dreamtime Being or aesthetic masterpiece? Cambridge Archaeological Journal 12(1):103-112. doi.org/10.1017/S0959774302000057 
Pike, A.W.G., D.L. Hoffman, M. García-Diez, P. Pettitt, J. Alcolea, R. De Balbín, C. González-Sainz, C. de las Heras, J.A. Lasheras, R. Montes, R. and J. Zilhão 2012. U-series dating of Paleolithic art in 11 caves in Spain. Science 336, 1409-1413.

Prideaux, G.J. 2004. Systematics and evolution of the sthenurine kangaroos. University of California Publications in Geological Sciences Volume 146: pp.1-623. University of Chicago Press, Berkley. doi.org/10.1525/california/9780520098459.001.0001

Reeves, J.M., H.C. Bostock, L.K. Ayliffe, T.T. Barrows, P. De Deckker, L.S. Devriendt, G.B. Dunbar, R.N. Drysdale, K.E. Fitzsimmons, M.K. Gagan, M.L. Griffiths, S.G. Haberle, J.D. Jansen, C. Krause, S. Lewis, H.V. McGregor, S.D. Mooney, P. Moss, G.C. Nanson, A. Purcell and S. Van der Kaars 2013. Palaeoenvironmental change in tropical Australasia over the last 30,000 years - a synthesis by the OZ-INTIMATE group. Quaternary Science Reviews. doi.org/10.1016/j. quascirev.2012.11.027

Roberts, R.G., H. Yoshida, R. Galbraith, G. Laslett, R. Jones and M. Smith 1998. Single-aliquote and single-grain optical dating confirm thermoluminescence age estimates at Malakunanja II rock shelter in northern Australia. Ancient TL 16:19-24.

Roberts, R.G., T.F. Flannery, L.K. Ayliffe, H. Yoshida, J.M. Olley, G.J. Prideaux, G.M. Laslett, A. Baynes, A., Smith, M.A., Jones, R. and B.L. Smith 2001. New ages for the last Australian megafauna: Continent-wide extinction 46,000 years ago. Science 29:1888-1892.

Sadier, B., J.-J. Delannoy, L. Benedetti, D.L., Bourlès, S. Jaillet, J.-M.Geneste, A.-E Lebatard and M. Arnold 2012. Further constraints on the Chauvet cave artwork elaboration. Proceedings of the National Academy of Sciences (PNAS) 109(21), 8002-8006.

Taçon, P.S.C. 1988. Identifying fish species in the recent rock paintings of western Arnhem Land. Rock Art Research 5(1):3-15.

Taçon, P.S.C. 2011. Special places and images on rock; 50,000 years of Indigenous engagement with Australian landscapes. In J. Anderson (ed.), Cambridge Companion to Australian Art, pp. 11-21. Cambridge University Press, Melbourne.

Taçon, P.S.C. and S. Brockwell 1995. Arnhem Land prehistory in landscape, stone and paint. Antiquity 69(259):676-95. doi.org/10.1017/S0003598X00082272

Taçon, P.S.C. and C. Chippindale 2000. Transformation and depictions of the First People: Animalheaded beings of Arnhem Land, N.T., Australia. In K. Helskog (ed.), Theoretical Perspectives in Rock Art Research, pp. 175-210. Novus Forlag, Oslo.

Taçon, P.S.C. and C. Chippindale 2008. Changing places: Ten thousand years of north Australian rock-art transformation. In D. Papagianni, H. Maschner and R. Layton (eds), Time and Change: Archaeological and Anthropological Perspectives on the Long-Term in Hunter-Gatherer Societies, pp. 73-94. Oxbow Books, Oxford.

Taçon, P.S.C., W. Brennan and R. Lamilami 2011. Rare and curious thylacine depictions from Wollemi National Park, New South Wales and Arnhem Land, Northern Territory, Australia. In J. Specht and R. Torrence (eds), Changing Perspectives in Australian Archaeology. Technical Reports of the Australian Museum online Volume 23, Issue 11, pp. 165-174. The Australian Museum, Sydney. doi.org/10.385 3/j.1835-4211.23.2011.1576

Taçon, P.S.C., M. Wilson and C. Chippindale 1996. Birth of the Rainbow Serpent in Arnhem Land rock art and oral history. Archaeology in Oceania 31(3):103-124. doi.org/10.1002/j.1834-4453.1996. tb00355.x 
Taçon, P.S.C., N.H. Tan, S. O’Connor, X. Ji, L. Gang, D. Curnoe, D. Bulbeck, B. Hakim, I. Sumantri, H. Than, I. Sokrithy, S. Chia, K. Khun-Neay and S. Kong 2014. Global implications of early surviving rock art of greater Southeast Asia. Antiquity 88:1050-1064. doi.org/10.1017/ S0003598X00115315

Trezise, P. 1971. Rock Art of South-East Cape York. Australian Institute of Aboriginal Studies, Canberra.

Walsh, G. 2000. Bradshaw Art of the Kimberley. Takarakka Nowan Kas Publications, Toowong, Queensland, Australia.

Webb, S. 2008. Megafauna demography and late Quaternary climatic change in Australia: A predisposition to extinction. Boreas 39:25-38. doi.org/10.1111/j.1502-3885.2008.00026.x

Webb, S. 2013. Corridors to Extinction and the Australian Megafauna. Elsevier, New York.

Welch, D. 2015. Thy Thylacoleo is a thylacine. Australian Archaeology 80(1):40-47. doi.org/10.1080/031 22417.2015.11682043

Welch, D. and A. Welch. 2015. Palorchestes or bunyip? International Newsletter on Rock Art 72: 18-24.

Wesley, D. 2013. Firearms in rock art of Arnhem Land, Northern Territory, Australia. Rock Art Research 30(2): 235-247.

Wright, B.J. 1972. Rock engravings of striped mammals: the Pilbara region, Western Australia. Archaeology and Physical Anthropology in Oceania 7(1):15-23.

Wroe, S. and J. Field 2006. A review of the evidence for a human role in the extinction of Australian megafauna and an alternative interpretation. Quaternary Science Review 25(21-22):2692-2703. doi. org/10.1016/j.quascirev.2006.03.005

Wroe, S., J.H. Field and D.K. Grayson 2006. Megafaunal extinction: Climate, humans and assumptions. Trends in Ecological Evolution 21(2):61-62. doi.org/10.1016/j.tree.2005.11.012

Wroe, S., J. Field, R. Fullagar and L.S. Jermiin 2004. Megafaunal extinction in the late Quaternary and the global overkill hypothesis. Alcheringa 28(1):291-331. doi.org/10.1080/03115510408619286

Wroe, S., J.H. Field, M. Archer, D.K. Grayson, G.J. Price, J. Louys, T. Faith, T., G.E. Webb, I. Davidson and S.D. Mooney 2013a. Climate change frames debate over the extinction of megafauna in Sahul Pleistocene Australia-New Guinea. Proceedings of the National Academy of Sciences (PNAS) 110(22):8777-9781.

Wroe, S., J.H. Field, M. Archer, G.K. Grayson, G.J. Price, J. Louys, J.T Faith, G.E. Webb, I. Davidson and S.D. Mooney 2013b. Reply to Brook et al: No empirical evidence for human overkill of megafauna in Sahul. Proceedings of the National Academy of Sciences (PNAS) 110(36):E3369. doi.org/ $10.1073 /$ pnas. 1310440110 



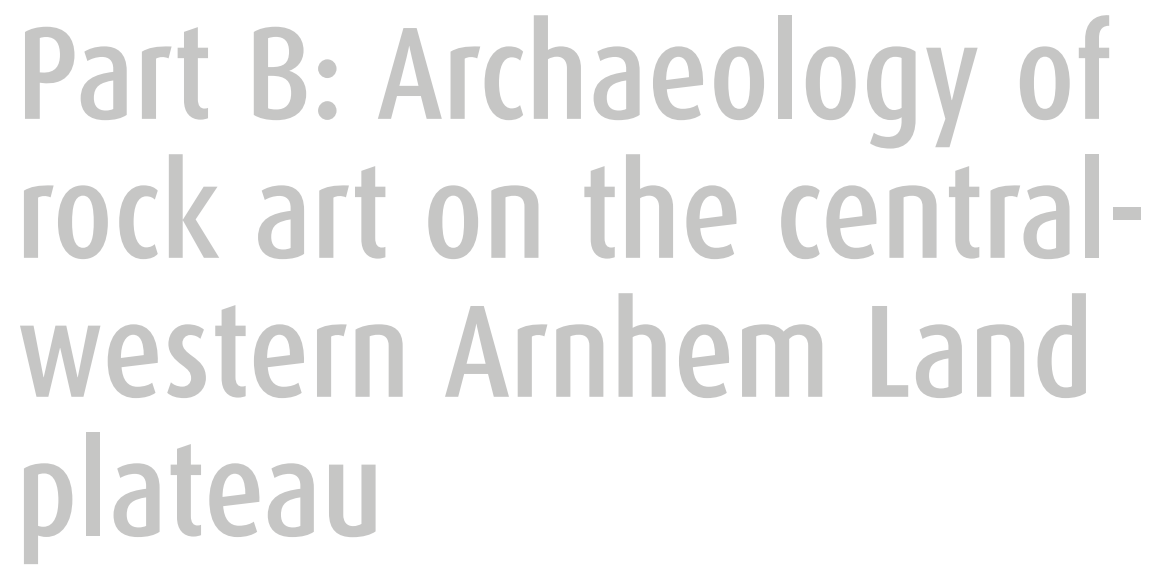





\title{
Postcards from the outside: European- contact rock art imagery and occupation on the southern Arnhem Land plateau, Jawoyn lands
}

\author{
Robert Gunn, Bruno David, Ray Whear, Daniel James, \\ Fiona Petchey, Emilie Chalmin, Géraldine Castets, Bryce Barker, \\ Jean-Michel Geneste and Jean-Jacques Delannoy
}

\section{Introduction}

The northwestern region of the Arnhem Land plateau has long been relatively well-documented and is renowned worldwide for its wealth of rock art, including numerous paintings referencing items of material culture, people and events of contact between local Aboriginal peoples, Macassans, Chinese and Europeans (e.g. Chaloupka 1993:190-206; Edwards 1979:32; May et al. 2010, 2013; Mountford 1956:162, 179; Wesley 2013). Many of these contact motifs depict Macassan and 19th- to early 20th-century European ships (Chaloupka 1993:190-205; Taçon et al. 2010); some are of newly acquired artefacts, such as rifles, knives and Macassan kris, and horses (May et al. 2013; Wesley 2013); others depict events from the 1880 gold rush in Pine Creek to the west of the plateau (Chinese miners; e.g. Edwards 1979); still others show themes relating to the Second World War (aeroplanes, Darwin wharf; Chaloupka 1993).

By contrast, the southern half of the Arnhem Land plateau is relatively poorly known. In 2005, the Jawoyn Association began to promote the systematic recording of rock art within Jawoyn lands in central-western to southwestern Arnhem Land, at first through the Jawoyn Rock Art and Heritage Project (JRAHP, 2005-2012) (Gunn and Whear 2007), followed in 2010 by a program of archaeological excavation and rock art dating (e.g. David et al. 2011; Geneste et al. 2012). These studies have focused on the little-studied rock art sites of Jawoyn lands, mostly but not exclusively on the Arnhem Land plateau itself (Figure 9.1). Here, the rock paintings revealed a wide array of artistic conventions in many cases much akin to those of the better-known northwestern parts of Arnhem Land, although across Jawoyn lands only seven sites have yet been seen to contain imagery depicting identifiable European or Asian contact themes (see below). This paucity of Western-contact imagery is despite what has arguably been the most intensive, systematic rock art recording project yet undertaken anywhere in Arnhem Land, and the largest database of rock art sites for any single region within the Arnhem Land plateau (Table 9.1; Figure 9.2). 
This chapter explores this incongruity in the distribution of Western-contact motifs contrasting northwestern and southwestern Arnhem Land in relation to the rich corpus of other kinds of rock art on the plateau. We stress from the onset that while images of 'Western-contact art' derive from a wide variety of responses to outsider influences, and include imagery that employs conventions akin and often indistinguishable to those of the pre-Western contact period, in this chapter we restrict our discussion to images of introduced objects and demonstrably foreign peoples.

Table 9.1 European contact-period rock paintings in Jawoyn lands, southwestern Arnhem Land plateau.

\begin{tabular}{|c|c|c|c|c|c|}
\hline Motif type & Colour & $\begin{array}{l}\text { Size }(\mathrm{cm}) \\
\text { (length } \geq \text { width) }\end{array}$ & Jawoyn Site \# & Condition & Comment \\
\hline Boat 1 & White & $167 \geq 89$ & \multirow[t]{7}{*}{ ARN-088/6 } & Good & People on board (6) \\
\hline Boat 2 & White & $28 \geq 15$ & & Good & People on board (4 or 10$)$ \\
\hline Boat 3 & White & $28 \geq 25$ & & Fair & People on board (10) \\
\hline Boat 4 & White & $25 \geq 28$ & & Good & People on board (8) \\
\hline Boat 5 & Yellow + red & $65 \geq 23$ & & very poor & Dotted infill \\
\hline Boat 6 & White + red & c. $130 \geq 50$ & & Poor & People on board (2) \\
\hline Boat 7 & White & $27 \geq 26$ & & Good & With anchor line \\
\hline Person with hat & White & $31 \geq 9$ & ARN-107/3 & Fair & Top hat \\
\hline Person with rifle & White & $70 \geq 25$ & ARN-019/M & Good & Rifle? and army hat \\
\hline Horse with rider & Red & $54 \geq 51$ & ARN-087/1 & Fair & Plus reins, no saddle \\
\hline Horse & White + red + grey & $347 \geq 236$ & ARN-074/A & Very poor & Under X-ray fish \\
\hline Metal axe & White + purple & $26 \geq 14$ & \multirow[t]{2}{*}{ ARN-082/1 } & Poor & In X-ray style \\
\hline Metal hoe & White & $20 \geq 12$ & & Fair & Blades (?) (2) \\
\hline Steer & White & $67 \geq 46$ & ARN-031/1 & Good & With neck-bell \\
\hline
\end{tabular}

Source: Authors' data.

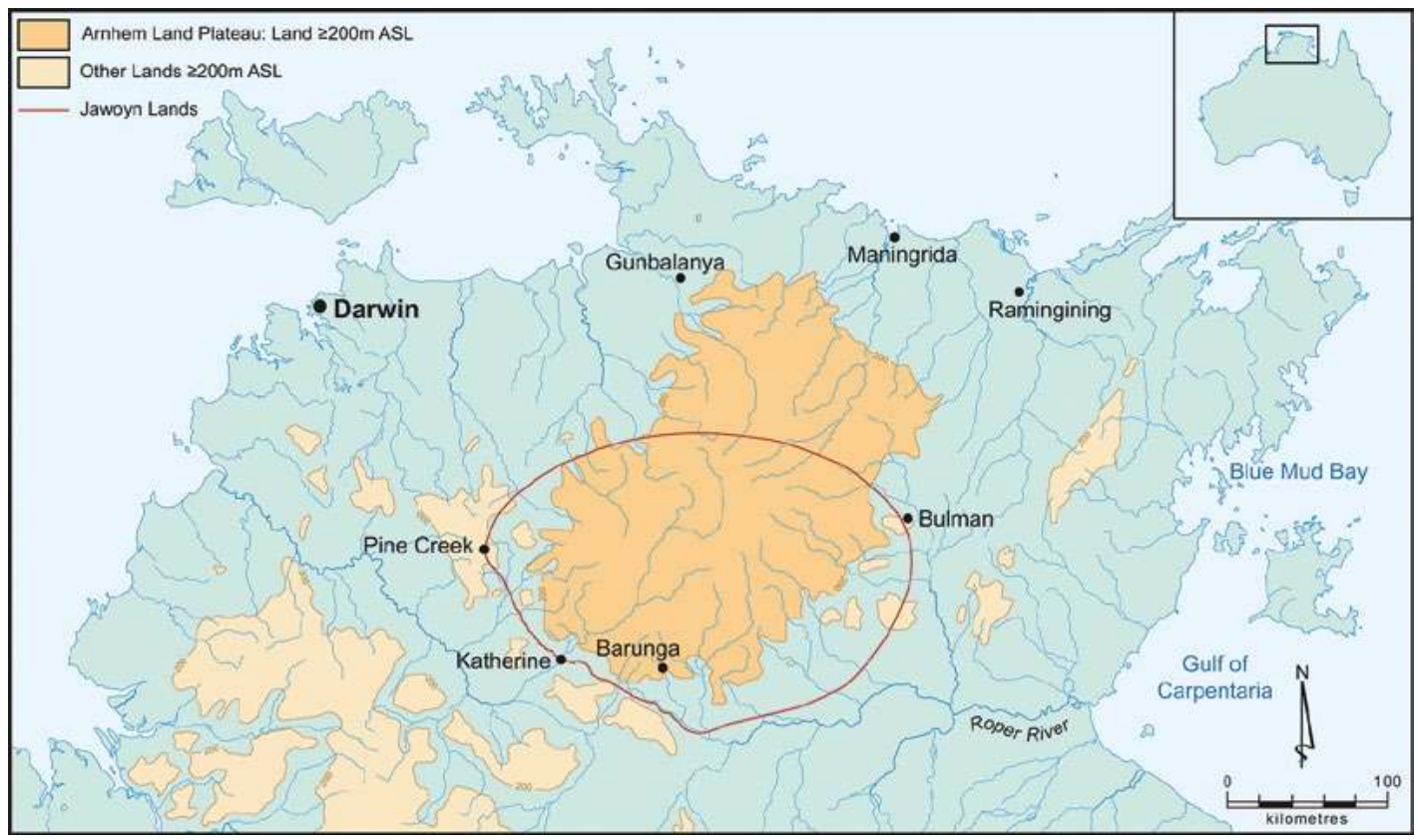

Figure 9.1 Location of Jawoyn lands.

Source: Kara Rasmanis. 


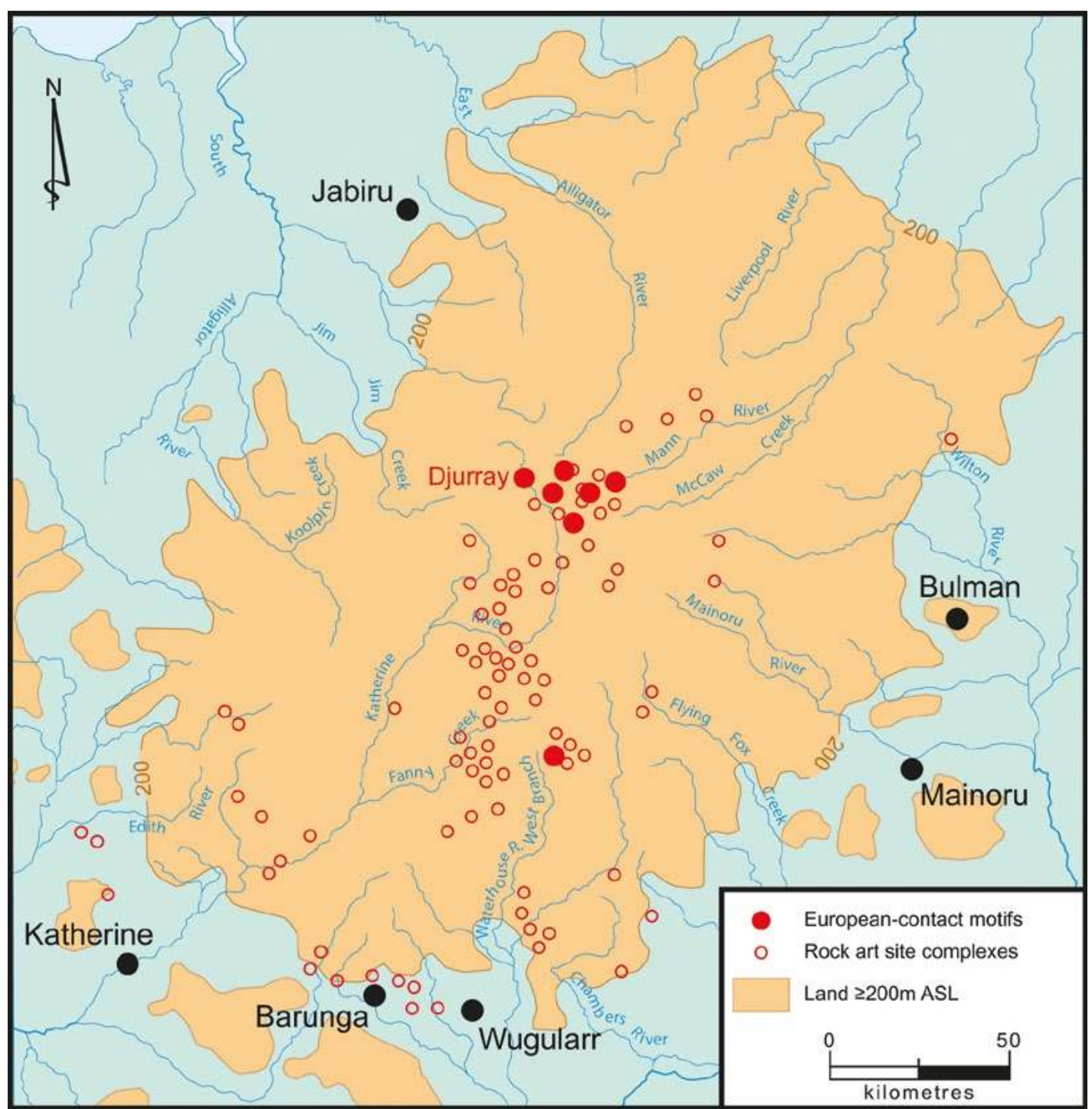

Figure 9.2 Distribution of rock art sites with European-contact motifs.

Source: Kara Rasmanis.

\section{Djurray: A major contact imagery site on the Arnhem Land plateau}

May et al. (2013:52) suggest that contact rock art need not be found only in the immediate area where cross-cultural meetings took place. Like traded objects, information regarding crosscultural encounters spreads quickly through wide-ranging social networks. People themselves commonly travelled across social boundaries, enabling new information to rapidly reach faraway places. Indeed the greatest number of demonstrably Western-contact images in Jawoyn lands occurs at Djurray (Jawoyn site ARN-088/6), a rock art site with maritime motifs some $150 \mathrm{~km}$ inland from the coast and separated from it by some of the most rugged terrain on the plateau and, more significantly, by lands that are not Jawoyn. The Djurray site is at the northern limit of Jawoyn lands, although its Jawoyn ownership is contested by an adjacent group. Margaret Katherine (pers. comm. 2011), the senior Jawoyn Traditional Owner for the lands immediately to the south, terms Djurray a 'shared site' between herself and her northern neighbours. 
The Djurray shelter is large, $23 \mathrm{~m}$ wide across its mouth, $6 \mathrm{~m}$ deep from overhang to back wall and $8 \mathrm{~m}$ high at the outer edge of the overhang. The shelter is open with a high rear wall that is extensively decorated with over 300 rock art images (both recent and older-looking paintings, stencils, prints and drawing), seven of which are depictions of European-contact objects (Table 9.1). The artwork at the shelter is dominated by a large white painting, Boat $\mathrm{A}$ ( $1.67 \mathrm{~m}$ long $\times 0.89 \mathrm{~m}$ high), with a crew of six wearing broad-brimmed European-style hats standing alongside square waist-high 'crates' (Figure 9.3). On the panel below the white boat are the three smaller Boats B-D, also in white, with hatless crews, triangular sails and steering oars (Figure 9.4). Below these again, there is Boat E, a three-masted vessel in yellow and red (Figure 9.5), in a relatively poor state of preservation caused by passing animals rubbing the pigment away. Two metres to the right of this group of images is Boat $\mathrm{F}$, also large and with a square sail and a crew of two (one wearing heeled boots), the ensemble of artworks painted in white and red with an unusual white-dotted infill (Figure 9.6). Boat $F$ is partially superimposed by Boat G, a small white sailing boat with a long rope line and anchor (Figure 9.6).

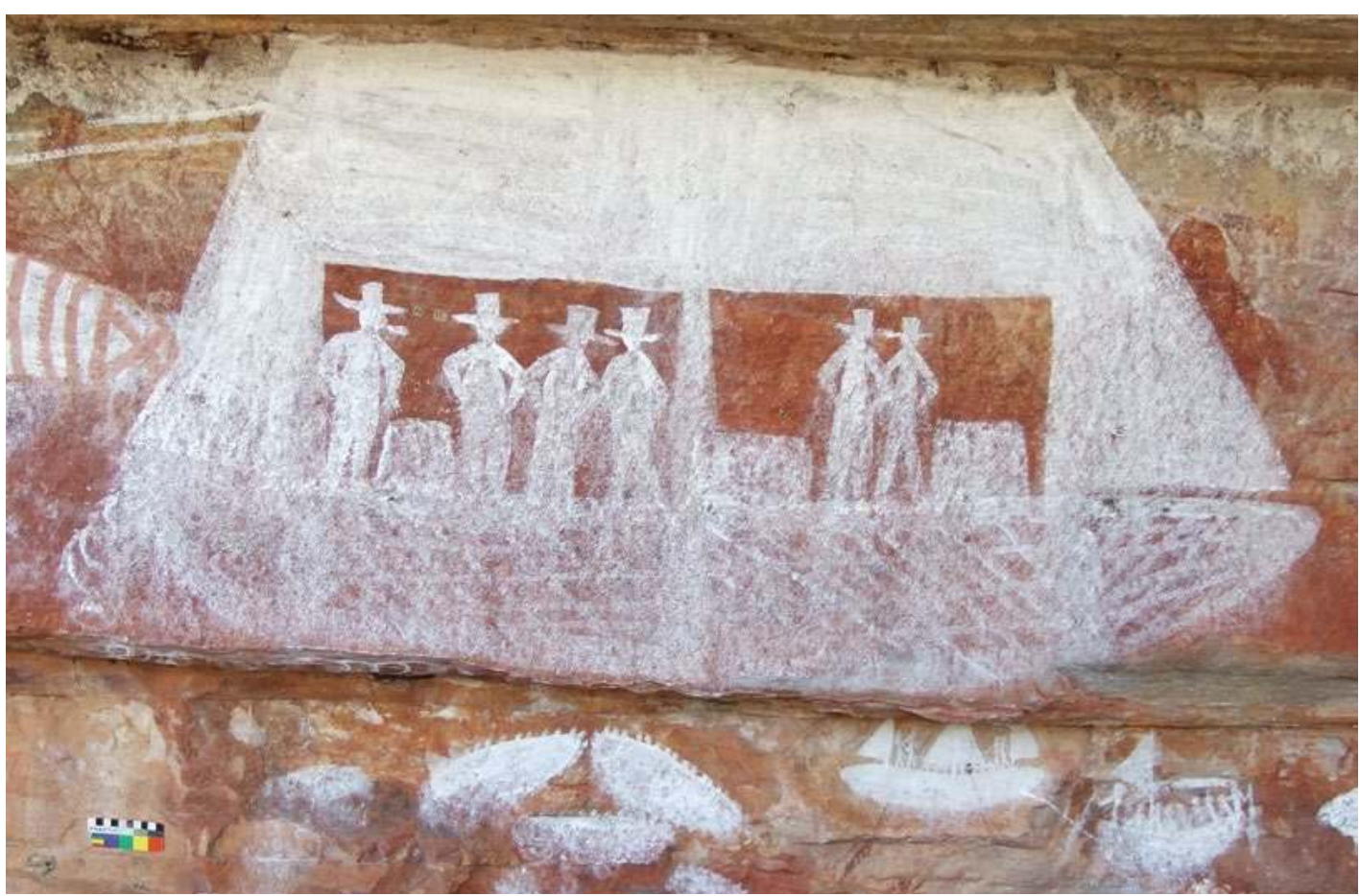

Figure 9.3 Boat A, site ARN-088/6. Scale $10 \mathrm{~cm}$.

Source: Photograph by Robert Gunn.

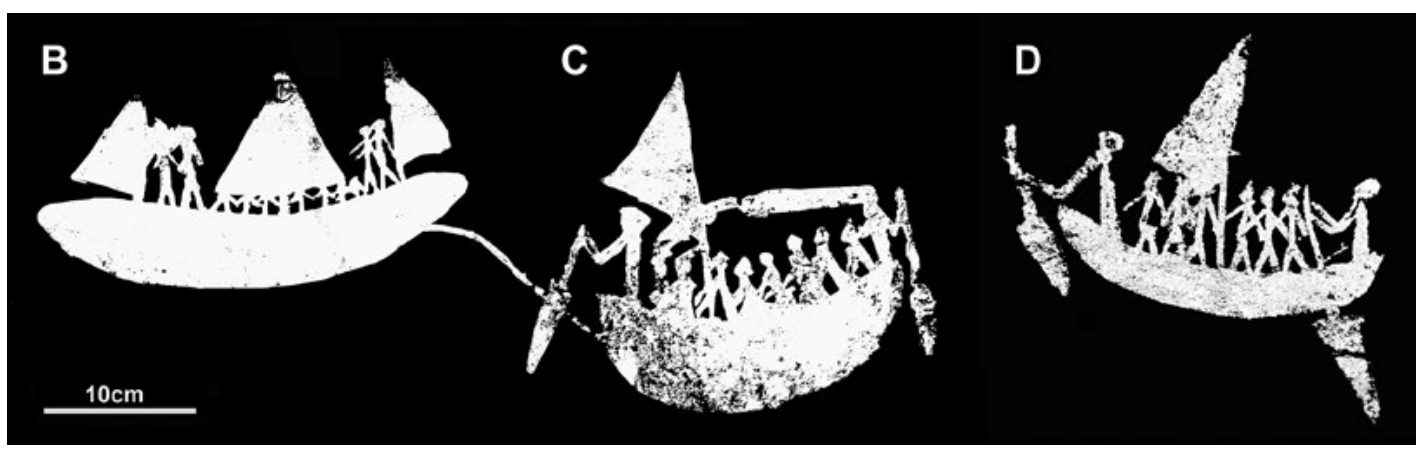

Figure 9.4 Boats B-D, site ARN-088/6.

Source: Robert Gunn. 

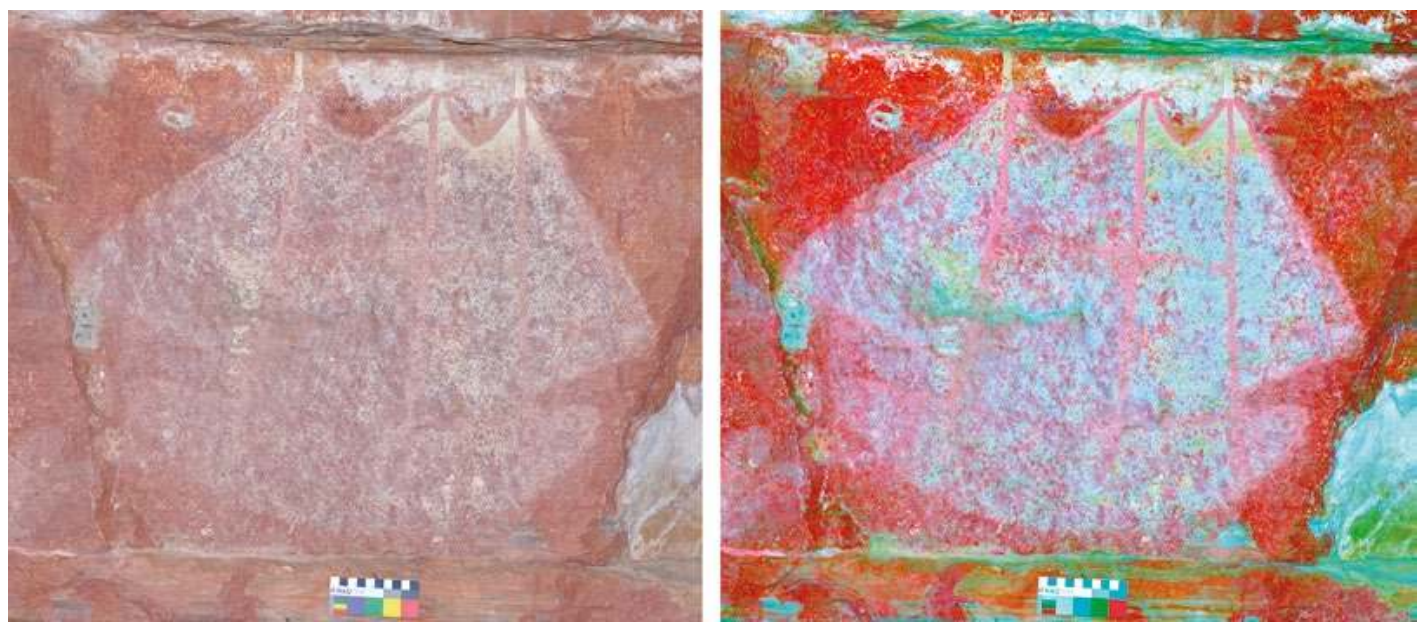

Figure 9.5 Boat E, site ARN-088/6. Left: Original image. Right: DStretch enhancement (ywe15). Scale $10 \mathrm{~cm}$.

Source: Photograph by Robert Gunn.

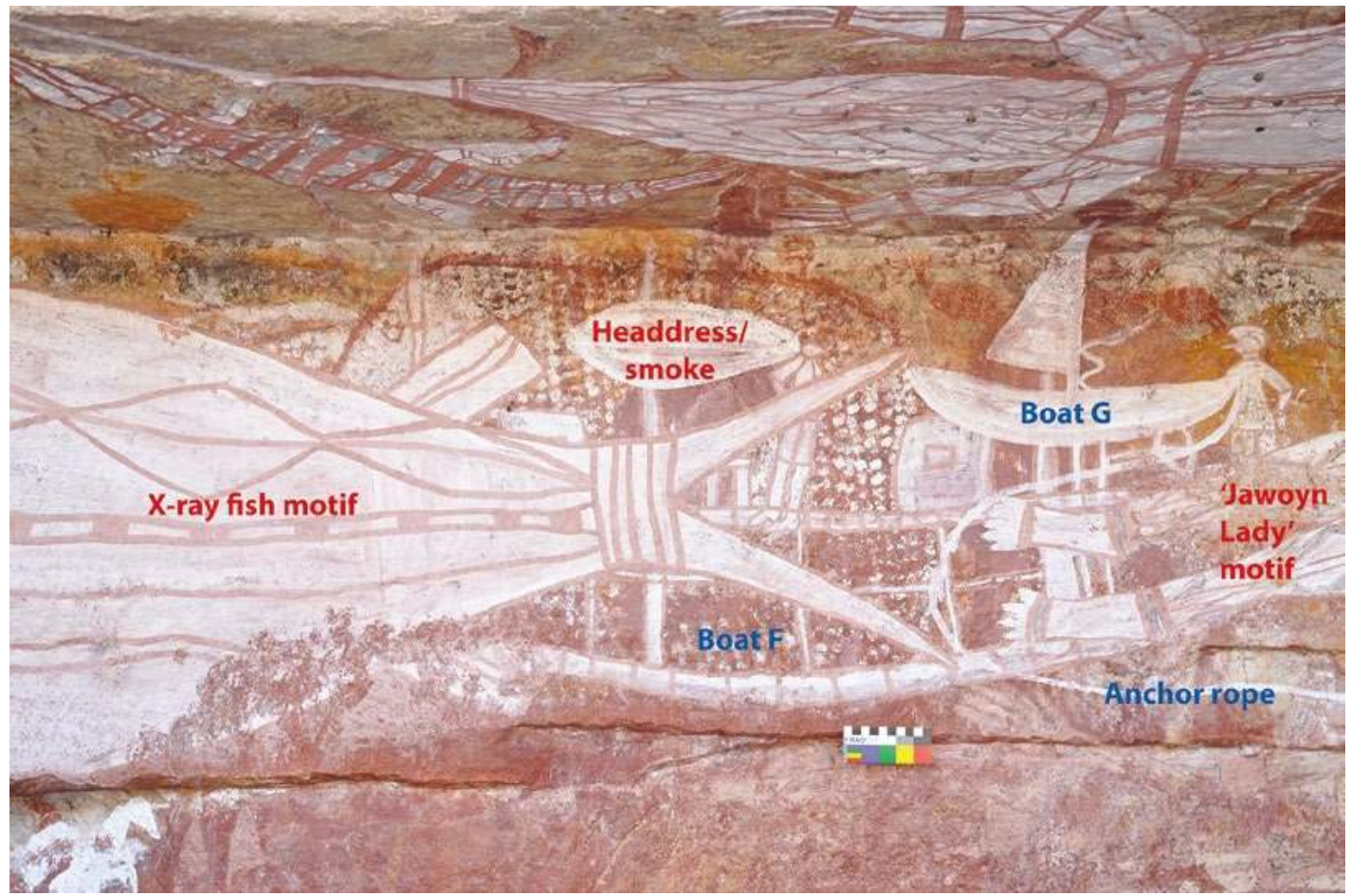

Figure 9.6 Overlapping boat motifs, site ARN-088/6. Scale $10 \mathrm{~cm}$.

Source: Photograph by Robert Gunn.

The larger vessel (Boat A; Figure 9.3) is most similar to either a three-masted schooner from the pearling industry or a river barge. The three smaller vessels (Boats B-D; Figure 9.4) are reminiscent of ocean-going sail canoes, schooners or coastal shunters (Paul Clark, pers. comm. 2010; David Steinberg, pers. comm. 2012). Those three smaller vessels exhibit features such as steering paddles/oars that suggest a non-European and non-south Sulawesi (Macassan) origin, with possible southern New Guinea or Tanimbar Islands (Maluku province east of Sulawesi) connections (Paul Clark, pers. comm. 2012). 
When visiting the site in 2008, the late Wamud Nadjamerrek, a senior Elder and rock art painter with close associations with Jawoyn lands (see Nadjamerrek et al. 2010), suggested that the boats at the Djurray shelter may have been painted as 'postcards' by visitors from the north coast of Arnhem Land to show Jawoyn people what they had seen (Wamud Nadjamerrek, pers. comm. to Ray Whear 2008). Given the many fine details of people and items of material culture in the paintings, the painter(s) themselves appear to have had considerable direct knowledge of the watercraft and their uses, reflecting their own personal experiences of having seen those vessels themselves rather than retelling second-hand knowledge. The depiction of the vessels is not entirely naturalistic, with some key features (such as the shape of the sails) being inaccurate and depicted in a non-functional manner (Adrian Horridge, pers. comm. 2012). This suggests that the boats were seen at a distance, perhaps in harbour, rather than the artist having knowledge of how they worked. Interestingly, Wamud Nadjamerrek showed greater interest in a pair of clap sticks shelved within a rock crevice at this site than in the boat paintings. Here, as at other Jawoyn art sites visited on this and other occasions, Wamud Nadjamerrek engaged more with the traditional images with which he could directly relate through his knowledge of cosmology or ceremony.

The boat images at the Djurray shelter are not the most recent paintings within this shelter, as two have been partially superimposed by large fish-like creatures in white with red outline and infill, one of which has X-ray features (Figure 9.6). The fish-like creature with the X-ray infill is painted in a similar manner to, and is similarly well-preserved as, a nearby large barramundi motif depicted with the classic X-ray form. The other fish-like creature has a spotted infill (sprayed dots); at the instruction of Wamud Nadjamerrek (pers. comm. to Robert Gunn 2008), it is not illustrated here due to its cultural sensitivities. For this chapter, this motif is simply termed the 'spotted fish'. Hence, the X-ray form of painting was being used here during the European-contact period. Similarly, Boat F has been superimposed by a large 'Jawoyn Lady' motif (Gunn 1992) in white with red and black infill (Figure 9.6), indicating that the 'Jawoyn Lady' motif type was also produced within the European-contact period. The anchor of the small sail boat (Boat G; Figure 9.6) passes neatly around the feet of the 'Jawoyn Lady' motif and over one of her toes, indicating that the anchor was added to the panel after the 'Jawoyn Lady' figure was painted. At some later time, as determined by patterns of superimposition, a white-infilled oval area - possibly a headdress or puff of tobacco smoke? - was added to the booted figure on Boat F (Figure 9.6). Comparable degrees of preservation suggest a range of other traditional motif types were also painted after Boats $F$ and $G$ were painted. Together, these patterns of superimposition and states of preservation suggest that the painting of traditional motifs at the Djurray shelter continued well into the European-contact period. A pattern of X-ray paintings overlying European-contact motifs was also observed in the Wellington Range, $200 \mathrm{~km}$ to the north of Djurray and closer to the coast (Taçon et al. 2010:61).

\section{Other European contact-period images}

Seven other images referencing European contact-period items of material culture or considered to represent European-contact events have been located from six rockshelters in Jawoyn lands. These seven paintings consist of two of European people, a horse with rider, a horse without rider, a bullock with a neck-bell and two of metal-headed axe/hoes (Figures 9.7-9.14, 13.33).

One of the European figures (Figure 9.7) was painted in white on the rear wall of a shallow rockshelter, ARN-107/3. The person, $31 \mathrm{~cm}$ tall, wears a top hat and leans to their right, as if leaning casually against some unportrayed object. Despite standing with hands on hips, the person does not strike the forceful pose usually attributed to such a stance (Ouzman 2003:14). 
Aboriginal people across much of Australia characteristically used such a pose to depict European men (e.g. see also May et al. 2013:50). The pose is also depicted on the crew of Boat A at Djurray, $20 \mathrm{~km}$ to the northwest of ARN-107/3 (see above). The ARN-107/3 hatted person is positioned centrally on a vertical panel between two larger macropod paintings in a traditional style (Figure 9.7). Both macropod images were painted in white with red outline and infill that, from differences in pigment preservation, appear to pre-date the hatted person. The macropod to the right of the panel, however, shows evidence of repainting as water-wash across the legs reveals the original underpainting with the red outline. The repainting was in a similar monochrome white to the hatted person, and both whites are similarly preserved. This suggests that the painting of the hatted person and the repainting of the macropod are contemporaneous. No further paintings were added to this panel following these two white paintings. The presence of other, better preserved monochrome white paintings of traditional motifs in adjacent shelters, however, suggests either that the hatted person at ARN-107/3 was painted during a phase of artistic activity that included other nearby rockshelters that provide better protection for their rock art, or that the hatted person was not the most recent image painted within this site complex.

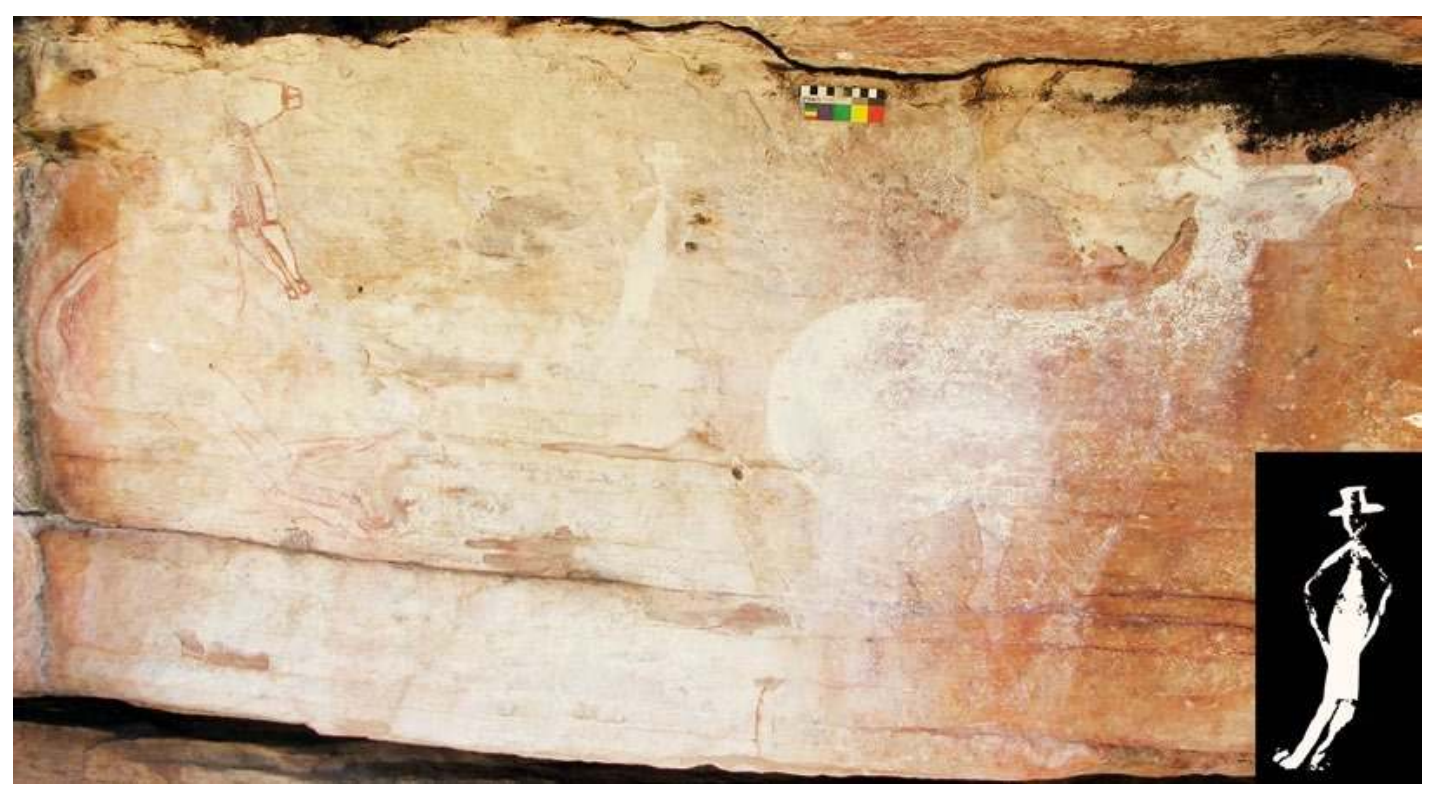

Figure 9.7 Art panel with European figure, site ARN-107/3. Insert is a photo-tracing of the central figure. Scale $10 \mathrm{~cm}$.

Source: Photograph by Robert Gunn.

A second human figure, arguably of the contact period and also painted in white (Figure 9.8), occurs in shelter ARN-019/M some $10 \mathrm{~km}$ east of Djurray. That figure is $70 \mathrm{~cm}$ tall and was painted on the underside of a rock ledge of an undercut rock wall $1.5 \mathrm{~m}$ above the floor. The painting is not visible from more than c. $1 \mathrm{~m}$ away. Here the human figure appears to be wearing a drooping hat (pith helmet?) of a shape not usually seen in the art of this region, and is holding a white bar across his hips. The shape of the bar (tapering from left to right) and the manner in which it is held suggest a rifle. This motif is one of seven white paintings in a similar state of preservation within the shelter; they are probably contemporaneous. None of the other six white paintings on an adjacent panel depict recognisably European-contact motifs. 


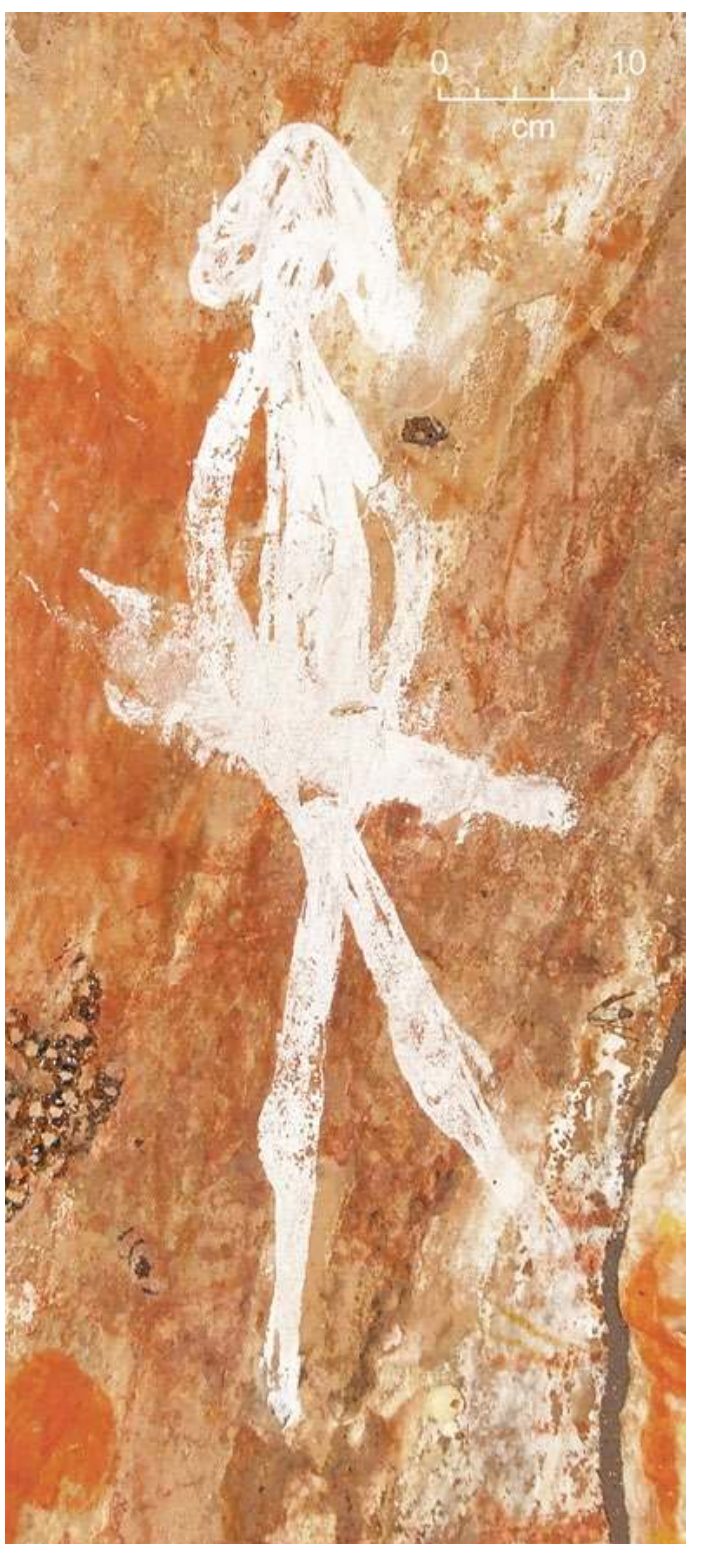

Figure 9.8 European figure with floppy hat and carrying a long object (rifle?), site ARN-019/M.

Source: Photograph by Robert Gunn.
At the remarkable and profusely decorated rockshelter site of Nawarla Gabarnmang (ARN-074/A), some $10 \mathrm{~km}$ to the south of Djurray, a large painting of a horse has been placed across a flat ceiling panel (Gunn et al. 2012a:61). The horse painting measures $3.5 \times 2.4 \mathrm{~m}$, on a multi-layered painted panel $4.7 \times 3.3 \mathrm{~m}$. Much of the horse is obscured by overlying, more recent paintings, but its overall shape can be tracked by connecting those parts of the horse that extend beyond the superimposing images, including its well-defined head, back and tail (Figure 9.9). The horse was painted with an unusual infill pattern; initially it was painted in a grey pigment, then outlined in white and then again in red. When completed, the painting would have been visually striking and readily apparent by anyone using the shelter. The many superimpositions on that panel (Figure 9.10) indicate that the horse was later overlain by at least four layers of paint represented by 17 paintings, including a number of X-ray fish and traditional Jawoyn-style anthropomorphs. The horse painting itself overlies another eight, and therefore older, layers of paint representing some 50 paintings of standard traditional Jawoyn motif types (such as macropods, 'spirit' figures, fish, turtle and hand stencils). None of the motifs under the horse are depicted in $\mathrm{X}$-ray. This sequence of superimpositions at Nawarla Gabarnmang, as with those involving European boats and more traditional motif forms at Djurray (see above), indicates the incorporation and articulation of new and traditional elements in the production of rock art over the European-contact period beginning with Leichhardt's travels across Arnhem Land in 1845 (cf. Gunn et al. 2012a) (see below). 


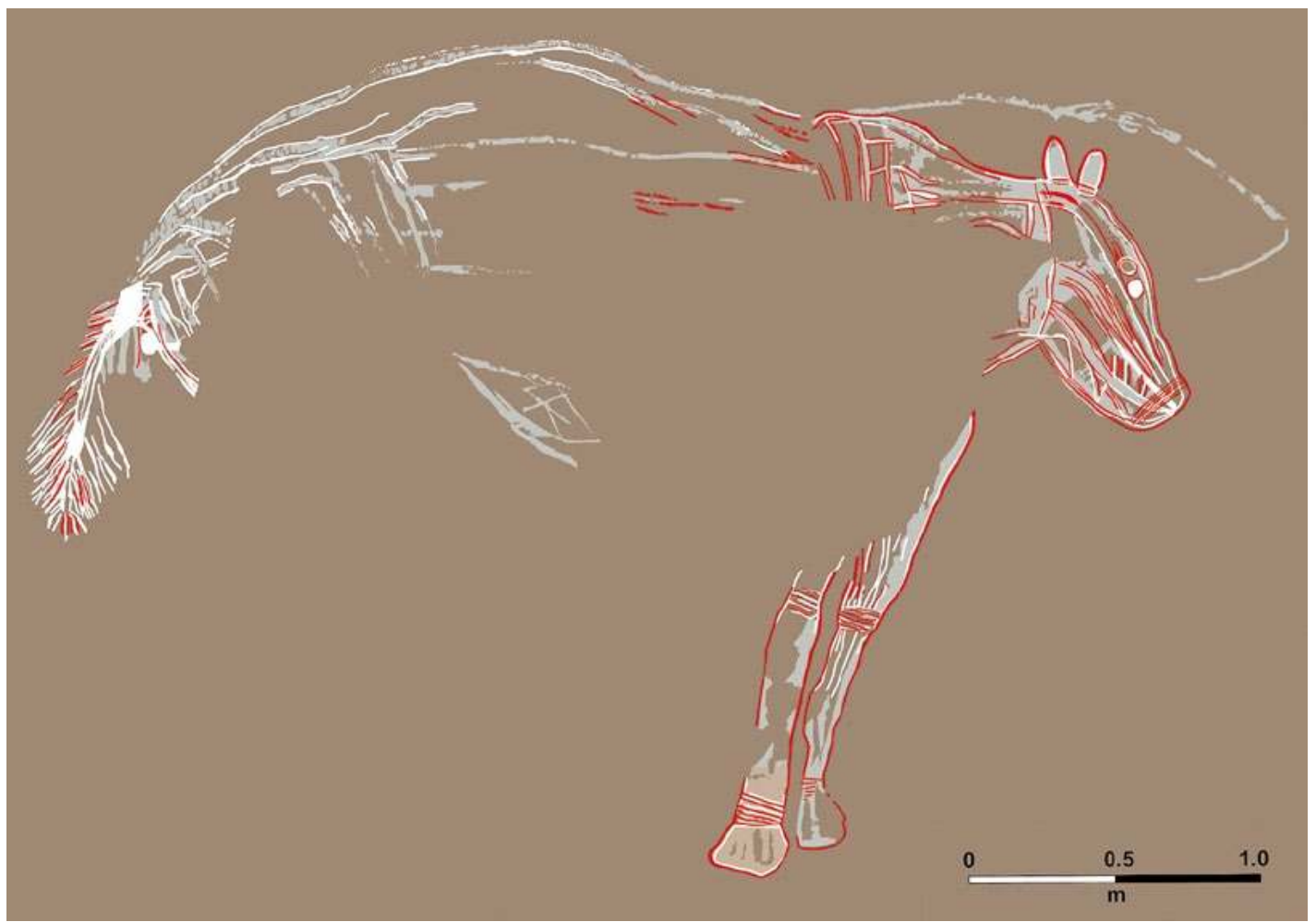

Figure 9.9 Horse painting, site ARN-074/A.

Source: Robert Gunn.

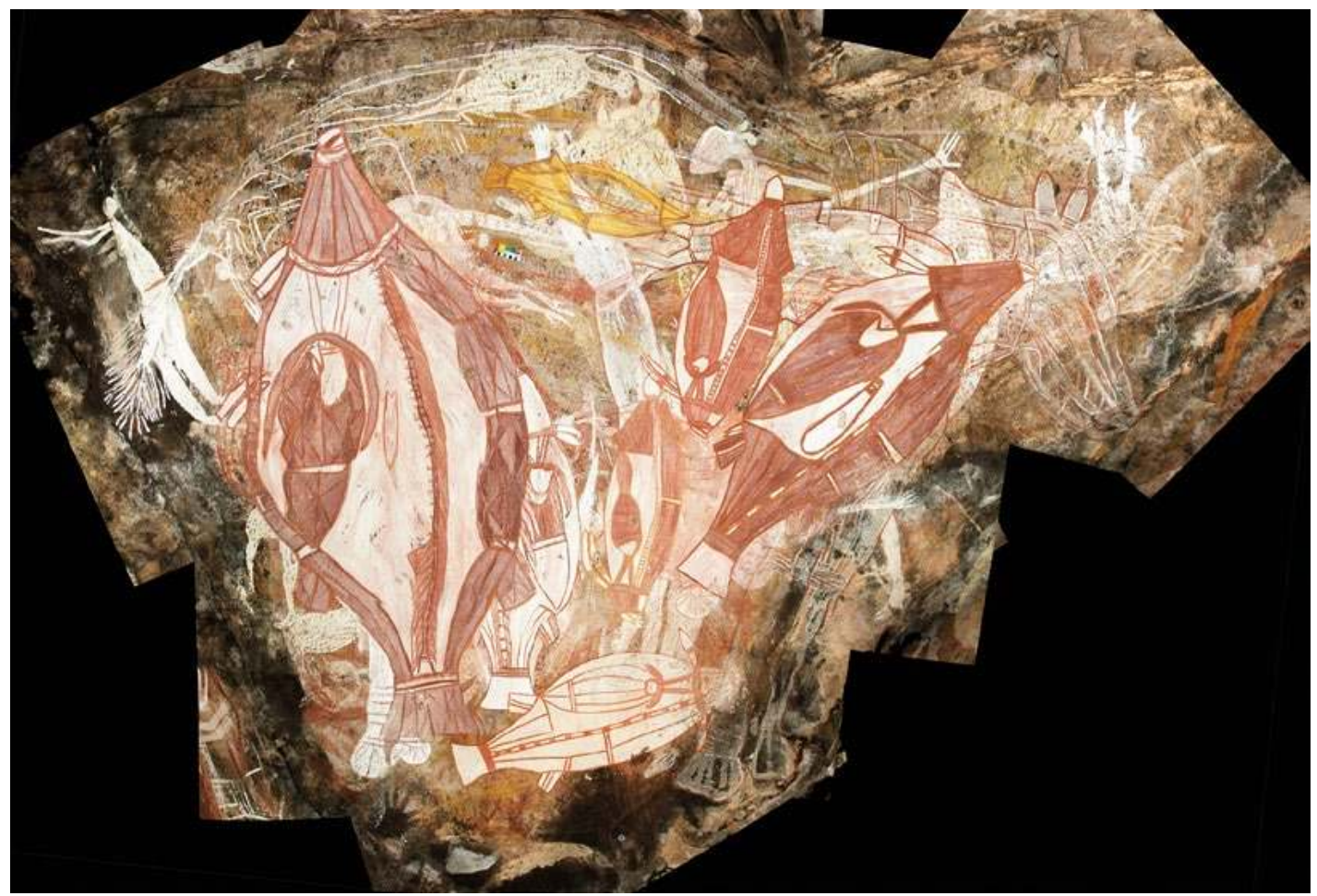

Figure 9.10 Panel with horse painting showing complex of superimpositions, site ARN-074/A. Head (at far right) and tail (at far left) of horse motif indicated. Scale $10 \mathrm{~cm}$. Source: Photograph by Robert Gunn. 
At the long but shallow shelter of site ARN-087/1, $15 \mathrm{~km}$ southeast of Djurray, an image of a person riding a horse was painted in red on the underside of a low ledge (Figures 9.11 and 9.12). The alcove is one of three conjoined alcoves that constitute the $70 \mathrm{~m}$ long shelter, which is prolifically decorated with over 600 images - mostly rows of small stick-figures - in all its alcoves. The horse-and-rider painting is $54 \mathrm{~cm}$ long. Along with many of the other images within this shelter, the horse-and-rider painting can only be viewed by lying on the floor beneath the ledge. The rider wears a broad, drooping hat similar to the one on the white figure at ARN019/M described above (Figure 9.8). A pair of reins, held by the rider, is clearly depicted and the criss-cross lines over the head appear to signify a halter, but no saddle is represented. The horse here has short front legs and longer hind legs, a kind of depiction more commonly seen on traditional paintings of macropods. The employment of this kind of macropod schema on early representations of horses was previously noted by Chaloupka (1993:195-196) for areas to the north of the plateau, to the north of Jawoyn lands. At ARN-087/1, the horse's tail was originally painted to curl between the hind legs, but was later repainted (i.e. corrected) to the standard tassel-like tail used on many other early contact paintings of horses elsewhere in Arnhem Land (Chaloupka 1993:200; Flood 1997:316; Lewis 1988:411; Murdoch 2009:1).

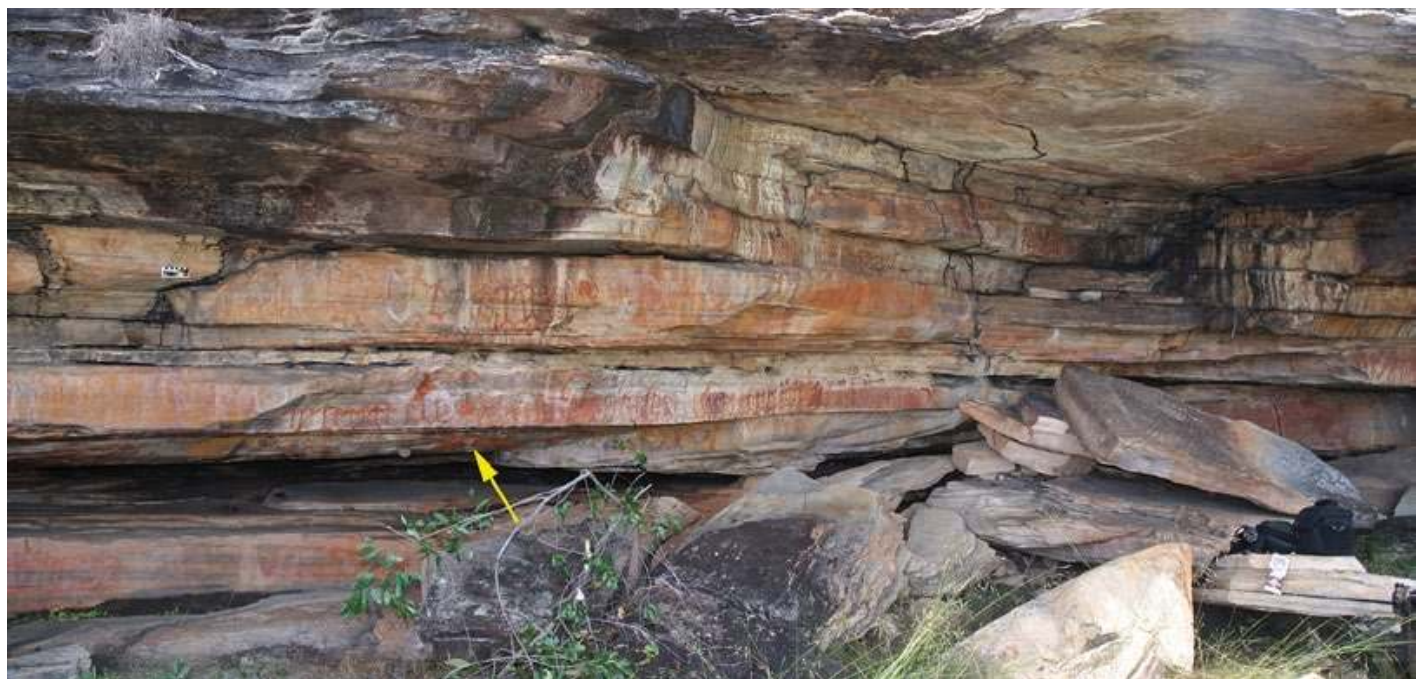

Figure 9.11 Site ARN-087/1 showing location of the horse-and-rider painting marked with yellow arrow.

Source: Photograph by Robert Gunn.
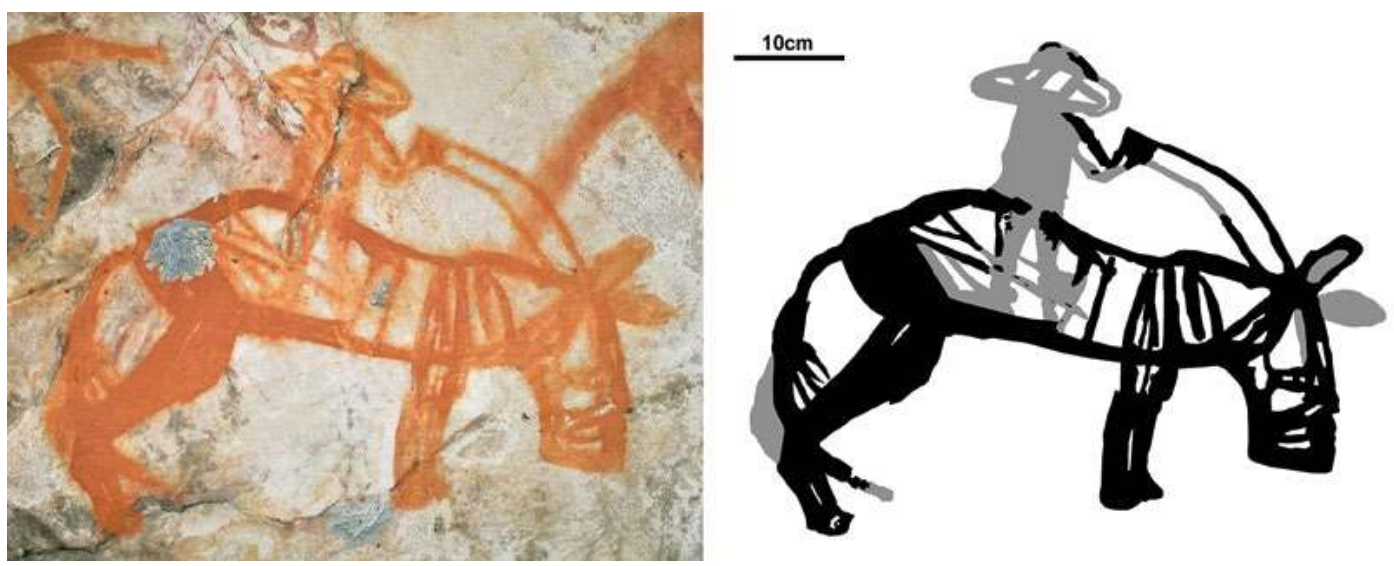

Figure 9.12 Horse-and-rider painting at site ARN-087/1.

Source: Photograph by Robert Gunn. 
Dalakngalarr 1 (ARN-082/1), $25 \mathrm{~km}$ east of Djurray, is another prolifically decorated shelter, with over 700 paintings. Two of the paintings are of metal-headed axe/hoes (see Figure 13.33). Both have typical swayed handles and large angular heads (see Figures 13.33B and 13.33D). The axe is painted in yellow with a purple outline and patterned infill, while the hoe is in plain yellow. Both axe/hoes are on the same outer wall section, to one side of the main occupation area, and superimpose at least one layer of earlier and considerably more faded red and yellow paintings. The colours and style of the axe at ARN-082/1 (see Figures 13.33A and 13.33B) are similar to those of a suite of adjacent X-ray fish paintings (Figure 9.15), suggesting that the axe is contemporaneous with the fish paintings. It also suggests that the $\mathrm{X}$-ray paintings here, like the stylistically similar ones at Nawarla Gabarnmang, are a European-contact period addition to the shelter (see also Chapters 11 and 13).

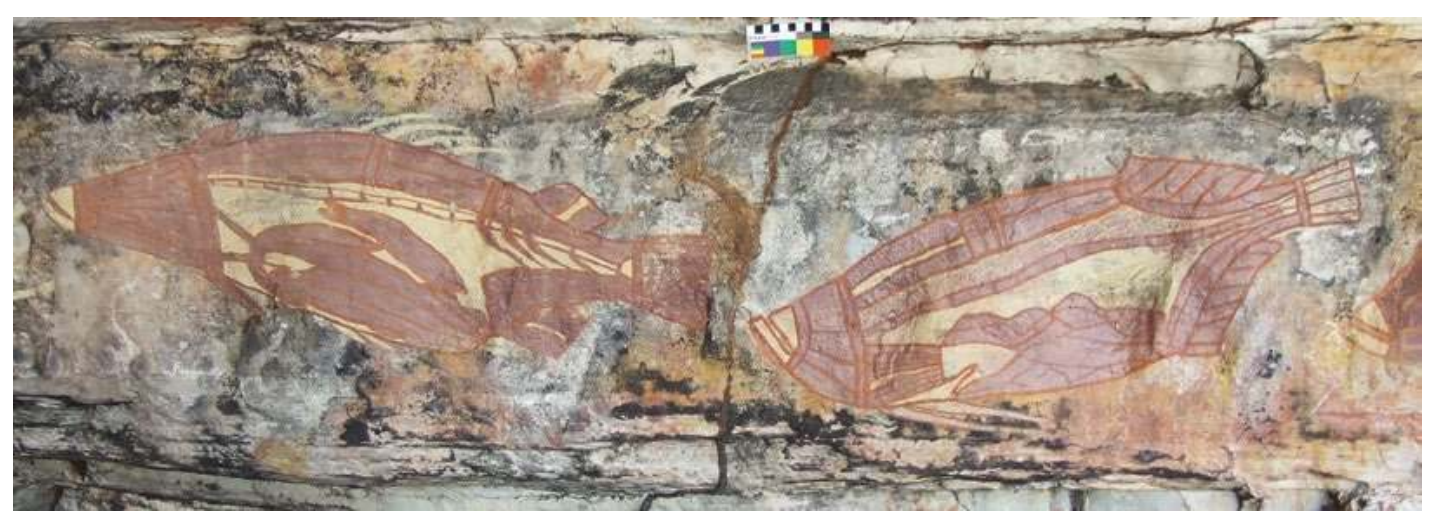

Figure $9.13 \mathrm{X}$-ray fish (barramundi and saratoga) painted with colours similar to those used on the axe painting, site ARN-082/1 (Dalakngalarr 1). Scale $10 \mathrm{~cm}$.

Source: Photograph by Robert Gunn.

The best preserved of the European-contact motifs on the plateau within Jawoyn lands is that of a bullock with neck-bell (Figure 9.13). It occurs on the rear wall of shelter ARN-031/1, towards the southern end of the plateau (Figure 9.2). The shelter is $28 \mathrm{~m}$ long and contains 360 mostly small paintings. The bullock is $67 \mathrm{~cm}$ long and painted with a white outline and striped infill, some of which has been discoloured by underlying yellow paintings. The bullock image is positioned centrally on a vertical panel and is one of the largest and clearest of the paintings in the shelter. Consequently, like the large boat (Boat A) at Djurray (see above), the bullock is the most notable image at ARN-031/1 (Figure 9.14). The bullock here appears to have been painted contemporaneously with an eel-tailed catfish (Tandanus tandanus) to its immediate right, where a similar pigment has been used; that eel-tailed catfish image is also outlined and stripe-infilled, with the two images being similarly well preserved. The eel-tailed catfish is $115 \mathrm{~cm}$ long and is positioned horizontally facing the bullock. Both the bullock and the catfish superimpose an array of poorly preserved white and yellow monochrome and white and red bichrome paintings, all of which overlie several layers of very faint red paintings. This sequence of superimpositions indicates that the bullock and the catfish are the final motifs painted on this panel. Their noticeably better state of preservation makes it likely that they were the last painted within the site complex. 


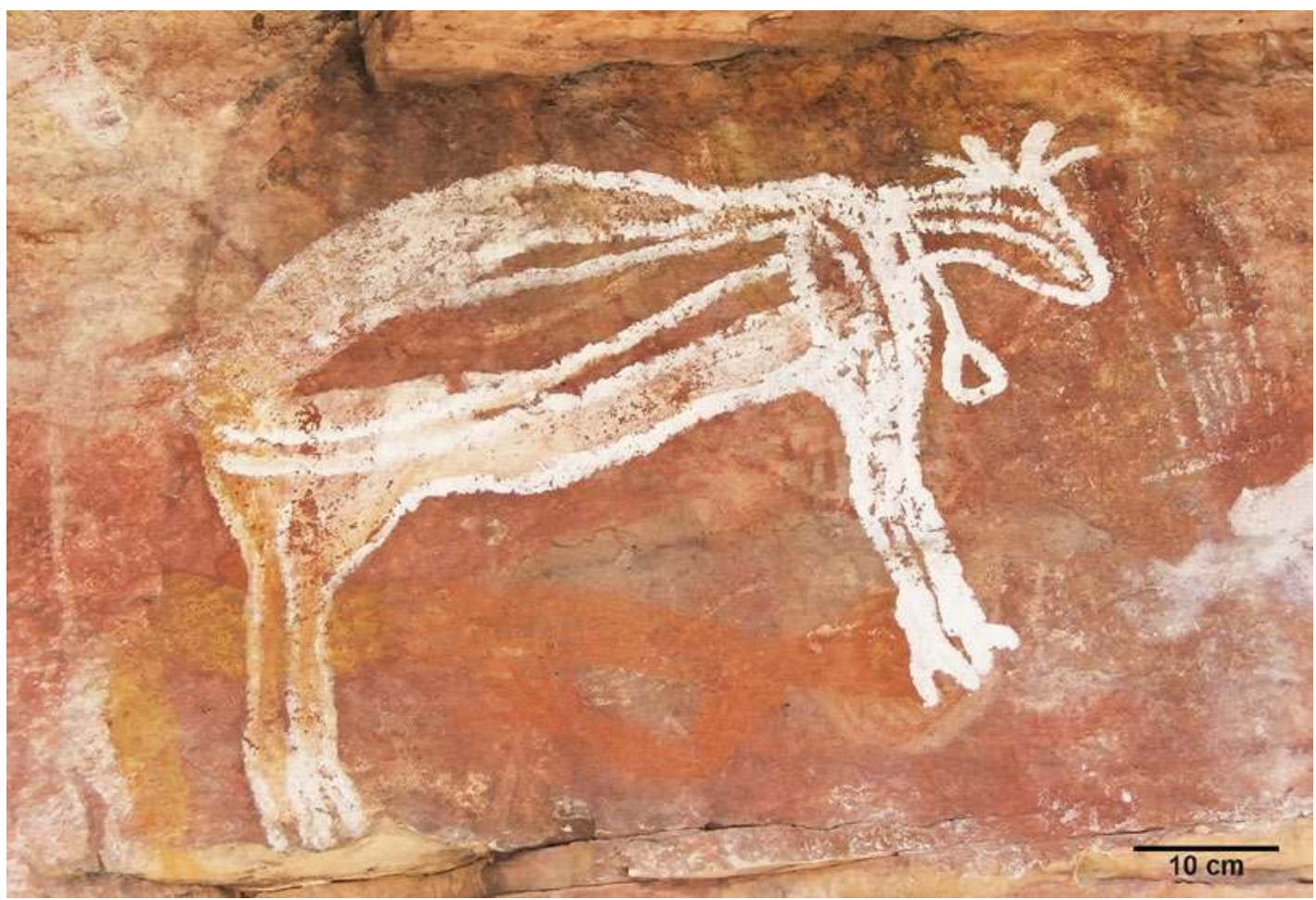

Figure 9.14 Bullock with bell panel, site ARN-031/1.

Source: Photograph by Robert Gunn.

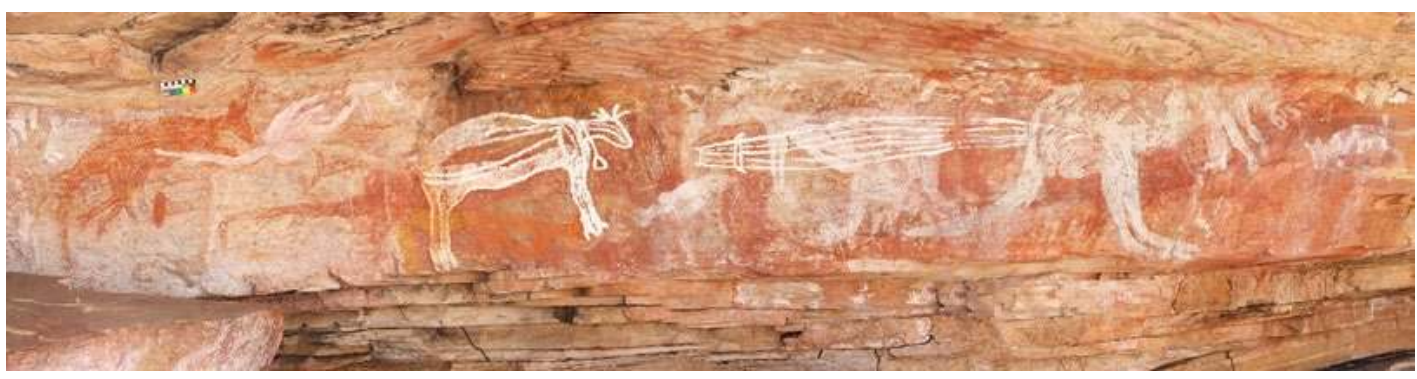

Figure 9.15 Panel of Bullock with bell, site ARN-031/1. Scale $10 \mathrm{~cm}$.

Source: Photograph by Robert Gunn.

\section{Overlying art}

Sixteen paintings, interpretable to motif type, have been recorded superimposed over Europeancontact motifs in Jawoyn lands (Table 9.2). These overlying paintings give an indication of artistic conventions demonstrably used during the period following initial European contact. The presence of X-ray fish and 'Jawoyn Lady' motifs over the contact motifs, and their absence below, indicate that they were part of the ensemble of artistic practices that followed initial European contact. While polychrome colouring may also be a feature of the rock art following initial European contact in Jawoyn lands, bichrome motifs also occur below, and hence precede, the production of the horse motif at Nawarla Gabarnmang. 


\section{Chemistry of white pigments from Boat A, the 'Jawoyn Lady' and a large spotted fish at Djurray site ARN-088/6: Identifying painting events}

Three small samples of white pigment were easily detached with the tip of a metal blade from Boat A, the 'Jawoyn Lady' and a large spotted fish to the left of Boat A (the latter cannot be shown for Jawoyn cultural reasons) at Djurray site ARN-088/6. The 'Jawoyn Lady' overlies Boat F, a demonstrably contact motif (see above for relationship to Boat G). We undertook specialist chemistry on the three detached samples to determine whether they were all painted with a single paint paste that would implicate a single painting event, or whether multiple events are more likely, as a means of further investigating the longevity of artistic practice into the period of European contact.

The three samples of white pigment were each examined under optical microscopy, revealing fine powder and clusters of powder grains (Table 9.3). Scanning Electron Microscope with Energy Dispersive X-ray Spectroscopy (SEM-EDS), using a LEO Stereoscan 440 SEM with a Brucker SDD X-FLASH 4030 EDS, indicates a crystalline structure of small plates for the Jawoyn Lady and spotted fish samples (Figures 9.16A and 9.16B). The plates of the spotted fish sample are composed mainly of $\mathrm{Al}$ and $\mathrm{Si}$ (at 1:1 ratio; Figure 9.16D). Specific alumino-silicate bands observed by Fourier Transform Infrared Spectroscopy (FTIR, using a Nicolet 380 spectrometer at $400-4000 \mathrm{~cm}^{-1}, 2 \mathrm{~cm}^{-1}$ resolution, 64 scans), indicate that each sample consists of kaolinite $\left(\mathrm{Al}_{2} \mathrm{Si}_{2} \mathrm{O}_{5}(\mathrm{OH})_{4}\right)$ (Figure 9.16C).

Table 9.2 List of paintings overlying European contact motifs in Jawoyn lands, southwestern Arnhem Land plateau.

\begin{tabular}{|c|c|c|c|}
\hline & \multicolumn{3}{|l|}{ Site } \\
\hline Time period & ARN-074 & \multicolumn{2}{|l|}{ ARN-088/6 } \\
\hline \multirow{5}{*}{ Most recent } & Polychrome $X$-ray fish $(\times 6)$ & \multirow[t]{5}{*}{ Bichrome fish-like creature } & White Boat G \\
\hline & Bichrome X-ray fish $(\times 2)$ & & \multirow[t]{4}{*}{ Bichrome 'Jawoyn Lady' and X-ray fish } \\
\hline & Bichrome 'Jawoyn Lady' (×2) & & \\
\hline & Bichrome anthropomorph & & \\
\hline & White macropod & & \\
\hline $\begin{array}{c}\text { Underlying } \\
\text { European-contact } \\
\text { motif }\end{array}$ & Polychrome horse & White Boat A & White Boat F \\
\hline
\end{tabular}

Source: Authors' data.

The presence of small, 10-15 $\mu \mathrm{m}$ long needle-like spicules of S-Ca in the 'Jawoyn Lady' and spotted fish samples is attributed to a calcium sulphate phase, probably indicating the presence of gypsum in stable, dry conditions. The presence of calcium sulphate could be due to natural precipitation on the wall, or anthropic mixing with the kaolinite pigment either to create a paint paste, or it could be unintentional as the kaolinite paint interacted with the surface of the rock wall. The weak presence of this calcium sulphate phase suggests a natural inclusion (i.e. contamination of the kaolinite) rather than anthropic mixing of components (i.e. intentional creation of a paint paste from multiple components). 
Table 9.3 Description of the pigment samples from Djurray site ARN-088/6.

\begin{tabular}{|c|c|c|c|}
\hline & \multicolumn{3}{|l|}{ PIGMENT SAMPLE } \\
\hline & Boat A & 'Jawoyn Lady' & Spotted fish \\
\hline General description & $\begin{array}{l}\text { Fine white powder }(<10 \mu \mathrm{m}) \\
\text { with few red and black grains } \\
\text { (c. } 30 \mu \mathrm{m})\end{array}$ & $\begin{array}{l}\text { Fine white powder } \\
(<10 \mu \mathrm{m}) \text { with few red and } \\
\text { black grains }(\text { c. } 30 \mu \mathrm{m})\end{array}$ & White powder and powder clusters \\
\hline Major elements & Al, Si & Al, Si, S, Ca, P & Al, Si, S, Ca, P \\
\hline Minor elements & $\mathrm{Fe}, \mathrm{S}, \mathrm{Mg}, \mathrm{K}$ & K & $\mathrm{Fe}$ \\
\hline Morphology & Fine plates $(1-7 \mu \mathrm{m})$ & Fine plates $(1-7 \mu \mathrm{m})$ & $\begin{array}{l}\text { Fine plates }(1-7 \mu \mathrm{m}), \text { small rounded } \\
\text { grains }(10 \mu \mathrm{m}) \text { and larger crystals } \\
(10-20 \mu \mathrm{m})\end{array}$ \\
\hline $\begin{array}{l}\text { Mineralogical } \\
\text { identification }\end{array}$ & Kaolinite & Kaolinite & Kaolinite \\
\hline Overall constitution & $\begin{array}{l}\text { Kaolinite with trace of iron } \\
\text { oxide }\end{array}$ & $\begin{array}{l}\text { Kaolinite with few } \\
\text { impurities mixed with } \\
\text { gypsum, alumino-phosphate } \\
\text { phase and trace of Fe }\end{array}$ & $\begin{array}{l}\text { Kaolinite mixed with quartz grains, } \\
\text { gypsum and alumino-phosphate } \\
\text { phase }\end{array}$ \\
\hline
\end{tabular}

Source: Authors' data.

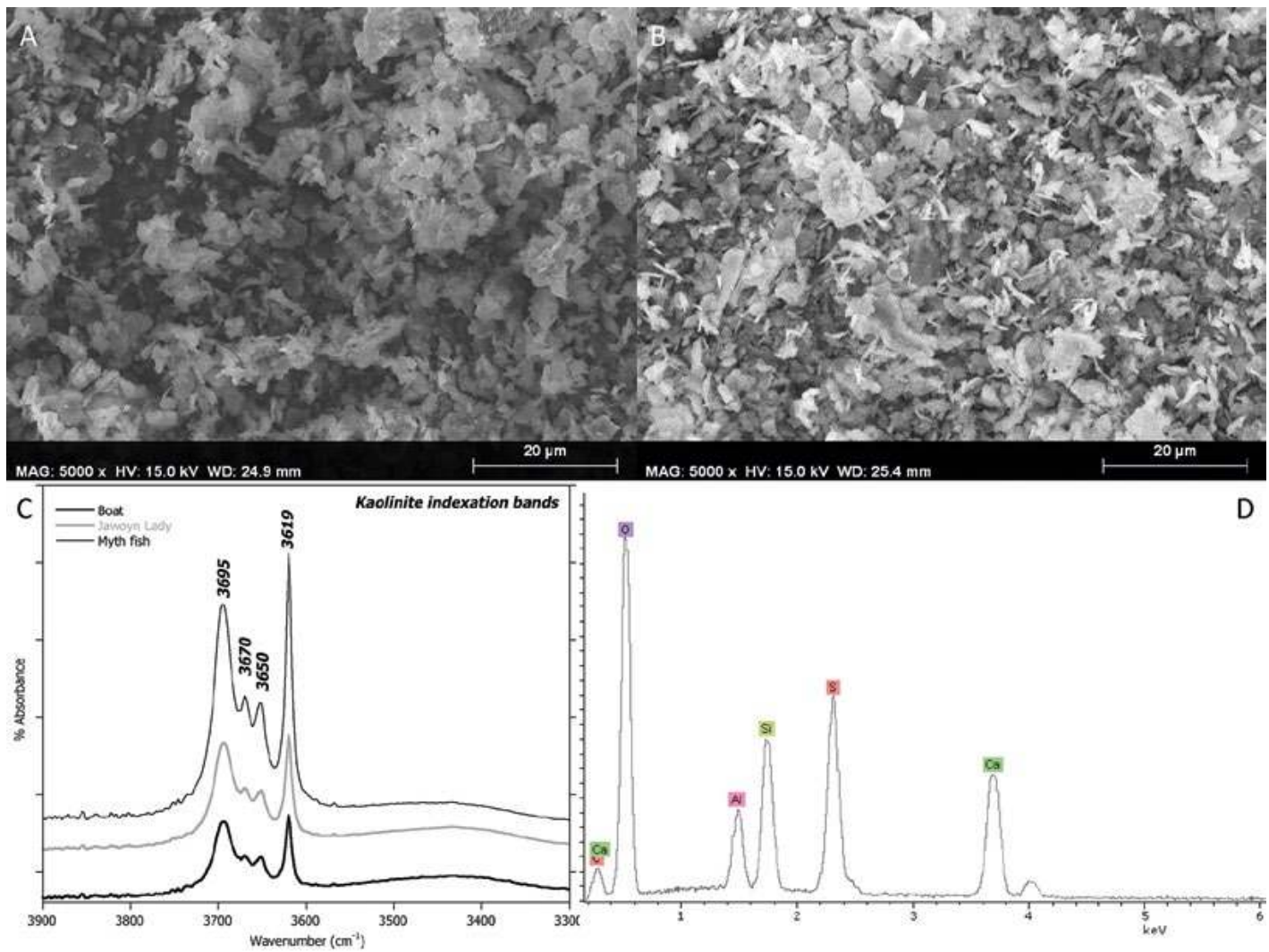

Figure 9.16 A: SEM-EDX (in secondary electron mode, $15 \mathrm{kV}$ ) micrograph of pigment sample from the 'Jawoyn Lady'. B: SEM-EDX (in secondary electron mode, $15 \mathrm{kV}$ ) micrograph of pigment sample from the spotted fish. C: FTIR spectra focused on the $3300-3900 \mathrm{~cm}^{-1}$ region. D: X-ray fluorescence spectrum from the spotted fish sample.

Source: Author's data. 
The 'Jawoyn Lady' and spotted fish samples exhibit large amounts of $\mathrm{P}$ in association with $\mathrm{Al}$, probably signalling an alumino-phosphate phase associated with weathering of the quartzite rock wall on which the paintings were undertaken.

Larger crystals of quartz $\left(\mathrm{SiO}_{2}\right)$ are only detected in the spotted fish sample. The quartz crystals probably came from the underlying rock rather than from the pigment. The composition of the spotted fish pigment sample differs a little from those of the other two pigment samples. This chemical difference in pigments may indicate either that the white paint from the spotted fish was prepared on a different occasion to that of Boat A and the 'Jawoyn Lady', or that different mixtures of paint paste were used contemporaneously on the different paintings. In addition, each of the three pigment samples exhibits its own unique combination of impurities $(\mathrm{Mg}, \mathrm{K}, \mathrm{Fe})$, suggesting multiple origins for the kaolinite pigment.

In summary, despite the common presence of kaolinite, the white pigments used to paint Boat A, the 'Jawoyn Lady' and the spotted fish each contain a different chemical signature, suggesting different combinations of elements and thus the use of different paint pastes or 'paint pots' (Chalmin et al. 2003). We cannot, therefore, confirm whether the three paintings imply a single painting event, as it is possible that the artist(s) had more than one paint paste with them during a single painting event, or whether the paintings were made on different occasions.

\section{The initial munanga contact period in Jawoyn lands}

The Jawoyn terms for non-Aboriginal people are munanga or mam (literally, 'devil' and/or 'white person'; Merlan and Jacq 2005). For several centuries prior to the European colonisation of Australia, Macassan sailors came annually to the northern coast of Arnhem Land to collect and process trepang (MacKnight 1972, 1986; Mitchell 1994; Mulvaney 1975; Taçon et al. 2010; Wesley et al. 2016). The extent of direct contact that inland groups such as the Jawoyn would have had with coastal mariners some $150 \mathrm{~km}$ to the northwest, if any, is unknown. Similarly, although British coastal outposts were established in 1827 at Fort Wellington (1827-1829) and in 1838 at Port Essington (1838-1849) - both to the northwest of the Arnhem Land plateau direct contact between Jawoyn and Europeans, or between Jawoyn and European animals such as horses and cattle, probably did not begin until Ludwig Leichhardt crossed the plateau from the southeast to the northwest in 1845 (Figure 9.17; Leichhardt 1847). Leichhardt's party travelled up the Flying Fox Creek valley that drains the southeastern side of the plateau on 1 November 1845. He noted in his journal that his party came across numerous Aboriginal camps and that he attempted to converse with and give gifts (such as brass buttons, horse-nails and a broken girth strap) to Aboriginal people whenever the chance arose (e.g. Leichhardt 1847:3 November 1845). Leichhardt and his party passed within $15 \mathrm{~km}$ southwest of Djurray and within $20 \mathrm{~km}$ southwest of Nawarla Gabarnmang (see Figure 9.17). Following an Aboriginal footpath beside the Roper River, to the south and southeast of the plateau, Leichhardt noted that 'cuts on various trees were made with an iron tomahawk' (Leichhardt 1847:19 October 1845) and, later, that while local Aboriginal people had seen or heard of 'white' people, they were much afraid of his party's horses and bullocks (Leichhardt 1847:22 October 1845).

Subsequent to Leichhardt's expedition, further exploration of the plateau by Europeans during the 1800 s was limited. In July 1862, J.M. Stuart passed through western Jawoyn Country in the southwestern corner of the plateau, but his party was wary of local Aboriginal people and only once did they exchange friendly greetings (Hardman 1865:25 June 1862). 


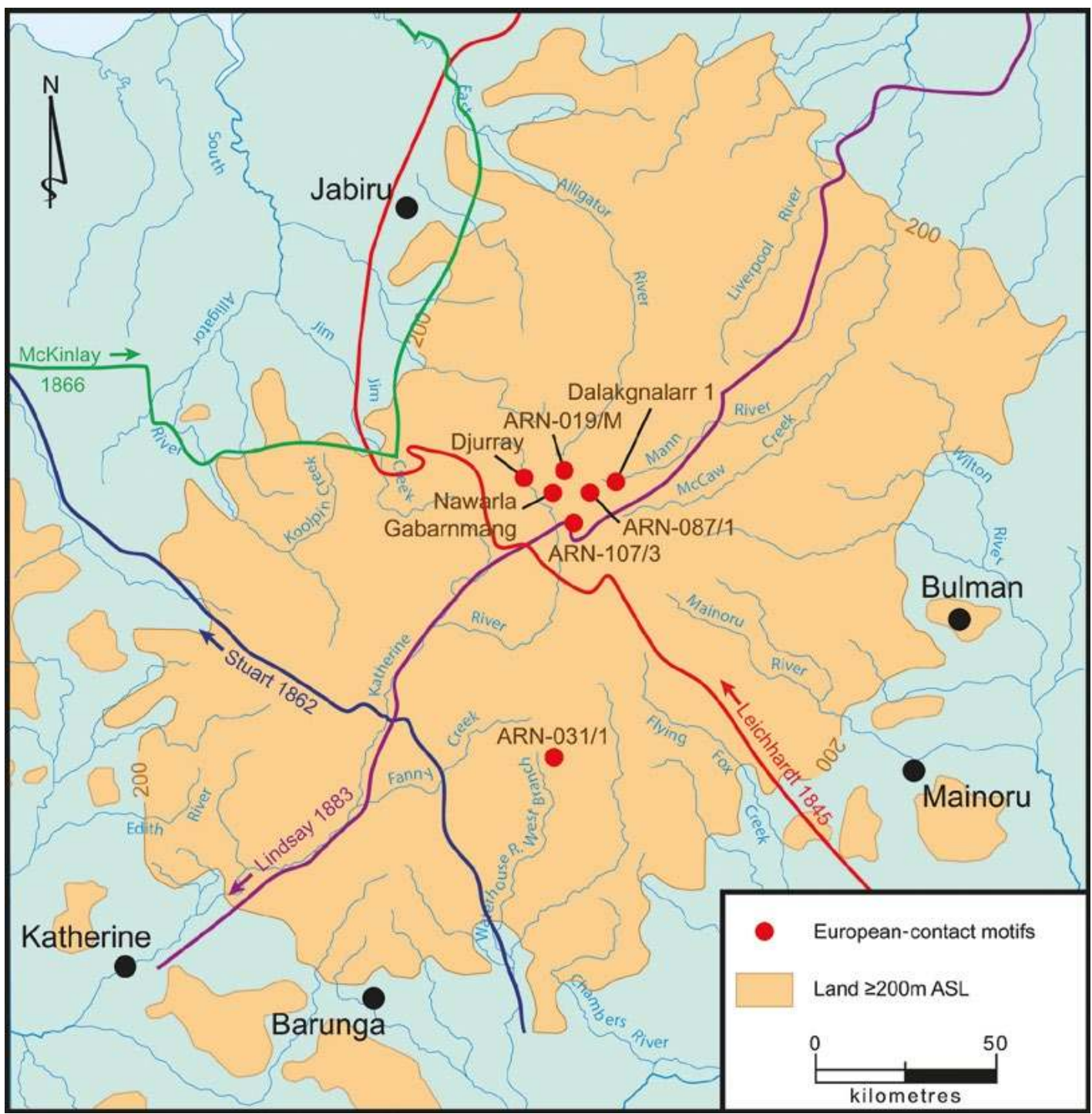

Figure 9.17 Early European travels on and around the Arnhem Land plateau. Leichhardt, Stuart, McKinlay and Lindsay's routes are plotted from maps and textual details in the explorers' published journals.

Source: Kara Rasmanis.

Four years later, J.M. McKinlay traversed the base of the northwestern escarpment (Australian Dictionary of Biography 1974; Davis 1863). Although McKinlay did not enter Jawoyn Country, doubtless his proximity would have been noticed by neighbouring groups and widely discussed.

In October 1883, David Lindsay, a government surveyor, was commissioned by the South Australian Government to assess the potential of eastern and central Arnhem Land for European settlement. Travelling by horse, Lindsay's party followed the Roper River from near the township of Katherine eastward around the south side of the plateau to the coast, deviating only to explore the upper reaches of the Wilton River. Cutting across the eastern, inland side of Arnhem Land they headed north to present-day Ramingining, west to the Liverpool River and then southwest over the plateau to the Katherine River, which they then followed downstream to the fledgling Katherine township (initially established as the Katherine Telegraph Station in 1872) (Figures 9.1 and 9.17). Lindsay was generally favourably disposed towards Aboriginal people and attempted to make peaceful contact with those he met, giving tobacco and small items (axes, fishing hooks and lines) in return for collecting word lists and receiving travel directions (Lindsay 1884). 
During two encounters, however - one near the mouth of the Roper River and one at Blue Mud Bay to the east of the Arnhem Land plateau - his party was attacked by armed warriors; Lindsay's party resorted to firearms to repel the assaults (McKinlay's party had also been threatened, on the East Alligator River).

Lindsay also mentions, and in some cases carefully describes, Aboriginal activities such as fishing and landscape-burning, as well as noting campsites, burial grounds and the location of stone quarries. From his notes, it is clear that the Roper River valley and the area around Ramingining were well populated by Aboriginal groups. Of the Roper River valley, which passes through southern Jawoyn lands, Lindsay writes: 'These evidences of an immense number of natives testifies to the excellence of the country' (Lindsay 1884:4). Despite his observations elsewhere, Lindsay makes no mention of seeing any people or campsite when crossing over the plateau on his return trip. It can be deduced from this lack of observations that the plateau was sparsely populated at that time. Whether this lack of encounters with Aboriginal people was due to the position of his route (which, to save his horses, deliberately avoided those areas where rock outcrops and rockshelters were densest), the effects of depopulation through earlier epidemics, or to the time of year (end of the dry season in October, when surface water is sparse) is unknown. Lindsay's party passed within $15 \mathrm{~km}$ of Djurray and $10 \mathrm{~km}$ south of the ARN-107 site complex, two key locations discussed in this chapter. With possible relevance for the paintings of horses at Nawarla Gabarnmang and the nearby ARN-087 site complex, it is of interest to note that the Aboriginal people Lindsay met near the western side of the Gulf of Carpentaria to the east of Jawoyn Country 'could speak a little English, were not afraid of us, but professed great fear of the horses and dogs' (Lindsay 1884:5). On another occasion, near the mouth of the Roper River, three of Lindsay's horses were speared by local Aborigines using spears tipped with either stone points or wire skewers. Before Lindsay could retrieve the wounded horses, one had been killed and disembowelled and his neck-bell taken (Lindsay 1884:6); during this early period when horses were first introduced into Arnhem Land, they were an object of keen interest to local Aboriginal groups.

Contact with munanga intensified with the completion of the overland telegraph line and the establishment of a repeater station near the present town of Katherine in 1872. The period between 1870 and 1890 also saw a rapid increase in the number of non-Aboriginal Australians, western Europeans and Chinese entering the western and southern sections of Jawoyn Country, as pastoral settlements became established and mineral exploration and gold-mining began (Levitus 1995:68-69, 74). Although few such intrusions were made onto the plateau, the pastoral industry isolated traditional waterholes and food reserves on surrounding lands, forcing local Aboriginal peoples to more or less rely on cattle stations, mines and/or market-gardens for labour and provisions to survive, at least seasonally. These places of work and access to resources became the foci of settlement for labourers and their families and, consequently, for the development of fringe camps. The presence of debilitating drugs such as opium, tobacco and alcohol, and often-rampant new diseases such as yaws and smallpox proved catastrophic, greatly reducing the population and thereby destroying or altering elements of culture, such as site-specific rites that required sizable gatherings for prolonged periods. By 1939, the Aboriginal population over most of the northern part of the Northern Territory, including the entire Arnhem Land plateau, had decreased dramatically, with estimated reductions of more than 95 per cent for each of the Alligator River region to the north and Victoria River region to the southwest of Jawoyn Country (Keen 1980; Rose 1992; Smith 1994:46). Following the Japanese bombing of Katherine in 1942, the Arnhem Land plateau was largely depopulated of Jawoyn and other Aboriginal groups through enforced resettlement into government compounds that later developed into residential communities, such as Rockhole at Katherine and small townships such as Barunga (Merlan 1998:5). 


\section{European contact-period occupation of the plateau}

'European contact' does not refer to a single period of time shared by all Aboriginal peoples across Australia. It, and its consequent effects on Aboriginal people, began at various times across the continent, depending on the timing of the expansion of European exploration and settlement. For the Guringai people of the Sydney region, initial European contact was in $1770 \mathrm{AD}$ and then again in $1788 \mathrm{AD}$ (McDonald 2008:16-22), while for some Western Desert groups initial European contact was not until around 1870 AD (Thompson 1975:x). For many Jawoyn, the European-contact period began in 1845 AD with Leichhardt's expedition across the plateau (above), that first phase of contact concluding with the development of local pastoral and mining industries in the 1890s. A second phase of contact in Jawoyn lands can be identified from $1890 \mathrm{AD}$ to the depopulation of the plateau in the 1940s. By the 1950s, the Maranboy tin mines had ceased production and most Jawoyn people from the plateau were now living in fringe camps around the towns and settlements off the plateau (Cooke 2009). Nevertheless, despite this broad exodus in the 1940s, Aboriginal people tell of continued movements across the region and of small numbers making prolonged visits to the plateau in the 1950s (Wamud Nadjamerrek and Margaret Katherine, pers. comm. 2006, 2010). Archaeologically, such a continued presence on the plateau is evident through at least two European-contact objects found in plateau rockshelters on Jawoyn lands: a decayed suitcase from site ARN-129/3 (Figure 9.18), likely to date to the first half of the 20th century; and a glass 'cat's-eye' marble (Figure 9.19) from site ARN-091/20a. Suitcases with similar catches to those at ARN-129/3 were being produced by 1911, and cat's-eye marbles began to be produced in the 1930s, gaining popularity in the 1940s and flooding the market in the 1950s. The glass marble could indicate occupation or visitation to the site in the 1930 s or early 1940 s, more likely in the post-World War II period after 1945 AD.
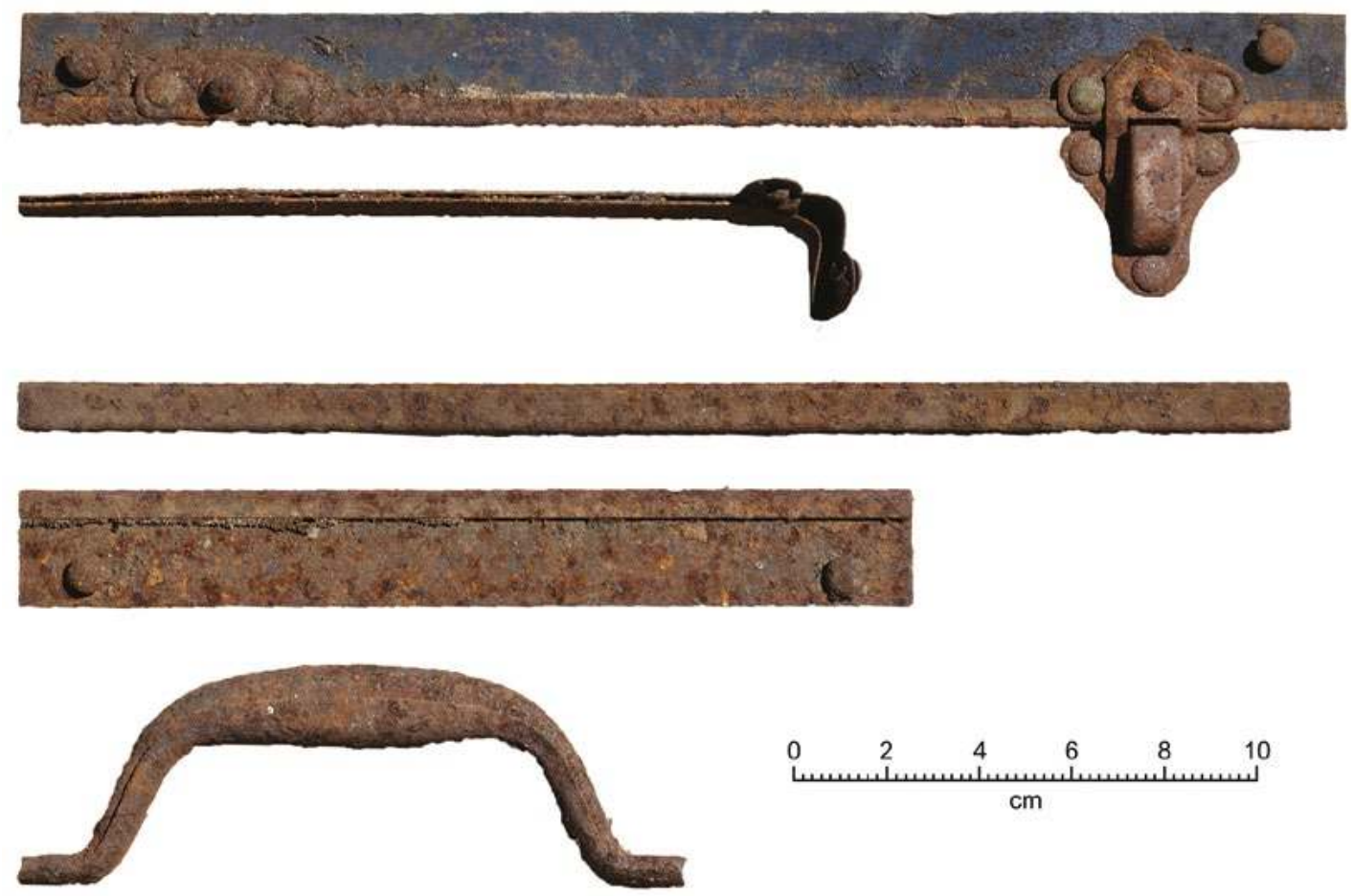

Figure 9.18 Suitcase frame elements from the European-contact period found as surface artefacts at site ARN-129/3.

Source: Photographs by Robert Gunn. 


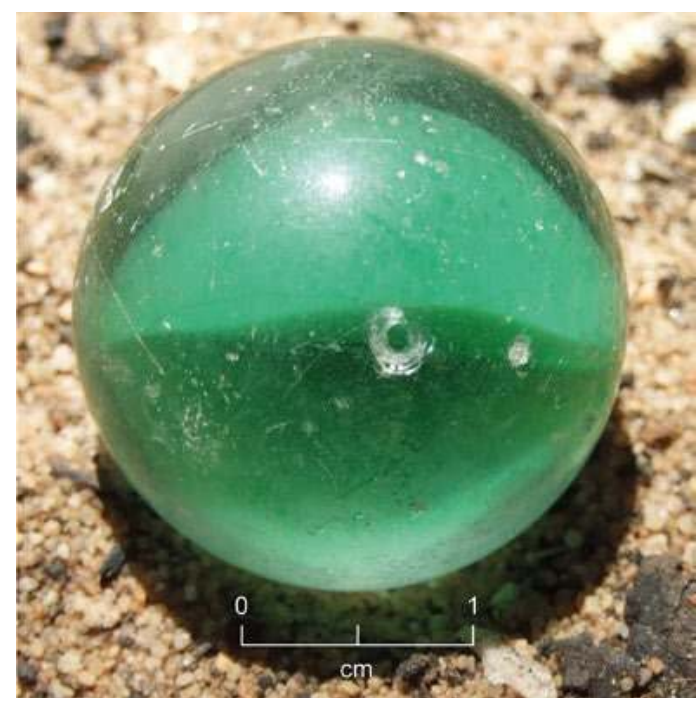

Figure 9.19 Cat's-eye marble from the Europeancontact period found as a surface artefact at site ARN-091/20a.

Source: Photograph by Robert Gunn.
Within Jawoyn lands on the Arnhem Land plateau, a number of portable artefacts of apparently limited antiquity have recently been found on rockshelter floors or carefully placed within rock outcrops. Those artefacts demonstrably from the European-contact period are those made of materials from nonAboriginal sources. To date, 45 artefacts of non-Aboriginal origins have been recorded from 33 site complexes (30 per cent of Jawoyn site complexes on the plateau) (Table 9.4).

Table 9.4 European contact-period artefacts found within rockshelters on the plateau (some sites contain more than one artefact type).

\begin{tabular}{|c|c|c|c|}
\hline Material & Artefact & \# of artefacts & \# of site complexes \\
\hline \multirow[t]{4}{*}{ Metal } & Metal piece & 4 & 4 \\
\hline & Tin can & 4 & 3 \\
\hline & Aluminium can & 1 & 1 \\
\hline & Suitcase & 1 & 1 \\
\hline \multirow[t]{3}{*}{ Glass } & Marble & 1 & 1 \\
\hline & Bottles & 1 & 1 \\
\hline & Beads & 2 & 2 \\
\hline \multirow[t]{2}{*}{ Cloth } & Bundle wrapping & 2 & 1 \\
\hline & Fragments & 4 & 3 \\
\hline \multirow[t]{8}{*}{ Wood cut with metal blade } & Burial poles & 4 & 2 \\
\hline & Clap sticks & 4 & 2 \\
\hline & Firewood & 2 & 2 \\
\hline & Highly carved small pointed implement & 1 & 1 \\
\hline & Barbed point & 5 & 4 \\
\hline & Piece & 3 & 3 \\
\hline & Pole & 3 & 1 \\
\hline & Ochred rods & 3 & 1 \\
\hline \multicolumn{2}{|l|}{ Total } & 45 & 33 \\
\hline
\end{tabular}

Source: Authors' data.

These items include objects or pieces of metal, glass or cloth (such as tin cans, iron nails, glass marbles, glass beads, canvas sheeting and so forth) (e.g. Figures 9.18-9.20; see Figure 13.32), and items made of wood such as barbed spear points, burial poles or cut firewood that have been clearly cut or fashioned by metal blades (e.g. Figures 9.21 and 9.22; see Figure 13.18). At Nawarla Gabarnmang (site ARN-074/A), the site with the large horse painting (see above), only one portable item of material culture demonstrably originating from non-Aboriginal sources 
has been found on the surface or in archaeological excavations: a blue glass bead $2.30 \times 2.56 \mathrm{~mm}$. The bead came from XU1 of excavation Square J, within the top $1.1 \mathrm{~cm}$ of sediment. Trade items were commonly carried by early European explorers travelling across northern Australia including Arnhem Land, although we do not know if they carried trade beads. As Wesley and Litster (2015) have noted, however, trade beads were present on the coast as currencies in AboriginalMacassan-European economies well before the first European explorers of the Arnhem Land plateau, and could thus have entered Jawoyn Country through northern Aboriginal interactions and movements. The absence of any known non-Aboriginal portable object other than the glass bead at Nawarla Gabarnmang indicates that the excavated bead was almost certainly deposited during the early (rather than later) European-contact period, and is likely to either precede, or to be broadly contemporaneous with, the horse painting located some $9 \mathrm{~m}$ to the southeast of Square J. Furthermore, of the 43 accelerator mass spectrometry (AMS) radiocarbon dates from near-surface charcoal dating to the past c. 400 years at Nawarla Gabarnmang (including from the area where the glass bead was found), not a single one exhibits evidence of the 'bomb pulse' (see below). The charcoal from the most recent campfires within the site thus almost certainly always pre-date $1945 \mathrm{AD}$ (by an unknown number of decades).

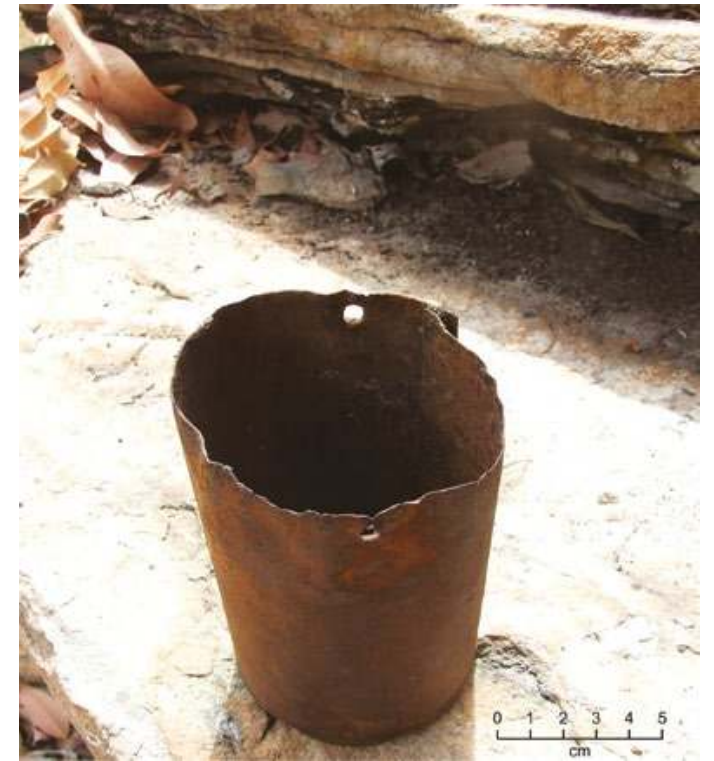

Figure 9.20 Small metal billy-can from the European-contact period found as a surface artefact at site ARN-116/1.

Source: Photograph by Robert Gunn.
Artefacts made from organic material such as plant fibre or wood are unlikely to survive for any extended period of time in Arnhem Land due to the acidic nature of the soils, the prevalence of termites and moulds, the scavenging activities of fauna (small to mediumsized mammals including dingoes, goannas, and birds), the high wet season rainfall, and the regular bushfires in the dry season (many initiated by the Jawoyn in the management of Country). Not surprisingly, therefore, most of the more recent artefacts recovered from rockshelters in Jawoyn lands, such as painted burial poles, ochred string, plant fibre bags and cloth pieces (e.g. Figures 9.23 and 9.24) come from sites close to European-period settlements located around the southern rim of the plateau, such as Barunga. Forty-seven artefacts made from locally available organic materials have been recorded from 35 site complexes (32 per cent of Jawoyn site complexes on the plateau) (Table 9.5).

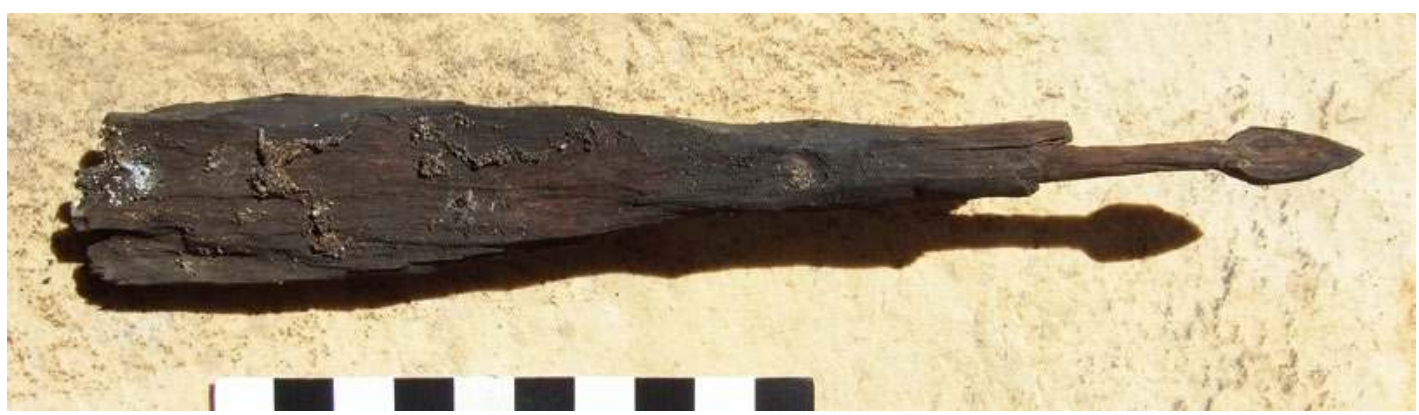

Figure 9.21 Non-European wooden artefact cut with a metal blade, site ARN-107/12. Scale $10 \mathrm{~cm}$.

Source: Photograph by Robert Gunn. 


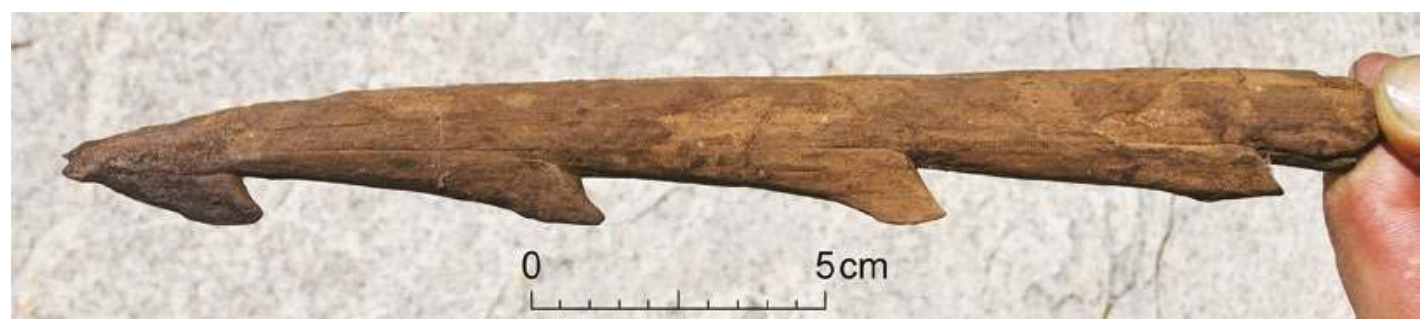

Figure 9.22 Non-European wooden spear point cut with metal blade, site ARN-133/29.

Source: Photograph by Robert Gunn.

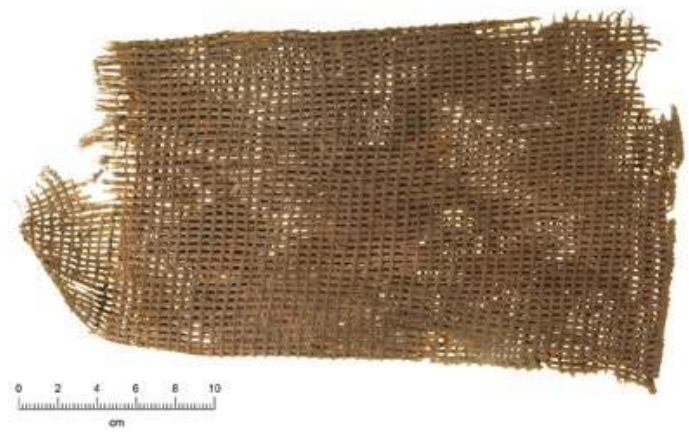

Figure 9.23 Non-European bag made from plant fibre, site ARN-110/1. Identified by Margaret Katherine (pers. comm. to Ray Whear 2009) as a bag for washing yams. AMS radiocarbon date Wk-31833 was obtained from a fragment of fibre from this bag.

Source: Photograph by Steve Morton.

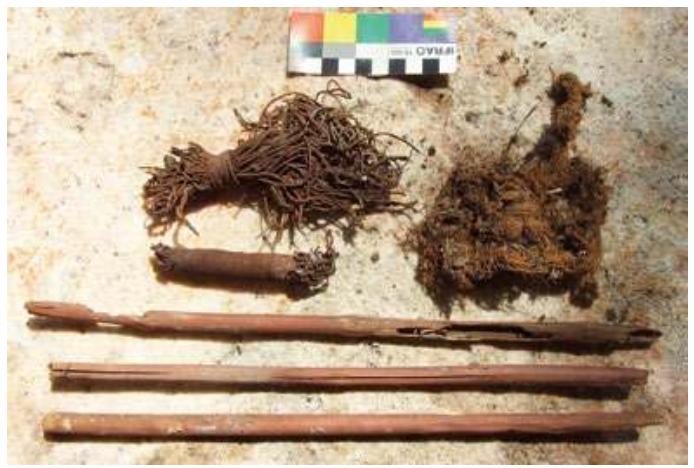

Figure 9.24 Non-European cache of cord and wooden artefacts, site EVA-12/4. Scale $10 \mathrm{~cm}$. Source: Photograph by Robert Gunn.

Table 9.5 Non-European artefacts made of organic materials found within rockshelters on the plateau (some sites contain more than one artefact type).

\begin{tabular}{|l|l|r|r|}
\hline Material & Artefact & \# of artefacts & \# of site complexes \\
\hline \multirow{5}{*}{ Fibre } & String skein & 1 & 1 \\
\cline { 2 - 4 } & Cord, tasselled \& ochred & 2 & 1 \\
\cline { 2 - 4 } & Fibre dillybag & 1 & 1 \\
\hline Paperbark & Sheets and bundle & 2 & 2 \\
\hline \multirow{3}{*}{ Other wood } & Cached stick & 3 & 3 \\
\cline { 2 - 4 } & Dillybag hook & 18 & 14 \\
\cline { 2 - 4 } & Bamboo shaft & 1 & 1 \\
\cline { 2 - 4 } & Wooden pole, straight & 3 & 2 \\
\cline { 2 - 4 } & Wooden pole, forked & 10 & 5 \\
\cline { 2 - 4 } & Wooden spear point, plain & 3 & 2 \\
\cline { 2 - 4 } & Other wooden implements & 3 & 3 \\
\hline \multirow{2}{*}{ Total } & & 47 & 25 \\
\hline
\end{tabular}

Source: Authors' data. 
In an attempt to establish the most recent use of the Arnhem Land plateau sites, surface and near-surface (i.e. most recent) in situ hearths on the Arnhem Land plateau were radiocarbondated (Table 9.6). Although few such surface cultural features have been encountered so far, the results are instructive. All bar one of these hearths are located within rockshelters; the exception is a hearth from an eroding creek bank at the ARN-079 rock art site complex (Table 9.6). Installations and portable items of material culture found on the surface of sites have also been radiocarbon-dated with these same aims in mind, including two canine bundle burials (Gunn et al. 2010, 2012b), a plant fibre dillybag (Figure 9.23), and four wooden items of material culture (Figure 9.25; see below). Direct radiocarbon dating of apparently relatively recent rock art has also been undertaken, in particular of beeswax figures (Gunn and Whear 2008).

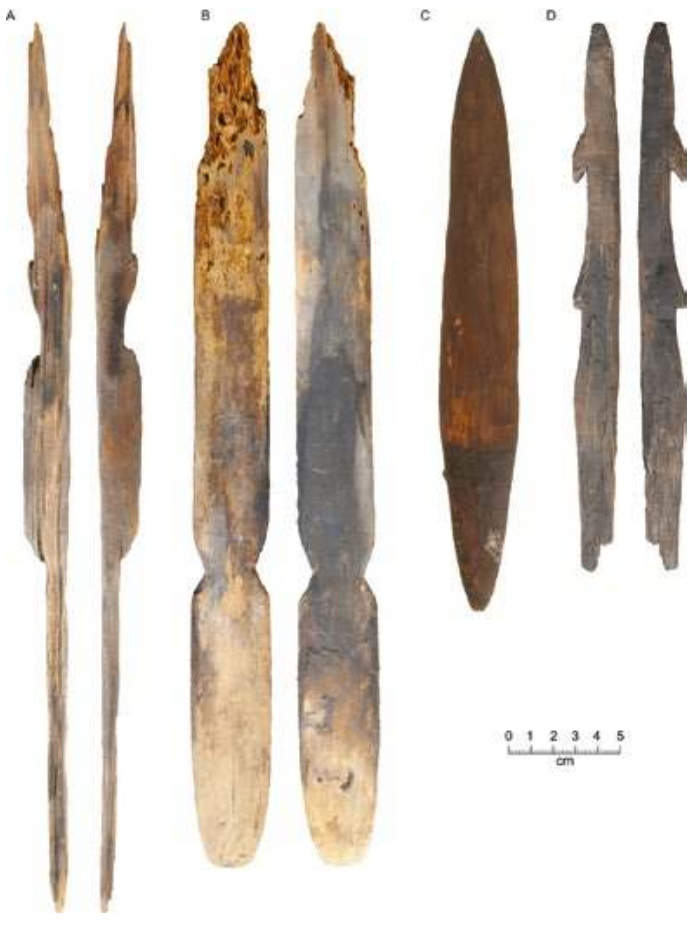

Figure 9.25 Non-European artefacts made of wood. A: Barbed spear point with radiocarbon date Wk-28114, site ARN-074/A. B: Spearthrower with radiocarbon date Wk-28113, site ARN-074/A. C: Point with adhering resin with radiocarbon date Wk-31834, site ARN-087/1. D: Barbed spear point with radiocarbon dates Wk-28115 and Wk31835, site ARN-074/A.

Source: Photographs by Bruno David, Steve Morton and Jean-Michel Geneste.
The testing of atomic bombs in the 1950s and early 1960s significantly increased the amount, and proportion, of ${ }^{14} \mathrm{C}$ in the atmosphere, so that radiocarbon dates with very high levels of ${ }^{14} \mathrm{C}$ exceeding the 1955 levels exhibit evidence of the 'bomb pulse', and can be used to date post-1955 samples to within six months' precision (e.g. see Wilson et al. 2001). It is significant that none of the radiocarbon dates from objects on the plateau in Jawoyn lands exhibit the bomb pulse. Of the six surface and near-surface hearths dated, the two most recent calibrate to sometime within the period 1693-1956 AD at 68.3 per cent probability, but most probably within the mid-1800 to early 1900s; so they almost certainly either predate the European-contact period or date to its early phase prior to depopulation of the plateau by 1942 . Similarly, both canine burials have a higher probability of calibrating to within the period 1877-1917 AD, again signalling ages of the early European-contact period prior to the bomb pulse. All six radiocarbon dates from the fragile (i.e. arguably relatively recent) wooden and plant fibre artefacts (Figures 9.23 and 9.25) recovered from shelter floors calibrate to within the period 1651-1956 AD, but again the highest probability age ranges fall in the 18th and 19th centuries relating to the pre- or early European-contact period and certainly to an overall period preceding the bomb pulse. The youngest five radiocarbon-dated beeswax images, similarly, all have highest probability peaks in the 18th and 19th centuries. Thus, all the cultural items investigated because they might be of very recent age are most likely of the early European-contact period or earlier, indicating a paucity or absence of traces of occupation into more recent times (Table 9.6). 
Table 9.6 Radiocarbon determinations on surface cultural features on the plateau, Jawoyn lands.

\begin{tabular}{|c|c|c|c|c|c|c|}
\hline Site complex & $\begin{array}{l}\text { Wk- laboratory } \\
\text { code }\end{array}$ & $\theta^{13} \mathrm{C} \% 0$ & $\begin{array}{l}\text { \% Modern } \\
\text { carbon }\left(\mathrm{F}^{14} \mathrm{C} \%\right)\end{array}$ & $\begin{array}{l}{ }^{14} \text { C age } \\
\text { (years BP) }\end{array}$ & $\begin{array}{l}\text { Calibomb 1yr smoothing } \\
\text { (68.3\% probability) }\end{array}$ & $\begin{array}{l}\text { European- } \\
\text { contact period }\end{array}$ \\
\hline \multicolumn{7}{|c|}{ Charcoal from surface hearths } \\
\hline ARN-115 & 30145 & $-25.4 \pm 0.2$ & $99.4 \pm 0.3$ & $51 \pm 25$ & $\begin{array}{l}1708-1718(0.144) \\
1826-1832(0.066) \\
1887-1912(0.771) \\
1956-1956(0.019)\end{array}$ & Probable \\
\hline ARN-055 & 30143 & $-25.5 \pm 0.2$ & $98.6 \pm 0.2$ & $115 \pm 35$ & $\begin{array}{l}1693-1707(0.149) \\
1719-1727(0.094) \\
1812-1826(0.137) \\
1832-1885(0.558) \\
1913-1919(0.062) \\
\end{array}$ & Probable \\
\hline ARN-055 & 30144 & $-24.1 \pm 2.0$ & $96.9 \pm 0.2$ & $254 \pm 32$ & $1645-1660(1.000)$ & No \\
\hline ARN-067 & 31071 & $-25.3 \pm 0.2$ & $95.7 \pm 0.4$ & $352 \pm 33$ & $\begin{array}{l}1473-1523(0.470) \\
1560-1560(0.000) \\
1572-1630(0.530)\end{array}$ & No \\
\hline ARN-087 & 31072 & $-26.1 \pm 0.2$ & $77.5 \pm 0.4$ & $2052 \pm 38$ & $\begin{array}{l}148-142 \text { BC }(0.033) \\
112 \text { BC-AD } 3(0.967)\end{array}$ & No \\
\hline ARN-079 & 25687 & $-25.4 \pm 0.2$ & $63.3 \pm 0.2$ & $3671 \pm 36$ & $\begin{array}{l}2131-2084 \text { BC (0.579) } \\
2056-2022 \text { BC }(0.375) \\
1990-1984 \text { BC }(0.046)\end{array}$ & No \\
\hline \multicolumn{7}{|c|}{ Canine (dog) bone } \\
\hline ARN-107 (dingo) & 25381 & $-13.5 \pm 0.2$ & $99.0 \pm 0.3$ & $77 \pm 35$ & $\begin{array}{l}1698-1722(0.285) \\
1817-1834(0.199) \\
1879-1916(0.514) \\
1956-1956(0.001)\end{array}$ & Probable \\
\hline ARN-057 (dog) & 31813 & n/a & $98.9 \pm 0.3$ & $88 \pm 25$ & $\begin{array}{l}1697-1725(0.317) \\
1815-1835(0.225) \\
1877-1917(0.459) \\
\end{array}$ & Probable \\
\hline \multicolumn{7}{|l|}{ Beeswax art } \\
\hline ARN-117 & 26415 & $-23.0 \pm 0.2$ & $98.3 \pm 0.2$ & $136 \pm 30$ & $\begin{array}{l}1681-1697(0.144) \\
1724-1739(0.123) \\
1744-1763(0.124) \\
1802-1815(0.107) \\
1835-1878(0.311) \\
1916-1938(0.183) \\
1954-1955(0.004) \\
1955-1956(0.004)\end{array}$ & Possible \\
\hline ARN-063 & 19299 & $-24.4 \pm 0.2$ & $98.2 \pm 0.4$ & $143 \pm 31$ & $\begin{array}{l}1674-1696(0.152) \\
1725-1778(0.364) \\
1799-1814(0.107) \\
1836-1844(0.047) \\
1851-1869(0.112) \\
1871-1876(0.029) \\
1917-1941(0.178) \\
1954-1956(0.011)\end{array}$ & Possible \\
\hline ARN-074 & 26418 & $-24.8 \pm 0.2$ & $98.1 \pm 0.2$ & $153 \pm 30$ & $\begin{array}{l}1677-1688(0.138) \\
1730-1765(0.496) \\
1772-1776(0.042) \\
1800-1809(0.126) \\
1926-1940(0.199)\end{array}$ & Possible \\
\hline ARN-074 & 28101 & $-22.9 \pm 0.2$ & $97.9 \pm 0.3$ & $173 \pm 30$ & $\begin{array}{l}1669-1683(0.173) \\
1735-1781(0.557) \\
1798-1806(0.094) \\
1930-1945(0.176)\end{array}$ & Possible \\
\hline
\end{tabular}




\begin{tabular}{|c|c|c|c|c|c|c|}
\hline Site complex & $\begin{array}{l}\text { Wk- laboratory } \\
\text { code }\end{array}$ & $\theta^{13} \mathrm{C} \% 0$ & $\begin{array}{l}\text { \% Modern } \\
\text { carbon }\left(\mathrm{F}^{14} \mathrm{C} \%\right)\end{array}$ & $\begin{array}{l}{ }^{14} \text { C age } \\
\text { (years BP) }\end{array}$ & $\begin{array}{l}\text { Calibomb 1yr smoothing } \\
\text { (68.3\% probability) }\end{array}$ & $\begin{array}{l}\text { European- } \\
\text { contact period }\end{array}$ \\
\hline ARN-063 & 19317 & $-24.3 \pm 0.2$ & $97.6 \pm 0.4$ & $195 \pm 31$ & $\begin{array}{l}1661-1681(0.226) \\
1738-1753(0.129) \\
1762-1803(0.463) \\
1937-1951(0.167) \\
1952-1954(0.016)\end{array}$ & Possible \\
\hline $\begin{array}{l}\text { ARN-074 } \\
\text { (resin?) }\end{array}$ & 31731 & $-12.2 \pm 0.2$ & $96.7 \pm 0.3$ & $267 \pm 29$ & $\begin{array}{l}1528-1545(0.243) \\
1547-1550(0.037) \\
1634-1661(0.702) \\
1951-1952(0.018)\end{array}$ & No \\
\hline ARN-074 & 31722 & $-24.1 \pm 0.2$ & $96.0 \pm 0.4$ & $327 \pm 31$ & $\begin{array}{l}1499-1504(0.044) \\
1512-1531(0.178) \\
1537-1601(0.592) \\
1616-1635(0.186)\end{array}$ & No \\
\hline ARN-074 & 31721 & $-24.2 \pm 0.2$ & $95.9 \pm 0.3$ & $340 \pm 25$ & $\begin{array}{l}1493-1526(0.320) \\
1555-1602(0.483) \\
1614-1633(0.197)\end{array}$ & No \\
\hline ARN-074 & 26416 & $n / a$ & $95.3 \pm 0.2$ & $383 \pm 30$ & $\begin{array}{l}1452-1487(0.942) \\
1604-1607(0.058)\end{array}$ & No \\
\hline ARN-074 & 26414 & $-23.3 \pm 0.2$ & $95.1 \pm 0.2$ & $406 \pm 30$ & $1447-1471(1.000)$ & No \\
\hline ARN-063 & 19318 & $-22.9 \pm 0.2$ & $86.9 \pm 0.3$ & $1124 \pm 32$ & $\begin{array}{l}890-907(0.236) \\
915-968(0.764)\end{array}$ & No \\
\hline \multicolumn{7}{|c|}{ Organic portable artefacts } \\
\hline $\begin{array}{l}\text { ARN-074 } \\
\text { (wood from } \\
\text { spearthrower) }\end{array}$ & 28113 & $-25.0 \pm 0.2$ & $99.4 \pm 0.3$ & $47 \pm 30$ & $\begin{array}{l}1708-1718(0.144) \\
1826-1832(0.066) \\
1887-1912(0.771) \\
1956-1956(0.019)\end{array}$ & Probable \\
\hline $\begin{array}{l}\text { ARN-074 (wood } \\
\text { from clap stick) }\end{array}$ & 28116 & $-25.3 \pm 0.2$ & $98.8 \pm 0.4$ & $99 \pm 32$ & $\begin{array}{l}1695-1726(0.286) \\
1813-1838(0.223) \\
1842-1853(0.087) \\
1860-1860(0.003) \\
1867-1897(0.257) \\
1902-1918(0.144)\end{array}$ & Possible \\
\hline $\begin{array}{l}\text { ARN-087 (resin } \\
\text { from spear point } \\
\text { hafting) }\end{array}$ & 31834 & $-23.1 \pm 0.2$ & $98.7 \pm 0.3$ & $109 \pm 25$ & $\begin{array}{l}1694-1726(0.305) \\
1813-1838(0.240) \\
1842-1853(0.101) \\
1859-1861(0.020) \\
1867-1892(0.233) \\
1907-1918(0.101)\end{array}$ & Possible \\
\hline $\begin{array}{l}\text { ARN-110 (plant } \\
\text { fibre from } \\
\text { dillybag) }\end{array}$ & 31833 & $-10.1 \pm 0.2$ & $98.4 \pm 0.3$ & $127 \pm 25$ & $\begin{array}{l}1670-1685(0.164) \\
1731-1780(0.542) \\
1798-1808(0.105) \\
1927-1944(0.177) \\
1954-1955(0.012)\end{array}$ & Doubtful \\
\hline \multirow{2}{*}{$\begin{array}{l}\text { ARN-074 (wood } \\
\text { from barbed } \\
\text { spear point) }\end{array}$} & 28115 & $-23.7 \pm 0.2$ & $98.0 \pm 0.3$ & $159 \pm 30$ & \multirow[b]{2}{*}{$\begin{array}{l}1666-1681(0.239) \\
1739-1750(0.119) \\
1762-1784(0.335 \\
1795-1802(0.105) \\
1937-1950(0.194) \\
1953-1954(0.009)\end{array}$} & \multirow[t]{2}{*}{ Doubtful } \\
\hline & 31835 & $-24.2 \pm 0.2$ & $97.2 \pm 0.4$ & $227 \pm 30$ & & \\
\hline $\begin{array}{l}\text { ARN-074 (wood } \\
\text { from barbed } \\
\text { spear point) }\end{array}$ & 28114 & $-23.9 \pm 0.2$ & $97.3 \pm 0.3$ & $218 \pm 30$ & $\begin{array}{l}1651-1669(0.415) \\
1781-1798(0.432) \\
1946-1953(0.153)\end{array}$ & Doubtful \\
\hline
\end{tabular}

All ${ }^{14} \mathrm{C}$ ages are AMS on single pieces of charcoal (hearths), bone (canine bone), beeswax or probable plant resin (rock art), wood or plant fibre (portable artefacts). Calibrations undertaken using Calibomb (IntCal13 and SHZ3) (Reimer et al. 2013; Hua et al. 2013). Numbers in bold represent the highest probability range.

Source: Authors' data. 
The distribution of these artefacts and dates across Jawoyn lands on the plateau (Figure 9.26) reveals evidence of people using rock art sites during the early European-contact period. The paucity of European-contact motifs relating to this early contact period cannot be seen simply as a reduction in population numbers. Nor can it be due to a reduction in artistic output over this same time frame, as well shown for example by the heavy superimpositioning at ARN074/A when output increases and images become bigger and are more polychrome. The evidence indicates that Aboriginal people remained numerous over many decades on the plateau during the early European-contact period. An explanation is called for other than rapid depopulation close to the initial period of contact.

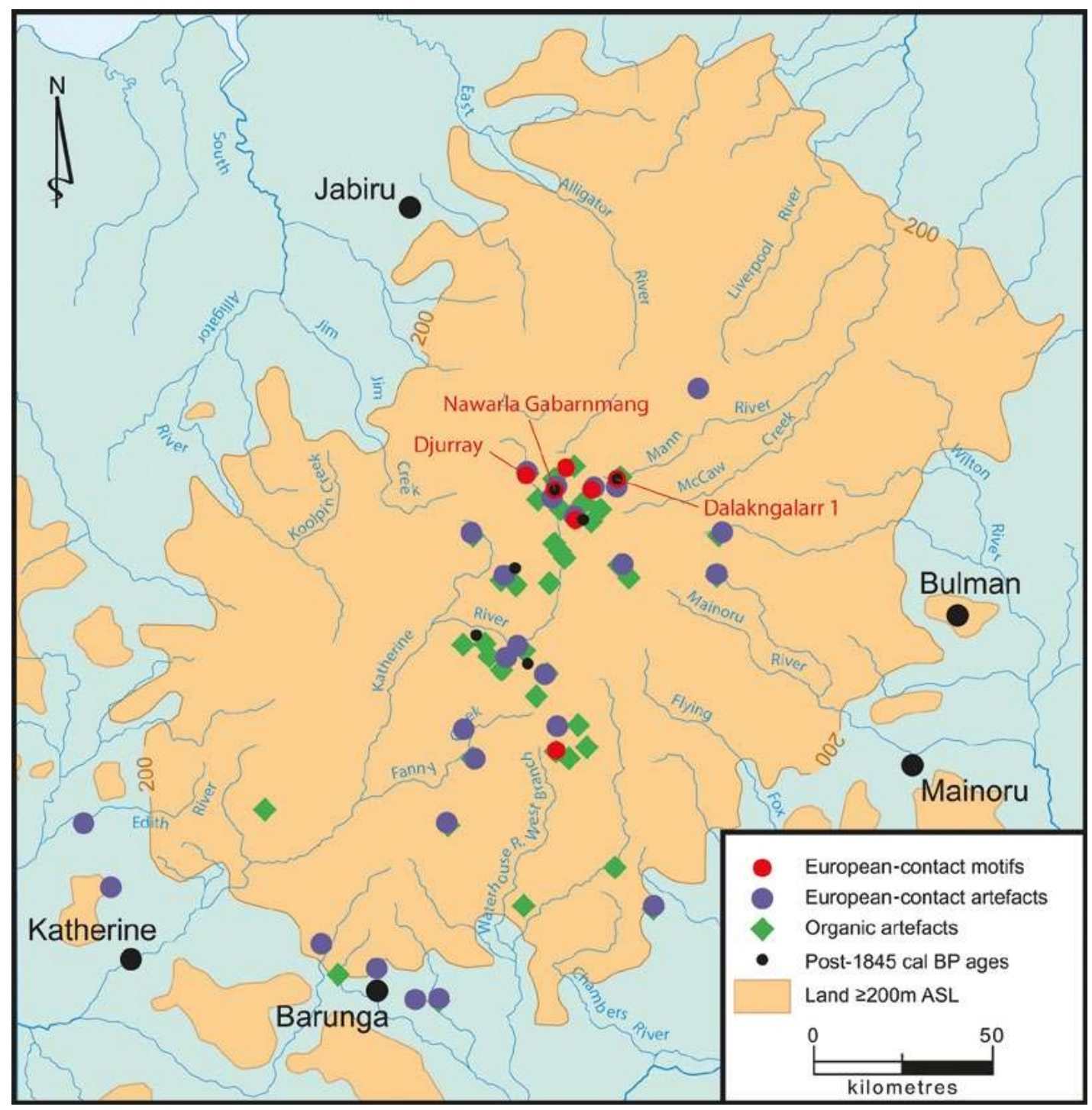

Figure 9.26 Distribution of European-contact period and organic artefacts in Jawoyn lands.

Source: Kara Rasmanis. 


\section{Discussion}

To date, 1079 rock art sites have been recorded from 127 site complexes in Jawoyn lands (including the plateau and surrounding uplands). Of these, only the seven reported here ( 0.6 per cent of sites) contain European-contact motifs of a kind discussed in this chapter (Figure 9.2). While a total survey of Jawoyn rock art sites is far from complete - we estimate that Jawoyn lands probably contain well over 1000 site complexes - the spatial patterning of European-contact imagery and portable items of material culture are based on extensive surveys covering the length and width of Jawoyn lands, and are thus considered to be representative of the region as a whole. In the Wellington Range $150 \mathrm{~km}$ to the north of Jawoyn lands and $30 \mathrm{~km}$ from the coast, paintings of boats account for 50 per cent of the non-Aboriginal-contact images (May et al. 2013:48), but paintings of European-contact objects occur in only 5 per cent of a sample of c. 150 sites (May et al. 2010:63, Figure 12). Hence, even in areas with close interactions with several waves of non-Aboriginal people (e.g. Macassan, European), contact motifs identifiably depicting contact events, personages and themes do not feature prominently in the rock art. The considerably lower proportion of contact motifs within Jawoyn lands is not surprising, given the relative paucity of interactions between Jawoyn people and outsiders over the period from 1845 to the turn of the 19th century and even later. Consequently, the dearth of contact motifs in Jawoyn lands can be directly attributed to a paucity of direct interactions with outsiders and the relatively minor direct intervention intruders had on traditional Jawoyn life during this period prior to depopulation of the Arnhem Land plateau (the devastating effects of introduced diseases such as yaws and smallpox notwithstanding).

Our work has found that European-contact motifs appear to be clustered in two general locations of the plateau in Jawoyn lands: six sites on the upper reaches of the Katherine River, and one site on the upper Waterhouse River (Figure 9.2). All but two are within large and welldecorated rockshelters (Table 9.7). The exceptional two, ARN-019/M and ARN-103/1, each contains a single image of what appear to be European men; indeed, they are the only locations where Europeans appear other than on depictions of boats. The images in the Katherine River headwaters can be subdivided on subject and stylistic grounds into three groups:

1. The standing figure at ARN-107/3 (Figure 9.7) and the figures on the large boat painting at ARN-088/6 (Boat A) (Figure 9.3) $17 \mathrm{~km}$ to the northwest, all of which share similar pigment colour, headwear (broad-brimmed European style hat), paint application (thickness of line work) and the body proportions of the figures.

2. The human figure painted in white at ARN-019/M (Figure 9.8), and the mounted red figure at ARN-087/1 (Figure 9.12), which both wear similar headwear (pith-helmets?) and, hence, probably relate to a similar period of time (or perhaps even to the same person or event).

3. The singular large polychrome horse motif at ARN-074/A (Figure 9.9).

Table 9.7 Sites with European-contact imagery on the plateau in Jawoyn lands.

\begin{tabular}{|l|l|l|l|l|}
\hline Site & \# of paintings & Shelter size: width $\times$ depth $\times$ height $(\mathbf{m})$ & Contact paintings & River catchment \\
\hline ARN-088/6 & 320 & $23 \times 8 \times 6$ & Boats $(7)$ & Katherine R. \\
\hline ARN-107/3 & 11 & $5 \times 2 \times 2$ & Man + top hat & Katherine R. \\
\hline ARN-019/M & 25 & $8 \times 2 \times 2$ & Man + rifle & Katherine R. \\
\hline ARN-074/A & $>800$ & $25 \times 15 \times 2$ & Horse & Katherine R. \\
\hline ARN-087/1 & 730 & $70 \times 4 \times 4$ & Horse + rider & Katherine R. \\
\hline ARN-082/1 & 350 & $14 \times 9 \times 2$ & Hatchets $(2)$ & Katherine R. \\
\hline ARN-031/1 & 344 & $28 \times 3 \times 4$ & Bullock & Waterhouse $R$. \\
\hline
\end{tabular}

Source: Authors' data. 
The images at ARN-087/1 (Figure 9.12) and ARN-074/A (Figure 9.9) are stylistically different from both each other and all other contact images within Jawoyn lands. The horse representations at these two sites are in very different styles and sizes. As the portrayal of the ARN-087/1 horse is truer to the active use of horses by people (e.g. presence of rider, reins) than is that of ARN074/A, the ARN-087/1 artist may have had better knowledge of horses than did the artist at ARN-074/A. The larger ARN-074/A horse may have been, therefore, painted following a first or relatively unfamiliar sighting of the animal. The subsequent superimpositioning of the large horse by an array of other motifs at this site also suggests that, with time, the original impact of the animal as a novel encounter diminished. On the other hand, the ARN-087/1 horse-andrider is both smaller in size and located in a more secluded position (where it could only be seen by one person at a time). Given the above factors, the ARN-087/1 horse-and-rider figure was arguably painted some time later than the ARN-074/A horse. The bullock with bell at ARN-031/1 (Figure 9.13) also shows good anatomical details, indicating first-hand knowledge of the animal; it was thus probably painted by someone who was already at least reasonably well acquainted with the animal, and possibly by someone who had themselves worked with cattle. If so, an early 20 th-century age is suggested for its creation, an interpretation consistent with the painting's excellent state of preservation.

Each of the European-contact paintings of animals within Jawoyn lands has a very different appearance. While these differences may reflect the artists' diverse attitudes, the varying states of preservation of the images coupled with the arguments made above suggest a progressive development of Jawoyn observation from an initial high impact of the unknown, to greater familiarity with the animals over time (Figure 9.27).

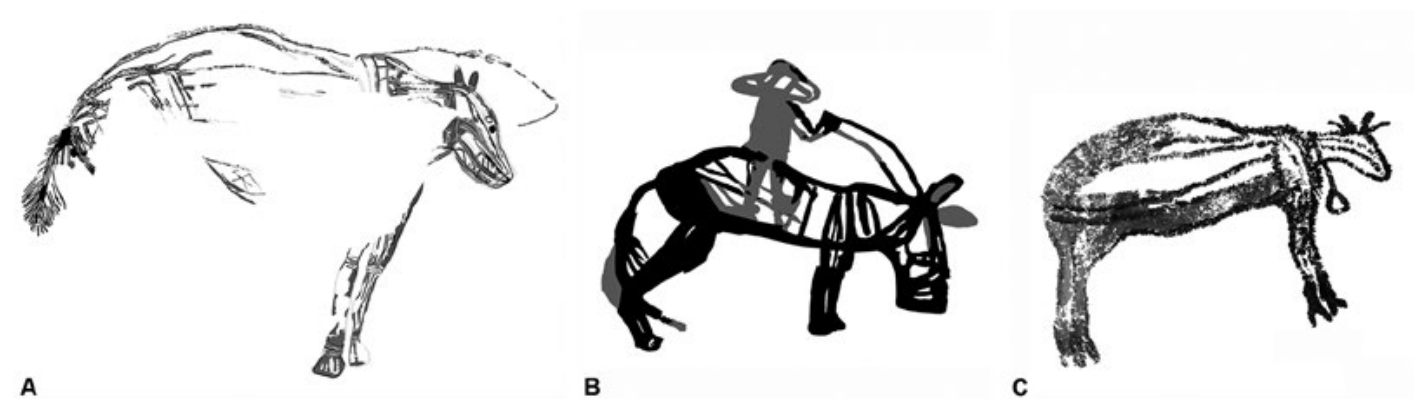

Figure 9.27 Proposed chronological sequence of introduced fauna (horse, cattle) motifs in Jawoyn lands. A: Early. B: Intermediate. C: Late.

Source: Robert Gunn.

Following the depopulation of the plateau in 1942, it appears that little, if any, rock art was produced in the Jawoyn lands of the Arnhem Land plateau, as use of rockshelters closer to newly established settlements seem to have replaced the more distant art shelters (see also Arndt 1962:169-170). Evidence in the form of a range of portable artefacts (e.g. suitcase and cat's-eye marble; Figures 9.18 and 9.19) indicates that Jawoyn and other Aboriginal peoples crossing the plateau probably continued to use rockshelters as camping places between 1910 and the closing of the Maranboy tin mines in the early 1950s. While it is possible that a small amount of rock art was produced in Jawoyn sites on the plateau during post-1940 crossings, no such images have yet been identified (Smith 1994:233, 235). When Wamud Nadjamerrek walked over the Arnhem Land plateau with his family in the 1930s, they camped at the spectacular rock art site of Nawarla Gabarnmang (ARN-074/A). On his return visit in 2008, he remembered the well-decorated ceiling and thought that there had been no additional rock art images added to the panels since his earlier visit (Wamud Nadjamerrek, pers. comm. to Ray Whear 2008). As this is one of the most decorated and, based on the size of the utilised floor space and density of surface cultural 
materials, one of the most visited camping shelters on the plateau in Jawoyn lands, it is likely that the shelter would have traces of any major recent period of rock art production occurring on the plateau following Nadjamerrek's visit. Consequently, an absence of any additional, recent artwork at Nawarla Gabarnmang is consistent with the notion that rock art production did not flourish on the plateau in Jawoyn lands in the period after 1930.

\section{Conclusion}

The Jawoyn lands of the Arnhem Land plateau were widely occupied during the early Europeancontact period, but effectively depopulated from the 1940s onwards. Here, rock art production appears to have continued until around 1930 (Gunn et al. 2012a). Despite this, nowhere in Jawoyn lands are paintings of European objects, people or events commonly found, and the few that have been found occur close to the routes taken by Leichhardt and Lindsay. Arguably, all of these European-contact motifs date to the early period of European contact (after 1845 AD) and, hence, these paintings depict very early, perhaps even first-contact encounters. The implication is that while Indigenous artists continued to paint on the plateau, it is not European themes that directed their artistic attention, nor Europeans or other outsiders, but rather everyday concerns that featured in established cosmologies that continued to guide how they viewed the world to operate. The exception appears to have been the early contact period, a time that necessitated the incorporation of foreigners into a pre-established world order. The key reference points for artistic works continued to be ancestral connections articulating the Spirit-Beings and stories that gave and continued to give shape to Country. Europeans had become a new presence, a powerful one that began to change Indigenous lives, but they did not feature significantly in the existential workings of the world, and so did not feature in the artworks that depicted those liminal spaces between the materially embodied living and the numinous. It is later, with the dislocation of people from the plateau during World War II, that the act of painting largely ceased, although Jawoyn individuals and groups visiting places on the plateau after that time continued to relate to places and 'artworks' as living presences of emplaced Spirit-Beings, sometimes deceased ancestors, sometimes not, but always mediated by Dreaming cosmologies.

\section{Acknowledgements}

This study was undertaken as part of the Jawoyn Rock Art and Heritage Programme (JRAHP), and was fully supported by Margaret Katherine, senior Traditional Owner of the Buyhmi clan estate, and the Board of the Jawoyn Association, Katherine. Our thanks also go to the many other Jawoyn people who assisted in this project: Larry Atkinson, Lily Bennett, Peter Bolgay, Mildred Brennnan-Kuawangai, Nell Brown, Nikabini Dalak, Dudley Lawrence, Peter Manaburra, Ken Murray, Wamud Nadjamerrek, Sybil Ranch, Ester Runyu, Jimmy Wesan, Phyllis Wiynjorrotj, Hitler Wood and Lily Wuy Wuy. Leigh Douglas, David Lee, Charlotte Anderson, Chris Urwin and Britt Wilson assisted with the fieldwork, and Chris Morgan flew us out to the majority of the sites recorded. Thanks to Paul Clark (maritime historian, Museum and Art Galleries of the Northern Territory), David Steinberg (maritime archaeologist, Northern Territory Heritage Branch) and Adrian Horridge (historian) for identifying and commenting on boat images. Thanks also to Nadia Iacono for identifying the site ARN-082/1 glass bead, Kara Rasmanis (Monash University) for drafting Figures 9.1, 9.2, 9.17 and 9.26, and Steve Morton (Scientific Imaging Services, Monash University) for the photographs in Figures 9.23 and 9.25. The JRAHP was funded by the Jawoyn Association and grants from the federal government's Indigenous Heritage Programme. Additional funding was provided under the George Chaloupka Fellowship, an initiative of the Museum and Art Gallery of the Northern Territory Foundation, sponsored 
by Energy Resources of Australia (ERA) Ltd, of which both RG (2009) and DJ (2012) were recipients. We thank the Australian Research Council for Linkage grant LP110200927 and Discovery Outstanding Research Award (DORA) Fellowship (to BD) DP130102514.

\section{References}

Arndt, W. 1962. The interpretation of Delamere lightning paintings and rock engravings. Oceania 32:163-177. doi.org/10.1002/j.1834-4461.1962.tb01759.x

Australian Dictionary of Biography 1974. McKinlay, John (1819-1872). Australian Dictionary of Biography. National Centre of Biography, The Australian National University, Canberra. adb.anu. edu.au/biography/mckinlay-john-4113/text6577 (accessed 31 March 2017).

Chalmin E., M. Menu and C. Vignaud 2003. Analysis of rock art painting and technology of Palaeolithic painters. Measurement Science and Technology 14:1590-1597. doi.org/10.1088/0957$0233 / 14 / 9 / 310$

Chaloupka, G. 1993. Journey in Time: The World's Longest Continuing Art Tradition. Reed, Chatswood.

Cooke, P.M. 2009. Buffalo and tin, baki and Jesus: The creation of a modern wilderness. In J. RussellSmith, P. Whitehead and P. Cooke (eds), Culture, Ecology and Economy of Fire Management in North Australian Savannas: Rekindling the Wurrk Tradition, pp. 69-83. CSIRO Ebooks, Canberra.

David, B., J.-M. Geneste, R.L. Whear, J.-J. Delannoy, M. Katherine, R.G. Gunn, C. Clarkson, H. Plisson, P. Lee, F. Petchey, C. Rowe, B. Barker, L. Lamb, W. Miller, S. Hoerle, D. James, E. Boche, K. Aplin, I.J. McNiven, T. Richards, A. Fairbairn and J. Matthews 2011. Nawarla Gabarnmang, a 45,185 $\pm 910 \mathrm{cal}$ BP site in Jawoyn Country, southwest Arnhem Land Plateau. Australian Archaeology 73:73-77.

Davis, J. 1863. Tracks of McKinlay and Party Across Australia. Westgarth, London.

Edwards, R. 1979. Australian Aboriginal Art: The Art of the Alligators Rivers Region, Northern Territory. Australian Institute of Aboriginal Studies, Canberra.

Flood, J. 1997. Rock Art of the Dreamtime. Angus and Robertson, Sydney.

Geneste, J.-M., B. David, H. Plisson, J.-J. Delannoy and F. Petchey 2012. The origins of ground-edge axes: New findings from Nawarla Gabarnmang, Arnhem Land (Australia) and global implications for the evolution of fully modern humans. Cambridge Archaeological Journal 22:1-17. doi.org/10.1017/ S0959774312000017

Gunn, R.G. 1992. Bulajang: A reappraisal of the archaeology of an Aboriginal cult. In J. McDonald and I.P. Haskovec (eds), State of the Art, pp. 174-194. Occasional AURA Publication 6. Australian Rock Art Research Association, Melbourne.

Gunn, R.G. and R.L. Whear 2007. The Jawoyn Rock Art and Heritage project. Rock Art Research 24:5-20.

Gunn, R.G. and R.L. Whear 2008. A singular beeswax representation of Namarrkon, the Lightning Man, from Western Arnhem Land. Australian Aboriginal Studies 2008(2):54-69.

Gunn, R.G., R.L. Whear and L.C. Douglas 2010. A dingo burial from the Arnhem Land plateau. Australian Archaeology 71:11-16. doi.org/10.1080/03122417.2010.11689380

Gunn, R.G., R.L. Whear and L.C. Douglas 2012a. Dating the present at Nawarla Gabarnmang: Time and function in the art of a major Jawoyn rock art and occupation site in western Arnhem Land. Australian Archaeology 75:55-65. doi.org/10.1080/03122417.2012.11681950 
Gunn, R.G., R.L. Whear and L.C. Douglas 2012b. A second recent canine burial from the Arnhem Land plateau. Australian Archaeology 74:103-105. doi.org/10.1080/03122417.2012.11681939

Hardman, W. 1865. Journal of Mr Stuart's Successful Expedition across the Continent of Australia from December 1861 to December 1862. eBooks@Adelaide, University of Adelaide Library, Adelaide. ebooks. adelaide.edu.au/s/stuart/john_mcdouall/journals/chapter6.html\#chapter6 (accessed 3 April 2013).

Hua, Q., M. Barbetti and A.Z. Rakowski 2013. Atmospheric radiocarbon for the period 1950-2010. Radiocarbon 55(4):2059-2072. doi.org/10.2458/azu_js_rc.v55i2.16177

Keen, I. 1980. The Alligator Rivers Aborigines: Retrospect and prospect. In R. Jones (ed.), Northern Australia: Options and Implications, pp. 171-186. Research School of Pacific Studies, The Australian National University, Canberra.

Leichhardt, L. 1847. Journal of an Overland Expedition in Australia, from Moreton Bay to Port Essington, a Distance of Upwards of 3000 Miles, during the Years 1844-1845. T. and W. Boone, London.

Levitus, R. 1995. Social history since colonisation. In T. Press, D. Lea, A. Webb and A. Graham (eds), Kakadu: Natural and Cultural Heritage Management, pp. 64-93. Australian Nature Conservation Agency, Darwin.

Lewis, D. 1988. The Rock Paintings of Arnhem Land, Australia. BAR International Series 415. British Archaeological Reports, Oxford.

Lindsay, D. 1884. Mr D. Lindsay's Exploration through Arnheim's Land. South Australian Government Printer, Adelaide.

MacKnight, C.C. 1972. Macassans and Aborigines. Oceania. 42:283-321. doi.org/10.1002/j.18344461.1972.tb01183.x

MacKnight, C.C. 1986. Macassans and the Aboriginal past. Archaeology in Oceania 21:69-75. doi.org/10.1002/j.1834-4453.1986.tb00126.x

McDonald, J. 2008. Dreamtime Superhighway: Sydney Basin Rock Art and Prehistoric Information Exchange. Terra Australis 27. ANU E Press, Canberra.

May, S.K., P.S.C. Taçon, A. Paterson and M. Travers 2013. The world from Malarrak: Depictions of Southeast Asian and European subjects in rock art from the Wellington Range, Australia. Australian Aboriginal Studies 2013(1):45-56.

May, S.K., P.S.C. Taçon, D. Wesley and M. Travers 2010. Painting history: Indigenous observations and depictions of the 'Other' in northwestern Arnhem Land, Australia. Australian Archaeology 71:57-65. doi.org/10.1080/03122417.2010.11689384

Merlan, F. 1998. Caging the Rainbow: Places, Politics and Aborigines in a North Australian Town. University of Hawaii Press, Honolulu.

Merlan, F. and P. Jacq 2005. Jawoyn-English Dictionary and English Finder List. Diwurruwurru-jaru Aboriginal Corporation, Katherine.

Mitchell, S. 1994. Culture contact and Indigenous Economies on the Coburg Peninsula, Northwestern Arnhem Land. Unpublished PhD thesis. Northern Territory University, Darwin.

Mountford, C.P. (ed.) 1956. Records of the American-Australian Scientific Expedition to Arnhem Land, Vol. 1: Art, Myth and Symbolism. Melbourne University Press, Melbourne.

Mulvaney, D.J. 1975. The Prehistory of Australia. Penguin, Ringwood. 
Murdoch, L. 2009. Lost and found: Leichhardt was here. Sydney Morning Herald 7 March 2009:1.

Nadjamerrek, L.B., K. Munro and Museum of Contemporary Art 2010. Bardayal 'Lofty' Nadjamerrek $A O$. Museum of Contemporary Art, Sydney.

Ouzman, S. 2003. Indigenous images of a colonial exotic: Imaginings from Bushmen southern Africa. Before Farming 1(6):239-256. doi.org/10.3828/bfarm.2003.1.6

Reimer, P.J., E. Bard, A. Bayliss, J.W. Beck, P.G. Blackwell, C. Bronk Ramsey, C.E. Buck, H. Cheng, R.L. Edwards, M. Friedrich, P.M. Grootes, T.P. Guilderson, H. Haflidason, I. Hajdas, C. Hatté, T.J. Heaton, D.L. Hoffmann, A.G. Hogg, K.A. Hughen, K.F. Kaiser, B. Kromer, S.W. Manning, M. Niu, R.W. Reimer, D.A. Richards, E.M. Scott, J.R. Southon, R.A. Staff, C.S.M. Turney and J. van der Plicht 2013. IntCal13 and Marine13 radiocarbon age calibration curves, 0-50 000 years cal BP. Radiocarbon 55 (4):1869-1887. doi.org/10.2458/azu_js_rc.55.16947

Rose, D.B. 1992. Dingo Makes Us Human: Land and Life in an Australian Aboriginal Culture. Cambridge University Press, Cambridge.

Smith, C. 1994. Situating Style: An Ethnoarchaeological Study of Social and Material Context in an Australian Aboriginal Artistic System. Unpublished PhD thesis. University of New England, Armidale.

Taçon, P.S.C., S.K. May, S.J. Fallon, M. Travers, D. Wesley and R. Lamilami 2010. A minimum age for early depictions of Southeast Asian praus in the rock art of Arnhem Land, Northern Territory. Australian Archaeology 71:1-10. doi.org/10.1080/03122417.2010.11689379

Thompson, D. 1975. Bindibu Country. Nelson, Melbourne.

Wesley, D. 2013. Firearms in rock art of Arnhem Land, Northern Territory, Australia. Rock Art Research $30: 235-247$.

Wesley, D. and M. Litster 2015. 'Small, individually nondescript and easily overlooked': Contact beads from northwest Arnhem Land in an Indigenous-Macassan-European hybrid economy. Australian Archaeology 80:1-16. doi.org/10.1080/03122417.2015.11682040

Wesley, D., S. O'Connor, S and J. Fenner 2016. Re-evaluating the timing of the Indonesian trepang industry in north-west Arnhem Land: Chronological investigations at Malara (Anuru Bay A). Archaeology in Oceania 51(3):169-195.

Wilson, M., M. Spriggs and E. Lawson 2001. Dating the rock art of Vanuatu: AMS radiocarbon determinations from abandoned mud-wasp nests and charcoal pigment found in superimposition. Rock Art Research, 18(1):24-31. 



\title{
Engineers of the Arnhem Land plateau: Evidence for the origins and transformation of sheltered spaces at Nawarla Gabarnmang
}

\author{
Jean-Jacques Delannoy, Bruno David, Jean-Michel Geneste, \\ Margaret Katherine, Benjamin Sadier and Robert Gunn
}

\section{Introduction}

Nawarla Gabarnmang is a large archaeological rockshelter on the Arnhem Land plateau (Figure 10.1). It was rediscovered in June 2006 when Ray Whear and helicopter pilot Chris Morgan sighted an unusually large overhang during a routine aerial survey. They landed the helicopter and found themselves in a stunning gallery with many hundreds of rock paintings (David et al. 2011). The site lies on Buyhmi clan lands in Jawoyn Country. The Jawoyn words 'nawarla gabarnmang' mean 'place of hole in the rock', a descriptive label given to it by the late Bardayal 'Lofty' Nadjamerrek in 2006-2007, and that is now generally used as the site's proper name both by members of the Jawoyn community and by others. That name refers to the rockshelter itself, but also to the area immediately around it that spans a few tens of metres. This includes a continuous array of shallow overhangs and rock faces often imbued with rock art, various landscape features including a southern 'courtyard' delimited by a long, pillared rock face to its south, and other archaeological manifestations (Figure 10.2). For the sake of clarity, in this chapter we refer only to the main rockshelter as Nawarla Gabarnmang, and other nearby features through descriptive terms befitting the specific discussion at hand.

Human occupation at Nawarla Gabarnmang began more than 47,200-51,700 cal BP (median age $=49,350 \mathrm{cal} \mathrm{BP}$ ), as determined by Bayesian statistics of radiocarbon dates from excavation Square F, with optically stimulated luminescence ages in adjacent Squares $\mathrm{I}+\mathrm{L}+\mathrm{M}$ indicating a slightly earlier antiquity (David et al. completed manuscript). Occupation continued into the ethnographic period of the late 1800s and early 1900s (see Chapters 9 and 12). The richness of the buried archaeological deposits dating from the earliest to the latest occupational levels, in particular the stone artefacts, makes Nawarla Gabarnmang a useful reference for understanding artefact characteristics in the central part of the Arnhem Land plateau (e.g. David et al. 2011, 2013; Geneste et al. 2010, 2012). Equally significant is Nawarla Gabarnmang's rock art; with 1391 paintings and stencils on the ceiling alone (i.e. excluding the extensively decorated walls of its numerous pillars), it is one of the most decorated rock art sites in all of Arnhem Land (Gunn 2016; see also Chapter 12) (Figure 10.3). The oldest art yet revealed from the site consists of a small piece of an originally larger decorated rock that retains part of a black charcoal painting or drawing excavated from Square E and dating to c. 26,739-27,657 cal BP (David et al. 2013, 2014:20). 


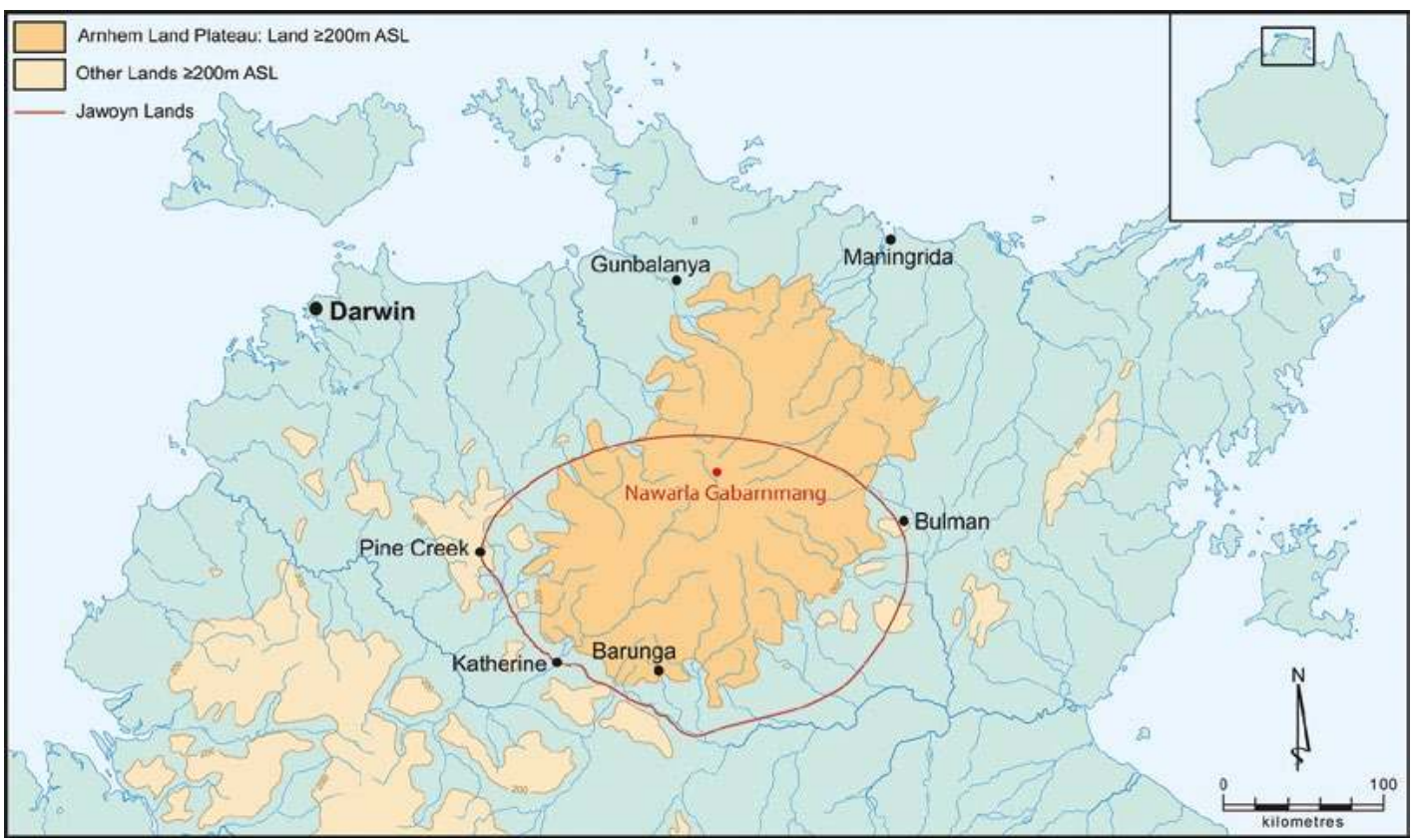

Figure 10.1 Location of Nawarla Gabarnmang on the Arnhem Land plateau.

Source: Illustration by Kara Rasmanis.

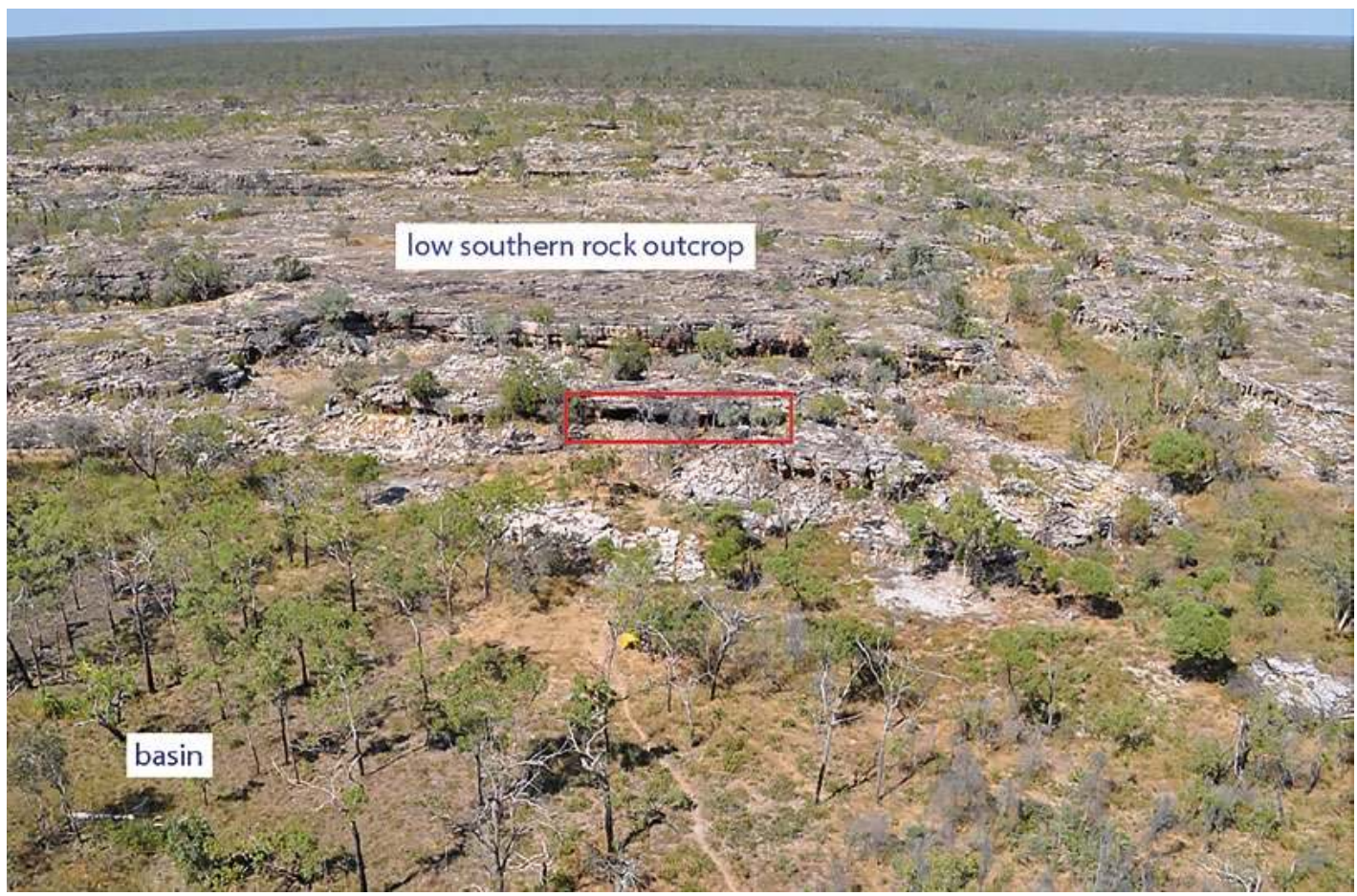

Figure 10.2 Aerial photograph of Nawarla Gabarnmang and surrounding features, looking south.

The red rectangle identifies the site's northern entrance.

Source: Photograph by Bruno David. 


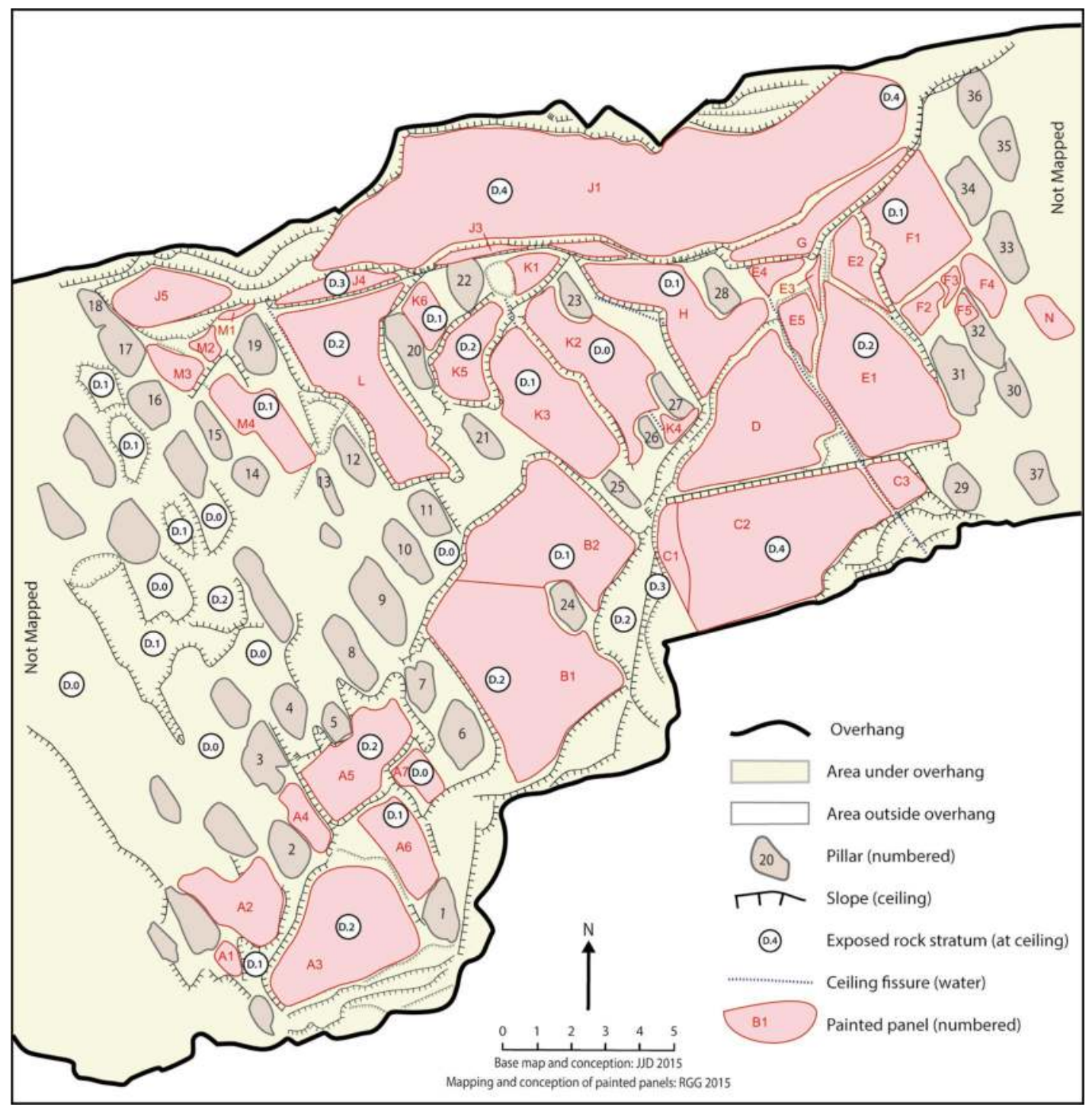

Figure 10.3 Location of rock art panels, with all features mapped on the ceiling.

Source: Illustration by Jean-Jacques Delannoy, Robert Gunn and Kara Rasmanis.

The study of the rock art, including hundreds of superimpositions, has enabled investigations of both the sequence of artistic conventions and the periodicity of occupation relating to some artistic phases (Gunn 2016; see also Chapters 11 and 12). Under the ground, the excellent preservation of buried layers, including the sharp boundaries and shallow sediment interfaces between many stratigraphic units (Figure 10.4) and the presence of buried horizontal rock slabs that have sealed some horizons (Figure 10.5), has resulted in a high degree of chronostratigraphic integrity for much of the deposit. This good preservation and high chronostratigraphic resolution is closely connected with the site's peculiar architecture; an expansive rockshelter measuring $32 \mathrm{~m}$ long $\times 23 \mathrm{~m}$ wide $\times 1.8-2.0 \mathrm{~m}$ high (these measurements correct and update previously published measurements), held aloft by 50 rock pillars supporting a large protective roof over a flat floor, at a high point on the Arnhem Land plateau (Figure 10.6). The long and wide, well-sheltered ceiling is made up of flat and horizontal, but staggered, sections, offering its art and accumulated sediments below good protection from the elements. No scree slope leads into the site, nor does vegetation grow on its surface, and so there is a total absence of sediment mixing caused by colluvial processes or surface water flow into the site. This absence of surface vegetation coupled with the presence of an extensive roof overhead has also protected the art and surface deposits from the effects of bushfires. 


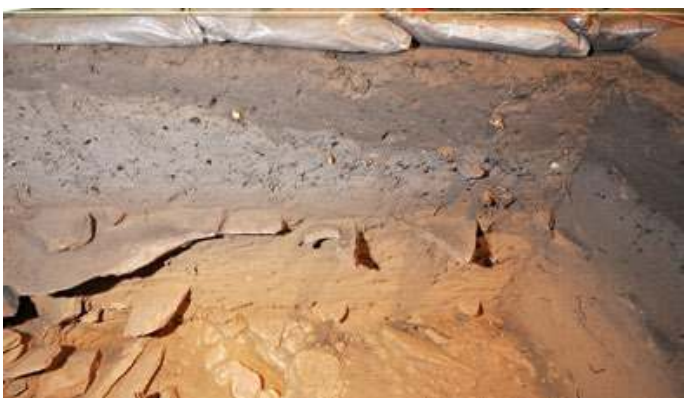

Figure 10.4 South wall of Squares $F+++L+M$, showing sharp and thin interfaces between stratigraphic units in the excavations in progress.

The ground surface is very close to the top of the photograph; the depth of the dig as shown here ranges between c. 53-60 cm.

Source: Photograph by Jean-Michel Geneste.

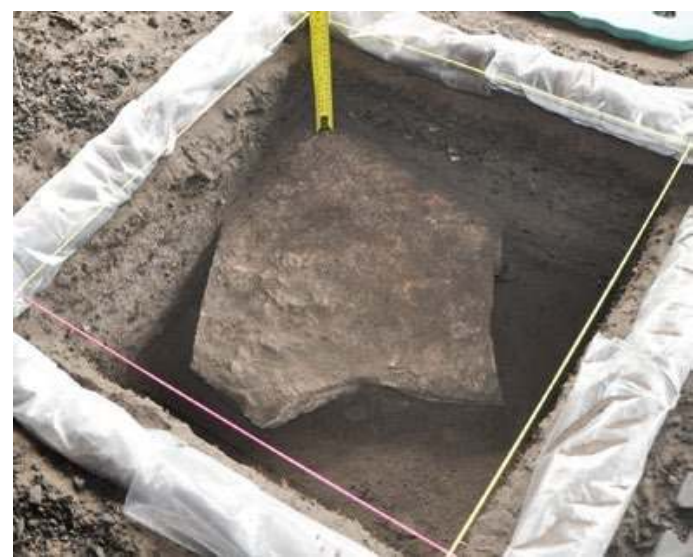

Figure 10.5 Flat rock slab originating from the ceiling, lying horizontally in Square $\mathrm{E}$.

Source: Photograph by Bryce Barker.

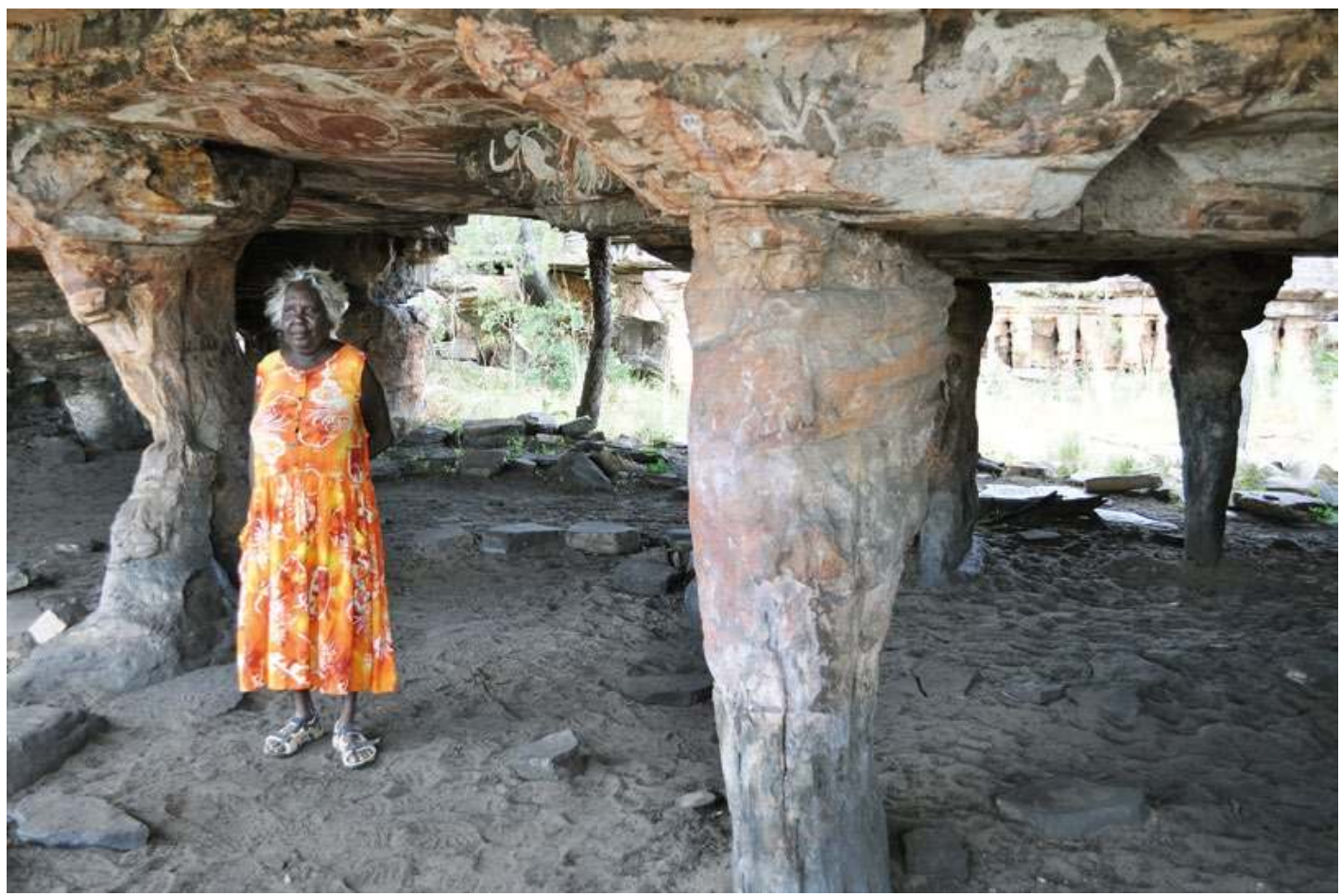

Figure 10.6 The sheltered pillarscape, with senior Jawoyn Elder and Traditional Owner Margaret Katherine.

Source: Photograph by Bruno David.

The unusual configuration of the pillared rockshelter requires interpretation, for it is by understanding the history of the site's architecture that we can come to understand the age of the decorated rock surfaces, the distribution across the site of buried occupational deposits of varied ages, and various kinds of landscape engagements. The site has an entirely different morphology to the more common rockshelters found under the edges of low and localised clifflines (such as Dalakngalarr; see Chapter 13) or under isolated rock stacks (such as JSARN-124 site 3; see Chapter 15). While Nawarla Gabarnmang was subject to the same kinds of geological processes as these other kinds of sites, unlike the others it has resulted in an impressive rock 
formation. A question of particular importance is thus how the rockshelter formed. There are a few rocks on its floor, and those that are present do not match the geological characteristics of the nearby ceiling or pillars. Indeed, one of the first things that senior Aboriginal Elders Bardayal 'Lofty' Nadjamerrek, Peter Bolgay and Jimmy Kalariya told Ray Whear in 2006-2008 (Ray Whear, pers. comm. 2010) when they first entered the site shortly after its rediscovery in 2006 was that the isolated blocks of rocks that can today be seen occasionally lying flat on the ground in the sheltered area was that they are 'pillows' placed there by the old people; this is where people slept. These rocks cannot, therefore, be explained as natural roof-fall or pillar collapse, as typically expected of rockshelter sites. Nawarla Gabarnmang is, in this aspect also, very different to other rockshelters in Arnhem Land, where evidence of roof-fall can readily be seen in the collapsed rock debris found beneath or adjacent to remnant overhangs.

Defining the nature and antiquity of Nawarla Gabarnmang's extant and past morphology is critical to understanding the site's occupational history, because the archaeological deposits and the rock art are both inscribed in the site's very particular physical configuration, a site morphology that has changed through the course of a long history of human presence. This chapter thus examines how people have interacted with the material fabric of the site, including what the site looked like when people first arrived, and how it has changed since those first arrivals. We also ask how the sub-surface archaeological evidence relates to the art currently visible on the rock, and to changes in the site's structure as evident from both detached blocks of rock and the present configuration of the bedrock base, pillars, ceiling and roof.

\section{Environmental context}

Nawarla Gabarnmang is situated at the heart of the Arnhem Land plateau, in an elevated region from which radiate the headwaters of the Katherine River to the south, South Alligator River and Jim Jim Creek to the west and northwest, East Alligator River to the north, and Mann River and McCaw Creek to the east (Figure 10.7). It is located $400 \mathrm{~m}$ above sea level (ASL), along the northern edge of an elevated rock outcrop that forms a low plateau. That rock outcrop is surrounded on the Arnhem Land plateau by a vast basin (380 m ASL). Numerous archaeological sites are found along the edges of the basin where exposed rock is found on either side. The basin effectively acts as a landscape-scale east to west corridor between the headwaters of the Katherine and Mann rivers and, a bit further afield, the Wilton and Roper rivers and their expansive watersheds (see Figure 9.17).

This geographical setting had great potential to have been used by Aboriginal people as a thoroughfare across the top of the plateau and to connect traversable basins between the headwaters of major river systems. The late senior Aboriginal Elders Bardayal 'Lofty' Nadjamerrek, Peter Billis and Jimmy Kalariya (pers. comm. to Ray Whear 2006-2008) had noticed this when they had commented that in this flat, grassy landscape 'everything looks the same' (Ray Whear, pers. comm. 2015). This was a place where 'you wouldn't walk alone' to avoid getting lost, 'even for us old people'. And they further stated that the featureless grassy basins of this high country were a renowned trademark of Buyhmi clan lands; it was when you began to approach Nawarla Gabarnmang that this featureless landscape started to become more rocky and to have clearer relief. 


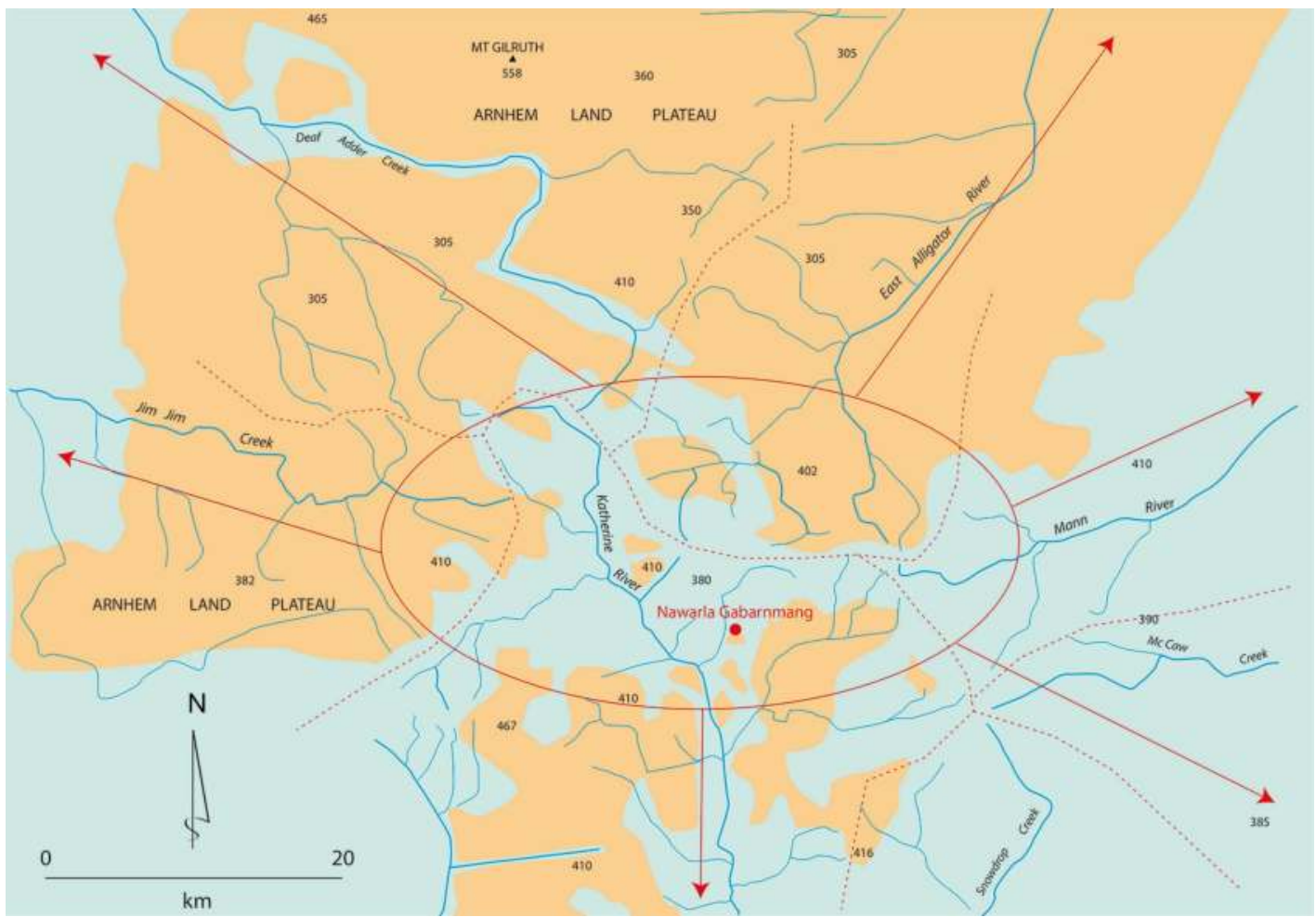

Figure 10.7 Location of Nawarla Gabarnmang, showing expanses of outcropping rock (orange) and the headwaters of river systems amidst the high basins of the central Arnhem Land plateau. Source: Illustration by Jean-Jacques Delannoy.

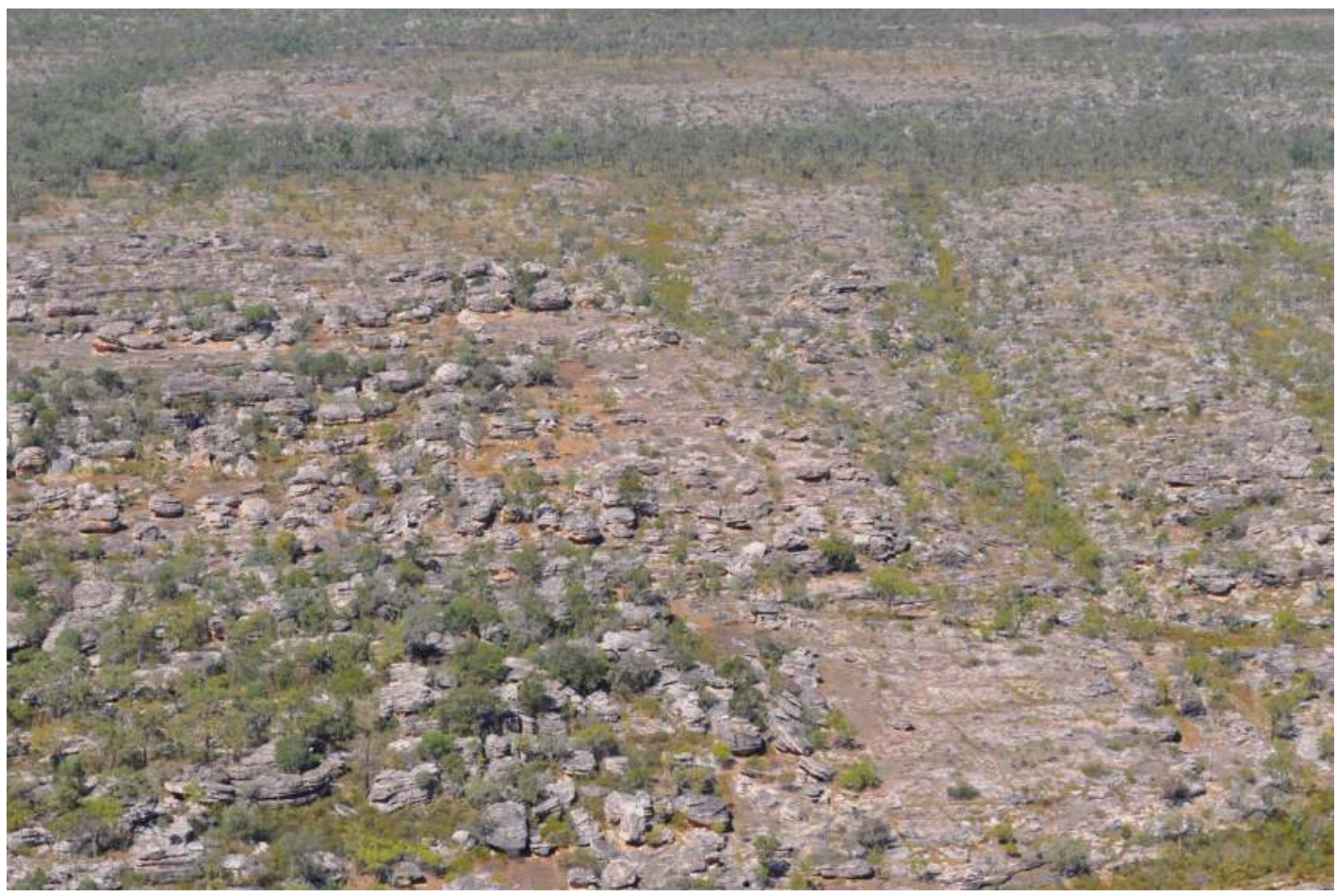

Figure 10.8 Rockshelter landscape of the western Arnhem Land plateau, Jawoyn Country. Source: Photograph by Bruno David. 
Even though the relief of the landscape from the basin to the elevated land on either side is only a few tens of metres high, these two landscape types have very different characteristics: while the basin consists largely of soft sediments and extensive grass cover, the surrounding elevated areas mostly consist of exposed outcropping rock largely devoid of vegetation (Figure 10.2). The elevated rock is dissected by a network of narrow fissures oriented in a triple-checkerboard pattern: east to west, south-southeast to north-northwest and north-northeast to south-southwest. The density of fissures is testimony to the bedrock's hardness and therefore resistance to tectonic deformation; rather than fold, as is more common among softer rocks, tectonic activity caused the hard quartzites of the Arnhem Land plateau to fracture under pressure. Across the landscape, the dissected low quartzitic plateaux have resulted in rich complexes of rockshelters, large numbers of which are decorated with rock art (Figure 10.8).

In the area of Nawarla Gabarnmang, the bedrock consists of Marlgowa Formation sandstones and quartzites (Kombolgie subgroup, Katherine River group, MacArthur geologic basin, Proterozoic; see Carson et al. 1999). These rocks were formed from ancient sands deposited some 1700 million years ago. The quartzites are essentially composed of quartz grains originating from littoral sands well rolled by repeated water action. These originally loose sands were then converted into rock through strong compaction caused by subterranean metamorphic processes. Traces of the original deposition of these sands have survived this metamorphic transition from sand to sandstone to quartzite, in the form of well-differentiated superimposed rock strata variably exhibiting ripple marks and evidence of cross-bedding. These individual rock strata can each be distinguished geologically, enabling us to determine how individual site morphologies changed over both geological and archaeological time frames (for specific examples, see Chapters 11 and 13-15). Here, the quartzitic bedrock lies deep underground over Gilruth Volcanic Member basalts rich in iron oxides (Ferenczi and Sweet 2004). These volcanic rocks outcrop c. $10 \mathrm{~km}$ to the north of Nawarla Gabarnmang. Less than $1 \mathrm{~km}$ to the south of the site, dolerite is found in association with one of Arnhem Land's major transverse fault lines.

Given that local waterways have low gradients and the local bedrock consists of hard quartzites highly resistant to erosion, the Nawarla Gabarnmang relief has been more shaped by the particular properties of the local bedrock geology than by river action. This is especially evident in the hydrography, where across the landscape minor and usually seasonal, low-energy waterways suddenly change their course along $90^{\circ}$ angles that directly map on to the network of bedrock fractures. The same situation applies to the rectilinear edges of the low basins drained by the upper reaches of the Katherine River. These low basins have characteristically flat beds containing alluvial sandy silts. Numerous swampy areas within these low basins are testimony to the presence of impermeable quartzitic bedrock at shallow depths. The thickness of these alluvial sediments in the basin that abuts the northern edge of Nawarla Gabarnmang is less than $1 \mathrm{~m}$. This shallow depth can be explained by the following causes:

1. The low quantity of available sediment, a result of the hard quartzite's strong resistance to erosion.

2. The low capacity of sediments to be transported by water, given the low gradient of waterways.

3. The evacuation of alluvial deposits from the plateau by wind action. The aeolian sands analysed from a number of archaeological excavations undertaken within $10 \mathrm{~km}$ of Nawarla Gabarnmang indicate that such aeolian activity is considerable on the Arnhem Land plateau (e.g. see Chapters 14 and 15). Jones and his colleagues (see individual chapters in Jones 1985) had elsewhere found that archaeological sites at the foot of the Arnhem Land plateau have accumulated vast quantities of sediment originating from the plateau, especially after the 
onset of human occupation (now dated around 65,000 years ago) when it is presumed firing practices cleared broad areas of surface grass cover thereby accelerating the mobilisation of sands by wind action.

While the structure of the landscape around Nawarla Gabarnmang is entirely consistent with the above, the archaeological site itself presents evidence of an entirely different agency for its present morphology.

\section{Nawarla Gabarnmang: How the shelter formed}

Nawarla Gabarnmang directly fronts this shallow basin (Figure 10.9). It is set in a small, largely isolated section of the rock plateau separated from the rest of the outcrop by a corridor of lowlying land that corresponds with a fracture-line oriented north-northwest to south-southeast. From this corridor, an elongated 'courtyard' of low-lying area aligns east-west and delimits the southern margin of the rockshelter (Figure 10.10). That elongated courtyard is delimited by a mass of large rocks at both its extremities, rendering it a semi-enclosed depression. Nawarla Gabarmnang both separates and connects the large basin to the north with this small semienclosed low-lying courtyard to the south. The outcropping rock of which Nawarla Gabarnmang is a part acts as a separation between the two low-lying areas, while the hollow of the shelter under the roof acts to connect them. Nevertheless, the bedrock at the base of the rockshelter is always noticeably more elevated than the low-lying areas on either side.
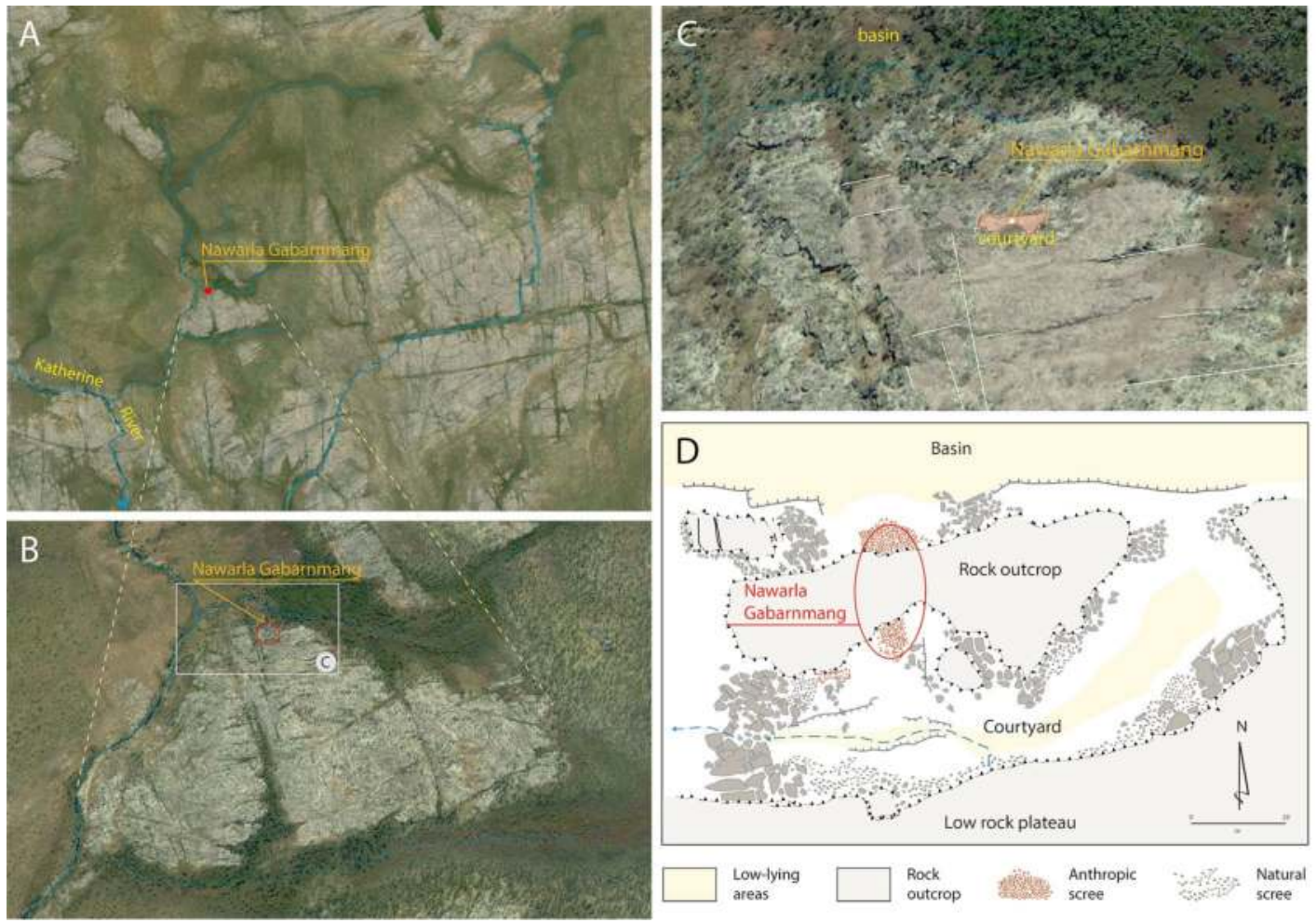

Figure 10.9 Environmental context.

A: Location of Nawarla Gabarnmang along the northern edge of a rock outcrop that abuts a basin drained by the headwaters of the Katherine River. B: Detail of A, the rock outcrop with Nawarla Gabarnmang, showing its east-west, NNE-SSW and NNW-SSE fissures. These same fissure lines are also found in the rock at the site itself. C: Detail of B, close-up of the northern edge of the rock outcrop that houses Nawarla Gabarnmang (area highlighted in pink). D: Map of Nawarla Gabarnmang relative to key landscape features mentioned in the text.

Source: Photographs and illustration by Jean-Jacques Delannoy.

\section{terira australis 47}



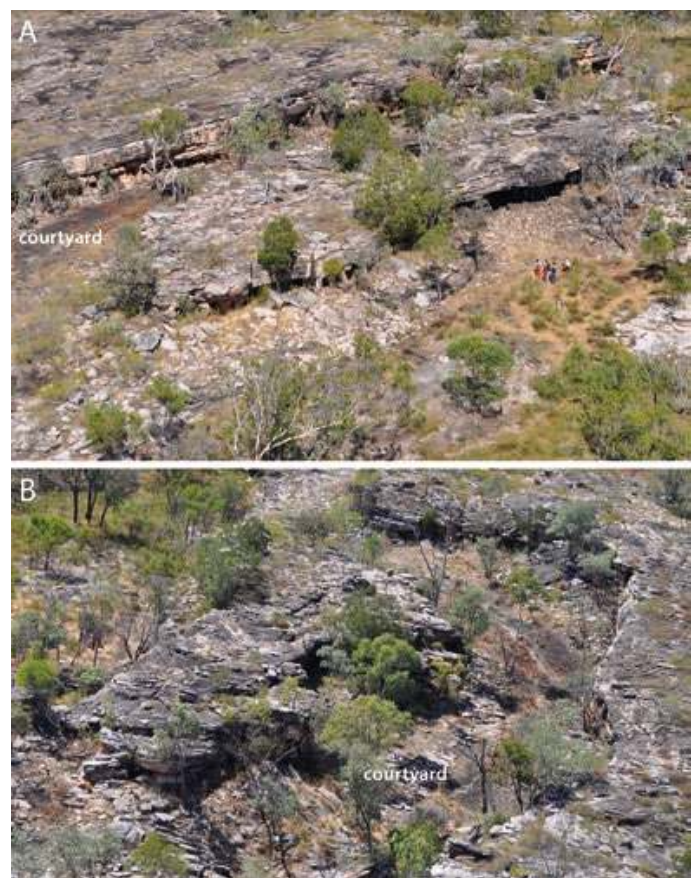

Figure 10.10 The low-lying 'courtyard' between Nawarla Gabarnmang and the edge of the rock outcrop to the south.

A: The courtyard as viewed from just east of the northern entrance. B: The courtyard as viewed from the southwestern side of the site.

Source: Photographs by Bruno David.
The rockshelter at Nawarla Gabarnmang has large ceiling surfaces supported by 50 rock pillars, 36 of which carry rock art (Figure 10.11). Many additional pillars are found beyond this archaeological area, in increasing numbers and densities (and therefore with decreasing space between them), until they merge into continuous rock. Of key interest to us is the open character of the inter-pillar space within the archaeological rockshelter. That open space in the northern, southern, central and central-eastern parts of the site is strongly distinguished from sectors further to the west and east, where the spaces between pillars become much smaller and labyrinth-like. Understanding this patterning of pillars across the site, and of the spaces between pillars, is of major significance to our overall archaeological project, for it is on these pillar walls and ceilings, and in these nowopen spaces, that people undertook various activities (see below).
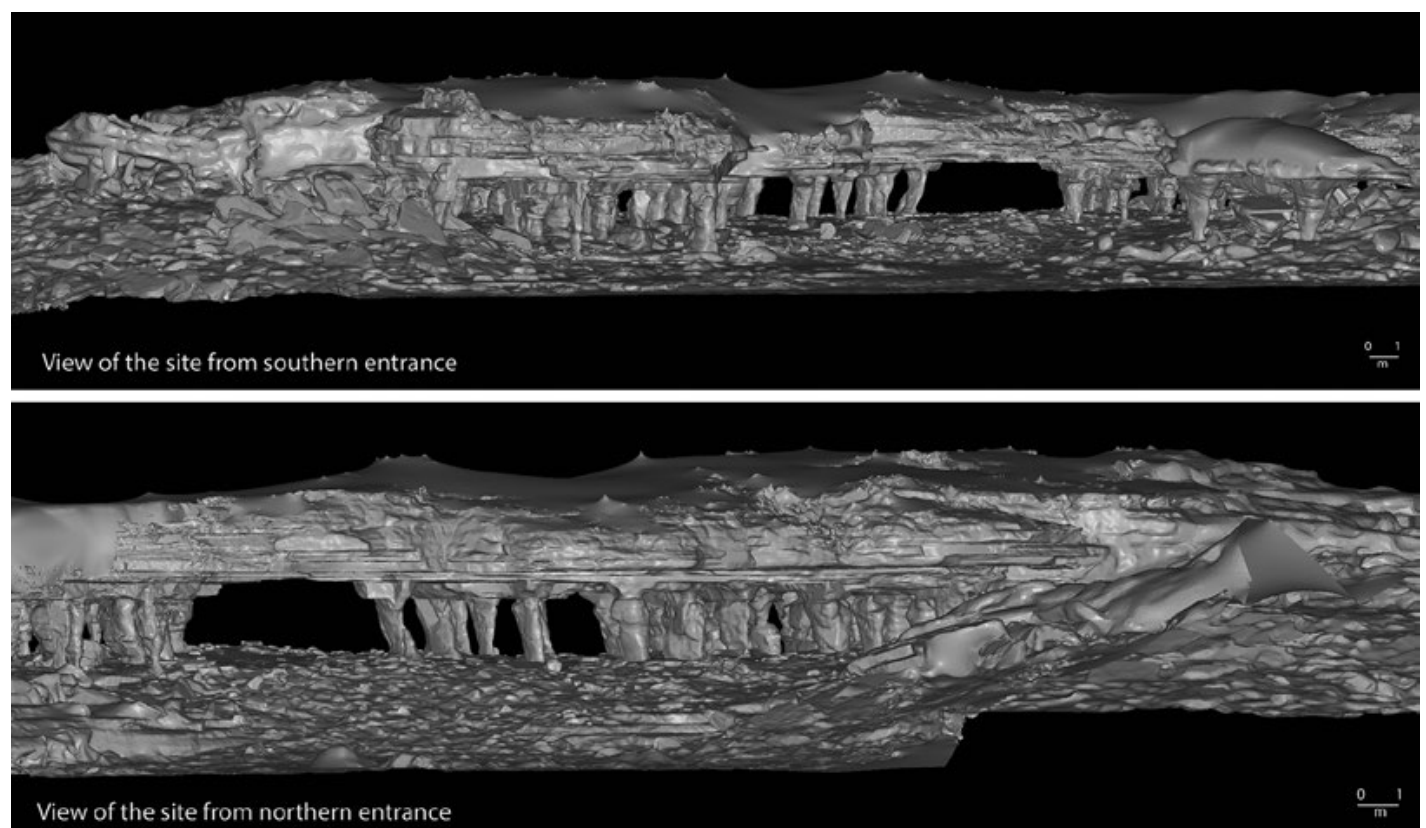

Figure 10.11 Views of Nawarla Gabarnmang from southern (top) and northern (bottom) entrances, as generated from the laser 3-D model.

Both views clearly show the sheltered area formed by a roof held aloft by pillars, along with the wide, open space of the contiguous central and central-eastern area.

Source: Illustration by Jean-Jacques Delannoy. 
Today, Nawarla Gabarnmang's ceiling is shaped like an inverted stairway, each step measuring between 10 and $40 \mathrm{~cm}$ thick (Figure 10.12). The horizontal surfaces between the steps are generally flat. The height above ground of each flat surface is a function of the thickness of the sum of missing rock strata on the ceiling; that is, the height of the stagger from step to step represents the thickness of the missing rock strata from one step to the next.

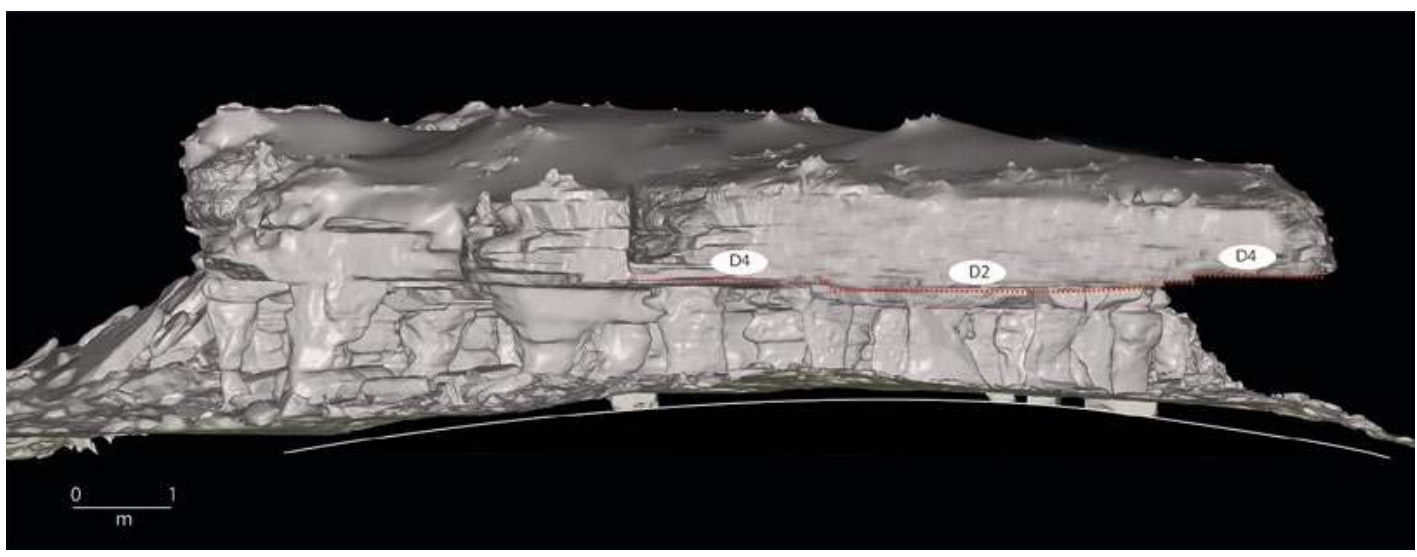

Figure 10.12 South-north transect across the open, central-eastern sector of the site, showing Squares $\mathrm{C}+\mathrm{G}+\mathrm{K}+\mathrm{N}, \mathrm{E}+\mathrm{J}$, and $\mathrm{F}+\mathrm{I}+\mathrm{L}+\mathrm{M}$ to their base.

Here the 'inverted stairway' ceiling profile is apparent, with the most elevated areas along the ceiling's southern and northern ends. The presently exposed rock strata (D2 to D4) are shown. The thin, curved white line at the base of the image shows the shape of the present ground surface; the line is offset downwards to highlight its curvature.

Source: Illustration by Jean-Jacques Delannoy.

From the centre of the site moving northward, the ceiling tends to get higher. We have numbered each rock stratum from a strategic rock layer labelled stratum D0, which originally spanned the entire site and is the first rock stratum above the pillars (Figures 10.13 and 10.14). Seventeen rock strata were unambiguously distinguished by their clear stratification and by the presence of characteristic reference marks (e.g. ripples of varied amplitude and frequency) (Figure 10.14). From strata D4 to D-12, each stratum can be identified by its thickness, presence of crossbedding and petrographic characteristics (e.g. texture and granulometry of constituent quartz grains). A more detailed characterisation of mineralogy has also been undertaken on thin sections of strata for which detached samples could be obtained from the archaeological excavations (Figure 10.15). Seven individual squares or sets of contiguous squares were excavated at the site (see Chapter 11), and each has revealed the presence of blocks or slabs of rock beneath the surface (e.g. Figure 10.5); from these we could investigate source pillars and ceiling strata. The geological characterisation of the sequence of rock strata permitted us to determine where these detached blocks came from. Coupled with detailed maps (see below) that enabled their repositioning to particular sectors of the site, and given that they could be radiocarbon dated through stratigraphic associations, the collapsed blocks enabled us to begin historicising Nawarla Gabarnmang's particular, and peculiar, extant architecture. 


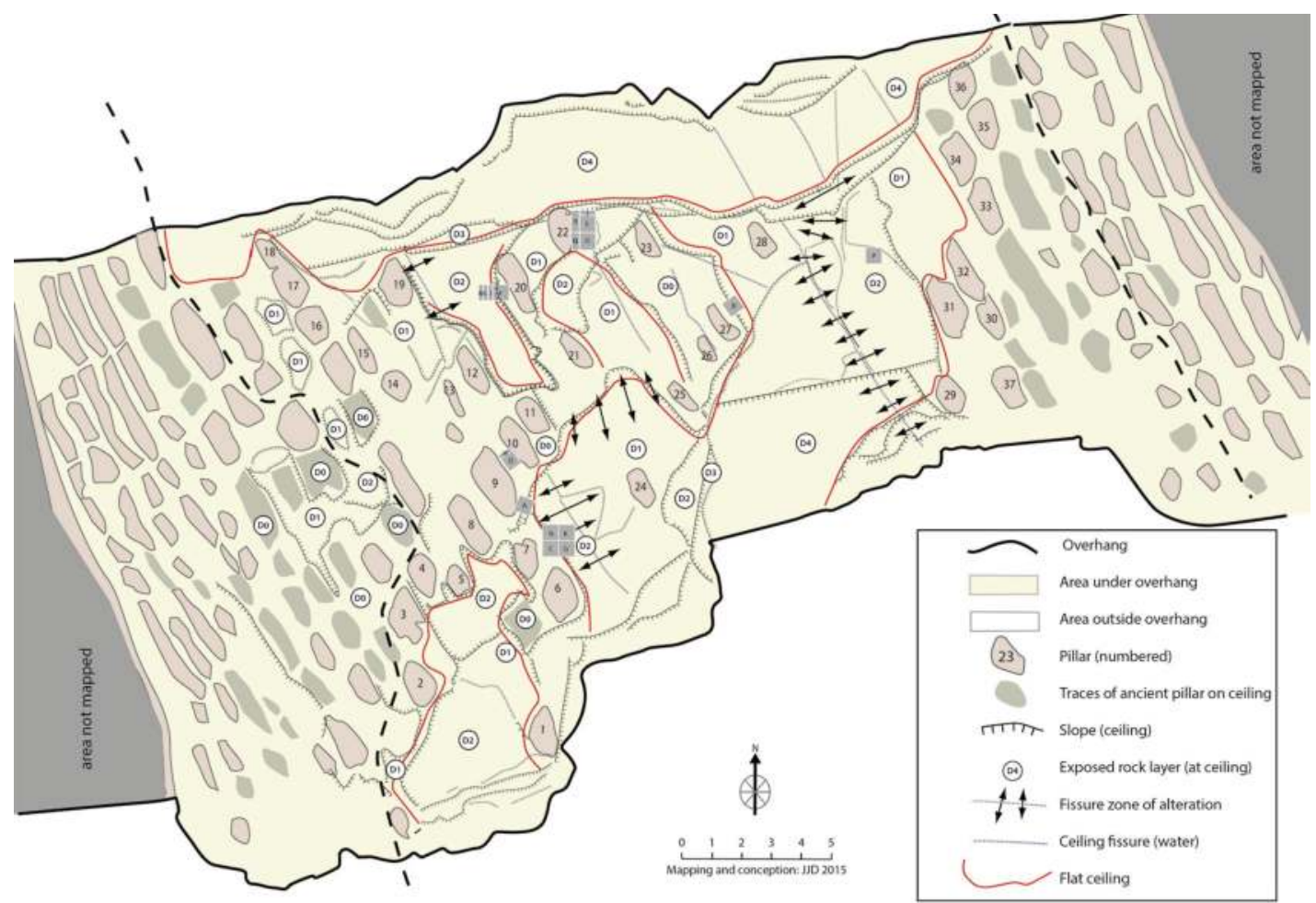

Figure 10.13 Geomorphological map of the ceiling. The zone between the dashed lines delimits the archaeological site studied in this chapter.

The map shows the natural high density of pillars in the western and eastern sectors of the site on one hand, versus the anthropic low density of pillars in the contiguous central and central-eastern sector.

Source: Illustration by Jean-Jacques Delannoy.
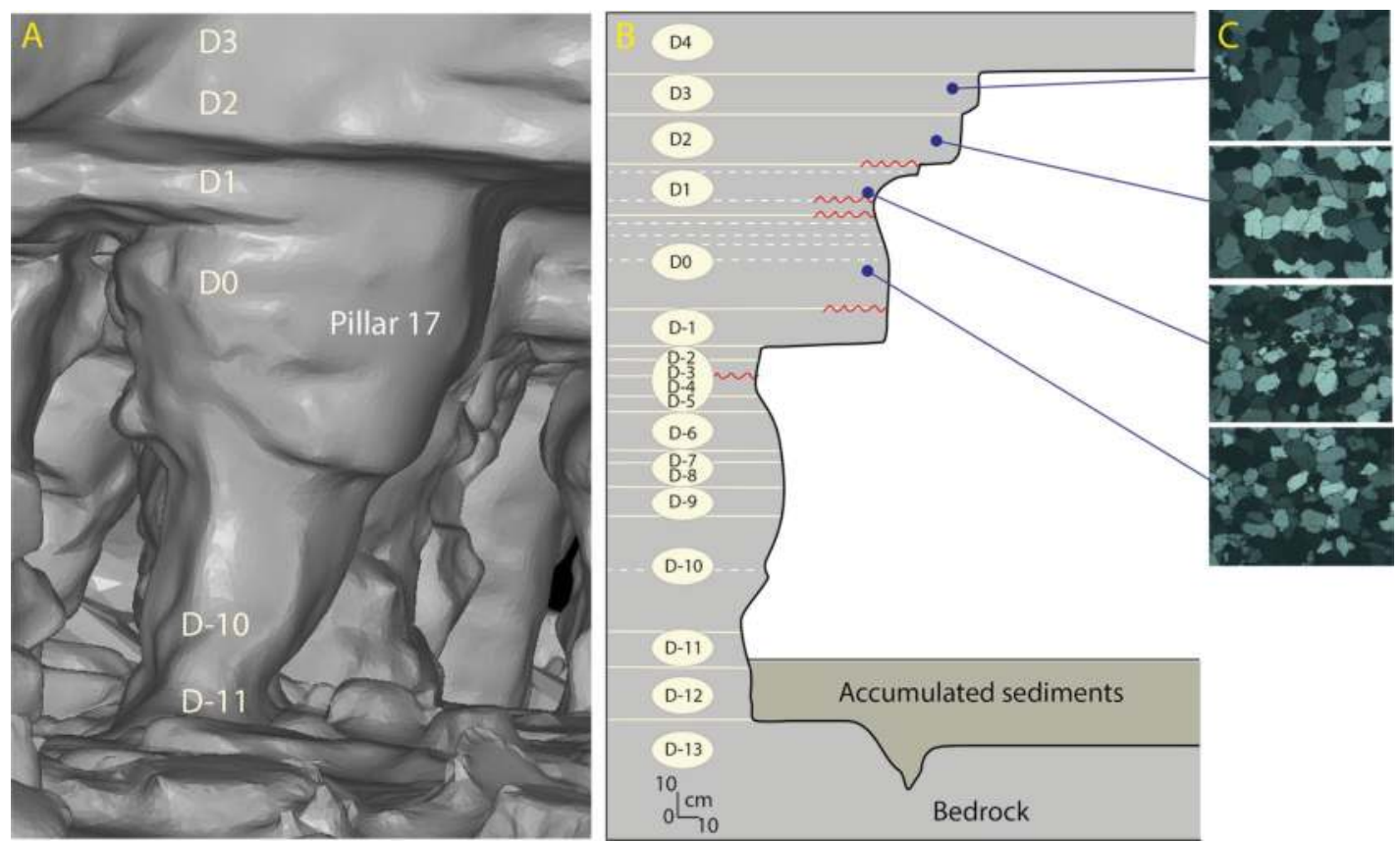

Figure 10.14 Rock strata making up the bedrock on the ground, pillar and ceiling levels.

A: View of Pillar 17 from the 3-D model. B: Sequence of rock strata at Pillar 17. C: Examples of thin sections of ceiling strata DO to D3.

Source: Illustration by Jean-Jacques Delannoy. 
The Archaeology of Rock Art in Western Arnhem Land, Australia

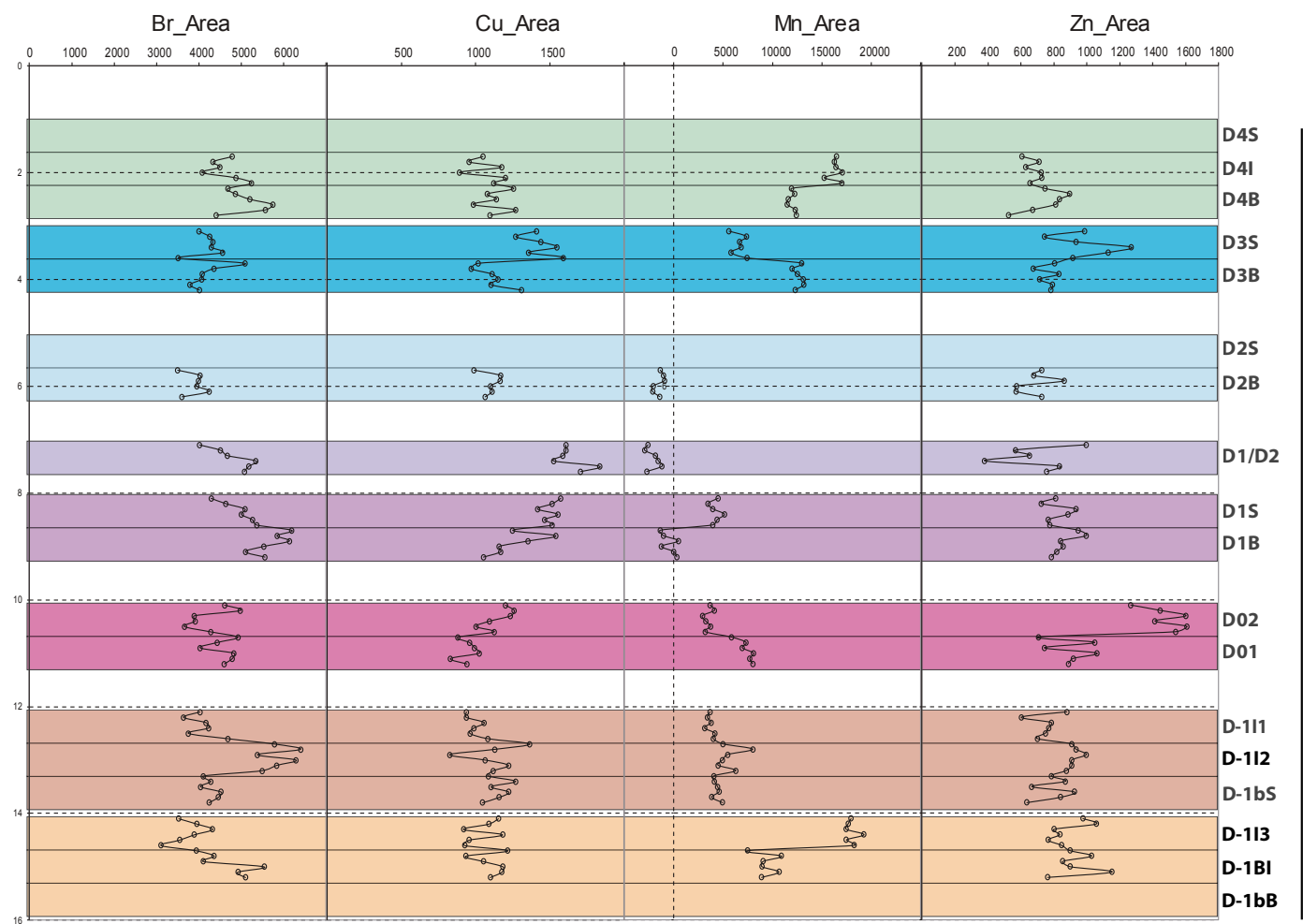

\section{Minor elements}

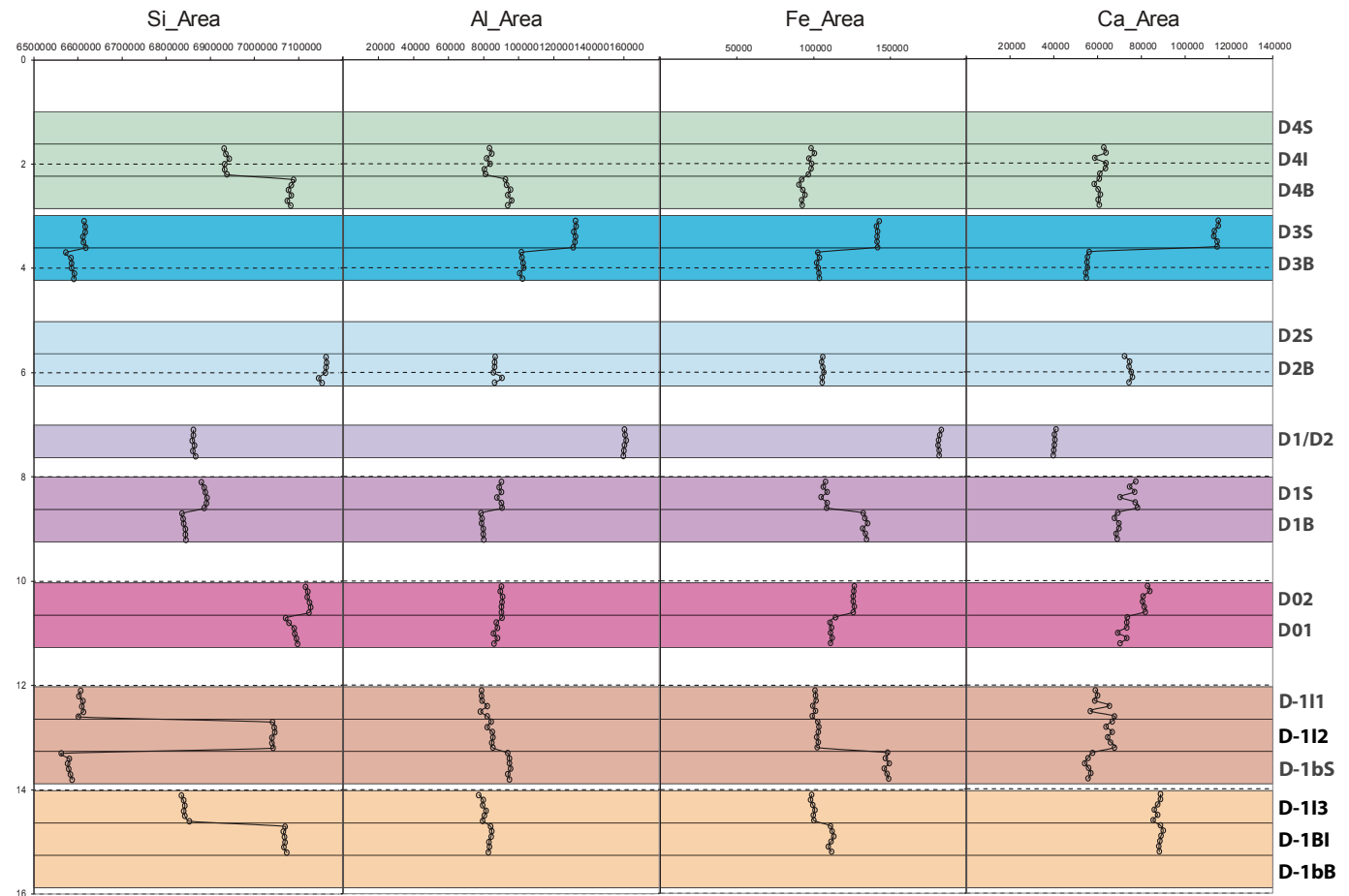

\section{Major elements}

Figure 10.15 Results of XRF core scanner analysis of individual rock strata.

Each rock stratum has a distinctive elemental fingerprint that can be used to identify collapsed blocks at various levels of the archaeological excavations. The Y-axis represents the individual rock strata (D4 to D-1), some of which are divided into subunits (e.g. D4S = upper layer of stratum D4; D4I = intermediary layer of stratum D4; D4B = basal layer of stratum D4).

Source: XRF core scanner analysis A.L Develle; illustration by Jean-Jacques Delannoy. 


\section{Of collapsed ceiling strata and missing rockfalls}

Today, the flatness of each ceiling level can be securely associated with the collapse of successive rock strata. We thus ask:

1. What did the ceiling look like before those ceiling strata collapsed?

2. When did those ceiling strata collapse?

Understanding the history of the ceiling's morphology is significant not just for understanding the history of the site's configuration, but more particularly to enable us to understand the context and age of the extant rock surfaces, and thereby to determine maximum ages for the art on those surfaces.

While the height above ground of the ceiling increases towards its northern and southern sides, the level of the ground surface does the opposite: it is lower along the site's northern and southern margins. This is not what we would expect to find; there should, rather, be piles of rock and correspondingly elevated floor levels under the highest ceiling levels where strata D1 to D3 have fallen and are now missing from the ceiling, such as along the northern and southern ceilings. But instead, the ground surface is largely devoid of rocks, and below the northern ceiling in particular, the ground level dips down towards the site's entrance. There is thus a noncorrespondence between geomorphological processes of ceiling collapse that we can see through the negative scars left by the missing (collapsed) rock strata on the ceiling, and the geometry of the floor level. Where has the missing rock gone?

\section{Scree slopes fronting Nawarla Gabarnmang's northern and southern entrances}

The ground level just outside the northern and southern entrances into Nawarla Gabarnmang consists of rocky screes that slope down from the rockshelter to the low-lying basin on the north and the courtyard on the south. Along these scree slopes, the rocks exhibit a remarkable character; they are of a consistent shape and size, typically 30-40 cm long $\times 20-40 \mathrm{~cm}$ wide $\times$ $10-20 \mathrm{~cm}$ thick (Figure 10.16). The thickness of these flat, tabular rocks matches the thickness and petrography of the various rock strata that make up the lower levels of the roof within the rockshelter. The northern scree slope in particular contains at least hundreds, and possibly thousands, of such rocks of regular shape and size, and these are limited to the slope that directly fronts the entrance (i.e. they are not spread further eastward or westward along other nearby parts of the northern edge of the rock outcrop, although isolated rocks of similar shape and size are occasionally found within the site; the 'pillows' of Aboriginal testimony). Here, the sediments of the northern scree, including the accumulated rocks, sit directly on a bedrock surface that steps downwards towards the low-lying basin. We note a similar situation to the south of the site, where the bedrock surface at the southern entrance steps downwards into the courtyard.

These two scree deposits emphasise Nawarla Gabarnmang's slightly perched character $3 \mathrm{~m}$ above the low-lying areas on either side (Figure 10.16). It is important to ask about the contents of these scree deposits and how they got there, because there is no evidence of localised overhang collapse that could account for them. These scree deposits are very distinct from the piles of rock that are often found below the edges of overhangs or cliff faces and that generally correspond with the collapse of overhangs (see Chapter 13) or with the detachment of sections of rock wall through mechanical weakening of cliff-lines. We are also curious to find out when these rocks accumulated as scree along the margins of the site, in particular whether, and how, their antiquity corresponds with patterns of human activity. To address these questions, we need further to understand the site's geological history. 

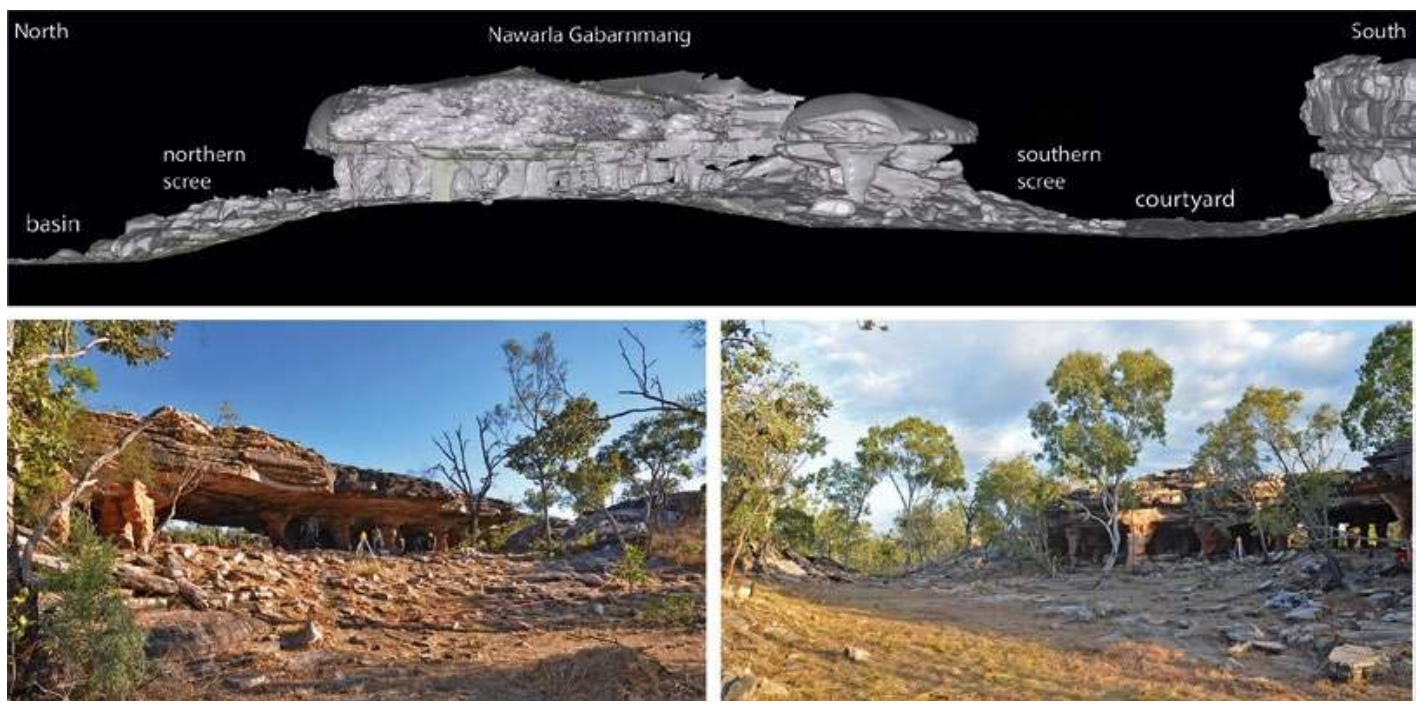

Figure 10.16 Transect across Nawarla Gabarnmang, relative to the basin to the north and the courtyard to the south.

Top: Generated from the laser 3-D model. Bottom left: From the basin looking towards the site's northern entrance. Bottom right: From the courtyard, looking towards the site's southern entrance.

Source: Photographs by Jean-Jacques Delannoy.

\section{The spacing of pillars}

The sheltered area (the height of the voids between pillars) under Nawarla Gabarnmang's ceiling clearly corresponds to a particular geological horizon. Across the landscape, this horizon is characterised by narrow and regularly spaced vertical cavities that map on to parallel fissure lines (see above). Figures 10.17 and 10.18 show the edge of the low rock plateau on the opposite side of the courtyard to the south of Nawarla Gabarnmang. It features the regular spacing of rock pillars and inter-pillar voids along a single geological horizon sandwiched between underlying and overlying quartzite strata that are not thus sculpted. The presence of this pillar landscape along a single stratigraphic horizon signals differential erosion of the rock conditioned by its geology; rock strata that are variably resistant to the formation of voids. Generally speaking, quartzites are not particularly soluble and thus not particularly amenable to the formation of cave-like voids. These voids could only form over very long periods of geological time.

At Nawarla Gabarnmang the voids between pillars are of interest because they represent the sheltered space. Here, the pillars are noticeably more widely spaced than in neighbouring areas where the voids are approximately the same width as the pillars. In order to understand how the spaces between the pillars became so wide at Nawarla Gabarnmang, let us begin by considering the edge of the low rock plateau to the south of the site (Figures 10.18 and 10.19). Here we can clearly see different stages of cavity-formation; from razorblade-thin fissures to nano-cavities to wide voids one can walk through. Five observations are pertinent:

1. Irrespective of their size (fine fissures to voids that are a few metres wide), vertically the voids directly map onto the network of fissures evident across the landscape, and horizontally they map onto joints between rock strata.

2. The geometry of connected spaces between the pillars has resulted in a labyrinthine network of corridors along the three axes of the fracture planes.

3. Between the pillars are found spaces with areas of variable stages of void production: a) fully formed voids up to a few tens of metres long; and b) soft, chemically altered rock that has not yet eroded away. 
4. Irrespective of the length of the voids ('corridors'), their terminals consist of altered, friable rock.

5. Patination has developed on the rock around the voids' circumference (pillars, ceiling and floor).

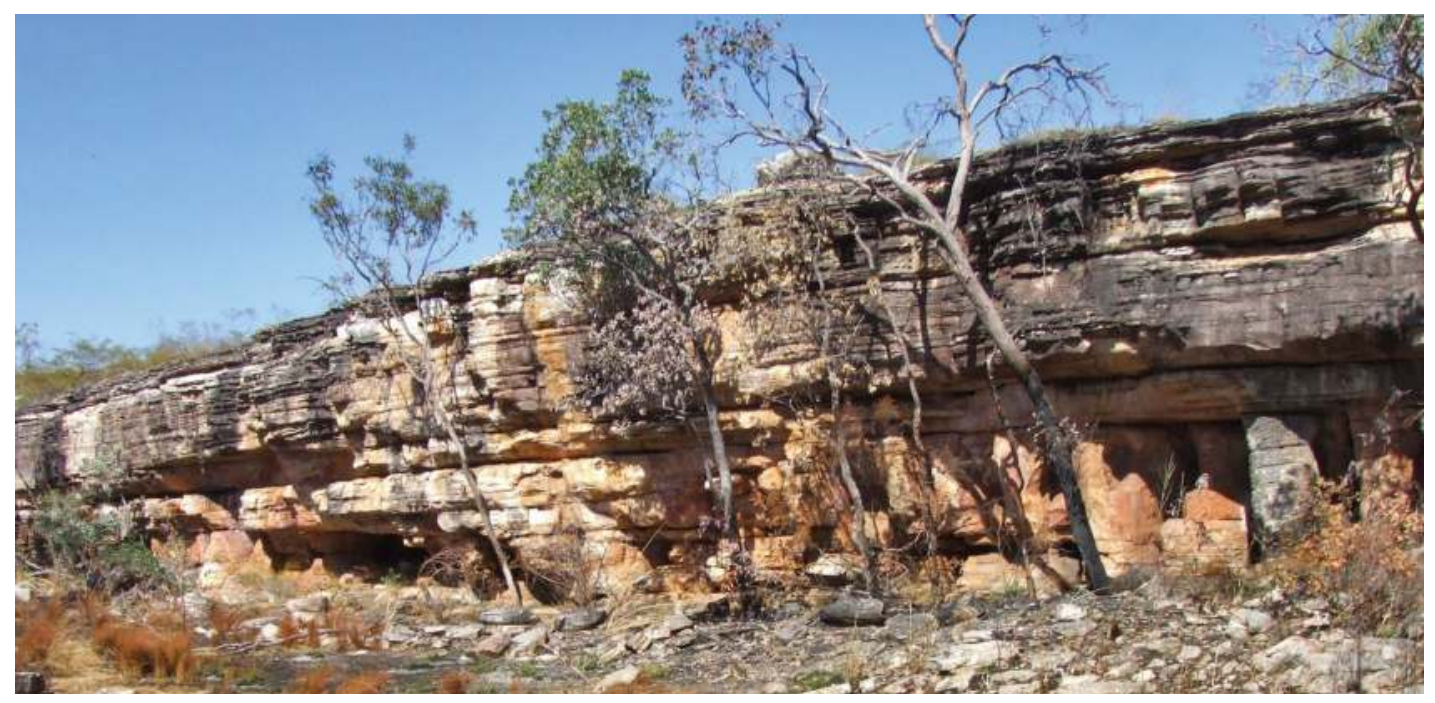

Figure 10.17 Northern edge of the rock outcrop that delimits the southern side of the courtyard, to the south of the site.

Source: Photograph by Jean-Jacques Delannoy.

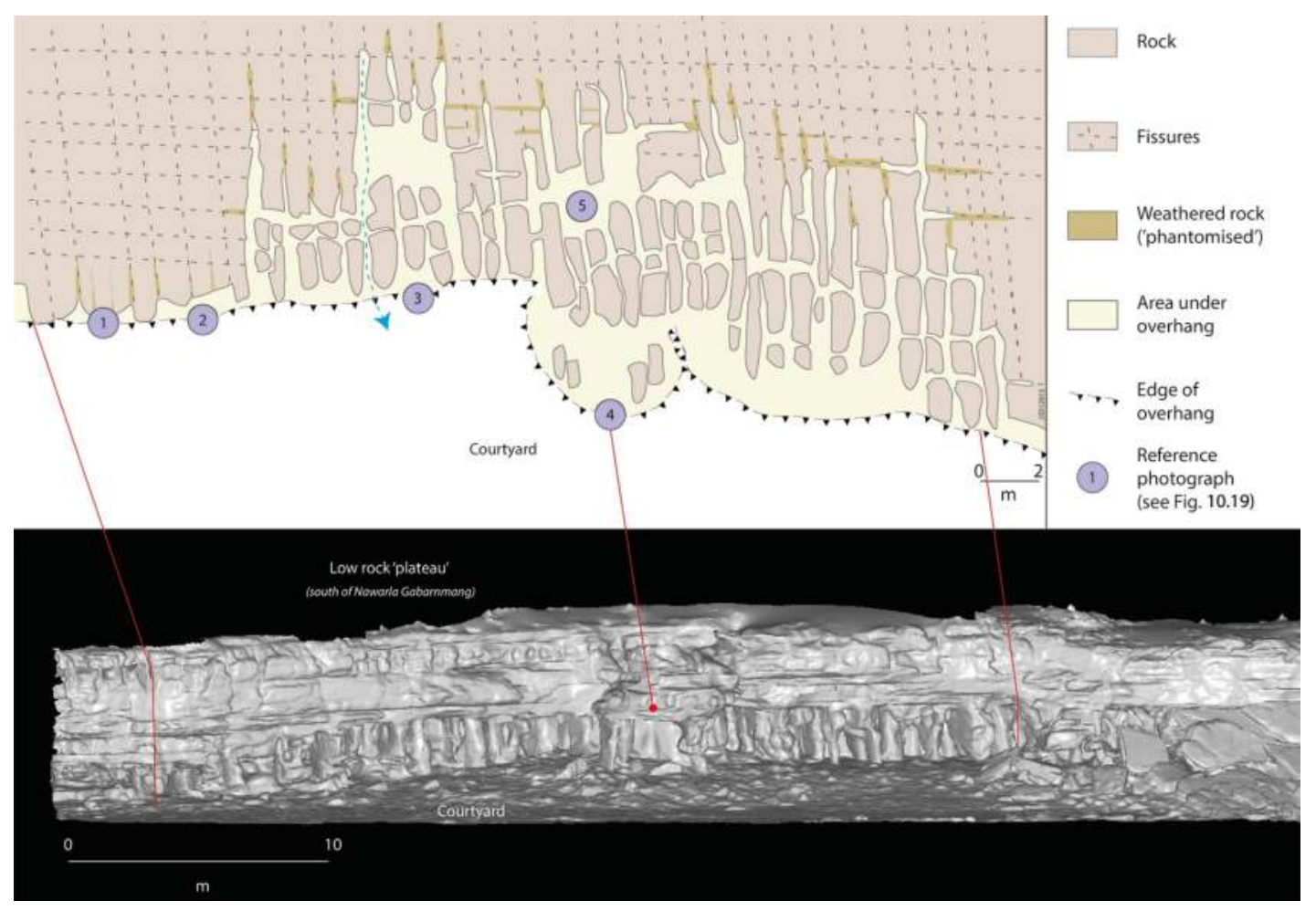

Figure 10.18 Different stages in the natural, geological evolution of the pillarscape along the edge of the rock outcrop that delimits the southern side of the courtyard.

The numbers in the purple circles refer to the rock features shown in Figure 10.19.

Source: Illustration by Jean-Jacques Delannoy. 


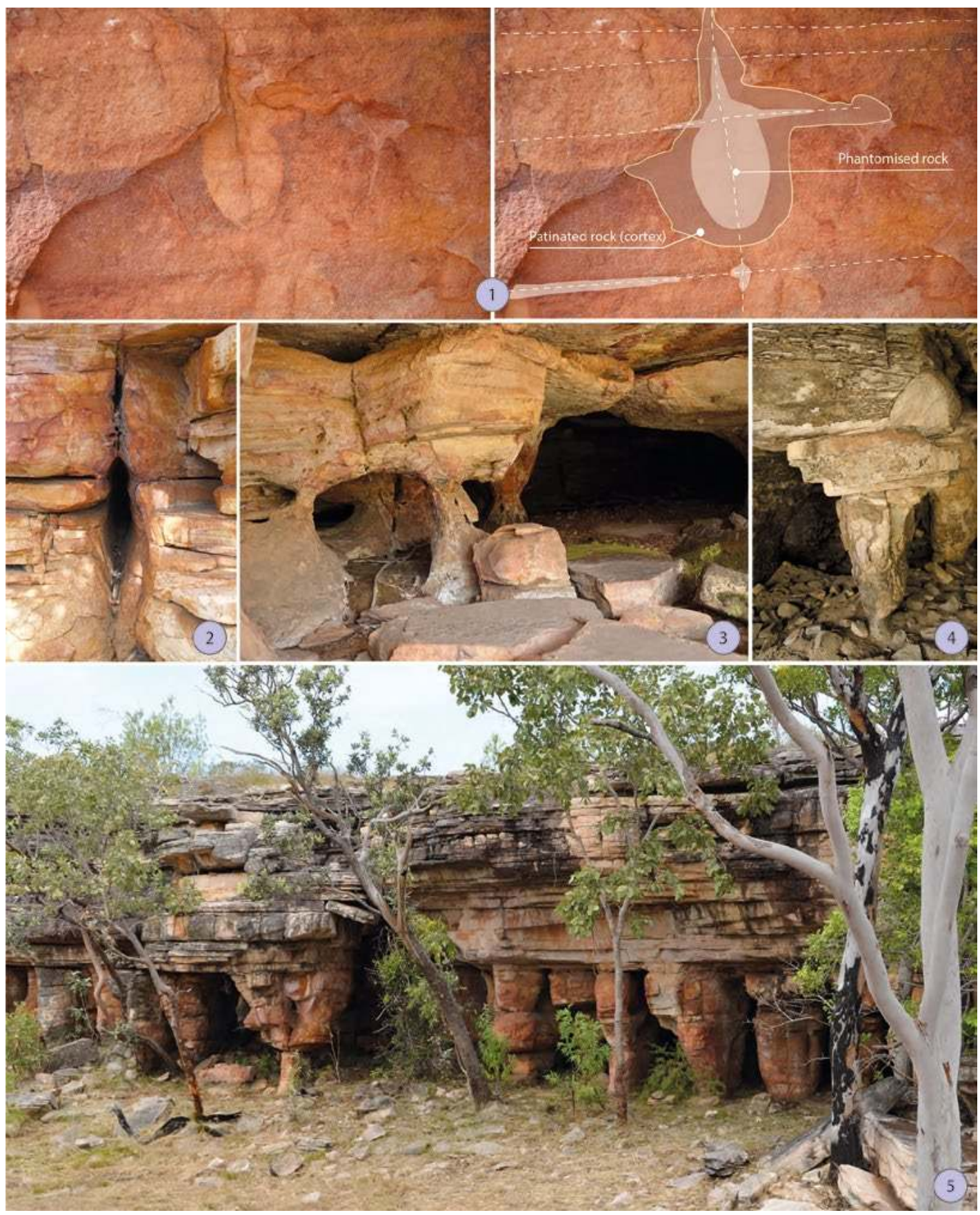

Figure 10.19 Different stages in the natural, geological evolution of the pillarscape along the edge of the rock outcrop that delimits the southern side of the courtyard, from thin fissure lines (1), to the weathering of the matrix surrounding the fissures (phantomisation), to the erosion of weathered products leading to the formation of remnant rock (pillars) separated by voids (2-5).

Source: Photographs by Jean-Jacques Delannoy.

These characteristics indicate a pillar landscape formed through dissolution of the rock along fissures over geologically very long periods of time. This phenomenon of 'ghost rock' formation or 'phantomisation' was first described and theorised by Erhard (1967) to explain altered pockets of rock that can go down to great depths below ground - $100 \mathrm{~m}$ or more - and then by Quinif (2010) to refer to different types of voids that cannot be accounted for by more classical processes of karstification, but found in soluble and apparently non-soluble types of rock (Figure 10.20). 

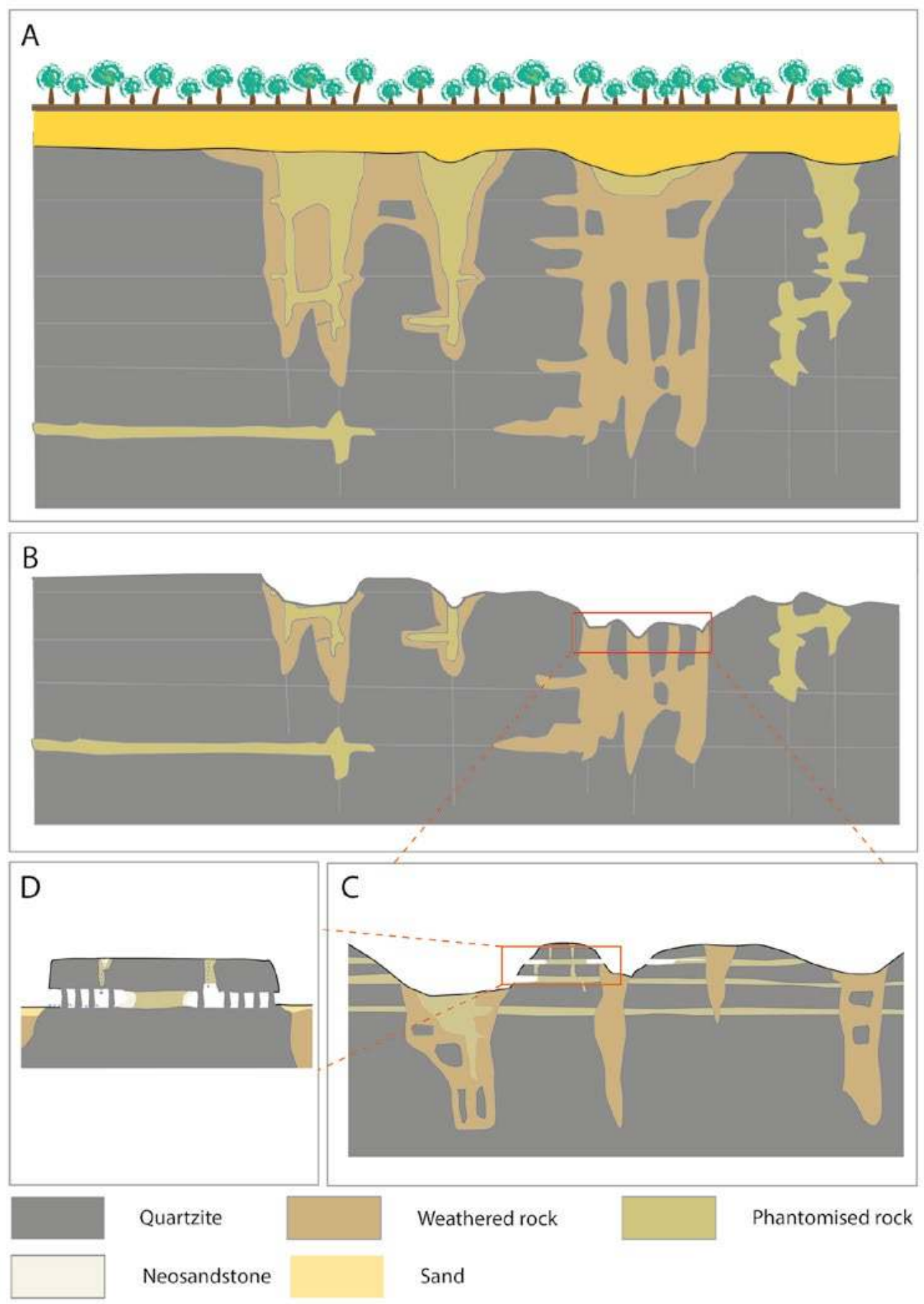

Figure 10.20 Stages in the process of phantomisation and creation of pillarscapes on the Arnhem Land plateau.

A: Over very long geological timescales, subterranean weathering of the quartzite along vertical fissure lines and horizontal joints (c. 120 million years ago). This process takes place below the watertable, where water circulates very slowly. The ensuing weathered rock is thus 'phantomised'. B: As the gradient of waterflows increase, surface levels collapse, causing the erosion of weathered rock. These basin areas are lower, relative to more elevated surrounding rock landscapes where the quartzite is more resistant. C: Close-up of an area between basins. Water passes through phantomised zones, exiting into the basins via phantomised joints. These waterflows help further evacuate weathered (phantomised) rock within the rock outcrop, creating inter-pillar voids. D: Present state in the evolution of Nawarla Gabarnmang. 'Neosandstone' refers to the reversion of quartzite to sandstone during its weathering (after Quinif 2010).

Source: Illustration by Jean-Jacques Delannoy. 
The process of phantomisation (see Armstrong et al. 2013; Martini and Grimes 2012) through slow dissolution of the rock along fissure lines at a time when the rock lay underground beneath the watertable was followed by the evacuation of altered products when the bedrock became raised above ground. This two-stage transformation enables us to understand the presence of voids that form corridors between rock pillars and the labyrinthine structure of the spaces both at Nawarla Gabarnmang and in nearby areas (Figure 10.13). But that process does not easily explain the large open spaces found in the main chamber of Nawarla Gabarnmang today. Here, the morphology of the pillars is similar to that present in the eastern and western sides of the site where the spaces between pillars are much narrower, and along the low rock plateau on the other side of the courtyard to the south. Yet, in the central, central-eastern, northern and southern sectors of Nawarla Gabarnmang, the spatial configuration of the pillarscape is very different to that of other places nearby, in that the density of pillars is noticeably less (Figure 10.13). This lower density of pillars is a key to understanding the processes that have shaped the wide, open spaces within Nawarla Gabarnmang.

At Nawarla Gabarnmang, the flatness of the surfaces on the extant ceiling indicates that it is the result of successive roof collapses (see above). Through those ceiling collapses, the space within the site has expanded upwards through time, but in doing so they have also erased traces of the shape of the earlier inter-pillar voids. These collapses could not have taken place if the ceiling was supported by numerous additional pillars to the ones currently present; they must have occurred in the absence of supporting pillars. So, why were those pillars missing?

To explore this question, we have constructed a three-dimensional (3-D) model of Nawarla Gabarnmang from a high-resolution laser-generated 3-D mapping of the site and surrounds, coupled with detailed geomorphological maps made on-site (see below). The 3-D model of the ceiling (Figures 10.13 and 10.21) clearly shows the strong negative correlation between the density of pillars and the width of the ceiling: the more pillars there are, the narrower the ceiling is. Yet those areas with few pillars have vast ceiling surfaces and wide, open spaces devoid of collapsed rocks at ground level, especially in the northern, southern, central and central-eastern sectors of the site. In these areas, the rock strata that constitute the extant ceiling surfaces are those most elevated in the site's geological series (strata D4-D3-D2) (Figure 10.21). On the other hand, where the density of pillars is greatest in the western part of the site, the ceiling level is lower, less flat and corresponds with rock strata that are less elevated in the geological series (strata D0 and D1). This suggests that the more or less open character of the site involved the disappearance of pillars and subsequent ceiling collapse.

From these initial observations of the site's extant configuration, we can work out the following evolutionary sequence for Nawarla Gabarnmang:

1. Creation of voids through processes of phantomisation.

2. Expansion of these voids by successive ceiling collapse in the face of disappearing pillar supports.

Why pillars disappeared has not yet been determined. To address this, we will need to turn to the evidence buried underground and revealed by the archaeological excavations. 


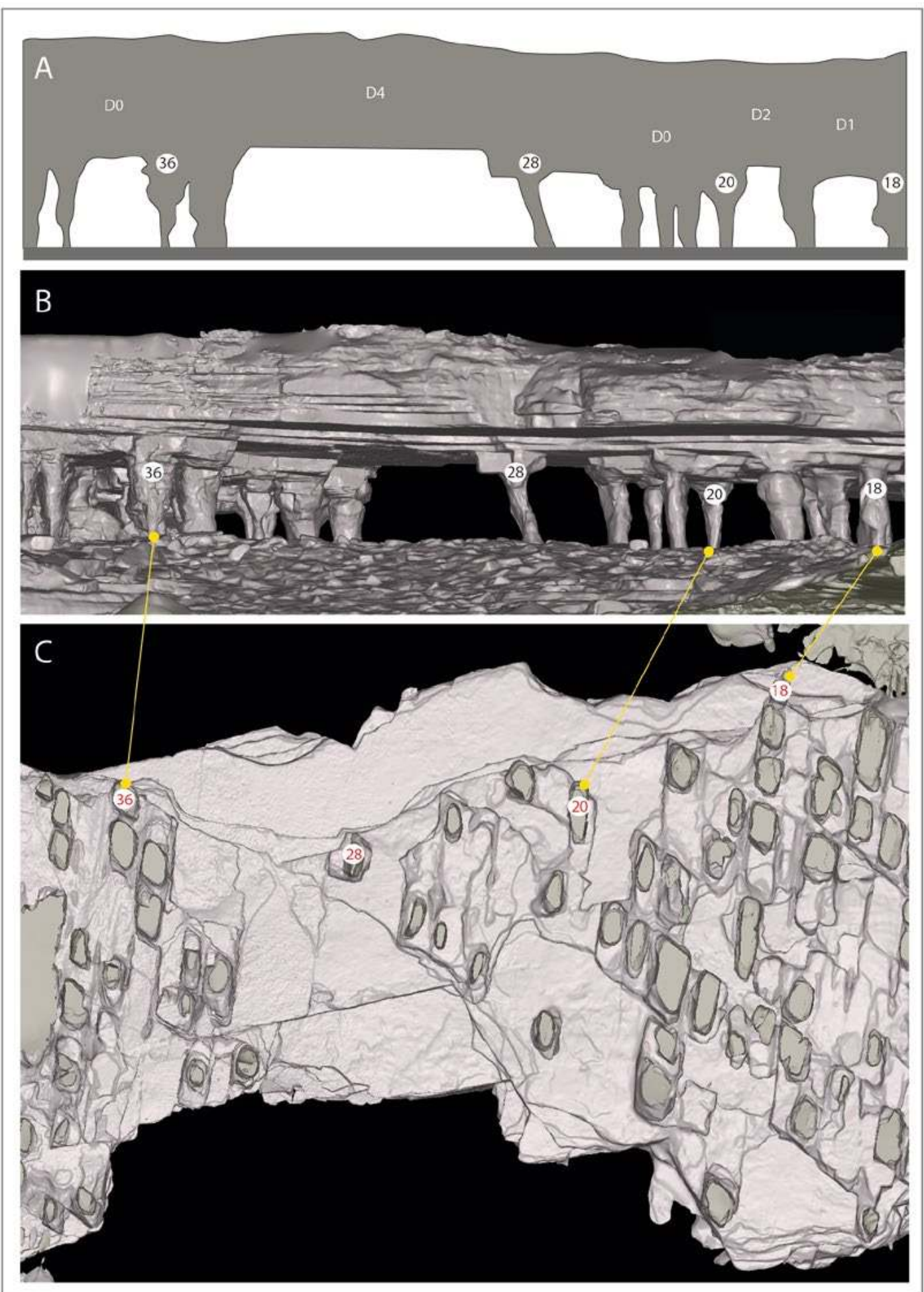

Figure 10.21 Nawarla Gabarnmang.

A: Looking southward from northern entrance. B and C: View of ceiling, showing extant pillars and remnant traces of missing pillars at ceiling level.

Source: Illustration by Jean-Jacques Delannoy. 
So far we have focused on Nawarla Gabarnmang's present configuration and on the geological origins of its pillarscape. The processes of phantomisation that caused the pillarscape in the first place are not now active because they take place below the watertable, and the hard quartzites are extremely resistant to erosion. So we can conclude that when people first arrived at the site around 50,000 years ago, what they encountered was a rockshelter much like the one we now see, but with a more regular set of pillars, less extensive ceiling surfaces; overall it had significantly less open sheltered space. So how did the site's internal space come to open up in more recent times, either preceding human occupation or coetaneous with it? Understanding this latter phase of the site's evolution is critical to understanding the age of the decorated rock surfaces, and therefore the maximum age of the rock art on those surfaces.

The general and more specific questions we now pose are:

- Why is the sheltered space at Nawarla Gabarnmang considerably more open than in nearby pillarscapes?

- Why are there fewer pillars, occurring in lower concentrations, at Nawarla Gabarnmang than in nearby pillarscapes?

- Why is there a lack of fit between the geometry of the ceiling and the shape of the ground level, and a non-correspondence between a large amount of missing ceiling strata along the northern and southern edges of the site yet a paucity of blocks on the ground?

- Why is there a large scree slope with blocks of regular shape and size immediately outside the northern and southern entrances of Nawarla Gabarnmang, and yet no evidence for collapsed overhangs in those areas?

Answering these questions requires knowledge of what lies underground, and geomorphological details obtained with good spatial resolution.

\section{The archaeological excavations}

Needless to say, from an archaeological perspective, Nawarla Gabarnmang is an exceptional site. We first began research at the site at the request of the Jawoyn Association, who asked us to determine whether or not in situ cultural deposits lay buried underground, and, if so, what these could tell us about the past. A number of isolated and juxtaposed squares were excavated across the site, each square usually being $50 \mathrm{~cm}$ wide or smaller to enhance chronostratigraphic and spatial control over excavated sediments; our aim was to eventually undertake a larger excavation in one or more parts of the site, after the broader pattern was understood. Table 10.1 lists the excavated squares, the year they were excavated, their size, where they occur in the site, their maximum depth and the maximum age of human occupation. Eighteen squares have been excavated; three are single (Squares A, B and P), and the rest are contiguous with one or more other squares to form four sets of spatially distinct pits covering especially the northwestern and southwestern sectors of the site (Squares $\mathrm{C}+\mathrm{G}+\mathrm{K}+\mathrm{N}, \mathrm{D}+\mathrm{H}, \mathrm{E}+\mathrm{J}+\mathrm{O}+\mathrm{Q}+\mathrm{R}, \mathrm{F}+\mathrm{I}+\mathrm{L}+\mathrm{M})$. The rationale for the location of some of the excavations had much to do with the sequence of results (e.g. dates, assemblages, ability to reveal evidence of the antiquity of the rock art on extant pillars and ceiling surfaces) we obtained from one year to the next; as results appeared, new questions were raised and new excavations undertaken where answers might best be found. Thus, in the first year of research (2010), we excavated Squares A and B. Unexpectedly for such shallow and well-stratified deposits, Square A revealed cultural deposits going down to 45,180 $\pm 910 \mathrm{cal}$ BP, but deeper cultural sediments were evident in a very narrow crack (a phantomised fissure line) in the bedrock at the bottom of the square (see David et al. 2011; Geneste et al. 2010, 2012), indicating that nearby excavations in well-protected areas might reveal evidence of that earlier occupation. Square D was opened the following year to further track the early evidence 
of human occupation revealed in Square A, and Squares $\mathrm{F}+\mathrm{I}+\mathrm{L}+\mathrm{M}$ were in part a continuation of this same tracking of old deposits across increasingly well-protected sectors of the site. Other squares were positioned to sample what appeared for contextual reasons to be deep soft deposits, intriguing sectors of the site, areas that would have been inaccessible or difficult of access to medium-sized or large animals and areas with high potential to shed light on the age of nearby rock art. These excavations were in all cases undertaken in very shallow arbitrary excavation units (very often measuring a few millimetres, the better to investigate questions of taphonomy and chronostratigraphy) following the stratigraphy.

Table 10.1 Details of the excavated squares, Nawarla Gabarnmang.

\begin{tabular}{|l|l|l|l|l|l|}
\hline $\begin{array}{l}\text { Excavation } \\
\text { squares }\end{array}$ & $\begin{array}{l}\text { Year(s) } \\
\text { excavated }\end{array}$ & $\begin{array}{l}\text { Size of pit } \\
(\mathrm{cm})\end{array}$ & $\begin{array}{l}\text { Location in site } \\
\text { (sector) }\end{array}$ & $\begin{array}{l}\text { Nature of material on } \\
\text { which deepest cultural } \\
\text { deposits lie }\end{array}$ & $\begin{array}{l}\text { Median age of occupation at base } \\
\text { (cal BP, all on charcoal dated by } \\
\text { AMS radiocarbon) }\end{array}$ \\
\hline A & 2010 & $50 \times 50$ & SW & bedrock & 45,180 \\
\hline$B$ & 2010 & $50 \times 50$ & Central & bedrock & 5046 \\
\hline $\mathrm{C}+\mathrm{G}+\mathrm{K}+\mathrm{N}$ & $2011-2012$ & $100 \times 100$ & SW & bedrock & 21,922 \\
\hline $\mathrm{D}+\mathrm{H}$ & 2011 & $60 \times 50$ & WSW & bedrock & 46,576 \\
\hline $\mathrm{E}+\mathrm{J}+\mathrm{O}+\mathrm{Q}+\mathrm{R}$ & $2011-2012$ & $130 \times 90$ & NW & bedrock & 46,278 \\
\hline $\mathrm{F}+\mathrm{I}+\mathrm{L}+\mathrm{M}$ & $2011-2012$ & $100 \times 50$ & WNW & sands and rocks & 49,350 (non-basal) \\
\hline $\mathrm{P}$ & 2012 & $50 \times 50$ & Central-eastern & rock slab & 4240 \\
\hline
\end{tabular}

Source: Authors' data.

So far we have obtained 196 accelerator mass spectrometry (AMS) radiocarbon dates on single pieces of charcoal from these 18 excavated squares. The spatial pattern of basal dates indicates the following:

1. Rich assemblages of flaked stone artefacts are found down to bedrock and in all stratigraphic units of every excavated square, except for contiguous Squares $\mathrm{F}+\mathrm{I}+\mathrm{L}+\mathrm{M}$. Here, the deepest artefacts overlie a thick layer of sands and rockfall that pre-date the period of human occupation (David et al. completed manuscript).

2. The onset of human occupation around 50,000 years ago (see David et al. completed manuscript for a more refined set of radiocarbon and OSL dates) is accompanied by the onset of deposition of aeolian sands within the site.

3. There is no evidence of in situ charcoal until after the arrival of people at the site.

4. The earliest evidence for human occupation is in the northwestern sector of the site, where cultural horizons overlie earlier pre-cultural sediments.

5. Evidence of pigment use in the form of in situ used ochre crayons, dried drops of paint, tiny fragments of imported pigments deposited during processing for the making of paint pastes, and tiny painted pieces of (exfoliated?) rock are present in large numbers underground, and variably go back into Pleistocene layers. The oldest excavated painted rock, dating to 26,739-27,657 cal BP, came from Square E (David et al. 2013, 2014; see also Chapter 11).

6. The ceiling is richly decorated with rock art, with 1391 paintings including some stencils identified. Hundreds more paintings, and cupules, occur on 36 pillars, but these have not yet been systematically recorded.

7. While some of the excavated squares have revealed isolated rock slabs buried horizontally underground (e.g. Squares E, F+I+L+M, P), there is a paucity of accumulated roof-fall and debris from pillar collapse. Exceptions are contiguous Squares $\mathrm{C}+\mathrm{G}+\mathrm{K}+\mathrm{N}$ and the area immediately abutting Pillar 20 in Square F; it remains to be determined whether the buried rocks in those two pits can account for the bulk of the missing adjacent pillar rock. What is clear is that they cannot account for the missing rock strata overhead. 
To make sense of the above findings, we turn to an integrated geomorphological-archaeological approach that we have come to term 'archaeomorphology' (Delannoy et al. 2013, 2017). Additional information aiding these investigations are five AMS radiocarbon dates obtained directly from the rock art (mainly beeswax figures), as well as two AMS radiocarbon dates on mud wasp nests (reported in Gunn 2016). Each of these samples comes from a ceiling surface, and is therefore useful for determining the minimum age of that extant ceiling surface.

\section{Nawarla Gabarnmang: Archaeomorphology}

As noted above, Nawarla Gabarnmang's internal structure contains wide, open spaces with few pillars and high ceilings near the central and central-east sections of the site along with its northern and southern margins, versus a dense pillarscape with lower ceiling to the west and to the east. The archaeological excavations and rock art have also revealed a similar spatial division, with the western sector having the oldest archaeological remains (Squares A, D+H, $\mathrm{E}+\mathrm{J}+\mathrm{O}+\mathrm{Q}+\mathrm{R}, \mathrm{F}+\mathrm{I}+\mathrm{L}+\mathrm{M})$ in the ground and the oldest art on the ceiling, in contrast to a central and central-eastern sector where both the excavated deposits (Squares B and P; see Chapters 11 and 12) and ceiling art tend to be relatively recent.

We now ask why there is such a west versus central and central-east differentiation in the physical structure of the site, buried archaeology and ceiling art. This question ventures into the site's spatial history, requiring detailed information of its spatial characteristics through time. Our approach has been to obtain evidence from specialist geological, geomorphological, sedimentological, archaeological and rock art studies, and to inter-relate these various lines of evidence. This interdisciplinarity is fundamental to our ability to understand how spatial patterns in the site's rock structure, accumulation of soft sediments at ground level, buried evidence of human activity and rock art may or may not be inter-related, including the role of taphonomy in those patterns. That is, to adequately understand how site formation processes have influenced the physical matrix of the site, human occupation, rock art and the preservation of rock surfaces and sediments, we need to involve disciplines capable of addressing each of these.

Two fundamental analytical tools have been used across all of these studies, and indeed it is these tools that have facilitated cross-communication and understanding: 1) archaeomorphological mapping (see below); and 2) 3-D mapping and modelling of the site.

Much of our analytical reasoning revolves around the geomorphological maps (Joly 1977; Delannoy et al. 2001, 2004). On such maps are plotted all material items deemed relevant. 'Everything' needs to be represented on a geomorphological map, not for the sake of being exhaustive, but to enable questions to be asked about each object, on their relationships with other adjacent or more distant static and movable objects and on the processes that caused them to be deposited where they are now. The act of representing each one of these objects on a map gives them an existence that requires explanation, and that requires a history. It is this line of enquiry that enables us to build a historic account of how Nawarla Gabarnmang's present state came to be.

In the first instance, archaeomorphological mapping has been of utmost importance, because it has enabled us to identify where specific objects, structures and surface characteristics are found across the site. It has also enabled all members of the research team, irrespective of their field of study, to work with a common map that includes the details from each of the specialist studies; in this way, all these aspects became usable and potentially meaningful to all participants. From an early stage, the maps focused on the rock surfaces, distribution of soft sediments, detached rocks found at ground level, archaeological objects and rock art. Two key maps came to be 
repeatedly consulted: one relating to ground level, the other to the ceiling (Figures 10.13 and 10.22). The juxtaposition of these two maps has enabled us to see how the archaeology and rock art map onto the spatial patterning of pillars and inter-pillar spaces (David et al. 2011; Delannoy et al. 2013); for an example of how this was applied in the area of Square P, see Chapter 11.

It soon became apparent, however, that the site's complex three-dimensional space (voids, pillars, staggered ceiling levels and so forth) required a more powerful tool than flat maps, one that was fully three-dimensional, so the site was mapped in 3-D by laser, enabling a high-resolution, virtual 3-D model to be built. This 3-D model has enabled us to visualise the site in new ways, to approach it from different perspectives to those from which we can see things in the field. The 3-D model allows visualisation of the site and its landscape at spatial scales that enable us more easily to connect cause and effect. This is in part due to the masking effects of features in the real world, where, for example, the aesthetic pull of the ceiling art may hinder us from seeing underlying rock surfaces, or where pillars in the foreground may stop us from seeing or relating to rock structures that lie beyond. The 3-D model enables us to move quickly between spatial scales, even to look through physical barriers such as paint layers or rock pillars or thick ceilings, and to bring forward background details, making them more easily compared with foreground details. The 3-D model also enables us to measure and quantify distances and volumes in ways that cannot be easily done in the field, be it for reasons of accessibility or conservation. The 3-D model also enables us to 'pick up' movable items such as blocks of rock lying on the ground, for example, to match their edges with original remnant joins on the site's pillar walls or ceilings (see Chapter 15 for a good example of where this has been done at JSARN-124 site 3 a few kilometres away). And at Nawarla Gabarnmang, the 3-D model proved its value when it brought together the evidence from each of the different analytical fields (see below).

\section{From geomorphological to archaeomorphological mapping}

Understanding what happened at the site through time is closely connected with understanding the changing physical shape of the site along with the processes that have caused those transformations. Objects on the ground today could have lain there since their original deposition, or they could have been displaced by geomorphological processes, by animals, by people or by a combination of these. Geomorphological investigations allow us to discriminate between these different causes, to measure their relative impacts and to determine what happened when. In effect, geomorphological analysis aims to explain the origins of particular forms and deposits by identifying phases when specific processes took place on those items of interest. Rock surfaces and deposits at Nawarla Gabarnmang could be put into historical order by associating specific processes with each form and with the present positioning of objects.

In this way, we distinguish between processes of erosion (removal of material), transport and sedimentation. Each process involves chemical, mechanical, gravitational and/or anthropic forces. Employing the high-resolution 3-D model, the specialist lines of evidence enabled us to (Figures 10.13 and 10.22):

1. Distinguish a range of natural morphogenic processes responsible for the general evolution of the site, through traces of chemical alteration of the rock, gravitational collapse of rock strata, water flow, aeolian deposition of sands and the like.

2. Bring to evidence anthropic actions that caused the configuration of the site to be modified, for reasons that remain to be determined (see below).

3. Determine where and when across the site those natural and cultural modifications took place. 


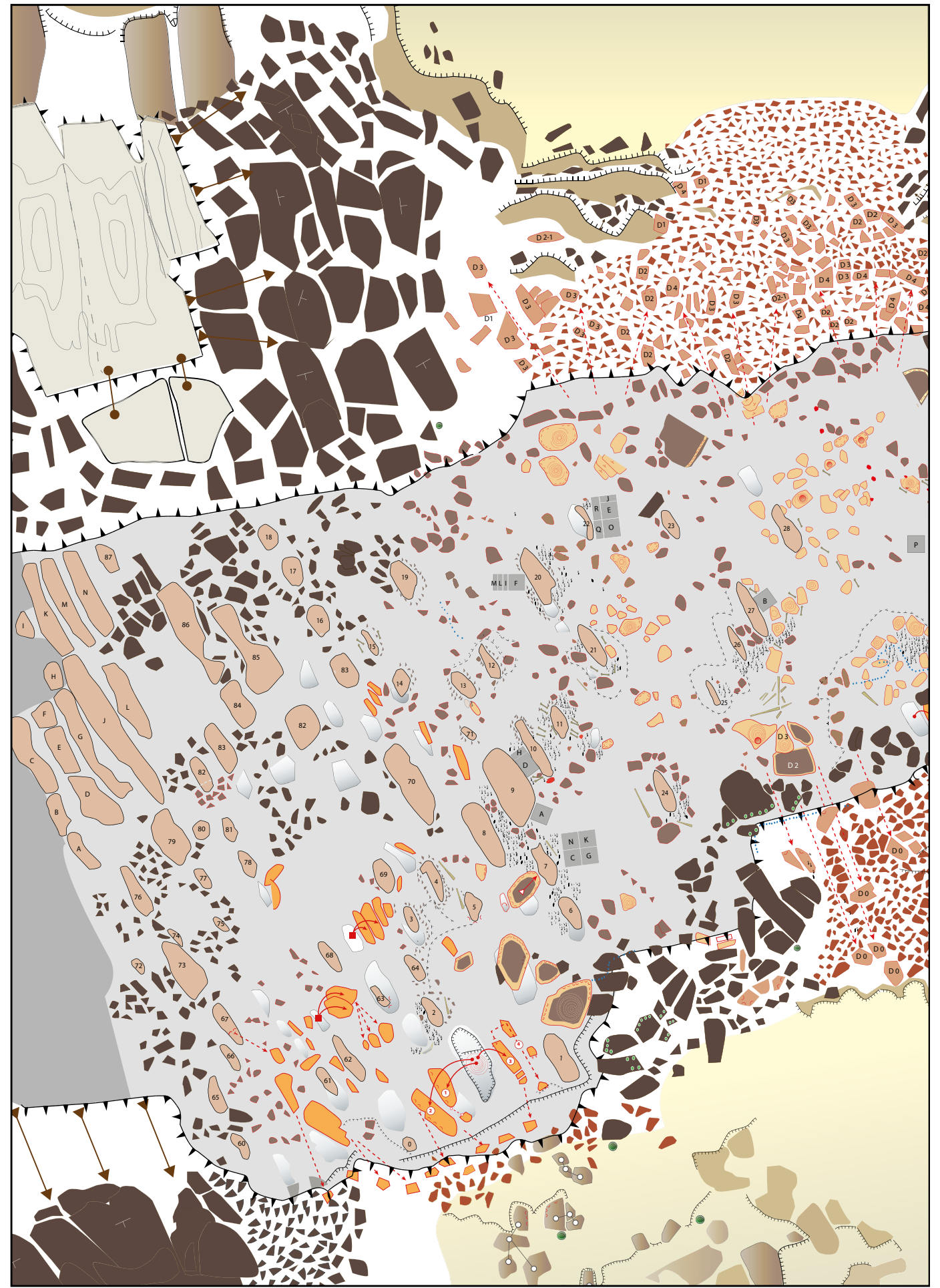

Figure 10.22 Plan of site floor, based on details recorded during on-site archaeomorphological mapping and the 3-D laser model.

Source: Illustration by Jean-Jacques Delannoy. 


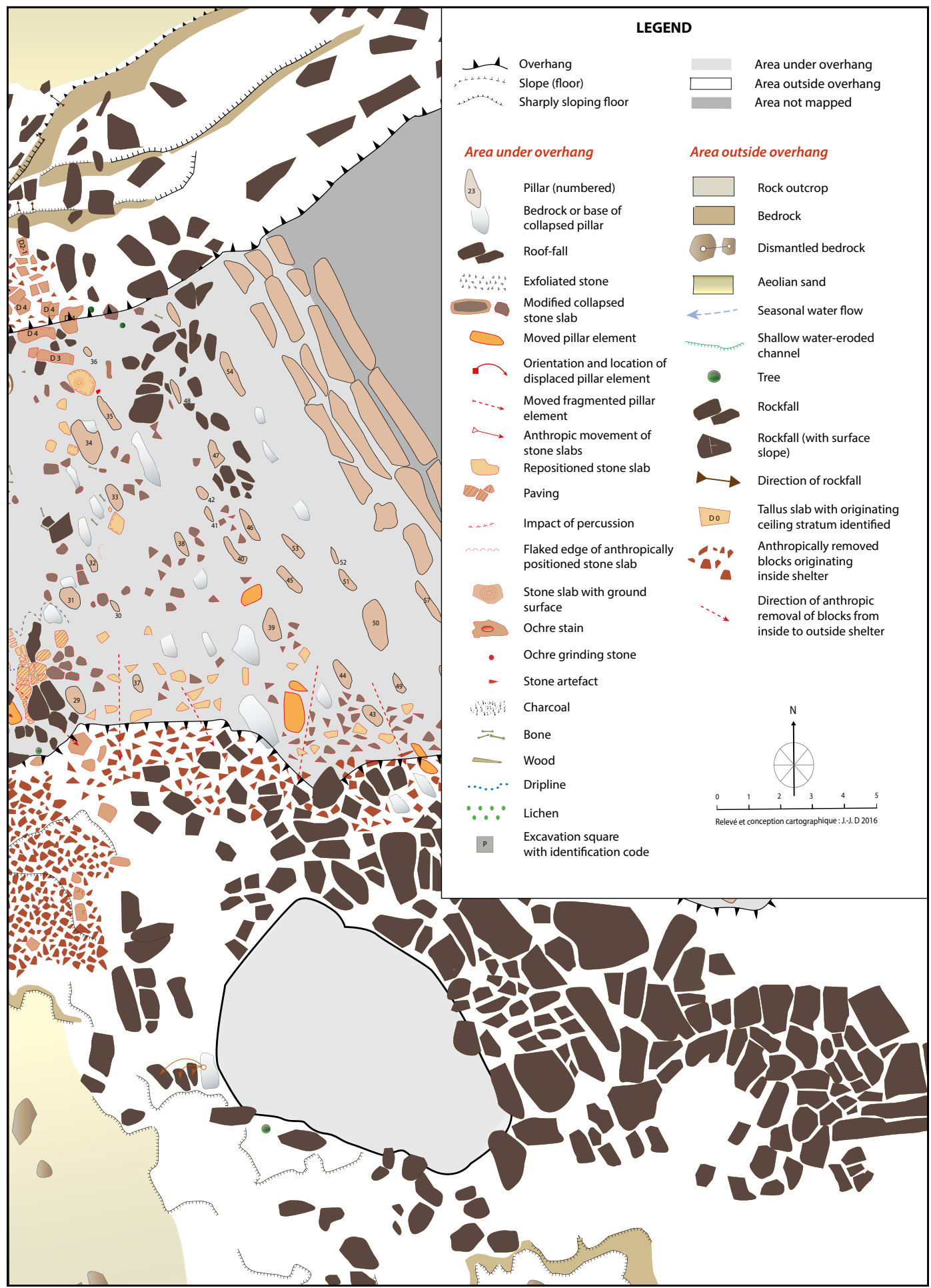

Figure 10.22 Continued. 


\section{Results of archaeomorphological mapping}

At Nawarla Gabarnmang, the rock structure, rock art and buried archaeological deposits each differ between the western and the contiguous central and central-eastern sectors of the site. Conventional geomorphological mapping does not explain what caused this spatial patterning. Nawarla Gabarnmang is a complex site that witnessed multiple and, through time, varying kinds of effects caused by a range of agencies. We now aim to identify those effects and their causes.

In studies of complex systems, it is often essential to define a vector by which the evolution and structuring of the system can be determined at given points in time. In the case of Nawarla Gabarnmang, the vector of morphogenesis we have focused on is the density of pillars across space. The wide, open nature of ceiling spaces across the central and central-eastern sector of the site appears to be associated with the collapse of ceiling rock strata following the weakening of mechanical support when the number of pillars was reduced. Understanding this differential density of pillars is essential to understanding the site as a whole.

\section{A problematic pillarscape}

We ask of the site's architecture: Does the current layout of pillars across the site have a geological origin explained by lateral variations in the properties of rock features indicating their formation ('facies')? Did pillars originally exist in the central and central-eastern, northern and southern sectors where today they are either absent or very widely spaced?

Lateral variations of facies are common in bedrock of littoral origins, across the site and continuing onto the rock pillars that form the northern edge of the low rock outcrop bordering the courtyard immediately to the south of Nawarla Gabarnmang. However, rock strata D4 to D-12 show similar petrographies and levels of compaction across space, indicating an absence of the kinds of variability that would have weakened mechanical support and thus a lesser density of pillars in parts of Nawarla Gabarnmang.

The rhythm and spacing of voids between pillars in sectors neighbouring those parts of the site with widely spaced pillars show that they map perfectly onto the network of fractures in the rock. In plan view, the pillars and their interstitial spaces have the same fractal pattern as the triplecheckerboard structure of the Arnhem Land plateau; this structure represents lacerations of the rock caused by geological forces. As noted above, those fractures are oriented in three intersecting directions: north-northwest to south-southeast, north-northeast to south-southwest and east to west. The first two of these feature prominently in the orientation of inter-pillar voids (as in the processes of phantomisation), and in the original spatial configuration of the pillars (see below).

Keeping in mind an absence of spatial variation in the facies, and the presence of a network of fractures in the rock, we compared the expected original distribution of pillars for the site (as determined by the intersection of the axes of alignment of the extant pillars) against those extant today (Figure 10.23). This pairing clearly shows that in some parts of the site expected pillars are absent; and those pillars are missing where there are vast flat ceiling surfaces. Using the 3-D model as well as field observations, geomorphological traces of now-missing pillars could clearly be seen on the ceiling. But unlike the extant pillars, these remnant pillar ceiling surfaces have not been heavily altered (they do not feature strong patination), indicating that they cannot have been chemically weathered away in deep geological time as would be required of phantomisation. While the discovery of these remnant pillar surfaces at ceiling level confirms the original full 
structure of the pillarscape within the site as proposed by the geological evidence (network of fractures and phantomised voids), they also point to other causes for how they disappeared. This is even more so given an absence of rocks at ground level that would normally be required to explain their collapse, for example. This lack of fit between the collapse of pillars (as well as ceiling strata) and the flatness of the ground level (indicating a paucity or absence of accumulated blocks below ground) has already been discussed above (Figure 10.24).
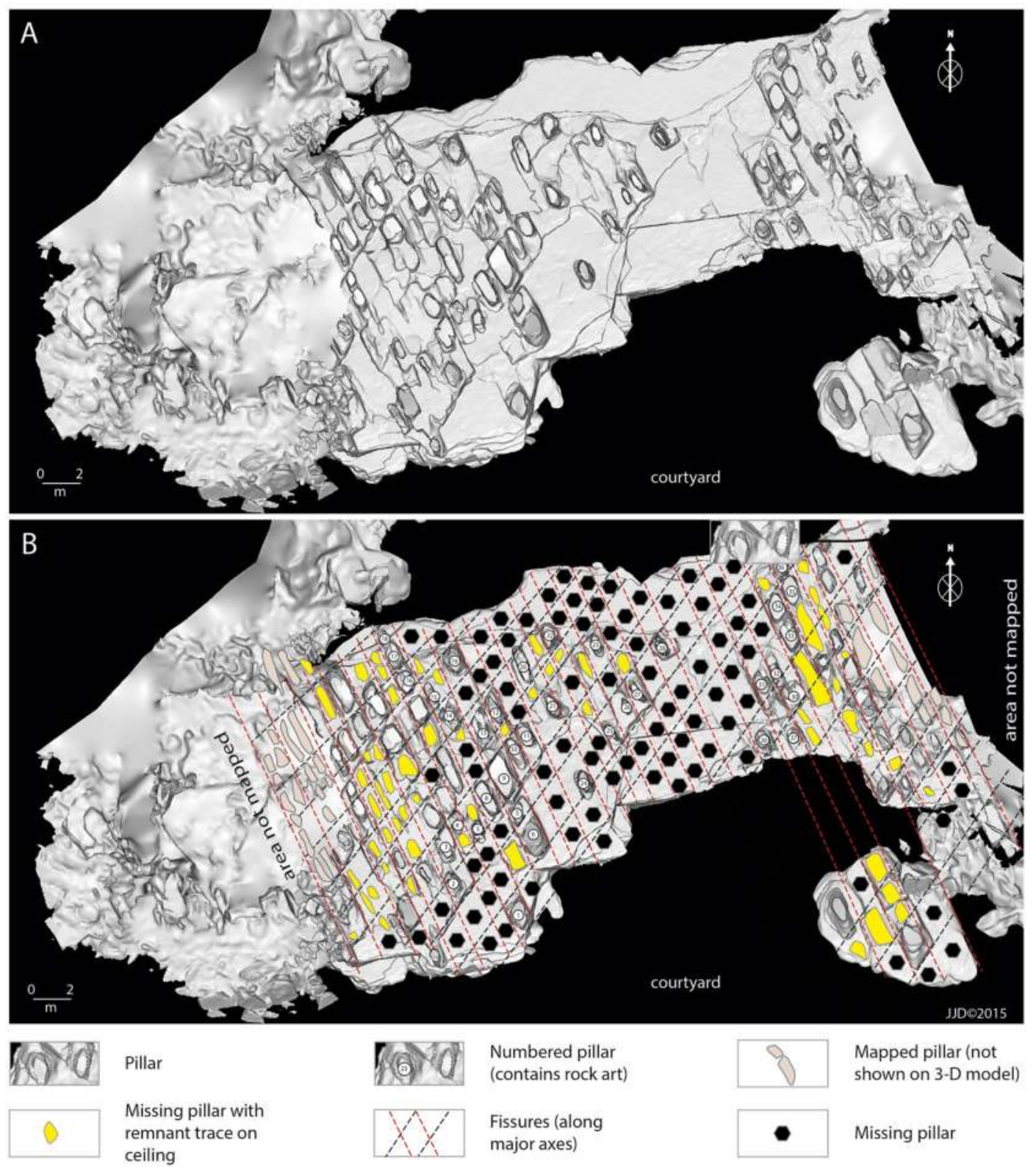

Figure 10.23 Nawarla Gabarnmang present ceiling, showing also remnant traces of missing pillars. A: View of ceiling from 3-D model. B: Reconstitution of the original distribution of pillars and inter-pillar voids, as evident from geological and geomorphological traces.

Source: Illustration by Jean-Jacques Delannoy. 


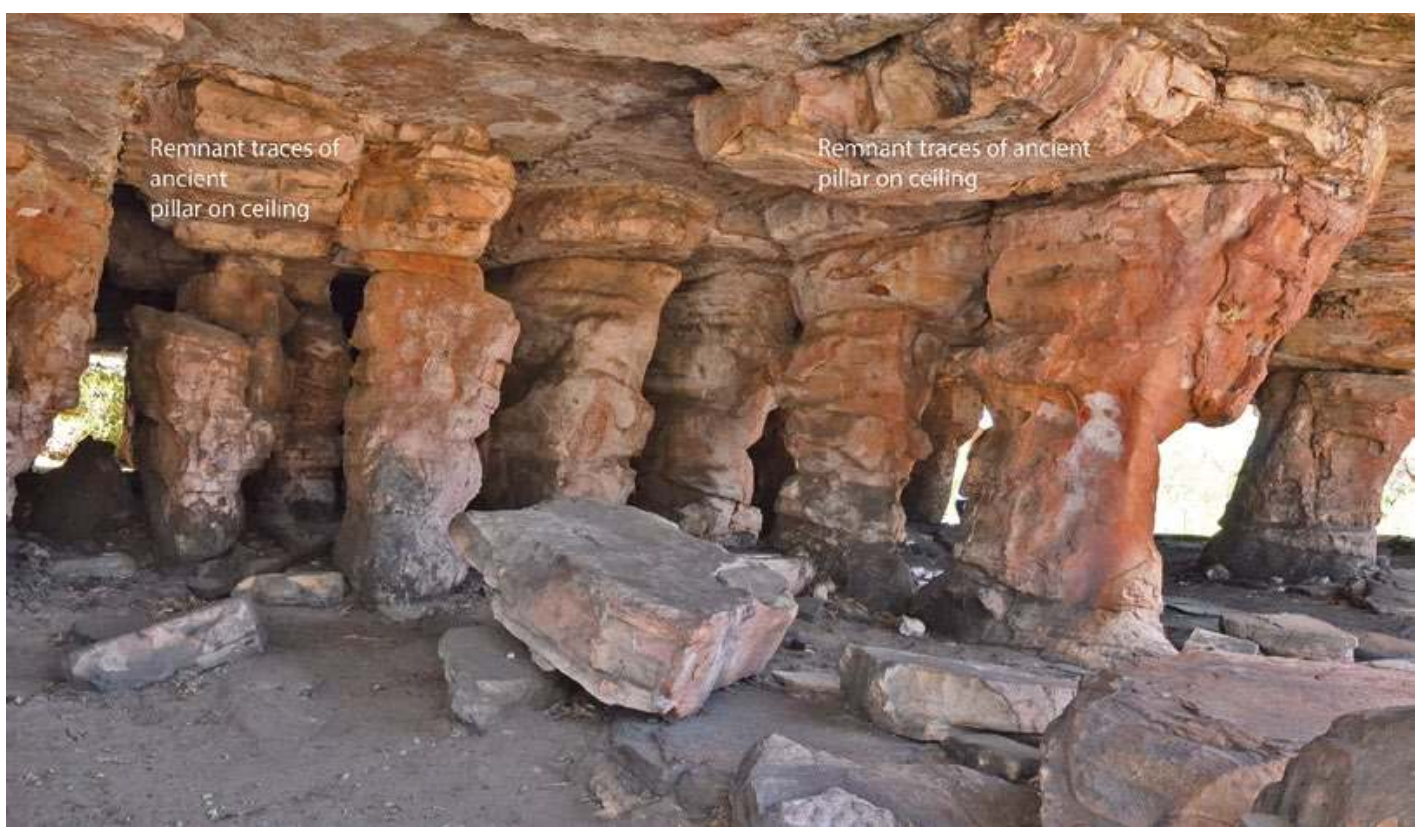

Figure 10.24 Southwestern sector, showing two remnant traces of missing pillars on the ceiling.

Source: Photograph by Jean-Jacques Delannoy.

Areas with missing pillars were examined more closely to understand their disappearance. Other than Square P (see Chapter 11), archaeological excavations have not been undertaken in or near areas where pillars are expected to have fallen. Rather, research has focused on the relatively open southwestern sector of the site where pillars have disappeared (Figure 10.24). Here, blocks of rock are commonly encountered on the ground, and traces of ancient pillars can be seen both at ground level and on the ceiling. Moreover, this sector is located close to excavated squares (Squares A and D) that have revealed long sequences of human occupation dating to more than 45,000 years ago and recurring to 'recent' times. Finally, this is also a richly decorated area, with paintings occurring both on the remaining pillars and on the flat ceilings.

\section{The aménagement of Nawarla Gabarnmang}

Nawarla Gabarnmang's southwestern sector contains two contiguous alcoves that open directly onto the courtyard to the south of the site (Figure 10.25). Both of these alcoves have flat ceilings caused by the collapse of overhead rock strata (Figures 10.24 and 10.26). They also both have blocks of rock resting directly on bedrock or on skeletal soils at ground level. The area to the north behind these two alcoves is dark, and the pillar and ceiling surfaces exhibit little art. Here, the space is largely enclosed where pillars are very closely spaced; the only easy access to this sector is by the site's southern edge and through the two alcoves. It contrasts starkly with the wide, open spaces of the northern, southern and contiguous central and central-eastern sectors. 

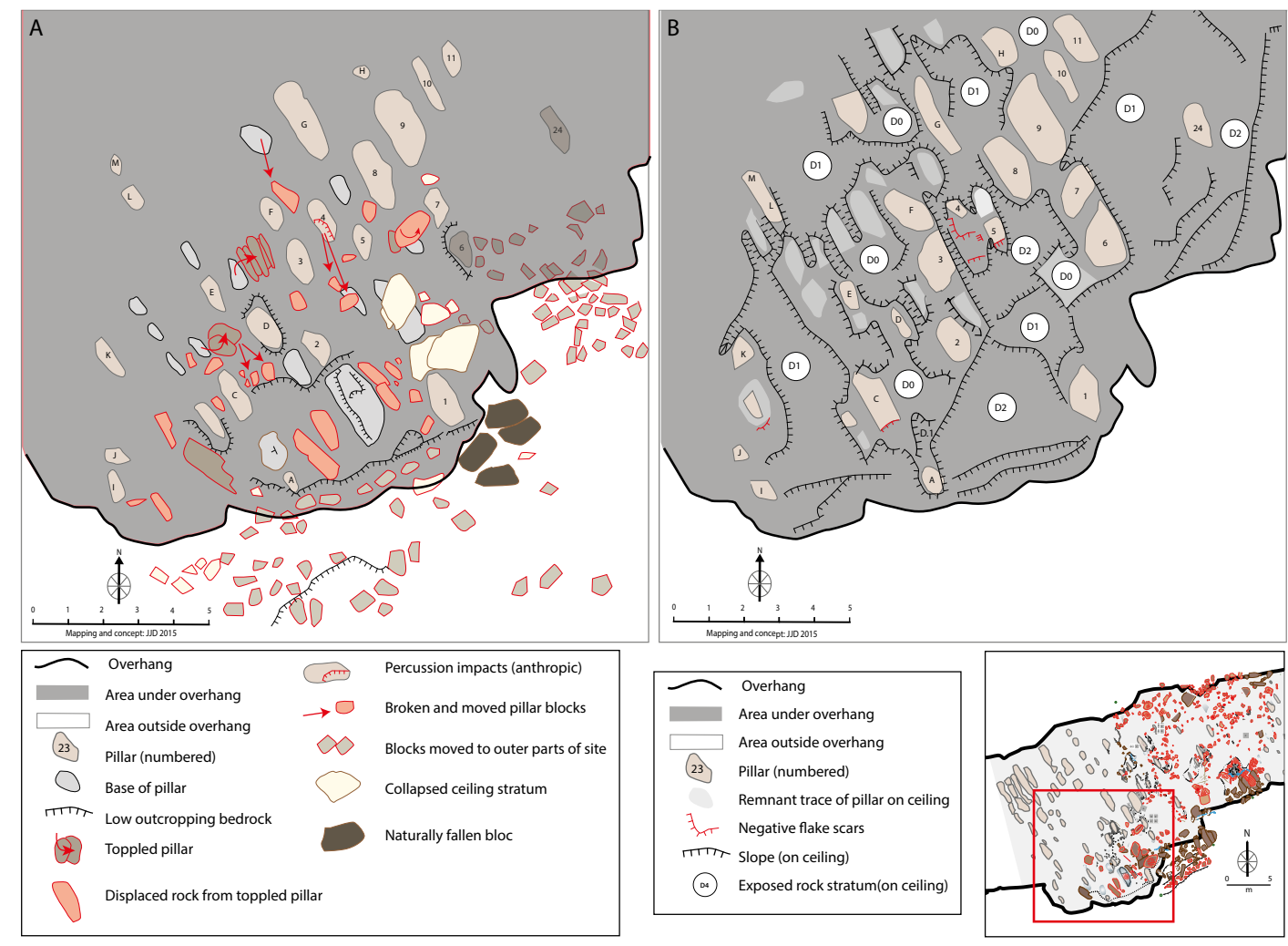

Figure 10.25 Archaeomorphologial mapping of southwestern sector of Nawarla Gabarnmang.

A: Floor plan. B: Map of ceiling. Seen together, these two maps highlight the anthropic aménagement of this part of the site, as the floor plan shows an absence of pillars whereas the ceiling map shows remnants of missing pillars.

Source: Illustration by Jean-Jacques Delannoy.

\section{Analysis of collapsed blocks: The first signs of anthropic actions}

The southwestern sector of the site is key to understanding the evolution of the site as a whole. We began by investigating the nature and origins of the large blocks strewn on the ground in the alcoves. Petrographic and morphogenic analyses revealed that some came from ceiling strata, while others came from pillars.

Let us begin with the fallen ceiling rocks; this is the only sector of the site where fallen ceiling rocks are today found in, or near, their fallen positions (Figure 10.25). However, even here not all of the fallen material occurs on the ground today; the missing parts of the ceiling collapse were removed by people sometime in the past. The evidence that it is people who removed the rocks is as follows:

1. The blocks that lie at ground level today are not necessarily those that fell last. On Figure 10.26, we show how material that fell from the collapse of ceiling stratum D1 is missing at ground level. All that remains today is one block, originating from a lower ceiling stratum that came from an earlier roof-fall.

2. The blocks still present at ground level carry clear negative flake scars from heavy hammer impacts - presumably aimed at breaking them up. Conjoining or matching flakes are sometimes found nearby, but mostly a moderate distance to the south immediately outside the site. Some of these removed flakes are very large, measuring tens of centimetres in length. 
3. Petrographic analysis of the blocks that have accumulated on the scree, right up to the entrance of the alcoves, indicates that they did not fall from the outer edges of the overhang, but rather from ceiling levels within the shelter.

4. Some fallen rock strata have been moved from the inner edges of the alcoves outwards.

5. Only the largest blocks - those of great weight and difficult to break up because of their large mass - remain in place; we see this as because they were too heavy to move (e.g. Blocks A, B and C on Figure 10.26).
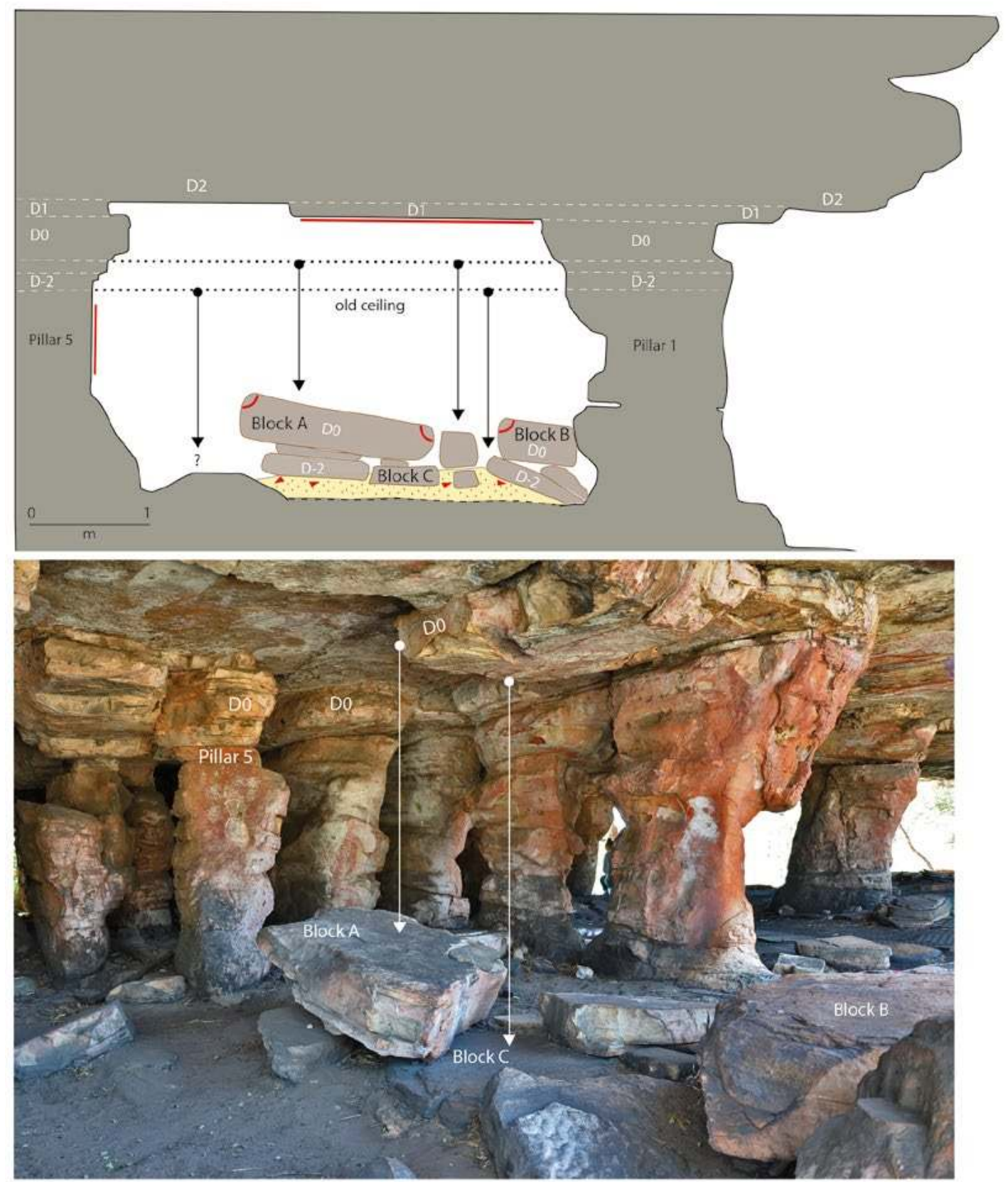

Figure 10.26 Alcove $A$ of the southwestern sector, showing the horizontal and vertical relationships of features discussed in text.

Source: Photograph and illustration by Jean-Jacques Delannoy. 
These first observations allow us to determine that clearly anthropic actions of aménagement have been undertaken; blocks fallen from the ceiling were dismantled on the ground and removed to areas outside the overhang. The reasons for these actions remain to be determined (see also Delannoy et al. 2013). We use the French word aménagement, as no English equivalent has the same nuances. Aménagement refers to the development of a place, or of one's affairs, through active human participation. It is more than 'fitting out' or 'ordering' a pre-existing location, going beyond the addition of new objects to involve its active construction through meaningful engagement.

Investigations were then made on the status of the ground surface on which the rock strata fell from the ceiling. Here, two different phases of rock collapse were distinguished, each bringing to light new evidence on the site's evolution. First, rock strata D-3, D-2 and D-1 from the upper parts of the pillar fell; a second, separate collapse of stratum D0, the first ceiling stratum, followed (Figure 10.25).

On falling, stratum D0 landed on, and in doing so damaged, those strata D-3, D-2 and D-1 blocks that were already on the ground and which themselves overlay stratified sands containing stone artefacts. The presence of this archaeological material under the collapsed blocks confirms that people were already at the site prior to or during the first collapse. This occupation precedes the collapse of both ceiling strata D-3 to D-1 (the first collapse) and stratum D0 (the second collapse) in the area between Pillars 6-7-8-5-3-2-1 (Figure 10.25). Here, it is possible to determine when strata D0 and D1 fell from the ceiling, as a radiocarbon date was obtained from a wasp nest underlying rock art on the extant (decorated) stratum D2 ceiling surface (a surface that now exhibits rock art Panels A3, A5 and A6; Figure 10.26). The radiocarbon date enables us to determine that strata D0 and D1 fell sometime before 10,154 $\pm 40 \mathrm{BP}$ (Wk-31730), calibrating at 11,624-12,024 cal BP (95.4 per cent probability) (median probability = 11,833 cal BP); so the rock art superimposed above the wasp nest is more recent than this. Such radiocarbon dates are valuable, because we currently have very few absolute dates at hand by which to date the various ceiling levels and pillars across the site.

We can take the analysis further, as some of the blocks that fell from the ceiling lie directly on top of a locally outcropping section of the bedrock. For example, Block A on Figure 10.27 came from the collapse of ceiling stratum D0; it lies directly on an exposed rock base. If we locate this locally outcropping bedrock onto the map that shows the location of the original pillars across the site (Figure 10.23), it is found to be where an ancient pillar once stood: the locally outcropping patch of elevated bedrock represents the base of an ancient and now-missing pillar.

We can now determine:

- Block A (originating from ceiling stratum D0) rests directly on the base of an ancient pillar, indicating also the absence of rocks fallen from lower-level (and therefore earlier) rock strata D-3, D-2 and D-1. We would have expected these to be sandwiched between the base of the pillar and Block A.

- Petrographic examination of a partly buried block indicates that it fell from strata D-11 and D-12; it thus belongs to an ancient pillar. Its original stratigraphic position was just above the same base of the pillar that is today capped by Block A.

- Block A has been extensively flaked along its periphery; it was also slightly moved towards Pillar 7. It was slightly rotated during its displacement; the orientation of the ripple marks on the block are different from those in its matching position on the ceiling. 


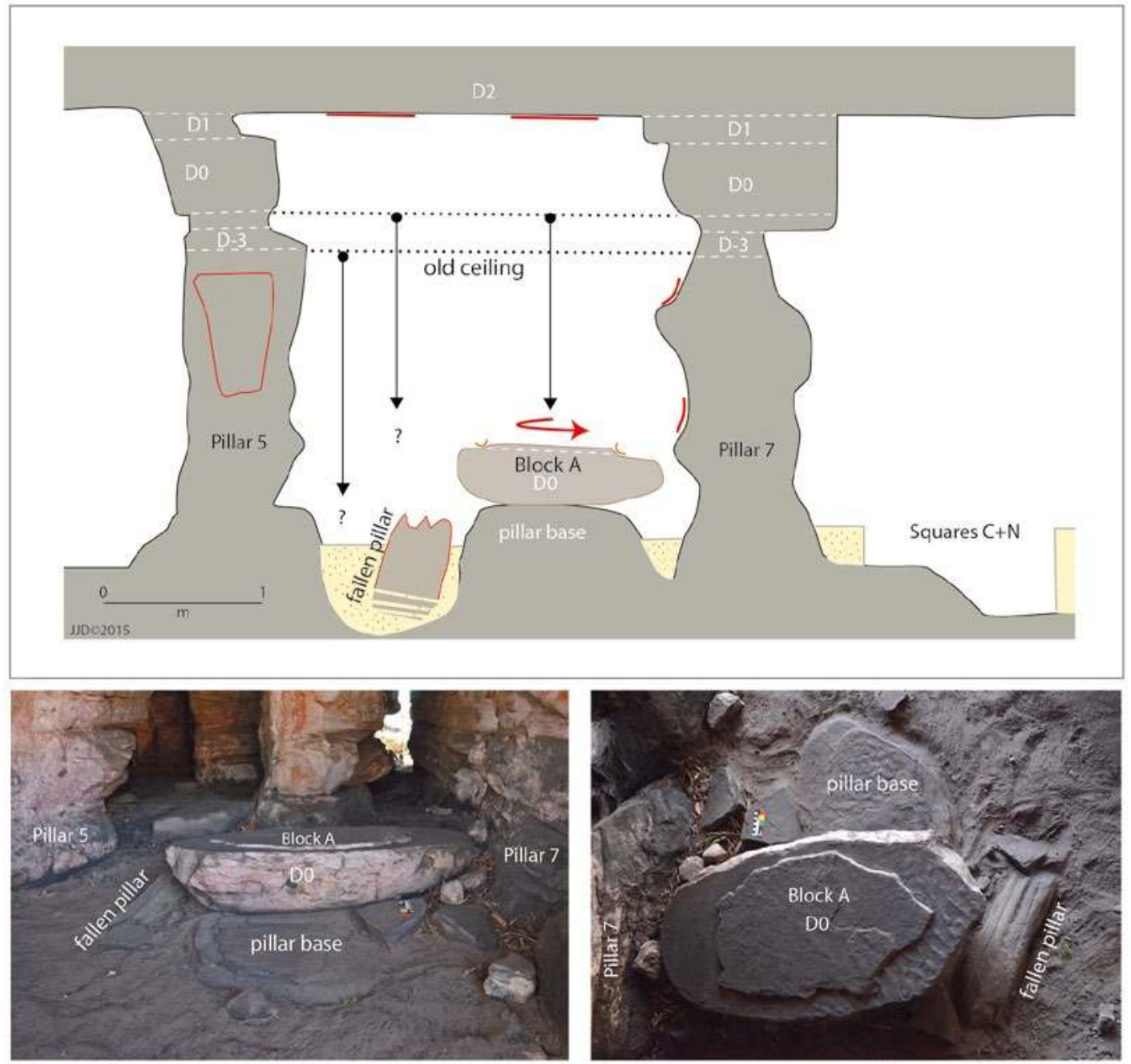

Figure 10.27 North-south transect across Alcove A in the southwestern sector.

Source: Photographs and illustration by Jean-Jacques Delannoy.

These observations, adding to others for the southwest sector of the site, highlight the important aménagement by people in the past. We can now determine that the pillars were removed before the collapse of ceiling strata, and that they were removed to outer parts of the site. In the studied southwestern sector, the fact that Block A (from stratum D0) rests directly on the footing (stratum D-13) of an ancient pillar indicates that pillar strata D-4 to D-12 had previously been removed from this part of the site, along with the blocks that fell from strata D-3 to D-1 higher up on the pillar.

Analysis of the collapsed blocks revealed: first, that people were directly implicated in removing collapsed blocks to areas immediately outside the site, in the process creating more open spaces in the cleared areas; second, the disappearance of pillars precedes the collapse of rock strata from the ceiling. The removal of blocks that had fallen from pillars was, in itself, due to the actions of people. It remains to be seen whether people just cleared fallen pillar blocks after they had collapsed naturally, or whether they intentionally removed standing pillars themselves. We now turn to this question. 


\section{The archaeomorphological study of pillars: The site's intentional aménagement}

In order to determine better human actions relating to the removal of pillars, three different states of pillar fragmentation were investigated. Do these states represent three different modes of operation, or three stages of a single strategy to expand the space within the site?

Let us first consider the base of an ancient pillar still clearly visible in the area of Alcove B. Located in the exact southern extension of extant Pillar 2 (Figures 10.28 and 10.29), this pillar base consists of a pedestal close to $2 \mathrm{~m}$ long $\times 1 \mathrm{~m}$ wide $\times 70-80 \mathrm{~cm}$ high. The pillar base corresponds with rock strata D-12 to D-10; it sits directly on top of the bedrock (whose upper level is stratum D-13). In this area, 15-20 cm thick blocks of rock are strewn flat across the floor. All exhibit percussion impact marks at their extremities (Figure 10.30). Petrographic study shows that they represent collapsed strata D-9 to D-6, which once lay on the extant pedestal. Blocks from the overlying strata are absent; they do not occur anywhere near the space of the ancient pillar. Taking into account the remnant base, extant ceiling and strewn blocks (Figures 10.25 and $10.28-10.30$ ), what is missing from the original pillar column are only strata D-5 and D-4. Here, a study of the positioning of the fallen blocks, including their morphologies and orientations at ground level, allows reconstruction of the sequence of actions that took place:

1. The dismantling of the different strata.

2. Their removal one-by-one from the area.

3. Their fragmentation into smaller pieces while on the ground.

4. Their removal to outer parts of the site.

The end-states created by this chaine opératoire are blocks of relatively homogeneous shape and size. We have previously discussed the presence of scree accumulations along the site's northern and southern entrances; here, the shape and size of blocks are regular, and they did not originate from nearby roof-fall or overhang collapse. Understanding the mode of operation relating to the removal of pillars informs equally on the origins of these accumulated blocks immediately outside the site. We will return to this association below when discussing the large volume of rock represented by four scree accumulations in relation to the creation of wide, open spaces within the archaeological site.

Other than this partially removed pillar, in the area of Alcove B, all other missing pillars have been entirely dismantled and removed from the area (Figure 10.25). This further brings to the fore the unfinished state of the partially dismantled pillar's removal. Does this signal the last throes of pillar removal and of the opening of space within the site? And, if so, when did this cessation take place? If its age precedes the last phases of human presence in the site, does it indicate a change in the conceptualisation, organisation and meaningfulness of space at Nawarla Gabarnmang? We will return to these questions below. 

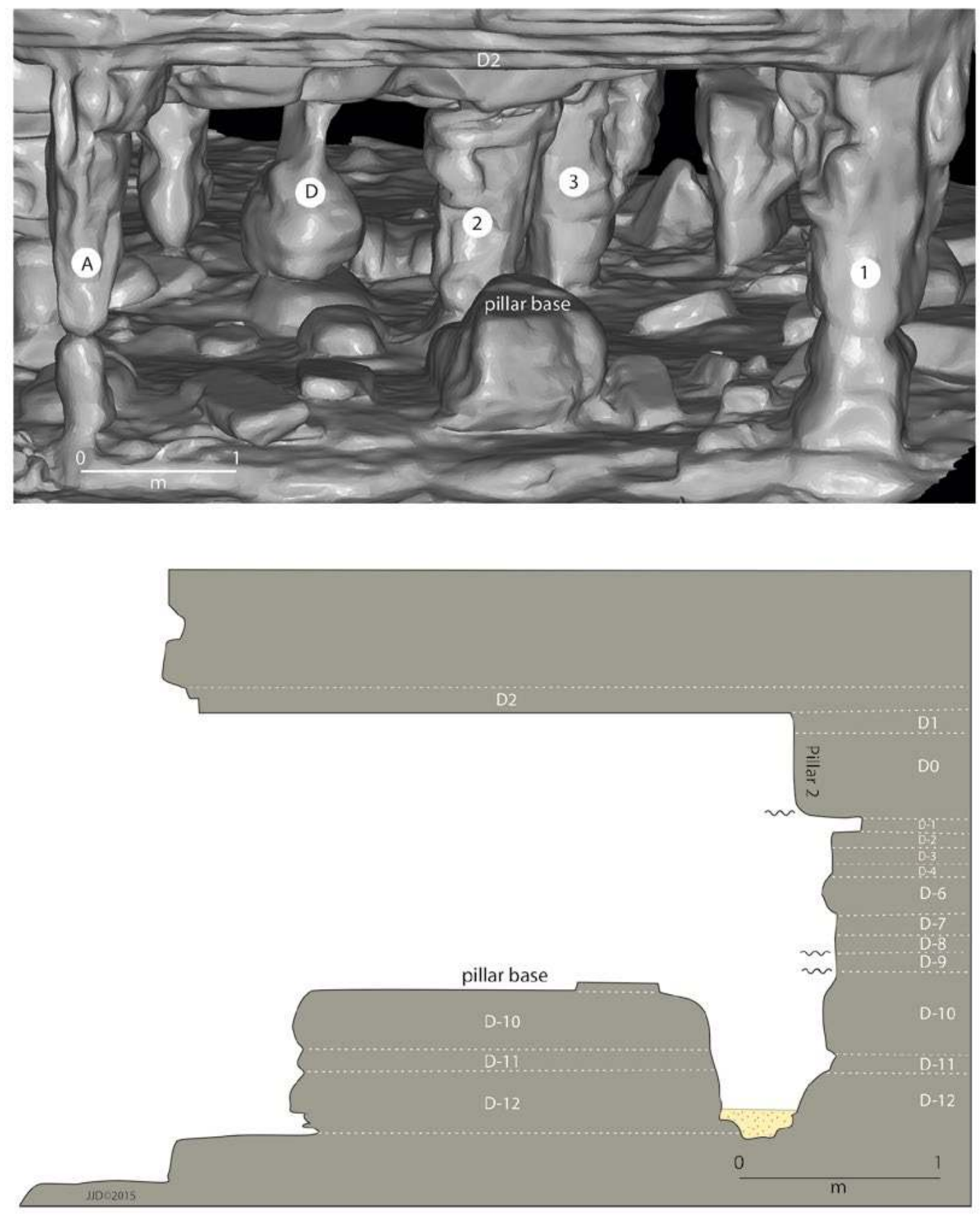

Figure 10.28 North-south transect across Alcove B, southwestern sector, as based on the laser 3-D model. This alcove retains elements of a partially dismantled pillar (including the 'pillar base'). Source: Illustration by Jean-Jacques Delannoy. 

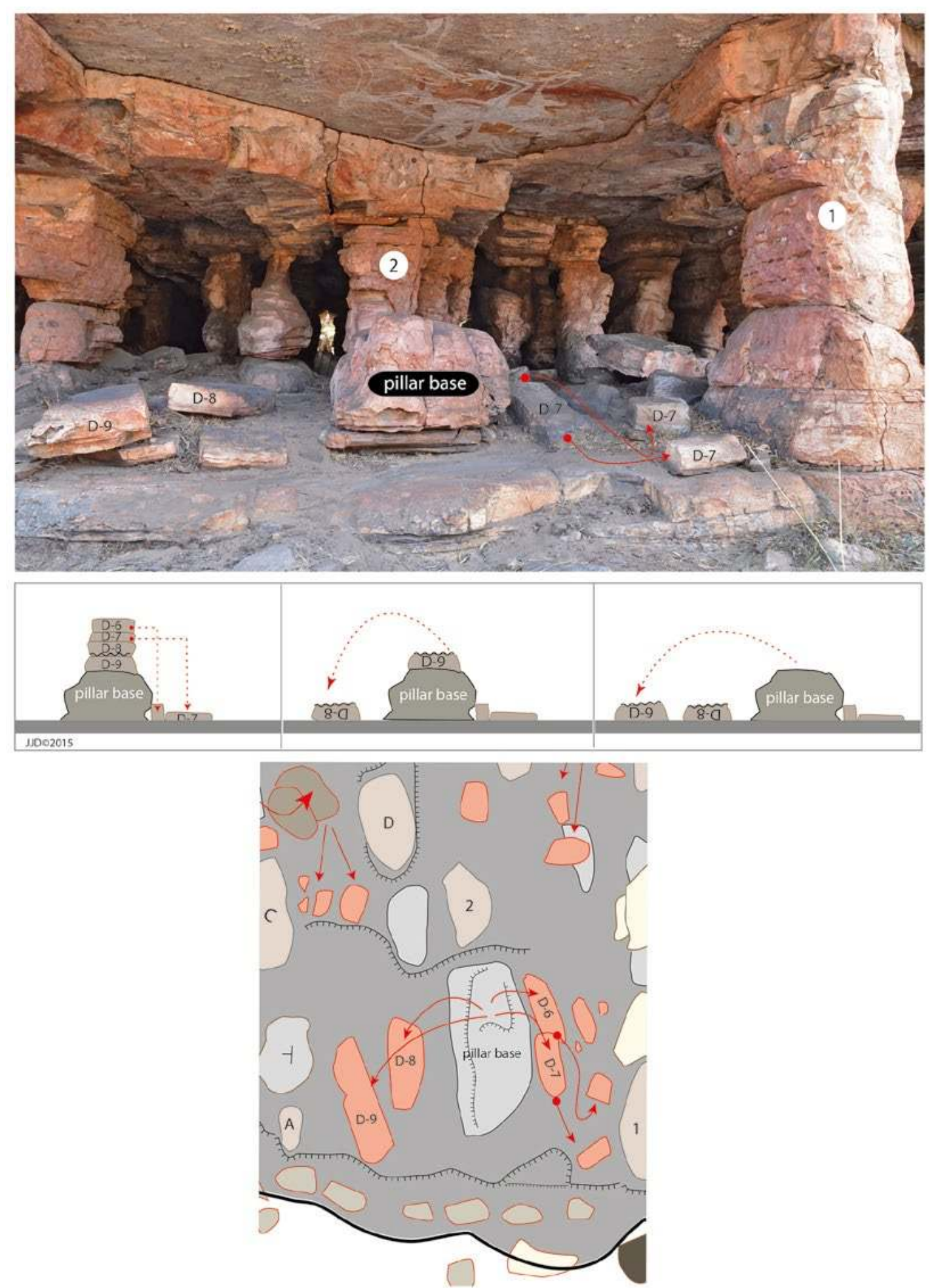

Figure 10.29 Photograph and reconstruction of sequence of events in Alcove B, southwestern sector. Source: Photograph and illustration by Jean-Jacques Delannoy. 


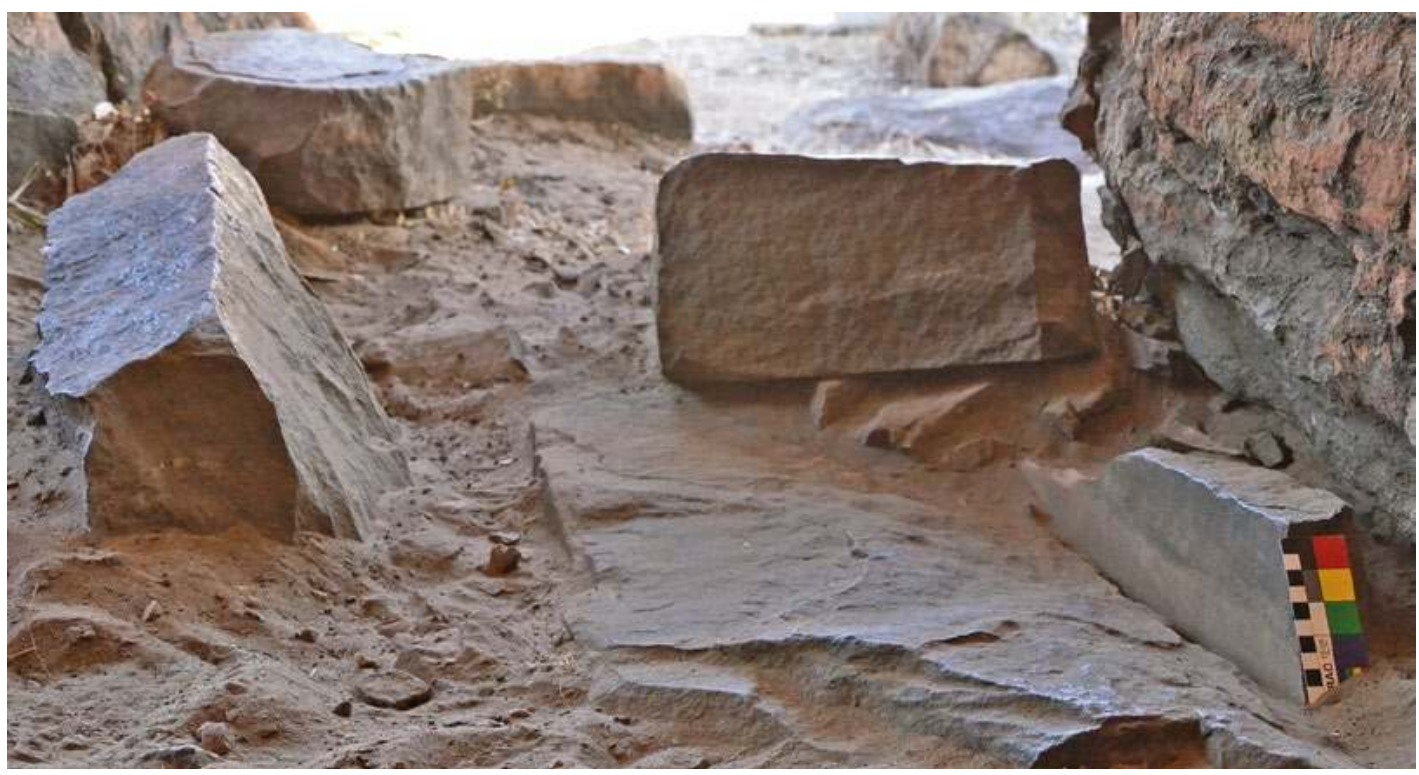

Figure 10.30 Strewn rocks on and near a remnant pillar base in Alcove B.

Source: Photograph by Jean-Jacques Delannoy.

Immediately north of the two alcoves discussed above, in the transition zone with the more enclosed space where pillars are more tightly packed (Figure 10.31), are a number of toppled pillars (see also Figure 10.25). Here the fallen blocks pertain to various states of dismantlement. In some cases, most of the strata making up the pillars are still present. In other cases, only the lower strata remain, the higher levels having been taken outside. Parts of these collapsed pillars can still be seen on the ground, lying between their original positions and the outside of the site. Again, we find indications that works in progress suddenly ceased; in this instance, toppled and dismantled blocks in the process of being removed were left behind on their way out of the site. The more we move away from these two alcoves in the southwestern sector of the site, the less the removal of toppled pillars appears to have been important. This spatial patterning of more or less dismantled and removed pillars suggests that, in the southwest of the site, spatial expansion was progressing northward. How this relates to what was happening in other parts of the site remains to be determined.

Finally, those blocks remaining on the ground indicate the systematic absence of the highest parts of pillars. This absence is a clue as to how the pillars were toppled. A pillar holding the weight of the ceiling cannot be toppled; it can only be tilted over if there exists a space between the pillar and the ceiling.

One possible sequence would start with removal of a less resistant rock stratum near ground level; we wondered if chemical alteration of the base of the pillar (e.g. through heightened humidity levels on the bedrock) caused that part of the pillar to weaken and the pillar to slump, creating a space between the top of the pillar and the ceiling. We searched for this kind of effect on all of the extant pillars across the site, but could find no trace of it.

A second approach to creating the needed void would be to remove the pillar's upper strata. Unambiguous evidence of this exists, again in the southwest sector of the site, where extant pillars show clear percussion impact marks on their uppermost, easily accessible sections. Partially removed upper sections of neighbouring pillars cannot be attributed to natural processes (Figures 10.32-10.34). This evidence confirms that it was indeed people who intentionally took these first steps, removing the upper parts of pillars, detaching them from the ceiling and toppling them, before dismantling them after they fell and taking the fragments outside the site. 


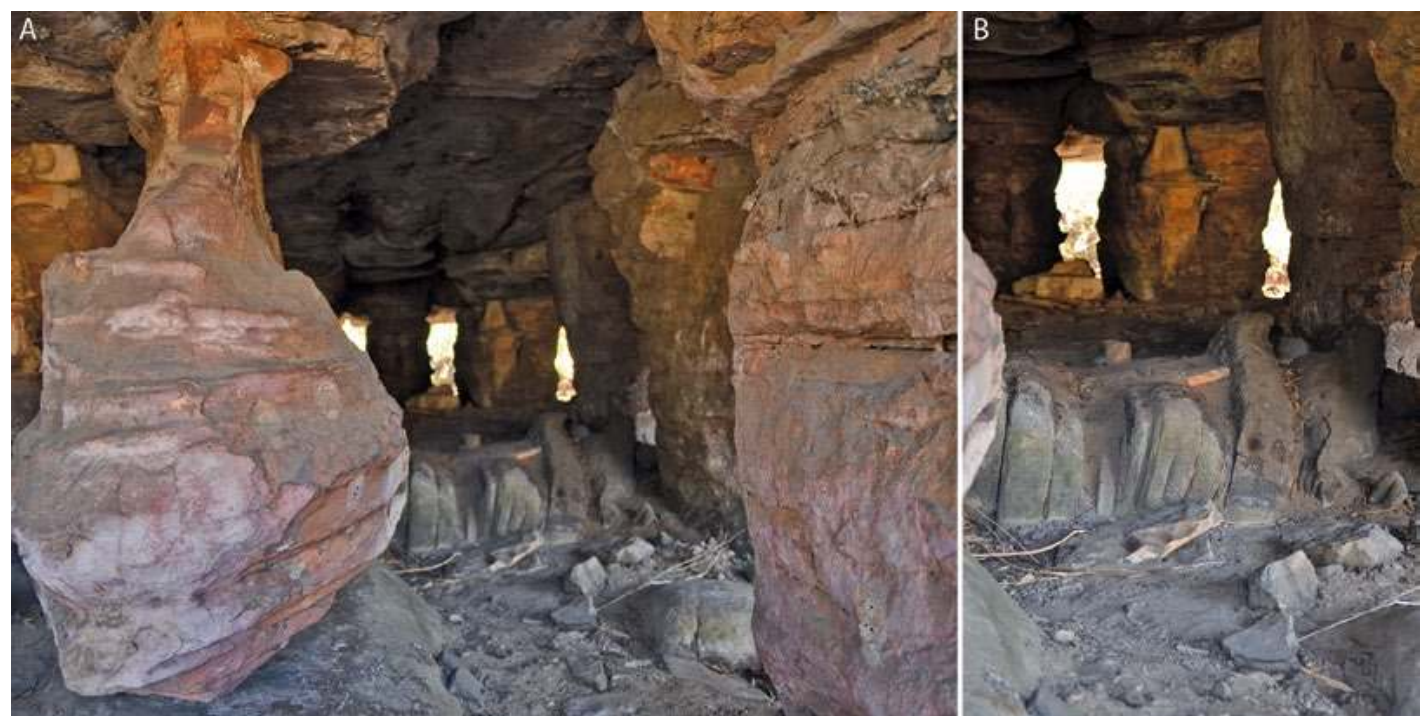

Figure 10.31 Transition zone between Alcoves A and B, and the darker, more close-knit pillar space immediately to the north, showing a toppled pillar on the floor in the mid-ground. Source: Photographs by Jean-Jacques Delannoy.
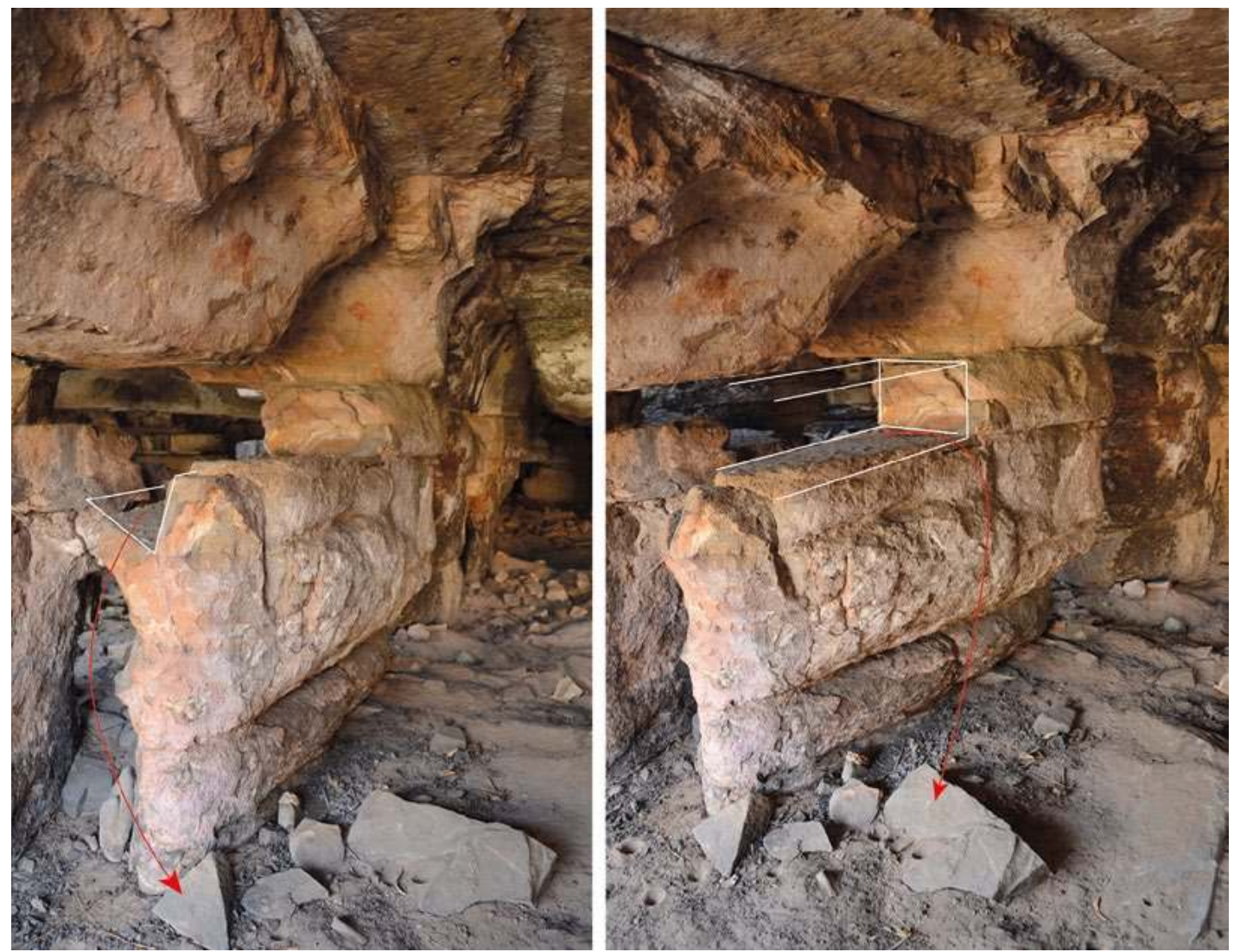

Figure 10.32 Partially removed pillar, with upper parts missing, southwestern sector. Source: Photographs by Jean-Jacques Delannoy. 

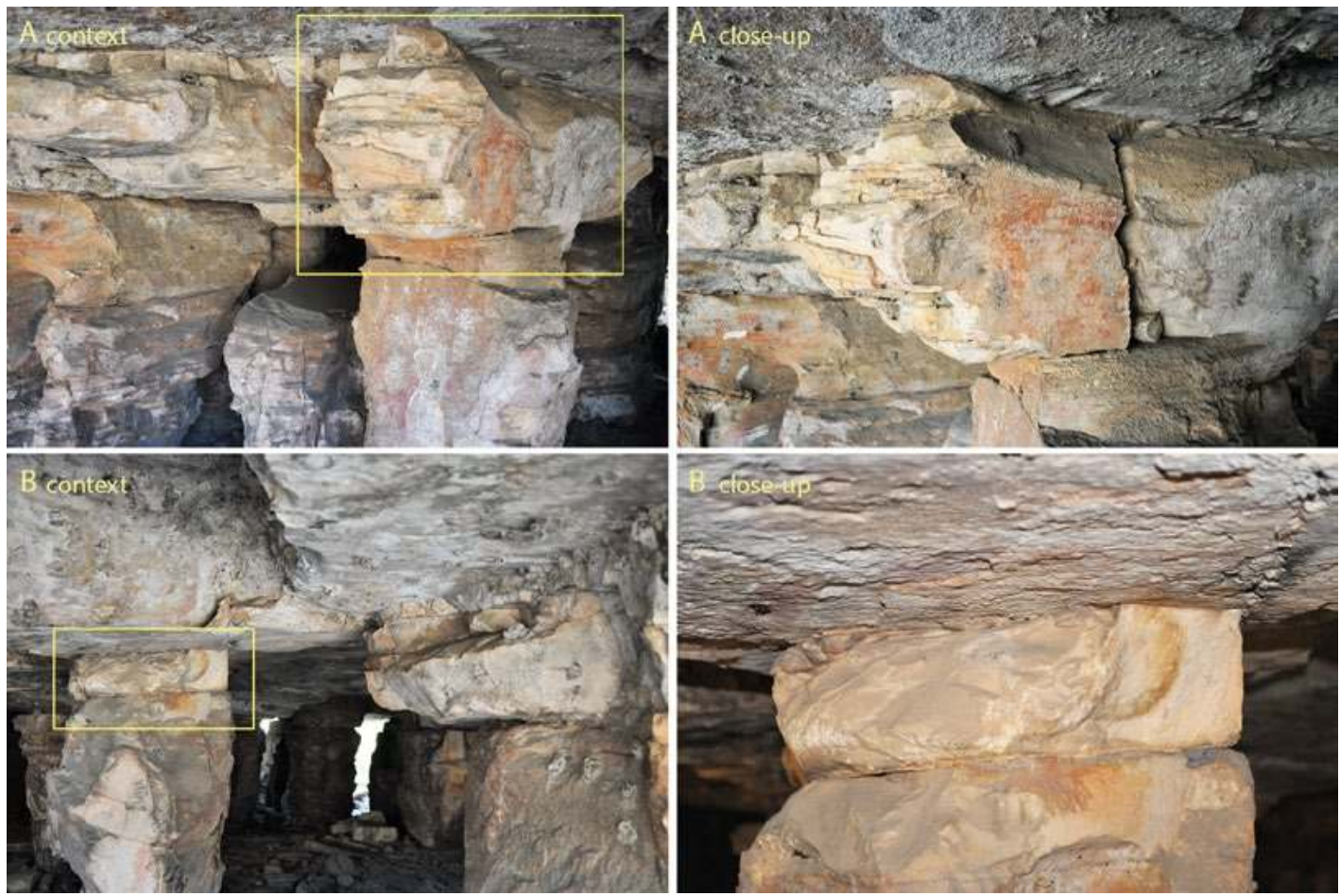

Figure 10.33 Two ways of removing the upper level of pillars prior to toppling, southwest sector of site. A: Sectioning by flaking of stratum D0 at top of a pillar. B: Gradual removal by flaking away of stratum D-1 at top of a pillar. Source: Photographs by Bruno David.

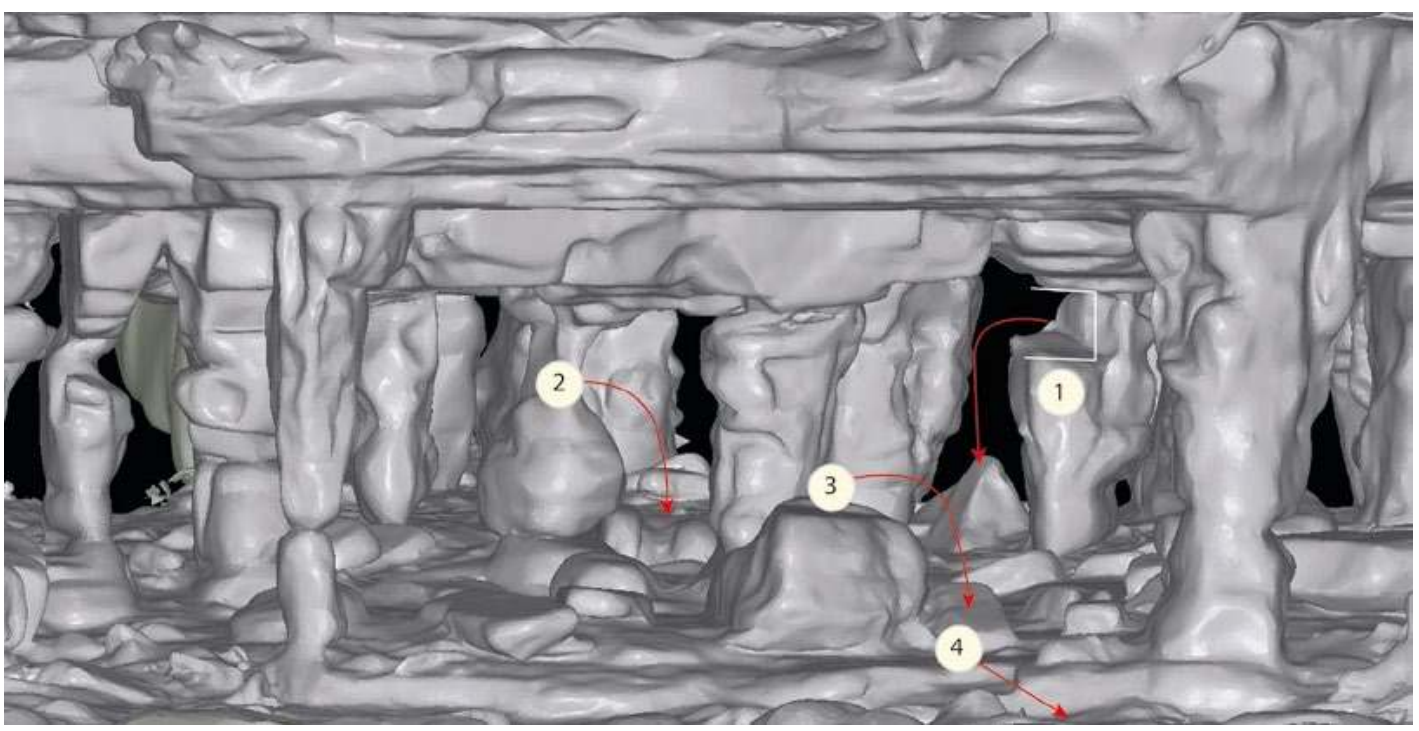

Figure 10.34 Alcove B in southwest sector, showing standing lower sections of pillars with upper sections missing (from laser 3-D model).

1: Upper part of pillar removed. 2: Toppled pillar. 3: Dismantling of pillar. 4: Removal of toppled pillar parts to outside the site. Source: Illustration by Jean-Jacques Delannoy. 
This sequence of events in the southwest sector of the site identifies Nawarla Gabarnmang's remarkable architecture as a feat of human engineering. It is an anthropic space, where material evidence of a historical sequence of human actions still lies on the ground. The pillars not completely removed, and the unfinished character of the site's construction makes us think that the southwestern sector is a space that began to be opened up later than elsewhere in the site.

\section{Understanding Nawarla Gabarnmang through archaeomorphology}

Archaeomorphological investigations have revealed clear material traces of Nawarla Gabarnmang as an actively refashioned and engaged space; its present configuration results from anthropic modifications of a natural pillarscape, in sequence:

1. The intentional removal of standing pillars by people.

2. The collapse of ceiling strata resulting from lack of support after the removal of pillars causing natural gravitational collapse or intentional removal by people.

3. The removal of toppled pillars and fallen ceiling strata onto scree deposits outside the northern and southern entrances of the site.

The volume of accumulated rock on the sum of the artificial scree deposits is proportional to the volume of the opened space within the site (that is, it is proportional to the sum of missing pillars and missing ceiling strata); its quantity is determined by volumetric calculations made from the 3-D model. Petrographic analyses of the scree blocks indicate that they came from removed pillars and collapsed ceiling strata, confirming that the blocks are a product of the opening of the site. They also show that the scree accumulated in a number of different phases, the phases representing the progressive removal of ceiling strata in particular. Rather than coming from a number of different strata, as would be expected of natural collapse of nearby overhangs, sections of the scree slope have accumulated rocks from single ceiling strata only; this indicates the accumulation of one stratum at a time, irrespective of the number of strata missing on the nearby extant ceiling. The spatial layout and patterns of superimposition of rocks originating from different ceiling strata now lying on the scree slopes signal that the most recent open spaces within the site are those of the contiguous central and central-eastern sector of the site, the zones where pillars are now most widely spaced.

Until now, we have focused on those processes that have led to the creation of Nawarla Gabarnmang's wide, open spaces. We now ask what the site would have looked like before people first came, or at least before people began removing rock pillars and transformed its layout. The internal space of the site - along with the entrance ways now made up of accumulated screes - has been so transformed that it is only those sectors exhibiting the least degrees of human modification where we can address this question. These sectors are those where the least number of pillars are missing and where the collapse of ceiling strata is so minimal that it is hardly noticeable: the western and northwestern sectors between Pillars 22-21-7-8-18. Here, in the northwestern sector, excavations in Squares $\mathrm{F}+\mathrm{I}+\mathrm{L}+\mathrm{M}$ and $\mathrm{D}+\mathrm{E}+\mathrm{J}+\mathrm{Q}+\mathrm{R}$ have revealed the oldest evidence of occupation. In the western and northwestern sectors, the ceiling art also appears to be more ancient in its styles than in the central and central-eastern sectors (see David et al. 2013, completed manuscript; Gunn 2016). It is also in the northwestern sector that highly weathered cupules are found on the vertical pillars; given the hardness of the quartzite, they undoubtedly have considerable antiquity. Excavations against those pillars have not yet commenced; we might there recover the tools used to make the cupules, and the crushed rock fragments caused by their manufacture. Like Squares A, D+H and $\mathrm{C}+\mathrm{G}+\mathrm{N}+\mathrm{K}$ in southwestern parts of the site, here we were curious to determine how the archaeological deposits sit relative to the bedrock, and whether they are preceded by earlier, pre-cultural deposits that could shed further light on the site's evolution. 

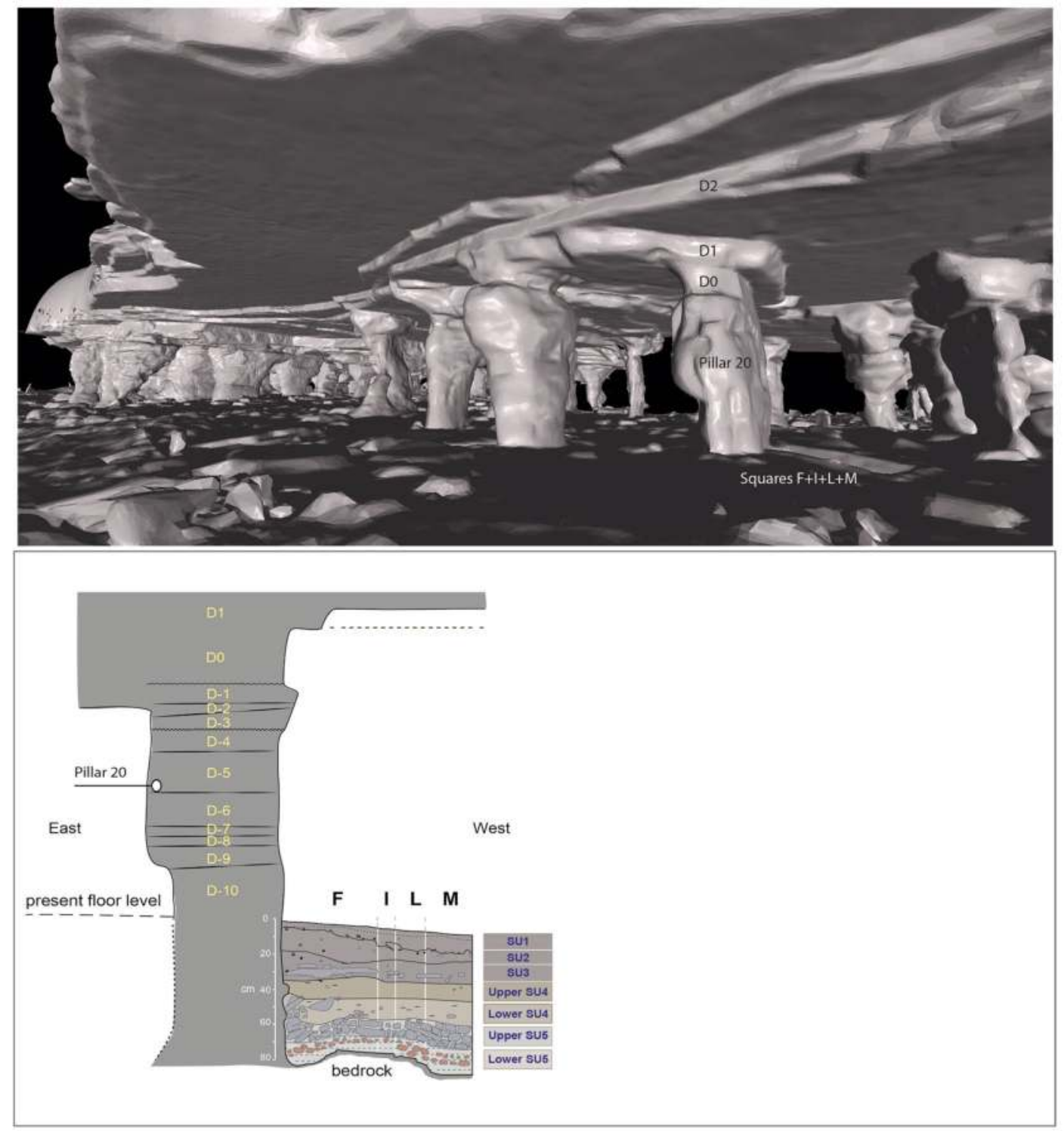

Figure 10.35 Area of contiguous Squares $F+l+L+M$, northwest sector, showing the stratigraphy along the south wall of the excavation against Pillar 20.

Source: Illustration by Jean-Jacques Delannoy.

Five major stratigraphic units (SU) are apparent in Squares $\mathrm{F}+\mathrm{I}+\mathrm{L}+\mathrm{M}$, each corresponding with one or more chronological phase. From the base upwards, the following chronostratigraphic sequence can be distinguished (for details, see David et al. completed manuscript) (Figure 10.35):

1. Lower SU5: At the base of the excavation, weathered quartzite lies immediately above the hard bedrock. This weathered quartzite represents the remains of ancient geological processes of phantomisation.

2. Upper SU5: Above the lower SU5 are found a layer of large rocks. Petrographic analysis indicates that they came from the collapse of ceiling stratum D1.

3. SU4: A layer of sand lies immediately above upper SU5. Granulometric and morphoscopic analyses of 5200 quartz grains from the contiguous Squares $\mathrm{I}+\mathrm{L}+\mathrm{M}$ sequence indicate that, unlike the sediment particles from underlying SU5, they overwhelmingly consist of aeolian sands. It is at the well-defined stratigraphic contact between upper SU5 and the base of SU4 
that the deepest and oldest stone artefacts are found at the site. Here, they have been dated to $47,200-51,700 \mathrm{cal}$ BP by AMS radiocarbon dating, and to slightly more than 50,000 years ago by single-grain OSL.

4. SU3: A mass of tabular blocks relates to a new phase of ceiling collapse; the age of this collapse was determined by radiocarbon dating of wood charcoal immediately below and immediately above the blocks. It dates to sometime between 17,936 $\pm 68 \mathrm{BP}$ (Wk-31713) and 19,601 $\pm 84 \mathrm{BP}$ (Wk-31714), equating to between 21,495 and 23,909 cal BP, taking the extreme ends of the 95.4 per cent probability calibration curves (with median probability ages of 21,734 cal BP and 23,619 cal BP, respectively).

5. SU2: This is overlain by a late Holocene layer of aeolian sand devoid of collapsed rocks but rich in stone artefacts and charcoal, with other artefactual materials such as ochre.

6. SU1: An upper level of culturally rich sandy sediments disturbed by treadage, dating to the past few hundred years.

These findings allow us to further refine our understanding of the site's evolution, including the role of people in its transformations. First, it allows us to imagine the site before the first arrival of people when the site exhibited a pillarscape similar to that seen today along the edge of the rock outcrop south of the site. At that time, the inter-pillar voids had already attained a height of 1.50$1.75 \mathrm{~m}$. The base of the void then corresponded with the weathered bedrock, and the top with the then-exposed surface of ceiling stratum D0. This natural pillarscape stood amidst labyrinthine passageways between the pillars. Some localised ceiling collapses had already taken place, but these were not spatially extensive. These collapses must have been greater along the edges than inside the site, by virtue of mechanical detent in the face of more open, less supported spaces.

This is what people saw when they first arrived at Nawarla Gabarnmang. Immediately upon this first arrival of people - as indicated by the deepest stone artefacts in Squares $\mathrm{F}+\mathrm{I}+\mathrm{L}+\mathrm{M}-$ the sediments began to take on a markedly different character, as considerable quantities of windblown sands were deposited, for which there was no previous evidence. During the period of human presence, the earliest ceiling collapse dates to between 21,495 and 23,909 cal BP. As this is in a sector of the site somewhat distant from the open spaces of the centre and eastern-centre where the main pillar removals and ceiling collapses took place, we do not know when those wide, open ceilings collapsed (Figure 10.36).

The chronological schema in the northwestern sector of the site compares well with that of the southwest. In both cases, the earliest layers of rock lying on or in the ground originated from the collapse of ceiling stratum D0, and on rare occasions stratum D1, representing the lowermost ceiling levels that join(ed) immediately onto the pillars. When people first arrived, this indicates, the exposed ceiling at or near both the northern and southern entrances consisted of strata D1 or D2 surfaces. The earliest evidence of ceiling collapse during the period of human presence occurred sometime between c. 33,998-35,129 cal BP (oldest evidence of roof-fall in cultural layers of Square D) and 11,624-12,024 cal BP (age of the dated wasp nest in southwestern sector); the phase of roof-fall dated to between 21,495 and 23,909 cal BP in Squares F+I+L+M also falls nicely within this time frame, as does all of the other evidence of roof-fall in Squares $\mathrm{A}, \mathrm{C}+\mathrm{G}+\mathrm{K}+\mathrm{N}, \mathrm{D}+\mathrm{H}, \mathrm{E}+\mathrm{J}+\mathrm{O}+\mathrm{Q}+\mathrm{R}$ and possibly $\mathrm{P}$. This broad window of time is important evidence for how people engaged with the site. If we can determine when during this time frame various ceiling levels collapsed across different parts of the site, we can construct a finer-grained spatial history for the site as a whole - a research in progress. In the meantime, we can now specify that across the site, the evidence indicates roof collapse only before c. 11,000 cal BP, the uncertainty of the age of the slab at the base of Square P notwithstanding (see Chapter 11). The age of the dated wasp nest on rock art Panel A3 in Alcove B in the southwestern sector of the site is consistent with these findings. 

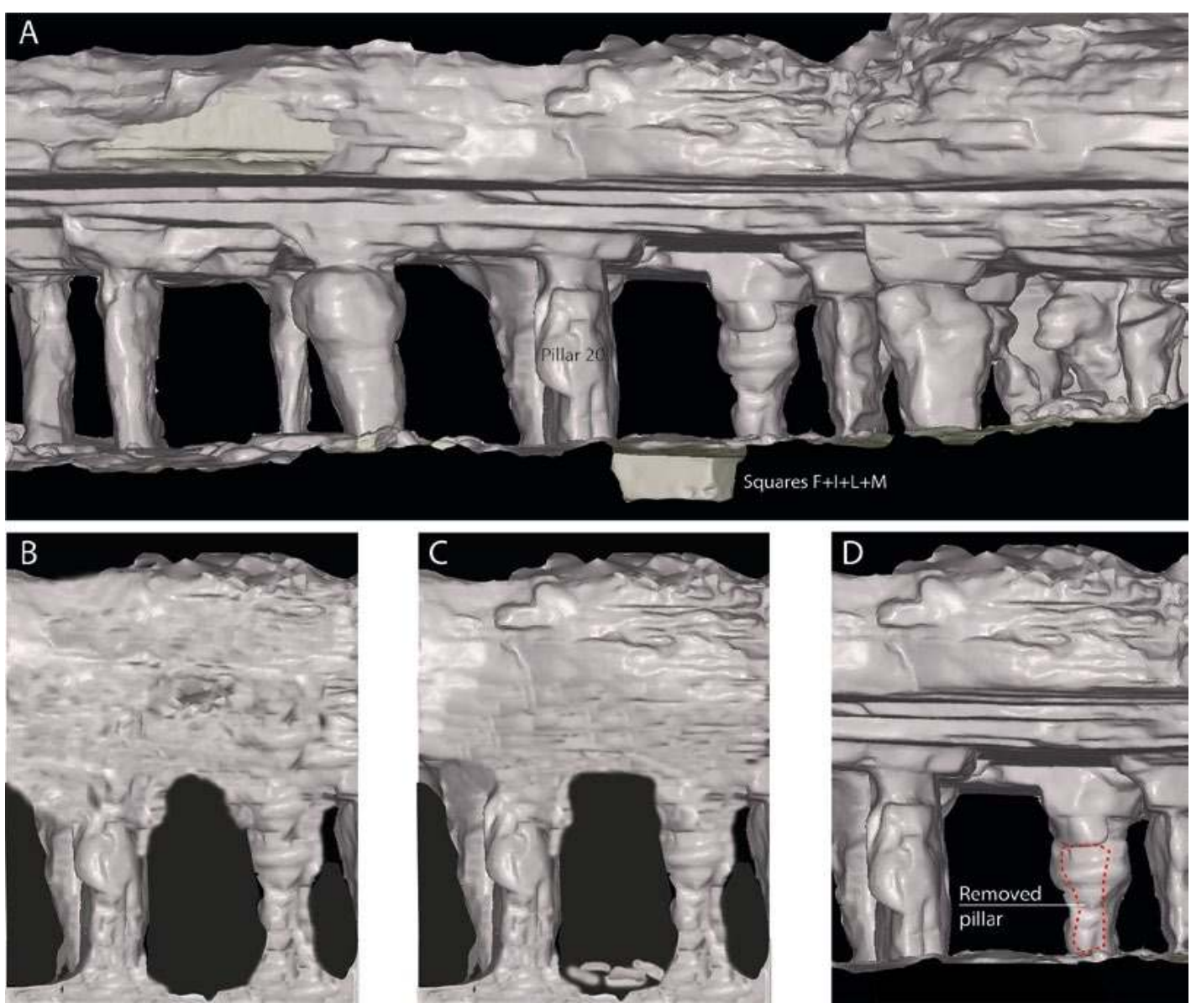

Figure 10.36 Area of contiguous Squares $\mathrm{F}+\mathrm{I}+\mathrm{L}+\mathrm{M}$ in the 3-D model, northwest sector, showing the natural accumulation of fallen rocks on the ground prior to human arrival $(B, C)$ followed by a more elevated floor caused by the accumulation of aeolian sands and removal of pillar during the period following the first arrival of people (D).

Source: Illustration by Jean-Jacques Delannoy.

These integrated geological (identification of rock strata, etc.) and geomorphological (study of the excavated sediments, etc.) and archaeological results enabled us to determine:

- What the site looked like at the time of first human arrival; a dense pillarscape with voids already $1.50-1.75 \mathrm{~m}$ in height.

- That when the first people arrived, the bedrock was not flat, but rather consisted of an undulating surface with numerous fissures largely infilled with weathered, gravelly sediments. In localised places, the ground was covered with blocks that had naturally collapsed from low ceiling.

- A general phase of ceiling collapse across more or less the entire area where archaeological excavations have been undertaken. This phase pre-dates c. 11,000 cal BP, but post-dates $35,000 \mathrm{cal} \mathrm{BP}$ at most (and probably began more recently than this, likely no earlier than c. 23,000 cal BP). The art on the most recently exposed ceiling surfaces, such as Panel A3 where the most recent signs of anthropic modification have been found for the site, is probably younger than 11,000 cal BP (see Gunn 2016).

- An entire Holocene phase of human occupation (evident in stratified artefacts dated by radiocarbon dates on wood charcoal) during which there is no evidence at all of further major transformations to the site, the uncertain age for the rock slab at the base of Square P notwithstanding (i.e. the ceiling ceases to collapse). 
This sequence of events from the northwestern sector of the site contrasts with the evidence from the southwestern sector for what appears to be the sudden cessation of the toppling of pillars, fragmentation of large rocks on the ground and removal of manageable blocks to outer parts of the site. This difference in human engagements across space and through time leads us to ask if they signal different modes of inhabitation for the site as a whole through time, or, rather, if they relate to different levels of preservation of archaeological materials. Two options are possible at this stage of analysis:

1. People first began to use the western sector of the site, as indicated by the distribution of earliest archaeological deposits across the site (cf. David et al. 2013, completed manuscript) and possibly by the location of the very heavily patinated cupules. The pillarscape in this western space has not been altered very much, with only rare pillars and only the lowermost ceiling strata (D0 and sometimes D1) having been removed. Human engagement then shifted further to the east in an intensive phase of modification with vast spaces created by the removal of pillars and collapsed ceiling strata.

2. All of the site has been occupied since the earliest phases of occupation. The removal of pillars and ceiling strata largely in the contiguous central and central-eastern sector of the site has removed any archaeological traces, including rock art, on those rock surfaces, and possibly on the floors as well. The oldest evidence of human presence has survived only in those sectors that did not witness the clearance of pillars and heightening of the ceiling level, that is, on the western side. Under this scenario, older cultural sediments were eroded out of those parts of the site with wide, open spaces by a combination of wind activity through the site and human (and animal) traffic, which through treadage and other activities repeatedly destabilised ancient surface sediments. Alternatively, ancient information remains preserved under collapsed ceiling strata that had not been removed, or that were only partly removed, from the ground, such as those at the base of the Square P excavations (see Chapter 11).

We cannot determine with the available evidence which of these best explains the spatio-temporal patterning of human presence across the site. New research involving excavation is required.

\section{Conclusion}

Detailed geological and archaeomorphological investigations at Nawarla Gabarnmang have revealed aspects of the site's history never previously encountered - or at least, never reported - at an Australian archaeological site: the intentional manipulation and transformation of the material fabric of the site - its rock walls and ceiling - dramatically to open up its interior space.

The question remains, why? - a more difficult question than the 'what', 'when', 'how' and 'where' that we have tried to address in this chapter. At this stage of analysis, it is clear that limited parts of the site were quarried for rock for the manufacture of stone tools, as is evident at many occupied rockshelters on the Arnhem Land plateau. But this sourcing of stone cannot explain the broad-scale toppling and removal of pillars and collapsed ceiling strata, which in the main do not exhibit traces of targeted quarrying, or why the fallen blocks were dumped outside the site rather than worked for stone tools (unless they were some kind of stockpile). In a similar vein, while the extant ceiling strata are today extensively painted, this does not appear to have been the case deeper in antiquity; the older surfaces do carry art, but nowhere as expansively or as densely as during the latter half of the past millennium (see Chapter 12; see also Gunn 2016). The buried archaeological evidence across the site also indicates a massive proliferation of small fragments of imported pigment late in the Holocene, further suggesting that making art with pigment was less common during earlier times. And last but not least, at Nawarla Gabarnmang much of the earliest art occurs on pillars rather than on horizontal ceilings - as indicated, for instance, by the cupules on Pillars 23 and 28 (Figure 10.37), 
and the only Dynamic Figure seen at the site (Figure 10.38) on the pillar of a slightly isolated alcove (other Dynamic Figures occur in other rockshelters within one to two minutes' walking distance). If upright pillar surfaces were preferred during early art phases, it would not make sense to topple those pillars and so create additional horizontal ceiling surfaces, remembering that the site contains numerous undecorated or poorly decorated pillars, and that pillar clearance appears only to have taken place during Pleistocene times (see above).

This leaves the expansion of the site's internal space as being for that reason, the opening-up of the sheltered space itself. We can conjecture specific motivations for this: To follow cosmological imperatives? To shelter from monsoonal rains? To create greater social space for community dwelling?
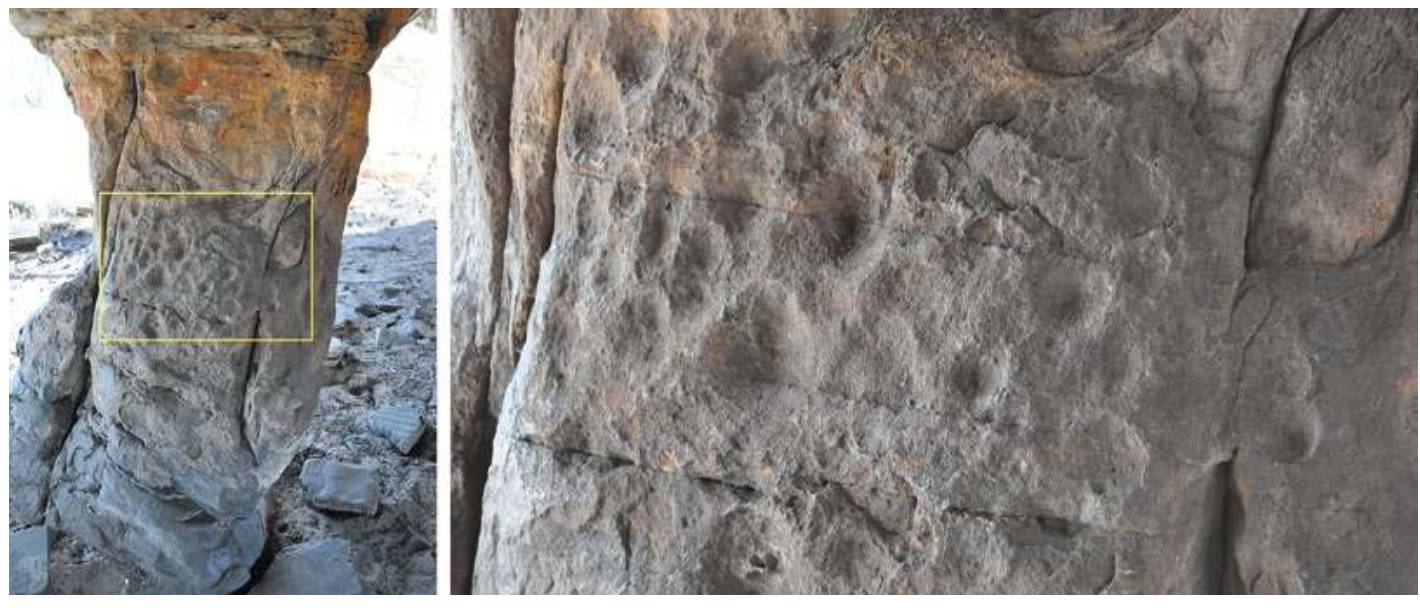

Figure 10.37 Heavily weathered cupules on the western side of Pillar 28.

Source: Photographs by Bruno David.
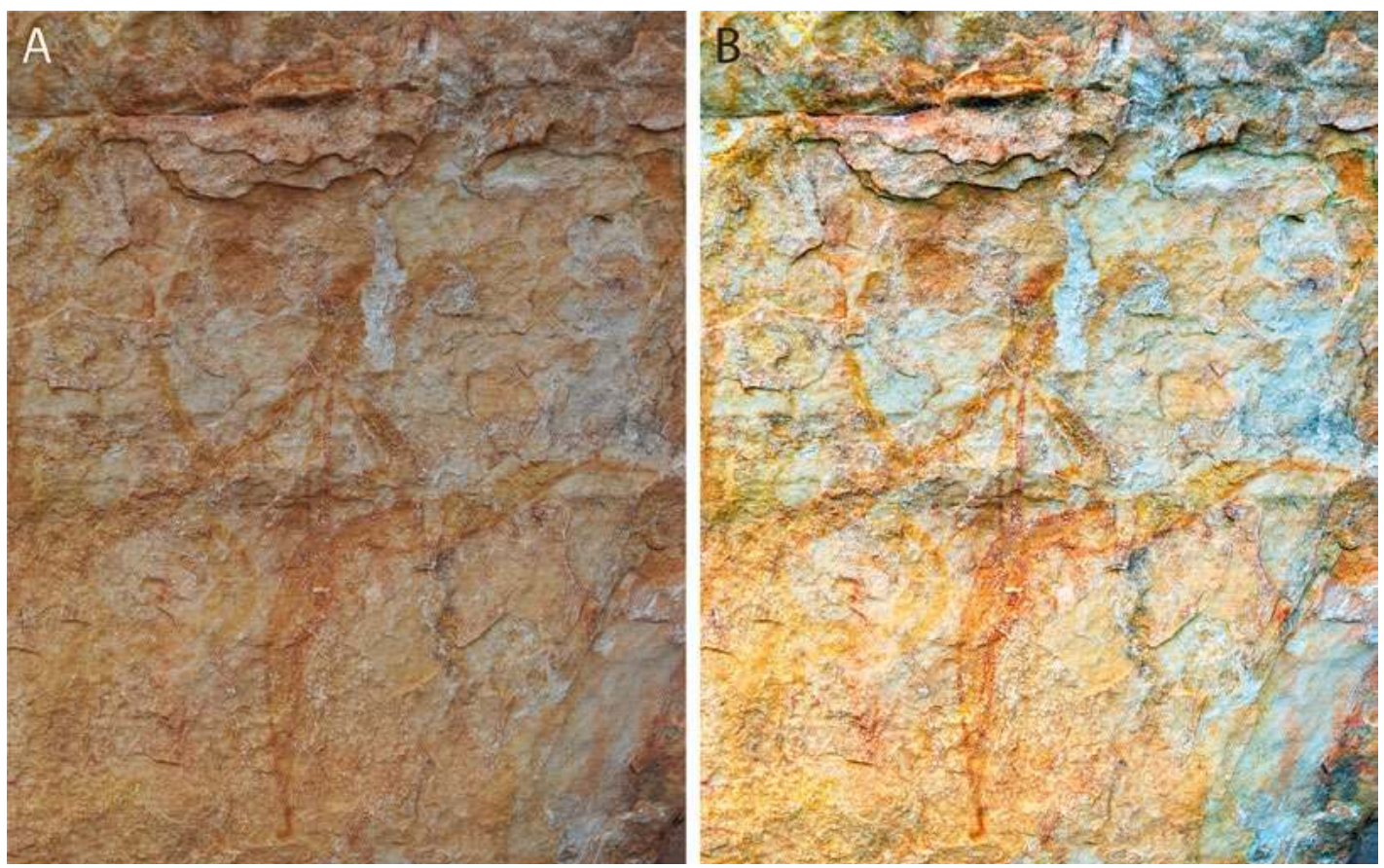

Figure 10.38 Dynamic Figure carrying boomerangs, Nawarla Gabarnmang.

A: Original photograph. B: Digitally enhanced photograph.

Source: Photographs and enhancement by Bruno David. 
That we can recount this spatial history of Nawarla Gabarnmang is made possible by our novel, closely integrated archaeomorphological approach to the site's material fabric, geological history and archaeological evidence. We doubt the key details of human inhabitation would have been noticed without that approach. This integrated vision has revealed, in the context of a geologically ancient, phantomised pillarscape, some 50,000 years of human presence beginning with initial landscape encounters and low-level occupation, followed much later during the terminal Pleistocene with evidence for complex engineering feats that turned a natural site into a constructed, architectural space. During this phase of history, the site's material fabric was dramatically modified as its internal space was gradually opened up by people, until suddenly - it appears - pillars were toppled and cleared for the last time shortly before 11,000 years ago.

Why people seem to have suddenly abandoned this clearance in the southwestern sector of the site remains a mystery. Nawarla Gabarnmang as we know it today is not the only rockshelter that witnessed clearances in the past: nearby, abutting the western side of the site's southwestern sector, a second rockshelter once stood, a now-collapsed sheltered entrance into the site via the courtyard to the south (Figure 10.39). We know that pillars had also been removed in that longgone shelter; while the large mass of tumbled rocks show evidence of past pillars, its configuration is not staggered as a collapsed pillarscape would be. We are tempted to see the shock of that collapse as the stimulus for the final abandonment of pillar clearances at Nawarla Gabarnmang. A detailed archaeomorphological research of that western, former shelter might tell us if its collapse was contemporaneous with the cessation of pillar clearance in the southwestern sector of Nawarla Gabarnmang.

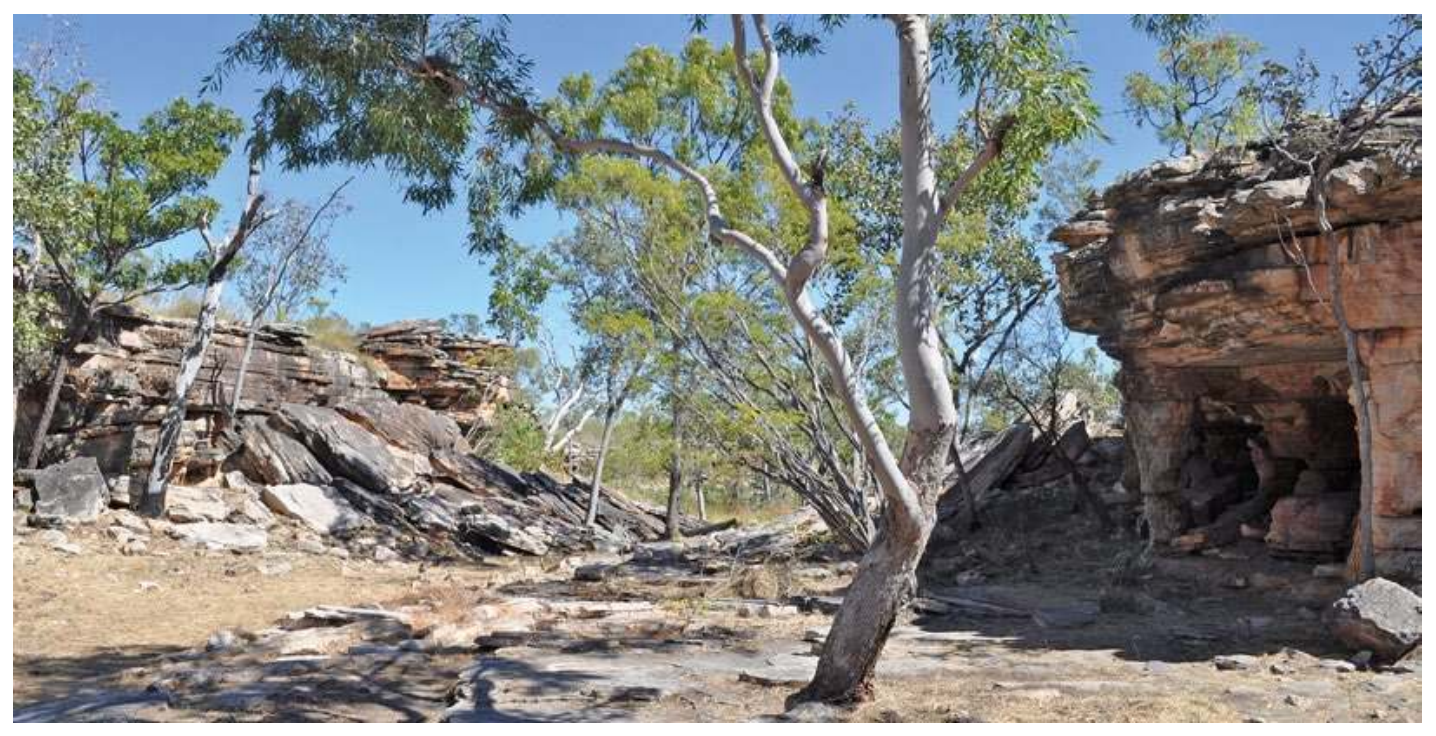

Figure 10.39 The collapsed rockshelter that once formed the entry way into the courtyard from the southwest of the extant Nawarla Gabarnmang.

The southwestern sector of the current site, as discussed in this chapter, can be seen on the right-hand side of the photograph. Source: Photograph by Bruno David.

Our archaeomorphological study of Nawarla Gabarnmang challenges us to think in new ways about how Aboriginal people interacted with their surroundings; here, a site of everyday engagement was a place of construction that retains material traces of those past engagements. While the scope and scale of activities during the era of pillar clearances at Nawarla Gabarnmang ended many thousands of years ago, other practices flourished, of which Arnhem Land's complex sequence of rock art conventions is an apt example. These artistic transformations, much like the era of pillar clearances long gone, are a clear answer to the kinds of critique that are sometimes 
made of archaeological stories - that they create an Aboriginal history that simply transfers ethnography progressively deeper into the past; that a present is 'historicised' by making that past a timeless image projected back from the first ethnographic encounters.

\section{Acknowledgements}

We thank Margaret Katherine and family, Wes Miller, Ray Whear and the Jawoyn Association Aboriginal Corporation for asking us to undertake archaeological research at Nawarla Gabarnmang. Thanks to Bryce Barker (University of Southern Queensland), Elisa Boche, Lara Lamb (University of Southern Queensland), Magen O'Farrell, Stéphane Hoerlé, Daniel James (Monash University), Jacqueline Matthews (University of Western Australia) and Chris Urwin (Monash University) for helping with the excavations; Kara Rasmanis (Monash University) for drafting Figure 10.1 and parts of Figure 10.3; and A.L. Develle (EDYTEM, Université de Savoie, France) for the XRF core scanner analysis (Figure 10.15). We thank the Australian Research Council for Linkage grant LP110200927 and Discovery grants, QEII and Discovery Outstanding Research Award (DORA) Fellowships DP0877782 and DP130102514.

\section{References}

Armstrong, R., L. Osborne, W.S. Weliange, P. Jayasingha, A.S. Dandeniya, A.K.P.P. Algiriya and R.E. Pogson 2013. Caves and karst-like features in Proterozoic gneiss and Cambrian granite, southern and central Sri Lanka: An introduction. Acta Carsologica 42(1):25-48.

Carson, L.J., P.W. Haines, A. Brakel, B.A. Pietsch and P.A. Ferenczi 1999. Milingimbi SD53-2, 1:250 000 Geological Map Series Explanatory Notes. Northern Territory Geological Survey, Government Printer of the Northern Territory, Darwin.

David, B., J.-J. Delannoy, R. Roberts, Z. Jacobs, B. Brook, J.-M. Geneste, F. Petchey, J. Mialanes, T. Richards, B. Barker, M.I. Bird, C. Clarkson, E. Boche, S. Hoerlé and M. Katherine completed manuscript. Human colonisation of Sahul prior to fifty-one thousand years ago.

David, B., J.-M. Geneste, R.L. Whear, J-J. Delannoy, M. Katherine, R.G. Gunn, C. Clarkson, H. Plisson, P. Lee, F. Petchey, C. Rowe, B. Barker, L. Lamb, W. Miller, S. Hoerle, D. James, E. Boche, K. Aplin, I.J. McNiven, T. Richards, A. Fairbairn and J. Matthews 2011. Nawarla Gabarnmang, a 45,185 \pm 910 cal BP site in Jawoyn Country, southwest Arnhem Land Plateau. Australian Archaeology 73:73-77.

David, B., B. Barker, F. Petchey, J.-J. Delannoy, J-M. Geneste, C. Rowe, M. Eccleston, L. Lamb and R. Whear 2013. A 28,000 year old excavated painted rock from Nawarla Gabarnmang, northern Australia. Journal of Archaeological Science 40:2493-2501. doi.org/10.1016/j.jas.2012.08.015

David, B., B. Barker, J.-J. Delannoy, J-M. Geneste, F. Petchey and L. Lamb 2014. A Pleistocene charcoal drawing or painting from northern Australia. INORA 69:18-22.

Delannoy, J.-J., B. David, R. Gunn, J.-M. Geneste and S. Jaillet 2017. Archaeomorphological mapping: Rock art and the architecture of place. In B. David and I.J. McNiven (eds), The Oxford Handbook of the Archaeology and Anthropology of Rock Art. Oxford University Press, Oxford.

Delannoy, J.-J., E. Debard, C. Ferrier, B. Kervazo and Y. Perrette 2001. Contribution de la cartographie morphologique souterraine dans l'étude spéléogénique de la grotte Chauvet: Implications paléogéographiques, préhistoriques et paléontologiques. Quaternaire 12:235-248. doi.org/10.3406/ quate.2001.1696 
Delannoy J.-J., Y. Perrette, E. Debard, C. Ferrier, B. Kervazo, A.S. Perroux, S. Jaillet and Y. Quinif 2004. Intérêt de l'approche morphogénique pour la compréhension globale d'une grotte à haute valeur patrimoniale: La grotte Chauvet (France). Karstologia 44:25-42.

Delannoy, J.-J., B. David, J.-M. Geneste, M. Katherine, B. Barker, R.L. Whear and R.G. Gunn 2013. The social construction of caves and rockshelters: Chauvet Cave (France) and Nawarla Gabarnmang (Australia). Antiquity 87:12-29. doi.org/10.1017/S0003598X00048596

Erhard, H. 1967. La Genèse des Sols en Tant que Phénomènes Géologique. Masson, Paris.

Ferenczi, P.A. and I.P. Sweet 2004. Mount Evelyn, Northern Territory 1:250 000 Geological Map Series, SE53-05 (Second Edition). Northern Territory Geological Survey, Darwin.

Geneste, J.-M., B. David, H. Plisson, C. Clarkson, J.-J. Delannoy, F. Petchey and R. Whear 2010. Earliest evidence for ground-edge axes: 35,400 410 cal BP from Jawoyn country, Arnhem Land. Australian Archaeology 71:66-69. doi.org/10.1080/03122417.2010.11689385

Geneste, J.-M., B. David, H. Plisson, J.-J. Delannoy and F. Petchey 2012. The origins of ground-edge axes: New findings from Nawarla Gabarnmang, Arnhem Land (Australia) and global implications for the evolution of fully modern humans. Cambridge Archaeological Journal 22:1-17. doi.org/10.1017/ S0959774312000017

Gunn, R.G. 2016. Art of the Ancestors: Spatial and Temporal Patterning in the Rock Art of Nawarla Gabarnmang, a Major Jawoyn Cultural Site on the Arnhem Land Plateau. Unpublished PhD thesis. Monash University, Clayton.

Joly, F. 1977. Point de vue sur la géomorphologie. Annales de Géographie 86(477):522-541. doi.org/ 10.3406/geo.1977.17626

Jones, R. (ed.) 1985. Archaeological Research in Kakadu National Park. Special Publication 13. Australian National Parks and Wildlife Service, Canberra.

Martini J.E.J. and K.G. Grimes 2012. Epikarst maze cave development: Bullita Cave system, Judbarra/ Gregory karst, tropical Australia. Helictite 41:37-66.

Quinif, Y. 2010. Fantômes de Roche et Fantômisation. Essai sur un Nouveau Paradigme de Karstogénèse. Karstologia Mémoires, Volume 18. Association Française de Karstologie, Mons. 



\title{
11
}

\section{Dating painted Panel E1 at Nawarla Gabarnmang, central-western Arnhem Land plateau}

\author{
Bruno David, Jean-Jacques Delannoy, Robert Gunn, Emilie Chalmin, \\ Géraldine Castets, Fiona Petchey, Ken Aplin, Magen 0'Farrell, \\ Ian Moffat, Jerome Mialanes, Jean-Michel Geneste, Bryce Barker, \\ Benjamin Sadier, Margaret Katherine, Meropi Manataki and \\ Ursula Pietrzak
}

\section{Introduction}

The southern Arnhem Land plateau contains a rich mosaic of thousands of rock art sites located in outcrops of Proterozoic Marlgowa Sandstone of the Kombolgie formation (Carson et al. 1999) (Figure 11.1). Within this region in Jawoyn Country can be found Nawarla Gabarnmang, an impressive rockshelter exhibiting a gridded network of pillars that supports a thick ceiling of $10 \mathrm{~cm}$ to $40 \mathrm{~cm}$ thick cross-beds of hard sandstone and quartzite (Figures 11.2 and 11.3; see also Chapter 10). The inter-layer joints and fissures between these compact and poorly soluble quartz-rich sandstones and quartzites have witnessed geologically slow dissolution of the bedrock, resulting in a hollowing out of the rock in a process known as 'ghost rock' formation or 'phantomisation' (Quinif 2010), a particular cave-forming process causing the regular gridshaped structure of underground cavities and pillars (for details of site formation processes, see Chapter 13).

The remnant pillars supporting ceiling rock strata at Nawarla Gabarnmang are an anthropic cave structure (Delannoy et al. 2013; see Chapter 10): in addition to the slow geological dissolution of the rock along layer planes and fissure lines, people have also entirely or partially removed individual pillars, and possibly ceiling strata, over a period commencing sometime after the site was first occupied around 50,000 years ago (e.g. David et al. 2011, completed manuscript). What catches one's attention at Nawarla Gabarnmang are the voids between the pillars, typically c. 1-2 $\mathrm{m}$ apart in the southwestern corner of the site, but more than $8 \mathrm{~m}$ apart in the centraleastern portion. In that noticeably more open central-eastern area, a large, sub-horizontal and flat ceiling is supported by some 20 sparsely distributed pillars. Here, as in most other parts of the site, the floor of the sheltered area is generally flat and sub-horizontal, consisting of ashy sand with sparsely scattered, relatively small blocks of rock originating from the ceiling but not in their original fallen positions (these blocks have all, without exception, been moved by people). Within the fill across the site are rich archaeological deposits including stone artefacts, ochre pieces and animal bones, as revealed in the archaeological excavations (David et al. 2011; 
Geneste et al. 2012). What we see today in the shelter are the results of tens of thousands of years of human occupation, modification of rock surfaces and site use that express well the notion of 'dwelling' and 'inhabitation' (e.g. David et al. 2013, 2014; Delannoy et al. 2013; Geneste et al. 2010; cf. Ingold 2000; Thomas 2008).

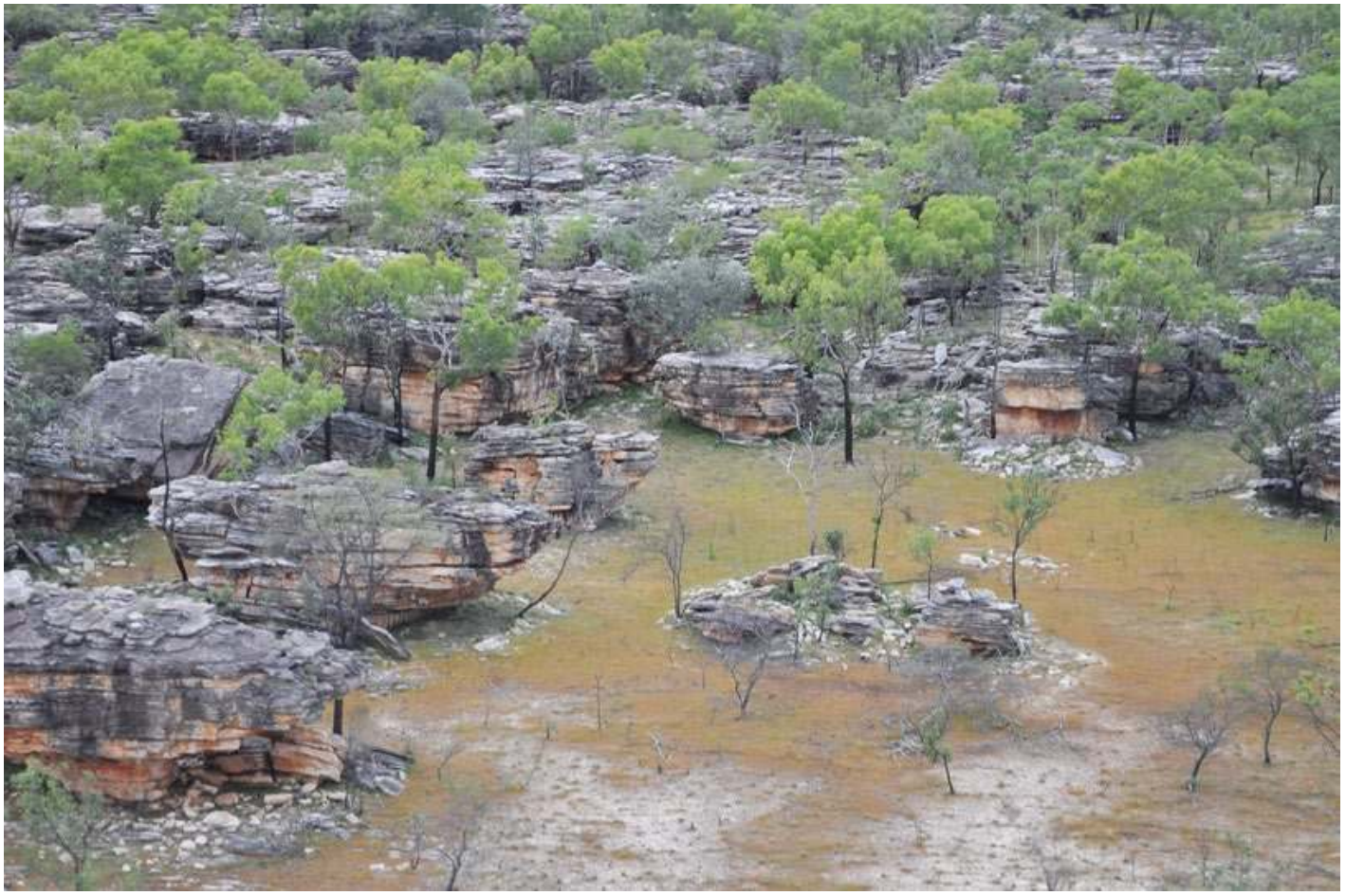

Figure 11.1 Detail of the vast rockshelter landscape of the central-western Arnhem Land plateau.

Source: Photograph by Bruno David.

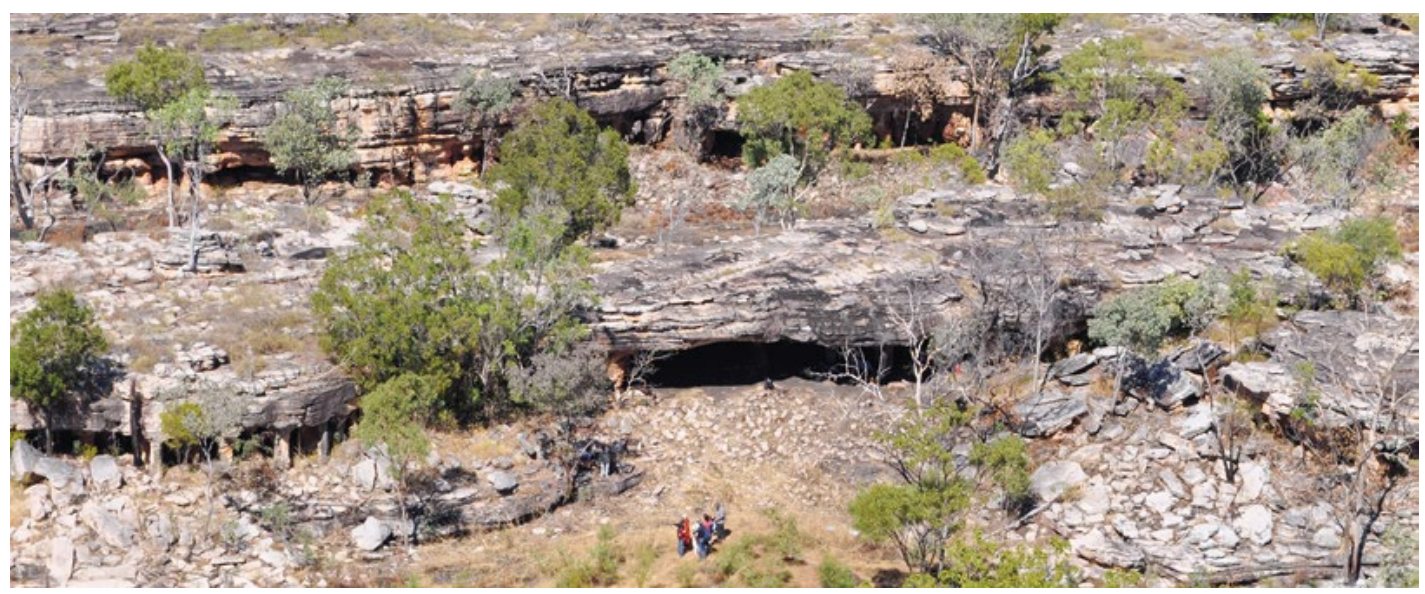

Figure 11.2 Nawarla Gabarnmang, northern entrance.

Source: Photograph by Bruno David. 


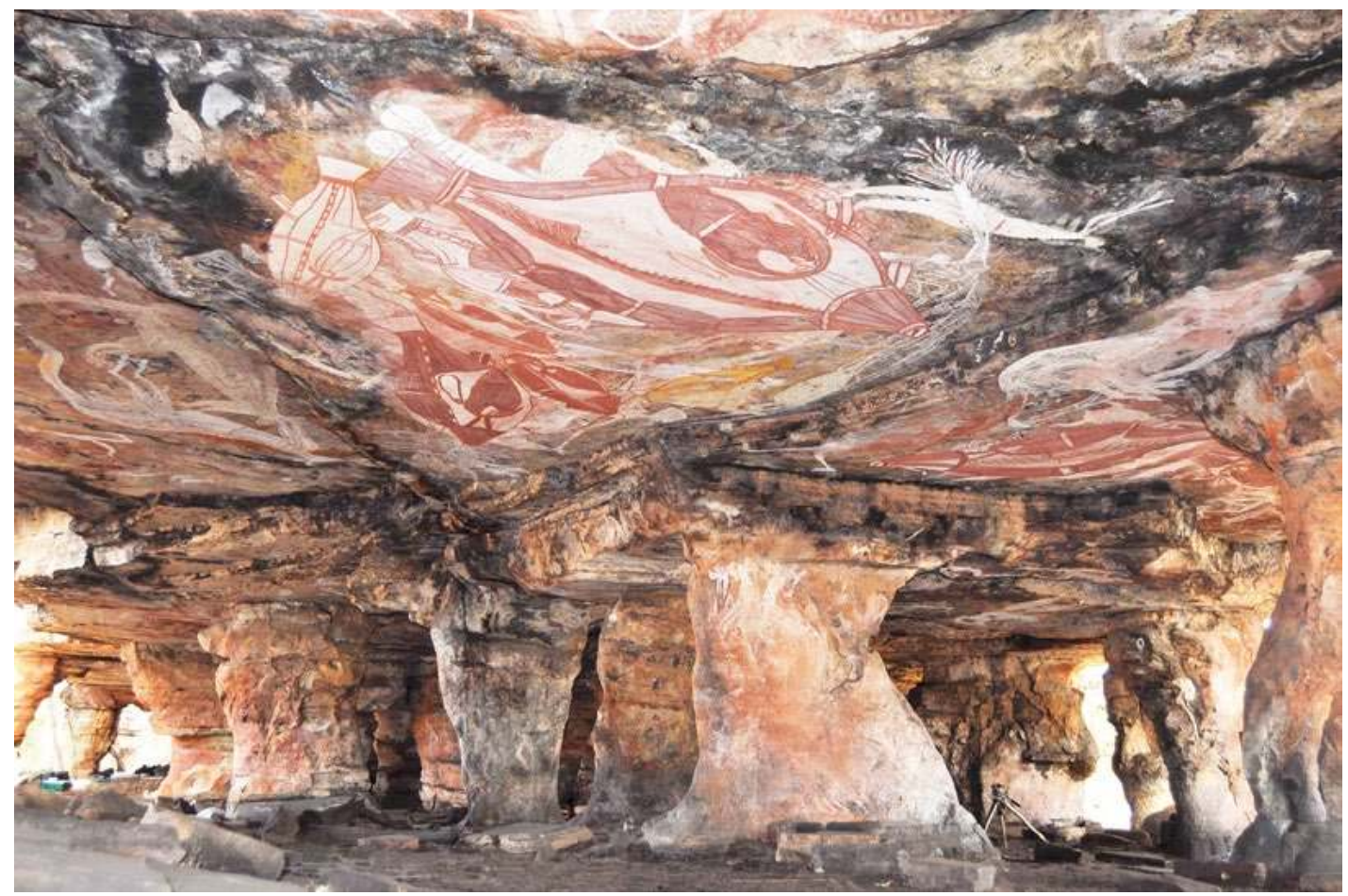

Figure 11.3 Inside Nawarla Gabarnmang, showing pillared site structure.

Source: Photograph by Jean-Jacques Delannoy.

Nawarla Gabarnmang is of special interest for rock art research because it has a rich and especially well preserved record of paintings under its well-protected overhang and, to a lesser extent, on its rock pillars (e.g. Figure 11.3). This art is, in some parts of the site, represented by expansive and overlapping concentrations of paintings (with minor quantities of other kinds of artworks also being present, such as cupules, beeswax designs and stencils). Elsewhere in the shelter, more or less discrete art panels usually have multiple and complex patterns of superimposition.

Gunn (2016) has divided the shelter's ceiling into 41 sections with pigment art (Figure 11.4), each section representing a more or less spatially discrete area of art. A total of 1391 images have been recorded in up to 49 layers of superimposition from the ceiling alone. The area reported in this chapter is Panel E1, located immediately above archaeological excavation Square P (Figures 11.4 and 11.5). While the complex superimpositions in Panel E1 reveal a chronological sequence of painted images, detailed three-dimensional (3-D) laser mapping of the site, geomorphological investigations and excavation of Square P have revealed surface and in situ buried information that individually and together enable us to understand better the ages of these sequential layers of artworks on the ceiling above.

The aim of this chapter is to cross-correlate information obtained from the painted ceiling at Panel E1 with geomorphological details and archaeological evidence buried immediately below the art panel in Square P. In this way, the information immanent in the rock art and in the strata below it are combined into an integrated understanding, in a way rarely attempted when studying Australian rock art. 


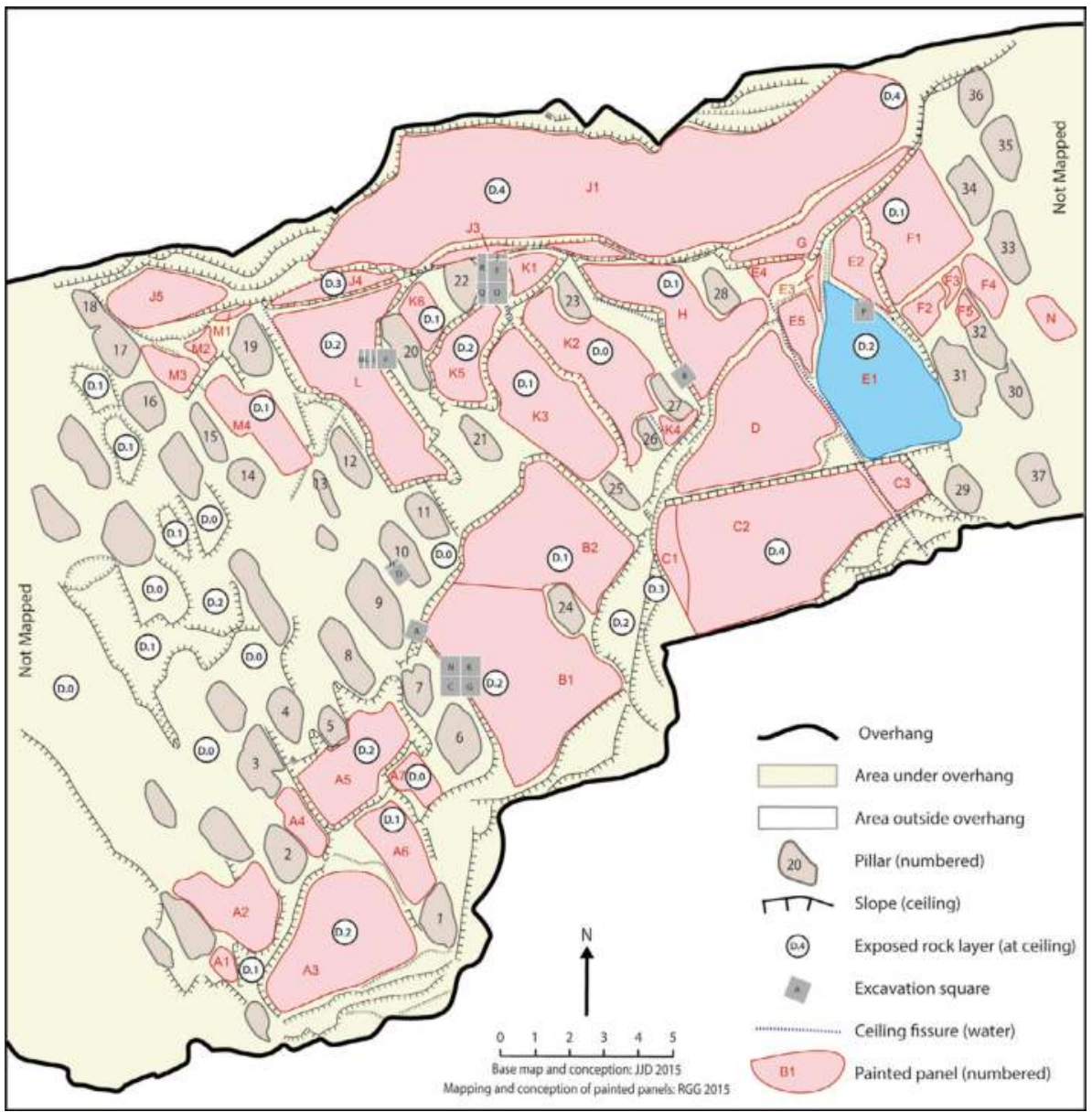

Figure 11.4 Map of ceiling of Nawarla Gabarnmang, showing location of Panel E1 relative to other ceiling art panels and excavation squares.

Note that the pillars are shown where they meet the ceiling, whereas the excavation squares are at ground level. Source: Illustration by Jean-Jacques Delannoy, Robert Gunn and Kara Rasmanis.

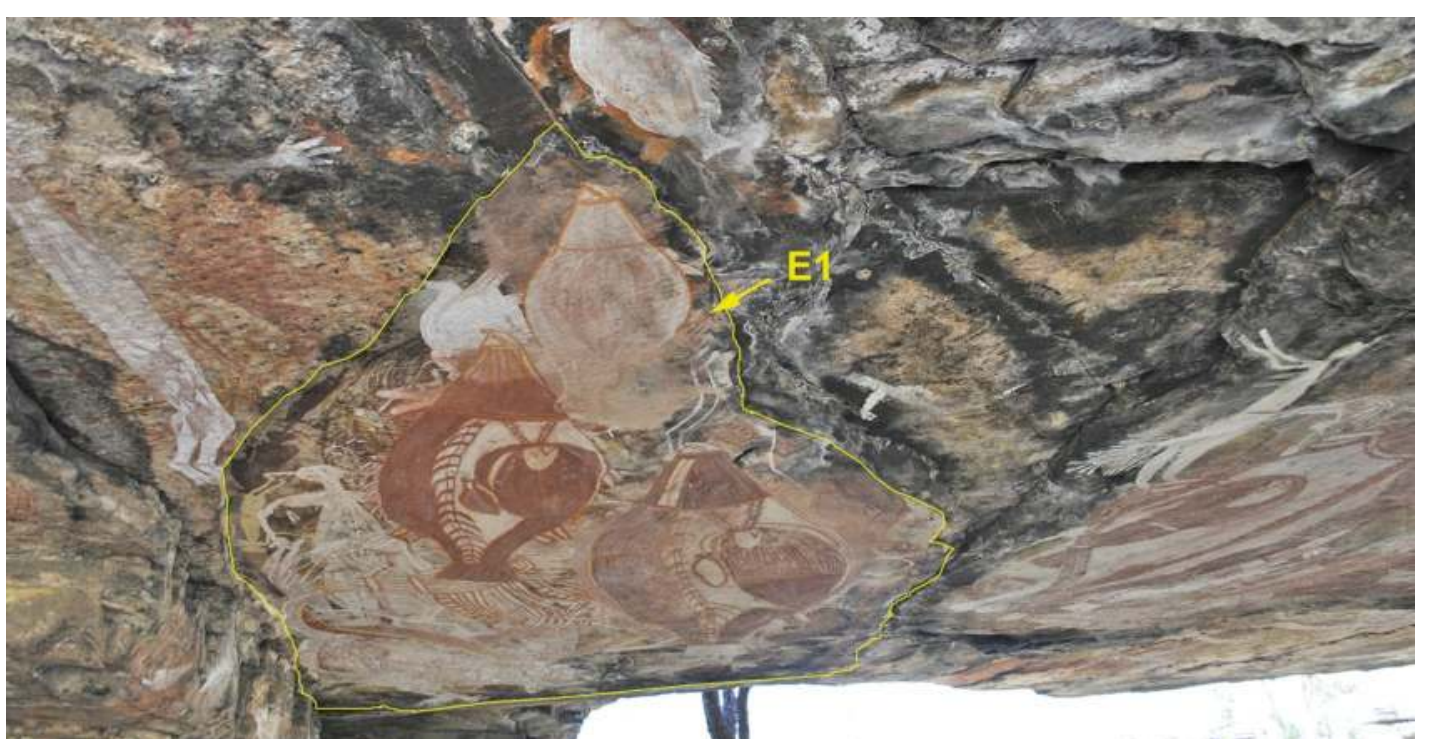

Figure 11.5 Location of Panel E1 within the centre-eastern ceiling.

Source: Photograph by Robert Gunn. 


\section{Panel E1}

Panel E1 is large, covering a roughly triangular area $5.4 \times 2.4 \mathrm{~m}$ in maximum dimensions. It is located in the central-eastern side of the shelter, in a part of the site where there is maximum spacing between pillars. The surface of the ceiling at Panel E1 is flat and sub-horizontal, exhibiting small and shallow ripple marks that provide minor rounded texture. Eighty-two painted or stencilled images are present on this panel, mostly concentrated towards its centre, with extensive superimpositioning virtually obliterating the central motifs of the underlying and therefore older layers (Tables 11.1-11.3; Figures 11.6 and 11.7).

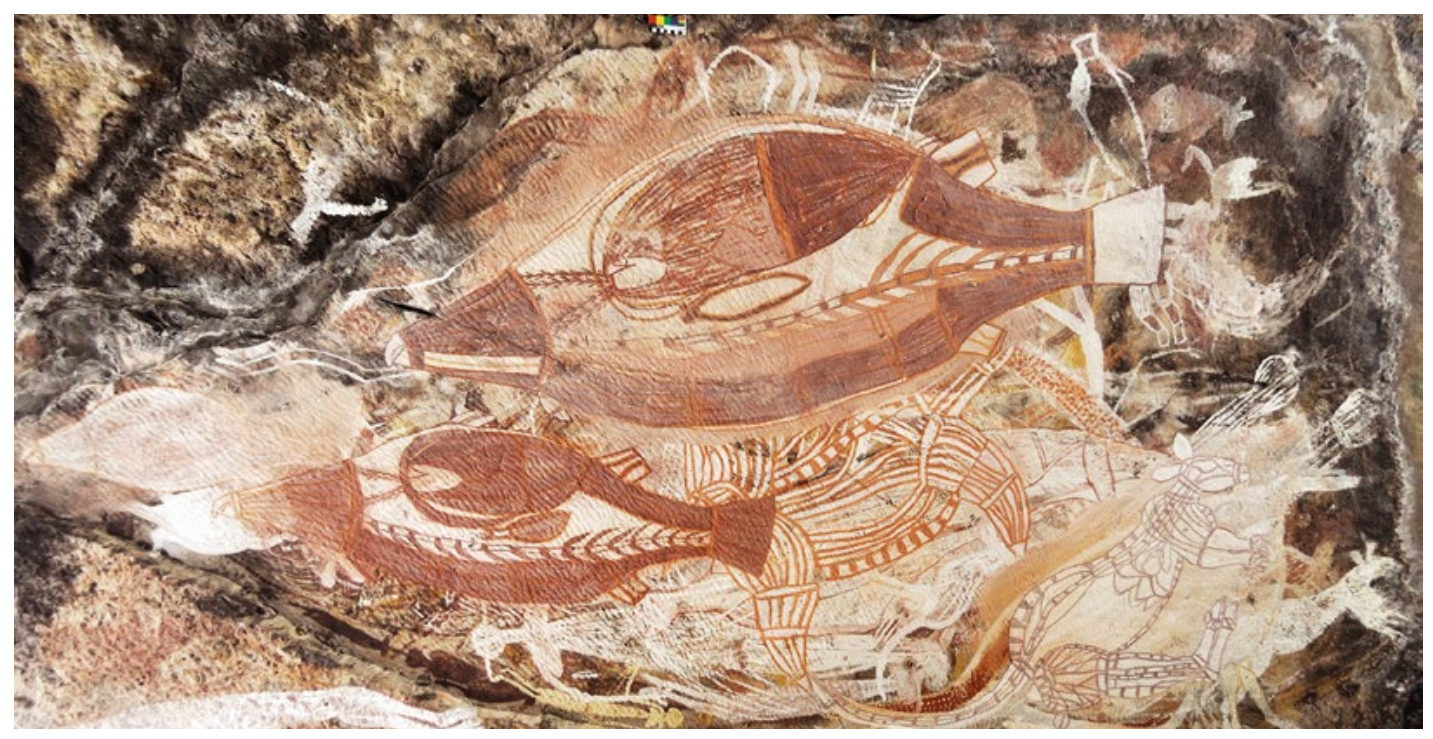

Figure 11.6 Panel E1.

Source: Photograph by Robert Gunn.

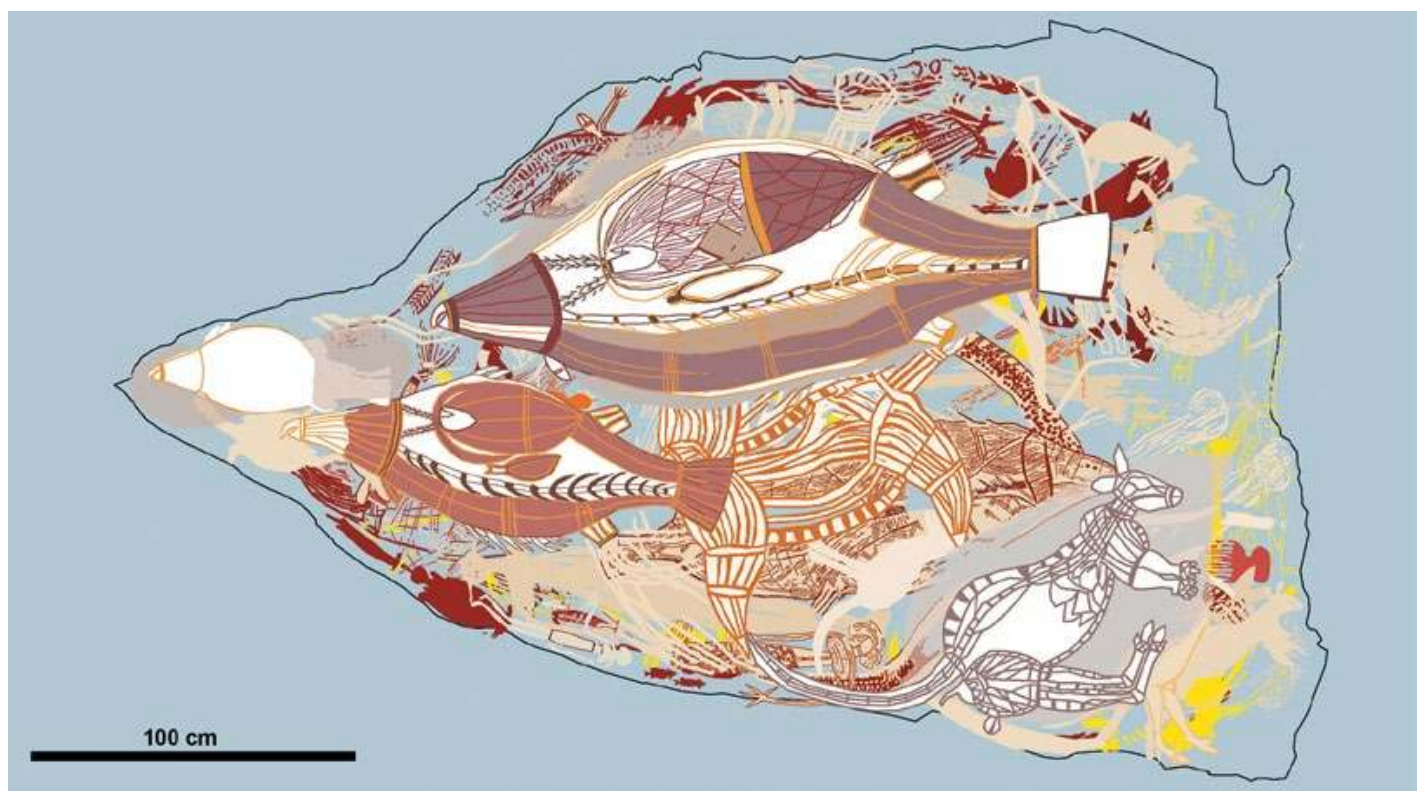

Figure 11.7 Photo-tracing of Panel E1.

The images are drawn in selected standardised colours that do not equate precisely with the hues of the original images. Here, as in the other photo-tracings presented in this chapter, a grey background (Pantone Cool Grey 9 C) was selected to provide good contrast for the overlying art colours.

Source: Illustration by Robert Gunn. 
In order to clarify patterns of superimposition across the whole of the panel, a Harris Matrix was constructed, incorporating all of the art present in Panel E1. The Harris Matrix approach, originally created to describe complex archaeological stratigraphies in intricate urban sites (Harris 1989; Russell 2012), was first used for rock art in western Arnhem Land (Chippindale and Taçon 1993). It models the relative superimposition of strata across space, in this case involving the micro-strata of superimposing artworks spread across the panel. The completed Harris Matrix depicts the minimum number of paint layers required to account for all the art and their superimpositions in Panel E1, as generated from the sum of individual superimpositions (Figure 11.8).

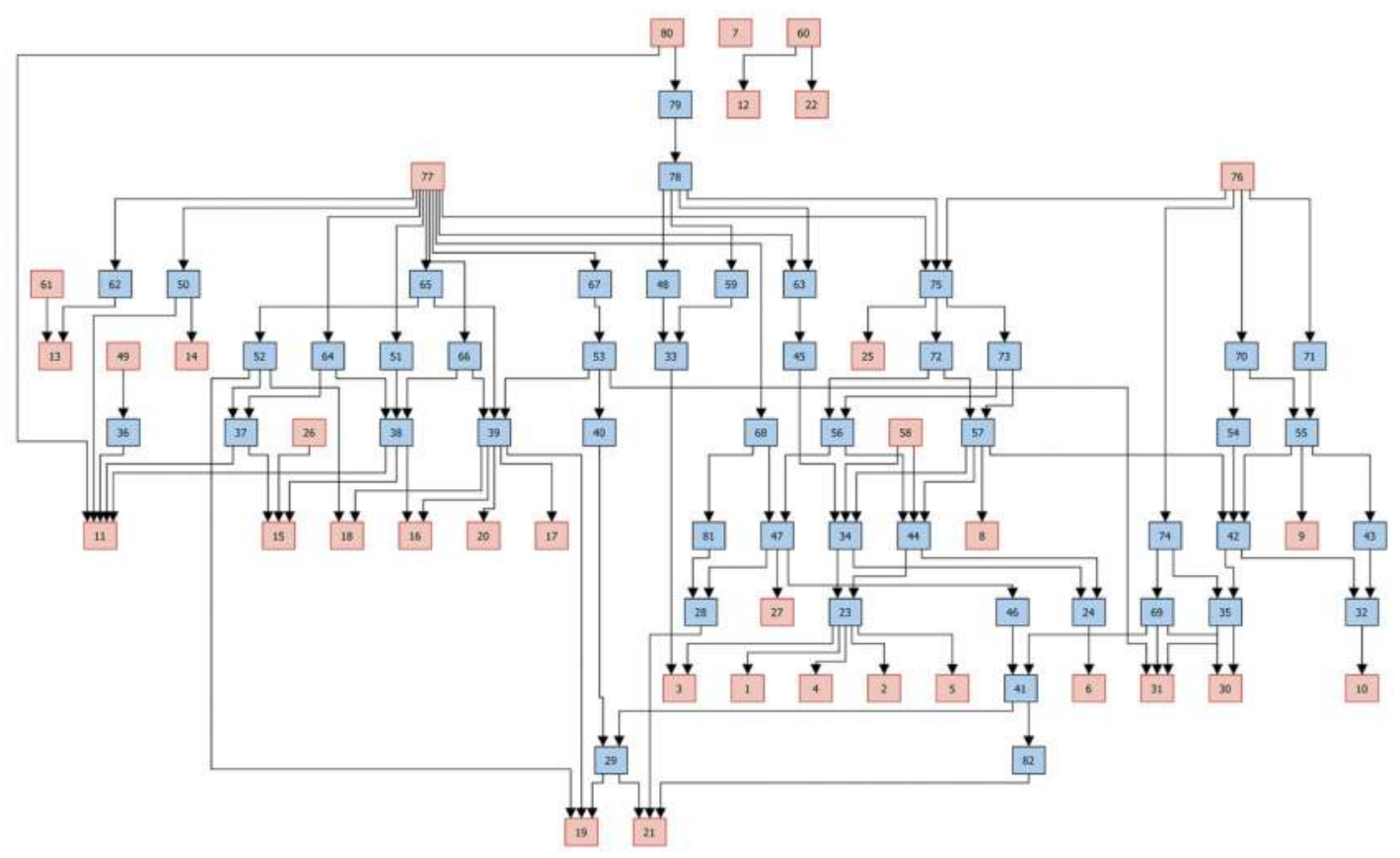

Figure 11.8 Harris Matrix showing pattern of superimpositions for all 82 images of Panel E1.

Red squares indicate images at the beginning or end of a sequence of superimpositions, and singular images not involved in superimpositions. Blue squares indicate images within a sequence of superimpositions (see Harris 1989; Russell 2012).

Note: To magnify the diagram please see the PDF version at: press.anu.edu.au

Source: Illustration by Robert Gunn.

The systematic computation integrating all the cases of superimposition in Panel E1 identifies at least 15 layers of superimposition involving all but one of its 82 images. That lone image (Image \#7) was assigned to Layer 13 on the basis of similarities in motif type, colour, size and preservation relative to adjacent Images \#6 and \#8. All 15 layers, numbered from the top down as Layers $1-15$, were grouped into six chronological phases, numbered from the bottom up as Phases I-VI (Figure 11.9):

- Phase I is made up of Layers 14 and 15: This earliest phase consists of 21 images in red in at least two separate layers. Of note is the presence of basic X-ray features in a monochrome red fish (Image \#15; with stylised backbone and ribs depicted) and a long snake (Image \#11; with backbone, ribs and eggs depicted) (Figure 11.10).

- Phase II is Layer 13: This layer consists of 12 yellow paintings, with only one simple design being clear enough to identify to motif type (Figure 11.11).

- Phase III is Layer 12: A layer of four red paintings also cannot be identified to motif type (Figure 11.11). 
- Phase IV is made up of Layers 5-11: The 39 images from this phase come from six distinct layers dominated by paintings in monochrome white and bichrome white and red (Figures 11.12-11.14). Within this phase, Layer 5 has two anomalous orange anthropomorphs, one of which (Image \#46) has a white headdress. The white monochrome and bichrome with basal white motifs do not occur as separate, discrete layers, suggesting that on this panel they are contemporaneous.

- Phase V is Layer 4: A single bichrome turtle motif in white and orange. This motif is distinctly different from all underlying or overlying motifs (Figure 11.14).

- Phase VI is made up of Layers 1-3: This most recent phase, which contains five images, shows a distinct change in the art towards larger and more visually dramatic images (Figure 11.15).

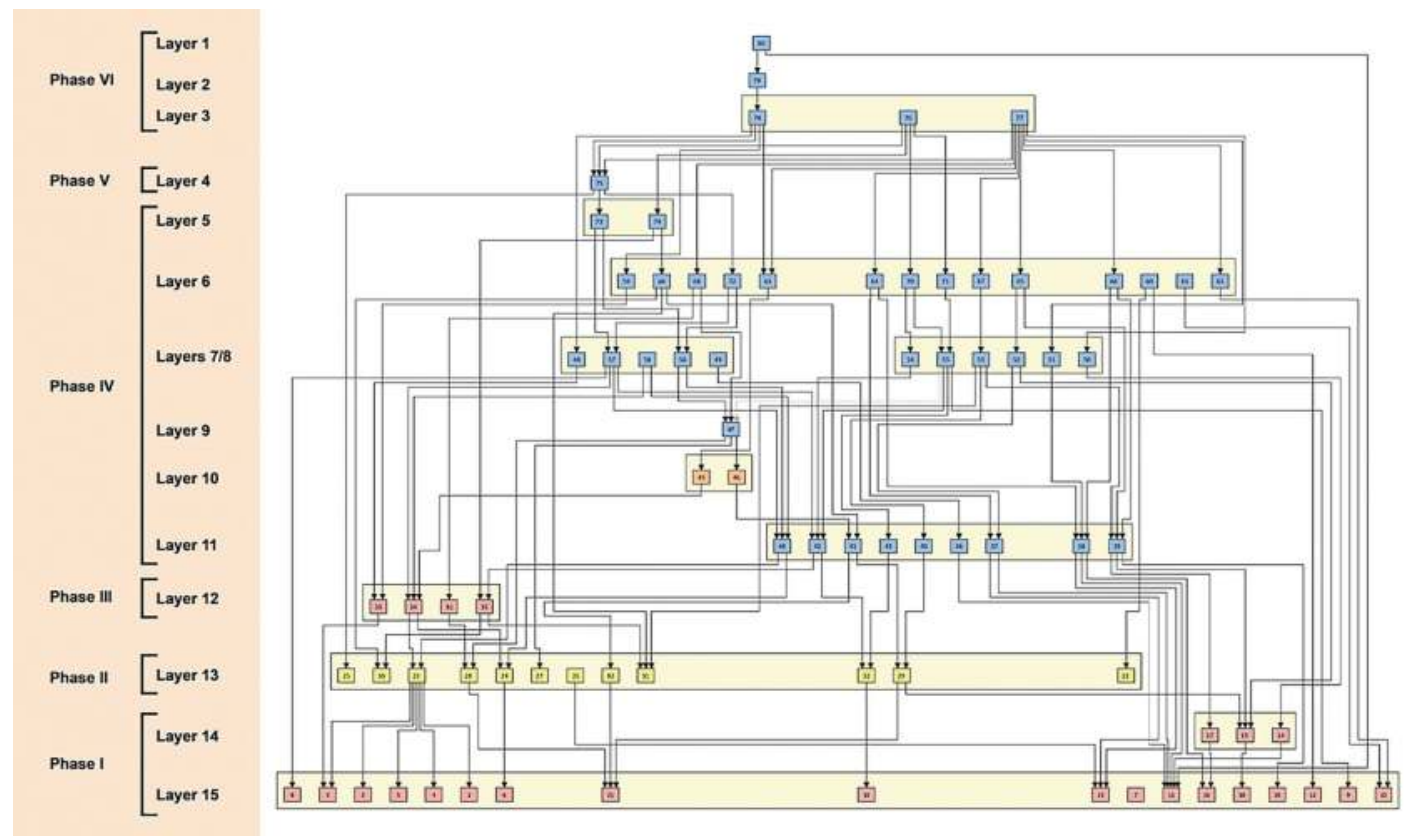

Figure 11.9 Interpretation of the Panel E1 Harris Matrix, with phases indicated.

Coloured squares indicate the principal colour of the image (in polychrome works, this is the underlying colour and usually the most abundant colour in that image, as in an X-ray image where the underlying colour forms a solid silhouette onto which lines in other colours are superimposed): blue = white, red = red, yellow = yellow, orange = orange (see Harris 1989; Russell 2012).

Note: To magnify the diagram please see the PDF version at: press.anu.edu.au

Source: Illustration by Robert Gunn.

Most of the larger motifs occur towards the central parts of the panel. However, a large snake (Image \#11) from the earliest Phase I (Layer 15) was positioned to curve around the panel's western edge (Figure 11.10). No consistency has been noted in the alignment of images relative to each other or to any other reference point. Unlike a vertical panel, this near-horizontal surface seems to have no top or bottom, and there is no 'right way up' or 'upside down' for the figures on it.

X-ray features occur among the lowermost (i.e. oldest) layers of Panel E1. This was unexpected, as elsewhere at Nawarla Gabarnmang (e.g. on Panel D) X-ray features occur only in the more recent art (Gunn 2016). The two X-ray motifs in the lowermost Layer 15 (Phase I) of Panel E1 are both in monochrome red: a fish (Image \#15) with stylised backbone and ribs; and the large red snake mentioned above (Image \#11) with backbone, ribs and eggs (Figures 11.10 and 11.16). 


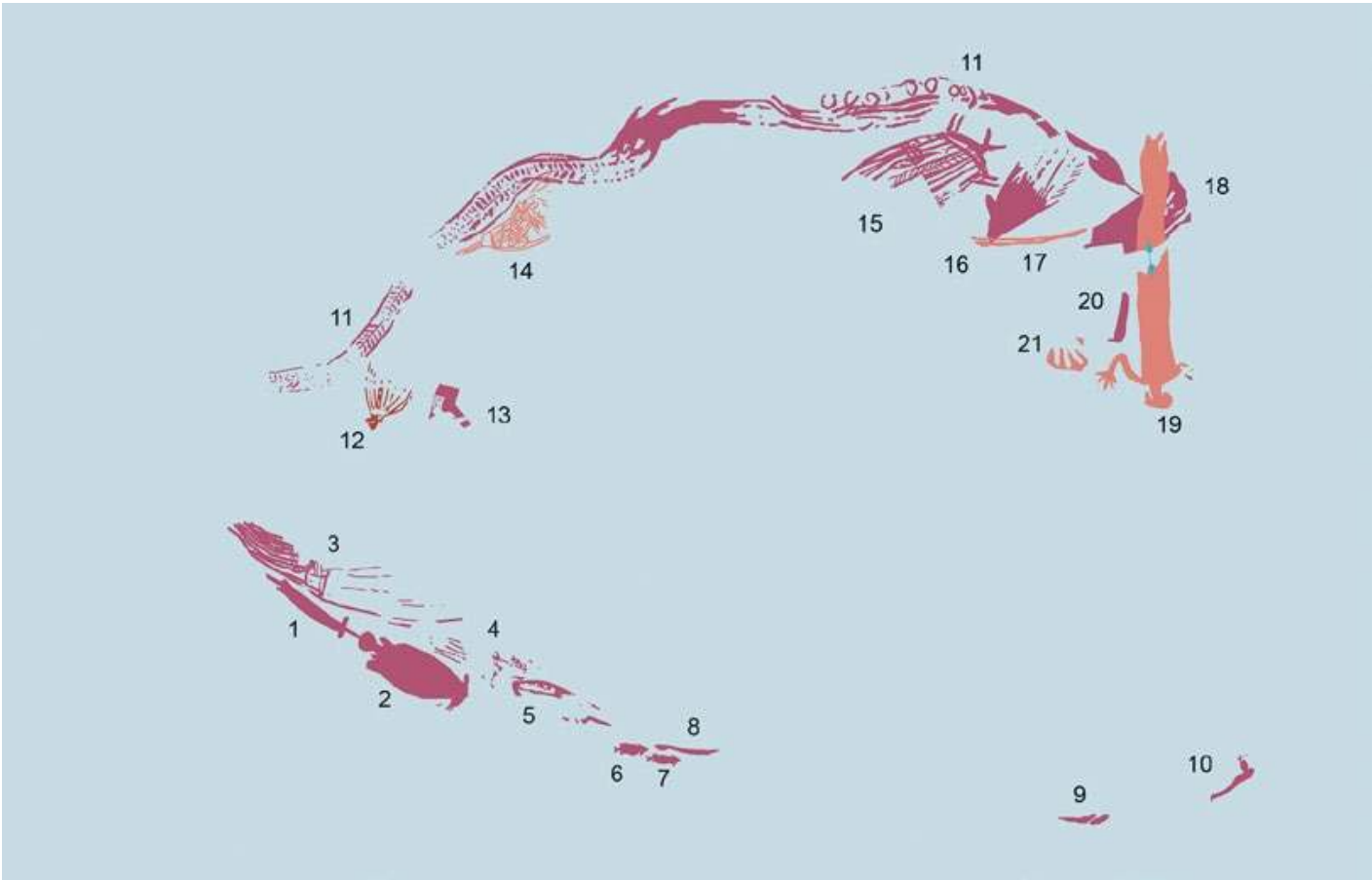

Figure 11.10 Phase I images (Layers 14 and 15), Panel E1.

Source: Illustration by Robert Gunn.

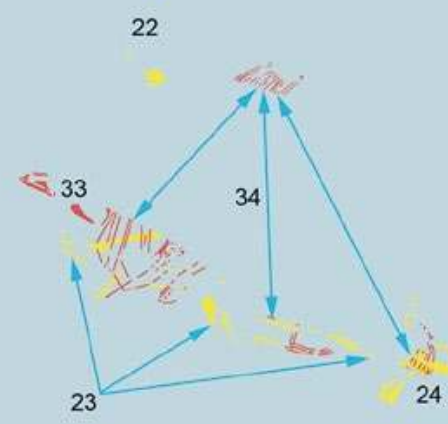

25

$28 \quad 82$

29

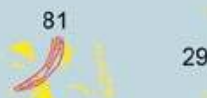

31

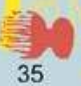

27

Figure 11.11 Phase II images (yellow = Layer 13) and Phase III images (red = Layer 12), Panel E1. Source: Illustration by Robert Gunn. 


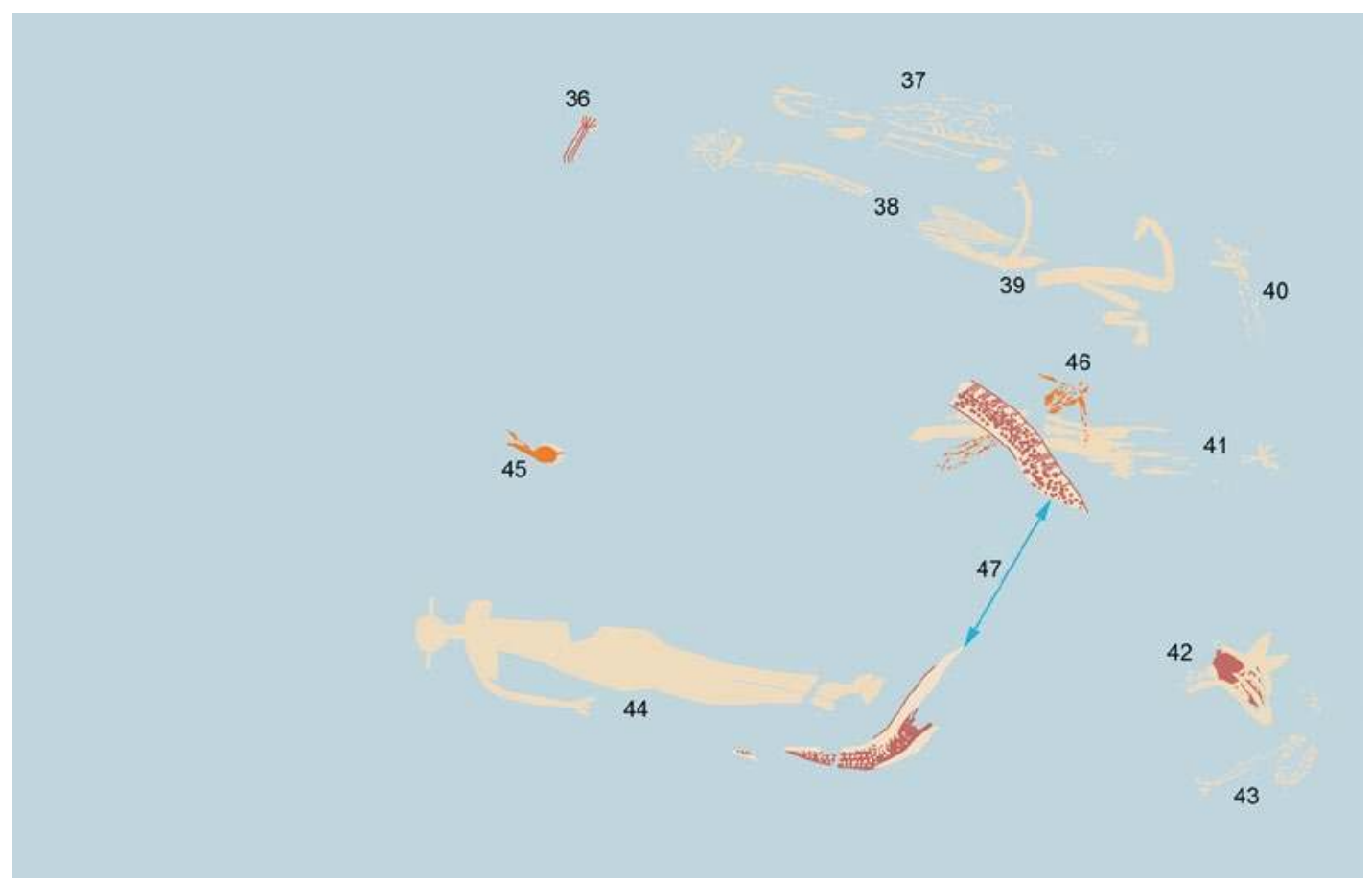

Figure 11.12 Phase IV images (Layers 9-11), Panel E1.

Source: Illustration by Robert Gunn.

49

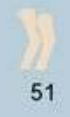

52

50

51

53

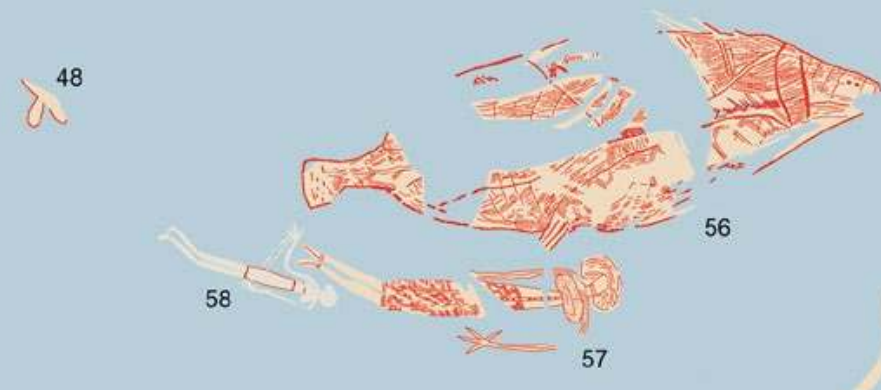

54

Figure 11.13 Phase IV images (Layers 7 and 8), Panel E1.

Source: Illustration by Robert Gunn. 


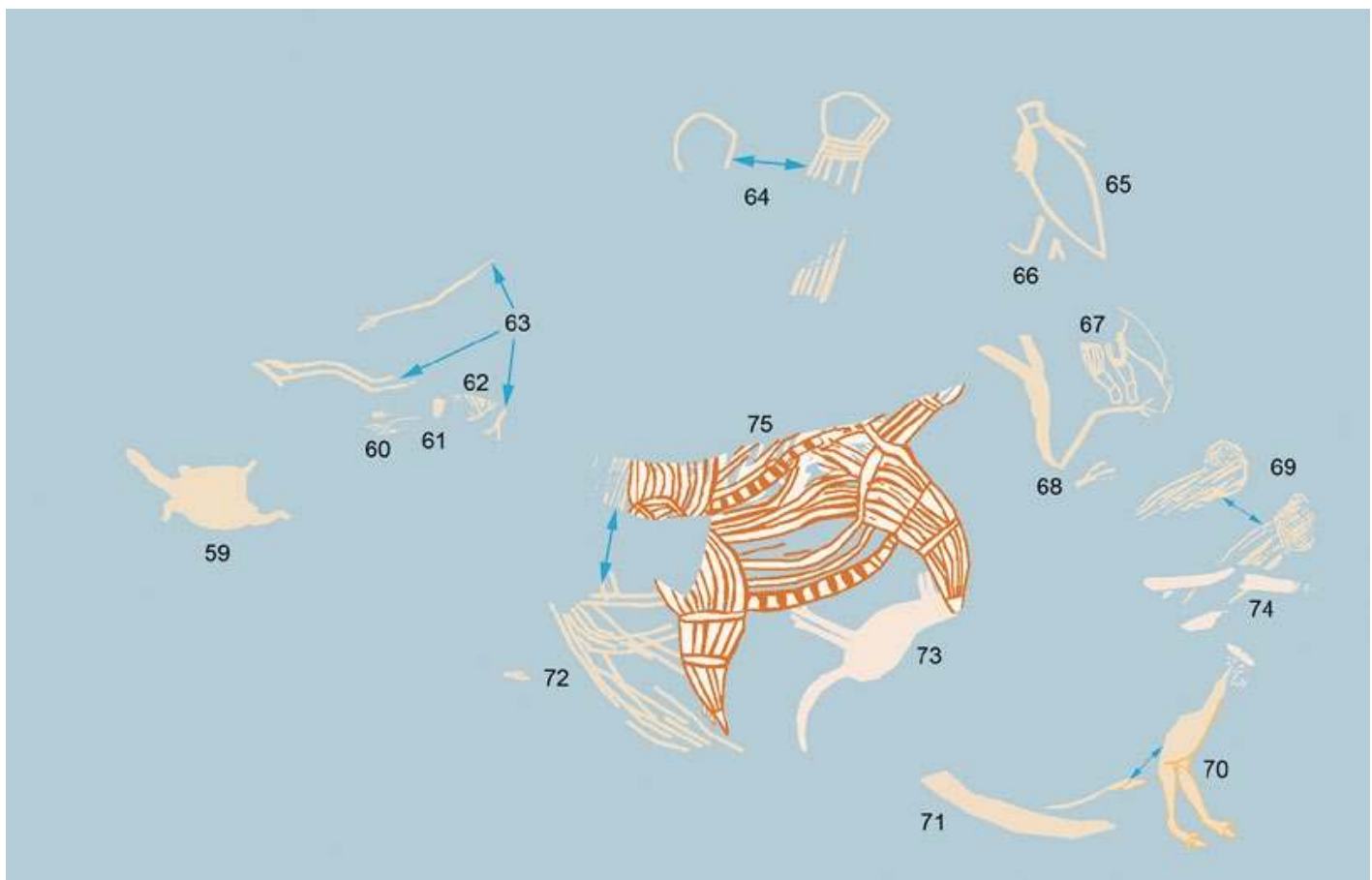

Figure 11.14 Phase IV images \#59-\#74 (Layers 5-6) and Phase V image \#75 (Layer 4), Panel E1. Source: Illustration by Robert Gunn.

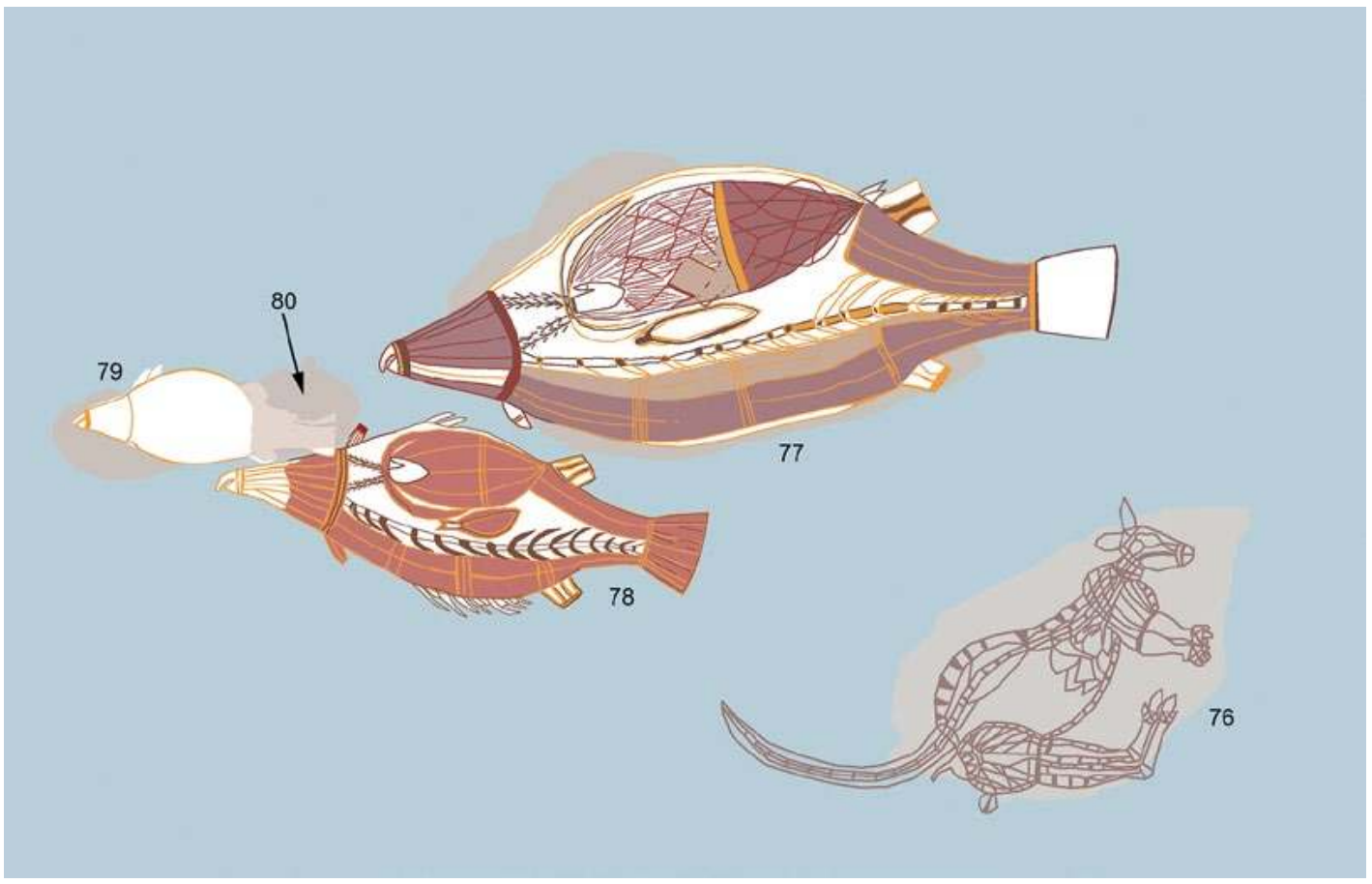

Figure 11.15 Phase VI images (Layers 1-3), Panel E1.

Source: Illustration by Robert Gunn. 


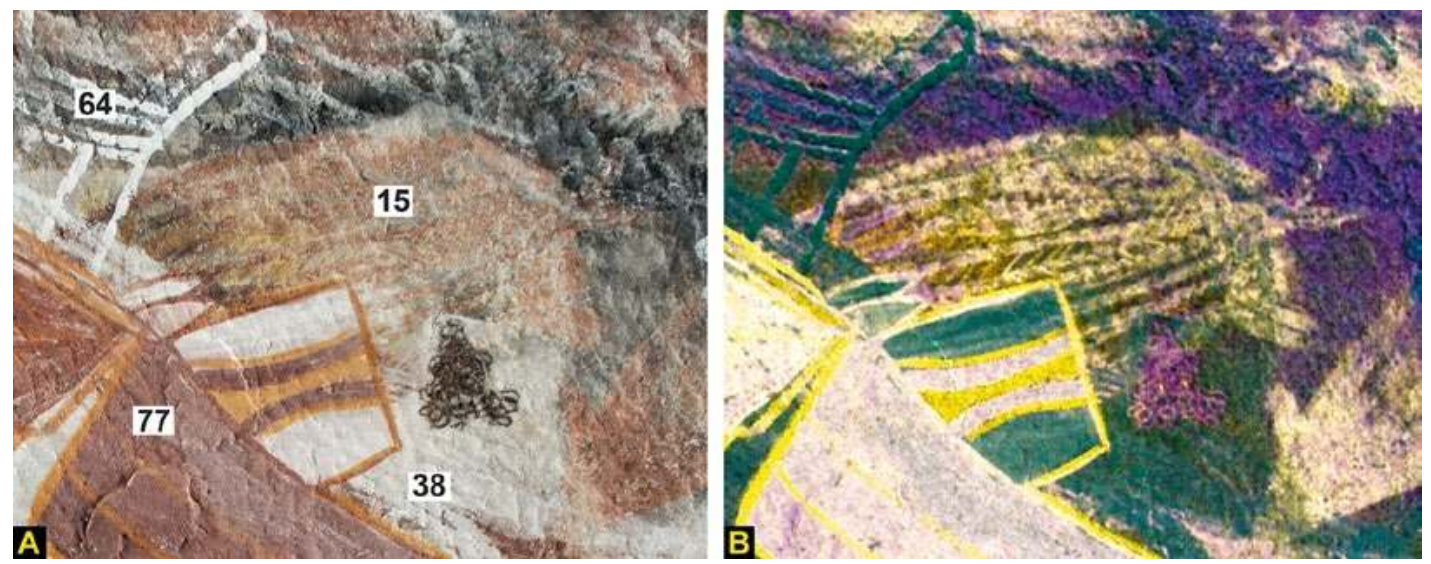

Figure 11.16 Details of monochrome X-ray fish Image \#15.

A: Original photograph. B: Digitally enhanced photograph using DStretch_labi10.

Source: Photographs and enhancement by Robert Gunn.

As noted above, the white monochrome and bichrome with basal white paintings occur within the same phase, suggesting that they are contemporaneous. The bichrome motifs include two 'Jawoyn Lady' paintings (Images \#57 and \#58) and a large fish with patterned infill (Image \#56) (Figures 11.13 and 11.17).

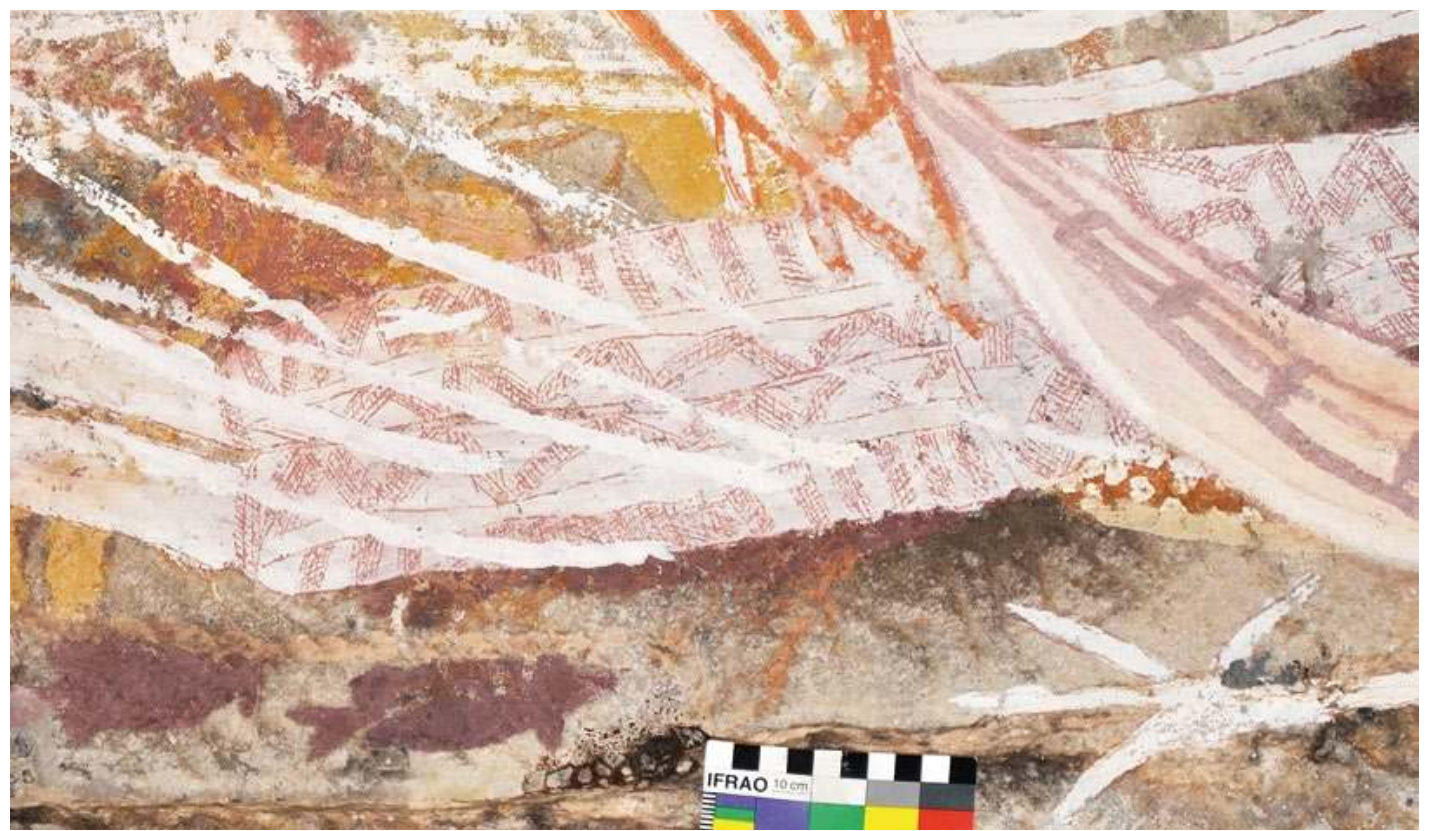

Figure 11.17 Details of body decoration on 'Jawoyn Lady' Image \#57.

Source: Photograph by Robert Gunn.

The uppermost, most recent paintings in the superimpositions show a distinct change in the art towards larger and more visually dramatic images. The lowermost of these impressively large images is a turtle (Image \#75; Figure 11.18) painted in 'Bula style'. Bula art is a style of painting relating to the ethnographic period and restricted to Jawoyn Country, defined by solid white silhouettes with bold red outline and infill line work (cf. Gunn 1992). Above the Bula-style turtle of Layer 4 in Panel E1 is an unusual form of X-ray macropod (Image \#76; Figure 11.19) and two large polychrome X-ray barramundi (Image \#77 and Image \#78; Figures 11.20 and 11.21), each of Layer 3; both barramundi have been later partially retouched on several occasions. 
The most recent image on Panel E1 is a barramundi that appears to have been only partially completed (Image \#79; Figure 11.22). It was painted on a prepared 'surface-smear' of pink paint (probably a blend of an applied white mixing with an existing red image). Subsequently, the barramundi (Image \#79) was partly over-painted by an off-white smeared area (Image \#80). Similarly, Images \#76 and \#77 were also painted over prepared surfaces. Ethnographically, Elkin (1952:245) reported the practice in Jawoyn Country of erasing a deceased person's painting by relatives smearing it with red ochre and over-painting another picture, usually a malindji (spirit figure) representing the deceased's spirit. He gives no actual examples of this practice, and no cases of smearing and over-painting with a spirit figure have been located in the recent extensive site recording in Jawoyn Country. Apart from these examples on Panel E1, smearing has only been recorded at the nearby shelter of Dalakngalarr (see Chapter 13). Whether the underlying smear was a preparation for making the over-painted image is unclear. Certainly, the practice of smearing was uncommon in Jawoyn Country.

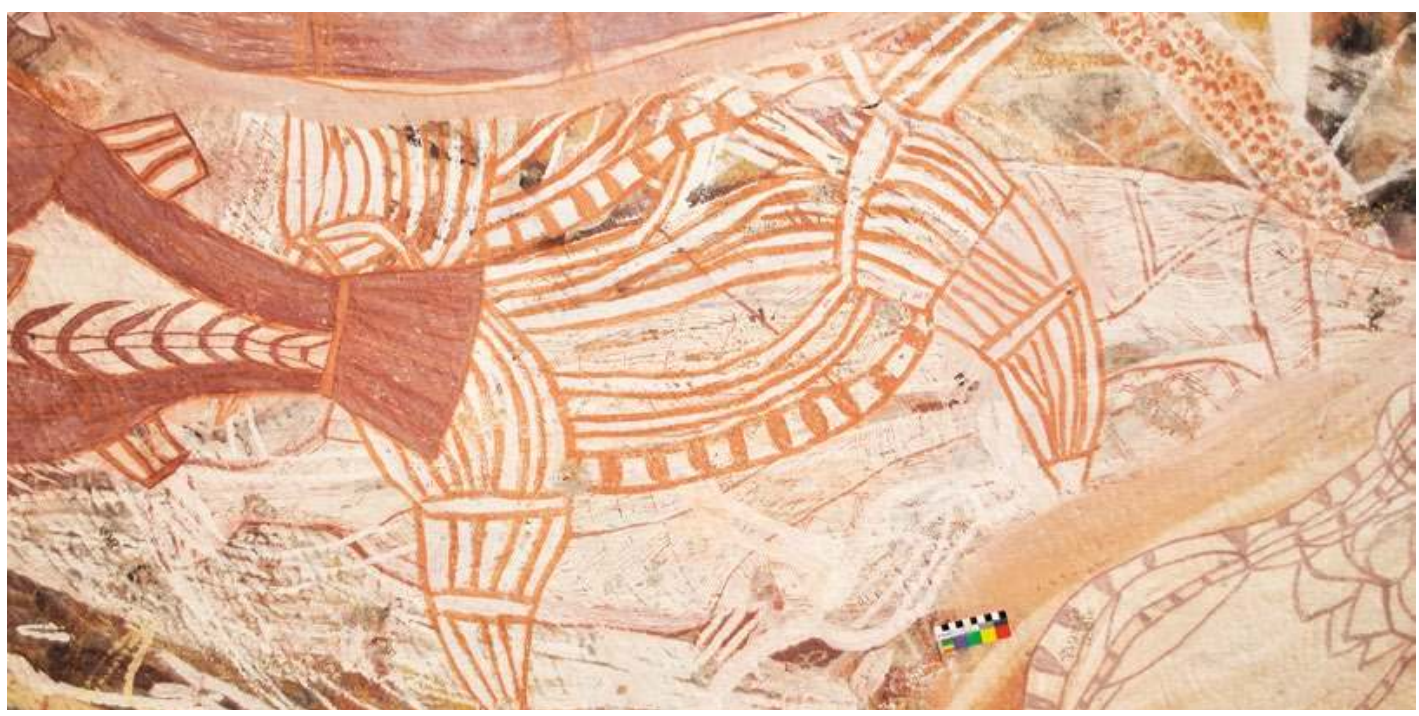

Figure 11.18 Bula-style turtle, Image \#75.

Source: Photograph by Robert Gunn.

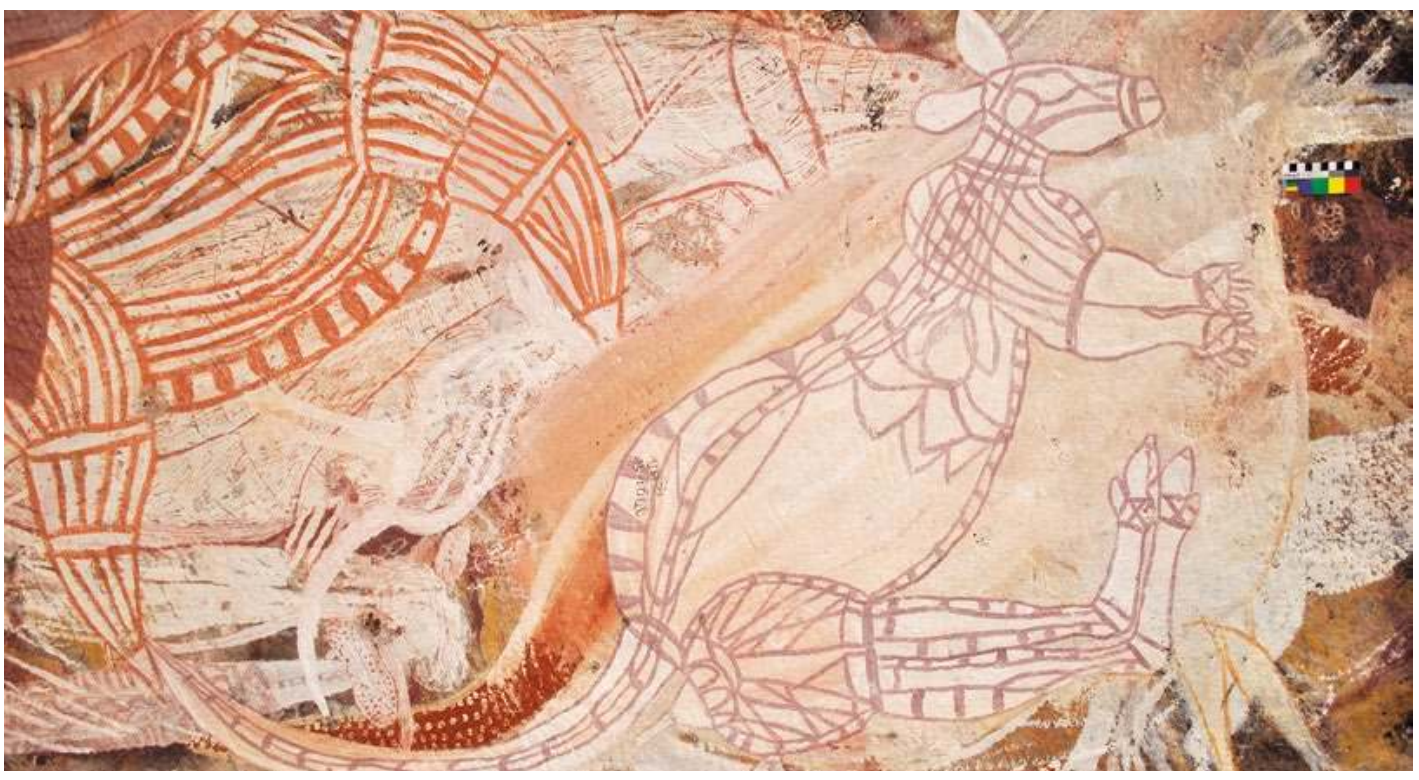

Figure 11.19 Macropod Image \#76 in a unique X-ray style variation.

Source: Photograph by Robert Gunn. 


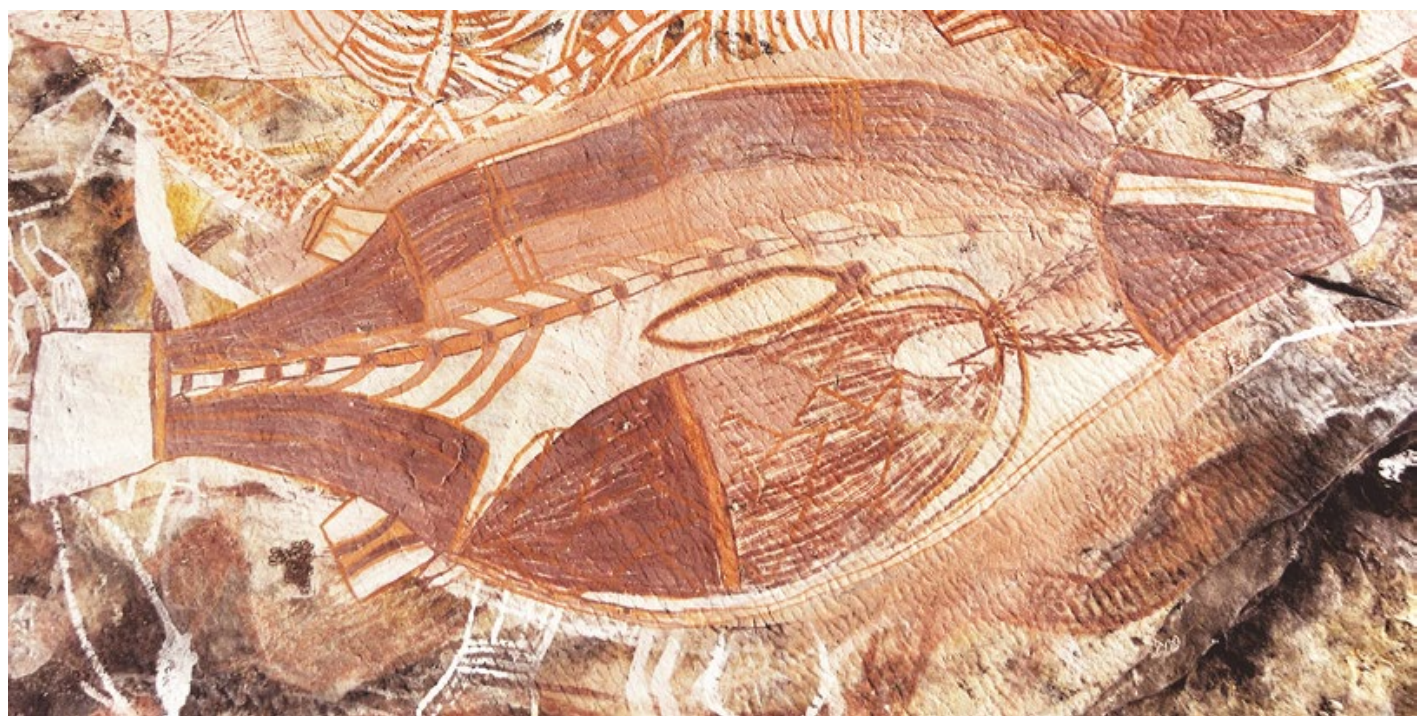

Figure 11.20 Large X-ray barramundi Image \#77.

Source: Photograph by Robert Gunn.

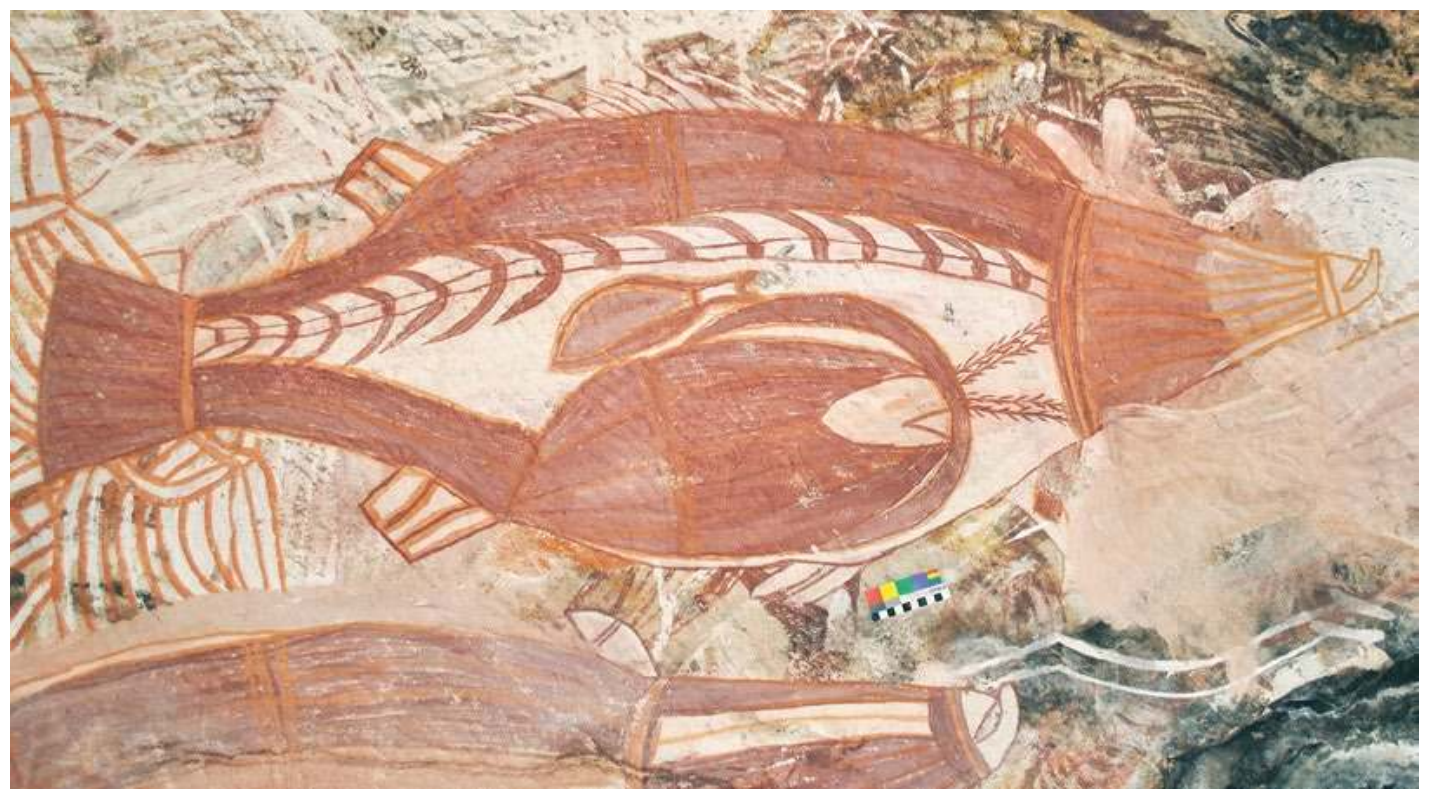

Figure $11.21 \mathrm{X}$-ray barramundi Image \#78.

Source: Photograph by Robert Gunn.

In the overall sequence, there is a change in colour from red to yellow to white and polychrome with basal white. Gunn et al. (2012) proposed that the turtle motif (Image \#75) of Panel E1 has stylistic connections - similarities in colour, size, form and visual impact - to paintings relating to the apocalyptic Bula cult of ethnographic times (cf. Gunn 1992), suggesting a past association between Nawarla Gabarnmang and that religious cult. The Bula cult incorporated restricted rock art and non-rock art sites across a small area in northern Jawoyn Country, some $30 \mathrm{~km}$ southwest of Nawarla Gabarnmang. The subsequent partial over-painting of the Bula-style turtle on Panel E1 was seen by a senior Jawoyn man, Peter Bolgay (pers. comm. to Robert Gunn 2006), as indicating a change in the function of the site, shifting away from an association with the Bula cult to becoming a place where visitors from the north of the plateau would camp while attending ceremonies with Jawoyn (Gunn et al. 2012). 


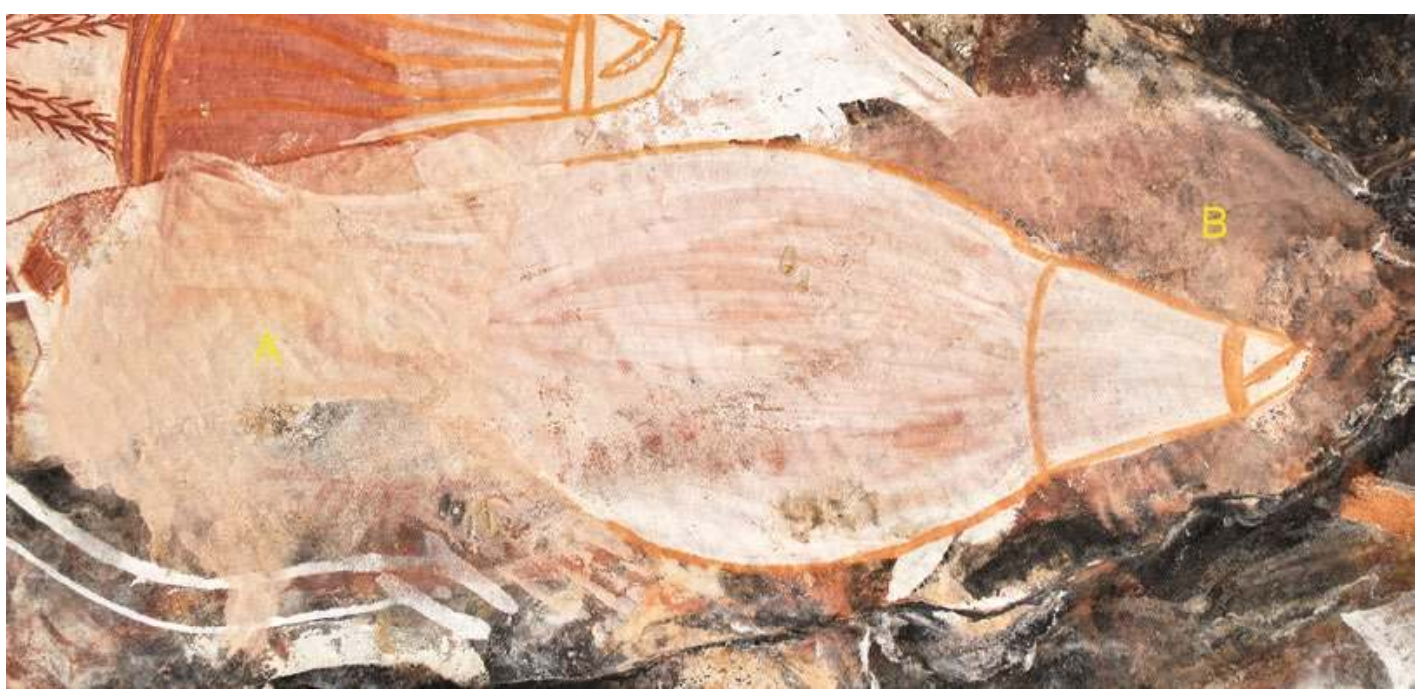

Figure 11.22 Image \#79 painted on a smeared background (B) and subsequently partially overpainted by a second smear (A).

Source: Photograph by Robert Gunn.

The quality and proficiency of the brushwork on Panel E1 also changes noticeably over time. Earlier paintings more often incorporate fine-line brushwork, occasionally also broad brushwork. More recent paintings generally have broader line works, and even their finer details are applied somewhat more coarsely than are the earlier line infills (Figures 11.23 and 11.24). Further evidence for this change in conventions is the later partial re-decoration of Image \#77, where an orange mesh design uncomfortably overlies the brown gut pattern beneath, and a partial purple infill of this mesh design has not been confined to the mesh compartments (Figure 11.25).

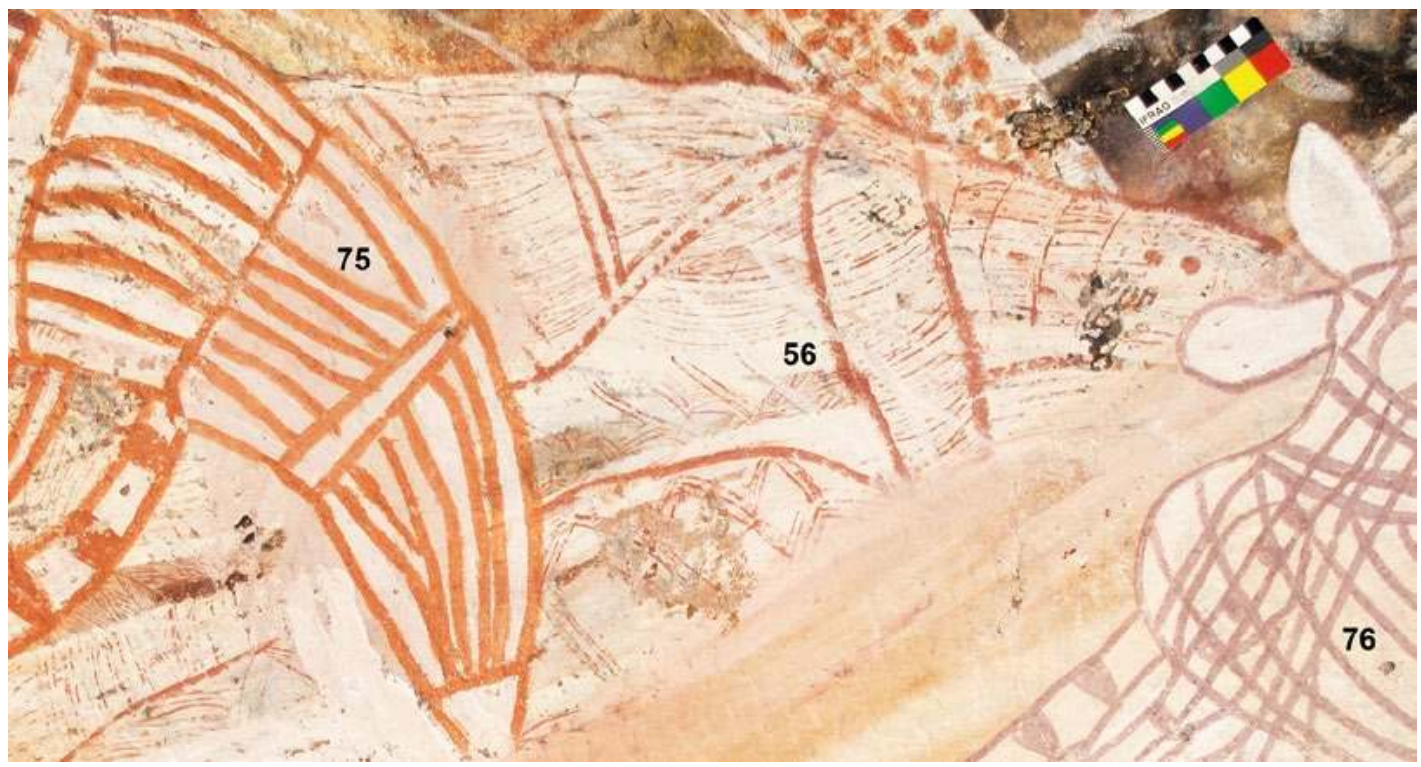

Figure 11.23 Contrasting the differences in brushwork between the underlying (older) fine and overlying (more recent) broad lines of Images \#56, \#75 and \#76.

Source: Photograph by Robert Gunn. 


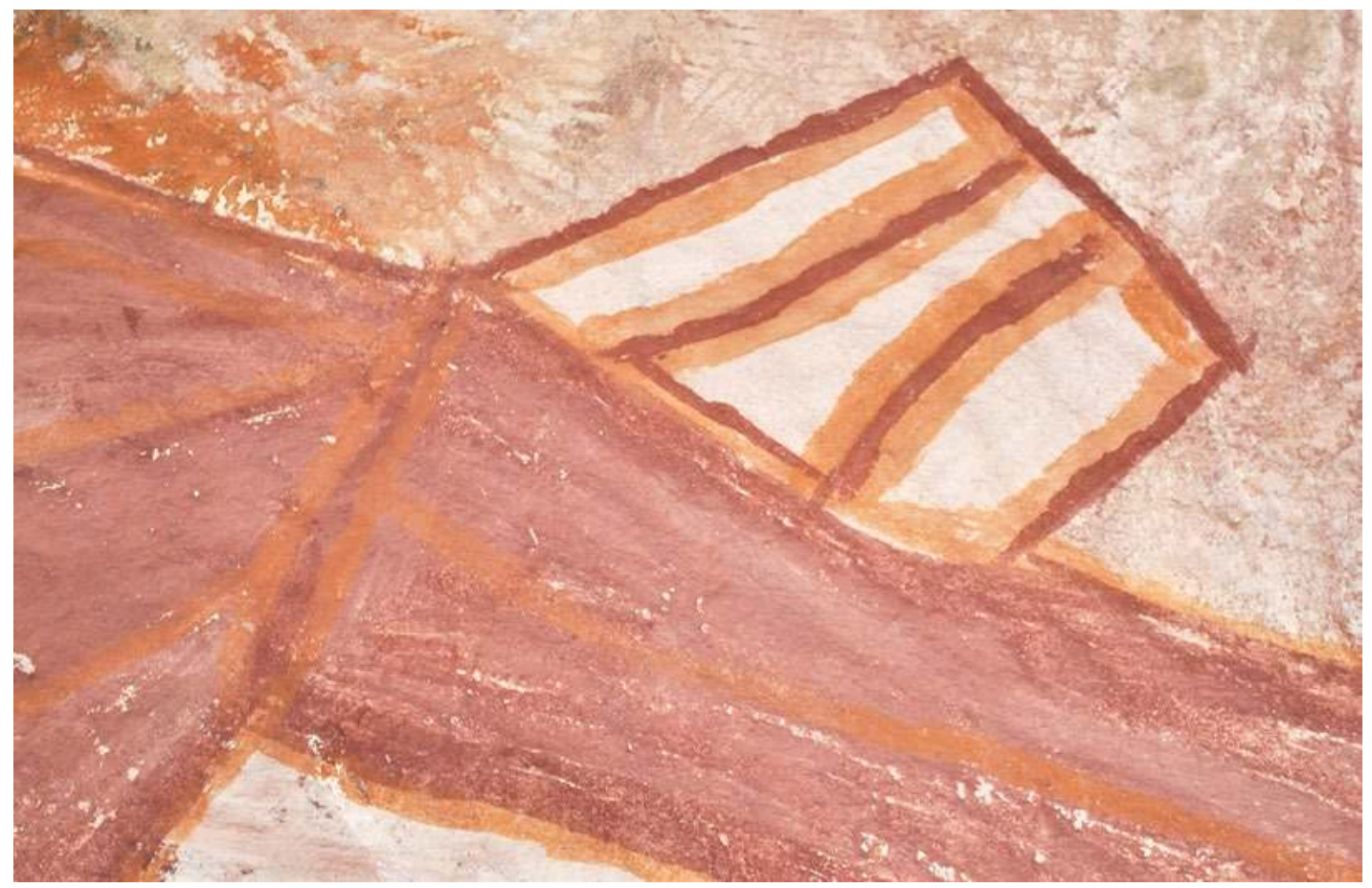

Figure 11.24 Detail of painting quality of Image \#78.

Source: Photograph by Robert Gunn.

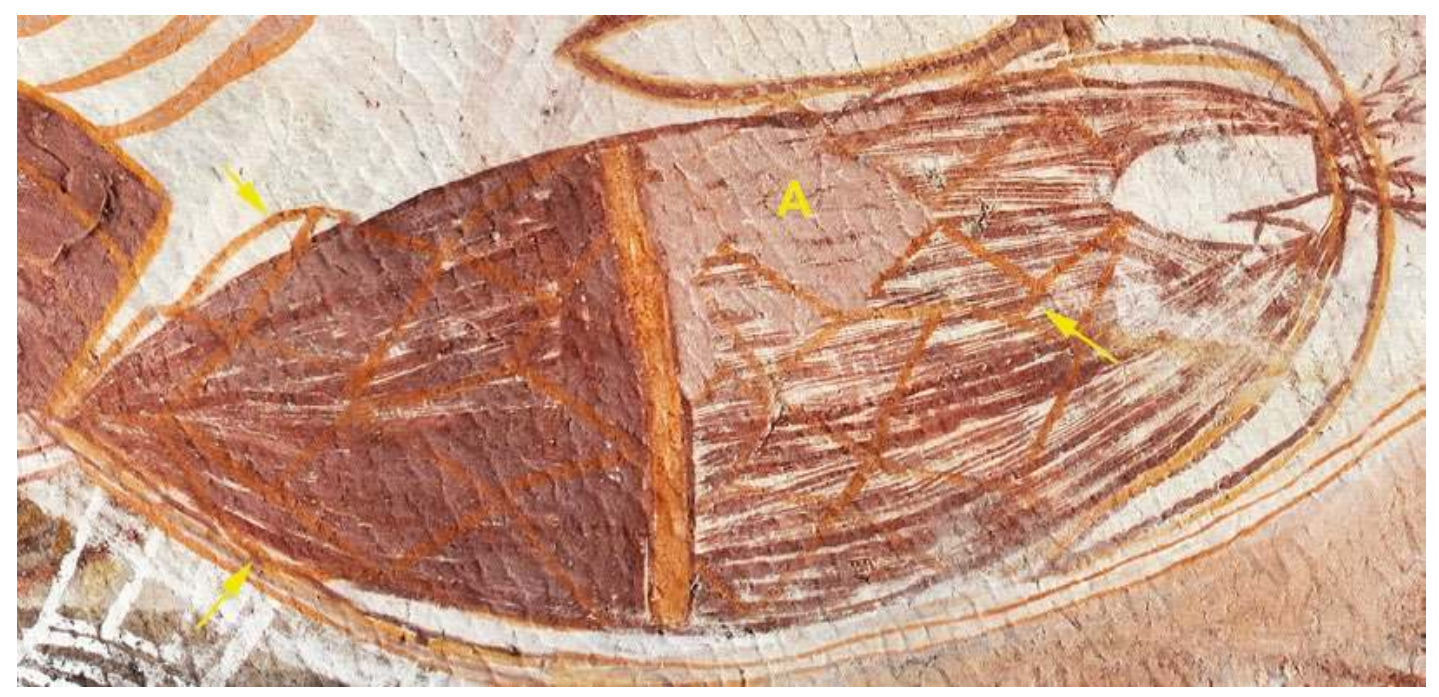

Figure 11.25 Detail of retouching over the stomach pattern of Image \#77. A = purple over-paint; arrows highlight underlying orange mesh pattern.

Source: Photograph by Robert Gunn.

The huge barramundi (Image \#77), $239 \mathrm{~cm}$ long $\times 86 \mathrm{~cm}$ wide, is the largest polychrome X-ray fish at Nawarla Gabarnmang (Figure 11.20; at $171 \times 73 \mathrm{~cm}$, the other painted barramundi on Panel E1 (Image \#78; Figure 11.21) is the fourth largest). Other large X-ray barramundi occur on Panels D and H, 2 m and $3 \mathrm{~m}$ away respectively (see Figure 11.4). 


\begin{tabular}{|c|c|c|c|c|c|c|c|c|c|c|c|c|c|c|c|c|c|c|c|c|c|c|c|c|c|}
\hline \multirow{2}{*}{$\stackrel{\approx}{\sim}$} & Width (cm) & \llcorner & $\simeq$ & & & & & $\gamma$ & $\nabla$ & 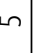 & & & & & & & & & & & & & & & \\
\hline & Length (cm) & $\stackrel{\infty}{m}$ & $\underset{\sim}{\infty}$ & & & & & $\stackrel{?}{r}$ & $n$ & $a$ & & & & & & & & & & & & & & & \\
\hline \multirow{5}{*}{ 을 } & Excellent & & & & & & & & & & & & & & & & & & & & & & & & \\
\hline & Good & $>$ & $>$ & & & & $\searrow$ & $>$ & $>$ & & & & & & & & & & & & & & & & \\
\hline & Fair & & & & & & & & & & & & & & & $>$ & $>$ & & & & $>$ & & & & \\
\hline & Poor & & & & & & & & & & & & $>$ & $>$ & $>$ & & & $>$ & $>$ & & & & $>$ & & \\
\hline & Very poor & & & $>$ & $>$ & $>$ & & & & $>$ & $>$ & $>$ & & & & & & & & $>$ & & $>$ & & $>$ & $>$ \\
\hline \multicolumn{2}{|l|}{ 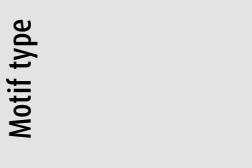 } & $\underset{\cong}{\cong}$ & $\stackrel{\underline{\cong}}{\cong}$ & $\sim$ & $\sim$. & $\sim$. & $\stackrel{5}{.}$ & & $\underline{\underline{\underline{E}}}$ & $\sim$ & $\sim$ & $\sim$ & 峁 & $\sim$ & $\sim$ & $\sim$ & $\stackrel{\check{E}}{\cong}$ & $\stackrel{\check{E}}{\cong}$ & $\sim$ & $\sim$ & 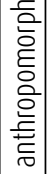 & $\sim$ & 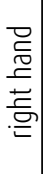 & $\sim$ & $\sim$ \\
\hline & Fragment & & & & $>$ & $>$ & & & & & & & & & & & & & $>$ & & & & & & \\
\hline & Pigment trace & & & & & & & & & $>$ & $>$ & $>$ & & & & & & & & & & & & $>$ & \\
\hline & Hand stencil & & & & & & & & & & & & & & & & & & & & & & $>$ & & \\
\hline & X-гау & & & & & & & & & & & & & & & & $>$ & & & & & & & & \\
\hline 튼 & Infill & & & $>$ & & & & & & & & & $>$ & $>$ & & $>$ & & & & & & & & & \\
\hline & Outline & & & $>$ & & & & & & & & & $>$ & $>$ & & $>$ & & & & & & & & & \\
\hline & Solid + linear & & & & & & & & & & & & & & & & & & & & & & & & \\
\hline & Solid & $>$ & $>$ & & & & 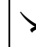 & $y$ & $>$ & & & & & & $>$ & & & $>$ & & $>$ & $>$ & $>$ & & & \\
\hline & Linear & & & & & & & & & & & & & & & & & & & & & & & & $>$ \\
\hline \multirow{11}{*}{ 흥 } & $\begin{array}{l}\text { White + red + } \\
\text { orange + purple }\end{array}$ & & & & & & & & & & & & & & & & & & & & & & & & \\
\hline & Cream + red & & & & & & & & & & & & & & & & & & & & & & & & \\
\hline & White + purple & & & & & & & & & & & & & & & & & & & & & & & & \\
\hline & White + orange & & & & & & & & & & & & & & & & & & & & & & & & \\
\hline & Orange + white & & & & & & & & & & & & & & & & & & & & & & & & \\
\hline & White + red & & & & & & & & & & & & & & & & & & & & & & & & \\
\hline & Orange & & & & & & & & & & & & & & & & & & & & & & & & \\
\hline & White & & & & & & & & & & & & & & & & & & & & & & & & \\
\hline & Cream & & & & & & & & & & & & & & & & & & & & & & & & \\
\hline & Yellow & & & & & & & & & & & & & & & & & & & & & & & $>$ & $>$ \\
\hline & Red & $>$ & $>$ & $>$ & $>$ & $>$ & $\searrow$ & tha & $>$ & $>$ & $>$ & $>$ & $>$ & $>$ & $>$ & $>$ & $>$ & $>$ & $>$ & $>$ & $>$ & $>$ & $>$ & & \\
\hline \multirow{2}{*}{ 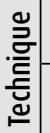 } & Stencil & & & & & & & & & & & & & & & & & & & & & & $>$ & & \\
\hline & Painting & $>$ & $>$ & $>$ & $>$ & $>$ & 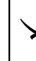 & 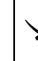 & $>$ & $>$ & $>$ & $>$ & $>$ & $>$ & $>$ & $>$ & $>$ & $>$ & $>$ & $>$ & $>$ & $>$ & & $>$ & $>$ \\
\hline \multicolumn{2}{|c|}{ 莺 } & - & $\sim$ & $m$ & $\nabla$ & \llcorner & 6 & $r$ & - & $\infty$ & $a$ & 이 & $\mp$ & $\simeq$ & $m$ & $\Xi$ & $\stackrel{ }{\leftarrow}$ & $\div$ & $\approx$ & $\stackrel{\infty}{\ulcorner}$ & $\stackrel{2}{\rightleftharpoons}$ & શ & $\succsim$ & $\approx$ & $\ddot{\sim}$ \\
\hline
\end{tabular}




\begin{tabular}{|c|c|c|c|c|c|c|c|c|c|c|c|c|c|c|c|c|c|c|c|c|c|c|c|c|c|c|}
\hline \multirow{2}{*}{$\stackrel{\sim}{\sim}$} & Width $(\mathrm{cm})$ & & & & & & & & & & & & & & & & & & & & & 유 & 는 & & & \\
\hline & Length (cm) & & & & & & & & & & & & & & & & & & & & & เ & 음 & & & \\
\hline \multirow{5}{*}{ 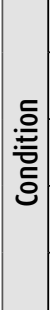 } & Excellent & & & & & & & & & & & & & & & & & & & & & & & & & \\
\hline & Good & & & & & & & & & & & & & & & & & & & & & & & & & \\
\hline & Fair & & & & & & & & & & & & & & & & & & & & & & $>$ & & & $>$ \\
\hline & Poor & & & & & & & & $>$ & $>$ & $>$ & & & $>$ & & & $>$ & $>$ & & & $>$ & $>$ & & $>$ & & \\
\hline & Very poor & $>$ & $>$ & $>$ & Y & & $>$ & $>$ & & & & $>$ & $>$ & & $>$ & $>$ & & & $>$ & $>$ & & & & & $>$ & \\
\hline \multicolumn{2}{|l|}{ 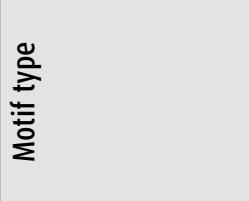 } & $\sim$ & $\sim$ & $\sim$ & $\curvearrowright$ & & $\sim$ & $\sim$ & $\sim$. & 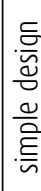 & $\sim$ & $\sim$ & $\sim$. & 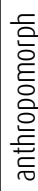 & 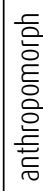 & $\underline{\underline{\underline{n}}}$ & $\begin{array}{l}\text { 응 } \\
\text { 음 } \\
\text { 음 } \\
\text { 을 } \\
\text { 듬 }\end{array}$ & $\begin{array}{l}\text { 등 } \\
\text { 응 } \\
\text { 음 } \\
\text { 을 } \\
\text { 듬 }\end{array}$ & $\sim$ & $\sim$ & 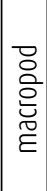 & 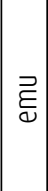 & 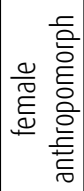 & $\begin{array}{l}\text { 등 } \\
\text { 을 } \\
\text { ह } \\
\text { 을 } \\
\text { 을 } \\
\text { 등 }\end{array}$ & 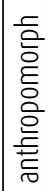 & $\frac{0}{\frac{0}{\sigma}}$ \\
\hline \multirow{9}{*}{ 틍 } & Fragment & $>$ & & & & & & $>$ & & & & & & & & & & & $>$ & $>$ & & & & & & \\
\hline & Pigment trace & & $>$ & & & & $>$ & & & & & & & & & & & & & & & & & & & \\
\hline & Hand stencil & & & & & & & & & & & & & & & & & & & & & & & & & \\
\hline & X-гау & & & & & & & & & & & & & & & & & & & & & & & & & \\
\hline & Infill & & & $>$ & & & & & & $>$ & & & $>$ & $>$ & $>$ & $>$ & $>$ & & & & $>$ & & & & & $>$ \\
\hline & Outline & & & $>$ & & & & & & $>$ & & & $>$ & $>$ & $>$ & $>$ & $>$ & & & & $>$ & & & & & $>$ \\
\hline & Solid + linear & & & & & & & & & & & & & & & & & & & & & & & & & \\
\hline & Solid & & & & & & & & $>$ & & $>$ & $>$ & & $>$ & & & & $>$ & & & & $>$ & $>$ & $>$ & $>$ & \\
\hline & Linear & & & & & & & & & & & & & & & & & & & & & $>$ & $>$ & $>$ & $>$ & \\
\hline \multirow{11}{*}{$\frac{\text { 응 }}{9}$} & $\begin{array}{c}\text { White + red + } \\
\text { orange + purple }\end{array}$ & & & & & & & & & & & & & & & & & & & & & & & & & \\
\hline & Cream + red & & & & & & & & & & & & & & & & & & & & & & & & & \\
\hline & White + purple & & & & & & & & & & & & & & & & & & & & & & & & & \\
\hline & White + orange & & & & & & & & & & & & & & & & & & & & & & & & & \\
\hline & Orange + white & & & & & & & & & & & & & & & & & & & & & & & $>$ & & \\
\hline & White + red & & & & & & & & & & & & & & $>$ & & & & & & $>$ & & & & & $>$ \\
\hline & Orange & & & & & & & & & & & & & & & & & & & & & & & & $>$ & \\
\hline & White & & & & & & & & & & & & & & & $>$ & $>$ & $>$ & $>$ & $>$ & & $>$ & $>$ & & & \\
\hline & Cream & & & & & & & & & & & & & & & & & & & & & & & & & \\
\hline & Yellow & $>$ & $>$ & $>$ & & & $>$ & $>$ & $>$ & $>$ & $>$ & & & & & & & & & & & & & & & \\
\hline & Red & & & & & & & & & & & $>$ & $>$ & $>$ & & & & & & & & & & & & \\
\hline \multirow{2}{*}{ 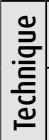 } & Stencil & & & & & & & & & & & & & & & & & & & & & & & & & \\
\hline & Painting & $>$ & $>$ & $>$ & & & $>$ & $>$ & $>$ & $>$ & $>$ & $>$ & $>$ & $>$ & $>$ & $>$ & $>$ & $>$ & $>$ & $>$ & $>$ & $>$ & $>$ & $>$ & $>$ & $>$ \\
\hline \multicolumn{2}{|c|}{ 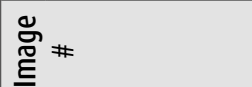 } & む & $\stackrel{\curvearrowleft}{\sim}$ & 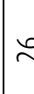 & & v & $\stackrel{\infty}{\sim}$ & શ & $\stackrel{\circ}{m}$ & $\bar{m}$ & $\approx$ & $m$ & ঙ & $\stackrel{n}{m}$ & $\stackrel{m}{m}$ & $\bar{m}$ & $\stackrel{\infty}{m}$ & m & ㅇ & ஏ & $\mathscr{\nearrow}$ & $\underset{\forall}{\eta}$ & ঔ & $\stackrel{\sim}{7}$ & † & જ \\
\hline
\end{tabular}




\begin{tabular}{|c|c|c|c|c|c|c|c|c|c|c|c|c|c|c|c|c|c|c|c|c|c|c|c|c|c|}
\hline \multirow{2}{*}{$\stackrel{\Xi}{\sim}$} & Width $(\mathrm{cm})$ & & & & & & & & & nิ & En & $\bar{m}$ & $\lesssim$ & $\stackrel{\sim}{\sim}$ & & & & & & $a$ & & & & & \\
\hline & Length $(\mathrm{cm})$ & & & & & & & & & 음 & $\infty$ & $\stackrel{ }{\circ}$ & เู & 뉴 & & & & & & 윤 & & & & & \\
\hline \multirow{5}{*}{$\begin{array}{l}\text { 을 } \\
\text { 응 }\end{array}$} & Excellent & & & & & & & & & & & & & & & & & & & & & & & & \\
\hline & Good & & & & & & & & & & & & $>$ & & & & & & & $>$ & & & & & \\
\hline & Fair & & & & & & $>$ & $>$ & & & $>$ & $>$ & & $>$ & & & & $>$ & & & & & & & \\
\hline & Poor & & & & & $>$ & & & $>$ & $>$ & & & & & & & & & $>$ & & & $>$ & $>$ & $>$ & $>$ \\
\hline & Very poor & $>$ & $y$ & 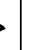 & $>$ & & & & & & & & & & $>$ & $>$ & $>$ & & & & $>$ & & & & \\
\hline \multicolumn{2}{|l|}{ 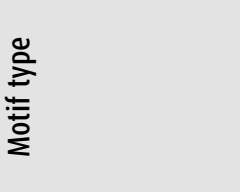 } & $\begin{array}{l}\text { 응 } \\
\text { 을 } \\
\text { हू }\end{array}$ & - & . & $\sim$ & $\sim$ & ह్ & $\sim$ & $\sim$ & 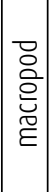 & $\stackrel{\underline{\underline{\underline{E}}}}{\underline{\underline{E}}}$ & 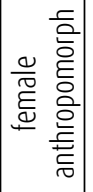 & 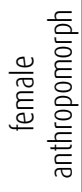 & 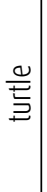 & $\sim$ & $\sim$ & $\sim$ & 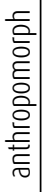 & $\sim$ & $\stackrel{\underline{\underline{E}}}{\cong}$ & $\sim$ & 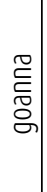 & 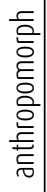 & $\sim$ & 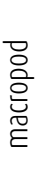 \\
\hline \multirow{9}{*}{ 톤 } & Fragment & & Y & 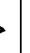 & $>$ & $>$ & & & $>$ & & & & & & $>$ & $>$ & $>$ & & & & $>$ & & & & \\
\hline & Pigment trace & & & & & & & & & & & & & & & & & & & & & & & & \\
\hline & Hand stencil & & & & & & & & & & & & & & & & & & & & & & & & \\
\hline & $\mathrm{X}$-гау & & & & & & & & & & & & & & & & & & & & & & & & \\
\hline & Infill & & & & & & & & & & $>$ & $>$ & $>$ & & & & & & $>$ & $>$ & & $>$ & & $>$ & $>$ \\
\hline & Outline & $>$ & & & & & & & & & $>$ & $>$ & $>$ & & & & & & $>$ & $>$ & & $>$ & & $>$ & $>$ \\
\hline & Solid + linear & & & & & & & & & & & & & & & & & & & & & & & & \\
\hline & Solid & $>$ & & & & & $>$ & $>$ & & $>$ & $>$ & $>$ & $>$ & $>$ & & & & & & & & & $>$ & & $>$ \\
\hline & Linear & & & & & & $>$ & $>$ & & & & & & & & & & $>$ & & & & & $>$ & & \\
\hline \multirow{11}{*}{ 흥 } & $\begin{array}{l}\text { White + red + } \\
\text { orange + purpl }\end{array}$ & & & & & & & & & & & & & & & & & & & & & & & & \\
\hline & Cream + red & & & & & & & & & & & & $>$ & & & & & & & & & & & & \\
\hline & White + purpl & & & & & & & & & & & & & & & & & & & & & & & & \\
\hline & White + orang & & & & & & & & & & & & & & & & & & & & & & & & $>$ \\
\hline & Orange + whit & & & & & & & & & & & & & & & & & & & & & & & & \\
\hline & White + red & $>$ & Y & $>$ & & & & & & & $>$ & $>$ & & & & & & & & & & & & & \\
\hline & Orange & & & & & & & & & & & & & & & & & & & & & & & & \\
\hline & White & & & & $>$ & $>$ & $>$ & $>$ & $>$ & $>$ & & & & $>$ & $>$ & $>$ & $>$ & $>$ & $>$ & $>$ & $>$ & $>$ & $>$ & $>$ & \\
\hline & Cream & & & & & & & & & & & & & & & & & & & & & & & & \\
\hline & Yellow & & & & & & & & & & & & & & & & & & & & & & & & \\
\hline & Red & & & & & & & & & & & & & & & & & & & & & & & & \\
\hline \multirow{2}{*}{ 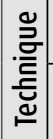 } & Stencil & & & & & & & & & & & & & & & & & & & & & & & & \\
\hline & Painting & $>$ & Y & $>$ & $>$ & $>$ & $>$ & $>$ & $>$ & $>$ & $>$ & $>$ & $>$ & $>$ & $>$ & $>$ & $>$ & $>$ & $>$ & $>$ & $>$ & $>$ & $>$ & $>$ & $>$ \\
\hline \multicolumn{2}{|c|}{ 兽 \# } & $\stackrel{\infty}{q}$ & & g/ & 유 & โn & กี & 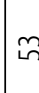 & เै & 는 & \llcorner & in & $\stackrel{\infty}{\curvearrowleft}$ & ฉิ & 8 & $\overline{6}$ & $\widetilde{\sigma}$ & $\tilde{b}$ & వे & เู & ๑ & $\hat{\sigma}$ & $\stackrel{\infty}{0}$ & ติ & 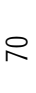 \\
\hline
\end{tabular}




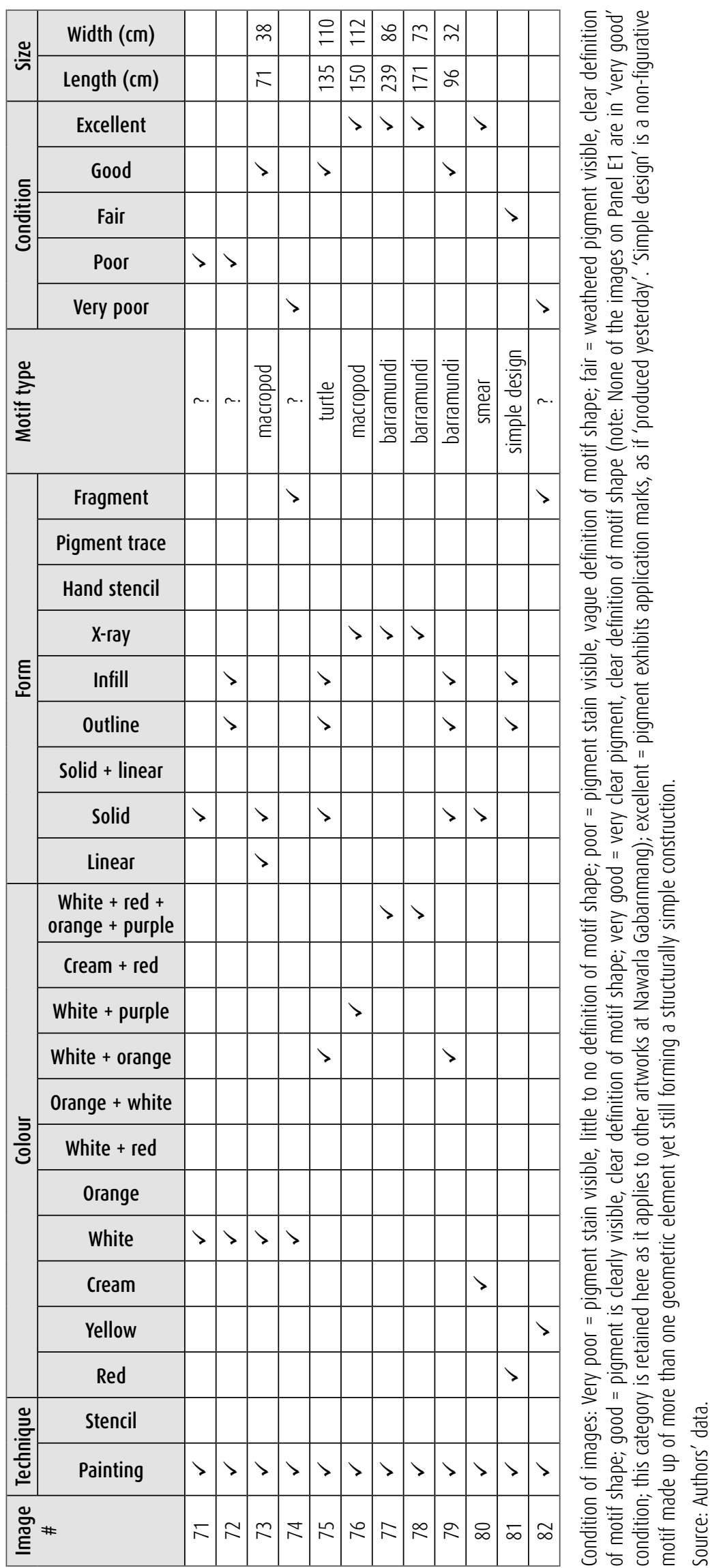


Table 11.2 Panel E1: Superimpositions.

\begin{tabular}{|l|l|}
\hline Image \# & Underlying images \\
\hline 16 & $(16: 17$ unclear $)$ \\
\hline 17 & $(16: 17$ unclear $)$ \\
\hline 18 & $(18: 19$ unclear $)$ \\
\hline 19 & $(18: 19$ unclear $)$ \\
\hline 23 & $1,2,3,4,5$ \\
\hline 24 & 6 \\
\hline 26 & 15 \\
\hline 28 & 21 \\
\hline 29 & 19,21 \\
\hline 32 & 10 \\
\hline 33 & 3 \\
\hline 34 & $1,2,4,5,23,24$ \\
\hline 35 & 30,31 \\
\hline 36 & 11 \\
\hline 37 & 11,15 \\
\hline 38 & $11,15,16$ (38:39 unclear) \\
\hline 39 & $16,17,18,19,20$ (38:39 unclear) \\
\hline 40 & 29 \\
\hline 41 & 29,82 \\
\hline 42 & $30,31,32,35$ \\
\hline 43 & 32 \\
\hline 44 & $2,3,4,5,23,24$ \\
\hline 45 & 34 \\
\hline 46 & 41,82 \\
\hline 47 & $27,28,41,46$ \\
\hline 48 & 3,33 \\
\hline 49 & 11,36 \\
\hline 50 & 11,14 \\
\hline 51 & 11,38 \\
\hline 52 & $11,18,19,37$ \\
\hline 53 & $19,29,31,39,40$ \\
\hline 54 & 30,42 \\
\hline
\end{tabular}

\begin{tabular}{|c|c|}
\hline Image \# & Underlying images \\
\hline 55 & $9,10,32,42,43$ \\
\hline 56 & $44,46,47$ \\
\hline 57 & $5,8,23,24,34,44,47$ \\
\hline 58 & $2,5,23,34,44$ \\
\hline 59 & 3,33 \\
\hline 60 & 12,22 \\
\hline 61 & 13 \\
\hline 62 & 13 \\
\hline 63 & 34,45 \\
\hline 64 & $11,15,37,38$ \\
\hline 65 & $11,16,17,18,37,39,52$ \\
\hline 66 & $16,17,38,39$ \\
\hline 67 & $19,20,21,29,39,53$ \\
\hline 68 & $19,28,29,41,46,47,81$ \\
\hline 69 & $29,30,31,41$ \\
\hline 70 & $32,42,54,55$ \\
\hline 71 & $9,32,55$ \\
\hline 72 & $8,23,24,34,44,56,57$ \\
\hline 73 & $44,47,56,57$ \\
\hline 74 & $30,31,35,69$ \\
\hline 75 & $24,25,41,44,47,56,57,72,73$ \\
\hline 76 & $\begin{array}{l}30,32,35,44,47,54,55,56,57,69,70, \\
71,72,73,74,75\end{array}$ \\
\hline 77 & $\begin{array}{l}13,15,17,18,20,21,25,28,34,38,39, \\
47,50,51,62,63,64,65,66,67,68,72, \\
75,81\end{array}$ \\
\hline 78 & $3,23,33,34,44,48,56,59,63,72,75$ \\
\hline 79 & 78 \\
\hline 80 & $11,63,79$ \\
\hline 81 & 21,28 \\
\hline 82 & 21 \\
\hline
\end{tabular}

Source: Authors' data.

Table 11.3 Panel E1: Summary of the art phases.

\begin{tabular}{|l|l|l|l|l|l|}
\hline Phase & Number of layers & Number of images & Major colours & Major conventions & Major motif classes \\
\hline VI & 3 & 5 & polychrome & X-ray & fish, macropod \\
\hline V & 1 & 1 & white+orange & solid+outline+infill & reptile \\
\hline IV & 7 & 39 & white, white+red & $\begin{array}{l}\text { solid, } \\
\text { solid+outline+infill }\end{array}$ & $\begin{array}{l}\text { macropods, fish, } \\
\text { reptile, anthropomorph, bird }\end{array}$ \\
\hline III & 1 & 4 & red & outline+striped infill & unknown \\
\hline II & 1 & 12 & yellow & solid, outline & complex abstract design \\
\hline I & 2 & 21 & red & solid, outline+infill & reptile, fish \\
\hline
\end{tabular}

Source: Authors' data. 


\section{Excavation Square $\mathbf{P}$}

In May 2012, we excavated a small, $50 \times 50 \mathrm{~cm}$ square immediately beneath Panel E1 (Figures 11.4 and 11.26). Our aims were threefold:

- To find and date any (now dried) drops of paint that may have fallen onto then-floor surfaces at the time of painting, thereby dating immediately overhanging paintings in those colours.

- To find and date fragments of pigment that fell from the overlying ceiling paintings, thereby giving minimum ages for those paintings.

- To date when the Panel E1 ceiling surface was created, by finding and dating buried slabs of rock from the previous ceiling rock stratum before the current one was painted, thereby giving a maximum age for the painted Panel E1.

Square $\mathrm{P}$ was excavated in 23 artificial Excavation Units (XU) following the stratigraphy (Table 11.4). Individual XUs averaged $1.3 \pm 0.3 \mathrm{~cm}$ in thickness. Excavation proceeded to a maximum $29 \mathrm{~cm}$ depth when a hard and continuous flat rock surface was reached. That rock surface is not the bedrock, but a layer of rock that fell from the ceiling (see below) in the process creating the current and subsequently painted ceiling rock surface

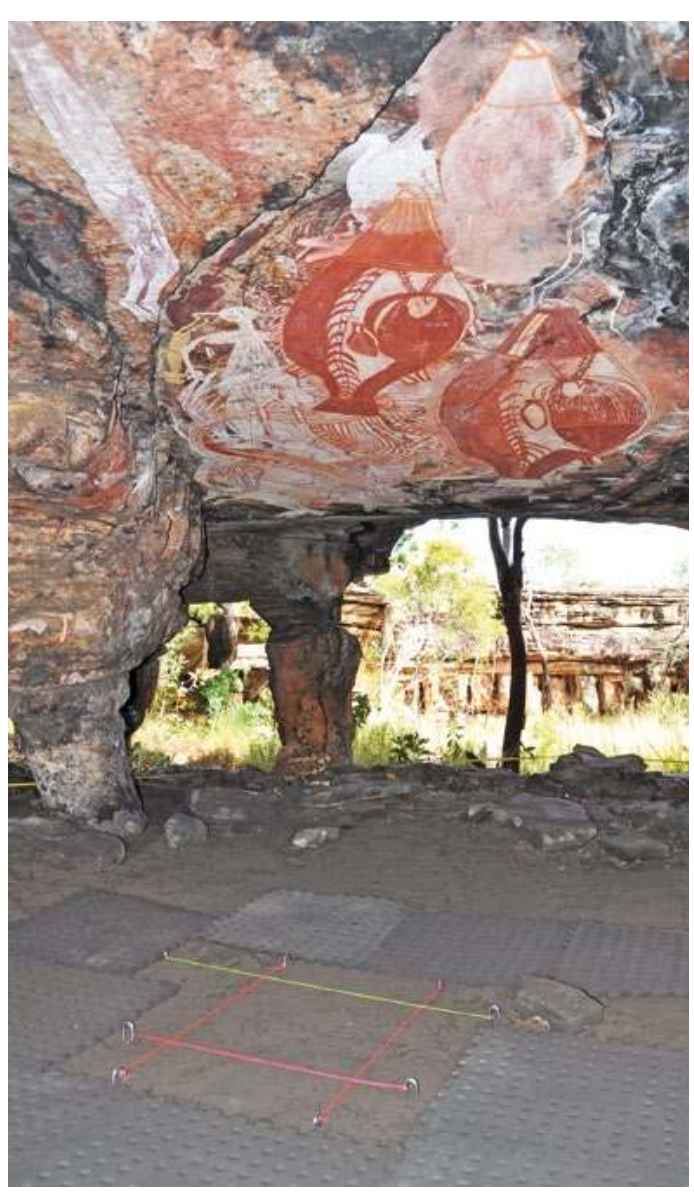

Figure 11.26 Square $P$ before excavation, below painted Panel E1.

Source: Photograph by Bruno David. of Panel E1 (Figure 11.27).

Table 11.4 Square P: Details of Excavation Units.

\begin{tabular}{|c|c|c|c|c|c|c|c|c|}
\hline$X U$ & SU & $\begin{array}{l}\text { Mean depth } \\
\text { at top }(\mathrm{cm})\end{array}$ & $\begin{array}{c}\text { Mean depth at } \\
\text { centre }(\mathrm{cm})\end{array}$ & $\begin{array}{c}\text { Mean depth at } \\
\text { base }(\mathrm{cm})\end{array}$ & $\begin{array}{c}\text { Mean thickness } \\
(\mathrm{cm})\end{array}$ & $\begin{array}{l}\text { Area } \\
\left(\mathrm{m}^{2}\right)\end{array}$ & $\begin{array}{l}\text { Weight } \\
(\mathrm{kg})\end{array}$ & $\begin{array}{l}\text { Volume } \\
\text { (litres) }\end{array}$ \\
\hline 1 & $1 a+1 b$ & 0.0 & 1.0 & 2.0 & 2.0 & 0.25 & 4.4 & 3.0 \\
\hline 2 & $1 a+1 b$ & 2.0 & 2.6 & 3.1 & 1.1 & 0.25 & 4.6 & 3.0 \\
\hline 3 & $1 b+2$ & 3.1 & 3.8 & 4.5 & 1.4 & 0.25 & 5.9 & 4.5 \\
\hline 4 & $1 b+2$ & 4.5 & 5.1 & 5.6 & 1.1 & 0.25 & 4.3 & 2.5 \\
\hline 5 & $1 b+2$ & 5.6 & 6.3 & 6.9 & 1.3 & 0.25 & 4.7 & 4.0 \\
\hline 6 & $1 b+2$ & 6.9 & 7.6 & 8.3 & 1.4 & 0.25 & 4.6 & 4.0 \\
\hline 7 & 2 & 8.3 & 9.0 & 9.7 & 1.4 & 0.25 & 5.4 & 4.5 \\
\hline 8 & $2+3 a$ & 9.7 & 10.5 & 11.3 & 1.6 & 0.25 & 5.4 & 5.0 \\
\hline 9 & $2+3 a$ & 11.3 & 12.0 & 12.7 & 1.4 & 0.25 & 4.3 & 3.0 \\
\hline 10 & $2+3 a$ & 12.7 & 13.6 & 14.5 & 1.8 & 0.25 & 6.0 & 5.5 \\
\hline 11 & $2+3 a$ & 14.5 & 15.2 & 15.9 & 1.4 & 0.25 & 4.8 & 4.0 \\
\hline 12 & $2+3 a$ & 15.9 & 16.5 & 17.1 & 1.2 & 0.25 & 4.6 & 3.5 \\
\hline 13 & $2+3 a$ & 17.1 & 17.8 & 18.4 & 1.3 & 0.25 & 4.5 & 4.0 \\
\hline 14 & $3 a$ & 18.4 & 19.3 & 19.7 & 1.3 & 0.25 & 3.3 & 2.5 \\
\hline
\end{tabular}




\begin{tabular}{|c|c|c|c|c|c|c|c|c|}
\hline XU & SU & $\begin{array}{l}\text { Mean depth } \\
\text { at top }(\mathrm{cm})\end{array}$ & $\begin{array}{l}\text { Mean depth at } \\
\text { centre }(\mathrm{cm})\end{array}$ & $\begin{array}{c}\text { Mean depth at } \\
\text { base }(\mathrm{cm})\end{array}$ & $\begin{array}{l}\text { Mean thickness } \\
(\mathrm{cm})\end{array}$ & $\begin{array}{l}\text { Area } \\
\left(m^{2}\right)\end{array}$ & $\begin{array}{l}\text { Weight } \\
\text { (kg) }\end{array}$ & $\begin{array}{l}\text { Volume } \\
\text { (litres) }\end{array}$ \\
\hline 15 & $3 a$ & 19.7 & 20.3 & 20.8 & 1.1 & 0.25 & 3.7 & 3.0 \\
\hline 16 & $3 a$ & 20.8 & 21.3 & 21.8 & 1.0 & 0.25 & 2.8 & 2.5 \\
\hline 17 & $3 a$ & 21.8 & 22.5 & 23.2 & 1.4 & 0.25 & 4.3 & 4.0 \\
\hline 18 & $3 a$ & 23.2 & 23.7 & 24.1 & 0.9 & 0.25 & 3.4 & 3.0 \\
\hline 19 & $3 a+3 b$ & 24.1 & 24.7 & 25.2 & 1.1 & 0.25 & 3.6 & 3.0 \\
\hline 20 & $3 a+3 b$ & 25.2 & 25.9 & 26.6 & 1.4 & 0.25 & 5.1 & 4.5 \\
\hline 21 & $3 a+3 b$ & 26.6 & 27.3 & 28.0 & 1.4 & 0.25 & 4.9 & 4.0 \\
\hline 22 & $3 a+3 b$ & 28.0 & 28.4 & 28.7 & 0.7 & 0.23 & 2.3 & 1.0 \\
\hline 23 & $3 a+3 b$ & 28.7 & 28.9 & 29.1 & 0.4 & 0.05 & 0.5 & $<0.5$ \\
\hline Total & & & & & $1.3 \pm 0.3$ & & 97.4 & 78.0 \\
\hline
\end{tabular}

SU numbers in bold contribute most to that XU's sediments.

Source: Authors' data.

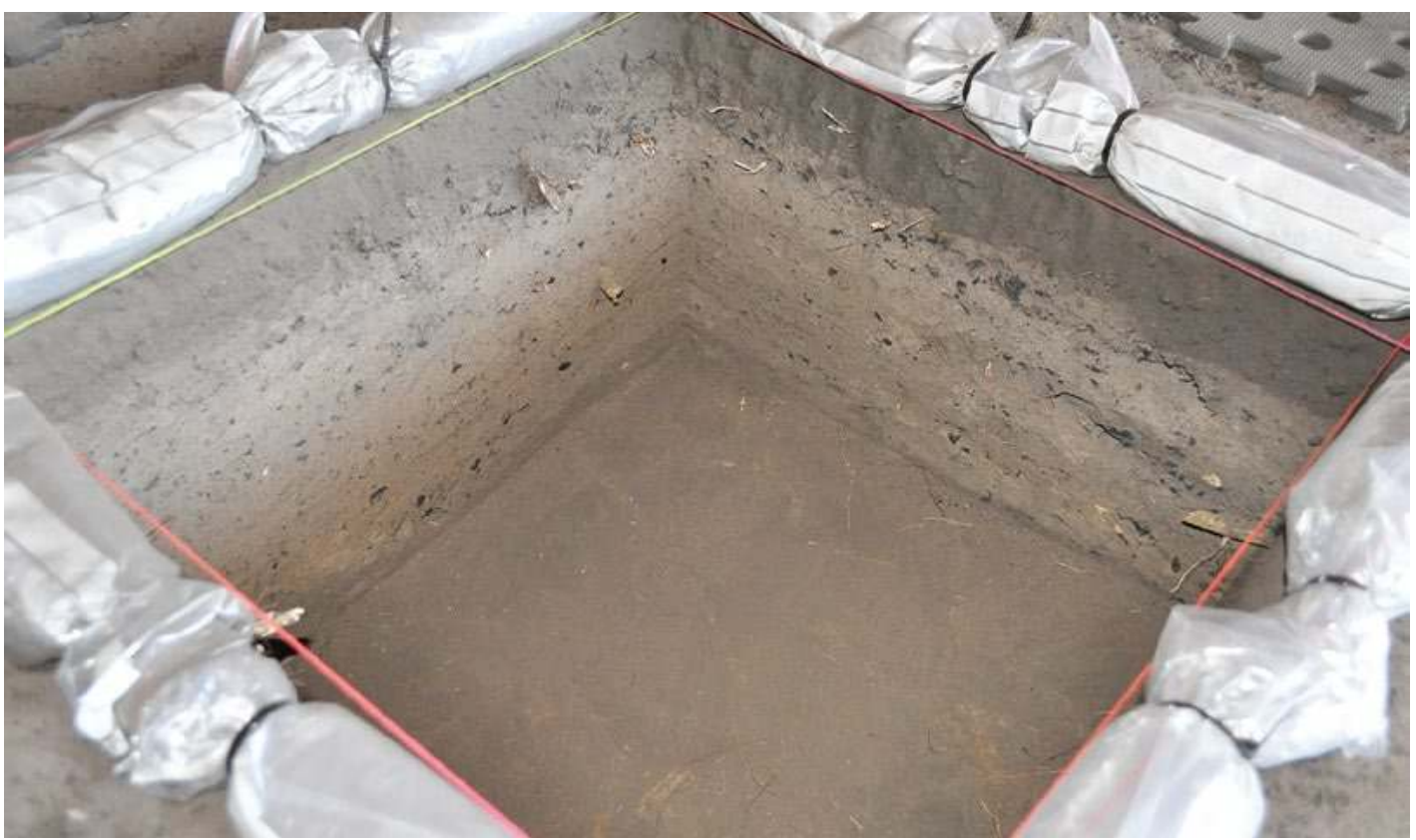

Figure 11.27 Square P after completion of excavation showing south and west walls (the green string is the south side of the square). Note the flat rock surface at base.

Source: Photograph by Bruno David.

\section{Stratigraphy of Square P}

The Square P sediment sequence consists of the following SUs from the top downwards (Figure 11.28); SUs define the sediment layers, unlike XUs that relate to units of excavation. An XU is almost always thinner than the $\mathrm{SU}$ in which it occurs. Where neighbouring sediment layers are similarly composed, they are divided into sub-SUs, differentiated by a capital letter (e.g. SU1A, SU1B) rather than given their own SU number:

- SU1A: The loose, disturbed surface sediments of the current treadage zone, consisting of fine, ashy, loamy sand with abundant charcoal. Sediments, dry at the time of excavation, are homogeneous in colour, texture and content across the square and with depth. The changeover to SU1B is ill-defined. No plants grow on the ground surface at the top of SU1A. 
- SU1B: Similar in all respects to SU1A, only being differentiated by a slightly greater consolidation of sediments. Like SU1A, SU1B is loose and should be treated as a near-surface, disturbed deposit below the looser surface zone that is SU1A. A few dry leaves in vertical or angled positions are present. Sediments are homogeneous across the square and with depth. The changeover to SU2 is fairly marked but not sudden.

- SU2: Moderately consolidated and slightly compact fine, ashy, loamy sand with abundant charcoal and with animal bone. Sediments, dry at the time of excavation, are homogeneous in colour, texture and content across the square and with depth. Rootlets are present. Sediments are noticeably lighter in colour than SU1 above and SU3 below. The changeover to SU3A is gradual, typically over c. $3 \mathrm{~cm}$ vertical depth, sometimes slightly more.

- SU3A: In many ways similar to SU2, SU3A sediments are darker in colour with less abundant charcoal. Rootlets are present throughout the square but less abundant than in SU2. Sediments are homogeneous in colour, texture and content across the square and generally with depth, except that during excavation small, c. $1 \mathrm{~mm}$ to $2 \mathrm{~cm}$ thick patches of consolidated and compact, very fine, light-coloured powdery pigment coagulated around the dry, ashy, loamy sand that makes up the bulk of SU3A occurred at c. $26 \mathrm{~cm}$ depth in XU18, with a minor presence continuing down into XU19. These distinctive patches of coloured sediment are densely distributed across much of XU18 (Figure 11.29), rapidly petering out towards the northeastern quadrant of the square. These very numerous patches are, in plan view, typically c. $2 \mathrm{~cm}$ in diameter with diffuse convex edges that often overlap at their margins because they are so abundant. They are interpreted as drops of paint that fell on the ground during the painting of Panel E1, became mixed with the surface ashy, loamy sand and then dried in situ (see below). The absence of dried paint drops in the northeastern corner of the square matches well the edge of painted Panel E1 overhead on the ceiling (see Figure 11.4, which was accurately mapped to sub-centimetre accuracy by 3-D laser). The interface between SU3A and SU3B is marked in many parts of the square and easily distinguished during excavation; in other parts, in the central and northern sections, SU3A was intermixed with SU3B onto the basal rock.

- SU3B: This $S U$ is the lowermost c. $4 \mathrm{~cm}$ of the sediment sequence across much of the square, although in some parts SU3B is intermixed with the basal levels of SU3A. Its sediments are less ashy and less charcoal-rich fine, loamy sand than those of SU3A. SU3B sediments are homogeneous in colour, texture and content across the square and with depth, and more humid than in higher SUs, although never 'wet'. Abundant, very fine rootlets grow against the surface of the rock at the very base of SU3B. The rock surface reached at the base of SU3B is flat across the square.

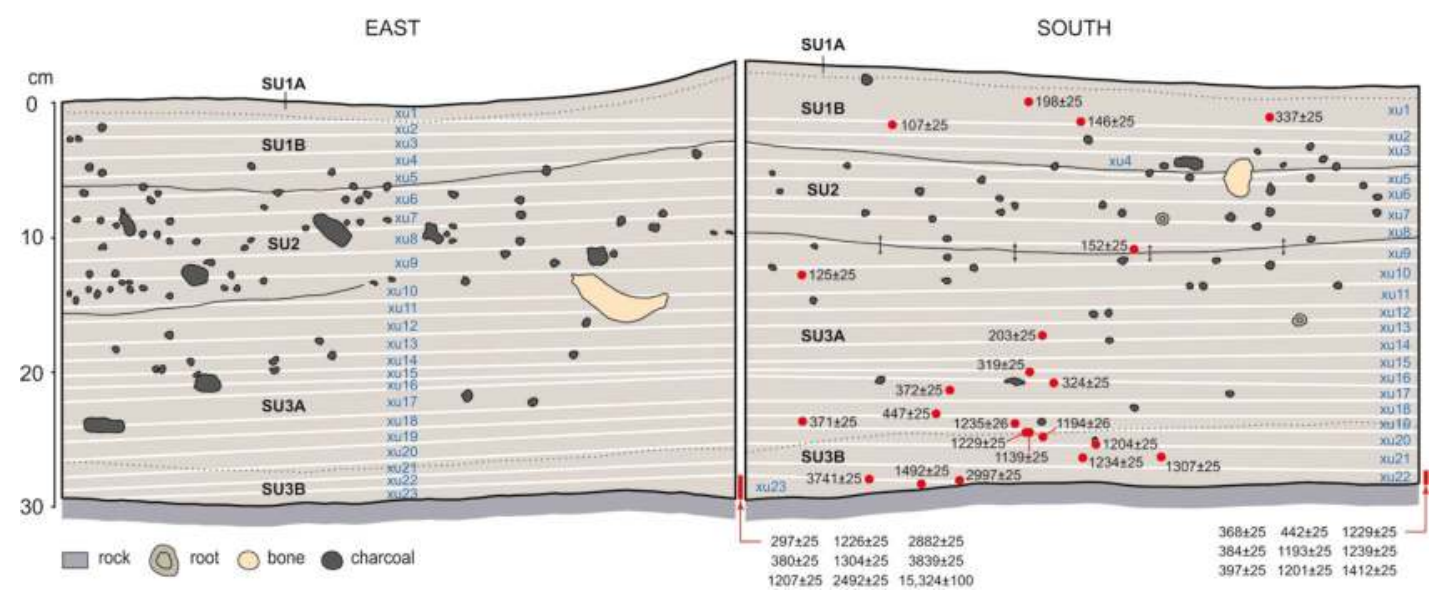

Figure 11.28 Square P east and south sections, with XUs and radiocarbon dates back-plotted.

Source: Illustration by Kara Rasmanis and Bruno David. 


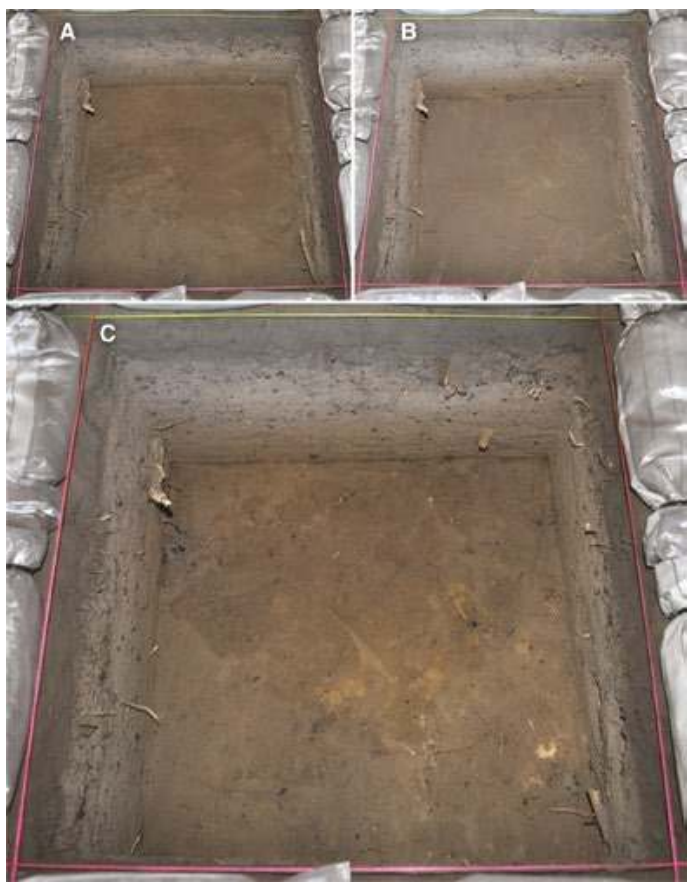

Figure 11.29 Square $P$ showing sediments at the base of A: XU16 (average basal depth $=22 \mathrm{~cm}$ below ground), a stratigraphic level above that of the dried paint drops; B: XU21 (average basal depth $=28 \mathrm{~cm}$ below ground), a stratigraphic level below that of the dried paint drops; C: XU18 (average basal depth $=24 \mathrm{~cm}$ below ground), at the stratigraphic level containing the dried paint drops, here visible as lighter-coloured patches.

Source: Photographs by Bruno David.

To better understand the origins and taphonomy of the Square P sediments and their cultural contents, analyses of $\mathrm{pH}$, percentage of organic matter and particle size were undertaken on bulk sediment samples by XU. Prior to analyses, all sediment samples were air-dried to constant weight at approximately $30^{\circ} \mathrm{C}$. There was no need to grind the samples as they were very sandy and noticeably well separated. All analyses were performed in duplicate.

\section{Particle size analyses of Square $\mathbf{P}$}

Each sample, $5 \mathrm{~g}$ of accurately weighed, airdried sediment considered representative of that $\mathrm{XU}$, was dispersed in 5 per cent tetra sodium pyrophosphate $\left(\mathrm{Na}_{4} \mathrm{P}_{2} \mathrm{O}_{7}\right)$, boiled for approximately 60 minutes and left overnight to disperse at room temperature. The samples were then wet-sieved in $600 \mu \mathrm{m}$-mesh. The $>600 \mu \mathrm{m}$ (coarse sand) particles retained in the sieve were transferred to pre-weighed petri dishes, air-dried to constant weight, and weighed. The $<600 \mu \mathrm{m}$ particles were then suspended in water and analysed with a Backman Culter LS 100 instrument.

The particle size distribution was classified using the Standard Association of Australia scheme (McDonald et al. 1998). The size fractions are defined as coarse sand $(>600 \mu \mathrm{m})$, medium sand $(600-212 \mu \mathrm{m})$, fine sand $(212$ $63 \mu \mathrm{m})$, silt $(2-63 \mu \mathrm{m})$, and clay $(<2 \mu \mathrm{m})$. The size fraction of the particles $>600 \mu \mathrm{m}$ was calculated as a weight percentage of the total sample, whereas the fractions of clay, silt and fine and medium sand size particles were calculated as volume percentage of the size fraction smaller than $600 \mu \mathrm{m}$.

\section{pH analyses of Square $\mathbf{P}$}

Soil $\mathrm{pH}$ was determined using the method described in the Soil Chemical Methods: Australasia handbook (Rayment and Lyons 2011). Measurement was based on a soil:water ratio of 1:5. The samples (1:5 water suspensions) were mechanically shaken (end-over-end shaker) for one hour. A Schott handlab Multi $12 \mathrm{pH}$ meter was standardised against buffer solutions of known $\mathrm{pH}$ to measure the $\mathrm{pH}$ of the samples.

\section{Organic matter in Square $\mathbf{P}$}

The content of organic matter was estimated by loss on ignition. The representative samples, c. $20 \mathrm{~g}$ of accurately weighed sediment, were oven-dried at $105^{\circ} \mathrm{C}$ to constant weight, weighed and then ignited in a muffle furnace at $550^{\circ} \mathrm{C}$ for two hours and re-weighed. The difference between the weight of ignited samples $\left(550^{\circ} \mathrm{C}\right)$ and oven-dry samples $\left(105^{\circ} \mathrm{C}\right)$ represents the weight of organic matter in the sample. The results are presented as a weight percentage of the oven-dry samples. 


\section{Results of analyses from Square $P$}

The results of the sediment analyses indicate that the Square $\mathrm{P}$ sediments are acidic $(\mathrm{pH}$ range: 3.83-4.55), loamy sand with high amounts of organic matter (4.0-8.3 per cent of weight by XU), consisting mainly of charcoal and ash (Table 11.5). The acidic nature of the sediments signal that buried bone is unlikely to have survived for very long.

Table 11.5 Square $\mathrm{P}$ : Sediment $\mathrm{pH}$, percentage of organic matter and particle size analysis by XU.

\begin{tabular}{|c|c|c|c|c|c|c|c|c|c|}
\hline \multirow[t]{2}{*}{$\mathrm{XU}$} & \multirow[t]{2}{*}{$\mathrm{pH}$} & \multirow{2}{*}{$\begin{array}{c}\text { Organic } \\
\text { matter } \\
\text { (\%weight) }\end{array}$} & \multirow{2}{*}{$\begin{array}{l}\text { Particles } \\
>600 \mu m \\
\text { (\% weight) }\end{array}$} & \multicolumn{5}{|c|}{ Particle size distribution of particles $<600 \mu m$ ( $\%$ volume) } & \multirow{2}{*}{$\begin{array}{c}\text { Soil } \\
\text { description }\end{array}$} \\
\hline & & & & $\begin{array}{c}\text { sand } \\
(600-63 \mu \mathrm{m})\end{array}$ & $\begin{array}{c}\text { medium } \\
\text { sand } \\
(600-212 \mu \mathrm{m})\end{array}$ & $\begin{array}{c}\text { fine sand } \\
(212-63 \mu \mathrm{m})\end{array}$ & $\begin{array}{c}\text { silt } \\
(63-2 \mu m)\end{array}$ & $\begin{array}{c}\text { clay } \\
(<2 \mu \mathrm{m})\end{array}$ & \\
\hline 1 & 4.51 & 7.32 & 7.1 & 74.6 & 41.8 & 32.8 & 22.9 & 2.5 & Loamy sand \\
\hline \multicolumn{10}{|l|}{2} \\
\hline 3 & 4.55 & 8.26 & 5.2 & 76.1 & 47.5 & 28.6 & 21.5 & 2.4 & Loamy sand \\
\hline \multicolumn{10}{|l|}{4} \\
\hline 5 & 4.55 & 8.19 & 5.3 & 76.2 & 42.9 & 33.3 & 21.9 & 1.9 & Loamy sand \\
\hline \multicolumn{10}{|l|}{6} \\
\hline 7 & 4.33 & 7.74 & 3.9 & 77.3 & 41.6 & 35.7 & 21.2 & 1.5 & Loamy sand \\
\hline \multicolumn{10}{|l|}{8} \\
\hline 9 & 4.31 & 6.31 & 5.7 & 76.3 & 41.3 & 35.0 & 22.0 & 1.7 & Loamy sand \\
\hline 10 & 4.13 & 5.78 & 4.3 & 73.7 & 40.3 & 33.4 & 24.3 & 2.0 & Loamy sand \\
\hline 11 & 3.96 & 5.15 & 5.3 & 77.2 & 44.9 & 32.3 & 20.9 & 1.9 & Loamy sand \\
\hline 12 & 3.94 & 5.23 & 3.1 & 77.5 & 46.1 & 31.4 & 20.4 & 2.1 & Loamy sand \\
\hline 13 & 3.86 & 5.51 & 3.5 & 75.3 & 43.1 & 32.2 & 22.8 & 1.9 & Loamy sand \\
\hline 14 & 3.85 & 5.23 & 2.9 & 79.9 & 47.5 & 32.4 & 18.5 & 1.6 & Loamy sand \\
\hline 15 & 3.85 & 5.19 & 2.8 & 78.9 & 45.0 & 33.9 & 19.3 & 1.8 & Loamy sand \\
\hline 16 & 3.83 & 4.98 & 3.3 & 77.5 & 43.3 & 34.2 & 20.5 & 2.0 & Loamy sand \\
\hline 17 & 3.87 & 4.76 & 3.1 & 78.1 & 49.0 & 29.1 & 20.1 & 1.8 & Loamy sand \\
\hline 18 & 3.86 & 4.03 & 2.9 & 74.1 & 41.2 & 32.9 & 23.5 & 2.4 & Loamy sand \\
\hline 19 & 3.91 & 5.65 & 4.6 & 71.9 & 38.5 & 33.4 & 25.6 & 2.5 & Loamy sand \\
\hline 20 & 3.98 & 5.35 & 2.9 & 76.4 & 46.6 & 29.8 & 21.4 & 2.2 & Loamy sand \\
\hline 22 & 3.98 & 4.34 & 2.9 & 78.2 & 43.4 & 34.8 & 19.5 & 2.3 & Loamy sand \\
\hline 23 & 3.96 & 4.17 & 3.2 & 86.0 & 55.4 & 30.6 & 12.3 & 1.7 & Sand \\
\hline 24 & 3.95 & 3.96 & 2.9 & 83.7 & 49.0 & 34.7 & 14.4 & 1.9 & Loamy sand \\
\hline
\end{tabular}

Source: Authors' data.

\section{Ground penetrating radar}

Ground penetrating radar (GPR) was used at Nawarla Gabarnmang to map the depth to bedrock and locate pieces of roof fall in the stratigraphic profile. A total of $28 \mathrm{GPR}$ lines were positioned in an approximately southeast to northwest orientation, with a spacing of $0.5 \mathrm{~m}$ between lines. The GPR data were obtained using a Mala X3M unit with a $250 \mathrm{Mhz}$ antenna using a sampling frequency of $10038 \mathrm{Mhz}$, time window of $102 \mathrm{~ns}$, trace interval of $0.02 \mathrm{~m}, 1024$ samples and four stacks. The data were processed and interpreted using ReflexW software using a suite of filters, including move start time, dewow, energy decay, background remove, bandpass and time cut. The methodology for processing GPR data is well summarised by Goodman and Piro (2013). The velocity of electromagnetic energy through sediment was estimated as $0.15 \mathrm{~m} / \mathrm{ns}$ for the site, based on comparison from similar sediments at other, nearby sites, in the absence of suitable 
hyperbola for velocity modelling coming directly from Nawarla Gabarnmang. This methodology, while necessary given the sub-surface conditions and the fixed geometry of the GPR transmitter and receiver, introduces a degree of uncertainty into our depth calculations.

\section{GPR Data}
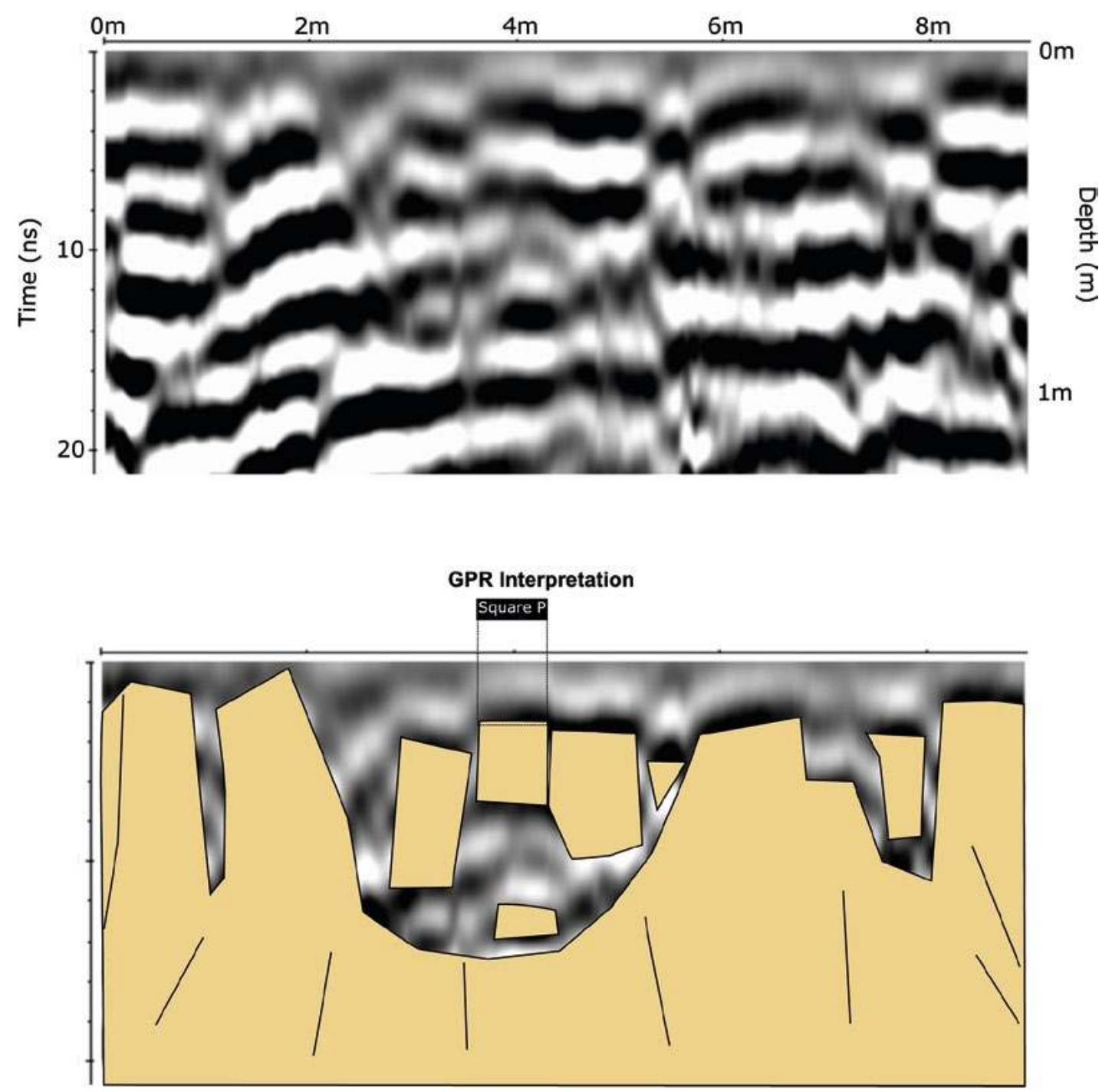

Figure 11.30 Profile view (top) and interpretation (bottom) of GPR data from the southeast to northwest ends of the rockshelter passing through Square $P$.

Source: Illustration by lan Moffat.

Interpretation of the GPR data (Figure 11.30) focused on a transect running across Square P, intended to map the geometry of the layer of rock that fell from the ceiling from the area of Panel E1. The results show that the slab of rock that forms the base of the excavation is c. $30 \mathrm{~cm}$ thick; it appears to sit over a deposit of unconsolidated sediment c. $30 \mathrm{~cm}$ thick. The bedrock surface appears to deepen significantly to a maximum depth of c. $1 \mathrm{~m}$ in the centre of the GPR line, rising nearly to the surface at the start and finish of the line. The base of Pillar 29 is indicated near the southeastern end of the line. The depths of features appear to be slightly underestimated, given that the surface of the rock slab appears by GPR at a depth of c. $25 \mathrm{~cm}$, whilst it was found at $30 \mathrm{~cm}$ in the excavation. 
A particular problem with interpreting these data is reliably defining the exact bedrock surface. This is due to the relatively low frequency of the antenna used; a $500 \mathrm{Mhz}$ or higher instrument would have been more appropriate for the depth of interest. The excavation, not having reached bedrock, does not provide a ground truth for just where this surface is. A further challenge to interpreting the data along the transect is the presence of blocks of roof-fall in localised places on the ground surface. These surface irregularities may have caused significant lateral discontinuities in the data, when the antenna bumped over the uneven ground surface during the survey.

Despite these challenges in interpreting the GPR data, the survey has demonstrated the potential of mapping the geometry of sub-surface features in rockshelter sites with this technique. In particular, the ability of GPR to image the geomorphology of the sub-surface bedrock, and so to validate whether an excavation ends on bedrock or on a slab of roof-fall, has important implications for siting excavations and determining whether they have found the maximum thickness of sediment within a site.

\section{Radiocarbon dates}

Forty accelerator mass spectrometry (AMS) radiocarbon dates on individual pieces of charcoal from Square P were obtained (Table 11.6). Throughout Square P, there is a high level of consistency in the calibrated radiocarbon ages within individual SUs, but poor depth-age sequencing within those SUs (Figure 11.28). That is, within a given SU the calibrated ages fit well within its delimited age range, but there is poor depth-age progression. There is good age differentiation between the SUs. It was not possible, therefore, to apply temporal constraints to the radiocarbon chronology within SUs, so we have identified four Radiocarbon Phases on the basis of age alone. To refine the chronological interpretation, the ${ }^{14} \mathrm{C}$ ages are grouped into four Radiocarbon Phases using the program Oxcal v4.2 (Bronk Ramsey 2009, 2013), and each phase is arranged within a sequence separated by a boundary that provides an estimated date of transition (Figure 11.31). All calibrated ages are based on the 68.3 per cent probability distributions.

The uppermost and most recent Radiocarbon Phase 4 consists of all the radiocarbon determinations with median ages of $180 \mathrm{cal} \mathrm{BP}$ or less, represented by all the radiocarbon dates from XU13 and above except for Wk-39278 (337 \pm 25 BP). All of these are in SU1A, SU1B, SU2 or in the SU2/SU3A interface. The single exception, the slightly older charcoal sample Wk39278 from the surface XU1, is probably a sample that originated from deeper levels in areas adjacent to Square $\mathrm{P}$ where trampling by feral water-buffalo has been documented, although the 'old wood' problem (e.g. Spriggs 1989; Wesley et al. 2016) cannot be discounted. In Square P, this treadage zone is limited to SU1A and SU1B.

Radiocarbon Phase 3, preceding Radiocarbon Phase 4, consists of the radiocarbon determinations with median ages from 390 to $510 \mathrm{cal} \mathrm{BP}$, found throughout SU3A and its interfaces with SU2 above and SU3B below (the single exception of Wk-39278 notwithstanding, as discussed above).

Radiocarbon Phase 2 consists of all the radiocarbon determinations with median ages from 1030 to $1370 \mathrm{cal} \mathrm{BP}$; these are all from SU3B or its interface with SU3A above it, indicating an intermixing of Radiocarbon Phases 2 and 3 (and 4, see below) at this interface.

Radiocarbon Phase 1 consists of all the radiocarbon determinations with median ages from 2580 to 4240 cal BP. Radiocarbon Phase 1 covers a wide time range whose many gaps indicate multiple phases of activity condensed into the basal $1.1 \mathrm{~cm}$ of the excavation in XU22 or XU23, immediately against or very close to the basal rock surface in SU3B or its interface with SU3A above it where sediments from Radiocarbon Phases $2-4$ are intermixed. 


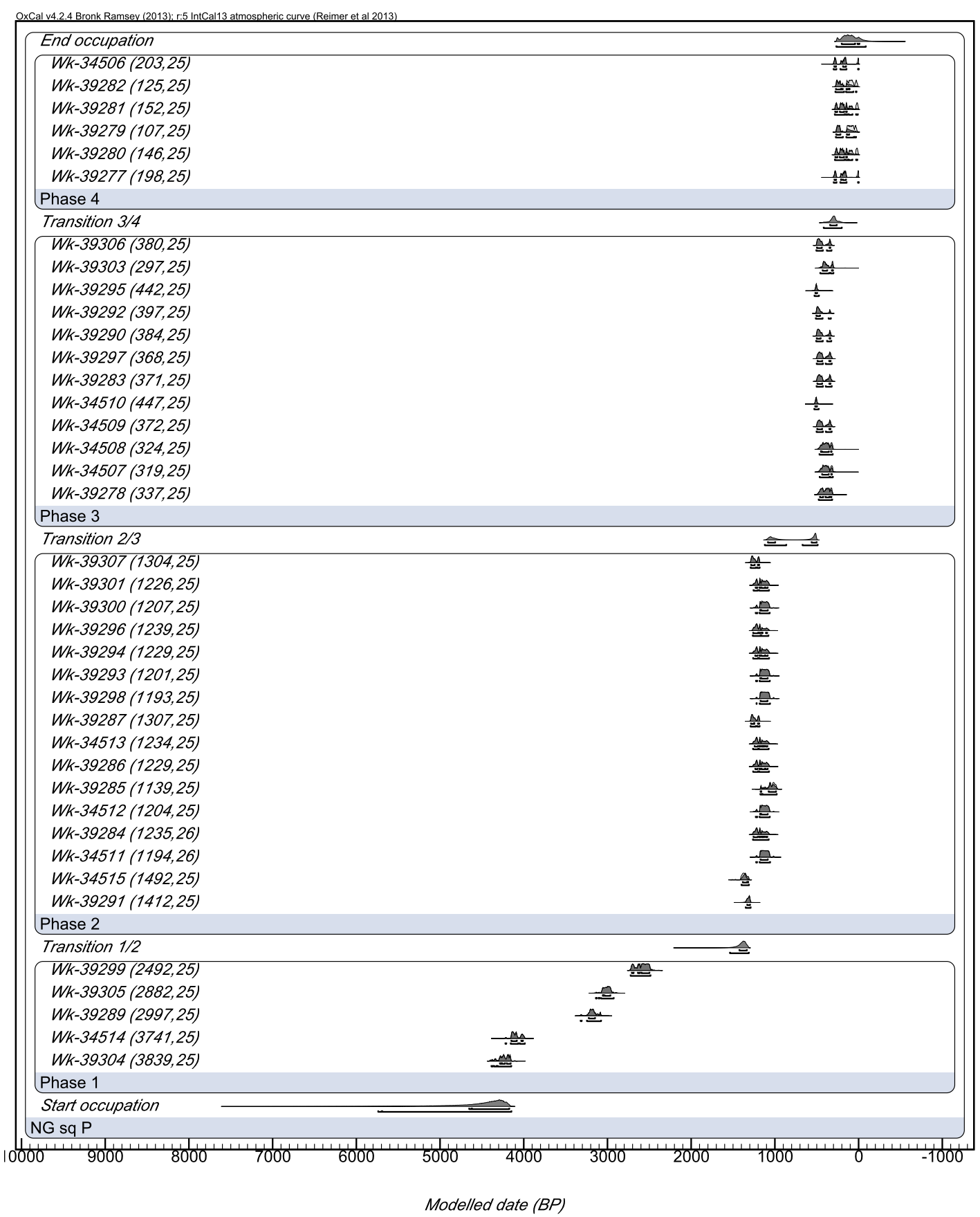

Figure 11.31 Bayesian age model for Square P produced with 0xCal v4.2 (see text for discussion).

Note: To magnify the diagram please see the PDF version at:press.anu.edu.au

Source: Illustration by Fiona Petchey.

This evaluation shows that the end of Radiocarbon Phase 4 began no earlier than 350-260 cal BP (1600-1690 AD), and may have taken place anytime between 210 and -10 cal BP (1740 and 1960 AD). It was closely preceded by Radiocarbon Phase 3, which began around 570-500 cal BP (1380-1450 AD). There is no evidence of activity between this era and the end of Radiocarbon Phase 2 (1090-990 cal BP), which may have been deposited as early as 1430-1330 cal BP. Radiocarbon Phase 1 represents a diffuse set of events starting around 4660-4170 cal BP. 
How is the single radiocarbon date of $15,324 \pm 100 \mathrm{BP}$ (Wk-39302), calibrating to 18,48918,713 cal BP, with a median probability of $18,594 \mathrm{cal} \mathrm{BP}$, from basal XU23 to be understood? On the one hand, it could be charcoal redeposited through foot treadage or wind action onto the exposed upper surface of the rock slab that now lies at the base of Square P after it collapsed from the ceiling. As we have not yet excavated below that rock slab, we do not know the age of the ground surface on which it fell; we therefore do not know whether there is any missing temporal window between the underlying deposits, the time of ceiling collapse and the base of the excavated deposits in Square P. Archaeological excavations across much of Nawarla Gabarnmang find that late Holocene sediments immediately overlie late Pleistocene sediments in Squares D, E, F, I+L+M, Q and R, squares that are 9-14 m west and west-southwest of Square P. In Square A, $14 \mathrm{~m}$ southwest of Square P, late Holocene deposits immediately overlie early Holocene sediments. Only in contiguous Squares C, G, K and N, 13-15 m southwest of Square P, do late Holocene sediments overlie mid-Holocene sediments. In those excavation squares, at all levels above sterile basal sands where these are present, sediments are rich in cultural materials, including abundant charcoal throughout most of the late-Pleistocene to late-Holocene levels. We can infer from this that when the rock slab that now lies at the base of Square P fell from the ceiling (see below), the soft sediments then on or near the surface across most parts of the site were of late Pleistocene age and could easily have been carried by foot, or blown by wind onto nearby surfaces. The isolated radiocarbon determination of this age at the very base of Square P, from a tiny charcoal sample weighing $0.01 \mathrm{~g}$, suggests that this could be how the Pleistocene charcoal fragment on top of the slab could have gotten there. On the other hand, it may be in its 'correct' chronostratigraphic position, indicating that the slab fell around that time. Excavation below the slab may resolve this question.

Table 11.6 Square P: Radiocarbon determinations.

\begin{tabular}{|c|c|c|c|c|c|c|c|c|c|}
\hline XU & $\begin{array}{l}\text { Depth } \\
\text { (cm) }\end{array}$ & SU & $\begin{array}{c}\text { Wk- } \\
\text { laboratory } \\
\text { code }\end{array}$ & $\delta^{13} \mathrm{C} \%$ & $\begin{array}{c}\% \text { modern } \\
\text { carbon } \\
\left(\mathrm{F}^{14} \mathrm{C} \%\right)\end{array}$ & $\begin{array}{c}{ }^{14} \text { C age } \\
\text { (years BP) }\end{array}$ & $\begin{array}{l}\text { Unmodelled } \\
\text { calibrated age } \\
\text { BP (68.3\% } \\
\text { probability) }\end{array}$ & $\begin{array}{l}\text { Unmodelled } \\
\text { calibrated age } \\
\text { BP (95.4\% } \\
\text { probability) }\end{array}$ & $\begin{array}{l}\text { Median } \\
\text { calibrated } \\
\text { age BP }\end{array}$ \\
\hline 1 & 0.5 & $\begin{array}{c}1 \mathrm{a}+ \\
1 \mathrm{~b}\end{array}$ & 39277 & Not available & $97.6 \pm 0.3$ & $198 \pm 25$ & $\leq 290$ & $\leq 300$ & 180 \\
\hline 1 & 1.4 & $\begin{array}{c}1 \mathrm{a}+ \\
1 \mathrm{~b}\end{array}$ & 39278 & Not available & $95.9 \pm 0.3$ & $337 \pm 25$ & $460-310$ & $480-310$ & 390 \\
\hline 2 & 1.4 & $\begin{array}{c}1 \mathrm{a}+ \\
1 \mathrm{~b}\end{array}$ & 39280 & Not available & $98.2 \pm 0.3$ & $146 \pm 25$ & $280-0$ & $290-0$ & 150 \\
\hline 2 & 2.2 & $\begin{array}{c}1 \mathrm{a}+ \\
1 \mathrm{~b}\end{array}$ & 39279 & Not available & $98.7 \pm 0.3$ & $107 \pm 25$ & $260-30$ & $270-10$ & 110 \\
\hline 9 & 10.9 & $2+3 a$ & 39281 & Not available & $98.1 \pm 0.3$ & $152 \pm 25$ & $280-0$ & $\leq 290$ & 170 \\
\hline 10 & 14.7 & $2+3 a$ & 39282 & Not available & $98.5 \pm 0.3$ & $125 \pm 25$ & $270-20$ & $280-10$ & 120 \\
\hline 13 & 17.3 & $2+3 a$ & 34506 & $-25.3 \pm 0.2$ & $97.5 \pm 0.3$ & $203 \pm 25$ & $\leq 300$ & $\leq 300$ & 170 \\
\hline 15 & 20.1 & $3 a$ & 34507 & $-26.1 \pm 0.2$ & $96.1 \pm 0.3$ & $319 \pm 25$ & $430-310$ & $470-300$ & 390 \\
\hline 16 & 21.1 & $3 a$ & 34508 & $-25.6 \pm 0.2$ & $96.1 \pm 0.3$ & $324 \pm 25$ & 440-310 & $470-300$ & 390 \\
\hline 17 & 21.3 & $3 a$ & 34509 & $-23.8 \pm 0.2$ & $95.5 \pm 0.3$ & $372 \pm 25$ & $500-330$ & 510-310 & 440 \\
\hline 18 & 23.2 & $3 a$ & 34510 & $-25.7 \pm 0.2$ & $94.6 \pm 0.3$ & $447 \pm 25$ & $520-490$ & $530-480$ & 510 \\
\hline 19 & 25.0 & $\begin{array}{c}3 a+ \\
3 b \\
\end{array}$ & 39283 & Not available & $95.5 \pm 0.3$ & $371 \pm 25$ & $500-330$ & $510-310$ & 440 \\
\hline 19 & 24.5 & $\begin{array}{c}3 a+ \\
3 b \\
\end{array}$ & 34511 & $-24.5 \pm 0.2$ & $86.2 \pm 0.3$ & $1194 \pm 26$ & 1170-1070 & $1230-1010$ & 1120 \\
\hline 19 & 24.2 & $\begin{array}{c}3 a+ \\
3 b\end{array}$ & 39284 & Not available & $85.8 \pm 0.3$ & $1235 \pm 26$ & $1260-1080$ & $1270-1070$ & 1180 \\
\hline 20 & 24.6 & $\begin{array}{c}3 a+ \\
3 b\end{array}$ & 34512 & $-24.7 \pm 0.2$ & $86.1 \pm 0.3$ & $1204 \pm 25$ & $1180-1080$ & $1230-1060$ & 1130 \\
\hline
\end{tabular}




\begin{tabular}{|c|c|c|c|c|c|c|c|c|c|}
\hline$X U$ & $\begin{array}{l}\text { Depth } \\
(\mathrm{cm})\end{array}$ & SU & $\begin{array}{c}\text { Wk- } \\
\text { laboratory } \\
\text { code }\end{array}$ & $\delta^{13} \mathrm{C} \%$ & $\begin{array}{l}\% \text { modern } \\
\text { carbon } \\
\left(\mathrm{F}^{14} \mathrm{C} \%\right)\end{array}$ & $\begin{array}{c}{ }^{14} \text { C age } \\
\text { (years BP) }\end{array}$ & $\begin{array}{c}\text { Unmodelled } \\
\text { calibrated age } \\
\text { BP (68.3\% } \\
\text { probability) }\end{array}$ & $\begin{array}{c}\text { Unmodelled } \\
\text { calibrated age } \\
\text { BP ( } 95.4 \% \\
\text { probability) }\end{array}$ & $\begin{array}{l}\text { Median } \\
\text { calibrated } \\
\text { age BP }\end{array}$ \\
\hline 20 & 24.7 & $\begin{array}{c}3 a+ \\
3 b\end{array}$ & 39285 & Not available & $86.8 \pm 0.3$ & $1139 \pm 25$ & $1070-980$ & $1180-970$ & 1030 \\
\hline 20 & 24.9 & $\begin{array}{c}3 a+ \\
3 b\end{array}$ & 39286 & Not available & $85.8 \pm 0.3$ & $1229 \pm 25$ & $1240-1080$ & $1260-1060$ & 1160 \\
\hline 21 & 26.8 & $3 b$ & 34513 & $-25.7 \pm 0.2$ & $85.8 \pm 0.3$ & $1234 \pm 25$ & $1260-1080$ & $1270-1070$ & 1180 \\
\hline 21 & 26.3 & $3 b$ & 39287 & Not available & $85.0 \pm 0.3$ & $1307 \pm 25$ & $1290-1180$ & $1300-1220$ & 1250 \\
\hline 22 & $\begin{array}{l}28.0^{-} \\
28.7\end{array}$ & $\begin{array}{c}3 a+ \\
3 b\end{array}$ & 39297 & Not available & $95.5 \pm 0.3$ & $368 \pm 25$ & $490-330$ & $500-310$ & 440 \\
\hline 22 & $\begin{array}{l}28.0^{-} \\
28.7\end{array}$ & $\begin{array}{c}3 a+ \\
3 b\end{array}$ & 39290 & Not available & $95.3 \pm 0.3$ & $384 \pm 25$ & $500-330$ & $510-320$ & 460 \\
\hline 22 & $\begin{array}{l}28.0^{-} \\
28.7\end{array}$ & $\begin{array}{c}3 a+ \\
3 b\end{array}$ & 39292 & Not available & $95.2 \pm 0.3$ & $397 \pm 25$ & $510-340$ & $520-330$ & 480 \\
\hline 22 & $\begin{array}{l}28.0^{-} \\
28.7\end{array}$ & $\begin{array}{c}3 a+ \\
3 b\end{array}$ & 39295 & Not available & $94.6 \pm 0.3$ & $442 \pm 25$ & $520-490$ & $530-470$ & 510 \\
\hline 22 & $\begin{array}{l}28.0- \\
28.7\end{array}$ & $\begin{array}{c}3 a+ \\
3 b\end{array}$ & 39298 & Not available & $86.2 \pm 0.3$ & $1193 \pm 25$ & $1170-1070$ & $1230-1050$ & 1120 \\
\hline 22 & $\begin{array}{l}28.0^{-} \\
28.7\end{array}$ & $\begin{array}{c}3 a+ \\
3 b\end{array}$ & 39293 & Not available & $86.1 \pm 0.3$ & $1201 \pm 25$ & $1180-1080$ & $1230-1060$ & 1130 \\
\hline 22 & $\begin{array}{l}28.0^{-} \\
28.7\end{array}$ & $\begin{array}{c}3 a+ \\
3 b\end{array}$ & 39294 & Not available & $85.8 \pm 0.3$ & $1229 \pm 25$ & $1240-1080$ & $1260-1060$ & 1160 \\
\hline 22 & $\begin{array}{l}28.0^{-} \\
28.7\end{array}$ & $\begin{array}{c}3 a+ \\
3 b\end{array}$ & 39296 & Not available & $85.7 \pm 0.3$ & $1239 \pm 25$ & $1260-1090$ & $1270-1070$ & 1200 \\
\hline 22 & $\begin{array}{l}28.0^{-} \\
28.7\end{array}$ & $\begin{array}{c}3 a+ \\
3 b\end{array}$ & 39291 & Not available & $83.9 \pm 0.3$ & $1412 \pm 25$ & $1340-1290$ & $1350-1280$ & 1320 \\
\hline 22 & 28.8 & $3 b$ & 39289 & Not available & $68.9 \pm 0.2$ & $2997 \pm 25$ & $3230-3080$ & $3220-3070$ & 3180 \\
\hline 22 & 28.7 & $3 b$ & 34514 & $-25.6 \pm 0.2$ & $62.8 \pm 0.2$ & $3741 \pm 25$ & $4150-4000$ & $4230-3980$ & 4100 \\
\hline 23 & $\begin{array}{l}28.7- \\
29.1 \\
\end{array}$ & $\begin{array}{c}3 a+ \\
3 b\end{array}$ & 39303 & Not available & $96.4 \pm 0.3$ & $297 \pm 25$ & $430-300$ & $460-290$ & 390 \\
\hline 23 & $\begin{array}{l}28.7- \\
29.1\end{array}$ & $\begin{array}{c}3 a+ \\
3 b\end{array}$ & 39306 & Not available & $95.4 \pm 0.3$ & $380 \pm 25$ & $500-330$ & $510-320$ & 460 \\
\hline 23 & $\begin{array}{l}28.7- \\
29.1\end{array}$ & $\begin{array}{c}3 a+ \\
3 b\end{array}$ & 39300 & Not available & $86.1 \pm 0.3$ & $1207 \pm 25$ & $1180-1080$ & $1230-1060$ & 1130 \\
\hline 23 & $\begin{array}{l}28.7- \\
29.1\end{array}$ & $\begin{array}{c}3 a+ \\
3 b\end{array}$ & 39301 & Not available & $85.8 \pm 0.3$ & $1226 \pm 25$ & $1230-1080$ & $1260-1060$ & 1150 \\
\hline 23 & $\begin{array}{l}28.7- \\
29.1 \\
\end{array}$ & $\begin{array}{c}3 a+ \\
3 b\end{array}$ & 39307 & Not available & $85.0 \pm 0.3$ & $1304 \pm 25$ & $1290-1180$ & $1290-1180$ & 1250 \\
\hline 23 & 29.2 & $3 b$ & 34515 & $-25.2 \pm 0.2$ & $83.1 \pm 0.3$ & $1492 \pm 25$ & $1400-1340$ & $1480-1460$ & 1370 \\
\hline 23 & $\begin{array}{l}28.7- \\
29.1\end{array}$ & $\begin{array}{c}3 a+ \\
3 b\end{array}$ & 39299 & Not available & $73.3 \pm 0.2$ & $2492 \pm 25$ & $2710-2490$ & $2730-2480$ & 2580 \\
\hline 23 & $\begin{array}{l}28.7- \\
29.1\end{array}$ & $\begin{array}{c}3 a+ \\
3 b\end{array}$ & 39305 & Not available & $69.9 \pm 0.2$ & $2882 \pm 25$ & $3060-2960$ & $3140-2920$ & 3010 \\
\hline 23 & $\begin{array}{l}28.7- \\
29.1 \\
\end{array}$ & $\begin{array}{c}3 a+ \\
3 b\end{array}$ & 39304 & Not available & $62.0 \pm 0.2$ & $3839 \pm 25$ & $4300-4150$ & $4410-4150$ & 4240 \\
\hline 23 & $\begin{array}{l}28.7- \\
29.1\end{array}$ & $\begin{array}{c}3 a+ \\
3 b\end{array}$ & 39302 & Not available & $14.8 \pm 0.2$ & $\begin{array}{c}15,324 \pm \\
100\end{array}$ & $18,720-18,480$ & $18,800-18,360$ & 18,590 \\
\hline
\end{tabular}

All ${ }^{14} \mathrm{C}$ ages are AMS on single pieces of charcoal. Calibrations undertaken using 0xCal 4.2 (IntCal13) (Reimer et al. 2013). Source: Authors' data. 


\section{Geomorphological history of area around Square $\mathbf{P}$}

Square $\mathrm{P}$ is located on the central-eastern side of the site, where widely spaced pillars create an open space beneath a large, more or less flat ceiling (Figure 11.4). Immediately to the east, this open space is delimited by the set of closely spaced Pillars 29-36, while to the west are the moderately spaced Pillars 25-28. In this central-eastern part of the site that contains Square P, the large ceiling measures $8 \mathrm{~m}$ wide by $12 \mathrm{~m}$ long. Elsewhere, from ground level to ceiling, the open space is interrupted by numerous pillars. It is on the ceiling of this large, open space that we find the most visually spectacular art panels at the site, including Panel E1.

Although Square P was shallow (29 cm deep) compared to the other excavation squares at Nawarla Gabarnmang, it contained rich archaeological deposits of stone artefacts, faunal remains and earth pigments dating to the past c. 4240 years, a similar period of time as that found in Square B $5 \mathrm{~m}$ to the west. The accumulated sediments in both these squares signal a recent history relative to the long sequences revealed in Squares $\mathrm{A}, \mathrm{D}+\mathrm{H}, \mathrm{F}+\mathrm{I}+\mathrm{L}+\mathrm{M}$ and $\mathrm{E}+\mathrm{J}+\mathrm{O}+\mathrm{Q}+\mathrm{R}$, which are all deeper (60-85 cm depth) and have an antiquity close to 50,000 years (David et al. completed manuscript).

This study of Square P and its immediate surroundings prompts two questions:

- Does the rock floor at the base of the square represent bedrock, or is it the upper surface of a collapsed ceiling slab?

- Why are there no pillars in this part of the site?

To answer these questions, we turned to the archaeology, geomorphology and the 3-D laser map of the site (cf. David et al. 2011, 2013, completed manuscript; Delannoy et al. 2013; Geneste et al. 2010, 2012; see also Chapter 10).

\section{Origin of the rock at the base of Square $P$}

To explore whether the rock surface at the base of Square $P$ is bedrock or the upper surface of a fallen ceiling slab, we looked at the configuration and geomorphology of the other excavated squares across the site. Confirmed bedrock was reached in a number of squares $(A, D+H, E+J$, $\mathrm{F}+\mathrm{I}+\mathrm{L}+\mathrm{M})$. These squares, all positioned close to pillars, are where the quarzitic bedrock is dissected by geologically ancient narrow crevices along fissure lines. These crevices rapidly taper to a depth of c. $20-35 \mathrm{~cm}$ below the bedrock surface (Figure 11.32). Square P is different in that it is some distance from extant pillars, the surface of the rock at its base is flat and there are no signs of a crevice or fissure in the basal rock. Initial indications are thus that the rock base of Square P is not the bedrock, but a fallen (or positioned) slab. Further investigation enabled a firmer determination. 

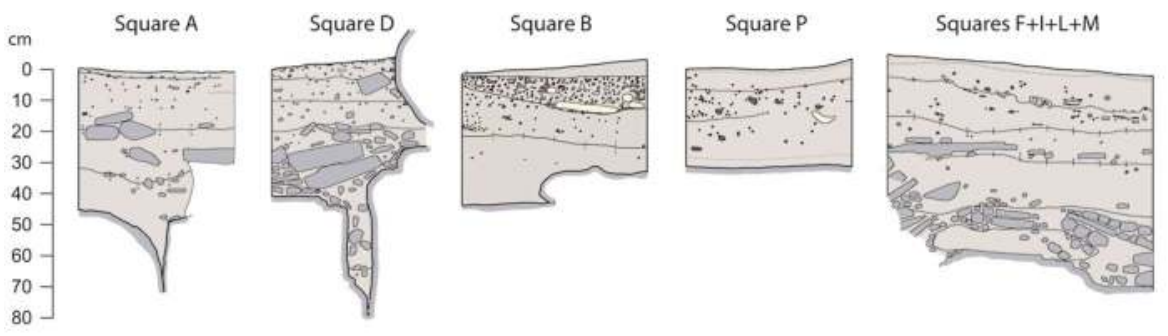

Squares $J+E$
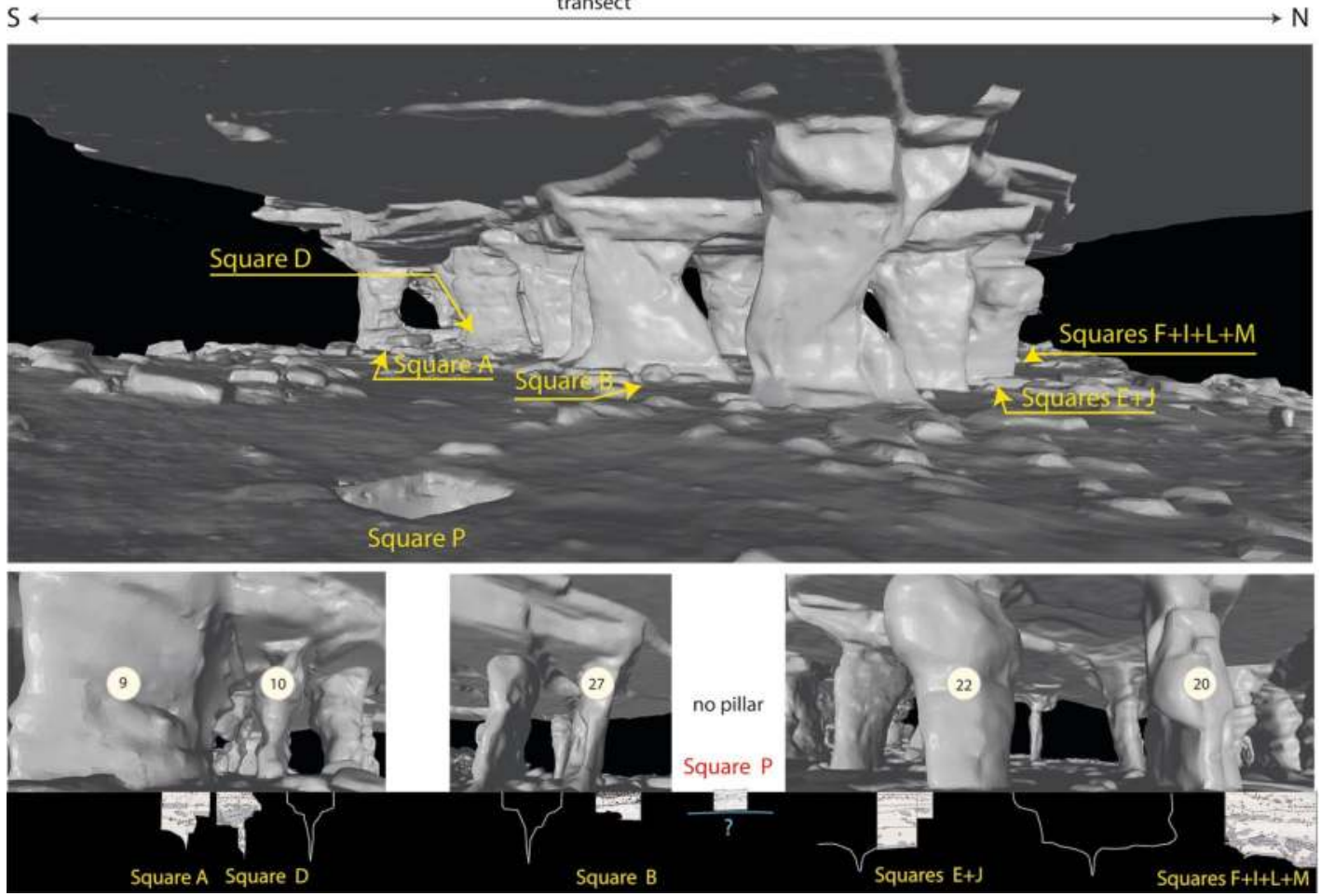

Figure 11.32 Section drawings of excavation squares, showing the relative depth of pits.

Source: Illustration by Jean-Jacques Delannoy, Bruno David and Kara Rasmanis.
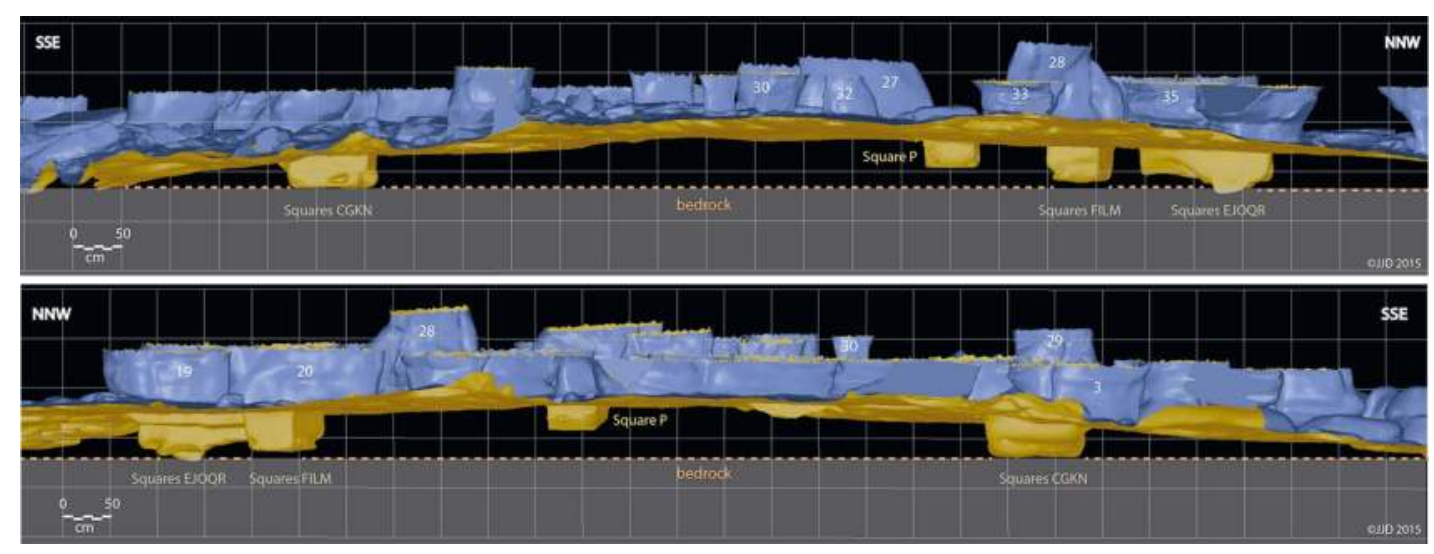

Figure 11.33 3-D projections of excavation squares, from the laser mapping of the site.

These two projections extrapolate via the 3-D model the alignment of the current ground level to reveal sub-surface (in yellow) and above-ground details (the base of the pillars, shown in blue). Here the base of Square $\mathrm{P}$ is perched above the expected bedrock level, as extrapolated from the bedrock levels revealed in Squares $C+G+K+N$, E+J+Q+R and F+l+L+M. The slightly domed configuration of the ground (more elevated at the centre than along the edges) is also apparent.

Source: Illustration by Jean-Jacques Delannoy. 

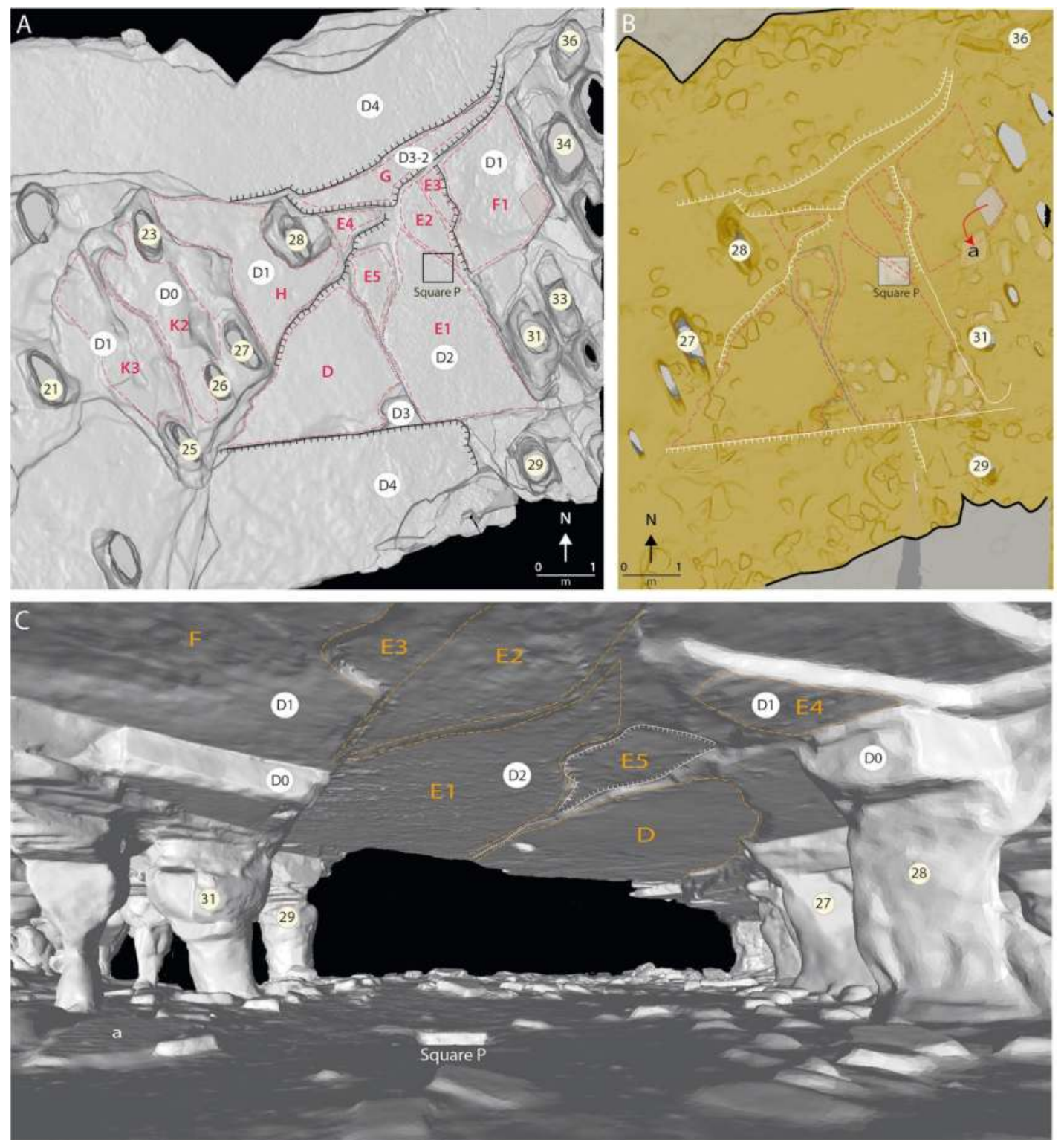

Figure 11.34 View of the ceiling $(A)$ and ground $(B)$ levels around Square $P$, as evident from the 3-D model.

A: Ceiling view showing the various rock art panels (red lines and lettering); the edges of the ceiling rock strata (D0-D4); and the extant Pillars 21-36. B: Ground view showing the individual blocks of rock currently present at ground level; the anthropically moved block (red arrow, showing movement from original to current positions); the extant pillars (numbered); and the major features of the current ceiling ledges representing the edges of the exposed rock strata (white), and rock art panel (red). C: The area around Square P, looking south-southwestward.

Source: Illustration by Jean-Jacques Delannoy.

At first look, the spatial relationship between the area of Square P and the location of past pillars is unclear, as some pillars across the site have been removed by people (Delannoy et al. 2013; see Chapter 10). So the base of Square P may correspond with the location of a now-removed ancient pillar whose base would have been at a high point of the bedrock. We addressed this question in two ways. We began by examining the depth of the bedrock across the excavated squares. As these are located along the northern (Squares $\mathrm{F}+\mathrm{I}+\mathrm{L}+\mathrm{M}$ and $\mathrm{E}+\mathrm{J}+\mathrm{O}+\mathrm{Q}+\mathrm{R}$ ) and southern (Squares $A, D+H$ and $C+G+K+N$ ) sides of the site, they enable a north-south transect to be drawn for bedrock across the site (Figure 11.33). Figure 11.33 places these excavated squares and their 
bedrock base in their correct spatial alignment: the blue areas represent the present surface topography together with the lower parts of the extant pillars; the brown areas represent the sub-surface sediments as extrapolated by the 3-D model from laser scanning of both the site and numerous excavated squares (those excavations were open when the laser scanning was done). The bedrock is approximately at the same elevation: see the dashed line identifying the level of the bedrock base in Squares $\mathrm{C}+\mathrm{G}+\mathrm{K}+\mathrm{N}, \mathrm{F}+\mathrm{I}+\mathrm{L}+\mathrm{M}, \mathrm{E}+\mathrm{J}+\mathrm{O}+\mathrm{Q}+\mathrm{R}$; Squares $\mathrm{A}, \mathrm{B}$ and $\mathrm{D}+\mathrm{H}$, excavated in 2010-2011, were already back-filled when the laser scanning was done in 2012, and therefore do not appear on Figure 11.33. Figure 11.33 clearly shows the rock at the base of Square P is higher than the bedrock in the other squares. Three possibilities can thus be entertained: 1) the bedrock is more elevated at the centre of the site, as represented by Square P; 2) the base of Square P represents the base of an ancient, now-collapsed pillar; or 3) the base of Square P represents the upper surface of an ancient collapsed ceiling slab.

The first option is ruled out by observing the dip of the bedrock around the pillars and on the ceiling rock strata. Figure 11.34 (viewed in 3-D) shows well the sub-horizontal alignment of the geological strata to the right (west) of Square P.

To explore the second option, we analysed the positions of pillars and ceiling fissure lines using the 3-D model (Figure 11.35). This analysis utilises the current distribution of pillars across the site, as well as the densely pillared, slightly elevated area that delimits the open 'courtyard' on the southern side of the site.

Figure 11.35 shows two projections.

Projection 1 (Figure 11.35A) is the ceiling as observed from ground level. Here we can clearly see that the pillars are aligned along two intersecting axes (SSE-NNW and ENEWSW); also shown are the currently exposed rock strata on the ceiling. The SSE-NNW axis represents fissures that resulted from regional tectonic activity; the ENE-WSW fissures are more localised stress fractures that formed after the voids between pillars had been created at Nawarla Gabarnmang. We again note the sparse distribution of pillars on the eastern part of the site where Square P is located.
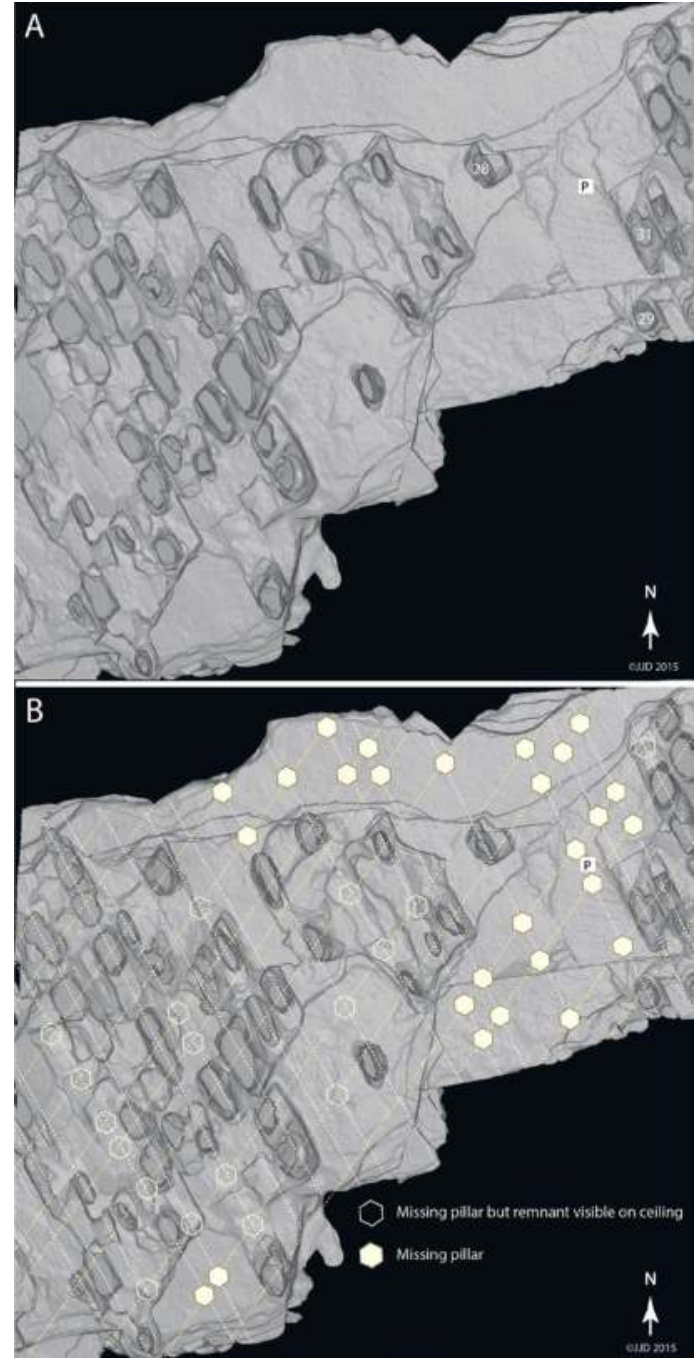

Figure 11.35 Ceiling view of the central-eastern and western parts of Nawarla Gabarnmang, showing the location of Square $P$.

A: Current ceiling and pillars: The pillars can be seen as darker areas. B: 'Original' ceiling: Missing pillars are identified from remnant traces on the ceiling, and their expected occurrences along the intersecting alignments (yellow and white lines) of the extant pillars.

Source: Illustration by Jean-Jacques Delannoy. 
Projection 2 (Figure 11.35B) shows the axes of the pillars with their parallel and criss-crossing alignments (white lines: SSE-NNW; yellow lines: ENE-WSW). The natural fissures exposed in the bedrock at the base of the excavations, aligned with matching ceiling fissures overhead, parallel those criss-crossing pillar alignments (the corridors between the dashes). The extant pillars are positioned where the two pillar axes meet. This on-site mapping coupled with the 3-D model allows us to identify the tops of the missing pillars (Figure 11.36): these remnant pillars on the ceiling are located where the alignments of the pillars cross. We can thus locate the pillars that once existed in the eastern and northern side of the site, where the largest sections of painted ceiling occur.

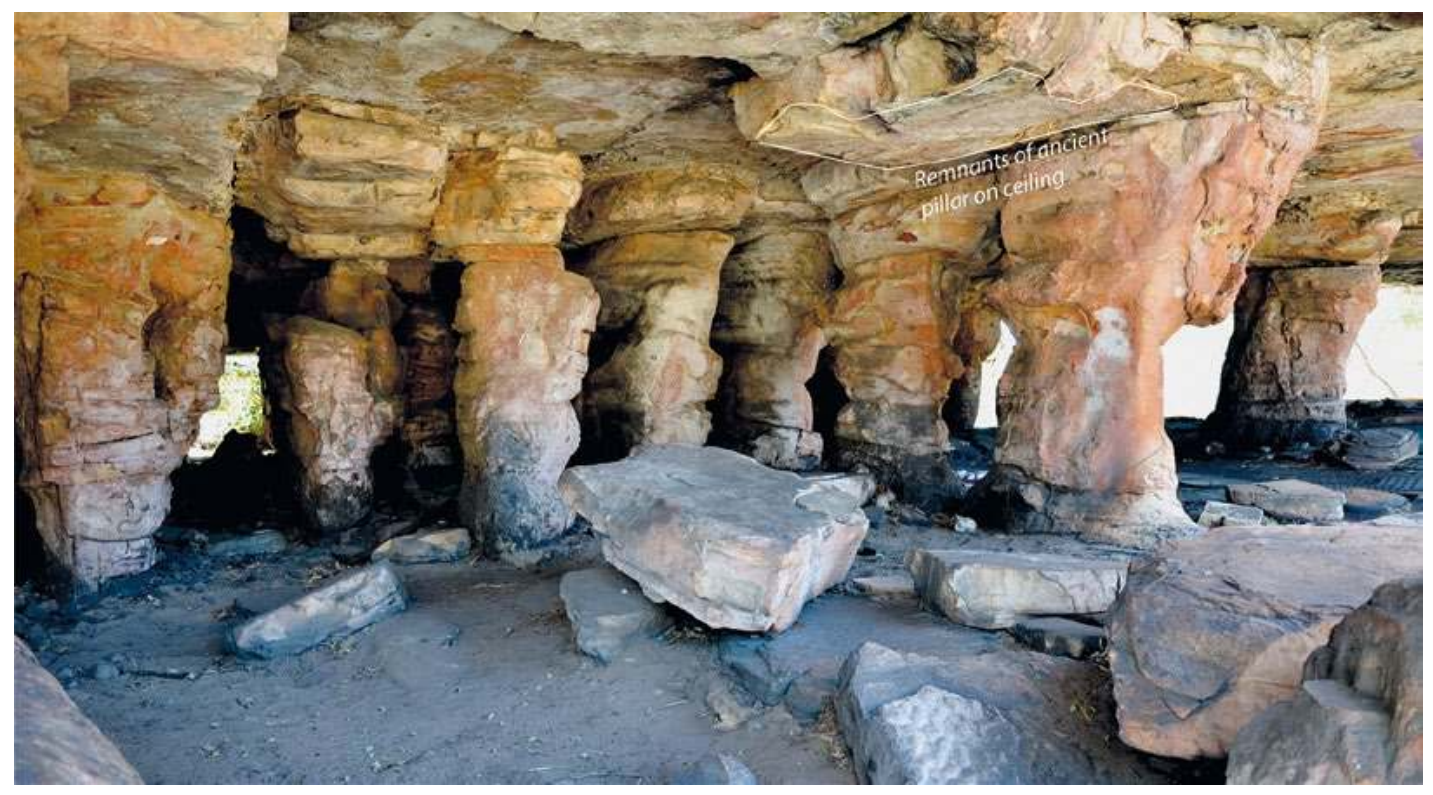

Figure 11.36 Southwest section of rockshelter, showing remnants of a missing pillar.

Source: Photograph by Jean-Jacques Delannoy.

To see whether the sparseness of pillars in the eastern side of the site was due to preferential weathering and erosion (lateral variation of geological facies that would have caused the eastern pillars to be less resistant), we have projected the NNW-SSE alignment of the pillars on the edge of the densely pillared, slightly elevated area to the south of the site (Figure 11.37). This projection, and the dense packing of pillars on the southern side, shows that these align along the same axis as the pillars under the rockshelter. The two 3-D views shown in Figure 11.38 confirm this. Figure $11.38 \mathrm{~A}$ is a north-south view from the northern entrance of the site, with the rockshelter shown in grey, the 'courtyard' to the south shown in green, the rock outcrop further to the south shown in light yellow and the background (southern) pillars under the overhang of the rockshelter shown in pink. This figure clearly shows the continuous alignment of the pillars and of the voids between them. Figure $11.38 \mathrm{~B}$ is a north-south view from the northern edge of the rockshelter (numbered pillars and Square P), through the central courtyard (green) and the northern edge of the densely pillared, slightly elevated area to the south of the site (light yellow). On this latter edge, the alignment of the site's pillars can be seen: for example, Pillar 28 of the rockshelter aligns with the 28 th pillar of the slightly elevated area to the south, and that sequence of pillar alignments progresses in good order across space. 


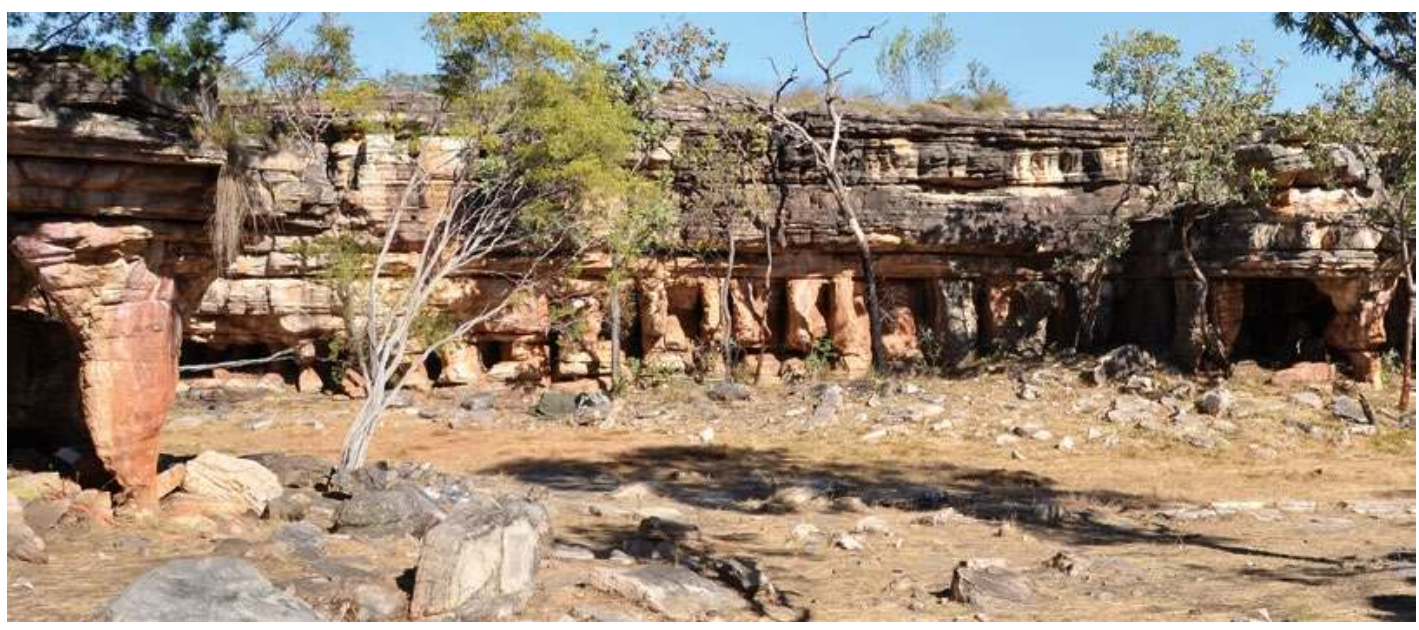

Figure 11.37 Edge of the densely pillared, slightly elevated area to the south of the shelter.

The spacing between the pillars differs noticeably from that inside the main shelter. This difference is not due to geological causes, as the same pillar and inter-pillar alignments project across the two areas (see Figure 11.35), along with the action of comparable weathering processes. The difference is due to the actions of people, who have altered the geological matrix in the shelter (and commenced also to remove pillars in the western part of the southern rock outcrop shown at the extreme right-hand side of the photograph).

Source: Photograph by Jean-jacques Delannoy.

These results allow us to conclude:

- The low density of pillars in the eastern part of the site is not due to differential weathering and erosion. The edge of the slightly elevated area to the south of the rockshelter demonstrates the regular presence of pillars along the same alignments as within the rockshelter. The same logic should thus also apply to the eastern part of the site where pillars are absent.

- The rock base in Square P does not correspond with the base of an ancient pillar, as the location of the square does not correspond with the alignment of the pillars (see Figure 11.35); instead, it is positioned along the NNE-SSW alignment of fissure lines in the bedrock. Those fissure lines are evident as narrow crevices in the bedrock that now lies underground and has been revealed in the excavations at the base of Squares $\mathrm{A}, \mathrm{D}+\mathrm{H}$ and $\mathrm{F}+\mathrm{I}+\mathrm{L}+\mathrm{M}$, and as corresponding fissures along the ceiling overhead.

Overall, the spatial configuration of the bedrock (Figure 11.33) and the distribution and alignment of extant and ancient pillars (Figure 11.35) enable us to be sure the rock base in Square $\mathrm{P}$ is neither an elevated part of the bedrock nor the base of a pillar. But it is consistent with a rock slab fallen from the ceiling. The location of the high points revealed by GPR mapping (Figure 11.30; see above) corresponds to the alignment of the pillars, so those high points can be interpreted as the bases of disappeared pillars. The GPR cross-section also confirms that Square $\mathrm{P}$ is located to the right of a deepening of the bedrock, consistent with the formation of a crevice caused by the weathering and evacuation of weathered products along fissure lines over long geological time frames.

This convergence of geological, GPR and 3-D modelling evidence lead us to conclude that the rock at the base of Square $\mathrm{P}$ is the upper surface of a collapsed portion of the ceiling rock rather than the actual bedrock of the shelter. 

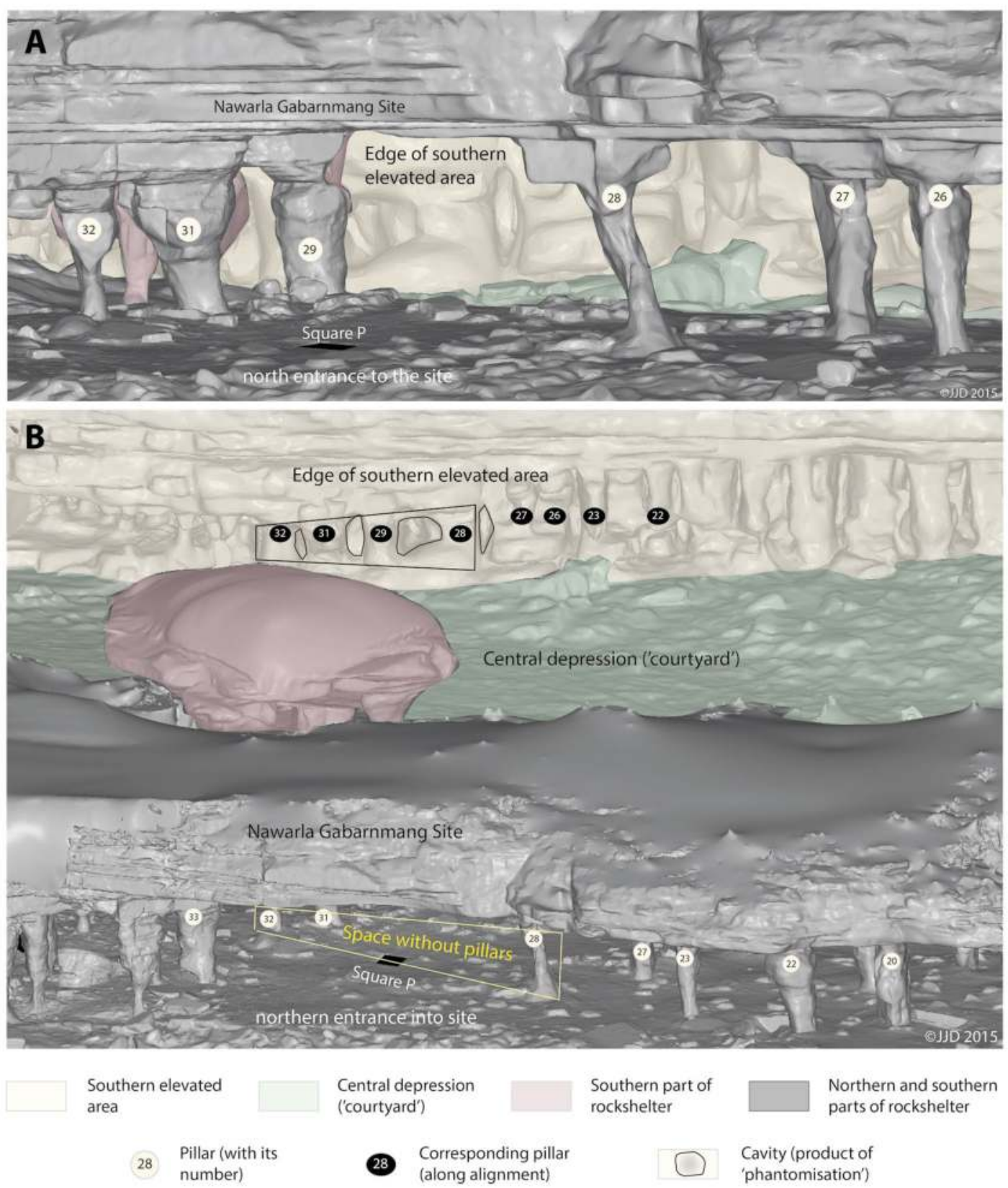

Figure 11.38 Projected view of the Nawarla Gabarnmang shelter and the densely pillared edge of the slightly elevated area to the south.

A: View from the northern entrance into the shelter, looking through the site across the 'courtyard' onto the dense pillars further to the south. The pillars align across the shelter onto the edge of the slightly elevated area to the south of the 'courtyard'. B: Angled view allowing us to compare the pillars within the shelter with those at the edge of the slightly elevated area (the alignment of the pillars follows the alignment of geological structures and fissure lines).

Source: Illustration by Jean-Jacques Delannoy. 


\section{Morphogenic reconstitution of Nawarla Gabarnmang to the east of Square $P$}

The preceding analysis has highlighted the paucity of pillars in the eastern sector, which created an expansive, flat ceiling space on which art Panels D-E1-E2-E3-F1 were made (Figure 11.34). This extant art could only have been made after the current ceiling rock surface was formed.

Figure 11.34 shows various views of the Square $P$ area. Figure 11.34A is a view of the ceiling with its art panels, exposed geological strata, and the extant pillars. Figure $11.34 \mathrm{~B}$ is a ground view showing the blocks exposed on the surface, and the edges of extant rock strata. Figure 11.34C shows the flatness of the ceiling, which is related to the sub-horizontality of the quartzitic strata (with strata D1 and D2 as the base layers) and to the resistance of those strata to weathering and erosion. In this part of the site, rock art predominantly occurs on stratum D2, less often on stratum D1. Along more northern and southern parts of the site, rock art is also found on a large surface of stratum D4 (not shown on Figure 11.34C).

These views show that no art phase on Panel E1 above Square P could have been done until strata D0 and D1 had fallen from the ceiling. The remnant ledges on the edges of strata D0 and D1 clearly have a rectilinear geometry, indicating where the missing strata have collapsed. This collapse took place when there were no pillars to give structural support. Here, the geometry of the remnant broken edges does not align with geological points of weakness; i.e. the broken edges do not align with the network of fissures. This is particularly visible on Figure 11.34, where the northern and southern edges of the overhang (transition slabs D3-2 and D4; see Figure 11.34A) are not aligned along these fissure lines (shown as white and yellow dashes in Figure 11.35B), but rather cut across them. This non-alignment of ceiling surface edges relative to the natural fissure lines results from ceiling slab collapse caused by an absence of structural support and ensuing mechanical stress, rather than from mechanical failure along zones of weakness. The ledge separating the rock art-bearing Panels G-E4-H from Panels F1-E1-E2E3-E5 corresponds to an area of weakness (fissure line) running in an ENE-WSW direction. The eastern rectilinear ledge of rock stratum D2 (Panel E1) and the fissure that runs through stratum D2 (between Panels E1 and D) are aligned with lines of weakness oriented SSE-NNW (Figure 11.34).

These ceiling strata ledges correspond to the edges of slab collapses. Analysis of the two collapsed strata D0 and D1, and their respective ledges, indicates that these collapses, whose exact timing we do not know, certainly did not all happen at the same time. In the area of Square P, we know that stratum D1, which caused the exposure of stratum D2, became exposed on the ceiling sometime before $3839 \pm 25$ BP (4150-4410 cal BP; see Table 11.6, Figure 11.28), as indicated by the minimum age for the collapse of the slab at the base of Square P. If the flat surface of the ceiling above Square $\mathrm{P}$ can be matched to the separation plane (the sub-horizontal joint) between strata D1 and D2, then we could conclude that the flat surface of the ceiling probably relates to a lack of pillars in this part of the site. In other parts of the site, ceilings with extant pillars are corbelled, and between pillars their flat surfaces are much smaller (e.g. the space between Pillars 21-23 and Pillars 25-27 that house art Panels K2-K3; see Figure 11.34A). If the flat surface of the ceiling above Square P relates to an absence of pillars in this part of the site before the collapse of stratum D1, then the question must be asked: What caused those pillars to disappear? This question is the more significant because the ground around Square $\mathrm{P}$ is relatively flat and its few large blocks suggest an absence of accumulated collapsed rocks below ground. The blocks 
of stone in this part of the site are mostly small and tend to sit on the ground surface, unlike other parts of the site where large and partly buried blocks emanate above ground level. These small and tabular surface blocks cannot account for the roof collapse, or for the mass of rock from the missing pillars.

The west side of the site (not mapped in Figure 11.34; see Chapter 10) demonstrates two important features. First, the collapse of pillars creates an uneven, densely cluttered floor surface. Second, from this we can conclude that some blocks from collapsed pillars in areas with flat surfaces were physically removed from the shelter; there is ample evidence of this in the large quantities of anthropically removed blocks, immediately outside the northern dripline in particular (see Delannoy et al. 2013). The absence of accumulated blocks, and the flatness of the ground surface in the area of Square P, indicate that many blocks from the collapsed pillars were removed before the collapse of stratum D1, at least in the area north of a line linking Pillars 28-31. Although the area south of this line lies under the same ceiling stratum (D2) as the area immediately to the north, the ground surface there is more chaotic and includes numerous blocks from stratum D1.

These observations allow us to conclude (see Figure 11.39):

1. Fallen blocks from 12 now-missing pillars were removed from the large, open central part of the site by people, whatever the cause(s) of those pillar collapses. Both the pillar collapses and the removal of their blocks pre-date the fall of stratum D1.

2. The absence of pillars from the large, open central part of the site led to the collapse of the entire stratum D1 from the ceiling in the space between Pillars 28, 27, 31 and 34. This collapse must have taken place before c. $4240 \mathrm{cal} \mathrm{BP}$, possibly during terminal Pleistocene times, as indicated by the minimum age of the stratum D1 collapse evident at the base of Square P.

3. Strata D2-D3 subsequently collapsed along the northern and southern edges of the site, exposing new flat surfaces upon which large panels of rock art were then created, Panel J1 in the north and Panel C2 in the south (see Figure 11.4). The collapse of the strata D2-D3 should have created a higher ground level in this part, but the reverse occurred: the ground level is slightly lower than in the central, open part of the site (Figure 11.33). This lowering of the ground level, and the blocks immediately outside the northern overhang in particular, result from removal of blocks under the overhang to beyond the dripline. This anthropogenic change to the site took place before the fall of stratum D1, i.e. before c. $4240 \mathrm{cal} \mathrm{BP}$. It is evidence of the social modification of a very large rockshelter through aménagement and inhabitation (cf. Delannoy et al. 2013; Thomas 2008; see also Chapter 10).

4. Today, we see numerous horizontal slabs of rock on the present ground surface. Local Jawoyn Elders call these 'pillows' (see Delannoy et al. 2013). Examination of one (slab 'a' on Figures $11.34 \mathrm{~B}$ and $11.34 \mathrm{C}$ ) indicates that it is not in its original position; it has come from the localised collapse of a section of stratum D0 near Pillar 34; its repositioning onto the ceiling was digitally tested with the 3-D model. After it fell from the ceiling, it was moved by people to its current location (red arrow on Figure 11.34B). 


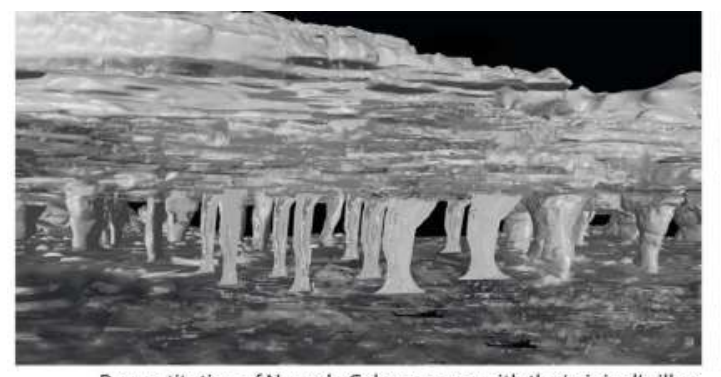

Reconstitution of Nawarla Gabarnmang, with the 'original' pillars

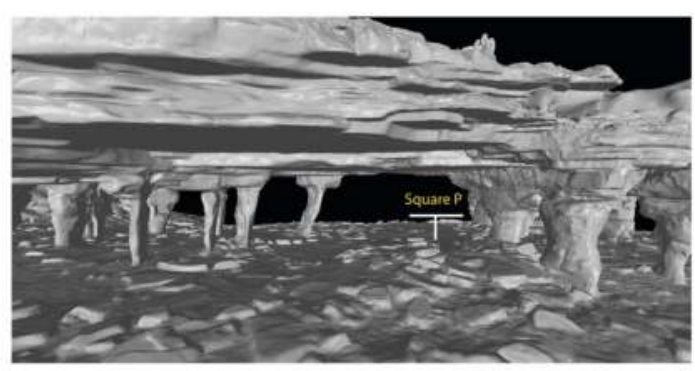

Distribution of extant pillars at Nawarla Gabarnmang

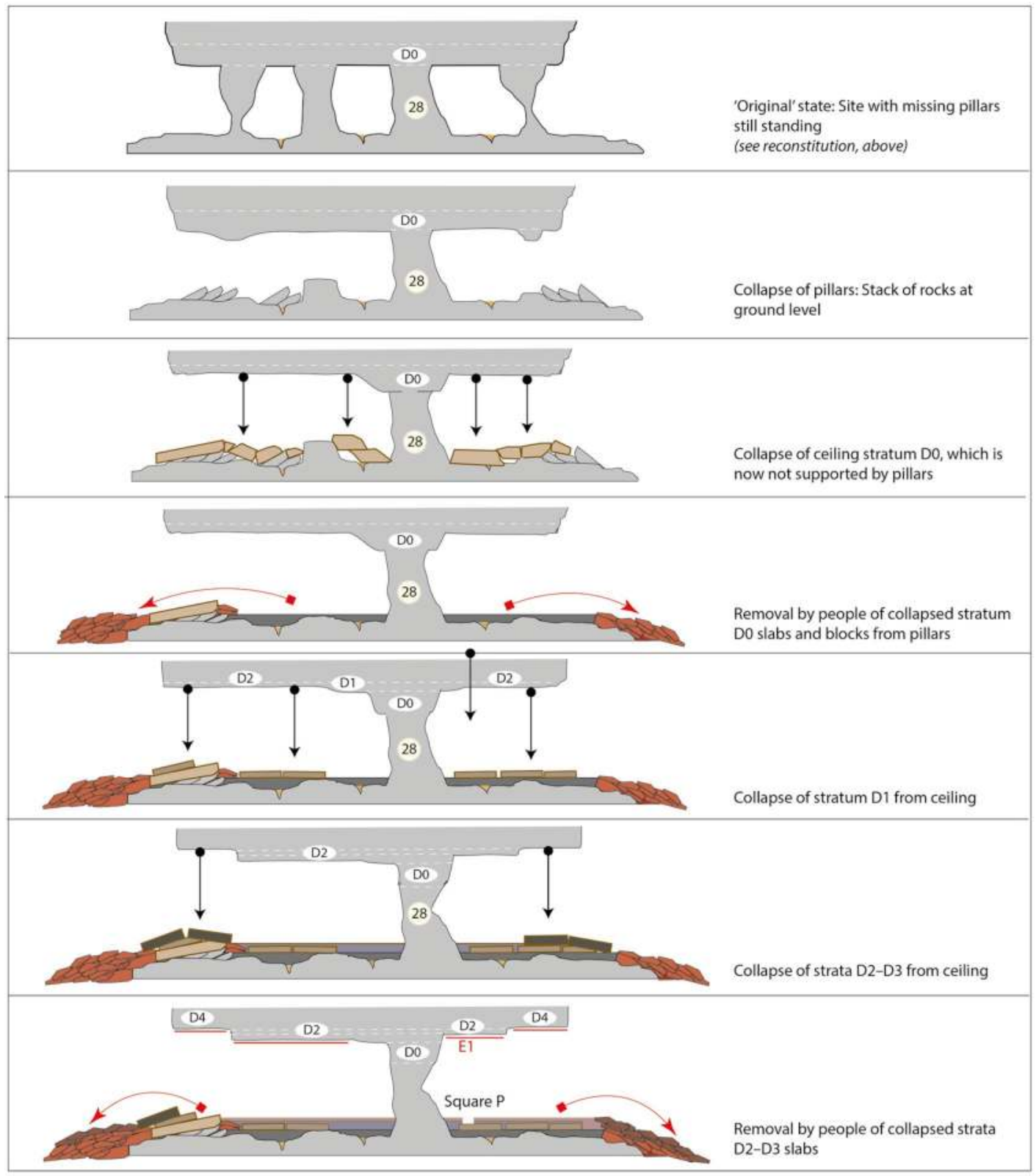

Figure 11.39 Geomorphological reconstitution of the area around Square P.

The two views from the 3-D model at the top of the figure show the 'original' (reconstituted) and current configurations of this part of the shelter, as seen from the southern entrance into the site. The illustrations below these two figures show the evolution of the site's physical matrix, as revealed by geomorphological and archaeological evidence.

Source: Illustration by Jean-Jacques Delannoy.

\section{terra australis 47}




\section{Cultural materials in Square P: Stone artefacts}

Having determined the site's extant configuration in the area around Square P, let us now explore its buried cultural materials. Our major aim is to understand better the sequence of paintings on Panel E1 overhead, and their cultural context.

A total of 793 definite stone artefacts weighing $304.8 \mathrm{~g}$ were recovered from Square P, nearly half from the uppermost XU1 to XU8 (Table 11.7; Figure 11.40). Stone artefacts weigh on average $0.38 \mathrm{~g}$, and the vast majority ( 89.4 per cent, $\mathrm{n}=708$ ) measure $<10 \mathrm{~mm}$ in maximum length. They appear to represent the by-products of on-site artefact manufacturing or retouching, an issue to be addressed in detail elsewhere.

Table 11.7 Square P: Distribution of excavated cultural materials.

\begin{tabular}{|c|c|c|c|c|c|}
\hline \multirow[t]{2}{*}{$\mathrm{XU}$} & \multirow[t]{2}{*}{ SU } & \multirow{2}{*}{$\begin{array}{c}\text { Charcoal } \\
(\mathrm{g})\end{array}$} & \multicolumn{2}{|c|}{ Stone artefacts } & \multirow{2}{*}{$\begin{array}{c}\text { Bone + teeth } \\
(g)\end{array}$} \\
\hline & & & (\#) & $(g)$ & \\
\hline 1 & $1 a+1 b$ & 140.11 & 54 & 3.28 & 7.90 \\
\hline 2 & $1 a+1 b$ & 117.20 & 57 & 6.95 & 5.54 \\
\hline 3 & $1 b+2$ & 138.14 & 56 & 195.91 & 27.12 \\
\hline 4 & $1 b+2$ & 111.20 & 38 & 4.95 & 14.02 \\
\hline 5 & $1 b+2$ & 137.63 & 38 & 1.69 & 19.35 \\
\hline 6 & $1 b+2$ & 191.26 & 52 & 29.40 & 5.71 \\
\hline 7 & 2 & 219.65 & 46 & 15.45 & 9.27 \\
\hline 8 & $2+3 a$ & 186.09 & 54 & 1.90 & 12.57 \\
\hline 9 & $2+3 a$ & 90.92 & 27 & 4.61 & 0.48 \\
\hline 10 & $2+3 a$ & 111.79 & 35 & 3.59 & 2.13 \\
\hline 11 & $2+3 a$ & 130.37 & 27 & 3.42 & 3.99 \\
\hline 12 & $2+3 a$ & 110.25 & 31 & 2.12 & 1.60 \\
\hline 13 & $2+3 a$ & 84.58 & 36 & 4.87 & 1.41 \\
\hline 14 & $3 a$ & 57.43 & 34 & 1.60 & 0.03 \\
\hline 15 & $3 a$ & 65.24 & 25 & 4.99 & 0.45 \\
\hline 16 & $3 a$ & 42.41 & 29 & 1.26 & 0.04 \\
\hline 17 & $3 a$ & 55.77 & 29 & 0.79 & 0.05 \\
\hline 18 & $3 a$ & 38.59 & 17 & 1.40 & 0.02 \\
\hline 19 & $3 a+3 b$ & 36.47 & 22 & 2.13 & 0.47 \\
\hline 20 & $3 a+3 b$ & 50.92 & 43 & 4.11 & 0.06 \\
\hline 21 & $3 a+3 b$ & 29.16 & 32 & 6.98 & \\
\hline 22 & $3 a+3 b$ & 2.32 & 10 & 3.39 & 0.04 \\
\hline 23 & $3 a+3 b$ & 0.31 & 1 & 0.02 & \\
\hline Total & & 2147.81 & 793 & 304.81 & 112.25 \\
\hline
\end{tabular}

Source: Authors' data.

Stone artefacts were made from five major types of raw material (Table 11.8; Figure 11.41): quartzite overwhelmingly predominates, followed by chert, quartz, siltstone and igneous rock. Three igneous flakes exhibit ground dorsal surfaces originating from ground-edge axes. Their occurrence in XU1 and XU9 suggests that axe maintenance was done in the area of Square P. 


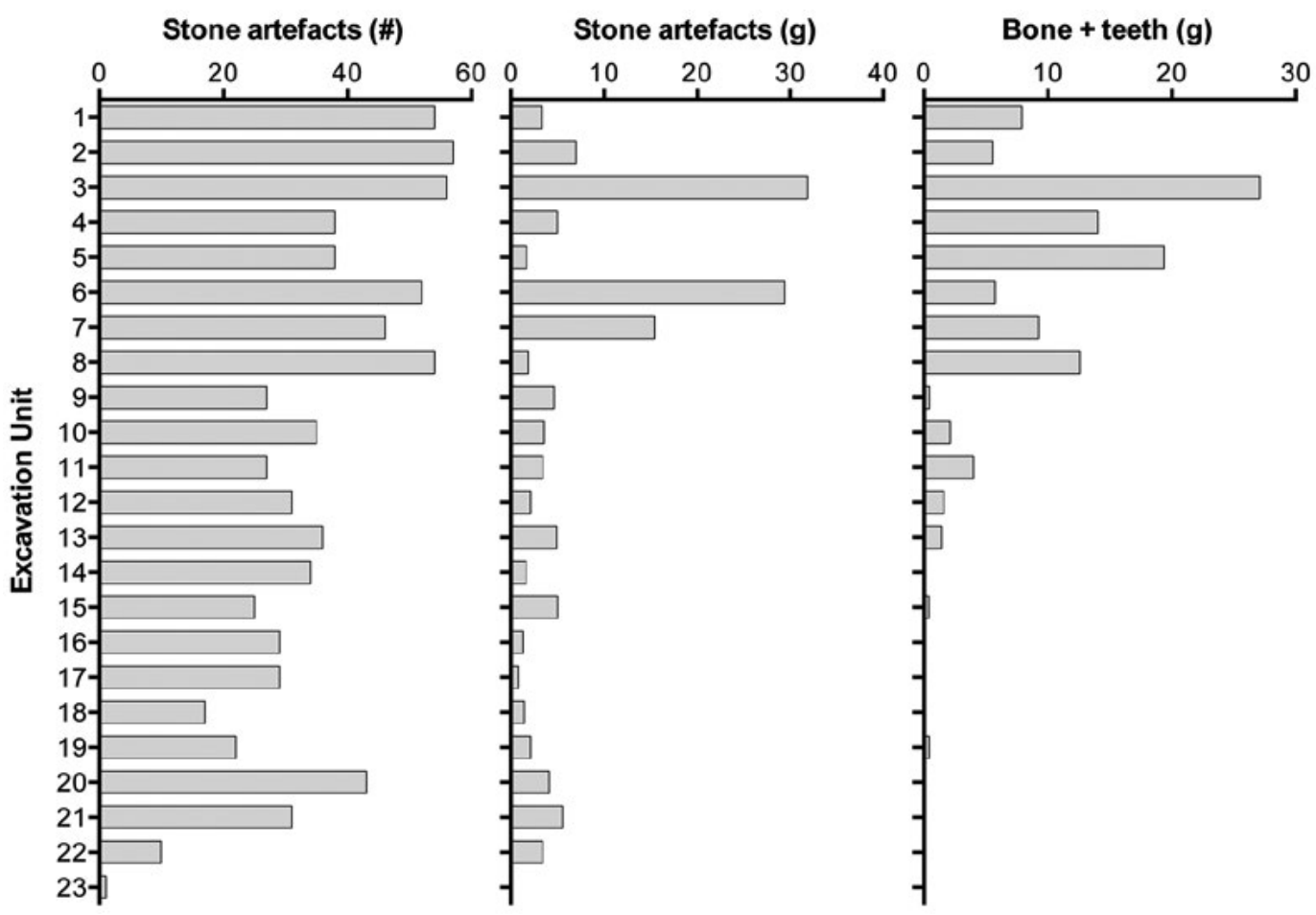

Figure 11.40 Square P: Distribution of stone artefacts and bone + teeth (excluding a particularly large stone artefact weighing $164.0 \mathrm{~g}$ from XU3, to enable better visualisation of the overall distribution down the XU profile).

Source: Illustration by Jerome Mialanes.

Table 11.8 Square P: Incidence of stone artefacts by raw material.

\begin{tabular}{|l|r|r|r|r|}
\hline Raw material & $\#$ & $\%$ & $\mathbf{9}$ & $\%$ \\
\hline Quartzite & 744 & 93.8 & 293.1 & 96.1 \\
\hline Chert & 26 & 3.3 & 3.7 & 1.2 \\
\hline Quartz & 14 & 1.8 & 4.7 & 1.6 \\
\hline Siltstone & 6 & 0.8 & 3.0 & 1.0 \\
\hline Igneous & 3 & 0.4 & 0.3 & 0.1 \\
\hline
\end{tabular}

Source: Authors' data.

A total of 10 modified artefacts other than the ground-edge axe fragments, all tools or tool fragments, were recovered from the topmost 12 XUs of Square P; all are made on quartzite (Figure 11.42). They include three unifacial, two bifacial and one unclassifiable point, as defined by Brindley and Clarkson (2015) (Figure 11.43). The unclassifiable point does not possess evidence of retouching, but its pointed distal end coupled with the presence of multiple fractures diagnostic of high velocity impact suggest that it is the tip of a projectile point (the complete left margin of the artefact has been removed by a burinating fracture along a length of $7.3 \mathrm{~mm}$; tip crushing extends onto the dorsal face; the distal end of the dorsal face has a $2.7 \mathrm{~mm}$ long fracture scar with a step termination; the end of the ventral face has a fracture scar $0.7 \mathrm{~mm}$ long with a step termination). Macro-fracture types diagnostic of high-velocity impacts, sometimes in the form of negative and sometimes as positive fracture lips 1 to $2 \mathrm{~mm}$ long with step terminations (Brindley and Clarkson 2015; Geneste and Plisson 1990, 1993; Normand et al. 2008; O'Farrell 2004), are also present on two of the five definite excavated points and suggest that they were also used as projectile points. A fuller analysis of the Square P stone artefacts in relation to those of all the excavated squares from Nawarla Gabarnmang will be presented elsewhere. 

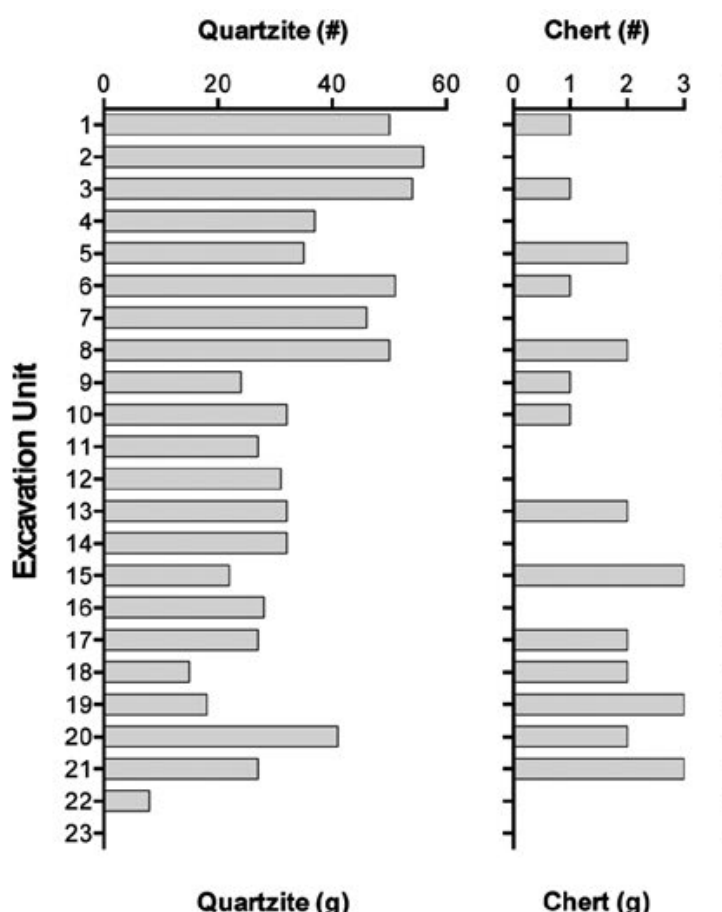

Quartz (\#)

Siltstone (\#)

Igneous (\#)
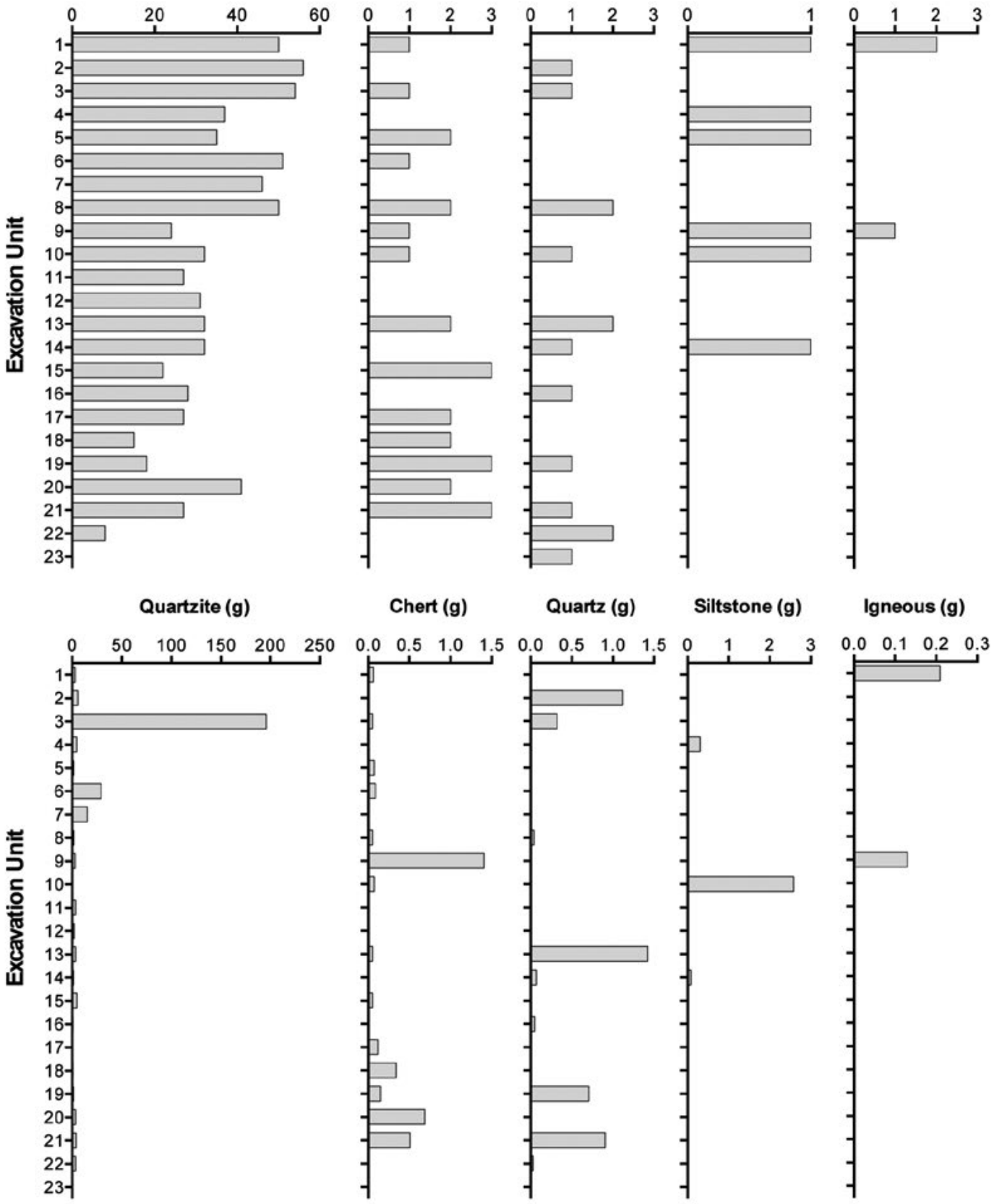

Figure 11.41 Square P: Raw material distribution by number and by weight.

Source: Illustration by Jerome Mialanes. 


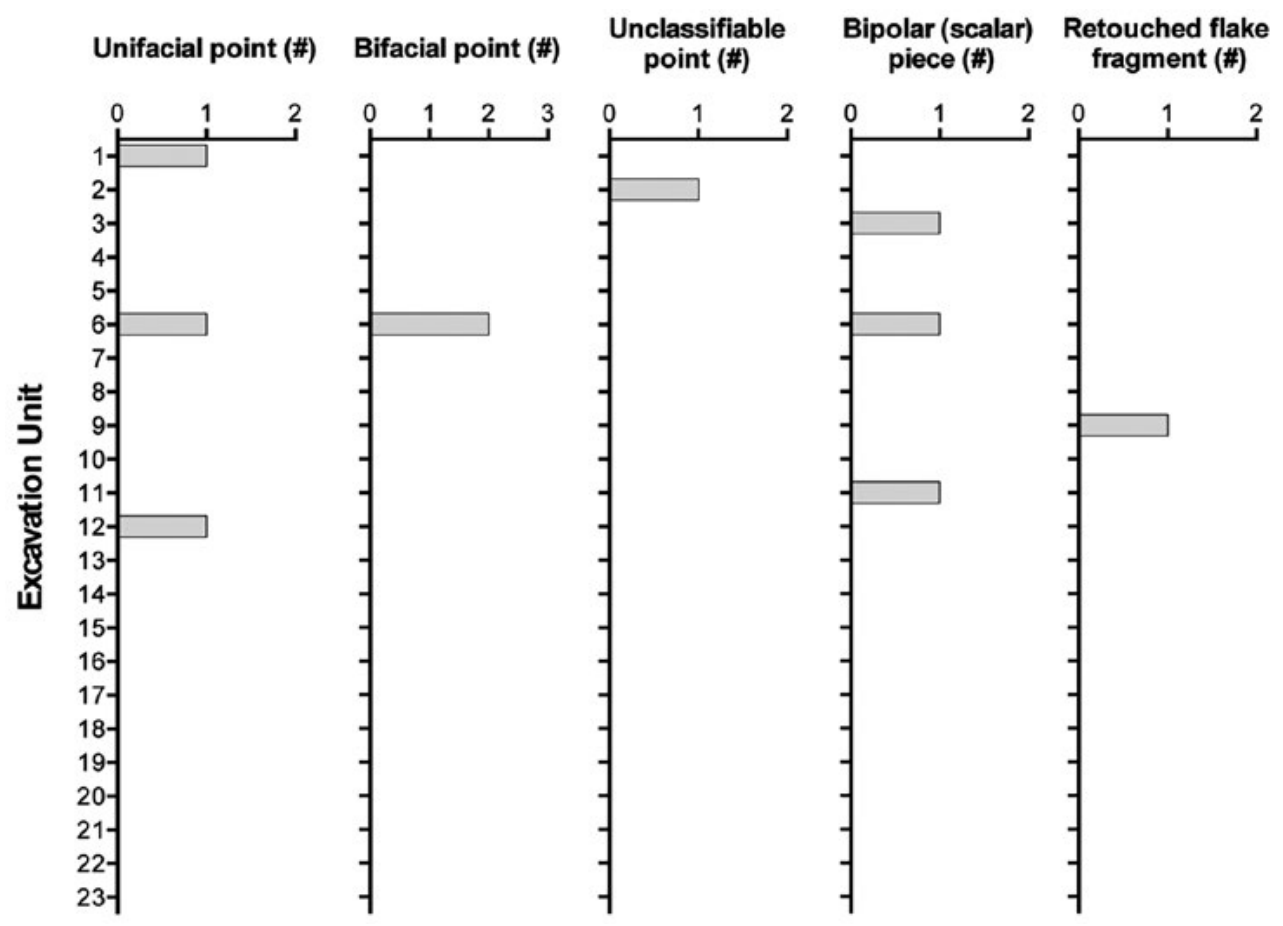

Figure 11.42 Square P: Distribution of stone artefact types by number. Source: Illustration by Jerome Mialanes.

A
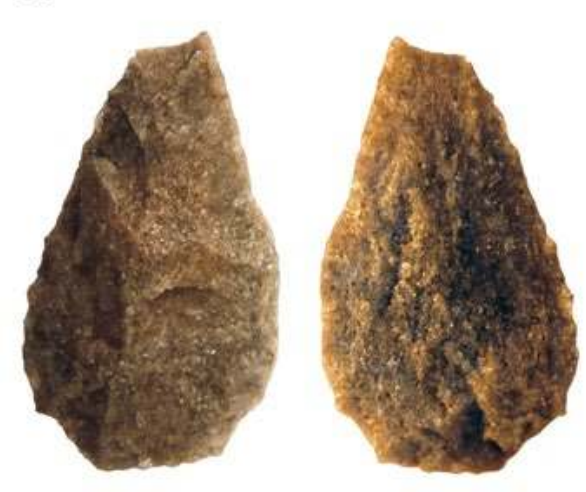

B

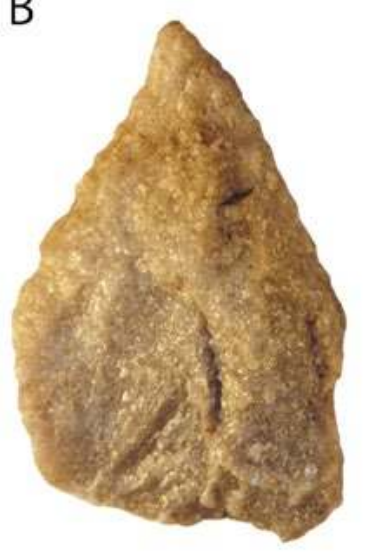

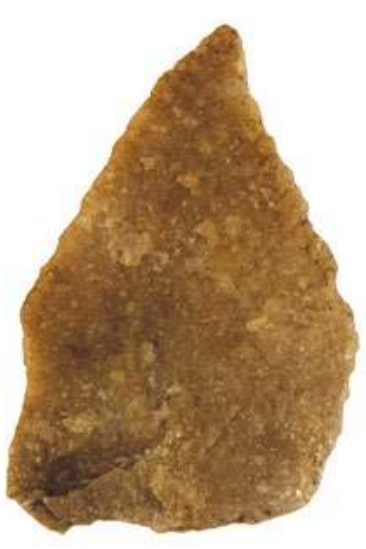

$E$

$\mathrm{F}$

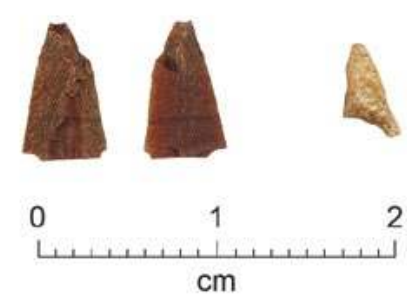

Figure 11.43 Square P: Formal stone tool types.

A: Bifacial point XU6(3); B: Bifacial point XU6(2); C: Unifacial point XU12(1); D: Unifacial point XU1(2); E: Unclassifiable point XU2(1); F: Unifacial point XU6(1).

Source: Photographs by Catherine Cretin and Mila Folgado. 


\section{Cultural materials in Square P: Faunal remains}

The faunal assemblage from Square P consists of a moderate quantity of fragmentary bones and teeth (Table 11.7), some mammalian faecal material and a tiny quantity of freshwater bivalve shell.

Well-preserved macropodid (wallaby or kangaroo) faecal pellets were recovered from XU2 and XU3. Other faecal material from XU1 and XU3 adheres to unburnt bone fragments and contains abundant mammal hair. These are interpreted as fragments of dog faeces. One example from XU1 contains part of a caudal vertebra of a macropodoid, while another also from XU1 contains a complete thoracic vertebra of an agamid (dragon lizard). Another example from XU3 contains a small sliver of unburnt cortical bone, probably from a medium-sized mammal.

Shell fragments, all from XU4-XU5, have a total weight of $0.03 \mathrm{~g}$. The fragments are extremely fragile and breaking up into laminar sheets.

The highest concentrations of bones and teeth were recovered from XU1-XU8, with a reduced quantity in XU9-XU13, and only occasional small fragments in XU14-XU22 (Table 11.7; Figure 11.40). The bulk of the assemblage thus dates from Radiocarbon Phase 4, i.e. since c. 180 cal BP. The oldest recovered remains from XU22 might be as old as the end of Radiocarbon Phase 2 (c. 990-1090 cal BP), but are more likely associated with the start of Radiocarbon Phase $3(500-570 \mathrm{cal} \mathrm{BP})$.

The most recent bones and teeth from XU1-XU3 are exceptionally and uniformly well-preserved, and show a relatively low prevalence of burning (Figure 11.44). Most remains from XU4-XU6 are similarly well-preserved; however, a few unburnt fragments show extensive corrosion along root channels and/or areas of surface damage interpreted as consumption by termites. Damage of both kinds becomes increasingly more prevalent from XU7 to XU15. Below XU15, virtually all of the recovered bone is heavily burnt to the point of being fully calcined (Figure 11.44); these fragments are visibly corroded and, with the exception of a few fragments of tooth crown, are taxonomically uninformative. The changes in the physical condition of the faunal remains through the deposit point to an aggressive preservation environment in which bones and even teeth are degraded to the point of non-recovery even by fine-scale excavation methods within a period of centuries. The principal degradation processes in this environment are likely to be microbial attack, much of it associated with rootlet contact and penetration, the acidity of sediments and direct consumption by termites (Hedges 2002; Jans et al. 2004). Fungal attack may also be prevalent, but this tends to work on the internal structure of bone and be less visible macroscopically.

The total sample contained 48 individual fragments for which it was possible to make a taxonomic determination to family level or below (Table 11.9). This includes a minimum of seven mammal species, including a species of quoll (Dasyurus sp.), an unidentified bandicoot (Peramelidae or Thyaclomyidae), the northern brushtail possum (Trichosurus vulpecula arnhemensis), a small rodent (the grassland melomys - Melomys burtoni) and at least three species of macropodid distinguishable by size. Small macropodid remains are probably from a rock wallaby (Peradorcas concinna) and/or a species of nail-tail wallaby (Onychogalea sp.). A medium-sized taxon is almost certainly the agile wallaby (Macropus agilis). Larger remains might be from the black wallaroo (M. bernardus), the antilopine wallaroo (M. antilopinus) and/or the euro (M. robustus). None are identified with certainty as diagnostic elements are absent. The agamid lizard remains include one dentary from XU6 positively determined as a frilled lizard (Chlamydosaurus kingii). A small crocodile, probably less than $1 \mathrm{~m}$ in total length, is represented by a small fragment of maxilla in XU2. A single calcined teleost fish vertebra comes from XU10. 


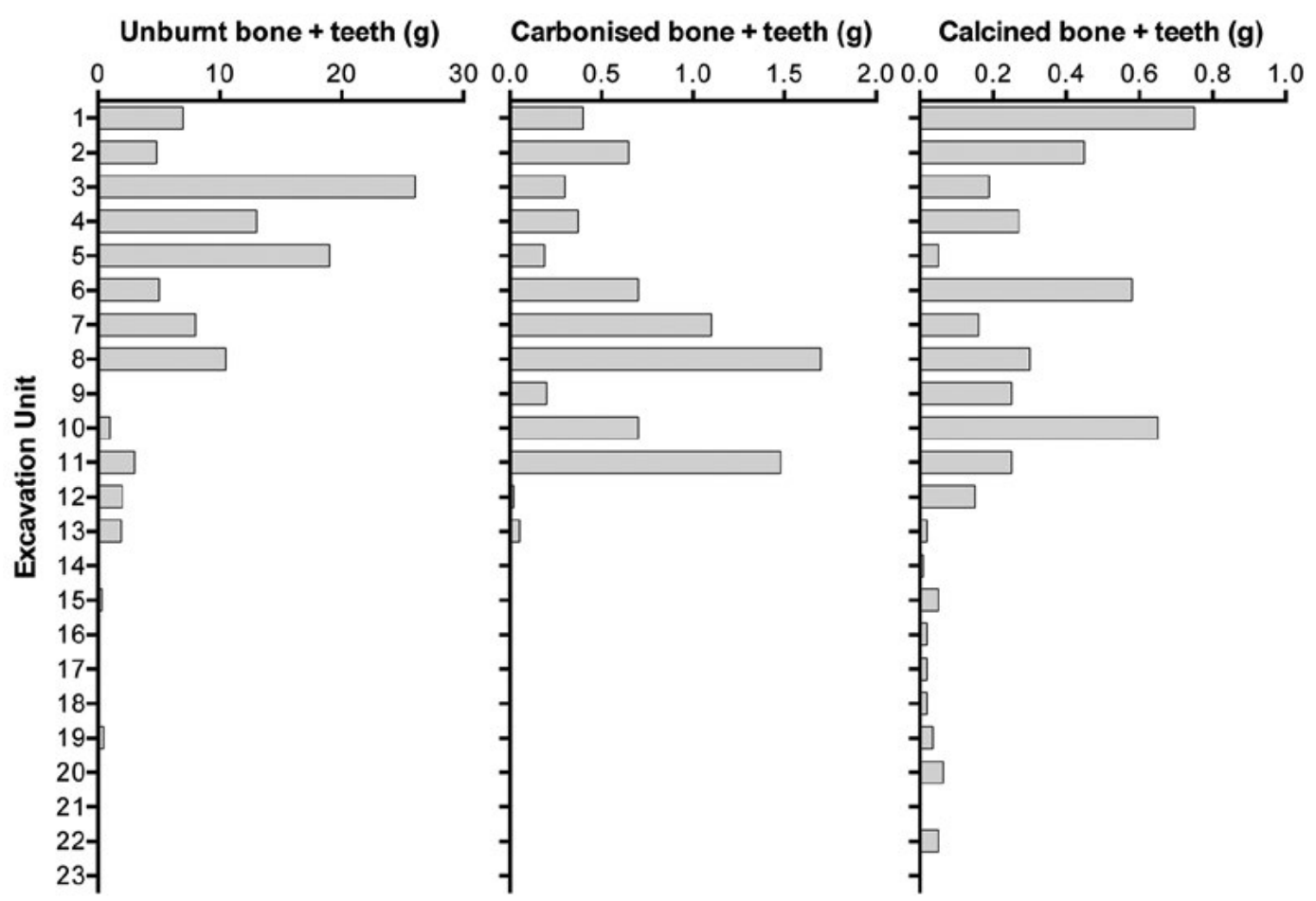

Figure 11.44 Square P: Burning composition (by weight) of recovered bones and teeth through the stratigraphic profile.

Carbonised = burnt but with retained carbon; calcined = all carbon has been pyrolised .

Source: Illustration by Jerome Mialanes.

Medium-sized macropodid (M. agilis) remains make up nearly 50 per cent of the total sample of identified fragments, with small macropodids and the brushtail possum accounting for 13 per cent and 17 per cent, respectively. The agile wallaby, which inhabits grassland/savannah habitats, appears to have been favoured during Radiocarbon Phase 4 times from c. $180 \mathrm{cal}$ BP. Brushtail possums are found in most habitats, including savannah and rocky gorges and breakaways.

Noteworthy in the assemblage from Square P is the high incidence of human modifications to bone fragments: the application of red ochre to bone surfaces; the occurrence of clusters of fine scratches and shaving marks (presumably made with stone artefacts); and modification by grinding. Examples of both ochre application and scratches/shaving marks occur in most XUs from XU1 to XU5; older examples are perhaps not recognised due to root and termite damage to the bone surfaces. Only one example of grinding was observed, on a small, unburnt cortical bone fragment from XU2. Bone from other parts of the site displays the same kinds of modifications. A detailed account of the entire assemblage is in preparation. 
11. Dating painted Panel E1 at Nawarla Gabarnmang, central-western Arnhem Land plateau

\begin{tabular}{|c|c|c|c|c|c|c|c|c|c|c|c|c|c|c|c|c|c|c|c|}
\hline 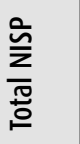 & $\sim$ & 0 & $\operatorname{Ln}$ & in & $m$ & $\ln 7$ & $\sim \nabla$ & $\mathrm{m}$ & $m$ & 0 o & $m 0$ & 0 & 0 & - & -0 & 0 & 0 & 0 & $0 \%$ \\
\hline 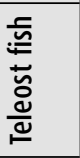 & & & & & & & & & - & & & & & & & & & & $\Gamma$ \\
\hline 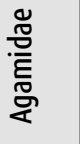 & $r$ & & & & & - & & & & $r$ & - & & & & & & & & n \\
\hline 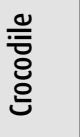 & & \ulcorner & & & & & & & & & & & & & & & & & $r$ \\
\hline 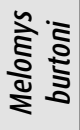 & & - & & & & & & & & & & & & & & & & & \\
\hline
\end{tabular}

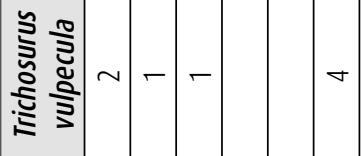

$\infty$

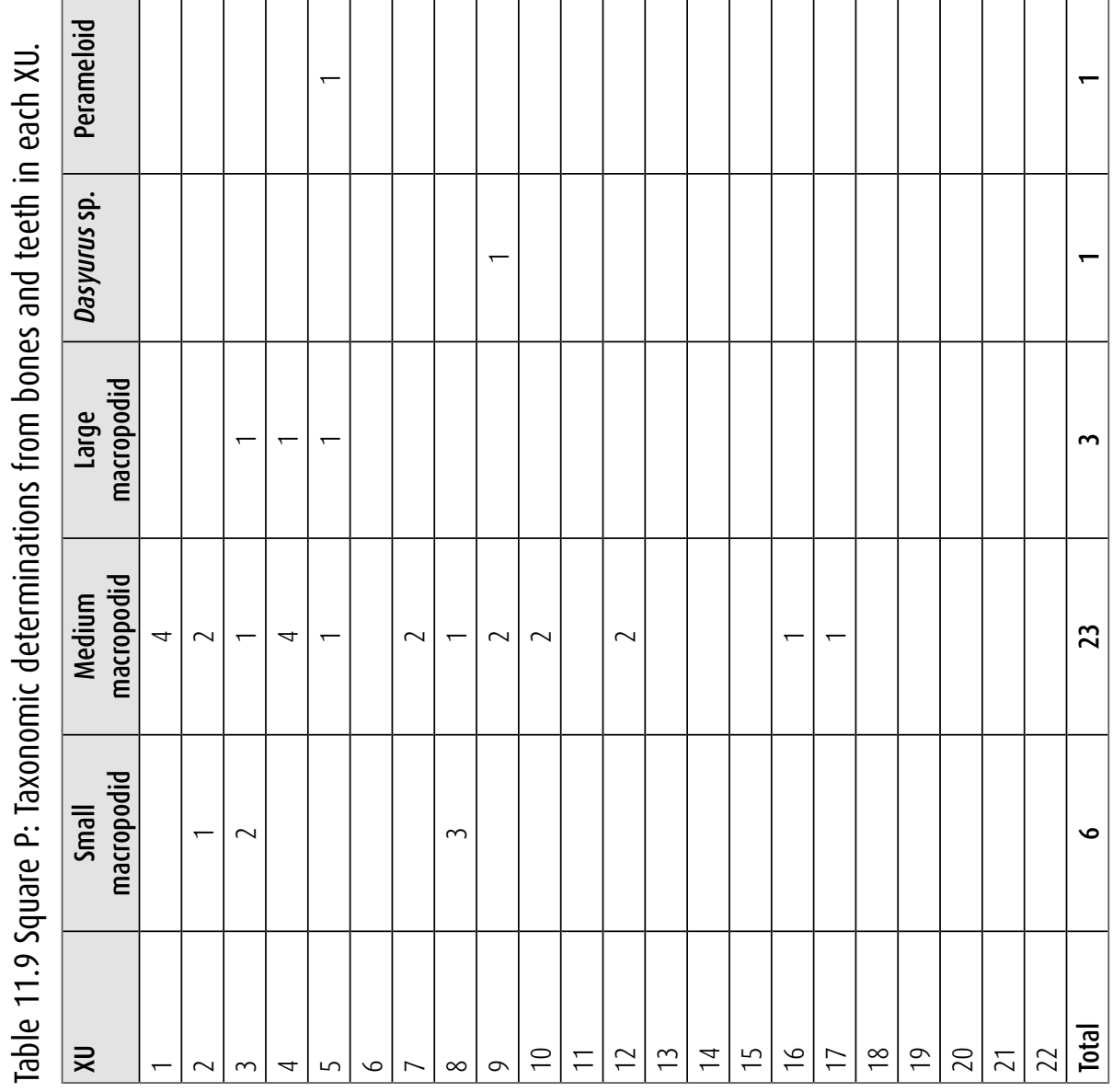

$\stackrel{\tilde{\hat{n}}}{\underline{\Sigma}}$

$\approx$ 嵌

岗

훙

हे

崩 产

岛 变

竞 


\section{Cultural materials in Square P: Excavated pigments}

Numerous small pieces of pigment were excavated from Square P. They occur as three different types:

1. Paint drops that fell from the ceiling and/or brushes as paintings were made immediately above the square. These fell as wet drops of paint, coagulated on the sandy surface when it was at the depth of XU18, impregnating the ashy loamy sand sometimes down to the level of XU19, and dried in situ. These now-dried paint drops were sampled during excavation as slightly accreted concentrations of pigment mixed with incorporated ashy loamy sand.

2. Tiny solid pigment pieces $(2-3 \mathrm{~mm}$ long, the $2 \mathrm{~mm}$ minimum size representing the mesh size of the sieves used in the excavation) to small (up to $1.7 \mathrm{~cm}$ long) fragments of pigment.

3. Small painted rocks (from $4 \mathrm{~mm}$ to $6 \mathrm{~mm}$ long), each consisting of a thin quartzite spall covered by a thin reddish layer of pigment on a single surface.

Both paint drops and solid pigment pieces were investigated by macroscopic observation and by microanalytical techniques (e.g. scanning electron microscope coupled with energy-dispersive $\mathrm{X}$-Ray spectroscopy [SEM-EDX]; X-ray fluorescence [XRF]) coupled with structural techniques (e.g. Raman microspectroscopy; X-ray diffraction [XRD]). A sample of pieces was analysed with a LEO Stereoscan 440 SEM with a Brucker SDD X-FLASH 4030 EDX, in high-vacuum mode at $20 \mathrm{kV}$. The elemental composition of the excavated pieces was analysed with a Bruker S1 Titan 500 portable X-Ray Fluorescence (pXRF) analyser equipped with a rhodium tube, a SDD detector and a $5 \mathrm{~mm}$ collimator (acquisition parameters: for $10 \mathrm{keV}, 30 \mathrm{~s}$ live-time count and for $30 \mathrm{keV}, 30 \mathrm{~s}$ live-time count). XRF analysis revealed major chemical components. XRD and Raman microspectroscopy were used to determine chemical structures. XRD patterns were measured by a diffractometer with an INEL XRG-3000 generator, an INEL CPS 120 curved detector (within an angular range of $0^{\circ}$ to $120^{\circ}$, in $2 \theta$ ), equipped with an anticathode in Cobalt $\left(K_{\mathrm{Co}}=1.78897 \AA\right)$ and a monochromator plan in Silicon. The Raman spectra were obtained with a green laser at $514 \mathrm{~nm}$ with a Jobin-Yvon-Horiba T640000 equipped with a microscope (at $\times 10$, $\times 50$ and $\times 100$ magnification).

\section{Paint drops}

As each paint drop sample contained a combination of fine pigment powder and ashy loamy sand, the powder was hand-separated under a binocular microscope. The powder samples are unambiguously dried paint drops because of 1) their physical characteristics as slightly accreted powder patches embedded in the ashy loamy sand; 2) their sudden appearance on an ancient ground surface beginning at c. $26 \mathrm{~cm}$ depth in XU18; 3) the sub-rounded plan shape of the individual accreted sample patches; and 4) the rapidly decreasing volumes of the individual patches with depth.

Six phials of light-coloured (Munsell: 7.5YR 4/3 brown [4 samples] to 7.5YR 6/4 light brown [2 samples]) pigmented sediment were analysed from XU18, representing paint drops excavated as dry pigment powder accreted around the ashy loamy sand. These pigment-rich sediments contrast with the homogeneous and unpigmented, very dark brown (7.5YR 3/1) to dark-brown (7.5YR 3/2) ashy loamy sand that surrounds them in SU3A (these Munsell colours were measured on sediments from each of the surrounding XU16, XU17 and XU20, where dried paint drops are absent).

SEM-EDX analysis indicates that the ashy loamy sand from XU18 is largely made up of Si, Al, $\mathrm{Fe}, \mathrm{P}, \mathrm{Ca}$ and $\mathrm{Ti}$, with $\mathrm{K}, \mathrm{Na}$ and $\mathrm{Mg}$ also present as minor elements. Five of the six dried paint samples show a composition similar to the ashy loamy sand; the sixth (XU18 in situ sample \#4), one of the two light-brown samples, was different. It contained a higher incidence of $\mathrm{Al}$ than the other samples, and a crystalline morphology consisting of plates (e.g. Figure 11.45). 


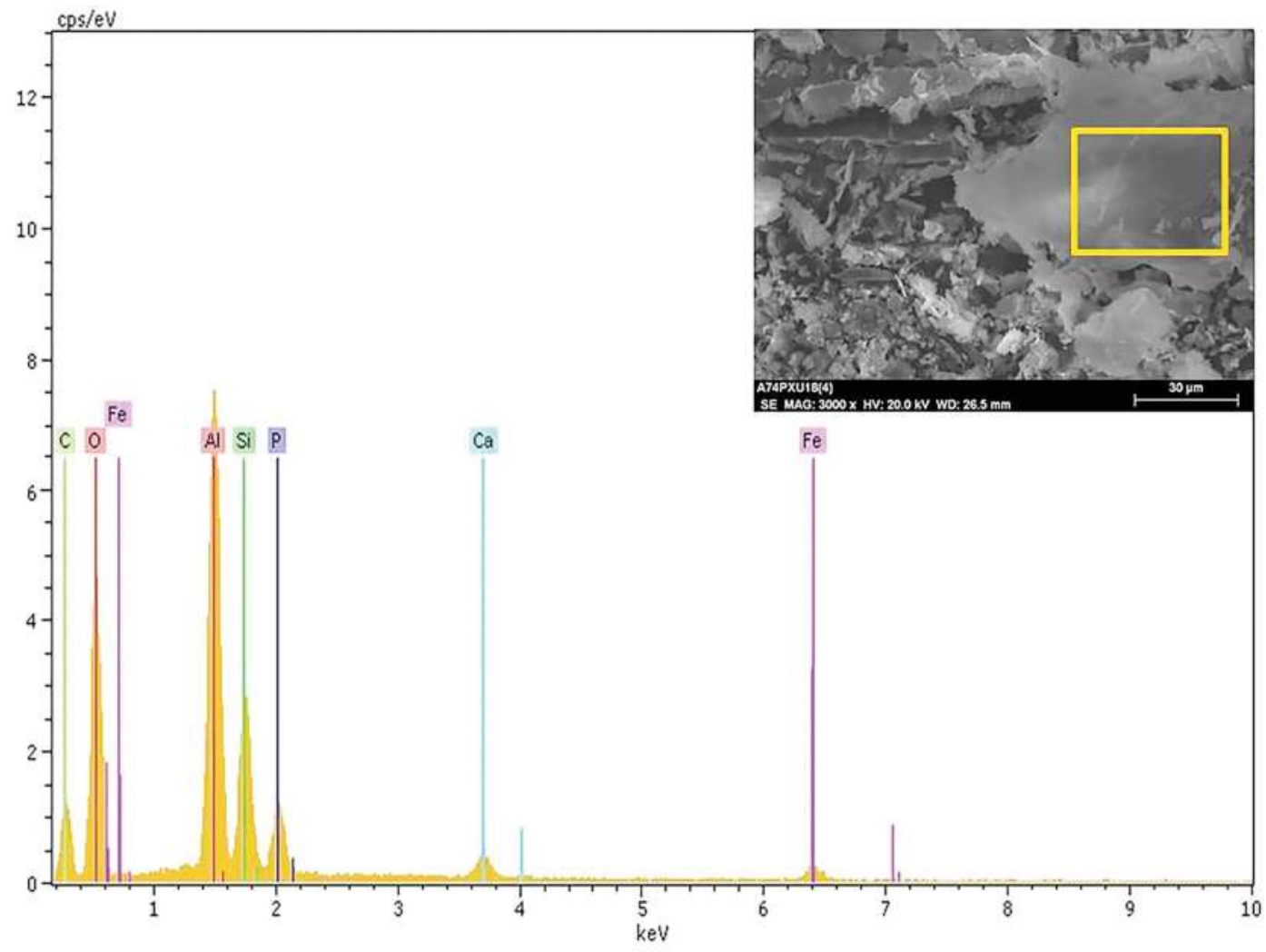

Figure 11.45 EDX spectrum of light-coloured pigment powder from XU18 in situ sample \#4.

Source: Illustration by Emilie Chalmin.

The elemental composition of that different light-brown pigment powder is distinctive from both the ashy loamy sand in which it is embedded, and from the other dried paint drop samples: it exhibits high $\mathrm{Ca}$ and $\mathrm{P}$ values (2 per cent as $\mathrm{CaO}$ and 7 per cent as $\mathrm{P}_{2} \mathrm{O}_{5}$ ), with minor $\mathrm{Si}, \mathrm{Al}$, $\mathrm{Na}, \mathrm{Mg}, \mathrm{S}, \mathrm{Cl}$ and $\mathrm{K}$, and a fluffy pellet morphology.

For the paint drop samples, the only structure identified through XRD is quartz. Nevertheless, it is not possible to determine if the quartz really comes from the paint or if its presence is due to contamination from the surrounding sediment. The structure of the light-coloured powder was more difficult to identify due to its weak crystallinity.

The two light-brown patches of pigmented ashy loamy sand sampled from XU18 mainly consist of alumino-silicates. One of these patches also contains apatite $(\mathrm{Ca} 5(\mathrm{PO} 4) 3(\mathrm{OH}, \mathrm{F}, \mathrm{Cl})$ ). The presence of apatite could suggest that the pigment was mixed with crushed bone in the making of a paint paste. However, apatite is rarely found in the dried paint drops of Square P, whereas it should be represented in numerous samples if the pigment had been systematically mixed with crushed bone. We thus conclude that the apatite found amidst the dried paint drop sample from XU18 more likely comes from a tiny fragment of heavily degraded bone that happened to lie in the ground at this level and that was included in the phial during sampling. A tiny, light-coloured fragment of heavily degraded bone was also separately sampled from XU20, and subsequently identified in the laboratory as apatite, confirming the presence of degraded bone in these sediments (see also the faunal remains section, above). 


\section{Solid pigment pieces}

One hundred and ninety-seven solid pieces of pigment (red, orange, brown, yellow, yellowand-red, white) were excavated from Square P. They are all tiny to very small. None have the morphology of fallen flakes of paint; rather, they all appear to be by-products of the on-site processing of originally larger lumps of pigment.
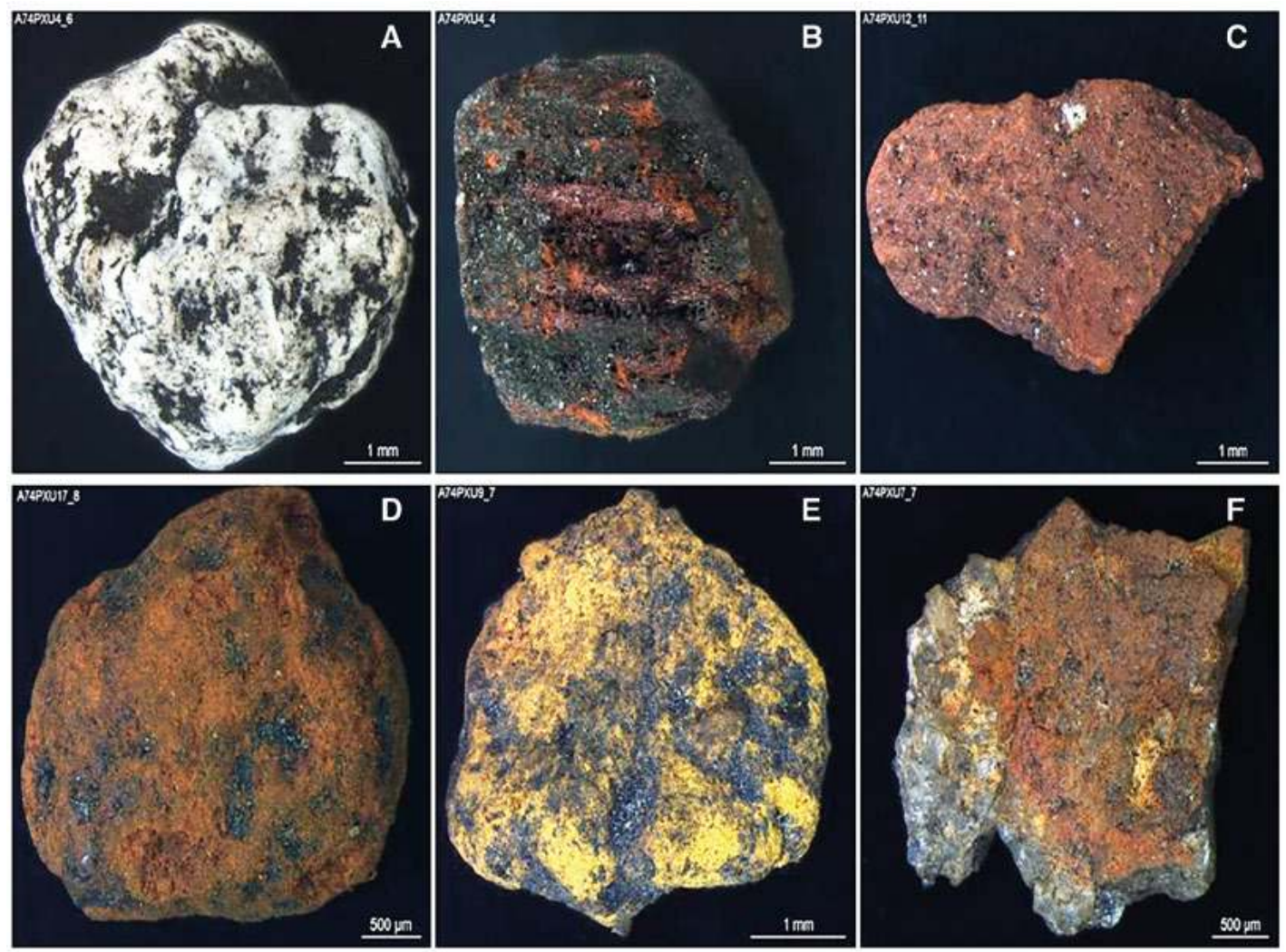

Figure 11.46 Square P: Examples of excavated solid coloured pieces showing the range of morphological characteristics, Nawarla Gabarnmang.

Note: The surface traces of black on individual pieces are ashy sediments from the archaeological layers from which they were excavated.

Source: Photographs by Géraldine Castets.

All pieces, regardless of their colouration, have a dull, earthy lustre. The three solid white pieces from XU4 and XU15 have a compact powder texture that produces a white streak (Figure 11.46A). In contrast, 11 pieces, some red, some orange, have strongly porous textures and a high iron content (Figure 11.46B). The great majority of pieces -183 tiny to small red, orange, yellow, and yellow-and-red lumps - contain iron oxides that would produce reddish or yellowish streaks when rubbed (Figure 11.46C, 11.46D and 11.46E). Some have a compact powdery texture, whereas others have a few cracks on their surfaces. Four of the 60 red pieces reveal a metallic lustre characteristic of a 'pure' iron mineral.

All the solid pieces other than the white ones contain iron $(\mathrm{Fe})$ in varied proportions, the iron causing their colouration. According to the results of the elemental analyses (Figure 11.47), iron is not associated with any other major chemical element ( $\mathrm{Si}, \mathrm{Al}, \mathrm{Ca}$ and $\mathrm{P}$ ). It reveals that the iron apparently only occurs in the form of oxide. It is difficult to classify the samples into a set of distinct chemical groups, as there is considerable overlap in the chemistries of individual samples. 


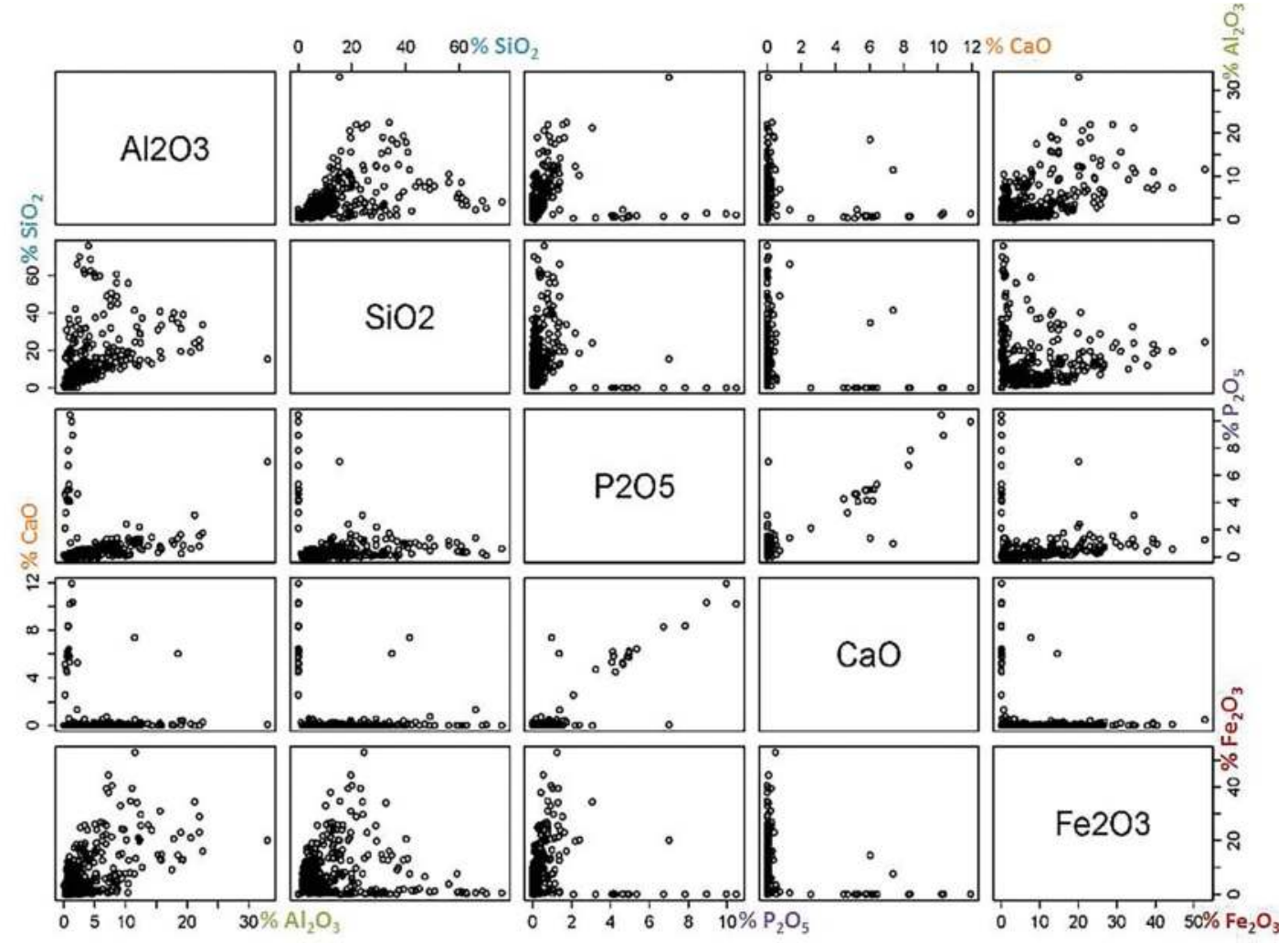

Figure 11.47 2-plot diagram representing the major element contents of solid pieces (in \% of oxide mass). Each circle represents a solid piece. The contribution of each oxide $\left(\mathrm{Al}_{2} \mathrm{O}_{3^{\prime}} \mathrm{SiO}_{2^{\prime}} \mathrm{P}_{2} \mathrm{O}_{5^{\prime}} \mathrm{CaO}, \mathrm{Fe}_{2} \mathrm{O}_{3}\right)$ is indicated for each sample by reading the per cent values along the horizontal and vertical axes.

Source: Illustration by Emilie Chalmin.

Alumino-silicates (presence of Si and Al) are only detected by XRF (which identifies the elements) and not by XRD (which reveals the structure of compounds). Two different Si:Al ratios are revealed by XRF quantitative analysis - 1:1 and 2:1 - indicating clays such as kaolinite and muscovite respectively. Weakly crystallised clay minerals may also be present.

Some tiny red pieces $<2 \mathrm{~mm}$ long excavated from XU14 were ground into powder to allow further analyses. A maghemite $\left(\gamma-\mathrm{Fe}_{2} \mathrm{O}_{3}\right)$ /magnetite $\left(\mathrm{Fe}_{3} \mathrm{O}_{4}\right)$ structure has been identified by XRD for one of these powdered pieces (Figure 11.48), whereas goethite $(\mathrm{FeOOH})$ has been detected on a solid yellow piece that also came from XU14. However, in these samples, the iron oxides are always mixed with abundant quartz grains from the deposit that makes the identification of the minor compounds difficult.

Raman microspectroscopy clearly identifies the presence of haematite $\left(\mathrm{Fe}_{2} \mathrm{O}_{3}\right)$ on several red pieces from XU14. A number of white particles, each a few micrometres long, embedded in the red matrix of sample A74PXU14R from XU14, were identified as rutile $\left(\mathrm{TiO}_{2}\right)$ (Figure 11.49).

The structural characterisation of several solid pieces of pigment confirms the presence of multiple compounds within individual pieces. Some of the iron oxides are well crystallised, others less so. The poorly crystallised oxides and clays are not always clearly identified. 


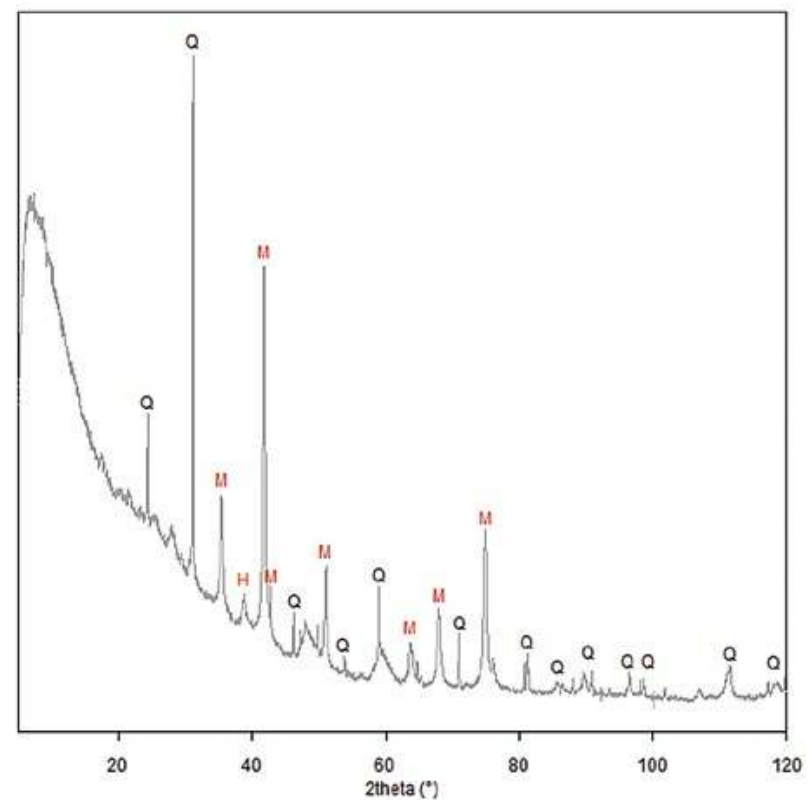

Figure 11.48 XRD pattern of a sample of red pigment from XU14 (laboratory sample code: A74PXU14_powder).

Q: Quartz; M: Maghemite/magnetite; H: Haematite.

Source: Illustration by Emilie Chalmin.

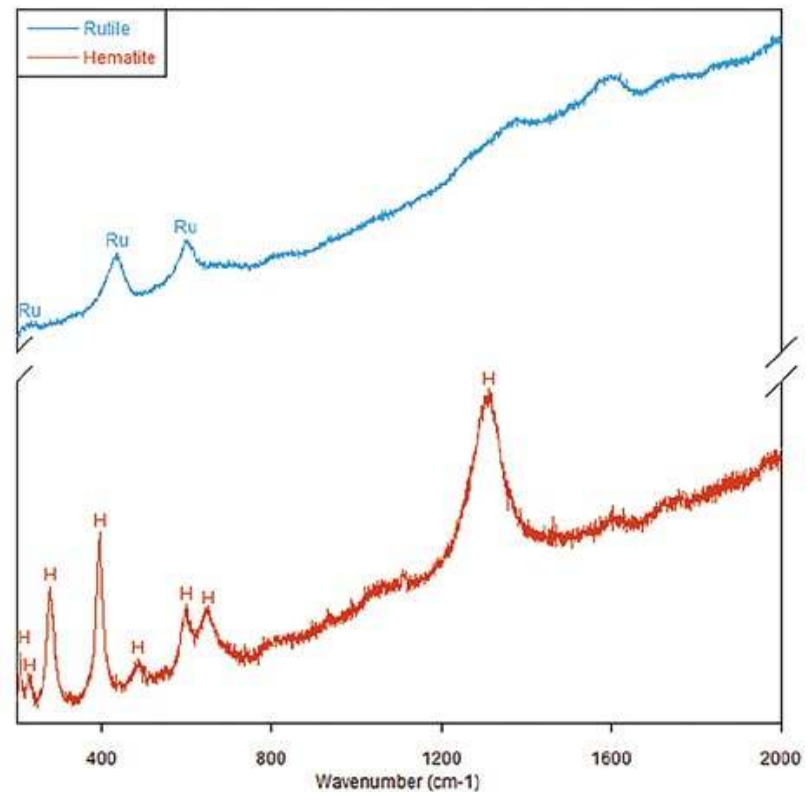

Figure 11.49 Raman spectra of a red piece with tiny white specks from XU14 (laboratory code: A74PXU14R).

H: Haematite; Ru: Rutile.

Source: Illustration by Emilie Chalmin. 


\section{Painted rocks}

Nine samples are small fragments of rock with red or orange pigment adhering on one surface only (Figure 11.46F). In all cases, the rock matrix is quartzitic sandstone. The continuous coloured layer covering the rock is largely iron oxide. The composition of these pigment layers is compatible with the similarly coloured solid pieces of pigment, but it could also be due to weathering of the rock surface prior to its falling, presumably from the ceiling. The pigmented surface could not have attained its colouring after burial as 1) only one face is coloured in each case; and 2) alteration of the rock would have required exposure to air if it was a natural byproduct of surface weathering.

\section{Discussion of the excavated pigments}

The excavated dried paint drops were overwhelmingly found in XU18 during excavation, with a minor presence in XU19. These paint drops fell onto an old, ashy loamy sand surface as paintings were made overhead. That much of the surface area was covered by now-dried paint drops in XU18 suggests a major painting event between 390-510 cal BP (Radiocarbon Phase 3), the time when the level of XU18 was the floor in this part of the site. The light colour of the paint drops indicates that this painting event made light-coloured, off-white paintings rather than yellow or red paintings. We identify this painting event with Panel E1 art Phases IV, V (see Figures 11.12-11.14) or Phase VI (see Figure 11.15), the three phases when numerous paintings in light-coloured pigments were made immediately overhead.

Solid pieces of pigment are found pretty much continuously through the stratigraphic sequence (Figure 11.50). The quantity of such solid pieces varies with depth, although no clear patterning is evident in the chrono-stratigraphic distribution of particular colours. The solid pieces of pigment may relate to rock art or to other kinds of painting activity, such as the coating of bone with red ochre that is evident in Square P and elsewhere at Nawarla Gabarnmang. We cannot determine whether or not these solid pieces of pigment relate to the Panel E1 art, although they do suggest repeated painting activity at Nawarla Gabarnmang given their high frequencies throughout the Square P sediment sequence.

Small, probably exfoliated pieces of painted rock were recovered from XU3 (4 pieces), XU6 (1 piece), XU7 ( 2 pieces) and XU15 (2 pieces). These are too small to indicate which items of rock art they came from, and only suggest minimum ages of 390-510 cal BP (the age of the ground levels onto which the small painted rock fragments fell) for the earliest artistic activities in this part of the site.

Chemical analysis has confirmed that the yellow solid pieces consist of goethite. The orange and red pieces owe their colours to the presence of iron oxides in the form of haematite and/or maghemite/magnetite. Maghemite can form naturally by weathering or by low-temperature oxidation of spinels containing ferrous iron, commonly magnetite. Its presence can also reveal heating in direct contact with organic materials (at moderate temperatures of $<350^{\circ} \mathrm{C}$, reachable in small open fires). The presence of red and orange pieces enriched in maghemite at Nawarla Gabarnmang Square P may indicate that these pieces of ochre have been in contact with wood and/or animal fats in a fireplace (see Cornell and Schwertmann 2003; Grogan et al. 2003; Salomon et al. 2015; Schwertmann and Cornell 2000). This evidence of probable heating of ochres at Nawarla Gabarnmang may indicate purposeful heat alteration of lumps of ochre for the production of paint pastes, or accidental heating in the presence of campfires. 


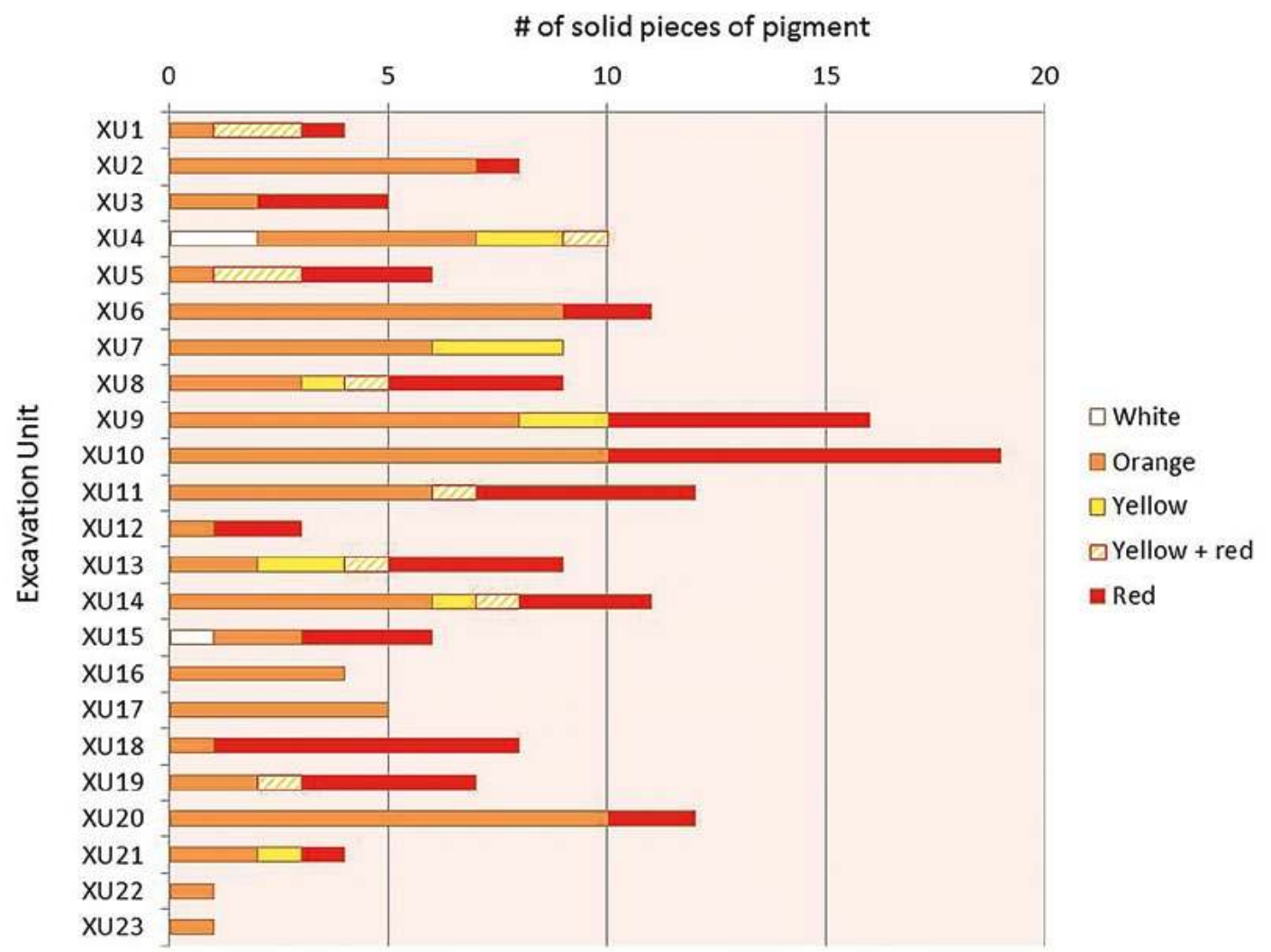

Figure 11.50 Square P: Number of solid pieces of pigment by colour, by XU.

Source: Illustration by Emilie Chalmin.

\section{Conclusion}

Our varied studies allow a series of clear conclusions about the painted rock art on Panel E1 at Narwala Gabarnmang:

1. The large, flat ceiling area encompassing art Panel E1 was caused by roof fall following the removal of supporting pillars sometime before c. $4240 \mathrm{cal} \mathrm{BP}$, and possibly in late Pleistocene times.

2. The rock base of Square P is not bedrock, but a large slab of roof fall (stratum D1) that must date to c. $4240 \mathrm{cal} \mathrm{BP}$ or older.

3. As the extant art on the ceiling surface at Panel E1 can only have been produced after the collapse of stratum D1 from the ceiling, it must be more recent than c. 18,594 cal BP, and possibly is more recent than c. $4240 \mathrm{cal} \mathrm{BP}$.

4. The evidence from stratified ochre in Square $P$, paint drops and small painted rocks indicates a major painting event during Radiocarbon Phase 3; this suggests that the bulk of the art in Panel E1 was produced 390-510 cal BP.

5. The light colour of the paint drops indicates white or off-white or light tan coloured pigments, rather than yellows or reds; so it is most likely to be associated with the most recent period of rock art production (artistic Phases IV, V or VI).

With an occupation history approaching 50,000 years and rock art dating to at least 27,000 years ago (David et al. completed manuscript, 2013, 2014), Nawarla Gabarnmang has a welldocumented chronology of long occupation and art production. The multi-faceted analysis of 
Panel E1 and excavation of Square P directly below it have allowed a further chronological refinement relating to the production of art at the site, clearly indicating that, although the paintings on Panel E1 are relatively recent, art production took place repeatedly over long periods of time at Nawarla Gabarnmang.

\section{Acknowledgements}

We thank Margaret Katherine and family, Wes Miller, Ray Whear, the late Peter Bolgay and the Jawoyn Association Aboriginal Corporation for asking us to undertake archaeological research at Nawarla Gabarnmang. Thanks to Elisa Boche, Magen O'Farrell, Daniel James (Monash University), Jacqueline Matthews (University of Western Australia) and Chris Urwin (Monash University) for helping with the excavations. Thanks to Valérie Reita and Denis Testemale (Institut Néel) for undertaking the Raman micro-spectroscopy; Pauline Martinetto for access to the X-Ray diffractometer (Institut Néel); and the University Grenoble Alpes for financial support to undertake the chemical analysis (NAÏADE, PEPS interdisciplinary project 2013). We thank the Australian Research Council for Linkage grant LP1 10200927 and Discovery grants, QEII and Discovery Outstanding Research Award (DORA) Fellowships DP0877782 and DP130102514. Thanks to Kara Rasmanis for drafting parts of Figure 11.4, Catherine Cretin for photographing and Mila Folgado for presentation of the artefacts on Figure 11.43.

\section{References}

Brindley, J. and C. Clarkson 2015. Beyond a suggestive morphology: Were Wardaman stone points exclusively spear armatures? Australian Archaeology 80:81-92. doi.org/10.1080/03122417.2015.116 82061

Bronk Ramsey, C. 2009. Bayesian analysis of radiocarbon dates. Radiocarbon 51(1):337-360. doi.org/ $10.1017 /$ S0033822200033865

Bronk Ramsey, C. 2013. OxCal Program v4.2.2. Radiocarbon Accelerator Unit, University of Oxford, Oxford.

Carson, L.J., P.W. Haines, A. Brakel, B.A. Pietsch and P.A. Ferenczi 1999. Milingimbi SD53-2, 1:250 000 Geological Map Series Explanatory Notes. Northern Territory Geological Survey, Government Printer of the Northern Territory, Darwin.

Chippindale, C. and P.S.C. Taçon 1993. Two old painted panels from Kakadu: Variation and sequence in Arnhem Land rock art. In J. Steinbring, A. Watchman, P. Faulstich and P.S.C. Taçon (eds), Time and Space: Dating and Spatial Considerations in Rock Art Research, pp. 32-56. Occasional AURA Publication 8. Australian Rock Art Research Association, Melbourne.

Cornell, R.M. and U. Schwertmann 2003. The Iron Oxides: Structure, Properties, Reactions, Occurrences, and Uses. Wiley-VCH, Weinheim. doi.org/10.1002/3527602097

David, B., J.-J. Delannoy, R. Roberts, Z. Jacobs, B. Brook, J.-M. Geneste, F. Petchey, J. Mialanes, T. Richards, B. Barker, M.I. Bird, C. Clarkson, E. Boche, S. Hoerlé and M. Katherine completed manuscript. Human colonisation of Sahul prior to fifty-one thousand years ago. 
David, B., J-M. Geneste, R.L. Whear, J-J. Delannoy, M. Katherine, R.G. Gunn, C. Clarkson, H. Plisson, P. Lee, F. Petchey, C. Rowe, B. Barker, L. Lamb, W. Miller, S. Hoerle, D. James, E. Boche, K. Aplin, I.J. McNiven, T. Richards, A. Fairbairn and J. Matthews 2011. Nawarla Gabarnmang, a 45,185 \pm 910 cal BP site in Jawoyn Country, southwest Arnhem Land plateau. Australian Archaeology 73:73-77.

David, B., B. Barker, F. Petchey, J.-J. Delannoy, J-M. Geneste, C. Rowe, M. Eccleston, L. Lamb and R. Whear 2013. A 28,000 year old excavated painted rock from Nawarla Gabarnmang, northern Australia. Journal of Archaeological Science 40:2493-2501. doi.org/10.1016/j.jas.2012.08.015

David, B., B. Barker, J.-J. Delannoy, J-M. Geneste, F. Petchey and L. Lamb 2014. A Pleistocene charcoal drawing or painting from northern Australia. INORA 69:18-22.

Delannoy, J.-J., B. David, J.-M. Geneste, M. Katherine, B. Barker, R.L. Whear and R.G. Gunn 2013. The social construction of caves and rockshelters: Chauvet Cave (France) and Nawarla Gabarnmang (Australia). Antiquity 87:12-29. doi.org/10.1017/S0003598X00048596

Elkin, A.P. 1952. Cave-painting in southern Arnhem Land. Oceania 22(4):245-255. doi.org/10.1002/ j.1834-4461.1952.tb00181.x

Geneste, J.-M. and H. Plisson 1990. Technologie fonctionnelle des pointes à cran solutréennes: L'apport des nouvelles données de la Grotte de Combe Saunière (Dordogne). In J.K. Kozlowski (ed.), Feuilles de Pierre: Les Industries à Pointes Foliacées du Paléolithique Supérieur Européen, pp. 293-332. Études et Recherches Archéologiques de l'Université de Liège 42, Liège.

Geneste, J.-M. and H. Plisson 1993. Hunting technologies and human behavior: Lithic analysis of Solutrean shouldered points. In H. Knecht, A. Pike-Tay and R. White (eds), Before Lascaux: The Complex Record of the Early Upper Paleolithic, pp. 117-137. CRC Press, Boca Raton.

Geneste, J.-M., B. David, H. Plisson, C. Clarkson, J-J. Delannoy, F. Petchey and R. Whear 2010. Earliest evidence for ground-edge axes: $35,400 \pm 410$ cal BP from Jawoyn country, Arnhem Land. Australian Archaeology 71:66-69. doi.org/10.1080/03122417.2010.11689385

Geneste, J-M, B. David, H. Plisson, J-J. Delannoy and F. Petchey 2012. The origins of ground-edge axes: New findings from Nawarla Gabarnmang, Arnhem Land (Australia) and global implications for the evolution of fully modern humans. Cambridge Archaeological Journal 22:1-17. doi.org/10.1017/ S0959774312000017

Goodman, D. and S. Piro 2013. GPR Remote Sensing in Archaeology. Springer-Verlag, Berlin. doi.org/ 10.1007/978-3-642-31857-3

Grogan, K.L., R.J. Gilkes and B.G. Lottermoser 2003. Maghemite formation in burnt plant litter at East Trinity, North Queensland, Australia. Clays and Clay Minerals 51(4):390-396. doi.org/10.1346/ CCMN.2003.0510404

Gunn, R.G. 1992. Bulajang: A reappraisal of the archaeology of an Aboriginal cult. In J. McDonald and I.P. Haskovec (eds), State of the Art, pp. 174-194. AURA Publication 6. Australian Rock Art Research Association, Melbourne.

Gunn, R.G. 2016. Art of the Ancestors: Spatial and Temporal Patterning in the Rock Art of Nawarla Gabarnmang, A Major Jawoyn Cultural Site on the Arnhem Land Plateau. Unpublished PhD thesis. Monash University, Clayton.

Gunn, R.G., R.L. Whear and L.C. Douglas 2012. Dating the present at Nawarla Gabarnmang: Time and function in the art of a major Jawoyn rock art and occupation site in western Arnhem Land. Australian Archaeology 75:55-65. doi.org/10.1080/03122417.2012.11681950 
Harris, E.C. 1989. Principles of Archaeological Stratigraphy. Academic Press, London.

Hedges, R.E.M. 2002. Bone diagenesis: An overview of processes. Archaeometry 44:319-328. doi.org/10.1111/1475-4754.00064

Ingold, T. 2000. The Perception of the Environment: Essays on Livelihood, Dwelling and Skill. Routledge, London. doi.org/10.4324/9780203466025

Jans, M.M.E., C.M. Nielsen-Marsh, C.I. Smith, M.J. Collins and H. Kars 2004. Characterisation of microbial attack on archaeological bone. Journal of Archaeological Science 31:87-95. doi.org/ 10.1016/j.jas.2003.07.007

McDonald, R.C., R.F. Isbell, J.G. Speight, J. Walker and M.S. Hopkins 1998. Australian Soils and Land Survey Field Handbook. CSIRO, Canberra.

Normand C., M. O'Farrell and J. Rios Garaizar 2008. The function(s) of archaic Aurignacian bladelets: Data and thoughts based on examples from Isturitz Cave (Pyrénées-Atlantiques, France). Palethnologie 1:6-44.

O'Farrell M. 2004. Les pointes de la Gravette de Corbiac (Dordogne) et considérations sur la chasse au Paléolithique supérieur ancien. In P. Bodu and C. Constantin (eds), Approches Fonctionnelles en Préhistoire. XXVeme Congrès Préhistorique de France, pp. 121-138. Société Préhistorique Française, Nanterre.

Quinif, Y. 2010. Fantômes de Roche et Fantômisation. Essai sur un Nouveau Paradigme de Karstogénèse. Karstologia Mémoires, Volume 18. Association Française de Karstologie, Mons.

Rayment, G.E and D.J. Lyons 2011. Soil Chemical Methods: Australasia. CSIRO Publishing, Melbourne.

Reimer, P.J., E. Bard, A. Bayliss, J.W. Beck, P.G. Blackwell, C. Bronk Ramsey, C.E. Buck, H. Cheng, R.L. Edwards, M. Friedrich, P.M. Grootes, T.P. Guilderson, H. Haflidason, I. Hajdas, C. Hatté, T.J. Heaton, D.L. Hoffmann, A.G. Hogg, K.A. Hughen, K.F. Kaiser, B. Kromer, S.W. Manning, M. Niu R.W. Reimer, D.A. Richards, E.M. Scott, J.R. Southon, R.A. Staff, C.S.M. Turney and J. van der Plicht 2013. IntCal13 and Marine13 radiocarbon age calibration curves, 0-50 000 years cal BP. Radiocarbon 55 (4):1869-1887. doi.org/10.2458/azu_js_rc.55.16947

Russell, T. 2012. No one said it would be easy. Ordering San paintings using the Harris Matrix: Dangerously fallacious? A reply to David Pearce. South African Archaeological Bulletin 67(196):26-272.

Salomon, H., C. Vignaud, S. Lahlil and N. Menguy 2015. Solutrean and Magdalenian ferruginous rocks heat-treatment accidental and/or deliberate action? Journal of Archaeological Science 55:100112. doi.org/10.1016/j.jas.2014.12.024

Schwertmann U. and R.M. Cornell 2000. Iron oxides in the Laboratory: Preparation and Characterization. Wiley-VCH, New York. doi.org/10.1002/9783527613229

Spriggs, M. 1989. The dating of the Island Southeast Asian Neolithic: An attempt at chronometric hygiene and linguistic correlation. Antiquity 63:587-613. doi.org/10.1017/S0003598X00076560

Thomas, J. 2008. Archaeology, landscape, and dwelling. In B. David and J. Thomas (eds), Handbook of Landscape Archaeology, pp. 300-306. Left Cost Press, Walnut Creek.

Wesley, D., S. O'Connor and J. Fenner 2016. Re-evaluating the timing of the Indonesian industry in northwestern Arnhem Land. Archaeology in Oceania. doi.org/10.1002/arco.5091 



\title{
The past 500 years of rock art at Nawarla Gabarnmang, central-western Arnhem Land
}

\author{
Robert Gunn, Bruno David, Jean-Jacques Delannoy \\ and Margaret Katherine
}

\section{Introduction}

The Arnhem Land plateau in northern Australia contains a particularly rich rock art assemblage. The area has a small number of large rockshelters with numerous and extensive suites of superimposed motifs (c. 2 per cent of 630 recorded shelters have $>200$ images). Studies of the rock art of Arnhem Land have primarily been concerned with attempting to understand the age of the art, with particular interest on the Pleistocene to mid-Holocene periods (Chaloupka 1977, 1984, 1985, 1993; Chippindale and Taçon 1993; Haskovec 1992; Lewis 1998; Taçon and Chippindale 1994). Most of these efforts have largely relied on interpretations of styles and their respective patterns of superimposition. Taçon (e.g. 1987, 1989a, 1989b, 1992) has written extensively on X-ray rock art from the northern perimeter of the plateau, and his work on 'recent' period art remains the most important study on this subject. The production of X-ray art has also been shown to have been popular during the European-contact period of the past 200 years or so (Chaloupka 1993; May et al. 2010; Wesley 2013). The most detailed study of rock art in the late Holocene period is the extensive radiocarbon dating of beeswax figures by Nelson et al. (2000), most of which fall within the past 500 years (but see Bednarik 2001).

Taçon (1989b:318) has noted, 'The most recent period of rock painting in western Arnhem Land ... was one of great diversity and elaboration. It differs from earlier periods in terms of subject matter, form, use of colour and symbolic content. It is this art that is still very important to Aboriginal people'. He found that, other than X-ray art, solid or stroke infill were common conventions that differed from X-ray only in their pattern of infill and that, in opposition to their Kunwinjku neighbours to the east (Taylor 1996:12), the 'Aboriginal people [of western Arnhem Land] argue that [monochrome paintings] depict "dead" or "cooked" beings while x-ray paintings depict living creatures' (Taçon 1989b:320). He also suggested that X-ray art reached its 'full potential' during the Freshwater Period of less than 3000 years ago (Taçon 1989b:330).

Other recent forms of art that Taçon (1989b:320-324) identified from western Arnhem Land are:

- Stick-figures, both static and active, depicting common activities (hunting, domestic, ceremonial or warfare).

- Hand stencils - some with finely painted patterned infill - and stencils of human and animal feet. 
- Painted sacred symbols and other geometric shapes, lines or patterns.

- Appliqué images in pressed beeswax.

- European-contact images (boats, horses, rifles, cattle, etc.).

- Sorcery images.

Overall, Taçon (1992:210-211) found that Aboriginal peoples of western Arnhem Land recognise five classes of rock art:

- 'Sacred Beings': images of Dreaming Beings who put themselves onto the rock face.

- 'Dreaming' paintings: mostly related to Dreaming stories or beliefs.

- 'Mimi': all older (predominantly red) paintings are said by local Aboriginal people to be produced by Spirit-Beings who dwell in the rock, and which some archaeologists assume to be $>6000$ years old (Taçon 1993:114).

- 'Sorcery' paintings: 'paintings used for revenge or to inflict harm, but these were relatively rare' (Taçon 1991:211). Berndt and Berndt (1977:323) viewed sorcery paintings of deformed or skewered figures, which were painted to cause death or illness to the victim, as a practice of social constraint. Chaloupka (1993:207) considered the majority of sorcery paintings to have been produced during the recent, European-contact period.

- 'Casual' paintings: including some hand stencils, recent stick-figures and European-contact motifs.

These five classes of rock art are essentially the same as those identified by Chaloupka (1993:87) who further includes the category 'bim bawarde garruy' (petroglyphs made in the 'Ancestral past').

In a study of regionalism in the rock art of western Arnhem Land, Taçon defined a Jawoyn substyle (that Chaloupka [1984:21] had first noted to be distinctive) as being:

composed primarily of red-and-white bichrome $\mathrm{x}$-ray paintings, with some red-and-yellow, as well as solid red or solid white images. Some yellow solid infill figures can be found but they are much rarer. Depictions of $\mathrm{x}$-ray and solid/stroke infill macropods and humans predominate. Hand stencils are found but painted hand or hand-and-arm stencils, typical of areas to the north, are not. Small, delicate strokes are characteristic of outlines and infill. Very small numbers of other forms, such as static stick figures, subjects and motifs are found at Jawoyn sites in comparison to those associated with other language groups (Taçon 1993:115).

In contrast to more northern sub-styles, where fish are the predominant faunal taxa depicted, the Jawoyn sub-style of X-ray art was said to be dominated by paintings of macropods (Taçon 1993:117). This contrast between fish-dominated art sites of the north and macropod-dominated sites of the south also highlights a substantial difference between the beliefs of the Jawoyn and those of their northern neighbours. This is well exemplified by an emphasis on the macropod Dreaming Beings Gupu and Barrk (Gunn 1992:180) in the south versus fish and 'brightness' with a visual reference to the Rainbow Serpent in the north (Taçon 1992:197). A further significant difference is the predominant use of red and white for bichrome paintings by the Jawoyn, while those groups to the north utilised a greater variety of colour combinations (Taçon 1989:125).

In this chapter, the relative chronology of motifs at the highly decorated rockshelter of Nawarla Gabarnmang in Jawoyn lands of the Arnhem Land plateau (see Figure 1.1) is examined, to test and refine the findings of these previous studies. Through patterns of superimposition and absolute ages that enable particular layers of art to be dated, the range of depicted styles and subjects that can be shown to be less than c. 500 years old within the shelter are illustrated and discussed. 


\section{Nawarla Gabarnmang}

Nawarla Gabarnmang is a large sandstone shelter (c. $25 \times 15 \times 2 \mathrm{~m})$ with a horizontal ceiling supported by a number of freestanding pillars (Figures 12.1 and 12.2). The pillars divide the ceiling into a series of panels, most of which have been decorated with art (Figure 12.3). Many of the central pillars have also been decorated with both recent paintings and, in some cases, very old petroglyphs (cupules and abradings). Occupation at the site has been dated to $>45,000$ cal BP (David et al. 2011; Geneste et al. 2010). The interior of the shelter has been substantially modified through the removal of pillars and the collapse or removal of layers of rock ceiling to produce a large, central occupation area (Delannoy et al. 2013; see Chapter 10).

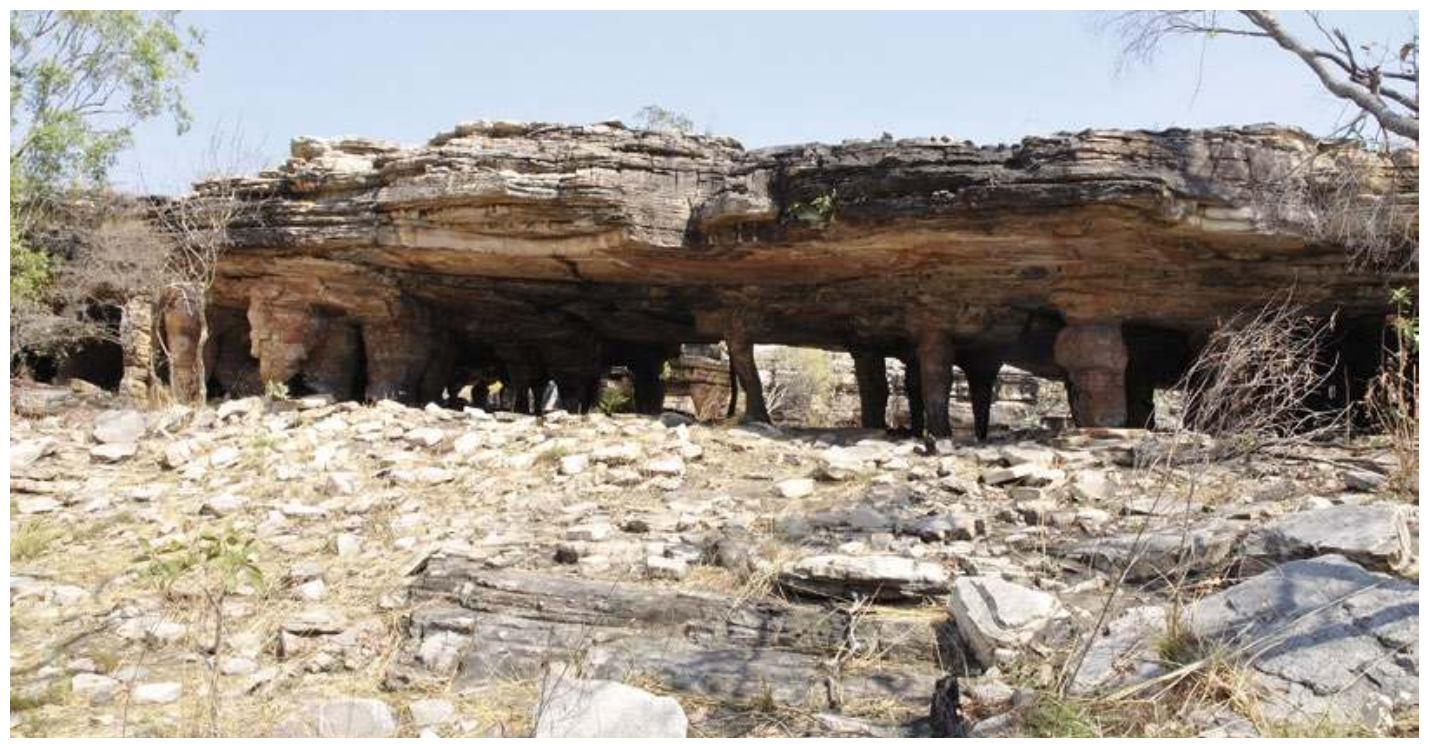

Figure 12.1 Nawarla Gabarnmang shelter from the northwest.

Source: Photograph by Robert Gunn.

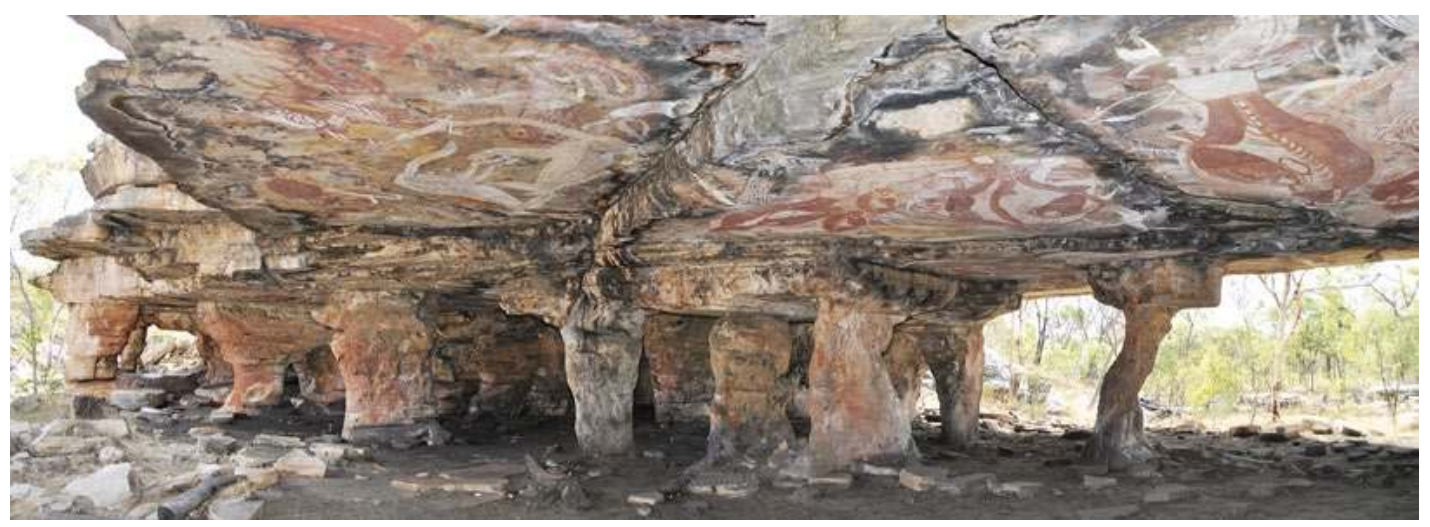

Figure 12.2 Interior of shelter showing the highly decorated ceiling.

Source: Photograph by Robert Gunn.

Throughout this chapter, the radiocarbon dates undertaken directly on rock art are calibrated as cal AD rather than cal $\mathrm{BP}$ ages in order to facilitate correlations with European-contact period historical events and documentary records. Within Nawarla Gabarnmang, the individual ceiling panels with art have been allocated unique codes for ease of identification (Figure 12.3). Two beeswax figures on Panel F1 have each been radiocarbon dated to the period 1433-1631 cal $\mathrm{AD}$, with another two beeswax figures on nearby Panels $\mathrm{H}$ and K4 dating to the period 
1658-1952 cal AD (Table 12.1). The two beeswax figures on Panel F1, and that on Panel H, are superimposed by paintings. The beeswax figure on panel K4 superimposes yellow paintings, but it is not itself superimposed by any art. Panel J1 has a fifth beeswax figure also dating to c. $400 \mathrm{cal} \mathrm{BP}$, but it is still being analysed and thus does not feature in this chapter. Panel D has a painted motif interpreted as a representation of a horse. As horses were unknown on the plateau before $1845 \mathrm{AD}$, the motifs that overlie the horse image must be more recent (Gunn et al. 2012; see also Chapter 9). The overlying motifs of the individual panels are discussed below prior to a general comment on the nature of the more recent art found in the shelter.

Table 12.1 Radiocarbon dates on beeswax rock art.

\begin{tabular}{|l|c|c|c|c|}
\hline Laboratory code & Panel & Image \# & ${ }^{14}$ C Age (BP) & Calibrated age AD (95.4\% probability) \\
\hline Wk-26414 & F1 & 28 & $406 \pm 30$ & $1430-1530$ \\
& & & & $1570-1630$ \\
\hline Wk-26416 & F1 & 27 & $383 \pm 30$ & $1440-1530$ \\
& & & & $1550-1640$ \\
\hline Wk-28101 & 122 & $173 \pm 30$ & $1650-1700$ \\
& & & & $1720-1820$ \\
& & & & $1830-1880$ \\
& K4 & 100 & $153 \pm 30$ & $>1910$ \\
\hline Wk-26418 & & & & $>1660-1890$ \\
& & & \\
\hline
\end{tabular}

Calibrations undertaken using 0xCal v4.2.4 (Bronk Ramsay 2013), IntCal13 (Reimer et al. 2013). For full sample details, see Gunn et al. (2012).

Source: Authors' data.

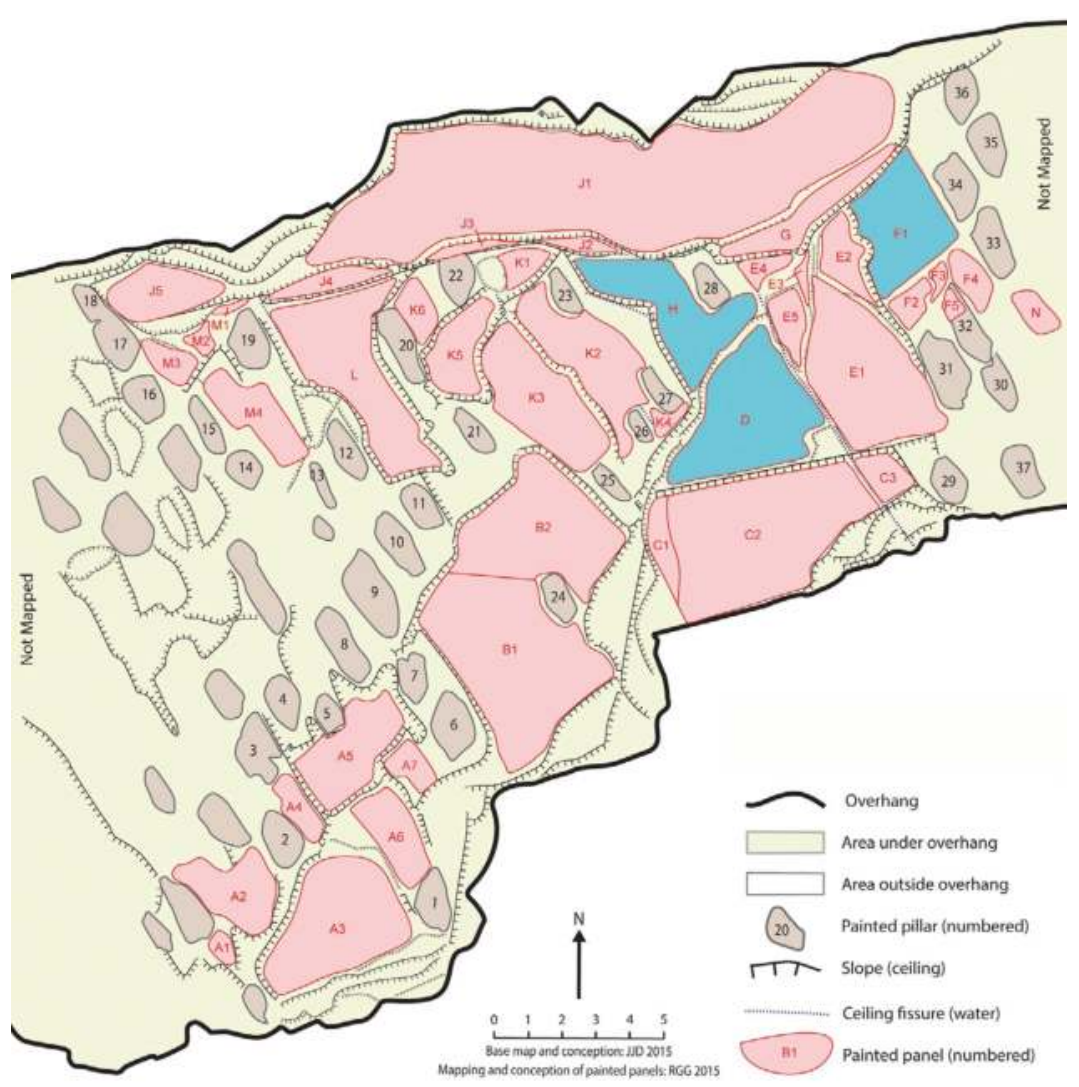

Figure 12.3 Plan showing location of the ceiling art panels. Panels D, F1 and $\mathrm{H}$ are highlighted. Source: Illustration by Jean-Jacques Delannoy and Robert Gunn. 


\section{Panel F1}

Panel F1 is one of the largest art panels in the shelter, $3.8 \times 2.7 \mathrm{~m}$ in size and generally rectangular in shape (Figure 12.4). It contains 126 identified images widely distributed across the panel (Figure 12.5). The only visually prominent motif is an X-ray snake $(94 \times 48 \mathrm{~cm})$ placed in the very centre of the panel. Other prominent images on the panel are the smaller of a pair of white macropods with red linear infill, and three female figures in white. Some of the many images on this panel appear to be among the most recent in the shelter in that they appear very 'fresh' relative to the other paintings, include fragile white pigments and occur as, or adjacent to, the top layer in the pattern of superimposition. Yet, Panel F1 has none of the painted X-ray fish that dominate the other large panels (Panels D, E1 and H; see Gunn et al. 2012; Chapter 11, this volume).

Panel F1 has at least 35 layers of superimpositions involving all of the 126 identified images (Gunn 2016). A Harris Matrix was produced relating all instances of superimposition (Figure 12.6). The Harris Matrix was then sorted into layers, each layer seen as representing an artistic episode of relatively short duration (Figure 12.7). In this sorting, images were allocated to particular layers on the basis of their relative location in the superimposition sequence coupled with common artistic traits - colour, form, infill, state of preservation, etc. The layers were then grouped into six broad phases by similarities in artistic traits between adjacent layers (Table 12.1).

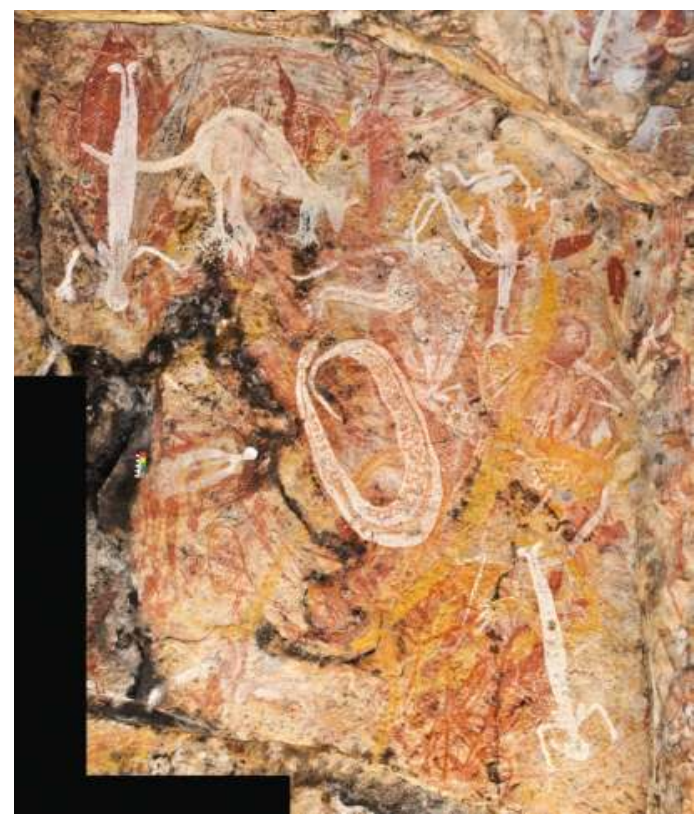

Figure 12.4 Photomosaic of Panel F1.

Source: Photographs by Robert Gunn.

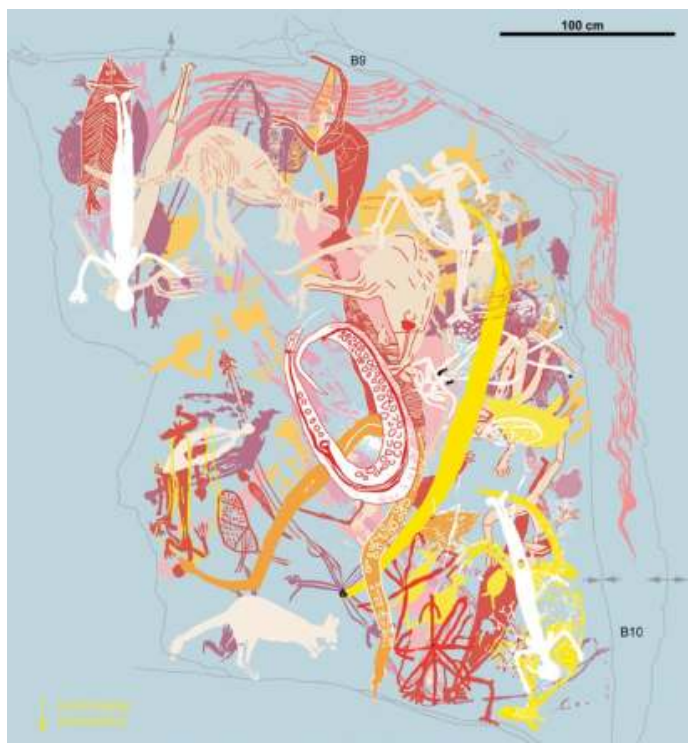

Figure 12.5 Tracing from the photomosaic of the Panel F1 art (colours approximate).

Source: Photo-tracing by Robert Gunn. 


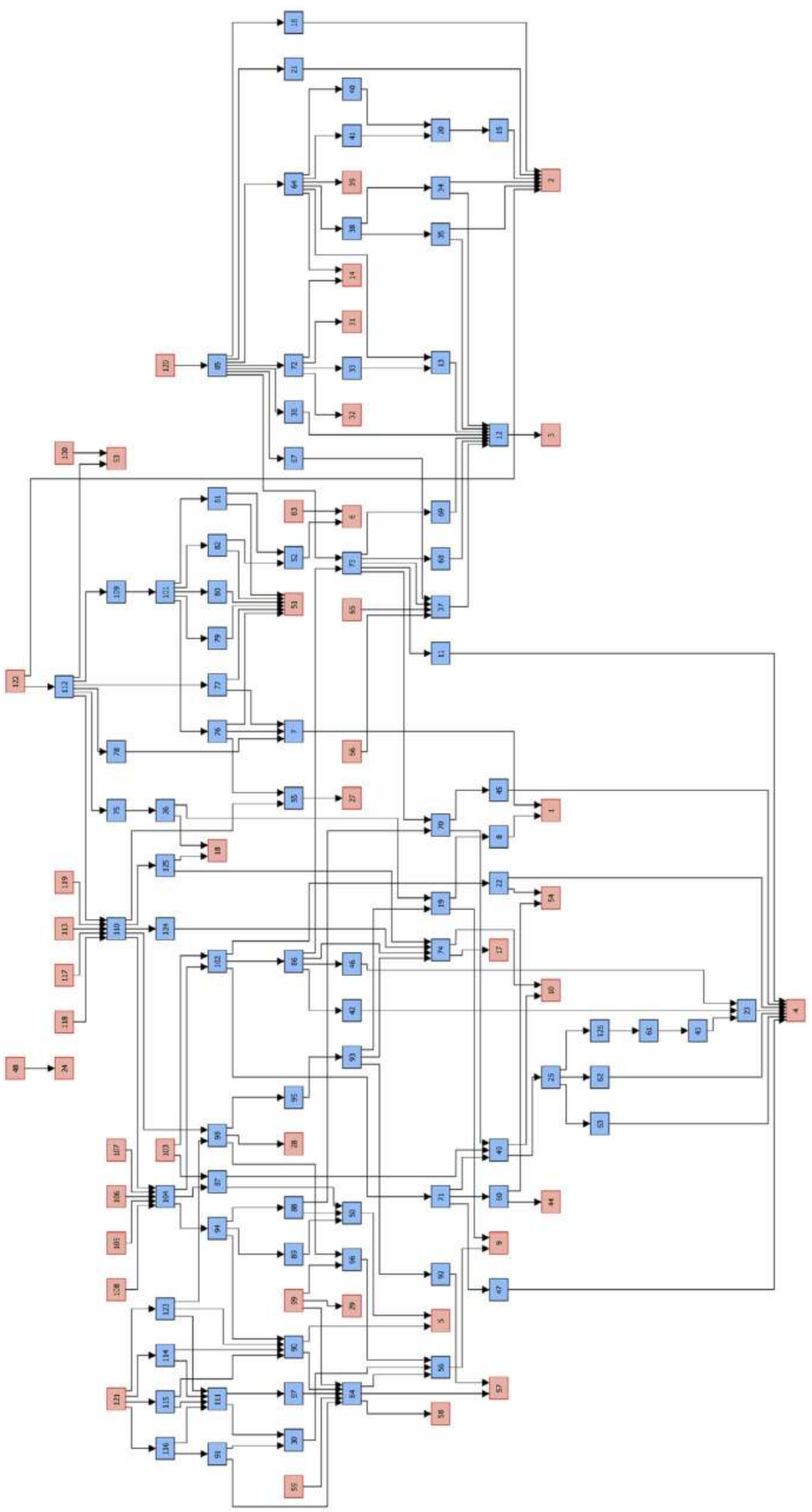

Figure 12.6 Harris Matrix of the Panel F1 superimpositions.

Red boxes = images at beginning or end of a superimposition sequence; blue boxes = images within a superimposition sequence. Source: Illustration by Robert Gunn. 

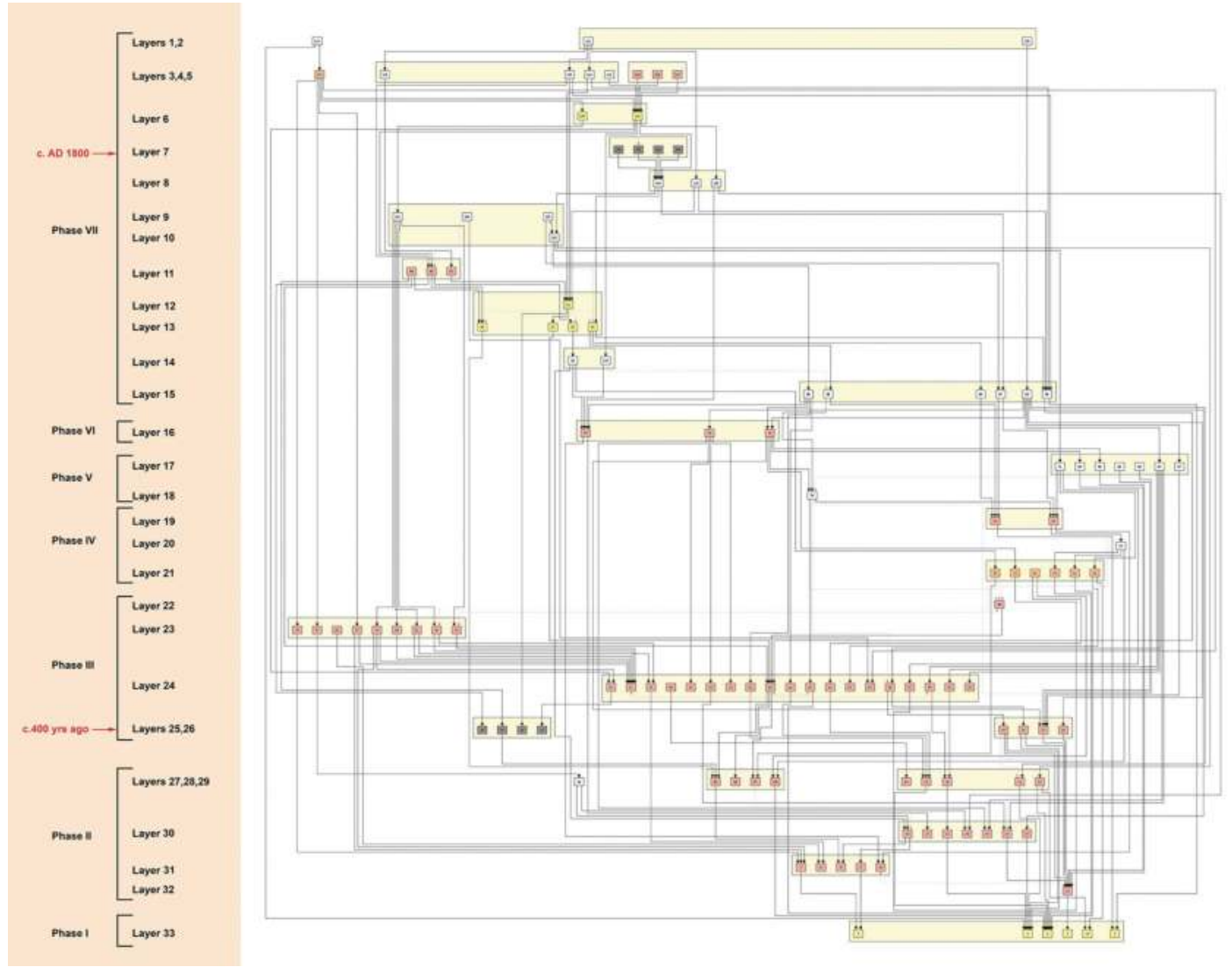

Figure 12.7 Interpretation of the Panel F1 Harris Matrix, grouping the motifs into contemporaneous layers on the basis of stylistic attributes and preservation.

Source: Illustration by Robert Gunn.

Beeswax pellets made before the painting were incorporated in four painted images, and one was added to a fifth image after it was painted. The pellets, each allocated an individual image number, are in two spatially distinct groups: pellets F-27 to F-30, associated with paintings F-55, F-91, F-98 and F-99; and pellets F-105 to F-108, associated with painting F-104. Pellets F-27 to F-30 are individual beeswax dots making the centres of red-painted radial designs (Figure 12.8). Pellets F-105 to F-108 are elaborations on a white-painted female figure (Figure 12.9). Radiocarbon dates on pellets F-27 and F-28 each calibrate within the period 1430-1640 cal AD (Table 12.1). As all four of the pellets within this group (F-27 to F-30) are in similar states of preservation, located within $85 \mathrm{~cm}$ of each other and positioned at the same level in the pattern of superimposition, it is likely that they were applied during a single artistic event. Pellets F-28 to F-30 are all small and central to red-painted radial designs, while pellet F-27 is larger and underlies a design in a darker shade of red and a yellow snake. Pellet F-28 also underlies the radial design, indicating that it was applied before the red radiating lines were painted; its relationship to an apparently underlying yellow flying-fox remains unclear. 


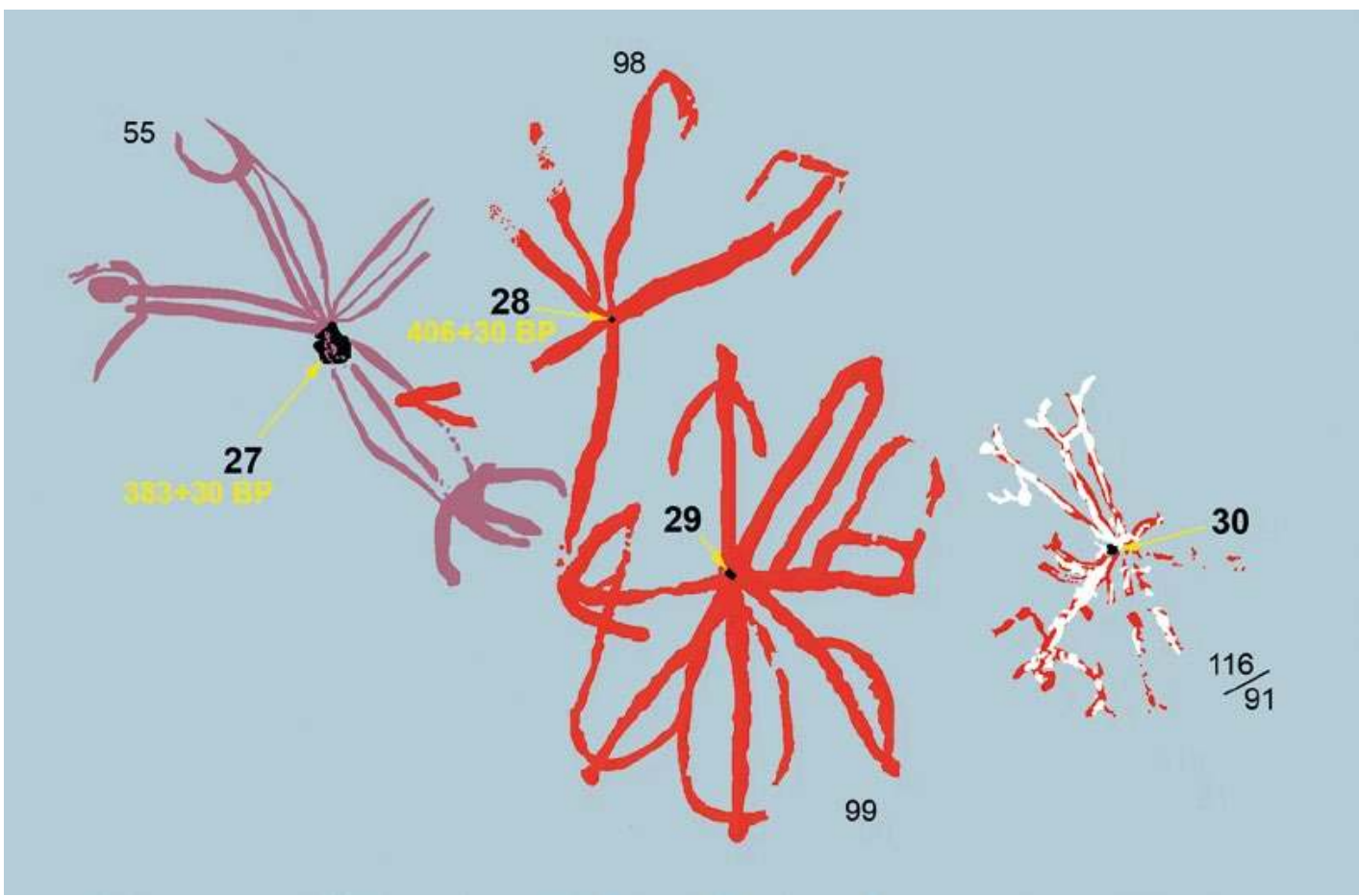

Figure 12.8 Beeswax pellets F-27 to F-30 showing overlying radial designs.

The two dated pellets were radiocarbon dated to 1430-1640 cal AD.

Source: Photo-tracing by Robert Gunn.
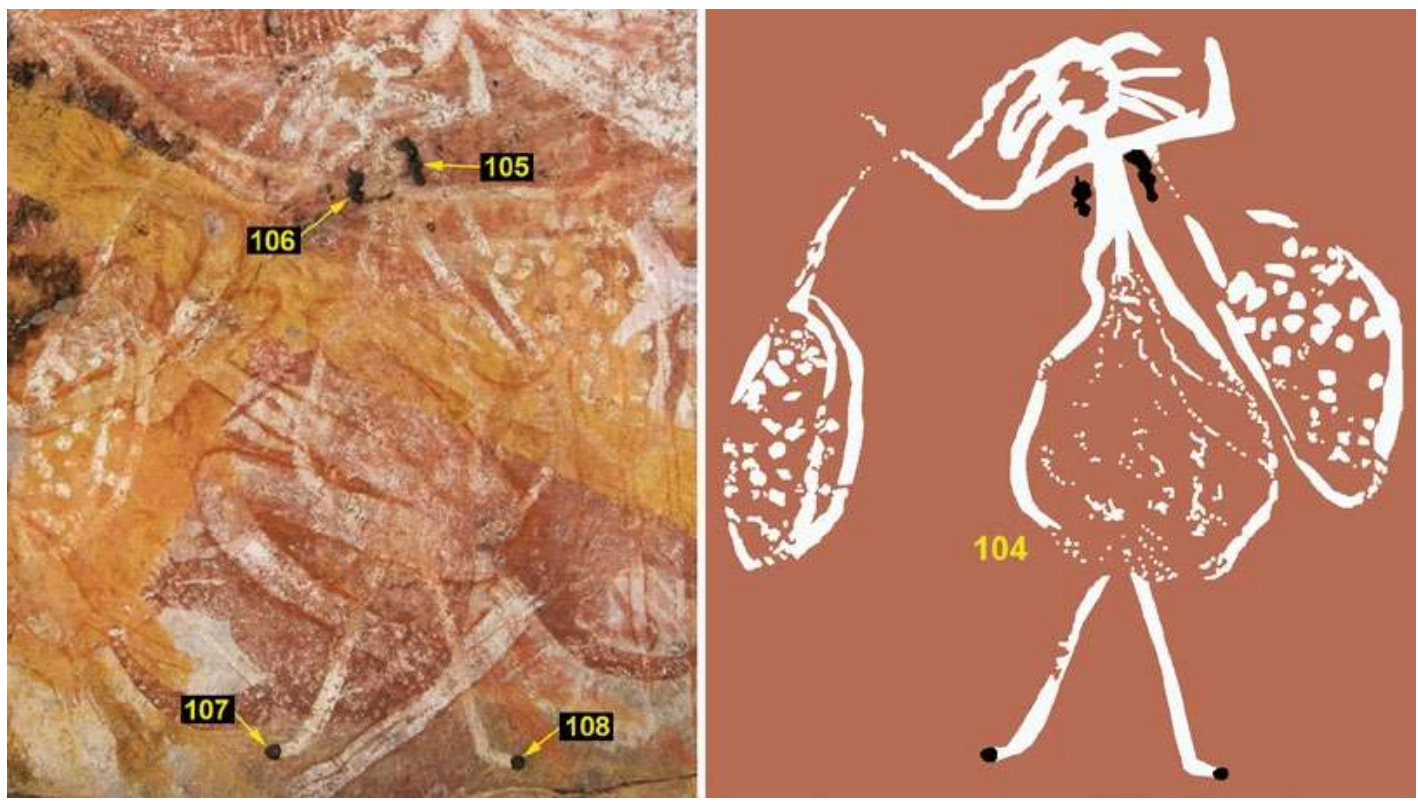

Figure 12.9 Beeswax Pellets F-105 to F-108 overlying painting F-104.

Source: Photograph and photo-tracing by Robert Gunn. 
Most of the art that underlie these dated pellets consists of poorly preserved fragments in monochrome pigment. The exceptions are a poorly preserved but intact long monochrome snake that encircles the panel, three paintings in red with fine-line white, hatched infill- and a yellow fragment partially outlined in red. These four bichrome paintings indicate that bichrome art was practised sometime before c. 400-500 years ago, as they underlie the beeswax pellets dated to that age.

The beeswax pellets F-105 to F-108 are undated. We know that, with time, beeswax pellets deteriorate from a shiny black to a crazed grey (Nelson 2000). Although these pellets are in comparable positioning under the well protected shelter, they are darker in colour than the beeswax of pellets F-27 to F-30 and lack the crazing of the c. 400-500-year-old pellets. This suggests that pellets F-105 to F-108 are younger than the dated pellets F-27 and F-28. Pellets F-105 to F-108 are in a comparable state of preservation to a beeswax figure on Panel K4 nearby (Figure 12.10), where a radiocarbon date calibrated to 1633-1953 cal AD has been obtained. We conclude that these two sets of beeswax pellets are likely to be of similar age,

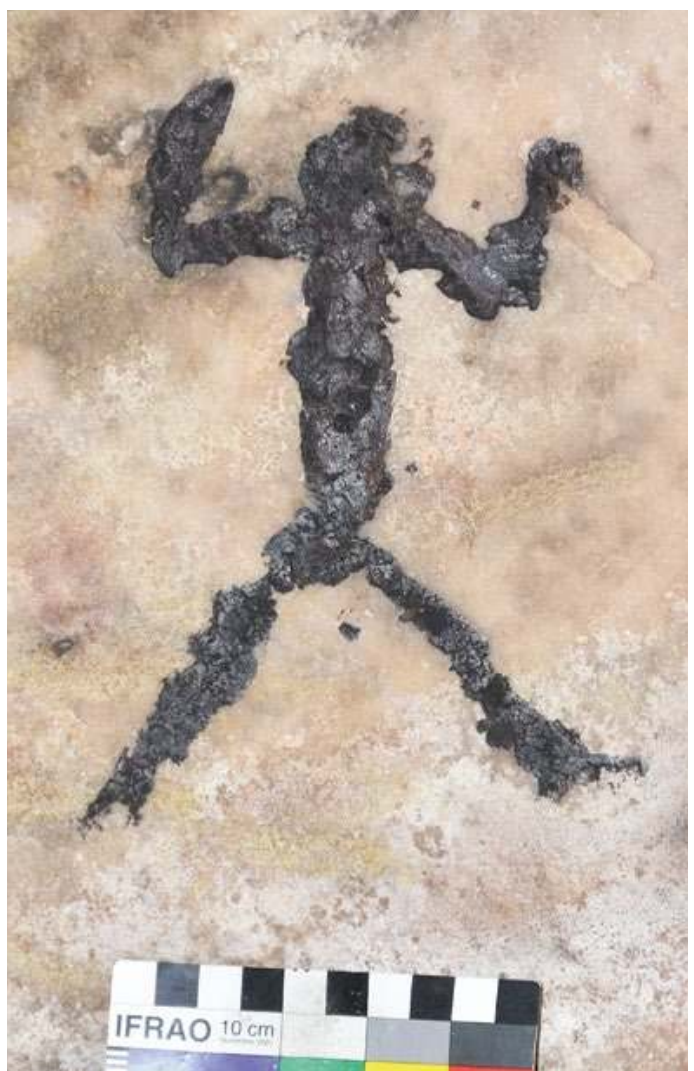

Figure 12.10 Beeswax figure dated to 1660$>1900$ cal AD on Panel K4.

Source: Photograph by Robert Gunn. within the past 400 years.

These radiocarbon dates place four of the art phases on Panel F1 Phases III-VI in the period after $1430 \mathrm{cal}$ AD. These four phases contain 97 images, or over three-quarters of the visible art of Panel F1. The 17 images in the most recent layer were all made after c. $1650 \mathrm{cal} \mathrm{AD}$, as indicated by the extrapolated ages of pellets F-105 to F-108 (Table 12.2).

Table 12.2 Summary of the Panel F1 art phases.

\begin{tabular}{|l|l|l|l|l|l|}
\hline Panel F1 phase & \# of layers & \# of images & Techniques & Colours & Major motifs \\
\hline VIb & 15 & 40 & paintings & $\begin{array}{l}\text { white, white+red, } \\
\text { orange+white, } \\
\text { yellow+red, } \\
\text { yellow, red, black }\end{array}$ & $\begin{array}{l}\text { Bichrome snakes; } \\
\text { Solid white anthropomorphs (females); } \\
\text { Outline+infill weapons }\end{array}$ \\
\hline 1660->1900 cal AD (age of beeswax pellets extrapolated from Panel K4) \\
\hline Vla & \multicolumn{7}{|l|l|l|l|}{$\begin{array}{l}\text { paintings, } \\
\text { stencil }\end{array}$} & $\begin{array}{l}\text { white, yellow, } \\
\text { red, white+red }\end{array}$ & $\begin{array}{l}\text { Solid white anthropomorphs (male and } \\
\text { female) and macropod; } \\
\text { frea of sprayed pigment; } \\
\text { Outline+infill radial designs, fish and bags; } \\
\text { Solid yellow flying fox, echidna and macropod; } \\
\text { Bichrome 'Jawoyn Ladies' and macropod }\end{array}$ \\
\hline V & 1 & 3 & paintings & white+red & $\begin{array}{l}\text { Bichrome anthropomorph (female), X-ray } \\
\text { macropod and fish }\end{array}$ \\
\hline
\end{tabular}




\begin{tabular}{|l|l|l|l|l|l|}
\hline Panel F1 phase & \# of layers & \# of images & Techniques & Colours & Major motifs \\
\hline IV & 5 & 17 & paintings & $\begin{array}{l}\text { white, white+red, } \\
\text { red, orange }\end{array}$ & $\begin{array}{l}\text { Bichrome anthropomorphs, Solid white } \\
\text { anthropomorph (females); } \\
\text { Outline+infill snake and fish; } \\
\text { Solid red possum; } \\
\text { Solid orange fish and echidna }\end{array}$ \\
\hline III & 7 & 37 & paintings & red & $\begin{array}{l}\text { Red solid or outline+infill fish, } \\
\text { anthropomorph, weapons and bags }\end{array}$ \\
\hline $\mathbf{1 4 3 0 - 1 6 4 0 ~ c a l ~ A D ~ ( d a t e d ~ b e e s w a x ~ p e l l e t s ) ~}$ & & paintings & red, red+white & $\begin{array}{l}\text { Striped red snake; } \\
\text { Solid red anthropomorph with fine white- } \\
\text { line infill; } \\
\text { Fragments of pigment art }\end{array}$ \\
\hline II & 6 & 23 & paintings & $\begin{array}{l}\text { yellow, } \\
\text { yellow+red }\end{array}$ & $\begin{array}{l}\text { Mainly yellow fragments } \\
\text { (2 solid and solid+outline animals) }\end{array}$ \\
\hline
\end{tabular}

Note that for bichrome paintings, the base colour is listed first and the later, additional colour second. For example, white+red is a white solid silhouette with red outline and/or infill.

Source: Authors' data.

Tabulation of motif types by phase for Panel F1 suggests that little change in artistic conventions took place over the past 400-500 years (Table 12.3). During that same period, there appears to have been a seven-fold increase in the use of white pigment and white-based bichrome painting, correlating with both a relative and an absolute decrease in the number of red and red-based bichrome motifs (Table 12.4). Panel F1 is a horizontal ceiling panel that is well protected from the elements, and beyond reach of passing animals. Consequently, it is unlikely that the observed increase in white pigment is simply a function of taphonomic factors, nor can it explain the absolute decline in the use of red pigment.

Table 12.3 Panel F1 motifs by art phase.

\begin{tabular}{|c|c|c|c|c|c|c|c|c|c|c|c|c|c|}
\hline \multirow{2}{*}{$\begin{array}{l}\text { Panel F1 } \\
\text { phase }\end{array}$} & \multicolumn{12}{|c|}{ Motif } & \multirow{2}{*}{$\begin{array}{c}\text { Total \# of } \\
\text { images }\end{array}$} \\
\hline & $\begin{array}{l}\text { 등 } \\
\text { 흥 } \\
\text { 흥 } \\
\text { 产 }\end{array}$ & $\frac{\mathscr{y}}{\tilde{\sigma}}$ & 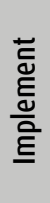 & 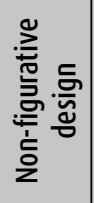 & 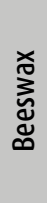 & 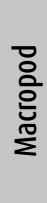 & 뜬 & 蒙 & 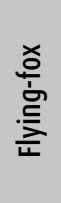 & క్ & $\frac{\grave{\Xi}}{\stackrel{\Xi}{\sigma}}$ & 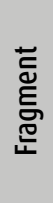 & \\
\hline VIb & 2 & 3 & 3 & 4 & 4 & & & & & & 1 & & 17 \\
\hline \multicolumn{14}{|c|}{ 1660->1900 cal AD (age of beeswax pellets extrapolated from Panel K4) } \\
\hline Vla & 6 & & 1 & 6 & & 4 & 1 & 1 & 3 & & 1 & & 23 \\
\hline V & & & & & & 1 & 1 & & & & 1 & & 3 \\
\hline IV & 2 & 1 & & 1 & & & 2 & 1 & & 2 & 6 & 2 & 17 \\
\hline III & 6 & & 8 & 1 & 4 & 1 & 12 & & & & 4 & 1 & 37 \\
\hline \multicolumn{14}{|c|}{ 1430-1640 cal AD (dated beeswax pellets) } \\
\hline II & 3 & 1 & & 3 & & & & & & & 2 & 14 & 23 \\
\hline 1 & & & & & & & & & & & 2 & 4 & 6 \\
\hline Total & 19 & 5 & 12 & 16 & 8 & 6 & 16 & 2 & 3 & 2 & 16 & 21 & 126 \\
\hline
\end{tabular}

Source: Authors' data. 
Table 12.4 Panel F1 colours by art phase.

\begin{tabular}{|l|c|c|c|c|c|c|c|c|c|c|}
\hline \multirow{2}{*}{$\begin{array}{l}\text { Panel F1 } \\
\text { phase }\end{array}$} & \multicolumn{7}{|c|}{ Colour } & Total \# of \\
images
\end{tabular}

Source: Authors' data.

\section{Panel H}

Panel $\mathrm{H}$ is a large, elongated panel forming a rough T-shape, $4.0 \times 2.9 \mathrm{~m}$ long along its two axes (Figure 12.11). It contains 132 widely distributed images, but the panel is visually dominated by two large polychrome X-ray barramundi $(180 \times 84 \mathrm{~cm}$ and $143 \times 53 \mathrm{~cm}$ respectively $)$ that may hide many underlying images. Panel $\mathrm{H}$ has at least 21 layers of superimposition involving all except for two of its 132 images (Images H-7 and H-116). Interpretation of the Harris Matrix (Figure 12.12) suggests at least six phases of art production on this panel (Table 12.5; Figure 12.13). The two outlying motifs were included in the Harris Matrix by allocating them to particular layers following artist traits that matched those of other nearby motifs.

Table 12.5 Summary of the Panel $\mathrm{H}$ art phases.

\begin{tabular}{|c|c|c|c|c|c|}
\hline Panel H phase & \# of layers & \# of images & Techniques & Colours & Major motifs \\
\hline $\mathrm{VI}$ & 1 & 2 & painting & white+red+black & Fish in polychrome X-ray \\
\hline $\mathrm{Vb}$ & 6 & 15 & $\begin{array}{l}\text { painting, } \\
\text { appliqué }\end{array}$ & $\begin{array}{l}\text { white, white+red, } \\
\text { red, black }\end{array}$ & $\begin{array}{l}\text { White solid anthropomorphs } \\
\text { and fish; } \\
\text { Red linear anthropomorph; } \\
\text { Solid white+red outline+infill } \\
\text { anthropomorphs and macropods }\end{array}$ \\
\hline \multicolumn{6}{|c|}{ 1660->1900 cal AD (dated beeswax anthropomorph) } \\
\hline Va & 2 & 22 & & white & $\begin{array}{l}\text { Solid white+red outline+infill } \\
\text { anthropomorphs and turtle; } \\
\text { White outline+infill anthropomorphs, } \\
\text { emu, dillybag and digging stick }\end{array}$ \\
\hline IV & 2 & 17 & $\begin{array}{l}\text { painting, } \\
\text { stencils }\end{array}$ & white, yellow & $\begin{array}{l}\text { White hand stencils; } \\
\text { White-painted outline+infill non- } \\
\text { figurative designs and macropod; } \\
\text { Yellow fragments of pigment art }\end{array}$ \\
\hline III & 2 & 10 & painting & red, red+white & $\begin{array}{l}\text { Solid red macropods and turtle; } \\
\text { Solid red+white outline+infill } \\
\text { macropod and snake }\end{array}$ \\
\hline
\end{tabular}




\begin{tabular}{|l|l|l|l|l|l|}
\hline Panel H phase & \# of layers & \# of images & Techniques & Colours & Major motifs \\
\hline II & 7 & 46 & $\begin{array}{l}\text { painting, } \\
\text { stencils }\end{array}$ & red, white, yellow & $\begin{array}{l}\text { White hand stencils; } \\
\text { White-painted arc design; } \\
\text { Red outline+striped infill } \\
\text { anthropomorph and macropod; } \\
\text { Yellow outline+infill bird }\end{array}$ \\
\hline I & 1 & 20 & painting & red & $\begin{array}{l}\text { Solid red animals and fragments of } \\
\text { red, yellow and white pigment art }\end{array}$ \\
\hline
\end{tabular}

Source: Authors' data.

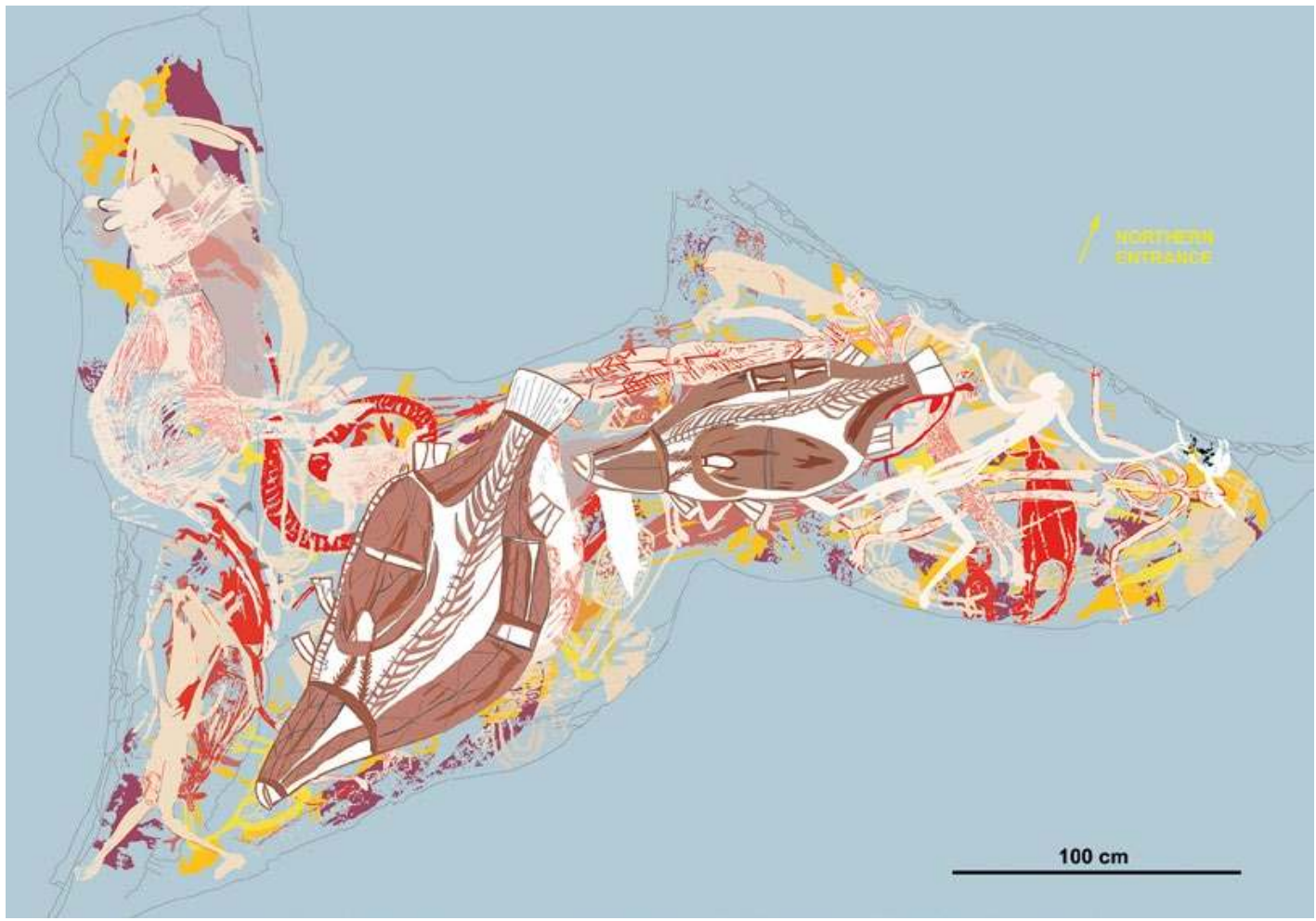

Figure 12.11 Photo-tracing of Panel H.

Source: Photo-tracing by Robert Gunn.

Motif H-122 is a beeswax figure radiocarbon dated to 1650->1910 cal AD (Wk-28101) (Table 12.1). The beeswax figure is overpainted by two white paintings (Figure 12.14), which are in turn overlain by a polychrome barramundi. Beeswax Image H-122 occurs midway within Phase $\mathrm{V}$ in the pattern of superimpositions. It is likely that other motifs within this phase, although in some cases produced prior to the beeswax figure, are roughly contemporaneous with each other due to similarities in their artistic traits.

As with Panel F1, there appears to have been little overall change in the range of motifs portrayed on Panel H over time (Table 12.6). Again, however, over the time period represented in Panel H, there has been a clear replacement of red and yellow by white pigment (Table 12.7). 


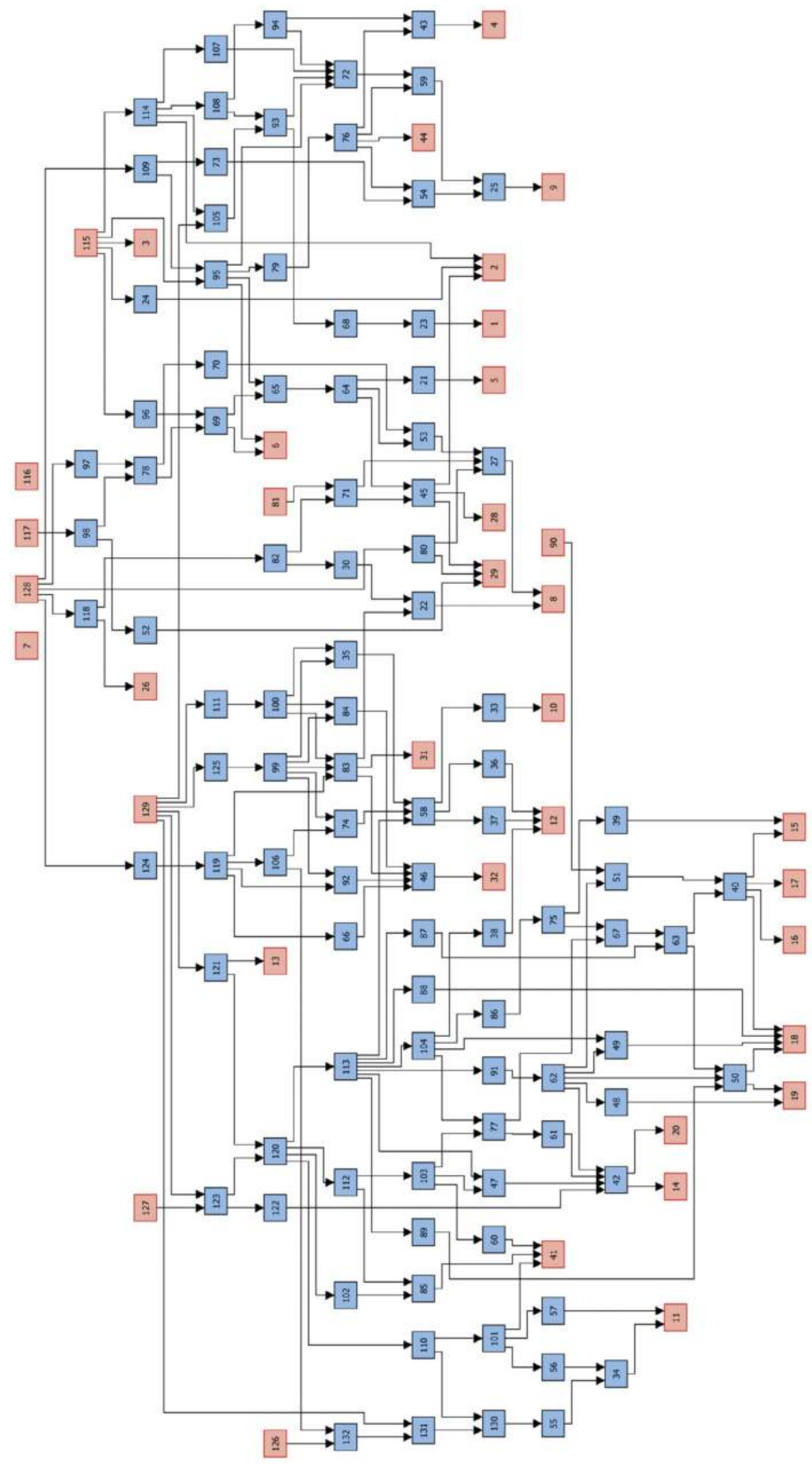

Figure 12.12 Harris Matrix of the Panel H superimpositions.

Red boxes = images at beginning or end of a superimposition sequence; blue boxes = images within a superimposition sequence. Source: Illustration by Robert Gunn. 


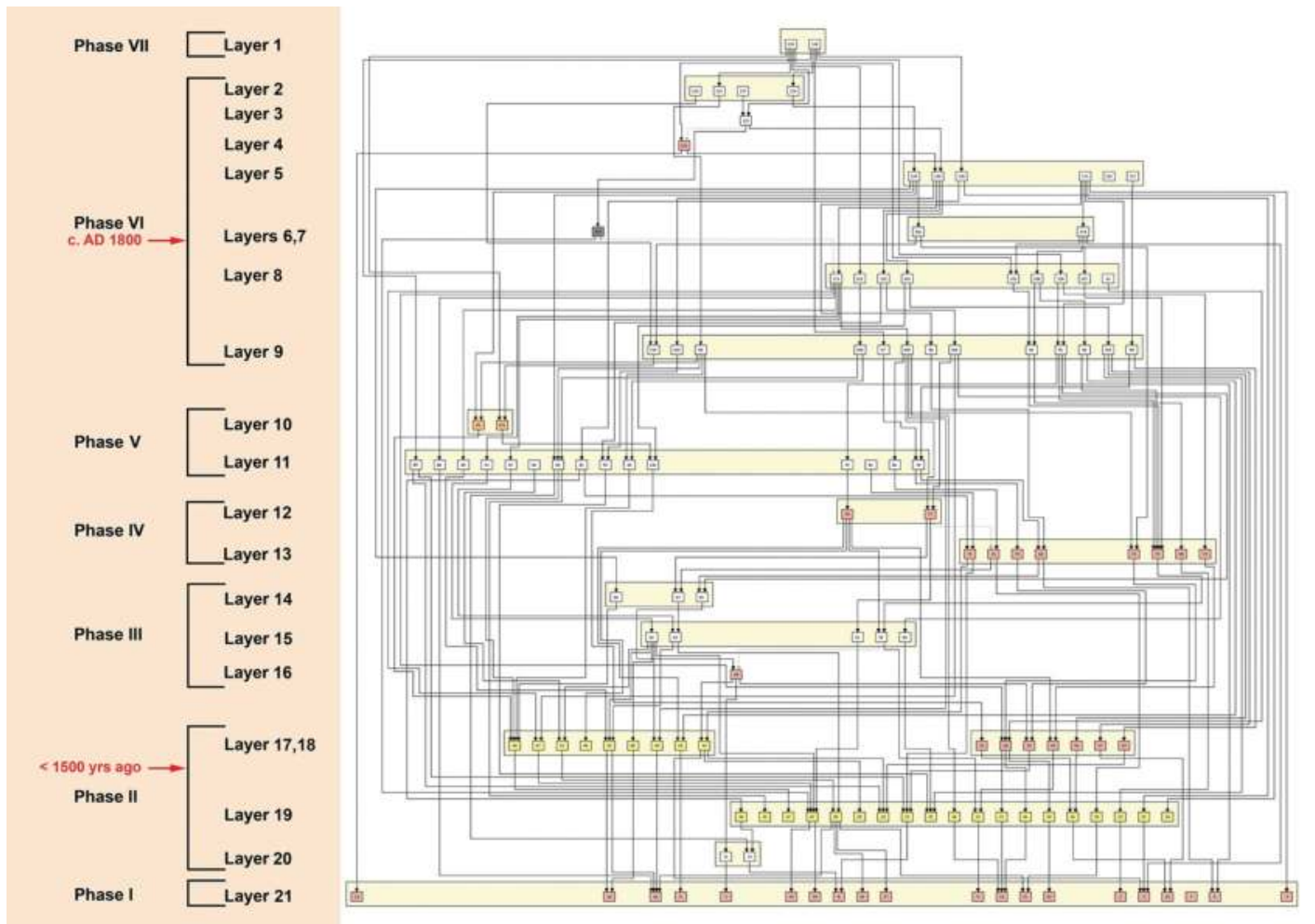

Figure 12.13 Interpretation and phasing of the Panel H Harris Matrix.

Source: Illustration by Robert Gunn.

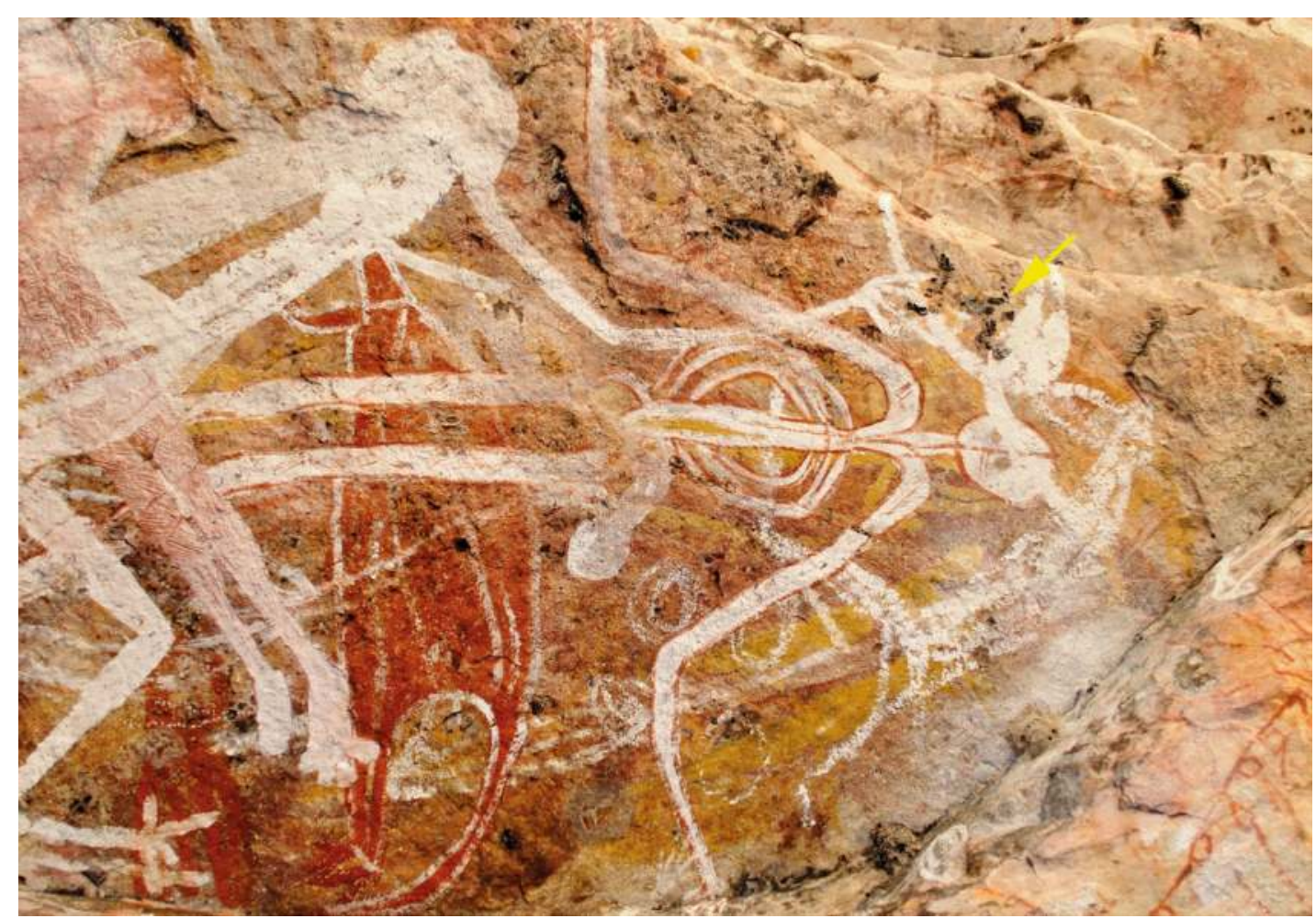

Figure 12.14 Beeswax Image H-122 (arrowed) dated to 1650->1910 cal AD.

Source: Photograph by Robert Gunn.

\section{terra australis 47}


Table 12.6 Panel H motifs by art phase (excluding fragments).

\begin{tabular}{|c|c|c|c|c|c|c|c|c|c|c|c|c|c|c|}
\hline \multirow{2}{*}{$\begin{array}{l}\text { Panel H } \\
\text { phase }\end{array}$} & \multicolumn{13}{|c|}{ Motif } & \multirow{2}{*}{$\begin{array}{c}\text { Total \# of } \\
\text { images }\end{array}$} \\
\hline & 든 & 离 & $\begin{array}{l}\text { ్ㅡ } \\
\text { 它 } \\
\text { 产 } \\
\text { 立 }\end{array}$ & $\stackrel{0}{\text { 窇 }}$ & $\frac{\mathscr{Q}}{\stackrel{0}{\tilde{n}}}$ & 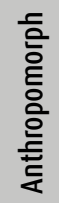 & $\begin{array}{l}\text { 응 } \\
\text { 응 } \\
\text { 이 }\end{array}$ & 릉 & $\begin{array}{l}\text { 음 } \\
\text { त्ञ }\end{array}$ & 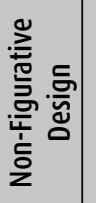 & 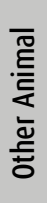 & $\begin{array}{l}\text { 咅 } \\
\text { 站 }\end{array}$ & $\begin{array}{l}\text { 芯 } \\
\text { 总 } \\
\text { 总 }\end{array}$ & \\
\hline $\mathrm{VI}$ & 2 & & & & & & & & & & & & & 2 \\
\hline $\mathrm{Vb}$ & 2 & 2 & & & & 4 & 2 & 1 & & 2 & & 2 & & 15 \\
\hline \multicolumn{15}{|c|}{ 1650->1910 cal AD (dated beeswax anthropomorph) } \\
\hline Va & & & 2 & 1 & & 9 & 2 & 1 & & & & 4 & 3 & 22 \\
\hline IV & & & & & & & 1 & & 2 & 9 & & 5 & & 17 \\
\hline III & & & 1 & 1 & 1 & & 3 & & & & & 4 & & 10 \\
\hline$\|$ & & & & & & 2 & 5 & 2 & 5 & 3 & 1 & 22 & 6 & 46 \\
\hline 1 & & & & & & & & & & 1 & 3 & 10 & 6 & 20 \\
\hline Total & 4 & 2 & 3 & 2 & 1 & 15 & 13 & 4 & 7 & 15 & 4 & 47 & 15 & 132 \\
\hline
\end{tabular}

Source: Authors' data.

Table 12.7 Panel H colours by art phase.

\begin{tabular}{|c|c|c|c|c|c|c|c|c|c|c|}
\hline \multirow{2}{*}{$\begin{array}{l}\text { Panel H } \\
\text { phase }\end{array}$} & \multicolumn{9}{|c|}{ Colour } & \multirow{2}{*}{$\begin{array}{r}\text { Total \# } 0 \\
\text { images }\end{array}$} \\
\hline & White+red+black & Pink & Black & White+red & Orange & White & Yellow & Red & Red+white & \\
\hline $\mathrm{VI}$ & 2 & & & & & & & & & 2 \\
\hline $\mathrm{Vb}$ & 1 & 2 & 1 & 3 & & 7 & & 1 & & 15 \\
\hline \multicolumn{11}{|c|}{ 1650->1910 cal AD (dated beeswax anthropomorph) } \\
\hline Va & & & & 5 & & 17 & & & & 22 \\
\hline IV & & & & & 2 & 15 & & & & 17 \\
\hline III & & & & & & & & 8 & 2 & 10 \\
\hline ॥ & & & & & & 7 & 28 & 11 & & 46 \\
\hline । & & & & & & & & 20 & & 20 \\
\hline
\end{tabular}

Source: Authors' data.

\section{Panel D}

Panel D is roughly triangular in shape, $4.8 \times 3.3 \mathrm{~m}$ in size and has at least 15 layers of superimposition involving all but one of its 66 images. The art is visually dominated by polychrome paintings of two large barramundi and a range of smaller bichrome fish (Figure 12.15). These fish paintings are the most recent art on the panel. The largest motif here (Image D-48), however, is that of a horse $(4.4 \times 2.9 \mathrm{~m}$; Figure 12.16) that underlies 17 paintings in five layers. Horses first entered the plateau in $1845 \mathrm{AD}$ (Leichhardt 1847). Consequently, all of the motifs overlying the horse painting are less than 170 years old. These overlying images include two fish in a Jawoyn $\mathrm{X}$-ray convention, six fish in X-ray conventions common to the north of Jawoyn Country and three 'Jawoyn Lady' paintings (see Gunn 1992:180). Interpretation of the Harris Matrix (Figures 12.17 and 12.18) divides the art into four phases, with the horse motif occurring midway through Phase III (Table 12.8). 
Table 12.8 Summary of the Panel $D$ art phases.

\begin{tabular}{|c|c|c|c|c|c|}
\hline Panel D phase & \# of layers & \# of images & Techniques & Major colours & Major motifs \\
\hline IV & 2 & 8 & $p$ & $\begin{array}{l}\text { white+red+black, white+red+purple, } \\
\text { white+red+yellow, white+red, } \\
\text { yellow+red }\end{array}$ & $\begin{array}{l}\text { X-ray, polychrome and } \\
\text { bichrome fish }\end{array}$ \\
\hline IIIb & 4 & 10 & P & white+red, pink, white+red+grey & $\begin{array}{l}\text { Bichrome } \\
\text { anthropomorphs; } \\
\text { Pink fragments; } \\
\text { Polychrome horse }\end{array}$ \\
\hline \multicolumn{6}{|l|}{ AD 1845} \\
\hline IIla & 6 & 26 & P & $\begin{array}{l}\text { white, white+red, red, cream, } \\
\text { cream+red }\end{array}$ & $\begin{array}{l}\text { Bichrome macropods, } \\
\text { bird, fish, turtle; } \\
\text { Solid white or cream } \\
\text { anthropomorph, birds, } \\
\text { macropods, hand stencils }\end{array}$ \\
\hline II & 2 & 13 & $P$ & red, red+white, black & $\begin{array}{l}\text { Red-striped macropod, } \\
\text { fragments of pigment art }\end{array}$ \\
\hline I & 1 & 9 & P & yellow & $\begin{array}{l}\text { Solid yellow } \\
\text { anthropomorphs; } \\
\text { Yellow linear } \\
\text { anthropomorph; } \\
\text { Fragments of pigment art }\end{array}$ \\
\hline
\end{tabular}

Source: Authors' data.

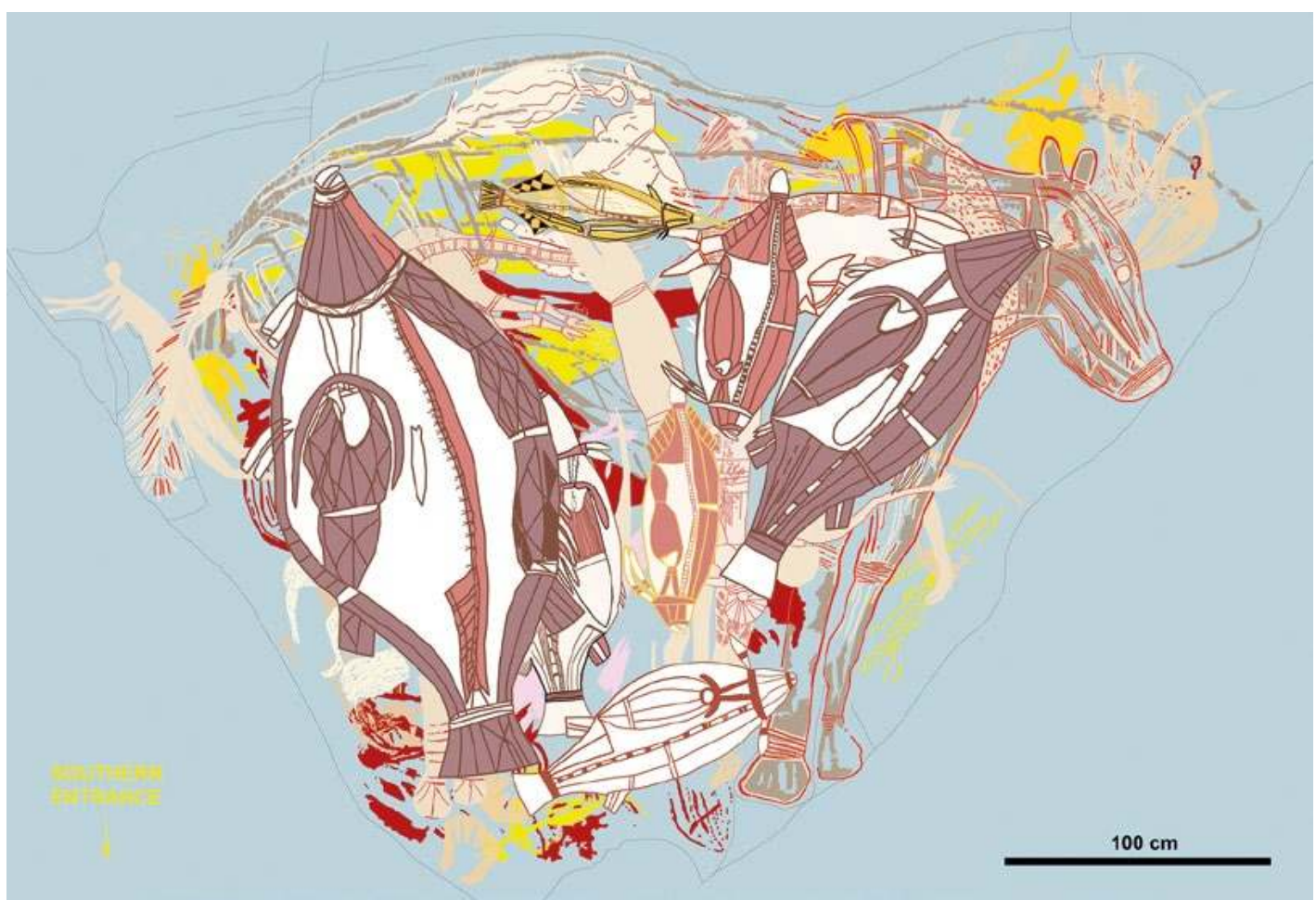

Figure 12.15 Photo-tracing of Panel D.

Source: Photo-tracing by Robert Gunn. 


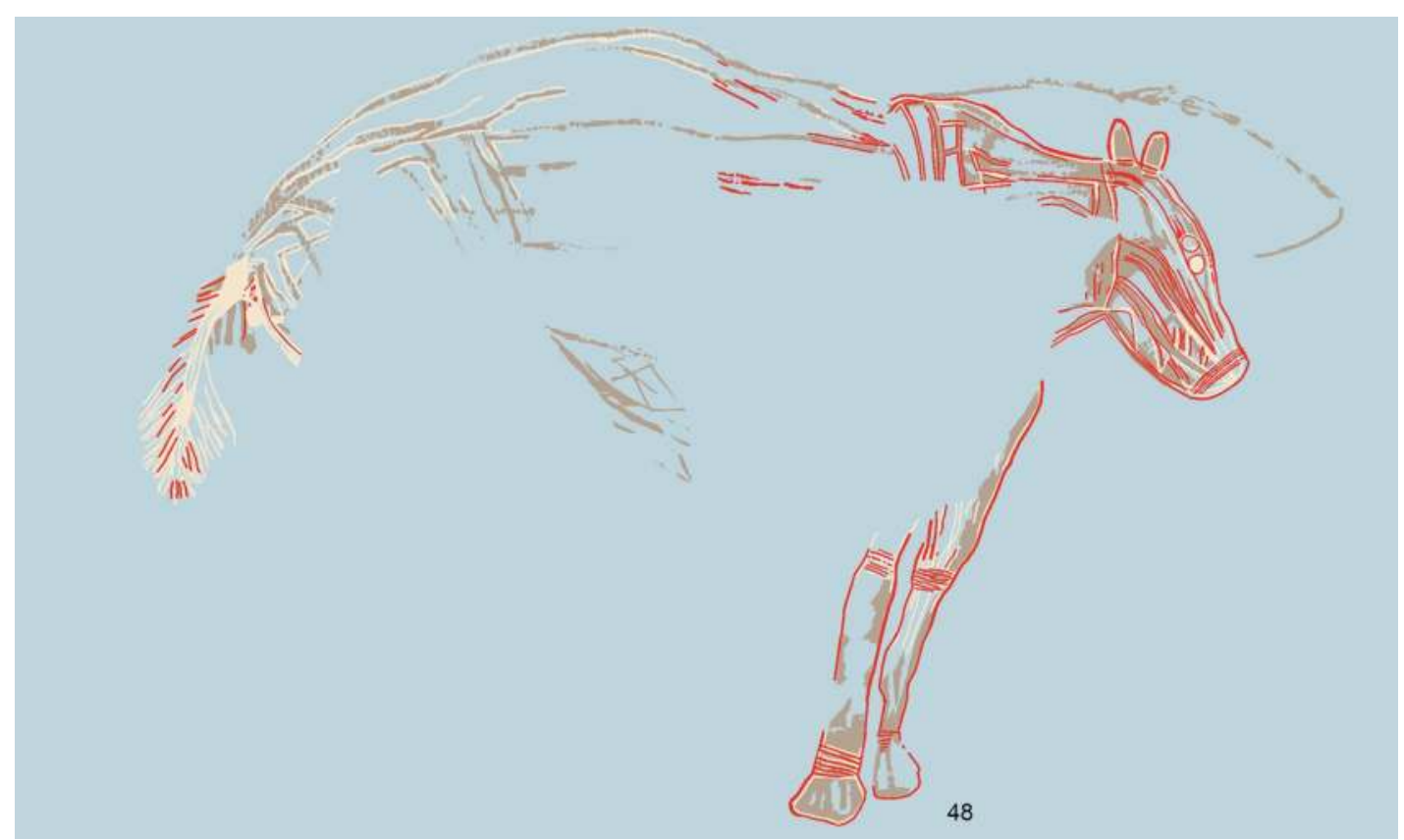

Figure 12.16 Horse image D-48, likely to represent a horse of the Leichhardt expedition in 1845 (see Chapter 9).

Source: Photo-tracing by Robert Gunn.

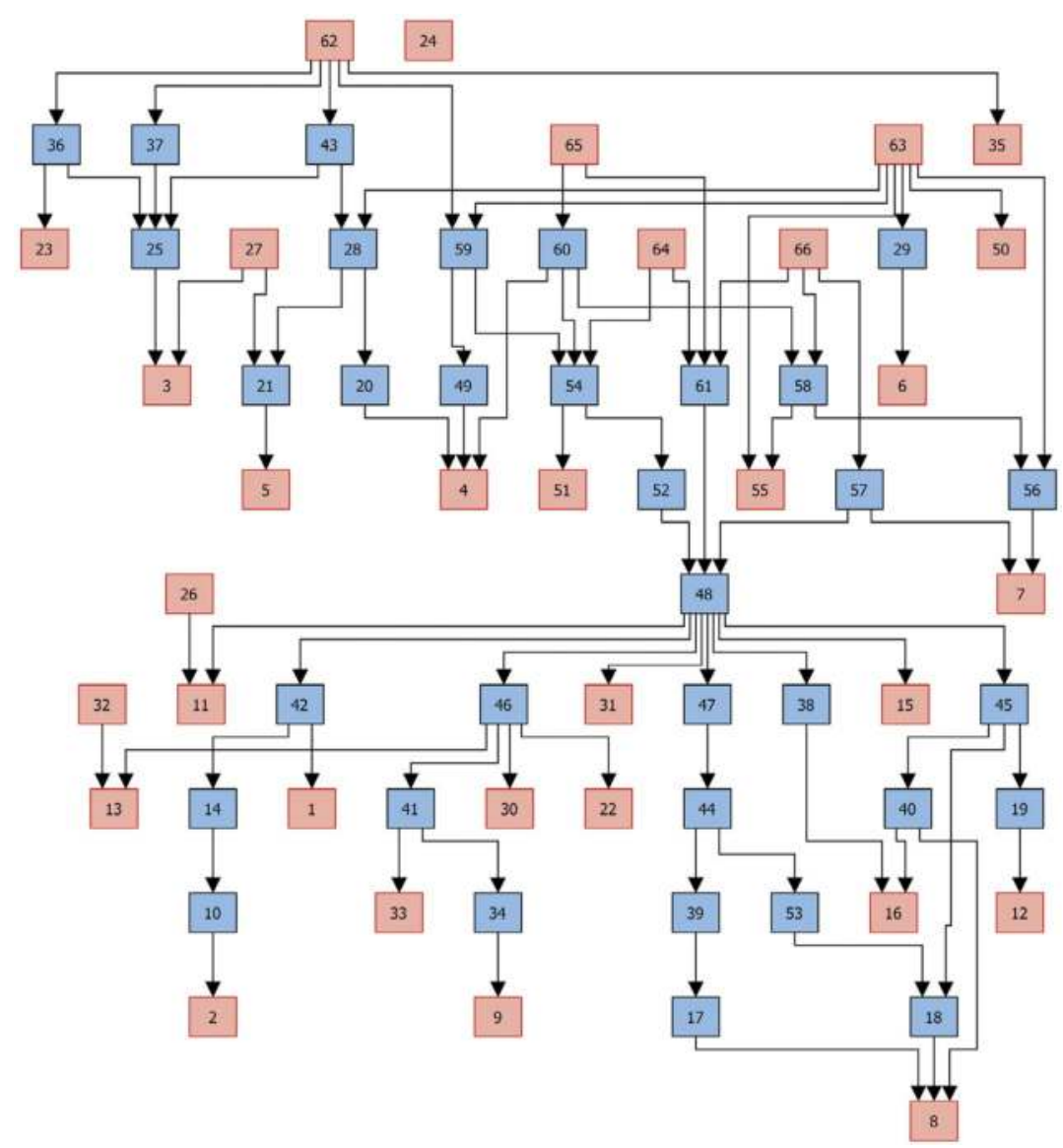

Figure 12.17 Harris Matrix of the Panel D superimpositions.

Red boxes = images at beginning or end of a superimposition sequence; blue boxes = images within a superimposition sequence. Source: Illustration by Robert Gunn. 

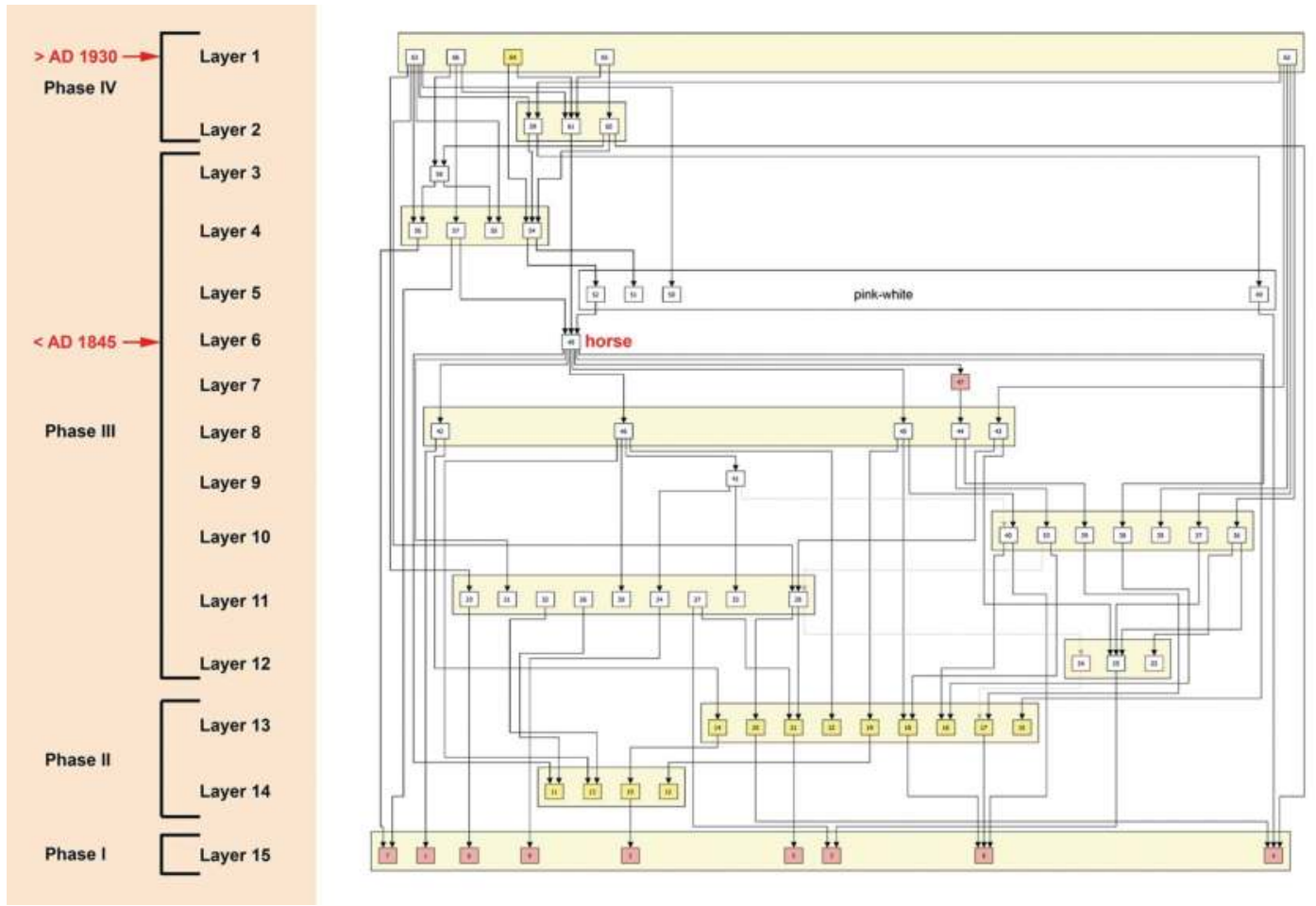

Figure 12.18 Interpretation and phasing of the Panel D Harris Matrix.

Source: Illustration by Robert Gunn.

The greater number of images in the upper layers of Panel D, however, cannot be seen as representing a period of flowering artistic activity. The reason for this is that the large size of, and density of pigment on, the polychrome fish mean that large areas that were probably decorated during earlier phases cannot now be seen. Hence, motif counts for these earlier phases are unlikely to be representative of the actual numbers of artworks produced.

From what is observable, and consistent with the other panels already described, there appears to have been little overall change in the range of motifs portrayed over time in Panel D (Table 12.9). In common with Panel $\mathrm{H}$, however, Panel $\mathrm{D}$ shows a clear trend for the replacement of red and yellow pigments with white-based paintings around or shortly before $1845 \mathrm{AD}$ (Table 12.10).

Table 12.9 Panel $D$ motifs by art phase.

\begin{tabular}{|l|c|c|c|c|c|c|c|c|c|c|c|}
\hline $\begin{array}{l}\text { Panel D } \\
\text { phase }\end{array}$ & \multicolumn{7}{|c|}{ Motif Type } & Total \# of \\
images \\
\hline IV
\end{tabular}

Source: Authors' data. 
Table 12.10 Panel $D$ colours by art phase.

\begin{tabular}{|c|c|c|c|c|c|c|c|c|c|c|}
\hline \multirow{2}{*}{$\begin{array}{l}\text { Panel D } \\
\text { phase }\end{array}$} & \multicolumn{9}{|c|}{ Colour } & \multirow{2}{*}{$\begin{array}{c}\text { Total \# of } \\
\text { images }\end{array}$} \\
\hline & Yellow+black & Polychrome & Cream+red & White+red & White & Pink & Cream & Yellow & Red & \\
\hline IV & 1 & 5 & & 2 & & & & & & 8 \\
\hline $\mathrm{IIlb}$ & & 1 & & 3 & 2 & 4 & & & & 10 \\
\hline \multicolumn{11}{|l|}{1845 AD } \\
\hline Illa & & & 3 & 6 & 13 & & 3 & & 1 & 26 \\
\hline$\|$ & & & & & & & & 13 & & 13 \\
\hline I & & & & & & & & & 9 & 9 \\
\hline Total & 1 & 6 & 3 & 11 & 15 & 4 & 3 & 13 & 10 & 66 \\
\hline
\end{tabular}

'Polychrome' refers to the use of three or more colours in a single image.

Source: Authors' data.

\section{Discussion}

Patterns of superimposition can be compared across the three panels by cross-correlating common artistic traits within individual phases. Given that some layers within some phases have been radiocarbon dated, we can assign absolute ages to those phases. The phases can thus be grouped into three chronological periods: 1) older than $1430 \mathrm{cal} \mathrm{AD;2)} \mathrm{within} \mathrm{the} \mathrm{period} \mathrm{1430-1640}$ cal AD; and 3) $1640 \mathrm{cal} \mathrm{AD} \mathrm{-} 1953 \mathrm{AD}$ (Table 12.11). As painting appears to have ceased at Nawarla Gabarnmang around 1930 AD (Gunn et al. 2012; see also Chapter 9, this volume), the most recent period can be contained within a 290-year period, from $1640 \mathrm{cal}$ AD to $1930 \mathrm{AD}$. No age for the underlying and oldest art on these panels is known, and hence the starting date and depth for the earliest time period is unknown (but see Chapter 11).

Table 12.11 Cross-correlation of panel phases and time periods.

\begin{tabular}{|l|c|c|c|}
\hline Time period & Panel F1 & Panel H & Panel D \\
\hline 1640-1930 cal AD & Vla \& VIb & VI & IV \\
\cline { 2 - 4 } & & Va \& Vb & IIla \& IIIb \\
\hline \multirow{3}{*}{$1430-1640$ cal AD } & V & & \\
\cline { 2 - 4 } & IV & IV & \\
\cline { 2 - 4 } & III & III & II \\
\hline Pre-1430 cal AD & II & II & I \\
\cline { 2 - 5 } & I & I & \\
\cline { 2 - 5 } & & & \\
\hline
\end{tabular}

Source: Authors' data.

Therefore, the three chronological Periods for Panels D, F1 and H are:

1. Recent: $1640 \mathrm{cal}$ AD - 1930 AD, with a sub-group from Panel D assigned to the time frame 1845-1930 AD by the horse depiction.

2. Second: $1430-1640 \mathrm{cal}$ AD.

3. First: Older than $1430 \mathrm{cal} \mathrm{AD.}$ 
Comparison of the art over these three Periods (Tables 12.12-12.13; Figures 12.19-12.23) indicates that:

- Polychrome paintings, including those incorporating an X-ray convention more commonly found in northerly parts of Arnhem Land (e.g. Figure 12.24), occur only in the Recent Period. All probably date to a time after $1845 \mathrm{AD}$ and so are less than 170 years old.

- Anthropomorphs and macropods, painted in white with delicate red infill, became prominent during the Recent Period, most probably after around $1640 \mathrm{cal}$ AD.

- The proportion of anthropomorphs and macropods increased in the Recent Period (after 1640 cal AD) relative to earlier Periods.

- The range of motifs increased during the Second Period and continued into the Recent Period.

- Fish and non-figurative designs became more prominent during the Second and Recent Periods.

- Most white motifs occur during the Second and Recent Periods, with a marked increase in white-based paintings (white, white-and-red bichromes and polychromes) during the Recent Period (72 per cent of images, compared with 29 per cent in the Second Period and 7 per cent in the First).

- The use of red and red-based (red-and-white bichromes) motifs declines notably after the beginning of the Recent Period (c. $1640 \mathrm{cal} \mathrm{BP}$ ).

Table 12.12 Motifs by cross-correlated time periods (total \# of images $=324$ ).

\begin{tabular}{|c|c|c|c|c|c|c|c|c|c|c|c|c|c|c|}
\hline \multirow[t]{2}{*}{ Time period } & \multicolumn{13}{|c|}{ Motif } & \multirow{2}{*}{$\begin{array}{c}\text { Total \# of } \\
\text { images }\end{array}$} \\
\hline & 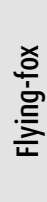 & : & $\stackrel{0}{\text { 壳 }}$ & $\overline{\frac{5}{4}}$ & 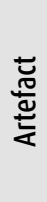 & 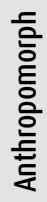 & 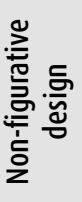 & $\begin{array}{l}\text { 응 } \\
\text { 은 } \\
\text { 이 }\end{array}$ & $\frac{\mathscr{\mathscr { \Sigma }}}{\check{\check{D}}}$ & 릉 & 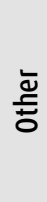 & 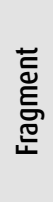 & క్ & \\
\hline 1640-1930 cal AD & 3 & 1 & 3 & 14 & 6 & 26 & 19 & 14 & 3 & 2 & 23 & 9 & & 123 \\
\hline 1430-1640 cal AD & & 1 & 1 & 15 & 9 & 8 & 15 & 6 & 2 & & 22 & 3 & 2 & 84 \\
\hline Pre-1430 cal AD & & & & & & 7 & 9 & 6 & 1 & 2 & 47 & 45 & & 117 \\
\hline
\end{tabular}

Source: Authors' data.

Table 12.13 Colours of images by cross-correlated time periods (total \# of images $=324$ ).

\begin{tabular}{|c|c|c|c|c|c|c|c|c|c|c|c|c|c|c|}
\hline \multirow[t]{2}{*}{ Time period } & \multicolumn{13}{|c|}{ Colour } & \multirow{2}{*}{$\begin{array}{c}\text { Total \# of } \\
\text { images }\end{array}$} \\
\hline & 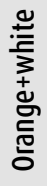 & 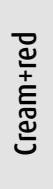 & E్ & 总 & 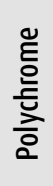 & 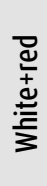 & 圶 & ષ્ષ & $\frac{3}{\overline{0}}$ & 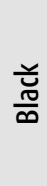 & $\begin{array}{l}\text { 인 } \\
\text { 京 } \\
\text { 은 }\end{array}$ & $\begin{array}{l}\text { ॅั } \\
\text { 휴 }\end{array}$ & 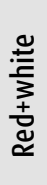 & \\
\hline 1640-1930 cal BP & 1 & 3 & 3 & 6 & 9 & 26 & 54 & 8 & 7 & 5 & 1 & & & 123 \\
\hline 1430-1640 cal BP & & & & & & 1 & 23 & 42 & & 4 & & 8 & 6 & 84 \\
\hline Pre-1430 cal BP & & & & & & & 8 & 58 & 46 & & 1 & & 4 & 117 \\
\hline
\end{tabular}

Source: Authors' data. 


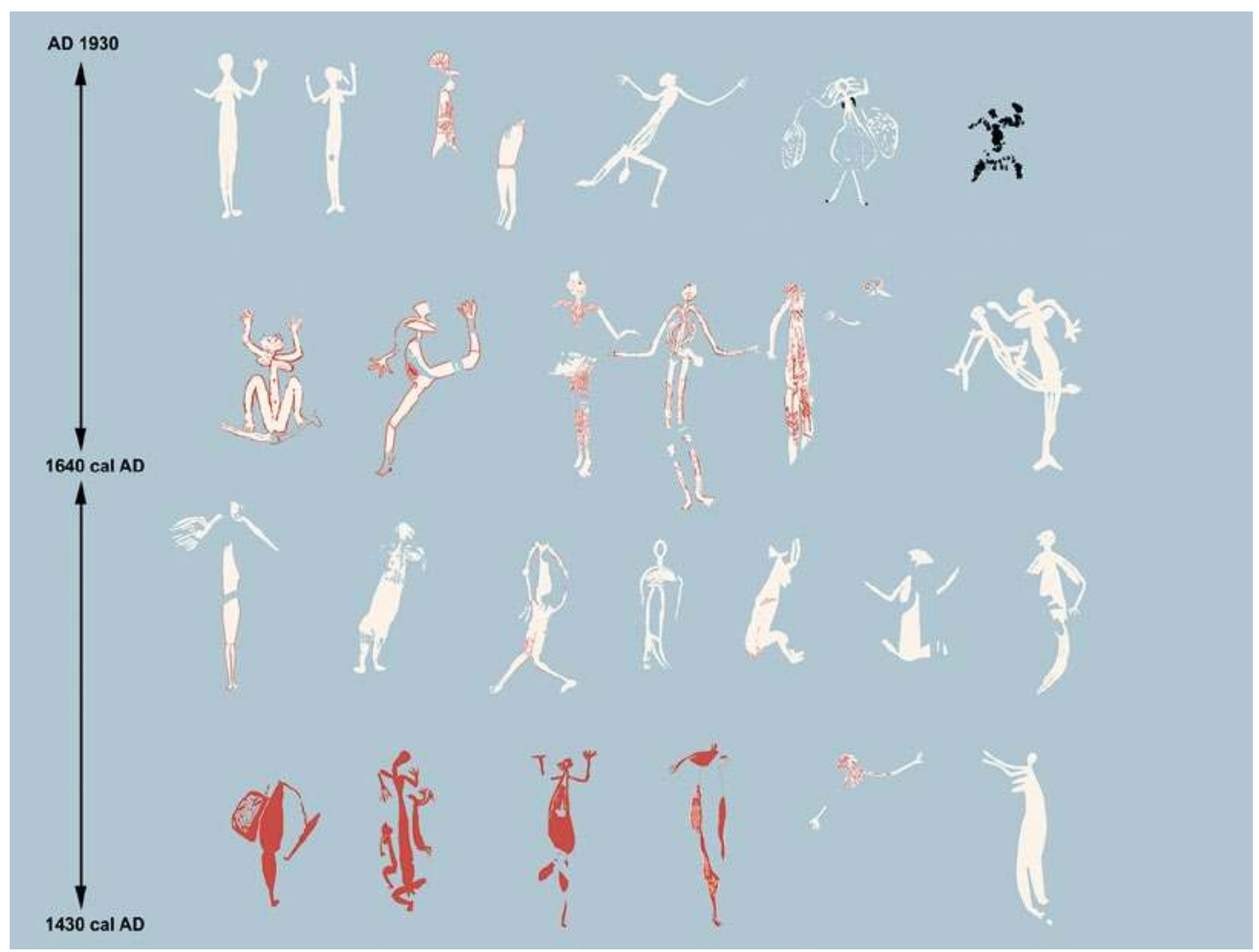

Figure 12.19 Anthropomorphs produced after $1430 \mathrm{cal}$ AD. Beeswax pellets and beeswax figures shown in black.

Source: Photo-tracing by Robert Gunn.

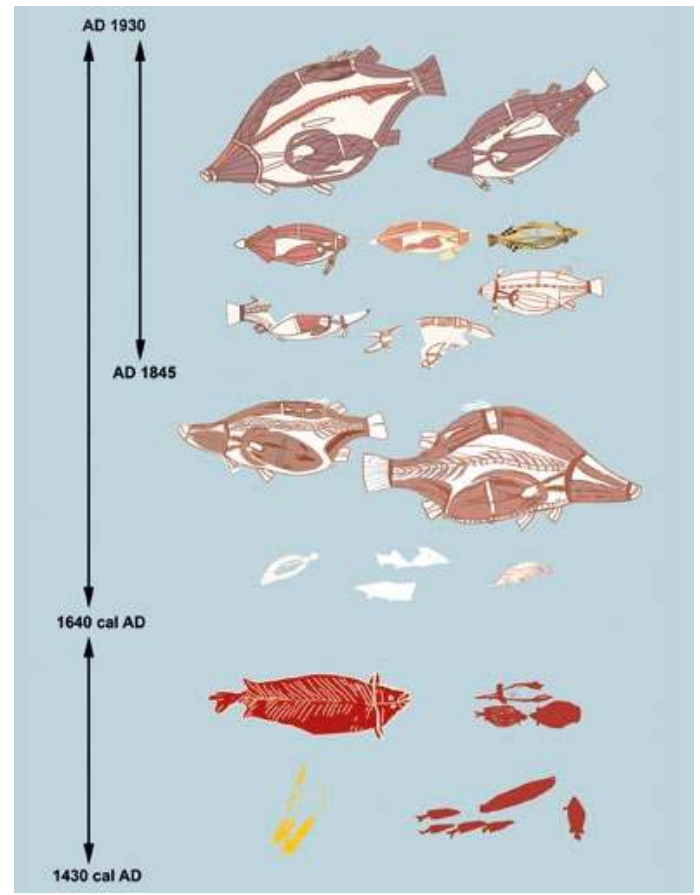

Figure 12.20 Fish images depicted after 1430 cal AD.

Source: Photo-tracing by Robert Gunn.

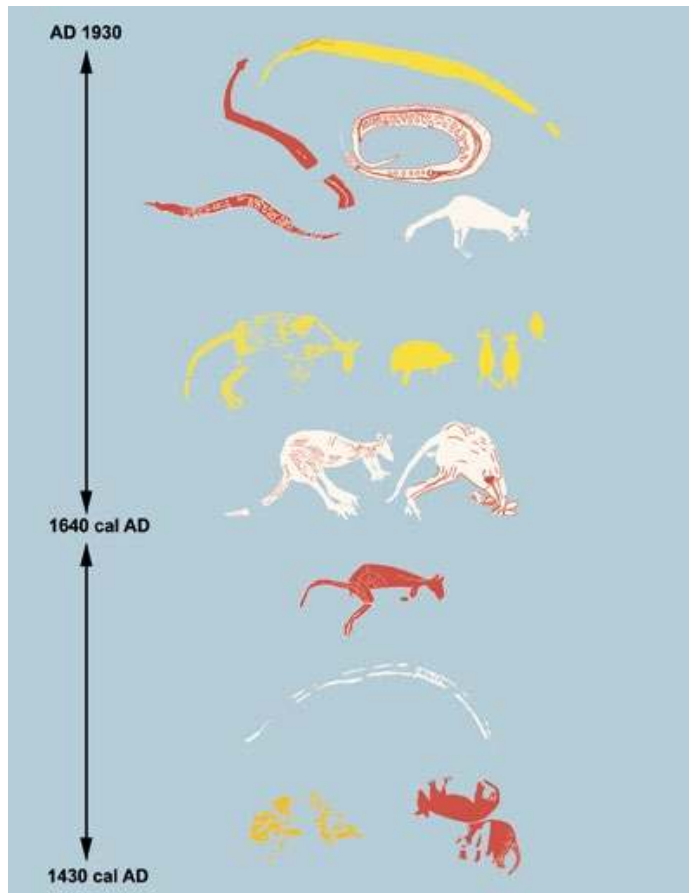

Figure 12.21 0ther faunal images depicted after 1430 cal $A D$.

Source: Photo-tracing by Robert Gunn. 


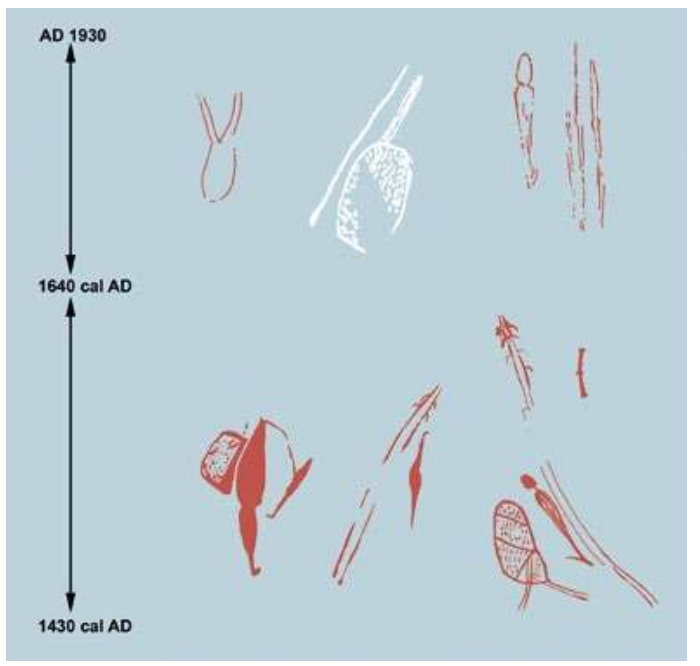

Figure 12.22 Implements depicted after 1430 cal AD.

Source: Photo-tracing by Robert Gunn.

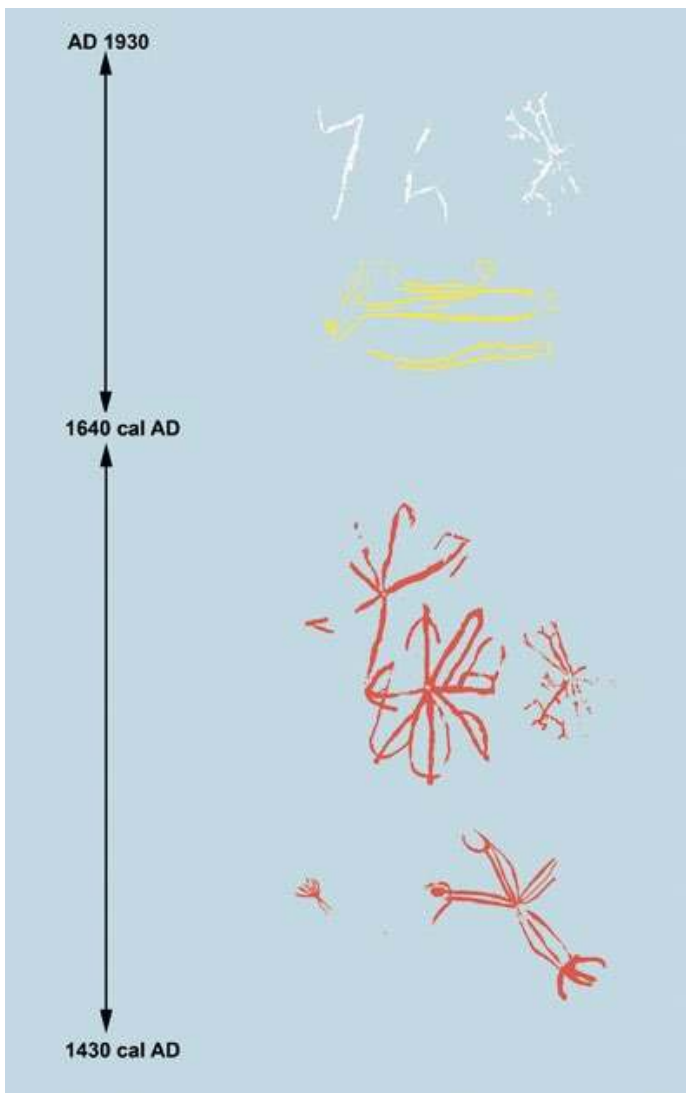

Figure 12.23 Non-figurative designs depicted after $1430 \mathrm{cal} A D$.

Source: Photo-tracing by Robert Gunn.
The art of Panels D, F1 and $\mathrm{H}$ have a number of changes in the use of colours and motifs over the period from pre-1430 cal AD times to $1930 \mathrm{AD}$. These changes appear to have been gradual, rather than occurring together as a single 'package' over a short period of time; the changes do not represent an abrupt and dramatic transformation of the overall repertoire. These results show:

- The specific impetuses behind the Recent Period art - cultural beliefs, understandings and codes relating to particular artistic practices - were also restricted to this period of time, the past 350-400 years.

- The time frame represented by the Recent Period is comparable with Chaloupka's (1993:191) 'Contact period', which he proposed began around 300 years ago, a period of cultural activity coincident first with the arrival of Macassans and then Europeans, Chinese and other outsiders.

- New 'traditional' styles such as polychrome X-ray fish and 'Jawoyn Lady' motifs (Figures 12.24 and 12.25; see also Chapters 11 and 13) developed during the Recent Period. These new styles contrasted with the stylistic conventions of the previous art periods when paintings were restricted to monochromes and bichromes and no female figures had achieved the high numbers, prominent positioning and wide distribution of the 'Jawoyn Lady' that became common in Jawoyn Country during the Recent Period (Gunn 1992:180). Chaloupka also pointed out, as we have also found, that 'stylistic conventions and painting techniques of the previous styles continued to be used' (Chaloupka 1993:191).

Overall, these results support Taçon's (1989b:318) finding: 'The most recent period of rock painting in Western Arnhem Land was one of great diversity and elaboration. It differs from earlier periods in terms of subject matter, form, use of colour and symbolic content'. His suggestion that most X-ray art was produced over the past 1500 to 300 years (Taçon 1989b:318, 330) may have unduly stretched 
out the chronology of this art form. We have found it only during the last 300 years and it is possible that X-ray art is younger in the southern half of the Arnhem Land plateau, which includes Nawarla Gabarnmang, than in the north.

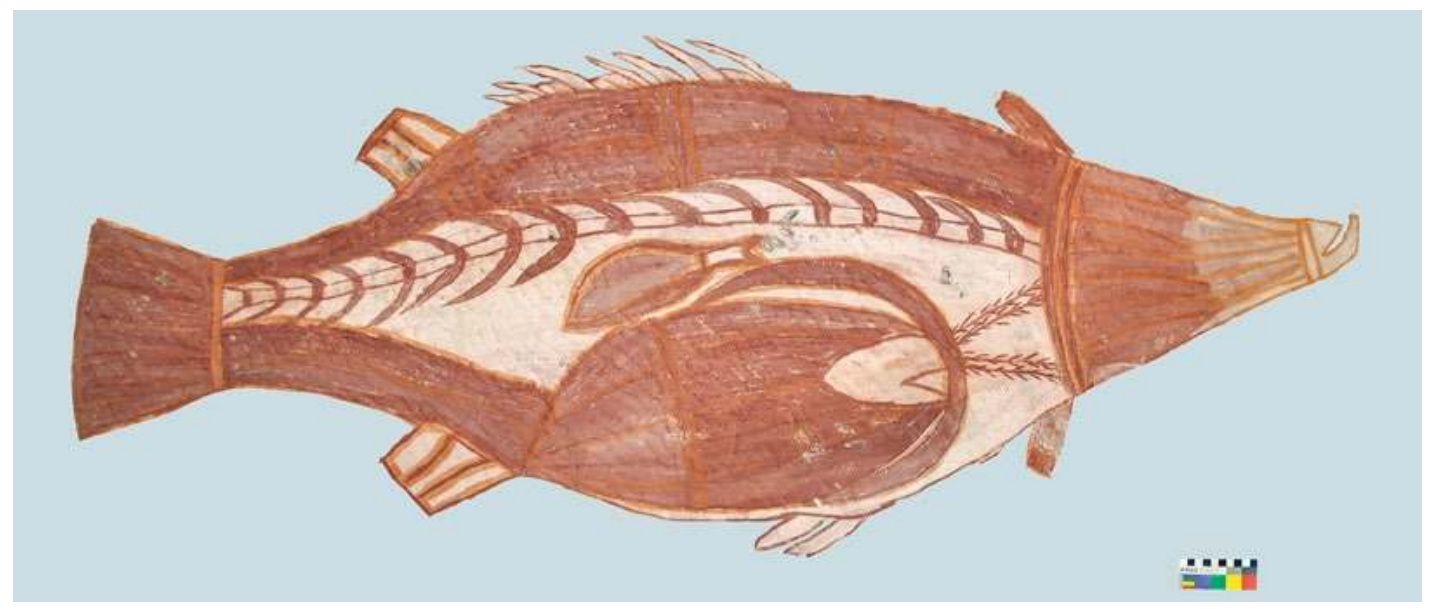

Figure 12.24 Polychrome X-ray fish (barramundi) from Panel E1. Scale $10 \mathrm{~cm}$.

Source: Photo-illustration by Robert Gunn.

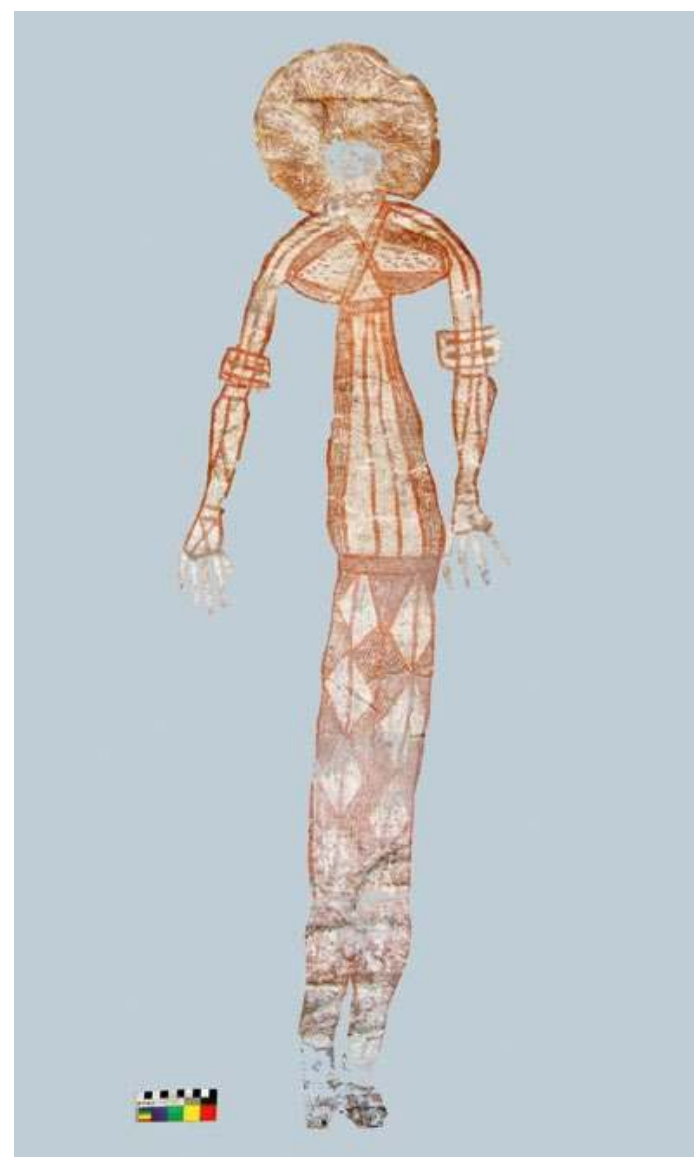

Figure 12.25 Bichrome 'Jawoyn Lady' from the nearby site A081-11. Scale $10 \mathrm{~cm}$.

Source: Photo-illustration by Robert Gunn.
A further implication of our results is that Taçon's concept of 'rainbowness', symbolised by bright combinations of colour through hatching, cross-hatching and solid bands of pigment (Taçon 1989b:326, 1991:197), may also be a recent phenomenon. This, in turn, implies his proposed 'shift in religious orientation' (Taçon 1989b:330) was also relatively recent.

Alternatively, these results from Nawarla Gabarnmang may relate to local circumstances in southern parts of Arnhem Land only. They may indicate recent and in some ways restricted contacts with people from the north and their polychrome X-ray fish art. 


\section{Conclusion}

Analyses of these three large art panels at Nawarla Gabarnmang have provided a chronological sequence for its recent rock art: an initial change in the recent art within the time period 1430-1640 cal AD, during which time white pigment became more popular and the range of motifs increased; followed by a further transition from $1640 \mathrm{cal} \mathrm{AD}$ to $1930 \mathrm{AD}$, when red pigment became relatively seldom used and white monochrome and white-based bichrome and polychrome paintings became much more common. Since white pigment is known to survive less well, the increase in white art may be thought to result from differential preservation. The ceiling surfaces, however, are very well protected from the elements and from animal activity, so we see the primary cause for the changes in colours used, and in artistic styles, as cultural. Whether the decrease in the use of red pigment and increase in white pigment at Nawarla Gabarnmang signals changing access to pigment types, or pigment sources, and/or whether they indicate a change in the choice of colour use relate to their symbolic associations remains unknown. No sources of either red or white pigment are known anywhere within tens of kilometres of Nawarla Gabarnmang.

\section{Acknowledgements}

We thank Fiona Petchey (Waikato Radiocarbon Dating Laboratory) for converting the radiocarbon dates with $\mathrm{OxCal}$ and discussing the results. Leigh Douglas provided invaluable help with fieldwork and editorial comments. The late Bardayal Nadjamerrek and Peter Bolgay provided invaluable background information on the site and interpretations of the artwork. Our colleague Jean-Michel Geneste (Centre National de Préhistoire, France) also contributed to on-site discussions. Ray Whear (then of the Jawoyn Association) provided logistical support, and the work was supported by the Board of the Jawoyn Association. Thanks also to our pilots Chris Morgan and Darren Stockton. At Monash University, thanks to the Monash Indigenous Studies Centre for support. We thank the Australian Research Council for Linkage grant LP110200927 and Discovery Outstanding Research Award (DORA) Fellowship (to BD) DP130102514.

\section{References}

Bednarik, R.G. 2001. The taphonomy of beeswax figures. Rock Art Research 18:91-95.

Berndt, R.M. and C.H. Berndt 1977. The World of the First Australians. Ure Smith, Sydney.

Bronk Ramsey, C. 2013. OxCal Program v4.2.2. Radiocarbon Accelerator Unit, University of Oxford, Oxford.

Chaloupka, G. 1977. Aspects of the chronology and schematisation of two prehistoric sites on the Arnhem Land plateau. In P.J. Ucko (ed.), Form in Indigenous Art, pp. 243-259. Australian Institute of Aboriginal Studies, Canberra.

Chaloupka, G. 1984. From Paleo Art to Casual Paintings. Monograph Series 1. Northern Territory Museum of Arts and Sciences, Darwin.

Chaloupka, G. 1985. Chronological sequence of Arnhem Land plateau rock art. In R. Jones (ed.), Archaeological research in Kakadu National Park, pp. 269-280. Special Publication 13. Australian National Parks and Wildlife Service, Canberra.

Chaloupka, G. 1993. Journey in Time: The World's Longest Continuing Art Tradition. Reed, Chatswood. 
Chippindale, C. and P.S.C. Taçon 1993. Two old painted panels from Kakadu: Variation and sequence in Arnhem Land rock-art. In J. Steinbring, A. Watchman, P. Faulstich and P.S.C. Taçon (eds.), Time and Space: Dating and Spatial Considerations in Rock-Art Research, pp. 32-56. Occasional AURA Publication 8. Australian Rock Art Research Association, Melbourne.

David, B., J.-M. Geneste, R.L. Whear, J.-J. Delannoy, M. Katherine, R.G. Gunn, C. Clarkson, H. Plisson, P. Lee, F. Petchey, C. Rowe, B. Barker, L. Lamb, W. Miller, S. Hoerle, D. James, E. Boche, K. Aplin, I.J. McNiven, T. Richards, A. Fairbairn and J. Matthews 2011. Nawarla Gabarnmang, a 45,185 \pm 910 cal BP site in Jawoyn Country, southwest Arnhem Land Plateau. Australian Archaeology 73:73-77.

Delannoy, J.-J., B. David, J.-M. Geneste, M. Katherine, B. Barker, R.L. Whear and R.G. Gunn 2013. The social construction of caves and rockshelters: Chauvet Cave (France) and Nawarla Gabarnmang (Australia). Antiquity 87:12-29. doi.org/10.1017/S0003598X00048596

Geneste, J.-M., B. David, H. Plisson, C. Clarkson, J.-J. Delannoy, F. Petchey and R. Whear 2010. Earliest evidence for ground-edge axes 35,400 \pm 410 cal BP from Jawoyn Country, Arnhem Land. Australian Archaeology 71:66-69. doi.org/10.1080/03122417.2010.11689385

Gunn, R.G. 1992. Bulajang - A reappraisal of the archaeology of an Aboriginal cult. In J. McDonald and I.P. Haskovec (eds), State of the Art, pp. 174-194. Occasional AURA Publication 6. Australian Rock Art Research Association, Melbourne.

Gunn, R.G. 2016. Art of the Ancestors: Spatial and Temporal Patterning in the Rock Art of Nawarla Gabarnmang, A Major Jawoyn Cultural Site on the Arnhem Land Plateau. Unpublished PhD thesis. Monash University, Clayton.

Gunn, R.G., R.L. Whear and L.C. Douglas 2012. Dating the present at Nawarla Gabarnmang: Time and function in the art of a major Jawoyn rock art and occupation site in western Arnhem Land. Australian Archaeology 75:55-65. doi.org/10.1080/03122417.2012.11681950

Haskovec, I.P. 1992. Mt Gilruth revisited. Archaeology in Oceania 27:61-74. doi.org/10.1002/j.18344453.1992.tb00285.x

Leichhardt, L. 1847. Journal of an Overland Expedition in Australia, from Moreton Bay to Port Essington, a Distance of Upwards of 3000 Miles, during the Years 1844-1845. T. and W. Boone, London. adc.library.usyd.edu.au/data-2/p00050.pdf. Accessed 13 February 2013.

Lewis, D. 1988. The Rock Paintings of Arnhem Land, Australia. BAR International Series 415. British Archaeological Reports, Oxford.

May, S.K., P.S.C. Taçon, D. Wesley and M. Travers 2010. Painting history: Indigenous observations and depictions of the 'Other' in northwestern Arnhem Land, Australia. Australian Archaeology 71:57-65. doi.org/10.1080/03122417.2010.11689384

Nelson, D.E. (ed.) 2000. The Beeswax Art of Northern Australia. CD publication. Simon Fraser University, Burnaby.

Reimer, P.J., E. Bard, A. Bayliss, J.W. Beck, P.G. Blackwell, C. Bronk Ramsey, C.E. Buck, H. Cheng, R.L. Edwards, M. Friedrich, P.M. Grootes, T.P. Guilderson, H. Haflidason, I. Hajdas, C. Hatté, T.J. Heaton, D.L. Hoffmann, A.G. Hogg, K.A. Hughen, K.F. Kaiser, B. Kromer, S.W. Manning, M. Niu R.W. Reimer, D.A. Richards, E.M. Scott, J.R. Southon, R.A. Staff, C.S.M. Turney and J. van der Plicht 2013. IntCal13 and Marine13 radiocarbon age calibration curves, 0-50 000 years cal BP. Radiocarbon 55 (4):1869-1887. doi.org/10.2458/azu_js_rc.55.16947

Stuiver, M. and P.J. Reimer 1993. Extended ${ }^{14} \mathrm{C}$ data base and revised CALIB $3.0{ }^{14} \mathrm{C}$ age calibration program. Radiocarbon 35:215-230. doi.org/10.1017/S0033822200013904 
Taçon, P.S.C. 1987. Internal-external: A re-evaluation of the 'X-ray' concept in western Arnhem Land rock art. Rock Art Research 4:36-50.

Taçon, P.S.C. 1989a. From Rainbow Snakes to 'X-Ray' Fish: The Nature of the Recent Rock Painting Tradition of Western Arnhem Land, Australia. Unpublished PhD thesis. The Australian National University, Canberra.

Taçon, P.S.C. 1989b. From the 'dreamtime' to the present: The changing role of Aboriginal rock painting in western Arnhem Land, Australia. Canadian Journal of Native Studies 1989:317-339.

Taçon, P.S.C. 1991. The power of stone: Symbolic aspects of stone use and tool development in western Arnhem Land, Australia. Antiquity 65:192-207. doi.org/10.1017/S0003598X00079655

Taçon, P.S.C. 1992. Somewhere over the Rainbow: An ethnographic and archaeological analysis of recent rock paintings of western Arnhem Land. In J. McDonald and I.P. Haskovec (eds), State of the Art, pp. 202-215. Occasional AURA Publication 6. Australian Rock Art Research Association, Melbourne.

Taçon, P.S.C. 1993. Regionalism in the recent rock art of western Arnhem Land, Northern Territory. Archaeology in Oceania 28:112-120. doi.org/10.1002/j.1834-4453.1993.tb00302.x

Taçon, P.S.C. and C. Chippindale 1994. Australia’s ancient warriors: Changing depictions of fighting in the rock art of Arnhem Land, (N.T.). Cambridge Archaeological Journal 4:211-248. doi.org/10.1017/ S0959774300001086

Taylor, L. 1996. Seeing the Inside: Bark Painting in Western Arnhem Land. Clarendon Press, Oxford.

Wesley, D. 2013. Firearms in rock art of Arnhem Land, Northern Territory, Australia. Rock Art Research $30: 235-247$. 


\title{
Archaeology of rock art at Dalakngalarr 1, central-western Arnhem Land
}

\author{
Daniel James, Bruno David, Jean-Jacques Delannoy, Robert Gunn, \\ Alexandria Hunt, Ian Moffat, Nadia lacono, Sean Paul Stephens \\ and Margaret Katherine
}

\section{Introduction}

In 2011, we began researching the subsurface archaeology, geomorphology and rock art of Dalakngalarr 1, a moderately sized rockshelter on top of the central-western Arnhem Land plateau in Jawoyn Country. Here, four lines of evidence give relative or absolute ages for rock art:

1. Archaeological excavations adjacent to a boulder that contains a painting of a red macropod reveal when that boulder attained its present position, so the red macropod must have been painted sometime afterwards.

2. Paintings of axe/hoes with metal heads indicate that they were painted during the Europeancontact period. A nearby group of X-ray images are painted in comparable pigments, suggesting that they are contemporaneous with the axe/hoes.

3. Geomorphological evidence suggests that parts of the site's ceiling collapsed at datable times in the past, indicating that the art on that roof must post-date the roof collapse.

4. Direct accelerator mass spectrometry (AMS) radiocarbon dates on beeswax art.

\section{Archaeological context}

Dalakngalarr 1 is an enclosed shelter, located deep in Jawoyn Country on the central-western Arnhem Land plateau, some $190 \mathrm{~km}$ southeast of Darwin (Figures 13.1 and 13.2; see also Figure 1.1). It was rediscovered in 2007 as part of the Jawoyn Rock Art and Heritage Project (Gunn and Whear 2007). Dalakngalarr 1 is part of a large, low-lying outcrop of Kombolgie sandstone that dips down towards the southeast. 


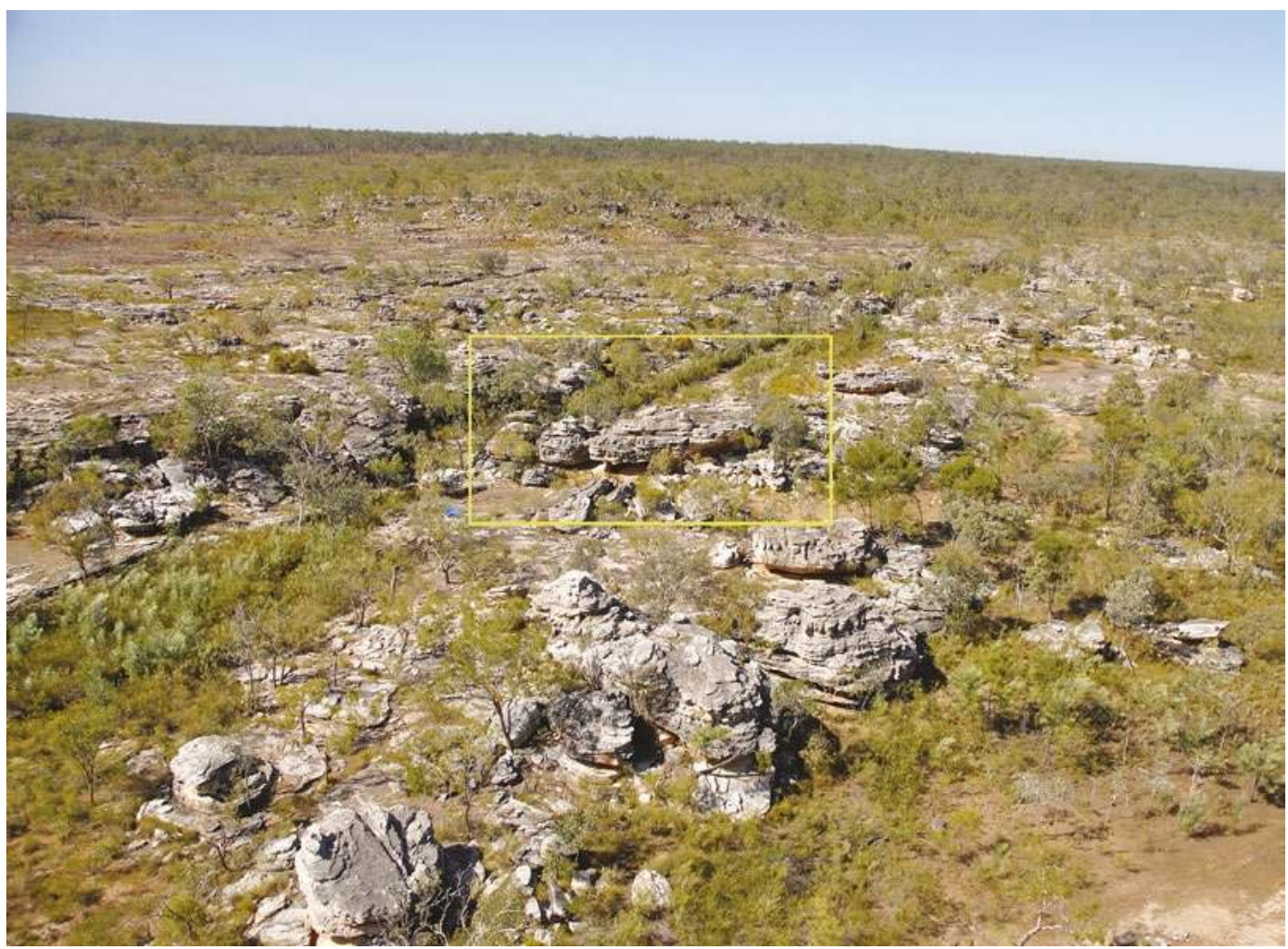

Figure 13.1 Dalakngalarr site complex, looking southeast. Yellow rectangle locates Dalakngalarr 1.

Source: Photograph by Daniel James.

The rock outcrops in the vicinity of Dalakngalarr 1 contain three adjacent complexes of archaeological sites: Dalakngalarr (allocated the code ARN-082 in the Jawoyn site database), LBX (ARN-083) and Dalakjarang (ARN-102). These three site complexes are separated by seasonal streams that flow along eroded joint lines in the bedrock. Each site complex is located in a distinct geomorphological setting and contains a locally major art and occupation site.

The three site complexes each contain distinctive archaeological sites (Tables 13.1 and 13.2). The landscape of Dalakjarang is of a long, low rock ridge within which are found a number of small shelters. The Dalakjarang site complex fronts a flat sand plain with a large expanse of flat rock to the southeast above and behind the rockshelters. This site complex contains a large linear stone arrangement, an unusually high number of standing stones (cf. Gunn et al. 2012) and a large and hitherto unique painted motif in its major shelter. Two sets of grinding patches occur on bedrock surfaces between the major site and the nearby creek. The large stone arrangement was interpreted by Margaret Katherine as a ceremonial site that was probably related to the regional Dalak (sand goanna, Varanus panoptes) Dreaming. This stone arrangement lies directly in front of the major art shelter that, in addition to housing the unusual motif mentioned above, also contains almost two-thirds of all the art within the site complex. Another unusual aspect of the rock art here is the high number of sites (10 of 23 art shelters) with 'Dynamic Figures' (cf. Chaloupka 1993:106-119). 

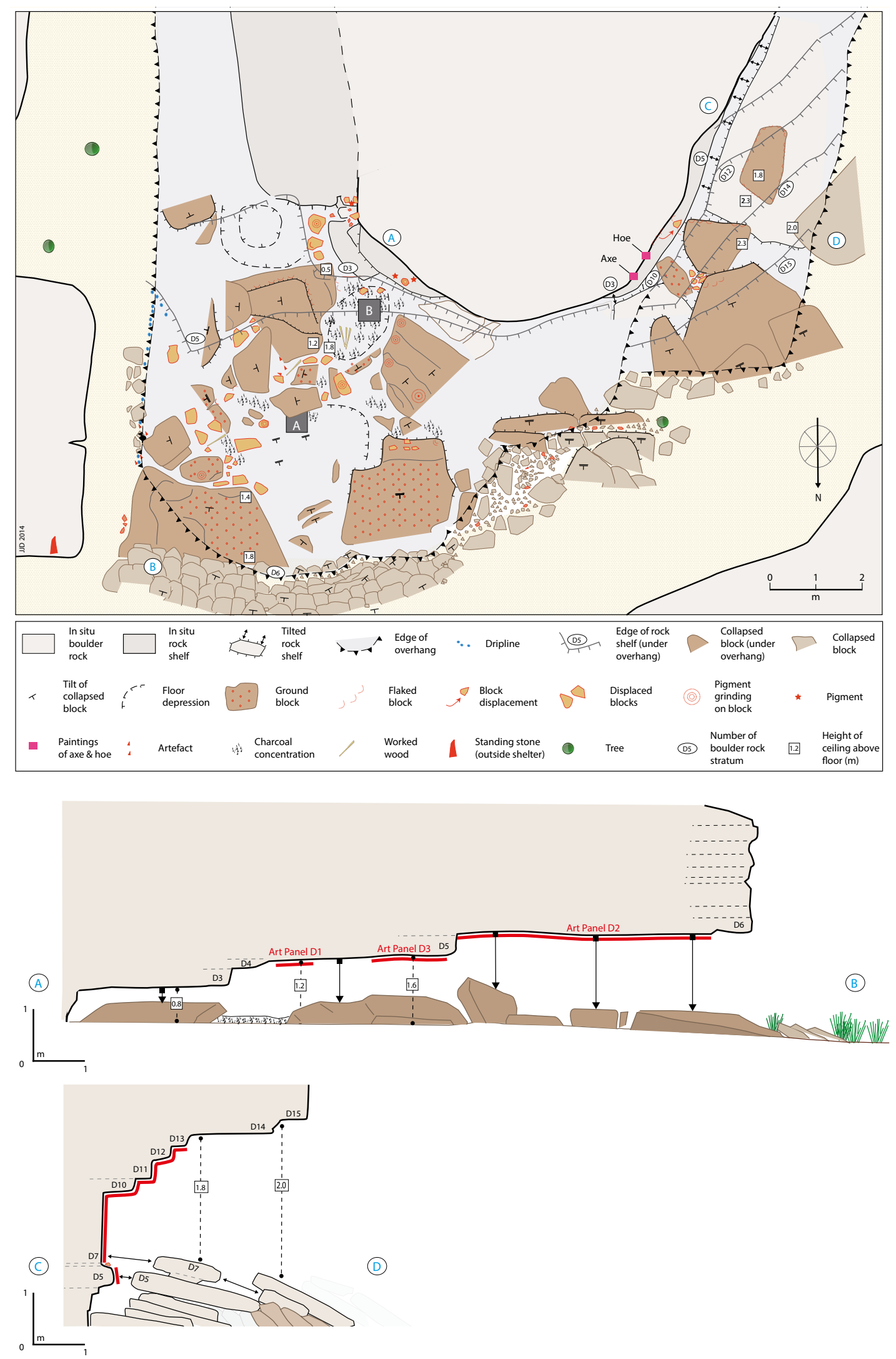

Figure 13.2 Plan and cross-sections of Dalakngalarr 1 showing location of rock art panels.

Source: Illustration by Jean-Jacques Delannoy. 
In contrast to that of Dalakjarang, the landscape of Dalakngalarr consists of a tumble of residual sandstone ridges and collapsed blocks. As with Dalakjarang, most of the artwork in this site complex is concentrated within one shelter (Dalakngalarr 1), but here, and throughout the site complex, the emphasis is on paintings of fauna with a much greater use of white pigment. A large number of 'older' red and yellow paintings occur within this site complex, but no classic Dynamic Figures have been located. Also, while another stone arrangement occurs here, it is much smaller and within a more confined space than that at Dalakjarang.

At site complex LBX, a small cluster of residual stacks stand in front of a solid outcrop of bedrock cut by a grid of narrow, joint-derived corridors (cf. Young et al. 2009:172). Here, most rockshelters occur at the corners of intersecting corridors. The artwork is focused on the larger ARN-083/1 shelter; however, it has only around one-third of the artworks in the complex, so the concentration at this one site is notably less than in the dominant site at the other two site complexes. At LBX, the art is predominantly older red and yellow art, with an emphasis on smaller paintings of fauna. No archaeological traces other than art shelters have been recorded here.

Neither archaeological excavations nor detailed art recording have yet been undertaken within either the Dalakjarang or LBX site complexes.

Table 13.1 Contents of site complexes.

\begin{tabular}{|l|c|c|c|c|c|c|}
\hline Site complex & Area $\mathbf{( m )}$ & $\begin{array}{c}\text { \# of art } \\
\text { sites }\end{array}$ & $\begin{array}{c}\text { \# of images } \\
\text { (estimated) }\end{array}$ & $\begin{array}{c}\text { Standing } \\
\text { stones }\end{array}$ & $\begin{array}{c}\text { Stone } \\
\text { arrangements }\end{array}$ & $\begin{array}{c}\text { Grinding } \\
\text { areas }\end{array}$ \\
\hline Dalakjarang (ARN-102) & $850 \times 450$ & 23 & 699 & 28 & 7 & 2 \\
\hline Dalakngalarr (ARN-082) & $200 \times 30$ & 9 & 887 & 3 & 1 & \\
\hline LBX (ARN-083) & $350 \times 200$ & 7 & 408 & & & \\
\hline
\end{tabular}

Source: Authors' data.

Table 13.2 Number of rock art images at the major site of each site complex.

\begin{tabular}{|l|l|c|}
\hline Site complex & Major site & \# of images \\
\hline Dalakjarang (ARN-102) & ARN-102/3 & 435 \\
\hline Dalakngalarr (ARN-082) & Dalakngalarr 1 (ARN-082/1) & 502 \\
\hline LBX (ARN-083) & ARN-083/1 & 134 \\
\hline
\end{tabular}

Source: Authors' data.

\section{Dalakngalarr 1}

During initial examination by Robert Gunn and Leigh Douglas in September 2007, Dalakngalarr 1 was seen to contain a high number of paintings for such an enclosed shelter, estimated at $>400$ visible images (Table 13.2). These images were thought to cover a broad span of time, with slim anthropomorphs holding boomerangs (cf. Lewis 1988) being of considerable age evident on the eastern and western outer walls, and demonstrably more recent art of the European-contact period in the form of two paintings of metal axe/hoes on the rear interior wall of the shelter. The more recent X-ray art appeared to have been painted in a strikingly similar style, and with similar pigments, to that at Nawarla Gabarnmang some $17 \mathrm{~km}$ to the west-southwest. This initial impression of similarity in style and composition of the fish paintings at the two sites prompts questions about connections between them, a topic of investigation currently being addressed by James (in prep.) and Gunn (Chapter 12). Dalakngalarr 1 was chosen for study because of its abundant rock art, and because its overhang houses the largest rockshelter of the site complex. 


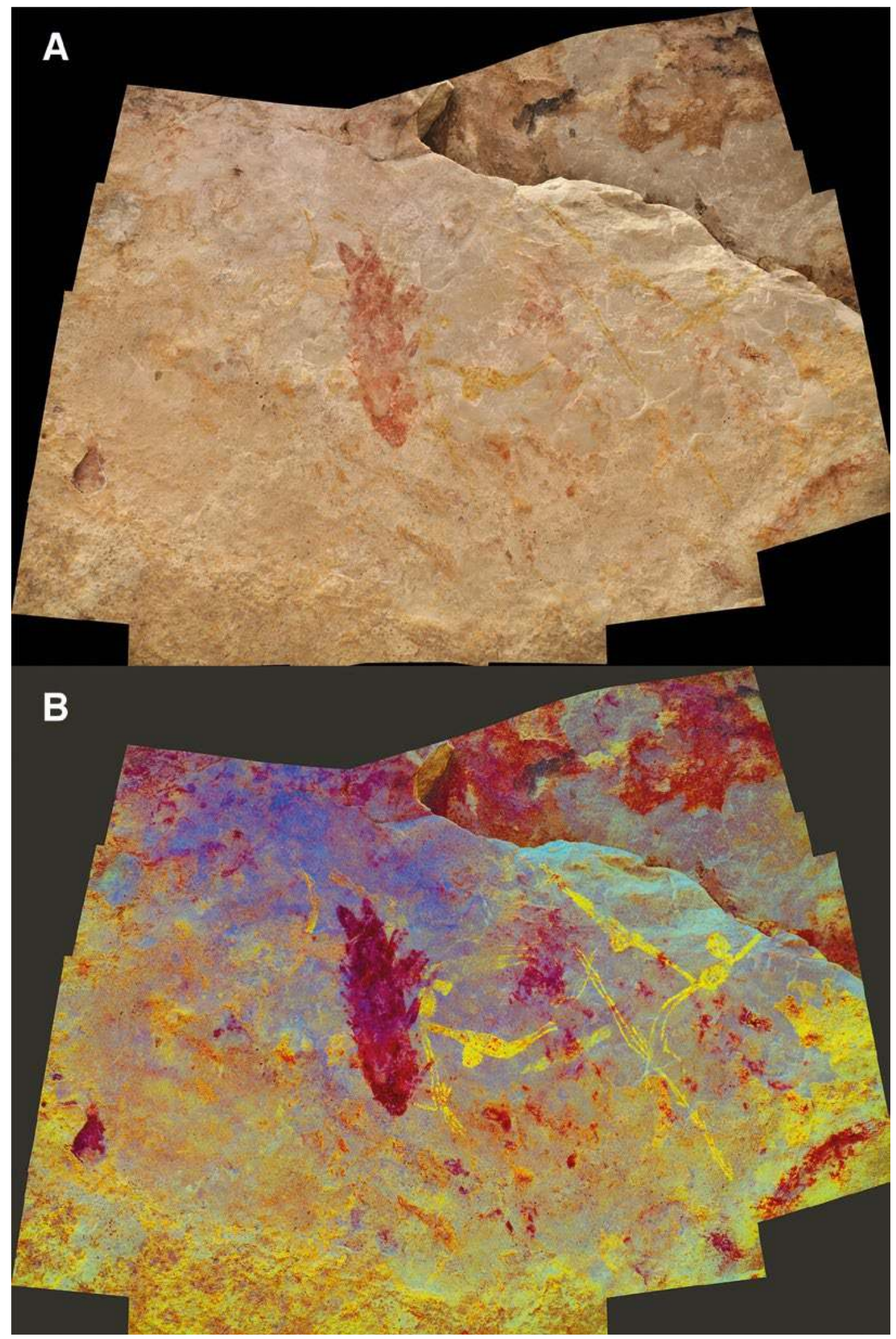

Figure 13.3 Faded, ancient rock art of Panel A5 on eastern wall of Dalakngalarr 1.

A: Original photograph. B: Digitally enhanced photograph using DStretch_Ids10 enhancement. Source: Photograph and enhancement by Daniel James. 
Stylistic and thematic elements, such as the presence of boomerangs that Lewis (1988), Chaloupka (1993) and others have attributed to Dynamic and Post-Dynamic Figures or their equivalents as older phases of rock art, show that the oldest visible art in the shelter occurs along the eastern and western walls. Of particular interest is ceiling Panel A5 with pictures of yellow anthropomorphs holding boomerangs (Figure 13.3). Sub-surface archaeological investigations in this eastern part would be problematic as there is considerable evidence of wet-season water flow over and into the soft sandy soil. The rock surface is also stained black by water flow. This black staining has affected much of the eastern outer wall's rock surface (see Figure 13.4, right-hand side of back wall); it is particularly prevalent in the area around Panel A5, limiting our ability in this part to understand the age of the art. On the opposite side of the site there are no excavatable deposits beneath the western wall's stepped rocky platform.

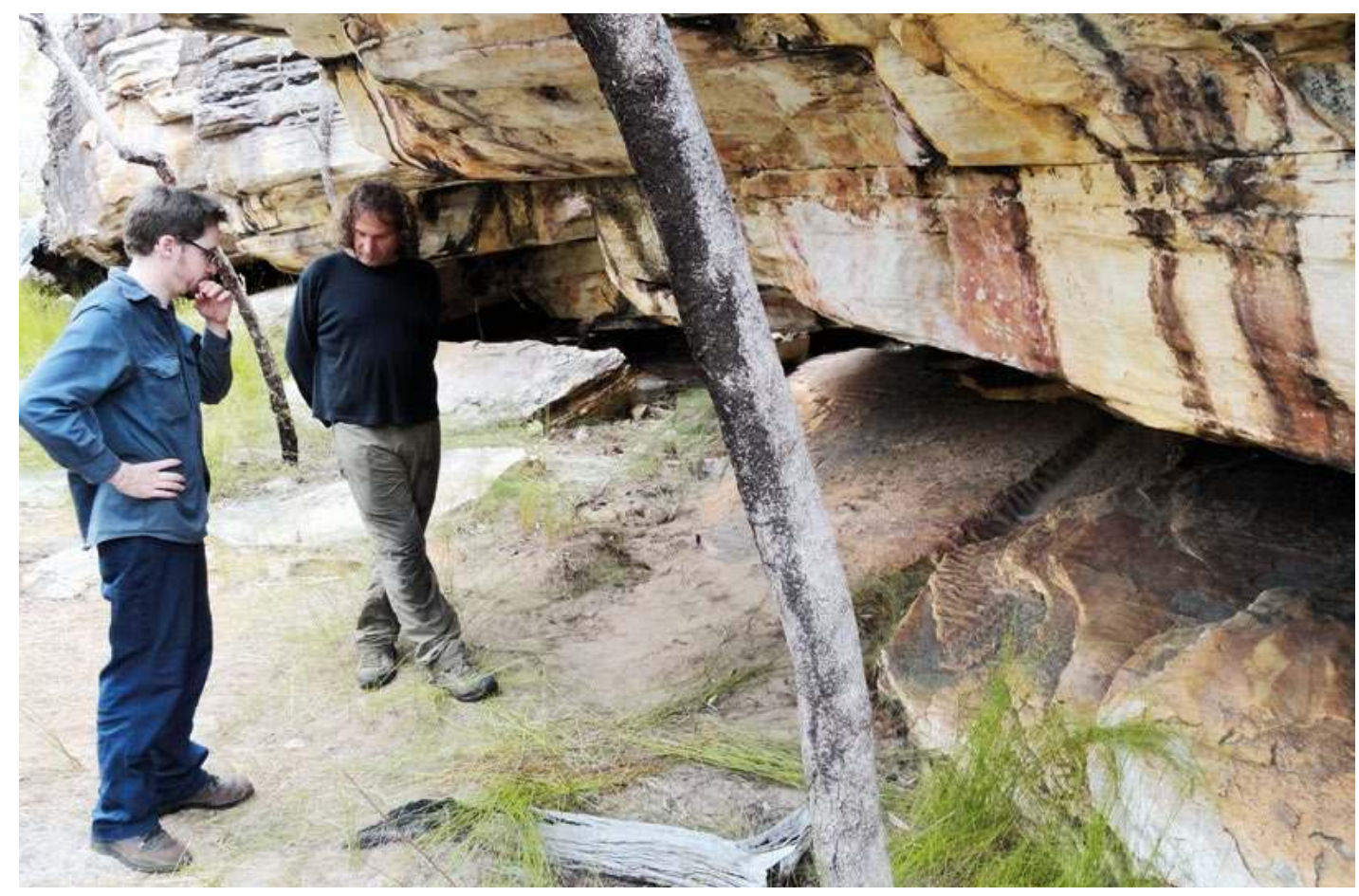

Figure 13.4 Evidence of water flow at ground level and along the eastern wall adjacent to Panel A5. Source: Photograph by Chris Urwin.

Aiming to contextualise the rock art, our choice of where to excavate took into account site formation processes in the broader environment. The present shelter cavity was formed by the collapse of layers of rock near the northern margin of the site. Today, the shelter has a wide, northwesterly to northeasterly aspect (Figure 13.5). The eastern rock face delimiting the edge of the shelter has undergone wall and ceiling collapse, with individual collapsed layers of rock now creating a sloping, rocky floor angled c. $30^{\circ}$ to horizontal (Figures 13.2 and 13.6). Here paintings on the outer rock face are found up to c. 1.0-1.5 $\mathrm{m}$ above ground; they also occur on the ceiling above the sloping rock floor. In contrast, the paintings on the western, outer wall are raised up to c. $4 \mathrm{~m}$ above ground, considerably higher than on the eastern outer wall, with roof and wall collapse forming a rocky shelf that fronts the western outer wall (Figures 13.7 and 13.8). Overhanging layers of rock form a mini-ceiling over some of the western wall, offering some protection from the elements, but overall it is quite exposed. Numerous paintings are found on the western rock face and on this secondary ceiling. 


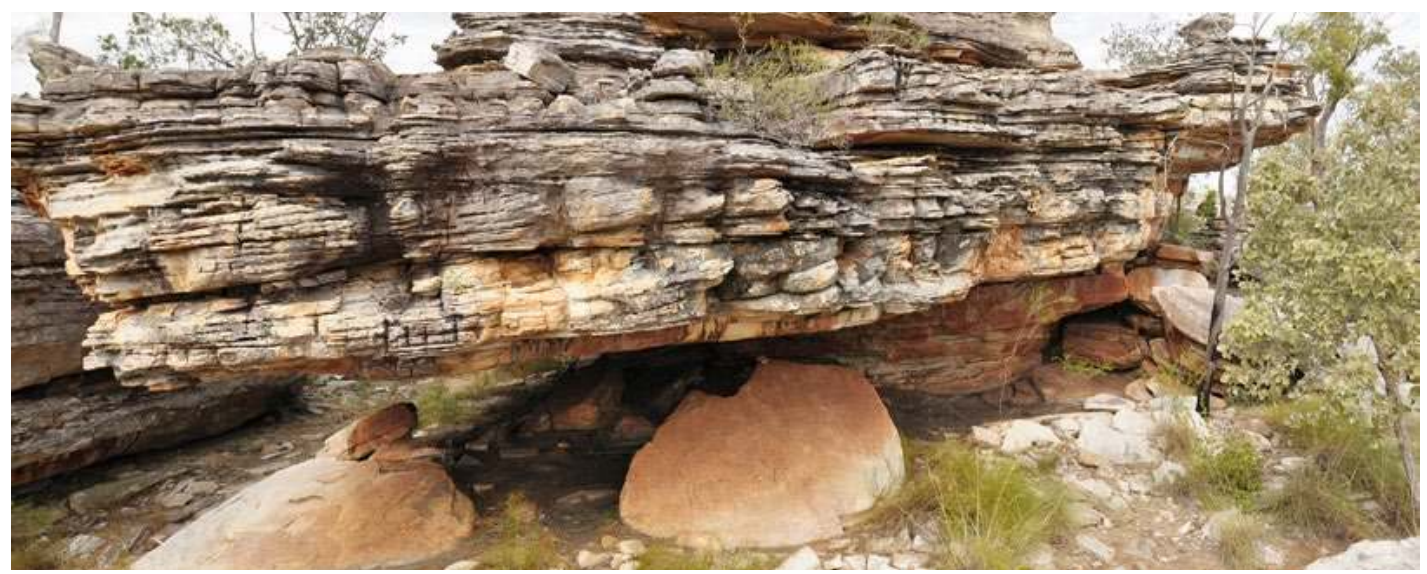

Figure 13.5 Dalakngalarr 1, looking south.

Source: Photograph by Daniel james.

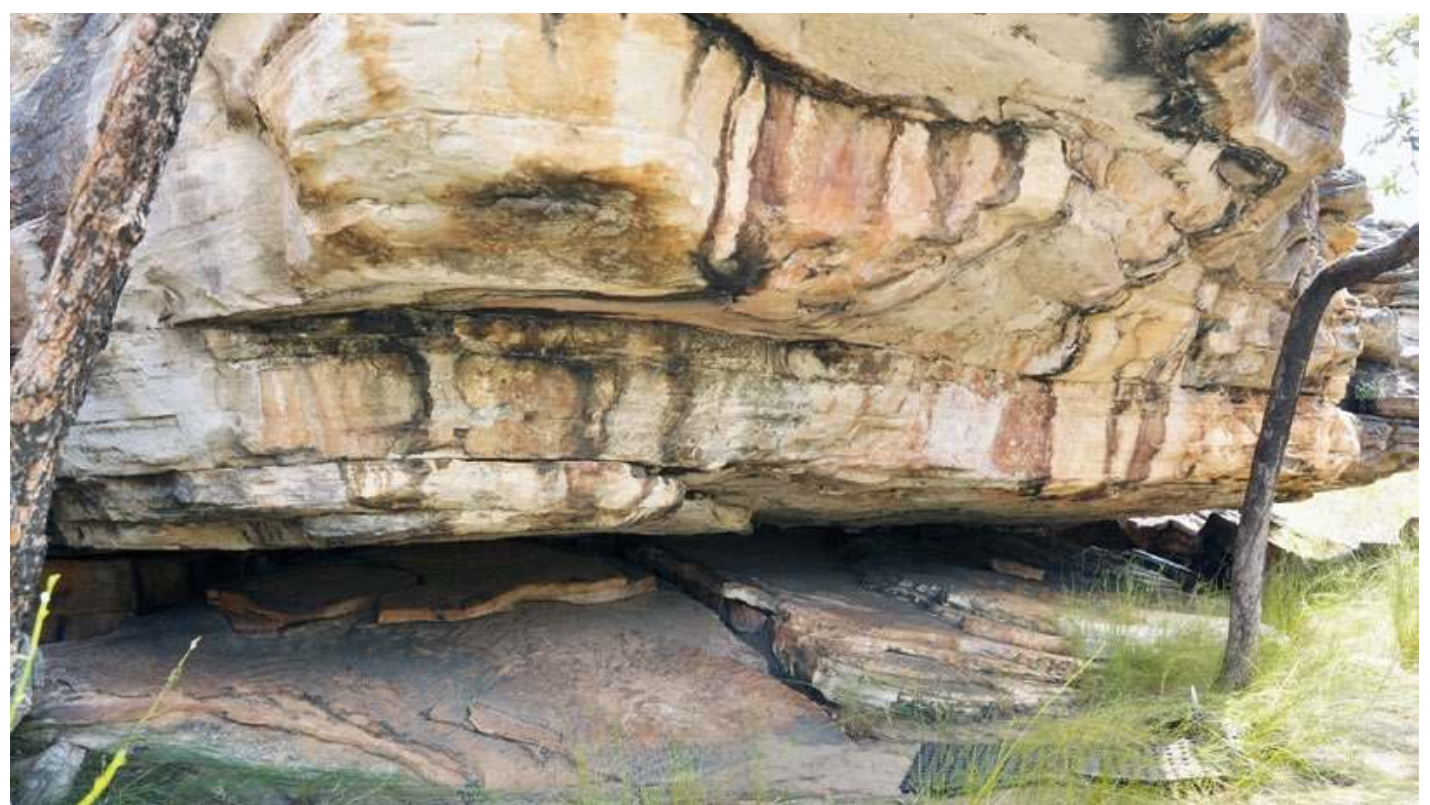

Figure 13.6 Eastern wall showing evidence of ceiling collapse at ground level, looking northwest. Source: Photograph by Daniel James.

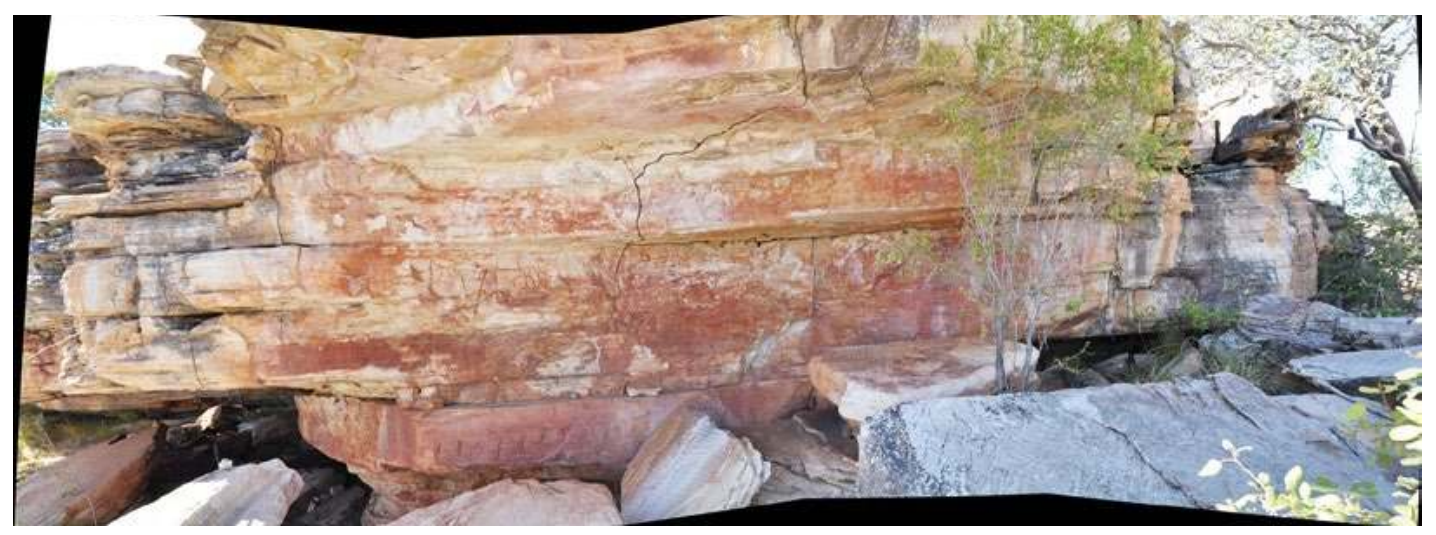

Figure 13.7 Stitched panorama of the western outer wall, looking east-southeast. Source: Photograph by Daniel james. 
Dalakngalarr 1 lies within the coarse-grained and at times pebbly sandstone and quartzite outcrops that occur within the Marlgowa Sandstone unit of the Kombolgie Formation (Ferenczi and Sweet 2004). Many parts of the shelter where finer-grained quartzite is exposed have been heavily quarried for stone tools. There is also evidence of flaking activity on fallen boulders and rock slabs. Many of the rock collapses on the shelter floor have resulted in the creation of surfaces suitable for walking or sitting, and many of these have been worn smooth (Figure 13.8).

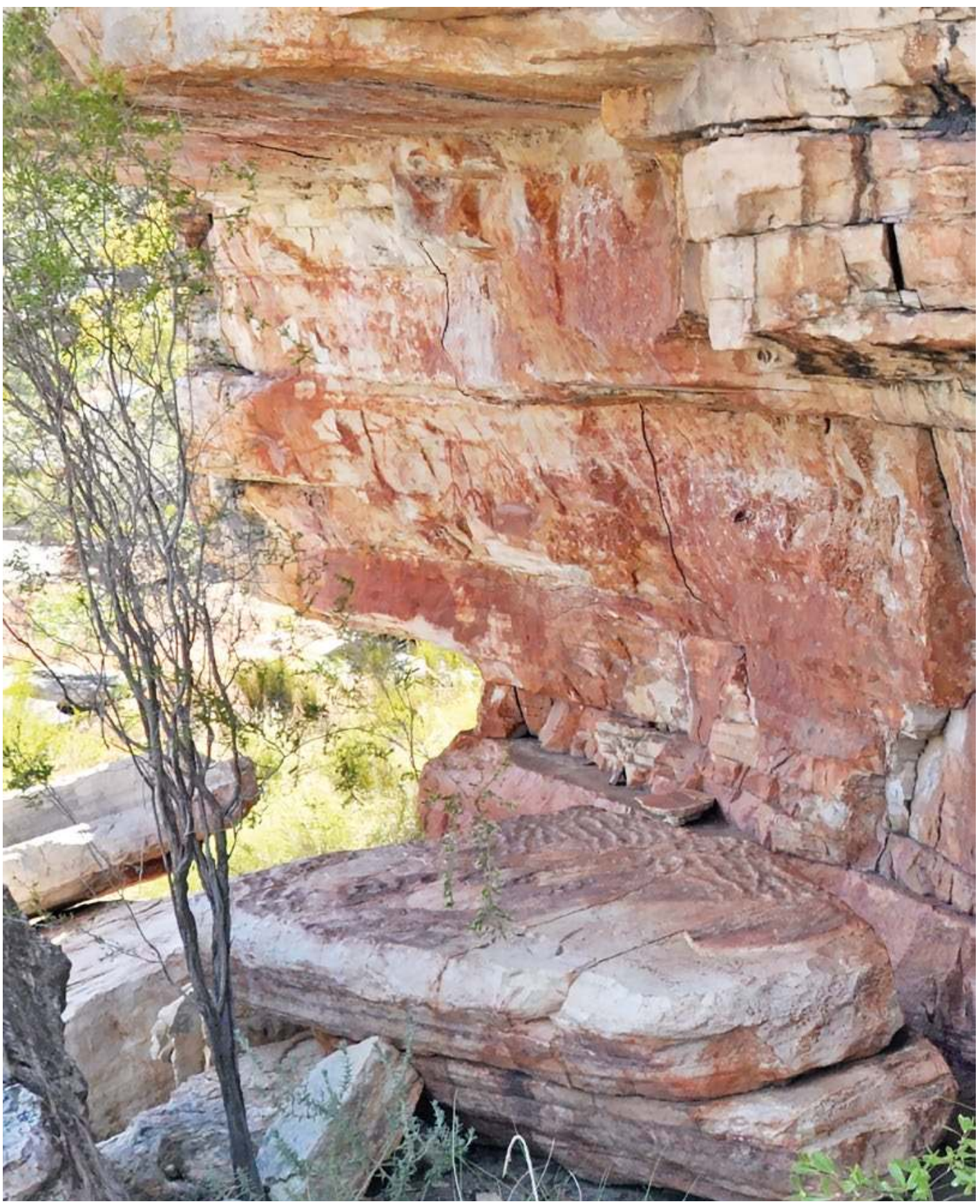

Figure 13.8 Western wall in a part of the site well protected from the elements and cool in the afternoon.

The large slab in the foreground, from the collapsed ceiling, is now elevated above ground level and worn smooth. Source: Photograph by Daniel James. 
In the early dry season months from May to July, the shelter enjoys the following daily rhythm: the easternmost wall is exposed to direct sunlight throughout the morning hours, peaking towards the middle of the day. From around midday onwards, the western wall becomes increasingly exposed to sunlight until c. 5-6 pm when direct light reaches the entire wall. The western wall is more protected from the elements, particularly wind and rain coming from the east to southeast. The shelter interior is generally well protected from conditions affecting both the eastern and western outer walls. As a result, the floor under the overhang is well preserved; it contains rich cultural deposits that have been darkened by fires lit by people (Figure 13.9).

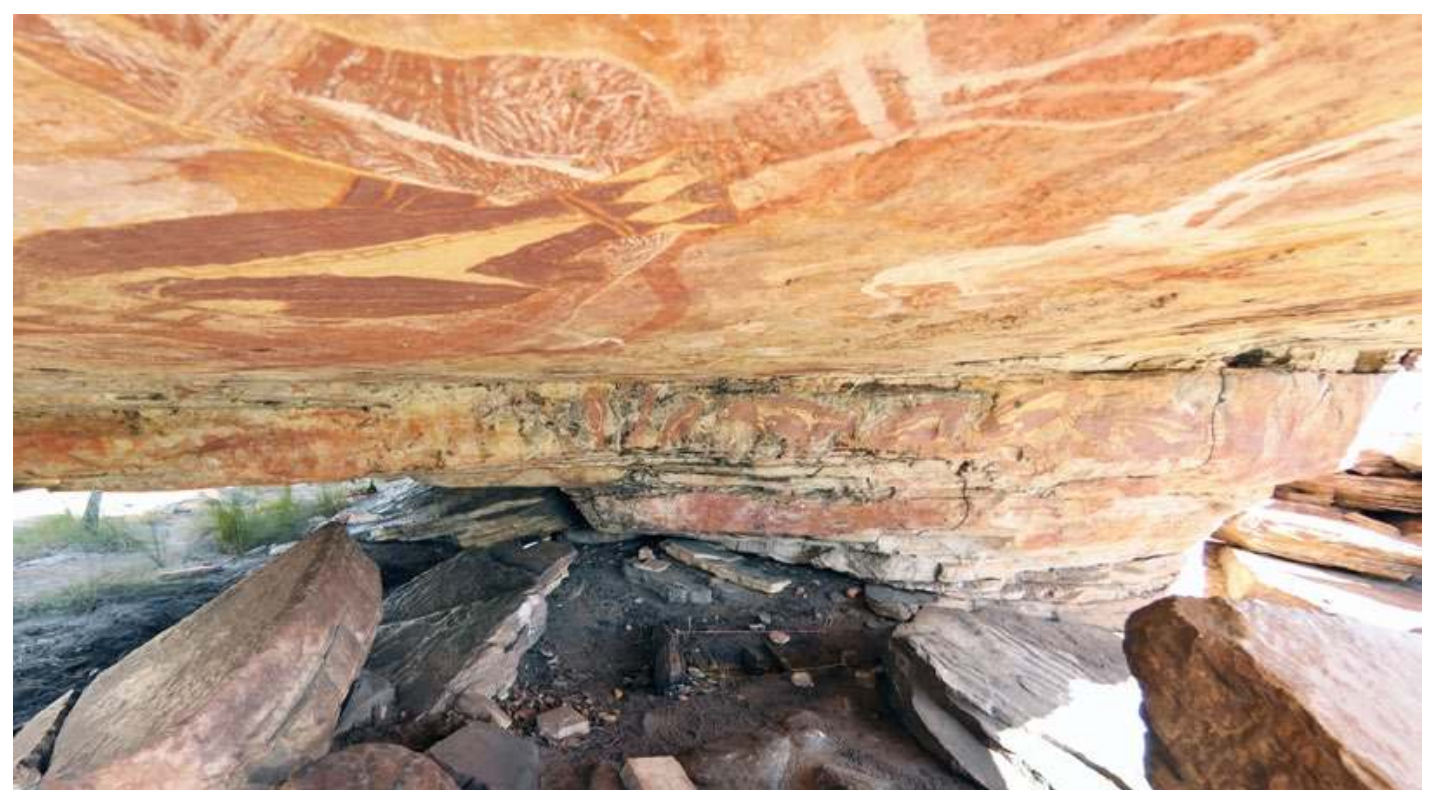

Figure 13.9 Shelter interior, looking south.

Source: Photograph by Daniel James.

The interior of the shelter is dominated by X-ray paintings in various reds and yellows, with a number of fish taxa (including saratoga, barramundi and eel-tailed catfish) and macropods represented (see Figure 13.10). Paintings are also found on some boulders under the overhang, but never as X-ray depictions. Stone artefacts are abundant on the ground just outside the shelter, as is a large volume of collapsed rock ceiling debris in part caused by quarrying of the wall. Some of the rock debris has been moved from its original position by people in times past (cf. Delannoy et al. 2013).

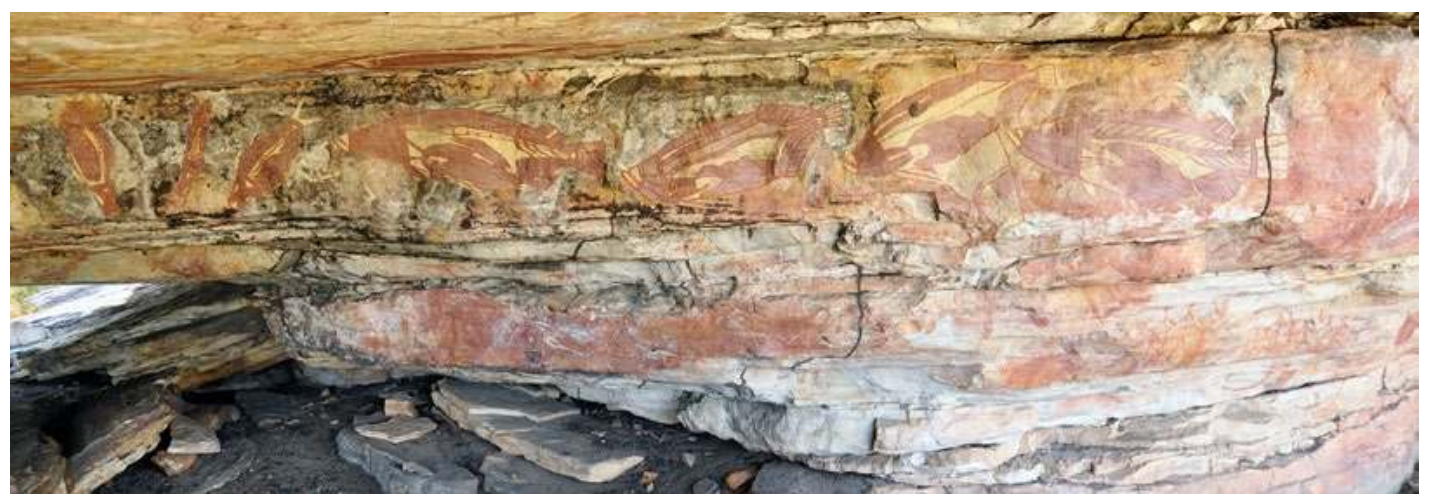

Figure 13.10 The X-ray paintings that dominate the back wall.

Source: Photograph by Daniel James. 


\section{Geophysics}

A number of natural and cultural processes such as pedogenesis, chemical weathering, burning and the addition of ochre can enhance the magnetic properties of sediments. Due to their strong association with anthropogenic fires, magnetic signals have the potential to be used as a proxy for mapping the spatial and temporal distribution of human occupation (e.g. Herries and Fisher 2010) through both field (Dalan 2007) and laboratory (Dalan and Banerjee 1998) studies. These techniques, particularly the analysis of the magnetic properties of sediments from excavations, have often been applied to rockshelter investigations, including occasionally in Australia (Lowe 2014; Marwick 2005). Far less common is the use of field magnetometry as a tool to investigate patterns of occupation in caves and rockshelters, although such methods have significant potential to map the spatial patterning of occupation within a site.

In order to investigate such spatial patterning at Dalakngalarr 1 , we have measured the magnetisation of sediments across much of the rockshelter floor using a Geometrics G-856 proton precession magnetometer. The survey was undertaken using measuring tapes for positioning and employed a $1 \mathrm{~m}$ line and $0.5 \mathrm{~m}$ station spacing. Data were corrected for drift with reference to a base station, de-spiked and processed using Magpick software before being overlain on the site plan, with magnetic intensity values plotted in nanoteslas (nT) showing magnetic highs in black and magnetic lows in white with a contour interval of $20 \mathrm{nT}$ (Figure 13.11).

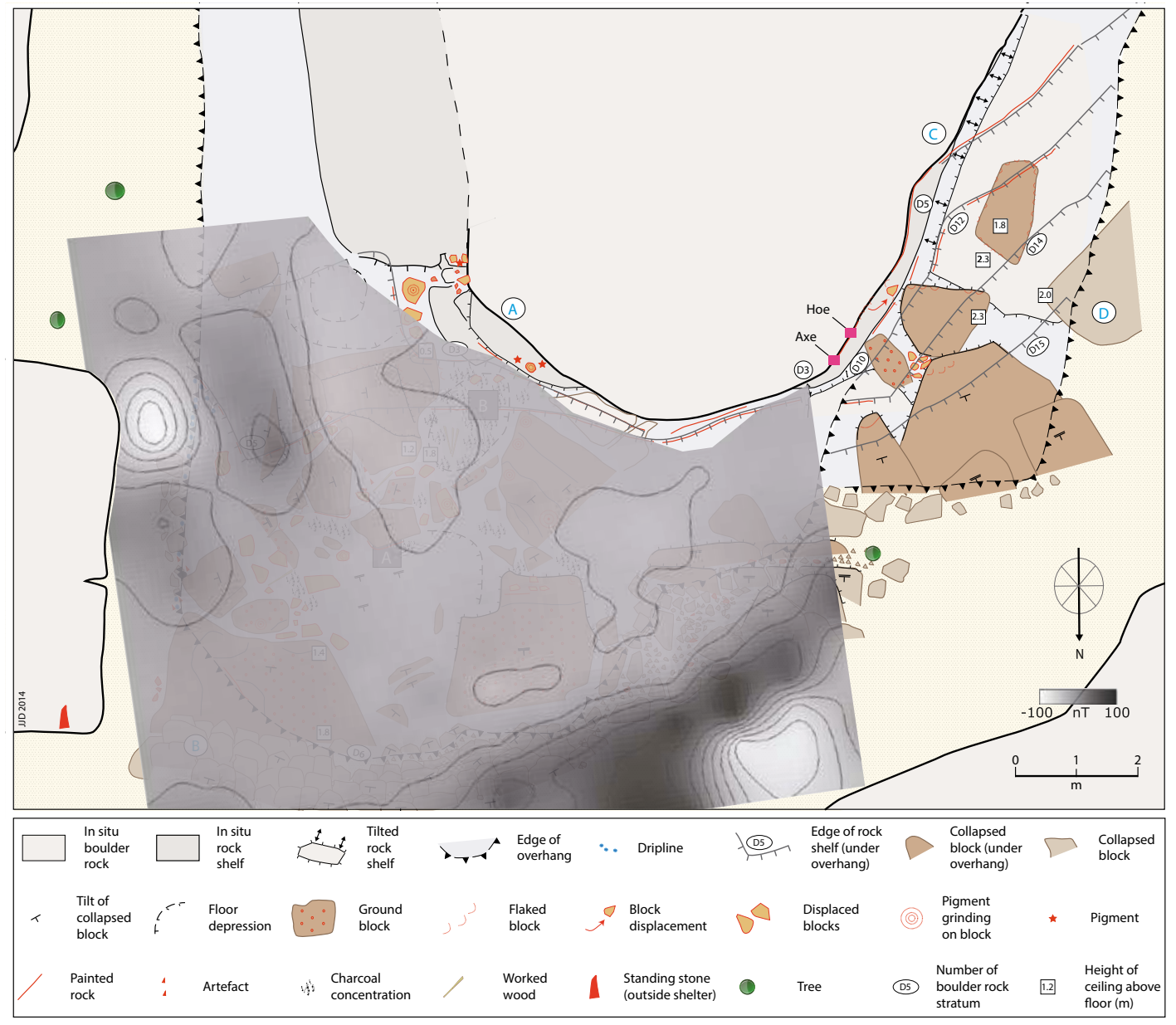

Figure 13.11 Plan of Dalakngalarr 1 showing magnetic intensity, with relative magnetic highs in black and relative magnetic lows in white.

Source: Illustration by lan Moffat and Jean-Jacques Delannoy. 
The results show that the area immediately beneath the dripline is associated with increased magnetism in all areas where this coincides with reasonably soft sediments rather than roof fall. There are areas of decreased magnetism immediately to the north, west and southeast of the dripline. The enhanced magnetism suggests that the area coincident with the dripline is either a locus of human occupation or, more likely, has the optimum combination of a suitable weathering regime, supply of organic materials and burning for magnetic enhancement. The magnetic lows may represent the background magnetic value of non-magnetic sediments sourced from the Marlgowa Sandstone (Ferenczi and Sweet 2004) of the Kombolgie Subgroup (Lane et al. 2007) that hosts the site.

Results from inside the shelter have a far more restricted range of magnetic values. Two clear trends are nevertheless apparent: areas of the shelter floor that have 1) blocks of roof fall; or 2) soft sediments adjacent to the back (south) of the shelter have lower levels of magnetic enhancement than sediments elsewhere in the site. This indicates both the inability of occupation to enhance bedrock magnetism and the probable lower intensity of occupation at the back of the shelter where the roof is closer to the ground. The extensive amount of roof fall at Dalakngalarr 1 precludes a more rigorous analysis of the spatial distribution of the magnetic signal within the major occupation area.

Further magnetic analyses at Dalakngalarr 1 are in progress, including magnetic susceptibility measurements, anhyseretic remanent magnetisation, saturation isothermal remanent magnetisation, hysteresis loops and high and low magnetic temperature magnetic measurements of the sediments from excavations. The results of these investigations will define the source of magnetism in the rockshelter sediments and enable us to explore its changes over time.

\section{The excavations}

These observations prompted archaeological excavations in what appeared from surface clues to be the thickest soft deposits of the shelter's interior (Figures 13.2, 13.12 and 13.13). Permission to excavate was provided by Traditional Owner and Buyhmi clan Elder Margaret Katherine, both directly and formally through the Jawoyn Association. Due to the relatively small exposed space between boulders inside the shelter, it was decided that two separate $50 \times 50 \mathrm{~cm}$ excavation squares (Squares A and B) would be opened, to help give an archaeological context to the rock art, in particular that of the European-contact period (see below), the X-ray art (Figure 13.10), the macropod painting on a boulder on the floor (Figure 13.14) and the paintings on the main ceiling (e.g. Figures 13.15).

Square A was positioned toward the middle of the shelter, c. $3.5 \mathrm{~m}$ inside the northern entrance (Figure 13.2). It was placed against a boulder collapsed from the ceiling, the northern, exposed face of which was subsequently painted with a red-infill macropod (Figures 13.13 and 13.14). Above the painted boulder the ceiling's surface is staggered rather than smooth, marked by negative scars of past collapses (Figure 13.16). In this part of the site, the dark sandy ground is littered with charcoal and leaf litter, indicating a likely area of inhabited space. We hoped to date the rock collapse event that brought down the boulder, now partly buried, on which the red macropod was then painted. 


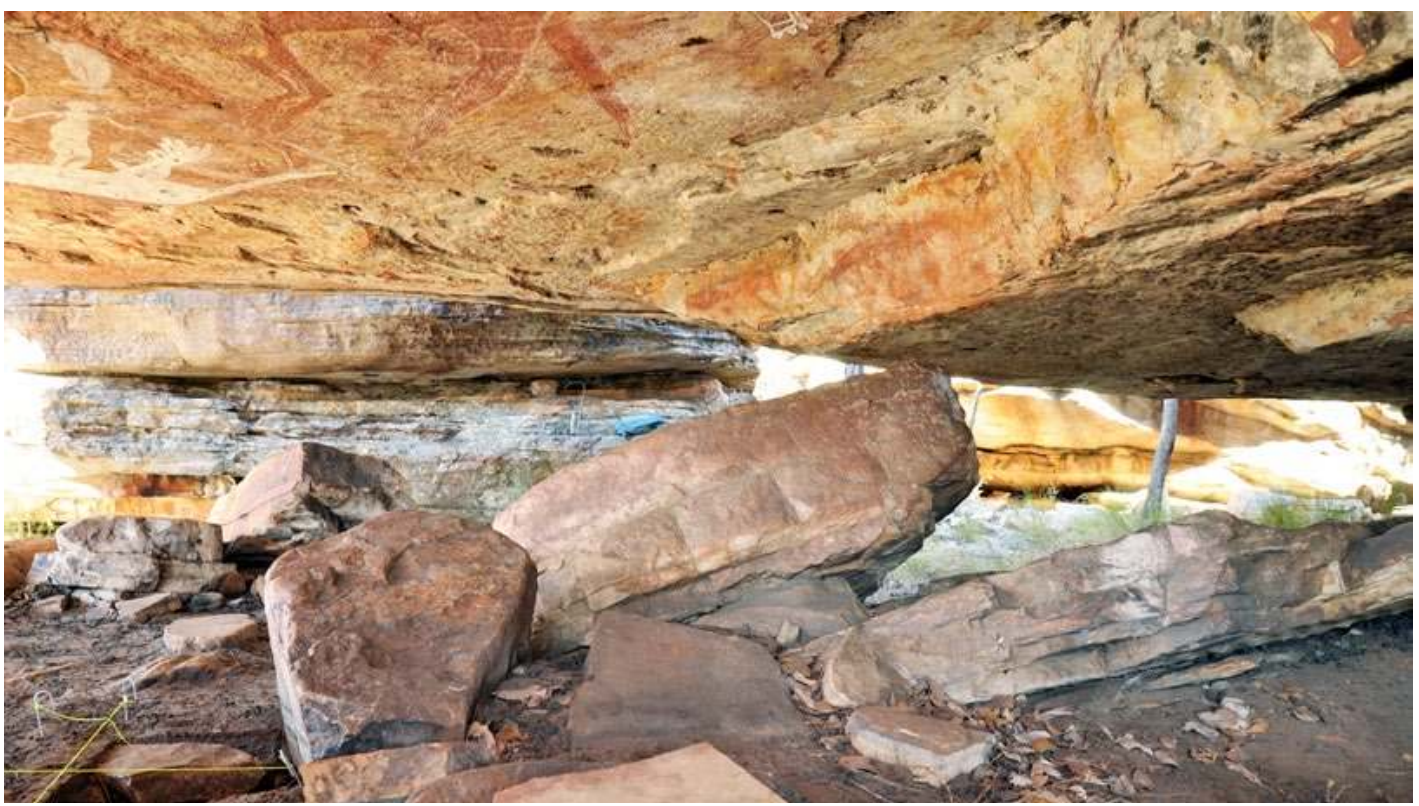

Figure 13.12 View from western side inside the shelter, looking eastward across Square A.

Source: Photograph by Daniel James.

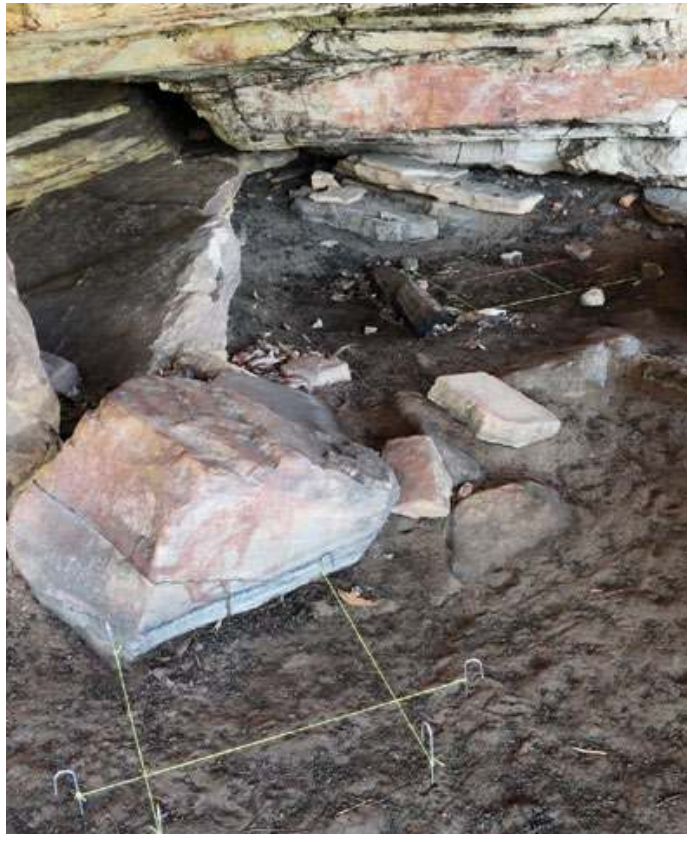

Figure 13.13 Square A (front) and Square B (rear) inside the shelter, prior to excavation. Source: Photograph by Daniel James.

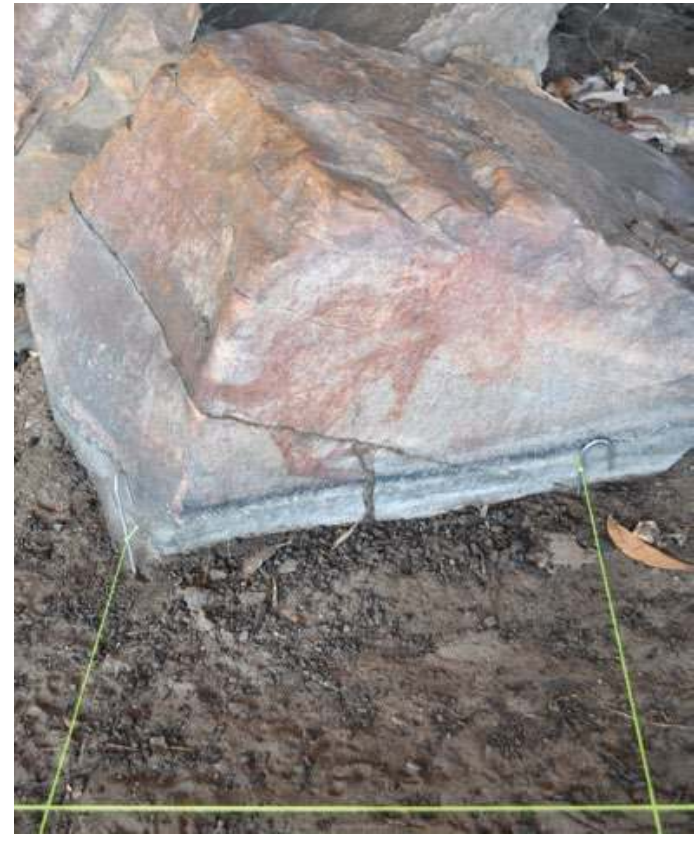

Figure 13.14 Square A prior to excavation, positioned against the boulder with painted macropod.

Source: Photograph by Bruno David. 


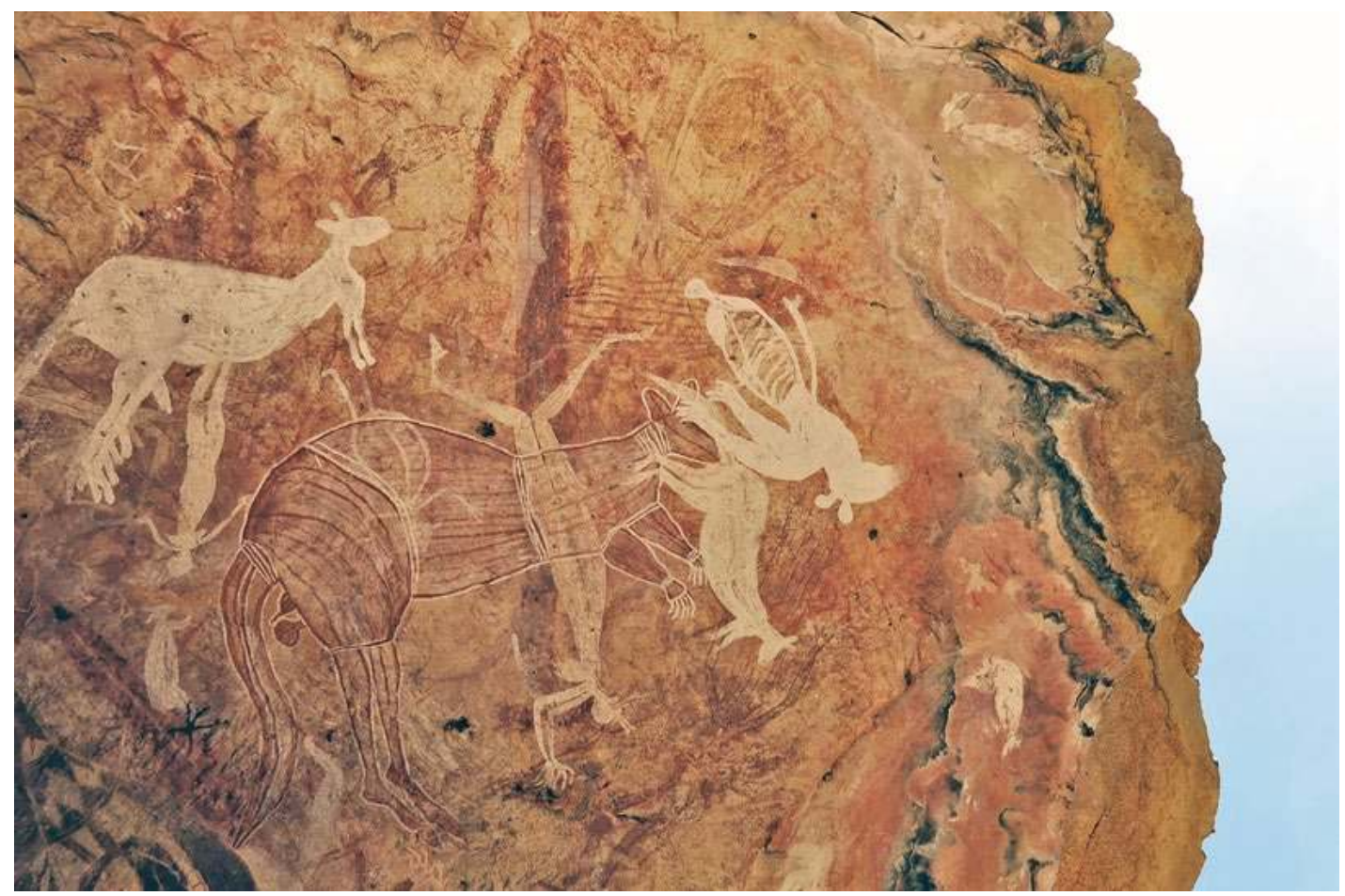

Figure 13.15 Rock art on the main ceiling.

Source: Photograph by Daniel James.

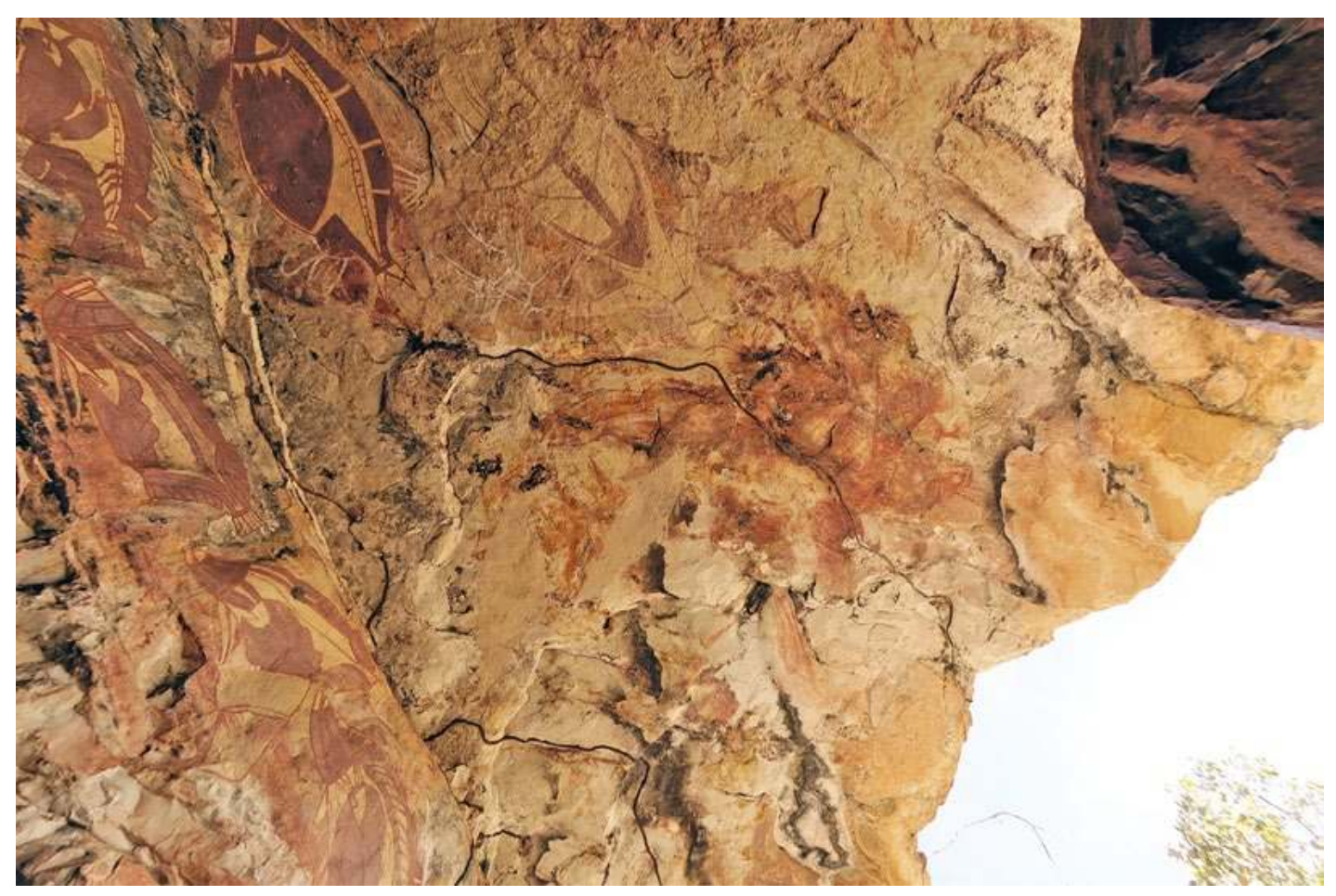

Figure 13.16 Staggered ceiling surface, indicating a history of collapse.

Source: Photograph by Daniel James. 
Square B was positioned c. $2.5 \mathrm{~m}$ to the southwest of Square A, in an area of darkened surface sediments close to the rear wall and adjacent to a partially burned log with cut marks made by a metal blade; it had potential to produce buried materials from the European-contact period associated with the cut $\log$ (Figures 13.2, 13.13, 13.17 and 13.18). Square B might also contain buried exfoliated or otherwise detached pieces of painted rock, by stratigraphic association giving ages for the deposition of the decorated rocks, and thereby minimum ages for the art, as the ceiling and rear wall in this part of the shelter are heavily painted (Figure 13.19).

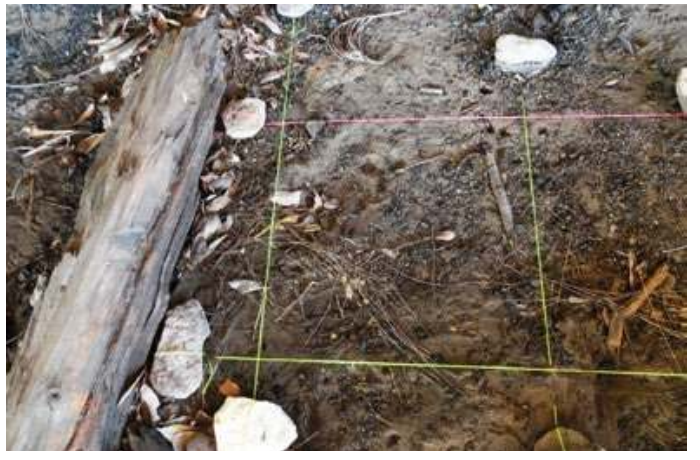

Figure 13.17 Square B prior to excavation.

Note the log with metal blade cut marks immediately to the left (east) of the excavation square. The pink string represents the south side of the square.

Source: Photograph by Daniel James.

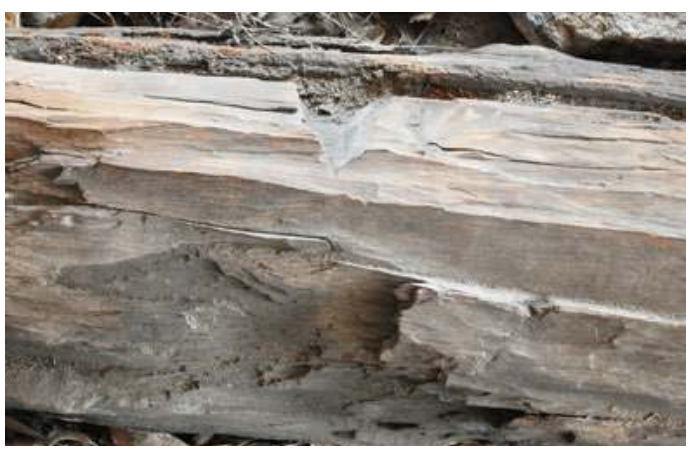

Figure 13.18 Details of metal blade cut marks on hardwood log near Square B.

Source: Photograph by Bruno David.

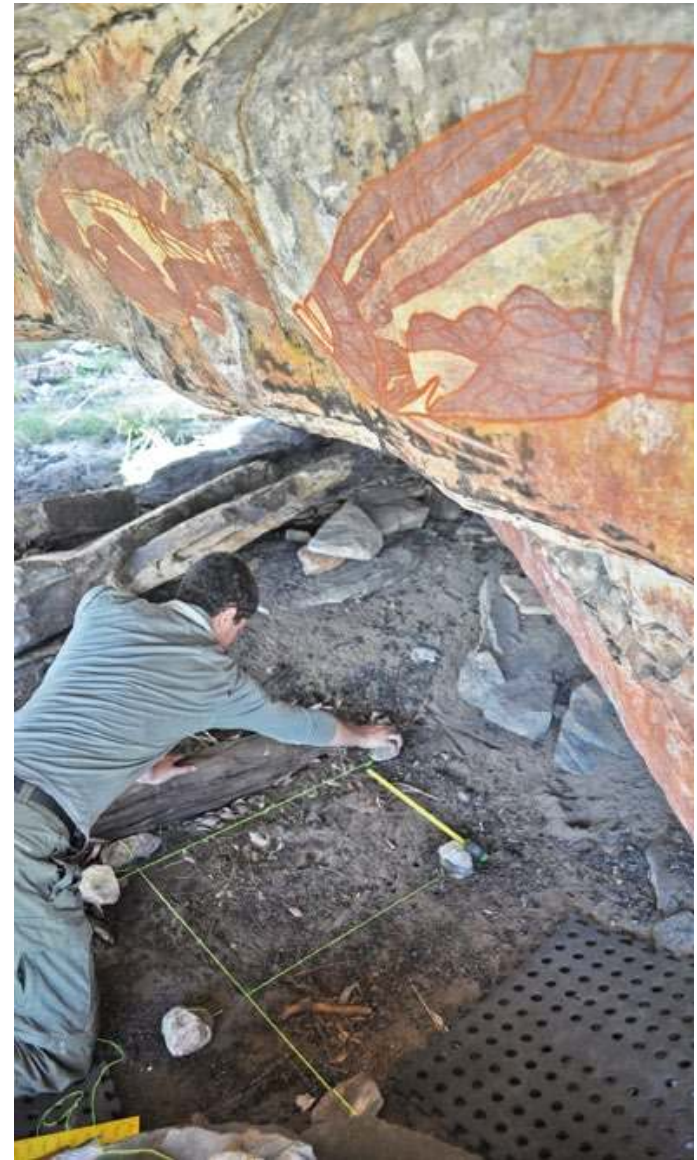

Figure 13.19 Chris Urwin stringing up Square B prior to excavation.

Source: Photograph by Bruno David.

The two squares were excavated in arbitrary units (XUs) following the stratigraphy where observed. The mean thickness of XUs was $2.9 \mathrm{~cm}$ for Square A and $1.3 \mathrm{~cm}$ for Square B. Unsieved sediment samples weighing 50-100 g were taken from each XU, the remaining excavated sediments being dry-sieved in $2 \mathrm{~mm}$ mesh over a tarpaulin some $40 \mathrm{~m}$ away. The sieved material was doublebagged on-site, packaged and shipped to Monash University for sorting and analysis.

The position of artefacts $\geq 2 \mathrm{~cm}$ long observed during excavation was recorded in three-dimensions (3-D); these artefacts were then individually bagged. A small number of charcoal pieces were also selectively sampled for 3-D recording and individual bagging from each XU. Some of these charcoal samples were then submitted for AMS radiocarbon dating. Field photographs were taken at the base of each $\mathrm{XU}$, and photographs and section drawings were made of wall profiles at the completion of excavation. The bulk-bagged excavated materials retained in the sieves were subsequently wet-sieved at Monash University, again using a $2 \mathrm{~mm}$ mesh sieve. The material 
was then air-dried for 3-5 days, rebagged and stored under controlled laboratory conditions (Figure 13.20). All excavated materials were minimally handled during excavation, sieving and laboratory sorting and analysis.

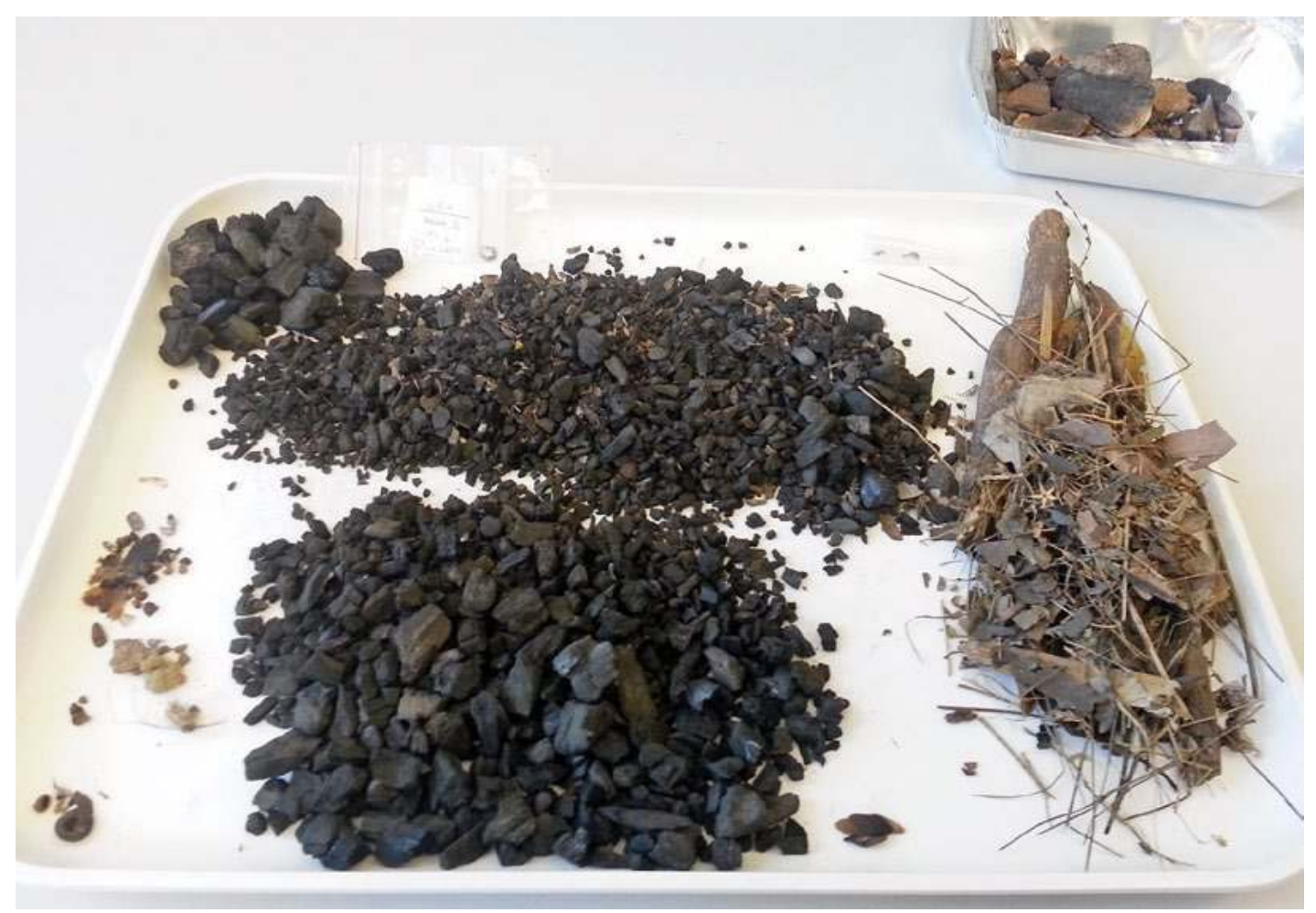

Figure 13.20 Sorting in progress, excavated materials from Square B XU1.

Source: Photograph by Bruno David.

\section{Square A results}

Square A was excavated to a maximum depth of $20 \mathrm{~cm}$, within which three major stratigraphic units (SUs) were identified (Tables 13.3 and 13.4; Figure 13.21). The topmost SU1 (excavated as XU1) consists of loose surface sediments containing charcoal and stone artefacts. Live and deceased insects are frequent in this layer, with antlions (Myrmeleontidae) being the most notable. Antlion nymphs live in soft sandy soil, making small and shallow cone-shaped pits into which ants and other soil arthropods fall and get eaten. The pits created by the nymphs have a depth of c. $2 \mathrm{~cm}$, causing limited impacts on the site's stratigraphy (Valerie Caron, pers. comm. to Daniel James 2013). The bulk of cultural materials came from SU2 (excavated mainly as XU2XU4), including three heavily rusted conjoining nail-like metal pieces recovered from the top of SU2 (Table 13.5). Limited debris from ceiling rock collapse was evident from XU2 (in SU2) downwards, but in SU3 large rocks from ceiling collapse appear in earnest. This culminated in XU7 at the base of SU3, a very rocky level spanning the entire width of the square and thus left in situ. At the base of XU7, only a narrow fissure some $7 \mathrm{~cm}$ wide remained exposed between what appears to be a split rock slab. That narrow fissure was filled with soft sandy sediments including charcoal. Exposed rock near the base of SU3 predominantly lies flat (Figures 13.21 and 13.22). The rock fissure signalled that further soft sediments occur below the large rocks at the base of the excavation: bedrock had not been reached. The base of the large boulder with the red-painted macropod that marked the southern edge of Square A was encountered in XU6 within mid-levels of SU3. There was no sediment between the bottom of that boulder and the top of the flat rock 
surface on which it lay. The boulder with the macropod painting thus fell into place sometime after XU7 had been fully laid down, and after XU6 sediments had begun to deposit (see below for dating). The red macropod was painted sometime after that.

Table 13.3 Details of Excavation Units, Dalakngalarr 1, Square A.

\begin{tabular}{|l|c|r|r|r|r|r|r|r|}
\hline XU & SU & $\begin{array}{c}\text { Mean depth } \\
\text { at top }(\mathbf{c m})\end{array}$ & $\begin{array}{c}\text { Mean depth at } \\
\text { centre }(\mathbf{c m})\end{array}$ & $\begin{array}{c}\text { Mean depth } \\
\text { at base }(\mathbf{c m})\end{array}$ & $\begin{array}{c}\text { Mean thickness } \\
(\mathbf{c m})\end{array}$ & $\begin{array}{l}\text { Area } \\
\left(\mathbf{m}^{2}\right)\end{array}$ & Weight $(\mathbf{k g})$ & $\begin{array}{l}\text { Volume } \\
(\text { litres })\end{array}$ \\
\hline 1 & 1 & 0.0 & 0.4 & 0.8 & 0.8 & 0.22 & 2.0 & 1.5 \\
\hline 2 & 2 & 0.8 & 1.4 & 1.9 & 1.1 & 0.19 & 2.5 & 2.5 \\
\hline 3 & 2 & 1.9 & 2.5 & 3.0 & 1.1 & 0.18 & 2.7 & 2.5 \\
\hline 4 & $2+3$ & 3.0 & 3.9 & 4.8 & 1.8 & 0.16 & 3.7 & 3.0 \\
\hline 5 & $2+3$ & 4.8 & 6.2 & 7.5 & 2.7 & 0.16 & 5.6 & 4.0 \\
\hline 6 & 3 & 7.5 & 10.6 & 13.7 & 6.2 & 0.03 & 25.3 & 16.0 \\
\hline 7 & 3 & 13.7 & 16.9 & 20.0 & 6.3 & 0.02 & 1.2 & 1.0 \\
\hline
\end{tabular}

SU numbers in bold indicate that most of the square is taken up by those SUs.

Source: Authors' data.

Table 13.4 Stratigraphic Units, Dalakngalarr 1, Square A.

\begin{tabular}{|l|l|}
\hline SU & Description of sediments \\
\hline 1 & $\begin{array}{l}\text { Dark grey to dark grey-brown, loose surface ashy sand. Stone artefacts present. Organic matter present in the form } \\
\text { of wind-blown leaves; charcoal pieces up to } 2 \mathrm{~cm} \text { in length are abundant. Small insects present. Interface with SU2 } \\
\text { is marked. }\end{array}$ \\
\hline 2 & $\begin{array}{l}\text { Dark grey to dark grey-brown, slightly compact and consolidated sandy sediments. Stone artefacts continue to be } \\
\text { present. Small, fibrous rootlets are common, with charcoal pieces continuing to be abundant. Interface with SU3 } \\
\text { is marked. }\end{array}$ \\
\hline 3 & $\begin{array}{l}\text { Grey to dark grey sandy loam, slightly more humid than SU2 at the time of excavation. In upper levels of SU3, } \\
\text { stone artefacts are more numerous than in su2. Small, fibrous rootlets continue to appear but are less frequent } \\
\text { with depth. Sediments are moderately compact and well consolidated. At base of su3, including the crack between } \\
\text { flat rocks, frequency of both stone artefacts and charcoal decreases. }\end{array}$ \\
\hline
\end{tabular}

Source: Authors' data.

Table 13.5 List of excavated materials by XU, highlighted by SU, Dalakngalarr 1, Square A.

\begin{tabular}{|c|c|c|c|c|c|c|c|c|c|c|c|}
\hline \multirow[t]{2}{*}{$X U$} & \multirow[t]{2}{*}{ SU } & \multirow[t]{2}{*}{ Charcoal (g) } & \multicolumn{2}{|c|}{ Stone artefacts } & \multicolumn{2}{|c|}{ Ochre } & \multicolumn{2}{|c|}{$\begin{array}{l}\text { Metal } \\
\text { pieces }\end{array}$} & \multirow[t]{2}{*}{$\begin{array}{l}\text { Insects } \\
\text { (g) }\end{array}$} & \multirow{2}{*}{$\begin{array}{l}\text { Roots and } \\
\text { other plant } \\
\text { matter }(\mathrm{g})\end{array}$} & \multirow{2}{*}{$\begin{array}{l}\text { Scat from } \\
\text { unidentified } \\
\text { fauna }(g)\end{array}$} \\
\hline & & & $\#$ & $g$ & $\#$ & $g$ & $\#$ & $g$ & & & \\
\hline 1 & 1 & 159.87 & 101 & 16.09 & & & & & 0.02 & 3.58 & 2.59 \\
\hline 2 & 2 & 109.75 & 73 & 9.28 & & & 2 & 1.04 & 0.03 & 1.83 & \\
\hline 3 & 2 & 72.22 & 83 & 44.67 & & & 1 & 0.45 & 0.03 & 3.24 & \\
\hline 4 & $2+3$ & 63.87 & 147 & 32.88 & & & & & 0.03 & 9.44 & \\
\hline 5 & $2+3$ & 65.47 & 246 & 806.81 & 1 & 0.58 & & & 0.01 & 5.88 & \\
\hline 6 & 3 & 40.16 & 132 & 339.44 & 1 & 36.2 & & & 0.02 & 25.99 & \\
\hline 7 & 3 & 0.05 & & & & & & & & & \\
\hline \multicolumn{2}{|c|}{ Total } & 511.39 & 782 & 1249.17 & 2 & 36.78 & 3 & 1.49 & 0.14 & 50.0 & 2.59 \\
\hline
\end{tabular}

SU numbers in bold indicate that most of the square is taken up by these SUs.

Source: Authors' data.

Stone artefact numbers, and even more so total weights, peaked in XU5 and XU6 in the upper levels of SU3. The only evidence of earth pigments came from this same stratigraphic level that also saw peak artefact numbers (XU5-XU6), indicating a period of heightened site use that included stone artefact flaking and painting activity. No stone artefacts were recovered from the base of the narrow fissure between rocks in XU7, but this could be a function of the very limited surface area covered by the fissure (Table 13.5). 


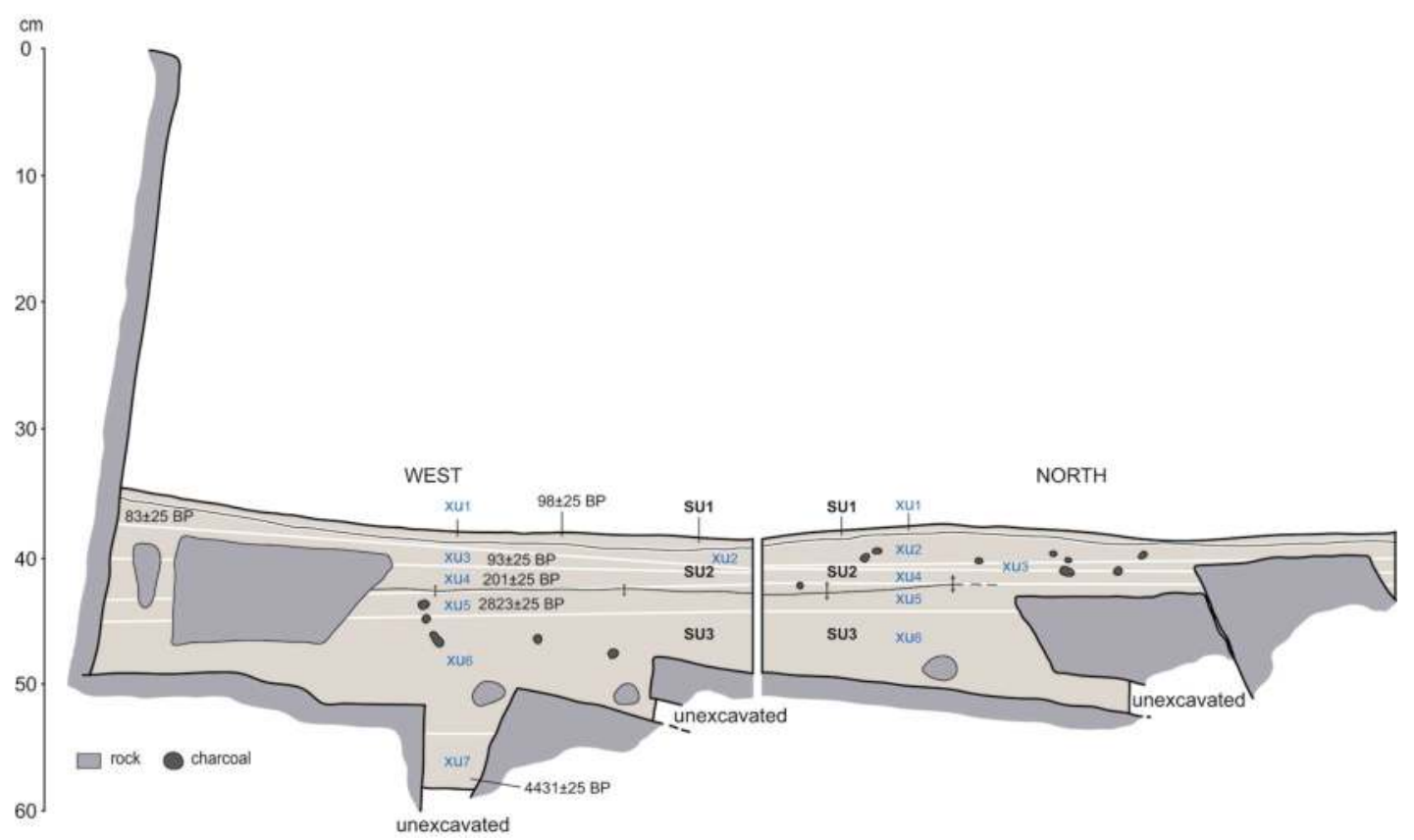

Figure 13.21 West and north sections of Square A, showing back-plotted XUs.

The rock surface that slants near-vertically above the top of the excavated sediments on the western section is the side of the boulder with the red-painted macropod seen in Figures 13.14 and 13.22 .

Source: Illustration by Kara Rasmanis and Bruno David.

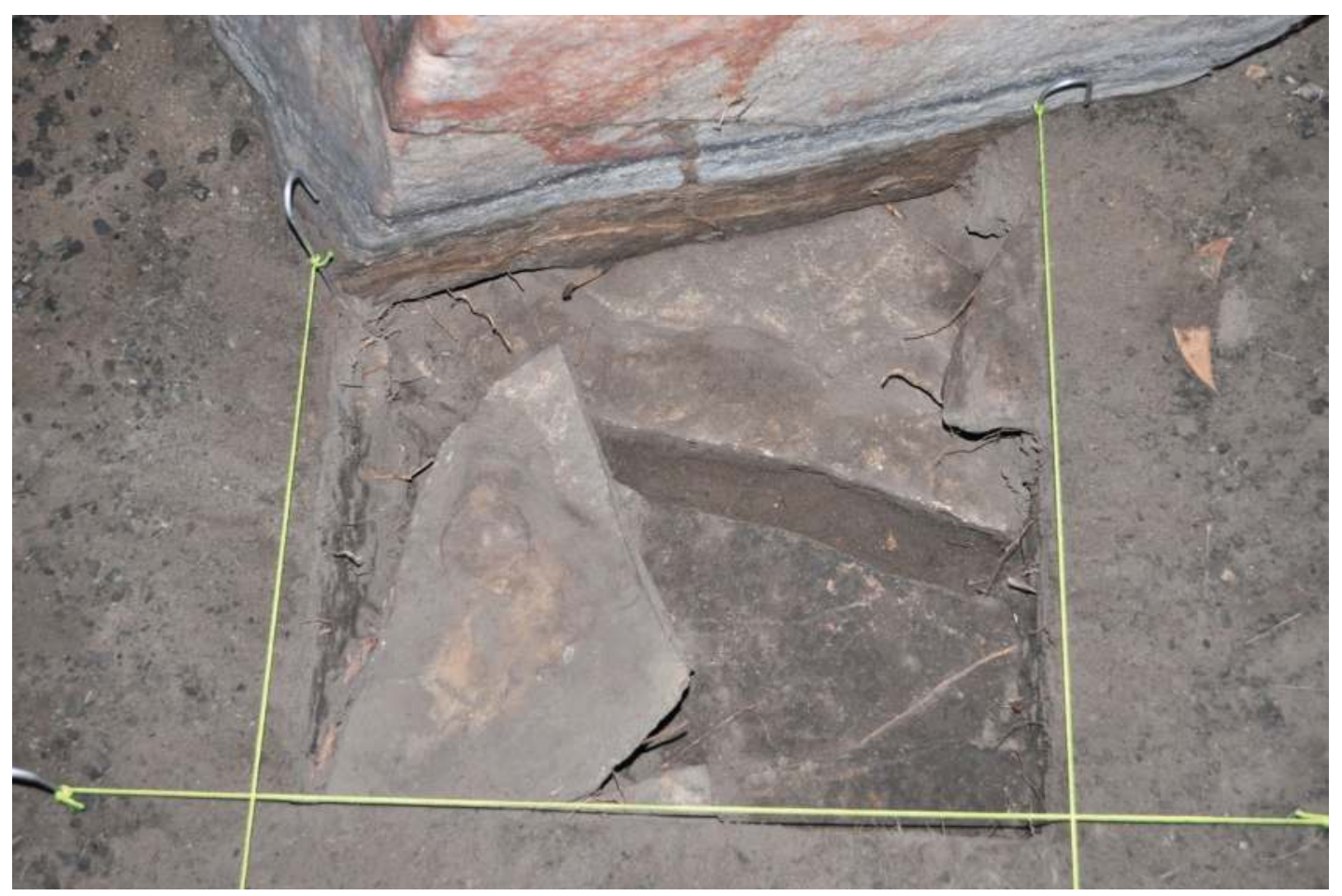

Figure 13.22 Rocks at base of Square A excavation.

Source: Photograph by Bruno David. 


\section{Square B results}

Square B was excavated to a maximum depth of $21 \mathrm{~cm}$ (Table 13.6). It contains five SUs, each homogeneous in colour and texture across the square and down the deposit (Table 13.7; Figure 13.23). The topmost SU1A (excavated as XU1-XU2) consists of disturbed surface sediments. As was the case with Square A, live and dead insects are frequent in this layer, with antlions again being the most notable. A single glass bead was recovered from XU2 at the SU1ASU1B interface. Quantities of stone artefacts are somewhat constant throughout XU1-XU8 in SU1A and SU1B, decreasing markedly in the lower, and older, SU1C and SU1D, beginning with XU9 (Table 13.8). Rocks were relatively sparse until XU9, where bedrock became exposed in the northeastern, northwestern and southwestern parts of the square. From XU8 downwards, disintegrating sandstone pebbles of SU2 became increasingly frequent across the square. The area of disintegrating sandstone became more expansive with depth, until it gave way to bedrock across the entire square in XU16. SU2 is culturally sterile (Figures 13.23 and 13.24).

Table 13.6 Details of Excavation Units, Dalakngalarr 1, Square B.

\begin{tabular}{|c|c|c|c|c|c|c|c|c|}
\hline$X U$ & SU & $\begin{array}{l}\text { Mean depth } \\
\text { at top }(\mathrm{cm})\end{array}$ & $\begin{array}{c}\text { Mean depth at } \\
\text { centre }(\mathrm{cm})\end{array}$ & $\begin{array}{c}\text { Mean depth at } \\
\text { base }(\mathrm{cm})\end{array}$ & $\begin{array}{c}\text { Mean } \\
\text { thickness }(\mathrm{cm})\end{array}$ & $\begin{array}{l}\text { Area } \\
\left(\mathrm{m}^{2}\right) \\
\end{array}$ & $\begin{array}{l}\text { Weight } \\
(\mathrm{kg})\end{array}$ & $\begin{array}{l}\text { Volume } \\
\text { (litres) }\end{array}$ \\
\hline 1 & $1 \mathrm{~A}$ & 0.0 & 0.6 & 1.1 & 1.1 & 0.25 & 2.9 & 2.5 \\
\hline 2 & $1 A+1 B$ & 1.1 & 1.9 & 2.6 & 1.5 & 0.25 & 4.1 & 3.0 \\
\hline 3 & $1 \mathrm{~B}$ & 2.6 & 2.9 & 3.2 & 0.6 & 0.25 & 2.1 & 2.0 \\
\hline 4 & $1 \mathrm{~B}$ & 3.2 & 4.1 & 5.0 & 1.8 & 0.24 & 4.5 & 3.5 \\
\hline 5 & $1 \mathrm{~B}$ & 5.0 & 5.5 & 6.0 & 1.0 & 0.23 & 3.5 & 3.5 \\
\hline 6 & $1 \mathrm{~B}+1 \mathrm{C}$ & 6.0 & 6.9 & 7.9 & 1.9 & 0.22 & 4.8 & 4.0 \\
\hline 7 & $1 B+1 C$ & 7.9 & 8.6 & 9.3 & 1.4 & 0.22 & 3.7 & 3.5 \\
\hline 8 & $1 B+1 C$ & 9.3 & 9.6 & 10.0 & 0.7 & 0.21 & 2.9 & 2.0 \\
\hline 9 & $1 C+1 D+2$ & 10.0 & 10.6 & 11.3 & 1.3 & 0.11 & 3.3 & 2.5 \\
\hline 10 & $1 C+1 D+2$ & 11.3 & 12.1 & 12.9 & 1.6 & 0.13 & 2.1 & 1.5 \\
\hline 11 & $1 C+1 D+2$ & 12.9 & 13.3 & 13.7 & 0.8 & 0.09 & 1.7 & 1.0 \\
\hline 12 & $1 C+1 D+2$ & 13.7 & 14.1 & 14.5 & 0.8 & 0.04 & 3.0 & 2.0 \\
\hline 13 & $1 C+2$ & 14.5 & 15.0 & 15.5 & 1.0 & 0.03 & 2.2 & 1.5 \\
\hline 14 & $1 C+2$ & 15.5 & 15.7 & 15.9 & 0.4 & 0.03 & 2.0 & 1.0 \\
\hline 15 & 2 & 15.9 & 17.8 & 19.8 & 3.9 & 0.01 & 1.5 & 1.0 \\
\hline 16 & 2 & 19.8 & 20.4 & 21.1 & 1.3 & 0.01 & 0.5 & 0.4 \\
\hline
\end{tabular}

SU numbers in bold indicate that most of the square is taken up by those SUs.

Source: Authors' data.

Table 13.7 Stratigraphic Units, Dalakngalarr 1, Square B.

\begin{tabular}{|l|l|}
\hline SU & Description \\
\hline 1A & $\begin{array}{l}\text { Loose, dry, ashy, dark grey to dark grey-brown sand. Disturbed surface sediments. Charcoal is abundant. Some } \\
\text { wind-blown leaves present, but no plants are growing on the site floor. Stone artefacts are present. Interface with } \\
\text { SU1A is gradual. }\end{array}$ \\
\hline 1B & $\begin{array}{l}\text { Loose, dry, ashy, dark grey to dark grey-brown sand. Sediments are slightly more consolidated but otherwise much } \\
\text { like SU1A. Rootlets are present. Stone artefacts are present. }\end{array}$ \\
\hline 1C & $\begin{array}{l}\text { Sediments are very rich in charcoal and more blackish than SU1A or SU1B. SU1C sediments are more consolidated, } \\
\text { more compact ashy sands than overlying sediments. Interface with SU1B takes place over 2-3 cm vertical depth. } \\
\text { Boundary with SU2 is marked. Quantities of stone artefacts are moderate in the uppermost levels of this SU as it } \\
\text { interfaces with SU1B, but rapidly decline at lower levels. }\end{array}$ \\
\hline
\end{tabular}




\begin{tabular}{|l|l|}
\hline SU & Description \\
\hline 10 & $\begin{array}{l}\text { Sediments are much like SU1C but lighter grey ashy sand, although here charcoal is less abundant. Interface with } \\
\text { SU1B and SU1C takes place over 1-2 cm vertical depth. SU1D immediately overlies SU2; SU1D sediments occur } \\
\text { within cracks in the uppermost, fragmenting SU2 sandstone rocks. SU1D is not present across the whole square, } \\
\text { but restricted mainly to its northern half. Small amounts of stone artefacts are present in decreasing numbers } \\
\text { with depth. }\end{array}$ \\
\hline 2 & $\begin{array}{l}\text { Disintegrating soft reddish sandstone rocks representing a layer of soft sandstone immediately overlying a hard rock } \\
\text { surface that is probably bedrock. SU1C and SU1D sediments are present between disintegrating sandstone pieces. } \\
\text { SU2 rocks tend to be more tabular and less disintegrating in the northern half of the square than in higher SUs. SU2 } \\
\text { is culturally sterile. }\end{array}$ \\
\hline
\end{tabular}

Source: Authors' data.

Table 13.8 General list of excavated materials by XU, Dalakngalarr 1, Square B.

\begin{tabular}{|c|c|c|c|c|c|c|c|c|c|c|}
\hline \multirow[t]{2}{*}{$X U$} & \multirow[t]{2}{*}{ SU } & \multirow{2}{*}{$\begin{array}{c}\text { Charcoal } \\
\text { (g) }\end{array}$} & \multicolumn{2}{|c|}{ Stone artefacts } & \multicolumn{2}{|c|}{ Glass bead } & \multirow{2}{*}{$\begin{array}{l}\text { Insects } \\
(g)\end{array}$} & \multirow{2}{*}{$\begin{array}{l}\text { Roots and } \\
\text { other plant } \\
\text { matter (g) }\end{array}$} & \multirow{2}{*}{$\begin{array}{l}\text { Scat from } \\
\text { unidentified } \\
\text { fauna }(g)\end{array}$} & \multirow{2}{*}{$\begin{array}{l}\text { Hair and fur from } \\
\text { unidentified } \\
\text { fauna }\end{array}$} \\
\hline & & & $\#$ & $g$ & $\#$ & 9 & & & & \\
\hline 1 & $1 \mathrm{~A}$ & 173.18 & 52 & 12.94 & & & 0.45 & 36.54 & 0.43 & 2.10 \\
\hline 2 & $1 \mathrm{~A}+1 \mathrm{~B}$ & 163.82 & 83 & 42.21 & 1 & 0.04 & 0.19 & 10.71 & & \\
\hline 3 & $1 \mathrm{~B}$ & 70.26 & 50 & 4.67 & & & 0.19 & 0.91 & & 0.01 \\
\hline 4 & $1 \mathrm{~B}$ & 141.01 & 87 & 121.87 & & & 0.01 & 4.44 & & \\
\hline 5 & $1 \mathrm{~B}$ & 101.51 & 58 & 11.81 & & & 0.01 & 7.56 & & \\
\hline 6 & $1 \mathrm{~B}+1 \mathrm{C}$ & 106.6 & 51 & 6.63 & & & 0.02 & 4.62 & & \\
\hline 7 & $1 \mathrm{~B}+1 \mathrm{C}$ & 56.88 & 57 & 4.93 & & & 0.04 & 2.21 & & \\
\hline 8 & $1 \mathrm{~B}+1 \mathrm{C}$ & 31.80 & 24 & 3.94 & & & 0.12 & 2.84 & & \\
\hline 9 & $1 C+1 D+2$ & 18.89 & 7 & 0.46 & & & 0.01 & 1.98 & & \\
\hline 10 & $1 C+1 D+2$ & 13.29 & 8 & 0.57 & & & 0.01 & 0.98 & & \\
\hline 11 & $1 \mathrm{C}+1 \mathrm{D}+2$ & 4.56 & 3 & 0.23 & & & 0.01 & 0.73 & & \\
\hline 12 & $1 C+1 D+2$ & 3.66 & 9 & 0.33 & & & 0.01 & 0.03 & & \\
\hline 13 & $1 C+2$ & 1.58 & 13 & 6.28 & & & & 0.01 & & \\
\hline 14 & $1 C+2$ & 0.78 & 4 & 1.91 & & & & & & \\
\hline 15 & 2 & 0.19 & & & & & & 0.01 & & \\
\hline 16 & 2 & 0.04 & & & & & & & & \\
\hline Total & & 888.05 & 506 & 218.78 & 1 & 0.04 & 1.07 & 73.57 & 0.43 & 2.11 \\
\hline
\end{tabular}

SU numbers in bold indicate that most of the square is taken up by those SUs.

Source: Authors' data.
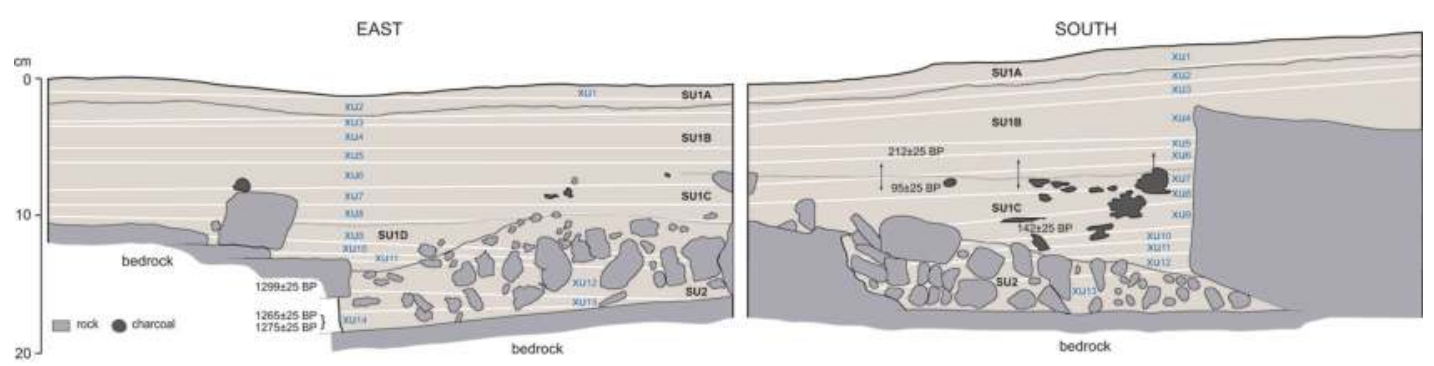

Figure 13.23 East and south sections of Square B, showing back-plotted XUs.

Source: Illustration by Kara Rasmanis and Bruno David. 


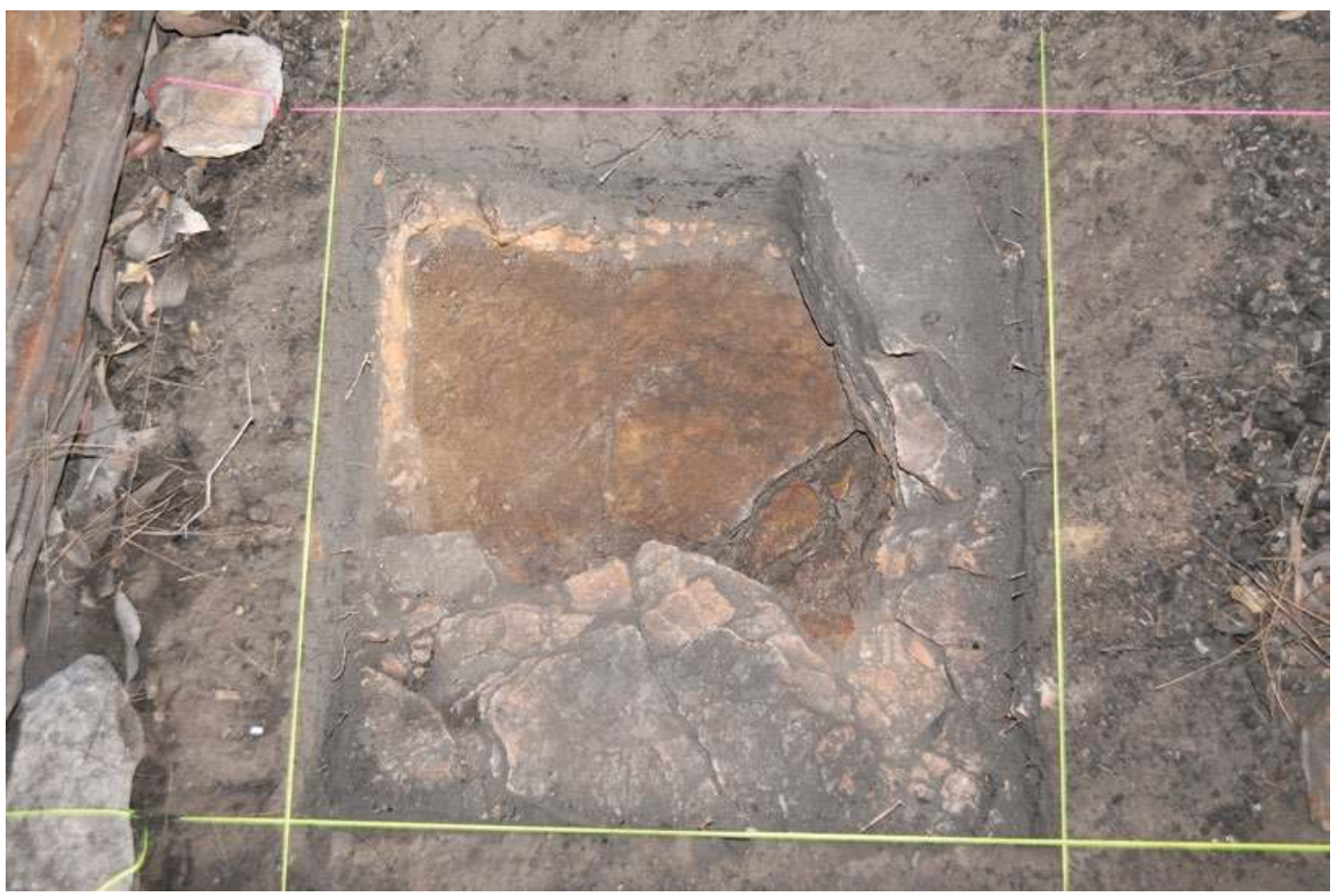

Figure 13.24 Collapsed rock over bedrock at base of Square B.

Source: Photograph by Bruno David.

The stratigraphic sequence is broadly consistent across both excavation squares, with the sum of Square B's SU1A and SU1B appearing to be spatially continuous, and contemporaneous, with SU1 and SU2 in Square A, as indicated by their relative stratigraphic positions and radiocarbon determinations (see below).

\section{Radiocarbon dating of charcoal from the excavations}

A total of twelve radiocarbon dates were obtained from Squares A and B (Table 13.9). All are AMS dates on single pieces of individually 3-D plotted wood charcoal, barring the sample from $\mathrm{XU} 7$ in Square A that was obtained from the sieve. The following discussion of calibrated ages is based on 68.3 per cent probability distributions.

The initial phase of occupation in Square A dates to sometime within the period 4969-5211 cal BP (in XU7), until 2882-2955 cal BP (in XU5). This period (Phase 1) is represented by XU7-XU5 in SU3. The dates do not permit us to determine whether occupation was continuous or intermittent (at archaeological time scales) during Phase 1. It is during this initial phase that the large boulder marking the southern side of Square A fell into position, and sometime after that the red macropod was painted on it. This part of the site then remained either unoccupied or subject to low-intensity occupation until sometime within the calibrated age range 0-290 cal BP (Phase 2). This second phase began either slightly before or during the European-contact period, as indicated by three separate radiocarbon dates each calibrating within that age range and by the presence of three conjoining pieces of metal. 
Initial occupation of the area of Square B dates from 1181-1264 cal BP to 1186-1281 cal BP, apparently an archaeologically instantaneous event. This was followed about a thousand years later by a more recent phase of occupation beginning 11-271 cal BP either shortly before, or during, the European-contact period, as indicated by the presence of a glass bead. This latter, recent phase is contemporaneous with the most recent Phase 2 of Square A.

Two broad depositional phases are thus evident from the excavated deposits:

- Phase 1, beginning 4969-5211 cal BP (Square A) and extending to 1186-1281 cal BP (Square B). The small size of the excavations does not permit us to determine whether this phase represents relatively continuous occupation, or a series of occupational pulses (as measured at archaeological time scales).

- Phase 2, beginning 0-290 cal BP (Square A), that is, either during or extending into the European-contact period, as shown by the presence of metal (Square A) and a glass bead (Square B).

Table 13.9 Radiocarbon dates from Dalakngalarr 1.

\begin{tabular}{|c|c|c|c|c|c|}
\hline $\mathrm{XU}$ & Laboratory code & $\delta^{13} \mathrm{C} \% 0$ & ${ }^{14} \mathrm{C}$ age BP & Calibrated age BP (68.3\% probability) & Phase \\
\hline \multicolumn{6}{|c|}{ Square A } \\
\hline 1 & Wk-36131 & $-27.1 \pm 0.2$ & $98 \pm 25$ & $\begin{array}{c}32-47(0.142) \\
55-82(0.230) \\
98-107(0.070) \\
113-136(0.245) \\
224-255(0.313) \\
\end{array}$ & \multirow[t]{4}{*}{2} \\
\hline 2 & Wk-36132 & $-24.5 \pm 0.2$ & $83 \pm 25$ & $\begin{array}{c}34-72(0.498) \\
116-134(0.207) \\
227-252(0.296) \\
\end{array}$ & \\
\hline 3 & Wk-36133 & $-25.4 \pm 0.2$ & $93 \pm 25$ & $\begin{array}{c}33-73(0.424) \\
102-105(0.025) \\
114-136(0.230) \\
225-254(0.321)\end{array}$ & \\
\hline 4 & Wk-36134 & $-25.1 \pm 0.2$ & $201 \pm 25$ & $\begin{array}{c}0-11(0.183) \\
150-186(0.537) \\
272-290(0.280)\end{array}$ & \\
\hline 5 & Wk-35506 & $-25.6 \pm 0.2$ & $2823 \pm 25$ & $\begin{array}{l}2882-2911(0.432) \\
2918-2955(0.568)\end{array}$ & \multirow[t]{2}{*}{1} \\
\hline 7 & Wk-35505 & $-25.2 \pm 0.2$ & $4431 \pm 25$ & $\begin{array}{l}4969-5049(0.902) \\
5197-5211(0.098)\end{array}$ & \\
\hline \multicolumn{6}{|c|}{ Square B } \\
\hline 5 & Wk-36135 & $-24.5 \pm 0.2$ & $212 \pm 25$ & $\begin{array}{c}0-8(0.151) \\
151-172(0.469) \\
277-298(0.380)\end{array}$ & \multirow[t]{3}{*}{2} \\
\hline 7 & Wk-36136 & $-24.5 \pm 0.2$ & $95 \pm 25$ & $\begin{array}{c}33-48(0.165) \\
53-74(0.218) \\
79-81(0.017) \\
100-106(0.051) \\
114-136(0.231) \\
225-254(0.317)\end{array}$ & \\
\hline 9 & Wk-36137 & $-25.7 \pm 0.2$ & $142 \pm 25$ & $\begin{array}{c}11-33(0.197) \\
74-99(0.168) \\
106-114(0.055) \\
136-150(0.119) \\
186-225(0.314) \\
254-271(0.149)\end{array}$ & \\
\hline
\end{tabular}




\begin{tabular}{|l|c|c|c|c|c|}
\hline XU & Laboratory code & $\delta^{13}$ C $\% 0$ & ${ }^{14}$ C age BP & Calibrated age BP (68.3\% probability) & Phase \\
\hline 12 & Wk-36138 & $-25.1 \pm 0.2$ & $1299 \pm 25$ & $1186-1205(0.352)$ & $1240-1250(0.140)$ \\
& & & & $1255-1281(0.507)$ & \\
& & & & $1181-1190(0.141)$ \\
& & & & $1198-1214(0.237)$ \\
& & & & $1221-1261(0.622)$ \\
& & & & $1183-1210(0.435)$ & \\
\cline { 1 - 5 } & & & & $1229-1264(0.565)$ & \\
\hline
\end{tabular}

Calibrations undertaken using Calib 7.1 (IntCal13) (Reimer et al. 2013).

Source: Authors' data.

\section{Ochre from the excavations}

Square A XU5 and XU6 revealed two pieces of 'ochre' (Table 13.10; Figure 13.25). Both pieces date to sometime between 4969-5211 cal BP (XU7) and 2882-2955 cal BP (XU5). The small piece of red ochre from XU5 shows evidence of use-wear in the form of two adjacent c. $2 \mathrm{~mm}$ wide longitudinal grooves that extend to the fragment's pointed end. This type of groove is not typically associated with grinding, scoring or rubbing an ochre piece against a surface (Hodgskiss 2010:3347-3356), but may indicate an alternative practice: shaving a piece of ochre with a sharpedged tool (Hodgskiss 2010; Rifkin 2012). We know of no ethnographic records of ochre shaving from Arnhem Land. This ochre piece is mainly composed of haematite $\left(\mathrm{Fe}_{2} \mathrm{O}_{3}\right)$, causing the red colour. Infrared spectroscopy identified also the presence of kaolinite $\left(\mathrm{Al}_{2} \mathrm{Si}_{2} \mathrm{O}_{5}(\mathrm{OH})_{4}\right)$. Raman spectroscopy indicated the presence of minor traces of quartz $\left(\mathrm{SiO}_{2}\right)$ and anatase $\left(\mathrm{TiO}_{2}\right)$.

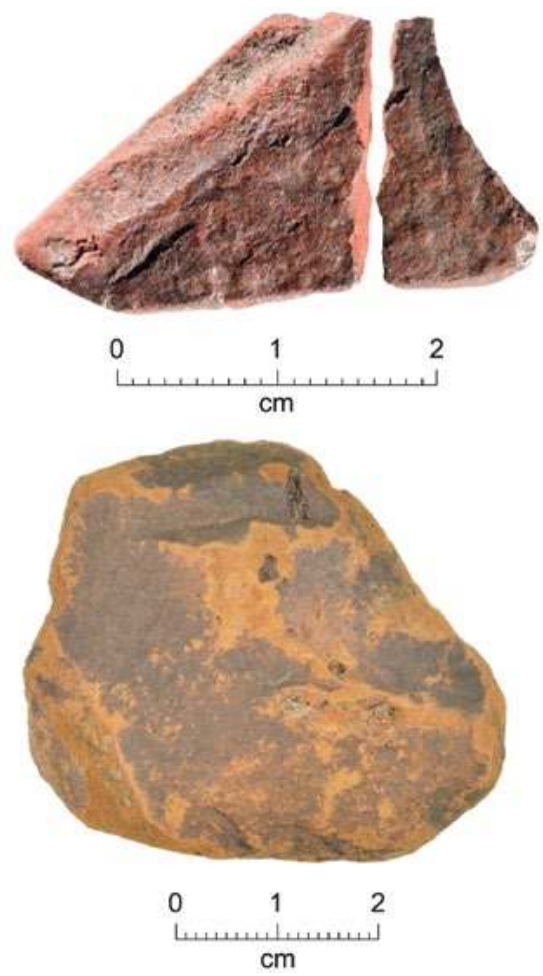

Figure 13.25 Top: Broken piece of red ochre from Square A XU5. Bottom: Piece of yellow 'ochre' from Square A XU6.

Source: Photographs by Steve Morton.
The piece of yellow 'ochre' from XU6 does not show obvious evidence of use-wear, but its soft, powdery surface is not amenable to the preservation of such evidence. This ochre has a much lower percentage of iron than the red ochre, with a relative composition by weight of 28 per cent iron, compared to 84 per cent for the red piece from XU5. The yellow ochre is largely composed of clay, with infrared spectroscopy indicating probable kaolinite. Raman spectroscopy shows peaks typical of iron oxides; however, the particular type of iron oxide could not be identified. The relatively low composition of iron leads to its yellow colour. There is no evidence of goethite or limonite, typical of many yellow ochres. The black covering on this piece showed evidence of the presence of charcoal and quartz, both major components of the deposit. 
The closest visible art to Square A where the ochre fragments were recovered is the red macropod located on the boulder at the edge of the excavation (Figures 13.14, 13.22 and 13.26). The XU5 red ochre fragment dates to shortly after the large boulder with the painted macropod fell into position at the edge of Square A; the ochre fragment could have been used for the painting of the macropod. If this was the case, the macropod painting would date closer to $2882-2955$ cal BP than to 4969-5211 cal BP, given the ochre piece's chrono-stratigraphic position in XU5.

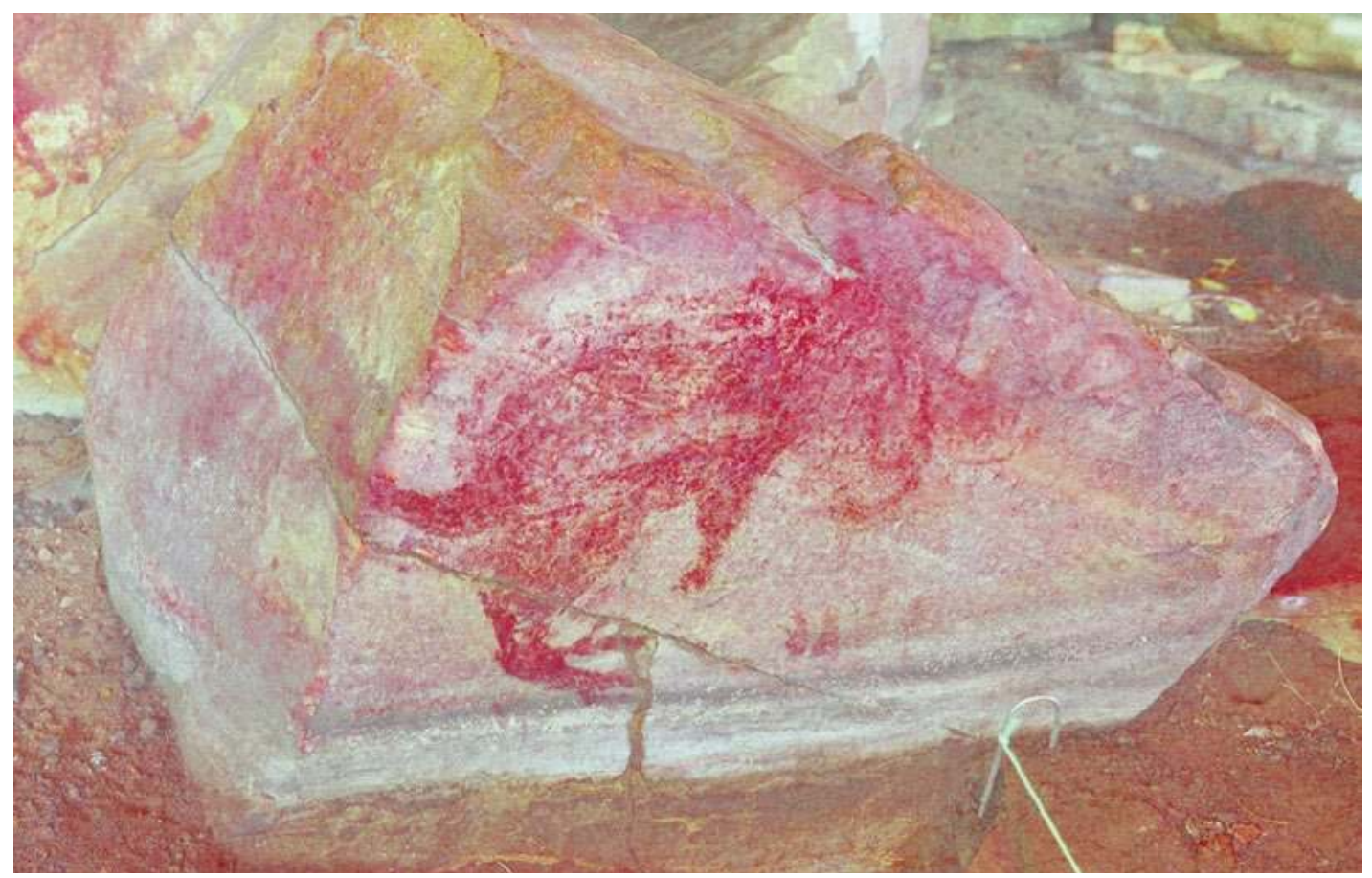

Figure 13.26 Digitally enhanced red-painted macropod on boulder at edge of Square A.

Source: Photograph by Daniel James. DStretch_yrd10 enhancement.

Table 13.10 0chre pieces excavated from Dalakngalarr 1, Square A.

\begin{tabular}{|l|c|c|l|}
\hline XU & Dimensions $(\mathbf{c m})$ & Weight $(\mathbf{g})$ & Munsell colour \\
\hline 5 & $1.48 \times 0.95$ & 0.6 & $7.5 R$ 3/8-7.5R 3/3 dark red/dusky red \\
\hline 6 & $4.85 \times 3.81$ & 36.2 & 10 YR 5/6-10YR 5/8 yellowish brown \\
\hline
\end{tabular}

Source: Authors' data.

\section{Stone artefacts from the excavations}

A total of 1288 stone artefacts - 782 from Square A and 506 from Square B - were recovered from the excavations (Tables 13.5 and 13.8). Other than charcoal, stone artefacts represent by far the most common type of cultural material in the excavations. The stone artefacts were predominantly made on a range of different types of quartzite in both squares and in both phases, followed in quantity by chert, volcanics, siltstone, possibly silcrete and quartz. It is likely that most quartzite artefacts were made on local raw materials, given the natural availability of quartzite in the walls and boulders of Dalakngalarr 1. Local quarrying and production would account for the paucity of cores and presence of cortical flakes in both excavation squares (Stephens 2013). This is consistent with rock walls at Dalakngalarr 1 having been extensively flaked (e.g. Figure 13.27). The few chert artefacts would have been brought in, as chert does not outcrop near the site. 


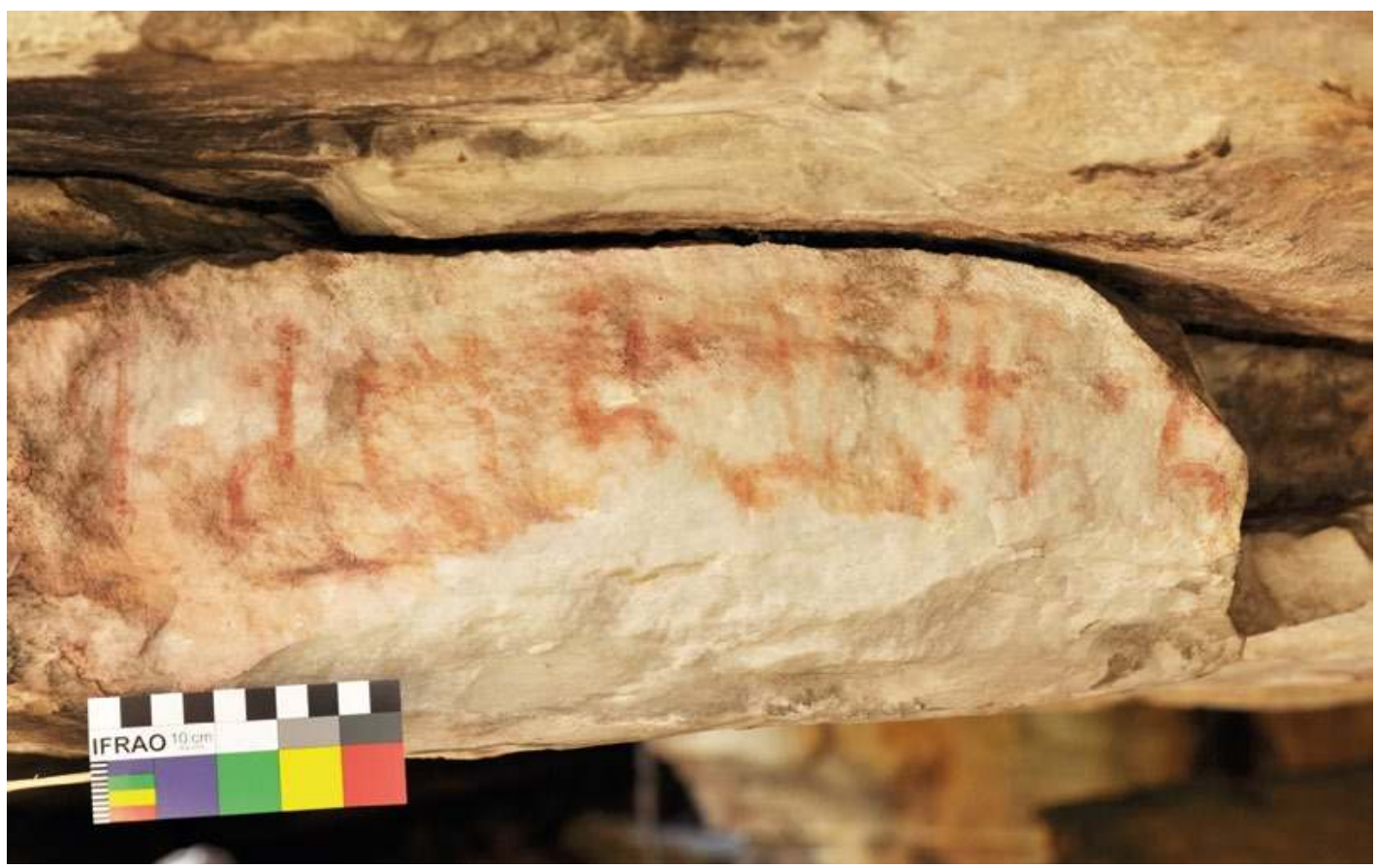

Figure 13.27 Evidence of quarrying at Dalakngalarr 1.5 sale $10 \mathrm{~cm}$.

Source: Photograph by Daniel James.

In both Squares A and B, stone artefact densities peak in Phase 2. In Square A, there are on average 1.8 artefacts/litre of sediment in Phase 1, followed by 42.5 artefacts/litre of sediment in Phase 2, indicating that the early European-contact period of Phase 2 has an artefact density 23.6 times that of Phase 1. Similarly, in Square B there are on average 5.3 artefacts/litre of sediment in Phase 1, followed by 17.7 artefacts/litre of sediment in Phase 2, indicating that during Phase 2 artefact densities were 3.3 times those of Phase 1 . These trends represent a consistent increase in intensities of site use as represented by the deposition of stone artefacts. They are consistent with an early European-contact phase of artistic activity across the site.

\section{Bone, paperbark and standing stones}

No bone was recovered from either Squares A or B, probably reflecting the acidic nature of deposits. On the central-western Arnhem Land plateau, bone destruction in acidic deposits primarily affects material older than c. 400 years old, as determined by excavations at Nawarla Gabarnmang (personal observations; cf. Allen and Barton 1989:30; Jones and Johnson 1985:222). The complete and surprising absence of faunal remains from Phase 2 in particular at Dalakngalarr 1 is unlikely to be related to preservation. Did site use not involve the consumption of notable amounts of animal foods during the European-contact period? Or is it simply that the two small excavation squares were positioned in areas not used either for cooking or food discard?

A limited quantity of surface bone, and of paperbark, was observed in other parts of the shelter (Figure 13.28). These remains are in the enclosed and protected southwestern corner of the shelter interior, which also contains a number of small standing stones piled below the opening of a small, narrow cleft that runs between the western outer wall and the shelter's interior (Figures 13.29 and 13.30). Standing stones are known to have been used as burial markers outside clefts in other parts of Jawoyn Country and elsewhere in Arnhem Land (Gunn et al. 2012; see also James in prep.). 


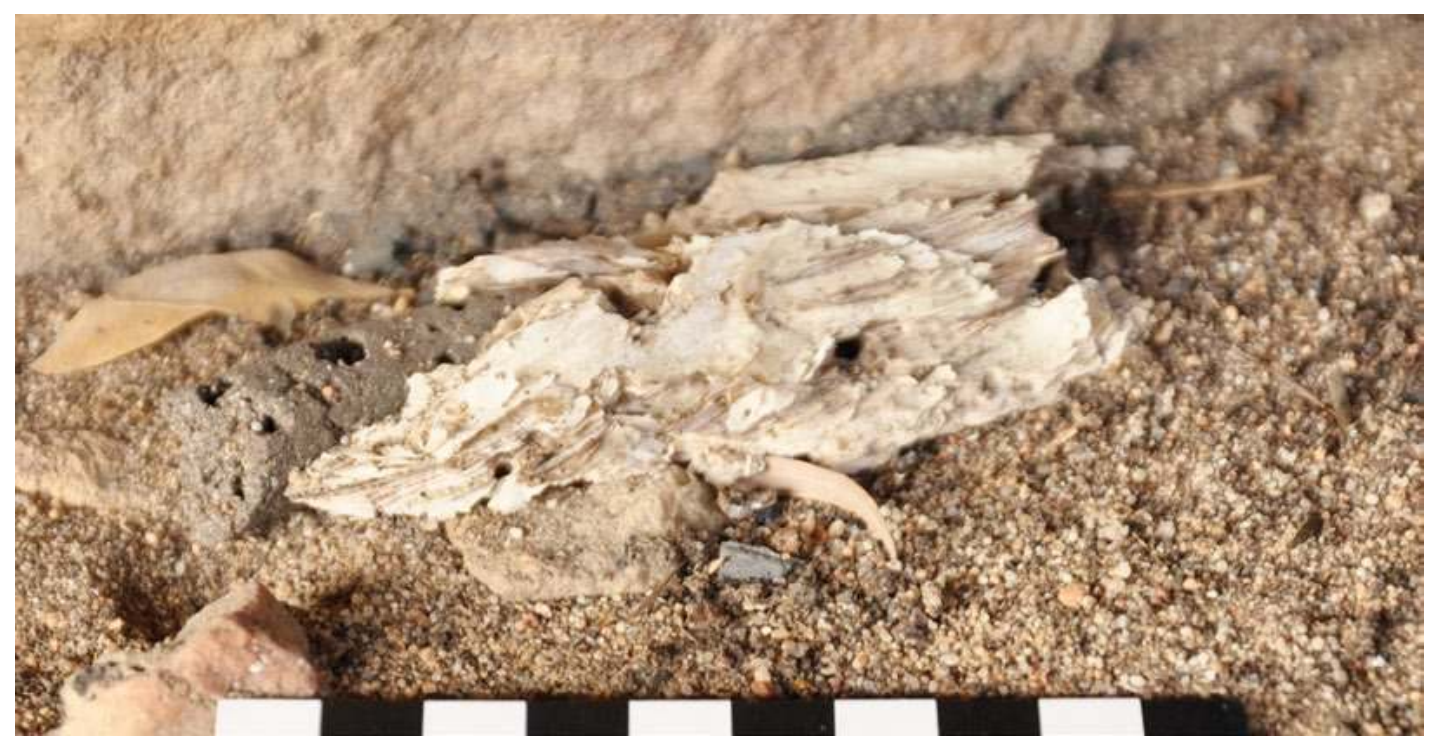

Figure 13.28 Faunal scat (likely echidna) attached to paperbark in the southwestern corner of Dalakngalarr 1.

Echidnas often crawl through paperbark burials (human or dingo) and paperbark pieces caught on their spines are later dislodged. Scale $10 \mathrm{~cm}$.

Source: Photograph by Daniel James.

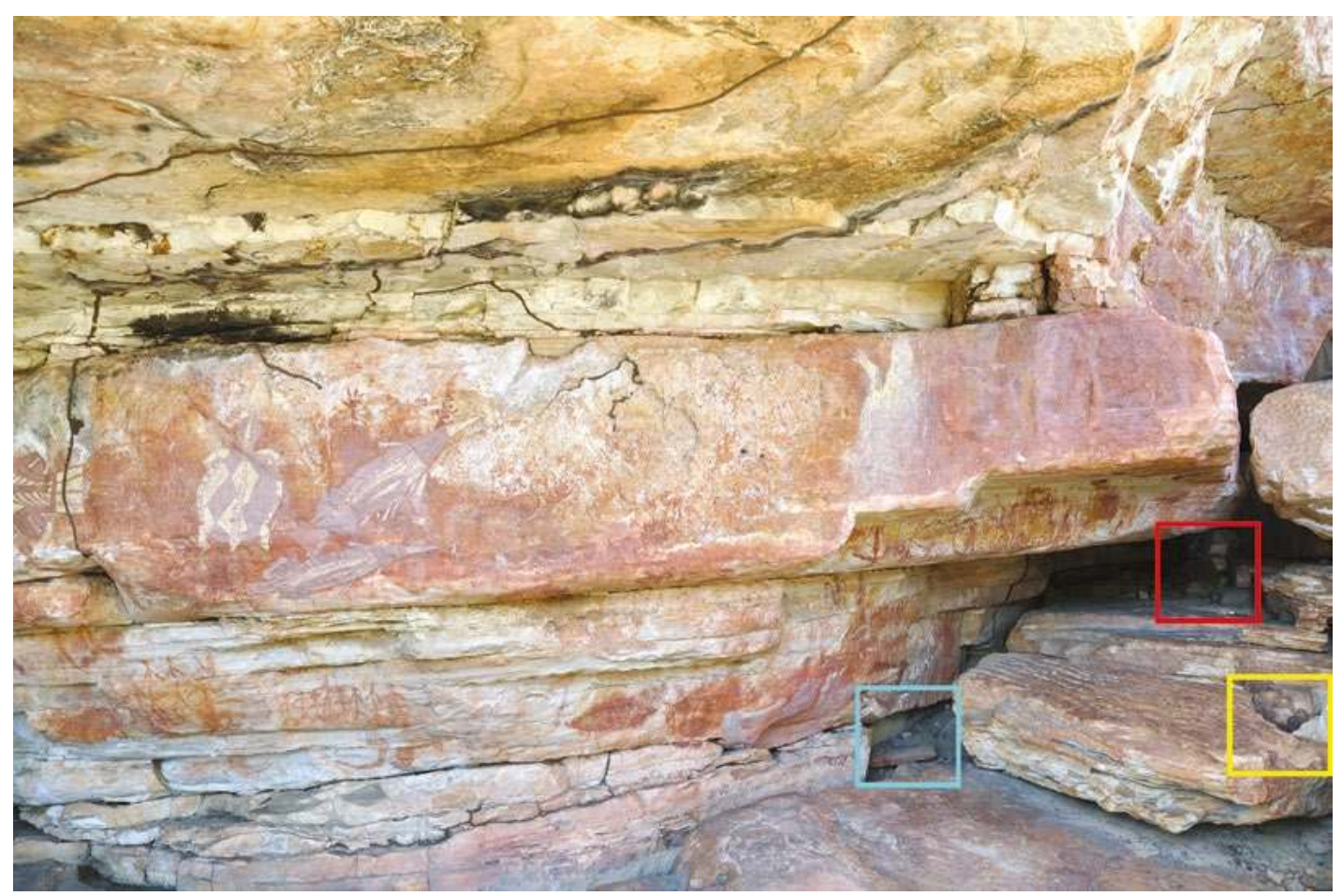

Figure 13.29 Southwestern corner of shelter interior, with cleft indicated by red box, standing stone by yellow box, and location of paperbark by blue box.

Source: Photograph by Daniel james. 


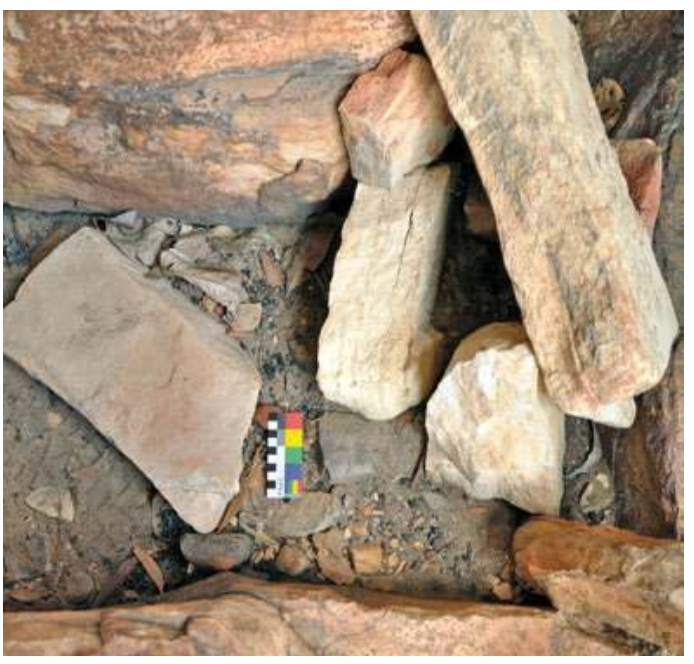

Figure 13.30 Standing stones in southwestern corner of shelter interior, photograph taken from above. Scale $10 \mathrm{~cm}$.

Source: Photograph by Daniel James.

The paperbark by the cleft and the fallen standing stones suggest that this corner of the shelter may once have contained a burial. Human burials have been observed within the Dalakngalarr site complex, further along the escarpment to the southeast of the site (Ray Whear, pers. comm. to Robert Gunn 2012), but their precise location has not been recorded and thus their exact distance from Dalakngalarr 1 is unknown.

\section{Metal artefacts from the excavations}

Three heavily corroded iron objects were excavated from Square A XU2 and XU3 (Figures 13.31A and 13.31B). Radiography (Figure 13.32) revealed that the two pieces from XU2 conjoin and appear to be from a c. $30 \mathrm{~mm}$ long nail, confirmed by the presence of a small 'head' and tapering 'point'. The piece from XU3, too corroded to identify with certainty, appears to be part of another nail. The objects were originally smaller than at present, having 'grown' as corrosion created an accreted outer layer (Selwyn 2004). Hollow sections, observable on the radiograph images, may be a result of manufacture or a by-product of vertical shearing during corrosion (Holly Jones, pers. comm. to Daniel James 2014).
A

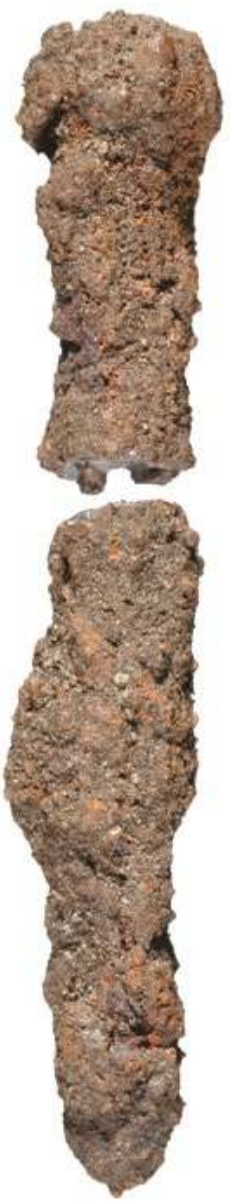

B

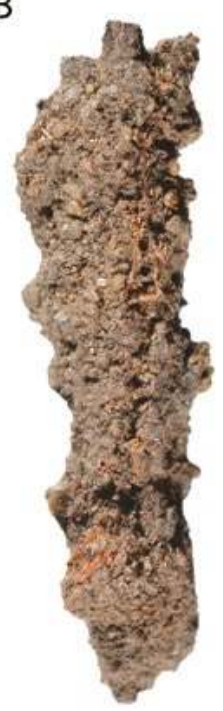

C

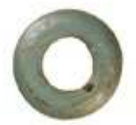

0 1

Figure 13.31 Excavated metal objects and glass bead.

A: Square A XU2; B: Square A XU3; C: Square B XU2.

Source: Photographs by Steve Morton.

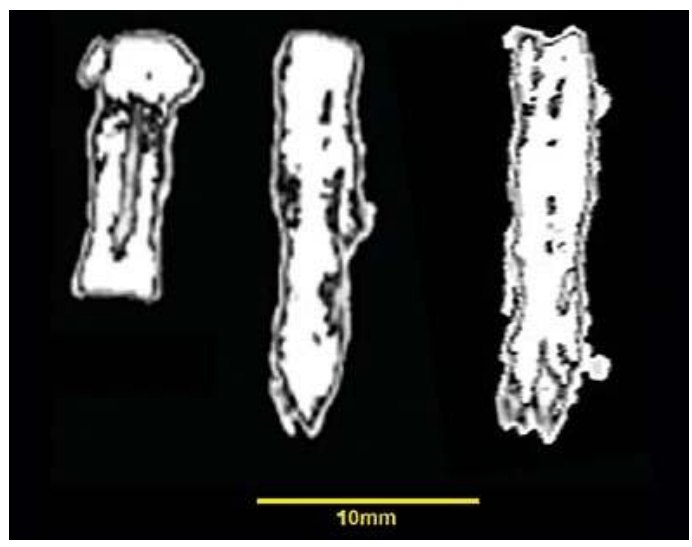

Figure 13.32 Radiograph image of metal objects recovered from Square A XU2 (left, centre) and XU3 (right).

Source: Photographs by Monash University School of Medical Imaging and Radiation Sciences. 


\section{Glass bead from the excavations}

A single glass bead was recovered from Square B XU2 (Figure 13.31C). The bead is blue-green in colour, with an opaque character. It is wider than it is long (width $=2.95 \mathrm{~mm}$ ), its shape a simple, annular form. The central hole is noticeably misshapen on one side, a common trait of wound, annular beads.

A small cavity on the outer bead surface, and the elongated shape and perpendicular position of this cavity relative to the central bead perforation shows this is a 'wound' bead (Harris 1987; Sprague 1985). As the name suggests, these are made by winding molten glass around a metal mandrel to the required size and shape, a costly and labour-intensive method of production. The style of wound bead found at Dalakngalarr 1 is called a 'seed-bead', a general term used to describe small beads of various manufacturing techniques. Beads manufactured this way were typical of Venetian glass bead-making practices, when Venice/Murano dominated the glass bead market by the 18th century. By then, Venetians had established workshops in Holland, France, Moravia and Bohemia (now the Czech Republic) (e.g. Dubin 2006:107; Francis 1991). Similar wound glass beads were also produced in Germany, India and China, and traded within complex networks of exchange over very long distances (cf. Dubin 2006; Francis 1991, 1994; Sprague 1985).

There are few references to the decorative uses of seed beads in Australian archaeology, although there are many instances of glass beads from archaeological sites (e.g. Wesley and Litster 2015). Beads are typically identified as items or currencies of trade. In the most recent discussion of beads in Arnhem Land, Wesley and Litster (2015) examined seed beads in the photographic records of early anthropologists visiting Arnhem Land, and as components of choker necklaces and headbands, a decorative function in body adornment.

The Dalakngalarr 1 bead is only the second to be recovered during excavations in Jawoyn Country. At Nawarla Gabarnmang, a blue glass bead was found in XU1 of excavation Square J (Bruno David, unpublished data), within sediments dating to the early European-contact period.

Glass beads have great potential as markers of cross-cultural contact and Indigenous trade, exchange and mobility in northern Australia. Wesley and Litster (2015) propose that beads were introduced into northern Australia as early as the 18th century by Macassan trepangers. Several bead assemblages from Indigenous sites in the Wellington Range appear to pre-date the first Christian missions established in the region in 1916.

As the Dalakngalarr 1 bead is associated with the latter part of Phase 2 occupation, it likely represents an exchange with members of European exploration parties, missionaries or buffalo shooters probably further to the north, or through interactions after 1880 with non-Indigenous peoples who established early mining and/or pastoral industries further west of Jawoyn lands (Daryl Wesley, pers. comm. to Daniel James 2014). Jawoyn Country is more than $120 \mathrm{~km}$ inland and divided from the coast by a number of territorial-language groups, so the likelihood of an early date and a Macassan source is reduced. A European contact-period age for the bead would be consistent with the iron (nail) pieces recovered from Square A at Dalakngalarr 1, the nearby cut $\log$ and the painted metal axe/hoe motifs (see below).

\section{Paintings of axe/hoes with metal heads and the $\mathrm{X}$-ray art}

Two paintings of axe/hoes with metal heads occur at Dalakngalarr 1 (Figure 13.33), so they must be of the European-contact period. They are done in a style and pigment also otherwise used only for X-ray paintings at the site, always on the rear wall and rear ceiling (e.g. Figure 13.10). Two colours are prominent on both axe/hoes: very pale orange (Munsell 10YR 8/2) was used on the axe painting as infill on the haft and some infill on the blade, and on the hoe painting as solid 
colour throughout; and a distinct iridescent moderate red (Munsell 5R 5/4) was used on the axe painting as linear internal decoration and outlining. Both colours are only found on paintings within the shelter interior rather than on outer rock walls, and they feature prominently on all the X-ray paintings, regardless of subject matter. It seems that the axe/hoe and X-ray paintings were painted with the same materials and surely at much the same time. The iridescent moderate red paint was not used for any other paintings.
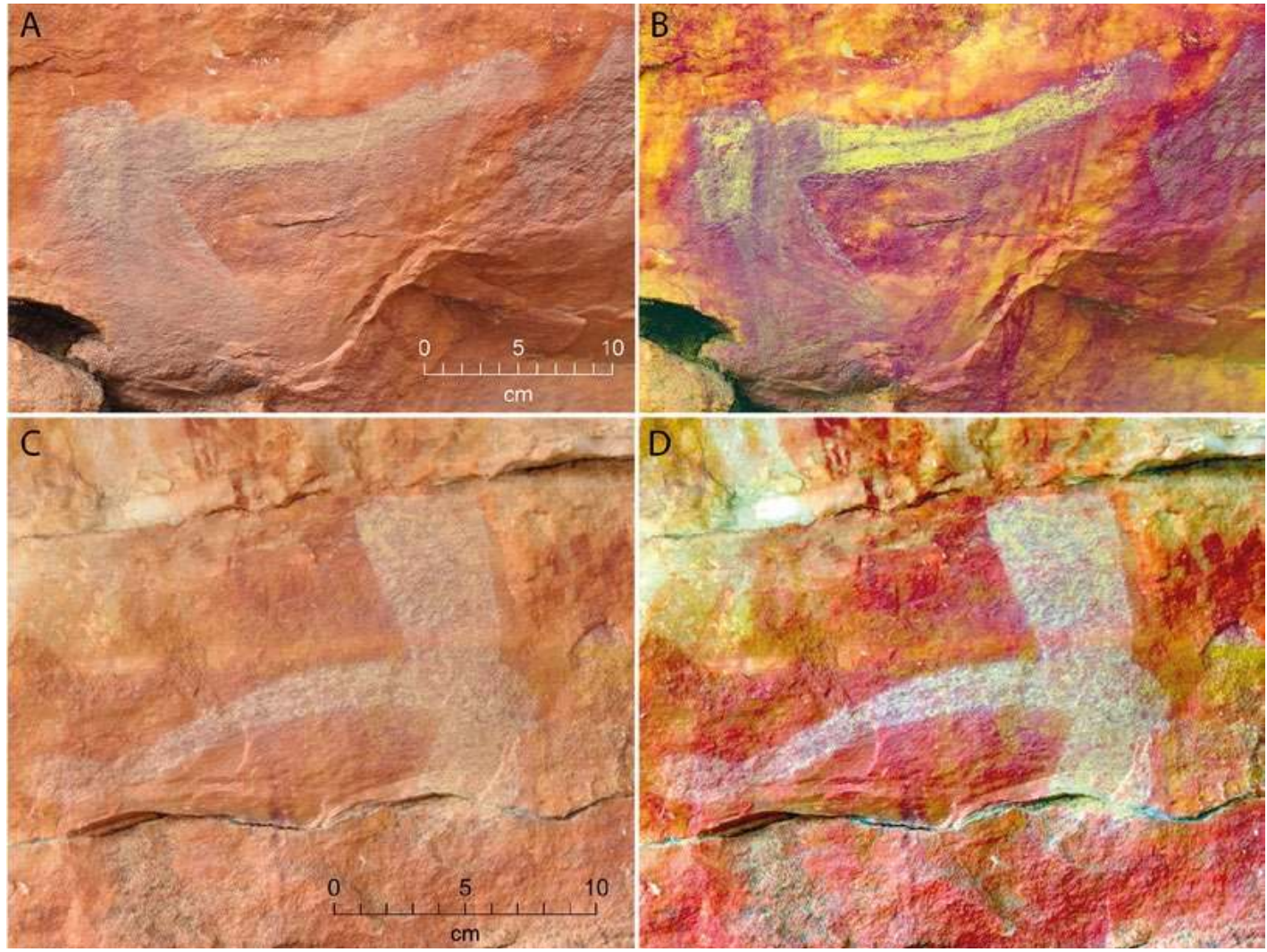

Figure 13.33 Paintings of two axe/hoes with metal heads, Dalakngalarr 1, Panel C1.

A: Axe, original photograph. B. Axe, DStretch_Ids10 enhancement. C: Hoe, original photograph. D: Hoe, DStretch_Ird10 enhancement.

Source: Photographs by Daniel James.

The choice of colour in X-ray art, and in X-ray fish in particular, is important in western Arnhem Land: Taçon (1989a:245-246) recorded ethnographic information across Arnhem Land that emphasised the importance of colour choice and decorative elements as boundaries between life and death, with solid colour paintings depicting fauna that were dead or cooked, with the colour roasted out of them'. Internal decorative elements, such as cross-hatching or other linear designs, were 'said to represent the being's flesh and colour and were what gave you "feeling" of Dreamtime essence' (Taçon 1989a:245; see also Taçon 1989b). Colour, particularly vibrant or shimmering colours on fish, may be associated with Bolung (Jawoyn: Rainbow Serpent, a powerful Dreaming being who is both a life-giver and destroyer), as well as qualities of reflection and shimmering, such as found in water and scales (Taçon 1989b). For the Yolngu of northeastern Arnhem Land, red ochre colours are often symbolically linked to blood and ritual power (e.g. Morphy 1992:196).

Infrared spectroscopy of the moderate red pigments on the X-ray paintings at Dalakngalarr 1 has revealed a fairly consistent combination of haematite and kaolinite, indicating a recurring blend of red and white pigments. Various signs point to a late 19th-century or early 20th-century age 
for the moderate red: its occurrence only in the X-ray and the axe/hoe paintings, that all these paintings occur in one part of the site, that they all make the uppermost and most recent layers in superimposition; and that they all have a very 'fresh' appearance.

A major implication of the above observations is that the X-ray art at Dalakngalarr 1 was painted during the same occupational phase as the axe/hoe paintings; that is, during the early Europeancontact period of the late 1800 s or early 1900 s.

\section{Dating the art panels through geomorphology}

Dalakgnalarr 1 occurs along the edge of an extensive rock outcrop rising up to a few tens of metres above a creek c. $100 \mathrm{~m}$ to the north. In this general area, the plain that surrounds the rock outcrop has a low gradient. The creek that drains it subdivides into numerous ill-defined and criss-crossing channels. Here rock stacks demarcate the edge of the outcrop from the surrounding sandy plain. These isolated rock stacks are each a few metres to a few tens of metres in height. The low rising rock outcrop from which the stacks formed has eroded over long geological time scales measured in the millions of years. The base of the outcrop is made up of Marlgowa Sandstone dating to $1740-1780$ million years ago, in the Proterozoic. It consists of hard quartzites that are highly resistant to erosion (see Chapter 10).

Dalakgnalarr 1 is separated from the edge of the rock outcrop by a small seasonal stream that follows a fissure line in the bedrock. A network of narrow fissures parallel to the creek cuts the edge of the outcrop in a criss-crossing checkerboard pattern. The eastern edge of Dalakgnalarr 1 corresponds with one of these north-south fissure lines, whereas the northern edge corresponds with an east-west and transverse fissure (cf. Figures 13.1, 13.2).

The general arrangement of the rock stacks, and the sudden edges of the outcrop, map precisely onto these geological fissures, and it is this same geological configuration that people saw when they first set foot on the Arnhem Land plateau around 50,000 years ago or somewhat earlier. The rich rock art assemblages on the low rise cover, in effect, the pedestals and overhangs of these rock formations on top and on the edge of the rock outcrop.

The site of Dalakgnalarr 1 is typical of rockshelter sites in this part of Arnhem Land: a rockshelter at the edge of rock outcrops, the size of the sheltered area depending on both the mechanical strength of the quartzite bedrock and the fragility of the strata that are more vulnerable to physical and chemical alteration. The decomposition of the weaker sedimentary layers causes the removal of parts of the rock along fissure lines, thereby producing the 'ghost rock' or pillar landscape evident at Nawarla Gabarnmang $17 \mathrm{~km}$ away (cf. Delannoy et al. 2013; see Chapter 10). At Dalakgnalarr 1, the most vulnerable rock strata are D0 and D1 (Figure 13.2). It is from these that the rockshelter we now know as Dalakgnalarr 1 began to take shape: after weathering, the strata D0 and D1 quartz grains that were poorly cemented onto the bedrock were drained away by water action. The creation of an open-ended, sheltered cavity in the rock mass led to a double phenomenon that applies also to the formation of many other rock stacks and rockshelters of this region (see also Chapters 10 and 15):

1. The continued enlargement of voids by chemical alteration and mechanical drainage, causing sections of overhanging ceilings to collapse.

2. As a result of the creation of voids caused by the evacuation of altered rock along one or more sub-horizontal rock strata consisting of less resistant matrix (1 above), the overlying boulder mass compresses the remnant underlying strata to such a degree that it became highly compact and highly resistant to further chemical weathering and drainage. Such underlying remnant strata become the overlying rock mass's pedestal upon which it now balances (Figure 13.34). 

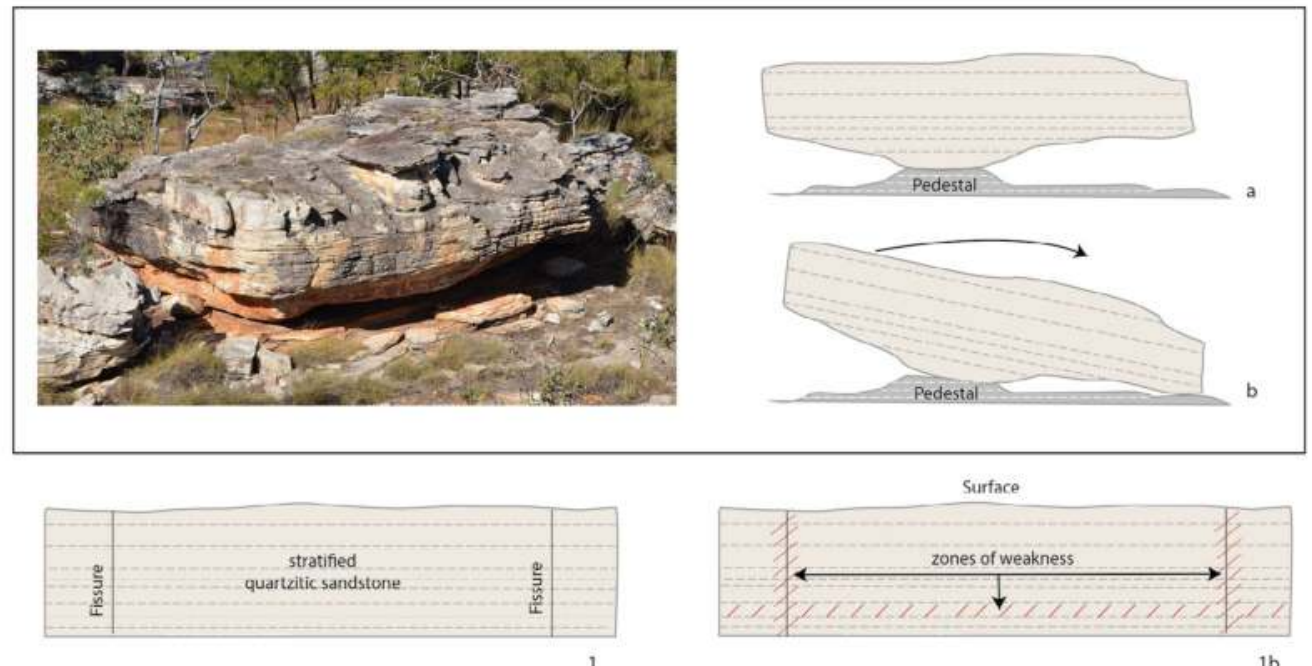

$1 \mathrm{~b}$
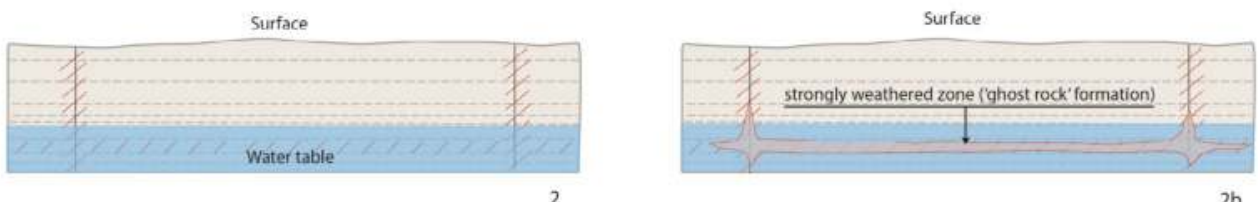

$2 b$
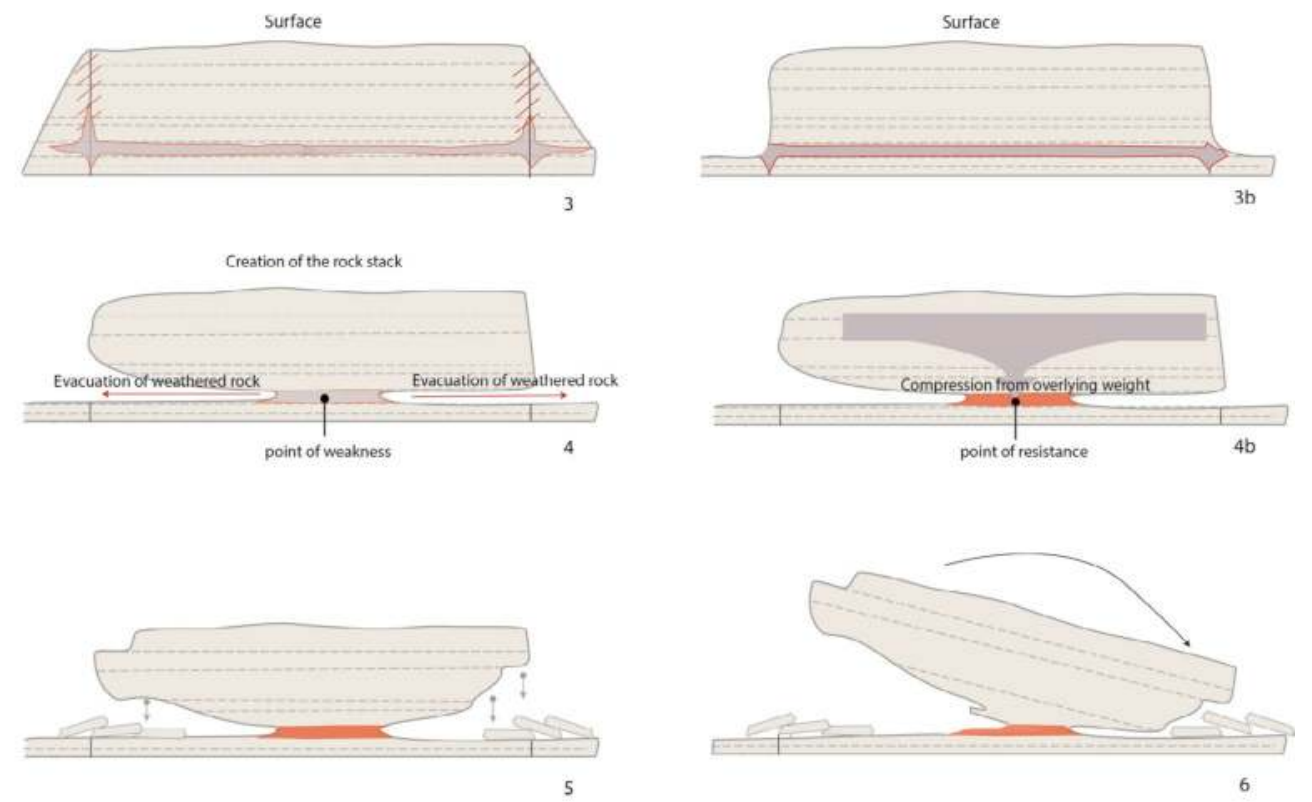

Figure 13.34 Evolution of rock stacks on the Arnhem Land plateau.

Photograph at top shows a typical rock stack from the vicinity of Dalakngalarr. Top right (a): Rock cap over pedestal. Top right (b): Tilted rock cap over pedestal. 1-4: Stages in the creation of the rock stack. 1 and 1b: Stratified sequence of quartzitic sandstone strata, showing vertical fissures and less compacted horizontal strata as zones more susceptible to weathering and erosion. 2 and 2b: Over long periods of geological time typically measured in the millions of years, fissure lines and less compacted strata become preferentially weathered through in the presence of groundwater. This in situ process of weathering, followed by the evacuation of alteration products, is known as 'ghost rock' formation or 'phantomisation'. 3 and 3b: Exposure of rock outcrop due to uplift of the Arnhem Land plateau or to incision by major waterways (e.g. Katherine River). 4 and 4b: The formation of rock stacks. The weathered rock is progressively evacuated (causing 'ghost rock' formations), in the process causing the overlying rock mass (cap) to overhang over its pedestal. The weight of this cap of overlying strata (4b) compresses the underlying pedestal, making it more resistant to further weathering. 5 and 6: Two possible scenarios in the evolution of the most common types of rock stacks in Arnhem Land.

Source: Illustration by Jean-Jacques Delannoy. 
Those strata with the initial voids caused by the chemical alteration and evacuation through water action of decomposed rock are those same remnant strata that constitute the base of rock stacks and of the rockshelter overhangs: the mechanical compression caused by the weight of the overlying rock mass has given strong resistance to those remnant parts of the rock mass that were initially vulnerable to chemical alteration.

This process of rock stack and shelter formation, particularly clear at Dalakgnalarr 1, allows us to frame the age of the rock art.

\section{Geomorphological evolution of the site: Archaeological implications}

The geomorphology of Dalakgnalarr 1 is structured in two different ways:

1. In the northeast, it is a large rockshelter of nearly $10 \mathrm{~m}$ depth with a low, extensively painted ceiling of $0.8 \mathrm{~m}$ to $1.8 \mathrm{~m}$ height. The ground level is cluttered with numerous blocks fallen from the ceiling.

2. In the southwest, the rockshelter becomes much narrower (maximum $3 \mathrm{~m}$ wide) and higher (1.8 $\mathrm{m}$ to $2.5 \mathrm{~m}$ high). It is bordered by a clutter of superimposed and overlapping blocks that slope towards the northwest, and separated from the rock stack's base strata by a deep and narrow corridor.

This two-fold layout was caused by differential geomorphological evolution, although both are subject to the same processes of rock collapse.

After the main chamber at the northeast section of the site had been created by weathering and drainage of strata D0-D1, the large, sheltered area under the overhang attained its particular morphology through the collapse of sections of ceiling strata (Figure 13.35). The geomorphological and archaeological evidence from the excavations suggest five major phases in the rockshelter's formation.

Drainage of the chemically weakened strata D0-D1 sediments, and continued expansion of this void through further chemical alteration and drainage, result in the formation of an initial cavity sheltered by overhanging strata D3 to D22 above it. Mechanical relaxation of parts of the rock structure, caused by the absence of underlying support, together with gravity, cause sections of the overhanging strata D2-D3 to collapse. The geophysical data (Figure 13.11) indicate the presence of a flat surface rock underneath an overlying clutter of fallen blocks. This flat rock could either be bedrock or an underlying collapsed rock slab that fell flat onto the ground from a shallow height given that the ceiling would only have been c. 50 to $60 \mathrm{~cm}$ above, as indicated by the thickness of the evacuated strata D0 and D1.

A process of gravitational readjustment then took effect with sections of the new stratum D4 ceiling collapsing, deepening the rockshelter southward in the process: a collapsed section of stratum D4 now forms the angular blocks revealed in the lower levels of the Square A excavation. The radiocarbon dating results from Square A indicate that the collapse of stratum D4 is older than $4431 \pm 25 \mathrm{BP}(4969-5211 \mathrm{cal} \mathrm{BP})$, as the charcoal sample came from between fallen blocks rather than from immediately underlying deposits. A new phase of rock collapse subsequently took place, simultaneously affecting both the front and rear of the shelter. Here, part of stratum D2 fell near the back of the shelter, while part of stratum D5 fell near the entrance. This is today evident at ground level by the presence of large, superimposed blocks arranged step-wise and inclined towards the north. Given this sequence of events, the artworks on the ceiling rock surfaces newly created by this last phase of rockfall must be later in age than the age of the stratum D5 (front of site) and stratum 
D2 (rear of site) rockfall events. The artworks located in the middle section of the site (dating to after the collapse of stratum D4) can themselves be older, but not older than 4969-5211 cal BP, given the age of the stratum D4 blocks found at the base of Square A.

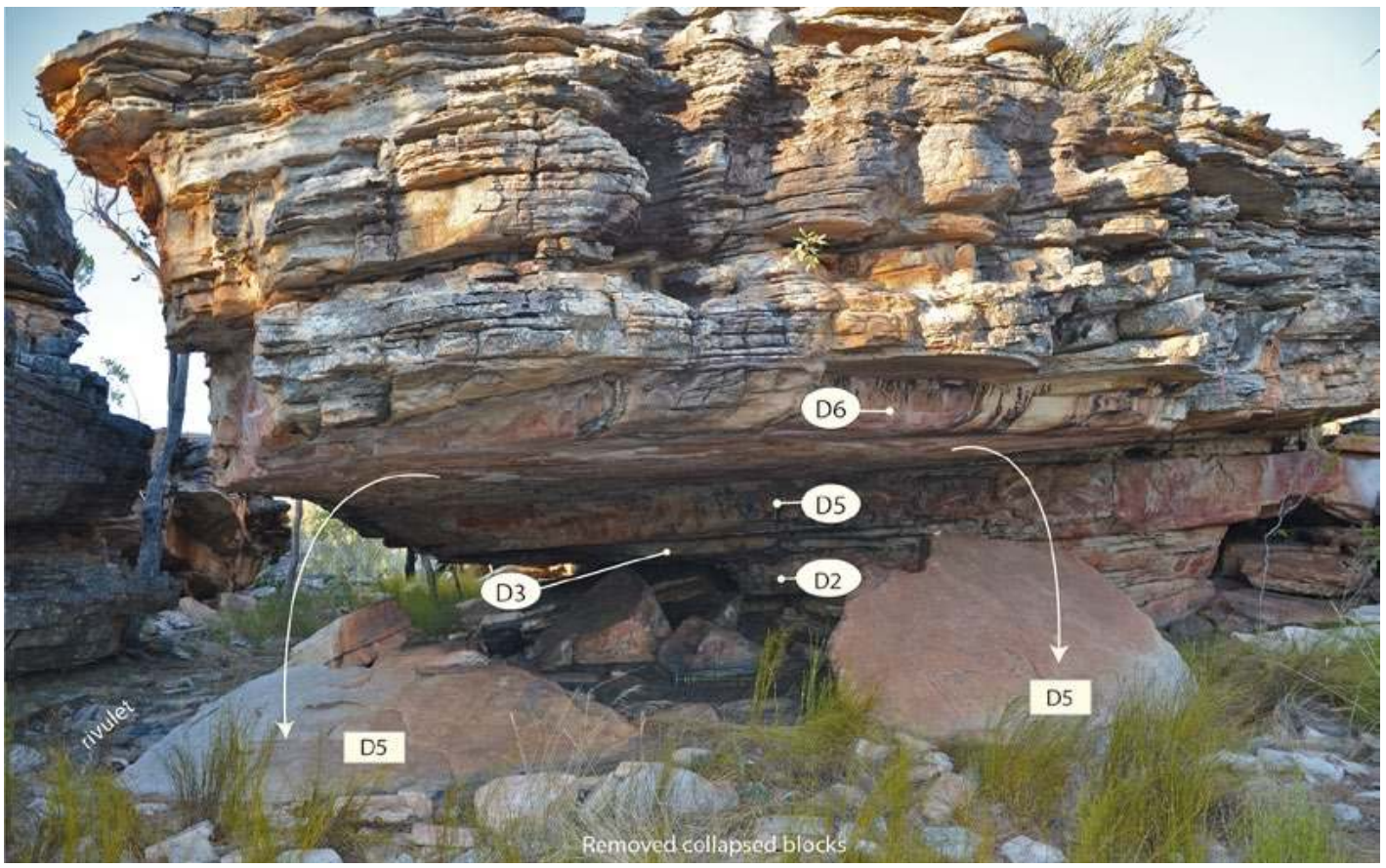

Figure 13.35 Northwestern section of Dalakngalarr 1, showing the different rock strata referred to in the geomorphological discussion.

Source: Illustration by Jean-Jacques Delannoy.

On the northern side of the shelter are found numerous blocks that appear from their location below the edge of the overhang to have originated from the overlying rock cap. However, the blocks' regular layout and relatively stable configurations suggests that they have been repositioned along this edge of the site. Petrographic analysis and the relative positioning of the rock strata from which these blocks came indicate that they came from within the rockshelter. Together, the presence of unusually open spaces within the sheltered space, and repositioned blocks at the northern edge of the overhang, indicate clearance of rock clutter at ground level. That cleared space cannot be explained by natural erosion of fallen blocks, as erosion of the hard quartzites that make up the rock stack's strata took place over very long geological time scales measured in hundreds of thousands of years; this is not consistent with the much shorter, c. 5000 years for the roof-fall indicated by the archaeological excavations. We can only conclude that the space within the site has been reworked by people in the past.

The southwest section of the site has witnessed a different evolution from that of the north, although here too roof-fall was prominent. In the southwest of the site, a section of the wall became detached from the parent rock mass (Figure 13.36). This detachment created the narrow corridor between the parent rock and the now-detached balancing rocks (cross-section $\mathrm{C}-\mathrm{D}$ on Figure 13.2). The detachment of rock slabs - and associated creation of the narrow corridor - appears to be very old, resulting in the stack of balancing rocks in adjacent areas to the northwest. The stepped arrangement of the superimposing slabs was caused by the slipping of slabs, rock stratum by rock stratum. The most elevated strata in this rock stratigraphy are those located furthest from the edge of the parent rock wall. This process of detachment and stacked accumulation at ground level enables ready access (e.g. for painting) to elevated ceiling surfaces. Accordingly, large sections of the back wall spanning from the base of the corridor to the ceiling 
are covered by artworks. It is likely that the oldest artworks are found in this part of the site, because here the corridor and associated stacked detached slabs formed prior to the extant rock surfaces in the northeastern sections of the shelter.

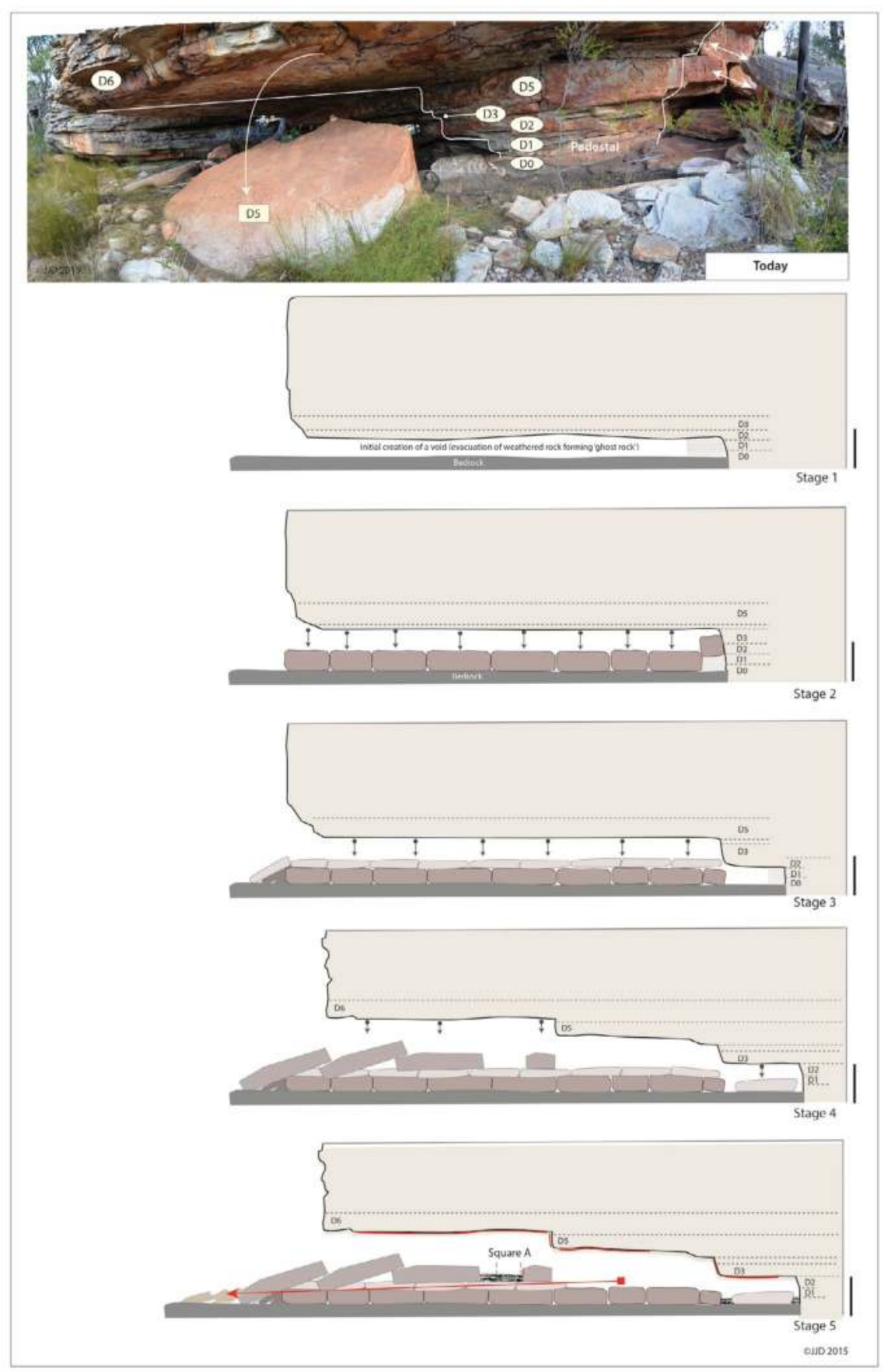

\section{Figure 13.36 Geomorphological evolution of Dalakngalarr 1.}

Stage 1: Evacuation of strata D0 and D1, previously heavily weathered over long geological time scales (see Figure 13.34). Stage 2: Collapse of stratum D3. The low height of the roof above the ground causes the blocks to fall flat onto the bedrock. Stage 3: New phase of roof-fall (D4) and evacuation of weathered materials from distal parts of strata D0 and D1 (at the back of the overhang). Stage 4: Roof-fall takes place along the front section of stratum D5 and the back section of stratum D3. Stage 5: Human occupation at the site causes the build-up of archaeological deposits at ground level, and creates artworks on rock surfaces. It is during these periods of occupation that collapsed blocks are removed from the sheltered area to areas outside the dripline.

Source: Illustration by Jean-Jacques Delannoy. 


\section{Dating the beeswax art}

Four examples of beeswax art have been recorded from Dalakngalarr 1 and directly radiocarbon dated (Table 13.11). Beeswax art must have been created soon after the beeswax was collected, as it quickly becomes brittle and unusable for rock art.

Table 13.11 Radiocarbon dates on the beeswax art of Dalakngalarr 1.

\begin{tabular}{|l|c|c|c|c|}
\hline Sample \# & Laboratory code & $\delta^{13}$ C\% & ${ }^{14}$ C age BP & Calibrated age BP (68.3\% probability) \\
\hline Beeswax Image 1 & Wk-35509 & $-21.9 \pm 0.2$ & $409 \pm 25$ & $471-507(1.000)$ \\
\hline Beeswax Image 2 & Wk-35510 & $-23.6 \pm 0.2$ & $367 \pm 25$ & $332-356(0.305)$ \\
& & & & $433-489(0.695)$ \\
\hline Beeswax Image 3 & Wk-35511 & $-25.8 \pm 0.2$ & $117 \pm 25$ & $25-39(0.115)$ \\
& & & & $63-118(0.489)$ \\
& & & & $123-140(0.140)$ \\
& & & & $221-232(0.095)$ \\
& & & & $242-260(0.160)$ \\
\hline Beeswax Image 4 & Wk-35512 & $-25.2 \pm 0.2$ & $1870 \pm 25$ & $1741-1755(0.131)$ \\
& & & & $1782-1796(0.113)$ \\
& & & & $1807-1867(0.756)$ \\
\hline
\end{tabular}

Calibrations undertaken using Calib 7.1 (IntCal13) (Reimer et al. 2013).

Source: Authors' data.

\section{Beeswax Figure 1}

This figure, located on the ceiling toward the centre of the shelter interior (Figures 13.37 and 13.38), is a star-shaped geometric design superimposed over two paintings. The beeswax has been AMS radiocarbon dated to $409 \pm 25$ BP (Wk-35509), which calibrates to 471-507 cal BP (with a median probability of 487 cal BP) (Table 13.11). So, the two paintings underneath Beeswax Figure 1 are of this age or older (Figure 13.37):

1. A small, solid-white macropod (Figures 13.38, 13.39 image \#406).

2. An indeterminate solid-red painting (Figures 13.38, 13.39 image \#460).

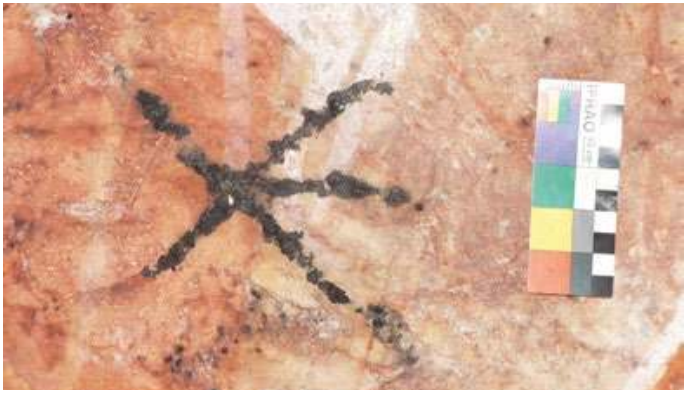

Figure 13.37 Beeswax Figure 1. Scale $10 \mathrm{~cm}$. Source: Photograph by Daniel James.

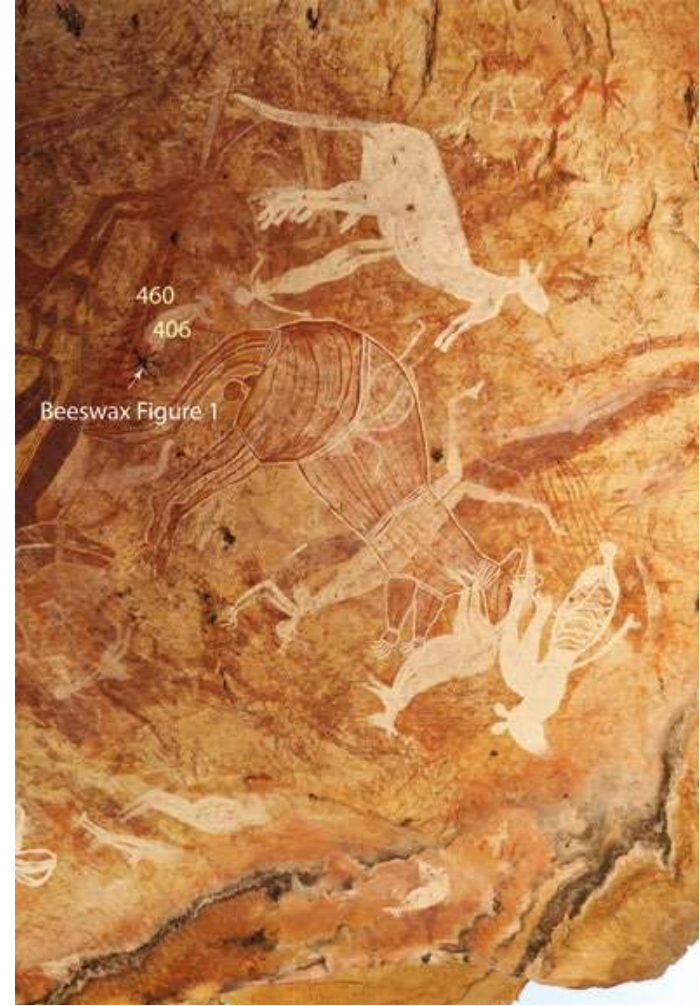

Figure 13.38 Ceiling panel showing location of Beeswax Figure 1 (in box) and picture numbers from Harris Matrix.

Source: Photograph by Daniel James. 


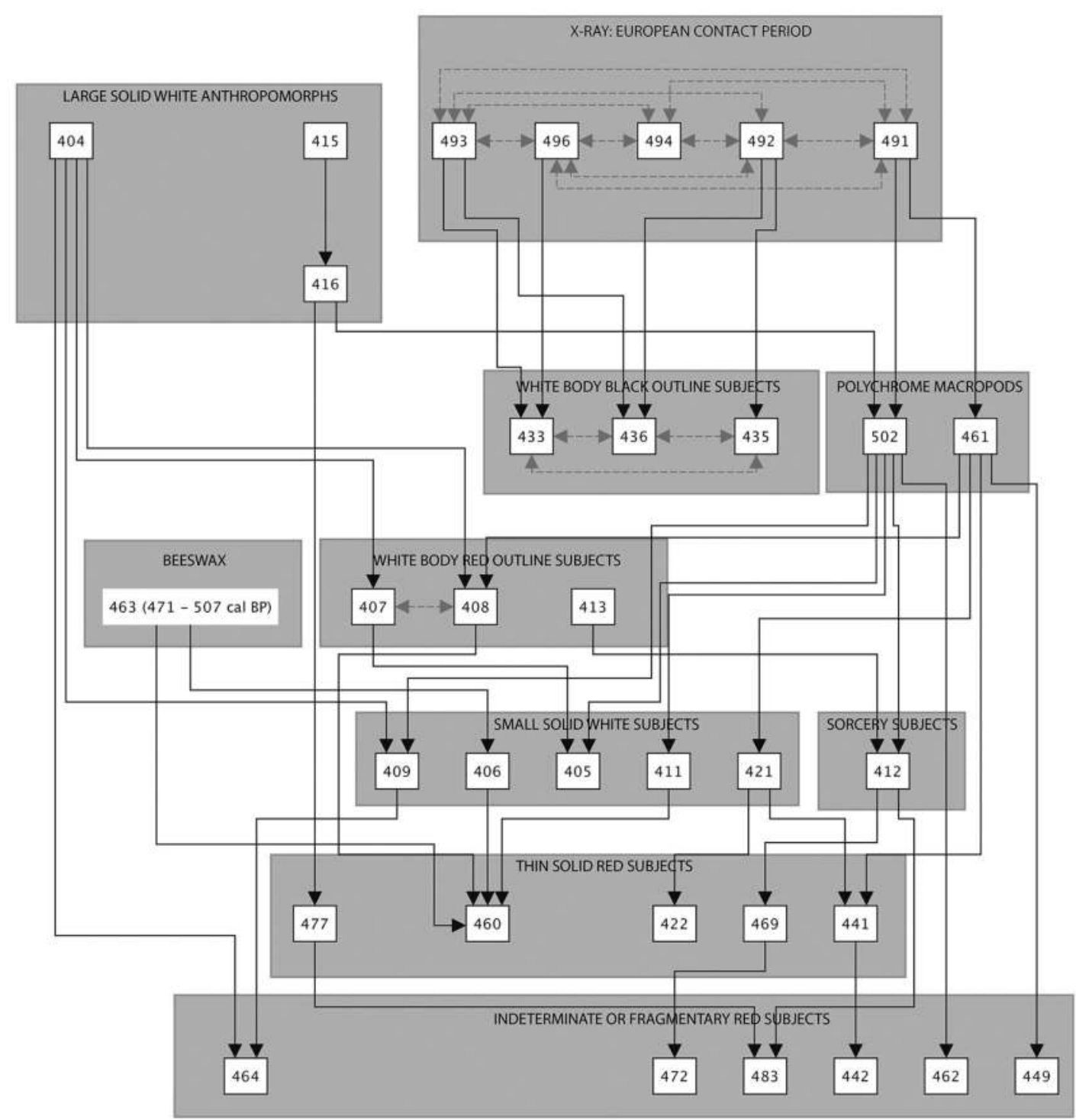

Figure 13.39 Harris Matrix showing chrono-stratigraphic relationship of images for painted ceiling at Dalakngalarr 1.

Note: Descriptive designations for images (e.g. 'Large solid white anthropomorphs', 'Sorcery subjects') are further elaborated in James in prep.

Source: Illustration by Daniel James.

\section{Beeswax Figure 2}

This figure, on the ceiling's flat, horizontal overhang a short distance from the rear wall of the shelter, consists of a nodule of beeswax superimposed by a red male anthropomorph with a macropod/bird foot (Figures 13.40-13.42). The macropod/bird-footed anthropomorph is unlike the macropod-footed anthropomorph found near Beeswax Figure 1. This one is not depicted in contorted perspective (compare Figures 13.40 and 13.43), arms and hand are sloped downwards, a penis is evident and the feet are shown in twisted perspective. But, like the other one, one foot appears to be human-shaped, the other either macropod or bird-like in shape. These similarities suggest that both paintings express a common system of meaning relating to Spirit-Beings and Dalakngalarr 1's repeated locational meaningfulness. 
The radiocarbon date for Beeswax Figure 2 is $367 \pm 25 \mathrm{BP}$ (Wk-35510), which calibrates to 332-489 cal BP (with a median probability of 437 cal BP; Table 13.11); the macropod/birdfooted being must be of similar age or younger.

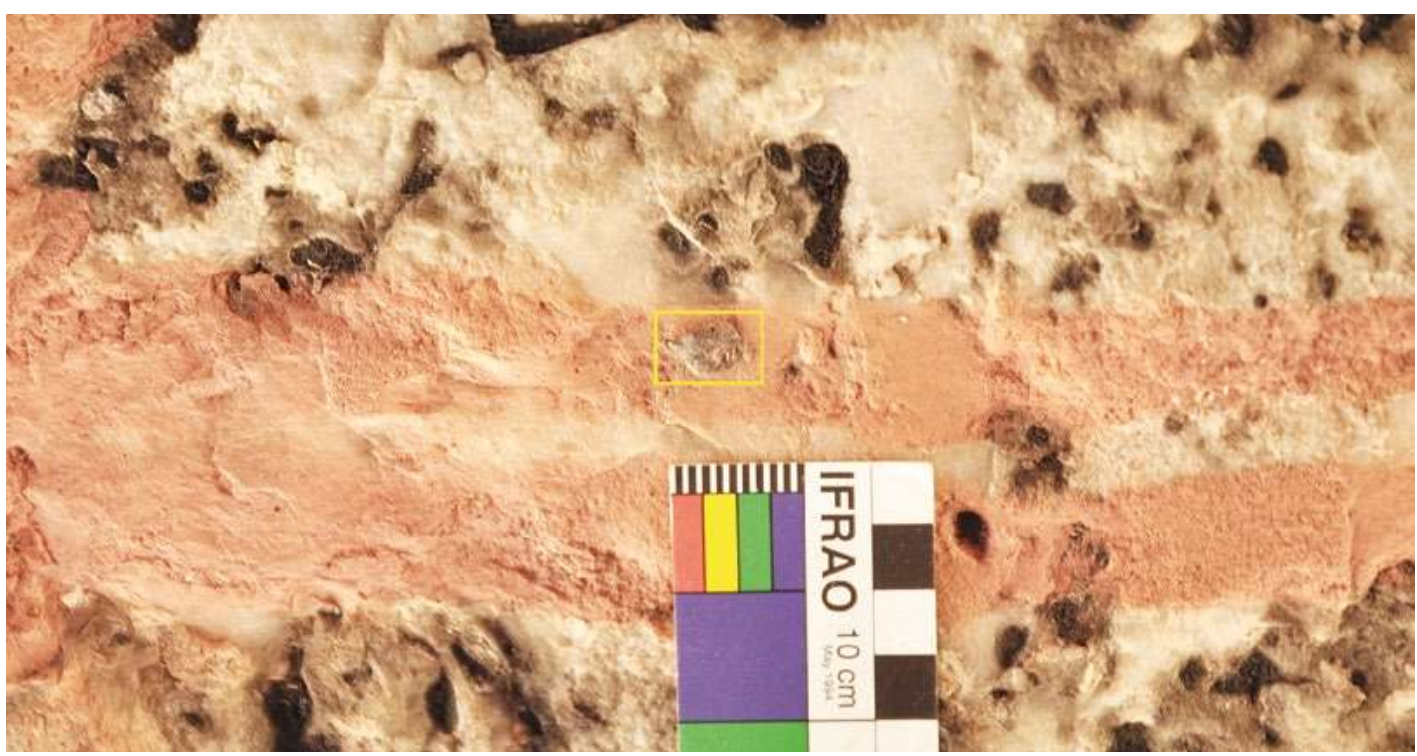

Figure 13.40 Location of Beeswax Figure 2 (yellow box). Visible portion of scale, $1 \mathrm{~cm}$ per black or white square.

Source: Photograph by Daniel james.

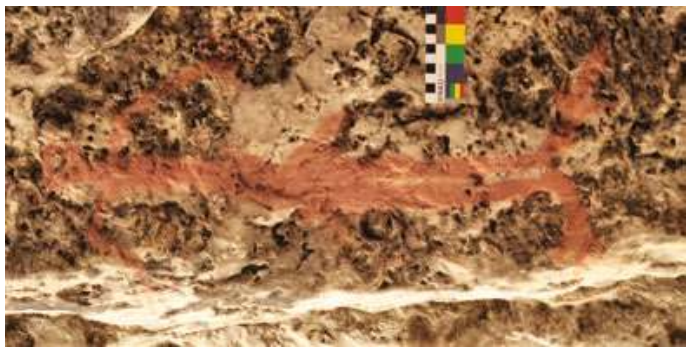

Figure 13.41 Red macropod/bird-footed anthropomorph superimposing Beeswax Figure 2, Panel C18.

Source: Photograph by Daniel James.

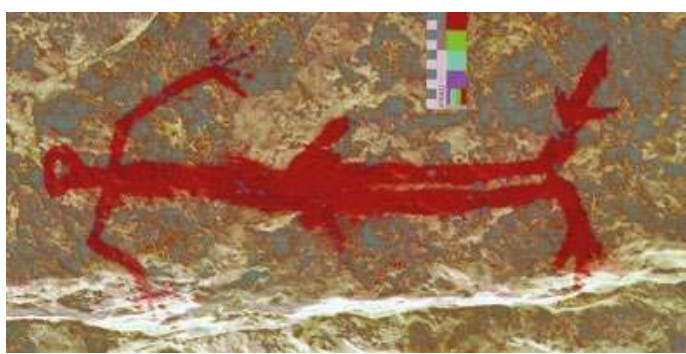

Figure 13.42 Red macropod/bird-footed anthropomorph beneath Beeswax Figure 2, Panel C18, after DStretch_yrd10 enhancement. Scale $10 \mathrm{~cm}$.

Source: Photograph and enhancement by Daniel James.

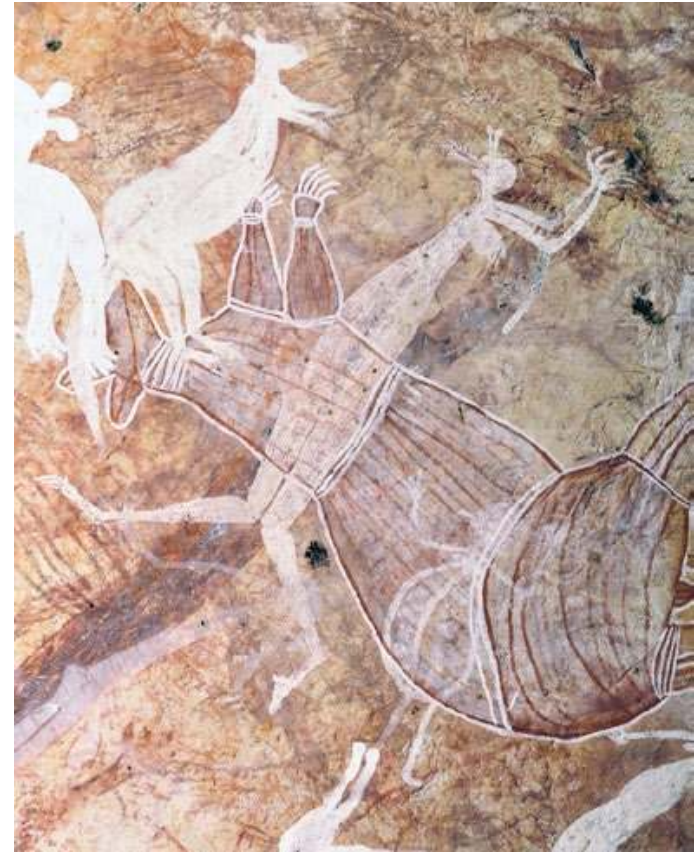

Figure 13.43 Macropod-footed female anthropomorph on ceiling panel that contains Beeswax Figure 1.

Source: Photograph by Daniel James. 


\section{Beeswax Figure 3}

This piece of beeswax is found on the rear wall in the southwestern corner of the shelter, on the topmost vertical surface. It is a small nodule of beeswax that had, at the time of recording, partially lifted off the rock surface (Figures 13.44 and 13.45). No paintings are evident under it. This beeswax nodule dates to $117 \pm 25 \mathrm{BP}$ (Wk-35511), which calibrates to 25-260 cal BP with a median probability of $115 \mathrm{cal} \mathrm{BP}$.

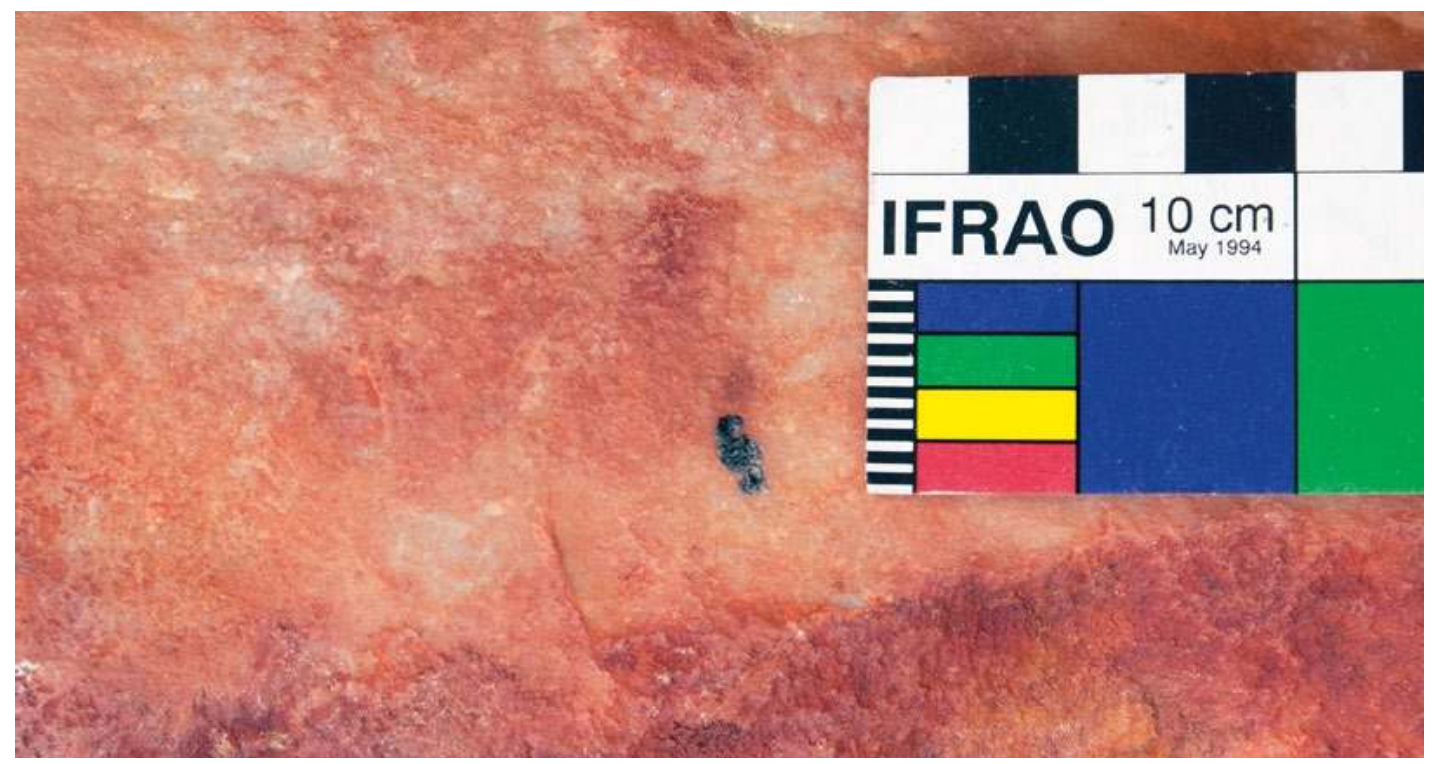

Figure 13.44 Close-up of Beeswax Figure 3. Scale units in $1 \mathrm{~cm}$ white or black squares.

Source: Photograph by Daniel James.

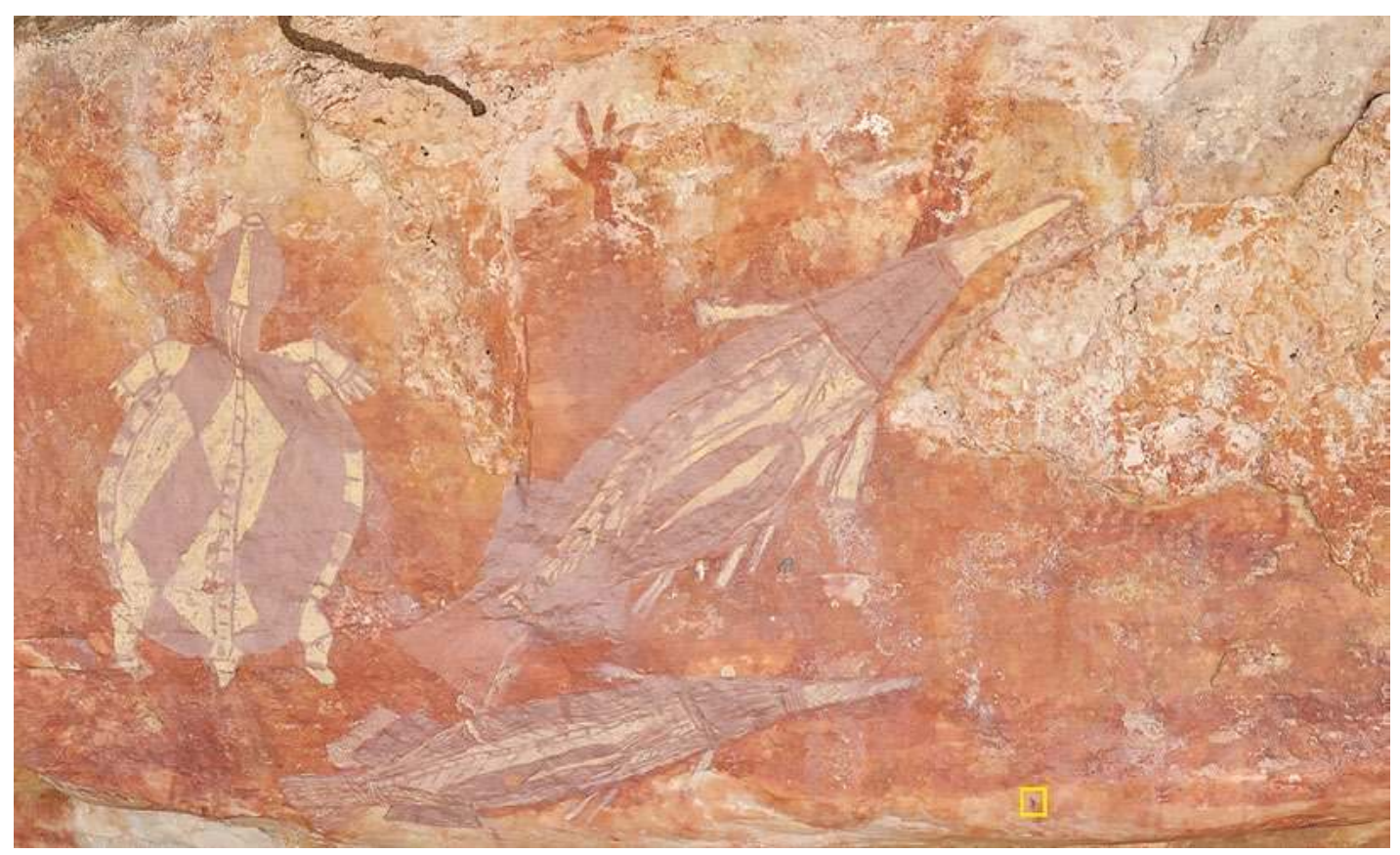

Figure 13.45 Location of Beeswax Figure 3, in small yellow square near bottom right.

Source: Photograph by Daniel James. 


\section{Beeswax Figure 4}

This small amorphous piece of beeswax is located on a small, overhanging rock surface towards the southwestern corner of the shelter, where rock art is generally poorly preserved. It superimposes very faded indeterminate traces of red pigment (Figures 13.46-13.48). A radiocarbon date of $1870 \pm 25$ BP (Wk-35512) for the beeswax gives a calibrated age of 1741-1867 cal BP with a median probability of $1817 \mathrm{cal}$ BP (Table 13.11). The underlying faded red paintings are of a similar age or older.

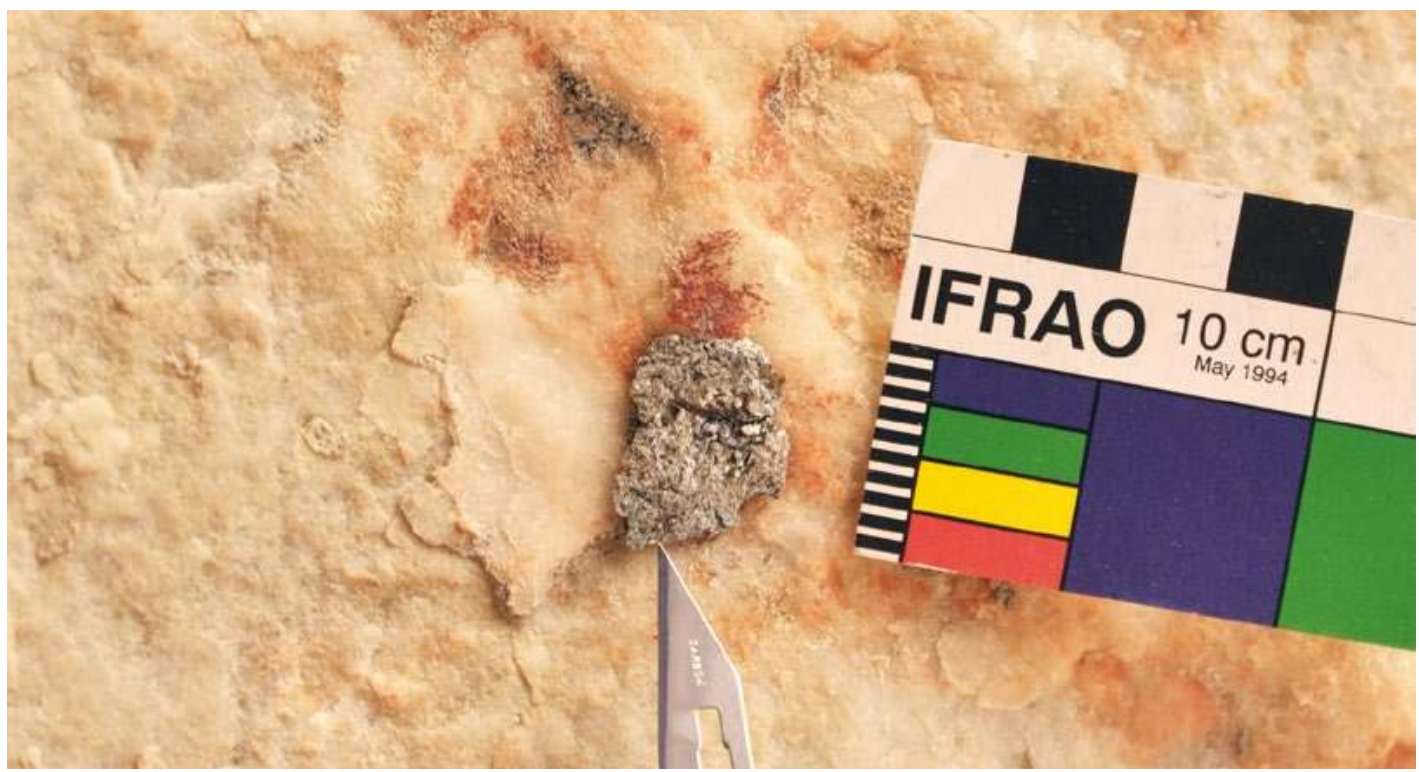

Figure 13.46 Close-up photograph of Beeswax Figure 4. Scale units in $1 \mathrm{~cm}$ squares.

Source: Photograph by Daniel James.

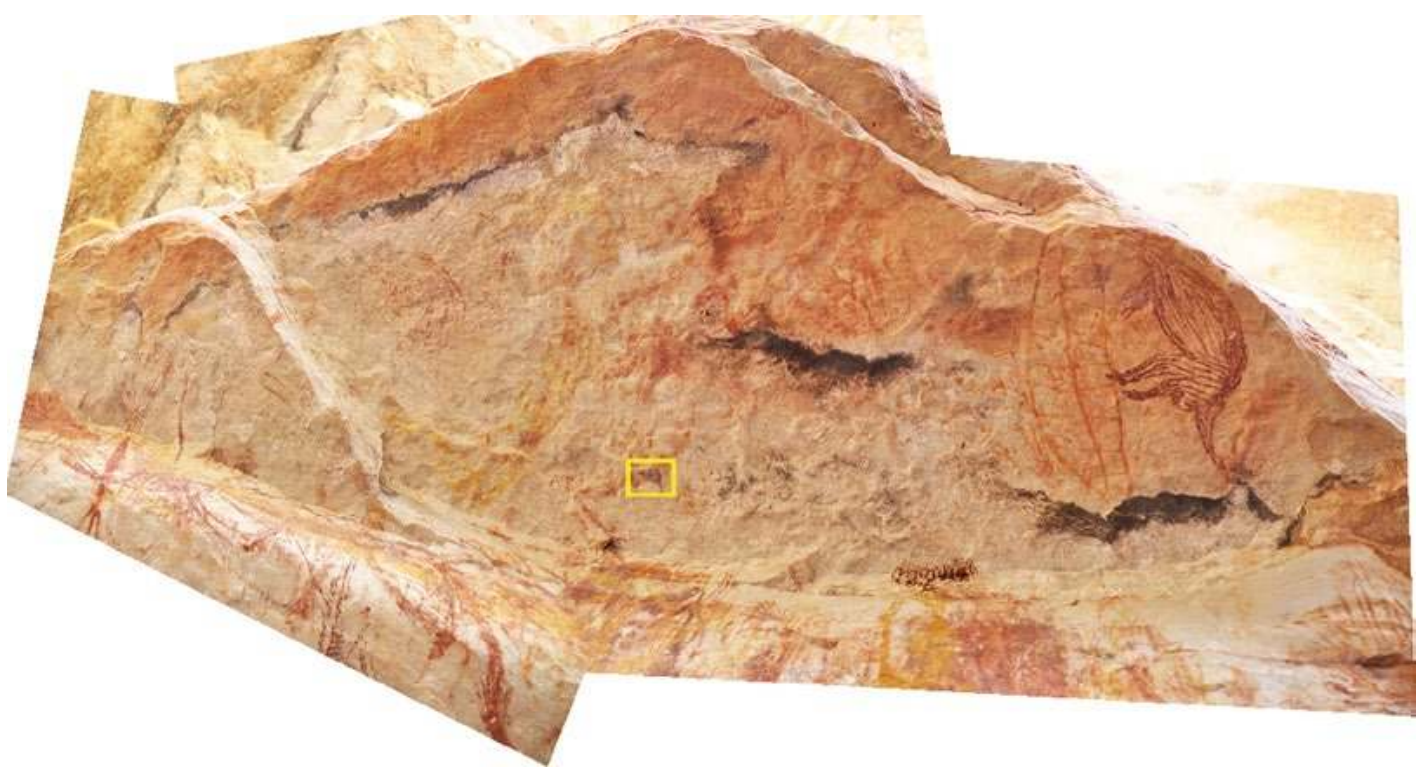

Figure 13.47 Panel C4 panorama showing location of Beeswax Figure 4, yellow rectangle.

Source: Photograph by Daniel James. 


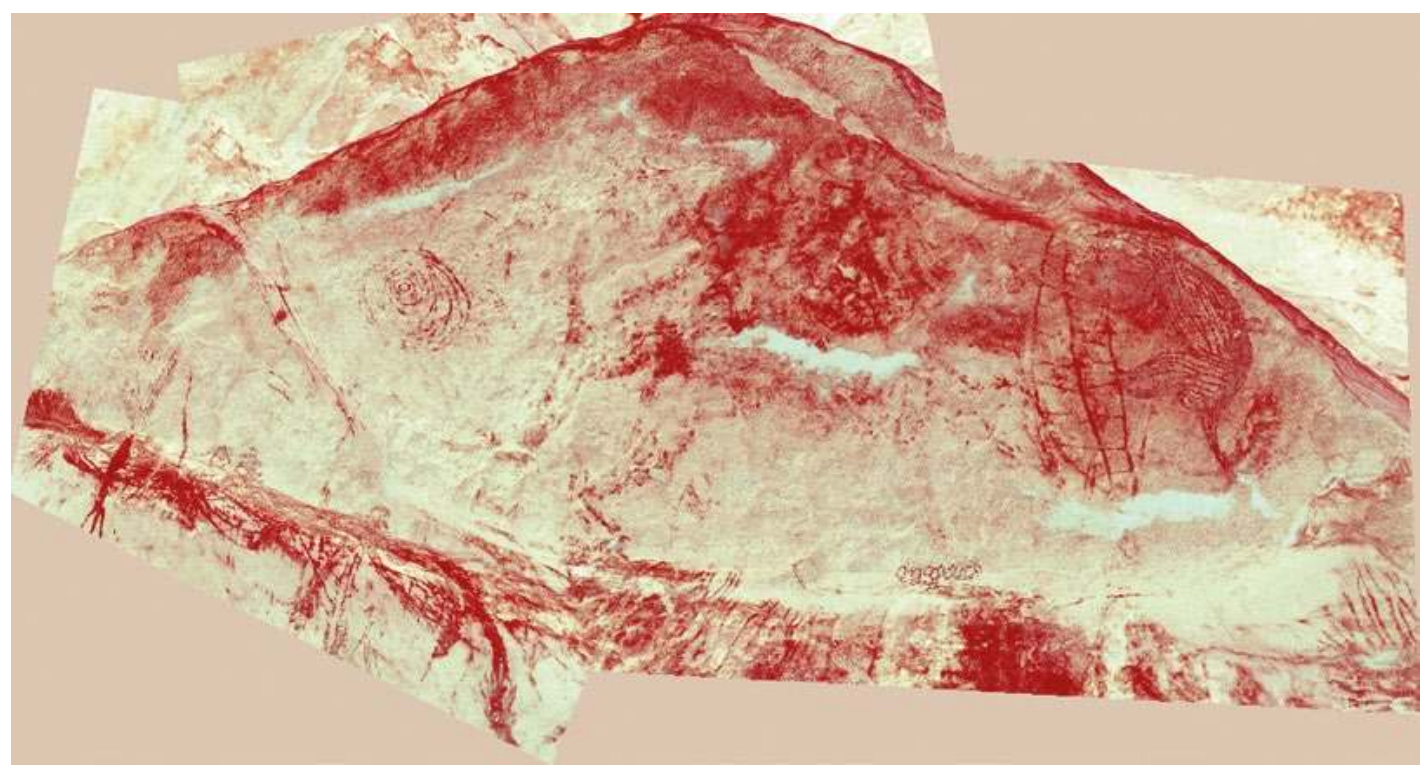

Figure 13.48 Panel C4 panorama of art panel with Beeswax Figure 4, after DStretch_yre10 enhancement.

See Figure 13.47 for location of the beeswax figure.

Source: Photograph and enhancement by Daniel James.

\section{Dalakngalarr 1 summarised}

Two broad depositional phases have been identified for Dalakngalarr 1: Phase 1 begins sometime between 4969-5211 cal BP (Square A) and extends either continuously or intermittently to the period 1186-1281 cal BP (Square B); Phase 2 begins between 0-290 cal BP (Square A) and ends sometime in the early European-contact period. Through a combination of four lines of evidence, we have been able relatively and 'directly' to date art to both depositional phases. Of particular interest is the attribution of forms or 'styles' of X-ray art and use of specific pigment colours to the early European-contact period. All this is consistent with other findings from Jawoyn Country (see Chapters 11 and 12).

\section{Acknowledgements}

This study was undertaken as part of Daniel James' $\mathrm{PhD}$ research in Jawoyn Country, fully supported by Margaret Katherine, senior Traditional Owner of the Buyhmi clan estate, and the Jawoyn Association, Katherine. Our thanks go to Chris Urwin (Monash University) and Britt Wilson for assisting with fieldwork, and Simon Owen who flew us to the site daily. Thanks to Valerie Caron (entomologist, Monash University) for information regarding antlion nymphs, Holly Jones (cultural materials conservator, Monash University) for comments on the metal tools, Steve Morton (Scientific Imaging Services, Monash University) for photographs of metal tools (Figure 13.31) and Monash University School of Medical Imaging and Radiation for Figure 13.32. We thank the Australian Research Council for Linkage grant LP1 10200927 and Discovery Outstanding Research Award (DORA) Fellowship (to BD) DP130102514, with additional funding provided under the George Chaloupka Fellowship, an initiative of the Museum and Art Gallery of the Northern Territory Foundation, sponsored by Energy Resources of Australia (ERA) Ltd, of which both DJ (2012) and RG (2009) were recipients. 


\section{References}

Allen, H. and G. Barton 1989. Ngarradj Warde Djobkeng: White Cockatoo Dreaming and the Prehistory of Kakadu. Sydney University Press, Sydney.

Chaloupka, G. 1993. Journey in Time: The World's Longest Continuing Art Tradition. Reed, Chatswood.

Dalan, R.A. 2007. A review of the role of magnetic susceptibility in archaeogeophysical studies in the USA: Recent developments and prospects. Archaeological Prospection 15(1):1-31. doi.org/10.1002/ arp.323

Dalan, R.A. and S.K. Banerjee 1998. Solving archaeological problems using techniques of soil magnetism. Geoarchaeology 13:3-36. doi.org/10.1002/(SICI)1520-6548(199801)13:1<3::AIDGEA2 $>3.0 . \mathrm{CO} ; 2-9$

Delannoy, J.-J., B. David, J.-M. Geneste, M. Katherine, B. Barker, R.L. Whear and R.G. Gunn 2013. The social construction of caves and rockshelters: Chauvet Cave (France) and Nawarla Gabarnmang (Australia). Antiquity 87:12-29. doi.org/10.1017/S0003598X00048596

Dubin, L.S. 2006. The History of Beads from 30,000 B.C. to the Present. Thames and Hudson, London.

Ferenczi, P.A. and I.P. Sweet 2004. Mount Evelyn, Northern Territory 1:250 000 Geological Map Series, SE53-05 (Second Edition). Northern Territory Geological Survey, Darwin.

Francis, P. 1991. Some thoughts on the bead trade. The Margaretologist 4(2):3-12.

Francis, P. 1994. Beads of the World. Schiffer Publishing, Atglen.

Gunn, R.G. and R.L. Whear 2007. The Jawoyn Rock Art and Heritage Project. Rock Art Research 24:5-20.

Gunn, R.G., L.C. Douglas and R.L. Whear 2012. Standing stones: An unrecorded form of stone arrangement from the Jawoyn lands of the Arnhem Land plateau. Australian Archaeology 75:37-45. doi.org/10.1080/03122417.2012.11681948

Harris, E. 1987. A Bead Primer. The Bead Museum, Prescott.

Herries, A.I.R. and E.C. Fisher 2010. Multidimensional GIS modeling of magnetic mineralogy as a proxy for fire use and spatial patterning: Evidence from the Middle Stone Age bearing sea cave of Pinnacle Point 13B (Western Cape, South Africa). Journal of Human Evolution 59:306-320. doi.org/10.1016/j.jhevol.2010.07.012

Hodgskiss, T. 2010. Identifying grinding, scoring and rubbing use-wear on experimental ochre pieces. Journal of Archaeological Science 37: 3344-3358. doi.org/10.1016/j.jas.2010.08.003

James, D. in prep. The Painted Past: The Rock-Art of Dalakngalarr 1, Jawoyn Country, Arnhem Land. Unpublished PhD thesis. Monash University, Clayton.

Jones, R. and I. Johnson 1985. Dead Adder Gorge: Lindner Site, Nauwalabila 1. In R. Jones (ed.), Archaeological Research in Kakadu National Park, 165-227. Special Publication 13. Australian National Parks and Wildlife Service, Canberra.

Lane, R., G. Beckitt and M. Duffett 2007. 3D geological mapping and potential field modelling of west Arnhem Land, Northern Territory. ASEG Extended Abstracts 1:1-9. doi.org/10.1071/ ASEG2007ab072

Lewis, D. 1988. The Rock Paintings of Arnhem Land, Australia. BAR International Series 415. British Archaeological Reports, Oxford. 
Lowe, K.M. 2014. Understanding Australia’s Cultural Heritage through Archaeological Geophysics. Unpublished PhD thesis. University of Queensland, St Lucia.

Marwick, B. 2005. Element concentrations and magnetic susceptibility of anthrosols: Indicators of prehistoric human occupation in the inland Pilbara, Western Australia. Journal of Archaeological Science 32:1357-1368. doi.org/10.1016/j.jas.2005.03.009

Morphy, H. 1992. From dull to brilliant: The aesthetics of spiritual power among the Yolngu. In J. Coote and A. Shelton (eds), Anthropology, Art, and Aesthetics, pp. 181-208. Clarendon Press, Oxford.

Reimer, P.J., E. Bard, A. Bayliss, J.W. Beck, P.G. Blackwell, C. Bronk Ramsey, C.E. Buck, H. Cheng, R.L. Edwards, M. Friedrich, P.M. Grootes, T.P. Guilderson, H. Haflidason, I. Hajdas, C. Hatté, T.J. Heaton, D.L. Hoffmann, A.G. Hogg, K.A. Hughen, K.F. Kaiser, B. Kromer, S.W. Manning, M. Niu, R.W. Reimer, D.A. Richards, E.M. Scott, J.R. Southon, R.A. Staff, C.S.M. Turney and J. van der Plicht 2013. IntCal13 and Marine13 radiocarbon age calibration curves, 0-50 000 years cal BP. Radiocarbon 55 (4):1869-1887. doi.org/10.2458/azu_js_rc.55.16947

Rifkin, R. 2012. Processing ochre in the Middle Stone Age: Testing the inference of prehistoric behaviours from actualistically derived experimental data. Journal of Anthropological Archaeology 31:174-195. doi.org/10.1016/j.jaa.2011.11.004

Selwyn, L. 2004. Metals and Corrosion: A Handbook for the Conservation Professional. Canadian Conservation Institute, Ottowa.

Sprague, R. 1985. Glass trade beads: A progress report. Historical Archaeology 19(2):87-105. doi.org/10.1007/BF03373477

Stephens, S.P. 2013. Snapshots of the Holocene: Analysis of Technological Organisation at Little Barra, Jawoyn Country, Western Arnhem Land. Unpublished BA (Hons) thesis, Monash University, Clayton.

Taçon, P. S. C. 1989a. Art and the essence of being: Symbolic and economic aspects of fish among the peoples of western Arnhem Land, Australia. In H. Morphy (ed.), Animals into Art, pp. 236-252. Unwin Hyman, London.

Taçon, P. S. C. 1989b. From Rainbow Snakes to 'X-Ray' Fish: The Nature of the Recent Rock Painting Tradition of Western Arnhem Land, Australia. Unpublished PhD thesis. The Australian National University, Canberra.

Wesley, D. and M. Litster 2015. 'Small, individually nondescript and easily overlooked': Contact beads from northwest Arnhem Land in an Indigenous-Macassan-European hybrid economy. Australian Archaeology 80:1-16. doi.org/10.1080/03122417.2015.11682040

Young, R.W., R.A.L. Wray and A.R.M. Young 2009. Sandstone Landforms. Cambridge University Press, Cambridge. 



\title{
14
}

\section{Determining the age of paintings at JSARN-113/23, Jawoyn Country, central-western Arnhem Land plateau}

\author{
Bruno David, Jean-Jacques Delannoy, Robert Gunn, Liam M. Brady, \\ Fiona Petchey, Jerome Mialanes, Emilie Chalmin, Jean-Michel \\ Geneste, Ian Moffat, Ken Aplin and Margaret Katherine
}

\section{Introduction}

Western Arnhem Land in northern Australia has the rare distinction, both at national and global scales, of containing a vast landscape of many thousands of rockshelters richly decorated with art, some of which was probably made tens of thousands of years ago, others as recently as a few decades ago. Yet the challenge remains as to how to date this art, how to find out how old it is. While relative dating methods have been commonly applied, in particular patterns of superimposition and changing faunal themes supposedly signalling changing environmental conditions, we still lack a clear understanding of the age of almost all the region's art styles or conventions.

Other chapters in this volume report direct dates for Arnhem Land art using radiocarbon determinations on beeswax figures with the likelihood that the 'art event', the time when a beeswax figure was made, is at most a few years different from the 'carbon event', the time of the last biological capture of atmospheric carbon, which is the actual date measured by radiocarbon. But many, in fact most, sites have no beeswax figures or other ways directly to date the art. Sometimes, as again reported in this volume, there is some indication of date when a radiocarbon determination is obtained on, for instance, charcoal in an archaeological deposit that can be related to the art. Often that route is also blocked: many a painted surface without beeswax figures is in no close relation to a deposit that might so be dated. What can be done then?

Here we present results of investigations at a small rockshelter in Jawoyn Country, in the centralwestern part of the Arnhem Land plateau. Since its art cannot be directly dated, we follow a different path. In the first instance, we aim to understand the history, and antiquity, of the decorated rock surfaces, since the exposed surfaces of the boulder have undergone repeated transformations over a long time. Determining when now-decorated rock surfaces were formed can give us maximum possible ages for the art, since we can date when the surface first was available. Taken with related archaeological evidence from deposits, such as ochre fragments with signs of use, we can arrive at some indications for the age of the art, or at least how the range of possible dates is constrained. This approach is akin to that used at other sites in Jawoyn Country (see Chapters 11 and 15) 


\section{Site JSARN-0113/23}

The small, shallow rockshelter site JSARN-113/23 in the Jawoyn Association's GIS database is on the southeastern side of a massive quartzite stack of the Kombolgie Formation that also contains site JSARN-113/19 on its opposite side (Figures 14.1-14.3). This boulder stack is located $150 \mathrm{~m}$ south of JSARN-124 site 3, which is studied in Chapter 15 (see Gunn et al. 2011 for details; Figure 1.1). All these sites are on Buyhmi clan lands in Jawoyn Aboriginal Country (see Gunn et al. 2011 for the site's environment).

The boulder stack sheltering JSARN-113/23 is a sub-horizontally bedded tilted block, individual rock strata dipping slightly southward. The shelter is $5 \mathrm{~m}$ wide across the dripline, $3 \mathrm{~m}$ deep from dripline to back wall, has an $87^{\circ}$ mean aspect (i.e. it faces east) and is well-shaded in the afternoon, with sunlight illuminating the floor and part of the wall in the morning. The back wall appears to be well protected from rainfall. The floor is flat and sandy. The northern end is bounded by massive rockfall that rises steeply above ground, demarcating the edge of the site. Across the shelter, the floor level is flush with the surrounding plain. Spinifex (Triodia sp.) hummocks and small Eucalyptus trees grow from the dripline onto the plain.

Square A was excavated under a low, convex, steep and slightly protruding rock overhang. Here, two superimposed rows of red stick-figure anthropomorphs (from here on, 'stick-figures') occur over red-and-yellow bichrome anthropomorphs on a fresh rock surface.

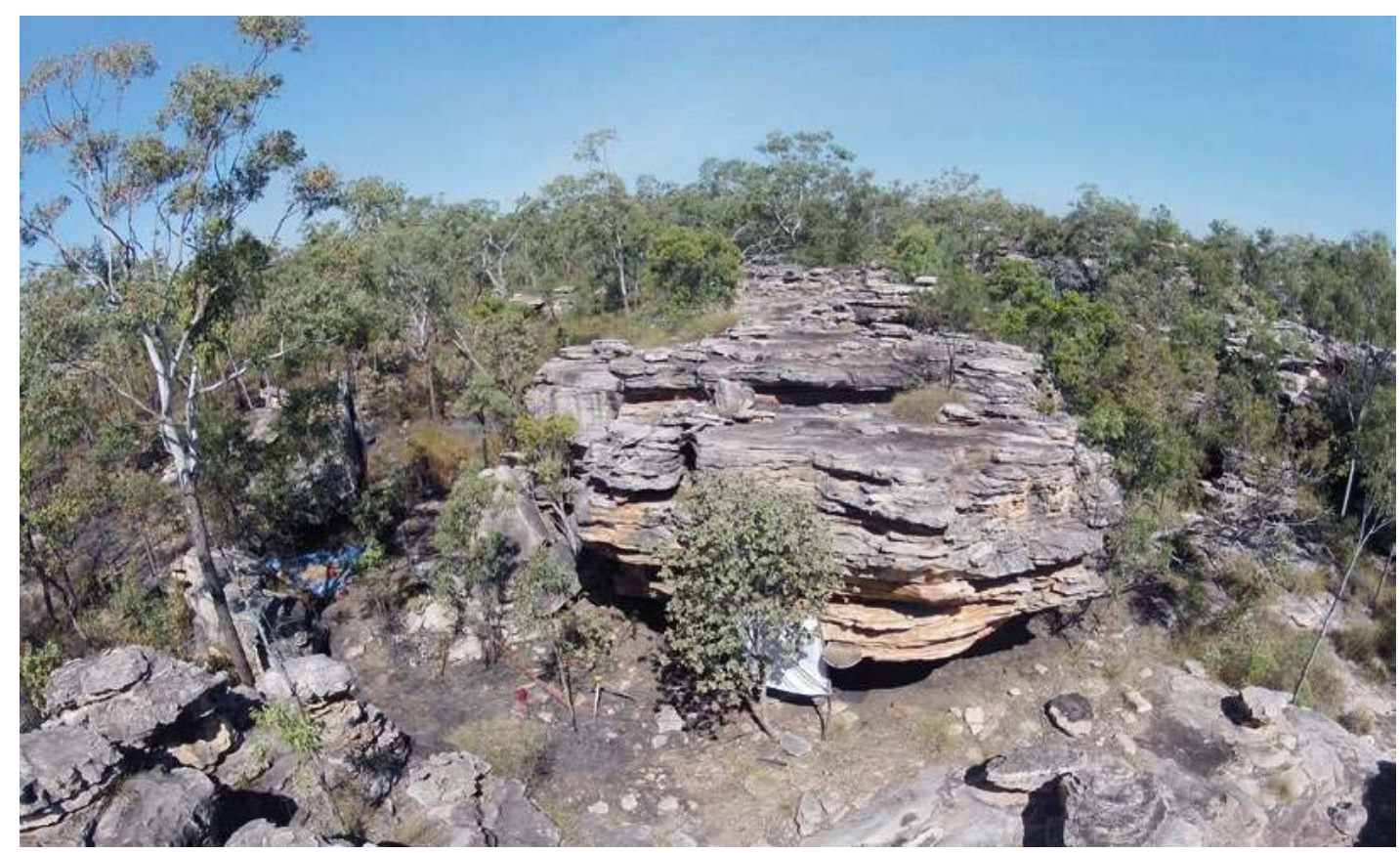

Figure 14.1 Massive quartzite boulder stack containing JSARN-113/23 (on left-hand side of boulder) and JSARN-113/19 (overhang, right-hand side of boulder) on opposite sides. Excavations in progress, 2012. Source: Photograph by Bernard Sanderre. 


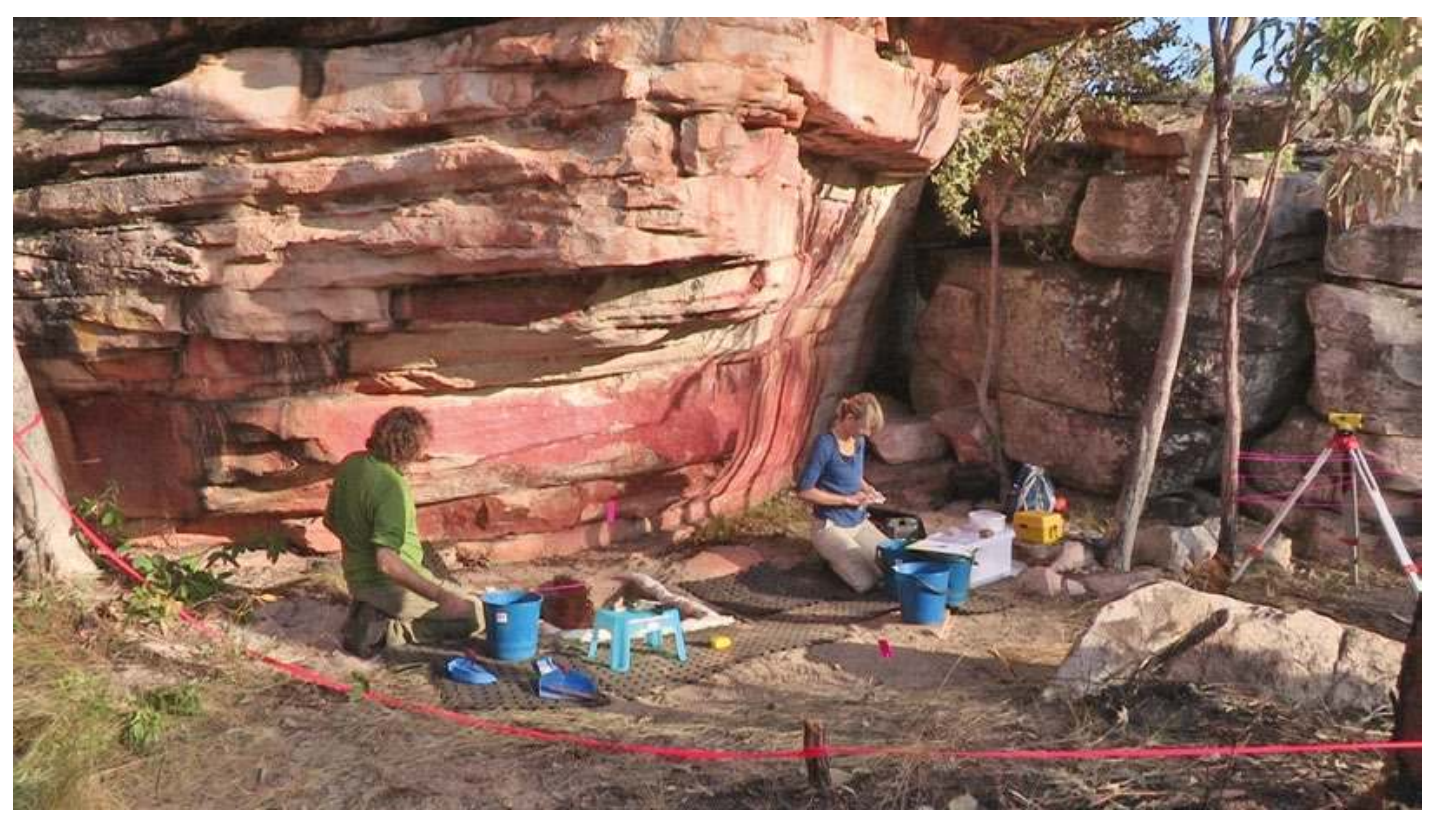

Figure 14.2 Site JSARN-113/23, excavation in progress.

Source: Photograph by Bernard Sanderre.

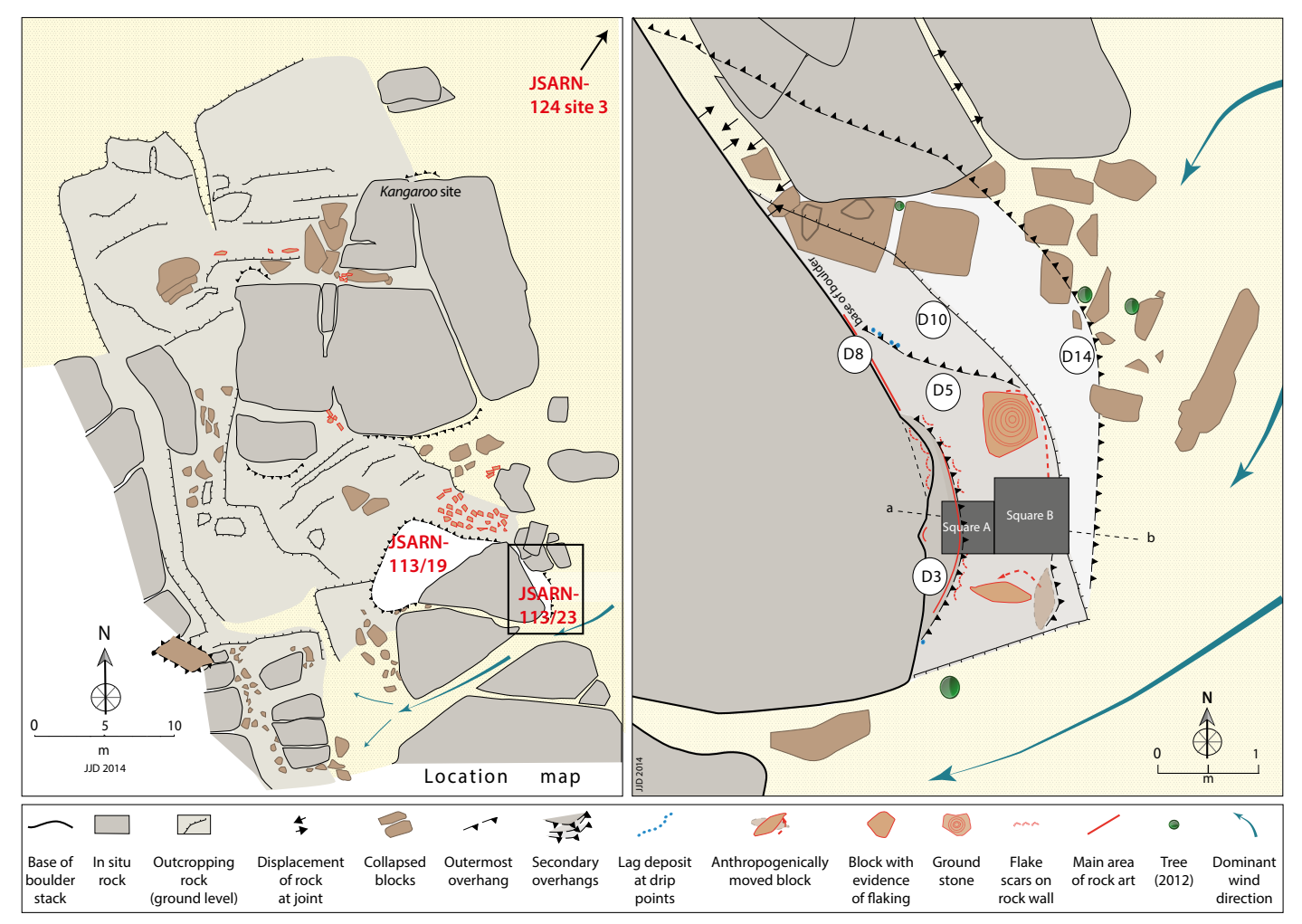

Figure 14.3 Plan of JSARN-113/23.

Source: Illustration by Jean-Jacques Delannoy. 


\section{Excavation methods}

Excavations were undertaken over two field seasons (2011 and 2012), under the shallow overhang that contains the stick-figures. Our aim was to recover fragments of rock that had detached from the wall prior to the paintings being made, creating the wall surface in the process and giving a maximum age for the art on it.

Square A began as a $50 \times 50 \mathrm{~cm}$ square, reduced to $50 \times 40 \mathrm{~cm}$ below $2.4 \mathrm{~cm}$ depth, to avoid a small termite runway at the western edge of the pit. Square A was excavated in mean $1.8 \pm 0.6 \mathrm{~cm}$ thick arbitrary Excavation Units (XUs) following the stratigraphy (Table 14.1). Excavation went down $39 \mathrm{XUs}$ to a maximum depth of $71.1 \mathrm{~cm}$.

In 2012, Square B, $75 \times 75 \mathrm{~cm}$ in area, was added against the eastern wall of Square A. It was reduced to an area $75 \times 50 \mathrm{~cm}$ when overhanging rocks were reached in XU14 (i.e. below $26 \mathrm{~cm}$ depth). Square B was excavated in $2.2 \pm 0.6 \mathrm{~cm}$ thick XUs following the stratigraphy (Table 14.2); excavation progressed for $19 \mathrm{XUs}$ to a maximum depth of $41 \mathrm{~cm}$ (Figures 14.3 and 14.4).

Table 14.1 Square A: Details of XUs.

\begin{tabular}{|c|c|c|c|c|c|c|c|c|c|}
\hline XU & SU & $\begin{array}{c}\text { Mean depth } \\
\text { at top }(\mathrm{cm})\end{array}$ & $\begin{array}{c}\text { Mean depth at } \\
\text { centre }(\mathrm{cm})\end{array}$ & $\begin{array}{l}\text { Mean depth } \\
\text { at base }(\mathrm{cm})\end{array}$ & $\begin{array}{c}\text { Mean thickness } \\
(\mathrm{cm})\end{array}$ & Area $\left(\mathrm{m}^{2}\right)$ & $\begin{array}{l}\text { Weight } \\
(\mathrm{kg})\end{array}$ & $\begin{array}{l}\text { Volume } \\
\text { (litres) }\end{array}$ & $\mathrm{pH}$ \\
\hline 1 & 1 & 0.0 & 0.6 & 1.2 & 1.2 & 0.25 & 3.9 & 2.5 & 6.30 \\
\hline 2 & $1+2$ & 1.2 & 1.8 & 2.4 & 1.2 & 0.25 & 4.4 & 3.0 & \\
\hline 3 & $1+2$ & 2.4 & 3.2 & 4.0 & 1.6 & 0.20 & 4.7 & 3.0 & \\
\hline 4 & 2 & 4.0 & 5.0 & 5.9 & 1.9 & 0.20 & 5.2 & 3.5 & \\
\hline 5 & 2 & 5.9 & 6.9 & 6.8 & 0.9 & 0.20 & 3.2 & 2.0 & 5.44 \\
\hline 6 & $2+3$ & 6.8 & 8.1 & 9.3 & 2.5 & 0.20 & 6.4 & 4.5 & \\
\hline 7 & $2+3$ & 9.3 & 9.7 & 10.0 & 0.7 & 0.20 & 3.4 & 2.0 & \\
\hline 8 & $2+3$ & 10.0 & 11.5 & 13.0 & 3.0 & 0.20 & 9.3 & 7.0 & \\
\hline 9 & $2+3$ & 13.0 & 13.7 & 14.3 & 1.3 & 0.20 & 4.7 & 3.0 & \\
\hline 10 & 3 & 14.3 & 15.5 & 16.6 & 2.3 & 0.20 & 5.0 & 4.0 & 4.88 \\
\hline 11 & 3 & 16.6 & 17.4 & 18.1 & 1.5 & 0.20 & 5.6 & 4.0 & \\
\hline 12 & 3 & 18.1 & 19.2 & 20.3 & 2.2 & 0.20 & 6.2 & 4.0 & \\
\hline 13 & 3 & 20.3 & 20.9 & 21.4 & 1.1 & 0.20 & 4.6 & 3.0 & \\
\hline 14 & 3 & 21.4 & 22.6 & 23.8 & 2.4 & 0.20 & 5.6 & 3.5 & \\
\hline 15 & 3 & 23.8 & 24.7 & 25.5 & 1.7 & 0.20 & 4.7 & 3.0 & 4.90 \\
\hline 16 & 3 & 25.5 & 26.1 & 26.7 & 1.2 & 0.20 & 5.5 & 4.0 & \\
\hline 17 & 3 & 26.7 & 27.6 & 28.5 & 1.8 & 0.20 & 4.6 & 3.0 & \\
\hline 18 & 3 & 28.5 & 29.5 & 30.5 & 2.0 & 0.20 & 6.4 & 5.0 & \\
\hline 19 & 3 & 30.5 & 31.4 & 32.2 & 1.7 & 0.20 & 5.5 & 4.0 & \\
\hline 20 & 3 & 32.2 & 33.3 & 34.3 & 2.1 & 0.20 & 6.1 & 4.0 & 4.86 \\
\hline 21 & 3 & 34.3 & 35.4 & 36.5 & 2.2 & 0.20 & 5.5 & 3.5 & \\
\hline 22 & 3 & 36.5 & 36.8 & 37.1 & 0.6 & 0.20 & 3.3 & 2.0 & \\
\hline 23 & 3 & 37.1 & 38.2 & 39.3 & 2.2 & 0.20 & 6.2 & 5.0 & \\
\hline 24 & 3 & 39.3 & 39.9 & 40.4 & 1.1 & 0.20 & 3.5 & 2.0 & \\
\hline 25 & 3 & 40.4 & 41.6 & 42.8 & 2.4 & 0.20 & 7.5 & 5.0 & 4.92 \\
\hline 26 & 3 & 42.8 & 44.4 & 45.9 & 3.1 & 0.20 & 6.3 & 5.0 & \\
\hline 27 & 3 & 45.9 & 46.7 & 47.4 & 1.5 & 0.20 & 6.8 & 5.0 & \\
\hline 28 & 3 & 47.4 & 48.1 & 48.7 & 1.3 & 0.20 & 5.1 & 3.0 & \\
\hline 29 & 3 & 48.7 & 49.9 & 51.1 & 2.4 & 0.20 & 5.6 & 4.0 & \\
\hline
\end{tabular}




\begin{tabular}{|l|r|r|r|r|r|r|r|r|r|}
\hline XU & SU & $\begin{array}{c}\text { Mean depth } \\
\text { at top }(\mathbf{c m})\end{array}$ & $\begin{array}{c}\text { Mean depth at } \\
\text { centre }(\mathbf{c m})\end{array}$ & $\begin{array}{r}\text { Mean depth } \\
\text { at base }(\mathbf{c m})\end{array}$ & $\begin{array}{r}\text { Mean thickness } \\
(\mathbf{c m})\end{array}$ & Area $\left(\mathbf{m}^{2}\right)$ & $\begin{array}{c}\text { Weight } \\
(\mathrm{kg})\end{array}$ & $\begin{array}{c}\text { Volume } \\
\text { (litres) }\end{array}$ & $\mathrm{pH}$ \\
\hline 30 & 3 & 51.1 & 51.7 & 52.3 & 1.2 & 0.20 & 5.0 & 4.0 & 4.97 \\
\hline 31 & 3 & 52.3 & 53.4 & 54.5 & 2.2 & 0.20 & 7.0 & 5.0 \\
\hline 32 & 3 & 54.5 & 55.0 & 55.5 & 1.0 & 0.17 & 6.1 & 4.0 \\
\hline 33 & 3 & 55.5 & 56.6 & 57.7 & 2.2 & 0.17 & 5.5 & 3.0 \\
\hline 34 & 3 & 57.7 & 58.5 & 59.2 & 1.5 & 0.18 & 5.2 & 3.0 \\
\hline 35 & 3 & 59.2 & 60.5 & 61.8 & 2.6 & 0.18 & 5.2 & 3.5 \\
\hline 36 & 3 & 61.8 & 63.1 & 64.3 & 2.5 & 0.18 & 5.2 & 4.0 \\
\hline 37 & 3 & 64.3 & 65.1 & 65.9 & 1.6 & 0.18 & 3.4 & 2.0 \\
\hline 38 & 3 & 65.9 & 67.2 & 68.4 & 2.5 & 0.18 & 4.2 & 3.0 \\
\hline 39 & 3 & 68.4 & 69.8 & 71.1 & 2.7 & 0.18 & 4.7 & 3.0 \\
\hline Total & & & & & $1.8 \pm 0.6$ & & 206.3 & 141.0 & \\
\hline
\end{tabular}

Source: Authors' data.

Table 14.2 Square B: Details of XUs.

\begin{tabular}{|l|c|r|r|r|r|r|r|r|}
\hline XU & SU & $\begin{array}{c}\text { Mean depth } \\
\text { at top }(\mathbf{c m})\end{array}$ & $\begin{array}{c}\text { Mean depth at } \\
\text { centre }(\mathbf{c m})\end{array}$ & $\begin{array}{r}\text { Mean depth } \\
\text { at base }(\mathbf{c m})\end{array}$ & $\begin{array}{c}\text { Mean thickness } \\
(\mathbf{c m})\end{array}$ & $\begin{array}{c}\text { Area } \\
\left(\mathbf{m}^{2}\right)\end{array}$ & $\begin{array}{c}\text { Weight } \\
(\mathbf{k g})\end{array}$ & $\begin{array}{c}\text { Volume } \\
(\text { litres })\end{array}$ \\
\hline 1 & $1+2$ & 0.0 & 1.1 & 2.2 & 2.2 & 0.56 & 24.3 & 16.5 \\
\hline 2 & $1+2+3$ & 2.2 & 2.8 & 3.4 & 1.2 & 0.56 & 10.6 & 7.5 \\
\hline 3 & $1+2+3$ & 3.4 & 4.5 & 5.5 & 2.1 & 0.56 & 14.8 & 10.5 \\
\hline 4 & $2+3$ & 5.5 & 6.6 & 7.7 & 2.2 & 0.56 & 16.9 & 13.0 \\
\hline 5 & $2+3$ & 7.7 & 8.4 & 9.1 & 1.4 & 0.56 & 16.7 & 13.0 \\
\hline 6 & $2+3$ & 9.1 & 10.3 & 11.4 & 2.3 & 0.56 & 14.6 & 11.0 \\
\hline 7 & $2+3$ & 11.4 & 12.4 & 13.4 & 2.0 & 0.56 & 16.2 & 11.5 \\
\hline 8 & $2+3$ & 13.4 & 14.3 & 15.2 & 1.8 & 0.56 & 15.8 & 11.0 \\
\hline 9 & $2+3$ & 15.2 & 16.5 & 17.7 & 2.5 & 0.56 & 17.9 & 13.0 \\
\hline 10 & $2+3$ & 17.7 & 18.4 & 19.1 & 1.4 & 0.56 & 14.6 & 10.5 \\
\hline 11 & 3 & 19.1 & 20.2 & 21.2 & 2.1 & 0.56 & 17.2 & 12.0 \\
\hline 12 & 3 & 21.2 & 22.5 & 23.7 & 2.5 & 0.56 & 16.2 & 10.5 \\
\hline 13 & 3 & 23.7 & 25.0 & 26.3 & 2.6 & 0.56 & 13.7 & 10.0 \\
\hline 14 & 3 & 26.3 & 27.2 & 28.0 & 1.7 & 0.45 & 12.7 & 9.0 \\
\hline 15 & 3 & 28.0 & 29.7 & 31.4 & 3.4 & 0.45 & 14.0 & 10.0 \\
\hline 16 & 3 & 31.4 & 32.6 & 33.6 & 2.2 & 0.45 & 12.0 & 7.5 \\
\hline 17 & 3 & 33.6 & 35.2 & 36.7 & 3.1 & 0.38 & 8.8 & 6.0 \\
\hline 18 & 3 & 36.7 & 37.3 & 37.9 & 1.2 & 0.38 & 4.2 & 3.0 \\
\hline 19 & 3 & 37.9 & 39.4 & 40.9 & 3.0 & 0.38 & 10.7 & 7.0 \\
\hline Total & & & & & $2.2 \pm 0.6$ & & 271.9 & 192.5 \\
\hline
\end{tabular}

Source: Authors' data. 


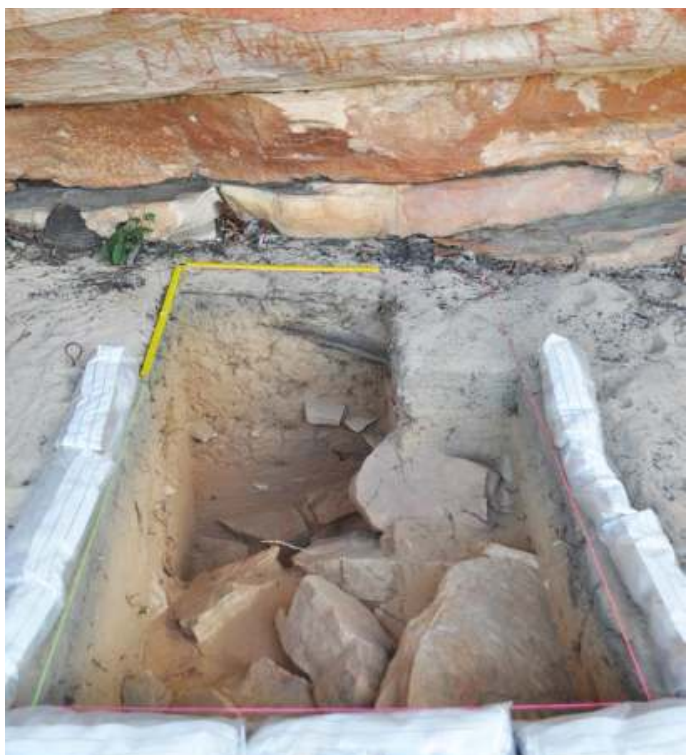

\section{Figure 14.4 Squares A and B after excavation} in 2012.

Source: Photograph by Bruno David.
Excavated sediments were dry-sieved in $2 \mathrm{~mm}$ mesh, with all retained material bagged for sorting at the Monash University archaeology laboratories. Stone artefacts $\geq 2 \mathrm{~cm}$ long were individually plotted and bagged. Bulk sediment samples were collected from each $\mathrm{XU}$ of each square. The walls of the excavated squares were photographed and sections were drawn (e.g. Figures 14.5-14.7).

The base of cultural sediments was not reached in either square; difficulty of access to this remote site, reached only by helicopter, has meant deferment of completion of the excavation.

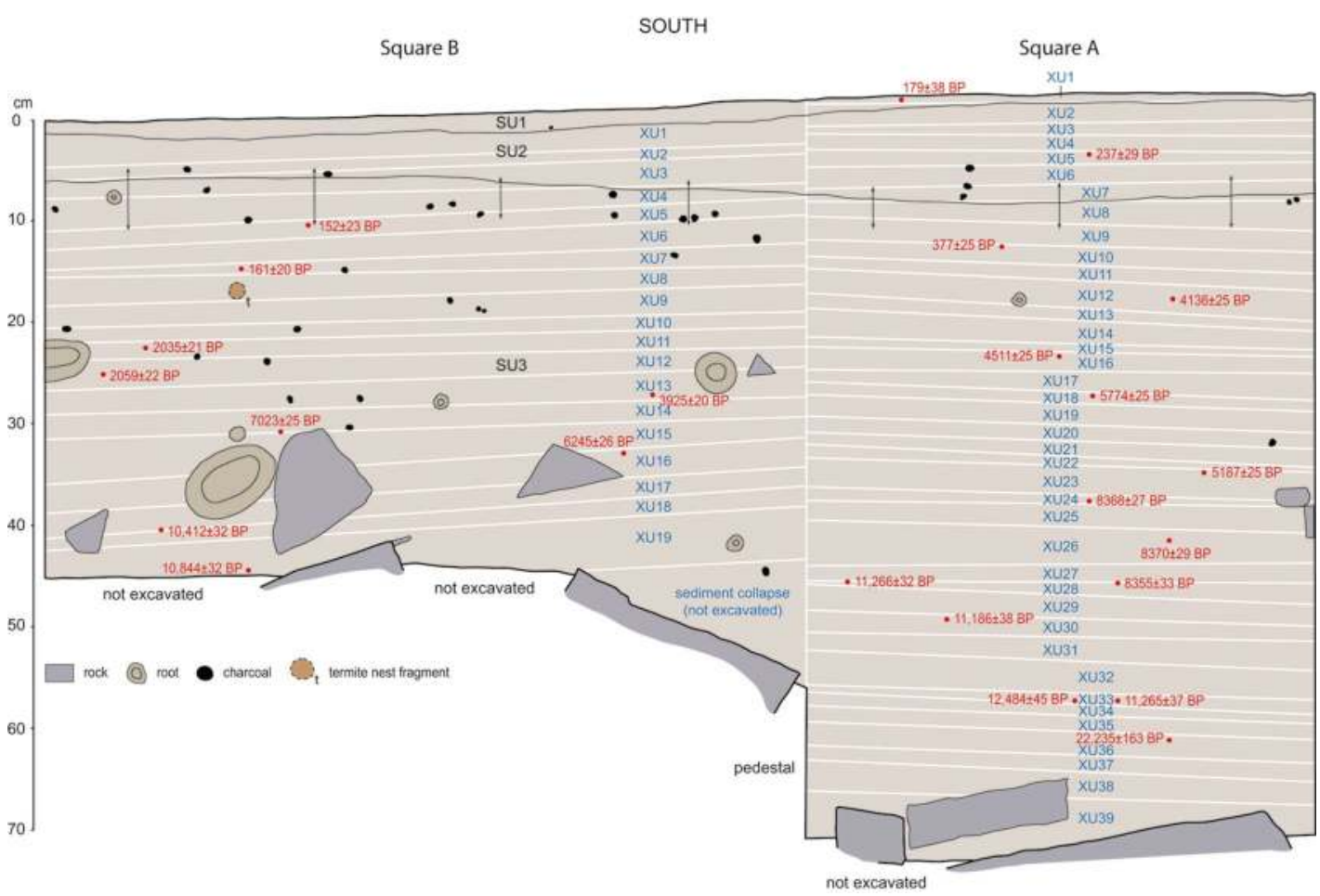

Figure 14.5 South section with XUs and radiocarbon samples back-plotted.

Vertical arrows between SU2 and SU3 represent the zone of stratigraphic interface as indicated by gradual sediment colour and texture changes.

Source: Illustration by Kara Rasmanis and Bruno David. 


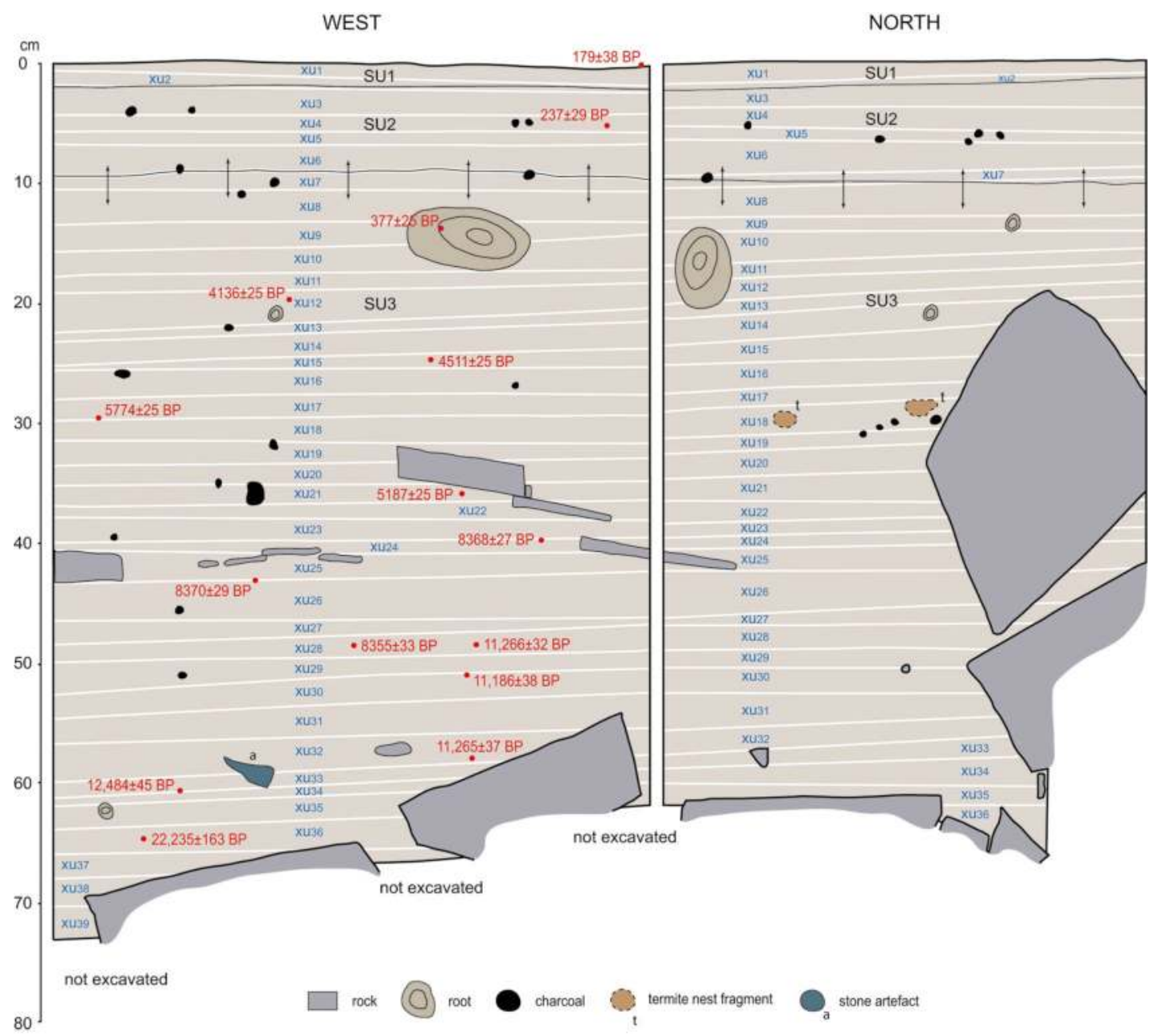

Figure 14.6 West and north sections of Square A with XUs and radiocarbon samples back-plotted.

Vertical arrows between SU2 and SU3 represent the zone of stratigraphic interface as indicated by gradual sediment colour and texture changes. Only the Square A radiocarbon dates are shown.

Source: Illustration by Kara Rasmanis and Bruno David.

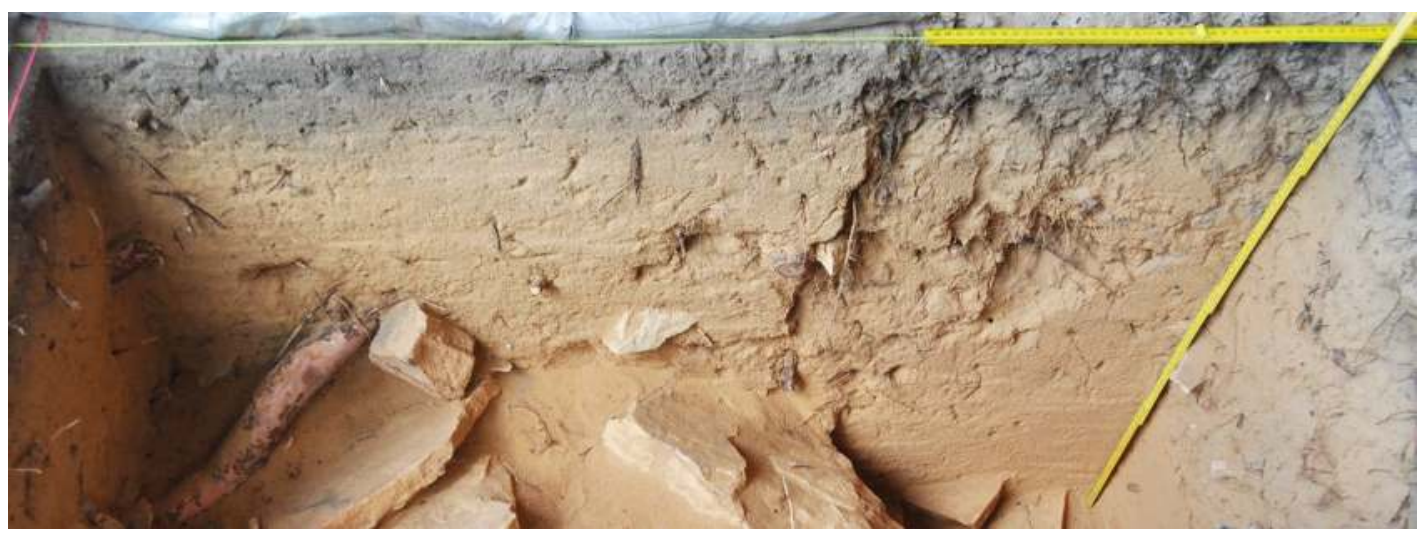

Figure 14.7 South wall of Squares A and B after completion of 2011 and 2012 excavations.

The slightly inset, uneven surface of the right-hand part of the section wall is from Square $A$; it represents the 2011 excavation pit whose walls were 'cleaned up' when the pit was re-opened in 2012.

Source: Photograph by Bruno David. 


\section{Stratigraphy}

Squares A and B contain three stratigraphic units (SUs) (Figures 14.5-14.7). SU1 is the loose surface layer, the present treadage zone. It consists of light brownish-gray (dry Munsell: 10YR 6/2) aeolian sand with minor leaf litter and charcoal. Its boundary with underlying SU2 is horizontal, flat and c. $1 \mathrm{~cm}$ thick. SU2 consists of slightly consolidated and slightly compact grayishbrown (10YR 5/2) ashy, aeolian sand with abundant charcoal and few rootlets. The interface with underlying SU3 is diffuse, c. $7 \mathrm{~cm}$ thick. SU3 is fairly compact and slightly consolidated yellowish-brown (10YR 5/6 to 10YR 5/8) aeolian sand; charcoal decreases with depth and is always more sparse than in SU2.

Within each SU, sediments are homogeneous except in SU3, where many small (typically $10 \mathrm{~cm}$ long and $0.5-2.5 \mathrm{~cm}$ thick) tabular quartzite fragments from the overlying rock wall lie flat or slightly slanted across a well-defined horizon at 35-45 cm depth in Square A (see the west stratigraphic section of Square A, Figure 14.6). At the base of SU3, quartzite rocks with flat surfaces and typically $>30 \mathrm{~cm}$ long occur in a sandy matrix; they lie either flat or slanted. Here, excavation ceased without reaching the base of cultural deposits. The level where the buried rocks were first encountered is deeper in Square A than in Square B, indicating that over c. $1 \mathrm{~m}$ from the back wall towards the dripline, under the overhang with the red and yellow bichrome anthropomorphs and the stick-figures, relatively little rockfall has occurred (see south stratigraphic section, Figure 14.5). It is within this sandy SU3 layer that we have found evidence for the age of the red and yellow bichrome anthropomorphs and stick-figures (see below).

\section{Ground penetrating radar}

Two ground penetrating radar (GPR) profiles were made in 2012, to understand better the site's stratigraphy, depth to bedrock and underground presence of isolated pieces of roof-fall. While GPR is rarely used in this way, it has obvious application in stratigraphic (Neal 2004) and rockshelter investigations (Conyers 2012:66-68). One transect line ran approximately west-east (from back wall to beyond the dripline) a short distance north of Square A, along the northern side of the subsequently excavated Square B. A second line ran approximately north-south (parallel to the back wall) through Square B, a short distance east of Square A. The GPR data were obtained using a Mala X3M unit with a $250 \mathrm{Mhz}$ antenna using a sampling frequency of $5791 \mathrm{Mhz}$, time window of $83 \mathrm{~ns}$, trace interval of $0.02 \mathrm{~m}, 480$ sample and four stacks. The data were processed and interpreted using ReflexW software using a suite of filters including subtract mean (dewow), bandpass, running average, energy decay, move start time, Fk migration and time cut (see Goodman and Piro 2013). Hyperbola modelling was used to define the velocity of electromagnetic energy through sediment as $0.13 \mathrm{~m} / \mathrm{ns}$ for the site. The results were initially interpreted after completion of the excavation without reference to the stratigraphic plans or photographs of Square B, to test the efficacy of GPR to locate subsurface features.

The interpreted results (see Figure 14.8) suggest a maximum depth of 'soft' sediments c. $1 \mathrm{~m}$ below ground, but these 'soft' sediments are universally armoured from the surface downwards by the presence of large pieces of rock. Several large blocks of rock surrounded by areas of 'soft' sediment containing small rocks are evident in the GPR plots. The three largest pieces of roof-fall subsequently exposed by excavation (see Figures 14.9 and 14.10) are clearly evident in the GPR results (Figure 14.8). 


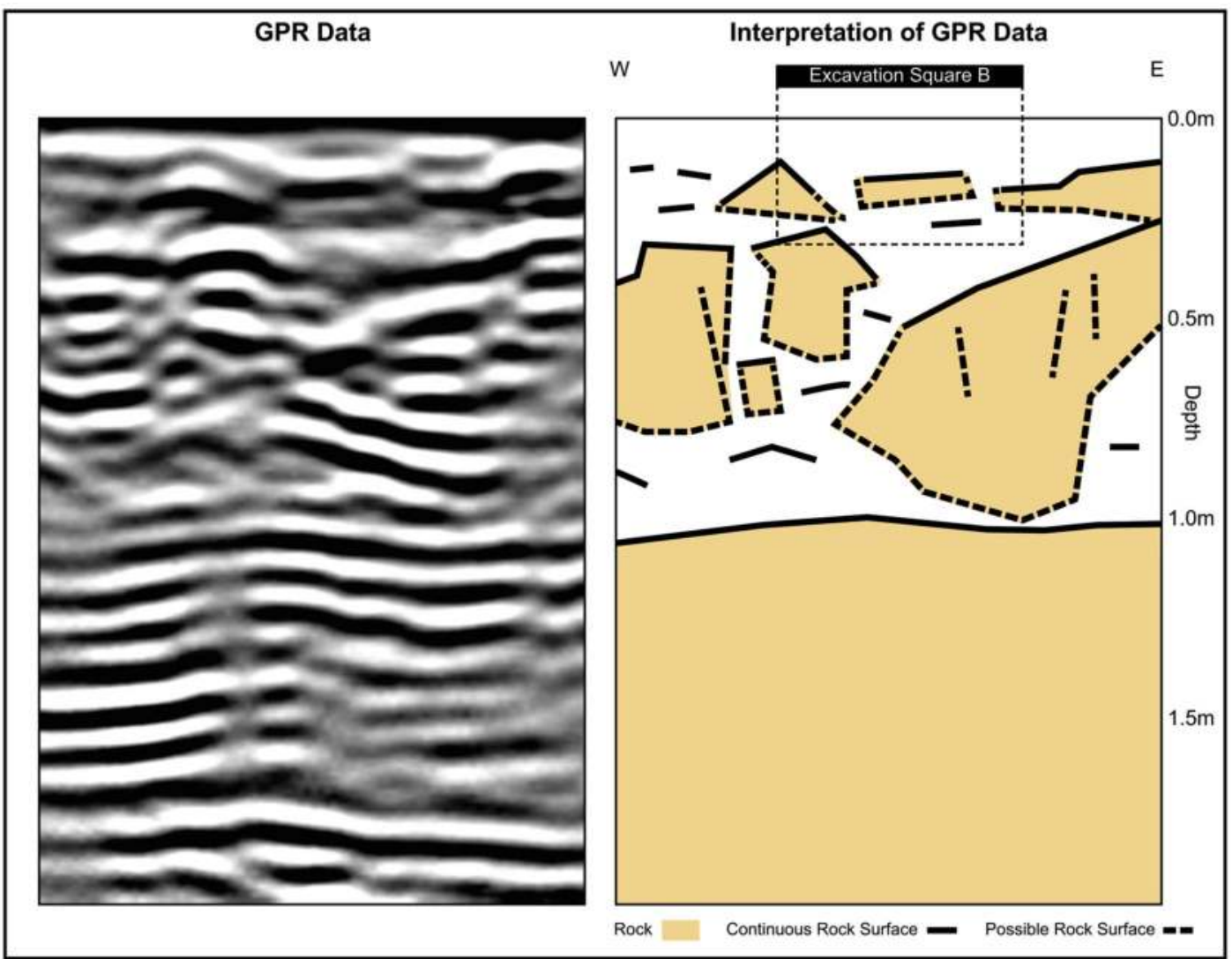

Figure 14.8 GPR data and GPR interpretation prior to excavation of Square B. Source: Illustration by lan Moffatt.

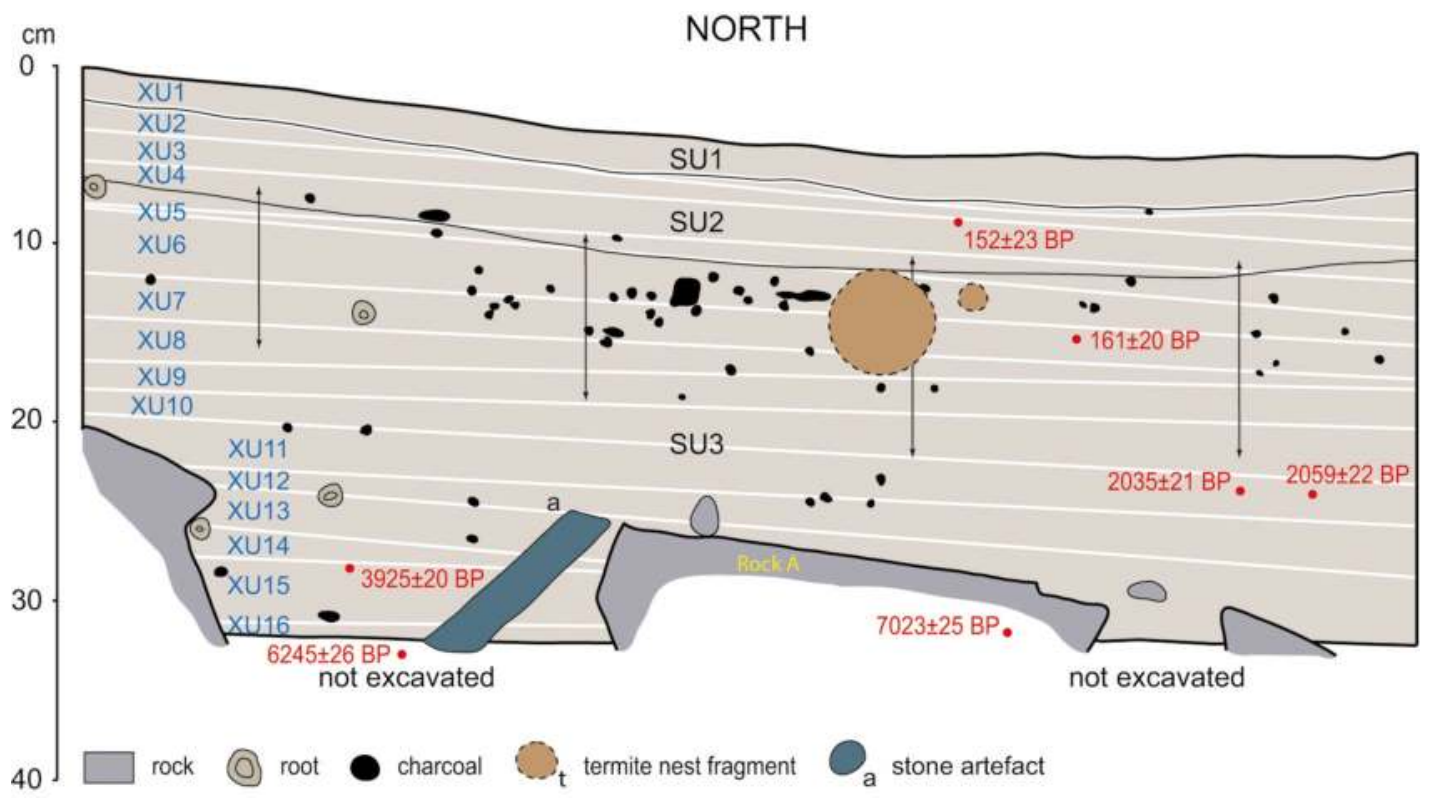

Figure 14.9 North section of Square B with XUs and radiocarbon samples back-plotted.

Vertical arrows between SU2 and SU3 represent the zone of stratigraphic interface as indicated by gradual sediment colour and texture changes.

Source: Illustration by Kara Rasmanis and Bruno David. 


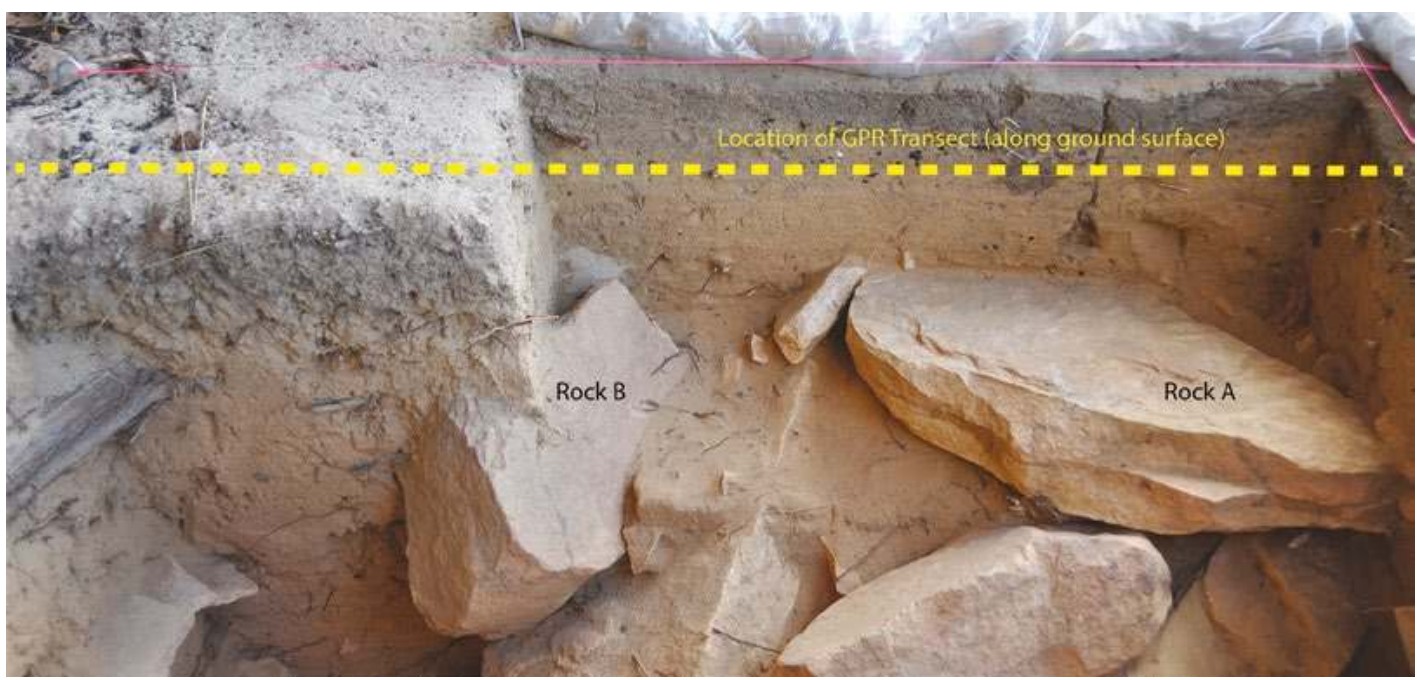

Figure 14.10 Location of the GPR transect line superimposed on a photograph of the Squares A and B excavation at a mean Square B excavation depth of $40.9 \mathrm{~cm}$.

Note slanted grindstone emerging from north wall at the centre of the photograph.

Source: Photograph by Bruno David.

Despite these positive results, improvements to field methods may further enhance the potential of GPR at this and other similar sites. Here, the deep penetration of the GPR, over more than $4.0 \mathrm{~m}$ depth before the use of time cut, indicates that a higher frequency unit in the range of 500-1000 Mhz would provide significantly higher vertical and horizontal resolution (Rial et al. 2009); this would facilitate the accurate detection and determination of the detailed geometry of sub-surface rocks. The depth of medium-sized rocks, as shown in Figures 14.8-14.10, is significantly underestimated by the GPR conditions used, although the broad geometries of the blocks are adequately represented. Small blocks of rock located close to larger rocks cannot generally be distinguished as separate items; however, this could be remedied with a higherfrequency antenna.

\section{Radiocarbon dating}

Twenty-five accelerator mass spectrometry (AMS) radiocarbon dates were obtained: 15 from Square A, nine from Square B and one from a beeswax pellet applied to the wall near the stickfigures (Table 14.3).

Table 14.3 Radiocarbon determinations.

\begin{tabular}{|c|c|c|c|c|c|c|c|c|c|}
\hline$X U$ & $\begin{array}{l}\text { Depth } \\
(\mathrm{cm})\end{array}$ & SU & $\begin{array}{l}\text { Wk- } \\
\text { laboratory } \\
\text { code }\end{array}$ & $\delta^{13} \mathrm{C} \% 0$ & $\begin{array}{c}\% \text { Modern } \\
\text { carbon } \\
\left(\mathrm{F}^{14} \mathrm{C} \%\right)\end{array}$ & $\begin{array}{l}{ }^{14} \text { C age } \\
\text { (years } \\
\text { BP) }\end{array}$ & $\begin{array}{l}\text { Unmodelled } \\
\text { calibrated age } \\
\text { BP (68.3\% } \\
\text { probability) }\end{array}$ & $\begin{array}{c}\text { Unmodelled } \\
\text { calibrated age } \\
\text { BP ( } 95.4 \% \\
\text { probability) }\end{array}$ & $\begin{array}{l}\text { Median } \\
\text { calibrated } \\
\text { age BP }\end{array}$ \\
\hline \multicolumn{10}{|c|}{ Square A } \\
\hline 1 & 0.6 & 1 & 32117 & $-23.8 \pm 0.2$ & $97.8 \pm 0.5$ & $179 \pm 38$ & $\begin{array}{r}30-0 \\
220-140 \\
290-260\end{array}$ & $\begin{array}{r}40-0 \\
120-70 \\
210-130\end{array}$ & 180 \\
\hline 5 & 5.7 & 2 & 32118 & $-24.5 \pm 0.2$ & $97.1 \pm 0.4$ & $237 \pm 29$ & $\begin{array}{l}170-150 \\
310-280\end{array}$ & $\begin{array}{r}20-0 \\
190-140 \\
220-200 \\
320-260 \\
430-390\end{array}$ & 280 \\
\hline
\end{tabular}

\section{terra australis 47}




\begin{tabular}{|c|c|c|c|c|c|c|c|c|c|}
\hline XU & $\begin{array}{l}\text { Depth } \\
\text { (cm) }\end{array}$ & SU & $\begin{array}{l}\text { Wk- } \\
\text { laboratory } \\
\text { code }\end{array}$ & $\delta^{13} \mathrm{C} \% 0$ & $\begin{array}{l}\text { \% Modern } \\
\text { carbon } \\
\left(\mathrm{F}^{14} \mathrm{C} \%\right)\end{array}$ & $\begin{array}{l}{ }^{14} \text { C age } \\
\text { (years } \\
\text { BP) }\end{array}$ & $\begin{array}{c}\text { Unmodelled } \\
\text { calibrated age } \\
\text { BP (68.3\% } \\
\text { probability) }\end{array}$ & $\begin{array}{l}\text { Unmodelled } \\
\text { calibrated age } \\
\text { BP ( } 95.4 \% \\
\text { probability) }\end{array}$ & $\begin{array}{l}\text { Median } \\
\text { calibrated } \\
\text { age BP }\end{array}$ \\
\hline 9 & 15.1 & $2+3$ & 32119 & $-27.9 \pm 0.2$ & $95.4 \pm 0.3$ & $377 \pm 25$ & $\begin{array}{r}350-330 \\
500-430 \\
\end{array}$ & $\begin{array}{r}380-310 \\
510-420 \\
\end{array}$ & 450 \\
\hline 12 & 20.6 & 3 & 32120 & $-25.2 \pm 0.2$ & $59.8 \pm 0.2$ & $\begin{array}{r}4136 \pm \\
25\end{array}$ & $\begin{array}{l}4710-4580 \\
4770-4750 \\
4810-4780\end{array}$ & $4830-4560$ & 4680 \\
\hline 15 & 25.8 & 3 & 32121 & $-25.3 \pm 0.2$ & $57.0 \pm 0.2$ & $\begin{array}{r}4511 \pm \\
25\end{array}$ & $\begin{array}{l}5190-5060 \\
5230-5210 \\
5300-5270 \\
\end{array}$ & $\begin{array}{l}5200-5040 \\
5300-5210\end{array}$ & 5160 \\
\hline 18 & 30.2 & 3 & 32122 & $-24.7 \pm 0.2$ & $48.7 \pm 0.2$ & $\begin{array}{r}5774 \pm \\
25 \\
\end{array}$ & $6640-6540$ & $6650-6490$ & 6580 \\
\hline 22 & 37.0 & 3 & 32123 & $-24.1 \pm 0.2$ & $52.4 \pm 0.2$ & $\begin{array}{r}5187 \pm \\
25 \\
\end{array}$ & $\begin{array}{l}5950-5910 \\
5990-5970 \\
\end{array}$ & 5990-5910 & 5940 \\
\hline 24 & 40.5 & 3 & 32124 & $-24.9 \pm 0.2$ & $35.3 \pm 0.1$ & $\begin{array}{r}8368 \pm \\
27 \\
\end{array}$ & $\begin{array}{l}9350-9320 \\
9470-9400 \\
\end{array}$ & $9470-9300$ & 9410 \\
\hline 26 & 44.1 & 3 & 32125 & $-24.6 \pm 0.2$ & $35.3 \pm 0.1$ & $\begin{array}{r}8370 \pm \\
29\end{array}$ & $\begin{array}{l}9350-9320 \\
9470-9400\end{array}$ & $9480-9300$ & 9410 \\
\hline 28 & 48.1 & 3 & 31586 & $-25.2 \pm 0.2$ & $35.3 \pm 0.1$ & $\begin{array}{r}8355 \pm \\
33 \\
\end{array}$ & $\begin{array}{l}9370-9300 \\
9450-9390\end{array}$ & $9470-9290$ & 9380 \\
\hline 28 & 48.5 & 3 & 32901 & $-25.0 \pm 0.2$ & $24.6 \pm 0.1$ & $\begin{array}{r}11,266 \\
\pm 32 \\
\end{array}$ & $13,150-13,080$ & $13,200-13,060$ & 13,120 \\
\hline 30 & 52.2 & 3 & 31587 & $-25.8 \pm 0.2$ & $24.8 \pm 0.1$ & $\begin{array}{r}11,186 \\
\pm 38 \\
\end{array}$ & $13,100-13,030$ & $13,130-12,980$ & 13,060 \\
\hline 33 & 57.1 & 3 & 34164 & $-24.3 \pm 0.2$ & $24.6 \pm 0.1$ & $\begin{array}{r}11,265 \\
\pm 37 \\
\end{array}$ & $13,150-13,070$ & $13,210-13,050$ & 13,120 \\
\hline 34 & 58.9 & 3 & 34165 & n/a & $21.1 \pm 0.1$ & $\begin{array}{r}12,484 \\
\pm 45 \\
\end{array}$ & $14,900-14,490$ & $15,030-14,290$ & 14,690 \\
\hline 36 & 62.9 & 3 & 34167 & $n / a$ & $6.3 \pm 0.1$ & $\begin{array}{r}22,235 \pm \\
163 \\
\end{array}$ & $26,680-26,190$ & $27,000-26,070$ & 26,470 \\
\hline \multicolumn{10}{|c|}{ Square B } \\
\hline 4 & 7.8 & $2+3$ & 37613 & $-24.3 \pm 0.2$ & $98.1 \pm 0.3$ & $152 \pm 23$ & $\begin{array}{r}30-0 \\
160-130 \\
230-170 \\
280-250\end{array}$ & $\begin{array}{r}40-0 \\
120-70 \\
290-130\end{array}$ & 180 \\
\hline 7 & 11.8 & $2+3$ & 37614 & $-26.6 \pm 0.2$ & $98.0 \pm 0.2$ & $161 \pm 20$ & $\begin{array}{r}30-0 \\
160-140 \\
220-170 \\
280-260 \\
\end{array}$ & $\begin{array}{r}40-0 \\
120-70 \\
230-130 \\
290-250 \\
\end{array}$ & 190 \\
\hline 11 & 19.6 & 3 & 37615 & $-24.2 \pm 0.2$ & $77.6 \pm 0.2$ & $\begin{array}{r}2035 \pm \\
21 \\
\end{array}$ & 2010-1940 & $2060-1920$ & 1980 \\
\hline 12 & 21.3 & 3 & 37616 & $-24.8 \pm 0.2$ & $77.4 \pm 0.2$ & $\begin{array}{r}2059 \pm \\
22 \\
\end{array}$ & $2060-1980$ & $2120-1940$ & 2030 \\
\hline 14 & 26.0 & 3 & 37617 & $-25.3 \pm 0.2$ & $61.3 \pm 0.2$ & $\begin{array}{r}3925 \pm \\
20\end{array}$ & $\begin{array}{l}4330-4290 \\
4370-4350 \\
4392-4389 \\
4430-4390 \\
\end{array}$ & $4430-4290$ & 4360 \\
\hline 14 & 27.9 & 3 & 34168 & $-24.9 \pm 0.2$ & $41.7 \pm 0.1$ & $\begin{array}{r}7023 \pm \\
25 \\
\end{array}$ & $\begin{array}{l}7880-7830 \\
7930-7890 \\
\end{array}$ & $7940-7790$ & 7870 \\
\hline 16 & 32.1 & 3 & 34169 & $-24.5 \pm 0.2$ & $46.0 \pm 0.1$ & $\begin{array}{r}6245 \pm \\
26 \\
\end{array}$ & $7250-7160$ & $\begin{array}{l}7120-7020 \\
7260-7150 \\
\end{array}$ & 7200 \\
\hline
\end{tabular}




\begin{tabular}{|c|c|c|c|c|c|c|c|c|c|}
\hline$X U$ & $\begin{array}{l}\text { Depth } \\
(\mathrm{cm})\end{array}$ & SU & $\begin{array}{l}\text { Wk- } \\
\text { laboratory } \\
\text { code }\end{array}$ & $\delta^{13} \mathrm{C} \% 0$ & $\begin{array}{c}\% \text { Modern } \\
\text { carbon } \\
\left(\mathrm{F}^{14} \mathrm{C} \%\right)\end{array}$ & $\begin{array}{c}{ }^{14} \mathrm{C} \text { age } \\
\text { (years } \\
\mathrm{BP} \text { ) }\end{array}$ & $\begin{array}{l}\text { Unmodelled } \\
\text { calibrated age } \\
\text { BP (68.3\% } \\
\text { probability) }\end{array}$ & $\begin{array}{c}\text { Unmodelled } \\
\text { calibrated age } \\
\text { BP (95.4\% } \\
\text { probability) }\end{array}$ & $\begin{array}{l}\text { Median } \\
\text { calibrated } \\
\text { age BP }\end{array}$ \\
\hline 17 & 40.8 & 3 & 34170 & $-26.2 \pm 0.2$ & $27.4 \pm 0.1$ & $\begin{array}{r}10,412 \\
\pm 32\end{array}$ & $\begin{array}{l}12,210-12,160 \\
12,360-12,230 \\
12,410-12,370 \\
\end{array}$ & $\begin{array}{l}12,430-12,090 \\
12,520-12,490\end{array}$ & 12,280 \\
\hline 19 & 35.6 & 3 & 34171 & $-24.5 \pm 0.2$ & $25.9 \pm 0.1$ & $\begin{array}{r}10,844 \\
\pm 32 \\
\end{array}$ & $12,750-12,700$ & $12,770-12,680$ & 12,730 \\
\hline \multicolumn{10}{|c|}{ Rock art } \\
\hline \multicolumn{3}{|c|}{$\begin{array}{l}\text { Beeswax image } \\
\# 56\end{array}$} & 31720 & $-24.5 \pm 0.2$ & $96.1 \pm 0.3$ & $321 \pm 25$ & $\begin{array}{l}340-310 \\
440-350\end{array}$ & $480-300$ & 390 \\
\hline
\end{tabular}

All ${ }^{14} \mathrm{C}$ ages are AMS on single pieces of charcoal except for the one age on beeswax rock art. Calibrations undertaken using 0xCal 4.2 (IntCal13) (Reimer et al. 2013).

Source: Authors' data.

All dates have been calibrated with OxCal v4.2.2 (Bronk Ramsey 2013) and subsequently evaluated using sequence analysis, with each phase of burning (as represented by the radiocarbon dates) separated by a uniform boundary (Bronk Ramsey 2009). All 24 dates from the excavation are in good chrono-stratigraphic order (Table 14.3; Figures 14.5 and 14.6). For the sequence analysis, six Burning Phases are identified. From oldest (deepest) to youngest, they are:

- Burning Phase 1: 28,740 to 26,160 cal BP (followed by a c. 10,000-year-long hiatus).

- Burning Phase 2: 15,570 to 11,530 cal BP (followed by a 2000-year-long hiatus, in SU3).

- Burning Phase 3: 9540 to 9260 cal BP (followed by a c. 700-year-long hiatus).

- Burning Phase 4: 8510 to 3670 cal BP (followed by a c. 1500-year-long hiatus, in SU3).

- Burning Phase 5: 2370 to 1650 cal BP (followed by a c. 1000-year-long hiatus, between the top of SU3 and base of SU2).

- Burning Phase 6: 520 to $-30 \mathrm{cal} \mathrm{BP.}$

Burning between Burning Phases 3 and 4 (9540-3670 cal BP) appears to have been nearcontinuous. Within SU3, in Square B the layer of large rocks ends 12,750-12,160 cal BP (Wk-34170 and Wk-34171). These radiocarbon determinations have been grouped, along with dates from Square A, into Burning Phase 2 dated from 15,570 to 11,530 cal BP. In Square A, adjacent to the back wall, large rocks occur in an earlier phase of rockfall dated earlier than 26,680-26,190 cal BP. The major period of rockfall thus ends with the onset of the Holocene in Square B, and does not seem to have affected the area against the back wall.

The horizon in SU3 containing the thin tabular quartzite pieces at 35-45 cm depth in Square A dates to after $9540 \mathrm{cal} \mathrm{BP}$, but before a phase of more rapid sediment build-up beginning 3670 cal BP (see Figure 14.6). These small tabular pieces of rock were first encountered in XU26 and continue upwards to XU15, with peak numbers in XU25. In XU21, they include small, thin pieces of rock cortex. Exactly when between c. 9540 cal BP (boundary between Burning Phases 3 and 2) and c. $3670 \mathrm{cal} \mathrm{BP}$ (boundary between Burning Phases 4 and 5) these tabular pieces began to fall is uncertain, as the deepest ones come from sediments deposited when sedimentation was slow. The sand in which these tabular pieces are now buried would have been loose at the time of deposition. However, that these tabular pieces lay flat when excavated, or slightly slanted where they were lying against small rocks, and that in XU25 many conjoining pieces lay next to each other in correct alignment and orientation indicates that post-depositional movement was minimal. The implication is that these tabular pieces were laid down close to $9540 \mathrm{cal} \mathrm{BP}$, when the level of the shelter floor was at XU25. 


\section{Excavated cultural materials: Charcoal}

Excavated cultural materials are limited to 970 flaked stone artefacts, three grindstones, and a red ochre crayon with striations from grinding or rubbing against a hard surface (Tables 14.4 and 14.5; Figure 14.11). While charcoal is abundant, no hearths or hearth stones were evident; much of the charcoal may be from landscape fires (anthropic or natural). Small fragments of disused termite runway in SU1, SU2 and the upper level of SU3 suggests minor bioturbation down to the SU2-SU3 interface, corresponding with Burning Phase 6 (330-520 cal BP to present).

Table 14.4 Square A: Distribution of excavated cultural materials.

\begin{tabular}{|c|c|c|c|c|c|c|c|}
\hline \multirow[t]{2}{*}{ XU } & \multirow[t]{2}{*}{ SU } & \multirow{2}{*}{$\begin{array}{c}\text { Charcoal } \\
(g) \\
\end{array}$} & \multicolumn{2}{|c|}{ Stone artefacts } & \multicolumn{2}{|c|}{ ochre crayon } & \multirow{2}{*}{$\begin{array}{c}\text { Disused termite runway } \\
\text { (g) }\end{array}$} \\
\hline & & & $(\#)$ & (g) & $(\#)$ & $(g)$ & \\
\hline 1 & 1 & 21.26 & 2 & 3.35 & & & 3.42 \\
\hline 2 & $1+2$ & 7.81 & 3 & 2.42 & & & 6.11 \\
\hline 3 & $1+2$ & 3.39 & 3 & 0.19 & & & 5.28 \\
\hline 4 & 2 & 11.30 & 2 & 0.10 & & & 16.07 \\
\hline 5 & 2 & 14.14 & 1 & 0.01 & & & 2.97 \\
\hline 6 & $2+3$ & 44.06 & 5 & 0.13 & & & 3.50 \\
\hline 7 & $2+3$ & 19.62 & 1 & 0.06 & & & \\
\hline 8 & $2+3$ & 39.63 & 4 & 0.30 & & & 5.58 \\
\hline 9 & $2+3$ & 16.61 & 1 & 0.13 & & & \\
\hline 10 & 3 & 15.10 & 16 & 1.91 & & & \\
\hline 11 & 3 & 9.95 & 12 & 6.60 & & & \\
\hline 12 & 3 & 10.07 & 11 & 0.94 & & & \\
\hline 13 & 3 & 9.06 & 10 & 0.28 & & & 0.22 \\
\hline 14 & 3 & 14.27 & 12 & 1.48 & & & \\
\hline 15 & 3 & 13.86 & 1 & 0.37 & & & \\
\hline 16 & 3 & 20.47 & 14 & 11.39 & & & \\
\hline 17 & 3 & 16.36 & 2 & 0.04 & & & \\
\hline 18 & 3 & 24.60 & 11 & 2.38 & & & \\
\hline 19 & 3 & 20.71 & 4 & 3.10 & & & \\
\hline 20 & 3 & 16.87 & 7 & 2.93 & & & \\
\hline 21 & 3 & 11.36 & 8 & 1.49 & & & \\
\hline 22 & 3 & 5.91 & & & & & \\
\hline 23 & 3 & 8.38 & 1 & 8.69 & & & \\
\hline 24 & 3 & 3.32 & 1 & 0.20 & & & \\
\hline 25 & 3 & 8.01 & 3 & 20.37 & & & \\
\hline 26 & 3 & 8.06 & 1 & 20.48 & 1 & 9.5 & \\
\hline 27 & 3 & 4.64 & 14 & 18.80 & & & \\
\hline 28 & 3 & 2.60 & 14 & 9.45 & & & \\
\hline 29 & 3 & 2.94 & 4 & 38.43 & & & \\
\hline 30 & 3 & 1.79 & 15 & 3.30 & & & \\
\hline 31 & 3 & 1.19 & 18 & 18.79 & & & \\
\hline 32 & 3 & 0.75 & 4 & 11.82 & & & \\
\hline 33 & 3 & 0.53 & 11 & 4.97 & & & \\
\hline 34 & 3 & 0.51 & 10 & 12.64 & & & \\
\hline 35 & 3 & 0.38 & 7 & 2.92 & & & \\
\hline 36 & 3 & 0.24 & 3 & 1.85 & & & \\
\hline 37 & 3 & 0.30 & 3 & 0.71 & & & \\
\hline 38 & 3 & 0.12 & 4 & 0.88 & & & \\
\hline 39 & 3 & 0.11 & 2 & 1.55 & & & \\
\hline Total & & 410.28 & 255 & 215.45 & 1 & 9.5 & 43.15 \\
\hline
\end{tabular}

Source: Authors' data. 
Table 14.5 Square B: Distribution of excavated cultural materials.

\begin{tabular}{|c|c|c|c|c|c|c|c|}
\hline \multirow[t]{2}{*}{$\mathrm{XU}$} & \multirow[t]{2}{*}{ SU } & \multirow{2}{*}{$\frac{\text { Charcoal }}{(\mathrm{g})}$} & \multicolumn{2}{|c|}{ Stone artefacts } & \multicolumn{2}{|c|}{ Grindstones } & \multirow{2}{*}{$\begin{array}{l}\text { Disused termite runway } \\
(g)\end{array}$} \\
\hline & & & (\#) & (g) & $(\#)$ & (g) & \\
\hline 1 & $1+2$ & 68.10 & 46 & 1.73 & & & 14.04 \\
\hline 2 & $1+2+3$ & 34.26 & 26 & 1.84 & & & 29.08 \\
\hline 3 & $1+2+3$ & 69.36 & 40 & 4.30 & & & 22.23 \\
\hline 4 & $2+3$ & 149.05 & 28 & 1.63 & & & 29.03 \\
\hline 5 & $2+3$ & 190.16 & 44 & 2.68 & & & 63.37 \\
\hline 6 & $2+3$ & 118.39 & 61 & 2.07 & & & 36.55 \\
\hline 7 & $2+3$ & 105.94 & 57 & 3.04 & & & 18.76 \\
\hline 8 & $2+3$ & 67.84 & 70 & 9.04 & & & 11.76 \\
\hline 9 & $2+3$ & 86.34 & 67 & 4.31 & & & 5.97 \\
\hline 10 & $2+3$ & 73.55 & 41 & 10.68 & & & 2.90 \\
\hline 11 & 3 & 70.49 & 46 & 11.91 & & & 3.90 \\
\hline 12 & 3 & 77.68 & 47 & 34.94 & & & 1.51 \\
\hline 13 & 3 & 77.44 & 41 & 8.89 & & & 0.24 \\
\hline 14 & 3 & 44.72 & 22 & 1.64 & & & 0.08 \\
\hline 15 & 3 & 66.31 & 39 & 12.40 & & & \\
\hline 16 & 3 & 11.28 & 2 & 0.06 & 1 & 427.0 & \\
\hline 17 & 3 & 27.55 & 13 & 1.68 & & & \\
\hline 18 & 3 & 8.84 & 12 & 6.66 & & & \\
\hline 19 & 3 & 22.01 & 13 & 5.31 & 1 & 207.8 & \\
\hline Total & & 1369.31 & 715 & 124.81 & 2 & 634.8 & 239.42 \\
\hline
\end{tabular}

Source: Authors' data.

Charcoal occurs in each XU. In Square A, their raw weights give a bimodal distribution, with peaks in XU1-XU9 in SU1 and SU2 (Burning Phase 6: 330-520 cal BP to present), and XU14-XU21 in the upper half of SU3 (Burning Phase 4: 7850-8510 to 3670-4400 cal BP) (Figure 14.11). However, each XU lasts a different length of time and covers a different area of the square (because of intruding rocks). For each Burning Phase, we have therefore calculated how much charcoal there is by standardised area and length of time: the mid-point of the start, and end, year range was used to calculate the length of time represented by each Burning Phase (Figure 14.12). For example, Burning Phase 4 begins between 7850 and $8510 \mathrm{cal} \mathrm{BP}$ and ends between 3670 and $4400 \mathrm{cal} \mathrm{BP}$, giving estimated start and end mid-ages of $8180 \mathrm{cal} \mathrm{BP}$ and 4035 cal BP, and thus a total duration of 4145 years.

These results again indicate a clear bimodal trend in Square A, with Burning Phase 6 having nine times as much charcoal as the preceding Burning Phase 4 (Burning Phase 5 is absent in Square A), and Burning Phase 3 having 139 times as much charcoal as the preceding Burning Phase 2 and nine times as much as the subsequent Burning Phase 4 (Figure 14.12). The reason why the peak distributions evident in the raw weights by XU (Figure 14.11) relate to Burning Phases 6 and 4, whereas they relate to Burning Phases 6 and 3 when calculated by the sum of XUs for each Burning Phase, is that Burning Phase 3 lasted a short time (90 years), giving high deposition rates for this period of time. These results indicate peak charcoal deposition during a short period of heightened burning activity between 9340-9540 cal BP and 9260-9440 cal BP (Burning Phase 3), and again between 330-520 cal BP and present (Burning Phase 6). 


\section{Square A}
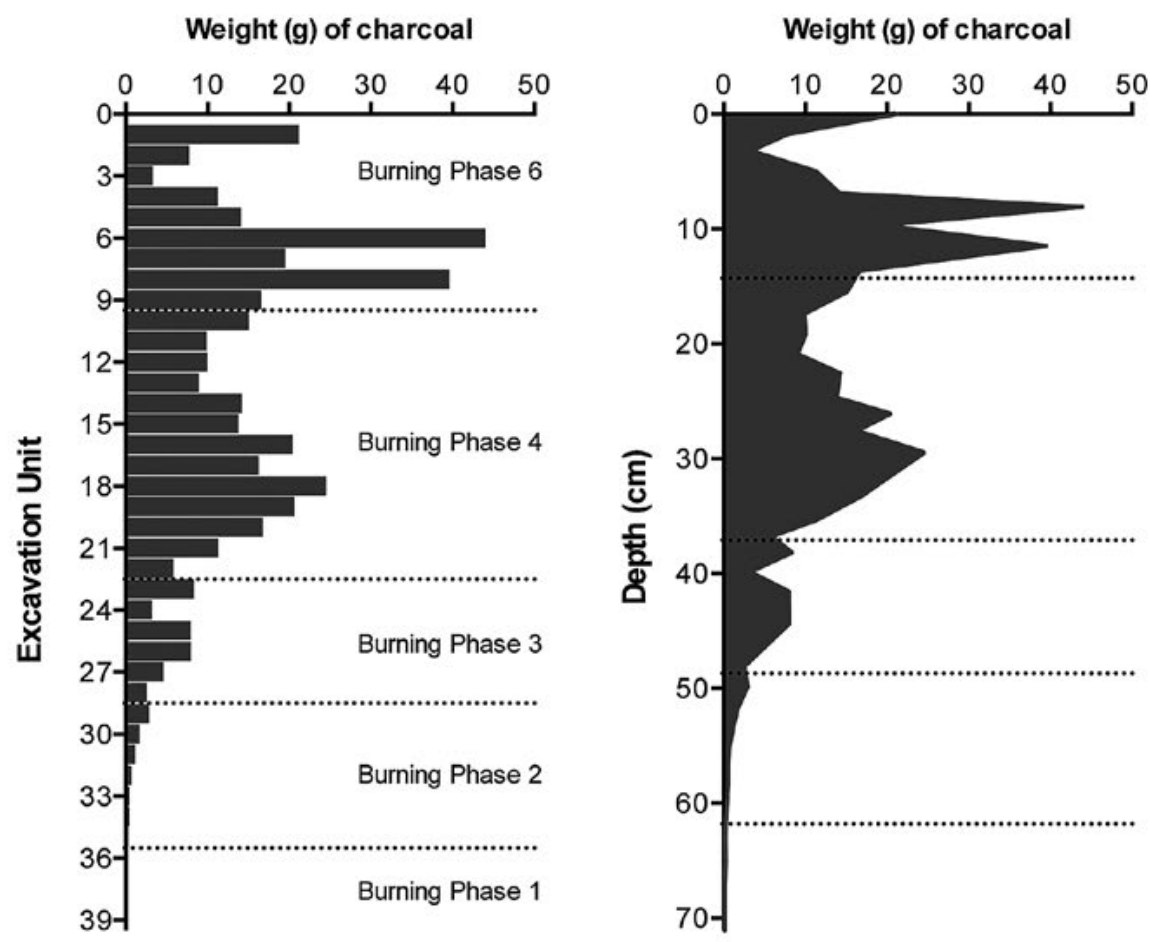

\section{Square B}
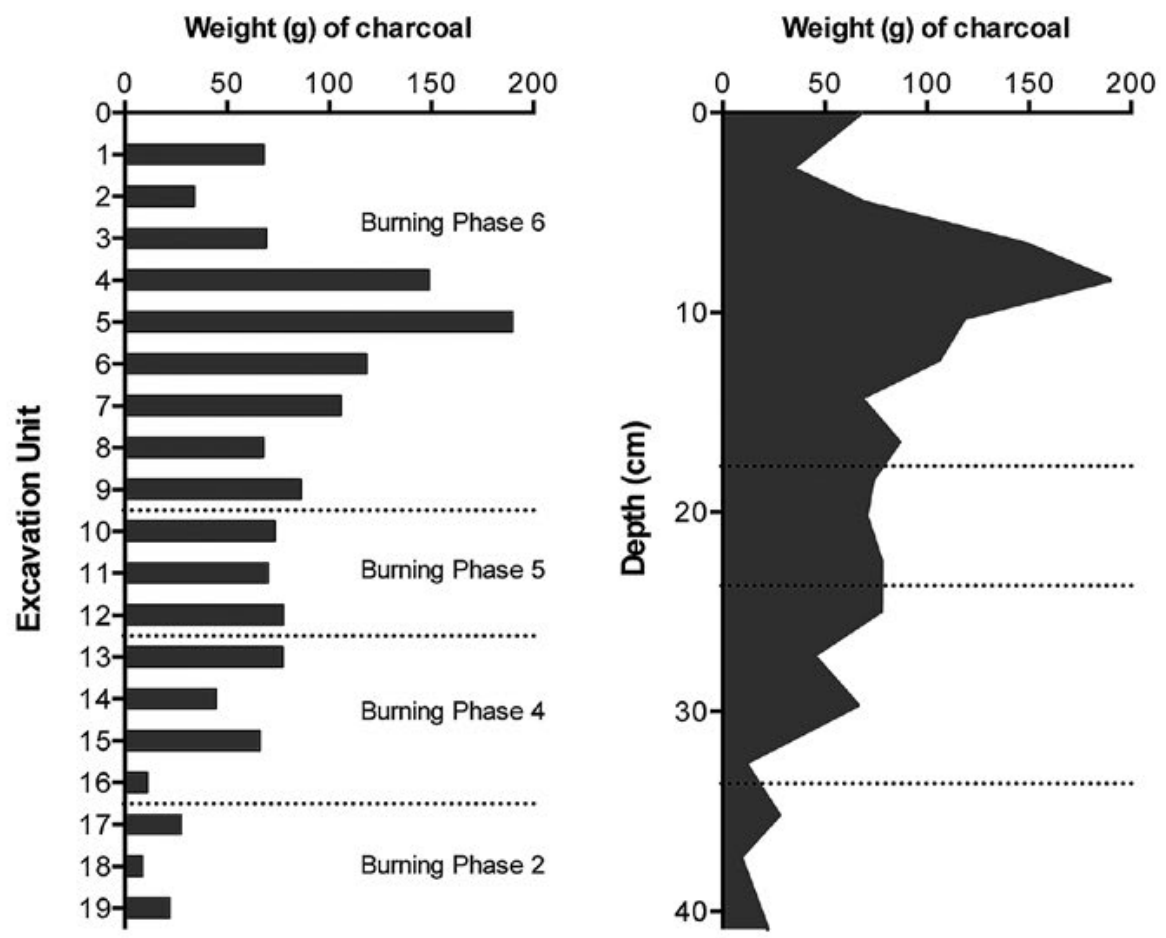

Figure 14.11 Squares A and B: Raw weight of charcoal by XU (right-hand graphs, converted to depths).

Source: Illustrations by Jerome Mialanes. 
Square A

Weight $(\mathrm{g})$ of charcoal $/ \mathrm{m}^{2} / 100$ years

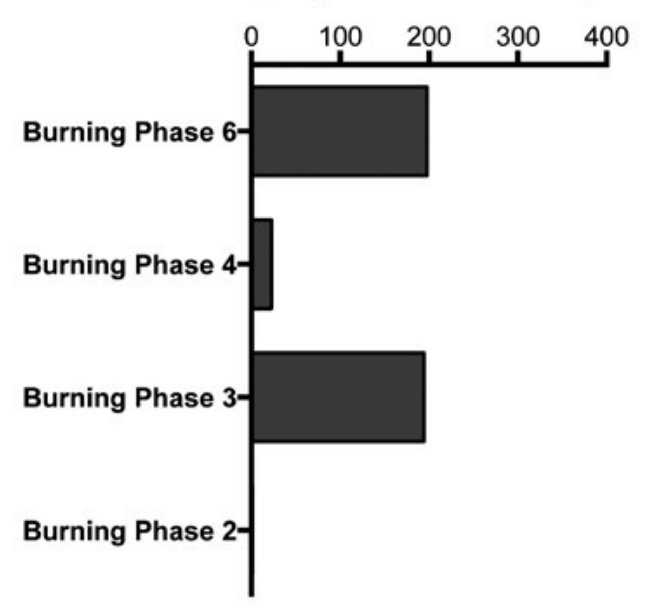

Square B

Weight (g) of charcoal $/ \mathrm{m}^{2} / 100$ years

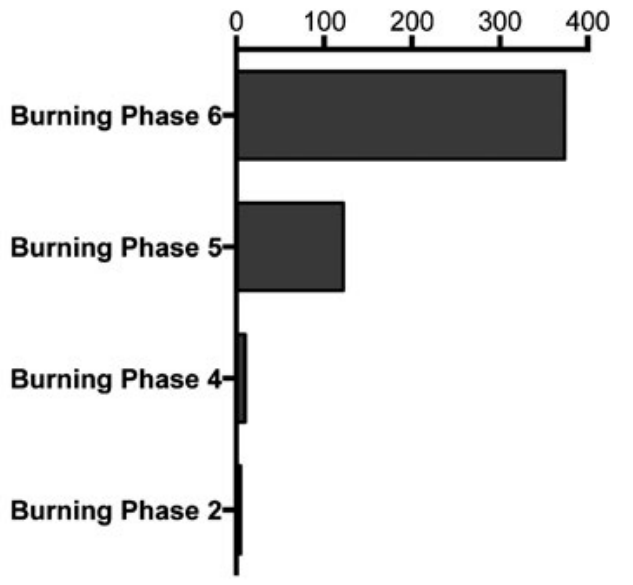

Figure 14.12 Squares $A$ and B. Standardised weight of charcoal per $\mathrm{m}^{2}$ per 100 years by Burning Phase.

A deposition rate cannot be calculated for Burning Phase 1 in Square A because the base of that phase has not been dated so its duration is unknown.

Source: Illustrations by Jerome Mialanes.
In Square B, the situation is both similar to and different from that in Square A (Figures 14.11 and 14.12). Here again, Burning Phase 6 (represented by XU1-XU9) shows a peak in charcoal both in amounts of charcoal by XU and by Burning Phase. This suggests that during Burning Phase 6, fires spanned the areas of both Squares A and B; they reached from close to the dripline to the back wall. However, in Square B this period from 330-520 cal BP to present is preceded by Burning Phase 5 (1970-2370 cal BP to 1650-2040 cal BP), which has a third the charcoal of Burning Phase 6 but 12 times that of the preceding Burning Phase 4. Burning Phase 3 is not evident in Square B, as there are no radiocarbon dates between 9340-9540 cal BP and 9260-9440 cal BP, whereas earlier and later ages do appear at that required depth $(41-48 \mathrm{~cm}$ in Square A). This suggests that the fire(s) that caused peak charcoal densities during Burning Phase 3 in Square A was close to the frieze with the stick-figures (see below).

\section{Excavated cultural materials: Faunal remains}

No faunal remains were recovered, despite the use of relatively fine-grained retrieval methods. This is unsurprising for the sandy and moderately acidic ( $\mathrm{pH}$ mostly <5; Table 14.1) older levels whose sediments are clearly not conducive to the long-term survival of organics. However, the upper units that have higher $\mathrm{pHs}(5.44-6.30)$ and that date only to the past 500 years would be expected to have to some degree preserved teeth and bone had they been present in the first place. Other Arnhem Land sites of essentially similar geomorphic nature, including site JSARN-113/19 that occurs under the same boulder stack as JSARN-113/23 and, a few kilometres away, Nawarla Gabarnmang, have produced faunal assemblages in quite good states of preservation dating to the past c. 500 years (for other Arnhem Land sites, see e.g. Foley 1985; Schrire 1982; White 1971; Wright et al. 2013). 
Given these observations, we suspect that the complete absence of degraded macroscopic fragments of bone, molluscan shell and even invertebrate exoskeleton in the upper levels of JSARN-113/23 is a primary feature of the deposit, presumably reflecting an absence of any 'on site' domestic or ritual activity that involved animal remains. Alternatively, this absence of faunal remains might reflect the operation of an especially aggressive destructive environment that is not commonly encountered. One possible candidate is termite activity, as termites have been observed to rapidly destroy unburnt bone that becomes invested in runways (Aplin, unpublished observation). However, this explanation seems unlikely to explain the absence of burnt or calcined bone, which is an improbable target for termites. The total absence of faunal remains in the upper levels of JSARN-113/23 thus suggests that the site was not used for meat-food production, consumption and discard during the late Holocene; the acidic nature of sediments does not allow us to make a call for earlier levels.

\section{Excavated cultural materials: Grindstones}

All three excavated grindstones came from a comparable depth in Square B: two were retrieved during excavation; the third was extracted from the north wall after the completion of excavation:

- XU16, base at $32 \mathrm{~cm}$ depth (Figure 14.13A). Fragment of orange quartzite lower grindstone measuring $80 \times 66 \times 59 \mathrm{~mm}$ and weighing $427.0 \mathrm{~g}$. It was intentionally broken, as indicated by impact marks. Its edges are naturally rounded. We estimate that the fragment represents one quarter of the original grindstone. The abraded surface is smooth, flat and slightly convex along its edges. The degree of abrasive wear indicates extensive use. In cross-section, the abraded surface is reddish grey and c. $2 \mathrm{~mm}$ thick. This colouring is clearly visible in the sectioned edges, and may represent natural, iron-rich components within the rock, perhaps enhanced by thermal alteration or mineral staining through ochre grinding.

- XU19 in situ item \#2, base at $41 \mathrm{~cm}$ depth (Figure 14.13B). Fragment of a small, yellowishorange quartzite block with two abraded surfaces. It measures $67 \times 71 \times 24 \mathrm{~mm}$ and weighs $207.8 \mathrm{~g}$. The grindstone originated from a rock with naturally rounded edges. The lateral surface (A) is uniformly smooth, finely abraded and slightly convex; it also displays older pitting marks. The other abraded surface $(\mathrm{B})$ is more irregular, grainy and convex, suggesting that it was used as the distal end of a top-stone. Its plano-convex surface is at the widest margin of the original block, before it split along a natural bedding plane, probably through use. The margins of the block were worked, hence the pitting marks, to shape it prior to use as a top-stone.

- North wall, base at $28 \mathrm{~cm}$ depth (Figure 14.13C). Whole lower grindstone originating from a slab of pale yellow quartzite with smooth, blunt edges fractured down the sides. It measures $130 \times 115 \times 36 \mathrm{~mm}$ and weighs $755.7 \mathrm{~g}$. The abraded surface is slightly concave from grinding, smooth, uniform, finely abraded and occupies one whole face of the artefact. Old pecking marks are visible. The opposite side is a split surface showing clear, invasive removals from the edges. 
A
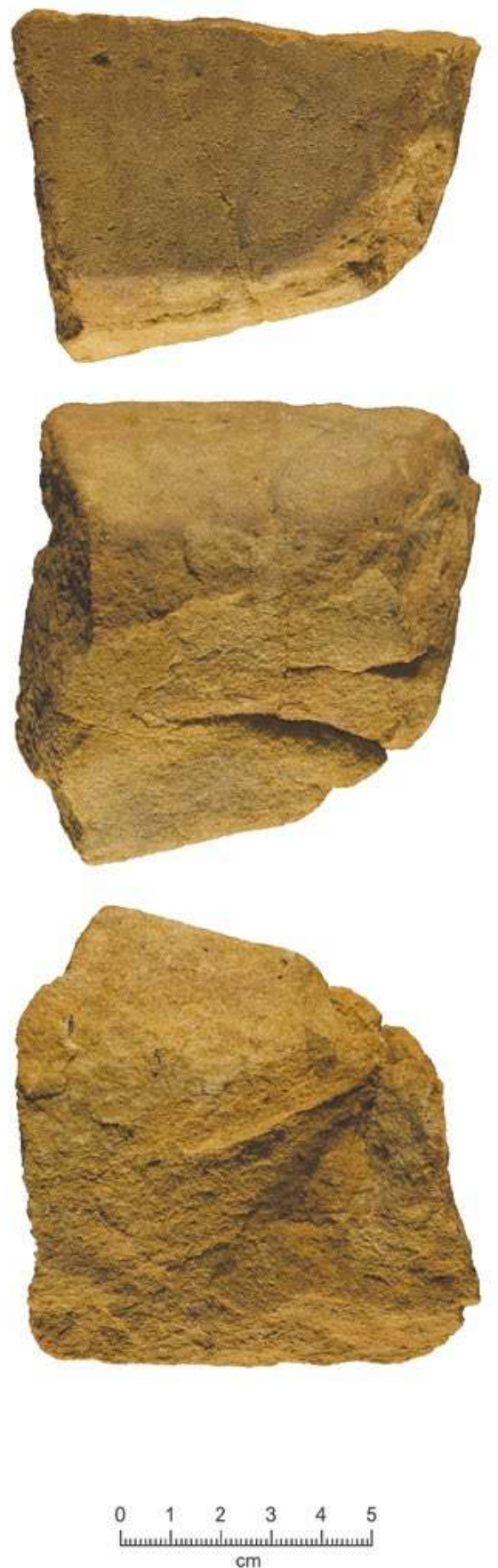

B
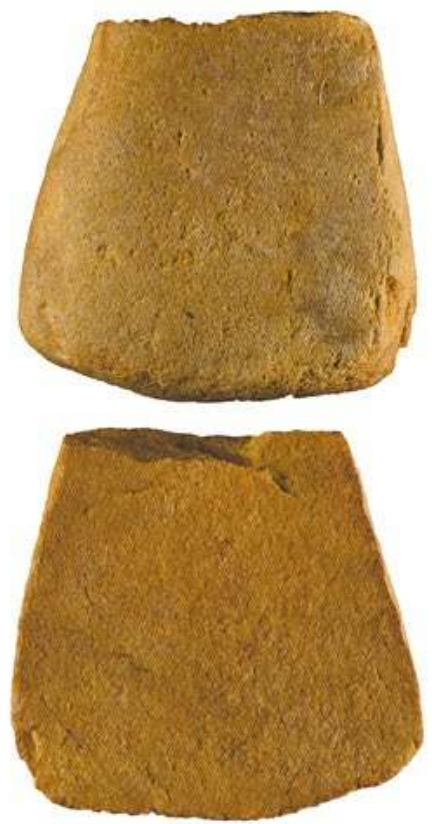

C
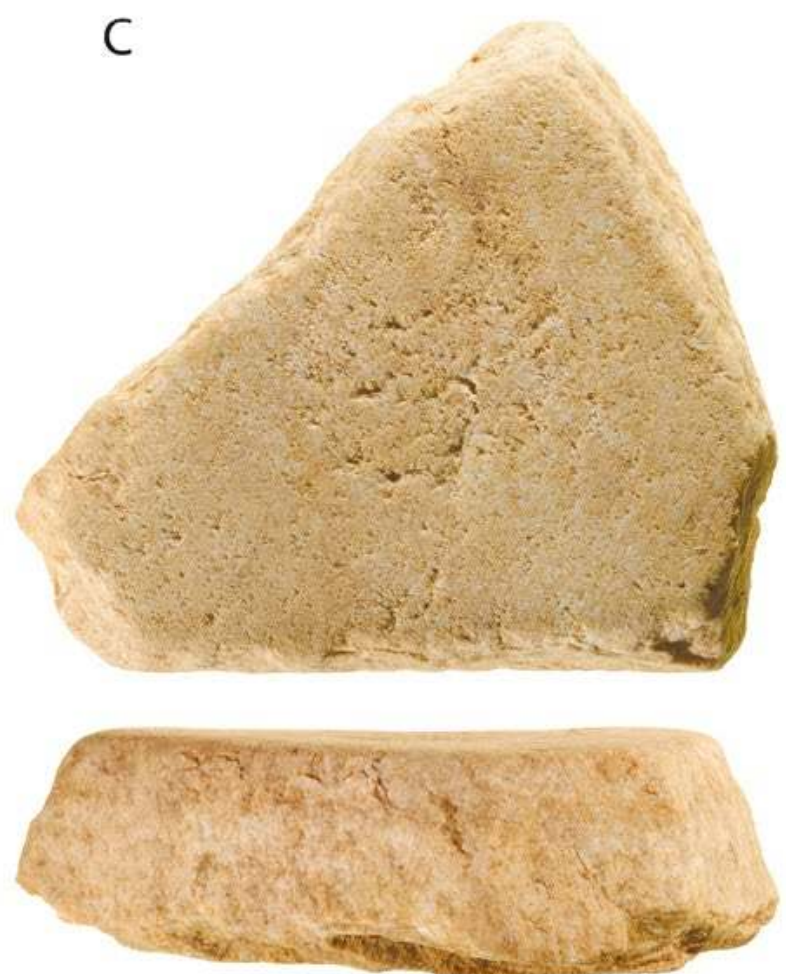

Figure 14.13 Square B: Excavated grindstones.

A: From XU16, at $32 \mathrm{~cm}$ depth. B: From XU19, at $41 \mathrm{~cm}$ depth. C: Extracted from north wall, at $28 \mathrm{~cm}$ depth (see Figures 14.9 and 14.10).

Source: Photographs: A, B: Emilie Lesvignes; C: Steve Morton. 


\section{Excavated cultural materials: Flaked stone artefacts}

A total of 970 flaked stone artefacts (255 from Square A; 715 from Square B) were recovered, with a total weight of $340.3 \mathrm{~g}$ (Tables 14.4 and 14.5). The lesser number of artefacts in Square A is probably related to the low headroom near the back wall; Square B is in a more open space. The types of raw materials discarded, and the timing of flaking events, are also different in the two squares (Figures 14.14 and 14.15). Square A saw a major peak in stone artefact discard during Burning Phase 3, when rates are 16 times those of Burning Phase 2 and 14 times those of Burning Phase 4. In Square B, the pattern is different, with peak discard rates occurring during Burning Phase 6 (Figure 14.16).
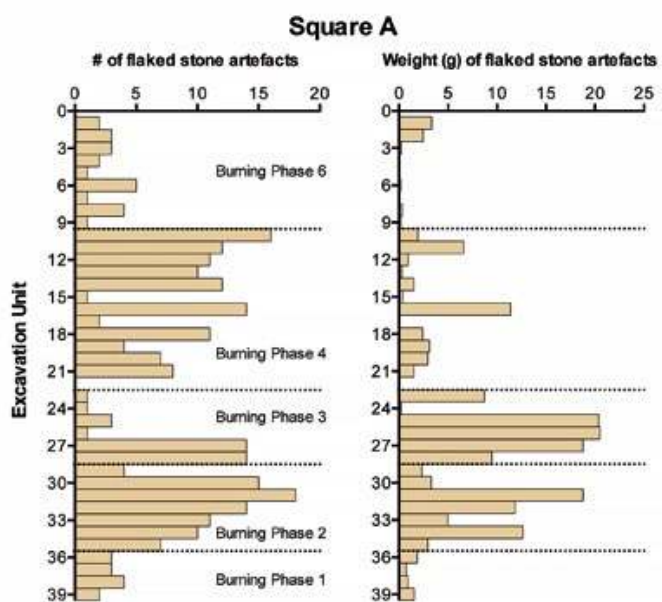

Square B
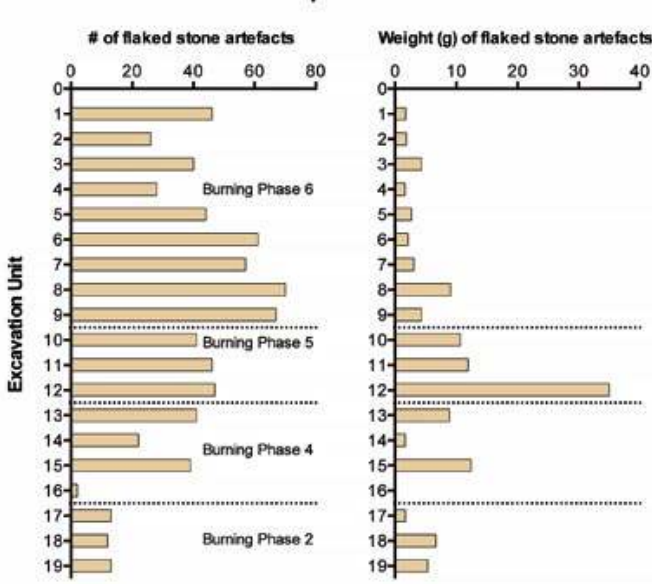

Figure 14.14 Squares A and B: Distribution of flaked stone artefacts by XU.

Source: Illustrations by Jerome Mialanes.

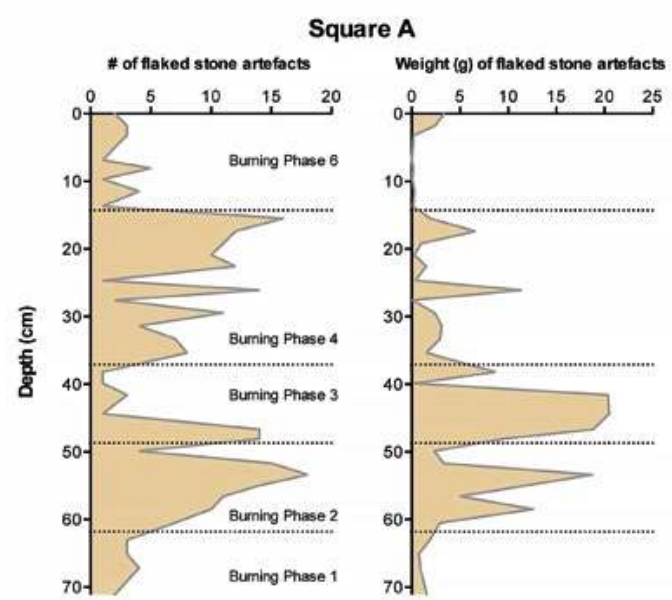

Square B

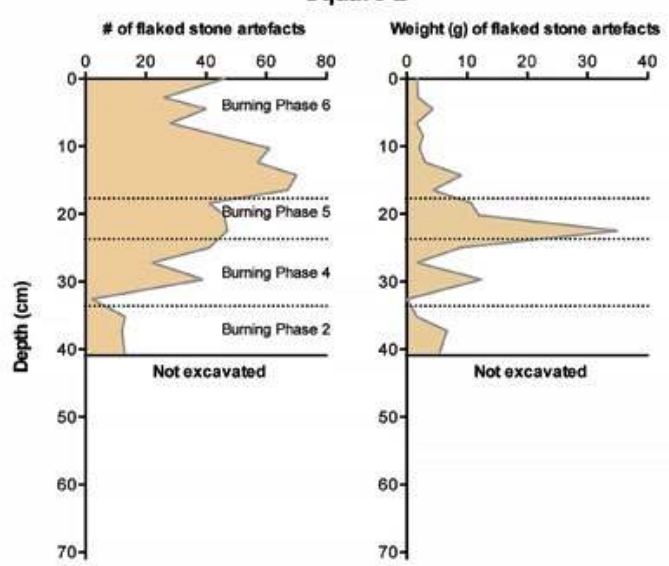

Figure 14.15 Squares A and B: Distribution of flaked stone artefacts by depth.

Source: Illustrations by Jerome Mialanes. 
Square $\mathrm{A}$

Weight $(\mathrm{g})$ of flaked stone artefacts $/ \mathrm{m}^{2} / 100$ years

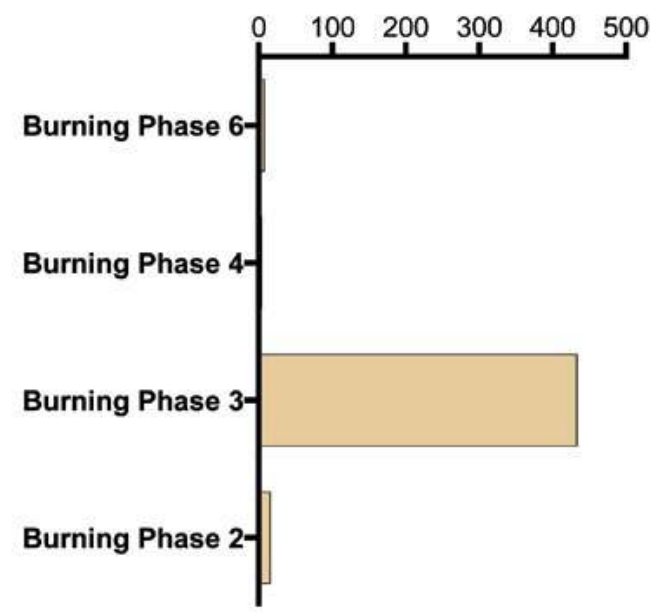

Square B

Weight (g) of flaked stone artefacts $/ \mathrm{m}^{2} / 100$ years

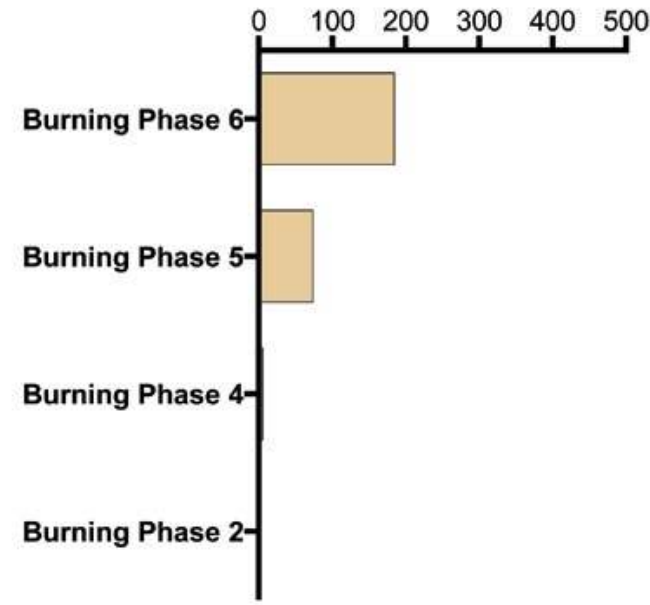

Figure 14.16 Squares A and B. Distribution of flaked stone artefact weight $(\mathrm{g}) / \mathrm{m}^{2} / 100$ years, by Burning Phase.

Source: Illustrations by Jerome Mialanes.

\section{Raw materials}

Flaked artefacts were made on seven types of raw material (Table 14.6). The most common is quartzite (silicified sandstone), ranging from coarse grained (with generally uniform grains, typically $1-2 \mathrm{~mm}$ long) to fine grained (grains <1 mm long). Most are made on locally available coarse-grained quartzite (77.3 per cent of the Square A assemblage; 73.1 per cent of Square B). Although coarsegrained quartzite varies widely in colour, very pale orange (10YR 8/2) and pale yellowishorange (10YR 8/6) predominate.

Table 14.6 Squares A and B: Flaked stone artefacts by raw material.

\begin{tabular}{|l|r|r|r|r|}
\hline & \multicolumn{2}{|c|}{ Square A } & \multicolumn{2}{c|}{ Square B } \\
\hline Raw material & \multicolumn{1}{c|}{$\#$} & \multicolumn{1}{c|}{$\mathbf{9}$} & \multicolumn{1}{c|}{$\#$} & \multicolumn{1}{c|}{$\mathbf{9}$} \\
\hline Coarse-grained quartzite & 197 & 197.7 & 523 & 101.1 \\
\hline Fine-grained quartzite & 43 & 12.1 & 165 & 19.6 \\
\hline Chert & 10 & 4.2 & 17 & 2.0 \\
\hline Crystal quartz & & & 4 & 0.1 \\
\hline Milky quartz & 1 & 0.2 & 1 & 0.5 \\
\hline Volcanic & & & 3 & 0.8 \\
\hline Silcrete & 3 & 1.1 & 2 & 0.8 \\
\hline Chalcedony & 1 & 0.1 & & \\
\hline Total & $\mathbf{2 5 5}$ & $\mathbf{2 1 5 . 5}$ & $\mathbf{7 1 5}$ & $\mathbf{1 2 4 . 8}$ \\
\hline
\end{tabular}

Source: Authors' data.

Fine-grained quartzite is the second-most abundant. It accounts for 16.9 per cent of artefacts in Square A, and 23.1 per cent in Square B. The main colours are very pale orange (10YR 8/2) and light brown (5YR 5/6 to 6/4). Other raw materials such as chert, microcrystalline silcrete (see Webb et al. 2013), chalcedony and milky to crystal quartz are present in small quantities.

There are major changes in raw material frequencies through time (Figures 14.17 and 14.18). In Square A, Burning Phase 3 mainly contains coarse-grained and, to a lesser extent, fine-grained quartzite. These raw materials also account for the peak deposition rates of Burning Phase 6 in Square B. Variations in the incidence of coarse- and fine-grained quartzites occur in tandem, suggesting a common source (see below). 

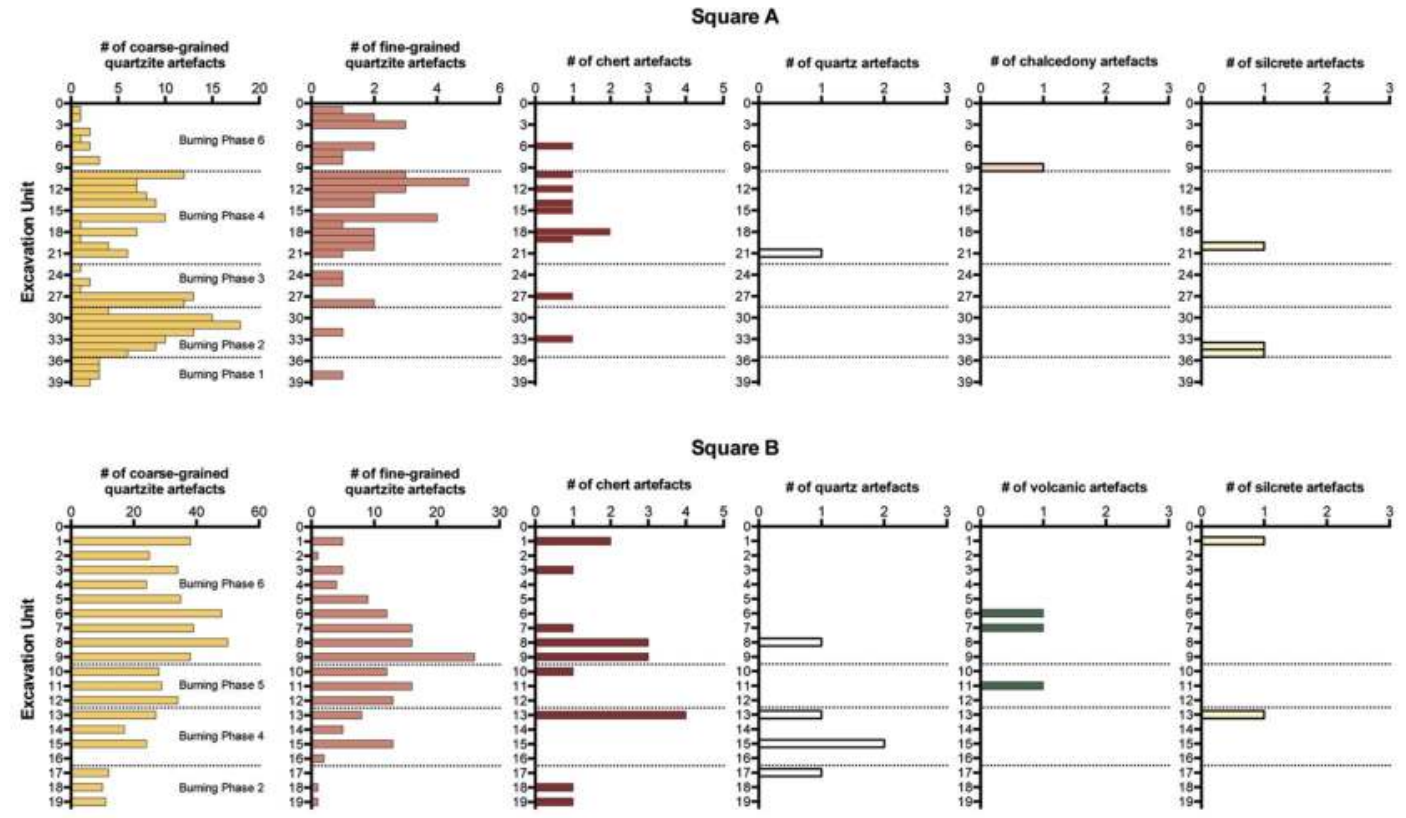

Square B

Figure 14.17 Squares A and B: Distribution of flaked stone artefacts by raw material, by XU. Source: Illustrations by Jerome Mialanes.
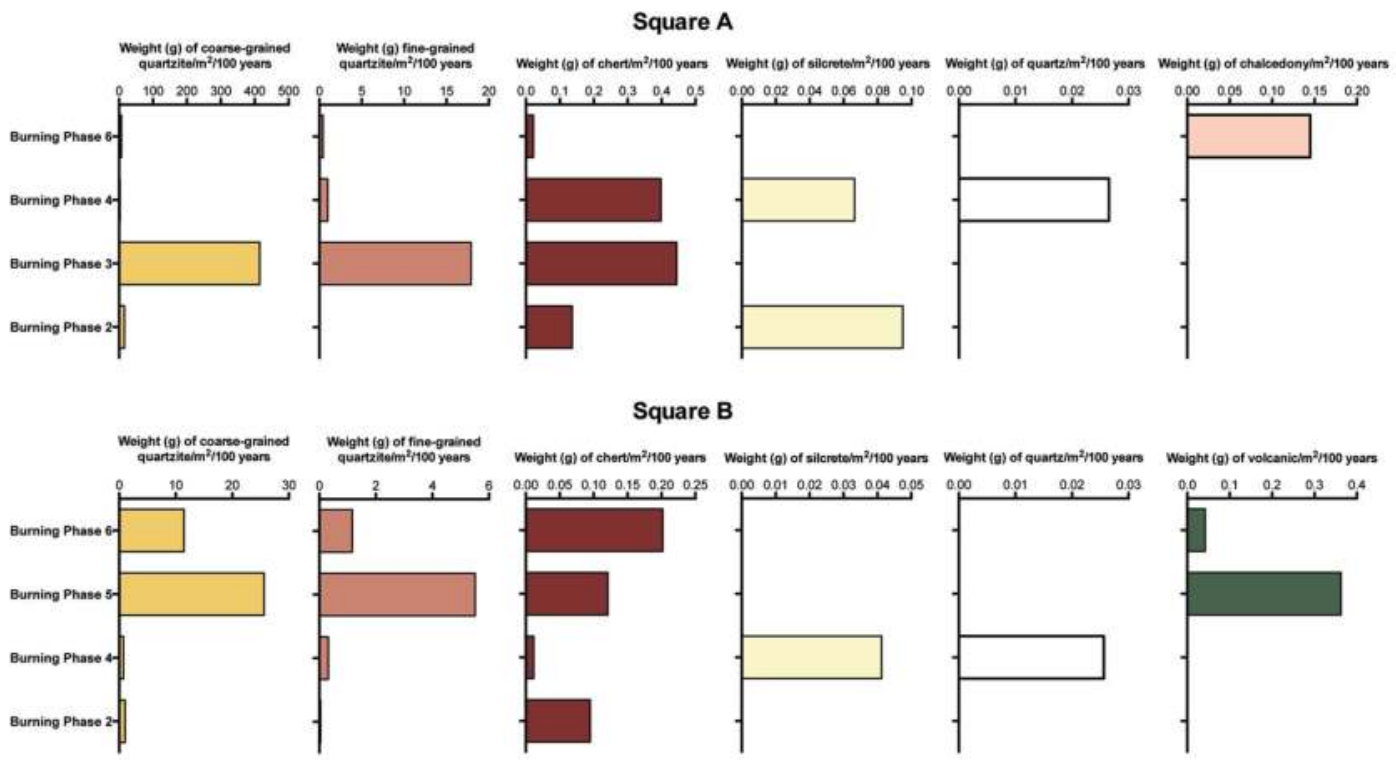

Figure 14.18 Squares A and B: Distribution of flaked stone artefacts by raw material weight $(\mathrm{g}) /$ $\mathrm{m}^{2} / 100$ years by Burning Phase.

Source: Illustrations by Jerome Mialanes.

\section{Quartzite}

All quartzite flakes were made by unipolar freehand percussion. Most are broken, followed by complete flakes and flaked pieces (Tables 14.7 and 14.8). The total absence of coarse-grained cores suggests manufacturing from the wall. In Square A, complete coarse-grained flakes are on average much heavier than those on fine-grained quartzite, while in Square B, coarse-grained quartzite flakes are slightly lighter than those made on fine-grained quartzite (Tables 14.9 and 14.10). 
Table 14.7 Square A: Flaked stone artefacts by fracture type.

\begin{tabular}{|l|r|r|r|r|r|}
\hline Raw material & \multicolumn{1}{c|}{$\begin{array}{c}\text { Unipolar } \\
\text { complete flakes }\end{array}$} & $\begin{array}{l}\text { Unipolar broken } \\
\text { flakes }\end{array}$ & Bipolar core & $\begin{array}{c}\text { Bipolar broken } \\
\text { flake }\end{array}$ & Flaked pieces \\
\hline Chalcedony & 2 & 1 & 1 & & \\
\hline Chert & 10 & 7 & & & \\
\hline Coarse-grained quartzite & 12 & 31 & & & \\
\hline Fine-grained quartzite & & & & & \\
\hline Milky quartz & 2 & 1 & & & \\
\hline Silcrete & 26 & 203 & 1 & 1 & 24 \\
\hline Total & & & & & \\
\hline
\end{tabular}

Source: Authors' data.

Table 14.8 Square B: Flaked stone artefacts by fracture type.

\begin{tabular}{|l|r|r|r|r|}
\hline Raw material & $\begin{array}{c}\text { Unipolar complete } \\
\text { flakes }\end{array}$ & $\begin{array}{c}\text { Unipolar broken } \\
\text { flakes }\end{array}$ & Bipolar core & Flaked pieces \\
\hline Chert & 6 & 10 & & 1 \\
\hline Coarse-grained quartzite & 56 & 460 & & 7 \\
\hline Fine-grained quartzite & 28 & 136 & 1 & \\
\hline Milky quartz & & & & \\
\hline Crystal quartz & 1 & 4 & & \\
\hline Silcrete & & 1 & & \\
\hline Volcanic & 91 & 614 & 1 & \\
\hline Total & & & &
\end{tabular}

Source: Authors' data.

Table 14.9 Square A: Complete quartzite flakes: Weights and dimensions.

\begin{tabular}{|l|r|r|r|r|r|}
\hline Square A & $\begin{array}{c}\text { Mean weight } \\
\mathbf{\pm} \text { S.D. }\end{array}$ & $\begin{array}{c}\text { Length } \mathbf{( m m )} \\
\mathbf{I} \text { S.D. }\end{array}$ & $\begin{array}{c}\text { Width (mm) } \\
\pm \text { S.D. }\end{array}$ & $\begin{array}{c}\text { Thickness (mm) } \\
\pm \text { S.D. }\end{array}$ & N \\
\hline Coarse-grained quartzite & $2.31 \pm 6.39$ & $13.5 \pm 13.4$ & $9.7 \pm 7.5$ & $3.0 \pm 3.4$ & 10 \\
\hline Burning Phase 6 & 0.05 & 4.8 & 6.3 & 1.2 & 1 \\
\hline Burning Phase 4 & $0.27 \pm 0.39$ & $9.1 \pm 5.6$ & $8.2 \pm 4.9$ & 1.6 & 4 \\
\hline Burning Phase 3 & $7.28 \pm 11.43$ & $26.0 \pm 20.3$ & $16.3 \pm 10.4$ & $6.7 \pm 4.6$ & 3 \\
\hline Burning Phase 2 & 0.05 & $8.0 \pm 2.2$ & $4.5 \pm 2.2$ & $1.4 \pm 0.4$ & 2 \\
\hline Fine-grained quartzite & $0.78 \pm 1.67$ & $13.4 \pm 15.2$ & $7.9 \pm 4.3$ & $2.1 \pm 1.7$ & 12 \\
\hline Burning Phase 6 & $0.07 \pm 0.04$ & $8.3 \pm 3.0$ & $4.9 \pm 2.5$ & $0.9 \pm 0.4$ & 2 \\
\hline Burning Phase 4 & $0.95 \pm 2.20$ & $12.9 \pm 18.4$ & $7.4 \pm 4.7$ & $2.0 \pm 2.1$ & 6 \\
\hline Burning Phase 3 & $1.06 \pm 1.55$ & $18.3 \pm 18.9$ & $10.8 \pm 4.4$ & $2.8 \pm 1.7$ & 3 \\
\hline Burning Phase 2 & 0.28 & 12.5 & 7.5 & 2.7 & 1 \\
\hline
\end{tabular}

Source: Authors' data.

Table 14.10 Square B: Complete quartzite flakes: Weights and dimensions.

\begin{tabular}{|l|r|r|r|r|r|}
\hline Square B & $\begin{array}{c}\text { Mean weight }(\mathbf{g}) \\
\pm \text { S.D. }\end{array}$ & $\begin{array}{c}\text { Length } \mathbf{( m m )} \\
\mathbf{\pm} \text { S.D. }\end{array}$ & $\begin{array}{c}\text { Width (mm) } \\
\pm \text { S.D. }\end{array}$ & $\begin{array}{c}\text { Thickness (mm) } \\
\pm \text { S.D. }\end{array}$ & N \\
\hline Coarse-grained quartzite & $0.24 \pm 0.47$ & $7.5 \pm 3.2$ & $8.1 \pm 4.4$ & $1.7 \pm 1.3$ & 56 \\
\hline Burning Phase 6 & $0.19 \pm 0.31$ & $6.8 \pm 2.7$ & $7.5 \pm 4.1$ & $1.5 \pm 1.1$ & 35 \\
\hline Burning Phase 5 & $0.22 \pm 0.24$ & $8.3 \pm 4.0$ & $9.0 \pm 3.7$ & $1.9 \pm 1.1$ & 15 \\
\hline Burning Phase 4 & $0.07 \pm 0.05$ & $8.5 \pm 1.5$ & $6.7 \pm 2.5$ & $1.3 \pm 0.1$ & 5 \\
\hline Burning Phase 2 & 2.95 & 15.2 & 24.2 & 7.3 & 1 \\
\hline
\end{tabular}




\begin{tabular}{|l|r|r|r|r|r|}
\hline Square B & $\begin{array}{c}\text { Mean weight }(\mathbf{g}) \\
\pm \text { S.D. }\end{array}$ & $\begin{array}{c}\text { Length }(\mathbf{m m}) \\
\mathbf{\pm} \text { S.D. }\end{array}$ & $\begin{array}{c}\text { Width (mm) } \\
\pm \text { S.D. }\end{array}$ & $\begin{array}{c}\text { Thickness (mm) } \\
\pm \text { S.D. }\end{array}$ & $\mathbf{N}$ \\
\hline Fine-grained quartzite & $0.38 \pm 0.95$ & $7.3 \pm 4.2$ & $7.7 \pm 5.2$ & $1.8 \pm 1.8$ & 28 \\
\hline Burning Phase 6 & $0.09 \pm 0.12$ & $5.9 \pm 3.1$ & $5.8 \pm 3.3$ & $1.3 \pm 0.8$ & 13 \\
\hline Burning Phase 5 & $0.45 \pm 1.09$ & $7.6 \pm 4.2$ & $8.2 \pm 5.8$ & $1.9 \pm 2.1$ & 9 \\
\hline Burning Phase 4 & $0.77 \pm 1.42$ & $9.6 \pm 5.9$ & $10.9 \pm 6.6$ & $2.6 \pm 2.7$ & 6 \\
\hline
\end{tabular}

Source: Authors' data.

In Square A, flaked stone artefacts are on average larger during Burning Phase 3 than at any other time (Table 14.9); the greatest volume of flaked coarse-grained quartzite also occurs then (Figure 14.19).

\section{Square $\mathbf{A}$}

\section{Volume $\left(\mathrm{cm}^{3}\right)$ of coarse-grained quartzite flaked artefacts}

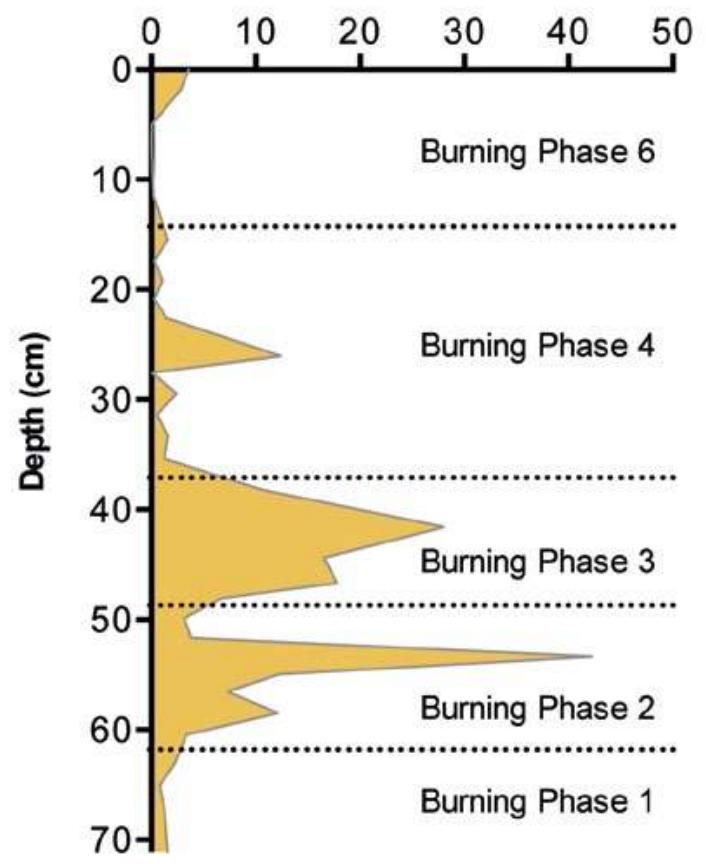

Square B

\section{Volume $\left(\mathrm{cm}^{3}\right)$ of coarse-grained quartzite flaked artefacts}

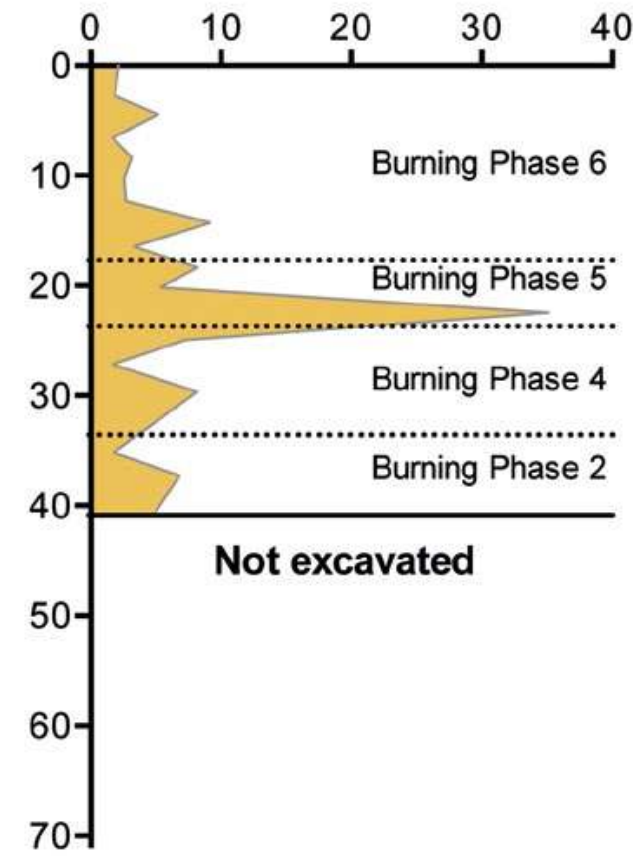

Figure 14.19 Squares A and B: Volume of coarse-grained quartzite artefacts by depth.

Source: Illustrations by Jerome Mialanes.

Square A is close to the back wall. Here, during Burning Phase 3, coarse-grained quartzite artefacts were made from a large block that detached from the wall during an intensive knapping phase (see below). As peak artefact densities are only evident in Square A at this time (Figures 14.14 and 14.15), knapping activity appears to have been restricted to the back wall. In contrast, Square B's coarse-grained quartzite assemblage consists of smaller complete flakes; with 82.1 per cent being $<10 \mathrm{~mm}$ long, they suggest later stages of reduction of selected flakes (Tables 14.9 and 14.10).

The absence of fine-grained quartzite cores suggests they were discarded elsewhere, or that flakes were manufactured directly from local on-wall strata. In Square A, fine-grained quartzite complete flakes average $13.4 \mathrm{~mm}$ in length, of which 58.3 per cent are less than $10 \mathrm{~mm}$ long. In Square B, they average $7.3 \mathrm{~mm}$ in length, nearly half the size, with 78.6 per cent being less 
than $10 \mathrm{~mm}$ long. This pattern suggests that later stages of reduction preferentially took place in Square B where headroom is greater than in Square A. The same pattern applies to the coarsegrained quartzite, with smaller complete flakes in Square B than in Square A.

Retouched quartzite artefacts are rare: only two, both fine-grained, were found. One is a broken flake with abrupt ventral retouching along one margin from XU11 in Square A (in Burning Phase 4). The other is a broken medial flake with fine ventral retouching along one lateral margin from XU10 in Square B (in Burning Phase 5). With a maximum width of $21.4 \mathrm{~mm}$, this is the third-largest fine-grained quartzite flake from Square B, suggesting that only flakes above a certain size met the requirements for an extended use-life.

The only formal artefact type is an unretouched fine-grained quartzite blade, $40 \mathrm{~mm}$ long by $11 \mathrm{~mm}$ wide (from Square A XU28 in Burning Phase 3).

\section{Other raw materials}

Most chert artefacts are broken flakes (Tables 14.7 and 14.8). A bipolar chert core $(21.1 \mathrm{~mm}$ long, $2.73 \mathrm{~g}$ ) from Square A indicates advanced reduction and raw material conservation. The largest flake scar on the core is $14.3 \mathrm{~mm}$ long by $7.6 \mathrm{~mm}$ wide, indicating the production of relatively small flakes. Complete chert flakes are also small, the only two examples from Square A being $5.4 \mathrm{~mm}$ and $13.3 \mathrm{~mm}$ long; in Square $B(\mathrm{n}=6)$ they are $3.3 \mathrm{~mm}$ to $12.9 \mathrm{~mm}$ long (average $=5.5 \mathrm{~mm}$ ). The use of bipolar percussion together with the making of small flakes indicates a high degree of curation of this non-local resource.

Both milky and crystal quartz artefacts are present. They include a distal bipolar flake from Square A, and a bipolar core from Square B, all other quartz flakes being too small and fragmented to ascertain how they were made. Water-rolled cortex on opposite sides of the bipolar core indicates the collection of quartz nodules from creek beds or the quartzite rock matrix.

Flaked artefacts made on chalcedony, silcrete and volcanic rock, all exotic raw materials, are few. No retouch is evident.

\section{Coarse-grained quartzite artefact conjoining on back wall}

One flaked piece from Square A XU29 is of particular importance for the painted panel with bichrome anthropomorphs and red stick-figures above Square A: the ventral surface of the XU29 flaked piece conjoins perfectly over two of the stick-figures (Images \#15 and \#36) and indeterminate Image \#43 (see below) (Figures 14.20 and 14.21). The XU29 artefact lay buried flat in sandy deposit, at $50.7 \mathrm{~cm}$ depth. It was found exactly $15 \mathrm{~cm}$ south, $10 \mathrm{~cm}$ east and 1.05 $\mathrm{m}$ below its conjoin scar on the shallow overhang, part of rock wall stratum D2 above Square A. None of the artefact's surfaces are patinated, nor do they show any other signs of weathering. The edges are sharp and use-wear is absent. The artefact is $7.4 \mathrm{~cm}$ long, $2.9 \mathrm{~cm}$ wide and $1.4 \mathrm{~cm}$ thick, and weighs $36.1 \mathrm{~g}$.

The XU29 conjoining flaked piece's dorsal surface (Figure 14.20) is convex and contains at least three, and possibly four, uni-directional flake scars sub-parallel to the longitudinal axis; there is no evidence of core rotation from these scars. It was once part of a larger block originally attached to the now-exposed rock wall at strata D3/D2. That block became detached from the wall, after which its convex dorsal surface was flaked, resulting in the creation of the excavated flaked piece.

The pronounced concave profile of the ventral surface of the excavated artefact, and the matching convex profile of the stratum D2 wall surface, indicate that the excavated artefact and the large block that originally contained it did not simply detach from the wall as a result 
of gravitational collapse. The absence of a striking platform, bulb of percussion, eraillure scar and ripple marks on the ventral surface of the excavated artefact suggests that the block was not removed from the wall by flaking. Rather, the curvature of the wall together with the position of the buried artefact beneath its originating scar on the wall suggest that the block was detached through thermal shock caused by fire; solar heat would have been insufficient, especially given the shadiness of this low part of the shelter. Here, the considerable length of the convex scar is testimony to the large volume of strata D3/D2 rock that collapsed, in the vicinity of $300 \mathrm{~kg}$. Images \#1-\#46 were painted on this newly created surface sometime after the block fell.

It is not known whether the fire that caused the thermal shock was purposefully built by people against the back wall, perhaps to quarry the rock, or whether it was a bushfire whose flames happened to reach this part of the wall. Irrespective of the cause, sometime after detachment by fire from the wall, the block was flaked, creating the dorsal scars on the artefact. Initial stages of that flaking took place at ground level where the block fell, explaining the flaking debris in and around XU29 of Square A.
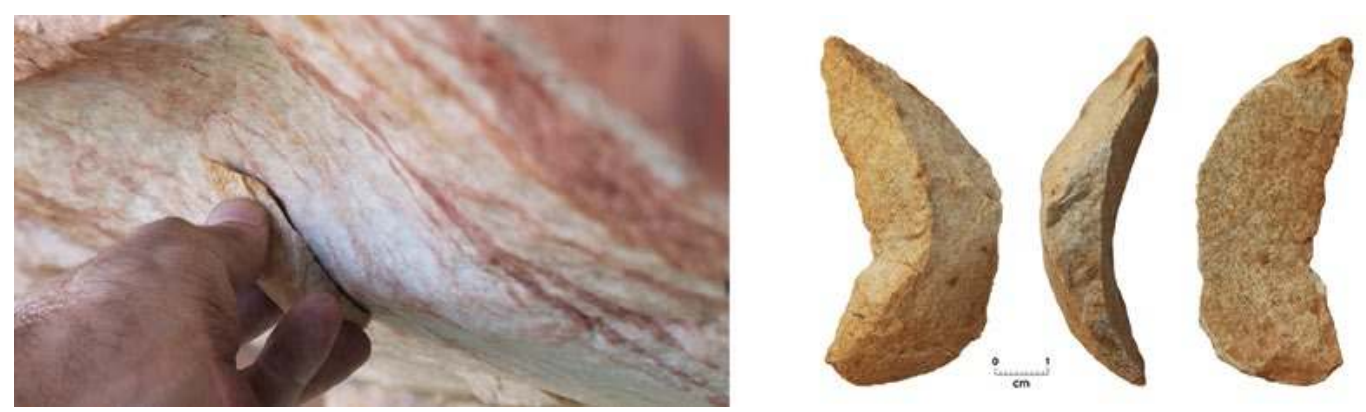

Figure 14.20 The quartzite flaked piece excavated from Square A XU29 that fits onto the painted rock wall. Source: Photographs by Jean-Jacques Delannoy.

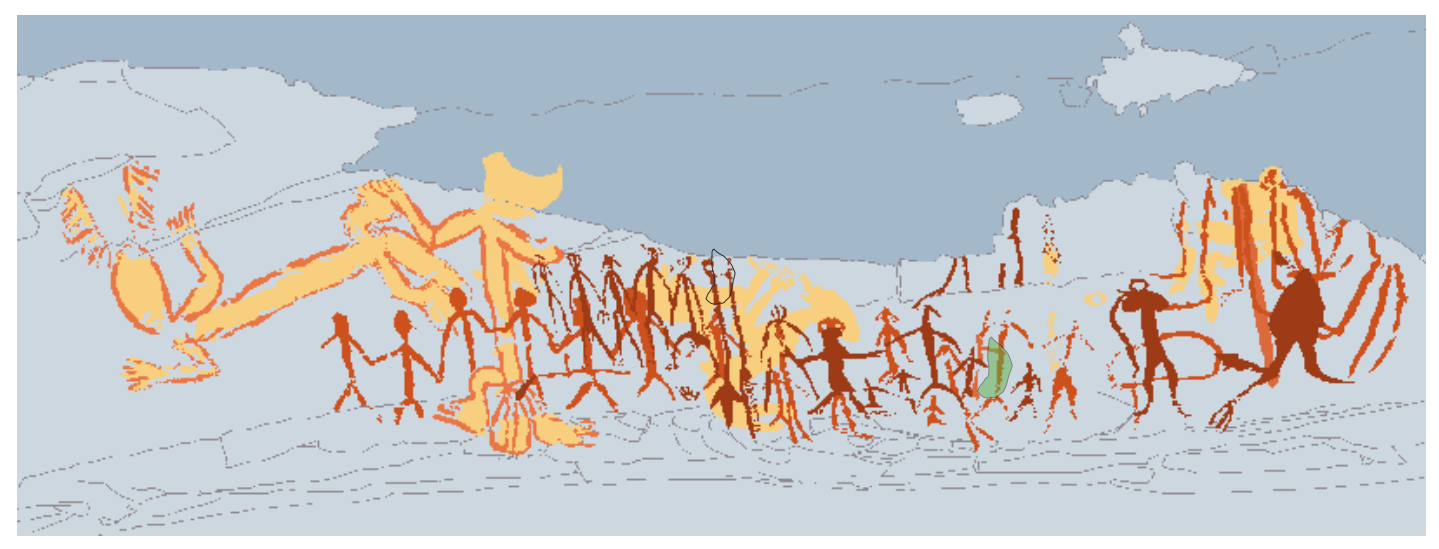

Figure 14.21 Digitally enhanced and traced frieze near base of Wall 2.

The paintings were enhanced using DStretch filters Ids, Ire and lye at Scale 10 (see Figure 14.46 for separation by layers of superimposition and numbering of individual paintings). The location of the conjoining quartzite flaked piece from Square $\mathrm{A}$ XU29 is shown in green.

Source: Illustration by Robert Gunn. 


\section{Excavated cultural materials: Ochre}

A use-worn red ochre crayon was found at $43-46 \mathrm{~cm}$ depth in Square A XU26 (the depth range of XU26; it was retrieved from the sieves), $6.3 \pm 1.5 \mathrm{~cm}$ above the XU29 conjoining stone artefact discussed above (Figure 14.22). It is very hard, measures $2.5 \times 2.0 \times 1.5 \mathrm{~cm}$ and weighs $9.5 \mathrm{~g}$. One convex, facetted surface is covered with multi-directional striations from grinding. All other surfaces are rough and irregular. The excavated piece broke from a larger crayon, probably during use, as evident by the sectioned ground surface. Under $\times 50$ magnification, particles of intense red powder, each c. $10 \mu \mathrm{m}$ wide, are seen near the centre of the ground surface (Figure 14.23).

Non-invasive analyses were undertaken both of the ground and rough surfaces. The elemental composition was determined by portable X-ray fluorescence (XRF) spectrometer (S1 Titan, Bruker, 10 and $30 \mathrm{kV}, 30 \mathrm{~s}$ of acquisition time, analysed area $=0.5 \times 0.5 \mathrm{~mm})($ Table 14.11) . As accreted aluminosilicates $\left(\mathrm{AlO}_{4} / \mathrm{SiO}_{4}\right)$ and sand grains $\left(\mathrm{SiO}_{2}\right)$ from surrounding sediments (i.e. contamination) could not be properly cleaned from the rough surface, it is the cleaner, ground surface that better indicates the chemistry of the ochre.

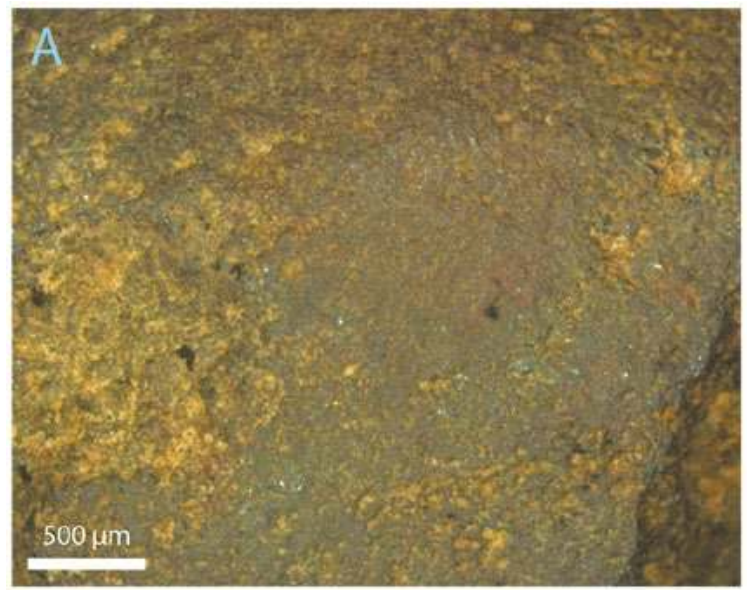

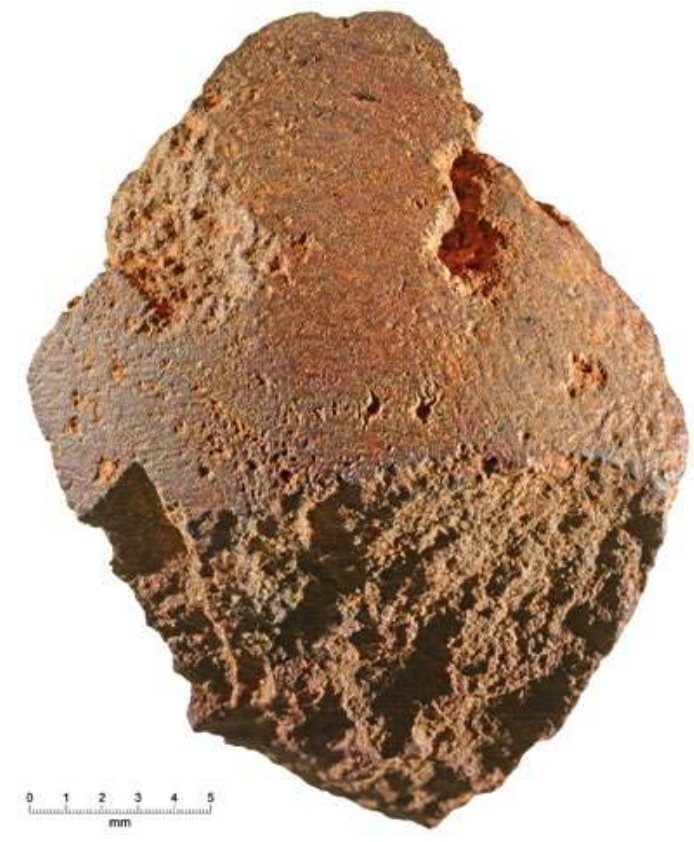

Figure 14.22 Red ochre crayon from Square A XU26.

Source: Photograph by Steve Morton.

Figure 14.23 A: Macro-observation of the red ochre crayon ground surface (Square A XU26). B: Raman spectra obtained on several points on and near the released red particles adhered to the ground surface, confirming the presence of well-crystallised haematite.

Source: Photograph and illustration by Emilie Chalmin. 
Raman spectroscopy (Jobin-Yvon-Horiba, T64000, green laser at $514.5 \mathrm{~nm}$ with $0.8 \mathrm{~mW}$ power, $\times 50$, with $4 \mathrm{~cm}^{-1}$ spectral resolution) identified the presence of well-crystallised haematite $\left(\mathrm{Fe}_{2} \mathrm{O}_{3}\right)$ both on the individual particles of red powder and on nearby areas of the ground surface (Figure 14.23).

$\mathrm{X}$-ray diffraction (XRD) (INEL, Co anode, 5-120 $\theta$ angular domain) confirms the predominance of haematite $\mathrm{Fe}_{2} \mathrm{O}_{3}$ and quartz $\mathrm{SiO}_{2}$ with an undefined secondary aluminosilicate phase on the rough surface. These two latter phases (quartz $\mathrm{SiO}_{2}$ and aluminosilicate) can be attributed to the fine sediments trapped in micro-cavities of the rough surface. XRD also confirms a wellcrystallised phase of relatively pure haematite for the ground surface.

Table 14.11 Square A XU26 red ochre crayon: Semi-quantitative chemical fingerprint of major (\%), minor $(\%)$ and trace $(\mathrm{ppm})$ elements on the ground surface of the crayon $(<L O D=$ below limit of detection).

\begin{tabular}{|c|c|c|c|c|c|c|c|c|c|c|c|}
\hline & & & op & & & & & Parts pe & millio & (ppm) & \\
\hline & $\mathrm{SiO}_{2}$ & $\mathrm{Al}_{2} \mathrm{O}_{3}$ & $\mathrm{Fe}_{2} \mathrm{O}_{3}$ & $\mathrm{~K}_{2} \mathrm{O}$ & $\mathrm{TiO}_{2}$ & $\mathrm{P}_{2} \mathrm{O}_{5}$ & V & $\mathrm{Cr}$ & $\mathrm{Cu}$ & $\mathrm{Rb}$ & $\mathrm{Ce}$ \\
\hline Ground surface & 25.4 & 28.2 & 64.6 & 0.21 & 0.18 & 0.10 & 470 & 130 & 46 & 124 & 810 \\
\hline Rough surface & 44.7 & 22.4 & 48.5 & 0.31 & 0.56 & 0.11 & 210 & $<L O D$ & 43 & 56 & 275 \\
\hline
\end{tabular}

Source: Authors' data.

\section{The art on the wall}

Much of the lower half of the hard quartzite wall is covered by a c. $1 \mathrm{~mm}$ thick, red-coloured rock skin. Here red paintings abound, many of which are hard to distinguish from the red crust because of their similar colours. Broad sections of this red crust have detached or been removed from the wall, exposing a fresh, light-coloured surface beneath. On that underlying surface, paintings are easier to make out. Exfoliation scars a few centimetres long also occur on both painted and unpainted parts of the cortex (see below).

All rock surfaces were examined in the field and photographed. The digital photographs were scrutinised for rock art both prior to and following computer enhancement in Adobe Photoshop CS6 and DStretch. Paintings were observed in three areas, which we refer to as 'Wall 1', 'Wall 2' and 'Wall 3' rather than 'panels', because the art is variably spread on each wall rather than necessarily forming spatially delimited art panels (Tables 14.12 and 14.13; Figure 14.24).

Table 14.12 Four-level hierarchical classification scheme applied to rock paintings and beeswax images.

\begin{tabular}{|l|l|}
\hline Level & Classification \\
\hline 1 & $\begin{array}{l}\text { Determinate: Where an image could be classified according to its formal attributes. } \\
\text { Indeterminate: An image that could not be formally identified because of its incompleteness due to deterioration. }\end{array}$ \\
\hline 2 & $\begin{array}{l}\text { Figurative: Motif with formal resemblance to an object, human, animal etc. } \\
\text { Non-Figurative: Abstract figure. }\end{array}$ \\
\hline 3 & $\begin{array}{l}\text { General Motif Form. } \\
\text { Figurative: Zoomorph, anthropomorph, item of material culture. } \\
\text { Non-Figurative: Closed geometrics, open geometrics, other linear. }\end{array}$ \\
\hline 4 & $\begin{array}{l}\text { Specific Motif Form. } \\
\text { 23 different forms (e.g. echidna, circular shape, straight line, dash cluster etc.). }\end{array}$ \\
\hline
\end{tabular}

Source: Authors' data. 


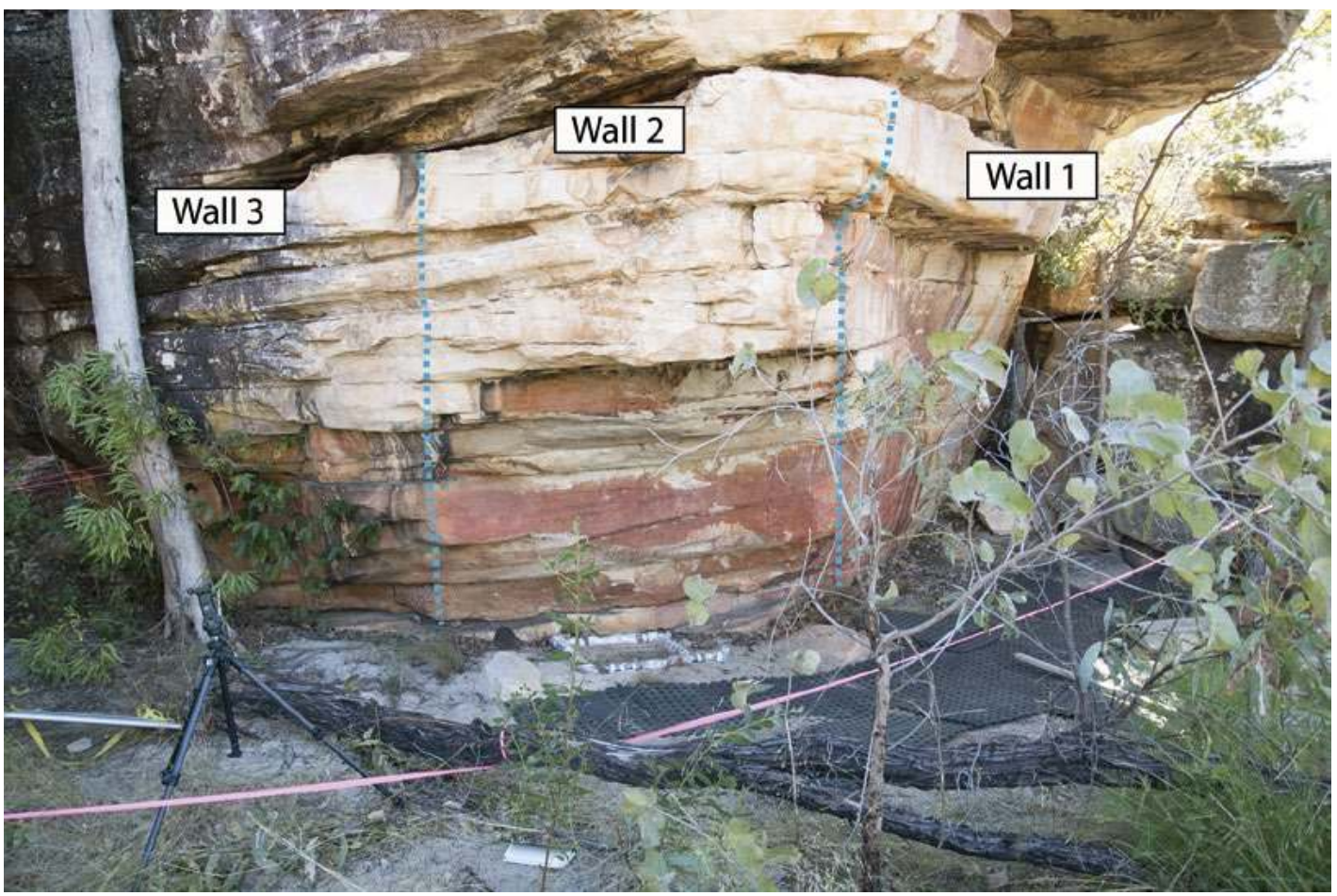

Figure 14.24 Location of the three wall sections.

Source: Photograph by Bruno David.

A total of 117 images in three techniques (paintings, beeswax figures, a stencil) were identified (Table 14.12). Sixty-seven (57 per cent) of these are distinct enough to make out their shapes; the other 50 are too degraded and thus treated as 'indeterminate' (Figure 14.25). Most images are paintings ( $\mathrm{n}=113,97$ per cent of images); the others are three beeswax figures ( 3 per cent) and a stencil ( 1 per cent). Eighty-three ( 73 per cent) of the 113 paintings are red, 18 (16 per cent) are yellow, eight ( 7 per cent) are white, two ( 2 per cent) are red and yellow, and two ( 2 per cent) are red and white (Table 14.14). The only hand stencil is red. Most $(n=52,83$ per cent) of the 63 determinate paintings are figurative; the other 11 (17 per cent) are non-figurative.

The figurative paintings are anthropomorphs ( $\mathrm{n}=44,70$ per cent of determinate paintings), zoomorphs ( $\mathrm{n}=5,8$ per cent) and items of material culture ( $\mathrm{n}=3,5$ per cent). Nonfigurative paintings include a range of 'open geometric' ( $n=5,8$ per cent), 'closed geometric' $(\mathrm{n}=3,5$ per cent) and 'other linear' designs $(\mathrm{n}=3,5$ per cent) (Table 14.13; Figure 14.26). 


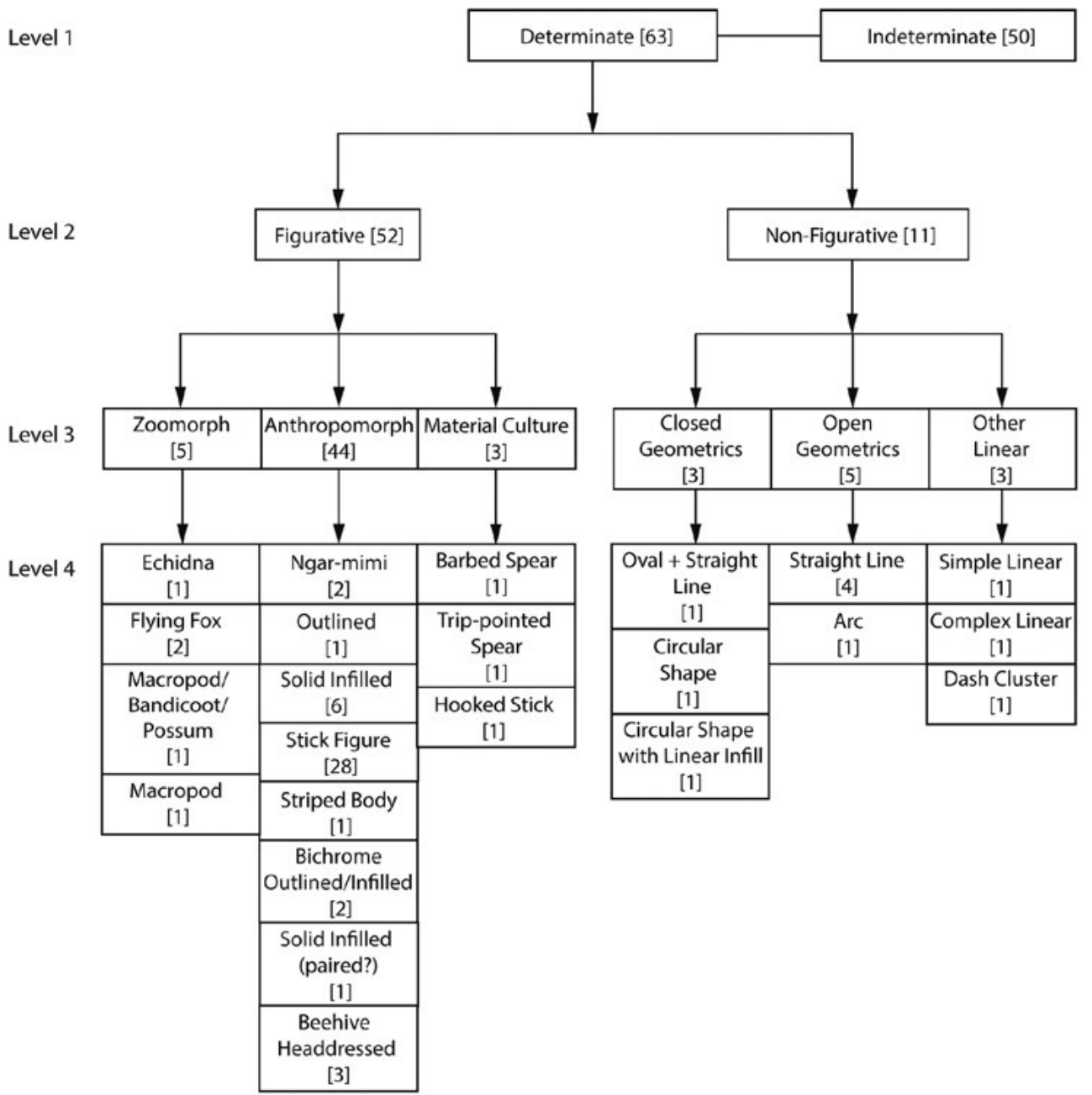

Figure 14.25 Four-level hierarchical classification scheme applied to the rock paintings, showing number of images in each category.

Source: Illustration by Liam Brady.

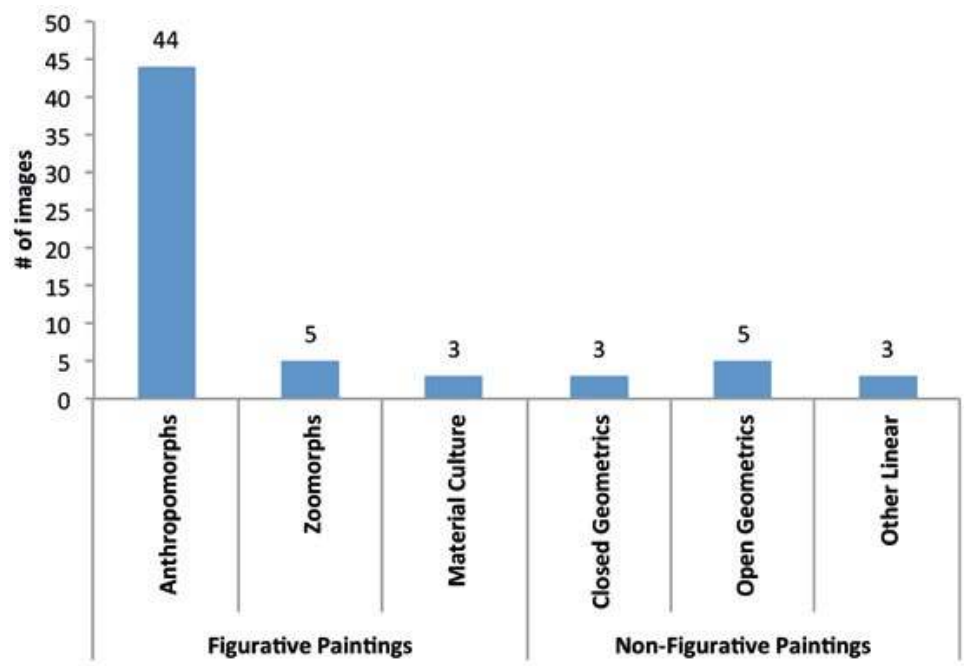

Figure 14.26 Number of determinate paintings by General Motif Form. Source: Illustration by Liam Brady. 
Table 14.13 List of Level 4 (Specific Motif Form) paintings and beeswax images, plus the hand stencil, on the bedrock wall strata.

\begin{tabular}{|c|c|c|}
\hline Image \# & Level 4 specific motif form & Bedrock wall strata \\
\hline 1 & Stick-figure anthropomorph & D3 \\
\hline 2 & Stick-figure anthropomorph & D3 \\
\hline 3 & Stick-figure anthropomorph & D3 \\
\hline 4 & Stick-figure anthropomorph & D3 \\
\hline 5 & Stick-figure anthropomorph & D3 \\
\hline 6 & Tri-pointed spear & D3 \\
\hline 7 & Barbed spear & D3 \\
\hline 8 & Stick-figure anthropomorph & D3 \\
\hline 9 & Straight line & D3 \\
\hline 10 & Indeterminate & D3 \\
\hline 11 & Solid-infilled anthropomorph & D3 \\
\hline 12 & Stick-figure anthropomorph & D3 \\
\hline 13 & Stick-figure anthropomorph & D3 \\
\hline 14 & Stick-figure anthropomorph & D3 \\
\hline 15 & Stick-figure anthropomorph & D3 \\
\hline 16 & Stick-figure anthropomorph & D3 \\
\hline 17 & Solid-infilled anthropomorph & D3 \\
\hline 18 & Solid-infilled anthropomorph & D3 \\
\hline 19 & Indeterminate & D3 \\
\hline 20 & Indeterminate & D3 \\
\hline 21 & Indeterminate & D3 \\
\hline 22 & Indeterminate & D3 \\
\hline 23 & Stick-figure anthropomorph & D3 \\
\hline 24 & Stick-figure anthropomorph & D3 \\
\hline 25 & Stick-figure anthropomorph & D3 \\
\hline 26 & Stick-figure anthropomorph & D3 \\
\hline 27 & Stick-figure anthropomorph & D3 \\
\hline 28 & Stick-figure anthropomorph & D3 \\
\hline 29 & Stick-figure anthropomorph & D3 \\
\hline 30 & Stick-figure anthropomorph & D3 \\
\hline 31 & Stick-figure anthropomorph & D3 \\
\hline 32 & Stick-figure anthropomorph & D3 \\
\hline 33 & Stick-figure anthropomorph & D3 \\
\hline 34 & Stick-figure anthropomorph & D3 \\
\hline 35 & Stick-figure anthropomorph & D3 \\
\hline 36 & Stick-figure anthropomorph & D3 \\
\hline 37 & Stick-figure anthropomorph & D3 \\
\hline 38 & Oval + straight line & D3 \\
\hline 39 & Complex linear non-figurative & D3 \\
\hline 40 & Bichrome outlined/infilled anthropomorph & D3 \\
\hline 41 & Bichrome outlined/infilled anthropomorph & D3 \\
\hline 42 & Solid-infilled anthropomorph(s) & D3 \\
\hline 43 & Indeterminate & D3 \\
\hline 44 & Indeterminate & D3 \\
\hline 45 & Indeterminate & D3 \\
\hline 46 & Straight line & D3 \\
\hline 47 & Echidna & $D 10+D 11+D 12+D 13$ \\
\hline
\end{tabular}




\begin{tabular}{|c|c|c|}
\hline Image \# & Level 4 specific motif form & Bedrock wall strata \\
\hline 48 & Straight line & D10 \\
\hline 49 & Dash cluster & D10 \\
\hline 50 & Indeterminate & D10 \\
\hline 51 & ArC & D10 \\
\hline 52 & Outlined anthropomorph & $\mathrm{D} 8+\mathrm{D} 9+\mathrm{D} 10$ \\
\hline 53 & Circular shape with linear infill & $\mathrm{D} 8+\mathrm{D} 9+\mathrm{D} 10$ \\
\hline 54 & Indeterminate & D3 \\
\hline 55 & Ngar-mimi anthropomorph & D3 \\
\hline 56 & Beeswax line + dots & $\mathrm{D} 3+\mathrm{D} 4$ \\
\hline 57 & Indeterminate & $\mathrm{D} 3+\mathrm{D} 4$ \\
\hline 58 & Beeswax dot cluster & D3 \\
\hline 59 & Simple linear non-figurative & D5 \\
\hline 60 & Indeterminate & D5 \\
\hline 61 & Stick-figure anthropomorph & D6 \\
\hline 62 & Ngar-mimi anthropomorph & D5 \\
\hline 63 & Indeterminate & D5 \\
\hline 64 & Beeswax dot cluster & $\mathrm{D} 3+\mathrm{D} 4$ \\
\hline 65 & Indeterminate & D3+D4 \\
\hline 66 & Beehive-headdressed anthropomorph & $\mathrm{D} 3+\mathrm{D} 4$ \\
\hline 67 & Indeterminate & $D 3+D 4$ \\
\hline 68 & Indeterminate & D3 \\
\hline 69 & Hooked stick & D3 \\
\hline 70 & (Beehive-headdressed?) Anthropomorph & $D 3+D 4$ \\
\hline 71 & Beehive-headdressed anthropomorph & D3+D4 \\
\hline 72 & Solid-infilled anthropomorph & D7 \\
\hline 73 & Indeterminate & D8+D9 \\
\hline 74 & Indeterminate & D8+D9 \\
\hline 75 & Indeterminate & D8+D9 \\
\hline 76 & Macropod/bandicoot/possum & $D 3+D 4$ \\
\hline 77 & Indeterminate & D13 \\
\hline 78 & Solid-infilled anthropomorph & $D 2+D 3$ \\
\hline 79 & Indeterminate & D3 \\
\hline 80 & Indeterminate & D3 \\
\hline 81 & Striped body anthropomorph & D3 \\
\hline 82 & Indeterminate & D3 \\
\hline 83 & Straight line & D10 \\
\hline 84 & Circular shape & D9 \\
\hline 85 & Indeterminate & D6 \\
\hline 86 & Indeterminate & D10 \\
\hline 87 & Indeterminate & D3 \\
\hline 88 & Hand stencil & D5+D6 \\
\hline 89 & Solid-infilled anthropomorph & D3 \\
\hline 90 & Flying-fox & D2 \\
\hline 91 & Flying-fox & D2 \\
\hline 92 & Stick-figure anthropomorph & D2 \\
\hline 93 & Indeterminate & $\mathrm{D} 2$ \\
\hline 94 & Indeterminate & D2 \\
\hline 95 & Indeterminate & D2 \\
\hline 96 & Indeterminate & D2 \\
\hline
\end{tabular}




\begin{tabular}{|l|l|l|}
\hline Image \# & Level 4 specific motif form & Bedrock wall strata \\
\hline 97 & Indeterminate & D2 \\
\hline 98 & Indeterminate & D2 \\
\hline 99 & Indeterminate & D2 \\
\hline 100 & Indeterminate & D3 \\
\hline 101 & Indeterminate & D3 \\
\hline 102 & Indeterminate & D3+D4 \\
\hline 103 & Indeterminate & D3+D4 \\
\hline 104 & Indeterminate & D3 \\
\hline 105 & Indeterminate & D2+D3 \\
\hline 106 & Indeterminate & D3 \\
\hline 107 & Indeterminate & D3+D4 \\
\hline 108 & Indeterminate & D2 \\
\hline 109 & Indeterminate & D2+D3 \\
\hline 110 & Indeterminate & D2 \\
\hline 111 & Indeterminate & D3 \\
\hline 112 & Indeterminate & D3 \\
\hline 113 & Macropod & D2+D3 \\
\hline 114 & Indeterminate & D3 \\
\hline 115 & Indeterminate & D3 \\
\hline 116 & Indeterminate & D3+D4 \\
\hline 117 & Indeterminate & D3+D4 \\
\hline
\end{tabular}

Source: Authors' data.

Table 14.14 Colour frequencies of all paintings, excluding the beeswax figures and stencil.

\begin{tabular}{|l|r|r|}
\hline Colour & Total number of images & \% of paintings \\
\hline Red & 83 & 73 \\
\hline Yellow & 18 & 16 \\
\hline White & 8 & 7 \\
\hline Red + Yellow & 2 & 2 \\
\hline Red + White & 2 & 2 \\
\hline Total & 113 & 100 \\
\hline
\end{tabular}

Source: Authors' data.

\section{Zoomorphs}

A single red-outlined echidna is depicted in plan-view on Wall 1 (faunal identifications are descriptions that resemble extant local fauna; they were not made from local Jawoyn identifications). It has irregularly criss-crossing straight lines inside its body and short parallel lines (quills) extending around its entire perimeter (Figure 14.27). The juncture between the head and body is partly exfoliated. Two small, red-outlined and white-infilled flying-foxes (Figure 14.28, Images \#90 and \#91) are also on Wall 1; they are superimposed over a red stick-figure anthropomorph (\#92) and six indeterminate red images (\#93-\#95 and \#97-\#99). The flyingfoxes are horizontal with triangular faces and ears. Nearby are the tail and legs (with back feet) of a macropod (\#113) superimposed over a red indeterminate image (\#96); the upper section of the macropod has weathered away. A probable macropod, bandicoot or, less likely, possum (\#76) is on Wall 3. It is depicted in profile view with a long, curving tail, small triangular ear and infilled body with curved lines (Figure 14.29). 


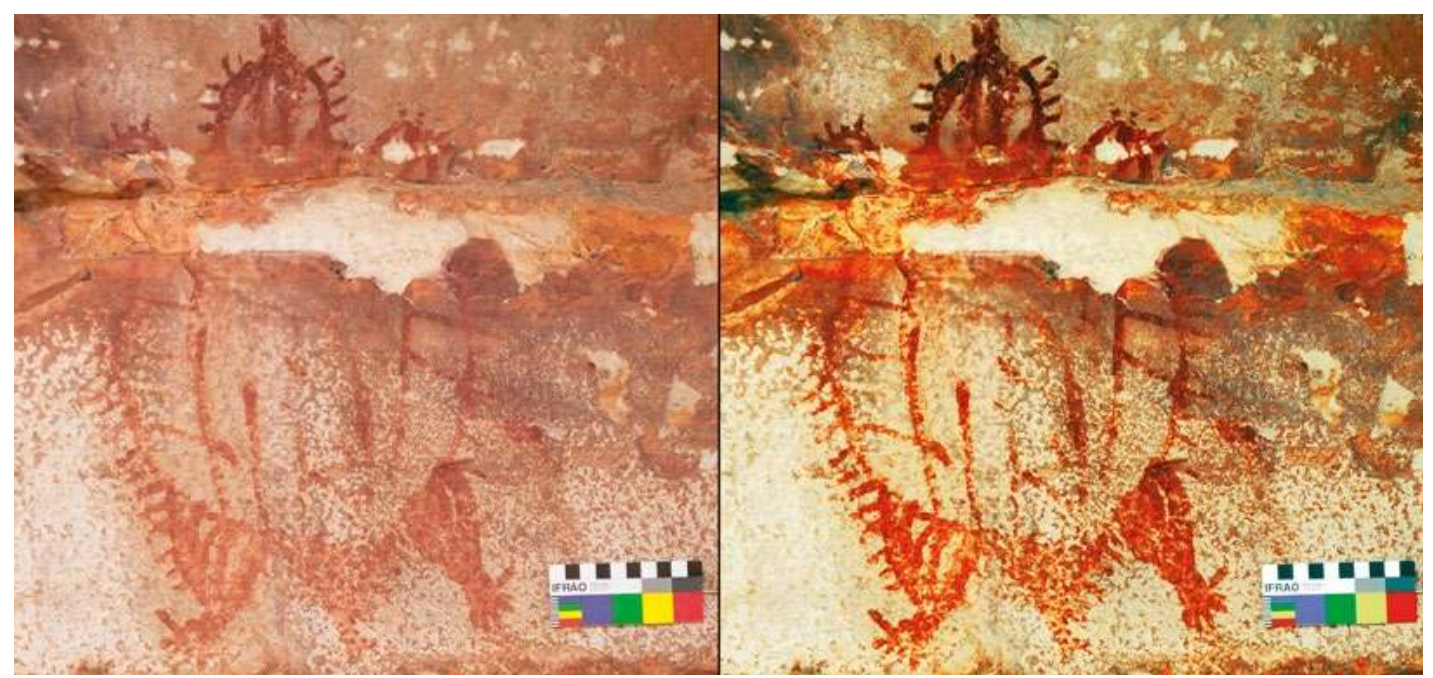

Figure 14.27 Echidna (\#47) on Wall 1.

Left: Original. Right: Digitally enhanced. Note exfoliation. Scale $10 \mathrm{~cm}$. Source: Photograph by Daniel James.

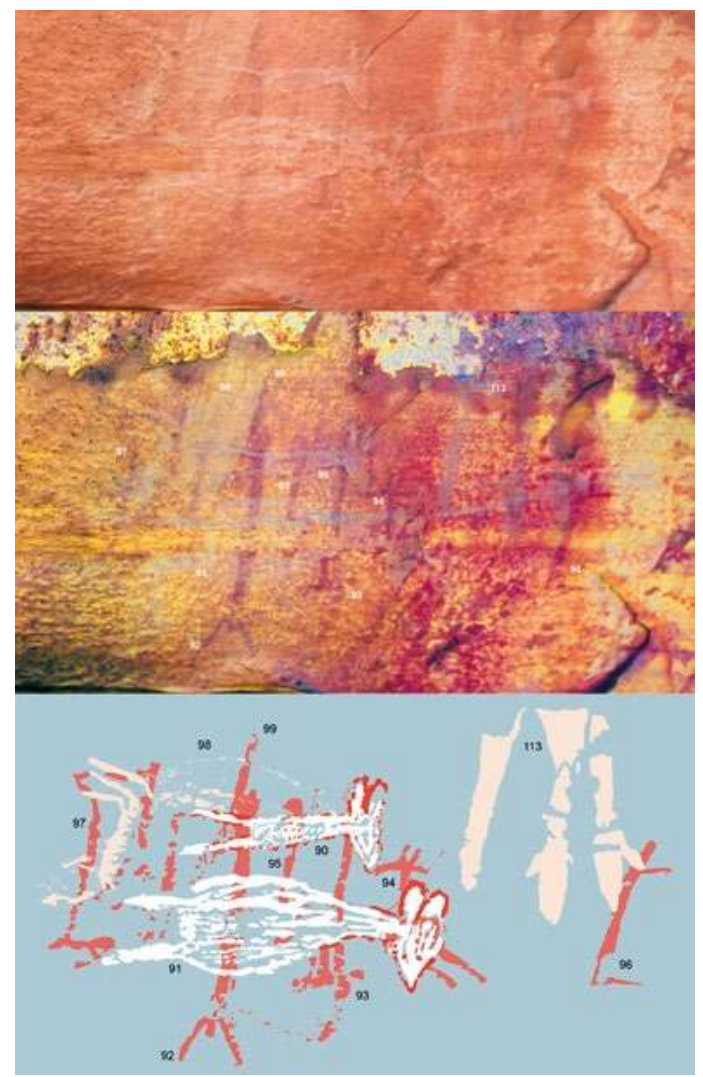

Figure 14.28 Two red-outlined and white-infilled flying-foxes (\#90, \#91), a macropod (\#113), a red stick-figure (\#92), and seven indeterminate images (\#93-\#99) on Wall 1.

Top: Original. Centre: Digitally enhanced. Bottom: Digitally traced.

Source: Photograph by Daniel James, enhancement and digital tracing by Robert Gunn.

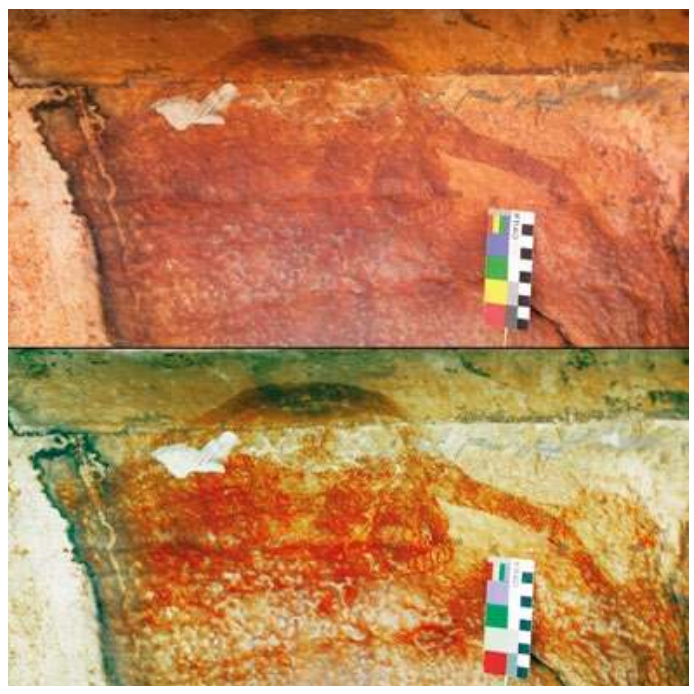

Figure 14.29 Probable macropod/bandicoot/ possum (\#76) on Wall 3.

Top: Original. Bottom: Digitally enhanced. Note exfoliation. Scale $10 \mathrm{~cm}$.

Source: Photograph by Daniel James and enhancement by Liam Brady. 


\section{Anthropomorphs}

There are 44 anthropomorphs, of eight motif types (see Figure 14.25); they occur on all three walls. Wall 1 has:

- A yellow-infilled horizontal anthropomorph (Figure 14.30, \#89).

- A white-infilled anthropomorph with outstretched arms, breasts, fingers and toes (Figure 14.30, \#78). It is superimposed over the yellow anthropomorph (\#89).

- A white anthropomorph with striped body. It has vertical lines on its torso, splayed feet and four fingers on each hand (Figure 14.30, \#81).

- A red stick-figure (Figure 14.28, \#92), superimposed by the flying-foxes (\#90, \#91).

- A red anthropomorph with outlined body and legs, and single-line arms; no fingers or feet are visible (Figure 14.31, \#52). Its head is missing through exfoliation. A small, circular shape with linear infill near the exfoliated head section may have been a headdress, but given the uncertainty here we treat it as a separate, non-figurative image.

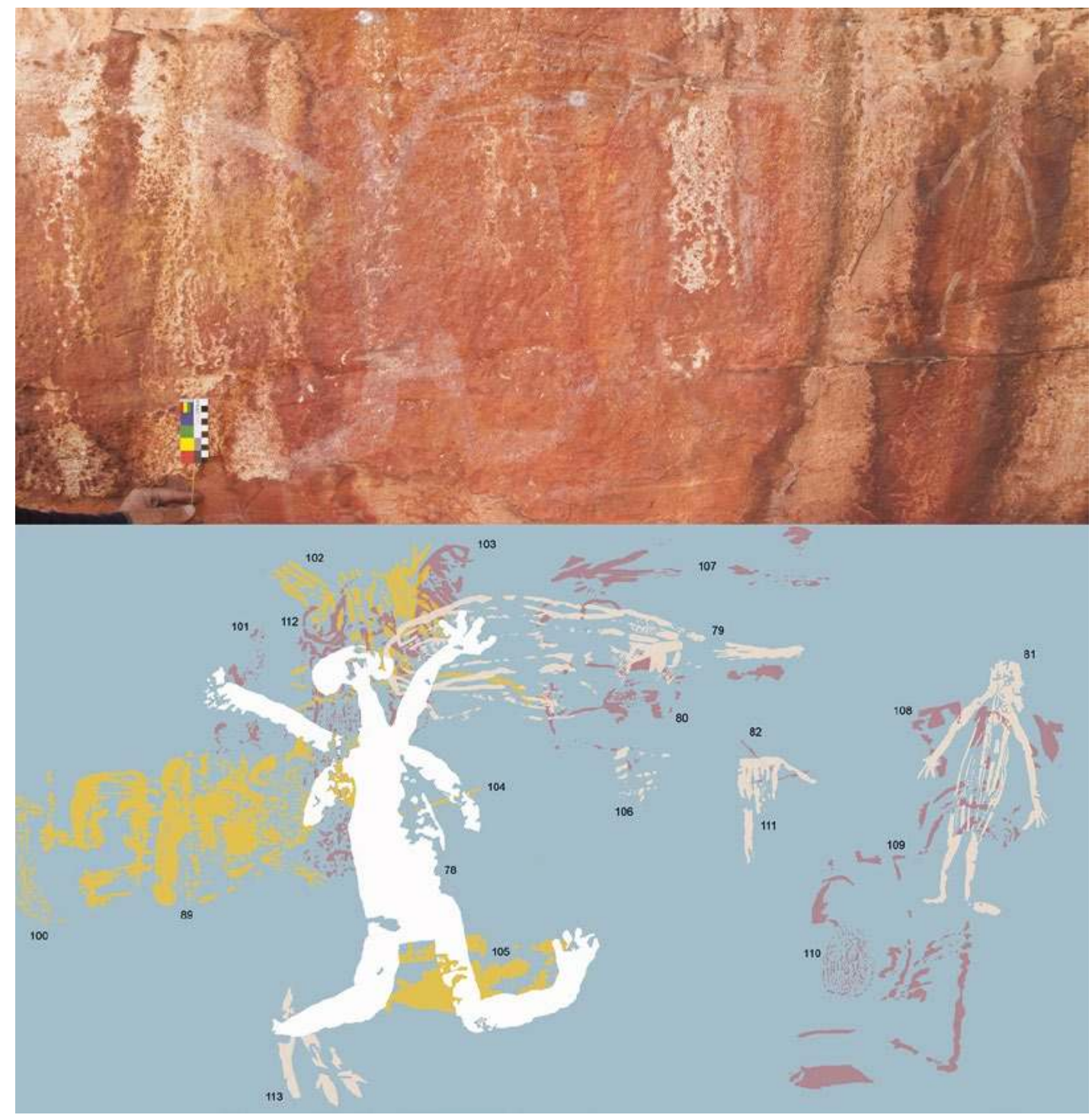

Figure 14.30 White anthropomorphs (\#78, \#81) and yellow anthropomorph (\#89) on Wall 1.

Top: Original. Bottom: Digital tracing of enhanced photograph. Scale $10 \mathrm{~cm}$.

Source: Photograph by Daniel James, enhancement and digital tracing by Robert Gunn.

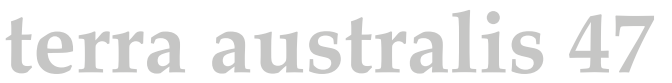




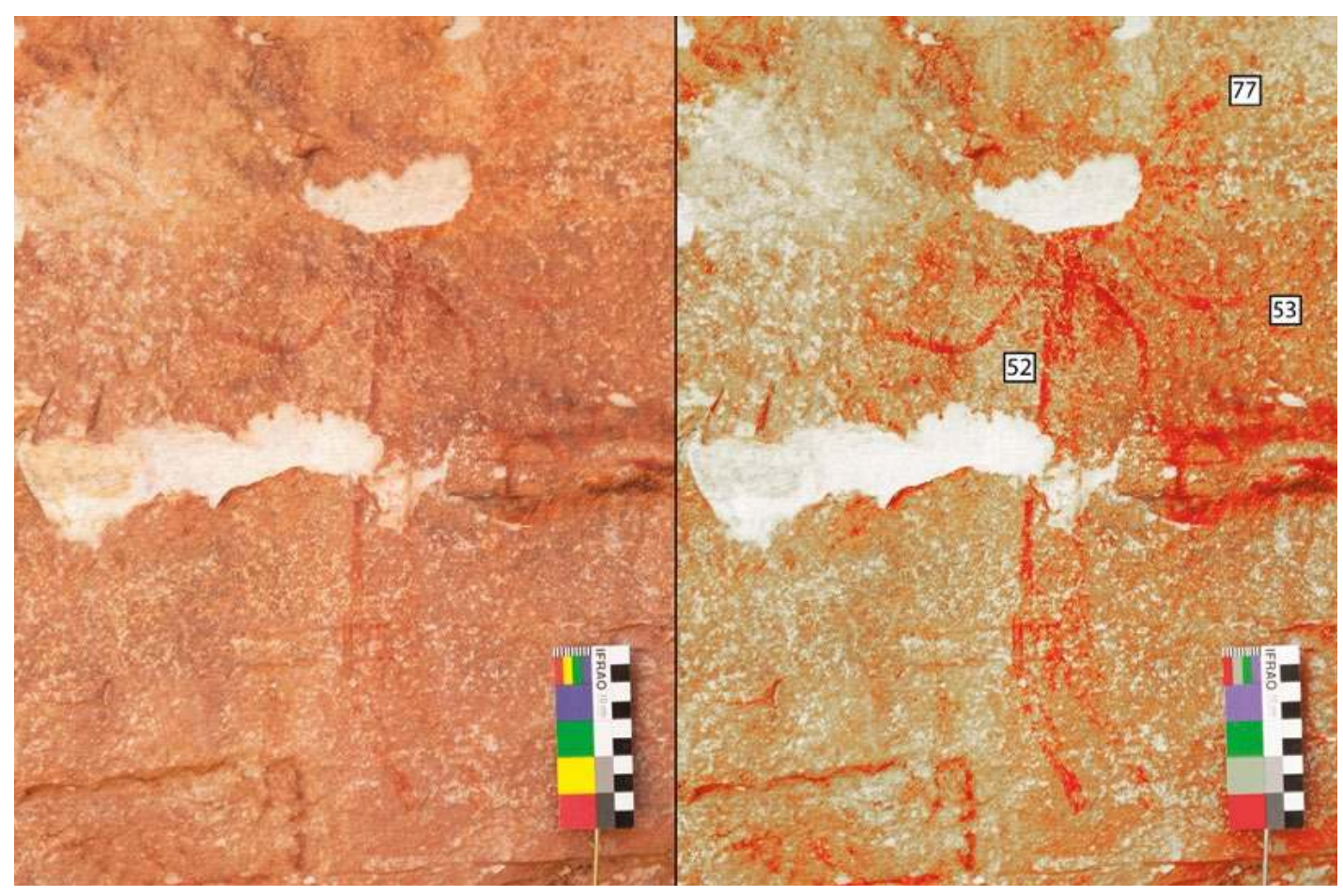

Figure 14.31 Red anthropomorph (\#52) on Wall 1.

Left: Original. Right: Enhanced. Note exfoliation. Scale $10 \mathrm{~cm}$.

Source: Photograph by Daniel James and enhancement by Liam Brady.

The upper half of Wall 2 has the following anthropomorphs:

- A yellow stick-figure (Figure 14.32, \#61).

- Two small round-headed (or round-headdressed) anthropomorphs of a common type in Jawoyn Country (Figures 14.33 and 14.34). Gunn et al. (2013:221) recently identified such motifs as 'Ngar-mimi' figures, following advice by members of the Jawoyn community (see also Gunn 2016). They describe Ngar-mimi paintings as having 'a large, round, infilled headdress placed centrally over a thin stick-like body that bifurcates into a pair of parallel stick-like legs, with a pair of short, straight arms (at c. $45^{\circ}$ to the body) holding a limited array of accoutrements'. One of the Ngar-mimi figures at JSARN-113/23 has a well-defined, red-infilled circular head, two short arms angled downward and the upper half of a torso; the lower parts of the torso and legs have been removed by a single large flake scar (Figure 14.34). The second example is on (or in) red cortex that makes the red painting more difficult to discern (Figure 14.33, \#55). Like its better-defined counterpart, it has a red-infilled circular head from which emanate two short, downward-angled arms and a torso; the torso is shorter than those of most other Ngar-mimi figures in Jawoyn Country. 


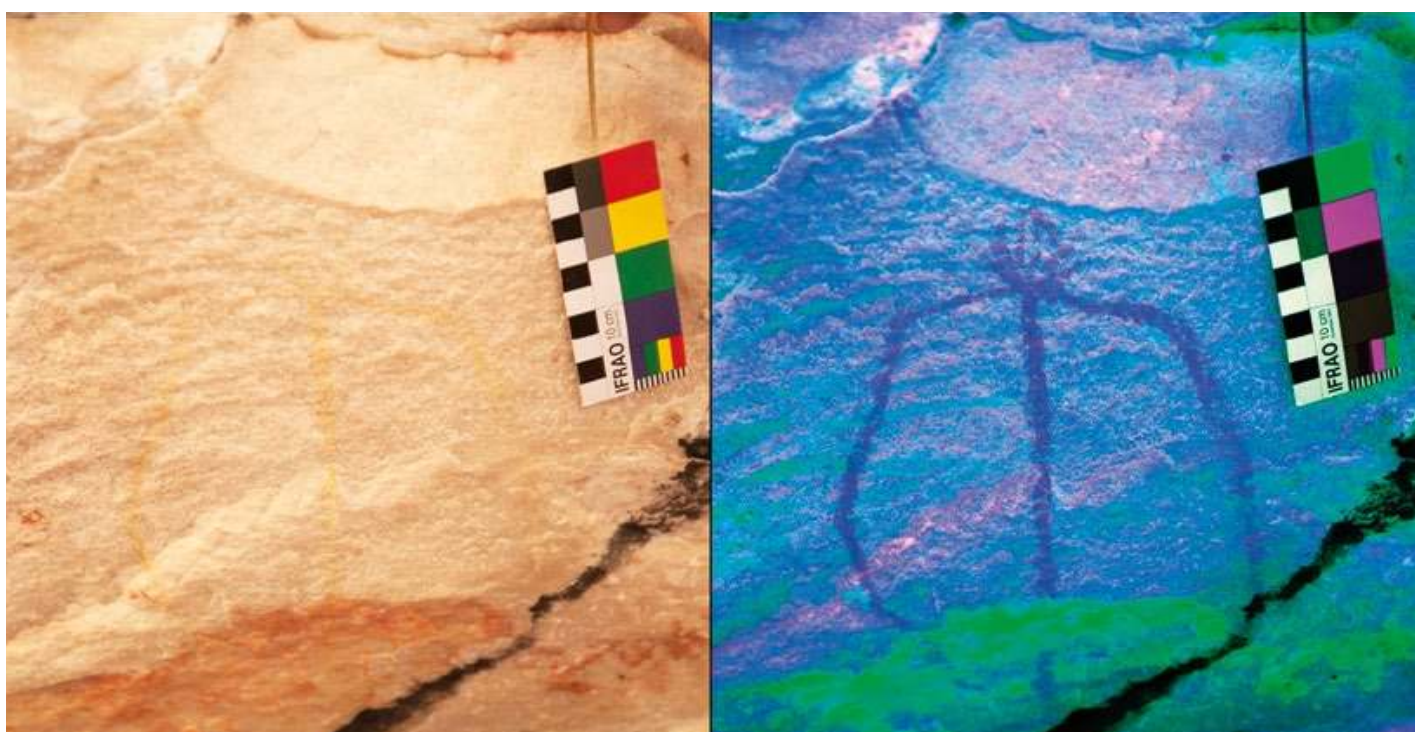

Figure 14.32 Yellow stick-figure (\#61) on Wall 2.

Left: Original. Right: Enhanced. Scale $10 \mathrm{~cm}$.

Source: Photograph by Daniel James and enhancement by Liam Brady.

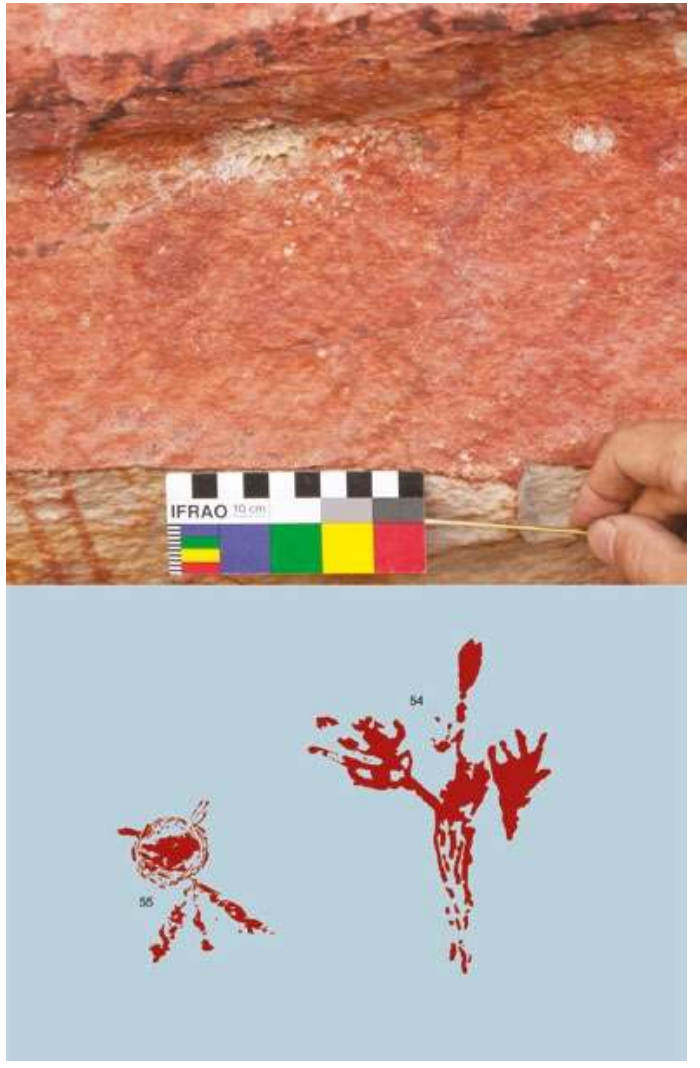

Figure 14.33 Red Ngar-mimi figure (\#55) on Wall 2.

Top: Original. Bottom: Digital tracing of enhanced photograph. Scale $10 \mathrm{~cm}$.

Source: Photograph by Daniel James and illustration by Robert Gunn.

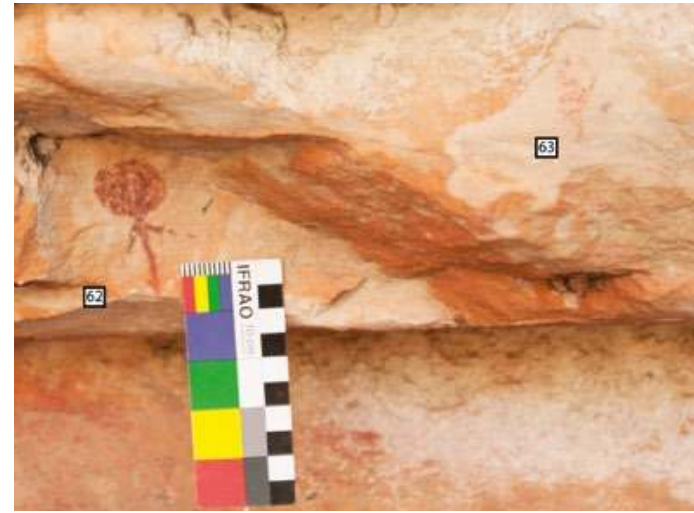

Figure 14.34 Red Ngar-mimi figure (\#62) on Wall 2. Scale $10 \mathrm{~cm}$.

Source: Photograph by Daniel James.

The lower part of Wall 2 has the densest concentration of paintings at the site, as follows:

- Two yellow anthropomorphs with 'beehive' headdresses (Figure 14.35, \#66, \#71). Welch $(1996,2007,2012)$ has argued that in northern Australia, similar headdresses were constructed from pliable roots or branches bound with hair twine and decorated with pigment, down or feathers. 'Beehive' headdresses are common in the rock art of the Arnhem Land plateau. They are varied and occur in several of the proposed early art phases, including Lewis's 
(1988) Boomerang and Hooked Stick periods; and Chaloupka's (1993) Dynamic, Yam, and Simple Figures with Boomerang periods. Neither Welch nor Chaloupka have recorded 'beehive' headdresses from any of the more recent art phases, suggesting that they were painted before 6000 BP (according to Lewis 1988) or 8000 BP (according to Chaloupka 1993).

- A white anthropomorph (\#70) superimposed over the yellow anthropomorphs with 'beehive' headdresses discussed above. It, too, appears to have a 'beehive' headdress, although it is too deteriorated to be certain.

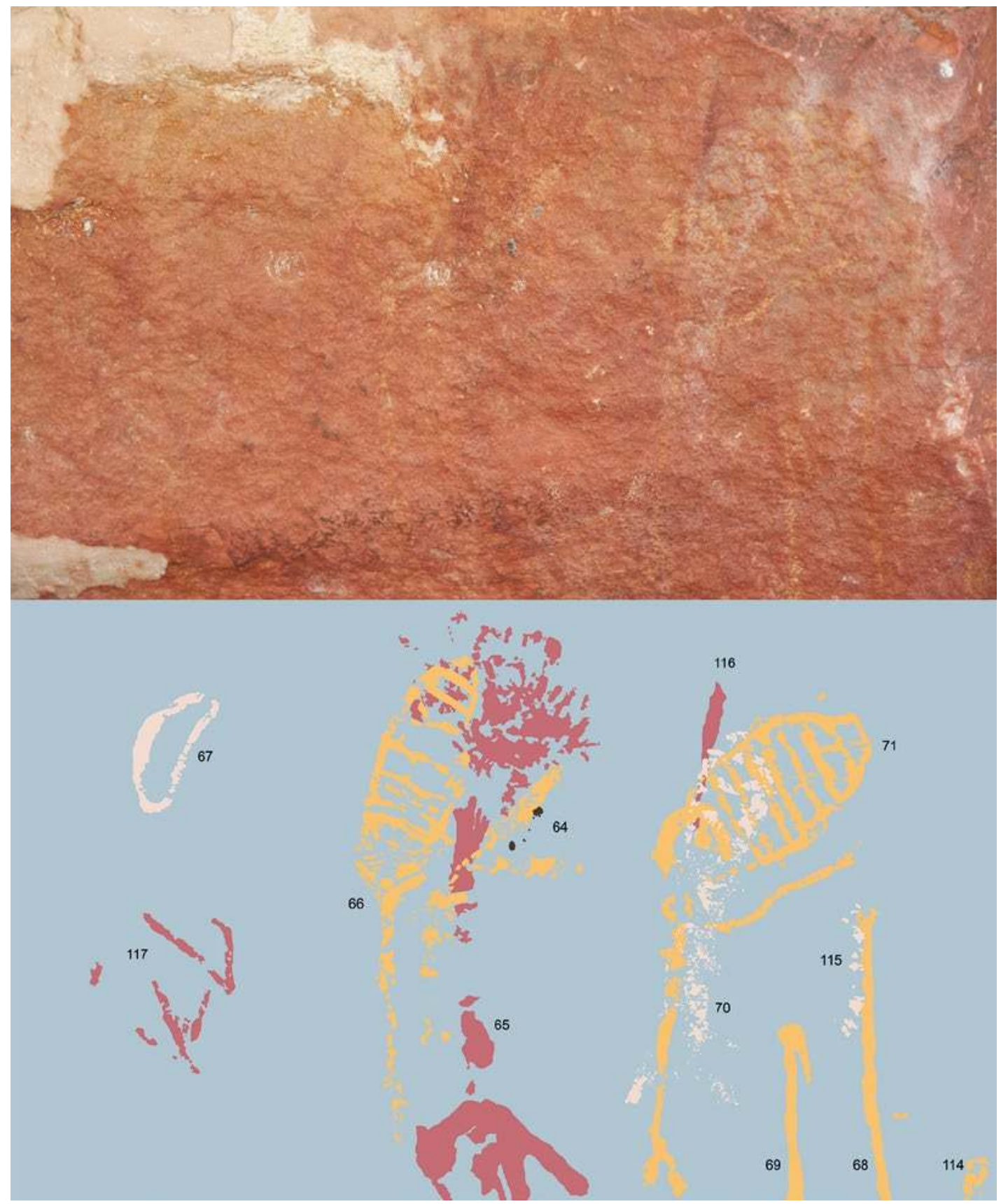

Figure 14.35 Anthropomorphs with 'beehive' headdresses (\#66, \#71, possibly \#70), a hooked stick (\#69) and a beeswax figure (\#64) on Wall 2.

Top: Original. Bottom: Digital tracing of enhanced photograph.

Source: Photograph by Daniel James and digital tracing by Robert Gunn. 
- The yellow anthropomorphs with 'beehive' headdresses are part of a frieze that also contains a clear example of what Lewis terms a 'hooked stick' (Figures 14.35 and 14.36, \#69; Lewis 1988:15). The function(s) of the hooked sticks depicted in Arnhem Land rock art is uncertain: they may represent spear-throwers, fighting picks or 'some other artefact', with more precise identification relying on context (Lewis 1988:15). To the right of, and parallel with, the hooked-stick is a vertical line with a 'top knob' (Figures 14.35 and 14.36, \#68) akin to a spear or light club.

The anthropomorphs with 'beehive' headdresses are similar in form to paintings from other parts of western Arnhem Land attributed to the Hooked Stick period by Lewis, and that are associated with paintings of hooked sticks (e.g. Lewis 1988:238, 244). Lewis (1988:92) has a 'loose estimate of about 9000 BP' for the start of hooked stick depictions, and c. $6000 \mathrm{BP}$ for its ending. While some Hooked Stick period painting scenes in western Arnhem Land contain both boomerangs and hooked sticks, others only have hooked sticks, indicating that boomerangs may have 'disappeared before the "hooked stick" period ended and more specialised spearthrowers were developed or introduced' (Lewis 1988:93). There are no definite boomerang depictions associated with the anthropomorphs with 'beehive' headdresses and hooked stick at JSARN-113/23.

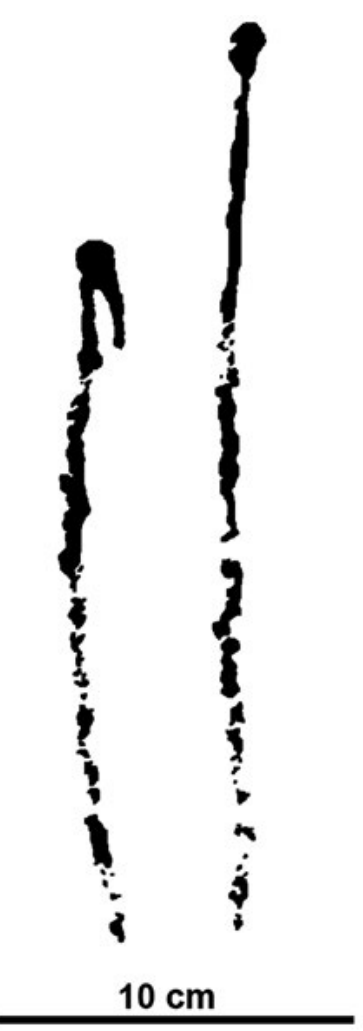

Figure 14.36 Wall 2: Left: Full hooked stick (\#69). Right: Adjacent vertical line that is either a spear - with spearhead above the haft thickening weathered away, probably because it was painted with a more fragile pigment - or a club (\#68).

These are traced from a different photograph to that in Figure 14.35 , so there is a slight variation in detail.

Source: Digital tracing by Robert Gunn.

- A short distance south but at comparable height to the anthropomorphs with yellow 'beehive' headdresses and the hooked stick, in a section of the wall devoid of red cortex, are some of the clearest and most distinctive motifs of the site (\#1-\#46): two bichrome infilled and outlined anthropomorphs; 26 stick-figures, many linked hand-to-hand to form rows; three infilled anthropomorphs; another infilled anthropomorph that seems to be part of a larger, nowfaded image; two spears; and four linear non-figurative designs (Figures 14.37 and 14.38). They were all painted after the large block of rock had detached from the wall through thermal shock, as described above; here the art must have been painted sometime, or at various times, after that event that exposed the present rock surface (see below). This now-painted, fresh, curved surface is c. $140 \mathrm{~cm}$ long and mostly c. $35 \mathrm{~cm}$ wide; it is perched parallel to the floor. That fresh surface extends further to the southwest as it curves around the back wall, where at times it approaches c. $50 \mathrm{~cm}$ width. The two red-outlined and yellow-infilled paintings (\#40,\#41) are found at the southern end of this fresh surface. Here, Image \#40 is horizontal, with arms and legs bent at the elbows and knees, head pointing upwards towards the top 
of the frieze; it has fingers and toes, and its 'headdress' has two E-shaped, winged features emanating from either side. The other bichrome anthropomorph (\#41) is juxtaposed to that horizontal one; it is vertical with raised arms bent at the elbows, and legs bent at the knees (see Figure 14.37). The upper half of the head extends onto the unexfoliated surface, where it is partly covered by a wasp nest. A yellow-infilled anthropomorph (\#42) is less clear than the two bichrome anthropomorphs, and may originally have been part of a larger image involving two copulating anthropomorphs, but it is too faded to be certain (see below).

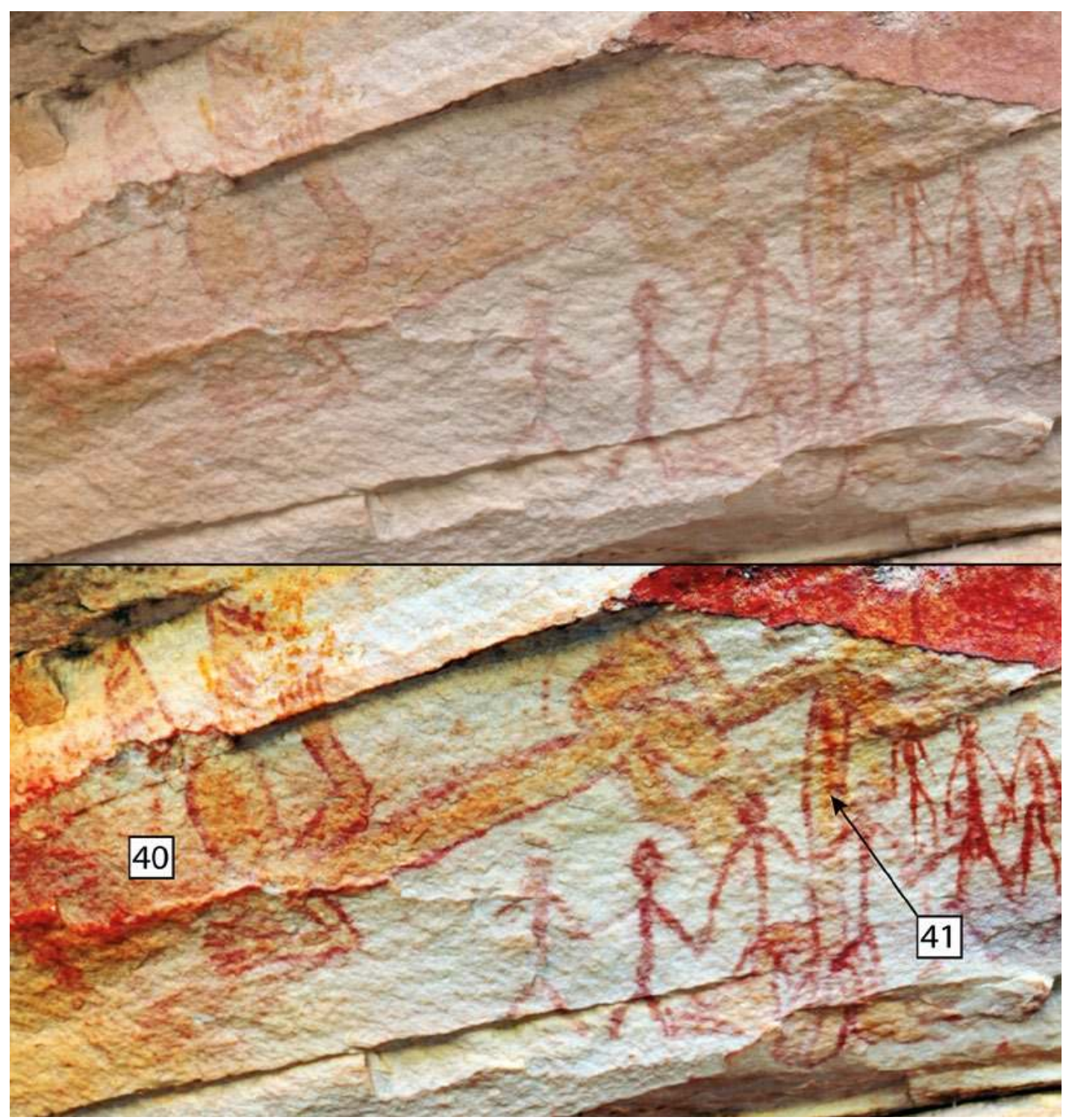

Figure 14.37 Two bichrome anthropomorphs (\#40, \#41) on Wall 2.

Top: Original. Bottom: Enhanced.

Source: Photograph by Bruno David and enhancement by Liam Brady.

- The surface with the two bichrome anthropomorphs at the base of Wall 2 also contains two sets of stick-figures in different shades of red. One group has seven stick-figures linked handto-hand (\#23-\#29), next to another group of nine stick-figures (\#30-\#37). At the northern end of that row of 16 stick-figures are an oval with vertical line (\#38), and a complex linear design (\#39) (Figure 14.38). 
- A second row of anthropomorphs consists of five stick-figures (some with fingers, eyes and ears) (\#1-\#5), again aligned hand-to-hand, next to a tri-pointed spear (\#6) and barbed spear (\#7) (see below). That frieze continues northward with a group of nine anthropomorphs depicted in a variety of ways, but always red linear or infilled (\#8-\#18). Image \#17 is the only clearly gendered anthropomorph on this frieze, the presence of breasts indicating a female (Figure 14.38).

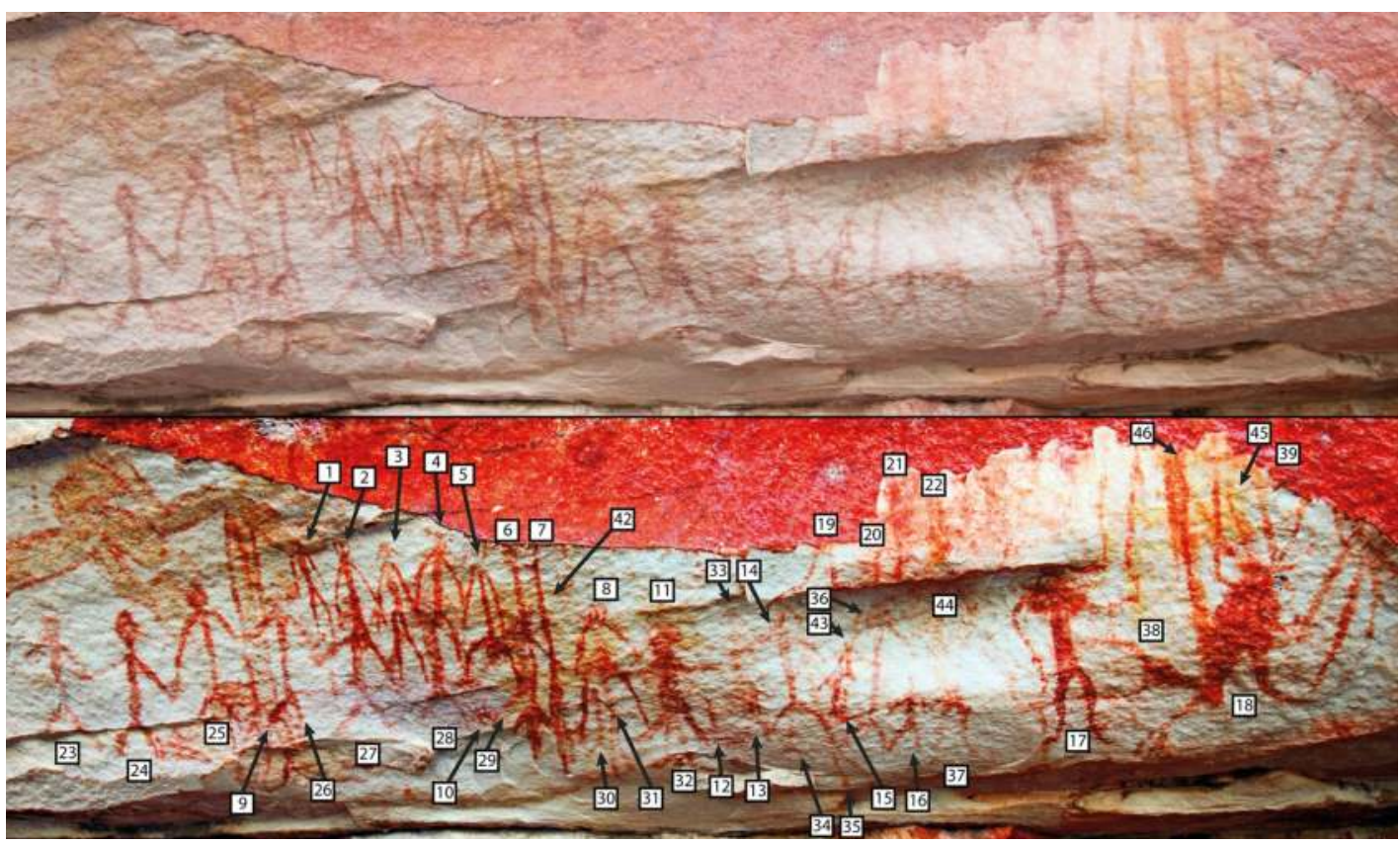

Figure 14.38 Anthropomorphs, spears and non-figurative figures near base of Wall 2.

Top: Original. Bottom: Enhanced.

Source: Photograph by Bruno David and enhancement by Liam Brady.

On Wall 3, some distance away, there is a single red-infilled anthropomorph with raised arms bent at the elbows and legs bent at the knees (Figure 14.39,\#72). No feet, hands, toes or fingers are visible.

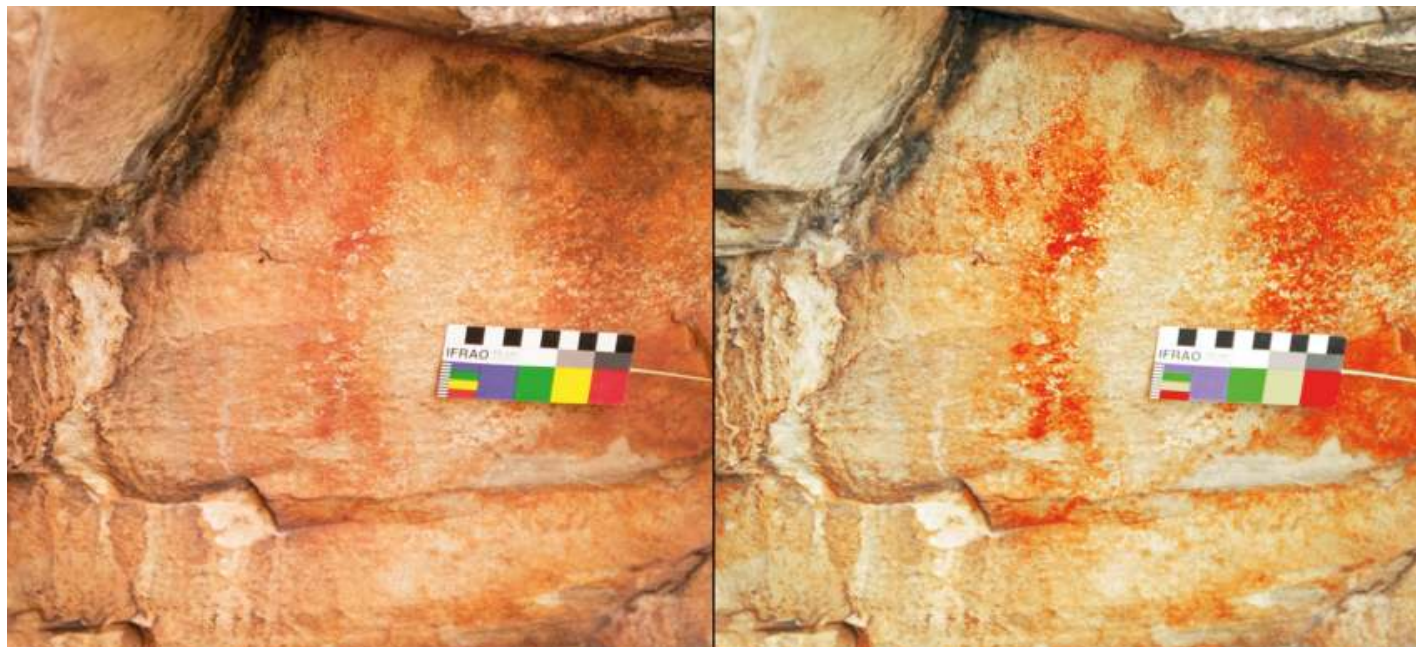

Figure 14.39 Red anthropomorph (\#72) on Wall 3.

Left: Original. Right: Enhanced. Scale $10 \mathrm{~cm}$.

Source: Photograph by Daniel James and enhancement by Liam Brady. 


\section{Items of material culture}

As previously mentioned, two paintings of spears are present amidst a row of stick-figures near the base of Wall 2 (Figure 14.38, \#6 and \#7). One of these, Image \#6, is what Lewis (1988:306 and elsewhere) calls a 'tri-pointed spear' of a 'type unknown in the ethnographic record'. He attributes such spears to his Broad Spearthrower period, which he estimates to have begun a maximum 6000 years ago and ended by at least 1000-2000 years ago (see Lewis 1988:95-98, 105, $324,325)$. Lewis places such spear depictions sometime within this period because tri-pointed spears are often associated with images of lanceolate spearheads that, for the first time in the art sequence, resemble stone points that first appear in excavations c. 6000 years ago. Furthermore, the Broad Spearthrower period art that has images of tri-pointed spears also has depictions of fauna that became extinct c. 3500-3000 years ago: The Tasmanian tiger (Thylacinus cynocephalus) and, apparently somewhat later, the Tasmanian devil (Sarcophilus harrisii). It is during this phase that colours other than red first become regularly apparent, a product of preservation rather than the real commencement of painting in multiple colours (Lewis 1988:95). This period includes what Brandl (1973) had called Late Mimi art, and it possibly but uncertainly continues until the beginning of early X-ray art (Lewis 1988:97-98). Chaloupka has no depictions of tri-pointed spears in his discussions of spears in the art (cf. Chaloupka 1993:146-148). An age between 6000 and 3000 years ago for the tri-pointed spear is consistent with our findings at site JSARN-113/23, which dates the underlying and therefore older red-and-yellow bichrome anthropomorphs to 9260-9540 cal BP (see below).

The second spear painting, Image \#7, is next to the tri-pointed spear and part of the same painted scene (Figure 14.38). This painting has a multi-pronged spearhead with a thickened base (probably indicating hafting), a kind of spear depiction also found in, but not restricted to, the Broad Spearthrower period (e.g. Lewis 1988:325, 367) (see below). Chaloupka (1993:146) identifies 'composite spears' with 'uniserially barbed wooden heads, with barbs cut in the solid and attached to the wooden shaft', such as the one discussed here, as first appearing in his Simple Figures with Boomerangs style, which he suggests came after both Dynamic and Post-Dynamic Figures, during the late Pre-Estuarine Period, which he estimates to date shortly before 8000 years ago. Such multi-barbed uniserial composite spears continue into subsequent styles, and could thus date to any time after the start of the Simple Figures with Boomerangs style.

We have already discussed the single example of a hooked stick in the art of JSARN-113/23 (Figure 14.35, \#69; see above).

\section{Non-figurative images}

The non-figurative paintings are straight lines $(\mathrm{n}=4)$ and one image each of an arc, an oval and straight line, a circular shape, a circular shape and linear infill, a simple linear design, a dash cluster and a complex linear design (e.g. Figure 14.40, \#83, \#84).

Wall 1 has a red-painted cluster of 48 dashes surrounding the end of a horizontal straight line (Figure 14.41, \#49). Some of the dashes are damaged by exfoliation.

There is also a complex set of lines associated with the row of stick-figures in the lower section of Wall 2 (Figure 14.38, \#39).

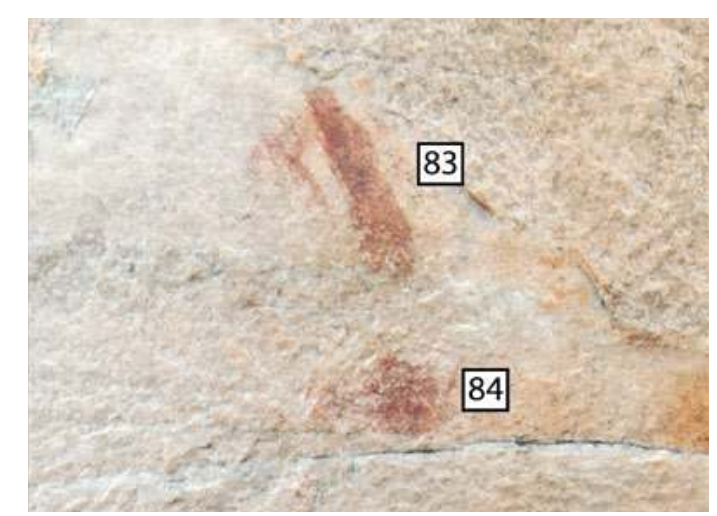

Figure 14.40 Non-figurative images (\#83, \#84) on Wall 1.

Source: Photograph by Daniel James. 


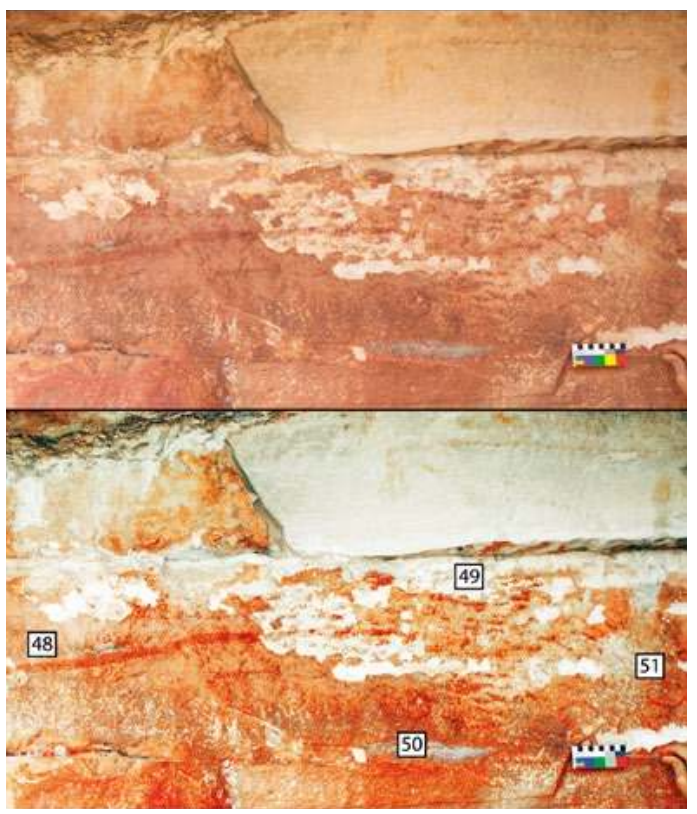

Figure 14.41 Non-figurative image (\#49) on Wall 1.

Top: Original. Bottom: Enhanced. Note exfoliation. Scale $10 \mathrm{~cm}$. Source: Photograph by Daniel James and enhancement by Liam Brady.

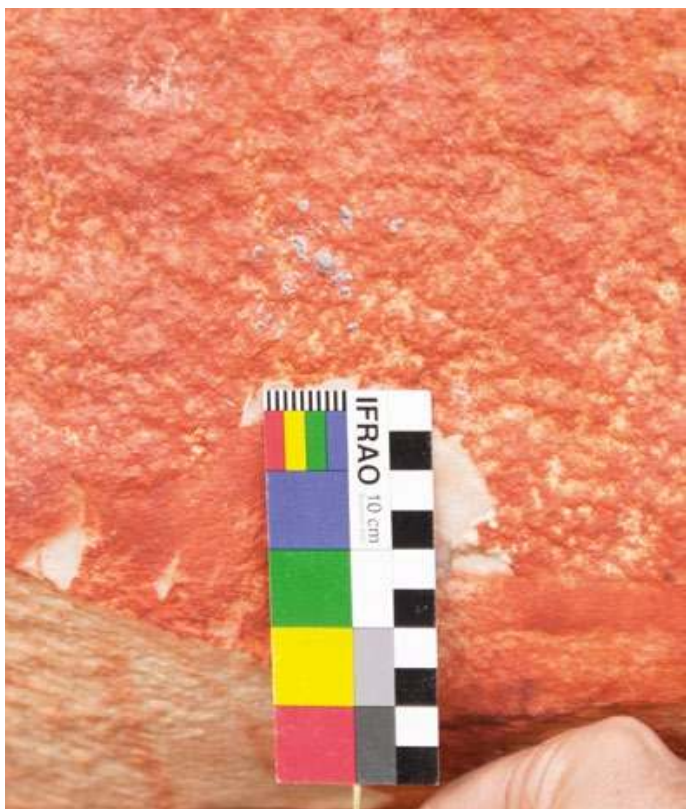

Figure 14.42 Beeswax figure (\#58) on Wall 2. Scale $10 \mathrm{~cm}$.

Source: Photograph by Bruno David.

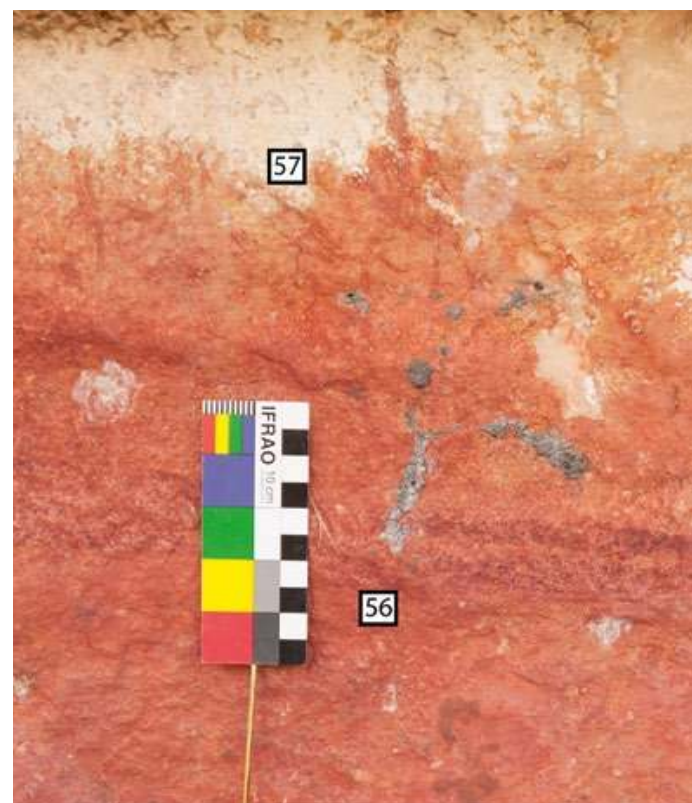

Figure 14.43 Beeswax figure (\#56) on Wall 2. Scale $10 \mathrm{~cm}$.

Source: Photograph by Bruno David.

\section{Beeswax figures}

There are three beeswax figures on Wall 2:

- An irregular cluster of 35 small dots applied on the red cortex of the wall; the red cortex is therefore older than the beeswax figure. It is probably the remnants of an originally larger single dot motif (Figure 14.42, \#58).

- An irregular cluster of six small dots that probably also represent the remnants of a larger image (Figure 14.35, \#64). It is superimposed over a red indeterminate painting (\#65) and a yellow anthropomorph with a 'beehive' headdress (\#66).

- A line-and-dots motif consisting of a vertical and near-adjacent horizontal line that extends to the right, and 18 dots of varying sizes above the two lines; it is probably the remnants of what was once a star shape (Figure 14.43,\#56). 


\section{Hand stencil}

A red left-hand stencil with wrist and lower part of the forearm occurs on a shallow, angled overhang at higher elevation than any other recorded image on Wall 1. It is in good condition and clearly visible (Figure 14.44, \#88).

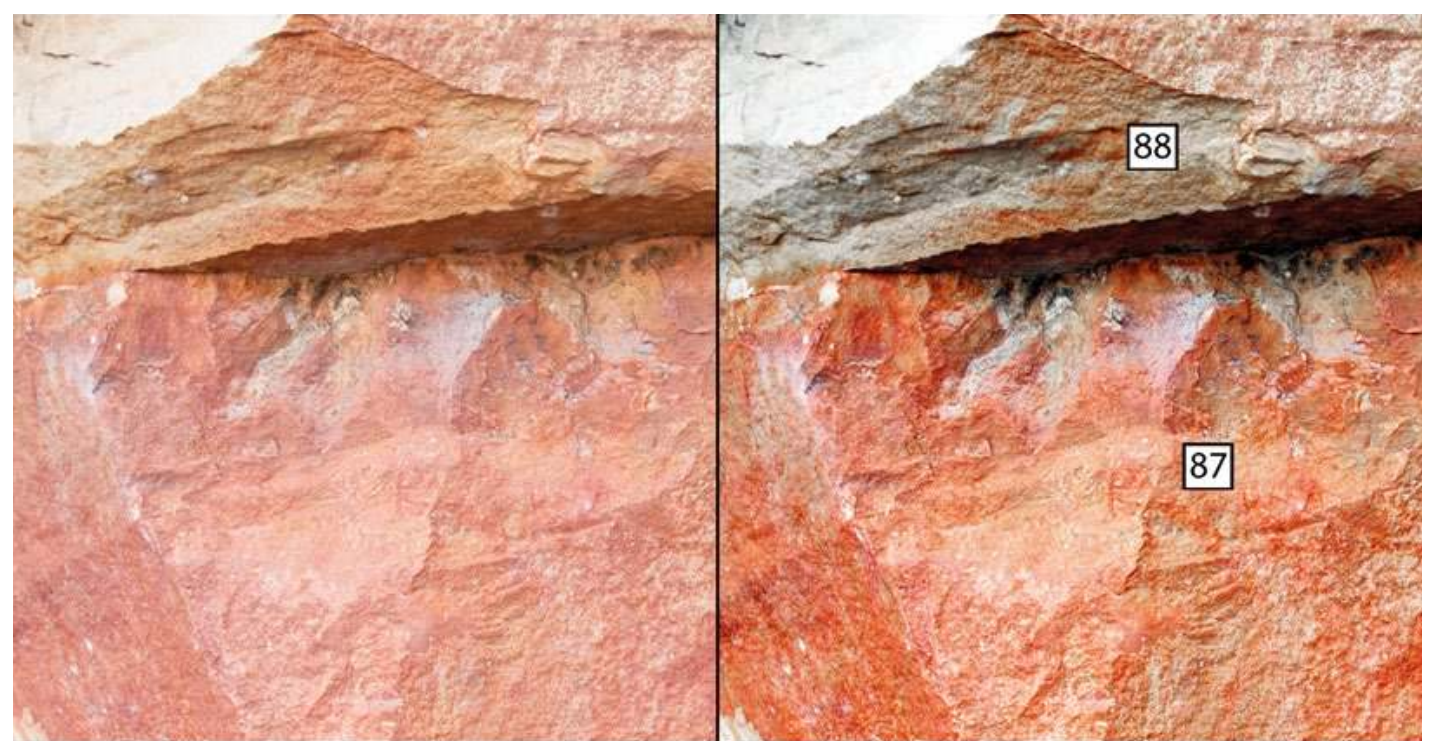

Figure 14.44 Hand stencil (\#88) on Wall 1.

Left: Original. Right: Enhanced.

Source: Photograph by Daniel James and enhancement by Liam Brady.

\section{Superimposition in the art}

The paintings include scenes dominated by rows of anthropomorphs on the fresh surface of the lower section of Wall 2 above Square A: this is where 32 (73 per cent) of the anthropomorphs occur, including the distinctive bichrome outlined/infilled motifs, and the stick-figures linked hand-to-hand. This localised panel closest to the archaeological excavations contains 41 per cent $(\mathrm{n}=46)$ of the 113 paintings at the site.

Several superimpositions offer insights into painting episodes, style changes and the sequencing of motifs. On Wall 1, a macropod (\#113) overlies an indeterminate red image (\#96); here the macropod is also superimposed by a white-infilled anthropomorph (\#78) that also superimposes a yellow anthropomorph (\#89) and various other indeterminate white, yellow and red images (\#79, \#102, \#103-\#105, \#112). A second set of superimpositions on Wall 1 has two redoutlined and white-infilled flying-foxes (\#90, \#91) over a composition of red indeterminate lines (probably weathered anthropomorphs, \#93-\#95, \#97, \#99), a red stick-figure (\#92) and an offwhite indeterminate image (\#98) (Figure 14.28). The white of the flying-foxes is noticeably clearer and fresher than the red images, suggesting that some time had elapsed between painting episodes. Based on these superimpositions and levels of clarity, the red paintings (\#92-\#97, \#99) were the earliest, followed by the macropod (\#113) and the indeterminate off-white image (\#98), followed by the red-outlined and white-infilled flying-foxes (\#90, \#91), with significant amounts of time elapsing between painting episodes. 
On Wall 2, superimpositions consist of the beeswax line-and-dots image (\#56) over an indeterminate red painting (\#57) (Figure 14.43), and a beeswax dot cluster (\#64), as well as a yellow indeterminate over a red indeterminate painting; the beeswax figures are the most recent. As one of these (\#56) has a calibrated age of 310-440 cal BP (see above), the underlying indeterminate red painting (\#57) must be older.

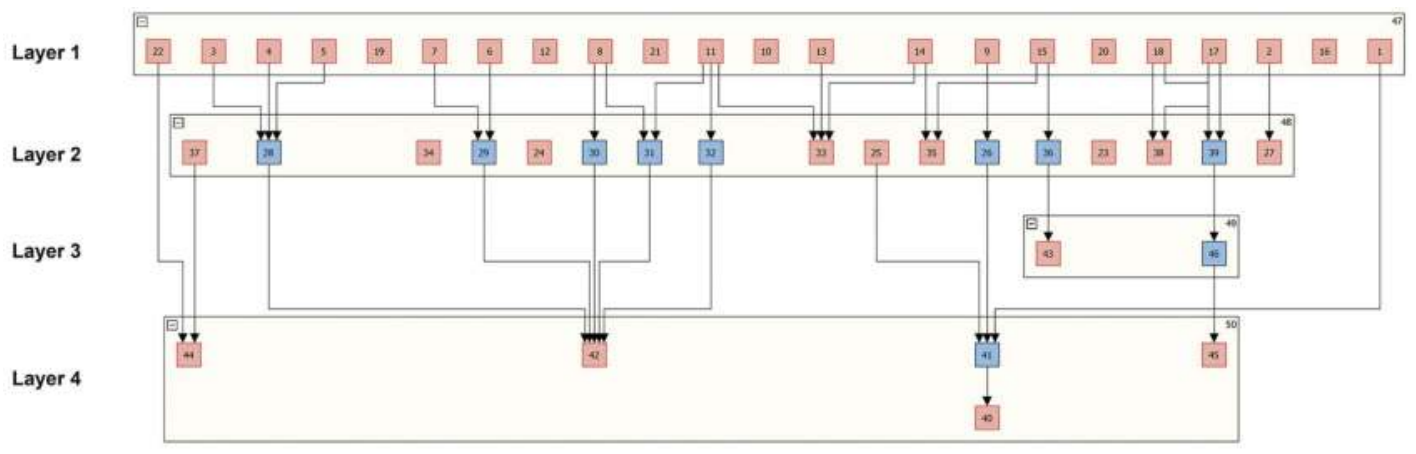

Figure 14.45 Interpretation of the Harris Matrix for the frieze at the base of Wall 2 immediately above Square $A$, showing the pattern of superimposed paintings.

Taking into account each instance of superimposition, individual images were then assigned to particular 'Layers' by differences and similarities in hue, motif character and state of preservation. Red squares indicate images at the beginning or end of a sequence of superimpositions, as well as images not involved in superimpositions. Blue squares indicate images within a sequence of superimpositions.

Source: Illustration by Robert Gunn.

The fresh, curved rock surface caused by thermal shock (see above) near the base of Wall 2, just above Square A, also has a number of superimpositions, the major ones being (see Figure 14.45 for a full list):

- The two bichrome infilled and outlined anthropomorphs (\#40, \#41) are superimposed by two red stick-figures (\#25, \#26) in the row of seven linked stick-figures (\#23-\#29), part of a larger scene (\#23-\#39).

- The yellow anthropomorph(s) of Image \#42, and the other, indeterminate yellow paintings (\#44, \#45) nearby, are superimposed by Images \#28-\#32, part of the red stick-figure scene (\#23-\#39). These superimpositions are consistent with the apparent contemporaneity of the two bichrome anthropomorphs (\#40, \#41) with the other yellow paintings (\#42, \#44, \#45) that, as a group, together represent the underlying and therefore oldest art layer on this surface.

- Overlying both the yellow and red Images \#40-\#42, \#44 and \#45 of the lowermost art layer, and the next layer up as represented by the red scene of Images \#23-\#39, is a third, uppermost and thus most recent layer of red paintings (\#1-\#22). This too is a scene, all in red: the stick-figures appear with more embellished heads, two spears and varied linear and infilled anthropomorphs (Figure 14.46).

From youngest to oldest, four superimposed painting layers can thus be identified on the frieze above Square A:

- Layer 1 = Images \#1-\#22 (Figure 14.46C).

- Layer 2 = Images \#23-\#39 (Figure 14.46B).

- Layer 3 = Images \#43, \#46: red lines of a slightly different hue to the red outlines of the bichrome anthropomorphs (\#40,\#41), and different also to those of the red paintings in Layers 1 and 2 (Figure 14.46A). They are similar in hue to some red images in Layer 4, so may be contemporaneous with that layer (see also the Harris Matrix in Figure 14.45).

- Layer 4 = Images \#40-\#42, \#44, \#45 (Figure 14.46A).

\section{terira australis 47}



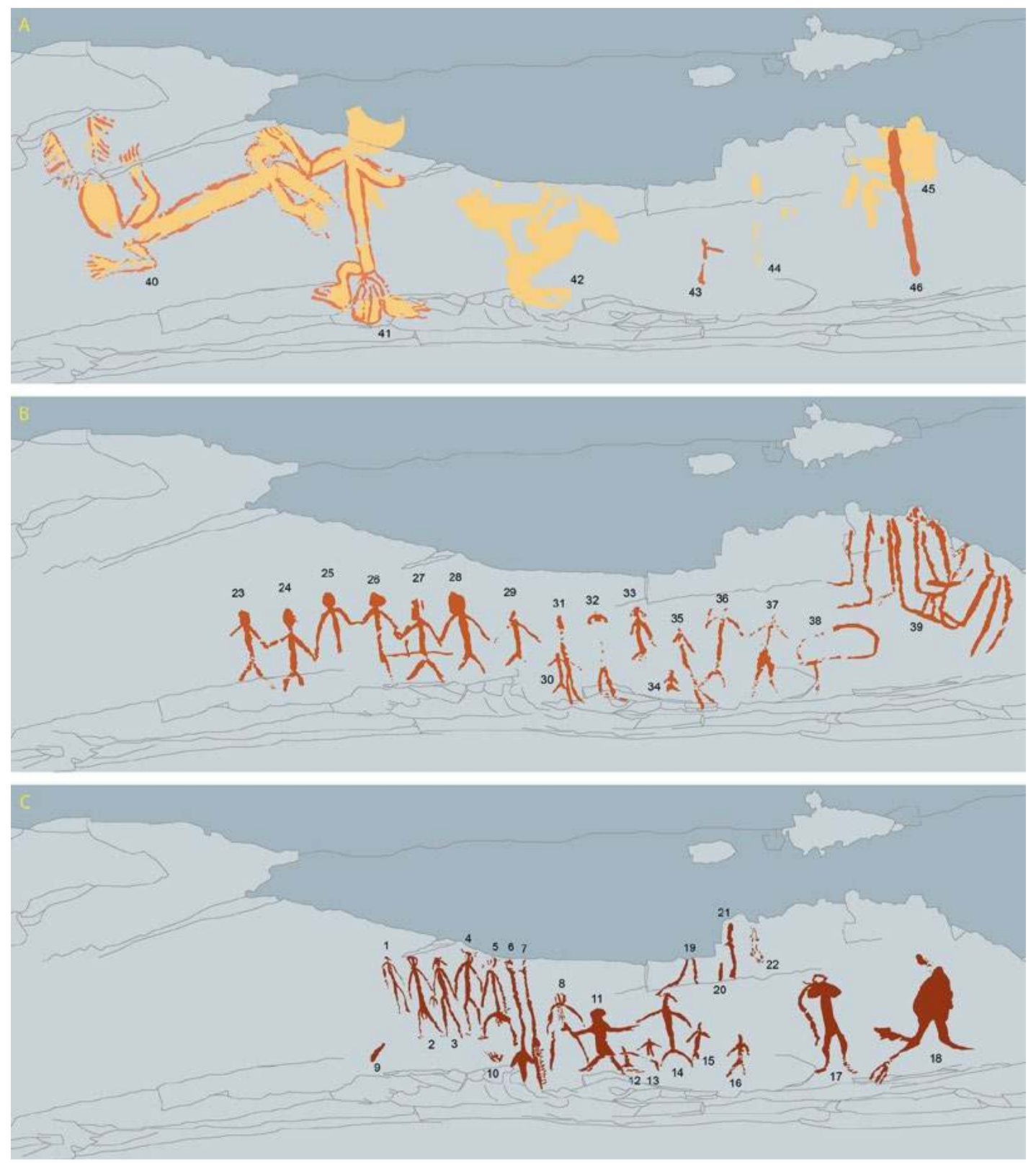

Figure 14.46 Digital tracings of the enhancement photograph of the D3/D2 frieze, showing separation of layers of superimposition as determined by the Harris Matrix (Figure 14.45).

A: Layers 3 and 4 (yellow always preceding the red); B: Layer 2; C: Layer 1.

Source: Illustrations by Robert Gunn.

Painting Layers 1, 2 and 4 are distinctive from each other in their modes of representation, colour, clarity and general degree of preservation. Each contains a scene that is somewhat different from the other, each made during a single painting event.

Layers 1 (\#1-\#22) and 2 (\#23-\#39), the most recent and middle layers respectively, each have a row of stick-figures on the left (as one views the painted scenes) next to a less tightly knit group of anthropomorphs and other depictions to their right. The two scenes are similar in composition, yet somewhat different in their individual paintings. We do not know if they were painted over a short period of time, such as by two separate artists in a single occupation, or over two shortly spaced events that, for example, required re-invigoration of the original scene, 
or whether they represent two essentially separate sets of depiction separated by a longer span of time. Either way, the lower scene (Layer 2) must to some degree have inspired the upper one (Layer 1), given their overlap and similarity of composition.

\section{Discussion: An archaeomorphological history for the art}

From bottom to top, the art of JSARN-113/23 spans $3.5 \mathrm{~m}$ of rock wall in a sequence of 14 stacked rock strata (Figure 14.47). Each stratum is distinctive in its thickness, upper and lower surface joint morphologies, mineralogy and grain structure. We can thus try to understand better the history of the art by investigating the history of the exposed ends of the rock strata (the rock surfaces) that carry it. We achieved this result by studying the fallen rocks on the ground, in the excavated sediments, and through the GPR data, relating each to the wall strata and to the radiocarbon dates to determine when the decorated rock surfaces formed, thereby offering maximum ages for the images.
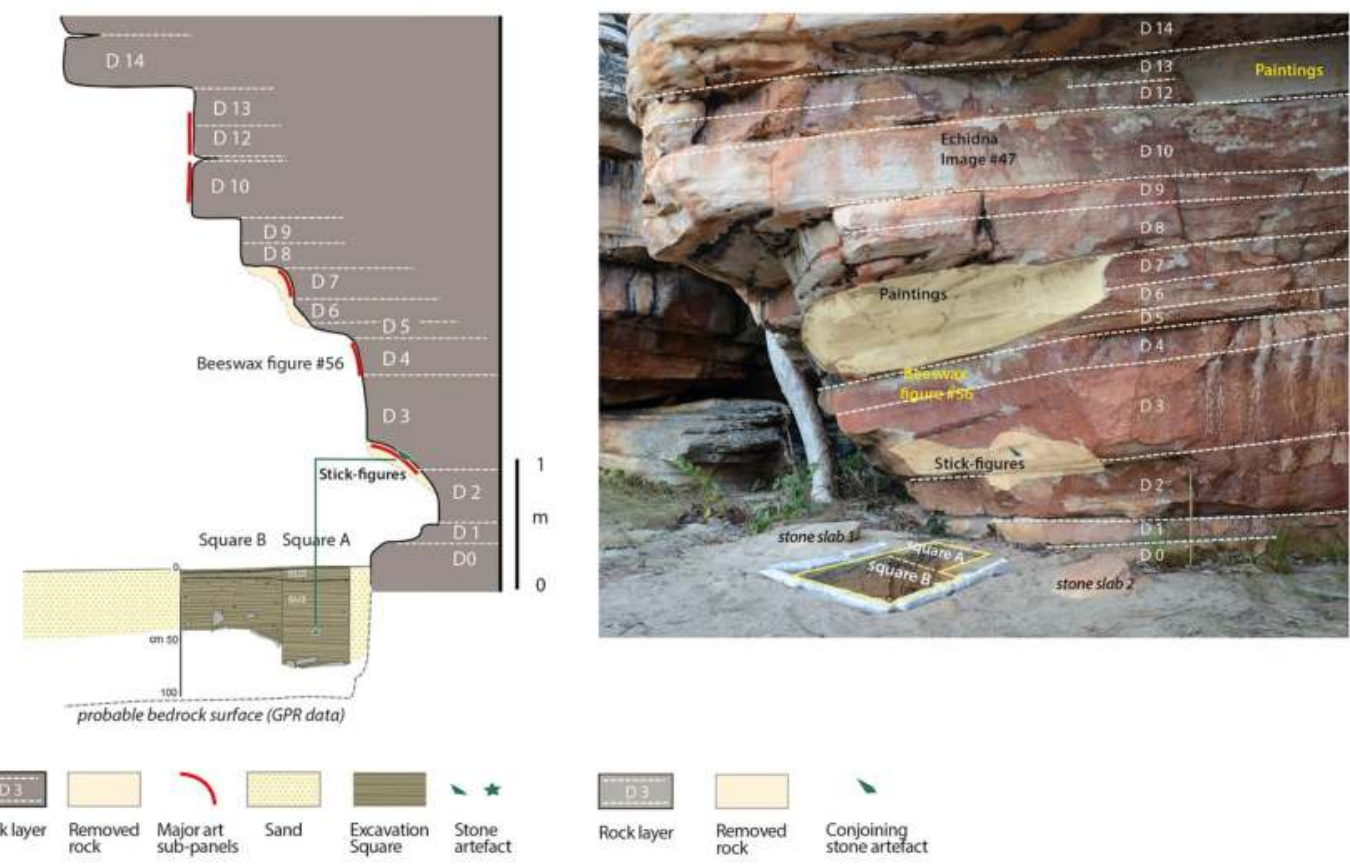

Figure 14.47 Bedrock strata, with interpretative cross-section showing the location of where the Square A XU29 flaked piece that fitted the rock surface above was found.

Source: Photograph and illustration by Jean-Jacques Delannoy.

The individual rocks, and the sediment samples, from the excavated deposits were analysed and matched to their sources. Particle size analysis and morphoscopy (shape and surface characteristics) of the sediment grains indicate aeolian deposition, with most grains derived from quartzite. The size and shape of the excavated and surface rocks range from large slabs several metres long to smaller pieces centimetres long. The largest rocks - metres to tens of centimetres in length have been matched to particular strata in the rock stack through their geological characteristics.

The outer ends of the wall strata indicate that four major processes of rock fall have taken place. Each has left its own, distinctive type of scar on the wall, including on its overhangs: 
1. Gravity (overhang collapse), which mainly affects rock overhangs. Gravitational collapse results in sub-angular (typically with right or perpendicular angles) remnant-edge morphologies. It is responsible for the progressive increase in the elevation of shelter floors (due to large blocks accumulating on the ground) and the retreat of overhangs. Gravitational collapse causes blocks of rock to exhibit clean breaks along joints and fissure planes. On the ground, collapsed blocks have angular edges, their thickness more or less corresponding to the thickness of the originating rock strata (and those of the remnant overhangs). Given the hardness and poorly soluble nature of the local quartzite, the source of collapsed blocks is usually relatively easy to identify.

2. Thermal shock, where intense heating causes sections of the wall to fracture. Convex wall surfaces near ground level are often shaped by thermal shock. Fires, either from camps, anthropic burning of the landscape or natural bushfires, cause curved sections of wall to detach, sometimes over distances measuring several metres (e.g. see the curved rock wall at D3/D2 on Figure 14.47).

Rock variably conducts heat, and in so doing also variably resists heat and thermal shock. But it also tends to shatter when exposed to high temperatures, the depth of detachment representing the critical threshold between the heated rock outside and the non-heated matrix inside. Shattering takes place at the location of maximum heat, causing detachments that can be from a few centimetres to a few tens of centimetres thick, depending on the type of rock at stake. Where heating has been minimal, the detached rock tends to be thinner. The inner, conjoining face of a detached block is typically sub-parallel to what was previously the exposed face of the wall (now the dorsal face of the detached rock).

Thermal shock can affect a rock wall in a number of ways; evidence of each can be seen at JSARN-113/23:

a. Laterally and vertically highly localised detachment scars, corresponding to locations of maximum heating.

b. The morphology of a detached rock surface reflects more the original rock wall surface morphology than the wall's stratigraphy, and in this differs from detachments caused by gravitational force (see Point 1 above).

c. Detachment surfaces are curved and smooth, demarcating the boundary between the underlying unheated rock (the remaining, undetached part of the rock wall) and the overlying heated rock (the detached rock).

Thermal shock is accentuated by brutal cooling, such as when a heated wall is rapidly cooled with water. Rocks shattered from thermal shock typically have sharp edges.

3. Thermoclastic exfoliation, caused by water and salt seeping through the matrix, compounding the expansion and contraction of rock surfaces through day-night temperature changes. This leads to the sub-centimetre deep exfoliation of rock surfaces (e.g. Figures 14.27, 14.29, 14.31 and 14.41).

Exfoliated spalls are small, centimetre(s)-long, thin lenses of rock that retain on their dorsal surfaces the features of the original rock wall surface. A number of processes can cause exfoliation, such as the repeated expansion and contraction of micro-fractures (typically through day-night humidity and temperature fluctuations), or low-temperature thermal shock. At JSARN-113/23, spalls are unlikely to have exfoliated from mechanical weakening of the rock such as along micro-fractures, as quartzite surfaces do not regularly fracture in this way. On the other hand, solar heating of the wall (thermoclastic exfoliation) is a likely cause, as it only affects the outer surface of the rock, notably where there is a red 'patina' caused either by an alteration, or by a reddening, of the rock through fire (from nearby bushfires 
or campfires, or intentional heating of the rock face), or by the application of red ochre. Whatever caused the JSARN-113/23 wall surface to redden, it is only here that exfoliation scars are found (e.g. Figures 14.27, 14.31, 14.33 and 14.43). The darker (reddened) surface covers a lighter parent rock, absorbing more heat than it reflects. Exfoliated spalls have detached at the level of contact between the outer surface heated by solar radiation, and the inner, non-heated rock. We can see the effects of exfoliation caused by solar radiation in the colour contrast between the underlying, unaltered and unreddened rock exposed by the exfoliation scars and the thin, reddened rock skin above it.

4. Anthropogenic flaking, identified by impact marks left by hammer blows on localised parts of the wall.

Figures 14.48 and 14.49 summarise the evidence for each of these processes at JSARN-113/23. Three phases of natural overhang collapse ('gravity') are evident from remnant wall configurations and corresponding buried blocks (Phases 1-3 on Figure 14.49). These collapses caused progressive retreat of the relatively high and outermost overhanging strata (D14 and higher), together with a localised retreat of the wall at D13/D12 and D9/D8. The excavations did not penetrate deep enough to sufficiently expose, and thereby date, the collapsed blocks from the earliest two of these three phases, but they must all be older than $27,000 \mathrm{cal} \mathrm{BP}$. The deepest radiocarbon date from Square A comes from near rocks that fell from D9/D8 (Phase 3), indicating that the most recent of those three phases dates to c. 26,190-26,680 cal BP. Any art on these upper sections of the present wall at D8 or higher (Images \#47-\#53, \#73-\#75; Table 14.13) must therefore be younger than c. $27,000 \mathrm{cal} \mathrm{BP}$, as this is when the present surface was created.

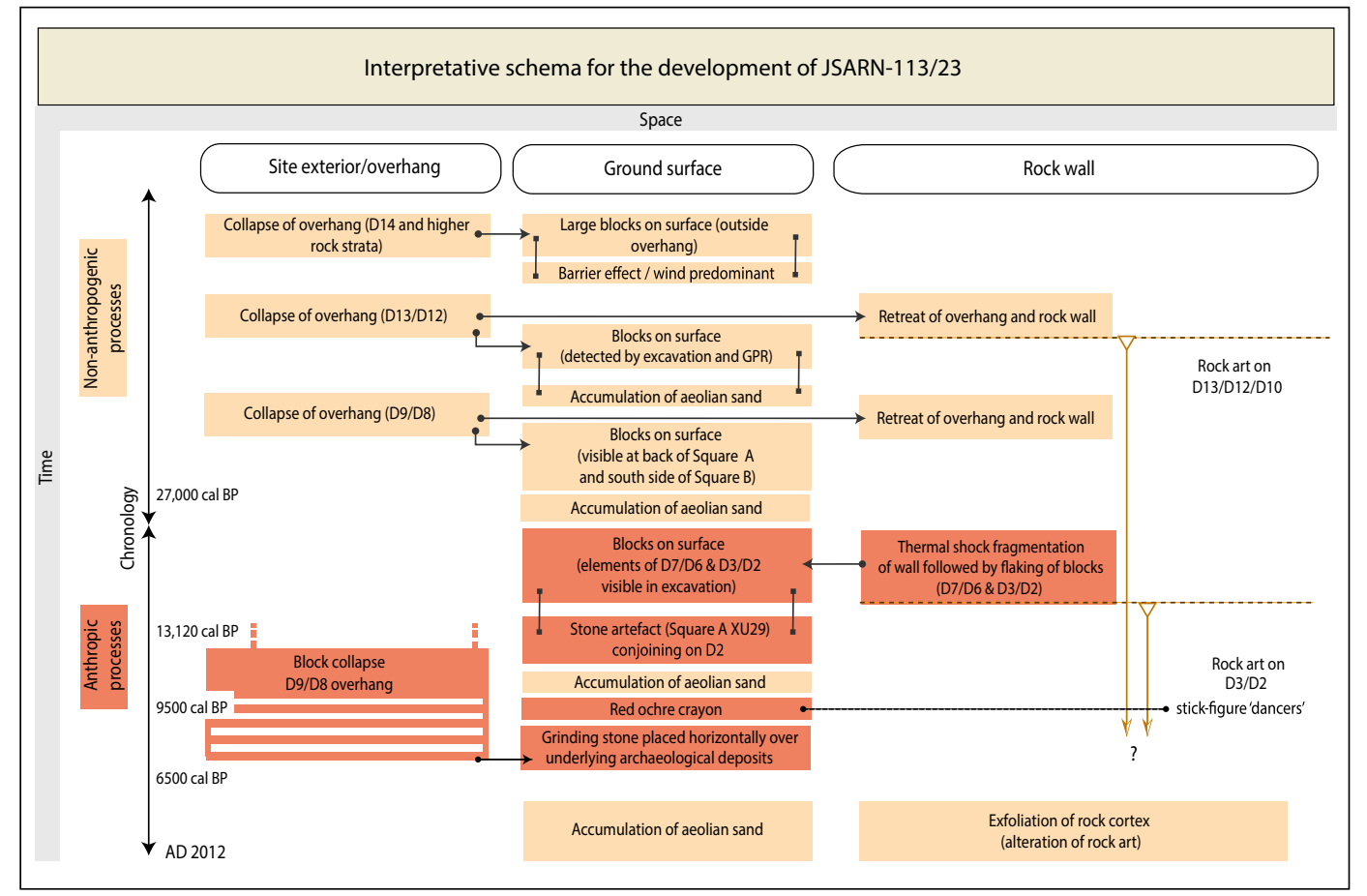

Figure 14.48 Summary interpretation of the development of the site.

Source: Illustration by Jean-Jacques Delannoy. 

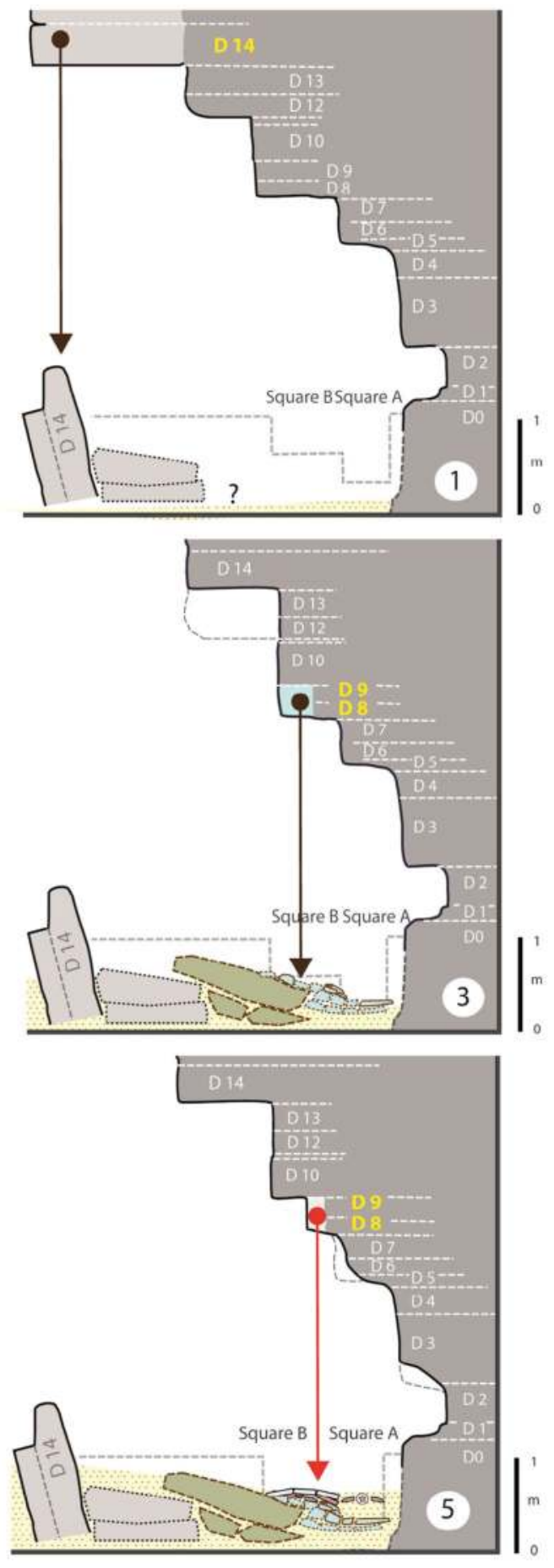
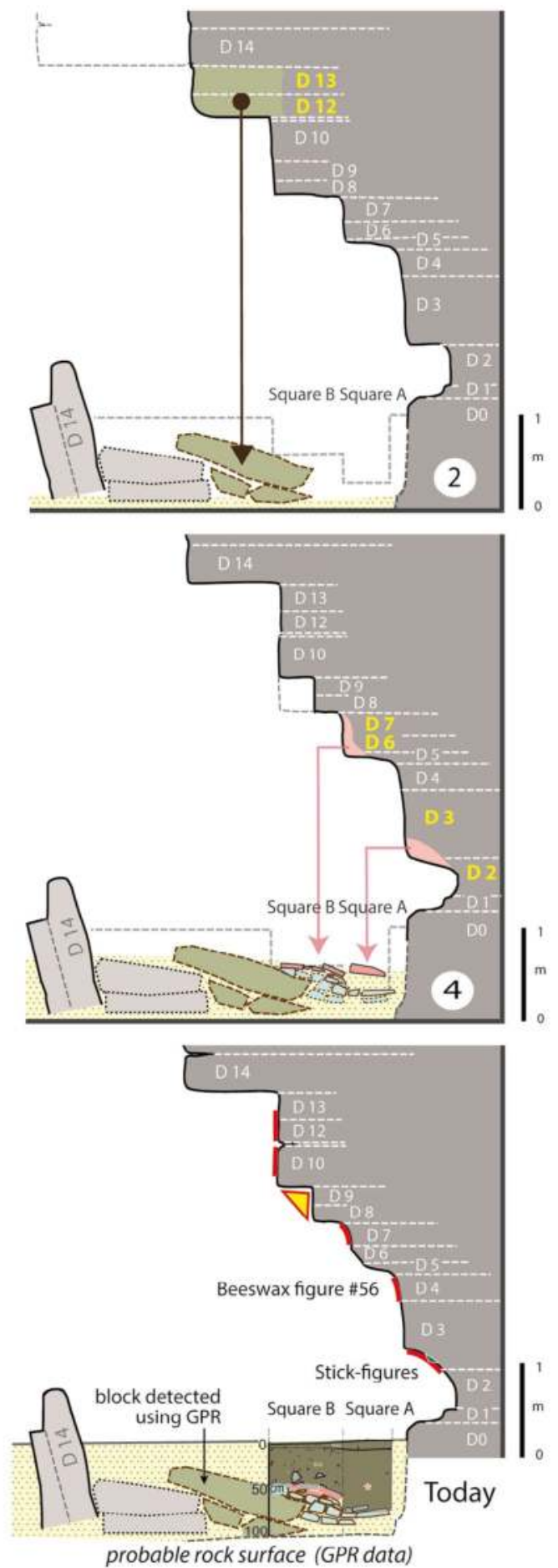

probable rock surface (GPR data)

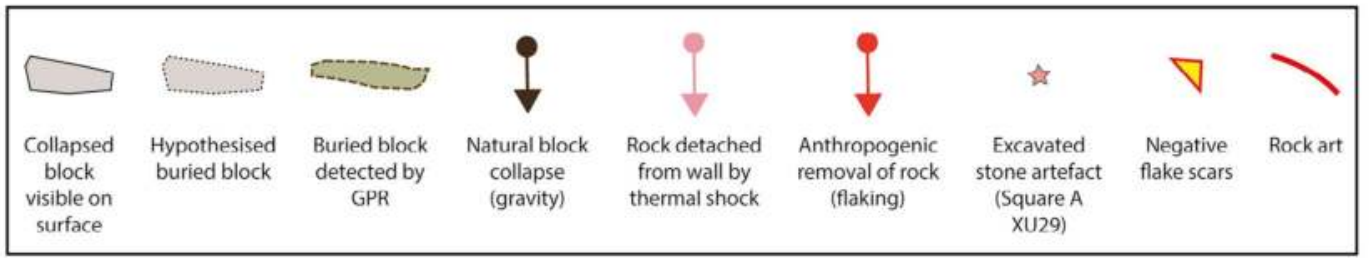

Figure 14.49 Graphic summary of the site's development.

Source: Illustration by Jean-Jacques Delannoy. 
During Phase 4, the curved rock wall close to ground level at D3/D2 has clear signs of having been shaped by thermal shock from intense heat (Figure 14.49). The largely uninterrupted curvature of the $\mathrm{D} 3 / \mathrm{D} 2$ scar indicates a single detachment event. This happened at a time when soft sediments were being deposited on the shelter floor. Sometime after the block (or blocks) became thermally detached from $\mathrm{D} 3 / \mathrm{D} 2$, it was flaked by people as it lay on the shelter floor, as evident by the clearly artefactual Square A XU29 conjoining flaked piece excavated from a level dated to $12,980-13,210 \mathrm{cal}$ BP (Figure 14.20). Thermal shock detachments originating from the light-coloured section of wall along D3/D2 (see Figures 14.21 and 14.47) are also found slightly deeper than the conjoining flaked piece. It is on this light-coloured section of the detachment scar that the superimposed layers of red-and-yellow bichrome anthropomorphs and related images (\#40-\#46) and stick-figures (middle Layer 2: \#23-\#39; upper Layer 1: \#1-\#22) are located (Figures 14.37 and 14.38), indicating that none of those paintings (\#1-\#46) can be older than c. $12,980-13,210$ cal BP.

The excavated conjoining flaked piece from Square A XU29 shows that the curving, hard quartzite wall surface from which it originated, low down in the shelter and well-protected from the elements, has remained relatively fresh and devoid of cortex for 13,210-12,980 years. This is significant, as it shows that other unpatinated hard quartzite wall surfaces in western Arnhem Land - let alone heavily patinated ones - could have great antiquity, with implications for better understanding the age of paintings on those surfaces.

The excavated ochre crayon from Square A XU26 came from just above the conjoining flaked piece, at a level of peak charcoal deposition near the back wall. A radiocarbon date from this charcoal dates the crayon to 9260-9540 cal BP (Burning Phase 3). There is a minimum $2.3 \mathrm{~cm}$ and maximum $5.4 \mathrm{~cm}$ of contemporaneous soft sediment above the ochre crayon; that depth range represents the thickness of XU26 within which the crayon was excavated. The sequence, then, has the detachment of the block from the wall c. 12,980-13,210 cal BP (based on geomorphological evidence), followed by the making of paintings 9260-9540 cal BP (based on paintings on the detachment scar, and the presence of a buried use-worn ochre crayon beneath the paintings on that scar).

If the crayon was used for the red outline of the two bichrome anthropomorphs (Figure 14.46A, \#40, \#41) then they would date to $9260-9540$ cal BP. This scene is the lowermost layer of art on that frieze, as indicated by the superimpositions. These paintings are also the most faded on the frieze. The two yellow anthropomorphs with 'beehive' headdresses (Figure 14.35, \#66, \#71) extend past the yellow hooked stick (\#69), spear/club (\#68) and bichrome anthropomorphs $(\# 40, \# 41)$ as part of the same frieze on the curved thermal scar of stratum D3. This suggests that this entire frieze of red-and-yellow paintings is contemporaneous and belongs to Lewis's (1988) Hooked Stick period; this is consistent with the radiocarbon dates and geomorphological history presented above. This interpretation is also consistent with the pattern of superimpositions, which has 1) the combined red-outlined, yellow-infilled anthropomorphs and yellow anthropomorphs with 'beehive headdresses' associated with the yellow hooked stick, superimposed by 2) the row of red stick-figures associated with the tri-pointed spear of the subsequent Broad Spearthrower period. This chronostratigraphic order matches Lewis's (1988) schema.

The above interpretation has the scene with Images \#23-\#39 painted after 9260-9540 cal BP, followed some time later by that with Images \#1-\#22. We do not know how much time elapsed between these painting events. This dating matches both Lewis's (1988) and Chaloupka's (1993) chronological models, each of which has the painted spears of the uppermost Layer 1 dating between the early Holocene and c. 3000 years ago, although we need to remember that their modelled ages are estimates not based on actual dates for art. 
The alternative would be that the excavated ochre crayon was used to paint one of the two scenes with red stick-figures. In that scenario, the underlying Layer 4 with the bichrome anthropomorphs (and possibly the two sets of red lines in Layer 3) would date between 12,980-13,210 cal BP (age of the rock surface) and 9260-9540 cal BP (age of the crayon). Either way, the frieze with the bichrome red-and-yellow figures, yellow anthropomorphs with 'beehive' headdresses, hooked stick and spear/club would date to either 9260-9540 cal BP (a phase associated with peak burning - Burning Phase 3), or between 12,980-13,210 cal BP and 9260-9540 cal BP.

It is always possible that the excavated ochre crayon was used for body decoration or the painting of portable items of material culture rather than to create rock art, but that explanation is not entirely satisfactory given that the used ochre crayon was excavated from Square A in deposits immediately below the localised D3/D2 painted frieze, under a low and shallow, cramped overhang where buried cultural materials are likely to be related to activities in the immediate proximity.

Finally, elsewhere in the shelter, sections of overhanging D9/D8 fell sometime before 12,160$12,750 \mathrm{cal} \mathrm{BP}$, with possible minor episodic collapses continuing until 9260-9540 cal BP to 5910-6650 cal BP (Phase 5) (Figure 14.49). We do not know if these overhang collapses were caused by knapping events, natural gravitational pull or other factors. Irrespective of cause, it is then that the jumbled rocks exposed at the base of the Square B (see Figure 14.10), including the rock for the grindstones, became detached from D9/D8. Given the numerous instances of flaking and, to a lesser extent, grinding on excavated blocks, this entire Phase 5 event is probably anthropic, even if the whole of the rock collapse was not anticipated.

We did not find any evidence of subsequent major phases of rock modification other than localised thermoclastic exfoliation over painted sections of the wall.

\section{Acknowledgements}

We extend our deepest thanks to Margaret Katherine and family, Wes Miller, Ray Whear and the Jawoyn Association Aboriginal Corporation for inviting us to research and making us feel at home in Jawoyn (Buyhmi clan) Country. Thanks to Elisa Boche, Magen O'Farrell, Daniel James (Monash University), Jacqueline Matthews and Chris Urwin (Monash University) for helping with the excavations, and Daniel James for systematically photographing the rock art. BD thanks the Australian Research Council for Linkage grant LP110200927 and Discovery grants, QEII and Discovery Outstanding Research Award (DORA) Fellowships DP0877782 and DP130102514. Thanks to Bernard Sanderre for Figure 14.1, Emilie Lesvignes for Figure 14.13 parts A and B, Kara Rasmanis (Monash University) for drafting Figures 14.5, 14.6, 14.8 and 14.9, and Steve Morton (Scientific Imaging Services, Monash University) for photographing the artefacts in Figures 14.13C and 14.22.

\section{References}

Brandl, E.J. 1973. Australian Aboriginal Paintings in Western and Central Arnhem Land. Australian Institute of Aboriginal Studies, Canberra.

Bronk Ramsey, C. 2009. Bayesian analysis of radiocarbon dates. Radiocarbon 51(1):337-360. doi. org/10.1017/S0033822200033865

Bronk Ramsey, C. 2013. OxCal Program v4.2.2. Radiocarbon Accelerator Unit, University of Oxford, Oxford. 
Chaloupka, G. 1993. Journey in Time: The World's Longest Continuing Art Tradition. Reed, Chatswood.

Conyers, L.B., 2012. Interpreting Ground-Penetrating Radar for Archaeology. Left Coast Press, Walnut Creek.

Foley, D. 1985. Faunal analysis of Anbangbang 1 and Djuwarr 1. In R. Jones (ed.), Archaeological Research in Kakadu National Park, pp. 97-102. Special Publication 13. Australian National Parks and Wildlife Service, Canberra.

Goodman, D. and S. Piro 2013. GPR Remote Sensing in Archaeology. Heidelberg, Springer. doi. org/10.1007/978-3-642-31857-3

Gunn, R.G. 2016. Art of the Ancestors: Spatial and Temporal Patterning in the Rock Art of Nawarla Gabarnmang, a Major Jawoyn Cultural Site on the Arnhem Land Plateau. Unpublished PhD thesis. Monash University, Clayton.

Gunn, R.G., L.C. Douglas and R.L. Whear 2011. What bird is that? Identifying a probable painting of Genyornis newtoni in Western Arnhem Land. Australian Archaeology 73:1-12.

Gunn, R.G., L.C. Douglas and R.L Whear 2013. The 'Ngar-mimi' motif from the Arnhem Land plateau. Rock Art Research 30(2):217-234.

Lewis, D. 1988. The Rock Paintings of Arnhem Land, Australia. BAR International Series 415. British Archaeological Reports, Oxford.

Neal, A. 2004. Ground-penetrating radar and its use in sedimentology: Principles, problems and progress. Earth-Science Reviews 66 (3-4):261-330. doi.org/10.1016/j.earscirev.2004.01.004

Reimer, P.J., E. Bard, A. Bayliss, J.W. Beck, P.G. Blackwell, C. Bronk Ramsey, C.E. Buck, H. Cheng, R.L. Edwards, M. Friedrich, P.M. Grootes, T.P. Guilderson, H. Haflidason, I. Hajdas, C. Hatté, T.J. Heaton, D.L. Hoffmann, A.G. Hogg, K.A. Hughen, K.F. Kaiser, B. Kromer, S. W. Manning, M. Niu R.W. Reimer, D.A. Richards, E.M. Scott, J.R. Southon, R.A. Staff, C.S.M. Turney and J. van der Plicht 2013. IntCal13 and Marine13 radiocarbon age calibration curves, 0-50 000 years cal BP. Radiocarbon 55 (4):1869-1887. doi.org/10.2458/azu_js_rc.55.16947

Rial, F.I., M. Pereira, H. Lorenzo, P. Arias and A. Novo 2009. Resolution of GPR bowtie antennas: An experimental approach. Journal of Applied Geophysics 67(4):367-373. doi.org/10.1016/j. jappgeo.2008.05.003

Schrire, C. 1982. The Alligator Rivers: Prehistory and Ecology in Western Arnhem Land. Terra Australis 7. Department of Prehistory, Research School of Pacific Studies, The Australian National University, Canberra.

Webb, J., B. Finlayson, G. Cochrane, T. Doelman and M. Domanski 2013. Silcrete quarries and artefact distribution in the Central Queensland Highlands, eastern Australia. Archaeology in Oceania 48:130-140. doi.org/10.1002/arco.5014

Welch, D. 1996. Material culture in Kimberley rock art, Australia. Rock Art Research 13:104-123.

Welch, D. 2007. Bradshaw art of the Kimberley. In M. Donaldson and K. Kenneally (eds), Rock Art of the Kimberley, pp. 81-100. Kimberley Society, Perth.

Welch, D. 2012. Two Kakadu headdresses. Rock Art Research 29:115-117.

White, C. 1971. Man and environment in northwest Arnhem Land. In D.J. Mulvaney and J. Golson (eds), Aboriginal Man and Environment in Australia, pp. 141-157. Australian National University Press, Canberra. 


\title{
Archaeology of JSARN-124 site 3, central-western Arnhem Land: Determining the age of the so-called 'Genyornis' painting
}

\author{
Bryce Barker, Lara Lamb, Jean-Jacques Delannoy, Bruno David, \\ Robert Gunn, Emilie Chalmin, Géraldine Castets, Ken Aplin, \\ Benjamin Sadier, Ian Moffat, Jerome Mialanes, Margaret Katherine, \\ Jean-Michel Geneste and Stéphane Hoerlé
}

\section{Introduction}

In 2011, Gunn et al. published the discovery in a remote part of the western Arnhem Land plateau of a rock painting that closely resembles the most recent reconstructions of an extinct megafaunal bird, the dromornithid Genyornis newtoni. Characteristics of the painting distinguish it from depictions of other bird species and support its identification as $G$. newtoni: a deep convex bill, unlike the shallow bill of an emu or cassowary; a globular cranium and relatively thick neck; indication of a crop (emus and cassowaries lack crops); non-pendulous posture of the wing (unlike the pendulous posture of emus); the proportions of the pelvic limb showing long tibiotarsi and stout tarsometatarsi; the short, broad toes that appear to terminate in blunt claws; and a dorsal profile paralleling that of reconstructed dromornithids and unlike an emu or any species of cassowary, in which the vertex of the back is more anterior. The several points of special resemblance between the painting and reconstructions of the extinct bird based on paleontological evidence led Gunn et al. (2011:10) to conclude, 'on the basis of probability the painting is indeed a representation of Genyornis newtoni.

This finding brings a conundrum. If the painting is indeed a contemporaneous depiction of G. newtoni, it becomes the oldest painting known in the world, for the bird is thought to have become extinct around 50,000 \pm 5000 years ago (Miller et al. 1999; Roberts and Brook 2010; Roberts et al. 2001) or even earlier (see Grellet-Tinner et al. 2016). Or that timing for the extinction of Genyornis is wrong; or a relic population survived longer on the Arnhem Land plateau (e.g. Murray and Vickers-Rich 2004), perhaps until the Last Glacial Maximum (LGM), which commenced around 25,000 years ago. And, as Gunn et al. (2011) acknowledged, there are still other alternatives. The painting might be of a 'mythological' animal: either one rooted in ancient memory of G. newtoni, as has been suggested for the 'mihirung' of southern Australian Aboriginal peoples (Vickers-Rich 1987) - although in societies without writing, social memory 
has not been found anywhere in the world to reliably extend in recognisable form over very long periods of time (cf. Bradley 2002) - or of a creature without a material counterpart that fortuitously resembled the fossil bird.

The painting occurs on a vertical rock wall under a shallow overhang. Could the motif really have survived there since Pleistocene times, whether 25,000 or 50,000 years ago? And the painting shows a speared bird, so it could be the first evidence for the hunting of extinct megafauna in Australia.

With these enigmas in mind, the Jawoyn Association asked us in 2010 to study the 'Genyornis' site, to investigate the age of the art and its archaeological and geomorphological context. Our major aims were to ask whether the painting dates, or theoretically could date, to the time of $G$. newtoni, or whether it must be more recent, and to uncover contextual ancient cultural information relating to the artworks and to occupation activities at the site in the past. Here, we present the results of these archaeological and geomorphological investigations along with a summary of the chemistry of the rock surface that houses the painting of the large bird thought by Gunn et al. (2011) to be of a Genyornis.

\section{Genyornis newtoni}

Genyornis newtoni (henceforth, just Genyornis) was the last known member of the endemic and extinct Australian bird family Dromornithidae. Although they have long been considered to be 'ratites' with likely affinities to emus and cassowaries, recent studies of the cranium suggest that dromornithids are more closely related to ducks, geese and screamers (members of the Order Anseriformes); they may be related specifically to another Australian endemic, the magpie goose (Anseranas semipalmata) (Murray and Megirian 1998), so characteristic of Arnhem Land wetlands today. Whatever its affinities, the Dromornithidae is an ancient family that attained its highest diversity more than 10 million years ago. Since that time, various branches of the Dromornithidae petered out, with Genyornis alone known to have survived into the Pleistocene.

The final extinction of Genyornis, the last of the dromornithids, is generally treated as part of a late Pleistocene megafaunal extinction 'event', which saw the demise of numerous large Australian vertebrate species, including many large marsupials and some reptiles (Roberts and Brook 2010; Roberts et al. 2001). Only a select few, Genyornis among them, are confirmed as having survived long enough to have co-existed with humans following the colonisation of Australia around 65,000 years ago (Miller et al. 1999; Roberts et al. 2001). Yet, even for these, the nature of the human-megafauna interaction and the causes and consequences of the extinctions remain shrouded in uncertainty.

What exactly do we know about Genyornis? And what do we know about the time and cause of its extinction?

The anatomy of Genyornis is quite well known from discoveries of almost complete skeletons. These indicate a bird only slightly taller than a modern emu (Dromaius novehollandiae) but of a much stockier build - estimates of adult body weights range between 220 and $275 \mathrm{~kg}$, compared with 40-50 kg for the emu (see Murray and Vickers-Rich 2004 for a fossil reconstruction of Genyornis newtoni). Such a bulky bird was long portrayed as slow moving, but recent studies of the limb skeleton suggest that it was capable of reaching speeds similar to those of the emu (Murray and Vickers-Rich 2004). 
Surviving fragments of the skull suggest a globular cranium with a short, heavily constructed beak (Murray and Megirian 1998). Although the massive beak has been interpreted by some as a sign of a carnivorous diet, other evidence, including gizzard stones in association with some skeletons, and the structure of the beak and feet all favour a herbivorous diet (Murray and Vickers-Rich 2004; Rich 1979).

Recent interpretations of both the distribution of Genyornis and of the timing of its extinction rest heavily on the attribution to this species (most likely erroneously, see below) of a distinctive and sometimes very abundant kind of fossil eggshell. This association was first made by Williams (1981), who distinguished two morphological kinds of eggshell from sites of late Pleistocene age in South Australia. Both kinds of eggshell were from eggs about the same size as those laid by the living emu (Dromaius novaehollandiae), but while some fragments had features consistent to those of modern emu, others showed differences in surface ornamentation and the arrangement of pores (Williams 1981). When eggshell of this 'Genyornis' type was mapped together with skeletal remains, the species appeared to be widely distributed across the Murray-Darling system of southeast Australia, the internally draining Lake Eyre and Lake Frome Basins of south-central Australia, and in the southwest corner of Western Australia. No skeletal remains or eggshell of the 'Genyornis' type has been reported from anywhere in northern Australia. However, it is worth noting that there are still relatively few Pleistocene fossil sites in this area and even fewer that have yielded remains of megafauna. The few sites that might have been expected to produce remains of Genyornis (but in each case have not) include the Quanbun site in the south Kimberley (Flannery 1984) and the alluvial terraces along the Leichhardt and Gregory rivers in the Gulf region of Queensland (Archer et al. 2006).

Eggshell, by virtue of its crystalline structure and organic content, is an ideal material for amino acid racimisation, radiometric dating and also for chemical analysis of dietary preferences. For these reasons, the ancient eggshell record from northern South Australia and surrounding regions was targeted for detailed studies by Miller and his co-researchers. Their studies showed that the two kinds of eggshell were deposited in the many sand dunes and beaches, more or less continuously from around 140,000 years ago until around 45,000-50,000 years ago, after which the Dromaius kind alone was deposited (Miller et al. 1999).

Miller et al. (2005) took their investigations one step further through dietary analysis of eggshell samples. The results indicated that the regional emu population had a less restricted dietary range than contemporaneous populations of the second, extinct species. Whereas the emu samples show highly variable chemical signatures that indicate a capacity to feed on a wide variety of plant foods including shrubs and trees as well as all kinds of grasses, the extinct species showed a narrower diet with a likely reliance on more nutritious grasses.

The study by Miller et al. (2005) was widely touted as compelling evidence for the regional (and even continental) extinction of Genyornis at 45,000-50,000 years ago, and the dietary analysis provided a plausible mechanism whereby the arrival of humans led to a change in the firing regime and changes in vegetation communities that caused the decline to extinction of a less adaptable species. Rare occurrences of burnt eggshell of the 'Genyornis' kind further indicated a brief period of regional overlap between humans and the extinct species and of predation (at least of nests) that might have hastened their decline (Magee and Miller 2007).

A new study by Grellet-Tinner et al. (2016) has seriously undermined this textbook example of how to study megafaunal extinction. By using a better preserved and more complete example of a 'Genyornis' egg, and consideration of both its size and micro-structure in comparison with eggshell attributed to other species of dromornithids from Oligo-Miocene fossil sites, the authors conclude that the second kind of eggshell studied by Williams (1981) and Miller et al. (1999, 2005 ) is not from Genyornis at all but from a different kind of bird, most likely a species of the 
genus Progura: large, extinct megapodes or mound-builders of which two species are recorded from late Pleistocene Australia (Grellet-Tinner et al. 2016). This change in taxonomic assignment aside, all of the other conclusions and interpretations made by Miller et al. (1999, 2005) and Magee and Miller (2007) remain valid, albeit now relevant to a different species.

Once the eggshell record is removed from consideration, there is very little evidence regarding the timing and cause of extinction of Genyornis. As Grellet-Tinner et al. (2016) point out, skeletal remains of Genyornis are remarkably rare and most records are from contexts demonstrably older than 100,000 years old. One controversial claim for later survival comes from the site of Cuddie Springs in western New South Wales, where radiocarbon dating of enclosing sediments suggests the survival of Genyornis until after 30,000 BP (Field and Boles 1998; Trueman et al. 2005). However, direct dating of the bones of Genyornis and other megafauna there indicates that the megafauna may all have reworked from underlying, much older sediments (Grün et al. 2010; Roberts and Brook 2010). An interesting irony derived from Grellet-Tinner et al.'s (2016) reinterpretation of the Lake Eyre Basin eggshell record is that Genyornis may actually have contributed no eggshell throughout the period 140,000-45,000 years ago, which might actually be the best evidence for its regional extinction prior to the penultimate interglacial. However, this possibility will need careful study of the large numbers of samples from the many sites across the region.

Murray and Vickers-Rich (2004) postulated that Genyornis may have survived longer in parts of Australia that acted as refugia during the climatic extreme of the LGM, seeing the rugged Arnhem Land escarpment as a potential refugium. This suggestion hinges on three principal assumptions: Genyornis actually occurred in the tropical north of Australia; its demise elsewhere was principally driven by climatic factors; and the environment of Arnhem Land during the late Pleistocene favoured its survival. This scenario also has two interesting corollaries: unless populations of Genyornis in each refugium fell below viable levels before the end of harsh conditions, it should have expanded out of its LGM refugia following climatic amelioration; and any extinction of Genyornis subsequent to climatic amelioration should have occurred for non-climatic factors, with human predation being a likely cause.

The possible painting of Genyornis is the only direct evidence to support the refugia hypothesis; the acidic soils of Arnhem Land are not good for the preservation potential of Genyornis bone and eggshell. However, two other lines of evidence encourage the notion. A recent study of emu DNA, using the methods of phylogeography (Thomson 2012), found evidence for major declines in emu populations on several occasions through the late Pleistocene, and a geographic patterning of modern genetic variation consistent with contraction into refugia. And estimates of the timing of the contractions align well with periods of extreme climatic conditions. Evidently, even the more adaptable emu suffered local population declines during the harshest conditions of the late Pleistocene. Genyornis, with its more specialised diet, may have suffered more, perhaps including regional extinction across large parts of its former range.

Another line of evidence concerns the modern distribution within Australia of clearly relictual species that today are restricted to small geographic areas (and usually to very specific habitats) but which fossil evidence shows to have been more widely distributed in the past. The Australian vertebrate fauna contain numerous examples of relictual species and many of these occur in the tropical north of Australia, typically in association with vegetation that contains many floristic elements derived from ancient Australian rainforests. A textbook example from Arnhem Land is the rock-haunting ringtail possum (Petropseudes dahli) - a species that belongs to an ancient evolutionary lineage that was widespread across Australia in the Miocene (Archer et al. 2006) but which today is otherwise represented in the modern rainforest faunas of the Queensland Wet Tropics and New Guinea. Other examples from the Queensland Wet Tropics include the 
green ringtail possum (Pseudochirops archeri), the Herbert River ringtail possum (Pseudochirulus herbertensis), the musky rat kangaroo (Hypsiprymnodon moschatus) and the doubled-wattled cassowary (Casuarius casuarius). An example from the Kimberley region of northwest Australia is the scaly-tailed possum (Wyulda squamicauda), whose closest known relatives are fossil species from the Miocene of Queensland (Archer et al. 2006). Each of these species represents an example of local to regional survival of an evolutionary lineage for periods of many millennia to millions of years after the regional extinction of the same or related species in other parts of Australia. In each case, the key factor that most likely underpinned the survival was the greater environmental stability within these sheltered and moist habitats, compared with surrounding areas. However, a lack of human predation is undoubtedly also important within the period since human settlement of Australia, especially for any larger species.

\section{JSARN-124 site 3}

The archaeological site thought by Gunn et al. (2011) to contain the painting of a Genyornis bird was given the survey identification number JSARN-124 site 3 by the Jawoyn Association. As one of the key aims of this chapter is to determine through archaeological, geomorphological and chemical evidence whether or not the painting can possibly be of a Genyornis bird, so as to not preconfigure the result we refer to the site with its original survey site number, JSARN-124 site 3, and to the previously called 'Genyornis' motif as 'the large bird motif'.

Geologically, the site is located on the Arnhem Land plateau at the contact zone of a low rise of Marlgowa Sandstone (of the Kombolgie Subgroup, Katherine River Group) that formed during the Protezoroic 1740-1780 million years ago, and a broad depression drained by a tributary of the upper reaches of the Katherine River (Figure 1.1). Within the overall depression, the bedrock is buried by a shallow layer of aeolian sands eroded from quartzitic sandstone benches.

At a broad, landscape scale, the contact zone between the low rise and the depression is today marked by a network of isolated rock stacks (Figure 15.1). These rock stacks represent the ancient edge of the low rise and are of uneven orientations, signalling their fragmentation through chemical and mechanical weathering and gravitational collapse (e.g. roof-fall). JSARN-124 site 3 is one of these rock stacks. The first people onto this landscape, between 65,000 and c. 50,000 years ago, entered a geological landscape that was very similar to the one visible today.

The JSARN-124 site 3 rock stack consists of superimposed quartzite strata measuring some $4.5 \mathrm{~m}$ thick $\times 11 \mathrm{~m}$ long $\times 7 \mathrm{~m}$ wide, sitting on and overhanging a narrow quartzite pedestal $2.5 \mathrm{~m}$ long $\times 6 \mathrm{~m}$ wide. The pedestal represented by rock strata D2-D1-D0 is narrower than the overlying, overhanging strata D3-D7 (see Figures 15.2 and 15.3). This is due to the pedestal having lower resistance to forces of erosion than the overlying strata. As a result of the narrowness of the pedestal, the overlying strata have tilted northward. This tilting, along with the collapse of large parts of the overhang, took place over a long, geological time frame sometime before the arrival of people in the landscape. 


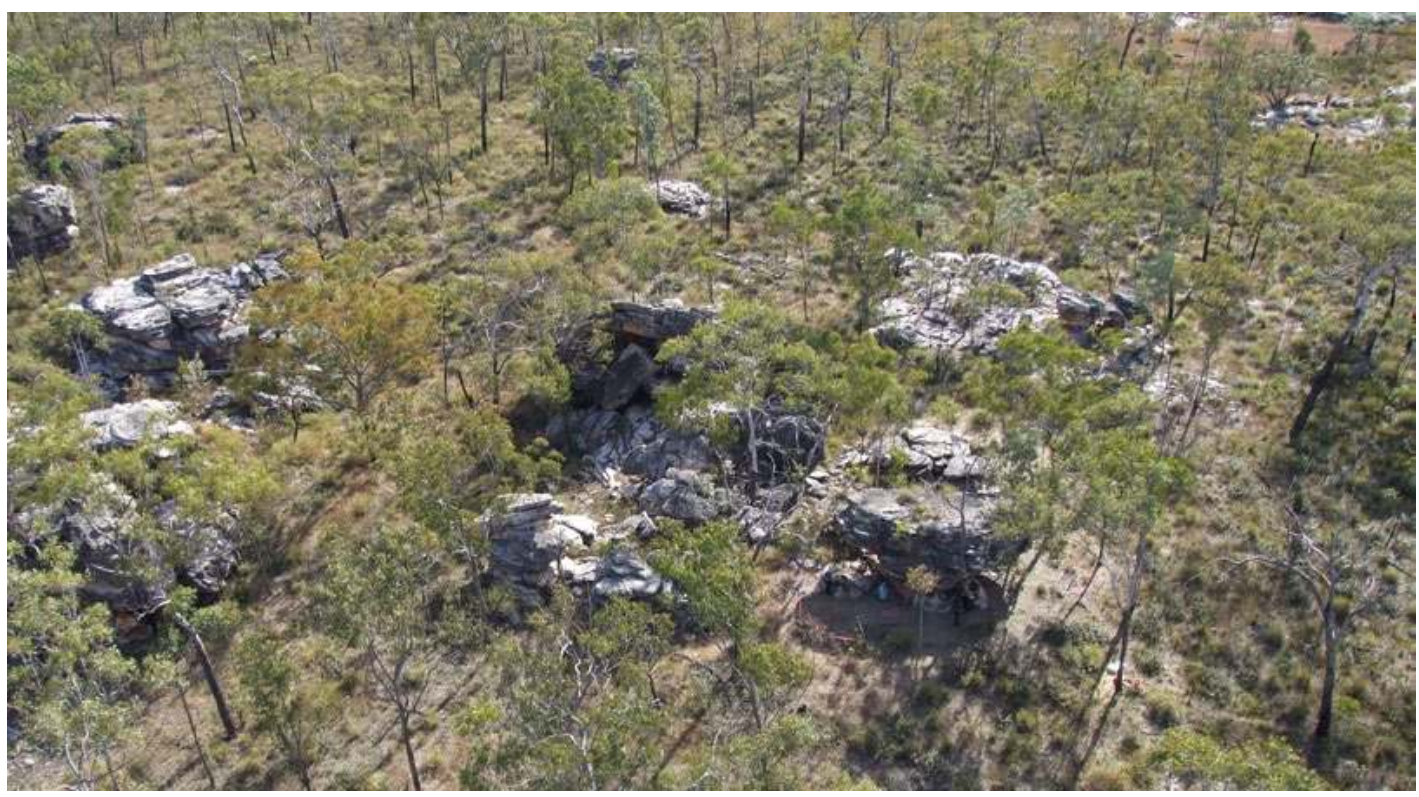

Figure 15.1 JSARN-124 site 3 (bottom right-hand rock stack), excavation of Squares B and D in progress. Source: Photograph by Jean-Jacques Delannoy.

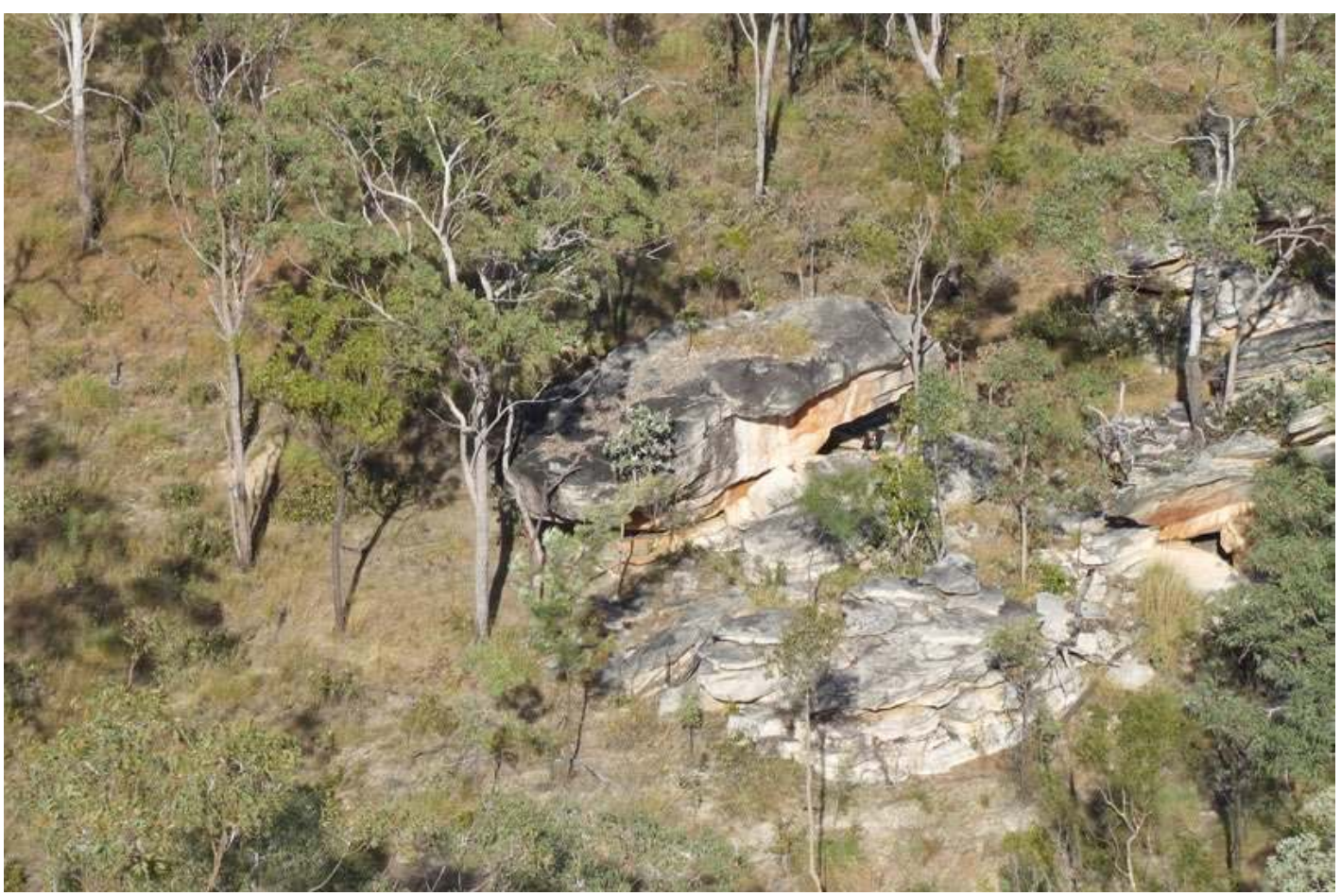

Figure 15.2 Northern side of JSARN-124 site 3, showing collapsed overhang at ground level.

Source: Photograph by Jean-Jacques Delannoy. 

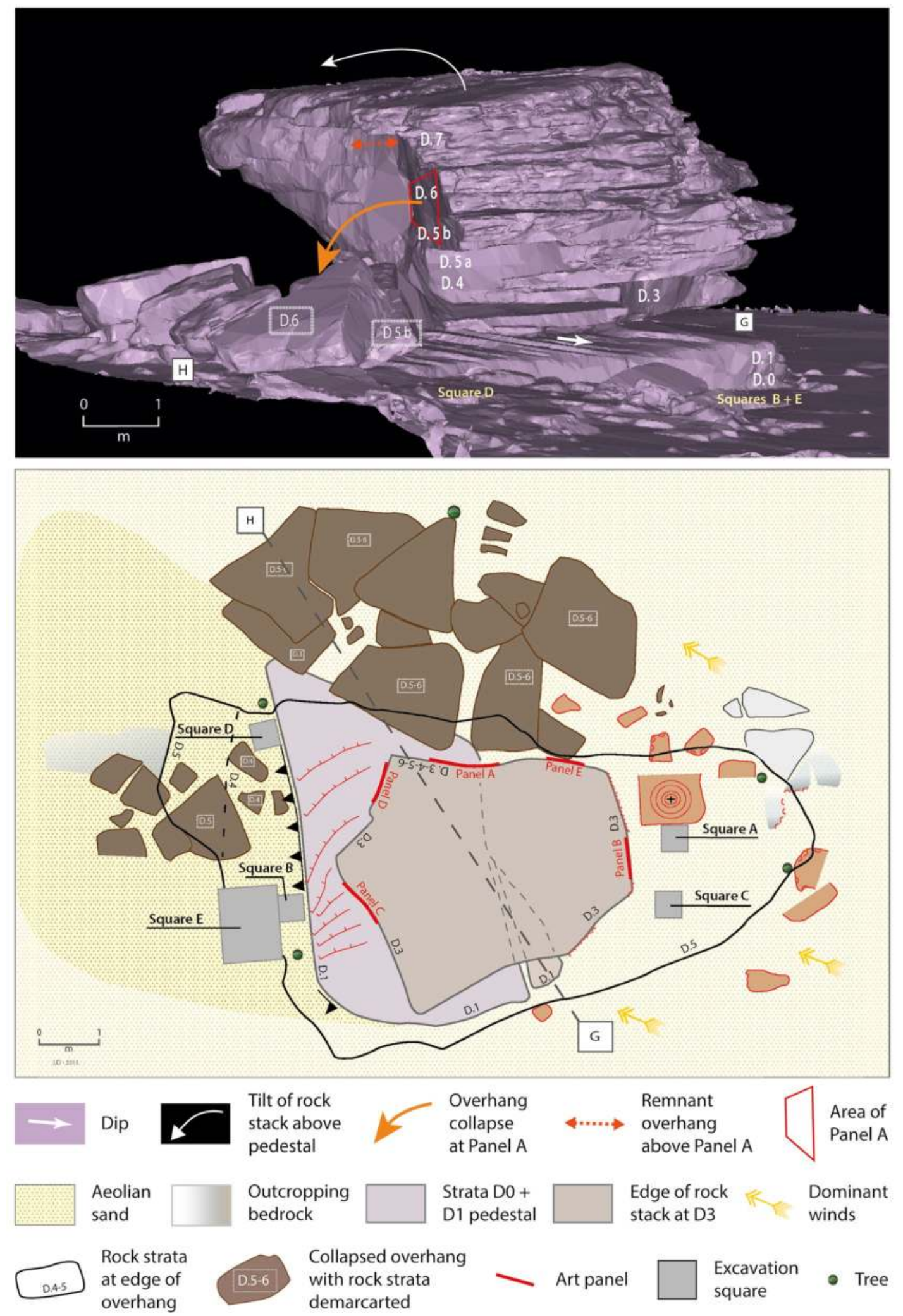

Collapsed overhang with rock strata $\quad$ Art panel demarcarted

Excavation square

- Tree

Figure 15.3 Profile view and map of JSARN-124 site 3, showing the collapsed overhang and location of excavation squares.

Source: Illustrations by Jean-Jacques Delannoy. 
The large bird motif is located on the northern face of the site. This flat northern face is the scar left by the collapse of what had been a much deeper overhang than the current one. The boulders that are now at ground level immediately to the north of the shallow remnant overhang are the fallen sections of strata D4-D5-D6 that previously made up the 'original' overhang (see below for further details).

\section{The rock art}

Rock art is found on five panels (Panels A-E) around the quartzitic sandstone stack (see Figure 15.3). Each panel is described separately below.

\section{Panel A}

Panel A faces slightly east of north. It is $5 \mathrm{~m}$ long $\times 3 \mathrm{~m}$ high, and is today protected by a shallow, $1.5 \mathrm{~m}$ deep overhang. As noted above, previously the overhang was considerably larger than it is now, as indicated by massive rock collapse beyond the present dripline (Figure 15.4; see below). Parts of Panel A have been subject to water-wash, which accounts for the variability of colour and partial erasure of images on the eastern side of the panel.

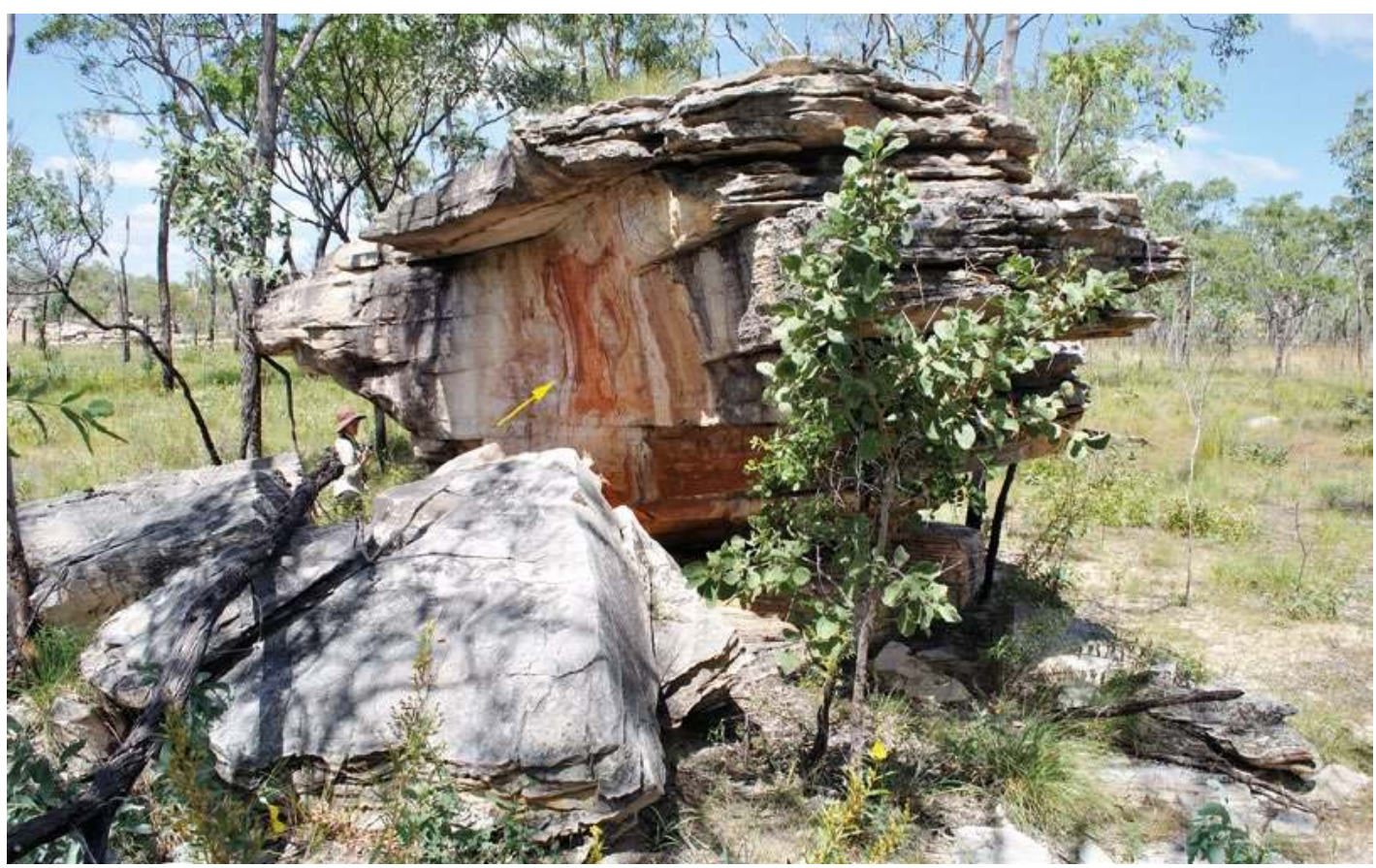

Figure 15.4 Location of art Panel A.

Source: Photograph by Robert Gunn.

Panel A contains 29 images in monochrome reds or yellows (Figures 15.5 and 15.6). It is dominated by a large painting of a bird (Image \#5), $1.66 \mathrm{~m}$ long $\times 1.07 \mathrm{~m}$ high - the one that might show Genyornis. Gunn et al. (2011) provide a detailed description of the panel, although an extra motif (Image \#29) has now been identified, and Image \#14 is reclassified here as a large macropod whose hind quarters and tail have been destroyed by weathering. 


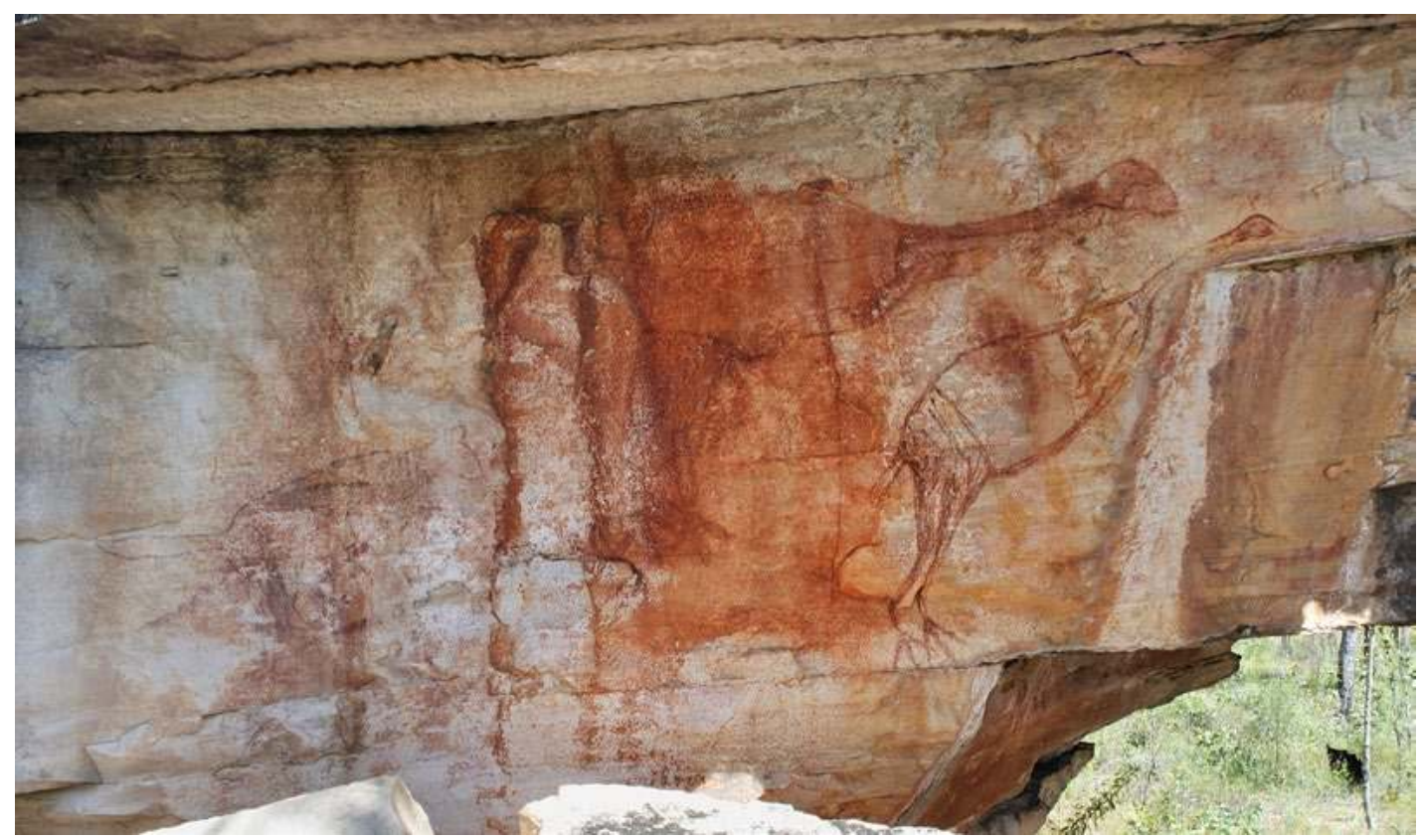

Figure 15.5 Panel A.

Source: Photograph by Robert Gunn.

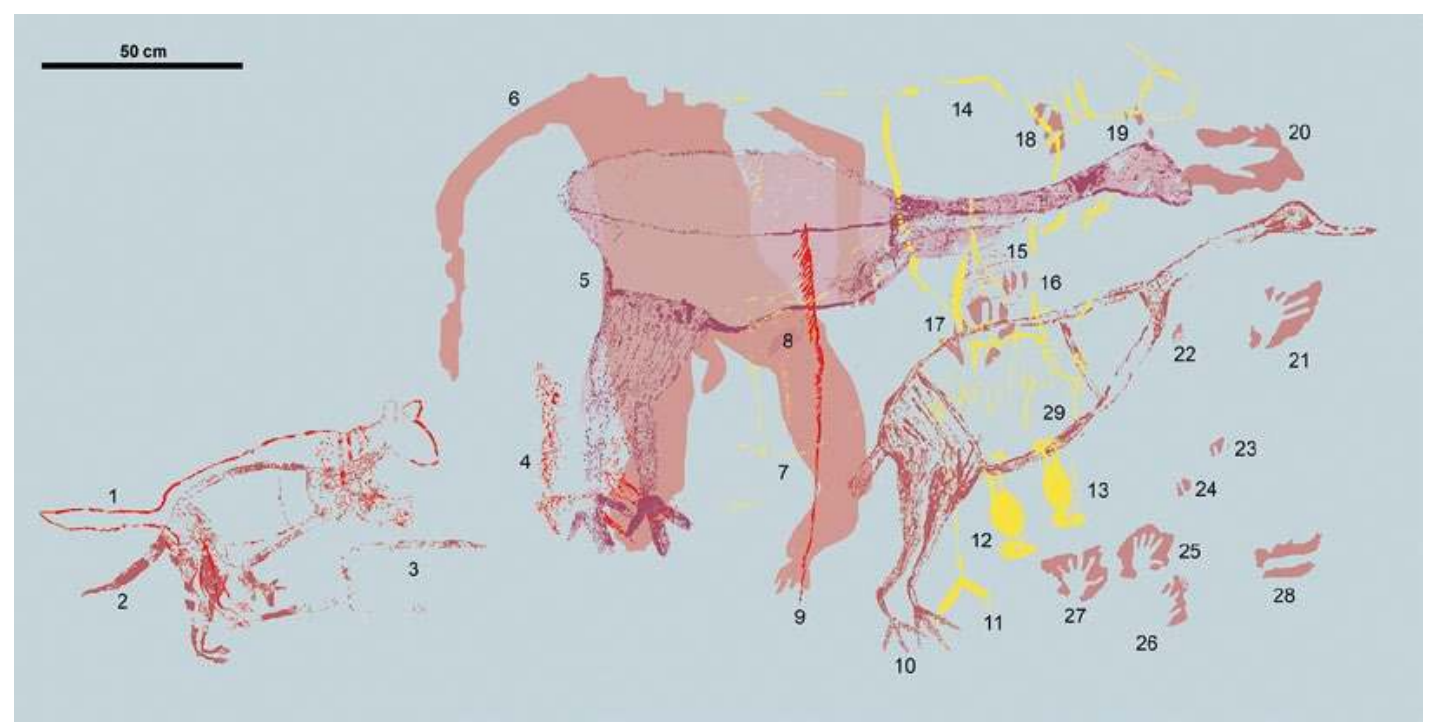

Figure 15.6 Photo-tracing of the Panel A images.

Source: Digital tracing by Robert Gunn.

The large bird motif post-dates a series of hand stencils including the 3MF (for three middle fingers together, with the thumb and small finger to one side) type generally associated with Chaloupka's Dynamic Figures style, which researchers provisionally think dates to around 10,000-12,000 years ago (Chippindale and Taçon 1998; Taçon and Brockwell 1995; but see Chaloupka 1993 who thought they may have been older; see Chapter 1). The large bird motif on Panel A overlies both hand stencil Image \#19 and the 3MF hand stencil (Image \#20), so it is younger (Table 15.1). In the initial recording, the large bird painting was thought to underlie at least four other images (Gunn et al. 2011), while the large, solid male figure (Image \#6) was thought as overlying the large bird motif. We have since shown elsewhere that Image \#6 underlies the large bird motif and is therefore older (Chalmin et al. 2017). 
Table 15.1 Panel A: Simplified superimposition sequence involving the earliest and latest images (most recent image at top of table; earliest at bottom).

\begin{tabular}{|l|l|l|l|l|}
\hline Image type & Image \# & Technique & Form & Colour \\
\hline Simple Design & 15 & Drawing & Grid & Red \\
\hline Unknown & 29 & Painting & Outline & Yellow \\
\hline Macropod & 14 & Painting & Outline+infill & Yellow \\
\hline Spear & 9 & Painting & Linear & Red \\
\hline Large bird motif & 5 & Painting & Solid+outline+infill & Reds ( 33$)$ \\
\hline Large solid anthropomorph & 6 & Painting & Solid & Red \\
\hline Hand stencils (including 3MF type) & $18,19,20$ & Stencil & Hand stencils & Red \\
\hline
\end{tabular}

Note that under microscopic examination of cross-sections of micro-samples, the stratification of paint layers confirms that the spear (Image \#9) lies over the large solid anthropomorph (Image \#6). Furthermore, the paint layer from the spear merges in cross-section with that of the large bird motif (Image \#5), and so the two are therefore probably contemporaneous.

Source: Authors' data.

Other recognisable images include a female macropod with joey, two flying-foxes, a unimarginal barbed spear, and two unidentified faunal taxa (a quadruped and a waterbird). As with the early suite of red hand stencils, the yellow images (Images \#11, \#12, \#13, \#14 and \#29) appear to be a contemporaneous group.

The painting of the spear (Image \#9) intersects the painting of 'Genyornis' (Image \#5) in a composition that implies a deliberate association (Figure 15.7). One interpretation of this composition could be of a speared bird, although in Arnhem Land the vertical upwards orientation of the spear is unusual for so-called 'hunting scenes'. However, the hunting theme is of particular interest because if the bird is indeed of Genyornis, and if the spear is contemporaneous with the Genyornis painting, then it would suggest that the bird was hunted.

The shape of the spear (Image \#9) on the large bird motif corresponds with Chaloupka's bokko spears, for which he does not offer an age but notes, 'the stone country people such as the Badmardi clan claim it as their own' (1993:148); that is, according to some recent oral traditions, it originated on the Arnhem Land plateau, although it was also then used on the low-lying plains. Lewis (1988) identified this spear type in all of his western Arnhem Land rock art phases, from the Boomerang, 'Hooked Stick', Broad Spearthrower to Long Spearthrower Periods. The shape of the spear

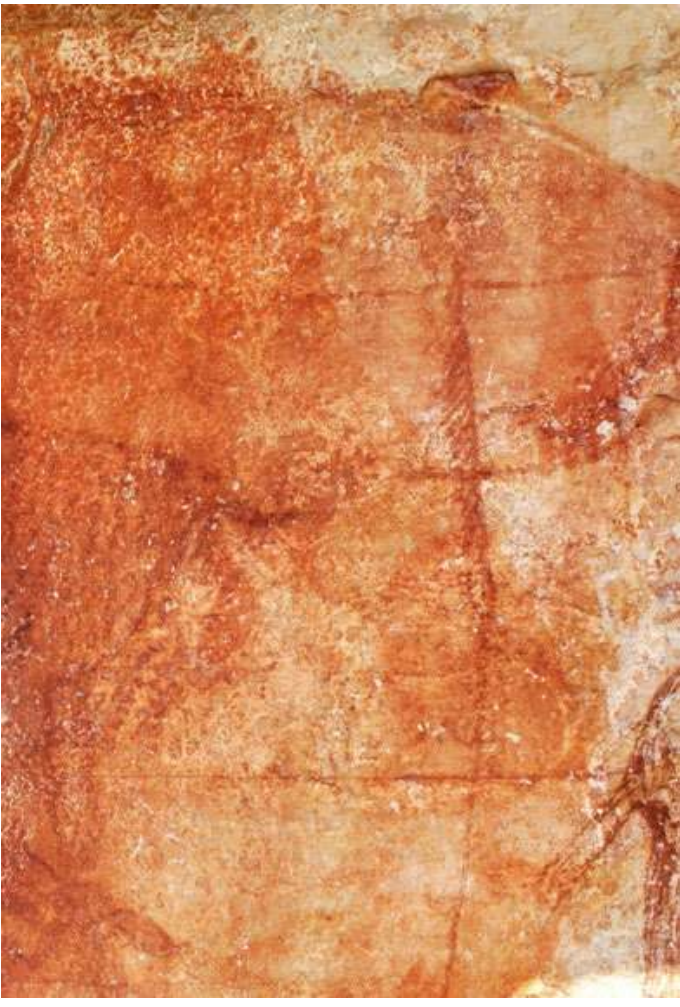

Figure 15.7 Detail of the placement of the spear (Image \#9), the large bird motif (Image \#5) and the large anthropomorph (Image \#6) paintings. Source: Photograph by Robert Gunn. cannot signal its antiquity. 
The waterbird (Image \#10) has a well-delineated but unpainted interior. Brandl (1972:27) sees such 'empty' interiors as a precursor to the development of X-ray features. Taçon suggests 'the approximate upper age limit for the early $\mathrm{x}$-ray period has been placed at 8000-6000 years BP' (1989:119), but further notes, 'in a sense, however, the upper age should remain open-ended as some aspect of 'internalness' has been found in earlier styles' (Taçon 1989:119; see also Taçon 1992:203). Subsequently, Chaloupka tentatively suggested that this convention of hollow body began towards the beginning of his Estuarine Period, around 8000 years ago. None of these suggested ages are based on any direct dating of art (Chaloupka 1993:183-185). The large bird motif is also hollow-bodied: did this artistic convention begin long before the early Holocene, prior to the LGM (see Gunn et al. 2011)?

\section{Panel B}

Panel B is on the rear wall of the alcove behind excavation Square A (Figures 15.8-15.10). The rock panel measures $2.3 \times 0.7 \mathrm{~m}$, but the irregular southern half is undecorated. Small areas of the panel have been damaged by exfoliation and the lower margin of the southern half has been extensively flaked.

The 12 images on the panel are all in monochrome red and very poorly preserved. The only recognisable images are of a solid macropod (Image \#33), a goose-like bird (Image \#31), a pair of macropod tracks (Image \#40) and a cluster of drawn lines (Image \#41). The macropod (66 cm long; height indeterminate) is the largest image on the panel. Image \#33 is superimposed over Images \#34, \#35 and \#37, but the sequential relationship of the other images cannot be determined due to their poor preservation.

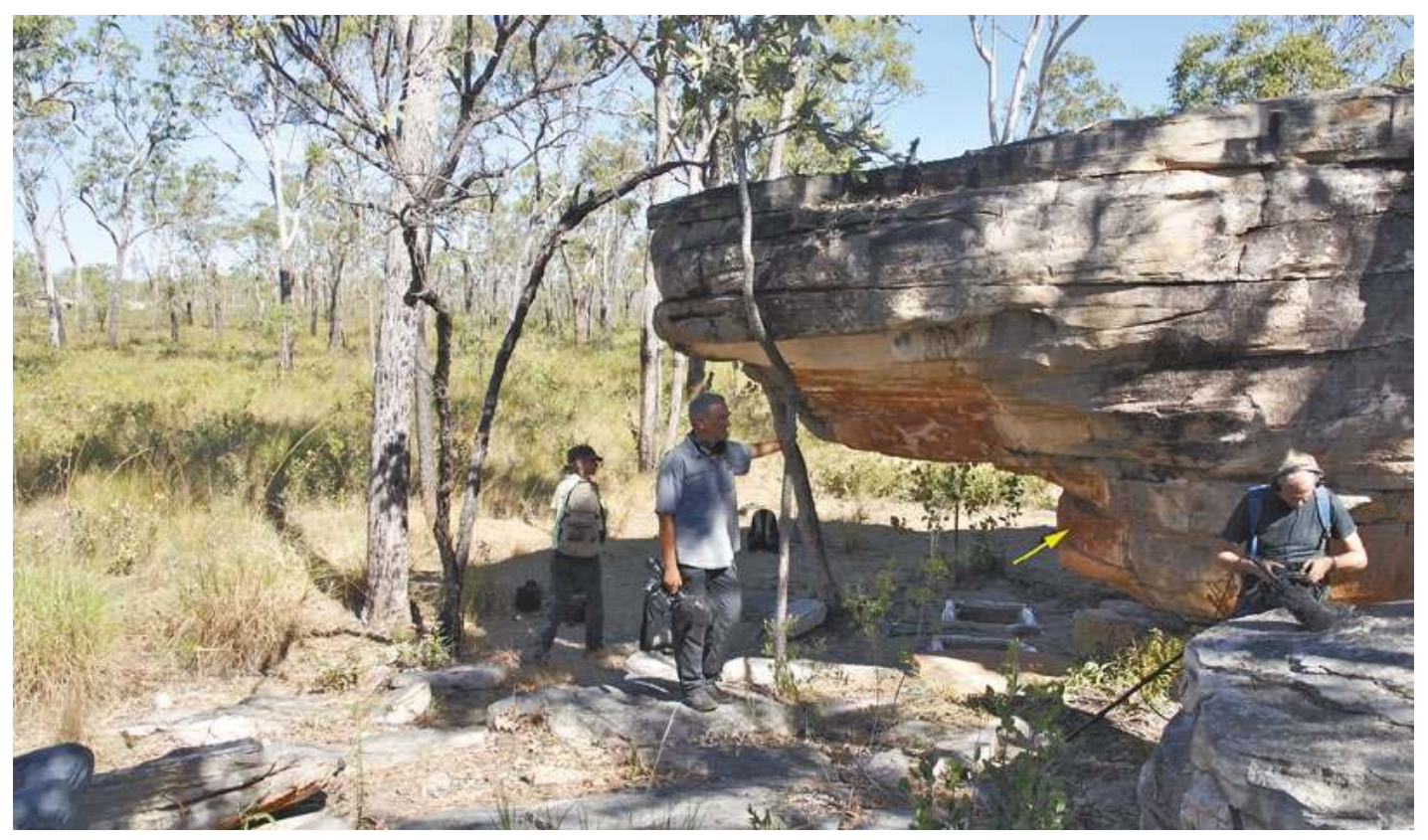

Figure 15.8 Location of Panel B.

Source: Photograph by Robert Gunn. 


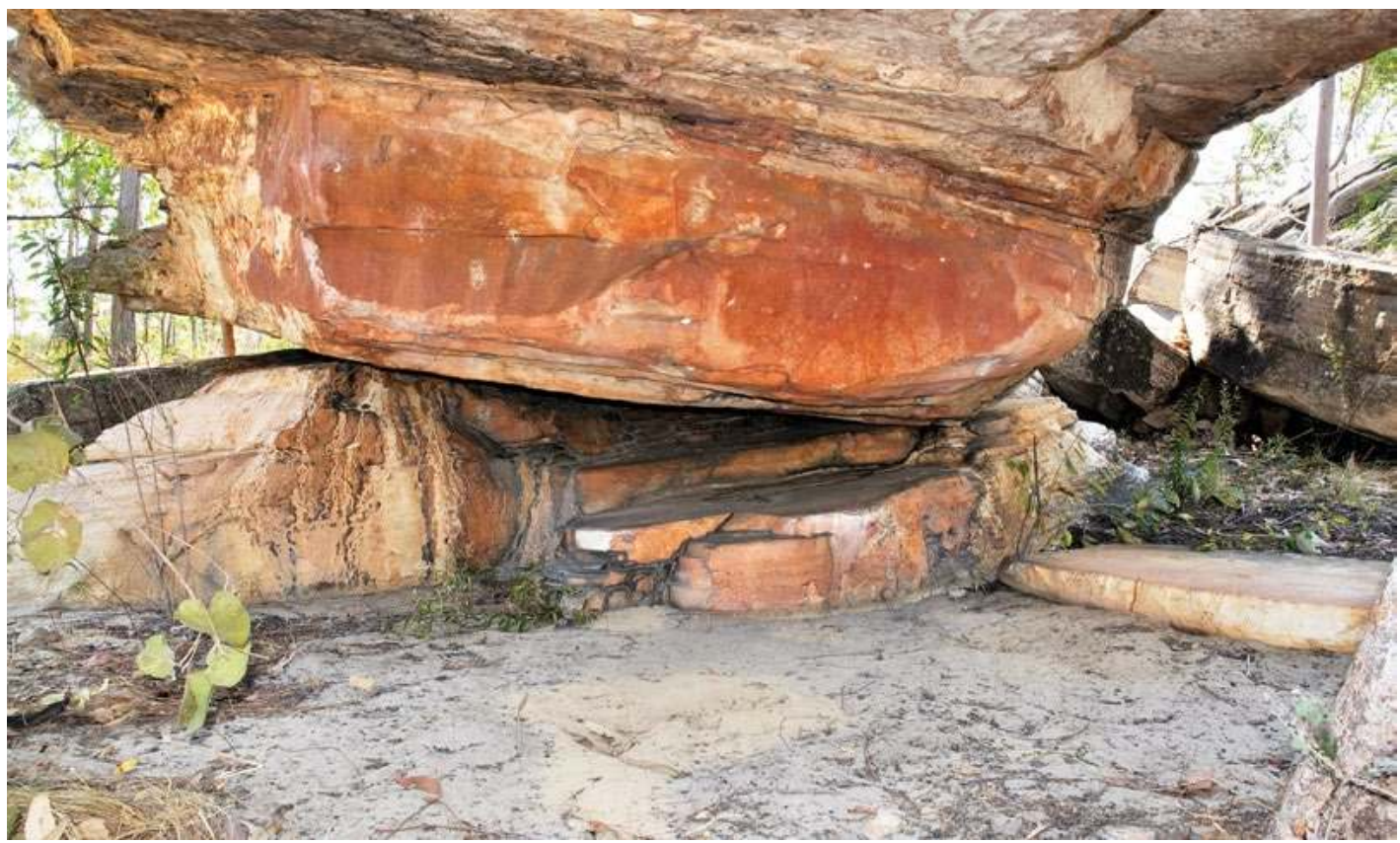

Figure 15.9 Panel B.

Source: Photograph by Robert Gunn.

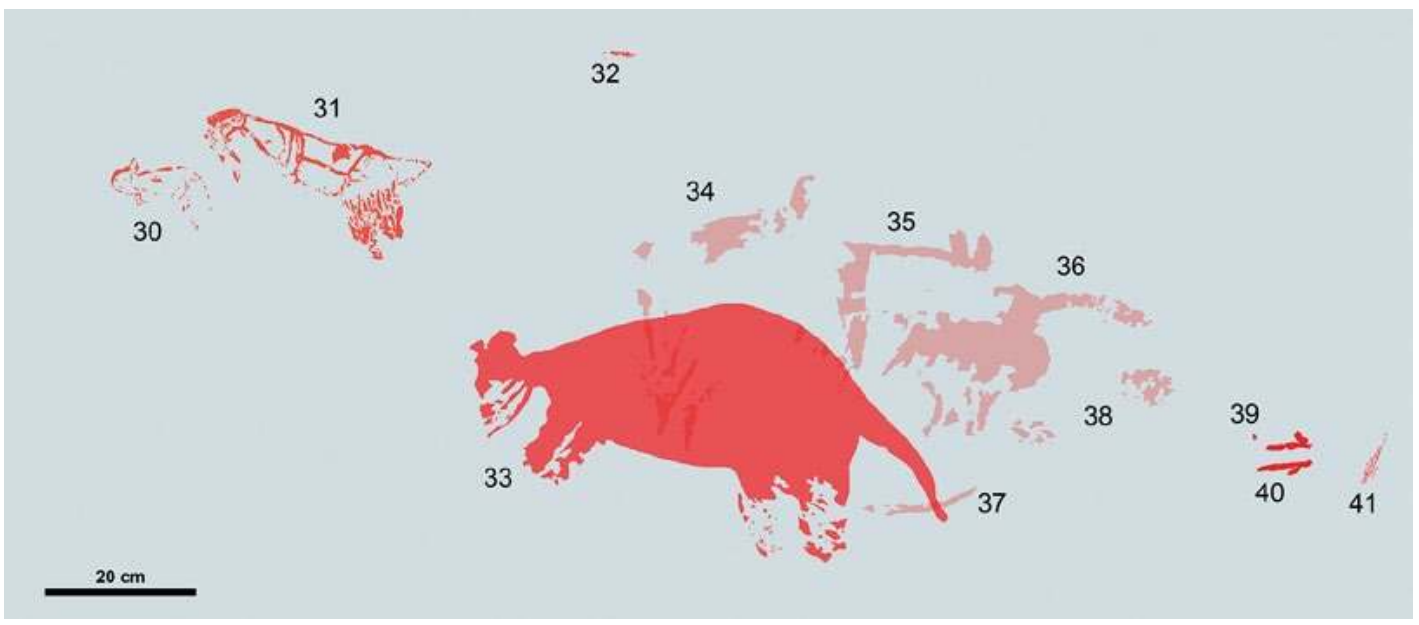

Figure 15.10 Photo-tracing of the Panel B images.

Source: Digital tracing by Robert Gunn.

\section{Panel C}

On a localised, vertical section of the wall directly above Square B are eight paintings that, on the basis of differences in form and preservation, can be seen to constitute three distinct groups (Figures 15.11-15.13):

- Two opposing birds (Images \#45 and \#46) and a bandicoot in red (Image \#49).

- Two lines and a small simple design, also in red (Images \#42-\#44).

- Two white angular fragments that may have represented bird tracks but are now too fragmented to determine the shapes of the original motifs (Images \#47 and \#48).

The bandicoot is the largest of the motifs at $47 \mathrm{~cm}$ long. 


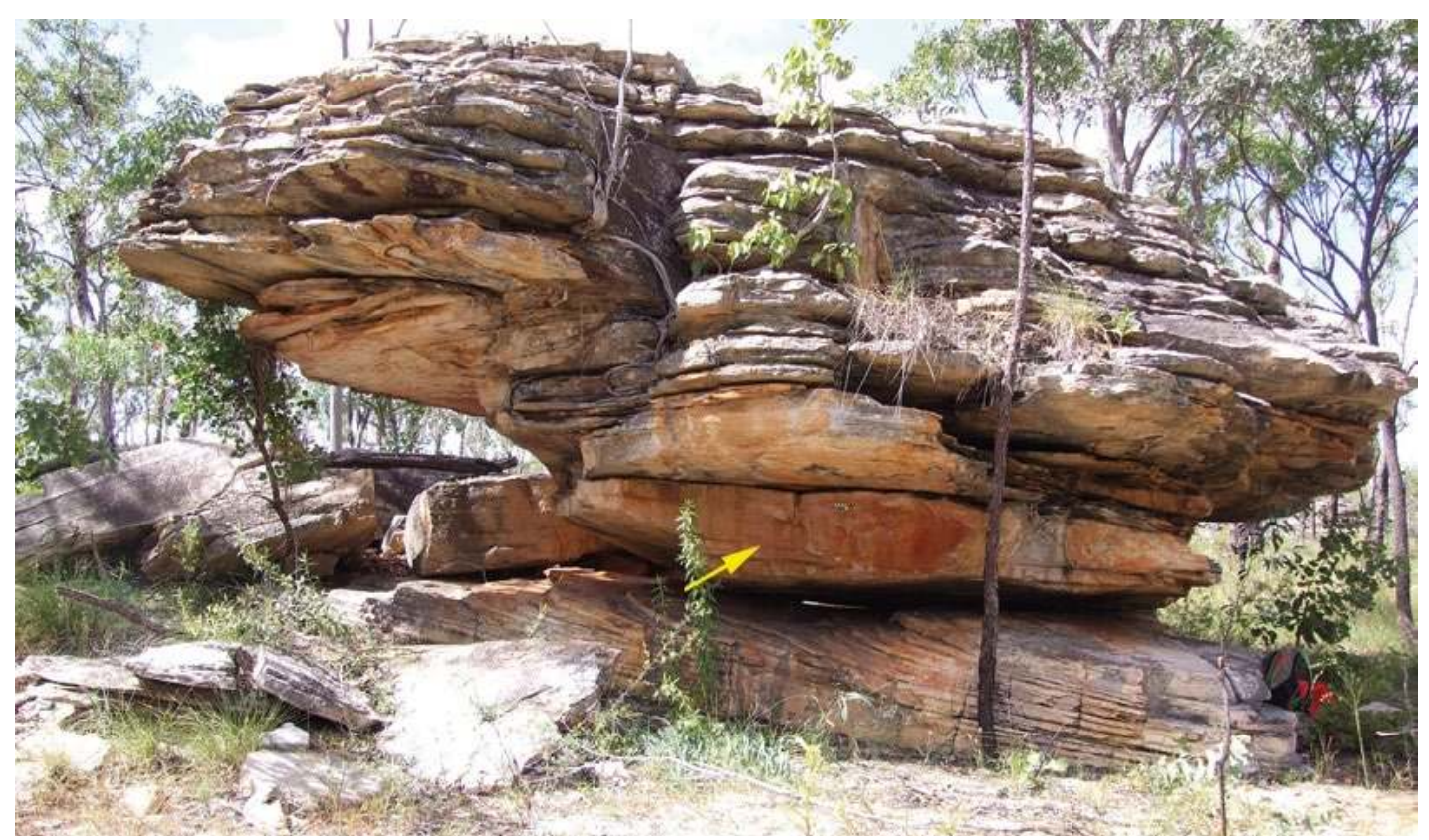

Figure 15.11 Location of Panel C.

Source: Photograph by Robert Gunn.

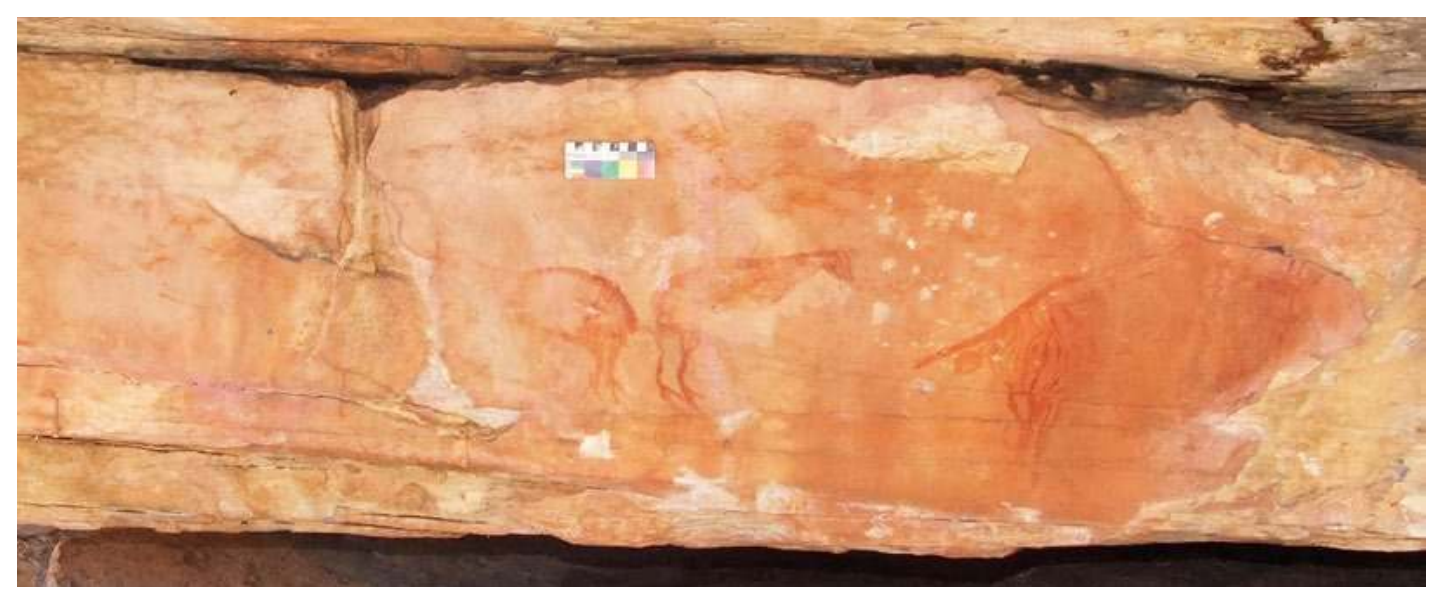

Figure 15.12 Panel $C$.

Source: Photograph by Robert Gunn.

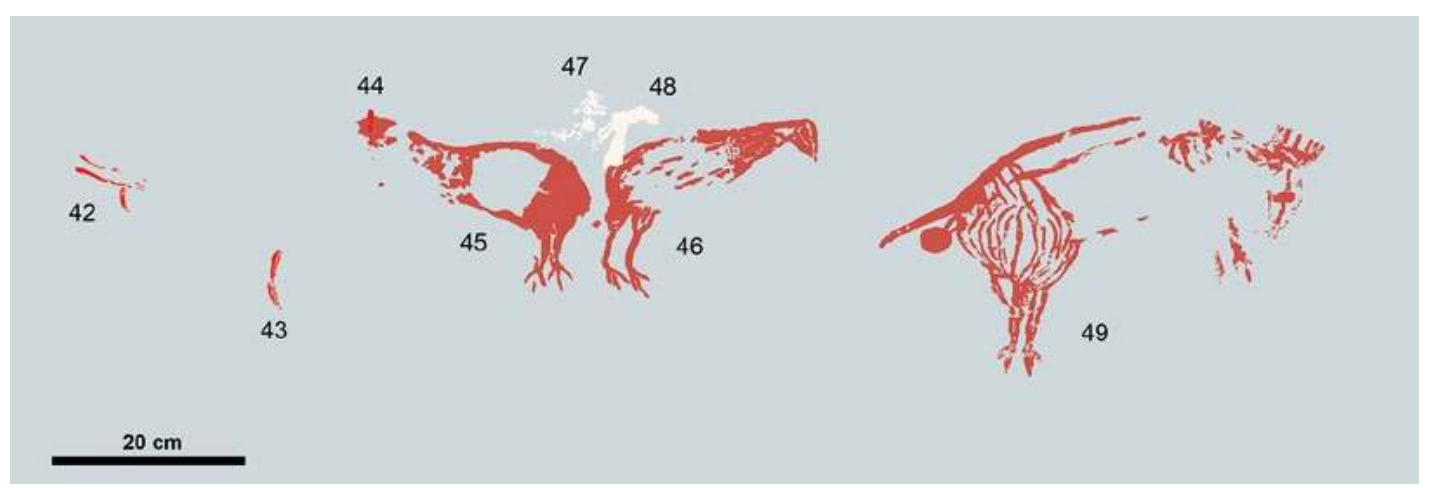

Figure 15.13 Photo-tracing of the Panel C images.

Source: Digital tracing by Robert Gunn. 
The type of bird represented by Images \#45 and \#46 is said, by Jawoyn people and also Aboriginal people in more northern parts of western Arnhem Land, to represent what are colloquially referred to as 'bush hens'. Although not specifically identified to species during those discussions, the bush hen (Amaurornis olivaceus) is a type of rail that frequents swamp forests and is recorded from the region (Pizzey and Knight 1997:148). An alternative identification is the jirrirti (brown quail; Coturnix ypsilophora), a character of Jawoyn oral traditions that is represented in a similar manner to the bush hen (Wynjorroc et al. 2001:36). This form of bird depiction, as determined by the general shape of paintings, is one of the most commonly represented birds in the early art of the plateau, often shown in linear groups of six or more. The 'empty' body cavity in Image \#45 is stylistically similar to that of the unidentified waterbird on Panel A (Image \#10).

The bandicoot Image \#49 is recognised by its short, straight tail, prominent testicles, short hind legs and two prominent macropod-like toes on the hind foot. Bandicoots are also common in early Jawoyn rock art on the plateau.

All of the images on this panel are badly weathered and, while the beak of the left bush hen/ brown quail has been destroyed by exfoliation, water-wash has been responsible for most of the erasures elsewhere.

Studies at the nearby site of Nawarla Gabarnmang (Gunn et al. 2011) suggest that most images painted with white pigment are less than 400 years old. If the Nawarla Gabarnmang situation signals a broader pattern for Jawoyn Country, the two white images on Panel C at JSARN-124 site 3 (Images \#47 and \#48) would be of a similarly recent age.

\section{Panel D}

A very weathered rock face, Panel D measures $2.0 \times 0.6 \mathrm{~m}$ in size and contains six red paintings, all in very poor condition (Figures 15.14-15.16). It is possible that the panel was once decorated more extensively, but no traces of other images now remain. The panel is directly behind excavation Square D. Patterns of superimposition indicate that the surviving images were painted in three groups:

- An early group consisting of a single striped fragment of an originally larger image (Image \#52).

- A middle group of three linear images including a pair of back-to-back anthropomorphs (Images \#50 and \#51).

- A later group of an anthropomorph (Image \#54) and a crooked line (Image \#53).

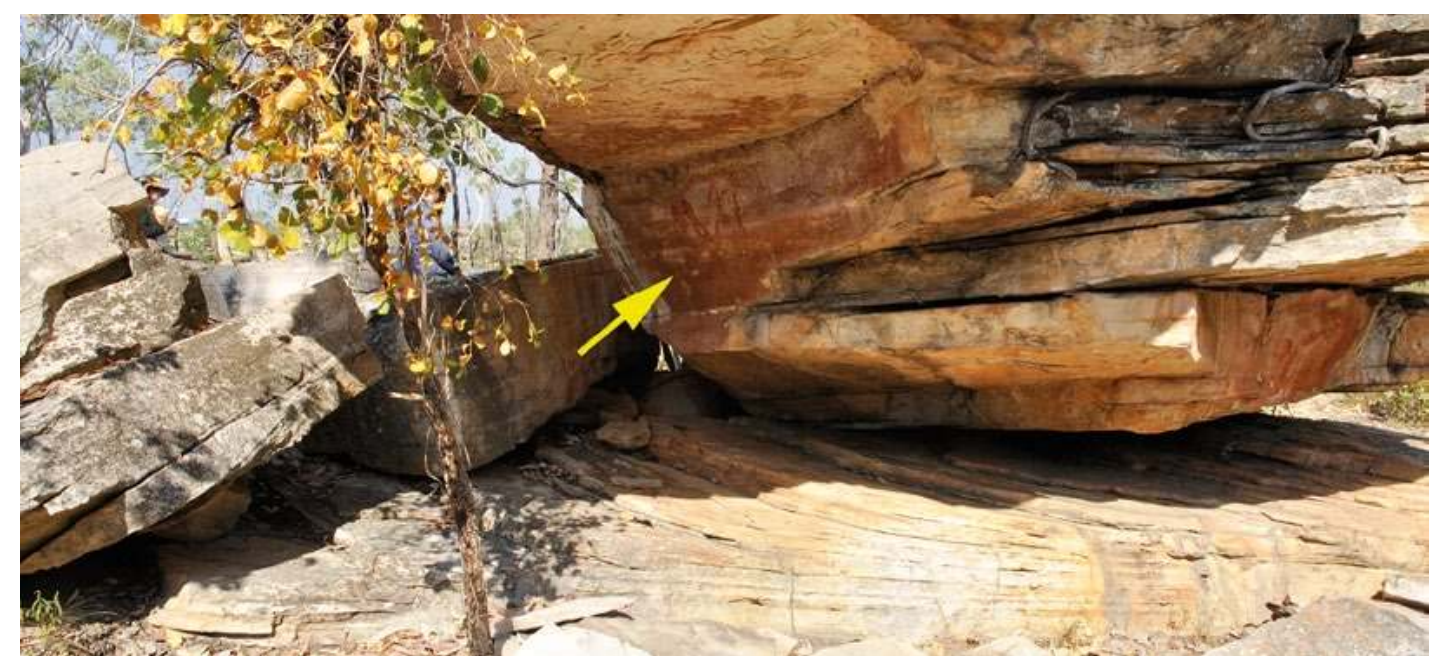

Figure 15.14 Location of Panel D.

Source: Photograph by Robert Gunn.

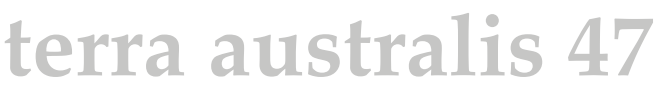




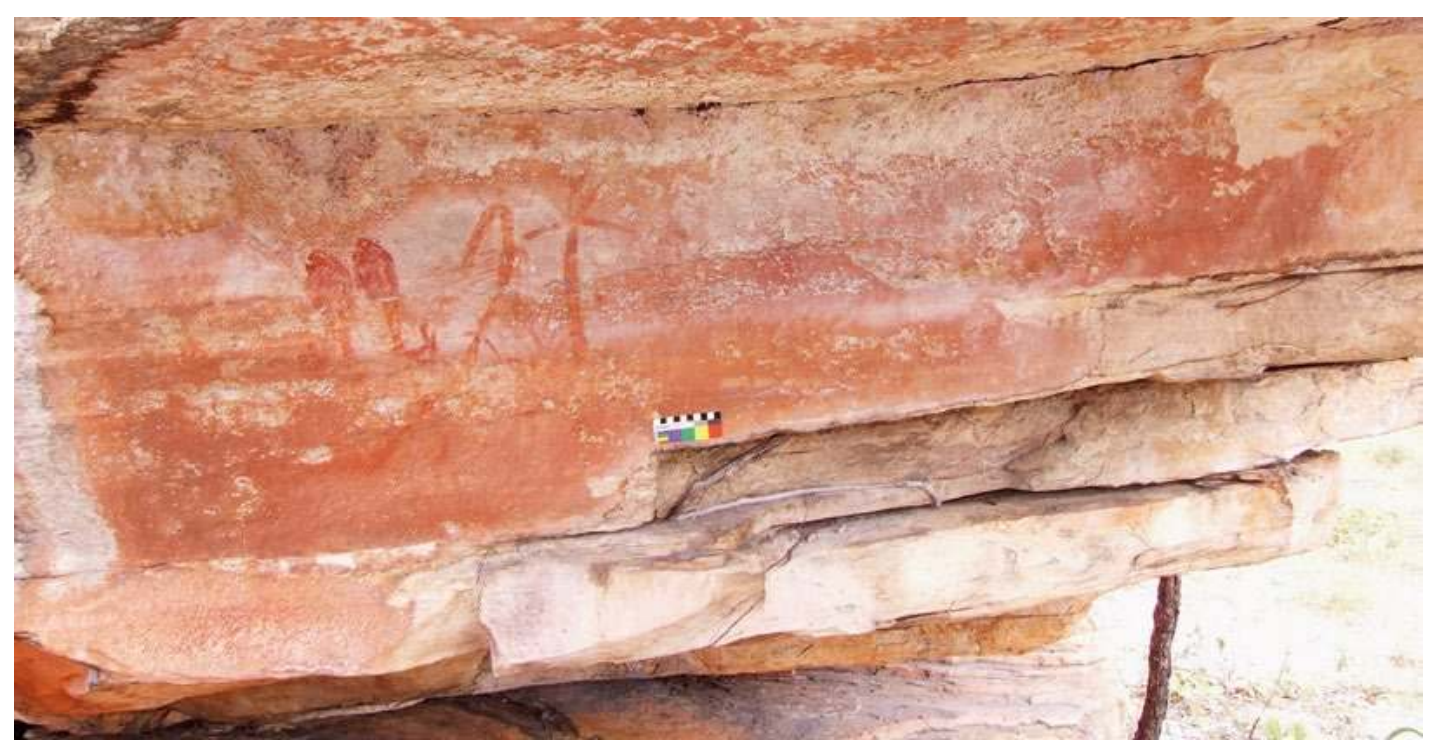

Figure 15.15 Panel D.

Source: Photograph by Robert Gunn.

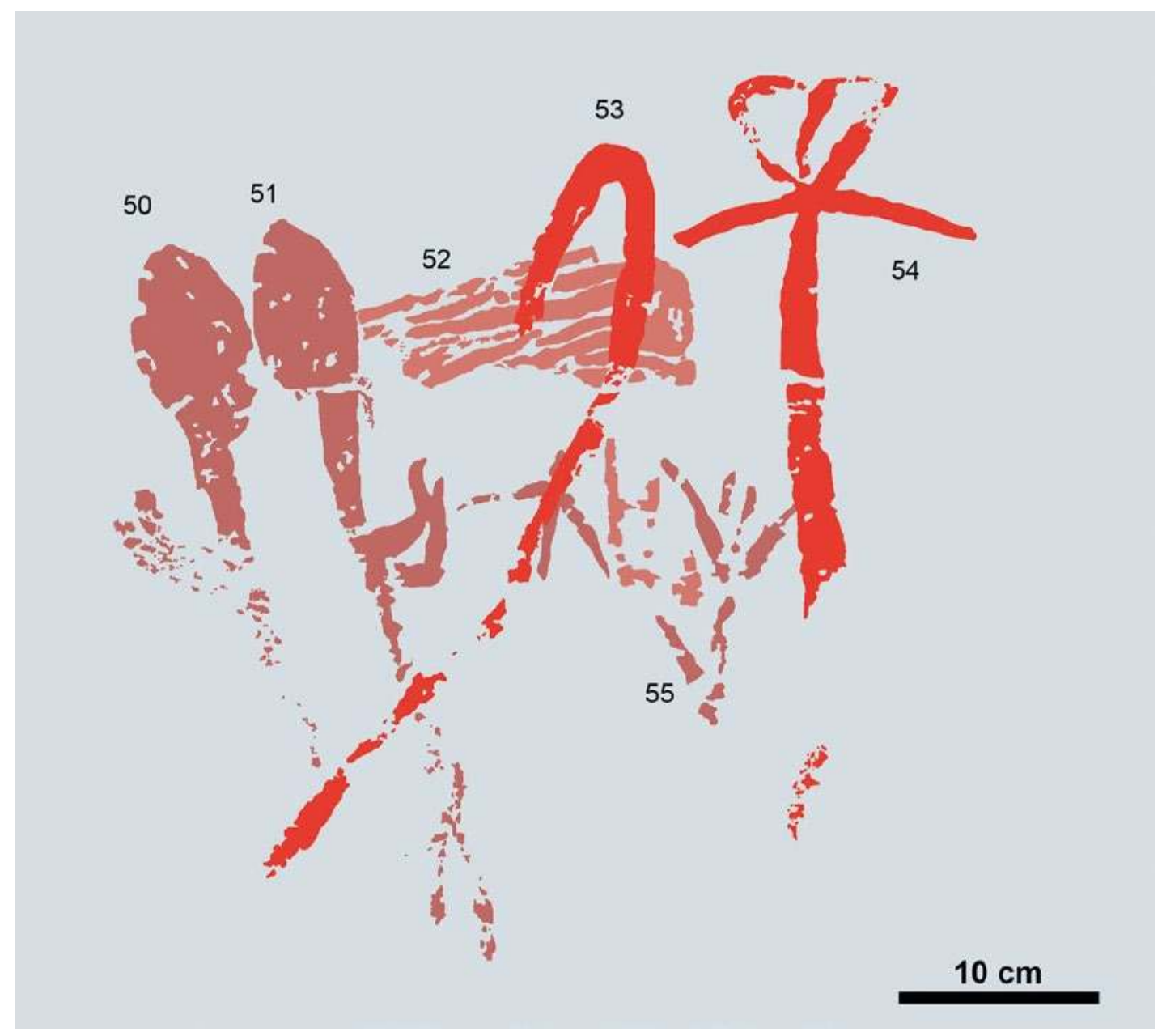

Figure 15.16 Photo-tracing of the Panel D images.

Source: Digital tracing by Robert Gunn. 


\section{Panel E}

Panel E is a small panel below and to the lower left of Panel A, at the same level above ground as Panel B. The panel is partially hidden by the rockfall from Panel A and is most readily photographed obliquely (Figure 15.17). The panel is approximately $2.0 \mathrm{~m}$ long $\times 0.8 \mathrm{~m} \mathrm{high}$; it contains five images in two layers of superimposition (Figures 15.18 and 15.19). The underlying image consists of a poorly preserved hand stencil (Image \#57), while the overlying images consist of a macropod (Image \#56), a goanna (Image \#58) and a bandicoot (Image \#60). The other image, Image \#59, is a poorly preserved fragment of an originally larger outline image. The images are made at a similar scale to those on the smaller Panels B-D. The bandicoot (Image \#60) on Panel E is similar in form and pose to the bandicoot on Panel D (Image \#49). Their similarity of representation suggests that the two are probably contemporaneous. The hand stencil (Image \#57) is in a similarly poor state of preservation as those on Panel $\mathrm{A}$, and may thus be contemporaneous with them, as both sets of hand stencils occur as the earliest images on their respective panels.

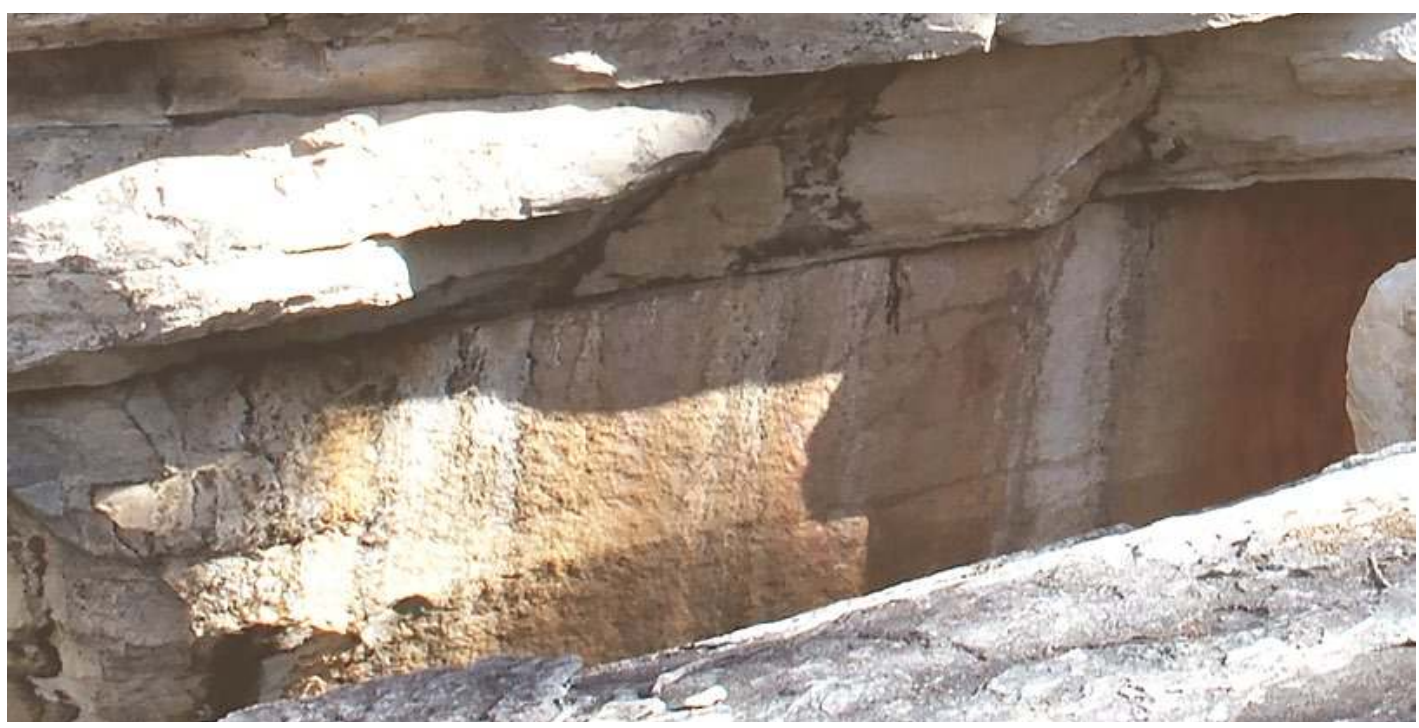

Figure 15.17 Location of Panel E.

Source: Photograph by Leigh Douglas.

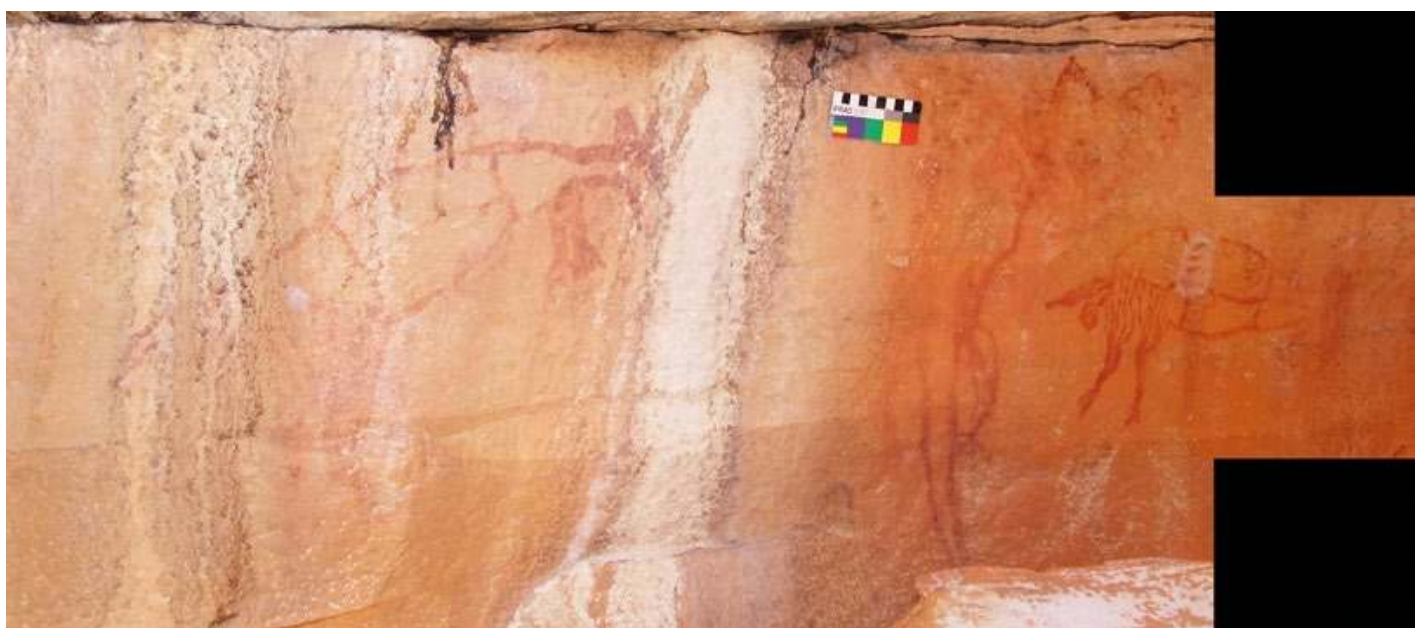

Figure 15.18 Stitched photograph of Panel E.

Source: Photograph by Leigh Douglas. 


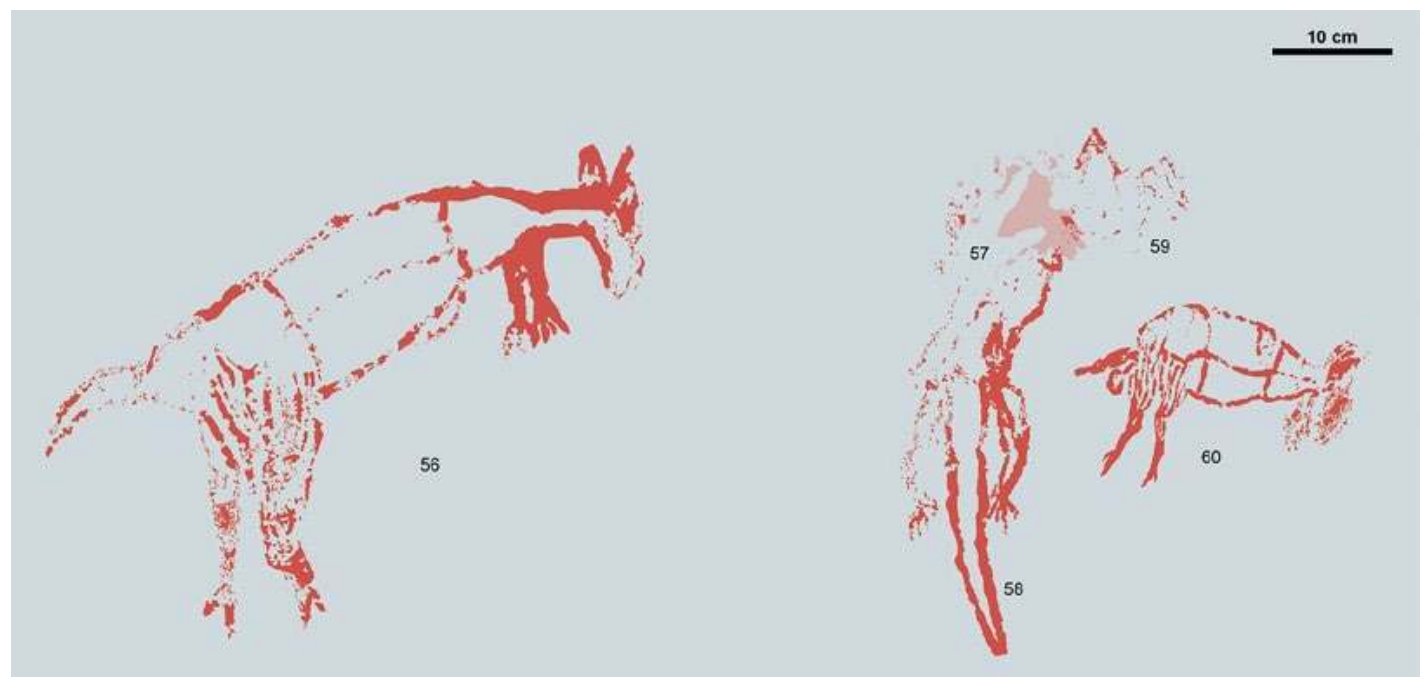

Figure 15.19 Photo-tracing of the Panel E images.

Source: Digital tracing by Robert Gunn.

\section{Discussion of the art}

JSARN-124 site 3 contains one large and four smaller art panels with a total of 60 images painted or stencilled in monochrome red, yellow or white. Regionally, this is a medium-sized art site. Patterns of superimposition show the earliest images appear to be the hand stencils, including of the $3 \mathrm{MF}$ type, on Panels A and E, while the most recent artworks are likely to be the remnant white images on Panel C. If 3MF hand stencils are around 10,000-12,000 years old and the bird is Genyornis, then something seems amiss: either the 3MF type of stencil is much older than currently thought, or Genyornis survived long after the LGM.

\section{Geochemical analyses}

To determine if the large bird motif could have survived on a relatively exposed rock surface since late Pleistocene times, chemical analyses were carried out on the micro-stratigraphy (including on-wall pigments) at a number of rock art panels. Very small fragments of the rock surface were sampled, in each case with a new scalpel blade and stored in individual phials (Table 15.2; e.g. Figure 15.20). In the laboratory, the colour, size, shape and texture of each sample were recorded prior to undertaking more detailed chemical analyses. The individual samples from painted or stencilled surfaces were then compared with surface wall samples devoid of pigment and with bulk bedrock samples. Some of the samples were embedded in epoxy resin in order to examine micro-stratigraphic relationships between the underlying rock, paint layer(s) and surface crusts. Details of these analyses have been presented in Chalmin et al. (2017).

Table 15.2 Description of samples from JSARN-124 site 3.

\begin{tabular}{|l|l|l|l|l|l|}
\hline Sample \# & Panel & Image \# & Description & Major compounds & $\begin{array}{l}\text { Minor and trace } \\
\text { elements }\end{array}$ \\
\hline GN1-1 & A & 5 & $\begin{array}{l}1 \text { compact and hard sample consisting of } \\
\text { a thin layer of red above a white opaque } \\
\text { matrix }\end{array}$ & $\begin{array}{l}\mathrm{SiO}_{2}, \mathrm{AlFePO}_{4^{\prime}}, \mathrm{Fe}_{2} \mathrm{O}_{3} \\
\mathrm{Na}, \mathrm{Mg}, \mathrm{S}, \mathrm{K}, \\
\mathrm{Ca}, \mathrm{Ti}\end{array}$ \\
\hline GN1-2 & A & 9 & $\begin{array}{l}\text { 2 hard samples, each consisting of: } 1) \\
\text { a partial crust covering; above 2) a thin } \\
\text { red layer; above 3) a translucent matrix }\end{array}$ & $\mathrm{SiO}_{2^{\prime}}, \mathrm{AlFePO}_{4^{\prime}}, \mathrm{Fe}_{2} \mathrm{O}_{3}$ & $\begin{array}{l}\mathrm{Na}, \mathrm{Mg}, \mathrm{S}, \mathrm{K}, \\
\mathrm{Ca}, \mathrm{Ti}\end{array}$ \\
\hline
\end{tabular}




\begin{tabular}{|c|c|c|c|c|c|}
\hline Sample \# & Panel & Image \# & Description & Major compounds & $\begin{array}{l}\text { Minor and trace } \\
\text { elements }\end{array}$ \\
\hline GN1-3 & $A$ & 10 & $\begin{array}{l}6 \text { compact and hard samples, each } \\
\text { consisting of a thin red layer above a } \\
\text { hard white matrix }\end{array}$ & $\mathrm{SiO}_{2^{\prime}} \mathrm{AlFePO}_{4^{\prime}} \mathrm{Fe}_{2} \mathrm{O}_{3^{\prime}} \mathrm{CaSO}_{4}$ & $\begin{array}{l}\mathrm{Na}, \mathrm{Mg}, \mathrm{K}, \mathrm{Ti}, \mathrm{V}, \\
\mathrm{Cr}, \mathrm{Mn}, \mathrm{Zn}, \mathrm{Rb}, \\
\mathrm{Sr}, \mathrm{Zr}, \mathrm{Ba}\end{array}$ \\
\hline GN1-4 & $A$ & 6,9 & $\begin{array}{l}3 \text { very hard samples, each consisting of } \\
\text { a thin red layer above a white matrix }\end{array}$ & $\mathrm{SiO}_{2^{\prime}} \mathrm{AlFePO}_{4^{\prime}} \mathrm{Fe}_{2} \mathrm{O}_{3^{\prime}}, \mathrm{FeOOH}$ & $\begin{array}{l}\mathrm{Na}, \mathrm{Mg}, \mathrm{S}, \mathrm{K}, \mathrm{Cl} \\
\mathrm{Ca}, \mathrm{Ti}, \mathrm{V}, \mathrm{Cr}, \mathrm{Mn}, \\
\mathrm{Zn}, \mathrm{Rb}, \mathrm{Sr}, \mathrm{Zr}, \mathrm{Ba} \\
\end{array}$ \\
\hline GN1-5 & A & 1 & $\begin{array}{l}2 \text { very hard samples, each consisting of: } \\
\text { 1) small grey concretions; above 2) a } \\
\text { thin red layer; above 3) a white matrix }\end{array}$ & $\mathrm{SiO}_{2}$, aluminosilicate, $\mathrm{Fe}_{2} \mathrm{O}_{3}$ & $\begin{array}{l}\mathrm{Na}, \mathrm{Mg}, \mathrm{P}, \mathrm{S}, \mathrm{K}, \\
\mathrm{Cl}, \mathrm{Ca}, \mathrm{Ti}, \mathrm{Mn}, \mathrm{Zn}, \\
\mathrm{Sr}, \mathrm{Zr}, \mathrm{Ba}\end{array}$ \\
\hline GN1-6 & $A$ & 2 & $\begin{array}{l}4 \text { very hard samples, each consisting of: } \\
\text { 1) an opaque crust layer; above } 2 \text { ) a thin } \\
\text { red layer; above } 3 \text { ) a white matrix }\end{array}$ & $\begin{array}{l}\mathrm{SiO}_{2 \prime} \text { aluminosilicate, } \mathrm{Fe}_{2} \mathrm{O}_{3^{\prime}} \\
\mathrm{FeOOH}\end{array}$ & $\begin{array}{l}\mathrm{Na}, \mathrm{Mg}, \mathrm{P}, \mathrm{S}, \mathrm{K}, \\
\mathrm{Ca}, \mathrm{Ti}, \mathrm{Mn}, \mathrm{Sr}, \\
\mathrm{Zr}, \mathrm{Ba}\end{array}$ \\
\hline GN1-8 & A & 11 & $\begin{array}{l}3 \text { samples each consisting of a thin layer } \\
\text { of yellow paint on the } 2 \text { faces of a small } \\
\text { rock that originally protruded from the } \\
\text { rock wall, with a white matrix inside }\end{array}$ & $\mathrm{SiO}_{2^{\prime}} \mathrm{AlFePO}_{4^{\prime}} \mathrm{Fe}_{2} \mathrm{O}_{3^{\prime}}, \mathrm{FeOOH}$ & $\mathrm{Na}, \mathrm{Mg}, \mathrm{S}, \mathrm{K}$, Ca \\
\hline GN1-9 & $D$ & 51 & $\begin{array}{l}3 \text { samples consisting of a thin red layer } \\
\text { above a white, translucent matrix }\end{array}$ & $\mathrm{SiO}_{2^{\prime}} \mathrm{AlFePO}_{4^{\prime}} \mathrm{CaSO}_{4^{\prime}} \mathrm{K}$ clay & $\mathrm{Na}, \mathrm{Mg}, \mathrm{Ti}$ \\
\hline GN1-11 & $A$ & 5,9 & $\begin{array}{l}4 \text { samples consisting of thin scattered } \\
\text { red areas above a translucent matrix } \\
\text { with large quartz crystals }\end{array}$ & $\mathrm{SiO}_{2^{\prime}} \mathrm{AlFePO}_{4^{\prime}} \mathrm{Fe}_{2} \mathrm{O}_{3^{\prime}} \mathrm{CaSO}_{4}$ & $\begin{array}{l}\mathrm{Na}, \mathrm{Mg}, \mathrm{K}, \mathrm{Cl}, \mathrm{Ti}, \\
\mathrm{Mn}, \mathrm{Zn}, \mathrm{Sr}, \mathrm{Cl}, \\
\mathrm{La}, \mathrm{Zr}, \mathrm{Ba}\end{array}$ \\
\hline GN1-16 & C & 49 & $\begin{array}{l}2 \text { hard samples each consisting of a thin } \\
\text { red layer above a porous white matrix }\end{array}$ & $\begin{array}{l}\mathrm{SiO}_{2^{\prime}} \mathrm{MgCO}_{3^{\prime}} \mathrm{AlFePO}_{4^{\prime}} \mathrm{Fe}_{2} \mathrm{O}_{3^{\prime}} \\
\mathrm{K} \text { clay }\end{array}$ & $\mathrm{Na}, \mathrm{S}, \mathrm{Ti}, \mathrm{Mn}$ \\
\hline GN1-17 & E & 58 & $\begin{array}{l}2 \text { samples consisting of a thin red layer } \\
\text { above a translucent matrix with large } \\
\text { quartz crystals }\end{array}$ & $\mathrm{SiO}_{2^{\prime}} \mathrm{AlFePO}_{4^{\prime}} \mathrm{Fe}_{2} \mathrm{O}_{3}$ & $\mathrm{Na}, \mathrm{S}, \mathrm{K}, \mathrm{Ca}, \mathrm{Ti}$ \\
\hline GN1-19 & A & 20 & $\begin{array}{l}1 \text { sample consisting of a very thin } \\
\text { translucent layer of red above a } \\
\text { translucent matrix }\end{array}$ & $\mathrm{SiO}_{2}, \mathrm{BaSO}_{4}, \mathrm{AlFePO}_{4}$ & $\mathrm{Mg}, \mathrm{Cl}, \mathrm{K}, \mathrm{Ca}$ \\
\hline
\end{tabular}

Source: Author's data.

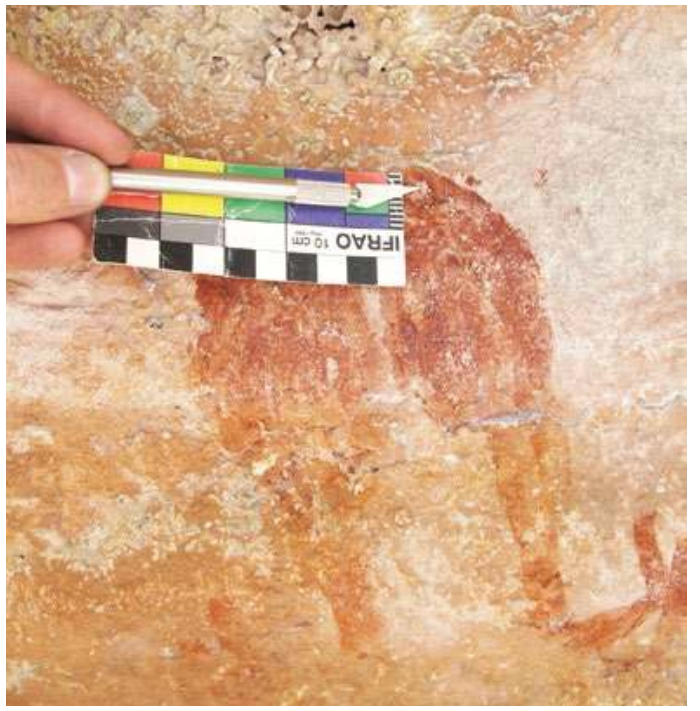

Figure 15.20 Panel D, Image \#51: The position of sample GN1-9 is marked by the tip of the scalpel blade.

Source: Photograph by Elisa Boche.

\section{Analytical methods}

Scanning electron microscopy with energydispersive X-ray spectroscopy (SEM-EDX) was carried out with a LEO Stereoscan 440 SEM with SEM-FEG (ZEISS-Ultra+ from the Institut Néel in Grenoble, France) in highvacuum mode at $20 \mathrm{kV}$, both instruments equipped with a Brucker SDD X-FLASH 4030 EDX for chemical analyses. Raman spectra were obtained with a laser at $514 \mathrm{~cm}^{-1}$ using a Jobin-Yvon-Horiba T640000 equipped with a microscope with three lenses $(\times 10$, $\times 50$ and $\times 100$ magnification) from Institut Néel. Major, minor and trace elements were quantified by particle induced X-ray emission (PIXE) analysis on the external microbeam of a 3MV tandem accelerator. The X-ray diffraction (XRD) computed tomography experiment was performed at the Institut Néel (Cersoy et al. 2015). 
The samples obtained from Panels A, C, D and E exhibit comparable micro-stratigraphies under optical magnification. In each case, these consist of 1) an underlying large white opaque or translucent matrix, superimposed by 2) a thin red or yellow layer of paint pigment (e.g. Figures 15.21 and 15.22). Three samples (GN1-2, GN1-5 and GN1-6) each exhibit an additional outer (surface) crust layer that entirely or partially covers and protects the paint layer.

The cross-section of sample GN1-4, originating from the intersection of Images \#6 and \#9, reveals a succession of 1) an underlying white matrix, covered by 2) a discontinuous yellowish layer, superimposed by 3) a layer of light red, itself superimposed by 4) a thin layer of dark red of similar thickness to the light red layer below it.

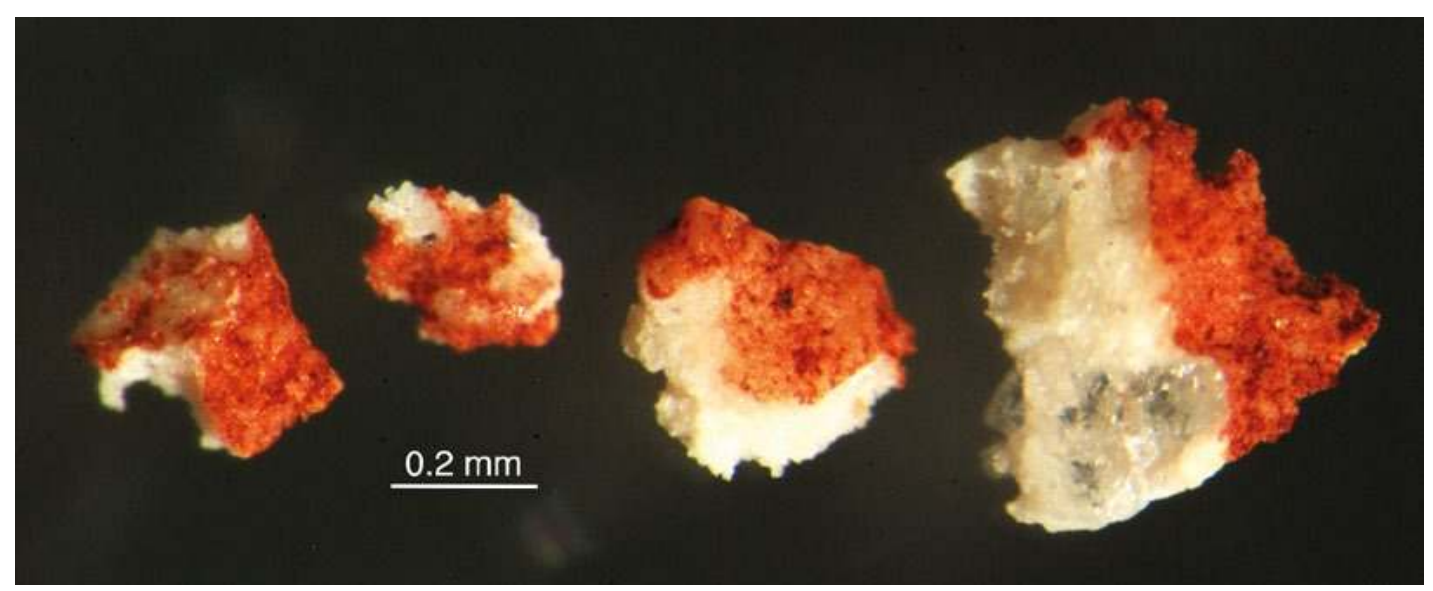

Figure 15.21 Four samples (together comprising GN1-11) from the intersection of the spear painting (Image \#9) and large bird motif (Image \#5).

Source: Photograph by Emilie Chalmin.
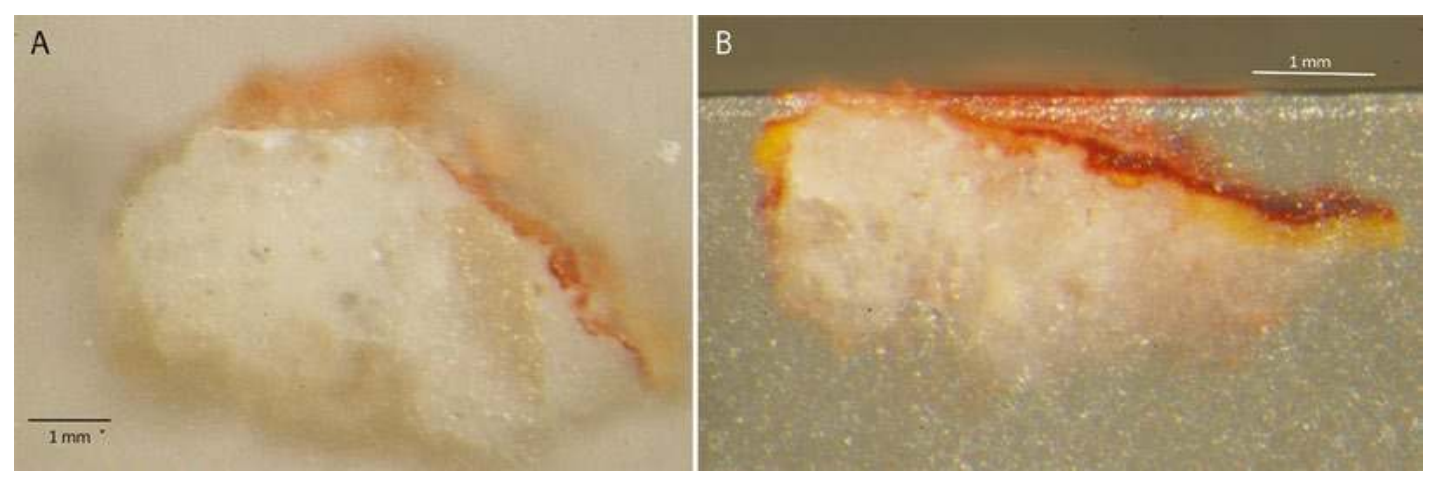

Figure 15.22 Cross-sections from Panel A.

A: Sample GN1-2, from the spear painting (Image \#9) associated with the large bird motif. B: Sample GN1-4, from the anthropomorph (Image \#6) and spear (Image \#9).

Source: Photographs by Géraldine Castets.

\section{The underlying rock matrix}

In each sample, the relatively thick white rock matrix that underlies the layer of paint is mainly opaque and can include more or less large translucent crystals of quartz 100-500 $\mu \mathrm{m}$ long. The presence of quartz is confirmed by the chemical composition of the crystals $\left(\mathrm{SiO}_{2}\right)$ and by their structure as revealed by both Raman micro-spectroscopy and XRD. The nature of the white opaque matrix is more difficult to identify due to its weak crystallinity. SEM-EDX chemical mapping across several cross-sections reveals an extensive matrix containing mainly $\mathrm{Al}, \mathrm{P}$ and 
$\mathrm{K}$, with minor $\mathrm{Na}$ and $\mathrm{Mg}$, in which are found small crystals of $\mathrm{SiO}_{2}\left(<50 \mu \mathrm{m}\right.$ long), $\mathrm{TiO}_{2}$ (c. $10 \mu \mathrm{m}$ long) and $\mathrm{CaSO}_{4}$ (c. $10 \mu \mathrm{m}$ long) (Figure 15.23). Tiny inclusions are also observed in this large matrix, including zircon $\left(\mathrm{ZrSiO}_{4}\right)$, barium sulphate $\left(\mathrm{BaSO}_{4}\right)$, compounds of $\mathrm{Sr}$ and, less commonly, $\mathrm{Ce}$ and La (only observed for sample GN1-11). All these associated chemistries are consistent with the composition of the quartzite bedrock.

Both the bedrock and the white matrix contain all of the above elements and compounds, but these occur in higher concentrations within the white matrix than in the bedrock. These higher concentrations are a result of the dissolution and redeposition of bedrock chemistries into the white matrix (Chalmin et al. 2017; Wray 2013). The white matrix is also composed of high proportions of alumino-potassic-phosphate, a compound that is not present in the bedrock. The alumino-potassic-phosphate is here identified as leucophosphite $\left(\mathrm{K}(\mathrm{Fe}, \mathrm{Al})_{2}\left(\mathrm{PO}_{4}\right)_{2}(\mathrm{OH})\right.$ $\left(\mathrm{H}_{2} 0\right)$ ), with a small percentage of $\mathrm{Fe}$ substituting for $\mathrm{Al}$, as determined by XRD-computed tomography on sample GN1-3 (Chalmin et al. 2015, 2017). The presence of leucophosphite in the white matrix enhances adherence of the overlying red paint onto the white matrix.
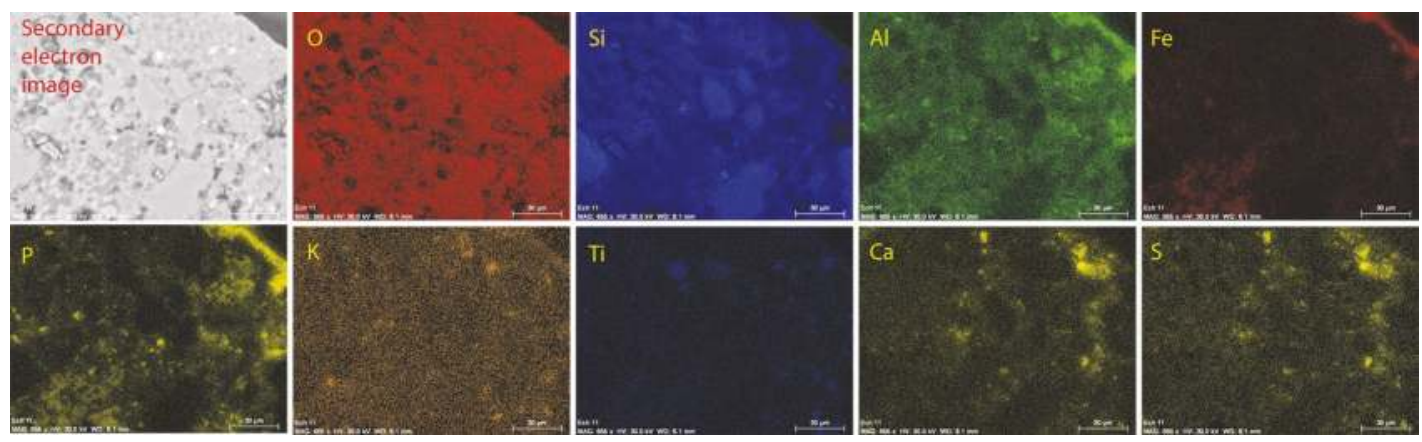

Figure 15.23 SEM-EDX (ZEISS-Ultra+, $30 \mathrm{kV}$ ) chemical mapping across the cross-section of sample GN1-11.

Source: Photographs by Emilie Chalmin.

Raman analyses on a number of samples reveal both chemical and structural evidence of gypsum $\left(\mathrm{CaSO}_{4} 2 \mathrm{H}_{2} \mathrm{O}\right)$. The gypsum is confirmed for samples GN1-3, GN1-4, GN1-5, GN1-6, GN1-8 and GN1-11; all are from Panel A. Additionally, even if this gypsum compound is not clearly identified for the samples coming from the two macropods (GN1-1, GN1-2), the presence of both elements $\mathrm{Ca}$ and $\mathrm{S}$ is consistent with its presence. Gypsum sometimes occurs as small crystals embedded within the white matrix (e.g. in sample GN1-11), and sometimes as a homogeneous sublayer between the white matrix and the overlying pigment layer (e.g. in sample GN1-3).

Optical microscopy reveals that black particles a few microns long are embedded in the white matrix of almost all samples. Raman analysis indicates that these are black soot, probably from landscape fires (cf. Gunn 2011).

\section{The paint layers}

The colour intensity of the paint layer relates closely to the thickness of the layer and thus to the quantity of paint. The chemical mapping as observed by the SEM-EDX in back-scattered electron (BSE) mode further confirms this close correlation between the intensity of red colouring (highlighting the red paint layer) and the incidence of iron in sample cross-sections. The spatial patterning of element distributions across sample cross-sections allows for an enhanced characterisation of the micro-stratigraphy of individual samples as well as a better determination of the thickness of each layer. The thickness of the paint layer varies from $3 \mu \mathrm{m}$ to $360 \mu \mathrm{m}$ between samples. The thickest paint layers occur in samples where the paint layer is capped by 
a mineral crust that protects the paint from leaching away. In many samples, the paint layer is well preserved in the micro-pores or micro-fractures of the bedrock's surface. Nevertheless, wherever a paint layer is found, it is particularly thin and it occurs close to the surface of the rock wall. The thinness of all the paint layers is largely explained by some degree of leaching of the rock wall surface. However, strong adhesion of paint matter on and in the rough rock surface has allowed for the preservation of paintings over considerable periods of time. In no sample did optical microscopy or chemical mapping reveal more than a single layer of paint in any of the cross-sections, except for sample GN1-4 that exhibits three layers of paint (see below). The chemical mapping carried out on the cross-sections confirms the absence of diffusion of pigment into the surrounding matrix, but rather suggests that paint layers on or near the rock surface exhibit considerable degrees of adherence and stability.

Raman micro-spectroscopy confirms the presence of essentially 'pure' iron oxides as the paint layers (but see below for associated trace elements observed independently): haematite $\left(\mathrm{Fe}_{2} \mathrm{O}_{3}\right)$ for the red pigment and goethite $(\mathrm{FeOOH})$ for the yellow (Figure 15.24).

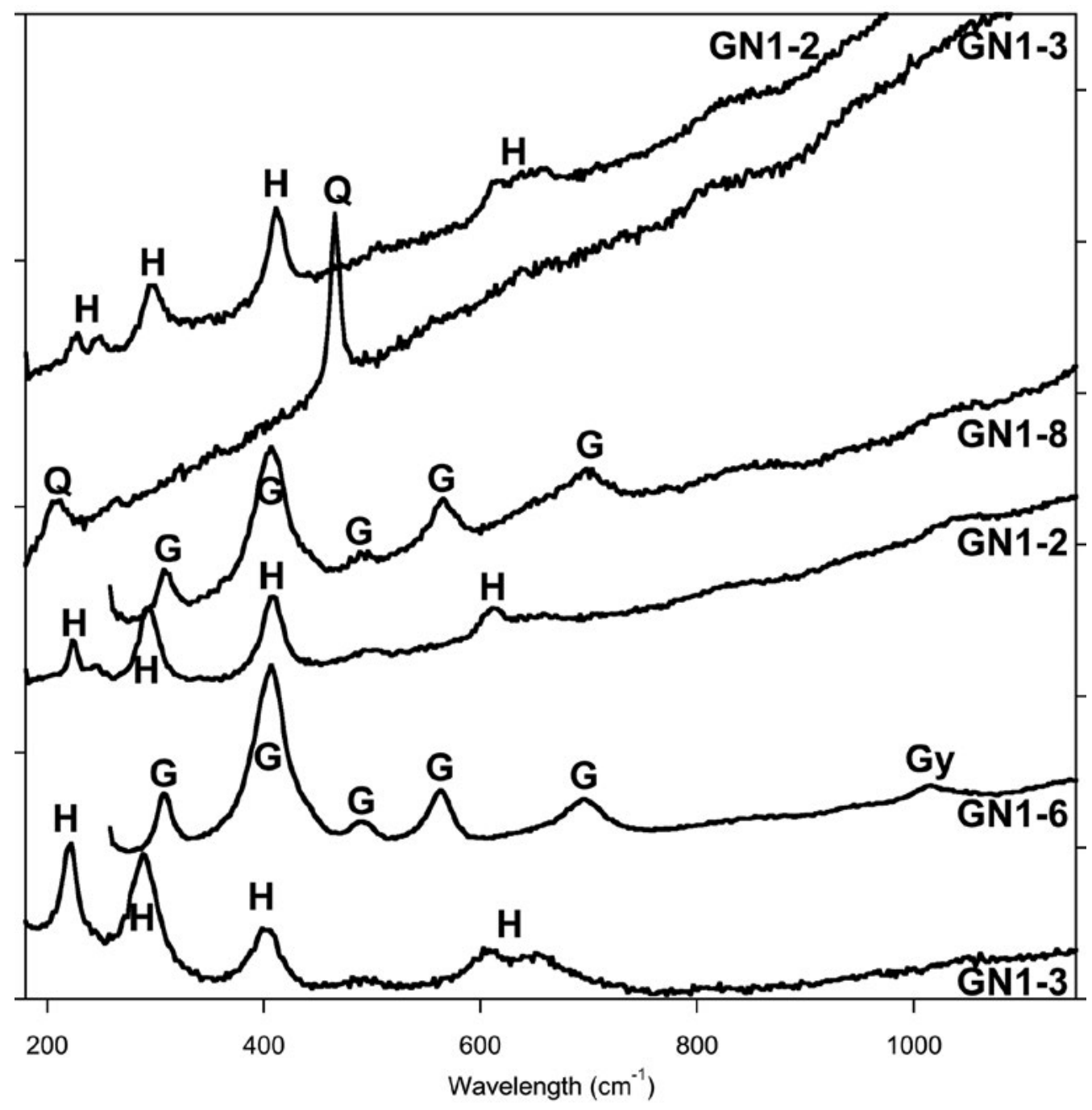

Figure 15.24 Raman spectra obtained on samples GN1-2, GN1-3, GN1-6 and GN1-8, revealing the presence of haematite $(H)$, goethite $(G)$, quartz $(Q)$ and gypsum (Gy).

Source: Illustration by Emilie Chalmin. 
The morphology of the haematite crystals is particularly difficult to observe due to their small size $(<1 \mu \mathrm{m}$ long). The good resolution of the SEM-FEG enables recognition of hexagonal sheets of haematite.

PIXE analyses on the paint layers reveal similar proportions of trace elements $\mathrm{Mn}, \mathrm{V}, \mathrm{Zn}$ and $\mathrm{Rb}$ in samples GN1-3, GN1-4, GN1-5, GN1-6 and GN1-11 (see Table 15.2). These elements are found together with the iron oxides; these associations have the potential to inform on whether or not the pigments have a common origin. The occurrence of these trace elements in similar proportions between samples suggests the employment of very similar paints in Images \#1, \#2, \#5 (the large bird motif), \#9 and \#10 (the large waterbird) on Panel A. The chemistry of this paint could, but does not necessarily, consist of the pigment from ochre crayons alone.

\section{The crusts}

The thin white or grey mineral crust that in some samples overlies the paint layer could have formed from a number of possible processes. The crust's white deposit is similar in composition to the white matrix that underlies the paint layer, and could thus represent a remobilisation of the weathered rock. Some grey crusts overlying paint layers are mainly composed of precipitated $\mathrm{NaCl}$ salt. In our analyses, organic compounds such as oxalates are not clearly detected by Raman micro-spectroscopy; only some unidentified bands in the spectra may suggest the presence of organic compounds. Gypsum is only detected as a layer immediately underneath paint layers. The surface of sample GN1-16 - from one of the birds (Image \#49) on Panel C - is covered with white magnesium salt (probably $\mathrm{MgCO}_{3}$ ), making the underlying red pigment's colour lighter than on the other panels.

\section{Discussion of geochemistry}

Physico-chemical analyses of rock art on four painted panels at JSARN-124 site 3 highlight the use of iron oxides as pigment, with both haematite and goethite having been employed. The small size of the iron oxide crystals, the micro-stratigraphy of the samples and the complex post-art mixing of minerals originating from weathering of the rock and from salt precipitates make it difficult to further characterise the pigment observed as very thin paint layers. Despite the fact that a number of colours were observed, there is a general homogeneity in the chemistry of the pigment layers (and therefore of the analysed paintings). However, the presence of some impurities (trace elements or minor differences) in several samples suggests that some iron oxides may have originated from different sources, or that a number of paint mixtures may have been used. A number of distinct red paint pastes can thus be distinguished among the paintings at JSARN-124 site 3, with Images \#1, \#2, \#5, \#9 and \#10 from Panel A having different characteristics to those of Images \#49 and \#51 from Panels C and D.

The physico-chemical analysis is not able to provide definitive information on the actual age of these paintings (but see below). As to the relative chronology of the layers of paint observed in many of the samples, the cross-sections have revealed a single paint layer on or very near the surface. These paint layers are very thin and in only one case do they show evidence of multiple painting events, although the thinness of the paint layers and their proximity to the surface would not always permit detection of multiple painting events using single colours. More specifically, in sample GN1-11, where the painting of the spear (Image \#9) intersects the large bird motif (Image \#5), there are no signs of two separate layers of red paint in cross-section, but rather the red paint appears as a single, merged layer. This observation - and the absence of any crust development between two layers of paint - suggests that the spear and the large bird were probably painted at approximately the same time. 
In the only sample exhibiting evidence of multiple paint layers, sample GN1-4 from the intersection of the spear (Image \#9) and the large anthropomorph (Image \#6), a layer of dark red and a separate layer of light red indicate two different painting events. It is not possible from the cross-sections alone to determine which of the two layers relates to 1) the spear (Image \#9) and 2) the anthropomorph (Image \#6). However, the dark red of the spear visually corresponds in colour to the upper, dark-red layer, while the light red of the anthropomorph corresponds in colour to the underlying, light-red layer. We therefore conclude that the spear overlies the anthropomorph, which is consistent with the pattern of superimposition evident from the D-Stretch enhancement (see Figure 15.6).

We may even say a little more about the relative age of the spear and anthropomorph paintings by reference to the relative thickness of their paint layers (the dark- and light-red layers respectively). As noted above, across the site as a whole, those samples with a protective surface crust have a noticeably thicker underlying paint layer than those without a crust. Sample GN1-4 does not have a protective crust on its surface. However, the dark-red layer acts as a protective veneer over the light-red layer, by the fact that it overlies it. That the two red layers of sample GN1-4 are of similar thickness, and that the uppermost, dark-red layer is currently exposed to the elements (i.e. devoid of a protective crust), suggests that the underlying light-red layer was originally thicker than it is now, having been slowly removed by minor water-wash and other forms of weathering over time. That is, we suggest that the two layers of red pigment were not painted in a single artistic event, but rather that some reasonable amount of time elapsed between the two painting events.

The discontinuous yellow layer under both the red layers is diffuse, making it difficult to determine whether it is a layer of pigment in its own right (i.e. representing a yellow painting that is too faded, weathered away or covered by subsequent paintings to see on Panel A today) or the product of alteration of the white matrix through weathering. It is unlikely to represent the 'bleeding' of the overlying red layer in contact with the white matrix, because in all other crosssections the pigment layers have relatively distinct boundaries when in contact with the white matrix, indicating great stability of the well-adhered pigment.

The presence of gypsum as a thin layer of crystalised salt below the pigment layers across the span of Panel A, as well as on Panels D and E, can be attributed to a period when salts were being leached out of the bedrock and re-deposited on the rock face through the prolonged condensation of water, prior to the making of the paintings. Prior to the artworks, the rock surface thus contained a thin, extensive but discontinuous crust of gypsum on its surface. This discontinuous crust layer induces a subsequent spalling effect, as observed locally on the present surface of Panel A (Doehne 2002; Hernanz et al. 2007). As previously documented at other rock art sites (Goodall et al. 2009; Hernanz et al. 2007), gypsum efflorescence tends to weaken the stability of rock surfaces. Elsewhere, in northeastern Australia, Goodall et al. (2009) have previously interpreted the presence of gypsum in stratified micro-layers over or under rock art as an indicator of dry climatic conditions, due to exposed gypsum's solubility in water during wetter conditions.

Overall, these results cannot falsify the idea that the oldest paintings at JSARN-124 site 3, including the large bird motif itself and its associated spear painting, have a late Pleistocene antiquity. Rather, these analyses indicate that 1 ) the paintings were made after a dry phase (see below for a more refined interpretation); and 2) they theoretically could have survived on such a surface over a very long period of time. As far as the chemistry is concerned, whether they did or did not remains in question. 


\section{Archaeological excavations}

Most of the art, including the large bird motif, occurs on Panel A along the northern side of the site. Our original objective was to excavate directly underneath the large bird motif, hoping we might retrieve exfoliated or otherwise collapsed fragments of rock by which to obtain stratigraphically a maximum age for the creation of the subsequently painted rock wall surface, and exfoliated spalls with traces of ochre from which to obtain minimum ages for the on-wall art, or in situ ochre crayons potentially dating the large bird motif overhead (for a comparable methodology, see Chapter 14). As noted above, the small overhang above the large bird motif measures just $1.5 \mathrm{~m}$ deep, but was once part of a larger overhang that has since collapsed (see below for details). Unfortunately, the collapsed overhang prevented any excavation from taking place directly below the art, and indeed precluded any excavation on the northern side of the outcrop (Figures 15.3 and 15.25). Consequently, five excavation squares were positioned elsewhere around the site: Squares $\mathrm{A}$ and $\mathrm{C}$ were located under a pronounced overhang on the eastern side, and Squares B, $\mathrm{D}$ and $\mathrm{E}$ on the western side against the near-vertical rock wall (Figure 15.3). The positioning of the squares was determined by their proximity to nearby art panels, perceived depths of deposits and potential to elucidate chronological and contextual details of the large bird motif panel a few metres away. Squares A, B, C and D each measured $50 \times 50 \mathrm{~cm}$; Square E was $1.2 \times 1.0 \mathrm{~m}$ in size. Excavated sediments were dry-sieved on-site in $2 \mathrm{~mm}$ mesh, and unsieved bulk sediment samples were collected from each XU of every square. The sieved sediments were subsequently sorted and analysed at the University of Southern Queensland archaeology laboratory. Munsell colour attribution and $\mathrm{pH}$ tests were carried out on bulk samples in the laboratory.

We present below the results of the excavations one square at a time.

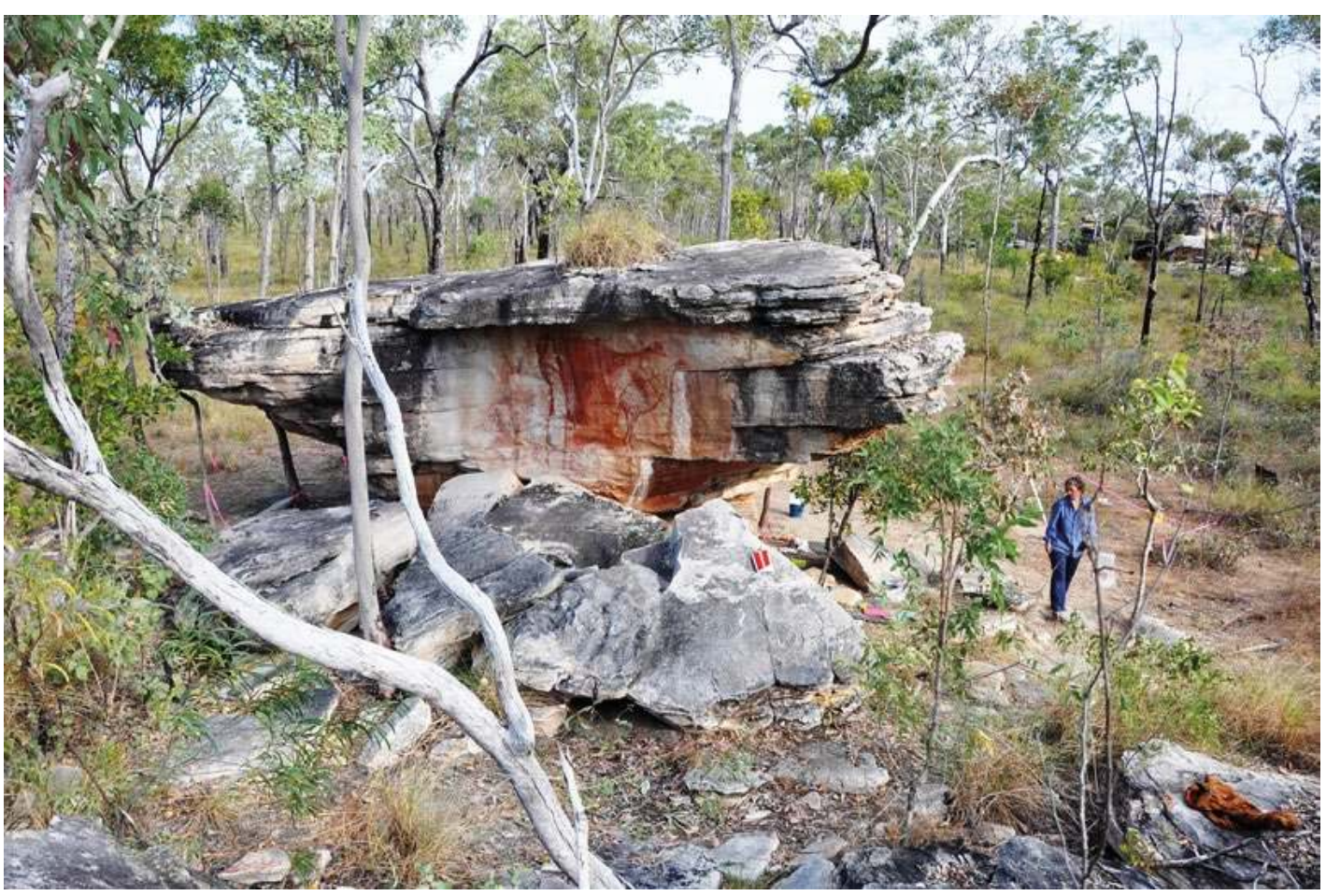

Figure 15.25 Main art panel (Panel A), showing collapsed overhang fronting the artworks.

Source: Photograph by Bryce Barker. 


\section{Square A}

Square A square was positioned on the closest excavatable deposit to the large bird motif, which is located c. $5 \mathrm{~m}$ to the northwest of the square. The northern side of Square A was positioned $60 \mathrm{~cm}$ to the east of Panel B, directly below a large, slightly overhanging, collapsed quartzite rock slab exhibiting evidence of flaking just above ground level (Figure 15.26).

\section{Stratigraphy}

Excavation progressed to a maximum depth of $11 \mathrm{~cm}$ before encountering the flat bedrock surface (Table 15.3). Two stratigraphic units (SUs) are evident in Square A. SU1, from the ground surface down to a maximum depth of $5 \mathrm{~cm}$ in the southwestern corner of the square, consists of loose, homogenous weak-red (2.5YR 5/3) fine sand containing stone artefacts and small pieces of charcoal. SU2 below it is a more compact, pale-brown (10YR 6/3) sand (Figure 15.27).

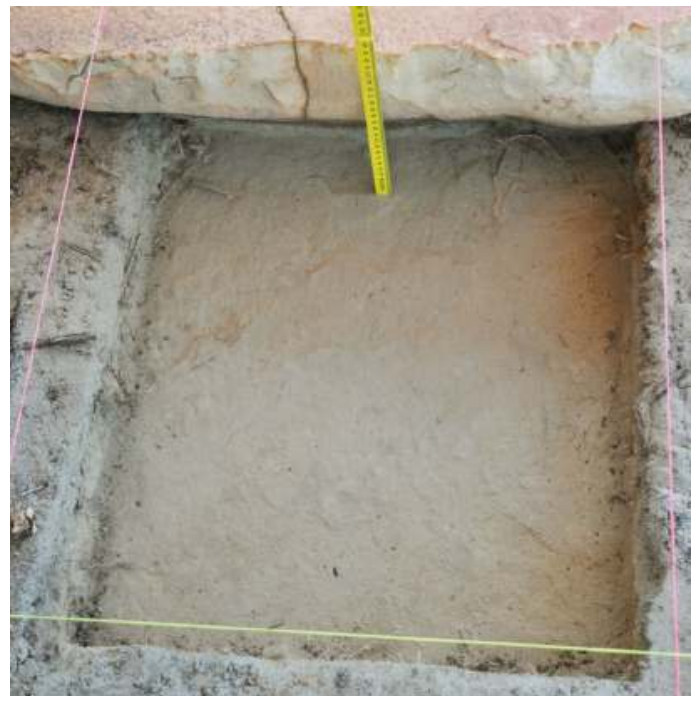

Figure 15.26 Square A after completion of excavation.

The green string marks the southern end of the square. Note negative flake scars on the rock slab at the northern end. Source: Photograph by Lara Lamb.

Table 15.3 Details of Square A excavation, by XU.

\begin{tabular}{|l|l|r|r|r|r|r|r|}
\hline XU & SU & $\begin{array}{c}\text { Mean depth } \\
\text { at top }(\mathrm{cm})\end{array}$ & $\begin{array}{c}\text { Mean depth at } \\
\text { centre }(\mathrm{cm})\end{array}$ & $\begin{array}{c}\text { Mean depth } \\
\text { at base }(\mathrm{cm})\end{array}$ & $\begin{array}{c}\text { Mean } \\
\text { thickness }(\mathrm{cm})\end{array}$ & $\begin{array}{c}\text { Weight of excavated } \\
\text { sediments (kg) }\end{array}$ & $\begin{array}{l}\text { Volume of excavated } \\
\text { sediments (litres) }\end{array}$ \\
\hline 1 & 1 & 0.0 & 0.6 & 1.1 & 1.1 & 3.2 & 2.5 \\
\hline 2 & $1 / 2$ & 1.1 & 2.1 & 3.2 & 2.1 & 8.3 & 6.0 \\
\hline 3 & $1 / 2$ & 3.2 & 3.8 & 4.4 & 1.2 & 4.5 & 3.0 \\
\hline 4 & $1 / 2$ & 4.4 & 5.6 & 6.8 & 2.4 & 10.0 & 7.0 \\
\hline 5 & 2 & 6.8 & 8.1 & 9.4 & 2.6 & 9.4 & 22.5 \\
\hline \multicolumn{2}{|l|}{ Total } & & & & 1.9 & 35.4 & \\
\hline
\end{tabular}

Source: Author's data.

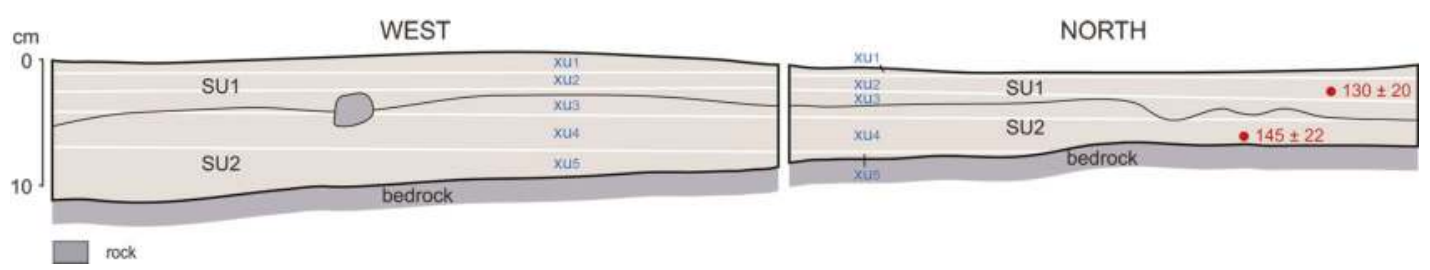

Figure 15.27 Square A west and north section drawings, with back-plotted XUs and radiocarbon dates. Source: Illustration by Kara Rasmanis and Bruno David.

\section{Chronology}

Two accelerator mass spectrometry (AMS) radiocarbon dates on individual pieces of charcoal obtained in situ and plotted in three dimensions (3-D) were obtained from Square A (Table 15.4):

- $130 \pm 20$ BP (Wk-40575), from XU2 at a depth of $1.5 \mathrm{~cm}$ below ground.

- $145 \pm 22$ BP (Wk-40576), from XU4 at a depth of $5.5 \mathrm{~cm}$. This represents the deepest charcoal observed in situ during the excavation. 
Table 15.4 Radiocarbon determinations from Squares A-E.

\begin{tabular}{|c|c|c|c|c|c|c|c|c|}
\hline$X U$ & SU & $\begin{array}{l}\text { Depth } \\
(\mathrm{cm})\end{array}$ & $\begin{array}{l}\text { Wk- laboratory } \\
\text { code }\end{array}$ & $\%$ modern & $\begin{array}{c}{ }^{14} \text { ( age } \\
\text { (years BP) }\end{array}$ & $\begin{array}{l}\text { Calibrated age BP } \\
\text { (68.3\% probability) }\end{array}$ & $\begin{array}{l}\text { Calibrated age BP } \\
\text { (95.4\% probability) }\end{array}$ & $\begin{array}{l}\text { Median } \\
\text { calibrated } \\
\text { age BP } \\
\end{array}$ \\
\hline \multicolumn{9}{|c|}{ Square A } \\
\hline 2 & 1 & 1.5 & 40575 & $98.4 \pm 0.2$ & $130 \pm 20$ & $\begin{array}{r}15-35 \\
71-117 \\
132-145 \\
214-229 \\
251-267 \\
\end{array}$ & $\begin{array}{r}11-42 \\
59-149 \\
186-270\end{array}$ & 104 \\
\hline 4 & 2 & 5.5 & 40576 & $98.2 \pm 0.3$ & $145 \pm 22$ & $\begin{array}{r}10-32 \\
83-97 \\
108-112 \\
137-150 \\
174-177 \\
185-224 \\
255-272 \\
\end{array}$ & $\begin{array}{r}5-37 \\
65-118 \\
124-152 \\
169-231 \\
243-281\end{array}$ & 138 \\
\hline \multicolumn{9}{|c|}{ Square B } \\
\hline 4 & 2 & 8.1 & 40577 & $81.6 \pm 0.2$ & $1632 \pm 20$ & $1526-1555$ & $\begin{array}{l}1418-1461 \\
1484-1489 \\
1517-1569 \\
1584-1598 \\
\end{array}$ & 1503 \\
\hline 8 & 2 & 14.9 & 40578 & $82.2 \pm 0.2$ & $1575 \pm 20$ & $\begin{array}{l}1415-1446 \\
1452-1464 \\
1478-1505 \\
1514-1522\end{array}$ & $1411-1526$ & 1468 \\
\hline 10 & 2 & 19.9 & 40579 & $80.9 \pm 0.2$ & $1702 \pm 20$ & $1564-1618$ & $\begin{array}{l}1553-1629 \\
1655-1692 \\
\end{array}$ & 1642 \\
\hline 12 & 3 & 22.6 & 40580 & $75.6 \pm 0.2$ & $2248 \pm 20$ & $\begin{array}{l}2184-2198 \\
2202-2233 \\
2305-2328 \\
\end{array}$ & $\begin{array}{l}2159-2252 \\
2300-2338\end{array}$ & 2276 \\
\hline 14 & 3 & 26.2 & 40581 & $57.2 \pm 0.1$ & $4482 \pm 20$ & $\begin{array}{l}5049-5069 \\
5109-5124 \\
5167-5198 \\
5211-5276 \\
\end{array}$ & $\begin{array}{l}5041-5092 \\
5097-5143 \\
5157-5286\end{array}$ & 5120 \\
\hline 17 & 3 & 36.3 & 40582 & $33.1 \pm 0.1$ & $8882 \pm 30$ & $\begin{array}{r}9921-9960 \\
9987-10,043 \\
10,055-10,095 \\
10,113-10,150 \\
\end{array}$ & $9901-10,171$ & 10,036 \\
\hline 19 & 3 & 40.4 & 32128 & $22.5 \pm 0.1$ & $11,983 \pm 35$ & $\begin{array}{l}13,748-13,848 \\
13,908-13,933\end{array}$ & $13,739-13,976$ & 13,857 \\
\hline \multicolumn{9}{|c|}{ Square C } \\
\hline 3 & 2 & 6.8 & 40583 & $96.3 \pm 0.2$ & $303 \pm 20$ & $\begin{array}{l}306-320 \\
379-427\end{array}$ & $\begin{array}{l}302-333 \\
351-436\end{array}$ & 342 \\
\hline 7 & 2 & 15.0 & 40584 & $92.5 \pm 0.2$ & $630 \pm 20$ & $\begin{array}{l}561-573 \\
577-595 \\
634-652 \\
\end{array}$ & $\begin{array}{l}556-607 \\
624-660\end{array}$ & 615 \\
\hline 8 & 2 & 17.0 & 40585 & $73.8 \pm 0.2$ & $2444 \pm 25$ & $\begin{array}{l}2380-2394 \\
2403-2412 \\
2423-2495 \\
2597-2611 \\
2638-2684\end{array}$ & $\begin{array}{l}2380-2394 \\
2403-2412\end{array}$ & 2398 \\
\hline \multicolumn{9}{|c|}{ Square D } \\
\hline 4 & 2 & 4.0 & 40586 & $98.9 \pm 0.2$ & $89 \pm 20$ & $\begin{array}{r}34-71 \\
116-133 \\
228-252\end{array}$ & $\begin{array}{r}31-138 \\
223-256\end{array}$ & 180 \\
\hline
\end{tabular}




\begin{tabular}{|c|c|c|c|c|c|c|c|c|}
\hline$X U$ & SU & $\begin{array}{l}\text { Depth } \\
\text { (cm) }\end{array}$ & $\begin{array}{l}\text { Wk- laboratory } \\
\text { code }\end{array}$ & $\%$ modern & $\begin{array}{l}{ }^{14} \text { C age } \\
\text { (years BP) }\end{array}$ & $\begin{array}{l}\text { Calibrated age BP } \\
\text { (68.3\% probability) }\end{array}$ & $\begin{array}{l}\text { Calibrated age BP } \\
\text { (95.4\% probability) }\end{array}$ & $\begin{array}{c}\text { Median } \\
\text { calibrated } \\
\text { age BP }\end{array}$ \\
\hline 8 & 2 & 13.3 & 40587 & $94.5 \pm 0.2$ & $458 \pm 20$ & 504-517 & $498-527$ & 512 \\
\hline 11 & 2 & 20.9 & 40588 & $73.7 \pm 0.2$ & $2448 \pm 20$ & $\begin{array}{l}2384-2388 \\
2432-2497 \\
2595-2612 \\
2637-2687\end{array}$ & $\begin{array}{l}2361-2539 \\
2587-2616 \\
2632-2699\end{array}$ & 2601 \\
\hline 15 & 3 & 27.8 & 40589 & $73.6 \pm 0.2$ & $2459 \pm 20$ & $\begin{array}{l}2461-2508 \\
2529-2536 \\
2590-2615 \\
2634-2697\end{array}$ & $\begin{array}{l}2379-2415 \\
2420-2545\end{array}$ & 2417 \\
\hline 20 & 3 & 31.3 & 40590 & $36.2 \pm 0.1$ & $8160 \pm 27$ & $\begin{array}{l}9030-9094 \\
9100-9121\end{array}$ & $\begin{array}{l}9014-9138 \\
9174-9207 \\
9216-9245\end{array}$ & 9190 \\
\hline 22 & 3 & 41.3 & 40591 & $40.5 \pm 0.1$ & $7254 \pm 27$ & $\begin{array}{l}8014-8056 \\
8091-8110 \\
8118-8133 \\
8138-8154 \\
\end{array}$ & 8008-8161 & 8084 \\
\hline \multicolumn{9}{|c|}{ Square $\mathrm{E}$} \\
\hline 4 & 1 & 5.9 & 50535 & $98.2 \pm 0.3$ & $149 \pm 20$ & $\begin{array}{r}9-31 \\
138-151 \\
173-179 \\
182-223 \\
257-274 \\
\end{array}$ & $\begin{array}{r}3-35 \\
71-117 \\
132-153 \\
169-229 \\
251-282 \\
\end{array}$ & 142 \\
\hline 5 & 1 & 6.4 & 40536 & $98.0 \pm 0.2$ & $164 \pm 20$ & $\begin{array}{r}8-21 \\
144-151 \\
172-216 \\
267-278\end{array}$ & $\begin{array}{r}0-32 \\
83-89 \\
91-97 \\
108-112 \\
137-155 \\
166-224 \\
256-284 \\
\end{array}$ & 110 \\
\hline 6 & 2 & 7.4 & 40537 & $98.1 \pm 0.2$ & $156 \pm 20$ & $\begin{array}{r}9-24 \\
141-151 \\
173-220 \\
262-275\end{array}$ & $\begin{array}{r}0-33 \\
74-114 \\
136-153 \\
168-225 \\
254-283\end{array}$ & 144 \\
\hline 7 & 2 & 10.1 & 40538 & $97.5 \pm 0.2$ & $207 \pm 20$ & $\begin{array}{r}0-8 \\
151-172 \\
278-292\end{array}$ & $\begin{array}{r}0-13 \\
147-188 \\
198-212 \\
269-300\end{array}$ & 193 \\
\hline 9 & 2 & 15.2 & 40540 & $86.7 \pm 0.2$ & $1143 \pm 20$ & $\begin{array}{r}987-1031 \\
1048-1068\end{array}$ & $\begin{array}{r}977-1088 \\
1108-1143 \\
1160-1172\end{array}$ & 1125 \\
\hline 11 & 2 & 21.1 & 40541 & $85.5 \pm 0.2$ & $1256 \pm 22$ & $\begin{array}{l}1180-1187 \\
1204-1256\end{array}$ & $\begin{array}{c}1092-1108 \\
1129-1132 \\
1147-1158 \\
1173-1277\end{array}$ & 1139 \\
\hline 12 & 2 & 23.8 & 40574 & $87.0 \pm 0.2$ & $1121 \pm 20$ & $\begin{array}{r}982-1013 \\
1020-1035 \\
1044-1056 \\
\end{array}$ & $970-1063$ & 1016 \\
\hline 13 & 3 & 26.7 & 40542 & $56.7 \pm 0.2$ & $4551 \pm 23$ & $\begin{array}{l}5084-5102 \\
5139-5161 \\
5283-5311\end{array}$ & $\begin{array}{l}5061-5113 \\
5118-5184 \\
5218-5221 \\
5269-5316\end{array}$ & 5201 \\
\hline
\end{tabular}




\begin{tabular}{|l|c|c|r|r|r|r|r|r|}
\hline XU & SU & $\begin{array}{c}\text { Depth } \\
(\mathbf{c m})\end{array}$ & $\begin{array}{r}\text { Wk- laboratory } \\
\text { code }\end{array}$ & \% modern & $\begin{array}{r}{ }^{14} \text { C age } \\
\text { (years BP) }\end{array}$ & $\begin{array}{r}\text { Calibrated age BP } \\
(68.3 \% \text { probability })\end{array}$ & $\begin{array}{c}\text { Calibrated age BP } \\
(95.4 \% \text { probability })\end{array}$ & $\begin{array}{c}\text { Median } \\
\text { calibrated } \\
\text { age BP }\end{array}$ \\
\hline 13 & 3 & 26.4 & 40543 & $42.1 \pm 0.1$ & $6946 \pm 27$ & $\begin{array}{r}7727-7798 \\
7808-7823\end{array}$ & $7694-7839$ & 7766 \\
\hline 14 & 3 & 28.0 & 40544 & $31.4 \pm 0.1$ & $9314 \pm 33$ & $\begin{array}{r}10,444-10,450 \\
10,495-10,573\end{array}$ & $10,412-10,590$ & 10,609 \\
\hline 16 & 3 & 27.3 & 40546 & $31.8 \pm 0.1$ & $9205 \pm 32$ & $10,282-10,408$ & $10,254-10,437$ & 10,447 \\
\hline 18 & 3 & 29.6 & 40548 & $28.9 \pm 0.1$ & $9968 \pm 35$ & $11,272-11,405$ & $11,264-11,502$ & 11,512 \\
& & & & & & $11,457-11,465$ & $11,523-11,606$ & \\
\hline 15 & 3 & 30.3 & 40545 & $11.9 \pm 0.1$ & $17,113 \pm 83$ & $20,520-20,759$ & $20,407-20,905$ & 20,656 \\
\hline
\end{tabular}

All ${ }^{14} \mathrm{C}$ ages are AMS on single pieces of charcoal. Calibrations undertaken using Calib 7.1 (IntCal13) (Reimer et al. 2013).

Source: Authors' data.

\section{Excavated materials}

A total of $114.2 \mathrm{~g}$ of charcoal was excavated from Square A. Discard rates were broadly consistent throughout the shallow deposit (Table 15.5; Figure 15.28).

Table 15.5 Excavated materials retained in $2 \mathrm{~mm}$ mesh sieves from Square A, by XU.

\begin{tabular}{|c|c|c|c|c|c|c|c|}
\hline \multirow[t]{2}{*}{ XU } & \multirow{2}{*}{$\frac{\text { Non-cultural sediments }}{g}$} & \multirow{2}{*}{$\begin{array}{c}\text { Charcoal } \\
\mathrm{g}\end{array}$} & \multicolumn{2}{|c|}{ Stone artefacts } & \multirow{2}{*}{$\begin{array}{c}\text { 0ther organics } \\
g \\
\end{array}$} & \multirow{2}{*}{$\begin{array}{c}\text { Insect larvae } \\
9 \\
\end{array}$} & \multirow{2}{*}{$\begin{array}{c}\text { Land snail shell } \\
g\end{array}$} \\
\hline & & & \# & $g$ & & & \\
\hline 1 & 3.8 & 2.3 & 1 & 0.6 & 96.5 & 0.1 & 0 \\
\hline 2 & 6.2 & 53.5 & 11 & 13.9 & 37.0 & & \\
\hline 3 & 7.6 & 17.2 & 12 & 6.6 & 14.2 & & \\
\hline 4 & 47.8 & 36.7 & 12 & 6.1 & 12.2 & & \\
\hline 5 & 88.7 & 22.5 & 17 & 7.7 & 8.5 & & \\
\hline Total & 154.1 & 114.2 & 53 & 35.0 & 168.4 & 0.1 & 0 \\
\hline
\end{tabular}

Source: Authors' data.

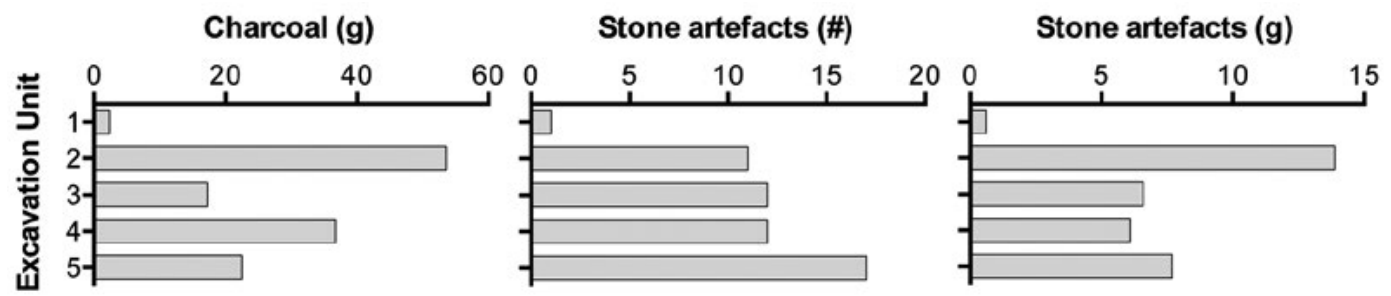

Figure 15.28 Distribution of charcoal and stone artefacts by XU, Square A.

Source: Illustration by Jerome Mialanes and Lara Lamb.

Square A contains 53 stone artefacts with a total weight of $35.0 \mathrm{~g}$ (Table 15.5; Figure 15.28). The assemblage is fairly homogenous in terms of mean weight and size (maximum dimensions), as well as length, width and thickness. The variable but small sample size by XU limits our conclusions (Figure 15.29). 
Mean max. dimension $(\mathrm{mm})$

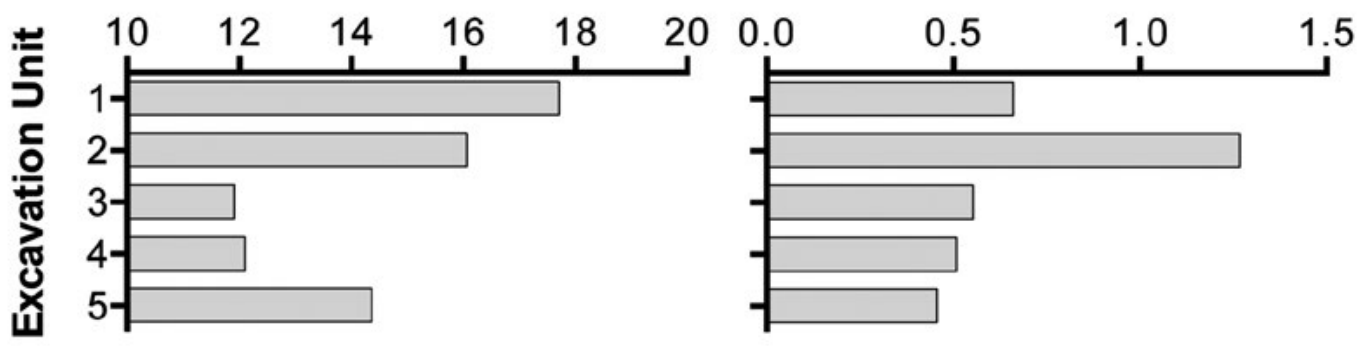

Figure 15.29 Mean maximum length and weight distribution of stone artefacts from Square A, by XU. Source: Illustration by Jerome Mialanes and Lara Lamb.

All artefacts are made of quartzite. These can be further sub-divided into two types, microcrystalline (grain size $<0.5 \mathrm{~mm}$, present in all XUs) and fine-grained quartzite $(0.5-1.0 \mathrm{~mm}$ grain size, present in XU4 and XU5 only; see Figure 15.30). A peak in the weight of micro-crystalline quartzite artefacts in XU2 is due to a single, relatively large artefact weighing $10.9 \mathrm{~g}$.

Fine-grained quartzite (\#) Micro-crystalline quartzite (\#)

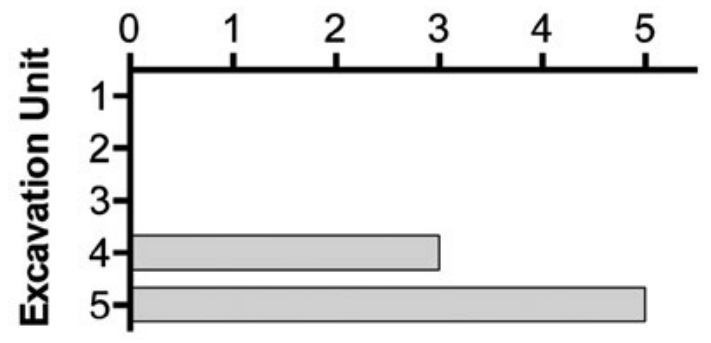

Fine-grained quartzite (g)
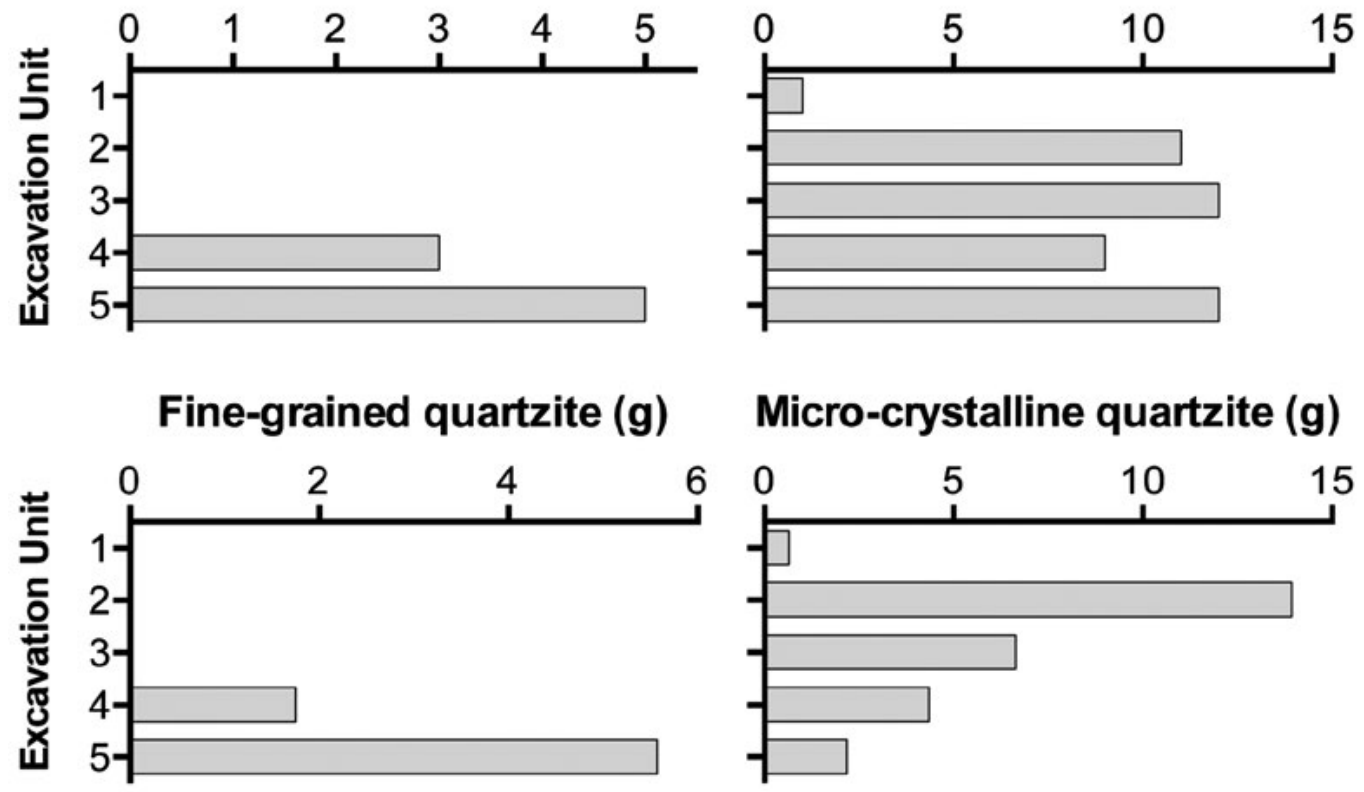

Figure 15.30 Distribution of stone artefacts by raw material type for Square A, by XU.

Source: Illustration by Jerome Mialanes and Lara Lamb.

Unipolar, freehand percussion (complete) flakes (47 per cent of all stone artefacts from Square A) dominate the stone artefact assemblage in all XUs, followed by flaked pieces ( 26 per cent) and broken 'other' (13 per cent), which is a category reserved for broken flakes that cannot be neatly categorised as proximal, distal, medial or lateral pieces (Table 15.6). A single retouched flake was recovered from XU2, produced on micro-crystalline quartzite of a similar Munsell colour $(2.5 \mathrm{Y} 8 / 1)$ to the quartzite block that rests atop the northern end of the square. This flake is retouched along 100 per cent of its two lateral margins, which run roughly parallel to each other. The flake is $55.5 \mathrm{~mm}$ along its longest lateral margin and $22 \mathrm{~mm}$ wide; it also has two parallel dorsal ridges, all of which give the artefact the appearance of a 'blade'. One heavily reduced bipolar core (rotated $90^{\circ}$ ) was recovered from XU3. It is $27 \mathrm{~mm}$ long (maximum dimension), 
and was reduced by two visible platforms; it has 14 negative flake scars originating from both platforms combined. The dominant colours throughout the artefact assemblage are light- to brownish-grey (10YR 8/1 to 10YR 6/2) and light-grey to greyish-yellow (2.5Y 8/1 to 2.5Y 7/2). Less than 5 per cent of the total flaked stone artefacts are reddish-grey (10Y 4/4 to 10R 6/6) in colour; these could not have come from the core stone slab immediately adjacent to Square A.

Table 15.6 Distribution of fracture types among the stone artefacts, Square A, by XU.

\begin{tabular}{|l|r|r|r|r|r|r|r|r|r|}
\hline XU & $\begin{array}{c}\text { Bipolar } \\
\text { core }\end{array}$ & $\begin{array}{c}\text { Broken flake } \\
\text { (other) }\end{array}$ & $\begin{array}{c}\text { Complete } \\
\text { flake }\end{array}$ & $\begin{array}{c}\text { Distal } \\
\text { flake }\end{array}$ & $\begin{array}{c}\text { Flaked } \\
\text { piece }\end{array}$ & $\begin{array}{c}\text { Proximal } \\
\text { flake }\end{array}$ & $\begin{array}{c}\text { Retouched } \\
\text { flake }\end{array}$ & $\begin{array}{c}\text { Right- } \\
\text { split cone }\end{array}$ & Total \\
\hline 1 & & 1 & & & & & & & 1 \\
\hline 2 & & 2 & 4 & 1 & 3 & & & & 1 \\
\hline 3 & 1 & 2 & 7 & & 2 & & & & 12 \\
\hline 4 & & 1 & 7 & & 4 & & & & 12 \\
\hline 5 & & 1 & 7 & 2 & 5 & 1 & & & 1 \\
\hline Total & 1 & 7 & 25 & 3 & 14 & 1 & 1 & 1 & 53 \\
\hline
\end{tabular}

Source: Authors' data.

\section{Square B}

The eastern side of Square B was positioned directly against the rock outcrop, some $2 \mathrm{~m}$ adjacent to art Panel C. Square B was excavated down to a maximum depth of $96.3 \mathrm{~cm}$, where bedrock was reached (Figure 15.31).

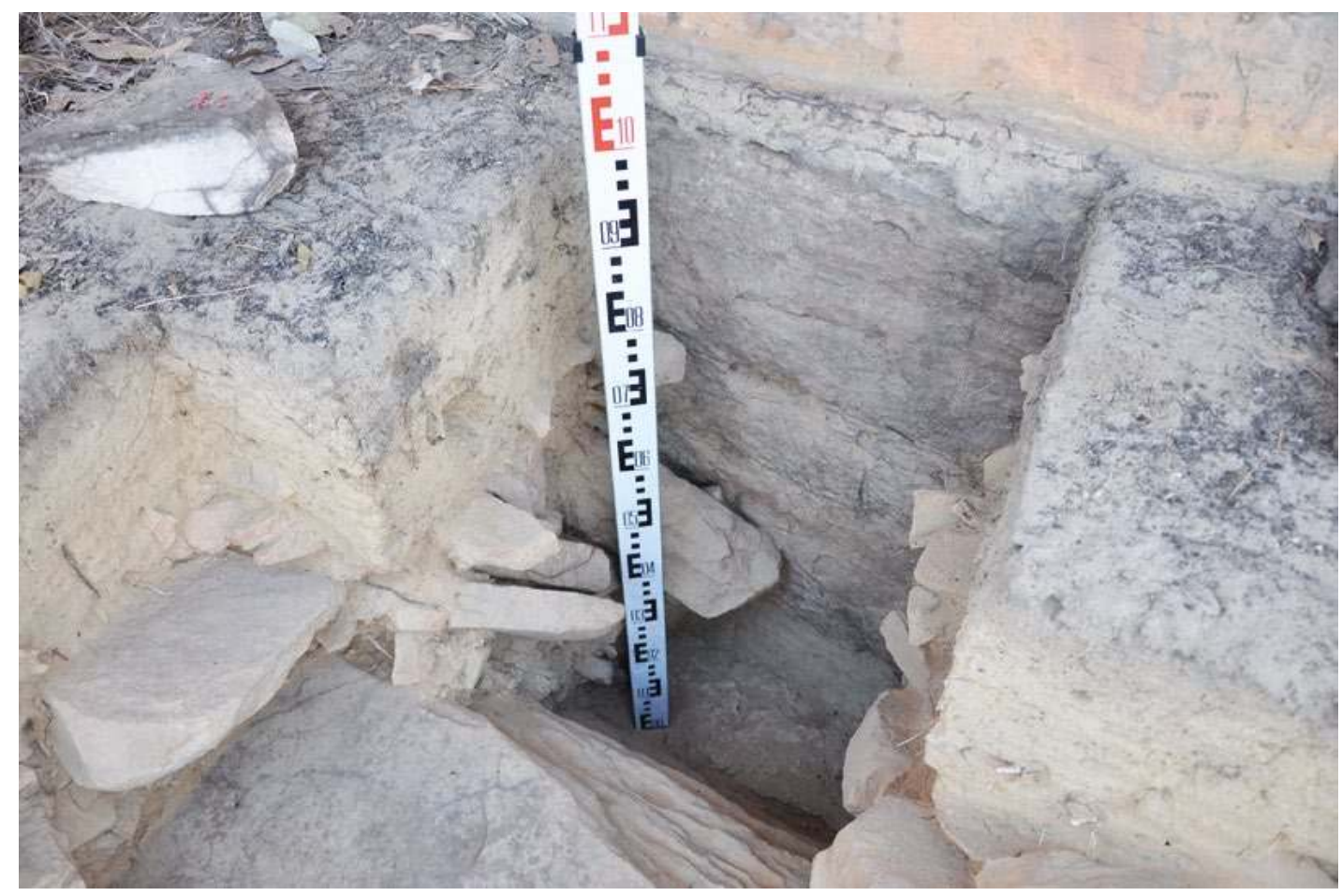

Figure 15.31 Square $B$ after completion of excavation.

Source: Photograph by Bryce Barker. 


\section{Stratigraphy}

Sediments in Square B consist of four SUs (Table 15.7). SU1 spans from ground surface to a maximum depth of $7 \mathrm{~cm}$; it consists of loose, homogeneous weak-red sand (2.5YR 5/3). SU2 below it extends to a maximum depth of $32.7 \mathrm{~cm}$ below ground, and consists of slightly more compact pale-brown sand (10YR 6/3). SU3 goes down to a maximum depth of $45 \mathrm{~cm}$, and consists of light yellowish-brown sand (10YR 6/4) with large, angular quartzitic sandstone blocks. SU4 consists of light yellowish-brown sand (10YR 6/4) with angular quartzitic sandstone blocks and small rounded pisoliths at its base (Figure 15.32).

Table 15.7 Details of Square B excavation, by XU.

\begin{tabular}{|c|c|c|c|c|c|c|c|}
\hline XU & SU & $\begin{array}{l}\text { Mean depth } \\
\text { at top }(\mathrm{cm})\end{array}$ & $\begin{array}{c}\text { Mean depth at } \\
\text { centre }(\mathrm{cm})\end{array}$ & $\begin{array}{l}\text { Mean depth } \\
\text { at base }(\mathrm{cm})\end{array}$ & $\begin{array}{c}\text { Mean thickness } \\
(\mathrm{cm})\end{array}$ & $\begin{array}{c}\text { Weight of excavated } \\
\text { sediments }(\mathrm{kg})\end{array}$ & $\begin{array}{l}\text { Volume of excavated } \\
\text { sediments (litres) }\end{array}$ \\
\hline 1 & 1 & 0.0 & 0.4 & 0.7 & 0.7 & 3.0 & 1.0 \\
\hline 2 & 1 & 0.7 & 1.7 & 2.6 & 1.9 & 6.0 & 4.0 \\
\hline 3 & $1 / 2$ & 2.6 & 3.7 & 4.8 & 2.2 & 6.0 & 5.5 \\
\hline 4 & $1 / 2$ & 4.8 & 6.1 & 7.4 & 2.6 & 9.6 & 6.5 \\
\hline 5 & $1 / 2$ & 7.4 & 8.2 & 9.0 & 1.6 & 5.0 & 3.5 \\
\hline 6 & 2 & 9.0 & 10.0 & 11.1 & 2.1 & 6.4 & 4.5 \\
\hline 7 & 2 & 11.1 & 12.1 & 13.2 & 2.1 & 7.4 & 5.0 \\
\hline 8 & 2 & 13.2 & 14.5 & 15.9 & 2.7 & 9.6 & 7.5 \\
\hline 9 & $2 / 3$ & 15.9 & 17.2 & 18.5 & 2.6 & 7.4 & 6.5 \\
\hline 10 & $2 / 3$ & 18.5 & 19.4 & 20.4 & 1.9 & 6.5 & 4.0 \\
\hline 11 & $2 / 3$ & 20.4 & 21.1 & 21.8 & 1.4 & 3.6 & 2.0 \\
\hline 12 & $2 / 3$ & 21.8 & 22.6 & 23.5 & 1.7 & 7.2 & 3.0 \\
\hline 13 & $2 / 3$ & 23.5 & 24.1 & 24.7 & 1.2 & 5.1 & 2.0 \\
\hline 14 & $2 / 3$ & 24.7 & 25.6 & 26.5 & 1.8 & 7.3 & 3.5 \\
\hline 15 & $2 / 3$ & 26.5 & 27.7 & 29.0 & 2.5 & 8.8 & 5.5 \\
\hline 16 & 3 & 29.0 & 29.9 & 30.9 & 1.9 & 8.6 & 5.0 \\
\hline 17 & 3 & 30.9 & 33.0 & 35.2 & 4.3 & 9.6 & 6.0 \\
\hline 18 & 3 & 35.2 & 36.6 & 38.1 & 2.9 & 9.3 & 6.0 \\
\hline 19 & $3 / 4$ & 38.1 & 39.9 & 41.7 & 3.6 & 8.6 & 4.0 \\
\hline 20 & $3 / 4$ & 41.7 & 42.7 & 43.8 & 2.1 & 6.8 & 4.0 \\
\hline 21 & $3 / 4$ & 43.8 & 44.4 & 45.0 & 1.2 & 7.1 & 4.0 \\
\hline 22 & 4 & 45.0 & 45.8 & 46.7 & 1.7 & 2.4 & 1.0 \\
\hline 23 & 4 & 46.7 & 46.9 & 47.2 & 0.5 & 0.8 & 0.5 \\
\hline 24 & 4 & 47.2 & 48.4 & 49.7 & 2.5 & 16.9 & 3.0 \\
\hline 25 & 4 & 49.7 & 50.3 & 50.9 & 1.2 & 3.8 & 2.0 \\
\hline 26 & 4 & 50.9 & 51.7 & 52.6 & 1.7 & 3.5 & 2.0 \\
\hline 27 & 4 & 52.6 & 53.6 & 54.7 & 2.1 & 5.0 & 2.0 \\
\hline 28 & 4 & 54.7 & 55.8 & 56.9 & 2.2 & 12.6 & 5.0 \\
\hline 29 & 4 & 56.9 & 57.2 & 57.6 & 0.7 & 3.8 & 1.5 \\
\hline 30 & 4 & 57.6 & 58.6 & 59.6 & 2.0 & 5.2 & 3.0 \\
\hline 31 & 4 & 59.6 & 59.9 & 60.3 & 0.7 & 6.8 & 3.5 \\
\hline 32 & 4 & 60.3 & 61.7 & 63.2 & 2.9 & 7.7 & 4.0 \\
\hline 33 & 4 & 63.2 & 63.8 & 64.5 & 1.3 & 4.5 & 3.0 \\
\hline 34 & 4 & 64.5 & 64.8 & 65.1 & 0.6 & 2.0 & 1.5 \\
\hline 35 & 4 & 65.1 & 65.8 & 66.5 & 1.4 & 3.2 & 2.0 \\
\hline 36 & 4 & 66.5 & 67.1 & 67.7 & 1.2 & 9.8 & 6.0 \\
\hline 37 & 4 & 67.7 & 69.2 & 70.7 & 3.0 & 7.6 & 4.0 \\
\hline
\end{tabular}




\begin{tabular}{|r|r|r|r|r|r|r|r|}
\hline XU & SU & $\begin{array}{c}\text { Mean depth } \\
\text { at top }(\mathbf{c m})\end{array}$ & $\begin{array}{r}\text { Mean depth at } \\
\text { centre }(\mathbf{c m})\end{array}$ & $\begin{array}{r}\text { Mean depth } \\
\text { at base }(\mathbf{c m})\end{array}$ & $\begin{array}{c}\text { Mean thickness } \\
(\mathbf{c m})\end{array}$ & $\begin{array}{c}\text { Weight of excavated } \\
\text { sediments (kg) }\end{array}$ & $\begin{array}{c}\text { Volume of excavated } \\
\text { sediments (litres) }\end{array}$ \\
\hline 38 & 4 & 70.7 & 71.6 & 72.5 & 1.8 & 8.1 & 4.0 \\
\hline 39 & 4 & 72.5 & 73.9 & 75.3 & 2.8 & 8.2 & 5.0 \\
\hline 40 & 4 & 75.3 & 76.3 & 77.4 & 2.1 & 7.2 & 4.0 \\
\hline 41 & 4 & 77.4 & 3.6 & 81.0 & 3.6 & 10.7 & 5.5 \\
\hline 42 & 4 & 81.0 & 82.9 & 84.8 & 3.7 & 8.6 & 5.0 \\
\hline 43 & 4 & 84.8 & 86.1 & 87.5 & 2.7 & 6.6 & 4.0 \\
\hline 44 & 4 & 87.5 & 88.7 & 89.9 & 2.4 & 6.4 & 4.0 \\
\hline 45 & 4 & 89.9 & 91.7 & 93.5 & 3.6 & 7.2 & 4.0 \\
\hline \multicolumn{2}{|r|}{ Total } & & & & 2.07 & 307.5 & 172.5 \\
\hline
\end{tabular}

Source: Authors' data.

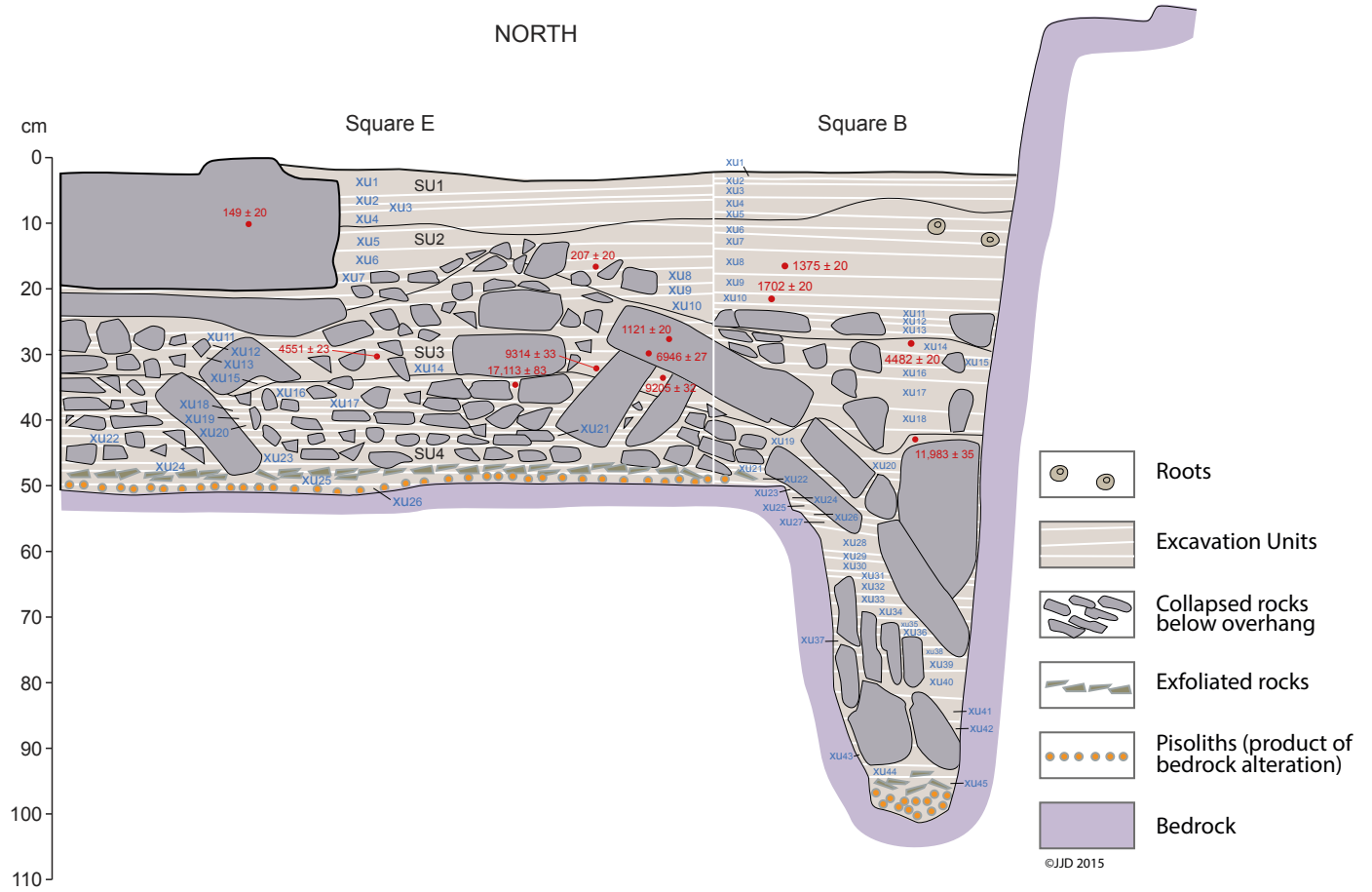

Figure 15.32 Squares B+E north section drawing, with back-plotted XUs and radiocarbon dates.

Source: Illustration by Kara Rasmanis, Bruno David and Jean-Jacques Delannoy.

\section{Chronology}

Seven AMS radiocarbon dates on individual pieces of charcoal collected in situ were obtained from Square B (Table 15.4). Radiocarbon dates of $1632 \pm 20 \mathrm{BP}$ (Wk-40577) from $8.1 \mathrm{~cm}$ depth in XU4, $1575 \pm 20$ BP (Wk-40578) from $14.9 \mathrm{~cm}$ depth in XU8 and $1702 \pm 20 \mathrm{BP}$ (Wk-40579) from $19.9 \mathrm{~cm}$ depth in XU10 all calibrate to a similar age within the range 1411-1692 cal BP (see Table 15.4 for details). All three determinations are from SU2. Below these in SU3, four dates of $2248 \pm 20 \mathrm{BP}$ (Wk-40580) from $22.6 \mathrm{~cm}$ depth, $4482 \pm 20 \mathrm{BP}$ (Wk-40581) from $26.2 \mathrm{~cm}$ depth, $8882 \pm 30 \mathrm{BP}$ (Wk-40582), from $36.3 \mathrm{~cm}$ depth and 11,983 $\pm 35 \mathrm{BP}$ (Wk-32128) from $40.4 \mathrm{~cm}$ depth are in correct chrono-stratigraphic order, indicating good stratigraphic integrity of deposits. No in situ charcoal was obtained from SU4. 
The Square B ages of 13,739-13,976 cal BP at $40.4 \mathrm{~cm}$ depth and 9901-10,171 cal BP at $36.3 \mathrm{~cm}$ depth, are separated by c. 3821 years over $4.1 \mathrm{~cm}$ vertical depth $(=0.11 \mathrm{~cm}$ of sediment build-up/100 years, taking the median calibrated ages). Those of 9901-10,171 cal BP at $36.3 \mathrm{~cm}$ depth and 5041-5286 cal BP at $26.2 \mathrm{~cm}$ depth, are separated by c. 4916 years over $10.1 \mathrm{~cm}$ vertical depth $(=0.21 \mathrm{~cm} / 100$ years $)$. And those of $5041-5286 \mathrm{cal} \mathrm{BP}$ at $26.2 \mathrm{~cm}$ depth and 2159-2338 cal BP at $22.6 \mathrm{~cm}$ depth, are separated by c. 2844 years over $3.6 \mathrm{~cm}$ vertical depth (= $0.13 \mathrm{~cm} / 100$ years). These results suggest a fairly consistent pattern of sediment build-up from terminal Pleistocene times through much of the Holocene.

\section{Excavated materials}

A total of $441.9 \mathrm{~g}$ of charcoal was excavated from Square B (Table 15.8). The pattern of discard for charcoal shows four distinct phases (Figure 15.33):

- Phase 1 (SU4): From XU45 to XU22 in SU4 in the undated lower levels of the square, which are older than 13,739-13,976 cal BP, charcoal densities are low with a total weight of $2.8 \mathrm{~g}$.

- Phase 2 (SU3): Charcoal densities increase markedly above XU21 at the SU4-SU3 interface, dating from c. 13,739-13,976 cal BP, to XU15 dating to c. 5041-5286 cal BP at the top of SU3. This period saw an average charcoal net deposition rate of $12.0 \mathrm{~g} / 1000$ years.

- Phase 3 (SU3-SU2 interface): From XU14 at the top of SU3 dating to c. 5041-5286 cal BP, to XU11 at the bottom of SU2 dating to c. 1553-1692 cal BP, there is a decrease to $7.2 \mathrm{~g} / 1000$ years in charcoal deposition rates, marking a hiatus or period of ephemeral occupation lasting c. 3500 years.

- Phase 4 (SU2): Charcoal deposition rates then increase gradually from XU12 dating to c. 2159-2338 cal BP, to XU10 dating to c. 1553-1692 cal BP in SU2. During that period, net charcoal deposition rates averaged $39.7 \mathrm{~g} / 1000$ years, and continued to increase to $1361.8 \mathrm{~g} / 1000$ years into XU4, dating to c. 1418-1598 cal BP (see Table 15.8 for raw data).

Table 15.8 Excavated materials retained in $2 \mathrm{~mm}$ mesh sieves from Square B, by XU.

\begin{tabular}{|c|c|c|c|c|c|c|c|}
\hline \multirow[t]{2}{*}{ XU } & \multirow{2}{*}{$\begin{array}{c}\text { Non-cultural } \\
\text { sediments }\end{array}$} & \multirow{2}{*}{$\begin{array}{c}\text { Charcoal } \\
9 \\
\end{array}$} & \multicolumn{2}{|c|}{ Stone artefacts } & \multirow{2}{*}{$\begin{array}{c}\begin{array}{c}\text { Other } \\
\text { organics }\end{array} \\
g\end{array}$} & \multirow{2}{*}{$\begin{array}{c}\text { Insect larvae } \\
9 \\
\end{array}$} & \multirow{2}{*}{$\begin{array}{c}\begin{array}{c}\text { Land snail } \\
\text { shell }\end{array} \\
g \\
\end{array}$} \\
\hline & & & \# & $g$ & & & \\
\hline 1 & 28.9 & 9.0 & & & 53.0 & 0.4 & 0.1 \\
\hline 2 & 30.0 & 7.0 & 4 & 0.8 & 2.2 & & \\
\hline 3 & 26.3 & 3.7 & & & 10.4 & & \\
\hline 4 & 20.2 & 7.9 & & & 7.7 & & \\
\hline 5 & 26.0 & 9.9 & & & 9.4 & & \\
\hline 6 & 33.1 & 25.0 & 1 & 0.09 & 5.0 & & \\
\hline 7 & 112.2 & 99.9 & 8 & 0.01 & 7.5 & & \\
\hline 8 & 309.7 & 98.0 & 8 & 0.3 & 7.6 & & \\
\hline 9 & 132.9 & 30.5 & & & 9.1 & & \\
\hline 10 & 114.0 & 16.8 & 15 & 0.01 & 9.5 & & \\
\hline 11 & 30.2 & 5.6 & 6 & 0.2 & 3.0 & & \\
\hline 12 & 29.0 & 5.2 & 11 & 1.38 & 2.2 & & \\
\hline 13 & 30.7 & 5.8 & 2 & 9.7 & 0.9 & & \\
\hline 14 & 146.0 & 8.6 & 15 & 3.8 & 2.0 & & \\
\hline 15 & 276.0 & 14.2 & 17 & 25.4 & 4.1 & & \\
\hline 16 & 1300.0 & 15.6 & 11 & 26.4 & 0.5 & & \\
\hline 17 & 1144.0 & 21.8 & 22 & 62.6 & 0.9 & & \\
\hline 18 & 818.0 & 30.0 & 39 & 44.9 & 2.0 & & \\
\hline
\end{tabular}




\begin{tabular}{|c|c|c|c|c|c|c|c|}
\hline \multirow[t]{2}{*}{ XU } & \multirow{2}{*}{$\begin{array}{c}\text { Non-cultural } \\
\text { sediments }\end{array}$} & \multirow{2}{*}{$\begin{array}{c}\text { Charcoal } \\
g\end{array}$} & \multicolumn{2}{|c|}{ Stone artefacts } & \multirow{2}{*}{$\begin{array}{c}\begin{array}{c}\text { Other } \\
\text { organics }\end{array} \\
9\end{array}$} & \multirow{2}{*}{$\begin{array}{c}\text { Insect larvae } \\
9\end{array}$} & \multirow{2}{*}{$\begin{array}{c}\text { Land snail } \\
\text { shell }\end{array}$} \\
\hline & & & $\#$ & $g$ & & & \\
\hline 19 & 573.0 & 15.1 & 16 & 11.7 & 0.6 & & \\
\hline 20 & 995.0 & 5.0 & 19 & 35.1 & 4.9 & & \\
\hline 21 & 894.0 & 3.4 & 17 & 42.1 & 5.8 & & \\
\hline 22 & 437.0 & 0.8 & 10 & 83.7 & 1.3 & & \\
\hline 23 & 233.8 & 0.4 & 6 & 2.0 & 1.2 & & \\
\hline 24 & 248.7 & 0.1 & 4 & 0.9 & 1.1 & & \\
\hline 25 & 911.0 & 0.6 & 11 & 47.8 & 0.1 & & \\
\hline 26 & 1007.5 & 0.4 & 16 & 10.1 & 0.8 & & \\
\hline 27 & 1300.0 & 0.1 & 10 & 8.6 & 1.3 & & \\
\hline 28 & 4580.0 & 0.4 & 13 & 18.7 & 0.9 & & \\
\hline 29 & 1421.0 & 0.05 & 7 & 1.6 & $<0.1$ & & \\
\hline 30 & 3512.0 & 0.1 & & & $<0.1$ & & \\
\hline 31 & 4438.7 & 0.3 & & & 1.0 & & \\
\hline 32 & 3254.0 & 0.04 & 3 & 9.6 & 0.9 & & \\
\hline 33 & 2982.0 & 0.06 & & & 1.4 & & \\
\hline 34 & 1538.0 & 0.01 & & & 0.1 & & \\
\hline 35 & 1649.7 & 0.03 & 5 & 30.3 & 0.1 & & \\
\hline 36 & 2941.8 & 0.03 & 7 & 90.2 & 0.3 & & \\
\hline 37 & 3841.4 & 0.02 & 3 & 60.2 & 0.6 & & \\
\hline 38 & 3944.0 & 0.01 & & & 0.2 & & \\
\hline 39 & 5439.5 & 0.01 & 2 & 7.9 & 0.2 & & \\
\hline 40 & 4547.5 & 0.03 & & & 0.2 & & \\
\hline 41 & 7306.6 & 0.5 & & & 0.1 & & \\
\hline 42 & 4795.0 & 0.1 & & & & & \\
\hline 43 & 4681.3 & 0.08 & & & & & \\
\hline 44 & 4985.0 & 0.03 & & & & & \\
\hline 45 & 2344.3 & 0.01 & & & & & \\
\hline Total & $79,160.3$ & 441.9 & 308 & 636.0 & 159.0 & 0.4 & 0.1 \\
\hline
\end{tabular}

Source: Authors' data.

Ochrous pisoliths. Two of the excavated pisoliths were analysed for their chemistry to determine whether or not such pisoliths could have been used to make some or all of the red artworks at the site. Both pisoliths are red (10R 4/6 to 2.5YR 4/8) in colour, as are many of the others found within the excavated sequence. No striations or other marks of use are evident under magnification.

For both pieces, SEM (at $20 \mathrm{kV}$ with a LEO Stereoscan 440 SEM coupled by EDX) reveals a structure consisting of microscopic sheets of red pigment. These sheets vary in thickness from a few microns to c. $10 \mu \mathrm{m}$ each. They mainly contain Fe as iron oxide mixed with 1:1 Al:Si ratios, as found in kaolinite clay.

PIXE analysis (3 MV microprobe, AGLAE Facility, Paris) indicates that the outer concretion coating the fragment from XU26 contains a higher content of $\mathrm{SiO}_{2}$ and $\mathrm{TiO}_{2}$ than internally. This outer coating is mainly composed of large quartz grains $(>200 \mu \mathrm{m}$ long). Minor elements of the inner parts of both samples include $\mathrm{Mg}, \mathrm{P}, \mathrm{S}, \mathrm{K}$. In both samples the low incidence of $\mathrm{Ca}, \mathrm{V}$ and $\mathrm{Mn}$ is comparable to those measured in the painting samples from art Panel $\mathrm{A}$ (see Table 15.9). 


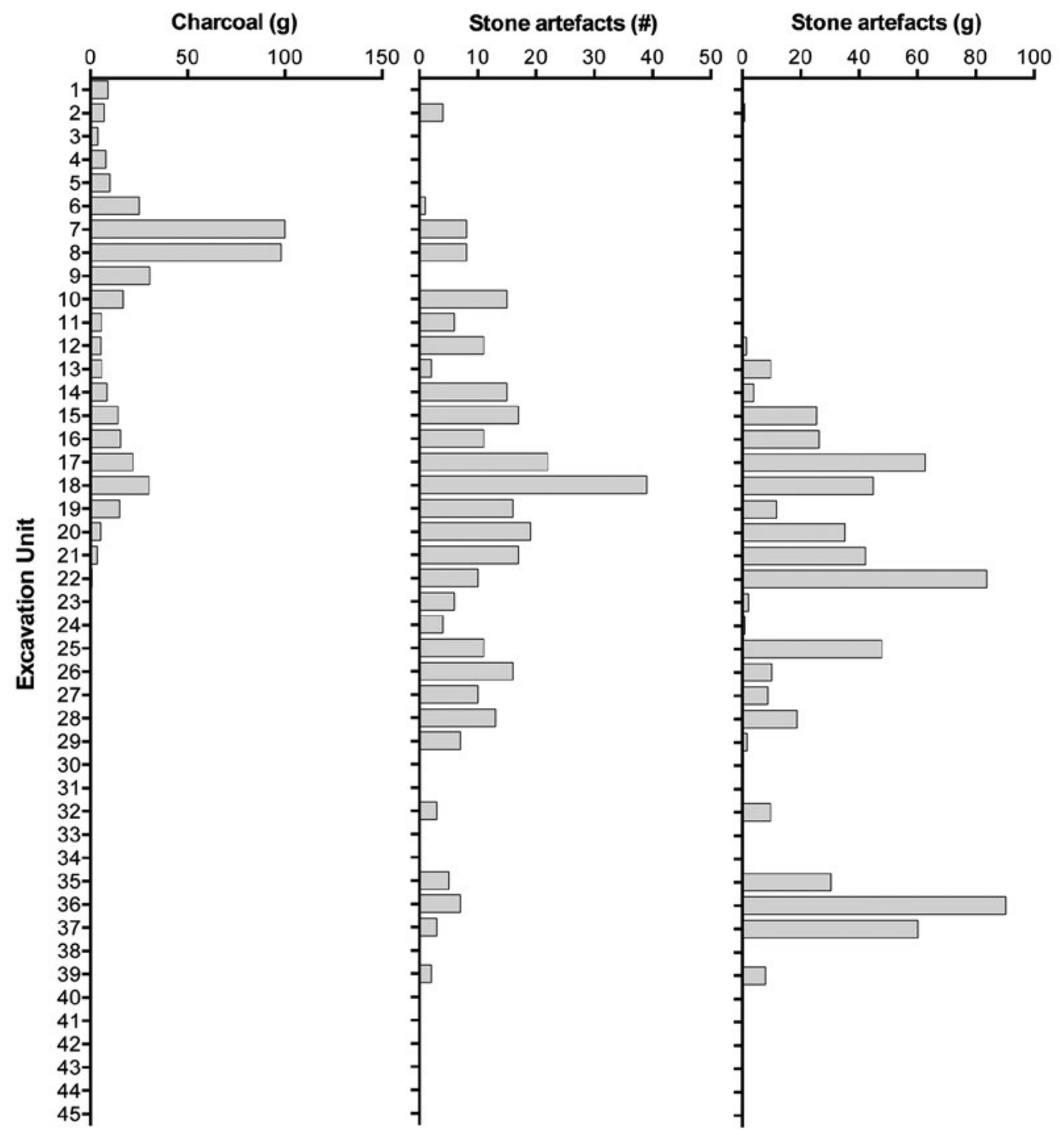

Figure 15.33 Distribution of charcoal and stone artefacts by XU, Square B.

Source: Illustration by Jerome Mialanes and Lara Lamb.

Table 15.9 Quantitative composition of the two analysed pisoliths from XU21 and XU26 in Square B, as determined by PIXE analyses (in oxide weights).

\begin{tabular}{|l|l|l|l|}
\hline Pisolith & Major elements & Minor elements (ppm) & Trace elements (ppm) \\
\hline XU21 & $\mathrm{Al}_{2} \mathrm{O}_{3}: 24.4 \%$ & $\mathrm{MgO}: 4130$ & $\mathrm{CaO}: 199$ \\
& $\mathrm{SiO}_{2}: 29.5 \%$ & $\mathrm{P}_{2} \mathrm{O}_{5}: 995$ & $\mathrm{~V}_{2} \mathrm{O}_{3}: 262$ \\
& $\mathrm{Fe}_{2} \mathrm{O}_{3}: 44.7 \%$ & $\mathrm{SO}_{2}: 609$ & $\mathrm{TiO}_{2}: 3720$ \\
& & $\mathrm{~K}_{2} 0: 1383$ & $\mathrm{ZrO}_{2}: 93$ \\
& & $\mathrm{Cr}_{2} \mathrm{O}_{3}: 9119$ & \\
\hline XU26 & $\mathrm{Ml}_{2} \mathrm{O}_{3}: 17.7 \%$ & $\mathrm{MgO}_{2}: 2463$ & \\
& $\mathrm{SiO}_{2}: 66.8 \%$ & $\mathrm{P}_{2}: 2007$ & $\mathrm{CaO}_{5}: 253$ \\
& $\mathrm{KiO}_{2}: 1.1 \%: 2355$ & $\mathrm{~V}_{2} \mathrm{O}_{3}: 645$ \\
& $\mathrm{Fe}_{2} \mathrm{O}_{3}: 13.0 \%$ & $\mathrm{Cr}_{2} \mathrm{O}_{3}: 3099$ & $\mathrm{MnO}_{2}: 150$ \\
& & $\mathrm{ZrO}_{2}: 3442$ & \\
\hline
\end{tabular}

Source: Authors' data. 
The chemical composition of both analysed pisoliths is consistent with the chemistry of the red paint layers in samples GN1-5 and GN1-6 of Panel A (Images \#1 and \#2), GN1-16 of Panel C (Image \#49) and GN1-9 of Panel D (Image \# 51). However, the chemistry of the clay-containing pisoliths is not consistent with that of the other on-wall paint samples, which do not show any evidence of the presence of clays. This suggests that local pisoliths could have been used to paint some of the red paintings analysed at the site, including but not limited to the two macropods on Panel A, but probably not all of the red paintings because, unlike the analysed local pisoliths, some are devoid of clays.

Stone artefacts. A total of 308 stone artefacts with a total weight of $636.0 \mathrm{~g}$ was excavated from Square B (Table 15.8; Figure 15.33). Eight raw material types are represented: fine-grained quartzite (41.6 per cent), micro-crystalline quartzite (39.3 per cent), sandstone (4.8 per cent), calcified quartzite (4.6 per cent), chert (3.6 per cent), coarse-grained quartzite (with $1.0-2.0 \mathrm{~mm}$ long grain size, 2.6 per cent), milky quartz ( 2.9 per cent) and silcrete ( 0.6 per cent).

Among the flaked stone artefacts, the frequency of fracture types is dominated by flaked pieces (60.7 per cent), followed by complete flakes ( 16.9 per cent), distal portions ( 8.4 per cent) and broken 'other' ( 7.5 per cent) (Table 15.10). Other fracture types represent $<2$ per cent of the assemblage. The single retouched flake in Square B comes from XU16. It consists of a piece of sandstone with one margin retouched along c. 50 per cent of its length. The assemblage also contains two unipolar cores, from XU36 (55 g) and XU37 (45 g), on sandstone and findgrained quartzite respectively. Their relatively large sizes contribute to the higher mean weights and maximum dimensions of these two XUs (Figure 15.34).

Table 15.10 Distribution of fracture types among the stone artefacts, Square B, by XU.

\begin{tabular}{|c|c|c|c|c|c|c|c|c|c|c|c|c|}
\hline$X U$ & $\begin{array}{l}\text { Bipolar } \\
\text { core }\end{array}$ & $\begin{array}{l}\text { Broken } \\
\text { flake } \\
\text { (other) }\end{array}$ & $\begin{array}{l}\text { Complete } \\
\text { flake }\end{array}$ & $\begin{array}{l}\text { Distal } \\
\text { flake }\end{array}$ & $\begin{array}{l}\text { Flaked } \\
\text { piece }\end{array}$ & $\begin{array}{l}\text { Left- } \\
\text { split } \\
\text { cone }\end{array}$ & $\begin{array}{l}\text { Medial } \\
\text { flake }\end{array}$ & $\begin{array}{l}\text { Proximal } \\
\text { flake }\end{array}$ & $\begin{array}{l}\text { Retouched } \\
\text { flake }\end{array}$ & $\begin{array}{l}\text { Right- } \\
\text { split } \\
\text { cone }\end{array}$ & $\begin{array}{c}\text { Unipolar } \\
\text { core }\end{array}$ & Total \\
\hline 1 & & & & & & & & & & & & \\
\hline 2 & & & 2 & & 2 & & & & & & & 4 \\
\hline 3 & & & & & & & & & & & & \\
\hline 4 & & & & & & & & & & & & \\
\hline 5 & & & & & & & & & & & & \\
\hline 6 & & & 1 & & & & & & & & & 1 \\
\hline 7 & & & 3 & & 5 & & & & & & & 8 \\
\hline 8 & & 1 & 1 & 1 & 4 & & & 1 & & & & 8 \\
\hline 9 & & & & & & & & & & & & \\
\hline 10 & & 1 & 4 & & 10 & & & & & & & 15 \\
\hline 11 & & & 2 & & 4 & & & & & & & 6 \\
\hline 12 & & 2 & 2 & 2 & 5 & & & & & & & 11 \\
\hline 13 & & & 1 & 1 & & & & & & & & 2 \\
\hline 14 & & & 3 & & 11 & & & & & 1 & & 15 \\
\hline 15 & & & 3 & 1 & 11 & & 1 & 1 & & & & 17 \\
\hline 16 & & & 3 & & 5 & 1 & 1 & & 1 & & & 11 \\
\hline 17 & & 1 & 5 & 3 & 13 & & & & & & & 22 \\
\hline 18 & & 2 & 4 & 6 & 25 & & & 2 & & & & 39 \\
\hline 19 & & 1 & 6 & 2 & 7 & & & & & & & 16 \\
\hline 20 & & 2 & 4 & 1 & 10 & 1 & & 1 & & & & 19 \\
\hline 21 & & & 2 & & 13 & 1 & & & & & & 16 \\
\hline 22 & & 3 & 1 & 1 & 5 & & & & & & & 10 \\
\hline 23 & & & & 2 & 4 & & & & & & & 6 \\
\hline
\end{tabular}




\begin{tabular}{|c|c|c|c|c|c|c|c|c|c|c|c|c|}
\hline XU & $\begin{array}{l}\text { Bipolar } \\
\text { core }\end{array}$ & $\begin{array}{l}\text { Broken } \\
\text { flake } \\
\text { (other) }\end{array}$ & $\begin{array}{l}\text { Complete } \\
\text { flake }\end{array}$ & $\begin{array}{l}\text { Distal } \\
\text { flake }\end{array}$ & $\begin{array}{l}\text { Flaked } \\
\text { piece }\end{array}$ & $\begin{array}{l}\text { Left- } \\
\text { split } \\
\text { cone }\end{array}$ & $\begin{array}{l}\text { Medial } \\
\text { flake }\end{array}$ & $\begin{array}{l}\text { Proximal } \\
\text { flake }\end{array}$ & $\begin{array}{l}\text { Retouched } \\
\text { flake }\end{array}$ & $\begin{array}{l}\text { Right- } \\
\text { split } \\
\text { cone }\end{array}$ & $\begin{array}{l}\text { Unipolar } \\
\text { core }\end{array}$ & Total \\
\hline 24 & & 1 & & 1 & 2 & & & & & & & 4 \\
\hline 25 & & 3 & 2 & 1 & 5 & & & & & & & 11 \\
\hline 26 & 1 & 3 & & & 12 & & & & & & & 16 \\
\hline 27 & & & & 2 & 6 & 2 & & & & & & 10 \\
\hline 28 & & & 2 & 1 & 10 & & & & & & & 13 \\
\hline 29 & & 2 & & & 5 & & & & & & & 7 \\
\hline 30 & & & & & & & & & & & & \\
\hline 31 & & & & & & & & & & & & \\
\hline 32 & & & & 1 & 2 & & & & & & & 3 \\
\hline 33 & & & & & & & & & & & & \\
\hline 34 & & & & & & & & & & & & \\
\hline 35 & & 1 & & & 4 & & & & & & & 5 \\
\hline 36 & & & & & 6 & & & & & & 1 & 7 \\
\hline 37 & & & 1 & & & 1 & & & & & 1 & 3 \\
\hline 38 & & & & & & & & & & & & \\
\hline 39 & & & & & 1 & & & & & 1 & & 2 \\
\hline Total & 1 & 23 & 52 & 26 & 187 & 6 & 2 & 5 & 1 & 2 & 2 & 307 \\
\hline
\end{tabular}

Source: Authors' data.

The flaked stone assemblage exhibits very little cortex (3.2 per cent of artefacts). Coupled with the overall small size of the artefacts, the implications are late stage reduction sequences.

There are clear peaks in numbers and total weights of stone artefacts around XU14XU21 and XU25-XU28 (Figure 15.33). These peaks are largely due to increased frequencies of the two principal raw material types, fine-grained and micro-crystalline quartzite (Figure 15.35). However, when calculated as deposition rates, there is little evidence of major variation through the sequence, with a minor decrease from 8.9 artefacts $/ 1000$ years to 6.7 artefacts $/ 1000$ years between 1503 $1642 \mathrm{cal} \mathrm{BP}$ and $0-1503 \mathrm{cal} \mathrm{BP}$.

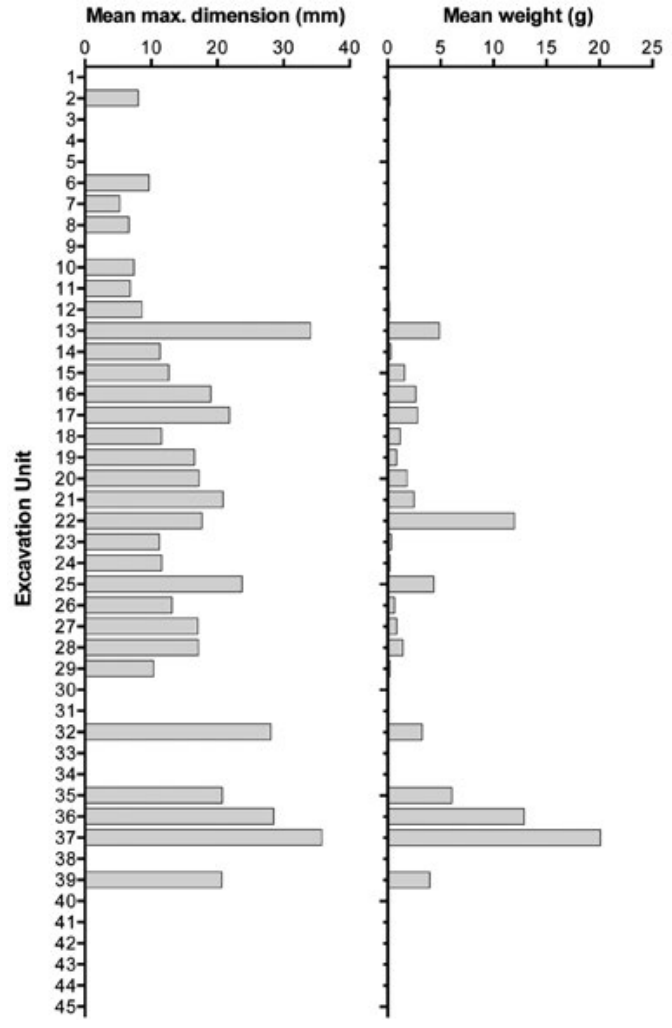

Figure 15.34 Mean weight and maximum length of stone artefacts from Square B, by XU.

Source: Illustration by Jerome Mialanes and Lara Lamb. 
A

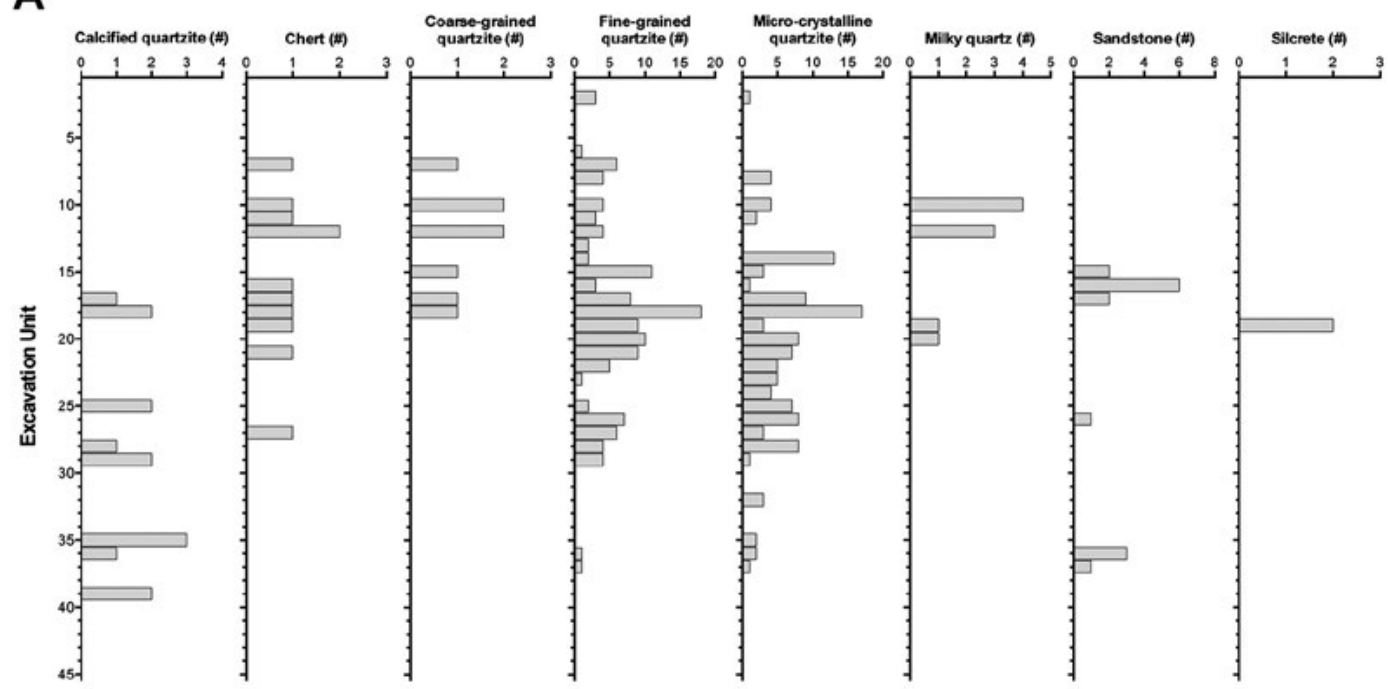

B

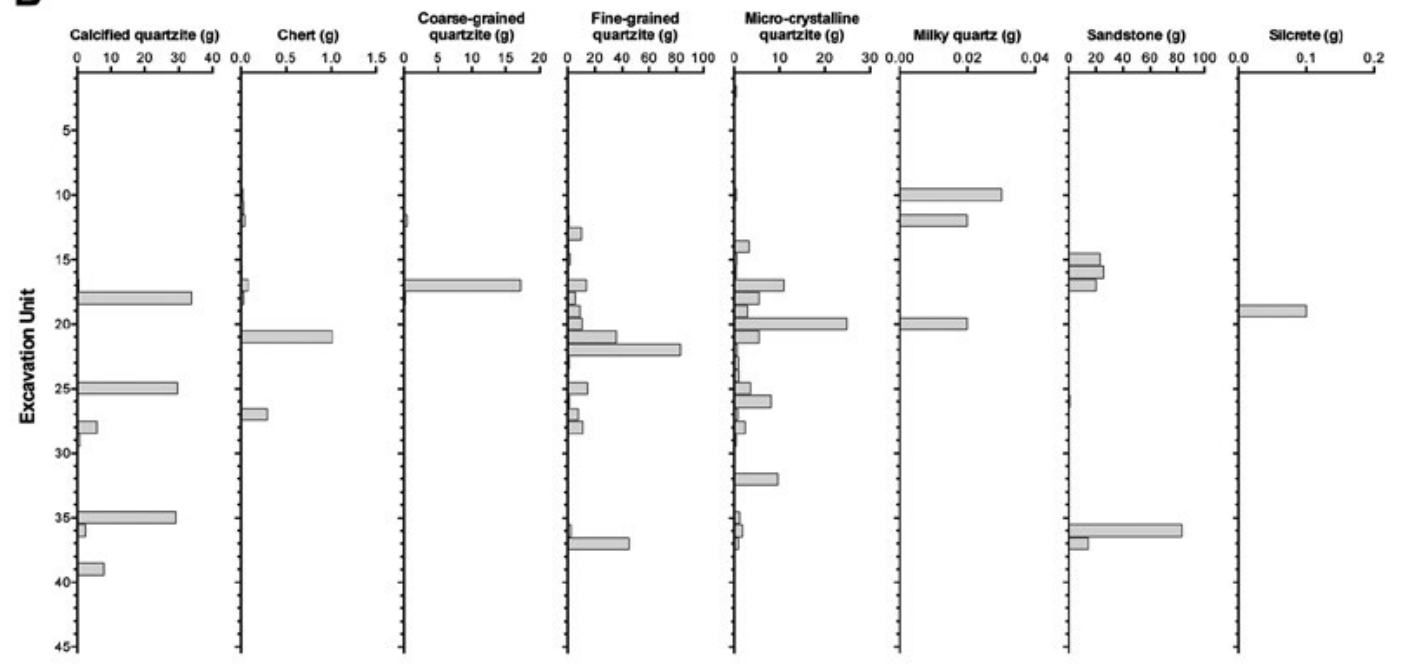

Figure 15.35 Number (A) and weight (B) of stone artefacts by raw material type for Square B, by XU. Source: Illustration by Jerome Mialanes and Lara Lamb.

\section{Square C}

Square $\mathrm{C}$ is located $1.0 \mathrm{~m}$ directly south of Square A. It was excavated to a maximum depth of $17.0 \mathrm{~cm}$ (Table 15.11). The square was positioned $50 \mathrm{~cm}$ to the east of rock art Panel B (Figures 15.3 and 15.36).

Table 15.11 Details of Square C excavation, by XU.

\begin{tabular}{|l|c|r|r|r|r|r|r|}
\hline XU & SU & $\begin{array}{c}\text { Mean depth } \\
\text { at top }(\mathbf{c m})\end{array}$ & $\begin{array}{c}\text { Mean depth } \\
\text { at centre }(\mathbf{c m})\end{array}$ & $\begin{array}{c}\text { Mean depth } \\
\text { at base }(\mathbf{c m})\end{array}$ & $\begin{array}{c}\text { Mean thickness } \\
(\mathbf{c m})\end{array}$ & $\begin{array}{c}\text { Weight of excavated } \\
\text { sediments }(\mathrm{kg})\end{array}$ & $\begin{array}{c}\text { Volume of excavated } \\
\text { sediments (litres) }\end{array}$ \\
\hline 1 & $1 / 2$ & 0.0 & 1.3 & 2.6 & 2.6 & 2.8 & 3.0 \\
\hline 2 & $1 / 2$ & 2.6 & 3.5 & 4.4 & 1.8 & 7.7 & 4.0 \\
\hline 3 & 2 & 4.4 & 5.2 & 6.0 & 1.6 & 5.9 & 5.0 \\
\hline 4 & 2 & 6.0 & 6.9 & 7.8 & 1.8 & 7.8 & 4.0 \\
\hline 5 & 2 & 7.8 & 8.9 & 10.0 & 2.2 & 7.2 & 4.5 \\
\hline 6 & 2 & 10.0 & 11.1 & 12.3 & 2.3 & 6.0 \\
\hline
\end{tabular}




\begin{tabular}{|l|r|r|r|r|r|r|r|}
\hline XU & SU & $\begin{array}{c}\text { Mean depth } \\
\text { at top }(\mathrm{cm})\end{array}$ & $\begin{array}{c}\text { Mean depth } \\
\text { at centre }(\mathrm{cm})\end{array}$ & $\begin{array}{c}\text { Mean depth } \\
\text { at base }(\mathrm{cm})\end{array}$ & $\begin{array}{c}\text { Mean thickness } \\
(\mathrm{cm})\end{array}$ & $\begin{array}{c}\text { Weight of excavated } \\
\text { sediments }(\mathrm{kg})\end{array}$ & $\begin{array}{c}\text { Volume of excavated } \\
\text { sediments (litres) }\end{array}$ \\
\hline 7 & 2 & 12.3 & 13.5 & 14.7 & 2.4 & 9.8 & 6.0 \\
\hline 8 & 2 & 14.7 & 15.8 & 17.0 & 2.3 & 9.8 & 7.0 \\
\hline \multicolumn{2}{|l|}{ Total } & & & & 2.1 & 56.4 & 39.5 \\
\hline
\end{tabular}

Source: Authors' data.

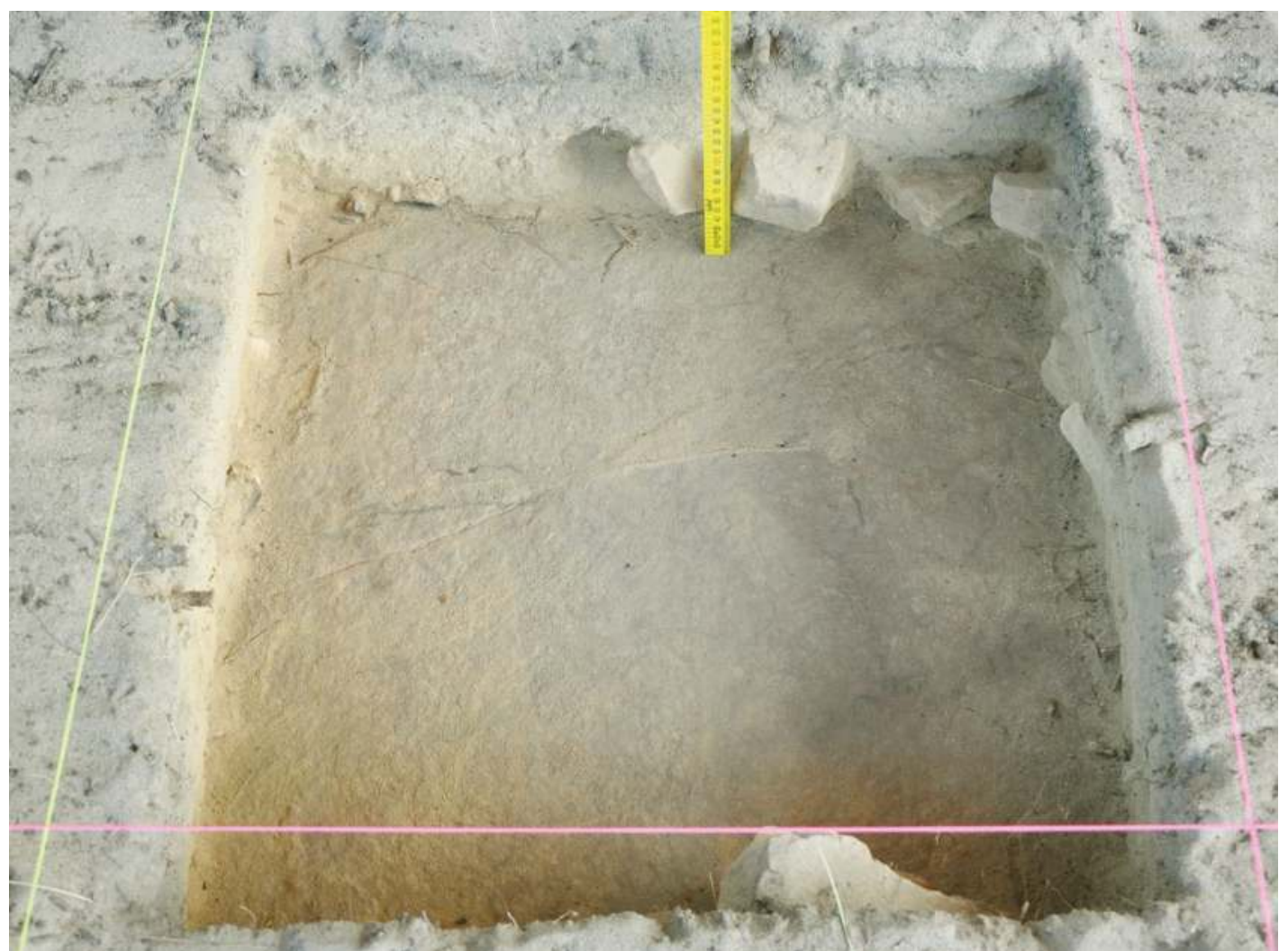

Figure 15.36 Square C after completion of excavation.

Green stringline (left-hand side of excavation) is on south side of square.

Source: Photograph by Lara Lamb.

\section{Stratigraphy}

Square C has two SUs. SU1 extends from the ground surface down to a maximum depth of $4 \mathrm{~cm}$. It consists of loose weak-red (2.5YR 5/3) sand with considerable quantities of charcoal and recent plant matter (e.g. leaves, rootlets). SU2 below it extends down to bedrock. It consists of more compact pale-brown (10YR 6/3) sand (Figure 15.37).

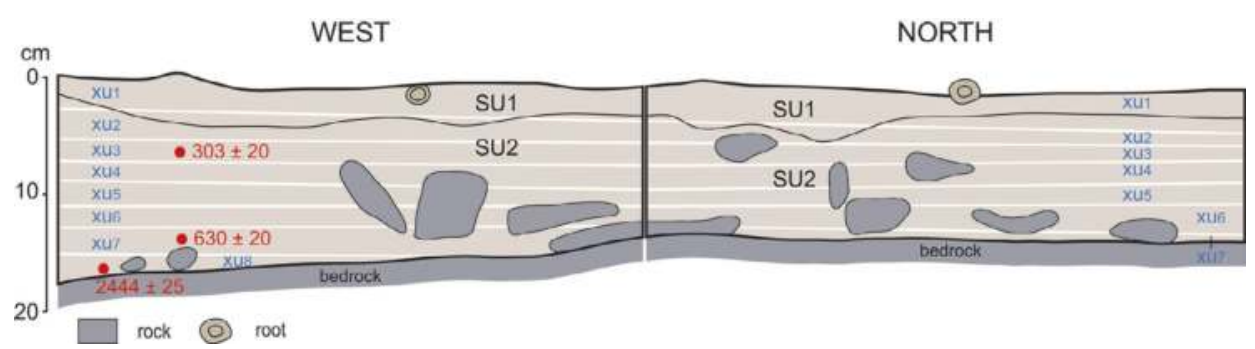

Figure 15.37 Square C west and north section drawings, with back-plotted XUs and radiocarbon dates.

Source: Illustration by Kara Rasmanis and Bruno David. 


\section{Chronology}

Three AMS radiocarbon dates on individual pieces of charcoal were obtained from Square C:

- $303 \pm 20$ BP (Wk-40583) (calibrating to 302-436 cal BP), from $6.8 \mathrm{~cm}$ depth in XU3.

- $630 \pm 20 \mathrm{BP}$ (Wk-40584) (calibrating to 556-660 cal BP), from $15.0 \mathrm{~cm}$ depth in XU7.

- $2444 \pm 25$ BP (Wk-40585) (calibrating to 2380-2412 cal BP), from $17.0 \mathrm{~cm}$ depth in XU8.

All dates are from SU2 and are in good chrono-stratigraphic order (Table 15.4). The $2 \mathrm{~cm}$ vertical depth of sediment spanning c. 1783 years (based on the median calibrated ages) separating the XU8 calibrated age of 2380-2412 cal BP and the XU7 age of 556-660 cal BP indicates low net sedimentation rates prior to $556-660 \mathrm{cal} \mathrm{BP}$.

\section{Excavated materials}

A total of $382.0 \mathrm{~g}$ of charcoal was excavated from Square C (Table 15.12; Figure 15.38). SU2 has average net deposition rates of $126.8 \mathrm{~g} / 1000$ years for charcoal, and 19.1 stone artefacts/1000 years.

Table 15.12 Excavated materials retained in $2 \mathrm{~mm}$ mesh sieves from Square C, by XU.

\begin{tabular}{|c|c|c|c|c|c|c|c|}
\hline \multirow[t]{2}{*}{ XU } & \multirow{2}{*}{$\begin{array}{c}\text { Non-cultural sediments } \\
\mathrm{g}\end{array}$} & \multirow{2}{*}{$\frac{\text { Charcoal }}{9}$} & \multicolumn{2}{|c|}{ Stone artefacts } & \multirow{2}{*}{$\begin{array}{c}\text { 0ther organics } \\
g\end{array}$} & \multirow{2}{*}{$\begin{array}{c}\text { Insect larvae } \\
\mathrm{g}\end{array}$} & \multirow{2}{*}{$\begin{array}{c}\text { Land snail shell } \\
g\end{array}$} \\
\hline & & & $\#$ & $g$ & & & \\
\hline 1 & 14.4 & 31.0 & 1 & 0.1 & 16.1 & 0.1 & \\
\hline 2 & 21.3 & 45.7 & 1 & 0.7 & 5.8 & & 0.2 \\
\hline 3 & 22.5 & 59.9 & 2 & 0.4 & 4.3 & & \\
\hline 4 & 62.5 & 48.4 & 8 & 1.0 & 2.9 & & \\
\hline 5 & 44.9 & 63.5 & 6 & 0.3 & 5.9 & & \\
\hline 6 & 154.3 & 55.2 & 3 & 0.4 & 0.8 & & \\
\hline 7 & 2012.2 & 45.6 & 14 & 2.3 & 0.9 & & \\
\hline 8 & 800.7 & 31.7 & 13 & 208.7 & 1.2 & & \\
\hline Total & 3132.8 & 382.0 & 48 & 214.1 & 37.9 & 0.1 & 0.2 \\
\hline
\end{tabular}

Source: Authors' data.

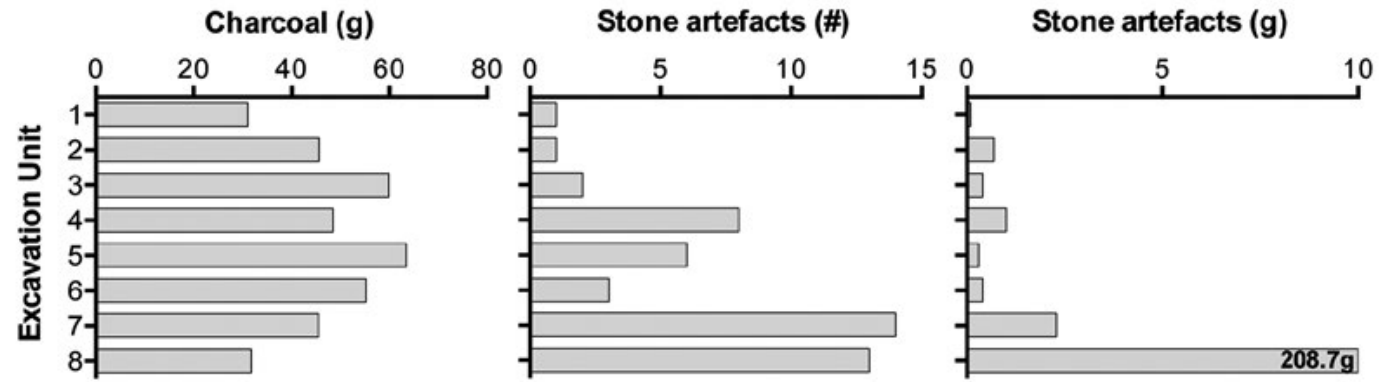

Figure 15.38 Distribution of charcoal and stone artefacts by XU, Square C.

Source: Illustration by Jerome Mialanes and Lara Lamb.

A total of 48 flaked stone artefacts was recovered from Square C, with a combined weight of $214.1 \mathrm{~g}$ (Table 15.12; Figure 15.38). Seven raw material types are represented, dominated by fine-grained and micro-crystalline quartzite ( 41.7 per cent and 35.4 per cent respectively). This is followed by silcrete ( 8.3 per cent) and chert ( 6.3 per cent). Also represented are crystalline quartz, a chert/silcrete composite, silcrete and calcified quartzite each comprising less than 5 per cent of the assemblage (Figure 15.39). 
A
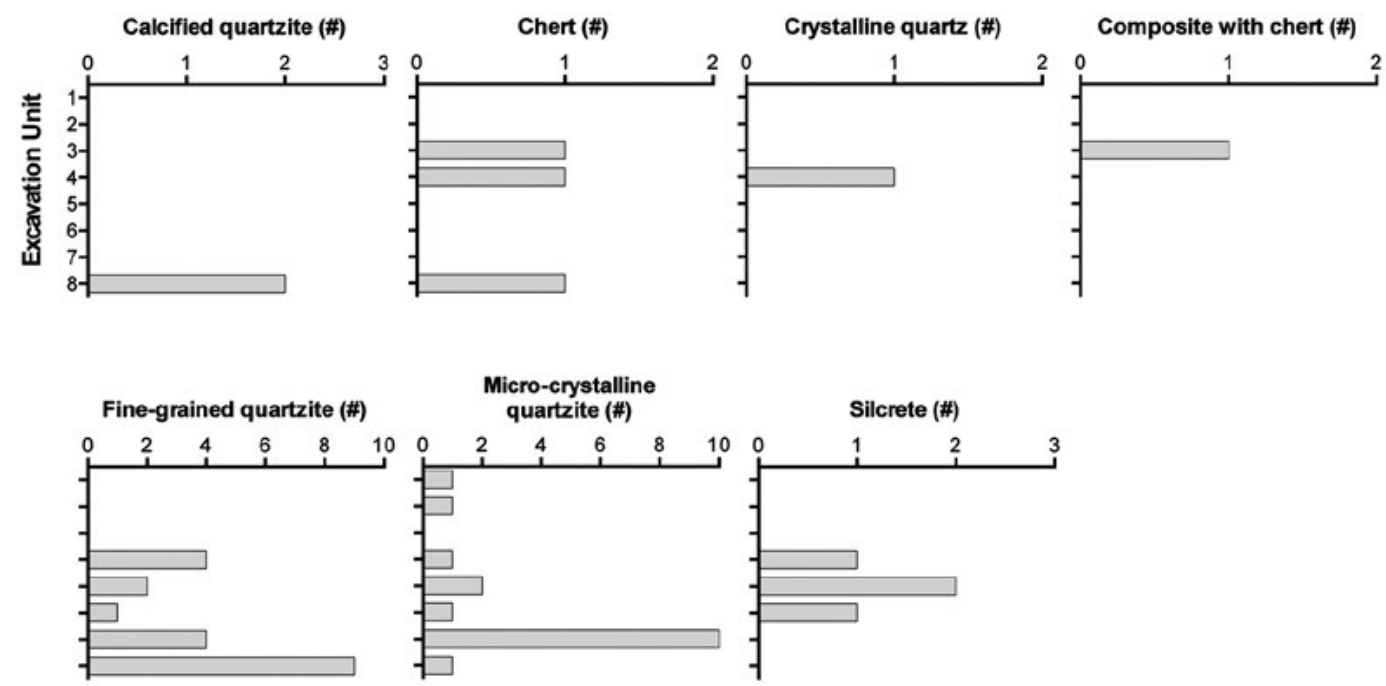

B
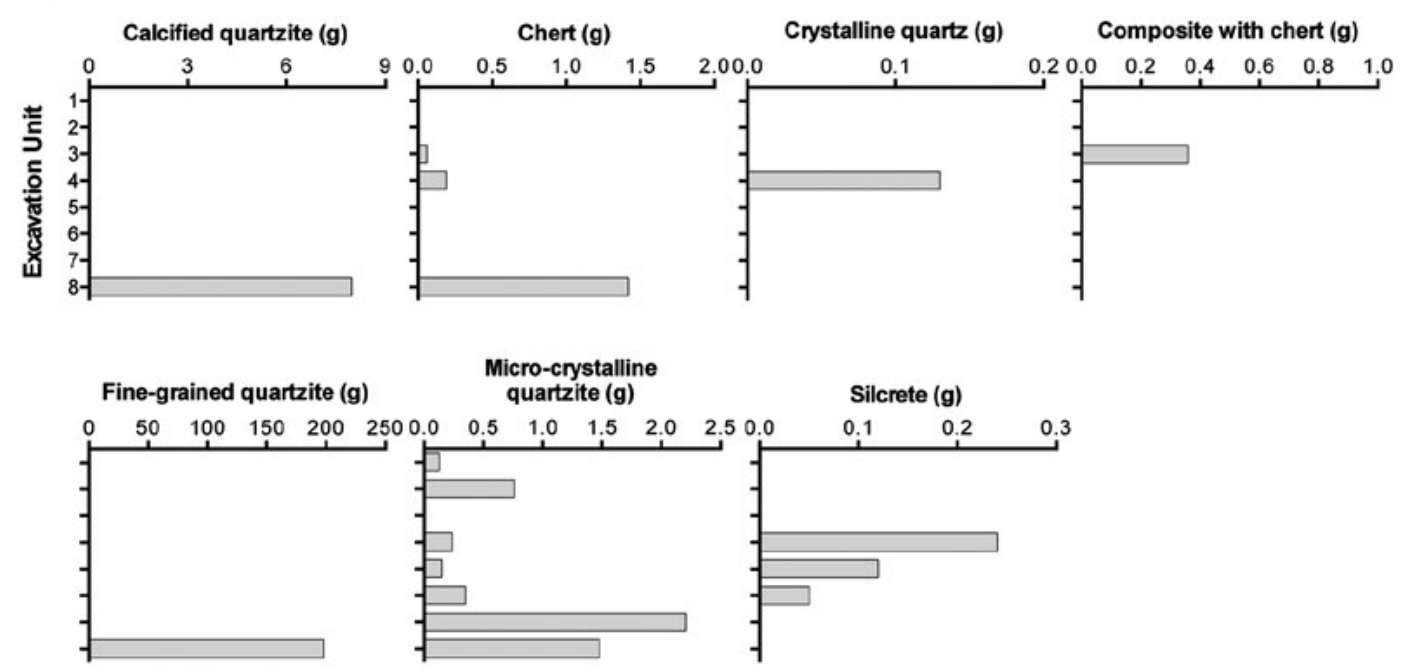

Figure 15.39 Number (A) and weight (B) of stone artefacts by raw material type for Square C, by XU. Source: lllustration by Jerome Mialanes and Lara Lamb.

Flaked pieces represent the highest proportion of the flaked artefacts ( 43.8 per cent), followed by complete flakes and distal portions (18.8 per cent each) and broken 'other' (6.3 per cent). The remaining fracture types all represent $<5$ per cent of the assemblage. There is a single unipolar core from XU8, made on fine-grained quartzite (Table 15.13). The core has two extant, adjacent platforms, with a combined three negative flake scars. Weighing $190 \mathrm{~g}$ and measuring $85 \mathrm{~mm}$ in maximum length, the core was far from exhausted when discarded. Given that quartzite is plentiful in this landscape, this is not remarkable. The large size of the core accounts for the major peak in mean weights of discarded artefacts in XU8, in what is otherwise a very sparse flaked stone artefact assemblage (Figure 15.40). 
Table 15.13 Distribution of fracture types among the stone artefacts, Square C, by XU.

\begin{tabular}{|l|r|r|r|r|r|r|r|r|r|r|}
\hline XU & $\begin{array}{c}\text { Bipolar } \\
\text { complete } \\
\text { flake }\end{array}$ & $\begin{array}{c}\text { Bipolar } \\
\text { core }\end{array}$ & $\begin{array}{c}\text { Broken } \\
\text { flake } \\
\text { (other) }\end{array}$ & $\begin{array}{c}\text { Complete } \\
\text { flake }\end{array}$ & $\begin{array}{c}\text { Distal } \\
\text { flake }\end{array}$ & $\begin{array}{c}\text { Flaked } \\
\text { piece }\end{array}$ & $\begin{array}{c}\text { Medial } \\
\text { flake }\end{array}$ & $\begin{array}{c}\text { Proximal } \\
\text { flake }\end{array}$ & $\begin{array}{c}\text { Unipolar } \\
\text { core }\end{array}$ & Total \\
\hline 1 & & & & & & & & 1 & & 1 \\
\hline 2 & & & & & & 1 & & & & 1 \\
\hline 3 & & & & & 1 & 1 & & & & 2 \\
\hline 4 & & & 1 & 4 & 1 & 2 & & & & 8 \\
\hline 5 & & & & & 1 & 4 & & & & 6 \\
\hline 6 & & & & & 2 & 1 & & & & 3 \\
\hline 7 & 1 & & 1 & 2 & 4 & 5 & 1 & & & 14 \\
\hline 8 & & 1 & 1 & 3 & & 7 & & & & 13 \\
\hline Total & 1 & 1 & 3 & 9 & 9 & 21 & 1 & 2 & & 48 \\
\hline
\end{tabular}

Source: Authors' data.

Mean max. dimension $(\mathrm{mm})$

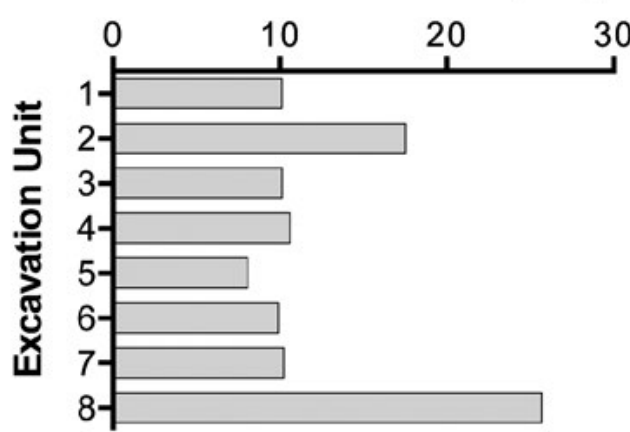

Mean weight (g)

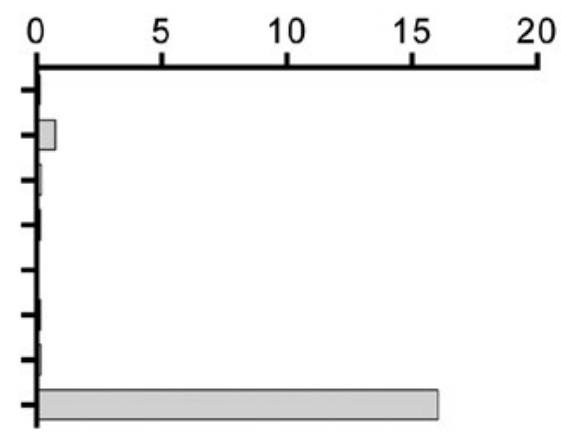

Figure 15.40 Mean weight of stone artefacts from Square C, by XU.

Source: Illustration by Jerome Mialanes and Lara Lamb.

\section{Square D}

Square D is located on the northwestern side of the rock stack, $2.5 \mathrm{~m}$ north of Square B. The excavation square's eastern wall directly abuts the outcrop's rock wall at ground level. The square is positioned c. $3.0 \mathrm{~m}$ southwest of art Panel A that contains the large bird motif (Figures 15.3 and 15.41).

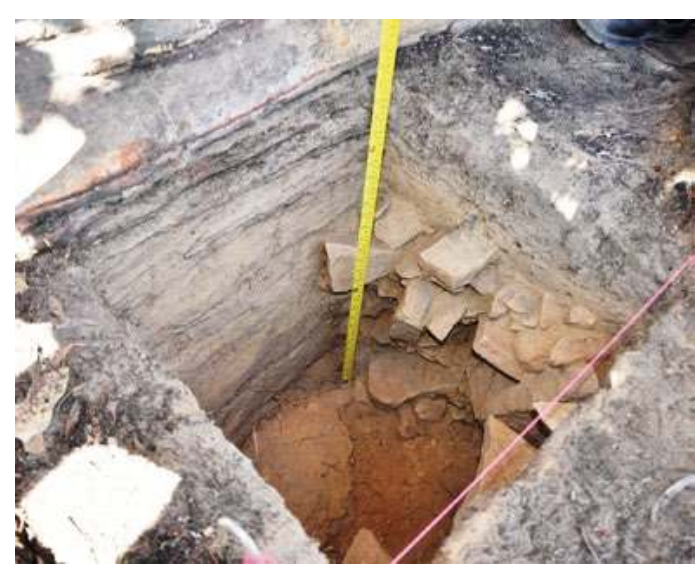

Figure 15.41 Square $D$, showing in situ termite nest at base of excavation.

The string line is along the west side of the square.

Source: Photograph by Lara Lamb. 


\section{Stratigraphy}

Square D contains three SUs; excavation proceeded to a maximum depth of $59.4 \mathrm{~cm}$ (Table 15.14). SU1 spans from ground surface to a maximum depth of $8 \mathrm{~cm}$. It consists of loose weak-red sand (2.5YR 5/3) that contains abundant plant matter (leaf litter, rootlets) and charcoal. SU2 below it extends to a maximum depth of $26 \mathrm{~cm}$ below ground; it is more compact pale-brown sand (10YR 6/3) with abundant charcoal and numerous stone artefacts. SU3 extends down to bedrock at $59.4 \mathrm{~cm}$ depth. It is light yellowish-brown sand (10YR 6/4), and contains large, angular quartzitic sandstone blocks. A large termite nest is present underground within SU3, spanning from $46 \mathrm{~cm}$ below surface down to bedrock. The termite nest is well delimited and abuts the rock wall in the northeastern corner of the square. The nest has a hard outer surface; it was left intact and not excavated (Figures 15.41 and 15.42).

Table 15.14 Details of Square D excavation, by XU.

\begin{tabular}{|c|c|c|c|c|c|c|c|}
\hline XU & SU & $\begin{array}{l}\text { Mean depth at } \\
\text { top }(\mathrm{cm})\end{array}$ & $\begin{array}{l}\text { Mean depth at } \\
\text { centre }(\mathrm{cm})\end{array}$ & $\begin{array}{l}\text { Mean depth } \\
\text { at base }(\mathrm{cm})\end{array}$ & $\begin{array}{c}\text { Mean thickness } \\
(\mathrm{cm})\end{array}$ & $\begin{array}{c}\text { Weight of } \\
\text { excavated } \\
\text { sediments }(\mathrm{kg})\end{array}$ & $\begin{array}{c}\text { Volume of } \\
\text { excavated } \\
\text { sediments (litres) }\end{array}$ \\
\hline 1 & $1 / 2$ & 0.0 & 0.3 & 0.6 & 0.6 & 0.8 & 0.7 \\
\hline 2 & $1 / 2$ & 0.6 & 1.4 & 2.2 & 1.6 & 4.0 & 2.8 \\
\hline 3 & $1 / 2$ & 2.2 & 2.8 & 3.5 & 1.3 & 4.0 & 4.0 \\
\hline 4 & $1 / 2$ & 3.5 & 4.4 & 5.3 & 1.8 & 5.6 & 5.0 \\
\hline 5 & $1 / 2$ & 5.3 & 6.3 & 7.3 & 2.0 & 6.5 & 5.0 \\
\hline 6 & $1 / 2$ & 7.3 & 8.2 & 9.2 & 1.9 & 6.1 & 5.0 \\
\hline 7 & 2 & 9.2 & 10.0 & 10.8 & 1.6 & 5.1 & 4.5 \\
\hline 8 & 2 & 10.8 & 11.8 & 12.8 & 2.0 & 6.8 & 6.0 \\
\hline 9 & 2 & 12.8 & 14.2 & 15.7 & 2.9 & 7.8 & 6.0 \\
\hline 10 & 2 & 15.7 & 17.0 & 18.3 & 2.6 & 8.2 & 6.0 \\
\hline 11 & 2 & 18.3 & 19.5 & 20.8 & 2.5 & 7.3 & 3.0 \\
\hline 12 & 2 & 20.8 & 21.5 & 22.3 & 1.5 & 5.8 & 3.0 \\
\hline 13 & $2 / 3$ & 22.3 & 23.0 & 23.7 & 1.4 & 4.8 & 3.5 \\
\hline 14 & $2 / 3$ & 23.7 & 24.5 & 25.3 & 1.6 & 5.2 & 3.0 \\
\hline 15 & 3 & 25.3 & 26.4 & 27.5 & 2.2 & 6.9 & 1.5 \\
\hline 16 & 3 & 27.5 & 28.1 & 28.8 & 1.3 & 5.9 & 3.0 \\
\hline 17 & 3 & 28.8 & 29.5 & 30.3 & 1.5 & 5.4 & 3.0 \\
\hline 18 & 3 & 30.3 & 31.0 & 31.7 & 1.4 & 5.2 & 3.0 \\
\hline 19 & 3 & 31.7 & 32.4 & 33.2 & 1.5 & 6.3 & 2.0 \\
\hline 20 & 3 & 33.2 & 34.0 & 34.8 & 1.6 & 7.2 & 4.0 \\
\hline 21 & 3 & 34.8 & 36.4 & 38.0 & 3.2 & 6.4 & 4.0 \\
\hline 22 & 3 & 38.0 & 38.9 & 39.9 & 1.9 & 5.4 & 4.0 \\
\hline 23 & 3 & 39.9 & 40.5 & 41.1 & 1.2 & 6.1 & 3.0 \\
\hline 24 & 3 & 41.1 & 42.4 & 43.8 & 2.7 & 7.0 & 4.5 \\
\hline 25 & 3 & 43.8 & 45.2 & 46.7 & 2.9 & 6.4 & 4.0 \\
\hline 26 & 3 & 46.7 & 48.5 & 50.4 & 3.7 & 13.7 & 6.7 \\
\hline 27 & 3 & 50.4 & 51.3 & 52.2 & 1.8 & 6.0 & 3.0 \\
\hline 28 & 3 & 52.2 & 54.8 & 57.5 & 5.3 & 9.3 & 6.0 \\
\hline \multicolumn{2}{|c|}{ Total } & & & & 2.0 & 175.2 & 109.2 \\
\hline
\end{tabular}

Source: Authors' data. 


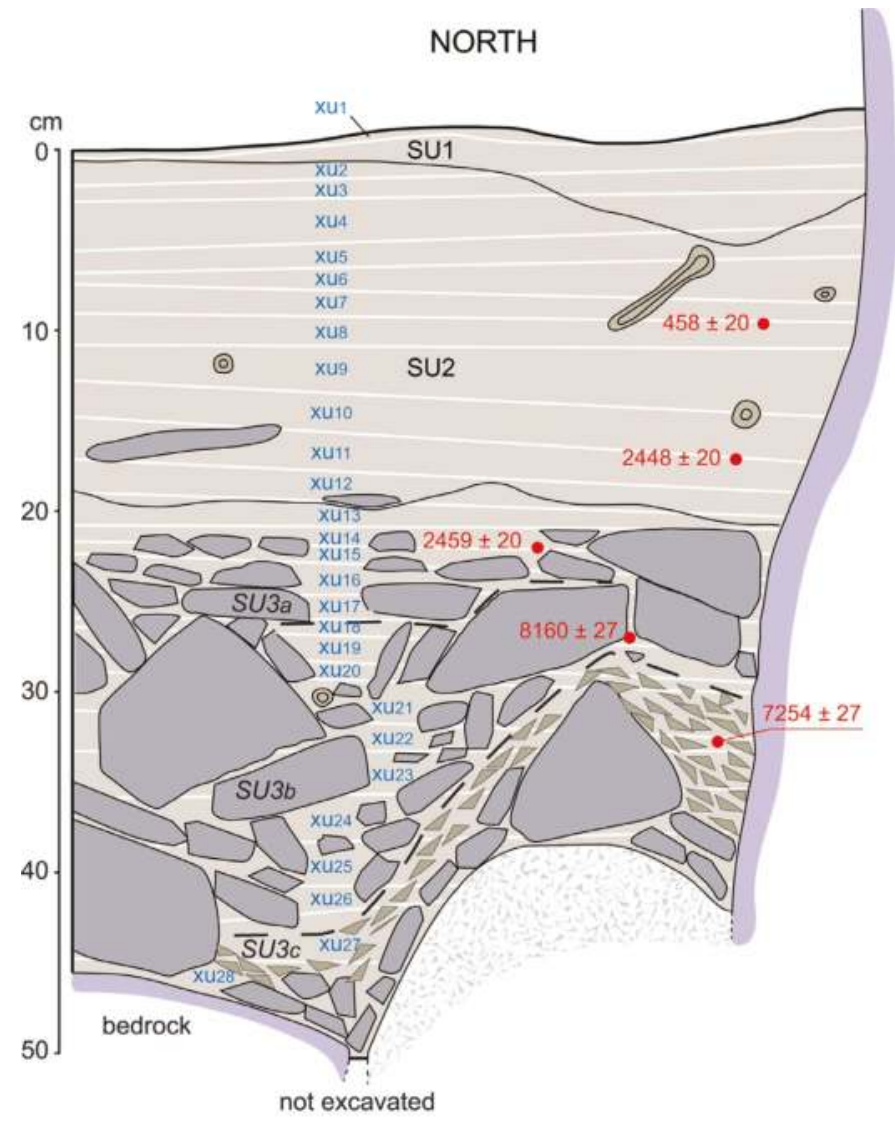

Figure 15.42 Square D north section with back-plotted XUs and radiocarbon dates.

Source: Illustration by Kara Rasmanis, Bruno David and Jean-Jacques Delannoy.

\section{Chronology}

Six AMS radiocarbon dates were obtained on individual pieces of charcoal from Square D. Three of these come from SU2, and three come from SU3:

- SU2: Dates of $89 \pm 20 \mathrm{BP}$ (Wk-40586) (calibrating to 31-256 cal BP) from $4.0 \mathrm{~cm}$ depth in XU4; $458 \pm 20$ BP (Wk-40587) (calibrating to 498-527 cal BP) from $13.3 \mathrm{~cm}$ depth in XU8; and $2448 \pm 20 \mathrm{BP}$ (Wk-40588) (calibrating to 2361-2699 cal BP) from $20.9 \mathrm{~cm}$ depth in XU11, are in good chrono-stratigraphic order. The determination of $2448 \pm 20 \mathrm{BP}$ dates the base of SU2, as indicated also by a similar date (see below) for the very top of SU3.

- SU3: $2459 \pm 20 \mathrm{BP}$ (Wk-40589) (calibrating to 2379-2545 cal BP) from $27.8 \mathrm{~cm}$ depth in XU15; $8160 \pm 27$ BP (Wk-40590) (calibrating to 9014-9245 cal BP) from $31.3 \mathrm{~cm}$ depth in XU20; and $7254 \pm 27 \mathrm{BP}$ (Wk-40591) (calibrating to 8008-8161 cal BP) from $41.3 \mathrm{~cm}$ depth in XU22.

Given that the two lowermost SU3 dates are considerably older than the SU2 dates, the determination of $2459 \pm 20 \mathrm{BP}$ that is akin to the age of the base of SU2 was probably postdepositionally displaced downwards from the SU2-SU3 interface: there are only $3.8 \mathrm{~cm}$ of sediment between the base of SU2 and that radiocarbon date. There is also a slight inversion within SU3 between dates of $8160 \pm 27 \mathrm{BP}(31.3 \mathrm{~cm}$ depth in XU20) and $7254 \pm 27 \mathrm{BP}$ (41.3 cm depth in XU22). The younger of these two dates came from very close to the rock wall in the eastern section of the square. That rock wall is fully exposed to the elements, and fine sediments including charcoal particles may have post-depositionally moved slightly downward through factors such as wet-season rainwater action against the rock wall. 
The sequence of dates in Square D shows a similar pattern of slow sedimentation rates as seen in Square B a few metres to the south. In Square D, the calibrated age of 9014-9245 cal BP at $31.3 \mathrm{~cm}$ depth is separated from a calibrated age of $2379-2545 \mathrm{cal} \mathrm{BP}$ at $27.8 \mathrm{~cm}$ depth, representing a period of c. 6773 years (based on median calibrated ages) for just $3.5 \mathrm{~cm}$ of deposit at an average net sedimentation rate of $0.05 \mathrm{~cm} / 100$ years (see Table 15.4 for radiocarbon dates).

\section{Excavated materials}

A total of $260 \mathrm{~g}$ of charcoal was excavated from Square D. As with Square B nearby, beginning c. $2600 \mathrm{cal}$ BP there is a major, seven-fold increase in net charcoal deposition rates through time from $10.2 \mathrm{~g} / 1000$ years in SU3 to $76.5 \mathrm{~g} / 1000$ years in SU2. In Square D, this increase in deposition rates is only apparent above XU12, representing the SU3-SU2 interface (Table 15.15; Figure 15.43).

Table 15.15 Excavated materials retained in $2 \mathrm{~mm}$ mesh sieves from Square $\mathrm{D}$, by XU.

\begin{tabular}{|c|c|c|c|c|c|c|c|}
\hline \multirow[t]{2}{*}{ XU } & \multirow{2}{*}{$\begin{array}{c}\text { Non-cultural } \\
\text { sediments }\end{array}$} & \multirow{2}{*}{$\begin{array}{c}\text { Charcoal } \\
g\end{array}$} & \multicolumn{2}{|c|}{ Stone artefacts } & \multirow{2}{*}{$\begin{array}{c}\begin{array}{c}\text { Other } \\
\text { organics }\end{array} \\
g\end{array}$} & \multirow{2}{*}{$\begin{array}{c}\text { Insect larvae } \\
9 \\
\end{array}$} & \multirow{2}{*}{$\begin{array}{c}\text { Land snail } \\
\text { shell }\end{array}$} \\
\hline & & & $\#$ & $g$ & & & \\
\hline 1 & 34.1 & 22.9 & & & 12.4 & 0.02 & 0.01 \\
\hline 2 & 38.2 & 16.3 & & & 10.6 & & \\
\hline 3 & 41.1 & 12.3 & 1 & 0.1 & 9.9 & 0.01 & \\
\hline 4 & 59.5 & 32.5 & & & 14.9 & & \\
\hline 5 & 81.7 & 20.0 & 1 & 0.2 & 31.0 & & \\
\hline 6 & 76.2 & 15.5 & 4 & 0.5 & 6.0 & & \\
\hline 7 & 101.4 & 6.3 & 2 & 4.03 & 17.3 & & \\
\hline 8 & 159.9 & 19.9 & 2 & 0.2 & 9.3 & & \\
\hline 9 & 195.4 & 18.2 & 5 & 0.5 & 5.4 & & \\
\hline 10 & 478.7 & 21.3 & 6 & 0.8 & 9.4 & & \\
\hline 11 & 348.4 & 13.1 & 4 & 1.06 & 0.8 & & \\
\hline 12 & 329.8 & 6.5 & 12 & 8.6 & 1.0 & & \\
\hline 13 & 442.9 & 3.6 & 12 & 46.5 & 3.1 & & \\
\hline 14 & 615.5 & 3.8 & 12 & 141.0 & 0.8 & & \\
\hline 15 & 255.0 & 2.9 & 10 & 13.3 & 0.3 & & \\
\hline 16 & 456.2 & 1.9 & 8 & 638.1 & 0.6 & & \\
\hline 17 & 545.9 & 8.9 & 9 & 23.6 & 1.3 & & \\
\hline 18 & 530.2 & 3.5 & 6 & 12.5 & 1.4 & & \\
\hline 19 & 342.5 & 4.4 & 5 & 223.0 & 2.1 & & \\
\hline 20 & 1124.9 & 5.9 & 14 & 205.0 & 2.4 & & \\
\hline 21 & 1005.2 & 5.2 & 6 & 5.1 & 1.3 & & \\
\hline 22 & 1213.0 & 9.6 & 6 & 21.1 & 2.4 & & \\
\hline 23 & 1612.6 & 1.0 & 5 & 119.4 & 1.2 & & \\
\hline 24 & 2018.3 & 0.8 & 3 & 26.5 & 2.2 & & \\
\hline 25 & 1733.9 & 1.4 & 4 & 1.2 & 1.5 & & \\
\hline 26 & 2632.9 & 0.7 & 2 & 1.7 & 0.8 & & \\
\hline 27 & 2387.8 & 1.9 & & & 3.0 & & \\
\hline 28 & 4006.3 & 0.2 & & & 3.2 & & \\
\hline Total & $22,868.0$ & 260.5 & 139 & 1494.8 & 155.6 & 0.03 & 0.01 \\
\hline
\end{tabular}

Source: Authors' data. 


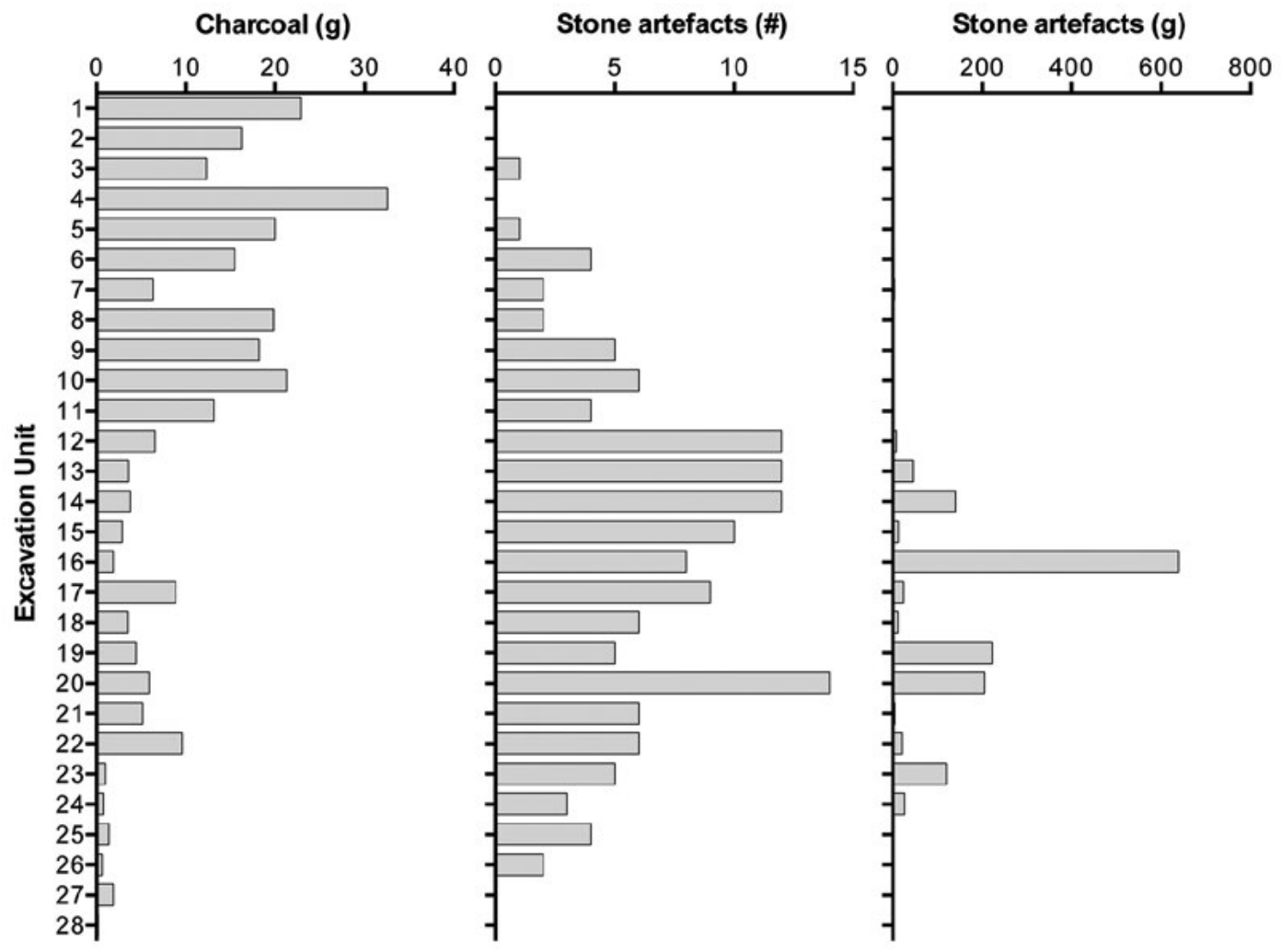

Figure 15.43 Distribution of charcoal and stone artefacts by XU, Square D.

Source: Illustration by Jerome Mialanes and Lara Lamb.

A total of 139 flaked stone artefacts with a combined weight of $1494.8 \mathrm{~g}$ was excavated from Square D (Table 15.15; Figure 15.43). Four raw material types are represented (Figure 15.44): fine-grained quartzite (41.7 per cent), sandstone (29.5 per cent), micro-crystalline quartzite (25.2 per cent) and coarse-grained quartzite (3.6 per cent). The high proportion of sandstone artefacts distinguishes the assemblage from those of other squares. These sandstone artefacts have a mean weight of $26.2 \mathrm{~g}$ (and maximum of $499 \mathrm{~g}$ ), adding considerably to the overall weight of the flaked stone artefacts.

Fracture types are dominated by flaked pieces ( 41.0 per cent), followed by complete flakes (33.1 per cent) and broken 'other' (10.8 per cent). Distal portions, left-split cones, medial and proximal portions, retouched flakes, unipolar cores and right-split cones each represent less than 5 per cent of the assemblage (Table 15.16). Each of the two retouched flakes was made on sandstone; they are both retouched on both the left and distal margins (along 21 per cent and 12 per cent of the length, respectively). 
A
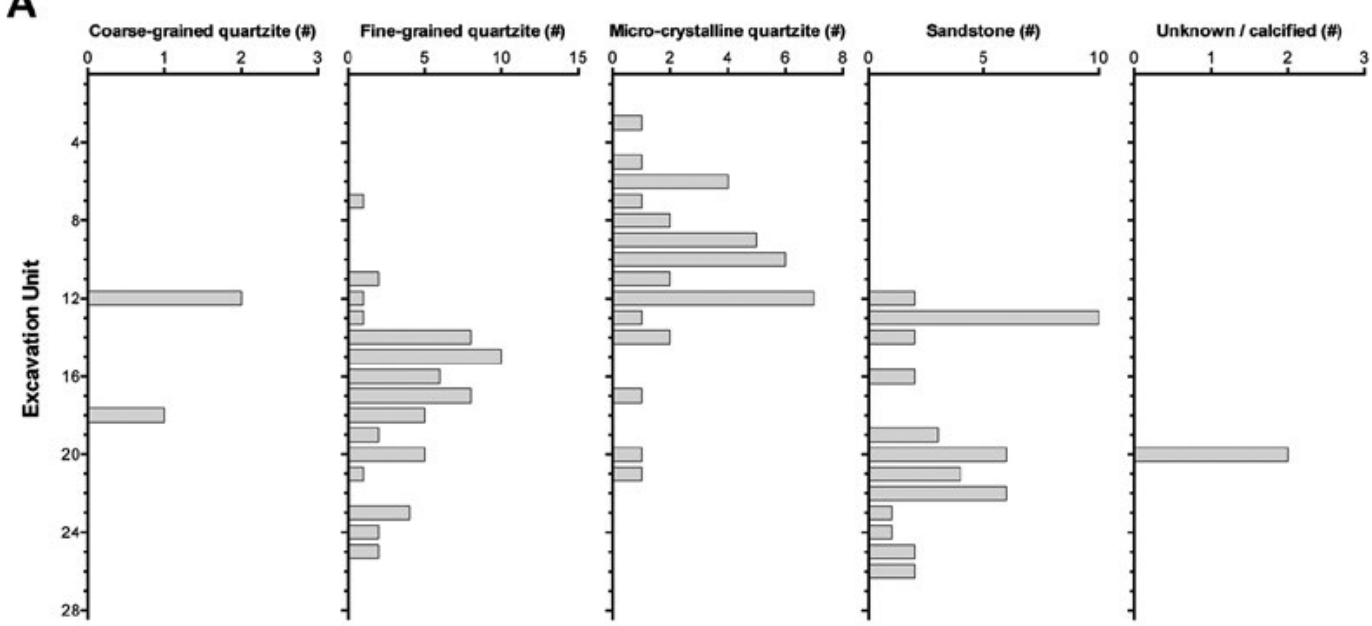

B
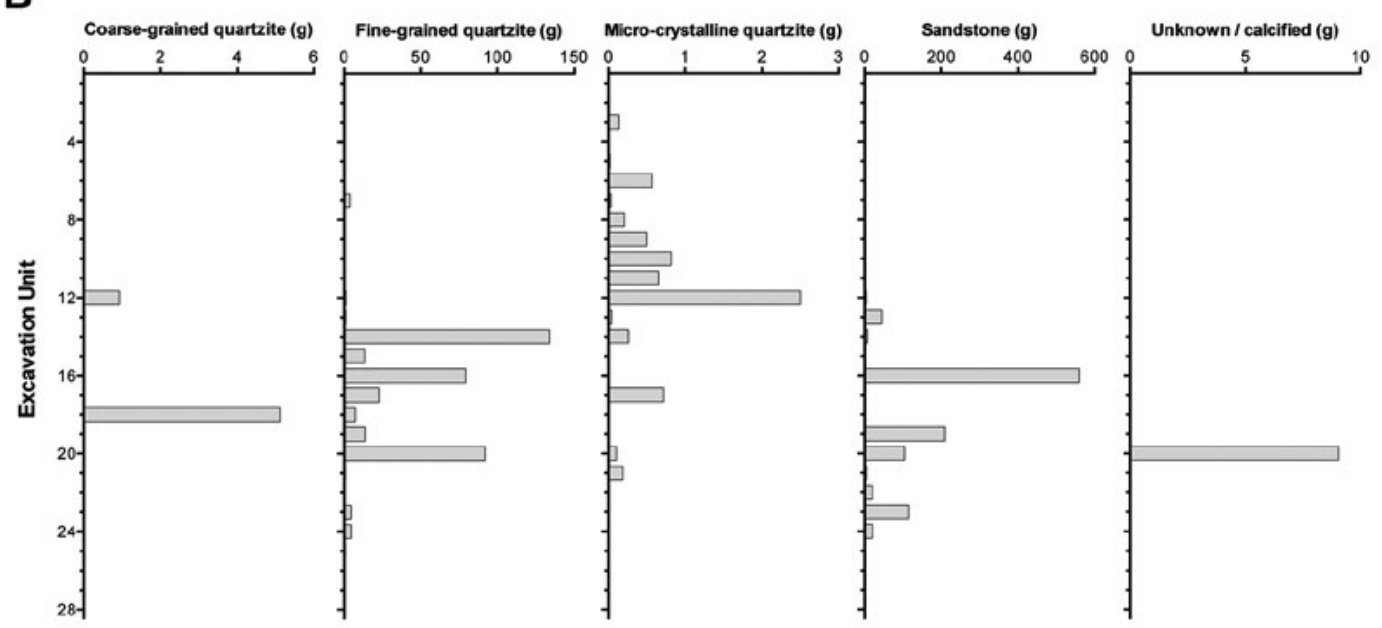

Figure 15.44 Number (A) and weight (B) of stone artefacts by raw material type for Square D, by XU. Source: Illustration by Jerome Mialanes and Lara Lamb.

Table 15.16 Distribution of fracture types among the stone artefacts from Square D, by XU.

\begin{tabular}{|c|c|c|c|c|c|c|c|c|c|c|c|}
\hline$X U$ & $\begin{array}{c}\text { Broken } \\
\text { flake } \\
\text { (other) }\end{array}$ & $\begin{array}{l}\text { Complete } \\
\text { flake }\end{array}$ & $\begin{array}{l}\text { Distal } \\
\text { flake }\end{array}$ & $\begin{array}{l}\text { Flaked } \\
\text { piece }\end{array}$ & $\begin{array}{l}\text { Left- } \\
\text { split } \\
\text { cone } \\
\end{array}$ & $\begin{array}{l}\text { Medial } \\
\text { flake }\end{array}$ & $\begin{array}{l}\text { Proximal } \\
\text { flake }\end{array}$ & $\begin{array}{c}\text { Retouched } \\
\text { flake }\end{array}$ & $\begin{array}{c}\text { Right- } \\
\text { split } \\
\text { cone }\end{array}$ & $\begin{array}{c}\text { Unipolar } \\
\text { core }\end{array}$ & Total \\
\hline \multicolumn{12}{|l|}{1} \\
\hline \multicolumn{12}{|l|}{2} \\
\hline 3 & & & & & & & 1 & & & & 1 \\
\hline \multicolumn{12}{|l|}{4} \\
\hline 5 & & & & 1 & & & & & & & 1 \\
\hline 6 & & 2 & & 1 & & 1 & & & & & 4 \\
\hline 7 & & 1 & & 1 & & & & & & & 2 \\
\hline 8 & & 2 & & & & & & & & & 2 \\
\hline 9 & & 3 & & 1 & & & 1 & & & & 5 \\
\hline 10 & 3 & 1 & & 1 & & & 1 & & & & 6 \\
\hline 11 & 1 & 1 & & 1 & & & & & & 1 & 4 \\
\hline 12 & & 9 & 1 & 2 & & & & & & & 12 \\
\hline
\end{tabular}




\begin{tabular}{|c|c|c|c|c|c|c|c|c|c|c|c|}
\hline$X U$ & $\begin{array}{l}\text { Broken } \\
\text { flake } \\
\text { (other) }\end{array}$ & $\begin{array}{l}\text { Complete } \\
\text { flake }\end{array}$ & $\begin{array}{l}\text { Distal } \\
\text { flake }\end{array}$ & $\begin{array}{l}\text { Flaked } \\
\text { piece }\end{array}$ & $\begin{array}{l}\text { Left- } \\
\text { split } \\
\text { cone } \\
\end{array}$ & $\begin{array}{l}\text { Medial } \\
\text { flake }\end{array}$ & $\begin{array}{l}\text { Proximal } \\
\text { flake }\end{array}$ & $\begin{array}{l}\text { Retouched } \\
\text { flake }\end{array}$ & $\begin{array}{l}\text { Right- } \\
\text { split } \\
\text { cone }\end{array}$ & $\begin{array}{l}\text { Unipolar } \\
\text { core }\end{array}$ & Total \\
\hline 13 & & 3 & 2 & 5 & 1 & 1 & & & & & 12 \\
\hline 14 & 1 & 4 & 1 & 5 & & & 1 & & & & 12 \\
\hline 15 & 1 & 2 & & 7 & & & & & & & 10 \\
\hline 16 & & 4 & 1 & 2 & & & & & & 1 & 8 \\
\hline 17 & 2 & 3 & & 4 & & & & & & & 9 \\
\hline 18 & & & & 4 & 1 & & 1 & & & & 6 \\
\hline 19 & 1 & 3 & & 1 & & & & & & & 5 \\
\hline 20 & 3 & 3 & & 8 & & & & & & & 14 \\
\hline 21 & 1 & 3 & 1 & & & & & & 1 & & 6 \\
\hline 22 & & 1 & & 4 & & & & & & 1 & 6 \\
\hline 23 & 1 & & & 3 & & & & 1 & & & 5 \\
\hline 24 & & & & 2 & & & & 1 & & & 3 \\
\hline 25 & 1 & & & 3 & & & & & & & 4 \\
\hline 26 & & 1 & & 1 & & & & & & & 2 \\
\hline Total & 15 & 46 & 6 & 57 & 2 & 2 & 5 & 2 & 1 & 3 & 139 \\
\hline
\end{tabular}

Source: Authors' data.

The distribution of raw materials through time reveals several patterns worthy of note. First, there are no exotic materials in Square D; both the sandstone and quartzite could have been sourced from the shelter itself. SU3 is characterised by a predominance of finegrained quartzite and sandstone. SU2 marks a noticeable shift in use from these raw materials to micro-crystalline quartzite of a brown/reddish hue (10YR, 2.5YR and 5YR) (Figure 15.44). SU2 is also characterised by a decrease in stone artefact discard rates, from 17.3 artefacts/1000 years in SU3 to 9.6 artefacts/1000 years in SU2, and by a decrease in the mean weight and maximum length of artefacts (Figure 15.45). There appears to be a correlation between the prevalence of micro-crystalline quartzite and smaller, complete flakes in SU2, although the sample size is probably too small to draw definitive conclusions from these patterns.

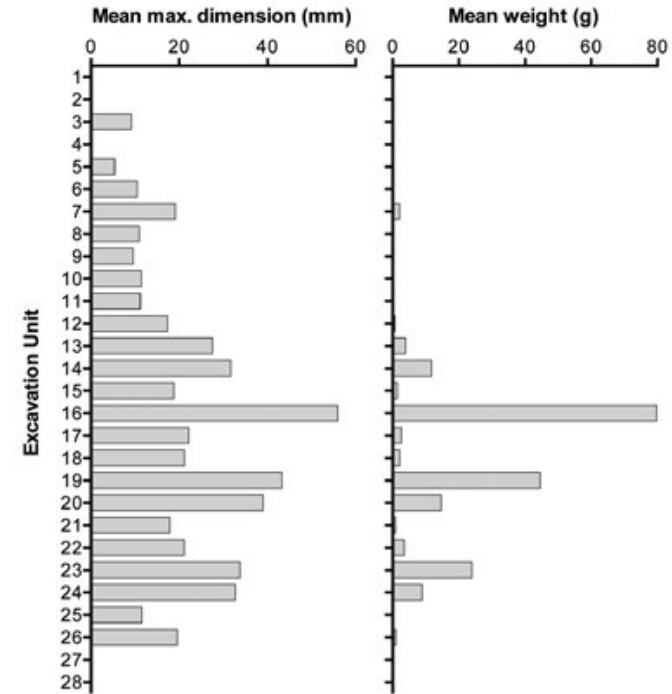

Figure 15.45 Mean weight and maximum length of stone artefacts from Square $D$, by XU.

Source: Illustration by Jerome Mialanes and Lara Lamb. 


\section{Square E}

Square E originally covered an area $1.0 \times 1.0 \mathrm{~m}$, but the square was extended by a further $20 \mathrm{~cm}$ along its northern edge in order to remove large unstable and unsupported rocks revealed during the excavation. Along its eastern edge, Square E is contiguous with Square B, and was thus positioned to continue excavating Square B to greater depth than would have otherwise been possible (Figure 15.46).

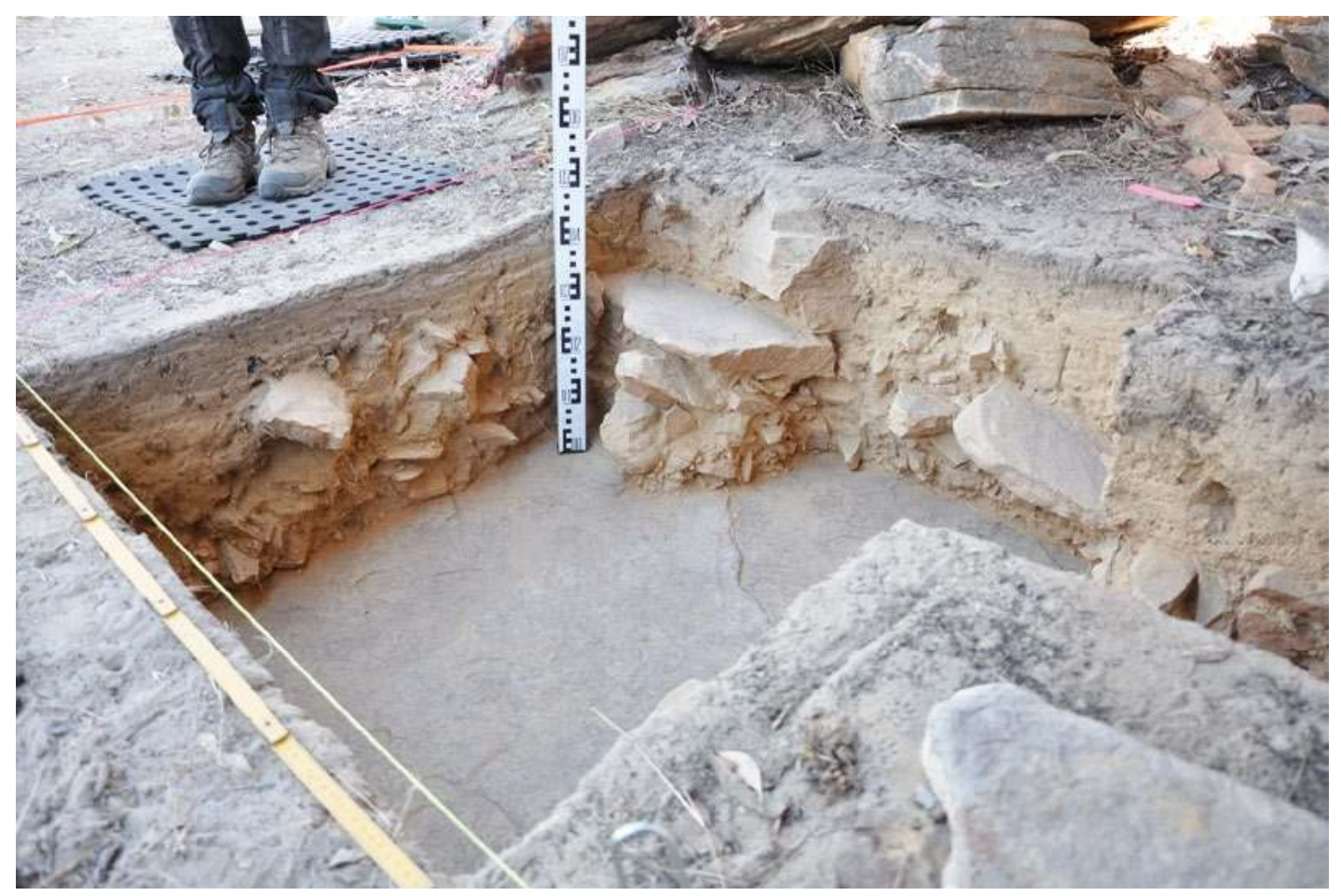

Figure 15.46 Square E after completion of excavation.

Note the Square B pit on right-hand side abutting the larger excavation pit of Square $E$.

Source: Photograph by Bryce Barker.

\section{Ground penetrating radar}

Ground penetrating radar (GPR) investigations were undertaken to the southwest and south of the rock stack (Figure 15.47), including the area of Squares $\mathrm{B}+\mathrm{E}$, and are extended over Squares $\mathrm{C}$ and A by a single profile. GPR lines were collected in an approximately east-west orientation with a spacing of $0.5 \mathrm{~m}$ between profiles using a Mala X3M instrument with a $250 \mathrm{Mhz}$ antenna. Acquisition settings include a sampling frequency of $10038 \mathrm{Mhz}$, a time window of $102 \mathrm{~ns}, 1024$ samples, a trace interval of $0.02 \mathrm{~m}$ and four stacks. The data were processed using ReflexW software with a scheme of filters including move start time, subtract mean (dewow), energy decay, background remove, bandpass and running average applied sequentially (Goodman and Piro 2013). The results show that the bedrock morphology revealed by excavation, being of a relatively flat surface with some small pieces of rock present in the stratigraphy above it, is present extensively around the site. The sharp topographic depression revealed in the Square B excavation continues to the south and widens to approximately $2 \mathrm{~m}$ with gently sloping sides rather than the precipitous topography shown in excavation. This change in subsurface geomorphology coincides with the southern edge of the sandstone stack. 


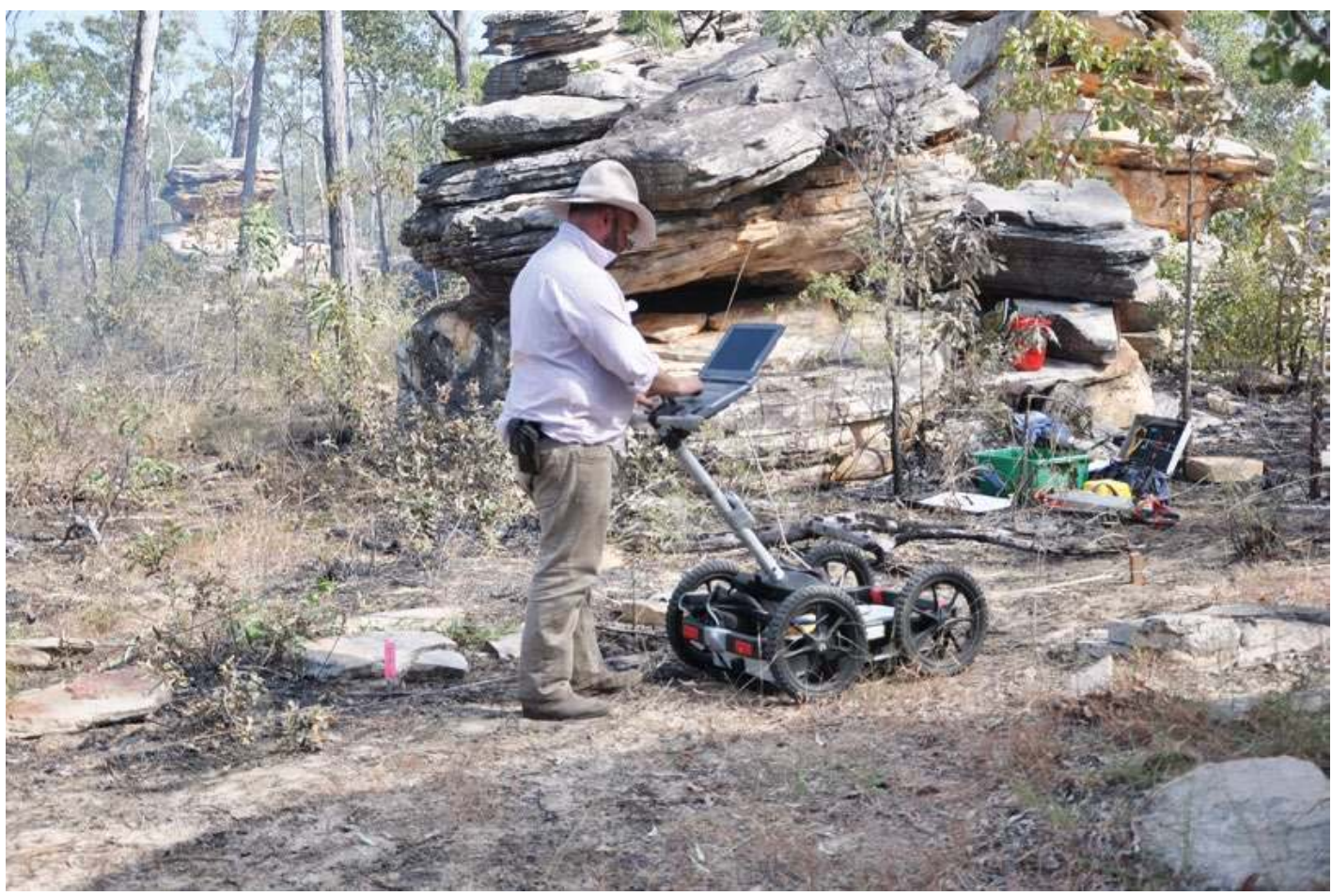

Figure 15.47 Ground penetrating radar work in progress in the area within and surrounding Square $E$, prior to excavation.

Source: Photograph by Bryce Barker.

\section{Stratigraphy in excavation}

Excavation in Square E reached a maximum depth of $48 \mathrm{~cm}$, ceasing at a flat bedrock surface (Table 15.17). Square E contains four SUs. SU1 reaches a maximum depth of $14 \mathrm{~cm}$; it consists of loose weak-red sand (2.5YR 5/3). SU2 extends to a maximum depth of $28 \mathrm{~cm}$, consisting of slightly more compact pale-brown sand (10YR 6/3) incorporating some large, angular quartzitic sandstone rocks. SU3 is light yellowish-brown (10YR 6/4) in colour and of similar soft sediment consistency to SU2; it extends to a maximum depth of $43 \mathrm{~cm}$. However, it is marked by a steep increase in the number of large angular sandstone rocks that originated from the rock outcrop above the square. SU4 extends down to bedrock. It consists of a similar light yellowish brown sand (10YR 6/4) to SU3 above it, but contains fewer large angular blocks and an abundance of small rounded pisoliths (Figures 15.32; see also Figure 15.31).

Table 15.17 Details of Square E excavation, by XU.

\begin{tabular}{|c|c|c|c|c|c|c|}
\hline XU & SU & $\begin{array}{c}\text { Mean depth at } \\
\text { top }(\mathrm{cm})\end{array}$ & $\begin{array}{l}\text { Mean depth at } \\
\text { centre }(\mathrm{cm})\end{array}$ & $\begin{array}{c}\text { Mean depth at } \\
\text { base }(\mathrm{cm})\end{array}$ & $\begin{array}{l}\text { Mean thickness } \\
(\mathrm{cm})\end{array}$ & $\begin{array}{l}\text { Weight of excavated } \\
\text { sediments }(\mathrm{kg})\end{array}$ \\
\hline 1 & 1 & 0.0 & 0.8 & 1.6 & 1.6 & 8.0 \\
\hline 2 & 1 & 1.6 & 1.9 & 2.3 & 0.7 & 19.9 \\
\hline 3 & 1 & 2.3 & 2.9 & 3.5 & 1.2 & 24.6 \\
\hline 4 & $1 / 2$ & 3.5 & 8.9 & 5.4 & 1.9 & 24.2 \\
\hline 5 & $1 / 2$ & 5.4 & 6.5 & 7.6 & 2.2 & 29.2 \\
\hline 6 & $1 / 2$ & 7.6 & 8.5 & 9.4 & 1.8 & 29.6 \\
\hline 7 & $1 / 2 / 3$ & 9.4 & 10.6 & 11.9 & 2.5 & 31.3 \\
\hline 8 & $1 / 2 / 3$ & 11.9 & 12.8 & 13.7 & 1.8 & 27.4 \\
\hline 9 & $2 / 3$ & 13.7 & 15.2 & 16.7 & 3.0 & 25.3 \\
\hline
\end{tabular}




\begin{tabular}{|c|c|c|c|c|c|c|}
\hline $\mathrm{XU}$ & SU & $\begin{array}{l}\text { Mean depth at } \\
\text { top }(\mathrm{cm})\end{array}$ & $\begin{array}{l}\text { Mean depth at } \\
\text { centre }(\mathrm{cm})\end{array}$ & $\begin{array}{c}\text { Mean depth at } \\
\text { base }(\mathrm{cm})\end{array}$ & $\begin{array}{l}\text { Mean thickness } \\
(\mathrm{cm})\end{array}$ & $\begin{array}{c}\text { Weight of excavated } \\
\text { sediments }(\mathrm{kg})\end{array}$ \\
\hline 10 & $2 / 3$ & 16.7 & 18.2 & 19.7 & 3.0 & 26.4 \\
\hline 11 & $2 / 3$ & 19.7 & 20.5 & 21.4 & 1.7 & 22.7 \\
\hline 12 & $2 / 3$ & 21.4 & 22.2 & 23.0 & 1.6 & 26.0 \\
\hline 13 & $2 / 3$ & 23.0 & 24.1 & 25.3 & 2.3 & 27.0 \\
\hline 14 & $2 / 3$ & 25.3 & 26.0 & 26.8 & 1.5 & 18.2 \\
\hline 15 & $2 / 3$ & 26.8 & 28.0 & 29.3 & 2.5 & 19.3 \\
\hline 16 & 3 & 29.3 & 29.9 & 30.5 & 1.2 & 34.4 \\
\hline 17 & 3 & 30.5 & 31.4 & 32.4 & 1.9 & 23.2 \\
\hline 18 & 3 & 32.4 & 33.3 & 34.2 & 1.8 & 20.1 \\
\hline 19 & 3 & 34.2 & 34.5 & 34.9 & 0.7 & 25.7 \\
\hline 20 & $3 / 4$ & 34.9 & 36.2 & 37.6 & 2.7 & 21.1 \\
\hline 21 & $3 / 4$ & 37.6 & 38.3 & 39.1 & 1.5 & 35.2 \\
\hline 22 & $3 / 4$ & 39.1 & 40.2 & 41.3 & 2.2 & 32.0 \\
\hline 23 & $3 / 4$ & 41.3 & 41.6 & 42.0 & 0.7 & 19.4 \\
\hline 24 & $3 / 4$ & 42.0 & 42.6 & 43.2 & 1.2 & 25.8 \\
\hline 25 & 4 & 43.2 & 43.8 & 44.5 & 1.3 & 24.0 \\
\hline 26 & 4 & 44.5 & 44.7 & 45.0 & 0.5 & 11.4 \\
\hline 27 & 4 & 45.0 & 45.4 & 45.8 & 0.8 & 6.9 \\
\hline 28 & 4 & 45.8 & 45.8 & 45.9 & 0.1 & 1.0 \\
\hline 29 & 4 & 45.9 & 56.5 & 47.1 & 1.2 & 3.4 \\
\hline \multicolumn{2}{|c|}{ Total } & & & & 1.6 & 642.7 \\
\hline
\end{tabular}

Source: Authors' data.

\section{Chronology}

A total of 13 radiocarbon dates was obtained from Square E. Two came from SU1, five from SU2 and six from SU3 (Table 15.4). No in situ charcoal was encountered in SU4, and thus no radiocarbon dates were obtained from this lowermost horizon. The dates are in good chronostratigraphic order both within and between SUs:

- SU1: $149 \pm 20 \mathrm{BP}(\mathrm{Wk}-50535)$ at $5.9 \mathrm{~cm}$ depth in XU4 and $164 \pm 20 \mathrm{BP}$ (Wk-40536) at $6.4 \mathrm{~cm}$ depth in XU5.

- SU2: All the dates from SU2 are late Holocene in age. The oldest is $1256 \pm 22 \mathrm{BP}$ (Wk-40541) (calibrating to 1092-1277 cal BP) from $21.1 \mathrm{~cm}$ depth.

- SU3: $4551 \pm 23$ BP (Wk-40542) (5061-5316 cal BP) from $26.7 \mathrm{~cm}$ depth; $6946 \pm 27 \mathrm{BP}$ (Wk-40543) (7694-7839 cal BP) from $26.4 \mathrm{~cm}$ depth; $9205 \pm 32$ BP (Wk-40546) (10,254$10,488 \mathrm{cal} \mathrm{BP})$ from $27.3 \mathrm{~cm}$ depth; $9314 \pm 33 \mathrm{BP}$ (Wk-40544) $(10,412-10,647 \mathrm{cal} \mathrm{BP})$ from $28.0 \mathrm{~cm}$ depth; $9968 \pm 35 \mathrm{BP}$ (Wk-40548) $(11,264-11,606 \mathrm{cal} \mathrm{BP})$ from $29.6 \mathrm{~cm}$ depth; and 17,113 \pm 83 BP (Wk-40545) (20,407-20,905 cal BP) from $30.3 \mathrm{~cm}$ depth.

Square E provides the earliest dated evidence for human use of the site, sometime within the calibrated age range 20,407-20,905 cal BP. However, this is a non-basal age, with a further $17 \mathrm{~cm}$ of sediment occurring below the level of this calibrated age. Extending a linear depth-age curve from the surface to the base of the square gives a broad-scale estimate of c. 34,860 years ago for the base of the excavation. However, the lower sediment rates in SU3 of just $3.9 \mathrm{~cm}$ every 12,890 years suggest that the base of the cultural sequence - located $15.1 \pm 0.4 \mathrm{~cm}$ (the depth range representing the thickness of $\mathrm{XU} 27$, where the lowest stone artefact is found) below the lowermost calibrated age of $20,407-20,905 \mathrm{cal} \mathrm{BP}$ at $30.3 \mathrm{~cm}$ depth - is almost certainly much older. 


\section{Excavated materials}

A total of $576 \mathrm{~g}$ of charcoal was excavated from Square E (Table 15.18, Figure 15.48). Charcoal densities are very low in SU3 and SU4, averaging $4.9 \mathrm{~g} / 1000$ years in SU3 compared with $384.4 \mathrm{~g} / 1000$ years in SU2. This represents a 78-fold increase between the two horizons. Stone artefact discard rates follow a similar pattern, with average deposition rates of 8.7 artefacts/1000 years in SU3 and 261.4 artefacts/1000 years in SU2, representing a 30-fold increase after c. 5061-5316 cal BP. The implication is that the two phases of stone artefact deposition rates, and charcoal densities, are related and the charcoal is probably indicative of landscape firing practices.

Table 15.18 Excavated materials retained in $2 \mathrm{~mm}$ mesh sieves from Square $\mathrm{E}$, by XU.

\begin{tabular}{|c|c|c|c|c|c|c|c|}
\hline \multirow[t]{2}{*}{$X U$} & \multirow{2}{*}{$\begin{array}{c}\text { Non-cultural } \\
\text { sediments }\end{array}$} & \multirow{2}{*}{$\begin{array}{c}\text { Charcoal } \\
9 \\
\end{array}$} & \multicolumn{2}{|c|}{ Stone artefacts } & \multirow{2}{*}{$\begin{array}{c}\begin{array}{c}\text { Other } \\
\text { organics }\end{array} \\
g\end{array}$} & \multirow{2}{*}{$\begin{array}{c}\text { Insect larvae } \\
9 \\
\end{array}$} & \multirow{2}{*}{$\begin{array}{c}\begin{array}{c}\text { Land snail } \\
\text { shell }\end{array} \\
g\end{array}$} \\
\hline & & & $\#$ & $g$ & & & \\
\hline 1 & 177.8 & 9.2 & 2 & 0.2 & 89.4 & 0.2 & \\
\hline 2 & 364.0 & 31.6 & 12 & 2.0 & 29.2 & & 0.1 \\
\hline 3 & 792.0 & 33.0 & 15 & 4.2 & 11.1 & & \\
\hline 4 & 666.6 & 31.1 & 11 & 2.6 & 7.1 & & \\
\hline 5 & 908.4 & 52.9 & 35 & 5.9 & 10.2 & & \\
\hline 6 & 977.3 & 62.3 & 20 & 5.3 & 8.3 & & \\
\hline 7 & 1135.4 & 71.8 & 32 & 9.8 & 10.2 & & \\
\hline 8 & 1014.9 & 55.1 & 30 & 37.6 & 6.3 & & \\
\hline 9 & 2118.5 & 66.6 & 46 & 58.6 & 7.6 & & \\
\hline 10 & 1372.5 & 37.0 & 19 & 154.6 & 4.5 & & \\
\hline 11 & 1489.9 & 28.8 & 42 & 255.3 & 3.7 & & \\
\hline 12 & 2143.5 & 21.2 & 46 & 636.9 & 4.1 & & \\
\hline 13 & 3079.5 & 15.0 & 36 & 253.5 & 1.5 & & \\
\hline 14 & 1973.2 & 11.5 & 18 & 132.7 & 1.0 & & \\
\hline 15 & 3339.1 & 7.2 & 24 & 246.8 & 1.6 & & \\
\hline 16 & 3218.3 & 8.7 & 22 & 387.0 & 1.2 & & \\
\hline 17 & 4061.7 & 4.3 & 16 & 512.3 & 1.2 & & \\
\hline 18 & 4163.4 & 5.0 & 20 & 1437.2 & 1.0 & & \\
\hline 19 & 6609.3 & 2.7 & 11 & 804.4 & 2.4 & & \\
\hline 20 & 5124.3 & 4.5 & 10 & 35.9 & 1.6 & & \\
\hline 21 & 7628.5 & 7.4 & 11 & 508.0 & 1.4 & & \\
\hline 22 & 9007.3 & 6.5 & 5 & 1390.9 & 1.8 & & \\
\hline 23 & 5141.3 & 1.7 & 1 & 95.5 & 0.9 & & \\
\hline 24 & 7707.4 & 1.0 & 4 & 4151.6 & 0.9 & & \\
\hline 25 & 7947.3 & 0.3 & 5 & 3499.0 & 3.2 & & \\
\hline 26 & 4673.1 & 0.1 & 2 & 0.8 & 0.6 & & \\
\hline 27 & 2181.2 & 0.2 & 2 & 0.2 & 0.2 & & \\
\hline 28 & 247.1 & 0.1 & & & $<0.1$ & & \\
\hline 29 & 1703.3 & 0.1 & & & 0.3 & & \\
\hline Total & $90,966.1$ & 576.9 & 497 & $14,628.8$ & 215.5 & 0.2 & 0.1 \\
\hline
\end{tabular}

Source: Authors' data. 


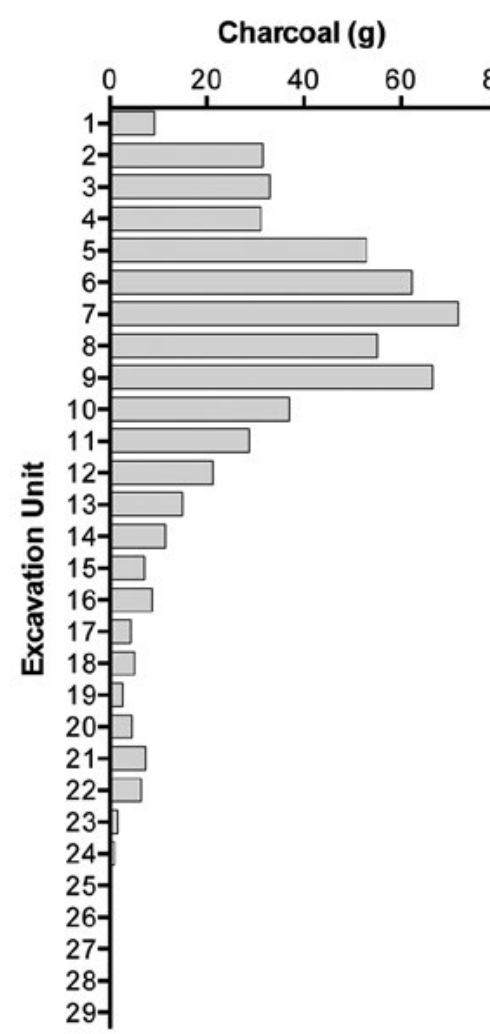

\section{Stone artefacts (\#)}

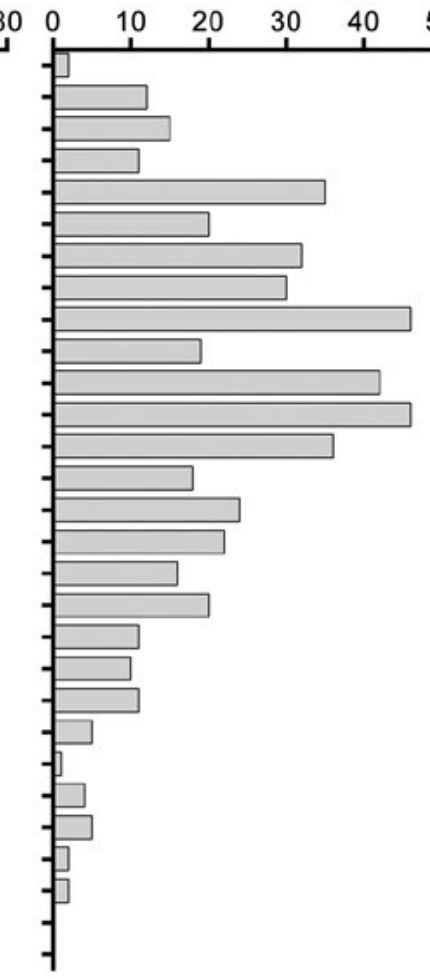

Stone artefacts $(\mathbf{g})$

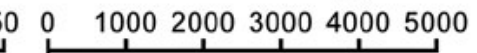

Figure 15.48 Distribution of charcoal and stone artefacts by $\mathrm{XU}$, Square $\mathrm{E}$.

Source: Illustration by Jerome Mialanes and Lara Lamb.

The stone artefacts consist of 497 artefacts with a combined weight of 14,628.8 g (Table 15.18; Figure 15.48). Of all the squares excavated at the site, Square $\mathrm{E}$ has the greatest diversity of raw material types, with 12 categories present (Figure 15.49). Predominant is micro-crystalline quartzite (61.2 per cent), followed by fine-grained quartzite ( 14.1 per cent), chert ( 6.6 per cent) and sandstone (6.6 per cent). Also present is crystalline quartz, coarse-grained quartzite, basalt, milky quartz, silcrete and a silcrete/chert composite (each $<5$ per cent). Five flaked artefacts exhibit distinct bands of both micro-crystalline and fine-grained quartzite, indicating that these two raw material types could have come from the same source. On these five specimens, the bands of fine-grained quartzite are closer than the micro-crystalline quartzite bands to the cortex.

The Square E assemblage is dominated by flaked pieces ( 50.3 per cent), complete flakes (24.5 per cent), distal portions (10.9 per cent) and broken 'other' (7.4 per cent). Also present are bipolar cores, bipolar flakes, left-split cone, right-split cones, retouched flakes and unipolar cores, each representing $<2$ per cent of the total assemblage from the square (Table 15.19). One of the retouched flakes is the broken tip of what appears to be a bifacially flaked point, made of chert. 

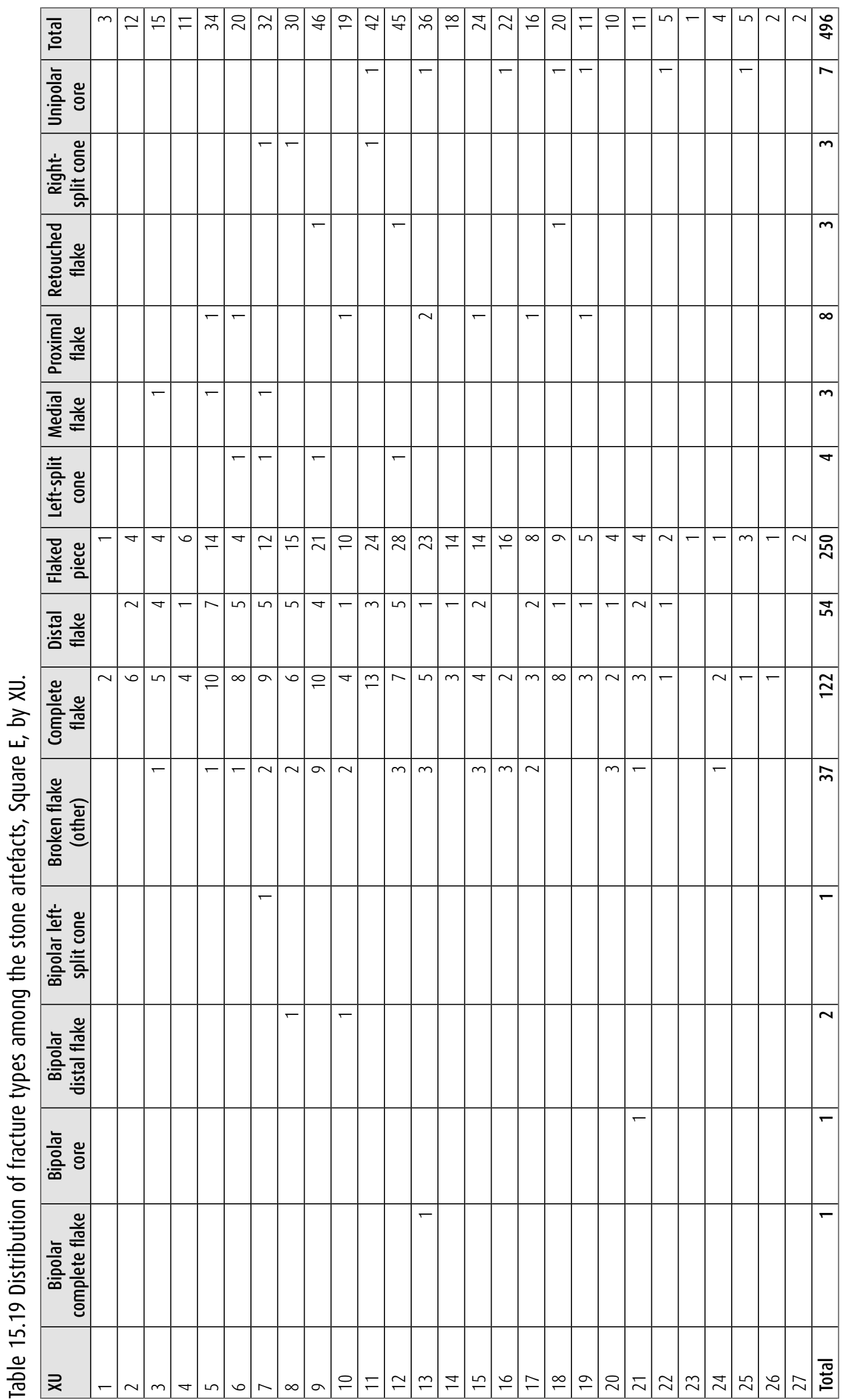

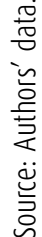


The pattern of raw material distribution through time indicates a higher reliance on sandstone in SU3 than elsewhere. A 28-fold increase in average discard rates from SU3 (8.8 artefacts/1000 years) to SU2 (257 artefacts/1000 years) is largely due to an increased incidence of microcrystalline quartzite, chert and coarse-grained quartzite in SU2. This suggests that the increase is not solely due to increasing use of local quartzites, but to exotic chert as well. Other raw material types are also introduced into SU2, including silcrete and milky quartz. In SU1, deposition rates average 107 artefacts/1000 years, with micro-crystalline quartzite remaining the predominant raw material type (Figure 15.49).
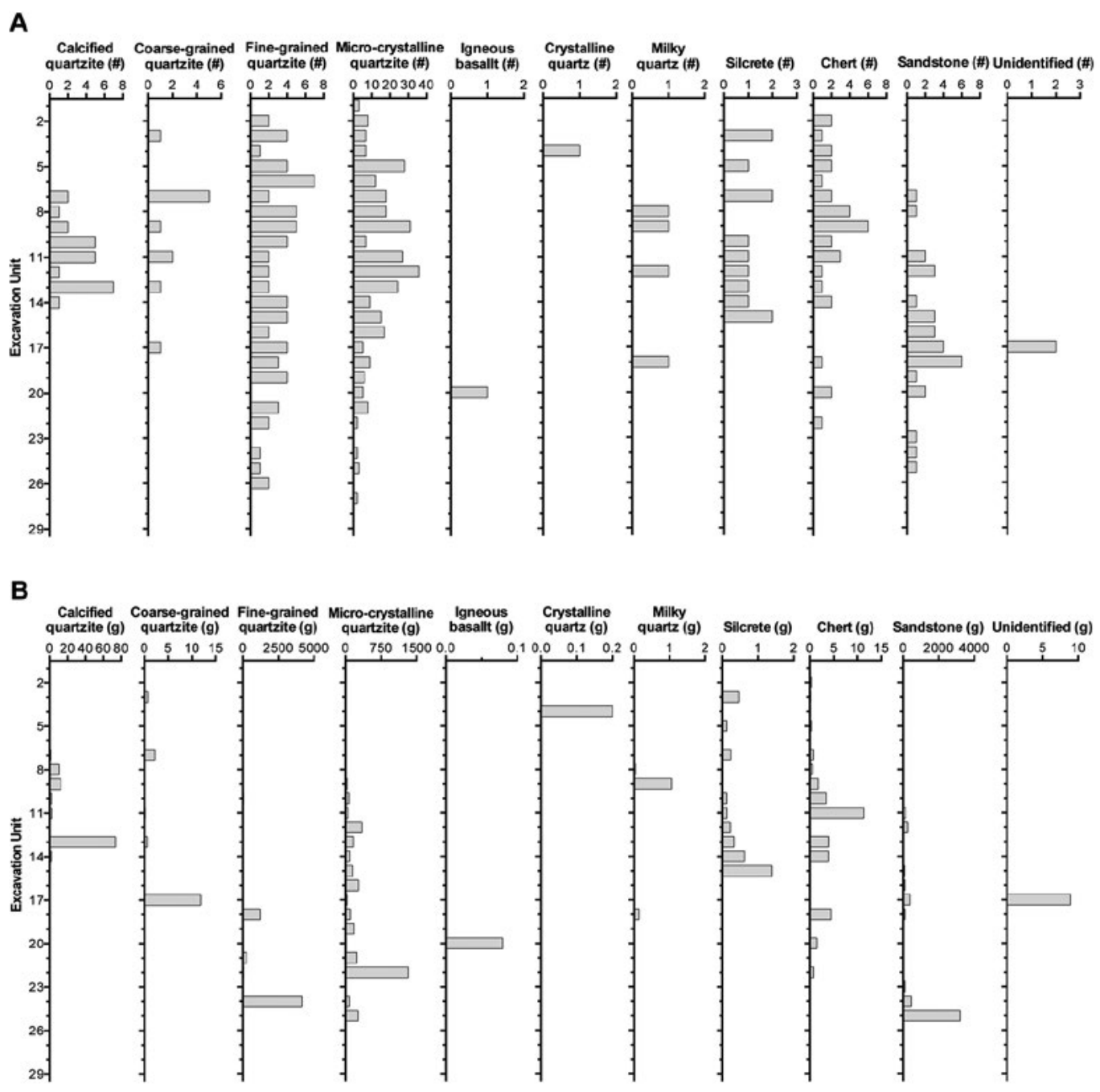

Figure 15.49 Distribution of stone artefacts by raw material type for Square $E$, by XU.

Source: Illustration by Jerome Mialanes and Lara Lamb.

The distribution of fracture types reveals an important trend (Table 15.19). With the exception of a single bipolar core in SU3, all artefacts exhibiting the use of a bipolar or bifacial technique are found in SU2. This corresponds with a horizon of diminished use of sandstone and increased use of micro-crystalline quartzite and exotic materials including silcrete, chert and milky quartz. Also apparent is the reduced mean weight and maximum dimensions of artefacts from SU3 to SU2, corresponding with the diminished use of sandstone, a raw material type that typically produced the larger and heavier flaked stone artefacts in the assemblage (Figures 15.49 and 15.50). 


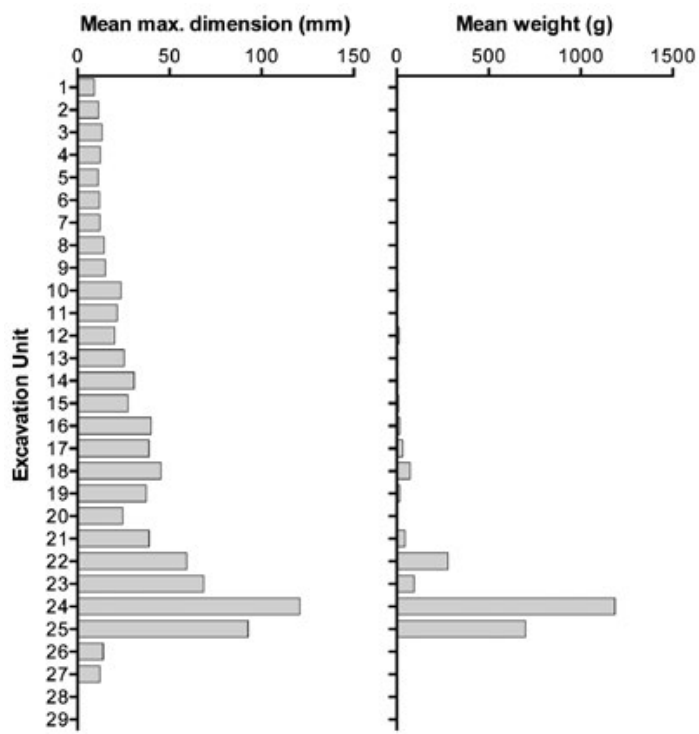

Figure 15.50 Mean weight and maximum length of stone artefacts from Square E, by XU. Source: Illustration by Jerome Mialanes and Lara Lamb.

\section{Working out the history of JSARN-124 site 3 through geomorphological reconstruction}

An important, albeit underused, way of exploring the history of decorated rock surfaces is through geomorphology. We can thus begin to explore the history of JSARN-124 site 3's paintings and hand stencils by seeing the rock stack as two articulating geological components: a geologically in situ base, rock strata D0 and D1; and a superimposing and partly overhanging cap, D3 to D8 (Figures 15.3, 15.51 and 15.52). The rock cap is inclined by the westward tilt of strata D3 to D8, a geologically ancient phenomenon long pre-dating any people in the landscape.

All of the artworks on Panels A-E are painted or stencilled on flat sections of the wall; the flatness of these vertical surfaces contrasts with the overall ruggedness of the profile of strata D0 to D8, each of which is variably resistant to erosion. Figure 15.51 demonstrates the rock stack's contrasting surfaces. The south face, associated closely with the effects of erosion, has a very rugged profile, whereas the north face on which is found the large bird motif of Panel A is characterised by expansive smooth surfaces. These smooth surfaces were created by the collapse of the outer reaches of a considerably longer overhang than that present today (and thus the art on those surfaces must be more recent than the age of the final collapse(s) that created the surfaces). For the area of Panel A, this is evident by the massive boulder collapse that fronts the north face. The situation is similar for the other smooth surfaces that house art panels (Panels B-E). Each of those smooth surfaces was produced by the collapse of part of the rock wall or overhang, effectively representing the sheer planes of those collapses. Determining the antiquity of those collapses is the key to understanding the maximum possible ages of the paintings that today decorate these smooth wall surfaces. As all of the artworks present today could only have been made after those rock surfaces formed, so we aim to understand the maximum possible age of the artworks by understanding the age of those surfaces. From the onset, one of our major aims of research at JSARN-124 site 3 has thus been to determine the antiquity of wall and overhang collapses in those areas that contain artworks. We have done this by cross-examining surface geomorphological details with the evidence revealed by each of the five archaeological excavations (Squares A-E). A major tool in these investigations was a 3-D laser mapping of the site. 

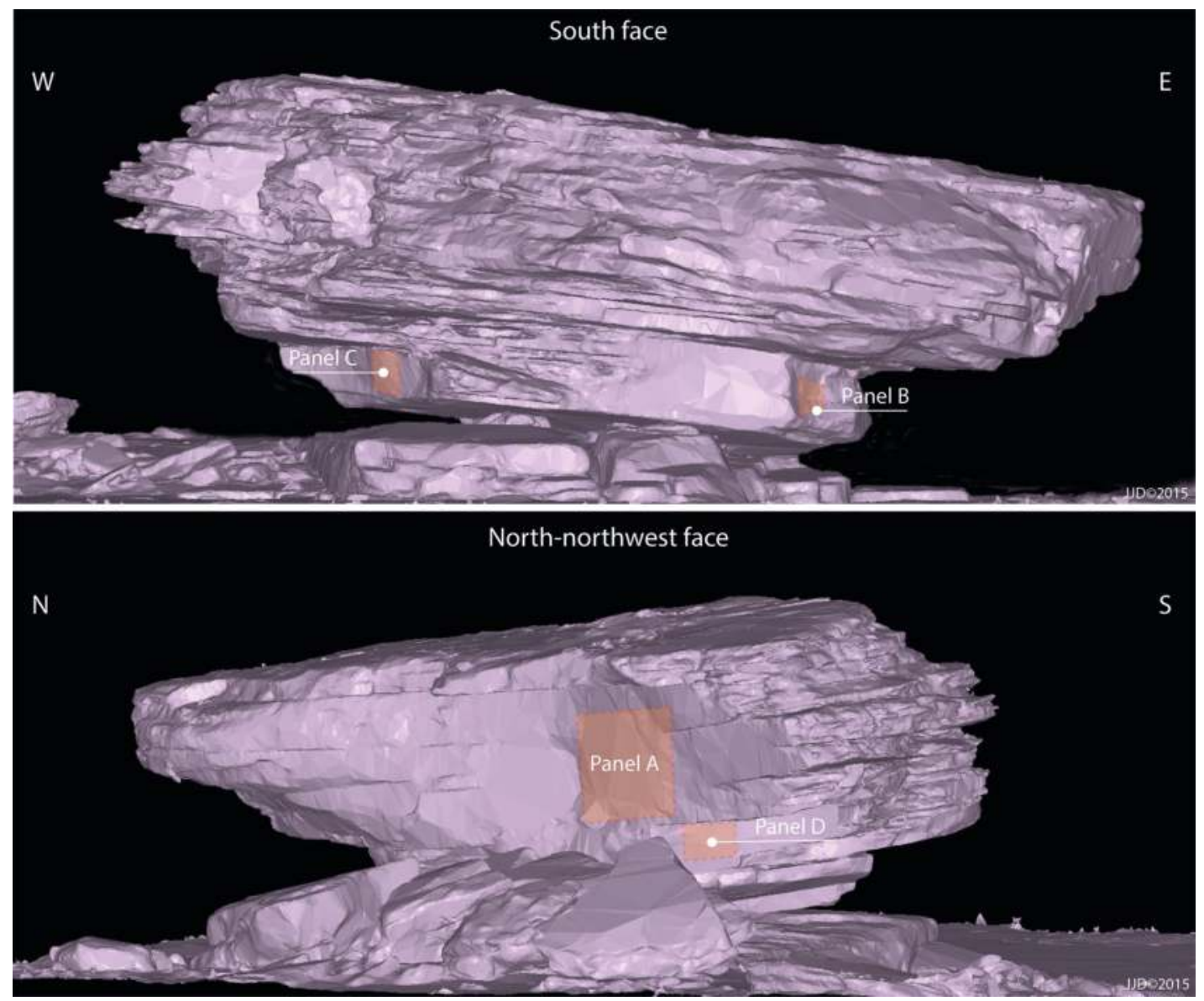

Figure 15.51 South and north-northwest faces of the rock stack at JSARN-124 site 3, showing the contrasting textures of the rock surfaces. Rock art Panels A-D are shown on those surfaces. Source: Illustrations by Jean-Jacques Delannoy.

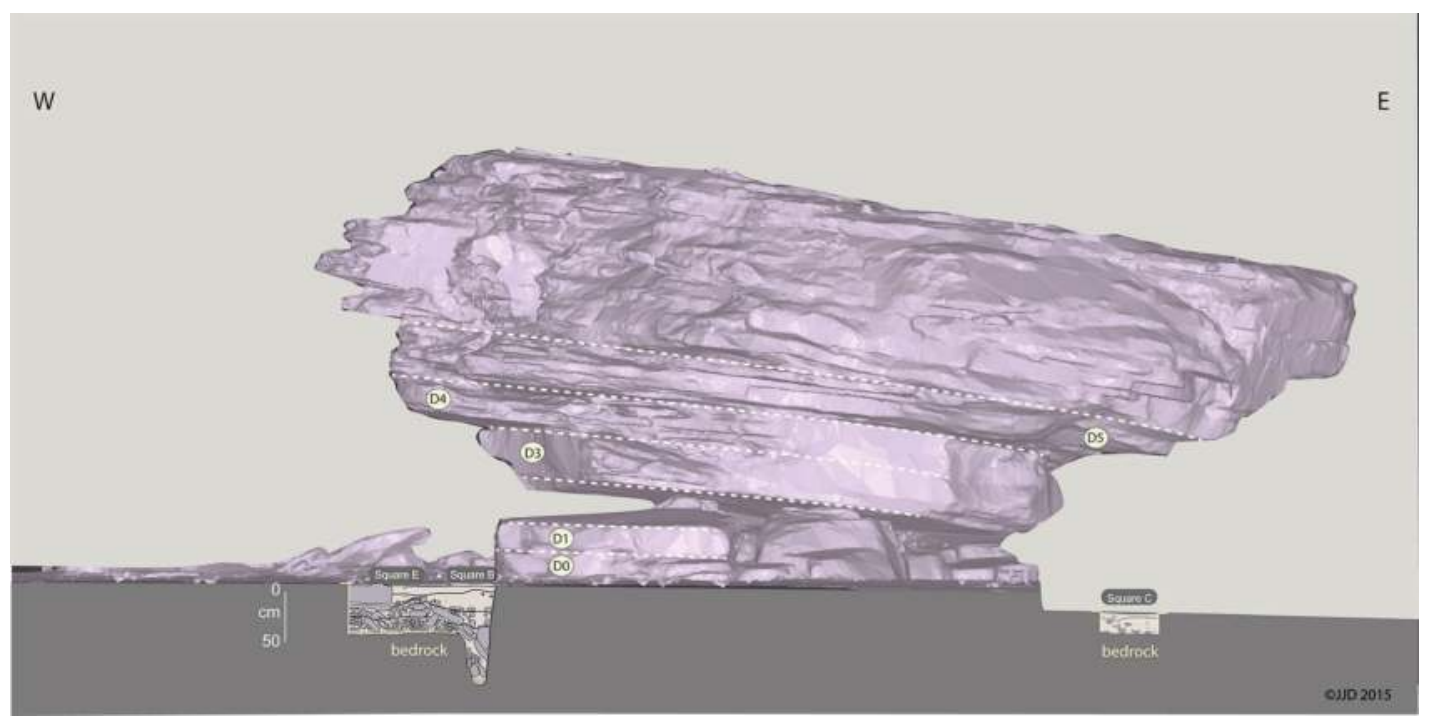

Figure 15.52 Excavation Squares B+E (western side) and Square C (eastern side), viewed from south side of the rock stack.

Source: Illustration by Jean-Jacques Delannoy. 
The spatial distribution of the excavation squares around the rock stack allows us to understand the changing configuration of much of the site before, during and after those periods when people were active at the site. We can do this fairly precisely for the eastern (Squares A and C) and western (Squares B+E and D) sides of the rock stack, with the evidence from those investigations allowing us to show conclusively an evolutionary schema for the site as a whole, including the north face that contains the large bird motif. The radiocarbon evidence from the excavations enables us to attribute a chronological framework for the major phases of wall and overhang collapse and, in doing so, for the artworks themselves.

\section{Geomorphology of areas near the excavated squares}

The geomorphological analyses and reconstructions in part focus on Squares A and C on the eastern side of the site, and in part in the area of Squares $\mathrm{B}+\mathrm{E}$ and $\mathrm{D}$ on the western side.

\section{Geomorphology in area of Squares $A$ and $C$}

Squares A and C are located on the eastern side of the rock stack (Figure 15.52), adjacent to the Panel B paintings on stratum D3. Both squares are protected from the elements by a c. $3 \mathrm{~m}$ wide strata D5-D8 overhang.

The base of Square A lies $9 \mathrm{~cm}$ below the present ground surface. The excavation square was positioned on the edge of an exposed rock slab with a smooth surface and flaked edge. This slab lies flat on sandy sediments under the strata D5-D8 overhang. The slab came from ceiling stratum D8. Its flat position on the ground and its flaked edges indicate that it had been moved and worked anthropically after detachment from the rock wall (Figure 15.53).

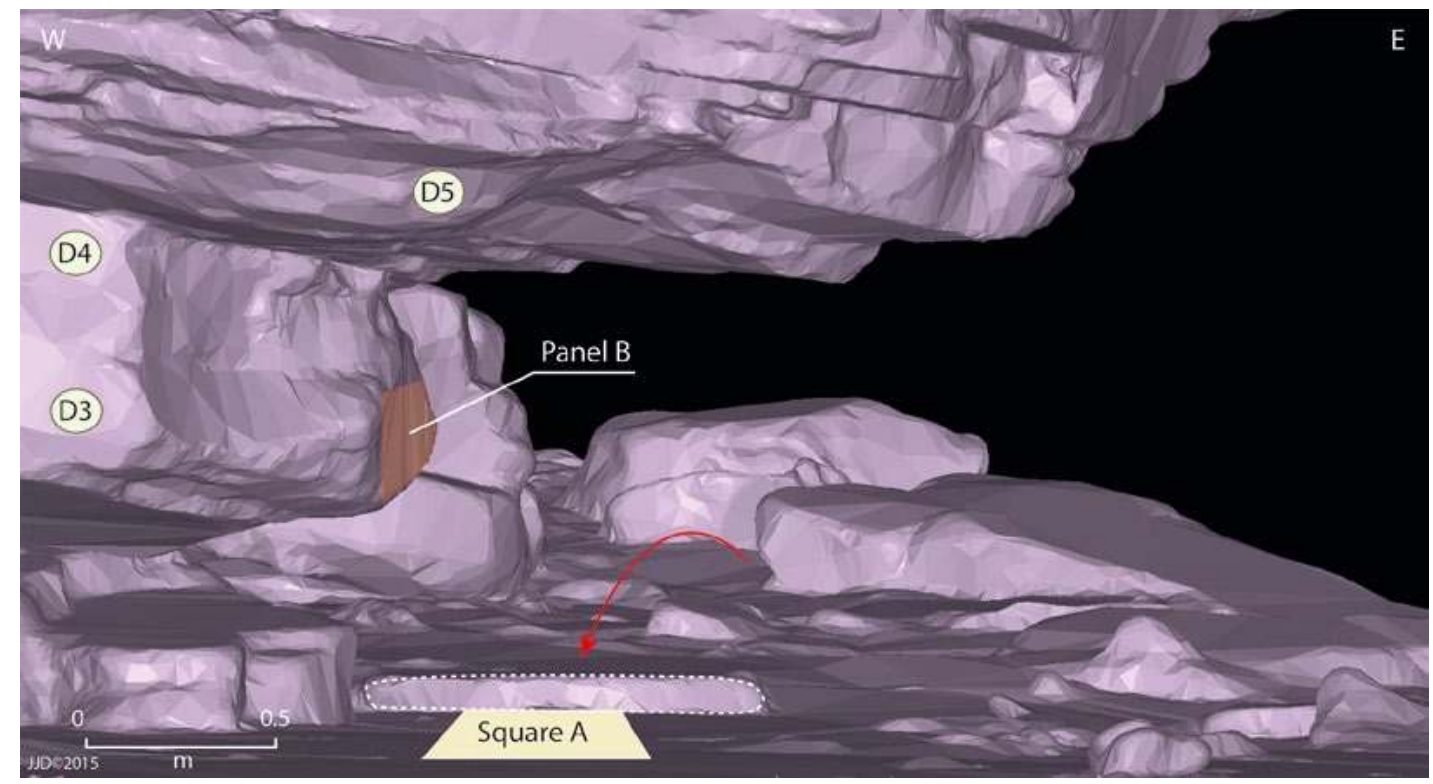

Figure 15.53 Location of Square A in relation to Panel B and the detached stratum D8 slab (outlined in white-dashed line) that was moved by people to its present position immediately to the north of Square $A$.

Source: Illustration by Jean-Jacques Delannoy.

The base of Square C is at $17 \mathrm{~cm}$ depth. The square is located $1.0 \mathrm{~m}$ to the south of Square A. Despite the presence of minor clastic elements, like those of Square A the Square C sediments are exclusively composed of sand grains that under microscopic examination exhibit aeolian impact marks (i.e. they are aeolian sands). 
The solid rock base of both Squares A and C is hard, flat and slightly sloping southward. The $3^{\circ}$ slope is similar to the dip of the rock stack's pedestal strata D1 and D0, suggesting that the base of the two excavation squares represent the surface of the bedrock (rather than a buried collapsed ceiling slab). To determine this better, we used the site's digital 3-D model to project the angle of the Square E bedrock base on the western side of the rock stack, towards Square C on its opposite, eastern side, revealing a common dip and perfect (continuous) alignment (Figure 15.54). Given that the base of Square E has been conclusively shown by excavation of the overlying sediments, extending to Square B and hence to the rock stack's western wall, to represent the quartzitic bedrock (see the results of the archaeological excavations, above), the rocky base of Squares A and $\mathrm{C}$ can also be securely identified as bedrock.

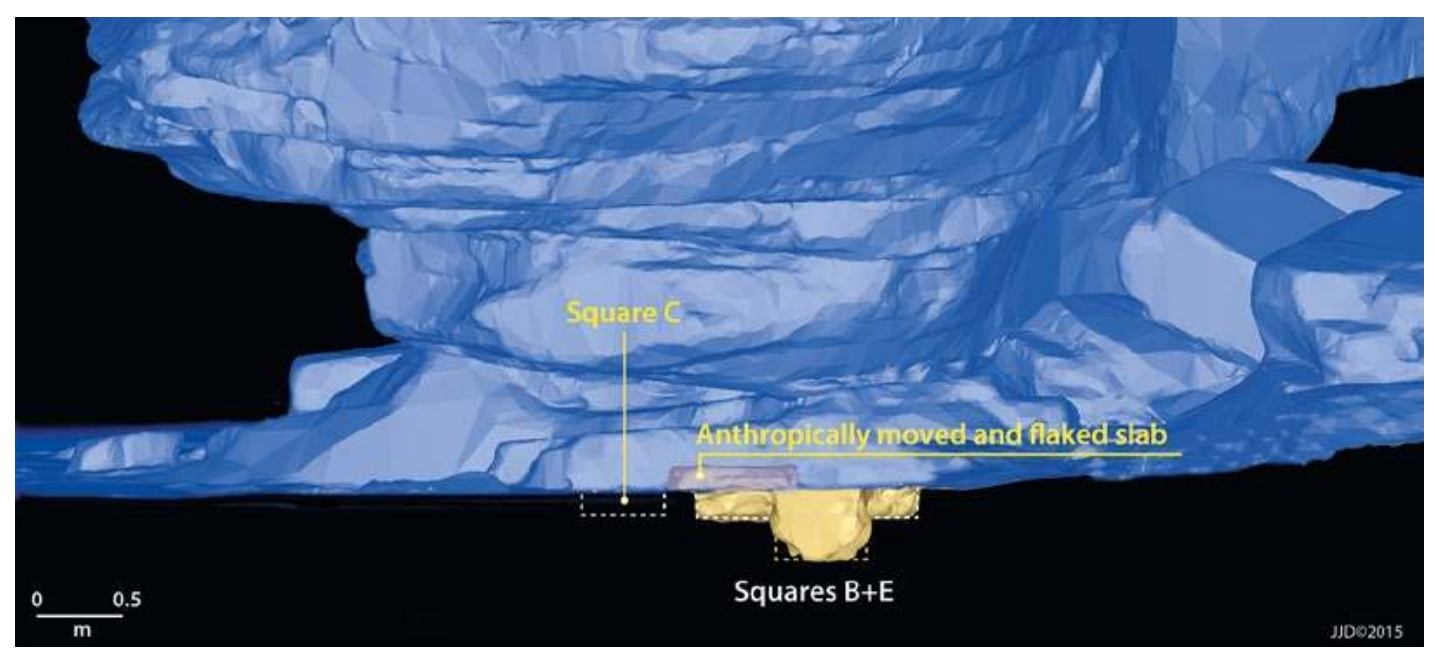

Figure 15.54 The dotted horizontal white lines represent the level of the flat rock surfaces at the base of Squares $\mathrm{C}$ and $\mathrm{E}$.

Source: Illustration by Jean-Jacques Delannoy.

The Panel B artworks occur on the flat, vertical wall surface of strata D3 and D4. That surface was created when parts of a low overhang became detached from the back wall; the collapsed rocks from that detachment are now neither on nor in the ground. In this part of the site, the ground consists of a blanket of aeolian sands directly overlying bedrock. This absence of the fallen rocks requires explanation and remains largely unanswered. Whatever its causes, the collapse of strata D3-D4 is of a considerable antiquity that precedes the presence of people at the site.

\section{Archaeological implications of the geomorphology}

The flat surface on which the Panel B artworks were made is thus also both very old and precedes human presence. The shallowness of the sand layer that blankets the bedrock in this part of the site can be explained by exposure to the dominant winds that, coming from the east-southeast, have a greater tendency to transport sand away from this part of the site than to deposit it here. It is difficult to estimate the sedimentation rates involved, as the deposited sands can be rapidly remobilised by wind to be redeposited further downwind on the western side of the rock stack in the vicinity of Squares B+E and D against the rock stack. The radiocarbon dates from Squares $\mathrm{A}$ and $\mathrm{C}$ are in correct chrono-stratigraphic order, indicating that the present sand sheet dates at least to the past $2444 \pm 25 \mathrm{BP}(2380-2412 \mathrm{cal} \mathrm{BP})$ (Table 15.4).

The detached rock slab at the northern edge of Square A (see Figure 15.26) is not in its original position. It originated from the collapse of the upper part of the overhang nearby (stratum D8), but its current location away from its originating position, its flat, sub-horizontal positioning on aeolian sands and the presence of extensive flaking along its edge indicate that it was moved and worked 
by people in the past (Figure 15.53). The timing of the slab's repositioning was probably late in the site's occupational history, given its stratigraphic position above the upper SUs of Square A. Nevertheless, the apparently fairly recent age of its current positioning remains to be confirmed, as it is possible that the aeolian sands beneath the slab remained in situ only once the slab was redeposited to its present position, but that it originated in earlier times than those of the current Square A sediments. We cannot test these possibilities as we have not excavated beneath the slab.

We do not have enough geomorphological data from this part of the site to determine the age of the artworks. But this is not the case for the western side of the site.

\section{Geomorphology in area of Squares $B+E$}

Squares $B+E$ are located along the western edge of the rock stack (Figure 15.3), sheltered from the dominant winds. The two squares were positioned along the longitudinal axis of the rock stack's strata D0 and D1 pedestal, close to the Panel C artworks (see Figure 15.11). Here, the art spans much of the height of the flat surface along the near-vertical edge of stratum D3.

Excavation of Squares B+E progressed down to bedrock, which steeply deepens against the rock stack wall in much of Square B. This steep deepening of the bedrock surface is due to chemical weathering along a north-south fissure that delimits the western edge of the rock stack's base.

Angular blocks tens of centimetres to metres in length are found both at depth and at ground level. These originated from a succession of strata D3-D6 overhang collapses above Squares B+E. The width of the original sheltered area under ceiling strata D4-D5 was about $2 \mathrm{~m}$ from the back wall to the outer edge of the overhang.

\section{The Squares B+E sediments}

The Squares $\mathrm{B}+\mathrm{E}$ section drawings reveal soft and rocky sediments that originated from a range of morphogenic processes, including roof-fall (Figure 15.52). The basal levels of the excavations also provide information on diagenic processes taking place at the deepest levels over bedrock. Petrographic analysis coupled with comparisons of the thicknesses of the excavated blocks against those of nearby rock strata have enabled the origins of the excavated rocks to be determined.

Analyses of sediments from the base of the excavated squares to the present ground surface (see Figure 15.55) reveals the following sequence of events:

1. The bedrock at the base of Squares B+E shows signs of considerable physical and chemical weathering. Such weathering is evident along the deep, disintegrating fissure that contains ferruginous pisoliths along the base of Square B where the weathering bedrock is in contact with rocky sediments. At the base of this weathering fissure - effectively a slow-forming but active solution channel against the rock stack's western wall - pisoliths are trapped in a soft, cement-like matrix. Although the composition of this cement-like matrix has not been analysed, it is characteristic of areas where groundwater pools in impermeable or semi-permeable quartzite concavities. Such sediments are a product of alteration of the surrounding rock. Over geological time scales measured in the millions of years, the entrapping dissolution channel gradually enlarges to form part of a 'ghost rock' or pillar landscape such as that found today in the pillared rockshelter of Nawarla Gabarnmang $9 \mathrm{~km}$ to the northwest of JSARN-124 site 3 (cf. Delannoy et al. 2013). At JSARN-124 site 3, it is this kind of slow geological process that saw the breakdown and mechanical collapse of rock strata D1 and D3 above the dissolution channel now evident at the base of Square B. The narrow but deep cavity of stratum D2 between rock strata D1 and D3 was caused by this same geological process of dissolution and geological evacuation of alteration products. It is from this stratum D2 level that overlying strata D3 to D7 became tilted. 
2. A horizon of pisoliths close to bedrock is capped by centimetre-size rock clasts that originated from breakdown of the overhanging rock ceiling. Today there is widespread millimetreto centimetre-scale fragmentation of the rock both along the overhang and along the wall. The scale of this fragmentation can differ in different areas, depending on its causes (e.g. thermoclastic exfoliation, gravitational block collapse, weakening of bedding planes).

3. Above this horizon of small, fragmented rock clasts is a pile of large rocks and angular gravels. At least two depositional events can be differentiated through the buried rocks located in SU4 and SU3. The first is the collapse of the underlying, overhanging section of rock stratum D3. The collapsed, now-buried blocks follow the surface configuration of the bedrock, having become jammed in the dissolution channel; where the bedrock is more or less horizontally flat, the collapsed rock has piled up. This first (lowermost) deposit of collapsed rock is covered by a second aggregation of rocks that signals collapse of the remainder of overhanging stratum D3. How much time elapsed between these two rock-fall events is difficult to estimate with the available evidence. It is the sum of these two overhang collapses that resulted in the creation of the smooth vertical rock surface that now exhibits art Panel C. The paintings of Panel C cannot therefore have been done before completion of the D3 rock collapse (see below).

4. Overlying the stratum D3 rock collapse are soft sediments largely comprised of aeolian sands. Not as abundant in underlying levels, these aeolian sands now become dominant, covering the collapsed stratum D3 rocks. Lying horizontally flat within these aeolian sands are rock slabs fallen from a localised section of the overhanging stratum D4 ceiling. These collapsed slabs are covered by aeolian sands.

5. Above the present ground surface near and to the north of Squares B+E are large blocks of rock that have collapsed onto each other step-wise. These correspond to the collapse of the outer overhanging edges of rock strata D4-D5 and D6.
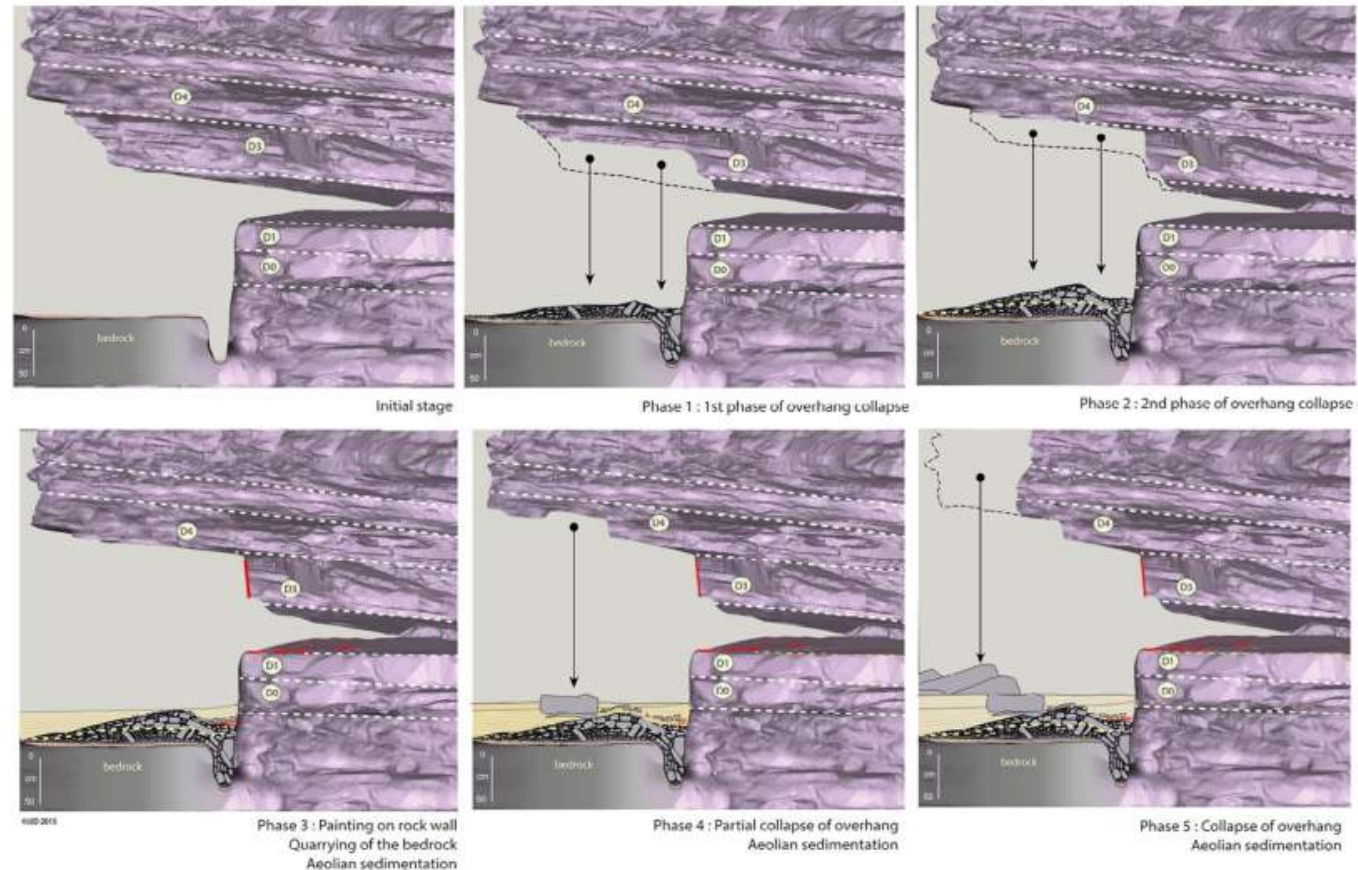

(i) Rock stratum

$\ldots . . .$. Weathering

RुS Rockfall

$\square_{\text {sedimentation }}^{\text {Aeolian }}$

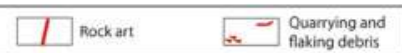

Figure 15.55 Evolution of the overhang above Squares $B+E$, showing the build up of sediments as evidenced from the north section of those two excavation squares.

Source: Illustrations by Jean-Jacques Delannoy. 
The above details enable us to reconstruct the main phases of this part of the site's geomorphological evolution and to cross-examine it against the archaeological evidence.

\section{Archaeological implications of the geomorphology}

We have tried to link the archaeology (including rock art), geomorphology and geochemistry, so as to understand better the art, and especially the large bird painting on art Panel A.

The red paintings adjacent to and above Squares $\mathrm{B}+\mathrm{E}$ were made on a relatively flat, vertical surface. This flat surface represents a scar created by the collapse of stratum D3. In Squares B+E, the layout of buried and surface rocks originating from this same stratum D3 indicates two phases of strata D3 and D4's collapse. The fallen rocks from the final stage of the stratum D3 collapse have accumulated on an ancient ground surface that represents an earlier phase of stratum D3's collapse, together evident in SU4 and SU3 of the excavations in Squares B+E. Radiocarbon determinations on charcoal date the first phase of the stratum D3 collapse to sometime before $17,113 \pm 83 \mathrm{BP}(20,407-20,905 \mathrm{cal} \mathrm{BP})$, and the second after 11,983 $\pm 35 \mathrm{BP}(13,739-13,976$ cal BP) (Table 15.4). It was at the end of these two phases of collapse that the overhanging rock that once completely and then partially covered the vertical rock surface on which art Panel $\mathrm{C}$ was subsequently painted fell, thereby creating the now-painted vertical rock surface. The paintings on Panel C must therefore post-date 13,739-13,976 cal BP.

The upper, horizontal surface of stratum D1 also displays negative flake scars, evidence of stone quarrying (Step 3 on Figure 15.55). Stone artefacts located above the material from the final collapse of stratum D3 in Square B originally came from the top of stratum D1. We know this because these now-buried artefacts exhibit the same thicknesses and petrographic characteristics as the removed rock evident in the stratum D1 scars. Radiocarbon dates on charcoal obtained from stratigraphic levels above the buried stratum D1 artefacts give an age of c. $4500 \mathrm{BP}$ (combined range: $5041-5316 \mathrm{cal} \mathrm{BP}$ ) (Table 15.4).

The combined geomorphological, archaeological and radiocarbon dating evidence allows us to further refine the timing of the second phase of rock collapse and stone quarrying to between 13,739-13,976 cal BP and 5041-5316 cal BP. We do not know when after 13,73913,976 cal BP the artworks on Panel $\mathrm{C}$ were made. However, in layers dated to sometime between 13,739-13,976 cal BP and 5041-5316 cal BP, the excavations in Squares B+E revealed a concentration of stone artefacts flaked from the adjacent sub-horizontal surface of stratum D1. If the artworks on Panel C were made at the same time as the working of stratum D1, representing a period of peak human activity in this part of the site, then the nearby Panel C artworks would also date to between 13,739-13,976 cal BP and 5041-5316 cal BP.

\section{Geomorphology in area of Square D}

Square $\mathrm{D}$ is located $2.5 \mathrm{~m}$ to the north of Squares B+E, also straddling the edge of the rock stack's strata D0-D1 pedestal. The excavation was undertaken adjacent to Panel D (see Figure 15.3), which occurs on the flat, near-vertical lower face of stratum D5 (hitherto D5a; see Figure 15.56 below).

The excavation reached bedrock at a maximum depth of $58 \mathrm{~cm}$ below ground (Figure 15.42). Here, there is clear evidence of a shallow weathering channel along the same north-south fissure line that was also reached in Square B.

The Square D excavation has revealed a similar sediment sequence to that of contiguous Squares $\mathrm{B}+\mathrm{E}$, with the presence of angular blocks measuring in the tens of centimetres originating from a number of phases of wall or overhang collapse (strata D5b-D6-D7-D8). These fallen blocks are varied in size and are covered by a horizontally aligned layer of smaller rocks that contrast with the overlying horizon by their relatively homogeneous lengths and thicknesses. This layer of 
horizontal, homogeneous and relatively small rocks is superimposed by approximately $20 \mathrm{~cm}$ of sandy deposit exclusively composed of indented quartz grains indicative of impacts from wind transport.
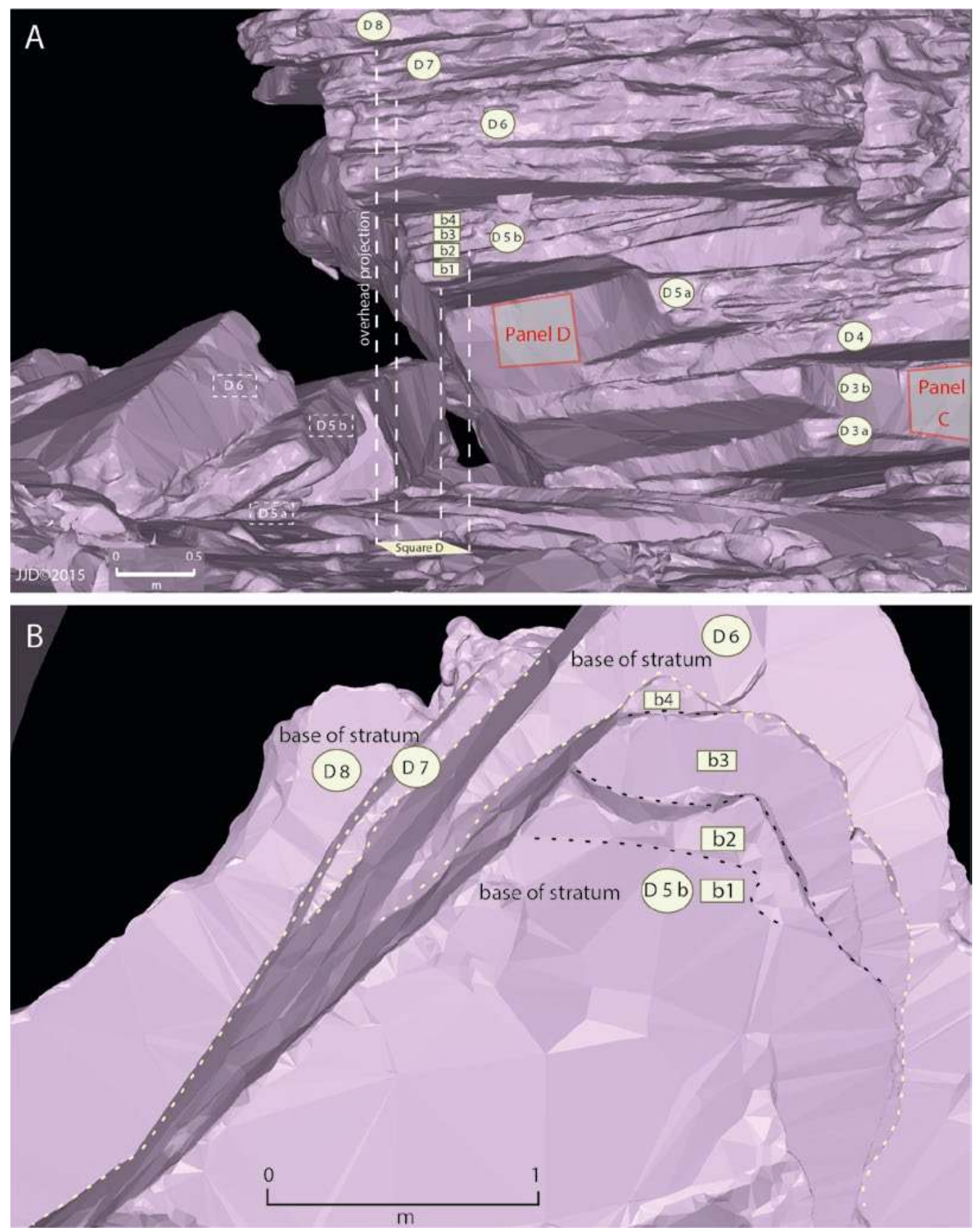

Figure 15.56 Northwestern corner of the rock stack showing location of Square D relative to nearby collapsed blocks and ceiling of present overhang immediately overhead.

Source: Illustrations by Jean-Jacques Delannoy.

The positioning of Square D away from the Panel C artworks is of interest, as it is located along the axis of the rock face that was formed by the collapse of strata D5-D6-D7, where the Panel A artworks are now found (including the large bird motif) (Figure 15.56). On Figure 15.56A, 
we show the position of Square D, together with its upward projection towards the overhang (on this figure, Panel A is on the left-hand side just around the corner of the overhang and of the upward projection of the left-hand corner of Square D, and therefore cannot be seen from this angle). On Figure 15.56B, the ceiling of the overhang is shown looking straight up from the position of Square D below. Here we can see that Square D is positioned directly under the detachment scar along which are found the artworks of Panel A. Given that the positioning of Square D allows us to simultaneously investigate the evolution of the rock in the area of Panels A and $\mathrm{D}$, we undertook a detailed analysis of the morphogenesis of this part of the site, both in the field and through the digital 3-D model.

\section{The Square D sediments: Archaeomorphological implications}

The stratigraphic sequence for Square D (Figure 15.41) brings to light materials that originated from different morphogenic processes. As previously noted (cf. Squares B+E), the sequence of collapsed materials found on and in the ground, coupled with the extant layout of the rock stack's strata, have enabled us to determine a suite of morphogenic stages for the area around Square D. The lithology and thickness of the fallen blocks revealed in the excavation and at ground level nearby permit us to reconstruct the origins of these blocks on the rock stack.

From the base of the Square D excavation to the ground surface, we identify the following sequence of events (Figures 15.41, 15.42 and 15.56-15.58):

1. The bedrock here carries traces of strong physical and chemical alteration. The evidence consists of the deepening of a fissure in, and the presence of ferruginous pisoliths on, the bedrock (alteration residues). These pisoliths are here held by a 'cement' (revealed at the base of the eastern edge of the excavation square, along the longitudinal axis of the rock stack's pedestal at D0). This indurated cement is the product of a very old phase of alteration of the quartzite bedrock.

2. The hard bedrock surface and pisolith cement are superimposed by angular blocks that are lying at varied angles, moulding to the shape of the solution channel. Lithological analysis permits us to identify these angular blocks as originating from stratum D3a.

3. Above this mass of rock collapse are clastic materials of smaller size that cover the underlying 'tumble' of blocks: these smaller overlying rocks are similar in lithology, size and shape to the exfoliated rocks found at the base of Square E. The origin of these clasts may be linked to mechanical weakening and thermoclastic exfoliation. These clasts mould to the shape of the underlying surface configuration, filling in the solution channel.

4. Above this clastic layer, we find a new accumulation of blocks and angular rocks whose origin is the collapse of a new section of the overhang that once sheltered Square D. The collapsed blocks that now lie on the ground surface were digitally reattached onto strata D3b-D4 and D5, confirming their original positions (Figure 15.58). It is at the end of this phase of collapse that the flat, vertical rock surface, on which the Panel D artworks now lie, was formed.

5. Under this collapsed material (SU3b), we find the presence of angular blocks that are relatively homogeneous in length and that lie sub-horizontally. These blocks came from stratum D1. They testify to the anthropic flaking of the surface of stratum D1, as evidenced by percussion scars on the present stratum D1 surface (Figure 15.57).

6. The upper levels of the excavation reveal an aeolian quartz sand sheet that seals the underlying rocky layers. 


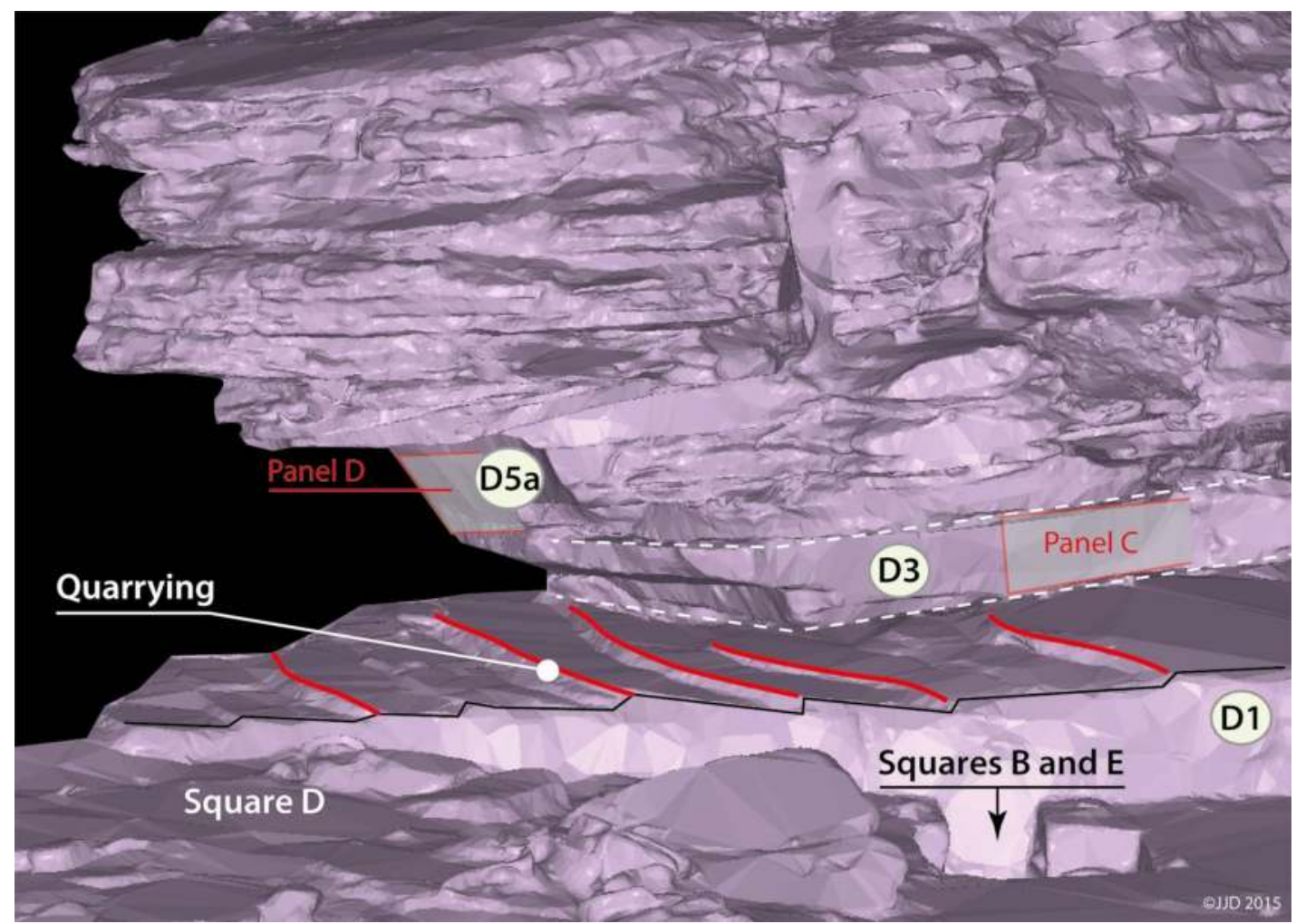

Figure 15.57 Western side of JSARN-124 site 3, in the vicinity of Squares B+E and Square D (laser mapping undertaken when Squares B+E pits were open).

Source: Illustration by Jean-Jacques Delannoy.
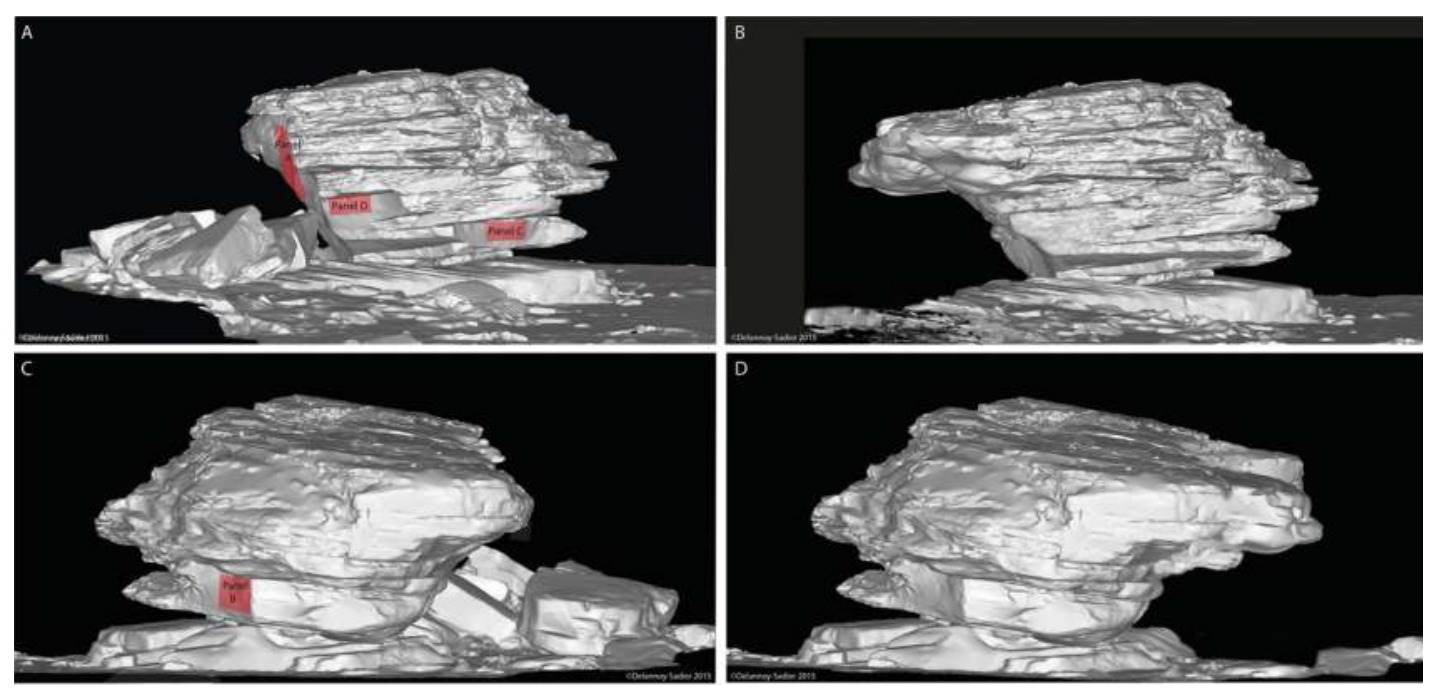

Figure 15.58 The JSARN-124 site 3 rock stack before and after the overhang collapses that resulted in the creation of the flat, vertical rock surfaces of Panels A-E.

$A$ and B: configuration of the western and northwestern sides of the site today (left) and immediately prior to the major overhang collapses and to the rock art (right). C and D: configuration of the eastern and northeastern sides of the site today (left) and immediately prior to the major overhang collapses and to the rock art (right).

Source: Illustrations by Jean-Jacques Delannoy. 
The Square D stratigraphic sequence recalls those of Squares B+E. The red paintings above Square D (Panel D) were made on the smooth vertical surface formed by the collapse of the overhang that previously existed. That collapse concerned strata D3b-D4 and D5 and took place after $8160 \pm 27 \mathrm{BP}(9014-9245 \mathrm{cal} \mathrm{BP})$, as indicated by the radiocarbon dates from XU19 under the fallen blocks. This timing from Square D is consistent with the second phase of collapse that has been identified in the Squares B+E excavations (dating to after 13,739-13,976 cal BP). Similarly, the horizon of anthropic artefacts originating from stratum D1 dates to a similar time frame to that of Square B, here dated to after $2459 \pm 20$ BP (2379-2545 cal BP) (Table 15.4).

The same sequence of events is apparent in the two excavation areas (Squares B+E, and Square D) on the western edge of the site. These same sequences allow us to highlight the existence of two major phases of rockfall, the rock debris from the first lying directly on the weathered bedrock and its alteration products (pisoliths). After these rockfall events, there is evidence of the human modification of the exposed, upper surface of stratum D1. This phase of quarrying may be contemporaneous with painting activity on nearby flat surfaces, although this is not certain. In both Squares B+E, and Square D, the overlying blanket of aeolian sands is dated from 2379-2545 cal BP continuing to today.

The sum of these observations permits us to construct a broad chronological canvas for the evolution of the site.

\section{Discussion of the geomorphology}

Geomorphological and archaeological investigations have revealed important dimensions relating to the physical evolution of JSARN-124 site 3, including the sequence and general age of major geological and anthropic events that gave shape to the site that we know today.

The presence of large fallen blocks at the base of the rock stack's northern face did not allow us to undertake archaeological excavations immediately below Panel A. Nevertheless, the geomorphological evidence obtained from the full circumference of the site, coupled with archaeological and radiocarbon dating evidence obtained from Squares B+E, and especially Square D at the northwestern corner of the rock stack, have enabled the collapse of the old overhang on the north side to be broadly dated. It is only after this collapse that the northern rock face became exposed and thus available to paint on (see Figure 15.59 for a synthesis).

All of the five squares were excavated down to bedrock. These bedrock surfaces show points of strength and weakness in the rock stack's structure: the base of Squares A, C and E have revealed the strongly resistant hard quartzite strata's upper surfaces, while the base of Squares B and D have exposed fissure lines that have been widened and deepened by chemical alteration. The pisoliths present at contact with the bedrock represent mineral aggregates accumulated on the impermeable quartzite bedrock: these pisoliths are largely made up of iron oxides and clay, and are themselves sources of red ochre that could have been used to make red paintings and stencils at the site.

JSARN-124 site 3 used to have larger overhangs on its western and northern sides than it does today (Figure 15.58). The vertical rock surfaces that today house art Panels A, C, D and E did not exist then: these smooth rock surfaces were formed by the collapse of the overhangs. The rock debris revealed in Squares B+E and D, and at ground level on the northern edge of the rock stack, are the products of those overhang collapses. The only art surface that could have existed prior to these collapses is the one that houses art Panel B near Squares A and C under the eastern overhang. None of the blocks that collapsed from stratum D3 and that resulted in the creation of the vertical rock surface subsequently painted as Panel B is presently visible along the eastern edge of the site, nor under the overhang where Squares A and C were excavated. This means that here the stratum D3 vertical surface is ancient, and therefore the Panel B rock art could theoretically be very old (or young). 


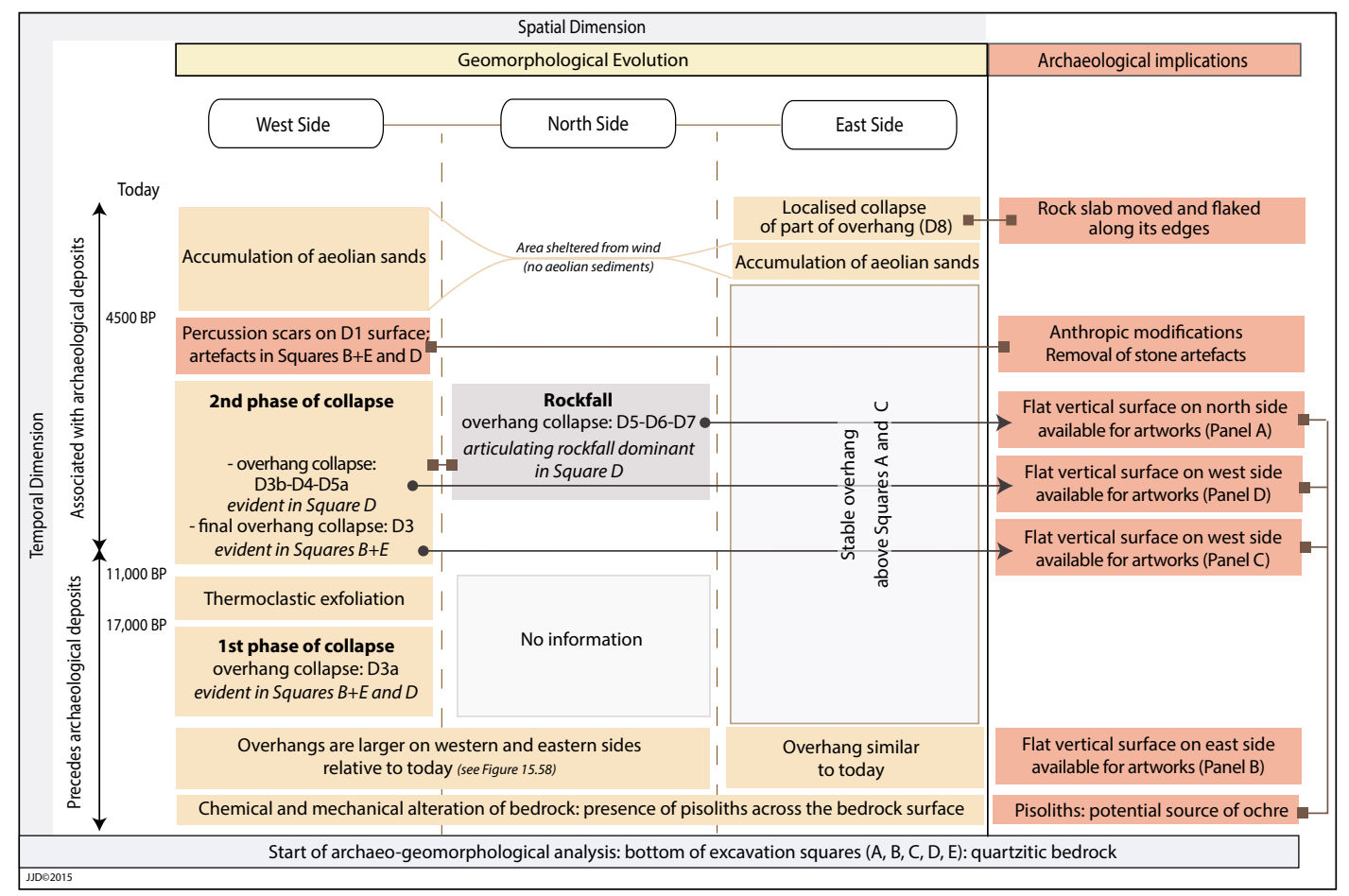

Figure 15.59 Summary chronological schema for JSARN-124 site 3.

Source: Illustration by Jean-Jacques Delannoy.

On the western side of the site, excavation Squares B+E, and Square D, have revealed two major phases of overhang collapse. The first pre-dates $17,113 \pm 83 \mathrm{BP}(20,407-20,905 \mathrm{cal} \mathrm{BP})$ (Figure 15.59) and the second post-dates $11,983 \pm 35 \mathrm{BP}(13,739-13,976 \mathrm{cal} \mathrm{BP})$. It is these two phases of collapse that caused the formation of the smooth, vertical rock surfaces on the western side of the site. The artworks on Panels C and D could only have been made after the second collapse dated to $13,739-13,976 \mathrm{cal}$ BP.

The area immediately above Square D lies at the intersection of the northern and western margins of the rock stack, a corner of the site that witnessed interconnecting rock collapse (Figures 15.56 and 15.60). The most obvious and most important of these collapses is particularly evident on the north side of the site. Digital 3-D refitting of the large collapsed block transverse surfaces onto the remnant rock stack conclusively shows that these collapsed blocks came from rock strata that overhang Square D. The stratigraphic sequence of collapsed blocks also conclusively shows that the north face's (strata D5b-D6-D7) ancient overhang collapsed at the same time as the second phase of collapse identified in both Square D and Squares B+E. That is, overhanging rock strata D5b-D6-D7 became detached from the rock stack in the area of art Panel A after 13,73913,976 cal BP, at the end of the LGM. The artworks of Panel A must therefore be more recent than 13,739-13,976 cal BP. As they cannot be older than this, they cannot be contemporaneous with the bird Genyornis newtoni, unless G. newtoni survived the LGM into the PleistoceneHolocene boundary. All evidence - zoological, paleontological, archaeological - from all parts of Australia currently argue against such a late survival. 


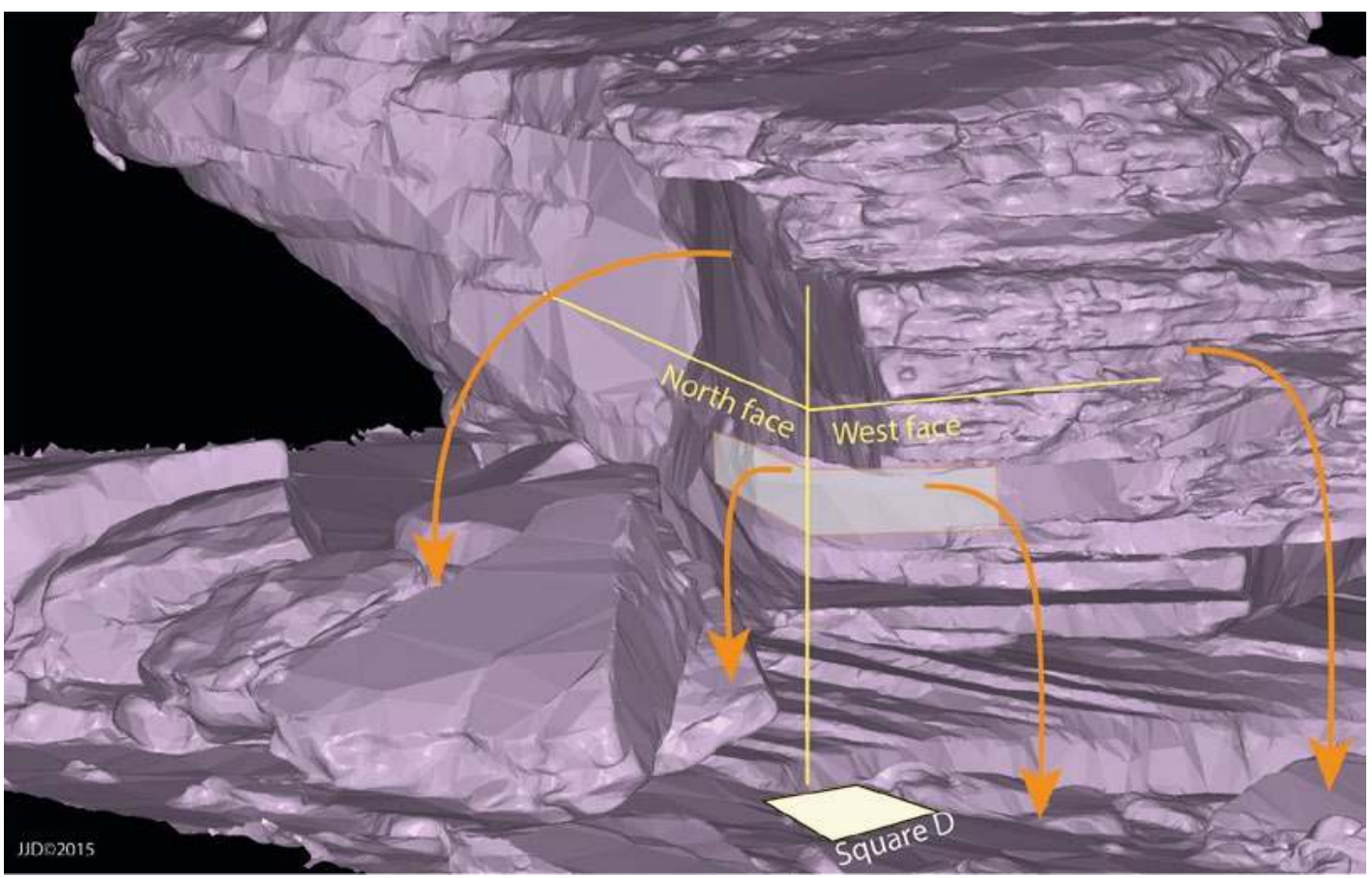

Figure 15.60 Collapse of northwestern overhang, resulting in the shown extant smooth vertical rock faces of Panels A, D and E.

Source: Illustration by Jean-Jacques Delannoy.

The rock mass from overhang collapse has greatest visibility at ground level on the northern side of the site, whereas it is buried along the western side. This spatial patterning is due to the variable quantities of collapsed material in different parts of the site. Along the western side, in the areas of Squares B+E, only stratum D3 became detached from the overhang. In the area above Square D, it is rock strata D3-D4 and D5a that fell, and here one part of that collapse is buried (as revealed by the excavation) while the rest lies exposed on the surface.

On the northern side of the site, it is the entire $2.7 \mathrm{~m}$ thickness of the overhang composed of strata D4-D5-D6-D7 that fell. Here the lower strata (D4 and D5a) are buried under the overlying strata (D5b-D6-D7) that are themselves visible on the surface as the tumble of blocks just beyond the northern edge of the rock stack. The paintings of Panel A were made by climbing onto those collapsed blocks.

The upper surface of the pedestal (stratum D1; Figure 15.57) has been quarried for stone. Here, evidence of stone flaking by percussion has resulted in the deposition of flaking debitage in the adjacent sediments of Squares B+E, and Square D. We suggest that as people quarried the upper stratum D1 surface, they further engaged with the site by removing collapsed blocks that must once have laid on top of the exposed stratum D1 surface but that are now absent. These cultural actions pre-date $4482 \pm 20 \mathrm{BP}(5041-5286 \mathrm{cal} \mathrm{BP})$, a radiocarbon determination that came from sediments overlying the level with the stratum D1 artefacts.

The area surrounding the rock stack then became blanketed with aeolian sands. These sandy sediments are more pronounced along the western side of the site, where the rock stack's wall acts as a protective screen from the wind; along the upwind southern and eastern sides, wind activity has prevented effective sedimentation. We note that minor overhang collapse is evident during the mid to late Holocene, as blocks are sometimes found buried amid the aeolian sediments 
of the upper sandy layer, and sometimes lie on the surface of the present ground surface. It is during this phase of sand accumulation that the flaked slab that originated from the collapse of the stratum D8 overhang was carried to its present location on top of aeolian sediments near Square A under the eastern overhang.

\section{Conclusion: How old is the large bird painting?}

Six lines of evidence inform us about the age of the large bird motif at JSARN-124 site 3:

1. The large bird motif is superimposed by a very thin, redeposited layer, protecting it from weathering. Theoretically, the painting could thus be of considerable but indeterminate age.

2. The paint from the large bird motif lies immediately over a layer of gypsum. As gypsum tends to mineralise under dry conditions, this may show the large bird was painted after a dry phase. A dry phase during the LGM began to end c. 14,700 cal BP in northern Australia (Reeves et al. 2013; Simon Haberle pers. comm. 2015), so the large bird motif is likely to be of later date.

3. The large bird painting superimposes a $3 \mathrm{MF}$ hand stencil, currently thought to date to less than c. 10,000-12,000 years old, so it is of that age if the estimated age of $3 \mathrm{MF}$ hand stencils is correct.

4. A number of paintings on Panel A (Images \#2, \#5, \#10, and possibly Images \#1 and \#14), Panel B (Images \#30 and \#31), Panel C (Image \#49, and possibly \#45 and \#46) and Panel E (Images \#56, \#60, and possibly the degraded Image \#58) are stylistically similar to each other, and would thus appear to be contemporaneous (within an archaeological time frame) (Figure 15.61). The large bird motif (Image \#5) is one of these. What these paintings each have in common is an overlapping combination of the following features, although not all features are represented on all paintings: outlining without solid infilling; hollow body; longitudinal line along full or partial length of body; transverse lines that divide the body into separate sections (sometimes with the central section being further divided in half by the longitudinal line); and hind legs infilled with longitudinal irregular 'stripes'. Taçon (1989, 1992) and Chaloupka (1993:183-185) have argued that the depiction of fauna with hollow bodies such as found on bird Image \#45 dates to the beginning of the Estuarine period, around 8000 years ago. At JSARN-124 site 3, all of the above paintings from Panels $\mathrm{A}, \mathrm{C}$ and $\mathrm{E}$ must have been done sometime after 13,739-13,976 cal BP, as the rock surfaces containing the whole of those panels formed sometime after that time. This conclusion is consistent with Taçon's and Chaloupka's chronologies.

5. Under microscopic examination of cross-sections of rock samples, the pigment making the large bird cannot be separated from that of the spear that intersects it, so the two motifs are probably contemporaneous. Probably it is a picture of a bird being hunted with a spear, rather than two separate images that chance to fall together.

In short, the smooth, flat vertical rock surfaces of art Panels A, C, D and E all formed between 13,739-13,976 cal BP and 5041-5286 cal BP. The large bird motif is on Panel A, so it cannot be older than 13,739-13,976 cal BP. 


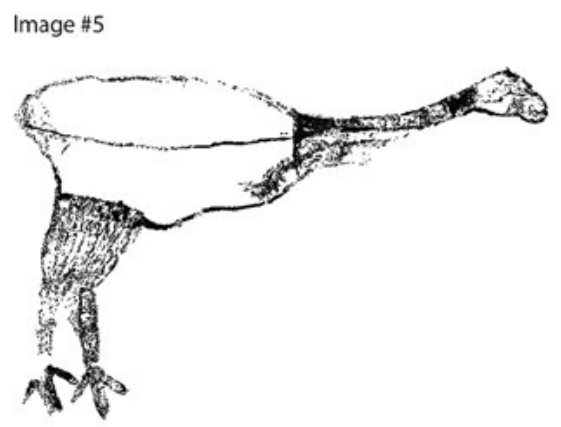

Image \#2

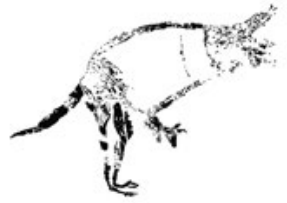

Images \#45, \#46, \#49

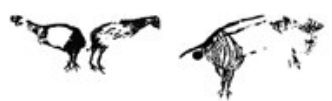

Image \#1
Image $\# 10$
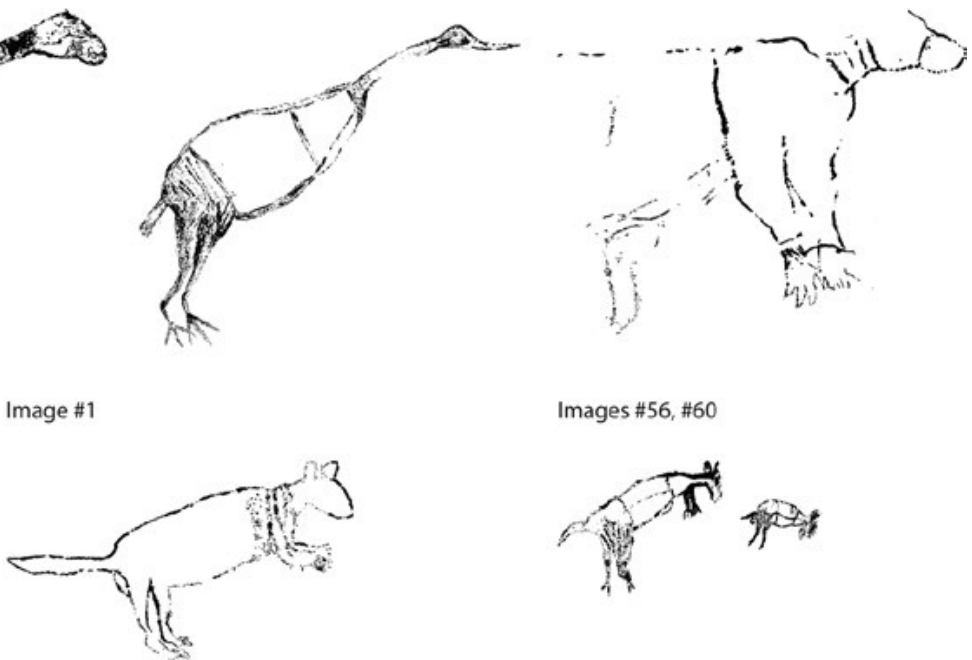

Images \#30, \#31

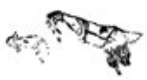

Images \#56, \#60
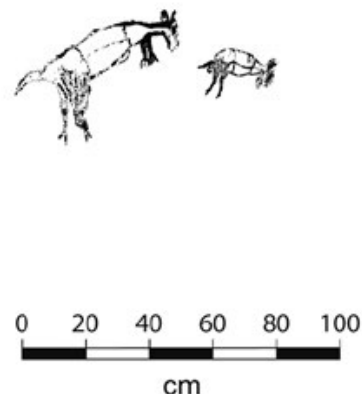

Figure 15.61 Zoomorphs painted with shared artistic conventions, or similar and apparently shared conventions, at JSARN-124 site 3.

Source: Illustration by Robert Gunn and Bruno David.

The fact that the large bird motif at JSARN-124 site 3 can now be shown to be more recent than 13,739-13,976 cal BP highlights the tentative nature of a supposed widespread early phase of 'large naturalistic paintings' that precedes the LGM and that can purportedly readily be recognised by paintings such as the large bird motif across northern Australia-Southeast Asia (e.g. Taçon and Chippindale 2008:75; Taçon et al. 2014), as has sometimes been argued.

Last but not least, the large bird motif at JSARN-124 site 3 is superimposed over a $3 \mathrm{MF}$ hand stencil on Panel A. That 3MF hand stencil also cannot possibly be older than 13,739-13,976 cal $\mathrm{BP}$, as the rock surface on which it occurs was only created at that time. As 3MF hand stencils are generally associated with Dynamic Figures across western Arnhem Land, if the example from JSARN-124 site 3 is contemporaneous with the other $3 \mathrm{MF}$ hand stencils of the region, and if such hand stencils are indeed contemporaneous with Dynamic Figures as argued by all rock art researchers who have researched the topic in Arnhem Land (e.g. Chaloupka 1993; Chippindale and Taçon 1998; Lewis 1988; Taçon and Brockwell 1995), then we can conclude that the age of Dynamic Figures began, or continued into, the period after 13,739-13,976 cal BP. In this context, it is important to emphasise Chaloupka's (1993:110) observation that 'the 3MF stencil is unique to the art of this period [Pre-Estuarine, to which Dynamic Figures belong]'. This inference is consistent with Chippindale and Taçon (1998) and Taçon and Brockwell's (1995) views that Dynamic Figures date to around 10,000-12,000 years ago, contra Chaloupka's (1993:89) preference for a somewhat greater antiquity estimated to approach nearer to 20,000 years ago (unless the style or set of related styles had a very long duration spanning some 10,000 years). 


\section{Acknowledgements}

We thank Margaret Katherine and family, Wes Miller, Ray Whear and the Jawoyn Association Aboriginal Corporation for asking us to undertake this research. Thanks to Charlotte Armstrong, Brenna Barker-Lamb, Leigh Douglas, Daniel James (Monash University), David Lee, Jacqueline Matthews (University of Western Australia), Chris Urwin (Monash University) and Brit Wilson for helping with site recording and excavations, and Elisa Boche for Figure 15.20. We thank the Australian Research Council for Linkage grant LP110200927 and Discovery grants, QEII and Discovery Outstanding Research Award (DORA) Fellowships DP0877782 and DP130102514. We also thank AGLAE (Accélérateur Grand Louvre, Centre de Recherche et de Restauration des Musées de France (C2RMF), Paris) and Charisma for PIXE analysis, and the Rhône-Alpes region for financial support to undertake the chemistry analyses (CIBLE Project, 2012-2013). Thanks to Valérie Reita and Denis Testemale for undertaking the Raman micro-spectroscopy (Institut Néel); Quentin Lemasson and FIXLAB for the PIXE beam time at AGLAE in Paris; Kara Rasmanis (Monash University) for initial drafts of Figures 15.27, 15.32, 15.37 and 15.42, and Simon Haberle (The Australian National University) for advice on palaeo-environments.

\section{References}

Archer, M., D.A. Arena, M. Bassarova, R.M.D. Beck, K. Black, W.E. Boles, P. Brewer, B.N. Cooke, K. Crosby, A. Gillespie, H. Godthelp, S.J. Hand, B.P. Kear, J. Louys, A. Morrell, J. Muirhead, K.K. Roberts, J.D. Scanlon, K.J. Travouillon and S. Wroe 2006. Current status of specieslevel representation in faunas from selected fossil localities in the Riversleigh World Heritage Area, northwestern Queensland. Alcheringa 30, Supplement 1:1-17. doi.org/10.1080/ 03115510609506851

Bradley, R. 2002. The Past in Prehistoric Societies. Routledge, London.

Brandl, E.J. 1972. Thylacine designs in Arnhem Land rock paintings. Archaeology and Physical Anthropology in Oceania 7(1):24-30.

Cersoy, S., O. Leynaud, M. Alvarez-Murga, P. Martinetto, P. Bordet, N. Boudet, E. Chalmin, G. Castets and J.L. Hodeau 2015. Laboratory implementation of X-ray diffraction/scattering computed microtomography. Journal of Applied Crystallography 48:159-165. doi.org/10.1107/ S1600576714027204

Chalmin, E., G. Castets, B. David, B. Barker, J.-J. Delannoy, L. Lamb, J.-M. Geneste, F. Soufi, S. Pairis, S. Hoerlé, E. Boche and M. Katherine 2015. Study of red pigments from the 'Genyornis' panel, Arnhem Land, Australia: What are the origins of the haematite? Anthropologica et Praehistorica 125/2014:1-22.

Chalmin, E., G. Castets, J.-J. Delannoy, B. David, B. Barker, L. Lamb, F. Soufi, S. Pairis, S. Cersoy, P. Martinetto, J.-M. Geneste, S. Hoerlé, T. Richards and R. Gunn 2017. Geochemical analysis of the painted panels at the 'Genyornis' rock art site, Arnhem Land, Australia. Quaternary International 430:60-80. doi.org/10.1016/j.quaint.2016.04.003

Chaloupka, G. 1993. Journey in Time: The World's Longest Continuing Art Tradition. Reed, Chatswood.

Chippindale, C. and P.S.C. Taçon 1998. The many ways of dating Arnhem Land rock-art, north Australia. In C. Chippindale and P.S.C. Taçon (eds), The Archaeology of Rock-Art, pp. 90-111. Cambridge University Press, Cambridge. 
Clifford-Gonzalez, D. B., D. R. Damrosch, J. Pryor and R. L. Thunen 1985. The third dimension in site structure: An experiment in trampling and vertical dispersal. American Antiquity 50:803-818. doi.org/10.2307/280169

Delannoy, J.-J., B. David, J.-M. Geneste, M. Katherine, B. Barker, R.L. Whear and R.G. Gunn 2013. The social construction of caves and rockshelters: Chauvet Cave (France) and Nawarla Gabarnmang (Australia). Antiquity 87:12-29. doi.org/10.1017/S0003598X00048596

Doehne, E. 2002. Salt weathering: A selective review. In S. Siegesmund, T. Weiss and A. Vollbrecht (eds), Natural Stone, Weathering Phenomena, Conservation Strategies and Case Studies, pp. 59-72. Geological Society Special Publication 205. The Geological Society, London. doi.org/10.1144/gsl. sp.2002.205.01.05

Field, J. and W. Boles 1998. Genyornis newtoni and Dromaius novaehollandiae at 30,000 b.p. from Cuddie Springs, southeastern Australia. Alcheringa 22:177-188. doi.org/10.1080/0311551 9808619199

Flannery, T.F. 1984. Re-examination of the Quanbun local fauna, a Late Cenozoic vertebrate fauna from Western Australia. Records of the Western Australian Museum 11:119-128.

Goodall, R.A., B. David, P. Kershaw and P.M. Fredericks 2009. Prehistoric hand stencils at Fern Cave, north Queensland (Australia): Environmental and chronological implications of Raman spectroscopy and FT-IR imaging results. Journal of Archaeological Science 36:2617-2624. doi.org/10.1016/j. jas.2009.07.007

Goodman, D. and S. Piro 2013. GPR Remote Sensing in Archaeology. Springer-Verlag, Berlin. doi.org/10.1007/978-3-642-31857-3

Grellet-Tinner, G., N.A. Spooner and T.H. Worthy 2016. Is the 'Genyornis' egg of a mihirung or another extinct bird from the Australian dreamtime? Quaternary Science Reviews 133:147-164. doi.org/ 10.1016/j.quascirev.2015.12.011

Grün, R., S. Eggins, M. Aubert, N. Spooner, A.W. Pike and W. Müller 2010. ESR and U-series analyses of faunal material from Cuddie Springs, NSW, Australia: Implications for the timing of the extinction of the Australian megafauna. Quaternary Science Reviews 29:596-610. doi.org/10.1016/j. quascirev.2009.11.004

Gunn, R. G. 2011. The impact of bushfires and fuel reduction burning on the preservation of shelter rock art. Rock art Research 28:53-69.

Gunn, R. G., L. C. Douglas and R. L. Whear 2011. What bird is that? Identifying a probable painting of Genyornis newtoni in western Arnhem Land. Australian Archaeology 73:1-12.

Hernanz, A., J. Gavira-Vallejo and J. Ruiz-Lopez 2007. Calcium oxalates and prehistoric paintings: The usefulness of these biomaterials. Journal of Optoelectronics and Advanced Materials 9:512-521.

Lewis, D. 1988. The Rock Paintings of Arnhem Land, Australia. BAR International Series 415. British Archaeological Reports, Oxford.

Magee, J.W. and G.H. Miller 2007. Timing and cause of Genyornis extinction and duration of humanGenyornis overlap in Australia. In M.L. Cupper and S.J. Gallagher (eds), Climate Change or Human Impact? Australia's Megafaunal Extinction. Selwyn Symposium of the GSA Victoria Division, September 2007, Geological Society of Australia, Extended Abstracts No. 79, pp. 31-78.

Miller, G.H., J.W. Magee, B.J. Johnson, M.L. Fogel, N.A. Spooner, M.T. McCulloch and L.K. Aylffe 1999. Pleistocene extinction of Genyornis newtoni: Human impact on Australian megafauna. Science 283:205-208. doi.org/10.1126/science.283.5399.205 
Miller, G.H., M.L. Fogel, J.W. Magee, M.K. Gagan, S.J. Clarke and B.J. Johnson 2005. Ecosystem collapse in Pleistocene Australia and a human role in megafaunal extinction. Science 309:287-290. doi.org/10.1126/science. 1111288

Murray, P.F. and D. Megirian 1998. The skull of dromornithid birds: Anatomical evidence for their relationship to Anseriformes (Dromornithidae, Anseriformes). Records of the South Australian Museum 31:51-97.

Murray, P.F. and P. Vickers-Rich 2004. Magnificent Mihirungs: The Colossal Flightless Birds of the Australian Dreamtime. Indiana University Press, Bloomington.

Pizzey, G. and F. Knight 1997. The Field Guide to the Birds of Australia. Harper Collins, Pymble.

Reeves, J.M., H.C. Bostock, L.K. Ayliffe, T.T. Barrows, P. DeDeckker, L.S. Devriendt, G.B. Dunbar, R.N. Drysdale, K.E. Fitzsimmons, M.K. Gagan, M.L. Griffiths, S.G. Haberle, J.D. Jansen, C. Krause, S. Lewis, H.V. McGregor, S.D. Mooney, P. Moss, G.C. Nanson, A. Purcell and S. van der Kaars 2013. Palaeoenvironmental change in tropical Australasia over the last 30,000 years a synthesis by the OZ-INTIMATE group. Quaternary Science Reviews 74:97-114. doi.org/10.1016/j. quascirev.2012.11.027

Reimer, P.J., E. Bard, A. Bayliss, J.W. Beck, P.G. Blackwell, C. Bronk Ramsey, C.E. Buck, H. Cheng, R.L. Edwards, M. Friedrich, P.M. Grootes, T.P. Guilderson, H. Haflidason, I. Hajdas, C. Hatté, T.J. Heaton, D.L. Hoffmann, A.G. Hogg, K.A. Hughen, K.F. Kaiser, B. Kromer, S.W. Manning, M. Niu, R.W. Reimer, D.A. Richards, E.M. Scott, J.R. Southon, R.A. Staff, C.S.M. Turney and J. van der Plicht 2013. IntCal13 and Marine13 radiocarbon age calibration curves, 0-50 000 years cal BP. Radiocarbon 55(4):1869-1887. doi.org/10.2458/azu_js_rc.55.16947

Rich, P. 1979. The Dromornithidae, an extinct family of large ground birds endemic to Australia. Bulletin of the Bureau of Mineral Resources, Geology and Geophysics 184:1-190.

Roberts, R. G. and B. W. Brook 2010. And then there were none? Science 327:420-422. doi.org/ $10.1126 /$ science. 1185517

Roberts, R.G., T.F. Flannery, L.K. Ayliffe, H. Yoshida, J.M. Olley, G.J. Prideaux, G.M. Laslett, A. Baynes, M.A. Smith, R. Jones and B.L. Smith 2001. New ages for the last Australian megafauna: Continent-wide extinction about 46,000 years ago. Science 292:1888-1892. doi.org/10.1126/ science. 1060264

Taçon, P.S.C. 1989. From Rainbow Snakes to 'X-Ray' Fish: The Nature of the Recent Rock Painting Tradition of Western Arnhem Land, Australia. Unpublished PhD thesis. The Australian National University, Canberra.

Taçon, P.S.C. 1992. Somewhere over the rainbow: An ethnographic and archaeological analysis of recent rock paintings of western Arnhem Land, Australia. In J. McDonald and I.P. Haskovec (eds), State of the Art: Regional Rock Art Studies in Australia and Melanesia, pp. 202-215. Occasional AURA Publication 6. Australian Rock Art Research Association, Melbourne.

Taçon, P.S.C. and S. Brockwell 1995. Arnhem Land prehistory in landscape, stone and paint. Antiquity 69:676-695. doi.org/10.1017/S0003598X00082272

Taçon, P. S. C. and C. Chippindale 2008. Changing places: Ten thousand years of north Australian rock-art transformation. In D. Papagianni, H. Maschner and R. Layton (eds), Time and Change: Archaeological and Anthropological Perspectives on the Long-term in Hunter-gatherer Societies, pp.73-94. Oxbow Books, Oxford. 
Taçon, P. S. C., N. H. Tan, S. O’Connor, X. Ji, L. Gang, D. Curnoe, D. Bulbeck, B. Hakim, I. Sumantri, H. Than, I. Sokrithy, S. Chia, K. Khun-Neayand and S. Kong 2014. Global implications of early surviving rock art of greater Southeast Asia. Antiquity 88:1050-1064. doi.org/10.1017/ S0003598X00115315

Thomson, V.A. 2012. Ancient DNA in the Australian Context: Investigating Evolutionary and Ecological Responses to Environmental Change. Unpublished PhD thesis. University of Adelaide, Adelaide.

Trueman, C.N., J.H. Field, J. Dortch, B. Charles and S. Wroe 2005. Prolonged coexistence of humans and megafauna in Pleistocene Australia. Proceedings of the National Academy of Sciences of the United States of America 102:8381-8385. doi.org/10.1073/pnas.0408975102

Vickers-Rich, P. 1987. A giant bird of the Pleistocene: Genyornis newtoni. In S. Hand and M. Archer (eds), The Antipodean Ark: Creatures from Prehistoric Australia, pp. 48-50. Angus and Robertson, Sydney.

Williams, D.L.G. 1981. Genyornis eggshell (Dromornithidae; Aves) from the late Pleistocene of South Australia. Alcheringa 5:133-140. doi.org/10.1080/03115518108565426

Wray, R.A.L. 2013. Solutional weathering and karstic landscapes on quartz sandstones and quartzite. In J.F. Shroder (ed.), Treatise on Geomorphology, pp. 463-483. Academic Press, San Diego. doi.org/ 10.1016/B978-0-12-374739-6.00140-8

Wynjorroc, P., H. Long, P. Long, N. Avalon, M. Coleman, L. Ranch and S. Tidermann 2001. Plants, Animals and People: Ethnoecology of the Jawoyn people. Batchelor Press, Batchelor. 


\section{Contributors}

\section{Ken Aplin}

Division of Mammals, National Museum of Natural History, Smithsonian Institution, Washington D.C., 20013-7012, USA. aplink@si.edu

\section{Bryce Barker}

School of Humanities and Communication, Public Memory Centre, University of Southern Queensland, Toowoomba, QLD, 4350, Australia. bryce.barker@usq.edu.au

\section{Liam M. Brady}

Monash Indigenous Studies Centre, 20 Chancellors Walk, Monash University, Clayton, Victoria, 3800, Australia.liam.brady@monash.edu

\section{Géraldine Castets}

Laboratoire EDYTEM, Université Savoie Mont Blanc, F-73376 Le Bourget du Lac Cedex, France. geraldine.castets@univ-savoie.fr

\section{Emilie Chalmin}

Laboratoire EDYTEM, Université Savoie Mont Blanc, F-73376 Le Bourget du Lac Cedex, France. Emilie.Chalmin-Aljanabi@univ-savoie.fr

\section{Bruno David}

ARC Centre of Excellence for Australian Biodiversity and Heritage, Monash Indigenous Studies Centre, 20 Chancellors Walk, Monash University, Clayton, Victoria, 3800, Australia. bruno.david@monash.edu

\section{Jean-Jacques Delannoy}

ARC Centre of Excellence for Australian Biodiversity and Heritage, Laboratoire EDYTEM, Université Savoie Mont Blanc, F-73376 Le Bourget du Lac Cedex, France. Jean-Jacques.Delannoy@ univ-savoie.fr

\section{Tim Denham}

School of Archaeology and Anthropology, College of Arts and Social Sciences, The Australian National University, Canberra, ACT, 2601, Australia.tim.denham@anu.edu.au

\section{Jean-Michel Geneste}

Centre National de Préhistoire, Ministère de la Culture et de la Communication, UMR PACEA, Université de Bordeaux 1, 24000 Périgueux, France. jeanmichelgeneste@wanadoo.fr

\section{Joakim Goldhahn}

School of Cultural Sciences, Linnæus University, Kalmar, 391 82, Sweden. joakim.goldhahn@lnu.se

\section{Robert Gunn}

Monash Indigenous Studies Centre, 20 Chancellors Walk, Monash University, Clayton, Victoria, 3800, Australia.gunnb@activ8.net.au

\section{John A. Hayward}

School of Archaeology and Anthropology, College of Arts and Social Sciences, The Australian National University, Canberra, ACT, 2601, Australia.dovetail@chariot.net.au

\section{Stéphane Hoerlé}

CNRS UMR 5199 PACEA, Université de Bordeaux, CS 50023, 33615 Pessac, France. stephane@rockart.wits.ac.za

\section{Alexandria Hunt}

University of Technology Sydney, PO Box 123, Broadway, NSW, 2007, Australia. Alexandria. M.Hunt@student.uts.edu.au

\section{Nadia Iacono}

3/25 Beaconsfield Parade, Lindfield, NSW, 2070, Australia.nadiazita@bigpond.com

\section{Daniel James}

Monash Indigenous Studies Centre, 20 Chancellors Walk, Monash University, Clayton, Victoria, 3800, Australia.daniel.james@monash.edu

\section{Iain G. Johnston}

School of Archaeology and Anthropology, College of Arts and Social Sciences, The Australian National University, Canberra ACT, 2601, Australia.iain.johnston@anu.edu.au 


\section{Tristen Jones}

Department of Archaeology and Natural History, School of Culture, History and Language, College of Asia and the Pacific, The Australian National University, Canberra ACT, 2601, Australia.tristen.jones@anu.edu.au

\section{Margaret Katherine}

C/- Barunga Community, PMB 25, via Katherine, Northern Territory, 0852, Australia.

\section{Lara Lamb}

School of Humanities and Communication, Public Memory Centre, University of Southern Queensland, Toowoomba, QLD, 4350, Australia. lara.lamb@usq.edu.au

\section{Vladimir Levchenko}

Institute for Environmental Research, Australian Nuclear Science and Technology Organisation, Locked Bag 2001, Kirrawee DC, NSW, 2232, Australia.vld@ansto.gov.au

\section{Meropi Manataki}

Laboratory of Geophysical-Remote Sensing and Archaeoenvironment, Institute for Mediterranean Studies, Foundation for Research and Technology, Hellas, PO Box 119, Rethymnon 74100, Crete, Greece.

and

Technical University of Crete, School of Mineral Resources Engineering, Laboratory of Applied Geophysics, University Campus, Kounoupidiana, 73100 Chania, Greece.

\section{Melissa Marshall}

School of Archaeology and Anthropology, College of Arts and Social Sciences, The Australian National University, Canberra, ACT, 2601, Australia.melissa.marshall@anu.edu.au

\section{Sally K. May}

Place, Evolution and Rock Art Heritage Unit (PERAHU), Griffith Centre for Social and Cultural Research, School of Humanities, Languages and Social Science, Griffith University, QLD, 4222, Australia.s.may@griffith.edu.au

\section{Jerome Mialanes}

Monash Indigenous Studies Centre, 20 Chancellors Walk, Monash University, Clayton, Victoria, 3800, Australia.jerome.mialanes@monash.edu

\section{Ian Moffat}

Geophysics, Geochemistry and Quaternary Geology, Precipice Training, PO Box 643, Yandina LPO, Yandina, QLD, 4561, Australia. ian.moffat@ precipicetraining.com

and

Department of Archaeology, Flinders University, GPO Box 2100, Adelaide, South Australia, 5001, Australia.

and

Institute for Mediterranean Studies, Foundation for Research and Technology, Hellas, PO Box 119, Rethymnon 74100, Crete, Greece.

\section{Magen O'Farrell}

UMR 5199 PACEA, CNRS/Université de Bordeaux 1, Avenue des Facultés, 33405 Talence Cedex, France. ofarrell.magen@gmail.com

\section{Fiona Petchey}

Radiocarbon Dating Laboratory, University of Waikato, Hamilton, 3240, New Zealand. fpetchey@waikato.ac.nz

\section{Ursula Pietrzak}

Monash Indigenous Studies Centre, 20 Chancellors Walk, Monash University, Clayton, Victoria, 3800, Australia.ursula.pietrzak@monash.edu

\section{Faye Prideaux}

PO Box 510, Bundaberg, QLD, 4670, Australia.

\section{Benjamin Sadier}

Laboratoire EDYTEM, Université Savoie Mont Blanc, F-73376 Le Bourget du Lac Cedex, France. nomad@gmx.fr

\section{Inés Domingo Sanz}

ICREA Research Professor at Universitat de Barcelona, Department de Prehistòria, Història Antiga i Arqueologia / SERP, 08001 Barcelona, Spain. ines.domingo@ub.edu

\section{Denis Shine}

Irish Archaeology Field School, Number 2, Grosvenor Terrace, Monkstown, Dublin, Ireland.

\section{Sean Paul Stephens}

Monash Indigenous Studies Centre, 20 Chancellors Walk, Monash University, Clayton, Victoria, 3800, Australia. 


\section{Paul S.C. Taçon}

Place, Evolution and Rock Art Heritage Unit (PERAHU), Griffith Centre for Social and Cultural Research, School of Humanities, Gold Coast campus, Griffith University, QLD, 4222, Australia.p.tacon@griffith.edu.au

\section{Steve Webb}

Faculty of Society and Design, Bond University, QLD, 4229, Australia. stwebb@bond.edu.au

\section{Daryl Wesley}

Department of Archaeology and Natural History, School of Culture, History and Language, College of Asia and the Pacific, The Australian National University, Canberra ACT, 2601, Australia. daryl.wesley@anu.edu.au

\section{Ray Whear}

PO Box 1350, Broadbeach, QLD, 4218, Australia. ray.whear@gmail.com

\section{Rose Whitau}

Department of Archaeology and Natural History, School of Culture, History and Language, College of Asia and the Pacific, The Australian National University, Canberra ACT, 2601, Australia.rose.whitau@anu.edu.au

\section{Duncan Wright}

School of Archaeology and Anthropology, College of Arts and Social Sciences, The Australian National University, Canberra, ACT, 2601, Australia.duncan.wright@anu.edu.au 
